\title{
Reactor Technology
}

Selected Reviews - 1964

Edited by Leonard E. Link Argonne National Laboratory

Prepared Under the Auspices of the UNITED STATES

ATOMIC ENERGY COMMISSION Division of Technical Information 


\section{DISCLAIMER}

This report was prepared as an account of work sponsored by an agency of the United States Government. Neither the United States Government nor any agency Thereof, nor any of their employees, makes any warranty, express or implied, or assumes any legal liability or responsibility for the accuracy, completeness, or usefulness of any information, apparatus, product, or process disclosed, or represents that its use would not infringe privately owned rights. Reference herein to any specific commercial product, process, or service by trade name, trademark, manufacturer, or otherwise does not necessarily constitute or imply its endorsement, recommendation, or favoring by the United States Government or any agency thereof. The views and opinions of authors expressed herein do not necessarily state or reflect those of the United States Government or any agency thereof. 


\section{DISCLAIMER}

Portions of this document may be illegible in electronic image products. Images are produced from the best available original document. 
Available from

Clearinghouse for Federal Scientific and Technical Information

National Bureau of Standards

U. S. Department of Commerce

Springfield, Virginia

Printed in the United States of America

USAEC Division of Technical Information Extension

Oak Ridge, Tennessee

July 1964 


\section{Preface}

This volume is meant to present some highlights of a year's progress in reactor technology. A subject is included for any of three reasons: it has reached a significant developmental stage; its coverage in the literature has been inadequate; or it has been emphasized by the over-all trends in reactor development. Choice of subjects was based on the deliberations of an Advisory Committee selected by the U. S. Atomic Energy Commission. This volume broadly reviews aspects of the field, and the attitude of bringing the reader up-to-date has tended to prevall.

The assumed audience for the volume is broad. It includes all active participants in the reactor program, from the scientists working in the more basic aspects of the applied field to the project managers whose duties generally become more administrative than technical. For those who wish to search in depth, most authors have cited references liberally. Technology is generally covered for the period extending into the summer of 1963, when the articles were essentially complete.

I am particularly grateful to the authors for their efforts. For the most part, writing such as that represented by the articles in this book is a task accepted over and above the regular ones of the authors. As a consequence I suspect that many evenungs were spent in preparing these articles. 
Each article was reviewed by three people technically competent in this field. Each reviewer provided a valuable contribution to the book. The reviewers and their affiliations are listed on the next page.

Members of the Advisory Committee were very effective in soliciting subjects from among their associates and in obtaining both authors and reviewers for articles. Members of the committee were Jack Chernick, Associate D1rector, Reactor Physics Division, Brookhaven National Laboratory; J. E. Cunningham, Assistant Director, Metals and Ceramics Division, Oak Ridge Natıonal Laboratory; R. E. Tomlınson, Manager, Advanced Technical Planning Research and Engineering Operation, Hanford Atomic Products Operation, General Electric Company; William R. Vorght, Chief, Water Reactors Branch, Division of Reactor Development, U. S. Atomic Energy Commission; and Leonard E. Link (Chairman), Senır Engineer, Laboratory Director's Office, Argonne National Laboratory.

Thanks are due also to the numerous people who are behind the scenes in preparing such a volume: those who do the final organization, examination, and editorial work; those whotype, proofread, and retype; those who prepare the final art work; and finally those who set up and print this book in an attractive, readable form. In particular I wish to thank John H. Martens and Michael R. Sims, for their guidance throughout the development of the volume, and James A. Lecky, for his editorial work. 


\title{
Reviewers
}

\author{
D. J. Anthony
}

General Electric Company

Knolls Atomic Power Laboratory

Schenectady, New York

John M. Batch

General Electric Company

Hanford Atomic Products Operation

Richland, Washington

Warren E. Berry

Battelle Memorial Institute

Columbus, Ohıo

G. E. Brand

Atomics International

Canoga Park, Calıfornı

S. H. Bush

General Electric Company

Hanford Atomic Products Operation

Richland, Washington

Arthur H. Dexter

E. I. du Pont de Nemours and Company

Savannah River Plant

Alken, South Carolina

J. R. Dietrich

General Nuclear Engineering Corporation Dunedin, Florida

Fred Hettman

Hettman Associates, Incorporated

Baltimore, Maryland

Arne B. Holt

United States Atomic Energy Commission Washington, D. C.

Albert R. Kaufmann

Nuclear Metals, Incorporated

Concord, Massachusetts 
James A. Lane

Oak Ridge National Laboratory

Oak Ridge, Tennessee

Stephen Lawrosk1

Argonne National Laboratory

Argonne, Illinors

S. Levy

General Electric Company

Atomic Products Division

San Jose, Calıfornia

Leonard E. Link

Argonne National Laboratory

Argonne, Illinoss

Walter C. Lipinski

Argonne National Laboratory

Argonne, llinnois

W. R. McDonell

E. I. du Pont de Nemours and Company

Savannah River Plant

Alken, Souih Carolina

Karl E. Plumlee

Argonne National Laboratory

Argonne, Illinois

Warren M. Rohsenow

Massachusetts Institute of Technology

Cambridge, Massachusetts

C. W. Showalter

United States Atomic Energy Commission

Washington, D. C.

E. F. Strucken

E. I. du Pont de Nemours and Company Savannah River Plant

Alken, South Carolina

R. E. Tomlinson

General Electric Company

Hanford Atomic Products Operation

Richland, Washington

A. F. Volght

Ames Laboratory

Iowa State University

Ames, Iowa

M. T. Wallıng, Jr.

General Electric Company

Hanford Atomic Products Operation

Richland, Washington

C. E. Weber

Atomics International

Canoga Park, Calıfornı

David B. Wehmeyer

Babcock and Wilcox Company

Lynchburg, Virginıa 


\section{Contents}

Preface

Reviewers

Commercial Power Reactors Cooled with Gas or Light Water

Stuart incLain

Commercial Power Reactors Cooled with Sodium, Heavy Water, or Organıc Liquids

Chad J. Raseman and Leon Green

Bolling "Burnout" for Reactor Design

R. P. Stein and P. A. Lottes

In-core Instrumentation

L. R. Boyd

Behavior of Cladding Materials in Water and Steam Environments

Sherman Greenberg

Metallic Fuels

Stanley F. Pugh and Benjamm R. Bulcher

Pyroprocessing of Reactor Fuels

R. Dean Puerce and Leslze Burius, Jr.

Reactor By-products

A. F. Rupp

Reactor-physics Data for Water-moderated Lattices of Slightly Enriched Uranium

Robert L. Hellens and Glenn A. Pruce

Index 


\section{Commercial Power Reactors Cooled with Gas or Light Water}

by

Stuart McLain

Consultant to

Argonne National Laboratory 
To one who looks at nuclear-power-plant development, it is apparent that there have been few spectacular advances in this field. Nevertheless, in spite of conservatism and lack of extended operating experience, there has been a normal but rapid development with advances in many parts of the technology. These advances have resulted in large and continuous decreases in capital costs and fuel costs. In short, a power industry has been created.

From its infancy the nuclear industry has stressed safety, and, in spite of the extremely hazardous character of some of the materials utilized, the safety record has been excellent. This fact, combined with the cleanliness of the plants and general increased understanding of nuclear matters, has led to increased acceptance of the industry by the public.

The experience and information obtained by the nuclear industry have been enormous. Specialists in all phases of nuclear-power-plant design and operation and integrated design groups capable of complete plant designs have developed. It is impossible to summarize their technical information and backgrounds in a short review such as this. Nor does it appear desirable to do so because the specialists are interested in many details of intlle interest to others. In addition, the information needed by the designers must include that published in the current operating and progress reports. For these reasons this article has been written for those interested in a broad review of the nuclear power industry. Consequently the technical detalls are not stressed, but rather the general features of the various power reactors are mentioned.

This article is limited to a discussion of gas-cooled and light-watercooled nuclear power reactors, both domestic and foreign. It surveys reactors being designed and constructed as well as those in operation; power costs; design problems; and trends in the construction of nuclear power plants using these coolants.

\section{GAS-COOLED POWER REACTORS}

Table 1 lists the names, owners, locations, power levels, and status of the gas-cooled power reactors of $100 \mathrm{Mw}(e)$ or larger ${ }^{1-9}$ that were authorized by mid-1963. These reactors have a net power of about 8800 $\mathrm{Mw}(\mathrm{e})$. Most are still under design and construction, and there has been little chance for feedback of large-scale reactor operatıng data into the design of the plants under design. All these reactors are of United Kingdom or French design, and all utılize natural uranium as fuel, graphite as moderator, and carbon dioxide as coolant. More-advanced prototype reactors are under design and construction in both countries and in the United States and Germany. In addition, extensive development programs on other types of reactors are being carried out in both the United Kingdom and France. 


\section{Reactor Programs}

The United Kingdom has the largest program for gas-cooled reactors, but France and the United States are also carrying out developmental programs.

UNITED KINGDOM The largest program for gas-cooled power reactors is that of the United Kingdom. In the early 1950's the high fossilfuel costs and temporary scarcity of coal led United Kingdom authorities to consider early construction of nuclear power reactors. The selection of the gas-cooled reactor, based on the use of natural uranium, graphite, and carbon dioxide, permitted early design and construction. Heavy water and slightly enriched uranium could have been produced, but high investment costs and possible delays would have resulted. Thus the decision was made to use the materials readily available. Actually this decision led to high capital costs, but these costs have been offset somewhat by the low interest rates in the United Kingdom.

Two alr-cooled nonpower reactors were constructed and operated at Windscale; then eight dual-purpose plutonium and power reactors were constructed. The first of the four power reactors at Calder Hall and the four at Chapelcross, Scotland, began operation in 1956; others began at intervals of about three months thereafter. Each of these reactors was designed to produce $38 \mathrm{Mw}(\mathrm{e})$, but the power levels were soon raised to $42 \mathrm{Mw}(\mathrm{e})$.

Twenty larger power reactors, using the same basic design, have been authorized or are being planned in Great Britain. Four began operation in 1961 and 1962, and others are scheduled for operation in 1963. All have been designed as twin-reactor stations. Single reactors of United Kingdom design are in operation in Italy and under construction in Japan.

All the reactors use natural-uranium-metal fuel clad with a finned magnesıum alloy, Magnox (alumınum, 0.25 to 4.0 percent; calcium, 0.02 to 0.4 percent; beryllium, 0.002 to 0.1 percent; and the remainder, magnesium). Thus the reactors are called the Magnox type. All are graphite moderated and carbon dioxide cooled. Contınued improvements in the Magnox reactor are expected with lowered power costs.

A prototype high-temperature gas-cooled reactor, the Advanced Gas Cooled Reactor (AGR), has been bullt in the United Kingdom. The design of the AGR is based on the use of slightly enriched uranium dioxide fuel, stainless-steel cladding, graphite moderator, and carbon dioxide coolant.

The United Kingdom has also had an important part in the design and construction of the DRAGON Reactor. It is a high-temperature reactor, fueled with uranium dioxide (ceramic), moderated with graphite, and cooled by helium. DRAGON is being bult by the European Nuclear Energy Agency (ENEA). 


\begin{tabular}{|c|c|c|c|c|c|c|}
\hline Name & Owner & Location & $\begin{array}{l}\text { Number } \\
\text { of } \\
\text { reactors }\end{array}$ & $\begin{array}{l}\text { Single- } \\
\text { reactor } \\
\text { power, } \\
\text { Mw(e) }\end{array}$ & $\begin{array}{c}\text { Net } \\
\text { power, } \\
\text { Mw(e) }\end{array}$ & $\begin{array}{c}\text { Year } \\
\text { of } \\
\text { startup }\end{array}$ \\
\hline Berkeley & $\begin{array}{l}\text { Central Electricity } \\
\text { Generating Board }\end{array}$ & $\begin{array}{l}\text { Berkeley, Gloucestershıre, } \\
\text { England }\end{array}$ & 2 & 137.5 & 275 & 1961,1962 \\
\hline Bradwell & $\begin{array}{l}\text { Central Electricity } \\
\text { Generating Board }\end{array}$ & Bradwell, Essex, England & 2 & 160 & 320 & 1961,1962 \\
\hline SIMEA, Latina & $\begin{array}{l}\text { Società Italıana Meridianale } \\
\text { per l'Energıa Atomıca }\end{array}$ & Foce Verde, Ituly & 1 & 200 & 200 & 1962 \\
\hline $\mathrm{EDF}-2$ & Electricité de France & Avoine, France & 1 & 199 & 199 & 1963 \\
\hline Hinkley Point A & $\begin{array}{l}\text { Central Electricity } \\
\text { Generating Board }\end{array}$ & $\begin{array}{l}\text { Hinkley Point, Somerset, } \\
\text { England }\end{array}$ & 2 & 250 & 500 & 1963,1964 \\
\hline Trawsiynydd & $\begin{array}{l}\text { Central Electricity } \\
\text { Generating Board }\end{array}$ & $\begin{array}{l}\text { Truwsfynydd, Merionethire, } \\
\text { Wales }\end{array}$ & 2 & 250 & 500 & 1963,1964 \\
\hline Hunterston & $\begin{array}{l}\text { South of Scotland Electricity } \\
\text { Board }\end{array}$ & $\begin{array}{l}\text { Hunterston, Ayrshire, } \\
\text { Scotland }\end{array}$ & 2 & 160 & 320 & 1964 \\
\hline Dungeness & $\begin{array}{l}\text { Central Electricıty } \\
\text { Generatıng Board }\end{array}$ & $\begin{array}{l}\text { Dungeness Point, Kent, } \\
\text { England }\end{array}$ & 2 & 275 & 550 & 1964,1965 \\
\hline Tokaı-Mura & Japan Atomic Power Co. & Tokaı-Mura, Japan & 1 & 158 & 158 & 1965 \\
\hline Sizewell & $\begin{array}{l}\text { Central Electricity } \\
\text { Generating Board }\end{array}$ & Suftolk, England & 2 & 290 & 580 & 1965 \\
\hline$E D F-3$ & Electricitê de France & Avone, France & 1 & $375-480$ & $375-480$ & 1965 \\
\hline Oldbury & $\begin{array}{l}\text { Central Electricity } \\
\text { Generating Board }\end{array}$ & Oldbury, England & 2 & 280 & 560 & 1966 \\
\hline Wylfa & $\begin{array}{l}\text { Central Electricity } \\
\text { Generating Bodrd }\end{array}$ & Wylta, Wales & 2 & 500 & 1000 & \\
\hline Hinkley Point B* & $\begin{array}{l}\text { Central Electricity } \\
\text { Generating Board }\end{array}$ & $\begin{array}{l}\text { Hinkley Point, Somerset, } \\
\text { England }\end{array}$ & 2 & 1000 & 2000 & \\
\hline $\operatorname{EDF}-4^{*}$ & Electricité de France & & 1 & 500 & 500 & \\
\hline $\mathrm{EDF}-5 *$ & Electricité de $\mathbf{F}$ rance & & 1 & $500-1000$ & $500-1000$ & \\
\hline
\end{tabular}

*Projected. 
FRANCE

The French program began with the construction of an aircooled reactor, G-1, followed by construction of two dual-purpose plutonium and power reactors at Marcoule, G-2 and G-3. G-2 and G-3, which began operation in 1958 and 1959, were designed for $28 \mathrm{Mw}(\mathrm{e})$ but are now operating at $38 \mathrm{Mw}(e)$, with $30 \mathrm{Mw}(\mathrm{e})$ net.

One power reactor, EDF-1, has been built, and two others, EDF-2 and EDF-3, have been authorized. All three are natural-uranium reactors cooled with carbon dioxide. EDF-1 began operation in 1962 at Avoine, near Chmon. It produces $82 \mathrm{Mw}(\mathrm{e})$. Two larger reactors, EDF2 and EDF-3, are under construction to produce 199 and $375 \mathrm{Mw}(\mathrm{e})$. $\mathrm{EDF}-4,500 \mathrm{Mw}(\mathrm{e})$, and EDF-5, which may be even larger, are being planned. EL-4, which utilizes a slightly enriched fuel, carbon dioxide cooling, and heavy-water moderation, is being bullt in France at Brennilis (Mont d'Arree Power Station) to produce $80 \mathrm{Mw}(\mathrm{e})$. France is also participating in the DRAGON project.

UNITED STATES Compared with United Kingdom and French programs, the United States program for gas-cooled power reactors is modest. A mobile power reactor of very low power is under test, and two prototype power reactors are under construction. They are the Experımental Gas Cooled Reactor (EGCR) at Oak Ridge, Tenn., and the Philadelphia Electric Company's Peach Bottom Atomic Power Station (HTGR) being built at Peach Bottom, Pa. The EGCR will use slightly enriched uranium dioxide with stainless-steel cladding, and the Peach Bottom reactor will be fueled with enriched uranium and thorium dicarbides clad with carbon and dispersed in graphite. Both reactors will be graphte moderated and helium cooled.

\section{Design and Operation of Reactors}

Some of the design data for the Calder Hall and Hinkley Point reactors and several prototype reactors being built in the United Kingdom and United States are presented in Table 2. The gas-cooled reactors are larger than reactors cooled with light water, but the larger size has resulted in less emphasis on close manufacturing tolerances, with the exception of the fuel, control, and reloading systems. Design of equipment has required consideration of every detall to meet the rigid spec1fications of leak rates and reliability. The gas-recirculation equipment has required considerable development because the blowers are varıable flow and completely sealed. The power requirements are about 6 percent of the total produced. ${ }^{11}$ Physically the heat exchangers have been large in these reactors owing to the relatively low heat-transfer coefficients and the use of tubes about $1 \mathrm{in}$. in diameter.

The use of natural uranium in a graphite-moderated reactor dictates the design because there is little excess reactivity; both the general de- 
Table 2 -DESIGN DATA FOR GAS-COOLED REACTORS ${ }^{7,10}$

\begin{tabular}{|c|c|c|c|c|c|c|}
\hline & Calder Hall & Hinkley Point $\mathrm{A}$ & AGR & EGCR & $\begin{array}{l}\text { Philadelphia } \\
\text { Electric }\end{array}$ & DRAGON \\
\hline Designer & UKAEA & English Electric & & $\begin{array}{c}\text { Kalser Engineers- } \\
\text { Allis-Chalmers }\end{array}$ & General Atomics & UKAEA \\
\hline Status & Operatıng & Under construction & Operating & Under construction & Under construction & Under construction \\
\hline Completion date & 1956 & & 1962 & & & \\
\hline Cycle & Indirect & Indirect & Indirect & Indireet & Indirect & Direct \\
\hline \multicolumn{7}{|l|}{ Power } \\
\hline $\mathrm{Mw}(\mathbf{e})$ & 42 & 250 & 27 & 25.7 & 40 & \\
\hline $\operatorname{Mw}(\mathrm{t})$ & 180 & 980 & 100 & 84.3 & 115 & 20 \\
\hline Fuel & $\mathrm{U}$ metal & U metal & $\mathrm{UO}_{2}$ & $\mathrm{UO}_{2}$ & $\mathrm{UC}_{2}+\mathrm{ThC}_{2}$ & $\mathrm{UO}_{2}, \mathrm{ThO}_{2}$ \\
\hline Fuel enrichment, \% & Natural & Natural & 1.17 & 2.2 & 16.0 & \\
\hline Claddıng & $\begin{array}{l}\text { Magnox, } \\
\text { tınned }\end{array}$ & $\begin{array}{r}\text { Magnox, } \\
\text { finned }\end{array}$ & S.S. & 304 S.S. & Graphite & \\
\hline Cladding size, in. & 0.630 (39 cyl.) & $(39)$ & $\sim 0.5$ & 0.750 (29 cyl.) & 4.15 (90 cyl.) & \\
\hline $\begin{array}{l}\text { Fuel weight, } \\
\text { metric tons }\end{array}$ & & & $14.6 \mathrm{UO}_{2}$ & $11.2 \mathrm{UO}_{2}$ & $0.19 \mathrm{U}^{235}, 1.19 \mathrm{Th}$ & \\
\hline \multicolumn{7}{|l|}{ Coolant } \\
\hline Inlet temp., ${ }^{\circ} \mathrm{F}$ & 284 & 324 & $482-617$ & 510 & 66,0 & 662 \\
\hline Outlet temp., ${ }^{\circ} \mathbf{F}$ & 636 & 707 & $932-1067$ & 1050 & 1380 & 1382 \\
\hline Inlet pressure, psi & 100 & 185 & 270 & 300 & 300 & 300 \\
\hline Moderator & Graphite & Graphite & Graphite & Graphite & Graphite & Graphite \\
\hline
\end{tabular}




\begin{tabular}{|c|c|c|c|c|c|c|}
\hline Core & & & & & & 3.52 \\
\hline Diameter, it & 31 & 49 & 15 & 16 & 9 & $\begin{array}{l}3.52 \\
5.25\end{array}$ \\
\hline Length, it & 21 & 25 & 14 & 19 & 7.5 & 5.25 \\
\hline Volume, eu ft & 15,850 & 47,100 & 2650 & 1400 & 476 & 51 \\
\hline $\begin{array}{l}\text { Power density, } \\
\text { kw/liter }\end{array}$ & 041 & 074 & 106 & 21 & 8 & 14 \\
\hline $\begin{array}{l}\text { Hedt flux, } \\
\text { Btu/(hr) (sq ft) } \\
\text { Pressure vessel }\end{array}$ & 60,500 & & & 66,800 & 87,400 & 76,000 \\
\hline Diameter, $\mathrm{ft}$ & 21 & 73 & & 20.7 & 14.3 & 11.5 \\
\hline Height, it & 70 & Spherical & & 46.3 & 34.5 & 58 \\
\hline $\begin{array}{l}\text { Thickness, in. } \\
\text { Material }\end{array}$ & $\begin{array}{l}2 \\
\text { Steel }\end{array}$ & $\begin{array}{l}3 \\
\text { Steel }\end{array}$ & Steel & $\begin{array}{l}4 \\
\text { Steel }\end{array}$ & $\begin{array}{l}2 \\
\text { Steel }\end{array}$ & 2.25 \\
\hline $\begin{array}{l}\text { Power cost, } \\
\text { mills } / \mathrm{kw}-\mathrm{h} r \\
\text { Capital cost, } \$ / \mathrm{kw}\end{array}$ & $\begin{array}{r}77 \\
660\end{array}$ & & & $\begin{array}{l}336 \\
957\end{array}$ & & \\
\hline
\end{tabular}


sign and general characteristics of the reactor are limited. The fuel must be clumped, 1.e., large rods, about 1 in. in diameter, with limited heat-transfer surface are required, and the lattıce spacing, as indicated by the fuel-to-moderator ratio, is low. Heat transfer is assisted by the good thermal conductivity of the metallic uranium and the use of finned cladding to increase transfer of heat to gaseous coolants.

Several factors can limit power production: the maximum temperature of the fuel, the surface cladding temperature, the life of the fuel in respect to stability, and the reaction between the carbon dioxide and the graphite. The central temperature of the fuel is limited to avoid the transformation of uranium to the beta phase at $1225^{\circ} \mathrm{F}$, which would cause formation of central cracks and gas pockets. A cladding temperature of $800^{\circ} \mathrm{F}$ when Magnox cladding is used is satisfactory. This temperature allows a difference of about $425^{\circ} \mathrm{F}$ between the central temperature and the cladding temperature: $90^{\circ} \mathrm{F}$ for the temperature drop between the finned cladding and the fuel; a drop of $306^{\circ} \mathrm{F}$ through the fuel; and about $30^{\circ} \mathrm{F}$ for slight variations. These conditions are approached in all the power reactors The life of the fuel is limited under these temperature conditions to about $4500 \mathrm{Mwd} / \mathrm{t}$. At higher burnups the fuel elements may swell and distort. Owing to the varıations in power level, a maximum fuel burnout of $4500 \mathrm{Mwd} / \mathrm{t}$ is reached at an average fuel burnup of about $3000 \mathrm{Mwd} / \mathrm{t}$. The fuel life is also limited by the reactivity to about $3000 \mathrm{Mwd} / \mathrm{t}$, depending upon the detailed design of the reactor. The cores of the Calder Hall and Chapelcross reactors are about the minimum size for operation at this burnup (see Table 2).

UNITED KINGDOM From experience with the Calder Hall reactors and trom economic studies, optimum specifications for the Berkeley station and others were estimated to be a fuel length of about $20 \mathrm{ft}$ per channel and spherical steel vessels. The pressure of the carbon dioxide has been limited by the maximum thickness of vessel that could be field welded and annealed. Optımum conditions with a 70-ft-diameter pressure vessel, for example, are a clad fuel temperature of $800^{\circ} \mathrm{F}$, which permits a bulk exit gas temperature of $704^{\circ} \mathrm{F}$, and an inlet pressure of $185 \mathrm{psig}$ to give $400 \mathrm{Mw}(\mathrm{e})$. Sizes of pressure vessels, wall thicknesses, and temperatures have been increased, with power levels rising from 274 to $580 \mathrm{Mw}(\mathrm{e})$ tor the two-reactor stations. Vessels $4 \mathrm{in}$. thick and $62.5 \mathrm{ft}$ in diameter have been field welded and annealed successfully. The reactors at Oldbury will utilize cylındrical pressure vessels of reinforced concrete, and the heat exchangers and the circulating pumps will be enclosed within the pressure vessels. The United Kingdom engineers claim that the use of reinforced-concrete pressure vessels is the greatest advance in design since the Calder Hall reactors were bunlt. ${ }^{12}$ The advantages of reinforced-concrete vessels are discussed later in this article. 
In all the Magnox reactors, the conversion ratio is about 0.83 . This conversion results in appreciable plutonium production $-3 \mathrm{~kg}$ per ton on discharge at $3000 \mathrm{Mwd} / \mathrm{t}$. Recycle of part of this plutonium could be used to flatten a large portion of the power distribution and to decrease the peak to average operating temperatures and fuel burnups or to increase the fuel life considerably. This subject has been given considerable study in the United Kingdom, as has the use of partially enriched fuel. However, the stability of the metallic fuel limits the applicability of enrichment.

Heat production in the reactors is leveled or flattened somewhat by poison rods. This flattening permits increases in the power levels since the maximum central temperatures of the fuel are lowered.

In the Calder Hall reactors, the fuel is clumped heavily by the use of 1-1n.-diameter rods in seven-rod clusters. The rods are $39.4 \mathrm{in}$. long and are assembled in rod-support structures to prevent bowing. Operating experience, in general, has been excellent. The fuel rods have been stable dimensionally with very little wrinkling, excessive growth, or swelling.

The major downtime for the Calder Hall reactors is that required for refueling because the reactors must be shut down and depressurized. A carbon dioxide atmosphere is maintained, and refueling is carried out remotely.

The reactors are equipped with sensing devices for detecting failed fuel elements, and each fuel channel is surveyed every half hour. The detection device will detect about $1 \mathrm{~mm}^{2}$ of exposed natural-uranium surface by measurement of the fission products in the coolant. A claddıng-surface uranium contamination of $1 \mu \mathrm{g}$ per fuel element is detectable. Thus, if false signals are to be eliminated in detection devices adjusted to locate defective fuel elements that have developed minute cracks or holes, rigorous manufacturing techniques and cleaning procedures for cladding fuel elements must be applied. ${ }^{13}$

Three fuel elements failed at irradiation levels of 125 to $250 \mathrm{Mwd} / \mathrm{t}$ in the first reactor completed. Postırradiation examination was inconclusive, but fallure was attributed to small manufacturing defects. Four others of the first 30,000 elements falled. Three of these had been irradiated to about $500 \mathrm{Mwd} / \mathrm{t}$ and had experienced surface temperatures of about $390^{\circ} \mathrm{F}$. All three were in the bottom, or coolant inlet, layer of fuel elements. These fallures were attributed to low ductility of the cladding. The condition was readily corrected by use of higher ductility Magnox. Later, six experimental fuel elements falled owing to vibrationinduced fatigue that resulted in cracks in the cladding. This condition was relieved by use of improved aerodynamic designs. Seven fuel elements falled owing to manufacturing defects or damage during loading. All these elements failed soon after intial irradiation because of cracks forming near the end caps. Fuel elements with manufacturing defects 
are now detected soon after loading by pressurizing the reactor at low power and gradually reducing the pressure. Elements with slight defects are detected and removed. Since this procedure was started, the re has been no unscheduled shutdown due to fuel-element fallure. ${ }^{14}$

The Calder Hall reloading equipment was originally planned for reloadıng durıng normal full-power operation. However, because the equipment is so complex, because it must operate through seals, and because operation is directed by indirect position-indication circuits, operations initially were very slow even with the reactor shut down and depressurized. Visual-inspection equipment, consisting of periscopes and television, was installed. This equipment has made fuel handling more satısfactory, and complete reloading of a depressurized reactor can be accomplished in 20 days. ${ }^{14-18}$ The experience has been utılized in the design of the reloading equipment for the larger power reactors since these reactors are apparently refueled successfully during fullpower operation.

Inspection, maintenance, and changes in the Calder Hall reactors are carried out during the refueling operation. This procedure, along with the improved reloading procedures and decreased troubles with reloading equipment, has reduced total downtıme of the Calder Hall reactors from 21 to 12 percent over the past five years. Now the reactors operate many months between shutdowns.

Other than loss of carbon droxide due to leakage, coolant maintenance has been simple. In the first Calder Hall reactor, leakage was 2 tons per day imitially. This leakage was reduced to less than 0.5 ton per day by simply sealing leaks located by inspection of probable leak areas with soap and glycerine bubbles. This leakage is equivalent to that from a hole of $0.03 \mathrm{~m}$. diameter in the total surface area ${ }^{15}$ of about $250,000 \mathrm{sq} f t$.

Argon-41 is formed from traces of air in the gas. Nitrogen-16 formed requires heavy shelding of the pumps and recirculation ducts. Very little particulate matter is circulated with the gas. At Calder Hall after one year's operation, the surface contamination in the heat exchangers was low enough to permit entry of personnel wearing dust masks and special clothing. No restrictions or special clothing were required for maintaining the circulating pumps. Two percent of the gas flow is filtered; as a result very little particulate entrainment is found in the coolant system.

The oxidation of the graphite in the Calder Hall reactor was estimated as 0.05 percent per year at the end of one year's operation. Since the maximum temperature of the fuel cladding permitted by the Magnox in the reactor is $770^{\circ} \mathrm{F}$ and this is never exceeded, no serious oxidation of the graphite occurs.

Difficulties now overcome in the Magnox cladding, in addition to the ductility problem, have included porosity and unsatisfactory welds. 
Because four external coolant circuits have been used with each Magnox type of reactor in the United Kingdom, routine maintenance is carried out by simply isolating a circuit. Inspection and maintenance of the heat exchangers are conducted during reloading operations.

Tests showed that the coolant flow of the original Calder Hall reactor differed from the measured heat production in parts of the reactor. Also the coolant-circuit pressure drops had been overestımated. Correction of the flow pattern and use of the greater flow, combined with improved performance of the circulating pumps, resulted in a 15 percent rise in power level to $200 \mathrm{Mw}(\mathrm{t})$. At the same time a slightly reduced outlet gas temperature resulted in an excess of low-pressure steam.

The original Calder Hall reactors have a wide range of power in that they may be operated at 15 to 100 percent of full power. The power may be raised from 30 to $180 \mathrm{Mw}(\mathrm{t})$ in $30 \mathrm{~min}$. This increase requires moving the control rods only a few centimeters and increasing reactivity by 0.15 percent. After startup the control rods are withdrawn slowly to adjust for the 1.6 percent of reactivity absorbed by the xenon at the maximum moderator flux of $10^{13}$ neutrons $/ \mathrm{cm}^{2} / \mathrm{sec}$.

A single coolant loop can be isolated in about $1 \mathrm{hr}$ by reducing the coolant flow at normal temperatures, closing the valves in the loop to be shut down, and then increasing the flow in the other three loops. The reactor can be operated on any number of the coolant loops, but the valves can be operated only with the loops at reactor pressure.

Engineers in the United Kingdom conducted an extensive investigation of the expected performance of the fuel and graphite in the Berkeley and Bradwell stations; as a result they introduced several changes in design from the design of the Calder Hall reactors. Cladding weld defects are minimized by control and inspection; cavitation or changes in the wall thickness of the cladding as it expands are controlled by grain size; springs are used at Bradwell to reduce vibration; and supports and braces were added to the fuel assemblies. ${ }^{19}$ Allowances are made for a 15 percent increase in fuel volume during irradiation.

Many minor difficulties with the on-load fuel-handling equipment occurred. These difficulties were due to operation in hot dry carbon dioxide without lubrication; difficulty in retaining rigidity; adjustment of interlocking safety and control devices; and flexibility of the fuelelement grab cable. All these problems have been solved. At Bradwell the electric cable to the fuel-movement head on the reloading machine falled. The head was replaced by a mechanical head.

The dimensional changes in the graphite resulting from 1 rradiation caused great concern. Not only were the lower, or inlet, layers of graphite interlocked but also fuel-hole liners were used in the inlet section. Some of these liners were undersized at Berkeley, and some graphite blocks at Bradwell were 0.04 in. under size. These flaws were detected 
early. At Berkeley slightly smaller fuel assemblies were used in the undersized channels.

FRANCE Basically the G-2 and G-3 reactors, or the first French power reactors at Marcoule, are similar to those at Calder Hall. However, the detalled designs differ considerably. The fuel channels are horizontal, and prestressed-concrete vessels rather than steel vessels are used. Uranium rods 1.10 and $1.24 \mathrm{in}$. in diameter by $13 \mathrm{in}$. long are used; the smaller rods are loaded in the center of the reactor. The rods are clad with a finned magnesium alloy containing 0.8 percent zirconium. The use of two sizes of rods produces a 4 percent increase in power; an increase of 2 percent in the conversion ratio; an increase of 6 percent in plutonium production; and a siight increase in efficiency due to a higher exit gas temperature in the outer zone. This gas is used to superheat the steam produced by the gas circulated through the central portion of the reactor, and its higher temperature permits a small increase in superheatıng. These improvements, however, require more uranium. ${ }^{20,21}$

The inlet temperature of the carbon dioxide to the internal zone is $302^{\circ} \mathrm{F}$, and to the outer zone, $176^{\circ} \mathrm{F}$; the corresponding exit temperatures are 581 and $669^{\circ} \mathrm{F}$. The maximum fuel temperature is $1022^{\circ} \mathrm{F}$, with a maximum fuel-cladding temperature of $752^{\circ} \mathrm{F}$. The inlet coolant to the outer zone is utilized to cool the pressure-vessel liner and the reflector graphite.

The French power reactors under the supervision of Electricite de France are of the same type. EDF-1, which began operation in 1962, is a $68-\mathrm{Mw}(\mathrm{e})$ plant. Magnesium-alloy-clad hollow rods $\left({ }^{35} / 64\right.$ in. internal diameter and $1 \frac{3}{8}$ in. outer diameter) with longitudinal fins are used. The core is installed with the fuel channels vertical in a steel pressure vessel.

EDF-2 was designed to produce $199 \mathrm{Mw}(\mathrm{e})$. It is of similar construction to EDF-1 and utilizes a spherical steel pressure vessel $60 \mathrm{ft}$ in inside diameter and $3 \frac{3}{4} \mathrm{in}$. thick. EDF-3 is designed to produce $375 \mathrm{Mw}(\mathrm{e})$ but utılızes higher temperatures and a prestressed-concrete pressure vessel. The coolant at $385 \mathrm{psig}$ enters at $464^{\circ} \mathrm{F}$ and leaves at $770^{\circ} \mathrm{F}$. It is planned to use hollow magnesium-alloy-clad uranium rods.

EDF-3 will be built with graphite moderator blocks, set vertically. Hexagonal blocks will be used, and each hexagon will be held in place with respect to its neighboring blocks by vertical pieces of graphite, about $1 / 2$ by $1 \mathrm{in}$., set in slots in the hexagonal blocks. This design will permit the entire moderator structure to move and be flexible.

Some startup troubles occurred with EDF-1. There was minor difficulty with reflector cooling; one fuel assembly stuck in an entry tube, and the reloading attachment was broken; the steel entry tubes were distorted 0.04 to $0.08 \mathrm{in}$. more than design; and some vibration of the control-rod cables occurred. All these difficulties were easily corrected. Construction, in general, was very good. ${ }^{22}$ 


\section{Prototype Reactors}

Several more-advanced prototype reactors are under design and construction.

ADVANCED GAS REACTOR The Advanced Gas Reactor (AGR) was designed and bult at Windscale, England, by the United Kingdom Atomic Energy Authority to obtain operating experience, particularly in respect to fuel hife and graphite behavior at higher temperatures. The reactor produces $100 \mathrm{Mw}(\mathrm{t})$ and $27 \mathrm{Mw}(\mathrm{e})$. The fuel is uranium dioxide clad in stainless steel with a tube size of $0.430 \mathrm{in}$. plus $0.006-1 \mathrm{n}$. roughing ribs to increase heat transfer. The fuel rods are clustered in groups of vertical channels (21 in. long and $5 \mathrm{in.}$ in diameter) in the graphite moderator and have a heat-production rate of $5 \mathrm{Mw}(\mathrm{e})$ per ton of fuel. The fuel life $\mathrm{e}^{23}$ is expected to be at least $12,000 \mathrm{Mwd} / \mathrm{t}$.

Pure carbon dioxide would react with the graphite moderator to form carbon monoxide and thus remove graphite. The reaction can be controlled by adding enough carbon monoxide to form 5 to 6 percent of the coolant. Modified graphites may eliminate the problem. ${ }^{24}$ The radiation effects on the graphite are expected to be largely self-healing in spite of the relatively low inlet coolant temperature of $270^{\circ} \mathrm{F}$. Diffusion of fission products from the fuel is considered one of the most significant problems.

The reactor was placed in operation late in 1962. It was expected that, by the end of 1963 , an evaluation could be made between the Magnox, AGR, and other reactors for construction of further power reactors in the United Kingdom. ${ }^{25-27}$

\section{EXPERIMENTAL GAS COOLED REACTOR}

The Experimental Gas Cooled Reactor (EGCR) is being built at Oak Ridge, Tenn., to obtain experience and operating data on gas-cooled reactors. It is similar to the AGR (see Table 2). Slightly enriched uranium dioxide is used in pellets, 0.750 in. in diameter, which have hollow centers for storing fission gases that diffuse from the fuel at about $3100^{\circ} \mathrm{F}$ and above. The reactor will use stainless-steel cladding, graphite moderator, and helium coolant. Each fuel cluster of seven rods is enclosed in a graphte sleeve, which supports the 29-1n. fuel elements. Experimental fuel assemblies with beryllium cladding are being tested in the reactor and in the test loops.

It is expected that the fission gases will gradually increase the internal pressure to the point at which the fuel cladding will swell because of creep. This condition may limit fuel life. A strain of 3 percent is expected ${ }^{28}$ at about $9000 \mathrm{Mwd} / \mathrm{t}$ at an average cladding temperature of $1600^{\circ} \mathrm{F}$ and $15,000 \mathrm{Mwd} / \mathrm{t}$ at $1400^{\circ} \mathrm{F}$. 
(HTGR) at Peach Bottom, Pa., for the Philadelphia Electric Company and 51 other utilities. The reactor is definitely an advanced type in that allceramic fuel and helium cooling will be used. The exit gas temperature will be $1380^{\circ} \mathrm{F}$, and steam at $1450 \mathrm{ps} 1$ and $1000^{\circ} \mathrm{F}$ will be generated.

The fuel consists of enriched uranium and thorium dicarbides dispersed in low-permeability graphite sleeves about $1 / 4 \mathrm{in}$. thick, which are enclosed in impervious graphite fuel cladding, which is in turn surrounded by impervious graphite outer sleeves. A purge gas of helium is forced through channels on the outside of the cladding, penetrates the cladding because of a pressure differential, and carries the gas that has diffused from the fuel to the lower temperature coolant inlet end of the fuel. Here the purge gas passes over a charcoal absorber, which retains most of the fission gases. The results obtained with this fuel in inreactor tests have been very successful. Activity in the purge gas was $25 \mu \mathrm{c} / \mathrm{ml}$, compared with the design of $5 \times 10^{4} \mu \mathrm{c} / \mathrm{ml}$. The activity ${ }^{29}$ in the mann coolant loop was about $3 \times 10^{-2} \mu \mathrm{c} / \mathrm{ml}$, compared with the design of $5 \times 10^{2} \mu \mathrm{c} / \mathrm{ml}$. These tests were run at a heat-production rate of $240,000 \mathrm{Btu} /(\mathrm{hr})(\mathrm{sq} \mathrm{ft})$, compared with the expected maximum heat production in the reactor of $102,000 \mathrm{Btu} /(\mathrm{hr})(\mathrm{sq} \mathrm{ft})$. A fuel life of 40,000 $\mathrm{Mwd} / \mathrm{t}$ was reached satisfactorily.

One problem of concern in the design of this reactor is contamination of the helium with water vapor because water will react rapidly with the carbon in the fuel-moderator assemblies. Because the amorphous carbon deposited in the pores of the graphite to give low permeability is most active chemically, this carbon might be preferentially attacked and lead to increases in the permeability of the graphite. Care in design of the heat exchangers and the heliumpurification system is expected to result in negligible changes over the fuel hife of 50,000 to $100,000 \mathrm{Mwd} / \mathrm{t}$.

The pressure vessel is double walled; coolant circulates between the walls. The inside wall carries no load, and the temperature of the walls is held near that of the inlet gas, $660^{\circ} \mathrm{F}$. Boron carbide poison control rods in cooled sleeves enter from the bottom of the pressure vessel. Reloading is conducted with the reactor cold at low pressure through openings in the vessel cover. The fuel assemblies, $12 \mathrm{ft}$ long, are close packed to give a core about $7 \frac{1}{2} \mathrm{ft}$ in diameter. The fuel is surrounded by a graphite reflector. Operation is expected in 1964.

DRAGON REACTOR The DRAGON reactor, which is similar to the Peach Bottom reactor, is very definitely an experiment in that $10 \mathrm{Mw}(\mathrm{t})$ and no power is produced. The reactor was designed by the United Kingdom, but the project is now under the supervision of the European $\mathrm{Nu}$ clear Energy Agency, which, in turn, is part of the Organization for Economic Cooperation and Development.

The fuel will be a homogeneous mixture of $\mathrm{U}^{235}$ and thorium oxides in graphite, and it will have surface temperatures as high as $1832^{\circ} \mathrm{F}$. 
Graphite will be used as a reflector, and helium will be used as coolant. The coolant will enter at $662^{\circ} \mathrm{F}$ and will exat at $1382^{\circ} \mathrm{F}$ at $350 \mathrm{psi}$. An extensive program of continued fuel and graphite development is planned, ${ }^{30}$ with an elght-year program estımated to cost $\$ 70,000,000$.

JULICH REACTOR The German program of reactor development has included gas-cooled reactor studies directed toward an advanced graphite-moderated helium-cooled pebble bed. The pebbles are to consist of graphite balls $2.36 \mathrm{in}$. in diameter; the fuel will be placed in a hole in the ball sealed with a threaded graphite plug. The fuel itself will consist of 20 percent uranium dicarbide mixed with about 70 percent graphite. The reactor, being bullt at Julıch, Germany, will produce 49 $\mathrm{Mw}(\mathrm{t})$ and $13.2 \mathrm{Mw}(\mathrm{e})$. The coolant exit temperature will be $1560^{\circ} \mathrm{F}$. The advantage of this reactor is the claimed ease of refueling, which can be contunuous or at intervals.

The United States is participating in the program to the extent of $\$ 5,500,000$. This participation is for development of an improved coated-particle fuel element, procurement of a core, and operation analysis. $^{31}$

\section{STEAM-COOLED REACTORS}

The U. S. Atomic Energy Commission (USAEC) has had studies made of steam-cooled reactors for use as superheaters, and the Russians have used internal superheat in the Byeloyarsk (Ural) Power Station. ${ }^{32-34}$ The General Electric Company 1s constructing the ESADA (Empire States Atomic Development Assoc1ates) Vallecitos Experimental Superheat Reactor, EVESR. This directcycle reactor is moderated with water and fueled with slightly enriched uranium dioxide. Fuel elements clad with stainless steel or nickel alloy are used. ${ }^{35}$

The reactor will produce 12.5 to $23.5 \mathrm{Mw}(\mathrm{t})$. Superheated steam at $810^{\circ} \mathrm{F}$ will be produced at $950 \mathrm{psig}$. Fuel enrichment is 4.9 percent. It is planned to raise the cladding surface temperature to $1300^{\circ} \mathrm{F}$ to give $1050^{\circ} \mathrm{F}$ steam with a heat flux of $375,000 \mathrm{Btu} /(\mathrm{hr})(\mathrm{sq} \mathrm{ft})$. Other reactor concepts are mentioned in Ref. 34 .

\section{LIGHT-WATER-COOLED REACTORS}

Experience with light-water reactors has been excellent in spite of the following disadvantages associated with the use of light water: (1) the relatively low conversion ratio of 0.5 to 0.6 , (2) the use of high pressures in the primary system, and (3) the need for corrosionresistant materials, such as zirconium alloys and stainless steel. Advantages that accrue from the use of light water are good heat transfer and smaller cores than those required with other moderators. The objections to light water have been met in various ways. The low conversion ratio has been overcome by use of fuel of higher enrichment and 
Table 3-LIGHT-WATER-MODERATED ANI -COOLED POWFR REACTORS ${ }^{1-5,7,8}$

Name

Owner

Location

Net power,

Mw (e)

Year of startup

Pressurized-water Reatots

Shipprngloot Atomic Power Station

Yankec Nuclear Power Station

Consolidated Edison Thorium Reactor

Enrico Fermi, SELNI

Nororonezh, VVPR-?

Chooz (SENA)

San Onofre Nuclear

Generating Station

Malibu Nuclear Plant

Connecticut Yankee Atoms

Power Station

Oyster Creek

Ravensw ood Reuctor Plant

Spectral Shilt
Atomic Enirgy Commission and Shippingport, Pa.

Rowe, Mass.

Yankee Atomic Electric Co.

Consolidated Edison Co. ol

New York, Inc.

Sucietà Elettronucleare Italiana

Min. of Power Stations

Societé d'Energie Nucleaire

Franco-Belge des Ardennes

Southern Calitornia Edison and San Diego Electric Co.

Los Angeles Department of

Water and Power

Connecticut Yankee Atomic Power Co.

Jersey Central Power Light Co.

Consulidated Edison Co. of

New York, Inc.

U. S. Atomic Energy Commission

Italy

Novoronezh, USSR
Indian Point, N. Y.

100

160

160

Chooz (Ardennes), France

San Clemente, Calit.

Malibu Beach, Calit.

Haddam Nech, Conn.

Oyster Creek, N. J.

Queens, Long Island City, N. Y.

\section{0}

360 (?)

242

375

$46:$

463

500

$705^{*}$

$150+$
1907

1968

1957

1960

1962

1963

1965

1965

1966

967

67

1970 
Boiling-water Reactors

Dresden Nuclear Power Station SENN A

Commonwealth Edison Co.

Morris, Ill.

200

Società Elettronucleare Nazionale Gargliano River, Italy

1959

Bodega Bay Atomic Park,

No. 1

KRB

Tarapur

Pacific Gas and Electric Co.

Kernkraftwerk-RWE-Bayernwerk

Bodega Bay, Calif.

150

1963

SENN B

Indian Department of Atomic

Gundermmingen, Bavaria, Germany 237

Tarapur, India Energy

Socıetà Elettronucleare Nazionale Garghıno River, Italy

*This plant may be equipped with an oil-fired superheater, which will add about $250 \mathrm{Mw}$ (e), or it may be all nuclear,

†Spectral-shift prototype, requested by U. S. Atomic Energy Commission in fiscal 1964 budget.

\$ The Pacific Gas and Electric Company has announced plans to build two additional units at Bodega Bay, five at Nipomo, three at South Moss Landing, and three at Montezuma Power Stations by 1980 for a total power, excluding Bodega Bay No. 1, of 8150 Mw (e). The capacities are estimated net capacities. All plants may be larger. 
1 mproved fuel management, which includes detailed studies of reloading the reactors and reshuffling the fuel, usually by movement toward the center, to give more uniform power production and longer fuel life as a result of more uniform fuel burnup. High pressures have been attained by construction of very heavy and costly tank type pressure vessels and by use of pressurized tubes in graphite or thermally insulated heavy water. Vessels more than $12 \mathrm{ft}$ in internal diameter are in use.

In these large vessels control rods can be placed under the pressure vessel attached to extended nozzles or introduced through the head of the vessel. The location at the bottom of the vessel is inconvenient, but the head is left free of extraneous equipment and thus can be removed easily. If the rods are attached to the vessel head, the head must be removed for loading or reloading, or the rod drives must be disconnected and loading carried out through holes in the head.

Corrosion of the fuel cladding and structural materials has been dealt with by use of stainless-steel or Zircaloy cladding and stainlesssteel or stainless-steel-lined vessels, piping, and heat exchangers. A minımum of other materials has been used in the primary coolant system.

The use of light water as moderator-coolant requires that slightly enriched uranium or a mixture of enriched and natural uranium be used as the fuel. Once the decision has been made to use slight enrichment, it is reasonable to use uranium dioxide and to consider stainless steel as well as zirconium and other metals for fuel cladding. Actually uranium dioxide in some form is usedinvirtually all the power reactors of $100 \mathrm{Mw}(\mathrm{e})$ or more, and stainless-steel cladding is used in most of them. Uranium dioxide has the disadvantage of low thermal conductivity, but this disadvantage is offset by the resistance of the oxide to irradiation, the fact that it does not react with water, and its high meiting point. The uranuum dioxide is usually used in the form of sintered pellets about $0.4 \mathrm{in}$. in diameter. They are usually ground after sintering to correct for distortion that occurs during sintering and are then placed in stainless-steel tubes, which are sealed by welding. For some fuel elements the pellets are ground so that they expand when irradiated to press against the tubes to give thermal contact. Several hundred fuel elements, which are usually 1 to $2 \mathrm{ft}$ long, are assembled into fuel assemblies. Calculated central temperatures may be 3000 to $4500^{\circ} \mathrm{F}$. Since fission gases diffuse from the fuel at appreciable rates above $3100^{\circ} \mathrm{F}$, some provision must be made for their storage.

\section{Status}

Table 3 lists the names, owners, locations, power levels, and status of power reactors of $100 \mathrm{Mw}(\mathrm{e})$ or more, moderated and cooled with pressurized and bolling light water, which were authorized and projected 
by mid-1963. Most are stıll in design or early construction; thus experience in operations is limited to a few plants. The total power of twelve pressurized-water reactors is nearly $4000 \mathrm{Mw}(\mathrm{e})$, and that of the five bolling-water reactors for which the power is known is $1200 \mathrm{Mw}(\mathrm{e})$. Japan and Spain plan to buld pressurızed-or bolling-water plants. The spectral-shift reactor, which is cooled by a mixture of light and heavy water, is discussed in this volume in the review entitled "Commercial Power Reactors Cooled with Sodıum, Heavy Water, or Organic Liquids."

\section{Pressurized-water Reactors}

As indicated in Table 3, four large pressurızed-water reactors are in operation. Only two of these, however, the Shippingport and Yankee reactors, have operated long enough to provide extensive operating data.

Pressurized-water reactors operate at 1500 to $2200 \mathrm{psi}$ with inlet water temperatures from 500 to $550^{\circ} \mathrm{F}$ and temperature rises in the coolant of 30 to $50^{\circ} \mathrm{F}$. Saturated steam at 530 to $580^{\circ} \mathrm{F}$ is produced.

SHIPPINGPORT REACTOR The Shippingport reactor was authorized in 1954 as a part of the USAEC program of constructing prototype reactors. The reactor was built by the USAEC. The Duquesne Light Company paid $\$ 5,000,000$ toward the development costs and supplied the turbine-generator equipment. The reactor was designed to produce 60 $\mathrm{Mw}(\mathrm{e})$. After some operating experience its power level was raised to $100 \mathrm{Mw}(\mathrm{e})$; now sufficient heat-removal equipment, including a heat sink, has been added to permit operation at the equivalent of $150 \mathrm{Mw}(\mathrm{e})$.

The reactor was first loaded with a seed-blanket core, core 1 ; in this core a fuel section of fully enriched uranium was used with internal and external blankets of natural uranium. The fully enriched section utilized zirconium-uranium alloy clad with Zircaloy in the form of fuel plates. The natural uranium was in the form of uranium dioxide in Zircaloy tubes. With the seed-blanket core, natural uranium can be used for a large part of the core, the enriched fuel can be used to partially level out the nonumform power production in the core, and the resonance absorption of neutrons in the natural uranium is enhanced. However, the buildup of plutonium in the natural uranium results in small changes in heat production in the different parts of the core. About 35 percent of the power production occurred in the enriched portion of the reactor at the start of the first fuel core; this decreased with burnup of the enriched fuel and buldup of plutonium in the blanket. The use of enriched fuel also results in higher enrichment costs.

An extensive development program was carried out concurrent with the design of the reactor. ${ }^{36,37}$ Large canned motor pumps, sealed valves, and special instrumentation were developed. The reactor andits auxiliary systems were all designed to very close tolerances, and very smooth surfaces and the highest quality materials were specified. During con- 
struction particular care was taken in makıng and inspecting all welds, and the entire plant was maintained in a very high level of cleanliness.

The primary loop was designed for $2500 \mathrm{psig}$ and $650^{\circ} \mathrm{F}$. The initial operating conditions, however, were set ${ }^{37,38}$ as $2000 \mathrm{psi}$ and a bulk outlet temperature of $538^{\circ} \mathrm{F}$. The maximum fuel-surface temperature was set as $636^{\circ} \mathrm{F}$, or $6^{\circ}$ below the predicted local film-boiling temperature. After some operating experience the bulk water temperature was permitted to rise to $636^{\circ} \mathrm{F}$. The maxumum heat flux was originally 325,000 $\mathrm{Btu} /(\mathrm{hr})(\mathrm{sq} \mathrm{ft})$ but was soon ralsed to $500,000 \mathrm{Btu} /(\mathrm{hr})(\mathrm{sq} \mathrm{ft})$. Later, local film boiling was permitted. Experimental measurements have been very close to the design values.

The primary coolant, demineralized light water, is conditioned by passage through a resin bed in the lithium hydroxide form with addition of lithium hydroxide to give a $\mathrm{pH}$ of 9.5 to 10.5 and addition of hydrogen to control the oxygen concentrations. This high $\mathrm{pH}$ specification was selected to limit corrosion of the Zircaloy fuel cladding and the stainless-steel structural material. Hydrazıne was used as an oxygen scavenger in the early operations during startups. Some corrosion of the fuel and of the hafnum-Zircaloy control-rod welds occurred, but corrosion of the steel has been low, as evidenced by the low content of "crud" (undissolved solids or particulate matter) carried by the coolant -3 to $5 \mathrm{ppb}$. Free hydrogen is maintained in the water at 15 to $60 \mathrm{~cm}^{3} / \mathrm{kg}$ at S.T.P. when the water temperature is above $200^{\circ} \mathrm{F}$. This concentration maintains the oxygen concentrations at less than the spec1fied $140 \mathrm{ppb}$ under operation since the gamma radiation fosters the formation of water with the dissolved hydrogen. Normally during operation excess hydrogen is producea at a rate of 4 to $7 \mathrm{~cm}^{3} / \mathrm{kg}$ (S.T.P.) per day. The oxygen deficiency could possibly be accounted for by corrosion.

One of the interesting problems encountered at Shippingport was "xenon tilt." Owing to erratic buildup of xenon, power fluctuations occurred in which one quadrant of the core would produce excess power, build up xenon, and, because of the poisoning effect of the xenon, produce less than average power. Meanwhile the opposite quadrant of the core would shift an equal amount but $180^{\circ}$ out of phase. In deliberate tests run at 85 percent of full power, slightly divergent oscillations as high as 7 percent were recorded. These oscillations may be overcome by core instrumentation and proper control. ${ }^{39}$

Extensive shutdowns for reloading and some short shutdowns for repairs and normal maintenance have been required. Serious operating difficulties occurred with the turbine dewatering equipment, one of the four heat exchangers leaked, and one of the main circulating pumps developed bearing trouble. Leakage in the new plant was greater than anticipated, but the total wastes were much less than anticipated. Reloading has required two to four months; however, the reloading times are being reduced. The first refueling required 134 workdays; the second, 43 ; the third, 32 . 
The reactor has proved to be capable of meeting all operational demands with a higher flexibility than the coal-fired plants on the same system. During operation to supply station load only, the power output can be increased to $20 \mathrm{Mw}(\mathrm{e})$ net in $1 \mathrm{~min}$ and to $60 \mathrm{Mw}(\mathrm{e})$ net in $20 \mathrm{~min}$ and returned to zero net output in the same times.

The fuel for core 2 consists of compartmented plates with wafers 0.036 by 0.25 by $1.5 \mathrm{~m}$. in the seed or enriched section. The seed wafers are made of enriched uranium with various amounts of diluents and burnable poison. The blanket is made of $0.25-$ by $1.5-1$ n. natural uranium dioxide wafers $0.100 \mathrm{~m}$. thick. Both fuels are clad with Zircaloy. The heat flux varies from 57,000 to 300,000 in the blanket and from 200,000 to $650,000 \mathrm{Btu} /(\mathrm{hr})(\mathrm{sq} \mathrm{ft})$ in the seed.

YANKEE REACTOR The Yankee Atomic Electric Company plant was built as a regular power reactor, and an effort has been made to operate the reactor as contınuously as possible. It began full-power operation in November 1960 and was shut down from January untll May 1961 for partial refueling. From May 1961 untıl late in 1962, it was operated steadily as a base-load plant. The design power was $141 \mathrm{Mw}(\mathrm{e})$, but it was increased to $155 \mathrm{Mw}(\mathrm{e})$ in 1962. The reactor is now operating at $160 \mathrm{Mw}(\mathrm{e})$ with the second core. Avallability was about 96 percent, and operation during core life was 70 percent. One run of 147 days was completed.

Shutdowns during the life of the reactor have been made for mechan cal troubles, for tests required by the USAEC as a part of the safetycheck program, and for special tests. The startup and initial operation compared favorably with those for conventional plants. The first partial reloading took four months compared with the planned two months. Delays were due to untoreseen difficulties, most of which are not expected to recur. ${ }^{40}$

Very few operating difficulties have occurred. Flux tilts due to xenon occurred, but they soon burned out. The reactor is not equipped with sufficient instrumentation to control the tilting properly. ${ }^{41}$ Boric acid was dissolved in the coolant of this reactor to simplify control. Success was questionable because "hideout" occurred, and this cond1tion led to discontinuance of the initial tests. ${ }^{41}$ The test was definitely not conclusive because the hideout of boric acid amounted to a temporary disappearance of about $1 \mathrm{~g}$ of boric acid. This amount may have been absorbed on the thousands of square feet of the surface of the primary coolant circuit. Since other changes in reactivity occurred at the same time, no definite conclusion was drawn from the tests. A more extensive test was started early in 1963. It is planned to continue this test indefinitely and to use the boric acid as a component of the regular control system. This practice is expected to eliminate the danger of power fluctuations due to nonuniform xenon bulldup. 
Thorium Reactor (CETR) at Indian Point, N. Y., was designed to produce $160 \mathrm{Mw}(\mathrm{e})$ by nuclear heat and to produce saturated steam at $449^{\circ} \mathrm{F}$ and $420 \mathrm{psia}$. The reactor is equipped with an oil-fired superheater, which heats the steam to $1000^{\circ} \mathrm{F}$ and increases the total power to $272 \mathrm{Mw}(\mathrm{e})$.

The reactor is unique in two ways. First, the steel containment building is surrounded by a 5 -ft-thick concrete shield to protect the public if radioactive materials are lost from the primary reactor core to the containment building. Second, the fuel is a mixture of enriched uranium and thorium oxides. This fuel has the advantage of a higher conversion ratio than that of slightly enriched fuel. The fabrication costs were higher, however, for the mixed fuel, and it is planned to use slightly enriched uranium dioxide for the second core.

Startup difficulties with this plant were nominal. A piping error in the conventional part of the plant caused a delay of two weeks. The control system was designed so that differences greater than $1 / 2$ in. in the positions of the various control rods would cause fast insertion of the rods. This procedure for rod insertion was adopted as a safety precaution. However, $1 / 2$ in. proved to be too small, and some trouble occurred before the proper adjustments were established. ${ }^{42}$ The controlrod limit switches were located in a region accessible to moisture; this condition caused trouble until corrected by a dry-gas purge.

\section{Boiling-water Reactors}

In the boiling-water reactors, bulk boiling occurs in a considerable portion of the core. Since this bolling creates voids, it results, under most conditions, in a large loss of reactivity and thus decreases the power. This fact is utilized as a safety feature.

EXPERIMENTAL BOILING WATER REACTOR

As a result of successful tests with the BORAX test reactors, the Experimental Boiling Water Readtor (EBWR) was developed under the supervision of Argonne National Laboratory as a part of the USAEC program of five prototype reactors adopted in 1954. It is designed for $20 \mathrm{Mw}(t)$, with a power production of $5 \mathrm{MW}(\mathrm{e})$. It is a natural-circulation reactor and produced 600 -psi saturated steam. The original core was about 4 ft in diameter and $4 \mathrm{ft}$ high. The fuel was slightly enriched uranium alloyed with zirconium and niobium with Zircaloy cladding.

Various instabilities have been found in boiling-water reactors. ${ }^{43,44}$ They have been investigated in the EBWR, the Dresden reactor, the Vallecitos reactor, and particularly in the BORAX and SPERT reactor experiments. First, as a result of the reactor kinetics, an instability due to power-to-reactivity feedback occurs. Second, flow oscillations occur in low-pressure boiling-water reactors because of fluctuations 
due to bubble formation. Third, an instability may be caused by large bubble formation at low pressures due to local superheating; in the SPERT-1A tests, local superheating of $3.4^{\circ} \mathrm{F}$ was measured. Fourth, surges due to two-phase flow in risers, such as those in use in the Dresden plant between the reactor and steam separator,occur. Finally, an instability due to increased feedwater flow using subcooled water may occur. When this instability occurs, the average temperature in the core is reduced owing to the increased subcooling of the recirculating water. In an extreme case this may lead to temporary doubling of the power production.

The EBWR was used to check the onset of instability. Theoretical studies indicated that the reactor with its initial core could operate at power levels up to about $66 \mathrm{Mw}(\mathrm{t})$. Therefore operation was carried out at increasing power levels up to $64 \mathrm{Mw}(\mathrm{t})$, at which point the reactor was still stable but with only a small margin. Operation was limited to a few minutes since the feedwater and steam-condenser systems were inadequate. The maximum heat-production rate at $60 \mathrm{Mw}(\mathrm{t})$ was calculated to be $464,000 \mathrm{Btu} /(\mathrm{hr})(\mathrm{sq} \mathrm{ft})$ with an average heat flux of 137,000 $\mathrm{Btu} /(\mathrm{hr})(\mathrm{sq}$. ft). Later the reactor was modified to operate at power levels up to $100 \mathrm{Mw}(\mathrm{t})$. The changes included increased feedwater capacity, additional fuel, improved steam separation, larger steam lines, and steam-air condensers to dissipate the extra heat. The add1tional feedwater required the installation of enlarged feedwater and steam nozzles in the pressure vessel. This installation was accomplished successfully by removing the fuel, cleaning the vessel remotely, and installing a steel and lead shield just below the inlet nozzle position. The larger core was about $5 \mathrm{ft}$ in diameter with an active height of $4 \mathrm{ft}$.

Operation at $100 \mathrm{Mw}(\mathrm{t})$ was just possible since the reactor was nearing unstable operating conditions and the steam-water separator was overloaded. The predicted steam-vold content of the core at $60 \mathrm{Mw}(\mathrm{t})$ was 12 percent, but 20 percent was actually measured. As the power level increased, the steam volds did not increase in the calculated amounts but actually leveled off and decreased. In other words, less reactivity was needed as the power level increased toward $100 \mathrm{Mw}(\mathrm{t})$. The explanation is that the water carryover in the steam became excessive and the return of the colder feed resulted in an actual decrease in volds. 45,46

The EBWR demonstrated that the use of large-scale bolling-water reactors is practical; nuclear instabilities do not become serious until relatively high heat-production rates, about $500,000 \mathrm{Btu} /(\mathrm{hr})(\mathrm{sq} \mathrm{ft})$, occur; the use of direct steam in turbines is practical; and the reactor is easily controlled when the electric generator is a part of a large power system.

Argonne, among others, has been investigating the theory and prac- 
tical effects of steam carryunder with the recirculating water. This problem is particularly troublesome in boiling-water reactors with natural circulation but is not a problem in the forced-circulation reactors, such as the Dresden reactor. Water carryover in the steam is a problem in all bolling-water reactors. It has been reduced by the development of improved steam-water separators and steam demisters.

After the EBWR the Vallecitos Bolling Water Reactor at Pleasanton, Calif., was placed in operation in 1957. This reactor was built by the General Electric Company to obtain design data for large power stations. It was designed for $20 \mathrm{Mw}(\mathrm{t})$ but has operated at $50 \mathrm{Mw}(\mathrm{t})$.

DRESDEN REACTOR

The Dresden Nuclear Power Station was built near Chicago, Ill., in the area served by the Commonwealth Edison Company. Although Commonwealth Edison owns the plant, a group of utilities and industrial companies contributed funds toward its development. It was the first regular nuclear electric power station using a boilingwater reactor to be placed in operation. It was designed for $180 \mathrm{Mw}(\mathrm{e})$ but is operating at $200 \mathrm{Mw}(\mathrm{e})$.

In the Dresden reactor bulk bolling of the coolant occurs, and the steam is run directly to the turbine. The circulated water is passed through heat exchangers to produce additional, but lower pressure, steam. At full power $1.6 \times 10^{6} \mathrm{lb} / \mathrm{hr}$ of steam is generated in the reactor core at $990 \mathrm{ps}$, and $1.3 \times 10^{6} \mathrm{lb} / \mathrm{hr}$ is generated at $520 \mathrm{ps}$. As the load decreases, the secondary steam pressure increases to $950 \mathrm{ps} 1$ as the volume decreases. A power increase requires increased steam flow to the turbine; this flow lowers the pressure in the secondary steam and increases the temperature drop in the heat exchanger. More steam is generated, and the lower temperature water increases the reactor power level.

The startup performance tests on the Dresden reactor began with the physics tests of the critical loading of 28 fuel assemblies. Temperature and vold coefficients, flux patterns, etc., were measured as fuel loading continued up to the original full load of 448 fuel assemblies. The negative temperature coefficient increased with temperature to about $-1.2 \times 10^{-4} \delta \mathrm{k} / \mathrm{k}^{\circ} \mathrm{F}$ (temperature rise of $83^{\circ} \mathrm{F}$ for 1 percent $\delta \mathrm{k} / \mathrm{k}$ ) at operating temperature. This coefficient ${ }^{47}$ decreased to $-5.7 \times 10^{-5}$ $\delta \mathrm{k} / \mathrm{k}^{\circ} \mathrm{F}$ (temperature rise of $175^{\circ} \mathrm{F}$ for 1 percent $\delta \mathrm{k} / \mathrm{k}$ ) with a fuel exposure of $1770 \mathrm{Mwd} / \mathrm{t}$.

There are 80 poison control rods in this reactor. Because of the relatively large core, power production can be partially leveled out in the radial direction by proper programming of the 80 rods. This flattening is very important in that it permits all fuel assemblies to develop more nearly equal amounts of power. Measurements of the neutron-flux-peaking factors compared with the design values are shown in Table 4. The neutron flux is measured by flux monitors placed in 16 extra fuel spaces in the core. 
Table 4-DRESDEN FLUX-PEAKING FACTORS 67.48

\author{
Measured \\ Design Startup* November $1960+$
}

$\begin{array}{llll}\text { Gross peaking factors } & & & \\ \text { Axial } & 1.60 & 1.60 & 1.50 \\ \text { Radial } & 1.15 & 1.14 & 1.35 \\ \text { Intercontrol rod } & 1.20 & 1.12 & \\ \text { Local peaking factors } & & & 1.40 \\ \quad \text { Corner rod } & 1.40 & 1.40 & \\ \text { Overpower factor } & 1.25 & 1.25+ & 2.85 \\ \quad \text { Product } & 3.85 & 3.64 & \end{array}$

*Reference 47 . †Reference 48 . Estimated.

The hydraulic system of the reactor was found to be conservatively designed. The coolant recirculation rate was $2.7 \times 10^{7} \mathrm{lb} / \mathrm{hr}$, compared with the design of $2.5 \times 10^{7} \mathrm{lb} / \mathrm{hr}$. With a water inlet subcooling of 53 $\mathrm{Btu} / \mathrm{lb}$, the peak heat flux of $350,000 \mathrm{Btu} /(\mathrm{hr})(\mathrm{sq} \mathrm{ft})$ gave an estimated fuel-burnout ratio of 2.1. The voids in the core were 11 percent of the channel coolant volume and 65 percent at the hot-channel exit under estimated overpower conditions. Stability measurements indicated that there was no instability near operating conditions.

One-fifth of the core is refueled at one time. This fuel is changed on the basis of a calculated scattering of the new fuel. This practice simplifies reloading and minimizes the reactivity changes.

During an inspection prior to a reactor startup, it was found that one poison blade had separated from the drive owing to a break in the index tube. Other index tubes were cracked. These cracks were caused by stress-corrosion cracking of the 17-4 $\mathrm{PH}$ steel aged at $900^{\circ} \mathrm{F}$. Samples of the tubes also failed in laboratory tests, and high stresses were found in the tubes. As a result the 17-4 $\mathrm{PH}$ steel was replaced with material aged at 1050 to $1100^{\circ} \mathrm{F}$. The original control blades we re boron stainless steel. After the blades had been in operation for about one year, several minor cracks occurred in the steel. Therefore the blades were replaced by boron carbide powder carried in small-diameter stainless-steel tubes. Minor cracks were found in the core grid structure during an inspection, but, at a later examination after several months of operation, there was no change in the number or extent of the cracks.

The thick-walled Dresden vessel, its flange, head, and primary steam drum require slow heating. The temperature differential in the steam drum is limited to $150^{\circ} \mathrm{F}$. The temperature differential between 
the flange and the midsection is usually the limiting temperature. The usual heatıng rates are 50 to $100^{\circ} \mathrm{F} / \mathrm{hr}$. The reactor power level may be dropped to 10 percent or less without appreciably changing the temperature of the vessel.

\section{Advanced Power Reactors}

The water-cooled nuclear power plants that have been discussed deliver steam to the turbines at relatively low temperature and low pressure, and the thermal efficiencies of the plants are low compared with those of the best coal-fired power plants Thermodynamically the nuclear power plants should produce the highest temperature steam because the nuclear heat is all avallable at as high a temperature as it can be removed; but this advantage of nuclear heat has not yet been utilized successfully in power plants In addition, the turbines for the lower pressures are more expensive than turbines for high-pressure superheated steam For these reasons there has been a continuous effort to develop higher temperature reactor systems

Designs of several types of water-cooled reactors have been made in the United States They have been succeeded by construction of three superheat reactors: BORAX-5, Pathfinder, and BONUS (see Table 5) These reactors ard a design for a once-through superheat reactor, the SCOTT-R, will be described briefly

BOILING SUPERHEATER REACTORS Three boiling-water reactors with internal superheat are in operation or under construction in the

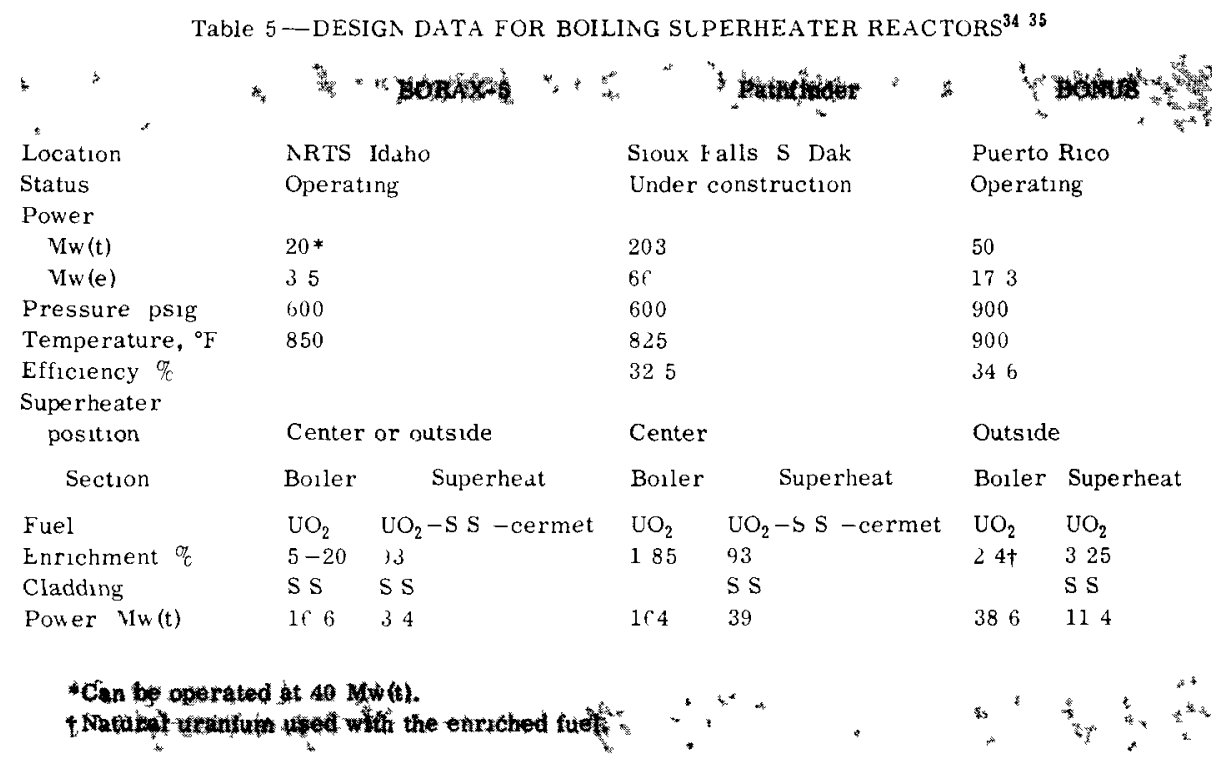


United States. In these reactors the primary steam produced in the boiling section is recirculated through the superheater portion of the reactor (see Table 5 and Refs. 44, 49-52). Design problems include dealing with the reactivity changes due to flooding of the superheater, selecting fuel cladding for use in high-temperature superheated steam, and balancing the heat production between the bolling and superheating sections.

SUPERCRITICAL REACTORS Westinghouse Electric Corporation conducted a study for the USAEC of two concepts of a supercritical reactor on a near-term and an advanced-technology basis for a 1000-Mw(e) nuclear power station. The year 1975 was taken as a suitable target date for initial operation of the advanced type. One concept, the Supercritical Once-Through Tube Reactor (SCOTT-R) utılized metal-clad fuel contained in coolant pressure tubes. In the second concept, the Fuel Bearing Graphite Reactor (FBGR), fuel was dispersed in graphite external to the coolant tubes. Calculations and designs were prepared for a steam plant known to be reasonably near optımum. ${ }^{53}$

In the SCOTT-R design several hundred pressure tubes are placed vertically in a graphite moderator block. Uranium dioxide clad with austenitic steel is used. Once-through water at $3500 \mathrm{psi}$ is heated to $1050^{\circ} \mathrm{F}$ to give a net efficiency of about 44 percent. Live-steam reheat was assumed.

\section{COSTS}

Extensive cost studies have been made on both gas-and watercooled power reactors. Some costs are peculiar to each type; others are common to both.

\section{Construction}

Experience with both gas- and water-cooled reactors has been extensive enough to permit the prediction of lower future costs. Cost estimates, however, are complicated by such factors as incomplete data and the uncertain effect of government subsidies.

GAS-COOLED REACTORS Construction costs for the various gascooled power reactors are presented in Table 6 , and the data are plotted in Fig. 1. Although the trend in capital costs is downward, the two factors of cost decreases due to construction and operational experience plus cost decreases due to increased size are present; thus the lowered costs must not be attributed only to cost decreases due to experience. ${ }^{13,16-18}$ Even with these advances the plants do notproduce electric power at costs as low as plants fired with o1l and coal. Estımates indicate $^{58}$ that capital costs of the Magnox stations w1ll be about $\$ 250 / \mathrm{kw}$ in 
Table 6 - CONSTRUCTION COSTS FOR GAS-COOLED POW ER REACTORS

\begin{tabular}{|c|c|c|c|c|}
\hline \multirow[b]{2}{*}{ Plant } & \multirow[b]{2}{*}{ Status } & \multicolumn{2}{|c|}{ Cost } & \multirow[b]{2}{*}{ Reterences } \\
\hline & & Total, $10^{6} \$$ & $\$ / \mathrm{ku}$ & \\
\hline Berkeley & Operating & $137^{*}$ & 495 & $16,17,19$ \\
\hline Bradwell & Operating & $144^{*}$ & 480 & $5,19,21,54$ \\
\hline Hinkley Point A & Construction & $199^{*}$ & 399 & $5,54,55$ \\
\hline Trawsfynydd & Construction & $190 *$ & 380 & 54,56 \\
\hline Hunterston & Construction & 122 & 380 & 56 \\
\hline $\mathrm{EDF}-3$ & Construction & 104 & $375-217$ & $6,55,56$ \\
\hline Dungeness & Construction & $172^{\star}$ & 312 & 54,56 \\
\hline Tokal-Mura & Construction & 100 & 632 & 57 \\
\hline Sizewell & Construction & $172^{*}$ & 296 & $4,54,56$ \\
\hline Oldbury & Construction & $175^{*}$ & 312 & 4,54 \\
\hline U ylfa & Design & 281 & 281 & \\
\hline Hinkley Point B & Projected & 477 & 238 & \\
\hline \multicolumn{5}{|c|}{ Predicted Future Costs } \\
\hline Magnox & & 119 & 238 & 5 \\
\hline Advanced & & 90 & 180 & 58 \\
\hline
\end{tabular}

* Costs estimated as of May 1963 (see Ref. 54).

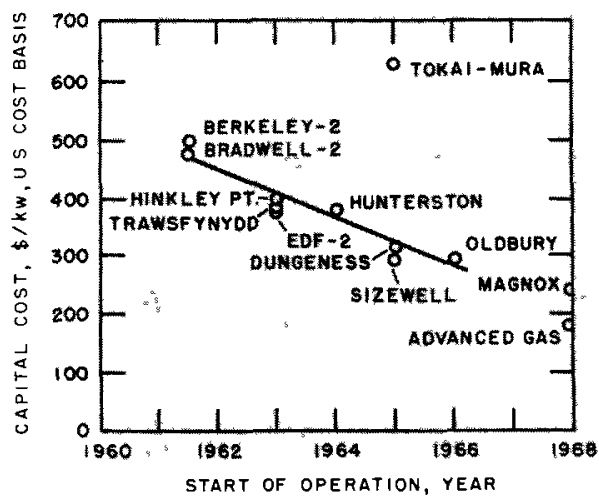

Fig. 1 - Capital costs for gas-cooled nuclear power plants.

1970. Although slightly enriched ceramic fuels could be utilized in any of the natural-uranium reactors, once a reactor has been built, it is not possible to optimize it to a different fuel. Furthermore, higher power levels would usually not be possible without considerable reconstruction of the piping, pumps, and heat exchangers and the installation of more turbine generators. The lower costs of uranium and fuel fabrication expected in the next 10 to 20 years will favor the use of natural uranium. Strips and hollow rods as fuel elements have been considered. 
Future larger plants are expected to have lower power costs. Under United Kingdom financing practice, a $700-\mathrm{Mw}(\mathrm{e})$ Magnox power plant is expected to produce power for $6.4 \mathrm{mills} / \mathrm{kw}-\mathrm{hr}$ at a 75 percent load factor, 6 percent interest, 20-year life, and present uranium prices. With a 90 percent load factor and 30 -year life,${ }^{58}$ the power would cost 5 mills/ kw-hr. At present, costs can be estimated closely enough that definite contracts can be let. Design, construction, and operation can be improved.

The AGR has a higher rate of heatproduction per unit volume of the core and therefore a smaller plant with reduced capital charges. It was estımated in April 1962 that costs may go as low as $\$ 182 / \mathrm{kw}$ in the 700 $\mathrm{Mw}(\mathrm{e})$ size in the United Kingdom. ${ }^{58}$ Data presented in Ref. 25 indicate costs in the United Kingdom for power produced in advanced Magnox, fully developed "advanced type" gas-cooled, CANDU (the naturaluranium heavy-water reactors being bullt in Canada), and bolling-water reactors, as 5.6 mills/kw-hr for two reactor stations for $1000 \mathrm{Mw}(\mathrm{e})$ total power. These data indicate that power costs may be quite independent of reactor type. In March 1963 power costs of 4.0 to $4.8 \mathrm{mllls}$ / $\mathrm{kw}-\mathrm{hr}$ were estimated on the basis of $20,000 \mathrm{Mwd} / \mathrm{t}$ with a fuel cost of $1.75 \mathrm{mllls} / \mathrm{kw}-\mathrm{hr}$ capital costs of $\$ 238 / \mathrm{kw}, 75$ percent load factor, 20 year amortization, and 6 percent interest. Technically the stanlesssteel cladding surface temperature assumed is $1385^{\circ} \mathrm{F}$, which would give $1161^{\circ} \mathrm{F}$ exit gas and $1050^{\circ} \mathrm{F}$ steam at 2350 psia with an efficiency of 43.5 percent. ${ }^{24,59}$

For advanced gas-cooled reactors, Oak Ridge National Laboratory has estimated ${ }^{60}$ that a fully developed $1000-\mathrm{Mw}(\mathrm{e})$ gas-cooled nuclear power plant, operated at 90 percent load factor with 13.2 percent fixed charges, would produce power at a cost as low as $4.1 \mathrm{mllls} / \mathrm{kw}-\mathrm{hr}$. No estimate of power costs is avallable for a large DRAGON type reactor (see Table 2).

WATER-COOLED REACTORS Construction costs for the large pressurized- and boiling-water reactors are presented in Table 7 and F1g. 2. The data avallable are incomplete because actual construction costs are not available for some reactors, subsidies of various kinds may be present, and too few plants have been bullt to provide accurate costs of fully developed plants built by fully experienced design and construction firms. The costs are for plants using slightly enriched fuel.

Table 7 indicates that the original capital costs of the Shippingport reactor were high; but they have been reduced from $\$ 1220 / \mathrm{kw}$ to $\$ 546 / \mathrm{kw}$ as the power level has been increased from $60 \mathrm{Mw}(\mathrm{e})$ to a potential of $150 \mathrm{Mw}(\mathrm{e})$. A lesser, but still important, reduction occurred with the Yankee reactor. The reactor was designed to produce $136 \mathrm{Mw}(\mathrm{e})$ at an estımated cost of $\$ 52,000,000$. Actual costs are now stated ${ }^{61}$ to have been $\$ 41,000,000$. With the second core the reactor now operates at $170 \mathrm{Mw}(\mathrm{e})$ gross and $160 \mathrm{Mw}(\mathrm{e})$ net, reducing the installed cost from 
Tabfe 7-CONSTRUCTION COSTS EOR LIGHT-WATER-COOLED AND -MODERATED POWER REACTORS ${ }^{65,68}$

Plant $\quad$ Status $\frac{\text { Cost }}{\text { Total } 10^{6} \$ \$ / k W}$ References

\begin{tabular}{|c|c|c|c|c|}
\hline Shıppingport & Operatıng & 729 & $1220-546 *$ & 56 \\
\hline Yankee & Operating & 410 & $301-256$ & 56,61 \\
\hline $\begin{array}{l}\text { Indian Point Con- } \\
\text { solıdated Edison }\end{array}$ & & & 250 & \\
\hline Enrico Fermı, SELNI & Construction & 564 & 320 & 56 \\
\hline San Onofre & Plannıng & $\sim 750$ & & $62 \quad 63$ \\
\hline Malıbu Beach & Planning & $\sim 790 \dagger$ & & 62 \\
\hline Ravenswood & Planning & $1750 \ddagger$ & 175 & 64 \\
\hline Spectral Shift Reactor & Planning & 300 & 233 & 62 \\
\hline
\end{tabular}

Bolling-water Reactors

$\begin{array}{llccc}\text { Dresden } & \text { Operating } & 510 & 280-226 & 6566, \\ & & & 255 & 67 \\ \text { SENN } & \text { Construction } & 632 & 420 & 56 \\ \text { Bodega Bay } & \text { Construction } & 610 & 188 & 68 \\ \text { Tarapur } & \text { Design } & 784 & 218 & 69 \\ \text { Malibu Beach } & \text { Planning } & \sim 720 & 180 & 64\end{array}$

Predicted Future Costs

Pressurized water

Bolling water

1250

$125 \S$

1250

$125 \S$

*Includes $\$ 9,000,000$ for extra heat-dumping equpment. The turbine capacty is lumited to 100. Mw(e).

Total plant costs The Malibu Beach "steam-geneqatung equipment" will cost $\$ 41.4 \times 10^{6}$ or $\$ 89.5 / \mathrm{kw}$.

\$ Ineludes 250-Mw te) oll-fired superheater in total cost of 1000-Mw(e) plant for $175,000,06$, , Detals of this plant are not fore, and the plant ray nuclear.

Lowest easts now considered for inmedrate contracts are about $\$ 140$ to $\$ 150 / \mathrm{kw}$.

$\$ 301$ to $\$ 256 / \mathrm{kw}$. The CETR at Indian Point was estimated to cost $\$ 89,300,000$, but much higher costs have been estimated for the plant by various individuals.

The contract of the San Onofre plant was let to Westinghouse Electric Corporation and Bechtel Corporation jointly for $\$ 69,800,000$. This excluded $\$ 13,800,000$ for on-site work and land costs. The on-site cost of $\$ 13,800,000$ included the transmission switchyards and presumably the transformers, which are normally included in the distribution cost. ${ }^{62,63}$ The cost of the plant is assumed here to be $\$ 75,000,000$. 


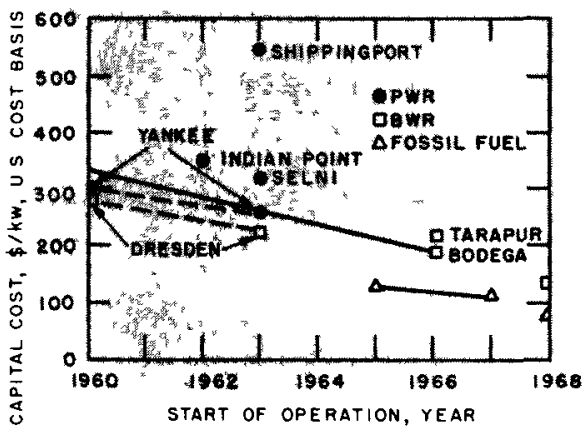

Fig. 2-Capital costs for commercial power plants in which pressurized and boiling light-water reactors or fossil fuels are used.

The cost of the Dresden reactor has been estimated by the USAEC as $\$ 60,900,000$, compared with earlier USAEC estımates of $\$ 51,000,000$ (Refs. 61 and 65). This figure was estimated ${ }^{65}$ as follows: “... contract price of $\$ 45$ million, cost of land at $\$ 0.55$ million, and overhead and interest during construction of $\$ 5.6$ million.' This cost estrmate was used in Table 7 and Fig. 2. Actually the Dresden plant was bult under a fixed-price contract, and the cost is unknown. In this respect D. $R$. Bower, Treasurer of Commonwealth Edison Company, stated ${ }^{67}$ in 1962: "Dresden is a superb achievement and indicates magnificent progress. The favorable contract price of $\$ 45,000,000$ has resulted in a real step toward economic nuclear power. There was a development effort of $\$ 15,000,000$. The base price of $\$ 30,000,000$ will glve a cost of $\$ 181 / \mathrm{kw}$ at the future expected power level or a total plant cost of $\$ 36,200,000$."

As indicated in Table 7 and Fig. 2, the power level of the Dresden reactor has been raised from 180 to $200 \mathrm{Mw}(\mathrm{e})$. The General Electric Company has estimated that Dresden can produce $270 \mathrm{Mw}(\mathrm{e})$. This increase in power would presumably require additional steam-generating equipment, steam piping, and a turbogenerator. I estimate that installation of this equipment would add $\$ 10,000,000$ to the cost of the plant.

Similar difficulties are present in respect to the Bodega Bay boilingwater reactor. The announced price of $\$ 61,000,000$ may be low, and the USAEC has used $\$ 66,400,000$ or $\$ 204 / \mathrm{kw}$ rather than the $\$ 188 / \mathrm{kw}$ shown in Table 7.

The bids for the Los Angeles Department of Water and Power reactor proposed for Malibu Beach included the General Electric Company bid of $\$ 36,500,000$ for a $400-\mathrm{Mw}(\mathrm{e})$ plant, the Babcock and Wilcox Company bid of $\$ 42,800,000$ for a $400-\mathrm{Mw}(\mathrm{e})$ plant, and the Westinghouse Electric Corporation bid of $\$ 41,400,000$ for a $490-\mathrm{Mw}(\mathrm{e})$ plant. The bids were for the nuclear components and, presumably, were for boiling-water, spectral-shift, and pressurized-water reactors. Since the entire project was estimated to cost $\$ 72,000,000$, it is estimated that the lowest cost of the various bids plus the cost of the remainder of the plant would be about $\$ 170 / \mathrm{kw}$, or $\$ 79,000,000$ for the plant. 
Tuble 8 - ITEMIZED CONS IRUCTION COS TS FOR SELECTED LIGHT-WATER NUCLEAR POW ER PLANTS ${ }^{56}$

\begin{tabular}{|c|c|c|c|c|c|c|c|c|}
\hline & \multicolumn{4}{|c|}{ Pressurized water } & \multicolumn{4}{|c|}{ Bolling water } \\
\hline & Shippingport & Yankee & Fermi & $\begin{array}{l}\text { Indıan } \\
\text { Point }\end{array}$ & Humboldt & $\begin{array}{l}\text { Big Roch } \\
\text { Point }\end{array}$ & SENA & Dresden \\
\hline Net capacity, Mu (e) & $100^{*}$ & $110-160$ & 176 & 255 & 48.5 & $48.5-72.8$ & 150 & $180-270$ \\
\hline Cost, $\$ / h w$ & & & & & & & & \\
\hline Land and land reghts & & $1.8-1.2$ & & 1.5 & & $3.1-2.1$ & 4.0 & \\
\hline $\begin{array}{l}\text { Structures and } 1 \mathrm{~m}- \\
\text { provements }\end{array}$ & 147 & t) $2-43$ & 54 & 95 & 59 & $125-83$ & 27 & \\
\hline $\begin{array}{l}\text { Reactor plant } \\
\text { equipment }\end{array}$ & 188 & $118-65$ & 105 & 118 & 182 & $2 \times 8-152$ & 157 & \\
\hline Tur bogenerator plant & $\begin{array}{r}100 \\
98\end{array}$ & $\begin{array}{r}10-00 \\
80-55\end{array}$ & & $\begin{array}{r}118 \\
198\end{array}$ & $\begin{array}{l}182 \\
108\end{array}$ & $\begin{array}{l}228-152 \\
116-78\end{array}$ & $\begin{array}{r}151 \\
51\end{array}$ & \\
\hline $\begin{array}{l}\text { Miscollune ous power } \\
\text { equument }\end{array}$ & 23 & $19-13$ & 65 & 18 & 5.9 & $11-7$ & 5,3 & \\
\hline Interest (construction) & 23 & $27-19$ & & 20 & & $37-25$ & 59 & \\
\hline $\begin{array}{l}\text { Indirect construction } \\
\text { costs } \\
\text { Contingencies } \\
\text { Escalation }\end{array}$ & 25.1 & $\begin{array}{r}122-84 \\
60-41\end{array}$ & 96 & 18 & 47 & $\begin{array}{l}20-14 \\
10-7\end{array}$ & $\begin{array}{r}87 \\
7 \\
24\end{array}$ & \\
\hline Total & 729 & $470-333$ & 320 & 350 & 400 & $550-370$ & 420 & $283-226 \dagger$ \\
\hline
\end{tabular}

*Desagn was $60 \mathrm{Mw}(\mathrm{e})$; plant now operatıng at equivalent to $150 \mathrm{Mu}(\mathrm{e})$; $100-\mathrm{Mw}$ (e) turbogenerators avaldable. $\uparrow \$ 10,000,000$ allowed for turbogenerator tor $90 \mathrm{Mw}(\mathrm{e})$ plus buildings and additional equipment. 
Other data Indicate that complete 500-Mw(e) nuclear power plants without the first cores can be purchased in the United States for initial operation in 1967 for about $\$ 140 / \mathrm{kw}$, and this value has been used in Fig. 2. These reactors are all cooled and mode rated with light water and use slightly enriched uranium dioxide fuel in stainless-steel or Zircaloy cladding. Enrichment would be perhaps 3.0 percent, and the conversion ratio, perhaps 0.60 .

Sufficient water-cooled tank type pressurızed-and bolling-water reactors are being built that components can be partially standardized. Capital costs of $\$ 150 / \mathrm{kw}$ by 1970 and $\$ 125 / \mathrm{kw}$ by 1980 , based on today's dollar, have been predicted. There appear to be opportunities for great advances with pressurized-and bolling-water types in respect to use of higher rates of coolant flow with higher heat-production rates, longer fuel life, and lowered costs. Nevertheless there are economic reasons that may permit other reactor types to be built at equal or lower capital costs. The inherent difficulties of reloading, the cost of the pressure vessels and primary-loop components, the large amounts of stored energy, and the extra contanment requirements for water reactors all add to the costs.

Bolling-water reactors are being bult with increased pressures and with internal superheat, whereas film bolling and even bulk boiling are being permitted in the pressurized-water reactors. The development of the once-through bolling-superheater reactor is a logical outgrowth of this experience. Boiling-water reactors with internal superheat, spectral-shift reactors, and seed-blanket pressurized-water reactors are being designed or built. Thus there are several types of water reactors, but which is the most promising is not yet apparent. The once-through bolling-superheater and the advanced gas reactors continue the trend toward higher temperatures with increased thermal efficiencies. At the same time lower fuel costs indicate the possibility for a slowdown in this trend. Other factors, such as turbine and materials costs and reactor physics in respect to conversion ratio and resonance effects (including nonfission absorption), are becoming more significant as costs decrease.

The costs for fossil-fuel plants were taken from estımates made by Sporn. ${ }^{70}$ Actually these costs may be low because apparently they are purchase prices and not startup-date prices. Consequently they have been moved two years to the right in Fig. 2. The future or predicted prices are for initial operation in about 1975.

Itemized construction-cost data for some pressurized and boiling light-water reactors are presented in Table 8.

\section{Fuel}

Source and fissionable materials used as nuclear fuels are almost entirely government owned and are government controlled in all coun- 
tries. In spite of this situation, a free marketin natural uranium is developing, particularly in Canada, and the United States government is planning legal steps to open the way to private ownership and a free market in nuclear fuels. It is expected that registration and inspection of enriched fuels will continue. The United Kingdom does, and the United States plans to, permit toll enrichment of uranium in the $U^{235}$ separation plants. This program permits reactor operators in other countries to contract for fuel enrichment on a long-term basis. The USAEC has signed a 20-year contract with the European Atomic Energy Community to provide slightly enriched uranium for the SENN reactor and to buy back plutonium produced by the reactor. ${ }^{71}$

Nuclear-fuel production costs are not generally avallable. Although prices have been set by the USAEC, some have been set at a level to produce incentıve, and others may not have included all interest and other charges. These prices and the Guade to Nucleal Pouel Cost Elaluation may be used to estimate nuclear fuel costs. ${ }^{72}$

The prices of nuclear fuels have been tending downward owing to oversupply of natural uranium, improvements in manufacturing techniques, and increased volumes. Uranium mining, ore concentration, and fuel-fabrication plants are privately owned in several countries, and a private plant for recovery of irradiated fuel is being built in the United States.

Prices for uranium-ore concentrates as 80 percent uranium oxide are $\$ 3$ to $\$ 8$ per pound. Natural uranıum as purıfied uranium dioxide or metal ingots has a value of $\$ 10$ to $\$ 25$ per kilogram (pounds are used for ores and kılograms or grams for all other nuclear fuel quantities). The prices of $\mathrm{U}^{235}$ in the United States, in dollars per gram, ${ }^{73}$ are: natural uranıum, 3.17; 1 percent enrıched uranıum, 4.77; and 90 percent enriched uranium (as $\mathrm{UF}_{6}$ ), 12.01 .

FABRICATION The fabrication costs of nuclear fuel assemblies have been very high. Operations are complex, and specifications and inspection are rigid and complex.

Costs in the United States of fabricating uranıum dioxide fuel assemblies clad with stainless steel, starting with slightly enriched $\mathrm{UF}_{6}$, are shown in Table 9 . There appears to be room for ingenuity in preparing specifications and for manufacturers to reduce costs in this area. Actually, broad development programs are being pushed in several countries, and costs are being reduced rapidly.

In some fuel elements oversized sintered pellets of uranium dioxide have been ground to precise dimensions. They have been ground and fitted into tubes selected so that expansions of the ceramic fuel pellets and tubes at operating temperatures provide a tight fit of the fuel. This fit is possible because of the higher temperatures during use and the higher coefficient of expansion of the fuel. The fuel is assumed to have excellent heat transfer. Grinding and fitting of pellets is now routine. 
Table 9 - FUEL-F ABRICATION COSTS IN THE UNITED STATES ${ }^{65,74,75}$

\begin{tabular}{|c|c|c|c|c|}
\hline Fuel & Claddıng & $\begin{array}{l}\text { Cladding } \\
\text { diameter, } \\
\text { In }\end{array}$ & $\mathrm{U}^{235}, \mathrm{C}_{\mathrm{C}}$ & $\begin{array}{l}\text { F abrication } \\
\text { cost, } \$ / \mathrm{hg}\end{array}$ \\
\hline Uranium oxide & Zircaloy & & & \\
\hline Dresden & & 0.563 & 15 & 190 \\
\hline SENN & & 0563 & 2.0 & 140 \\
\hline Uranıum oxide & Stannless steel & & & \\
\hline Yanhee & & 0.340 & 34 & 200 \\
\hline EGCR & & $034 \times 075^{*}$ & 2.55 & $52 \dagger$ \\
\hline \multicolumn{5}{|l|}{ Uranlum and } \\
\hline thorlum oxide & Stainless steel & & & \\
\hline Indian Point & & 0304 & 930 & 435 \\
\hline Elk River & & 0452 & 930 & 105 \\
\hline
\end{tabular}

* Tubular elements.

†The value of $\$ 150 / \mathrm{kg}$ was given in the USAEC cost data published in January 1961 , but the actual price was $\$ 52 / \mathrm{kg}$ However, this cost does not include all charges, such as fuel use charge, which are incorporated in the othe $r$ costs

Tests have also been conducted in which presintered powder has been placed in tubes and compacted with vibration. Results of irradiation tests have been generally excellent although no full reactor loadings have been tested.

Oak Ridge Natıonal Laboratory has developed a "sol-gel" process for making high-density oxides. In this process uranium, thorium, and plutonium nitrates in various combinations are converted to dense oxide particles by denitration, preparation of sols, drying to gels, and calcination at $2100^{\circ} \mathrm{F}$ for densification. Hanford Laboratories has developed a process for producing massive samples of high-density uranıum dioxide-plutonium dioxide by mechanical impaction. Densities greater than 99 percent of theoretical are obtained in both processes. Powders of these materials may be compacted in tubes by vibration only to give densities of over 90 percent of sintered pellets. Both processes show promise of low-cost fabrication; however, no production data are avallable. ${ }^{76,77}$

PLUTONIUM RECYCLE Plutonium recycle is being studied intensively in several countries. Owing to its different nuclear properties, plutonium would appear to be less valuable in thermal reactors but more valuable in fast reactors than $\mathrm{U}^{235}$. Its value as a fuel in thermal reactors compared with $\mathrm{U}^{235}$ varies from about $\$ 4$ to $\$ 11$ per gram. It is difficult to compute its true value because (1) the value of $\mathrm{U}^{235}$ varies with enrichment; (2) plutonium is an alpha emitter and must be handled in glove boxes; and (3) the value of plutonium varies with the type of reactor, position in the reactor, and the content of nonfissionable $\mathrm{Pu}^{240}$ and 
$\mathrm{Pu}^{242}$ isotopes. In a free market the minimum value of plutonium is its value as recycle material in the producer's reactor, and the maximum value is its worth as a substitute for $\mathrm{U}^{233}$ or $\mathrm{U}^{235}$. Thus the price would tend to level out at the price that permits the plutonium producer and user to produce power at their lowest costs. Addition of plutonium to natural or recycled uranium eliminates partial enrichment or adds materially to fuel life in natural-uranium reactors. The higher value of plutonium in fast reactors is illustrated in Fig. 3. Calculations for this graph were based on: 9 percent interest on inventory; 70 percent plant utilization factor; and a price of $\$ 6$ per pound of uranium oxide. Without the USAEC buyback program, there would be very little, if any, current market for plutonium.

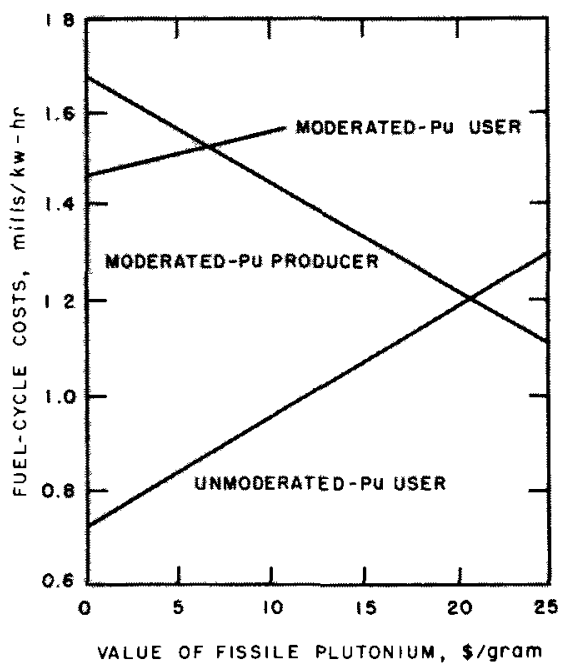

Fig. 3-Effects of the mode of plutonium utilization on fuel-cycle costs in a free market for nuclear materials. ${ }^{78,79}$

REPROCESSING

Shipping charges for nonirradiated fuel assemblies are, at most, a few dollars per kilogram; irradiated-fuel shipment charges have been as high as $\$ 5$ to $\$ 15$ per kilogram. They may be as low as $\$ 1$ to $\$ 2$ per kilogram of contained uranium in the future in the case of low-burnup low-enrichment fuels, and costs for irradiated-fuel recovery range from $\$ 17$ to about $\$ 70$ per kilogram, depending upon the amount of fuel per shipment and the plant turnaround costs. The reprocessing cost for slightly enriched uranium estimated for the privately owned Nuclear Fuel Services, Inc., plant, which is being built in western New York, will be about $\$ 23.50$ per kilogram of uranium. This 
plant will have a capacity of $1000 \mathrm{~kg}$ per day. ${ }^{75}$ Larger plants would have lower costs. For example, whereas a plant to process 1 metric ton per day costs about $\$ 30,000,000$, a plant to process 10 metric tons per day would cost about $\$ 70,000,000$. Since the capital costs are the major costs, the processing costs of the larger plant would be $\$ 5$ to $\$ 6$ per kılogram of uranium. ${ }^{80}$

Fuel-reprocessing prices are based on the solvent-extraction process for separation and recovery of uranium, thorium, and plutonium from irradiated fuels. Newer processes are being developed. One consists of forming the fluorides of the irradiated fuel and separating the uranium and plutonium in the form of pure uranium hexafluoride and pure plutonium hexafluoride by volatility and fractionation. The uranium hexafluoride produced is of sufficient purity that it may be recycled directly to the uranium-enrichment plants, and the plutonium hexafluoride may be processed to plutonium dioxide or metal and recycled as nuclear fuel. ${ }^{81}$ Another process consists of dissolving the fuel elements as chlorides in a fused chloride bath and recovering the partly decontaminated uranium and plutonium as the dioxides of uranium and plutonium by electrodeposition. Both these processes result in low volumes of wastes and may result in greatly lowered costs for shipment and recovery of irradiated fuel. ${ }^{82}$

USE CHARGE The USAEC charges an annual rental of 4.75 percent on nuclear materials. When private ownership of nuclear fuels becomes a reality, the fuel use charges may increase significantly because private-capital charges will be higher. Just what these charges will be is difficult to estimate since they depend on whether the nuclear fuels are considered as easily recoverable materials and therefore subject to mortgage loans or whether private working capital must be used. In the former case the use charge would be perhaps 6 to 7 percent; in the latter, 10 to 12 percent. ${ }^{83}$

FUEL CYCLE Fuel-cycle costs vary widely with reactor type and fuel life or fuel burnout obtained. Although the natural-uranium gascooled power reactors in the United Kingdom and France were designed originally for a fuel hfe of $3000 \mathrm{Mwd} / \mathrm{t}$, it is hoped that $6000 \mathrm{Mwd} / \mathrm{t}$ may be obtained in the future. Present fuel costs ${ }^{84}$ for the Berkeley and Bradwell reactors are about $4.4 \mathrm{mills} / \mathrm{kw}-\mathrm{hr}$. Future costs of the fuel for the Magnox reactors at Berkeley, Bradwell, Hinkley Point A, and Trawsfynydd have been estımated ${ }^{13,85}$ as equivalent to 3.0 to 3.5 mills/ kw-hr.

The use of slightly enriched uranium dioxide in the United States has permitted much longer fuel life-from 25,000 to $40,000 \mathrm{Mwd} / \mathrm{t}$. This longer fuel life has been one of the most significant factors in reducing nuclear power costs. The estimated fuel-cycle costs, in mills per kilowatt-hour, for a 450-Mw(e) pressurized-water reactor with a fuel life of $21,700 \mathrm{Mwd} / \mathrm{t}$ are as follows: ${ }^{75}$ 


\begin{tabular}{lr} 
Fuel fabrication & 0.67 \\
Feed, 3.75\% $\mathrm{U}^{235}$ & 2.07 \\
Shipping spent fuel & 0.04 \\
Reprocessing & 0.14 \\
Credit for returned uranium & -0.88 \\
Credit for plutonium & -0.42 \\
Fuel lease charge & 0.29 \\
Fabrication interest & 0.16 \\
\multicolumn{1}{c}{ Total cost } & 2.07
\end{tabular}

Long fuel life will presumably be obtained in the Advanced Gas Cooled Reactor as well as the pressurized-water reactors. For example, advanced designs of gas-cooled reactors using $\mathrm{U}^{233}$ and thorium are expected to have a fuel life of 50,000 to $100,000 \mathrm{Mwd} / \mathrm{t}$.

A fuel life of $30,000 \mathrm{Mwd}(\mathrm{t})$ or more can be obtained with $\mathrm{U}^{235}$ in light-water reactors only with good fuel management. Fuel enrichments higher than average are used in the fresh fuel; the fresh fuel is placed in the outer core positions, where the heat production is low, and is moved toward the center as the fissile-material content decreases. Usually five to seven moves are considered reasonable for a large reactor. This practice not only lengthens the fuel life materially but may also result in more-uniform total heat production for a given reactor. It has resulted in increased power levels or lower capital costs in several reactors. In the Dresden reactor the fresh fuel is placed in a calculated pattern spread throughout the reactor core to raise the reactivity uniformly. A typical curve prepared for one set of assumptions is presented in Fig. 4. Assumptions used were a thermal efficiency of 28 percent, stainless-steel cladding, and various enrichments. Table 10 presents some calculated fuel-cycle costs for a pressurized-water plant that utilizes slightly enriched uranium.

\section{Operating}

Operating costs for nuclear power reactors have been higher than for conventional power plants of equal sizes. Operating costs for large fossil-fueled plants are about $0.2 \mathrm{mill} / \mathrm{kw}-\mathrm{hr}$, whereas costs in nuclear plants, such as Dresden and Yankee, are probably near $1.0 \mathrm{mill} / \mathrm{kw}-\mathrm{hr}$. Estimates of 0.5 to $0.6 \mathrm{mill} / \mathrm{kw}-\mathrm{hr}$ have been made for the near future for large nuclear plants, with $0.3 \mathrm{mill} / \mathrm{kw}-\mathrm{hr}$ probable in about 10 years.

Dresden is being manned with five operators per shift. Two are licensed operators, one is an analytical chemist, one is a radiation surveyor, and one is an engineer. In addition, there are maintenance, clerical, technical, service, and management people, with a total of 94 employees. ${ }^{86}$ Yankee has a staff of 69 operating people at the plant plus 12 in Boston. ${ }^{40}$ To date the nuclear plants have required more super- 


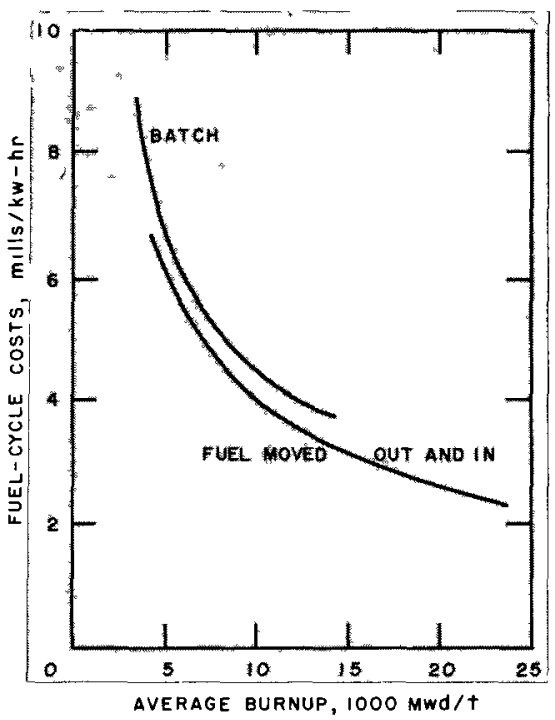

Fig. 4-Fuel-cycle costs for a pressurized-water reactor.

Table 10 -FUEL-CYCLE COSTS AS A FUNCTION OF FUEL BURNOUT ${ }^{65}$

\begin{tabular}{ccccccccc}
\hline \multirow{2}{*}{$\begin{array}{c}\text { Irradiation } \\
\text { level, } \\
1000 \mathrm{Mwd} / \mathrm{t}\end{array}$} & $\begin{array}{c}\text { Initial } \\
\mathrm{U}^{235} \\
\text { conc., \% }\end{array}$ & $\begin{array}{c}\text { Fabri- } \\
\text { cation }\end{array}$ & $\begin{array}{c}\text { Trans- } \\
\text { port }\end{array}$ & $\begin{array}{c}\text { Fuel recov. } \\
\text { and conv. }\end{array}$ & $\begin{array}{c}\mathrm{U}^{235} \\
\text { burnup }\end{array}$ & $\begin{array}{c}\text { Pu } \\
\text { credit }\end{array}$ & $\begin{array}{c}\text { Use } \\
\text { charge }\end{array}$ & Total \\
\hline 5 & 2.55 & 2.98 & 0.30 & 1.19 & $2.55^{*}$ & -1.26 & 0.52 & 6.18 \\
10 & 2.90 & 1.49 & 0.15 & 0.66 & 2.25 & -1.07 & 0.44 & 3.96 \\
15 & 3.27 & 0.99 & 0.10 & 0.48 & 2.15 & -0.99 & 0.43 & 3.16 \\
20 & 3.63 & 0.74 & 0.07 & 0.38 & 2.05 & -0.91 & 0.45 & 2.78 \\
25 & 3.98 & 0.60 & 0.06 & 0.33 & 1.98 & -0.86 & 0.47 & 2.58 \\
\hline
\end{tabular}

*Based on uranium prices in effect before July 1, 1962. The $\mathrm{U}^{235}$ burnup costs would be about 10 percent less using present prices.

vision by top management than have coal-fired plants of equal size in the same system. However, it is not certain that this would be true for a 50-50 fossil fuel-nuclear system.

The cost of working capital depends upon the detailed accounting practices followed by the individual utilities, but, in general, the cost will be higher for nuclear than for coal-fired plants. For a 500-Mw(e) plant, the nuclear working-capital costs may be double those for a coalfired plant, and the working capital may be of the order of $\$ 10,000,000$. The USAEC Guide includes fuel-investment charges in working capital and gives $\$ 5,000,000$ for USAEC leased fuel and $\$ 15,000,000$ for privately owned nuclear fuels. In this case the major fraction of the 
working-capital item is in the fuel-cycle operations costs. However, these costs are frequently included as part of the fuel-cycle costs. When they are thus included, the working capital required is much smaller. ${ }^{72}$

Other costs that may be required for nuclear plants are in-core instrumentation and more-sophisticated automation and computing equipment. In addition, the analytical and area surveys may add to the ope rating costs. Although each of these costs is small, they all contribute to the higher costs of nuclear plants.

\section{Predicted Costs}

Costs for nuclear power have been predicted several times. These predicted costs have decreased, but the actual costs have decreased faster than predicted.

Potential power costs were estimated ${ }^{87}$ in 1959 by the USAEC for plants for immediate construction and for construction in 1966. Selected data are presented in Table 11. All calculations are for $300-\mathrm{Mw}(\mathrm{e})$ single-turbine stations. All reactors were assumed to use slightly enriched fuel, private financing, and 80 percent load factors. The costs were all substantially above 6 mills $/ \mathrm{kw}-\mathrm{hr}$.

Table 11 - POTENTIAL NUCLEAR-POWER COSTS ${ }^{66}$

\begin{tabular}{lcccc}
\hline & \multicolumn{4}{c}{ Cost, mills/kw-hr } \\
\cline { 2 - 5 } & $\begin{array}{c}\text { Pressurized } \\
\text { water }\end{array}$ & $\begin{array}{c}\text { Bolling } \\
\text { water }\end{array}$ & $\begin{array}{c}\text { Bollıng water } \\
\text { with superheat }\end{array}$ & $\begin{array}{c}\text { Gas } \\
\text { cooled }\end{array}$ \\
\hline 1959 technology & & & & \\
Capital & 5.05 & 5.26 & & 5.97 \\
Fuel & 3.38 & 3.47 & & 3.21 \\
Operating & 0.85 & 0.88 & & 1.18 \\
$\quad$ Total & 9.28 & 9.61 & & 10.36 \\
Fuel life, 1000 Mwd/t & 13.00 & 19.00 & & 10.00 \\
1966 potential & & & & \\
Capital & 4.40 & 4.31 & 3.88 & 4.09 \\
Fuel & 2.56 & 2.29 & 1.99 & 2.80 \\
Operating & 0.85 & 0.88 & 0.88 & 0.78 \\
$\quad$ Total & 7.81 & 7.48 & 6.75 & 7.67 \\
Fuel life, 1000 Mwd/t & $\sim 35.00$ & 40.00 & & 14.50 \\
\hline
\end{tabular}

More-recent projected power costs assembled by the USAEC were released in July 1962 (see Table 12). Included are data developed by Sporn. ${ }^{70,89}$ Except for the USAEC estimates, the costs are for $437-\mathrm{Mw}(\mathrm{e})$ plants with an 80 percent load factor. The General Electrıc Company estimated the equilibrium, or second-core, fuel costs as $1.79 \mathrm{mills} / \mathrm{kw}-\mathrm{hr}$. 
With the use of the same difference between the first and equilibrium cores for all nuclear plants and the use of fossil-fuel costs of 204 per million British thermal units, the power costs with equilibrium cores were computed and compared with conventional power costs with the lower priced fuel. The projected power costs for nuclear and fossil fuels are both about $4 \mathrm{mllls} / \mathrm{kw}-\mathrm{hr}$.

The papers presented at the Sixth World Power Conference in October 1962 gave information of particular interest because so many of the papers were presented by government officials and represented official policy. The nuclear-power cost data in Table 12 were confirmed by the following cost estimates:

$\begin{array}{lll}\text { Canada } & \text { First CANDU } & 6 \text { to } 7 \mathrm{mills} / \mathrm{kw}-\mathrm{hr} \\ & \text { Second CANDU } & 5.8 \text { to } 6.8 \mathrm{mills} / \mathrm{kw}-\mathrm{hr} \\ \text { France } & \text { EDF-3 } & \text { Competıtive } \\ \text { United Kingdom } & \text { Future units } & \$ 238 / \mathrm{kw} ; 5.8 \mathrm{mills} / \mathrm{kw}-\mathrm{hr} \\ \text { United States } & 1963 \text { contracts } & \$ 160 \text { to } \$ 180 / \mathrm{kw} ; 5.5 \text { to } 6.0 \mathrm{mills} / \mathrm{kw}-\mathrm{hr} \\ \quad \text { (General Electric) } & & \text { with fuel cycle of } 2 \mathrm{mills} / \mathrm{kw}-\mathrm{hr}\end{array}$

Benedict, ${ }^{4}$ in reviewing the papers presented at the conference, concluded: “. . it should be apparent that nuclear energy has a significant role to play in the generation of electric power in highly industrialized nations, and that the decade following 1968 will see the rapid expansion of the world's nuclear generating capacity."

Pittman, in his review of the USAEC program at the Forum Meeting in November 1962, presented the data in Tables 13 and 14. These data are close to those in Table 12. Several factors were taken conservatively in calculation of the nuclear cost data presented in Table 13:

1. The maximum improvement in coal-fired plants that has been projected was used.

2. Capital costs were computed for one nuclear plant per site. As much as $\$ 15$ to $\$ 25 / \mathrm{kw}$ might be saved by locating several plants on a single site. Hazards due to locating several plants at a single site are believed to be no greater than for a single plant because it may be assumed that the reactors are independent. Coal plants with two to four bollers at a single site were assumed.

3. Experience in construction is expected to lower the costs of the nuclear plants.

4. Plutonium credit of $\$ 7$ per gram was assumed.

5. Increases in power levels above the plant rating probably will be higher for the initial nuclear plants than for the coal-fired plants. Experience with the Yankee and Dresden reactors indicates this may be true.

Recent studies of very large reactors have indicated that greatly decreased costs may be obtained with fast oxide breeder reactors. ${ }^{92,93}$ It 
rable 12 - PROJEC TED NUCLEAR AND CONVEN IIONAL POWER COS IS ${ }^{88}$

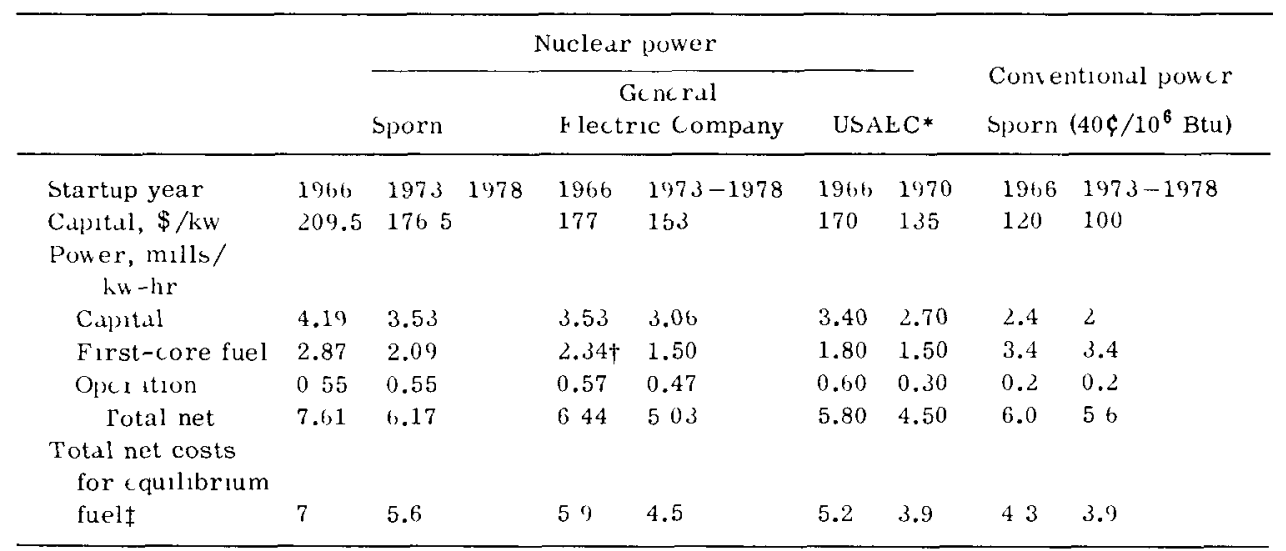

*Based on a 600-Mw(e) plant with fuel lite of $16,000 \mathrm{Mwd} / \mathrm{t}$.

† Equilibrium fuel would be $1.79 \mathrm{mill} / \mathrm{hw}-\mathrm{hr}$.

$\$$ B istd on GE correction and $20 \mathrm{C} / 10^{6} \mathrm{Btu}$ for conventional fuel. No escalation costs included 
Table 13-PROJECTED COSTS FOR 500-Mw(e) NUCLEAR POWER PLANT WITH EQULLIBRIUM CORE ${ }^{90}$

\begin{tabular}{lcccc}
\hline & \multicolumn{4}{c}{ Year placed in service } \\
\cline { 2 - 5 } & 1966 & 1970 & 1975 & 1980 \\
\hline Fuel life, 1000 Mwd/t & 18 & 22 & 25 & 25 \\
Efficlency, \% & 32 & 34 & 37 & 40 \\
Capital, \$/kw & 159 & 146 & 135 & 125 \\
Mills/kw -hr at 80\% & 3.1 & 2.8 & 2.6 & 2.4 \\
Mills/kw-hr at 60\% & 4.6 & 4.2 & 3.9 & 3.6 \\
Operation, mills/kw-hr & 0.5 & 0.4 & 0.4 & 0.3 \\
Fuel, mills/kw-hr & 1.9 & 1.5 & 1.1 & 1 \\
Power & & & & \\
Mills/kw -hr at 80\% & 5.5 & 4.7 & 4.1 & 3.7 \\
Mills/kw-hr at 60\% & 7 & 6.1 & 5.4 & 4.9 \\
\hline
\end{tabular}

Table 14 - PROJECTED COSTS FOR 500-Mw(e) COAL POWER PLANT ${ }^{91}$

\begin{tabular}{lrrrr}
\hline & \multicolumn{4}{c}{ Year placed in service } \\
\cline { 2 - 5 } & 1966 & 1970 & 1975 & 1980 \\
\hline Heat rate, Btu/kw-hr & 8500 & 3250 & 8000 & 7500 \\
Capital, \$/hu & 129 & 123 & 117 & 110 \\
Mills $/ \mathrm{kw}-\mathrm{hr}$ at $80 \%$ & 2.5 & 2.4 & 2.3 & 2.1 \\
Mills $/ \mathrm{kw}-\mathrm{hr}$ at $60 \%$ & 3.7 & 3.5 & 3.4 & 3.2 \\
Operation, mills $/ \mathrm{kw}-\mathrm{hr}$ & 0.2 & 0.2 & 0.2 & 0.2 \\
Fuel, 20 $/ 10^{6}$ Btu & 1.7 & 1.7 & 1.6 & 1.5 \\
Power & & & & \\
MLlls $/ \mathrm{kw}-\mathrm{hr}$ at $80 \%$ & 4.4 & 4.3 & 41 & 3.8 \\
Mills $/ \mathrm{ku}-\mathrm{hr}$ at $60 \%$ & 5.6 & 5.4 & 5.2 & 4.9 \\
\hline
\end{tabular}

is indicated that very large process-steam and power reactors can produce power at a cost of 1.5 to $3 \mathrm{mills} / \mathrm{kw}-\mathrm{hr}$ and process steam at a cost of less than $10 \mathrm{c} / 10^{6} \mathrm{Btu}$.

In one respect the nuclear-power cost predictions may be optimistic because plant load factors of 80 percent have been assumed. Actually all the nuclear power plants in the United States and the United Kingdom are being utılized as base-load plants. Plant utılization factors of over 70 percent have been attained, and plant avallability of over 90 percent has occurred for long periods.

No data on life or obsolescence of nuclear power plants are available. All that can be sald is that production reactors that began operation in 1944 are still operating; they are operating at power levels never considered possible by the designers; and, owing to the expected low 
fuel costs, obsolescence will not be a problem. Because most plants are built with materials of very high quality, corrosion is very low; pumps, heat-exchanger tubing, and valves can be replaced. Thus the life of nuclear power plants should be greater than that of fossil-fueled power plants.

Table 12 presents data published in September 1962 on predicted costs of conventional power produced in plants burning fuel costing 40 and $20 \mathrm{c} / 10^{6} \mathrm{Btu}$. These costs are 6.0 and $4.3 \mathrm{mllls} / \mathrm{kw}-\mathrm{hr}$ for plants purchased for construction in 1966.

At the World Power Conference in October 1962, data were presented that indicated rapid improvement in the efficiency of coal-fired plants. For example, the new Tennessee Valley Authority Bull Run Plant has an efficiency of 40.7 percent. In addition, the improved economics resulting from higher voltage and d-c transmission lines, coal pipelines, larger oll tankers, and unitized trains were stressed.

At the November 1962 meeting of the Atomic Industrial Forum, it was pointed out: (1) that coal prices have been reduced in the past five years; (2) that increased productivity has been limited to a few coal mines; (3) that some mines produce 47 tons per man-day compared with the average of 14 tons per man-day; and (4) that new trains and schedules with automatic loading and unloading could reduce delivered coal prices at New York by $5 \mathfrak{c} / 10^{6}$ Btu or more. It was confidently stated that "coal will be the basic fuel for many years to come.' The proposed coal pipeline from the coal fields to New York would reduce the transportation ${ }^{94-97}$ costs to $6 \mathrm{c} / 10^{6} \mathrm{Btu}$. The coal price is projected to be $20 \mathrm{c} / 10^{6}$ Btu in 1970 , and an efficiency of 50 percent will give fuel costs ${ }^{97}$ of 2 mills $/ \mathrm{kw}-\mathrm{hr}$.

Capital investment in conventional plants is also being reduced and is now about $\$ 130 / \mathrm{kw}$ for $500-\mathrm{Mw}(\mathrm{e})$ coal-fired plants. The Ravenswood Unit No. 3, a $1000-\mathrm{Mw}(\mathrm{e})$ plant, will cost $\$ 112 / \mathrm{kw}$. The plant is designed for oll firing, but it can be converted to coal. ${ }^{98}$

\section{Actual Costs}

The limited cost data avallable on pressurized-water reactors include information on the Yankee Atomic power plant. Yankee is producing power at costs under $10 \mathrm{mills} / \mathrm{kw}-\mathrm{hr}$ and it is confidently expected that costs will be under $9 \mathrm{mills} / \mathrm{kw}-\mathrm{hr}$ in the future. ${ }^{40}$ This cost compares with estimates for a coal-burning plant in the same area of 8 mills for a 140-Mw(e) plant. Longer fuel infe is gradually reducing the cost of power. In general, the owners are pleased with the results obtained to date, and some of the group of utilities that own the plant are planning construction of the larger Haddam Neck plant in the near future. On Oct. 6, 1962, the $N_{c}$, Yolk Times reported ${ }^{99}$ that Yankee recelves 9.5 mills $/ \mathrm{kw}-\mathrm{hr}$ for the power produced, whereas other types of power 
plants receive 8 to $10 \mathrm{mlll} / \mathrm{sw}-\mathrm{hr}$ in New England; fuel costs for the Yankee plant are $2.5 \mathrm{mills} / \mathrm{kw}-\mathrm{hr}$ compared with the regional average of $4.2 \mathrm{mills} / \mathrm{kw}-\mathrm{hr}$ for conventional fuels; and the lowest cost plant pays $3.2 \mathrm{mills} / \mathrm{kw}-\mathrm{hr}$.

Fuel costs of the first core of the CETR are about twice those of the lowest cost fossil-fuel plant in the Consolidated system. ${ }^{42}$ Fuel costs with future uranium dioxide cores are expected to be equal to conventional fuel costs. Future plants in sizes equal to the largest conventional plant in the system can be bult at costs equal to conventionalplant costs and with lower fuel costs. The capital costs for the Indian Point reactor were stated to be 1.5 times the costs for conventional fossil-fuel plants.

The projected nuclear Ravenswood plant of Consolidated Edison ${ }^{64}$ will produce $1000 \mathrm{Mw}(\mathrm{e})$ and cost $\$ 175,000,000$ to give $\$ 175 / \mathrm{kw}$. No projected power costs have been published; however, the costs are expected to be less than those for the best coal-fired plant in the Consolidated Edison system.

Costs of power produced in bolling-water reactors are reported for Dresden $^{67}$ to be near the goal of $7.5 \mathrm{mllls} / \mathrm{kw}-\mathrm{hr}$. Presumably this est1mate is based on a capitalization of $\$ 30,000,000$, which may be low.

In 1961 the Pacific Gas and Electric Company ${ }^{68}$ announced that the nuclear power plant being bullt at Bodega Bay is expected to have power costs with a 90 percent operational factor of $5.62 \mathrm{mllls} / \mathrm{kw}-\mathrm{hr}$. The USAEC has estımated the power costs as $6.76 \mathrm{mllls} / \mathrm{kw}-\mathrm{hr}$, based on an 80 percent operational factor and the announced $\$ 61,000,000$ capital costs.

\section{Effects of Subsidies}

The commercial power plants in France, the United Kingdom, and Russia are all owned by the federal governments. In the United Kingdom the nuclear power plants are subsidized since none of the plants produces electrıc power as cheaply as coal-or oll-fired power plants. ${ }^{58}$ Although future nuclear plants are expected to be economic, the subsidies have made the development of the Magnox reactors possible in the six years since the first reactor became critical.

In the United States the situation is not clear, and an involved study would be required to obtain the basic information. The prices paid for uranium have been higher than would normally have been required for a nuclear power industry because large amounts of uranium were required for the weapons program. Also the plants for producing enriched uranium and heavy water were bull for weapons materials. Now that uranium is in oversupply, purchases by the United States government hold the price stable but maintain it artificially high. On the other hand, the uranium-enrichment and heavy-water plants have made the use of 
slightly enriched uranium practical, which has resulted in lower heavywater costs.

In recent years the use charge for nuclear fuels has been 4.75 percent per year of the calculated value of the fuel. This charge is less than invested-money costs, which are perhaps 10 to 12 percent in the United States for nondepreciating materials. As mentioned earlier, mortgage money may be avallable to cover fuel-inventory costs at perhaps 7 percent total cost.

The fuel use charge is computed for a practical reactor in the Gude to Nuclear Pouev Plant Evaluation ${ }^{72}$ as about $\$ 10$ per kilogram for uranium with 1.7 percent $\mathrm{U}^{235}$. To this amount should be added about $\$ 2.75$ for use charge before irradiation and about $\$ 0.85$ after irradiation. For a fuel life of $20,000 \mathrm{Mwd} / \mathrm{t}$ and a thermal efficiency of $32 \mathrm{per}-$ cent, these amounts are equrvalent to a total use charge of $0.09 \mathrm{mull} /$ $\mathrm{kw}-\mathrm{hr}$ at 4.75 percent; $0.13 \mathrm{mlll} / \mathrm{kw}-\mathrm{hr}$ at 7 percent; and $0.22 \mathrm{mlll} / \mathrm{kw}-\mathrm{hr}$ at 12 percent. Some engineers assume longer preirradiation and cooling times than the 180 days assumed here. For 240 days the preirradiation charge would be $\$ 3.75$ per kılogram of uranıum.

These numbers are possibly low, since the increased use charge under private ownership of the fuel would apply to mined ore, ore concentrates, etc., which are not included here. On the 7 percent basis perhaps $0.1 \mathrm{mill} / \mathrm{kw}-\mathrm{hr}$ and on the 12 percent basis perhaps $0.2 \mathrm{mill} /$ $\mathrm{kw}-\mathrm{hr}$ should be added to the nuclear-power costs presented in Table 12 because this table was based on a use charge of 4.75 percent. This modıfication applies to plants using slightly enriched uranum.

\section{Future Costs}

There are many variables in estimating nuclear-power-plant costs, and the assumptions made in respect to site, size of nuclear plant, allowable heat-production rates, fuel life, fuel costs, interest rates, ownership of fuel, etc., may be as significant as the difference between reactor types. Regarding choice of reactor, it is significant that each design and development group can foresee so many improvements with reductions in costs that each group is convinced that the reactor type it is working on will eventually produce power at the lowest cost. Several companies in the United States and Canada are now offering large nuclear power plants for use with slightly enriched uranium, which, under the USAEC rules for nuclear-plant cost estımates, will produce nuclear power at near 6 mills $/ \mathrm{kw}-\mathrm{hr}$.

The present capital costs in the United States for the purchase of large water-cooled nuclear power plants are $\$ 20$ to $\$ 30 / \mathrm{kw}$ greater than costs for coal-fired plants. This difference is equivalent to 0.50 to 0.74 $\mathrm{mlll} / \mathrm{kw}-\mathrm{hr}$ based on a 15 percent annual charge and 70 percent operating factor. 
Cost reductions have been predicted as a result of various studies, such as those made by ESADA and Westinghouse. Westinghouse expects the development of a superheat reactor in large sizes to reduce nuclearpower costs by 0.4 to $0.5 \mathrm{mill} / \mathrm{kw}-\mathrm{hr}$ and capital costs by $\$ 10$ to $\$ 15 / \mathrm{kw}$ owing to use of standard and smaller turbine plant components. This reactor does not have the size limitations imposed by restrictions on pressure-vessel construction extrapolated to large sizes, and it can be used with more than one bolling-water reactor. ${ }^{34}$ For the SCOTT-R reactor, fuel-cycle costs were computed to be 1.1 to $1.5 \mathrm{mllls} / \mathrm{kw}-\mathrm{hr}$, and capital costs were estimated to be $\$ 125 / \mathrm{kw}$. With operating costs of $0.3 \mathrm{mill} / \mathrm{kw}-\mathrm{hr}$, the power $\operatorname{costs}^{53}$ would be $4.1 \mathrm{mllls} / \mathrm{kw}-\mathrm{hr}$.

The cost of $6.75 \mathrm{mills} / \mathrm{kw}-\mathrm{hr}$ projected in 1959 for boiling-water superheat reactors purchased in 1966 (Table 11) was identical with the costs announced for a bolling-water plant purchased in 1961, both on the basis of 80 percent load factors. Furthermore, the equilibrium fuel (Table 12) was based on $16,000 \mathrm{Mwd} / \mathrm{t}$; fuel life of $25,000 \mathrm{Mwd} / \mathrm{t}$ or greater is now predicted for future reactors. The predicted and actual costs are shown in Fig. 5. This figure includes the actual bid for the Oyster Creek plant.

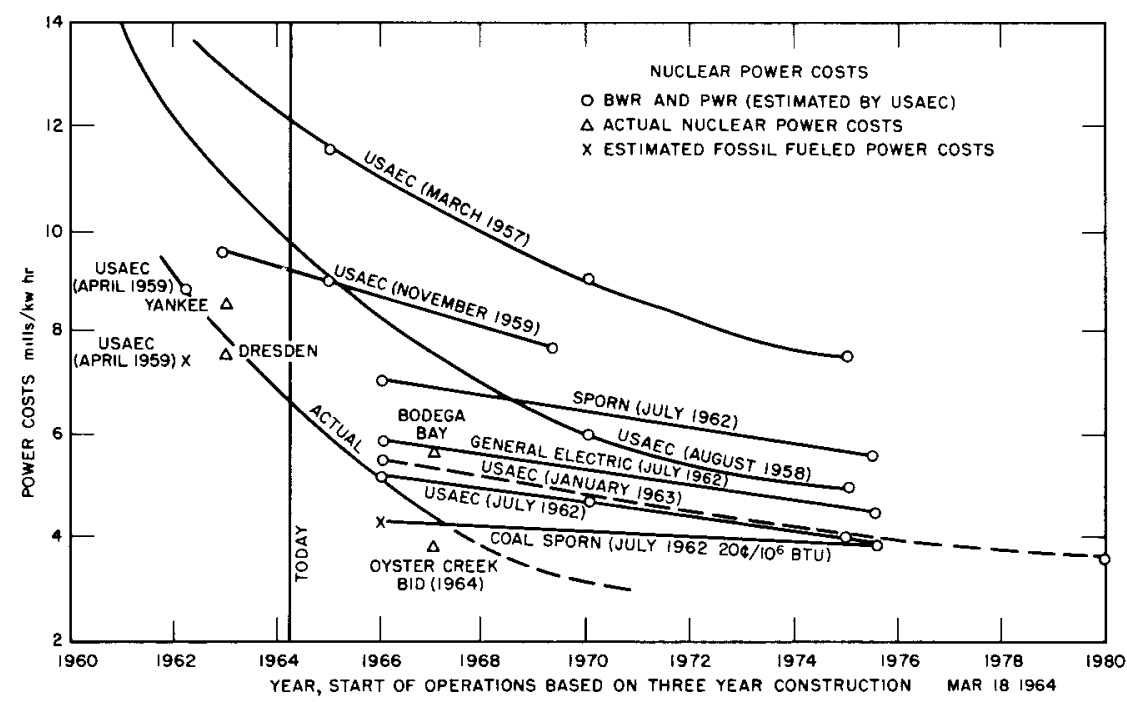

Fig. 5-Predicted and actual nuclear-power costs

\section{DESIGN AND CONSTRUCTION PROBLEMS}

Problems in desıgn and construction include organızing a staff, using operational data, and selecting materials of construction. 


\section{Design Staff}

A design staff for a commercial nuclear power plant consists of groups of scientists and engineers that may total as many as 200 people. The assembly and training of these staffs has been one of the most significant developments in the nuclear-power field because these people have the experience necessary to analyze the operating data and to design more-economic plants. ${ }^{19,100,101}$

The design of a large nuclear power plant, combined with manufacturing and testing some of the components, requires three to four years. Even then it may not be possible to optimize all component costs because of lack of time. The United Kingdom experience in respect to design and construction shows that about 80 months is required for constructing a two-reactor power station: ${ }^{19}$

Function

Apply for statutory consent

Issue enquiry to bidders

Receive proposals

Award contracts

Start construction

Complete first reactor

Complete second reactor

Commission first reactor

Commission second reactor
Total time, months

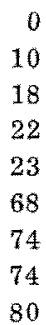

This is comparable to United States experience, which is that from four to seven years is required from initial project discussions to full-scale operation of nuclear power plants.

\section{Use of Operating Data}

There is a continual feedback of information from the operating groups to the design groups and a forward feed from the development groups. The operating data may be broadly classified in five areas. ${ }^{13}$

1. Precise measurements on the completed plants lead to refinement of theory and application of design data. Coolant-flow temperatures, flux levels, and shielding effectiveness are examples.

2. Actual operating and maintenance experience permits improved layouts of maintenance and reduction of excess capacity. An example is the reduction in waste-disposal facilities of plants currently in design compared with those of earlier plants. In the United Kingdom twin- 
reactor power plants are being laid out in smaller areas, even though the power produced is being increased.

3. Design errors are exposed.

4. Fuel elements are tested under service conditions.

5. Behavior of various structural materials under service conditions is learned.

Feedback of operating data has reduced uncertaintıes in the designs, indicated that some of the special equipment is uneconomic, and permitted the designers to reduce the excess capacity bull into the various components in the reactor plants. ${ }^{16-18}$ Only recently have enough contracts for nuclear power plants been awarded to a single concern to permit standardization of components. It would be expected that the fuel assemblies, control-system components, and external loops of the pressurized-water reactors now being bult in the United States can be standardized as additional loops can be added to produce higher-power plants.

\section{Materials of Construction}

Suitable materials must be provided for manufacture of the fuel cladding and connections, fuel-assembly supports, pressure vessels, primary loop pıpıng and components, and heat exchangers. The nuclear requirements of the reactor core and the physical and chemical properties of materials limit the choice of materials for gas-and water-cooled thermal reactors to the metals beryllıum, magnesium, aluminum, zirconum, and steel and to ceramic materials, such as graphite and various oxides and carbides. Beryllium and zirconium are more expensive than the other metals; the approximate costs, in dollars per pound, are beryllıum, 40 to 80 ; magnesium, 1.0 to 1.5 ; alumınum, 0.4 to 1.0 ; and zirconıum, 10 to 30 . Hanford aluminum-alloy process tubes ${ }^{102}$ cost $\$ 3$ per pound.

Materials for cladding fuel elements for use in water and in steam are discussed in this volume in the review entitled "Behavior of Cladding Materials in Water and Steam Environments." Full information on corrosion, mechanical properties, development of new materials, reactor experience, and other aspects will be found there.

BERYLLIUM Development of beryllium has been slow owing to its poor ductility. A very extensive development program in the United Kingdom has been reduced because of poor success, but development is continuing in the United States and France. Beryllium-clad uranium rods are being tested in the EGCR at Oak Ridge. Gradual improvements in ductility are being made, and it is quite possible that satisfactory largescale production technques will be developed in the near future. If so, beryllium may be widely used. 
MAGNESIUM Although magnesium alloys are used as fuel cladding in the gas-cooled graphite-moderated power reactors in the United Kingdom and France, they are not used in the United States because of poor corrosion resistance in water. Magnesium is used with a uranium matrix with stainless-steel cladding in the USSR water-cooled power reactor.

ZIRCONIUM Zirconium alloys, such as Zircaloy 2 (average, 1.45 wt. $\%$ tin, 0.125 wt. $\%$ iron, $0.100 \mathrm{wt} . \%$ chromium, and $0.050 \mathrm{wt} . \%$ nickel), have been developed in the United States and elsewhere and used in the Shippingport and Dresden reactors. The cost of Zircaloy is high, and its use is limited by corrosion to temperatures of 600 to $700^{\circ} \mathrm{F}$ in watercooled reactors. ${ }^{103}$

ALUMINUM Aluminum as the 0.5 percent nickel alloy has been developed for use in water-cooled reactors. Performance of aluminum fuel elements was poor in BORAX-4, but it was good in SL-1. Excellent corrosion resistance has been obtained in laboratory tests, but the alloy has not yet been produced in large quantities with uniform corrosion resistance. Its use has been limited ${ }^{104}$ to about $575^{\circ} \mathrm{F}$.

Iron-aluminum alloys have been developed in France and the United States as a compromise between the use of aluminum and stainless steel. To date they have not been used extensively in large power reactors. Ductility has been a difficulty, but recent alloys made with high-purity materials have been satisfactory. ${ }^{105}$

STAINLESS STEEL Stainless steel has been used in most watercooled power reactors in the United States and the USSR and in the AGR in the United Kingdom. Corrosion resistance and structural strength are high, and reaction with uranium dioxide is negligible at temperatures of interest in water-cooled reactors. In the high-temperature heliumcooled reactors, such as the DRAGON and Peach Bottom reactors, stainless steel cannot be used because of corrosion and carbonization due to impurities in the helium; therefore graphite mixed with the fuel in dispersions and as cladding will be used in both these reactors.

The performance of stainless steel in water-cooled reactors has been good. The tubing for fuel cladding is inspected by eddy-current and ultrasonic methods, and all tubes with cracks, inclusions, or slight defects are rejected before use. All end welds are examined visually and by dye penetration for cracks and by $\mathrm{X}$ rays for inclusions or porosity. Severe stress-corrosion cracking and failure of tubes in steam generators have occurred with austenitic stainless steel in a few cases. This experience has led to the use of Inconel tubes as the heat-exchanger tubes in one installation. Stainless-steel internally clad vessels with all stainless-steel or internally clad piping and fittings have been used in all the water-cooled reactors in the primary reactor system. Excellent results have been obtained. These results are partially due to the use of 
water of very high purity; usually the resistance is over 500,000 ohms/ $\mathrm{cm}$.

MODERATOR MATERIALS Graphite has been used as the moderator in all the gas-cooled power reactors bullt to date, with the exception of one small reactor in the United States. It has also been used in many watercooled reactors, including the production reactor and the new power reactor at Hanford.

Experience with graphite has been excellent even though it undergoes dimensional changes, stores considerable amounts of energy, has large changes in thermal conductivity due to the effects of irradiation, reacts with impurities in the gas, and requires large volumes as a moderator. The dimensional changes are allowed for in design and operation, and the relatively high temperatures reduce the irradiation effects to acceptable limits.

Reaction of carbon dioxide with graphite increases quite uniformly with temperature, but the rate is acceptable with temperatures up to about $900^{\circ} \mathrm{F}$. The reaction rate appears to be proportional to gas pressure and gamma-flux density. Between 900 and $950^{\circ} \mathrm{F}$, adding carbon monoxide or coating the graphite would appear necessary. ${ }^{106}$ The radiation effects and stored energy in the graphite are minımızed above $480^{\circ} \mathrm{F}$; thus graphite used at 500 to $800^{\circ} \mathrm{F}$ is expected to have a life in excess of 20 years.

Beryllium oxide may be used with helium at higher temperatures. Experience with radiation effects has been limited, but dimensional changes are believed not to be serious. Beryllium metal has been used in the Materials Testing Reactor. Many published summaries list the properties of materials and the conditions under which they may be used in various reactors. ${ }^{107-109}$

\section{Thermodynamic Cycles}

In all the gas-cooled stationary power plants in operation or under construction, the gaseous coolant is circulated through the reactor, steam generator, and superheater (Rankine cycle). Owing to the limitations in conventional turbine practice, steam temperatures are limited to about $1050^{\circ} \mathrm{F}$; but reactor exit gas temperatures near $1500^{\circ} \mathrm{F}$ are required for economic production of steam at $1050^{\circ} \mathrm{F}$. Perhaps $1500 \mathrm{psi}$ is a reasonable steam pressure, although higher pressures have been considered. In the direst cycle the hot coolant gas is expanded through a turbine, cooled, and compressed (Brayton cycle). ${ }^{110}$ If direct-cycle turbocompressors were avallable for use at temperatures of $1500^{\circ} \mathrm{F}$, higher efficiencies would be obtained than with the indirect cycle. The DRAGON and Peach Bottom designs call for a gas exit temperature of $1380^{\circ} \mathrm{F}$, which is perhaps a practical limit today. 
Table 15 - STEAM PRESSURES AND TEMPERATURES

PRODUCED IN COMMERCIAL NUCLEAR POWER PLANTS

\begin{tabular}{|c|c|c|c|}
\hline Plant & $\begin{array}{l}\text { Pressure, } \\
\text { psia }\end{array}$ & $\begin{array}{l}\text { Temp., } \\
{ }^{\circ} \mathrm{F}\end{array}$ & $\begin{array}{c}\text { Net efficiency, } \\
\%\end{array}$ \\
\hline \multicolumn{4}{|c|}{ Gas Cooled } \\
\hline Calder Hall & 245 & $599 *$ & 18 \\
\hline Bradwell & $277 \dagger$ & 705 & 28 \\
\hline $\mathrm{EDF}-3$ & 761 & 752 & 30 \\
\hline AGR & 850 & 650 & 27 \\
\hline DRAGON & 350 & 1382 & \\
\hline Philadelphia Electric & 295 & 1380 & 34 \\
\hline \multicolumn{4}{|c|}{ Pressurized $W$ ater } \\
\hline Yankee & 485 & 525 & 29 \\
\hline Indian Point & 420 & $454 \ddagger$ & \\
\hline \multicolumn{4}{|c|}{ Bolling Water } \\
\hline Dresden & 1000 & $546 \S$ & 29 \\
\hline Bodega Bay & 1075 & 553 & 32 \\
\hline \multicolumn{4}{|c|}{ Bolling Superheater } \\
\hline Bonus & 865 & 900 & 35 \\
\hline Pathfuider & 535 & 825 & 31 \\
\hline
\end{tabular}

* Plus steam at $360^{\circ} \mathrm{F}$ and 75 psia.

Plus steam at 214 psia.

\$Superheated by oil-fired superheater to $1000^{\circ} \mathrm{F}$.

Primary steam plus lower pressure steam.

The reactor gas temperature is limited by the materials. The magnesium-alloy cladding material, Magnox, used in the United Kingdom gas-cooled power reactors is limited to fuel-cladding surface temperatures of about $900^{\circ} \mathrm{F}$ to give gas temperatures of about $800^{\circ} \mathrm{F}$. Uranium dioxide fuel clad with stainless steel may be utilized with a cladding temperature as high as about $1600^{\circ} \mathrm{F}$ with a coolant exit of perhaps $1400^{\circ} \mathrm{F}$. This temperature may be utilized for long periods only with inert gases, such as helium.

The United Kingdom and French gas-cooled and the Russian watercooled reactors produce superheated steam. The Dresden and Yankee plants produce saturated steam, but the Indian Point and Elk River plants utilize oil- and coal-fired superheaters. Prototype boiling-water reactors with integral nuclear superheaters are being placed in operation in the United States. In all cases steam pressures have been relatively low. The steam pressures in the boiling-water reactors have increased from 600 to $1200 \mathrm{psi}$, and further increases are probable. The steam conditions produced by several reactors are presented in Table 15. 


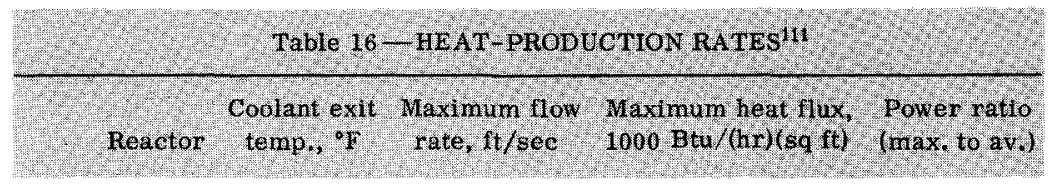

Gas Cooled

$\begin{array}{lrrrr}\text { Calder Hall } & 644 & 43.0 & 143 & 2.6 \\ \text { Bradwell } & 734 & 85.3 & 145 & 1.8 \\ \text { AGR } & 1067 & & & \\ \begin{array}{l}\text { Philadelphia } \\ \quad \text { Electric }\end{array} & 1380 & & & \end{array}$

Pressurized Water

$\begin{array}{lllll}\text { Ravenswood } & 588 & 11.71 & 473 & 3.2 \\ \text { Yankee } & 533^{*} & 15.5 & 440 \dagger & 3.8 \\ \text { Indian Point } & 519 & 21.5 & 560 & 4.1\end{array}$

Boiling Water

$\begin{array}{lllll}\text { Dresden } & 546 & & 390 & 3.6 \\ \text { Big Rock } & 550 & 5.6 \neq & 510 & 4.1\end{array}$

Boiling Superheater

Pathfinder

$13.9+\S$

$462 \S$

$3.6 \S$

245 भ 3.2 T

* Average.

SBoller.

t At $540 \mathrm{Mw}(\mathrm{t})$.

SSuperheater.

tinlet.

Because a nuclear reactor can produce heat at extremely high rates and temperatures, the capital costs depend on the rate at which the heat can be removed, and the thermal efficiency depends on the average coolant exit temperature. As a result the nuclear-reactor designer attempts to use maximum rates of heat transfer uniformly throughout the reactor with the maximum coolant exit temperatures. The maximum rate of heat transfer and maximum coolant exit temperatures are limited by the materials, and the uniformity of heat production is limited by the inherent characteristics of the type of reactor. Heat-production rates may be compared on the basis of British thermal units per hour per square foot transferred from the fuel to the coolant. Some of the results obtained in the power reactors are presented in Table 16.

The maximum to average power ratio may be decreased and therefore the total power increased by use of fuel of varying enrichment. With natural uranium there is not sufficient reactivity to permit flexibility, 
particularly in the gas-cooled graphite-moderated reactors, and the fuel life in these reactors is limited to 3000 to $6000 \mathrm{Mwd} / \mathrm{t}$. Slight enrichment with proper use of the control system permits the heat production to be quite uniform. This may require rearrangement of the fuel several times during its life. With proper operation, a fuel life of $35,000 \mathrm{Mwd} / \mathrm{t}$ may become practical for slightly enriched fuel in large reactors. The addition of burnable poisons to the fuel permits higher initial enrichment and longer fuel life. ${ }^{112}$

\section{Pressure Vessels}

The vessels for the gas-cooled Hunterston Station reactors were built on the site from fine-grain, clean, aluminum-killed, highmanganese steel with carbon below 0.16 percent. Welding of the plates was conducted by hand with slag-free electrodes heated to $150^{\circ} \mathrm{F}$. The welding rods had characteristics that matched the pressure-vessel steel. Six thousand two hundred feet of seams were $\mathrm{X}$-rayed. In add1tıon to $\mathrm{X}$ rays, ultrasonic, magnetıc-partıcle, and eddy-current detectors were used. ${ }^{113}$

Most pressure vessels built in the United States have been made from low-alloy firebox steels, such as SA 212 grade B. Roll-clad, spotwelded, and total-welded stainless-steel linings have been used. The vessels manufactured for water-cooled reactors have been bult with regular industrial equipment following regular industrial practices. The welding and stress relieving have been done in the shops. Automatic welding with the base metal heated to $200^{\circ} \mathrm{F}$ or so has been utılized almost entirely.

Difficulties have been encountered, e.g., the stainless-steel liners have cracked and in one case a pipe weld to a nozzle cracked, possibly because stainless-steel pipe was being attached to ferritic base metal.

Since irradiation of steels by fast neutrons increases the brittlefracture transition temperature, the vessels must be designed and used with care. ${ }^{114,115}$ The general effects of radiation are to raise the tensile yield point but not the ultimate tensile strength, to increase hardness, and to raise the ductile-to-brittle fracture temperature. The net result of these changes in respect to possible fallure of the reactor vessels in the presence of creep, the temperature differences and possible annealing due to gamma and neutron heating of the steel, and the fatigue is not well known. To be safe it is assumed that nuclear pressure vessels used in pressurized-water reactors must not be used at temperatures below the brittle-fracture temperature of the steel.

The effects of neutron irradiation on steels become measurable at integrated neutron dosages of about $10^{17}$ neutrons of over $1 \mathrm{Mev}$ energy per square centimeter. Effects are small below about $2 \times 10^{18}$ neutrons/ $\mathrm{cm}^{2}$ but increase logarithmically with exposures up to $5 \times 10^{19}$. Few data 
are avallable at higher exposures. The effects are also a function of temperature in that the increase in nil ductility temperature decreases with increases in the temperature of irradiation. Most test data have been taken on subsize test specimens; there is need therefore for tests made on specimens cut after irradiation from large sizes.

The pressure vessels used in boiling- and pressurized-water reactors may be subject to fast-neutron irradiation. However, sufficient data are avallable to permit design of internal shielding to protect these vessels. In many cases samples of steel from the plates used in manufacture of the vessel have been irradiated and tested. For small power reactors developed for air transport, very small pressure vessels have been used to minimize size and weight. Owing to their small internal diameter, the vessel walls are close to the reactor core and are subject to greater neutron 1 rradiation. As a consequence the effects of radiation may limit the life of some of these vessels. The requirements added to the ASME Boiler and Plessure Vessel Code for vessels for nuclear service may add 25 percent or even more to the cost of primary vessels and heat exchangers. ${ }^{72}$ The detalled wording of the specifications is important since the costs reflect slight changes in tolerances, clearances, or special requirements in manufacture. Heat-exchanger tubing is inspected ultrasonically and by eddy currents, and all nonunform sections are rejected. All welds are $\mathrm{X}$-rayed. These tests add materially to the price of the tubing. In some nuclear power plants, Inconel tubes have been specified for use in the heat exchangers.

The first prestressed-concrete pressure vessels were used by the French in the Marcoule G-2 and G-3 reactors. The horizontal vessels are approximately cylindrical ${ }^{20,21}$ with maximum internal diameters of $45.8 \mathrm{ft}$ and lengths of $51.3 \mathrm{ft}$. The walls are $9.8 \mathrm{ft}$ thick. The vessels are constructed with concave ends (as seen from the outside) so designed that the concrete is in compression owing to the coolant pressure. Prestressing cables are run lengthwise and circumferentially. Since the circumferential cables are prestressed at the bottom and do not overlap, additional cables are used to support this section. The coolant gas is fed into the reactor in concentric insulated ducts around the hot exit gas lines to protect the vessels.

The experience with the use of prestressed-concrete vessels has confirmed the design, and the French are using a prestressed vessel for the 375-Mw(e) EDF-3 Reactor now under construction. ${ }^{116}$ This vessel is of entirely different design in that the vessel is cubical in general shape with the cables placed in the form of webbing in the outer regions of the cube.

The United Kingdom Sizewell plant, now under construction to produce $580 \mathrm{Mw}(\mathrm{e})$ in two reactors, will utllize prestressed-concrete vessels to contain the cores and associated equipment. The heat exchangers and carbon dioxide circulating pumps will be housed inside the 
pressure vessels and separated from the cores by steel and graphite walls to permit entry during shutdown for heat-exchanger repair and to reduce the effects of radiation. It is believed that single reactors to produce $1000 \mathrm{Mw}(\mathrm{e})$ can be bullt using prestressed-concrete pressure vessels.

In the prestressed-concrete vessels, the prestressing cables are stressed to levels above their expected loads to allow for friction during prestressing, shrinkage of the concrete, and creep in the cables. Since many cables are used, fallure of one cable will not cause fallure of the vessel, and, in fact, individual cables can be replaced during normal reactor operation. The walls are shielded so that the concrete will not be subjected to serious radiation effects. The reactor liners of 1-in.thick steel are internally cooled. The cables are located far out in the concrete and undergo negligible irradiation.

Because the use of a prestressed-concrete vessel is believed to result in high inherent safety, no outer containment vessels are required. In theory, if an internal pressure in excess of the prestressed-concrete compression should occur, the concrete would crack, and the internal vessel would fall. This fallure would create a leak, which would largely self-seal as soon as the internal pressure fell to the prestressed pressure. ${ }^{117}$ Hinton ${ }^{59}$ has stated that the use of prestressed-concrete pressure vessels does not reduce capital costs but removes "the fear of precipitate fallure of the mild steel vessels and opens the path to the development of reactors of larger size."

\section{Construction}

The construction of nuclear power plants follows normal powerplant practice, except that the nucleas components must be kept absolutely clean. Although this has been attempted and has been accomplished by use of clean rooms for assembly of fuel components, heat exchangers, pumps, etc., conditions of pipe assembly in the field have been unsatisfactory because of poor liaison with the workers. Consequently, after construction has been completed, it has sometimes been necessary to clean the plants, particularly the piping, before installation of the core components and fuel. They are installed under clean conditıons by highly trained operating people.

Workmanship, in general, in the United States plants has been satisfactory, but some difficulties have occurred. A higher order of skill is necessary for construction and installation of nuclear-power-plant components, and this has not always been recognized or understood by the equipment suppliers. For example, "leaktight" to the nuclear designer means that high-vacuum techniques should be used in constructing the equipment, whereas "leaktight" to most equipment suppliers means that regular water-boller techniques can be used. These technıques differ greatly in cost and results obtained. 
Rejection of castings has been high in the nuclear field. Although castings have been approved for use in nuclear vessels, stringent inspection and repair requirements have been established.

The construction of nuclear power plants in the United States has been difficult because of the severe requirements for containment imposed here. Because of the cost of contanment structures, they are made as compact as possible. Thus the space for the reactor and heat exchangers is limited, and the equipment is placed in cubicles rather than in the open. When a steel containment vessel is used, the bottom may be built in the field by preheating the steel plates to about $275^{\circ} \mathrm{F}$ and hand welding. No stress relieving has been required because the plates have been thin. However, the welds must be X-rayed before they are covered up. Concrete is then poured to support the vessel and th. equipment to be installed. The heavy equipment, such as pressure vessels and heat exchangers, is installed, and the containment building is completed and pressure tested. Later the remainder of the equipment is installed. These steps result in relatively high construction costs and increased capital costs. Once the equipment is installed, the plant is cleaned, and the core components are installed. Next, component tests are made prior to fuel loading.

Delays of about 15 months were experienced in constructing and commissioning the Berkeley and Bradwell plants. The actual costs were 19 and 17 percent over the estimates owing to changes in core design; additional instrumentation, control equipment, and shielding; changes in the equipment for handling irradiated fuel; extra auxiliary construction; miscellaneous items; and a considerable increase in the cost of labor and materials.

\section{SAFETY}

Commercial nuclear power plants have had no accident, so far as known, in which any person has received more than his permissible dose of radiation. The emphasis on safety in design and location of these reactors has added materially to their capital costs.

\section{Codes and Standards}

As a result of the interest in nuclear power, codes and standards are being developed in the United States. The American Standards Association has organized the Sectional Committee N6. Varıous subcommittees have prepared standards for containment, shipping containers, etc. The American Society of Mechanical Engineers, through its Boller and Pressure Vessel Committee, has appointed a Special Committee on Nuclear Power. Several cases that specify code design or test changes 
have been issued for vessels to be used in nuclear service. These cases have been written into a new section of the Code, which is to be issued as Sec. III. Section III will include requirements for nondestructive testing of the plates, repair requirements, design requirements, provision for nonuniform heating, stresses, welding, stress relieving, and final inspection of the primary circuit vessels.

\section{Site Selection}

Several factors affect selection of sites for nuclear power plants. Since they require large volumes of condenser water, reactors have been located on rivers, lakes, or oceans. In the United Kingdom and the United States, some of the sites are on rivers and others on the oceans, whereas the French reactors are inland on rivers. In the United Kingdom, the USSR, and France, the plants are connected to the national electrical grids, whereas in the United States they are connected to the various local utility grids. Nuclear power plants have been located at 1solated sites as a safety precaution. The geology and hydrological conditions are studied to make certain that the soil conditions will provide adequate foundation and will also provide dissipation of radioactive materials in the event of an accident. Sites over major geological faults are usually consiciered unsatisfactory.

The costs of site surveys are high since the geology, hydrology, and atmospheric conditions are studied in detail. Once a site is chosen, surveys of the surrounding areas are made to establish the background levels of natural radioactivity.

In the United States preliminary hazards reports are prepared covering the sites and conceptional designs of the nuclear portions of the plants. Each report may cost $\$ 100,000$ or more to prepare in addition to the cost of collecting the data. If serious questions concerning the adequacy of a site are raised, long delays may occur before the construction permit is issued by the USAEC. When the detalled design is complete, a Hazards Summary Report is prepared by the nuclear designer and reviewed by the USAEC and the Advisory Committee on Reactor Safeguards. Public hearings are also held. Questions of safety may delay operation of a power plant for months or even years, as has been true with the Fermi fast reactor. Such investigations may result in total costs of millions of dollars. The investigations involved with the surface cracks encountered in the Elk River reactor vessel resulted in a delay of about one year, and they probably cost all parties several millions of dollars, including the capital charges on the investment.

The United States criteria for site selection are published in the Federal Regisler. 118,119 These criteria include radial distances for the controlled areas and distances to population centers as a function of the reactor thermal power. The controlled areas for large power reactors 
are from 0.5 to 1.0 mile in radius, and the distances to population centers are from 10 to 20 miles. Fortunately experience lends conf 1 dence in the safety of the nuclear power plants. Technical improvements and containment may be substituted for distance.

The United Kingdom follows a system of review of the hazards involved with nuclear power plants similar to that described for the United States. ${ }^{19}$ The 1959 Nuclear Installations Act invests responsibility in the Minister of Power, who has power of inspection. A license is granted for construction of the plant, and consents are issued for acceptance of fuel, loading, and commissioning. Preparing the initial reports for the Berkeley and Bradwell stations cost $\$ 110,000$, and the final reports cost about $\$ 700,000$ each.

Since the land areas on which the plants are bullt are larger than for conventional power plants, roads and rallroad spurs may add $\$ 250,000$ to construction costs. Construction costs may also be higher because of transportation of equipment and workmen. Power lines may be longer, and operating costs, including power-line losses, must be considered. Isolation may add one-half million dollars or more to construction of a large nuclear power plant.

The development of air-cooled condensers is reducing their costs; they may therefore become competitive with water condensers. Cooling towers may also become less expensive. Thus it may be economical to locate nuclear power plants at load centers racher than at condenserwater sources. Little attention has been given to small reactor power plants. Perhaps they can be developed and used as nearly automatic power stations at load centers without the requirement for high-voltage transmission.

\section{Containment}

In the United States and to a lesser extent in France, power reactors have been constructed in containment buldings that are essentially very large pressure vessels designed to hold the entire coolant in the event of a break in the primary coolant system. These vessels are steel or concrete or a combination of the two. Such a vessel may cost $\$ 1.5$ million more than a conventional bullding of the same size. ${ }^{72}$ Underground construction has been utilized in Sweden, Norway, and France.

Reduction in containment requirements is possible through the use of such equipment as pressure suppression. The Humboldt Bay and Bodega Bay plants incorporate pressure-suppression devices that are designed to condense some of the steam that would be released in the event of fallure of the primary coolant system. On the other hand, the Indian Point reactor is built with a concrete missile and gamma-ray sheld surrounding the containment vessel, with increased construction costs. 
The Ravenswood reactor of the Consolidated Edison Company is the first commercial power reactor intended to be located in the heart of a metropolitan area. It is proposed to buld the reactor in a special vessel that is designed for missile protection, gamma-ray shielding, and containment. The vessel would consist of $0.25 \mathrm{in}$. of carbon steel; $2 \mathrm{ft}$ of pervious concrete for missile stoppage; $0.25 \mathrm{in}$. of carbon steel; and $5 \mathrm{ft}$ of reinforced regular concrete for strength, inertia, and shelding. ${ }^{64}$ Shielding would be required in case of release of fission product from the reactor. If this plant is approved, it may open the way for largescale construction of nuclear power plants in cities.

\section{Disposal of Radioactive Wastes}

The radioactive wastes discharged at commercial reactor sites include solıds, gases, and liquids. Solid wastes are ordinarily packaged and shipped to isolated burial areas. The particulate matter is removed from the gaseous wastes, and the liquid wastes are (1) diluted to very low levels, usually 2 to 100 times normal background levels; (2) concentrated and stored for decay; or (3) reduced to solids.

Dresden has discharged from 500 to $1000 \mu \mathrm{c}$ of gaseous wastes per second. They are mainly $\mathrm{N}^{13}$, which has a half-life of $10 \mathrm{~min}$. Slight amounts of xenon and krypton are also discharged. By the time of discharge, the $\mathrm{N}^{16}$ has decayed and the $\mathrm{N}^{13}$ can have no effects because it disappears rapidly.

Yankee is discharging an average of about $200 \mu \mathrm{c}$ of gaseous wastes per month. The amount has varied widely. Shippingport discharged an average of $16,000 \mu \mathrm{c}$ per month for nine months in 1959 .

Dresden, from April 1960 to August 1961, discharged an average of $20,000 \mu \mathrm{c}$ of liquid wastes per month. They were diluted to about twice the normal radioactivity content of the river water before discharge. During the first nine months of 1961 , Yankee discharged $700 \mu \mathrm{c}$ of liquid wastes. Shippingport discharged $20,000 \mu \mathrm{c}$ of liquid wastes, mainly tritium, during the first seven months of 1958 .

The quantities of wastes have all been far below that permitted by the operating licenses. Considering the dilution in the atmosphere and in the rivers and the rapidity of decay, the wastes are negligible in respect to the total radioactivity present in natural air and water..$^{33,112,120}$ The recovery of by-products from wastes is discussed in this volume in the review entitled "Reactor By-products."

\section{Shipment of Irradiated Fuels}

Many shipments of irradiated fuels have been made in the United Kingdom and the United States, but no serious accident has been reported. The higher enrichment fuels, with the high concentration of fis- 
Sion products, used in the United States power reactors require that the fuel elements be artificially cooled during shipment by immersion in circulating water or materials of high heat conductivity. As a result the shipping casks are designed according to rigid specifications prepared by the American Standards Association Committee, with approval by the USAEC, to prevent loss of coolant.

\section{CONCLUSIONS AND TRENDS}

The commercial nuclear power industry has entered the normal highly competitive business channels in which nuclear power plants are being purchased on the basis of economics. When the plants now being designed or built for scheduled operation before the end of 1965 are completed, the investment will be about $\$ 2.1$ billion, assuming an average of $\$ 300 / \mathrm{kw}$ as average cost. The cost of total power production at 80 percent load and $6 \mathrm{mills} / \mathrm{kw}-\mathrm{hr}$ will be about $\$ 300,000,000$ per year. Although no definite statements can be made, the trend is upward, and the indications are that many of the completely new power plants of $300 \mathrm{Mw}(e)$ or over ordered in the future will be nuclear fueled.

Quite possibly, no nuclear power plant now in operation is completely economic in comparison with coal-fired plants. However, the amount of financial assistance is decreasing rapidly as the power levels are increased and operational fuel costs are lowered. Some of the plants now in operation and others being built are expected to produce power at costs equal to or less than coal-fired plants of equivalent size, at least after a few years of operation.

In the United Kingdom and the United States, full-scale plants have been brought to full power with startup or break-in difficulties comparable to those encountered with conventional plants. The EDF-1 in France was brought to full power with only minor difficulties.

The water-cooled power reactors and the prototype gas-cooled reactors have been operated at power levels higher than their design levels. This trend is expected to continue, but at decreased percentages of power increases, as design and operational experience are obtained. Increased power levels depend upon maximum heat production throughout the reactor cores or increased heat-removal rates, which, in turn, depend upon increased heat transfer, coolant-flow rates, and fuel surface area. Heat removal is normally limited by a single factor, such as fuel-surface temperature. A fuel design change that raises this limit results in higher power but brings into operation some other limiting factor. Thus power-level increases are made in a series of steps that may continue over several years. It is expected that the power levels of the commercial power reactors now in operation will be raised to levels considerably above the present ones. 
Operation and maintenance costs for nuclear power plants are higher than those for coal-fired plants. As experience in design of equipment improves, this differential is expected to decrease, but it is doubtful that the nuclear-plant operating costs will equal those of the coal-fired plants simply because the nuclear plants include more complex instrumentation and intricate equipment. However, nuclear plants are bult with very high-grade materials, and maintenance costs may prove to be lower than now estımated. The size of operating staffs per shift in nuclear plants may decrease below that of the staffs of coalfired plants, but it is expected that the number of specialists will be higher in the nuclear plants. The importance of the present nuclear power plants is that their extensive design, construction, and operational experience have demonstrated the economic potential of nuclear power.

\section{The Role of the Government}

The various national governments have fostered nuclear power by research and development in government laboratories and by subsidies in various forms. Since several types of reactors have been developed in the different countries to the point that turn-key plants may be purchased, the need for government support has lessened. Industry and the utilities in the United States through organizations such as ESADA are conductung development of advanced superheat, sodium-cooled, and gascooled reactors.

Although the Magnox plants in the United Kingdom represent the largest group of power reactors being bult, authorities the re appear uncertain concerning future construction of this type reactor. The question of whether to use the Magnox, the AGR, or the DRAGON type will require evaluation of future operational data. Meanwhile United Kingdom authorities are considering the CANDU because of its advantages: it uses natural or very slightly enriched uranium and it can be scaled up to very large sizes. Hinton ${ }^{59}$ concluded in a talk in Japan, “... while the Canadian system has advantages and shows potential, there are difficult problems to be overcome before it can advance to the higher temperatures and pressures that we must hope to achieve in the 1970's." In the United Kingdom construction of a 100-Mw(e) heavywater-moderated pressure-tube reactor is also proceeding.

\section{Nuclear Fuels}

Natural uranium is now in oversupply, and its price is definitely downward. It is estimated that uranium will continue in oversupply until about 1970. By 1990 the supply of slightly enricheduranium and natural 
uranium may limit the growth of the nuclear power industry because of the large quantities required for inventory as well as for fuel. The trend is toward a free market in the United States and Canada.

The trend in respect to fuel life is upward-estımates of future fuel life as high as $35,000 \mathrm{Mwd} / \mathrm{t}$ (about 4.5 at.\% burnout) have been made. This estimate compares with the design life of $3000 \mathrm{Mwd} / \mathrm{t}$ for the Magnox plants. The use of slight enrichment or plutonium recycle in the natural-uranium plants extends the fuel life. The trend in light-watercooled reactors is toward the use of fuel with relatively high enrichment, up to about 4 percent, and the use of the fuel to high burnups.

Very extensive efforts are being made to use plutonium and $\mathrm{U}^{233}$ as recycle fuels. Procedures for fuel-element manufacture, measurement of isotope and reactivity changes with fuel burnout in reactors with various neutron-energy spectra, and tests of plutonium in the Experimental Breeder Reactor I, Experimental Bolling Water Reactor, and Plutonium Recycle Reactor are being made.

\section{Power Costs}

The trend of nuclear power costs is downward. Plants now benng built in the United States are expected to be economic and to produce power at 6 to $7 \mathrm{mllls} / \mathrm{kw}-\mathrm{hr}$. Large future plants are expected to produce power at 4 to $5 \mathrm{mills} / \mathrm{kw}-\mathrm{hr}$. The trend of prices for coal and coal-fired power plants is also downward; thus future coal-fired and nuclear power plants may be nearly equal for a tıme in respect to power costs. Lowered freight rates on coal are being announced; some of these cuts are over 50 percent. ${ }^{121}$

Obviously not all the suggested possible reductions in costs are additive. Estimates of 3.5 to 4 mills/kw-hr by 1975 , based on today's dollar, appear to be realistic. The fast reactor, when fully developed and in very large sizes, has the potential of $3 \mathrm{mills} / \mathrm{kw}-\mathrm{hr}$ or less for power. It is also possible that a large aggregate of heavy-water reactors combined with a large fuel-reprocessing plant could result in 3 mills/kw-hr power.

\section{Selection of Reactor Site}

Properly designed nuclear power plants have such high inherent safety features, built-in safety devices, and containment features that it should be possible to locate them in the heart of metropolitan areas. Nuclear reactors are being accepted by the public because of their cleanliness and possibly also because of their architectural characteristics. 


\section{Utilization}

Nuclear power plants are basically base-load plants. Their use as industrial heat sources either for direct secondary heat or electric heat is expected to expand at a very rapid rate. They are expected to be used extensively in conjunction with pumped water and with hydroelectric plants.

No valid prediction regarding the future comparative cost positions of coal-fired and nuclear-fired plants can be made. Although the USAEC has predicted comparative cost data, the cost of power produced in coalfired plants is decreasing. Lower coal prices may occur, lower shipping costs are being announced, and the trend to very large single units, such as Ravenswood No. 3, is rapidly reducing conventional power costs.

The use of film boiling in pressurized-water reactors plus the use of forced circulation, higher pressures, and superheat in boiling-water reactors are merging these two types. The proposed use of once-through water-cooled reactors in which feedwater is heated to boiling, converted to steam, and superheated at 2500 to 4000 psi appears logical. Combining power production and process-heat production may also reduce power costs from nuclear fuels. ${ }^{122}$

\section{New Supporting Industries}

New supporting industries are expected to grow up in support of the nuclear power industry. The industries may include shield design and construction; reloading; waste handling, concentration, and storage; and reactor control.

\section{REFERENCES}

1. Divectory of Nuclear Reactors, Vol. IV, Power Reactors, International Atomic Energy Agency, Vienna, 1962.

2. Nuclear Reactors Built, Being Bult, or Planned in the United States as of June 30, 1962, USAEC Report TID-8200(6th Rev.).

3. World Reactor Chart, 3rd ed., Nucl. Pouer, 7(69): facing p. 66 (January 1962).

4. M. Benedict, Nuclear Power as Discussed at the Sixth World Power Conference, Nucl. Neus, 6(1): 3-7 (1963).

5. Reactor Development in Europe-A Comparative Chart, Nucl. Eng., 7(12): 488 (December 1962).

6. EDF-4 Designers Face a Dilemma, Nucleoncs, 21(4): 29 (April 1963).

7. E. R. Appleby (Comp.), Review of Power and Heat Reactor Designs, Domestic and Foreıgn, USAEC Report HW-66666 (Vols. 1 and 2), Hanford Atomic Products Operation, March 1961.

8. M. Benedict, Cooperation and Competition with the Soviet Union in the Peaceful Uses of Atomic Energy, Nucl. Neus, 6(7): 3-9 (July 1963).

9. Gas-Cooled Reactors, J. Fr anklun Inst., Vonoglaph Sel. 7, (Mav 1960). 
10. C. S. Lankton, Gas Cooled Reactors, Chap. 18, Reactor Handbook, Vol. 4, Enganeerıng, J. H. Martens and S. McLain (Eds.), Interscience Publishers, Inc., New York, 1964.

11. L. J. Goudy and R. D. Teire, The Development of Compressors and Drives for GasCooled Reactors, in Gas-Cooled Reactors, J. Franklm Inst., Monograph Se') . 7, p. 254 (May 1960).

12. Oldbury Contract Awarded to TNPG, Nucleonics, 20(4): 31 (April 1962).

13. R. V. Moore, H. Kronberger, and L. Grainger, Advances in the Design of Gas-Cooled Graphite-Moderated Power Reactors, in Proceedings of the Second United Nations International Conterence on the Peaceful Uses of liomic Energi, Genta, 1958, Vol. 9, pp. 104-114, United Nations, New York, 1958.

14. V. R. Goodwin and T. N. Marsham, Increasing Plant Avallability, Nucleonics, 20(4): 52-56 (Apr1l 1962).

15. J. K. Smith and J. Cheetham, Leak Tests in Calder Hall Type Reactors, J. Br it. Nuclea) Eneigv Cont., 6(1): 62 (January 1961).

16. K. W. Cunningham, G. V. Hough, and D. Allaga-Kelly, The Detection of Burst Fuel Elements in Nuclear Reactors, in Proceedings of the Second United Nations Internahonal Conterence on the Peacetul Uses of Atomu Energl, Genera, 1958, Vol. 7, pp. 478-485, United Nations, New York, 1958.

17. R. R. Gallie, H. H. Gott, and F. C. W. Colmer, Practical Problems of Fueling in Industrial Calder Hall Type Reactors, in Proceedings of the Second Unied Natzons Inter national Conterence on the Peacetul Uses of Atomic Energl, Genera, 1958, Vol. 13, pp. 314-324, United Nations, New York, 1958.

18. H. G. Davey, J. Gawthrop, and T.N. Marsham, Operating Experience at Calder Hall, in Proceedings of the Second Unted Nations International Conference on the Ptaceful Uses of Atomic Enègv, Genera, 1958, Vol. 8, pp. 10-17, United Nations, New York, 1958.

19. E. S. Booth et al., The Experience of the Central Electricity Generating Board in the Siting, Construction and Commissioning of the Initial Nuclear Power Stations, in Sixlh World Poue, Conference, Melbourne, Australta, Oct. 20-27, 1962, Vol. 4, pp. 1618-1639, Australıan National Committee, Melbourne, Australıa, 1963.

20. M. Pascal, J. Horowitz, J. Bussac, M. Joatton, F. de Lagge, M. de Meux, and R. Martin, Reactors G2 and G3, in Proceedings of the Second United Nations Inte national Conference on the Peaceful Uses of Atome Energv, Geneva, 1958, Vol. 8, pp. 329-333, United Nations, New York, 1958.

21. France Atome, Description of Reactors G2 and G3, in Proceedings of the Second Unted Nations International Conference on the Peacciul Lses of Alomic Encigi, Geneia, 1958, Vol. 8, pp. 334-355, United Nations, New York, 1958.

22. Personal communication.

23. AGR-A Brief Evaluation, Nucl. Eng., 63(4): 115 (Aprıl 1963).

24. AEA Optımistic About Commercial-size AGR Prospects, Nucleonics, 21(5): 24-25 (May 1963).

25. Reactor Development in Europe, Mucl. Eng., 7 (December 1962).

26. W. Cook, The United Kingdom Program, in Gas-Cooled Reactors, J. Fianklin Inst., Monograph Ser. 7, p. 227 (May 1960).

27. W. Cook and R. V. Moore, Advanced Reactor Systems in the United Kingdom, in Sixth World Power Conference, Melboume, Australla, Oct. 20-27, 1962, Vol. 4, pp. 1666-1676, Australian National Committee, Melbourne, Australia, 1963.

28. G. Samuels, Fuel Elements for Gas Cooled Reactors, in Gas-Cooled Reactors, J. Franklın Inst., Monogr aph Ser. 7, p. 138 (May 1960).

29. R. A. Meyer and C. L. Rickard, The Impact of Graphite Fuel Development on HighTemperature Steam Generation, Report GA-4051, General Atomics.

30. The Dragon Reactor, Power Reactor Technol., 6(1): 74 (December 1962).

31. AEC Authorizing Legislation Fiscal Year 1964, Heaings Bctore the Joml Committee on Atomic Energy, 88th Congress, April 9-10 and May 2, 1963, p. 21, U. S. Government Printing Office, Washington. 
32. N. A. Dollezhal, A. K. Krasın, P.J. Aleshchenkov, A. N. Galanın, A N. Grigoryants, I. Ya. Emelyanov, N. M. Kugushev, M. E. Minashin, U. I. Mityaev, B. V. Florinsky, and B. N. Sharapov, Uranium-Graphite Reactor with Superheated High Pressure Steam, in Proceedings of the Second Unted Nations International Conference on the Peaceful Uses of Atomic Energv, Geneva, 1958, Vol. 8, pp. 398-414, United Nations, New York, 1958.

33. V. S. Emelyanov, The Future of Atomic Energy in the U.S.S.R., in Proceedings of the Second Unted Nations Inter national Conterence on the Pcaceful Lses of Alomk Eneigv, Geneva, 1958, Vol. 1, pp. 68-72, United Nations, New York, 1958.

34. Evaluations: Steam-Cooled Power Reactors, Pouer Reactor Technol., 5(3): 71 (June 1962).

35. E. R. Acker et al., The ESADA Programme for Obtaining High Temperature Steam in Nuclear Power Plants, in Sixth World Poucs Conterence, Melbownt, Austraha, Oct. 20-27, 1962, Vol. 4, pp. 1552-1570, Australian National Committee, Melbourne, Australıa, 1963.

36. The Shippingport Pressurized Water Reactor, Addison-Wesley Publishing Company, Inc., Reading, Mass., 1958.

37. Westinghouse Electric Corporation, PWR Hazards Summary Report, USAEC Report WAPD-SC-541, September 1957.

38. Westınghouse Electric Corporation, Pressurızed Water Reactor (PWR) Project Technical Progress Report for the Period June 24,1962-August 23, 1962, USAEC Report WAPD-MRP-99.

39. J. E. Gray, W. H. Hamilton, and W. E. Wynne (Eds.), Shippıngport Operations from Start-up to First Refueling, December 8, 1957, to October 7, 1959, USAEC Report DLCS-364, Duquesne Light Company and Westinghouse Electric Corporation, Sept. 30, 1960.

40. W. Webster, An Industry Assessment, presented at the Atomıc Industrial Forum, Inc., Washington, D. C., Nov. 26, 1962.

41. Nuclear Utılity Services, Inc., A Review of Yankee Operatıng Data, USAEC Report NYO-2482, November 1961.

42. G. R. Milne, Indian Point Project, presented at Atomic Industrial Forum, Inc., Washington, D. C., Nov. 26, 1962.

43. E. S. Beckjord, Hydrodynamıc Stabılity in Reactors, Nucl. Safet, 4(1): 1 (September 1962).

44. R. P. Anderson and P. S. Lottes, Bolling Stability, J. Nucl. Energl: Pl. B, 2: 3 (February 1962).

45. M. Petrick, Additional Hydrodynamic Test Data from EBWR at Powers to $60 \mathrm{Mw}$, Argonne National Laboratory internal report, EBWR Test Report 105-A, Oct. 3, 1962.

46. M. Petrick and E. A. Spleha, An Explanation of the Behavior of EBWR at the Higher Power Levels $(>65 \mathrm{Mw}$ ), Argonne National Laboratory internal report, EBWR Test Report 105-B, Nov. 29, 1962.

47. E. R. Owen, Performance Measurements of the Dresden Nuclear Power Station, in Plocetdings of the 24th American Pouel Conterence, Chucago, Mll, March 27-29, 1962, pp. 240-257, Illinois Institute of Technology, Chicago, Ill., 1962.

48. T. Trockı, Modification and Inspection of Reactor Components, in Proceedings of the 24th American Pouer Conference, Chucago, Ill., March 27-29, 1962, pp. 284-289, Illinois Institute of Technology, Chicago, Ill., 1962.

49. General Nuclear Engineering Corporation, A Brief Study of Bolling Water Reactors in the 5 to $40 / \mathrm{Mw}(\mathrm{e})$ Range, USAEC Report TID-8510, Oct. 10, 1959.

50. Small Power Reactor Projects of the United States Atomic Energy Commission, USAEC Report TID-8538, Sept. 28, 1961.

51. Puerto Rico Water Resources Authority, Bolling Nuclear Superheater (BONUS) Power Statıon Prelıminary Desıgn Study and Hazards Summary Report, Vols. 1-4, USAEC Report TID-8524, June 1960. 
52. Allis-Chalmers Manufacturing Company, Bolling Water Reactor with Internal Superheater: Pathfinder Atomic Power Plant Final Feasibility Report, USAEC Report ACNP-5917, Aug. 31, 1959.

53. S. N. Tower, $1000 \mathrm{Mw}(\mathrm{e})$ Supercritical Pressure Nuclear Reactor Plant Study: Selection of Preferred Reactor Concept, USAEC Report WCAP-2042, Westinghouse Electric Corporation, July 1962.

54. Estımated Capital Costs of Current Nuclear Stations, Nucl. Eng., 8(5): 148 (May 1963).

55. EDF-1, EDF-2, EDF-3 Design and Performance Data, French Atomic Energy Commission, information sheet distributed at the Atomic Fair, Washington, D. C., November 1962.

56. Costs of Nuclear Power, USAEC Report TID-8531, January 1961.

57. For um Memo, p. 19, July 1962.

58. G. Bainbridge, The New Power Stations, Nucl. Eng., 7(4): 153 (Apr11 1962) and 7(5): 158 (May 1962).

59. Hinton Updates Evaluation of Nuclear Power Prospects, For um Memo, p. 15, January 1963.

60. ORNL Evaluation Favorable to Big Gas Cooled Reactor, For um Memo, p. 38, December 1962.

61. Development, Growth, and State of the Atomic Energy Industry, Hearings Bcfore the Jomt Committee on Alomic Energy, 88th Congress, 20-21 Feb., 1963, Part 1, Appendix 1, p. 189, U. S. Government Printing Office, Washington.

62. A Good Month for Westinghouse, For um Vcmo, p. 15, February 1963

63. AEC Authorizing Legislation Fiscal Year 1964, He aings Befor $t$ the Joint Committe on Atomic Energy, 88th Congress, Apr 9 and 10 and Mav 2, 1963, p. 376, U. S. Government Printing Office, Washington.

64. 3 New Reactor Starts Scheduled, Pendleton Site Released; Consolidated Edison Plans 1000-Mwe Unit in Heart of New York City, Nucleonlcs, 21(1): 17 (January 1963).

65. Costs of Nuclear Power, Pout, Reactor Tcchnol., 4(4): 2 (September 1961).

66. General Electric Company, commercial announcement, 1962.

67. D. R. Bower, Dresden Project, presented at the Atomic Industrial Forum, Inc., Washington, D. C., Nov. 26, 1962.

68. P. G. \& E. Orders Big Reactor; Southern Califorma Edison Advances, Nucleoncs, 19(8): 22 (August 1961).

69. Tarapur Contract, Nucl. Energy, 7(11): 437 (November 1962).

70. AEC Optımistic on Imminence of Competitive Nuclear Power, Nucleomic $s, 20(9): 17$ 18 (September 1962).

71. AEC Signs First Long-term Fuel Sales Contract Abroad: Provides Enriched Fuel to Euratom for SENN Reactor, USAEC Public Information Release, E-434, Nov. 28, 1962.

72. Kaıser Engineers, Guide to Nuclear Power Cost Evaluation, Fuel Cycle Costs, USAEC Report TID-7025(Vol. 4), Mar. 15, 1962.

73. Enriched and Depleted Uranium-Base Charges, Special Charges, Specifications, and Packaging, Feder al Register, 27, 5006, May 29, 1962.

74. W. F. Banks, Sensitivity of Nuclear Fuel Costs to Selection of Coolant Gas, Nul. Ene' gi, 7(11): 422 (November 1962).

75. M. Benedict, E. A. Mason, and F. L. Culler, Production and Utilization of Nuclear Fuels in the United States, in Sixth World Power Conterence, Melbour ne, Aushalia, Oct. 20-27, 1962, Vol. 4, pp. 1409-1421, Australian National Committee, Melbourne, Australıa, 1963.

76. Thorium Fuel Cycle Development Emerging from Shadow, Nucleoncs, 21(2): 24 (February 1963).

77. New Impaction Process Produces High Density $\mathrm{PuO}_{2}-\mathrm{UO}_{2}$, Plutomum $R$ \& $D$ Neusletter, Hanford Laboratories, Richland, Washington, Issue 2, January 1963. 
78. S. Golan, S. Siegel, and D. J. Stocker, Uranium Utılization Patterns in a Free and Expanding Nuclear Economy Based on Sodium-Cooled Reactors, USAEC Report AI7980, Atomics International.

79. D. J. Stocker, S. Golan, and S. Siegel, Wanted: A Balanced Nuclear Economy, Nucleoncs, 21(6): 79-82 (June 1963).

80. C. M. Slansky and J. A. McBride, The Case for Small Reprocessing Plants, Nucleonlcs, 20(9): 43-47 (September 1962).

81. G. I. Cathers and R. J. Jolley, Recovery of $P u F_{B}$ by Fluorination of Fused Fluoride Salts, USAEC Report ORNL-3298, Oak Ridge National Laboratory, Oct. 8, 1962.

82. Salt Cycle Studies Yield $\mathrm{PuO}_{2}$ for Reactor Test, Plutonum $R$ \& $D$ Newsletter, July, August, and September 1962, Hanford Laboratories, Richland, Washington.

83. W. N. Oberly and G. M. Roy, How Far Can We Go with BWR's? Nucleonacs, 21(6): 68-71 (June 1963).

84. Royal Opening, Nucl. Eng., 8(5): 147 (May 1963).

85. R. A. Charpie and A. M. Perry, Gas-Cooled Reactors-A Summary, Gas-Cooled Reactors, J. Franklin Instutute, Monograph Ser. 7, p. 3 (May 1961).

86. H. K. Hoyt, Plant Description, in Proceedings of the 24 th American Pouer Conference, Chicago, Ill., March 27-29, 1962, pp. 234-240, Illnois Institute of Technology, Chicago, Ill., 1962.

87. F. K. Pittman, Power Reactor Potentials, presented at Atomic Industrial Forum, Inc., Washington, D. C., Nov. 3, 1959.

88. C. Hoilfield, statement released by Joint Committee on Atomic Energy, July 30, 1962.

89. Sporn, Clapp, View Nuclear Outlook and Sporn Finds It Bleak, Nucleonics, 20(7): 24 (July 1962).

90. Figures Show Economic Nuclear Power Turning That Corner, Nucleonics, 21(1): 1920 (January 1963).

91. F. K. Pittman, A Government Assessment, presented at the Atomic Industrial Forum, Inc., Washington, D. C., Nov. 26, 1962.

92. A. Sesonske and R. P. Hammond, A Prelımınary Evaluation of Fast Oxıde Breeder Reactors for Sea Water Conversion, USAEC Report LA-2733, Los Alamos Scientific Laboratory, August 1962.

93. I. Spıewak, A Large Desalınization Reactor Based on Current Technology, Nucleontcs, 21(7): 64 (July 1963).

94. A. Gerber, Observations of a Power Plant Operator,presented at Atomic Industrial Forum, Inc., Washington, D. C., Nov. 26, 1962.

95. S. L. Jewell, Views of a Coal Producer, presented at Atomic Industrial Forum, Inc., Washington, D. C., Nov. 26, 1962.

96. W. L. Bailes, Jr., Outlook for Rail Transport, presented at Atomic Industrial Forum, Inc., Washington, D. C., Nov. 26, 1962.

97. T. R. Scallen, A Government Assessment, presented at Atomic Industrial Forum, Inc., Washington, D. C., Nov. 26, 1962.

98. H. W. Dierman, F. P. Kuhl, and T. R. Galloway, General Design of a $1000 \mathrm{MW}$ Unit for Ravenswood, in Proceedings of the 25th American Pouer Conference, Chicago, Ill., March 26-28, 1963, pp. 289-297, Illinois Institute of Technology, Chicago, Ill., 1963.

99. Neu York Times, p. 28, Oct. 6, 1962.

100. N. J. Palladino and H. L. Davis, The Engineering Design of Power Reactors, Nucleontcs, 18(6): 85 (June 1960).

101. L. Owen, Some Experiences in the Industrial Group of the UK Atomic Energy Authority, in Proceedings of the Second Unted Nations International Conference on the Peaceful Uses of Atomic Energ\}, Geneva, 1958, Vol. 8, pp. 3-9, United Nations, New York, 1958.

102. C. R. Tipton (Ed.), Reactor Handbook, 2nd Ed., Vol. 1, Materials, Interscience Publishers, Inc., New York, 1960.

103. B. Cox, Recent Developments in Zirconium Alloy Corrosion Technology, J. Nucl. Energy, Pt. B, 2: 166 (February 1962). 
104. J. E. Draley and W. E. Ruther, The Corrosion of Aluminum Alloys in HighTemperature Water, in Corrosion of Reactor .Malevals, I, p. 477, International Atomic Energy Agency, Vienna, 1962.

105. Iron-Aluminum Alloys, Pone) Reactor Tcchnol., 6(1): 40 (December 1962).

106. F. Roberts et al., Graphite Technology, J. Nucl. Enclgi, Pl B, 2: 105 (February 1962).

107. J. H. Martens and S. McLain (Eds.), Reactoi Handbook, Vol. 4, Engineering, Interscience Publishers, Inc., New York, 1964.

108. Harold Etherington (Ed.), Nucleas Engineen ing Handhook, McGraw-Hill Book Company, Inc., New York, 1958.

109. Reactor Materals, Vols. 1-5, U. S. Government Prıntıng Office, Washington, 19581962.

110. W. F. Banks, Thermodynamic Advantages of Gases as Power Reactor Coolants, Nuclear Eneigv, 7(11): 413 (November 1962).

111. D. Mars and G. Gans, Jr., Spectral Shıft Control Reactor Desıgn and Economıc Study, USAEC Report BAW-1241, Babcock and Wilcox Co., December 1961.

112. General Nuclear Engineerıng Corp. and Combustion Engineering, Inc., A 200-Mw(e) Direct Cycle Bolling Water Reactor with Integral Nuclear Superheat, USAEC Report GNEC-212, Jan. 29, 1962.

113. Nucl. Eneigy, 7(7): 296 (July 1962).

114. W. S. Pellinı, L. E. Steele, and J. R. Hawthorne, Analysis of Engineering and Basıc Research Aspects of Neutron Embrittlement of Steels, USAEC Report NRL-5780, Naval Research Laboratory, Apr. 17, 1962.

115. Radiation Embrittlement of Steels, Polt) Reactol Tollinol., 5(4): 34 (September 1962).

116. Prestressed Concrete Pressure Vessels, Pouel Rcac lor T/chmol., 5(4): 78 (September 1962).

117. S. Gill and I. W. Hannah, Prestressed Concrete Pressure Vessels, Nucl. Pouti, 7(71): 48 (March 1962).

118. Code of Federal Regulations, Title 10, Part 100, Fedelal Regis/e /, Apr. 12, 1962.

119. Reactor Site Criteria, Niul. Satel, 4(1): 11 (September 1962).

120. W. Kiedaisch, Experience with Liquid Waste Handling at Dresden Nuclear Power Station, paper presented at American Institute of Chemical Engineers, Lake Placid, N. Y., Sept. 27, 1961.

121. Cut-rate Coal, Rallroads Joun Mines in Slashing Fuel Costs for Steel Mills, Utılıties, U all Street Joun nal, p. 1, Feb. 19, 1963.

122. N. Rydell, Agesta, Nucl. Eng., 8(3): 40 (March 1963). 



\section{Commercial Power Reactors \\ Cooled with Sodium, \\ Heavy Water, \\ or Organic Liquids}

by

Chad J. Raseman and Leon Green

Brookhaven National Laboratory 
$T$ his article reviews the recent technical progress in advanced commercial power reactors. These reactors have been defined by Weinberg $^{1}$ as those which significantly exceed current technology either in respect to temperature, simplicity of fuel cycle, or neutron economy (breeding). Included are sodium-graphite reactors, fast reactors, reactors moderated with heavy water, and reactors moderated with organic fluids.

Reactors in the current-technology class, such as those cooled with gases, pressurized water, or boiling water, have been highly developed in the United States, England, ${ }^{2}$ and France, and they are represented by several power plants of commercial size. These reactors are described in the review entitled "Commercial Power Reactors Cooled with Gas or Light Water."

The reactors reviewed here show early promise of exceeding current technology and have resulted in significant technical advances in design, testing, and prototype experience. The types included were chosen because they have reached a stage of development in which the concept appears to be technically feasible and economically promising for the production of electric power in the near future. Sodium-graphite and organic-cooled type reactors are promising because of their unique coolant properties, which could lead to plants with higher thermal efficiencies for sodium - graphite reactors and to plants of lower capital cost for organic-cooled reactors. Fast reactors are breeders that can utilize the $\mathrm{U}^{238}-\mathrm{Pu}$ and $\mathrm{Th}-\mathrm{U}^{233}$ cycles to maximum advantage. Heavywater reactors are promising because they use tratural uranium most efficiently. With enriched fuel, heavy-water reactors have higher conversion ratios than light-water reactors.

Reactors utilizing fluid fuels are not discussed extensively here because they do not appear to fit the established definition of "advanced commercial power reactors"; i.e., they do not appear economically promising for the near future. Much work has been done on fluid-fuel systems such as the aqueous homogeneous and the liquid-metal-fueled reactors, but very little research and development work has been pursued in the past two years. A very large effort on the molten-salt concept is under way at the Oak Ridge National Laboratory, and the 10$M w(t)$ Molten Salt Reactor Experiment is now being built. However, it was decided that a review of the technical advances of this concept should await more experimental experience.

\section{SODIUM-GRAPHITE REACTORS}

Initial studies ${ }^{3,4}$ for a reactor system to produce plutonium and by-product electric power resulted in the Sodium Graphite Reactor (SGR) program, started in 1949. A survey of several potentially promis- 
ing systems showed that the sodium-graphite combination was an optimum system for this dual-purpose reactor. In 1952 the dualpurpose approach was deemphasized, and the sodium-graphite reactor concept was analyzed on the basis of power generation alone. Consequently the SGR was selected as one of the five reactor systems to be developed in the U. S. Atomic Energy Commission Civilian Power Reactor Program.

\section{Sodium Reactor Experiment}

An essential first step in the development of the SGR was the construction and operation of a reactor experiment. A facility was needed to establish reactor characterıstics and sodium-system behavior unde $\mathbf{r}$ steady-state and transient conditions and to determine the reliability and accessibility of the components of the reactor and primary coolant system under actual operating conditions. Such a reactor experiment was built at Santa Susana, Calıf., by Atomics International (AI), a division of North American Aviation, Inc. This reactor, the 20-Mw(t) Sodium Reactor Experıment (SRE), was bult in a cost-sharıng arrangement with the USAEC. The facility is the property of the USAEC, which also pays the cost of operation by AI, and the Southern California Edison Company, which owns the turbogenerator.

The design of this reactor experiment was based on experience gained through construction and operation of the $\mathrm{NaK}$-cooled Experimental Breeder Reactor No. I (EBR-I) by Argonne National Laboratory (ANL) and of the sodium-cooled Seawolf S2G Sodium Reactor under the Naval Reactors Program. In addition, USAEC-sponsored developmental work was performed at $\mathrm{AI}$ to determine the feasibility of using commercially avallable components, such as pumps and valves, for liquidsodium service.

Construction of the SRE was started in January 1955 and was completed in April 1957. Initially the SRE was planned solely as an experimental installation, and no effort was made to utılize the power it would produce. Instead, an air-blast heat exchanger was installed to dissipate the $20 \mathrm{Mw}$ of heat generated at full power. However, shortly after construction was started the Southern Calıfornia Edison Company offered to install a steam generator and turbine system. The construction of the turbine plant proceeded parallel with that of the reactor, and on July 12, 1957, electric power was first generated with SRE heat. W1th a thermal power of $20 \mathrm{Mw}$ and with many experimental features, the SRE is not a true prototype because components cannot be extrapolated directly to a full-scale plant for economic power generation. However, it is an essential tool for verifying or indicating changes in design and operating philosophy, information that only an operating system can provide. 
Experience obtained from the construction and initial operation of the SRE provided the basis for design of a true prototype, the 75-Mw(e) Hallam Nuclear Power Facility (HNPF). It is a prototype embodying the state of the art in sodium-graphite reactors as of 1959 .

Atomics International, supported by a group of private utilities, is now working on an extension of the SGR concept, the Advanced Epithermal Thorlum Reactor, a $360-\mathrm{Mw}(\mathrm{e})$ sodium-cooled reactor system operating on the $\mathrm{U}^{233}-\mathrm{Th}$ cycle. This reactor system, now in the study stage, holds promise of breeding $\mathrm{U}^{233}$ from thorium.

TECHNICAL ASPECTS The SGR is a sodium-cooled graphite-moderated thermal-neutron-spectrum reactor. It is characterized by a lowpressure system for heat removal with a high temperature rise in the coolant passing through the reactor. A temperature rise of 149 to $316^{\circ} \mathrm{C}$ $\left(300\right.$ to $\left.600^{\circ} \mathrm{F}\right)$ is practical; thus the pumping power necessary to remove reactor heat is reduced. In its present heterogeneous, solid-fuel form, this system does not offer the possibility of breeding. Conversion ratios between 0.50 and 0.65 can be expected with reasonable mechanical designs using fuel of low $\mathrm{U}^{235}$ enrichment. High-temperature fuels are required to match the excellent heat-removal characteristics of liquid sodium. Heat fluxes of the order of 1 to 3 million Btu/ ( $\mathrm{sq} \mathrm{ft}$ )(hr) are anticıpated. Fuel material of high thermal conductivity is required to take advantage of the properties of sodium. Currently, uranium monocarbide appears to offer the greatest possibility of longterm radiation stability and high-temperature performance. An extensive uranium carbide development program is now in progress at $\mathrm{AI}$.

Although forced convection of the sodium coolant is required, natural convection assists in circulating the sodium, and it is ample to remove decay heat from the reactor after a scram. Primary and secondary sodium cooling systems are employed to ensure against a sodium-water reaction with radioactive sodium, to exclude hydrogen from the reactor core, and to avoid radiolytic decomposition of the boller water in the steam generators by gamma radiation produced by $\mathrm{Na}^{24}$ in the primary sodium system. Since heat is transferred from the radioactive sodium to the nonradioactive sodium in an intermediate heat exchanger, the secondary nonradioactive system may be arranged in a convenient configuration with no particular attention to radioactivity considerations. These benefits are not without cost. The additional coolant loop increases capital costs and results in a drop in steam temperature.

Several core configurations based on methods of separating sodium from graphite have been proposed. The SRE and the HNPF are cannedmoderator types in which graphite logs are individually clad with zirconium or stainless steel and cooled by sodıum. The calandria con- 
cept uses one large moderator container pierced by fuel tubes, thus eliminating sodium from moderator regions.

OPERATING EXPERIENCE The SRE has been an extremely valuable research and development tool. Five years of operating experience has provided information on reactor-physics plant-control characteristics, sodium-system behavior, reactor and plant safety, operating procedures, accessibility, and maintenance procedures. The SRE is described in detail in Ref. 5. A flow diagram is shown in Fig. 1.

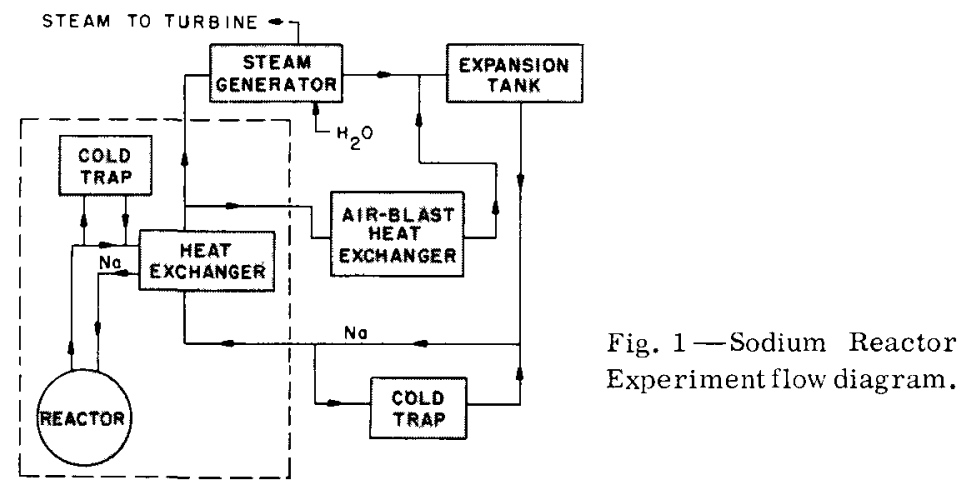

Operation of the SRE provided the first opportunity to st.duy the physics of this type of reactor under both static and dynamic conditions with imposed temperature gradients. The first core loading was unalloyed uranium metal enriched to $2.78 \mathrm{wt} . \% \mathrm{U}^{235}$. The second core loading, now in the reactor, is a thorium-uranium alloy containing $7.6 \mathrm{wt} . \%$ uranium enriched to 93 percent $\mathrm{U}^{235}$.

Excellent reactor stability has been demonstrated through operating experience and measurement of power coefficients. Temperature effects on reactivity changes in fuel, coolant, and moderator were found to be approximately as anticipated. The rapid (seconds) fuelplus-coolant temperature coefficient is negative, whereas the much slower (minutes) moderator coefficient is positive. With this combination of coefficients, the reactor has good dynamic stability and is selfregulated. The over-all reactivity change associated with bringing the reactor up to temperature is less than 1 percent. Measurements on the first core loading failed to reveal undesirable pressure or flow coefficients of reactivity. In the second loading of thorium-uranium alloy elements, there was a surprising discovery of a positive fuel-rodbowing coefficient because of thermal gradients that counteracted the negative Doppler coefficient, and this resulted in a positive power coefficient for the reactor. This effect in the second loading was due to the blackness of the fuel to thermal neutrons and to a change in element design that permitted more rod bowing than was possible in the 
first core. This condition was corrected by restraining the rod to prevent bowing, and the self-regulating feature of the reactor was fully restored. Additional measurements on SRE have provided information on xenon effects in transients, on control-rod worth, and on poison effects of such items as the neutron source. All the physics tests have provided a means for checking the validity of theoretical analysis and extrapolation from critıcal experiments.

The SRE has contributed valuable information on sodium systems associated with reactors. Although the system design was based on information gained from the EBR-I and the Seawolf submarine program, the SRE design is unique in that there was a major attempt to adapt commercially avallable components and there was a desire to increase the reactor coolant outlet temperature and temperature rise across the core. The sodium systems have operated well and show every indication that SGR's are good load-following reactors. Test transients of up to 20 percent power increase per minute have been induced and successfully followed manually with the reactor. Since the SRE is designed for a large temperature gradient across the core, it is necessary to match coolant flow to decay-heat generation to avoid thermal shocks to the reactor and system components. During the final stages of design, it was anticipated that excess thermal convection would have to be controlled after a scram. This difficulty was resolved by installing an eddy-current brake on the primary and secondary coolant lines. With this modification the full reactor gradient can be maintained for about 2 hr after shutdown.

Two major design deficiencies were discovered in the intermediate heat exchangers. First, sodium tended to stratıfy at low flow rates after a reactor scram. It was found that a temperature difference of more than $93^{\circ} \mathrm{C}\left(200^{\circ} \mathrm{F}\right)$ could develop between the top and the bottom of the heat exchanger, which could result in a thermal stress that produced some buckling of the heat-exchanger shell. The intermediate heat exchanger is a horizontal U-tube unit. A new unit now on hand will be installed on end to avoid the recirculation problem. A second defect in design of the intermediate heat exchanger was poor baffling in the bend area of the U-tubes, which resulted in a log-mean temperature difference about 50 percent higher than was anticipated.

Difficulties with the freeze seals of the SRE sodium pumps have been sources of considerable operating difficulty because of shaft binding, sodium extrusion, and gas inleakage. The temperature gradient in the seal provides a diffusion trap for sodium oxide, which collects in the seal area. On three occasions, twice with the main primary pump and once with the main secondary pump, barriers have permitted leakage of the auxiliary coolant, tetralın, into the sodium system. On the last occasion the tetralin admitted to the primary system produced severe plugging of the fuel channels in the reactor. Because of the 
problems with the freeze seals, these pumps will be replaced with freesurface pumps, which do not require auxiliary cooling. In this type of pump, the impeller operates in a pool of sodium with inert cover gas. The seal is then made on the cover gas.

Valve performance in the SRE has been generally satisfactory. Some bellows-sealed valves have falled at the bellows because of $1 \mathrm{~m}$ proper operation during startup. No difficulties have been encountered with freeze-seal valves. General system cleanliness has been maintained through the use of cold traps. The impurity of most concern is sodium oxide since some air is introduced into the system during fuelchanging operations or when the system is open for any reason. After such operations it has been possible to reduce oxide content of the sodium to $10 \mathrm{ppm}$ or less and to maintain this purity by cold trapping.

An SRE accident has provided valuable data on safety and containment characteristics of the SGR. The leakage of tetralin from the freeze seal on the main primary pump previously discussed resulted in partial blockage of coolant flow in several fuel channels. In these areas of restricted flow, temperatures resulted that were high enough to promote formation of low-melting alloys between uranium and the constituents of type 304 stainless-steel cladding. Thirteen fuel elements failed, and about 10,000 curies of fission-product activity was released into the primary cooling system. With the instrumentation available at the time, the reactor operators did not detect the condition of the fuel until a scheduled shutdown for fuel examination revealed the damaged elements. The condition of the reactor after the fuel-element fallures provided an opportunity to develop practical repair procedures for an SGR. During the removal of the broken elements, fuel slugs and preces of cladding were scattered over the top of the moderator logs. Three fuel elements had become wedged in the process channels owing to swelling of the fuel slugs. This condition made it necessary to remove the moderator cans.

Decomposition of the organic coolant tetralin in the hot sodium left a flocculent layer of carbonaceous material over the top of the reactor and deposits of this same material throughout the primary system. The sodium was drained, and by remote manipulations through openings in the top shield, the fuel-element debris was transferred to containers, which were removed with the fuel-handling machine. Most of the carbonaceous material was removed with a shielded vacuum sweeper; the remainder was absorbed by the sodium hot trap. The three stuck fuel elements were removed with the moderator assemblies, and 16 damaged moderator assemblies were replaced. This work was accomplished with no excess radiation exposures to maintenance personnel.

Several modifications were made to prevent recurrence of this accident. Among them were eliminating tetralin as an auxiliary coolant and adding an instrument to monitor the fission-product activity of the 
core cover gas so that even minor cladding fallures can be quickly detected.

The incident of the fuel damage to the SRE also provided data on sodium chemistry. Analysis of the reactor cover gas revealed no fission products other than the noble gases. A search for $\mathrm{I}^{131}$ falled to reveal its presence in the cover gas; this indicated, as was expected, that lodine and bromine fission products immediately combine chem1cally with sodium.

The SRE provided much of the data on which to base design of the HNPF. It continues to be the most valuable of the SGR development facilities. Modification of the SRE is planned to permit operation at higher power levels and temperatures, to provide a facility in which to irradiate fuel elements under the conditions of advanced SGR's, and to permit long-term performance tests of components at high temperatures.

FUELS AND MATERIALS DEVELOPMENT To exploit the high-temperature capability of the SGR concept, the development of a fuel element with high-temperature capability is a key factor. When the SRE was built, the best avallable fuel was unalloyed uranium metal. Six experimental elements were added to the first core loading. These elements contained thorium-uranium alloys and molybdenum and zirconium alloys of uranium. Supplementing the experimental SRE elements were capsule tests in the Materials Testing Reactor (MTR). Of the alloys studied, the best in terms of radiation stability were thorium-uranium and uranium-molybdenum alloys.

Present development efforts are centered around ceramic fuels because these fuels can go to higher burnups than are possible with metallic fuels. Oxide elements were first considered because they appeared to have the high-temperature and high-burnup capability desired. An experimental oxide element was inserted into the SRE, but it was removed, after the SRE fuel-damage incident, before much radiation exposure had accumulated. Oxide fuel was considered for the Hallam reactor. In fact, the core was sized to accept a loading of oxide elements, each consisting of a cluster of 43 rods having a length of $13.5 \mathrm{ft}$ and containing pellets 0.439 in. in diameter. Many smalldiameter rods were required to avoid melting of the oxide. The basic difficulty with oxide is its low thermal conductivity. Several other fuels were studied in the hope of finding one with satisfactory radiation stability at high temperature and good thermal conductivity to permit the use of fuel rods with larger diameters. Of the materials studied, uranium monocarbide appears to hold the most promise for the SGR. The thermal conductivity of this carbide is about $13 \mathrm{Btu} /(\mathrm{hr})(\mathrm{ft})\left({ }^{\circ} \mathrm{F}\right)$, whereas that of uranium dioxide falls in the range of 1 to $2 \mathrm{Btu} /(\mathrm{hr})(\mathrm{ft})\left({ }^{\circ} \mathrm{F}\right)$.

Recent capsule-irradiation tests with uranium monocarbide have shown very promising results. In these tests fuel central temperatures 
to $1330^{\circ} \mathrm{C}\left(2430^{\circ} \mathrm{F}\right)$, surface heat fluxes above $10^{6} \mathrm{Btu} /(\mathrm{hr})(\mathrm{sq} \mathrm{ft})$, and exposures of $25,000 \mathrm{Mwd} / \mathrm{t}$ were achieved. The irradiated uranium carbide has a generally good macroscopic appearance, and release of fission gas is usually less than 2 percent. However, cracking does occur, and swelling to a few percent has been observed. In addition to the capsule tests, eight uranium carbide elements are planned for installation in the Hallam reactor early in its operation, and the third core loading for the SRE will be uranium carbide.

It has been found that, in fuel elements in which the uranium carbide is thermally bonded to stainless steel with a liquid metal, carbon is transported from the fuel to the steel cladding. The chromium oxide layer that normally protects the stanless steel is not present when the steel is exposed to the reducing conditions of carbon-bearing sodium at high temperatures. This problem has been attacked by limiting the amount of carbon avallable for transfer. The carbon content in uranium monocarbide is limited to less than stolchiometric (4.8 wt.\%). Under these conditions the uranium carbide does not exhibit a carburization potential toward stainless-steel cladding. Because the irradiation tests show no difference in stability between hypostoichiometric uranium monocarbide (less than $4.8 \mathrm{wt}$.\%) and hypersto1chiometric materials, the low-carbon material is specified for fuel elements utılizing stainless steel and a sodium thermal bond. Maximum permissible operating temperatures have not yet been established. It is anticipated that the maximum central temperature will be $992^{\circ} \mathrm{C}\left(2000^{\circ} \mathrm{F}\right)$ or higher; the melting point of uranium monocarbide is about $2370^{\circ} \mathrm{C}$ $\left(4300^{\circ} \mathrm{F}\right)$. With a central temperature of $1205^{\circ} \mathrm{C}\left(2200^{\circ} \mathrm{F}\right)$, the power that can be generated in a unit length of fuel rod is about twice that which can be obtained in an oxide rod of the same diameter operating near the melting point of uranium dioxide - about $2640^{\circ} \mathrm{C}\left(4800^{\circ} \mathrm{F}\right)$. Technical information obtained to date on uranium carbide is generally encouraging. However, its position relative to oxide in terms of overall fuel-cycle cost has yet to be established.

Significant progress in the development of structural materials has also been made. A high-temperature zirconium alloy, $3 \mathrm{Z} 1$, has been developed which has a tensile strength equivalent to that of type 304 stanless steel at $650^{\circ} \mathrm{C}\left(1200^{\circ} \mathrm{F}\right)$. The $3 \mathrm{Z} 1$ alloy contains, in addition to zirconium, $1.25 \mathrm{wt} . \%$ aluminum, $1 \mathrm{wt} . \%$ tin, and $1 \mathrm{wt} . \%$ molybdenum. The creep strength at high temperature is only one-third that of stainless steel, but it may be adequate for cladding fuel elements or moderator. Another alternative under investigation is $\mathrm{Nb}-1 \mathrm{wt} .{ }_{0}^{\circ} \mathrm{Zr}$ alloy, which has higher strength than type 304 stainless steel at high temperatures. In the hope of finding a suitable substitute for this stainless steel as a major material of construction, several ferritic steels have been tested for high-temperature strength and resistance to decarburization by hot sodium. The steels were, basically, $2 \frac{1}{4} \mathrm{wt} . \% \mathrm{Cr}-1 \mathrm{wt} . \%$ Mo with 
small additions of vanadium, niobium, nickel, titanıum, or combinations of these elements. The two most promising of the alloys tested were designated $4 \mathrm{~S} 4$ and $4 \mathrm{~S} 8$, which contain $0.6 \mathrm{wt} . \% \mathrm{~V}$ and $0.6 \mathrm{wt} . \% \mathrm{~V}$ or 0.1 wt.\% $\mathrm{T} 1$, respectively, in addition to the $2 \frac{1}{4} \mathrm{wt} . \% \mathrm{Cr}-1 \mathrm{wt} \% \mathrm{Mo}$. These materials are as strong as type 304 stannless steel at $650^{\circ} \mathrm{C}\left(1200^{\circ} \mathrm{F}\right)$, but they are difficult to weld.

COMPONENT DEVELOPMENT The engineering problems encountered in the design of sodium-cooled reactor systems stem from the same properties of sodium that make it an ideal heat-transfer fluid. Because of the almost complete lack of fllm resistance to heat transfer at the heattransfer surfaces, there is practically a step change at the heat-transfer boundary. Temperature gradients and their associated stresses can be propagated with unusual rapidity. Hence, wherever possible, sodium systems and components should be cylindrical and of uniform cross section to resist thermal shock most adequately. Because it is obviously impossible to design components that are always cylindrical and uniform in cross section, careful stress analysis combined with experience and empirical testing must be utilized in the designing of components for maximum simplicity. Ultimately it appears that full-scale testing is a prime requisite for developing a sodium-cooled system.

An example of this type of testing is the Large Component Test Loop (LCTL) at AI, which was constructed to administer thermal shocks to full-scale core components and to verify their performance in service. The LCTL was used for testing full-scale moderator assemblies for the Hallam plant and is now being used for thermal-shock tests of a flow controller. It has also been used as a pump test loop. The facility will next be used in testing core assemblies at high temperatures for more-advanced SGR designs.

A new test facility soon to be put into operation is the Sodium Components Test Installation. This facility duplicates a complete reactor heat-transfer system with a gas-fired sodium heater substituted for the reactor. The primary sodium loop transfers heat from the gasfired furnace, through an intermediate heat exchanger, to a secondary sodium loop. The secondary sodium is used to generate high-pressure high-temperature steam to test steam-generator units. The facility, which has a thermal capacity of $35 \mathrm{Mw}(\mathrm{t})$, is designed to test model steam generators under steady-state and severe transient conditions.

Bellows expansion joints have also been studied and tested extensively by AI. These expansion joints are of great interest in hightemperature low-pressure sodium service, l.e., $100 \mathrm{psig}$ and $650^{\circ} \mathrm{C}$ $\left(1200^{\circ} \mathrm{F}\right)$. Experience with expansion joints has led to confidence in their use in sodium systems and will allow closer coupling of equipment with subsequent reduction in plant costs.

A leak detector for steam generators has been developed. The re- 
action of steam or water with sodium yields hydrogen; the instrument developed for detecting hydrogen incorporates a nickel membrane that is evacuated on one side and in contact with sodium on the other. If hydrogen is present in the sodium stream, some will diffuse through the nickel membrane and can be detected with a standard Piranı vacuum gauge. The instrument will detect 1 to $2 \mathrm{ppm}$ hydrogen, and even small steam-generator leaks can be detected within a few seconds.

The general development program also includes reactor safety. Current experiments in sodium boiling will assist in the predicting of the conditions of a postulated uncontrolled runaway type of accident. Meltdown experiments with uranium carbide are planned for the Transient Reactor Test Facility (TREAT) in Idaho. Work is also being carried out to determine the disposition of fission products released to the sodium coolant. The fuel-damage incident in the SRE and recent experiments indicate that fission products, except for the noble gases, will quantitatively be retained by the sodium. Experiments are also being conducted on the disposition of fission products in contaminated sodium when sodium burns. Preliminary data indicate that a large part of the fission-product radioactivity will remain with the residue.

\section{Hallam Nuclear Power Facility}

The HNPF was bullt by the USAEC as part of the Power Demonstration Reactor Program. The facility is owned by the USAEC and is operated by the Consumers Public Power District at their Sheldon Station site, 20 miles south of Lincoln, Nebr Plant characteristics are as follows:

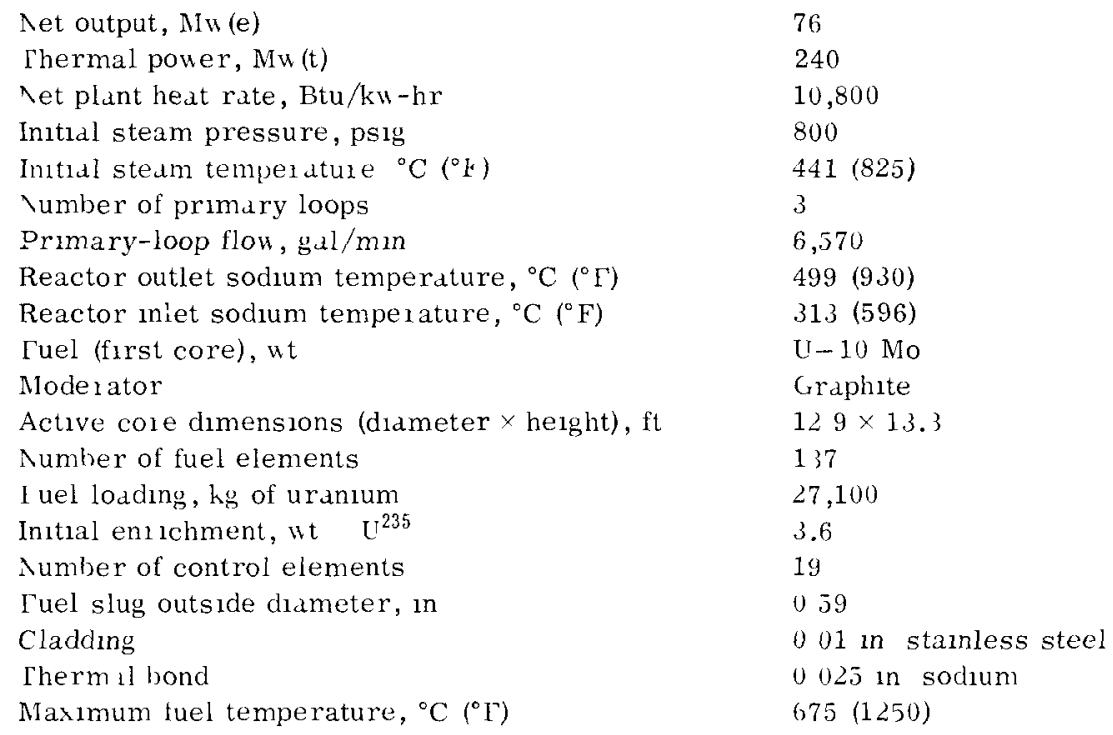


The complete facility includes a coal-fired conventional plant with a steam turbine generator. A vertical section of the reactor ${ }^{6}$ is shown in Fig. 2. In addition to the nuclear plant, a central control room for both nuclear and conventional facilities allows use of steam for the turbine from either source. Construction began in April 1959, and the plant was essentially completed by July 1961 . The reactor was first brought to dry critıcality on Jan. 19, 1962. Wet criticality was obtained in August 1962,

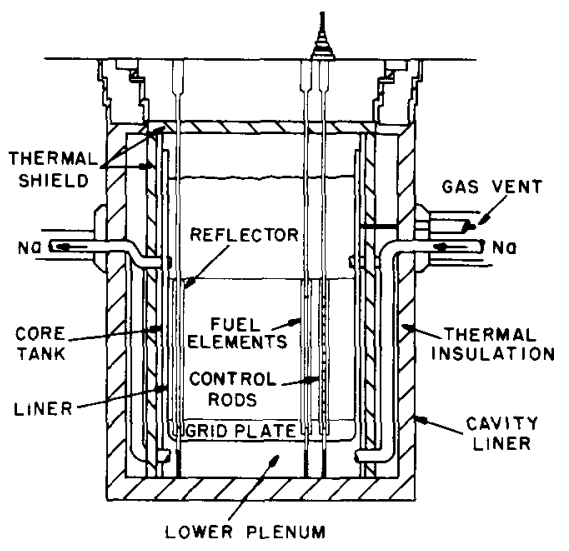

Fig. 2-Hallam reactor. ${ }^{6}$

but operations have been limited to 15 percent of power. Hence it has not been possible to test steam generators and superheaters. The reactor was shut down for a month from mid-November 1962 because of a sodium leak in an intermediate heat exchanger. The leak was suspected when operators noticed that the sodium level in the secondary-system expansion tank in loop No. 1 of the three loops was beginning to fall, and it was observed that the sodium level in the reactor tank was rising. In the HNPF design the secondary system operates at higher cover-gas pressure and at higher elevation than the primary system so that, if there is a leak, flow is backed toward the reactor. With the primary sodium still only slightly activated, it was fairly simple to shut the reactor down, drain the secondary sodium from loop No. 1, and start cutting out the faulty heat exchanger from the system and make repairs. When the HNPF had completed its runs at 15 percent of full power, authorization was given to go to full power. Hallam has now operated successfully at full power and under load-following conditions.

The approximate cost of the nuclear facility is $\$ 473$ per net kilowatt of capacity for the nuclear facility. The cost of the turbine generator 
is included in the conventional plant. The estimated fuel cost is 4.3 mills/kw-hr with the initial core of uranium-molybdenum fuel. This cost includes a $4 \frac{3}{4}$ percent inventory charge on fissionable material based on a plant factor of 80 percent. It is planned to replace the initial uranium-molybdenum fuel with uranium monocarbide fuel elements as the original fuel is burned. The reference design for the carbide elements is an eight-rod fuel cluster, which would be used with the same process tube, variable orifice, and shield plugs as the uraniummolybdenum fuel. These uranium monocarbide elements will produce a maximum of $1.9 \mathrm{Mw}(\mathrm{t})$ each at a peak fuel temperature of about $788^{\circ} \mathrm{C}\left(1450^{\circ} \mathrm{F}\right)$. The expected maximum burnup for the carbide elements is $20,000 \mathrm{Mwd} / \mathrm{t}$. The estimated fuel costs of a steady-state carbide fuel cycle are 0.5 to $1.0 \mathrm{mill} / \mathrm{kw}-\mathrm{hr}$ below the costs with uranium-molybdenum fuel. Higher thermal efficiency, reduced fabrication costs, and better neutron economy of larger sodium-graphite reactors will further reduce fuel costs in future plants.

\section{Advanced Sodium-cooled Reactor}

The technical potential of the SGR appears to be clearly in line with future developments in competitive fossil-fuel plants First, there is no evidence to indicate that the reactor cannot be increased in size to achieve very large capacities. Now under consideration is a prototype plant that may lead to a $1000-\mathrm{Mw}(\mathrm{e})$ plant. Second, steam of high quality can be generated; thus an advanced SGR may utllize advanced steamturbine designs almed at steam conditions of 3500 psig and $565^{\circ} \mathrm{C}$ $\left(1050^{\circ} \mathrm{F}\right)$. Although the SGR appears technically sound, two technical areas require additional research and development: (1) developing a satisfactory uranium carbide fuel of acceptable cost and (2) establishing the reliability of sodium components, mode rator cladding, and plantmaintenance procedures. Laboratory experience with sodium pumps, valves, etc., has been good, but much more information will be required to prove that these components will operate satisfactorily with a minımum of downtime

In considerıng the development of a $1000-\mathrm{Mw}(\mathrm{e})$ plant, the USAEC is following two approaches. The first involves the design of a prototype that would incorporate components and structures large enough for a 1000-Mw(e) design. However, the prototype would have a capacity of about $300 \mathrm{Mw}(\mathrm{e})$ and would use only one primary and one secondary loop. After successful operation this plant could be modified to increase the output to a full $1000 \mathrm{Mw}(\mathrm{e})$. The second approach would be more conventional in that a $300-\mathrm{Mw}(\mathrm{e})$ prototype based on extrapolations from experience with the Hallam reactor would be built. This plant would then be used to design and construct a full-size 1000-Mw(e) plant. 
A further consideration is the possibility of converting a sodiumgraphite reactor into a fast-breeder reactor system when the feasibility of this concept is established. In the consideration of a 1000-Mw(e) power plant, the use of supercritical steam appears to offer the most promise. Increasing steam temperatures above $1050^{\circ} \mathrm{F}$ would require higher cost materials and thus reduce the incentive to improve the plant heat rate. Supercritical steam is advantageous in an SGR since in a sodium-heated steam superheater the controlling resistance to heat transfer is on the steam side. The use of supercritical pressure increases the over-all heat-transfer coefficient from about $250 \mathrm{Btu} /$ $(\mathrm{hr})(\mathrm{sq} \mathrm{ft})\left({ }^{\circ} \mathrm{F}\right)$ for a 2400 -psi unit to about $800 \mathrm{Btu} /(\mathrm{hr})(\mathrm{sq} \mathrm{ft})\left({ }^{\circ} \mathrm{F}\right)$ for a 4500-psi unit; the saving in plant cost for a $1000-\mathrm{Mw}(\mathrm{e})$ plant is est1mated to be at least $\$ 5$ per kılowatt.

The design and operating data for a $1000-\mathrm{Mw}(\mathrm{e})$ supercritical plant are as follows:

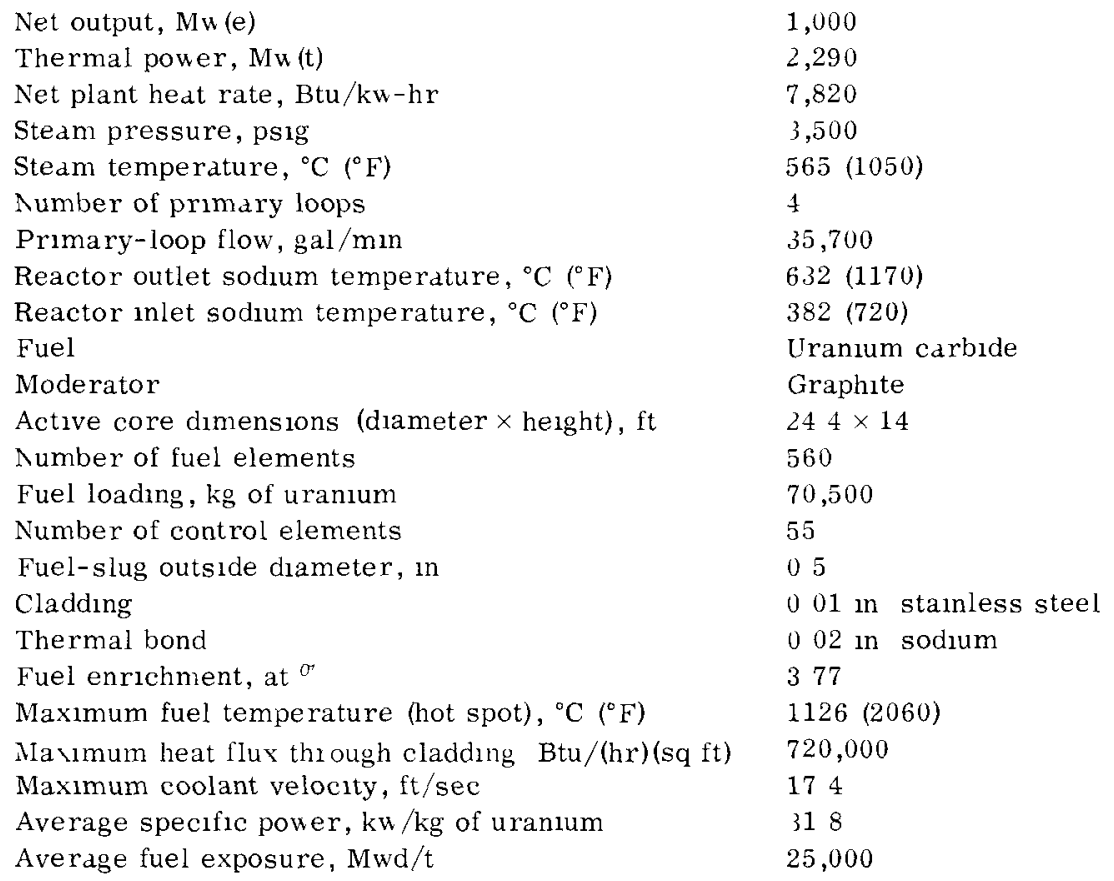

In this plant design it was assumed that the uranium monocarbide fuel would have a rather high power density and high maximum fuel temperature. It was also assumed that sodum-system components, such as large valves and large sodium pumps, could be made avallable and would operate with few or no maintenance problems. Assuming that a plant of this type could be bullt for $\$ 175$ per kllowatt and that the average fuel exposure would be $25,000 \mathrm{Mwd} / \mathrm{t}$, a power cost of $5.62 \mathrm{mllls} /$ 
$\mathrm{kw}-\mathrm{hr}$ is estimated. The fuel-cycle costs, in mills per kilowatt hour, would be 0.41 for fabrication, 0.86 for burnup, 0.12 for inventory, and 0.17 for reprocessing, giving a total of 1.56 .

\section{FAST REACTORS}

Development of fast reactors was started in the United States when at was generally realized that this was the one way that power plants with nuclear fuel could fully utilize avallable uranium. A review of these reactors is given in Ref. 8. The EBR-I, bull at the National Reactor Testing Station (NRTS) in Idaho, was the first fast reactor project undertaken by the USAEC. The EBR-I reached criticality in August 1951. The first electric power generated by nuclear energy was produced by the EBR-I on Dec. 20, 1951. Since then the reactor has operated through three cores. On Nov. 27, 1962, the EBR-I Mark IV core reached criticality; this was the first time that plutonium was used as a primary fuel in a power-producing reactor. The Experimental Breeder Reactor No. II (EBR-II), also at NRTS, is an experımental fast power reactor directed at establishing the technical and economic feasibility of fast reactor, central-station power plants with a completely integrated fuelrecycle processing plant. The use of an integrated plant for fuel reprocessing and fuel-element fabrication will represent the firstattempt to recycle fuel in a fast reactor, to process spent fuel by pyrometallurgical methods, and to fabricate fuel elements by remote control. Argonne National Laboratory has the prime responsibility of building and operating both the EBR-I and the EBR-II.

The Enrico Fermi project was undertaken in 1956 by the Power Reactor Development Company (PRDC), Detroit, Mich., under the USAEC Power Demonstration Reactor Program. Because of both technical and legal setbacks, the project is at least two years behind schedule. However, this plant is a major step in fast reactor development because it will be the first unit of commercial size built and will be a main source of operational experience for several years.

The major British effort in fast reactor development is centered around the Dounreay Fast Reactor (DFR). On Oct.14, 1962, this reactor achieved the distinction of becoming the first fast reactor in the world to continuously generate electricity into a commercial grid system.

The Russian effort in fast reactor development started in 1949 and

is now centered around the BR-5, an experimental fast reactor at Obninsk. This reactor, which became operational in 1959 , is fueled with plutonium dioxide, some of which has received 5 percent burnup. ${ }^{9}$ The $\mathrm{BR}-5$ is a research reactor, and its main uses are to test fuel and blanket elements, gather operating experience, and test components. No power is generated. 


\section{Technical Aspects}

In the fast reactor, ${ }^{7}$ which contains no moderator, neutrons are slowed down only by inelastic collision with structural, coolant, and fissile materials to about 0.1 to $0.2 \mathrm{Mev}$. A reactor operating at high neutron-energy levels is characterized by a small core with high power density, a high breeding ratio, low parasitic absorption of neutrons by structural materials and fission products, absence of large hot-spot effects, small reactivity requirements for control, and a fuel-element lifetime limited by irradiation damage rather than buildup of fission products. Because most of the present concepts consider using sodium as a coolant, it is possible to attain high thermal efficiency with low operating pressures in the primary system. Most of the problems with fast reactors center around the need for a high density of fissile material in the core. A high power density is required to keep the fuelinvestment charges low. This requirement of high power density becomes less important as the cost of fissile material decreases. Since the fissionable fuel in a fast reactor must be recycled many times before it is completely burned, the cost of chemical reprocessing and refabrication becomes a significant factor in attaining economic power. Hence the development of fuels capable of attaining high burnups such as the ceramic fuels is essential.

Current studies on fuels containing plutonium carbide and plutonium dioxide indicate that these fuels are more stable under irradiation than are metallic fuels. Some cast $\mathrm{PuC}-90 \mathrm{wt} \% \mathrm{UC}$ specimens have been irradiated to $22,000 \mathrm{Mwd} / \mathrm{t}$ at 700 to $800^{\circ} \mathrm{C}\left(1292\right.$ to $1472^{\circ} \mathrm{F}$ ) with no detectable dimensional changes and very little fission-gas release. ${ }^{10}$ Capsule irradiations to $100,000 \mathrm{Mwd} / \mathrm{t}$ on mixed $\mathrm{PuO}_{2}-\mathrm{UO}_{2}$ fuels at reactor operating temperatures have shown good results. ${ }^{11}$

Refabrication costs could be reduced to a minimum if fluid or mobile fuels, such as pastes or settled beds, were developed. Nonaqueous processing, such as slagging and zone melting, for example, is suggested for reducing chemical reprocessing costs. This alternative, however, does not avoid the problem of remote refabrication of solid fuel elements.

Questions have been raised concerning the inherent safety characteristics of fast reactors because of the behavior and meltdown of the EBR-I during special reactor-physics tests. Consequently many features of fast power reactors related to safety and control have been studied. The positive temperature coefficient once connected with the EBR-I was traced to bowing of fuel rods, and this condition has been eliminated. Therefore it is probably fair to say that there are no inherent nuclear characteristics in fast reactors that make them less safe than other types. 


\section{Experimental Breeder Reactor No.I}

After the November 1955 meltdown incident on the Mark II core of EBR-I, a new core, the MarkIII, was designed to test the hypothesis that bowing of the fuel elements was the cause of the positive temperature coefficient of reactivity observed in the Mark I and Mark II designs. ${ }^{8}$ The fuel rods consisted of a highly enriched uranium, 2 wt.\% zirconium alloy slug, coextruded with a 0.02-1n. zirconium jacket. Similarly extruded natural-uranium, 2 wt.\% zirconium sections are welded above and below the enriched fuel section to provide the upper and lower blanket. Coextruded construction prevents bowing of the fuel slugs inside the jacket. Inner blanket rods are simllarly constructed. Three ribs of $0.046-1 n$. zirconium wire are welded on with $120^{\circ}$ spacing. The rods are fitted with triangular tips to so orient them that each $\mathrm{rib}$ contacts the adjacent fuel element. The central rod is a non-fuel-bearing rod capable of being expanded after insertion into the assembly. When expanded, the tightening rod forces the fuel elements against each other and against the hexagonal subassembly can, thus preventing bowing of fuel elements inside the assembly. The fuel assemblies are positioned at the lowered tube plate, clamped at the reactor midplane, and clamped just above the coolant inlet to eliminate the possibility of subassembly bowing.

Coolant flow is directed in series or parallel by the inlet and throttle valves. The reactor is thoroughly instrumented with thermocouples in fuel and blanket elements, coolant passages, and structura. members. Tests have been conducted on Mark III at powers up to 1200 $\mathrm{kw}$ and at flows as low as $110 \mathrm{gal} / \mathrm{mm}$. Flow changes at power revealed no indication of a prompt positive reactivity coefficient. In 1962 the EBR-I Mark III was operated on a part-tıme basis. ${ }^{12}$ Many capsuleirradiation studies were performed, and the reactor was used to train EBR-II operating personnel. The EBR-I Mark III was shut down in September 1962 with a total operating time of $3220 \mathrm{Mw}-\mathrm{hr}$. The extremely successful operation of this core confirmed the suspicion that bowing of the fuel was the main cause of instability and has done much to dispel fears about the safety of fast reactors.

The EBR-I Mark IV core, which became critical on Nov. 27, 1962, 1s fueled with plutonium alloyed with $1.25 \mathrm{wt} . \%$ aluminum. The rods are clad with zirconium. The fuel was made at ANL. The total weight of plutonium was $28.7 \mathrm{~kg}$ fabricated into 327 rods, each $0.3 \mathrm{in}$. in diameter. An inner blanket of natural-uranium rods, about $0.4 \mathrm{~m}$. in diameter, surrounds the core. There is also an outer air-cooled breeding blanket of natural-uranium bricks that can be moved to control the fission reaction. One of the purposes of this new core is to allow measurement of the over-all breeding gain in a plutonium-fueled reactor. 


\section{Experimental Breeder Reactor No. II}

The EBR-II, built at NRTS, is an experimental fast power reactor directed primarily at establishing the technical feasibility of fast reactors for central-station power plants. ${ }^{8}$ Figure 3 is a flow diagram for

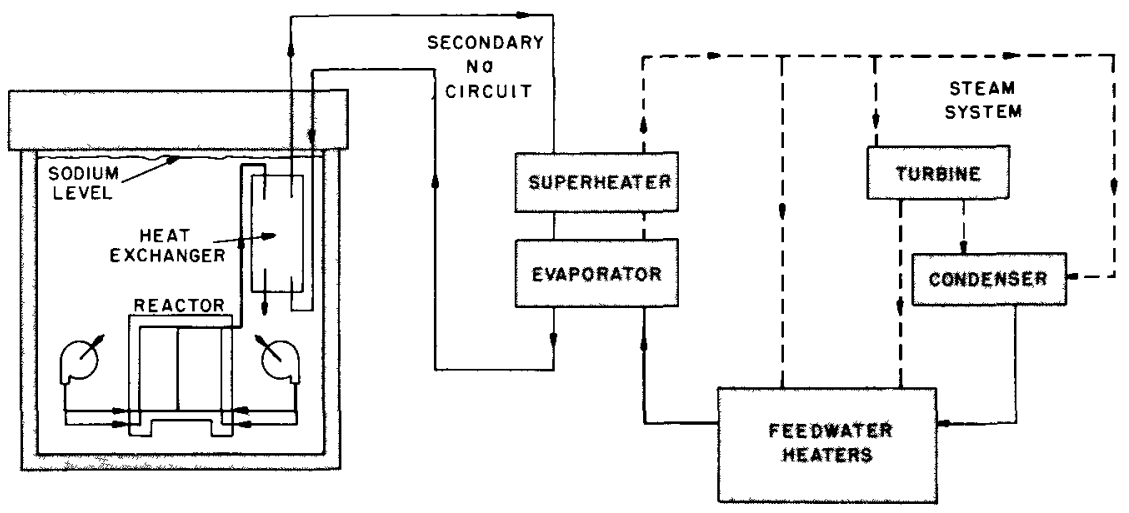

Fig. 3-Experimental Breeder Reactor No. II flow diagram.

the EBR-II. It is a completely integrated nuclear power plant incorporating the reactor, sodium boiler, and fuel-recycle processing plant. The EBR-II is the first attempt to recycle fuel in a fast reactor, to process spent fuel elements by pyrometallurgical methods, and to fabricate fuel elements by remote control. The thermal power rating of the reactor is $62.5 \mathrm{Mw}$; the gross electric output rating is $20 \mathrm{Mw}$. The power cycle is comprised of three major systems: (1) the primary system, consisting of the reactor and the primary sodium cooling system; (2) the secondary system, or the intermediate sodium heat-transfer system; and (3) the steam-electric system. ${ }^{7}$ In the primary system the sodium pumps circulate 8600 gal of sodium per minute. The temperature of the sodium in the primary system is $371^{\circ} \mathrm{C}\left(700^{\circ} \mathrm{F}\right)$ at the reactor inlet and $476^{\circ} \mathrm{C}\left(890^{\circ} \mathrm{F}\right)$ at the reactor outlet. The reactor is unmoderated and sodium cooled and is controlled by the movement of fuel into, and out of, the core with 12 peripheral control rods employed for regulation. The blanket is located at the top, bottom, and sides of the core. The major fraction of breeding takes place in the blanket, and the remainder occurs in the core. For initial reactor loadings the fissionable material is $\mathrm{U}^{235}$. Subsequent loadings will contain $\mathrm{Pu}^{239}$. The approximate breeding ratio expected with the $U^{235}$ loading is 1.2

The steam-electric system is essentially a conventional design employing a standard extracting, condensing, single-flow turbine. An automatic full-capacity steam bypass system dumping excess steam directly to the condenser is incorporated to prevent major load changes 
from effecting changes in the secondary-system conditions. Turbine throttle flow is $192,200 \mathrm{lb} / \mathrm{hr}$. Outlet steam conditions are $1250 \mathrm{psig}$ and $449^{\circ} \mathrm{C}\left(840^{\circ} \mathrm{F}\right)$.

The fuel-cycle facility is a 16-sided hot cell that contains the equipment for decladding fuel elements, melt refining the spent fuel, fabr1cating new fuel pins, and assembling new fuel elements. An auxiliary cell is used for remote assembly of the completed fuel assemblies and for servicing the main cell equipment.

Construction of the reactor, power, and fuel-reprocessing plants is essentially complete. Dry-criticality experiments began in September 1961. However, owing to problems that have arisen during plant checkout, the scheduled operational design full power has been delayed untıl some time in 1964. The major problem encountered during the checkout was in connection with the freeze seals on the two rotating shield plugs on the reactor. ${ }^{12}$ The primary function of these two plugs is to permit proper positioning of the fuel-machine mechanism for extracting or inserting fuel or blanket subassemblies. Each plug is equipped with a freeze seal to prevent gas leakage into, or out of, the primary tank. Each seal consists of a vertical cylindrical blade or skirt attached near the periphery of the plug, and it meets with an angular trough attached to a stationary plug support. The general arrangement is shown in Fig. 4 As the plug is rotated, the blade rotates within the trough. The trough contains a metal alloy with a low melting point [58 wt. $\% \mathrm{Bi}-42$ wt. $\%$ Sn; melting point, $\left.139^{\circ} \mathrm{C}\left(281^{\circ} \mathrm{F}\right)\right]$. When the plug is rotated, the

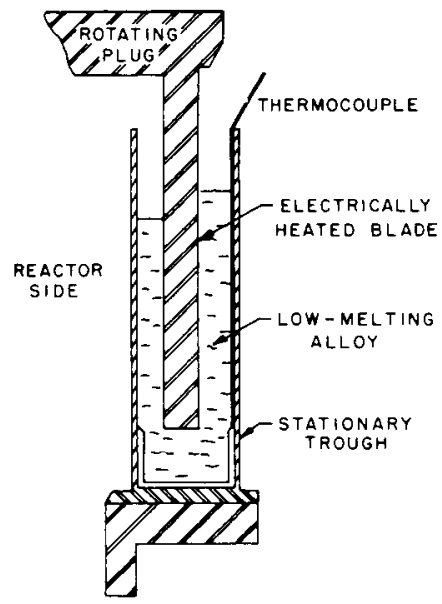

Fig. 4-Large rotiting-plug freeze seal.

alloy is maintained in a completely molten state. During reactor operation the alloy is maintained frozen at the top but molten at the bottom. The seal blade is comprised essentially of an upper stainless-steel ring and a lower copper ring. The copper ring was incorporated pri- 
marly to minimize circumferential thermal gradients. Electric heaters for melting the alloy are located within the rod.

Difficulty was first noted during check-out of the fuel-handling system and prior to filling of the primary tank with sodium. Occasional "sticking" of the plug during rotation was observed. It was first thought that this sticking was due to excessive thermal expansion of the large gear ring on the plug because the plug had been operating at abnormally high temperatures as a result of several days' operation with the seals molten and without cooling air. Prior to this time, before the seals were filled, the plug had been operating primarily at room temperature with no difficulty. After clearances between gears were increased, the unit at first appeared to operate freely. The sticking occurred again, however, and became progressively worse. It was then decided that the problem might be related to heating of the free seal. Hence the seal trough was drained, and examination with borescopes confirmed that portions of the lower copper ring had become separated, owing to corrosion, and had settled to the bottom of the trough. Both seal plugs were removed for further examination. Examination of the large seal plug revealed that severe corrosion had occurred in the lower copper ring of the seal blade. The bismuth-tin alloy had attacked the copper most heavily in the vicinity of the heaters, where the highest temperatures existed. There was no physical damage on the small plug seal; however, excessive corrosion of the lower ring was noted. The plans for correction involved two basic modifications in the design and operation of the seal: (1) replacing the copper ring with a stainless-steel ring and (2) minimizing oxidation of the molten seal alloy by operating at minimum practicable temperatures and by reducing the amount of oxygen avallable to the freeze-seal alloy.

\section{Enrico Fermi Plant}

The Enrico Fermi project was undertaken in 1956 by the PRDC under the Power Demonstration Reactor Program of the USAEC. The Enrico Fermi core and blanket consist of an assembly of square core and blanket assemblies arranged to approximate a cylinder about $80 \mathrm{in}$. in diameter and $70 \mathrm{in}$. in height. The core containing the enriched-fuel alloy approximates a right-circular cylinder $30.5 \mathrm{in}$. in diameter and is surrounded by a breeder blanket. Regulating and safety control is provided by boron carbide poison rods inserted in the core. As in EBR-II, heat is removed from the reactor core and blanket by the primary sodium coolant, transferred to the secondary sodium coolant, and finally transferred to water and steam in a steam generator. There are three primary coolant loops and three secondary coolant loops. Primary sodium ${ }^{8}$ enters the reactor at $288^{\circ} \mathrm{C}\left(550^{\circ} \mathrm{F}\right)$ and leaves at $427^{\circ} \mathrm{C}$ $\left(800^{\circ} \mathrm{F}\right)$. 
The initial output of the plant will be about $60 \mathrm{Mw}(\mathrm{e})$, but it is hoped that this will eventually be raised to $150 \mathrm{Mw}(\mathrm{e})$. The PRDC originally believed that the output of this reactor would be $94 \mathrm{Mw}(\mathrm{e})$. However, the original fuel elements were abandoned when experiments revealed a warping that would cause localized restrictions in the flow of sodium coolant. A new subassembly was therefore designed to permit reactor operation. The new design overcame fuel-element distortion, but it inherently presented greater resistance to coolant flow. Therefore, so that the reactor could operate without exceeding the specified maximum fuel and cladding temperatures, the power level was restricted to $200 \mathrm{Mw}(\mathrm{t})$.

Extensive non-nuclear tests have been carried out on the plant, and most of the plant, in particular the sodium system, has proved very satisfactory. Several faults discovered during the testing have caused considerable delay. The most serious fault was in the graphite neutron shielding, which falled during a test in which the reactor system was raised to $537^{\circ} \mathrm{C}\left(1000^{\circ} \mathrm{F}\right)$ - well in excess of the normal operating temperature. ${ }^{13}$ Deterioration of the graphite was traced to oxygen leaking into the graphite region during the high-temperature test and to graphite that did not conform to design specificaitions.

Another problem, noticed during hydrostatic testing, was leaks in the tubes of one of the steam generators. Investigation revealed that 49 of the total of 1200 tubes exhibited cracks, which probably resulted from stress corrosion. The steam generator had to be completely retubed.

The fuel-handling equipment was damaged whlle it was being tested with dummy fuel elements. Repair to this equipment required draining the sodium from the reactor. Repairs to the fuel-handling equipment were made by personnel, clothed in "space suits," who entered the reactor vessel through a specially constructed air lock. This was done to minimize the amount of moisture and oxygen introduced to the sodium system. Repair work on the vessel shield and heat exchangers has been completed, but, since other mechanical difficulties outside the reactor have caused a delay in the fuel loading, plant operation is not expected until 1964 (Ref. 14).

\section{Dounreay Fast Reactor}

The DFR in the United Kingdom is an experiment designed to study the operational characteristics of a fast reactor system and to evaluate large-scale handling of a liquid-metal coolant. ${ }^{15}$ The other major function of the experiment is to develop a fuel element which can withstand the required high burnup and which is compatible with a hightemperature liquid-metal coolant. Figure 5 is a flow diagram for this reactor. 
Early in the design of the Dounreay reactor, it was decided that facilities for circuit-component testing would not be provided and that an economic cooling system would not be the prime objective. Rather, the philosophy was that the experimental part of the reactor system should be in the reactor vessel and, outside of this, every effort would be made to reduce to a minimum the risk of breakdown of the cooling system.

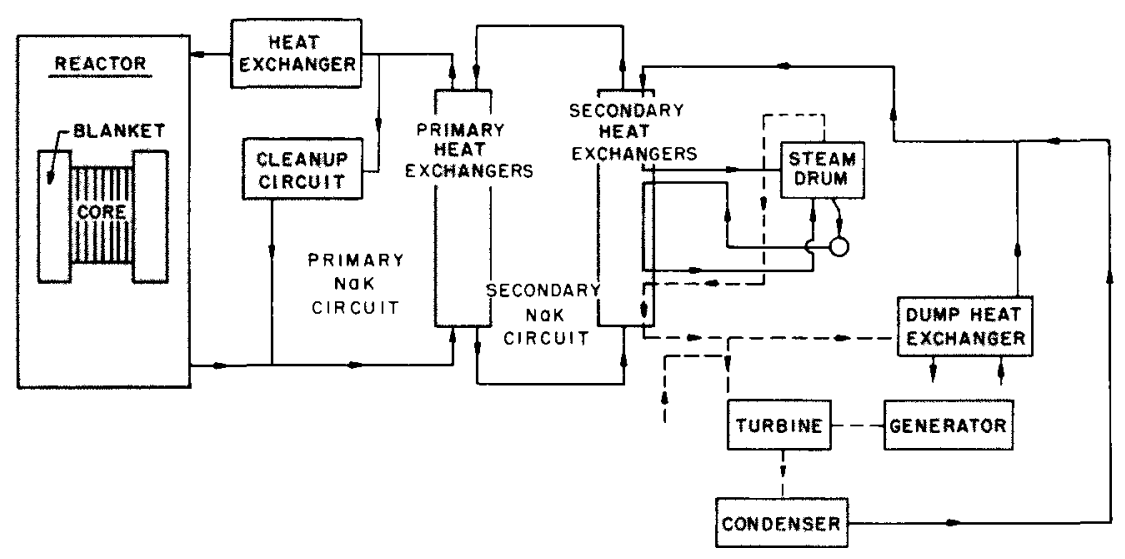

Fig. 5-Dounreay Fast Reactor flow diagram. ${ }^{15}$

The heat-transfer system, which consists of 24 primary and 12 secondary circuits, is designed to remove $60 \mathrm{Mw}(\mathrm{t})$ from the core and $12 \mathrm{Mw}(\mathrm{t})$ from the blanket, with $70 \mathrm{wt} . \% \mathrm{Na}-30 \mathrm{wt} . \% \mathrm{~K}$ alloy (NaK) as coolant. The reactor coolant inlet temperature is $200^{\circ} \mathrm{C}\left(392^{\circ} \mathrm{F}\right)$; the outlet temperature is $350^{\circ} \mathrm{C}\left(662^{\circ} \mathrm{F}\right)$. The control of the oxide or hydride level in the coolant is maintained by the use of both cold and hot traps. The primary gas blanket is nitrogen, and the design pressure at full power is 50 psig. The reactor core is approximately $21 \mathrm{in}$. high by 21 in. in diameter; it consists of 345 annular enriched-uranium fuel elements. The coolant flow is down through the centers and outside of hollow fuel elements, which are clad on the inside with niobium and on the outside with vanadium. The blanket elements, solid rods of natural uranium, surround the core at the sides and top. Reactivity is controlled by moving groups of fuel elements in and out of the core. There are 12 such groups, each containing 10 elements held within a carrier and actuated from below the core. Three $\mathrm{B}^{10}$ control rods are included as an alternative device for emergency shutdown. After the EBR-I incident and the subsequent analysis, it became apparent that similar coefficients, due to thermal bowing of the fuel elements, could arise in a Dounreay core. It was decided, therefore, to provide mechanical re- 
straint for the fuel elements. This was achieved by a "core tube nest," which gives lateral restraint at the top, center, and bottom.

The DFR first became critical on Nov. 14, 1959. Early experiments showed that changes in the coolant flow rate led to unexpected changes in reactivity, and it was found that the blanket gas, then nitrogen, was becoming entrained in the coolant. In addition, a number of pipes were blocked by sodium oxide. The first series of tests was completed by April 1960, and the reactor was shut down for fuel replacement.

The second charge, like the first, was an alloy of enriched uranium with chromium. In 1961, after the second group of tests, power in the megawatt range was reached. The reactor was then shut down to allow modifications to be made to eliminate gas entrainment. In the third recharging, a new fuel, uranium-molybdenum alloy, was used. At this tıme it was also decided to carry out a major cleanup of the whole coolant circuit to remove contamination, mainly sodium oxide and hydride.

With the reactor operating at $30 \mathrm{Mw}(\mathrm{t})$, the third core loading reached a burnup level of $1000 \mathrm{Mwd} / \mathrm{t}$. Selected fuel elements have been removed for examination from both core and blanket, and preliminary results indicate that the fuel is performing satisfactorily. In October 1962 the reactor began feeding power into the system of the North of Scotland Hydro-electric Board. ${ }^{13}$ The amount generated, $3 \mathrm{Mw}(\mathrm{e})$, supplied the Dounreay establishment during the day, with approximately $500 \mathrm{kw}$ being fed to the grid during off-peak hours. The output was increased to 100 percent of full capacity during 1963 . The turbogenerator is a mult stage impulse type rated at $15 \mathrm{Mw}(e)$.

\section{The BR-5 Reactor}

The Russian-built $5-\mathrm{Mw}(\mathrm{t})$ fast reactor, $\mathrm{BR}-5$, is a plutoniumfueled zero-energy assembly. ${ }^{16,17}$ It was preceded by the BR-1 and the $B R-2$. The $B R-1$, built in 1955, was used for experiments in fast reactor physics. The BR-2, a 100-kw experimental reactor built in 1956 , was fueled with plutonium and cooled with mercury. It was later dismantled, and some parts of it have been used for the present BR-5 reactor, which began operation in the summer of 1959 .

In the BR-5 the primary reactor coolant, sodium, flows up through the reactor core. The primary sodium system is divided into two circuits, each with its own mechanical pump and cold trap. The reactor inlet and outlet temperatures are $430^{\circ} \mathrm{C}\left(806^{\circ} \mathrm{F}\right)$ and $500^{\circ} \mathrm{C}\left(932^{\circ} \mathrm{F}\right)$, respectively. Total flow through both primary circuits is about 300 $\mathrm{gal} / \mathrm{min}$. The secondary coolant is eutectic sodium-potassium alloy. Different cooling systems are used for the two secondary loops. One loop is air cooled, whereas the other is equipped with a double-wall shell-and-tube exchanger generating steam at $230 \mathrm{psi}$. Mercury is used as an intermediate heat-exchange medium to prevent any possibility of sodium-water interaction. 
Fuel elements consist of sintered plutonium oxide clad in 0.197-in.OD stainless-steel tubes having a wall thickness of $0.016 \mathrm{~m}$. and an active length of $11 \mathrm{~m}$. Each fuel element contains 19 tubes, and 88 elements function as a core. A ring of tubes loaded with natural uranium surrounds the core. These tubes serve as a blanket and a thermal shield and provide a location for high-flux experiments. A second reflector, located outside the reactor vessel, consists of two concentric nickel cylinders. The inner cylinder, which is 2 in. thick, can be raised or lowered on cables for coarse control of reactivity. The outside nickel cylinder, $4 \mathrm{in}$. thick, consists of two movable sections that provide for fine control.

Shielding is provided by $20 \mathrm{in}$. of water immediately surrounding the nickel shield for neutron moderation. Outside the water shield is an assembly of cast-1ron rings $16 \mathrm{in}$. thick surrounded by concrete approximately $43 \mathrm{in}$. thick. Above the core are eccentric rotating plugs filled with boron carbide.

The BR-5 attained criticality in January 1959 and has been operating for extended periods of time at maximum or near maximum power. An event similar to one encountered at Dounreay occurred soon after the reactor came into operation. It was discovered that the higher the sodium pressure, the higher the reactivity. A pressure change of $1 / 2 \mathrm{~atm}$ led to a change in reactivity that was greater than the delayed-neutron fraction, and it was found that the reactivity change occurred in an inverse ratio to the pressure. This reactivity change was due to the presence of a large quantity of argon bubbles in the sodium entrained from the gas blankets. These bubbles concentrated in the core in spaces between the fuel elements; thus a change in pressure led to a change in the volume of the bubbles and hence to a corresponding change in reactivity. The effect was eliminated by modifying the pumps and increaslng the sodium temperature. Russian reports indicate that there has been no serious trouble in the use of sodium in the primary circuit and that they have been able to keep oxide contamination to an acceptable level.

At the International Atomic Energy Agency (IAEA) symposium on power-reactor experiments in October 1961, Bondarenko disclosed that a faulty fuel element had been detected in the BR-5. However, since the only method of detecting damaged fuel assemblies in the reactor was by individual removal and testing, operations were contınued because the reactivity due to the escape of gaseous fission products remained at a low level. A burnup value of 5 percent had been reached with the fuel, ${ }^{9}$ although, when the reactor was designed, the maximum hoped for was 2 percent. With the experience gained on the $\mathrm{BR}-5$, it was planned to follow this with two power reactors - the $\mathrm{BN}-50,50 \mathrm{Mw}(\mathrm{e})$, and the $\mathrm{BN}-250,250 \mathrm{Mw}(\mathrm{e})$. These plans, however, have been abandoned, and design work is now proceeding on an $800-\mathrm{Mw}(\mathrm{e})$ plant. 


\section{Fast Ceramic.fueled Reactors}

The major objective of studies carried out by the Atomic Power Equipment Department of General Electric Company for the USAEC over the past few years has been to demonstrate the capability for low fuel-cycle costs through the development of high-burnup ceramic fuels, operating at high specific power.$^{15,18}$ Breeding systems have a potential for very low fuel-cycle cost if high burnup in the fuel can be achieved. In the current designs for fast reactors using metallic fuels with lowburnup capabilities, fabrication and reprocessing costs have been very high. Recent studies have indicated that fast reactors using uranium oxide or other ceramic fuels which are capable of very long burnups offer particular promise for achieving low total fuel-cycle costs. The characteristics of fast reactors utılizing ceramic fuels differ significantly from those of most present metal-fueled units. In particular, a large volume and a high internal-breeding ratio are desirable since they permit long burnup of the ceramic fuel without the occurrence of unacceptably large swings in reactivity of the system. The neutron spectrum of such a unit using mixed uranium-plutonium oxide fuel also will have a greater epithermal component than that of most metal-fueled units. Studies show systems of this type to have an appreciable negative power coefficient due to the Doppler effect. This power coefficient appears to be more dependable and quicker acting than the negative coefficient based on the mechanical movement of fuel due to thermal expansion. Most present fast reactor concepts depend on thermal expansion.

The development program now in progress is aimed at demonstrating the key features of a ceramic-fueled fast reactor. The radiation tests have been completed for several 0.25-1n.-OD fuel pins of mixed plutonium oxide and uranium dioxide clad with stainless steel, operating at temperatures and specific power ratings representative of large fast oxide reactors. Burnups of up to $100,000 \mathrm{Mwd} / \mathrm{t}$ have been achieved. ${ }^{11}$ The General Electric Company has prepared proposals for a 10 - to 50 $\mathrm{Mw}(\mathrm{t})$ test reactor and considers a $500-\mathrm{Mw}(\mathrm{e})$ station possible by 1975 . Another General Electric proposal incorporates a coupled fast-thermal system utilizing a central fast core for steam heating surrounded by a bolling-water thermal region.

\section{RAPSODIE}

French fast reactor plans, linked with those of Euratom, include a critical assembly, RACHEL, now in operation; the 20-Mw(t) plutoniumfueled fast breeder experiment, RAPSODIE; and eventually a 300-Mw(e) industrial reactor. The RAPSODIE, a fast sodium-cooled breeder reactor, is being built at Cadarache in southern France. ${ }^{13,15}$ A section of the 
reactor is shown in Fig. 6. Design work on RAPSODIE started in 1957. It makes use of sodium technology developed in France during the past 10 years on several experimental sodium and sodium - potassium loops. It was decided that, along with the preliminary design, a full-scale mockup of the reactor vessel and loops should be built before the reactor itself was built. This mockup was built in 1960, and tests were completed near the end of 1961 . The reactor itself is scheduled to be commissioned in mid-1965. This experimental reactor will be used to

Fig. 6-A section of the RAPSODIE reactor.

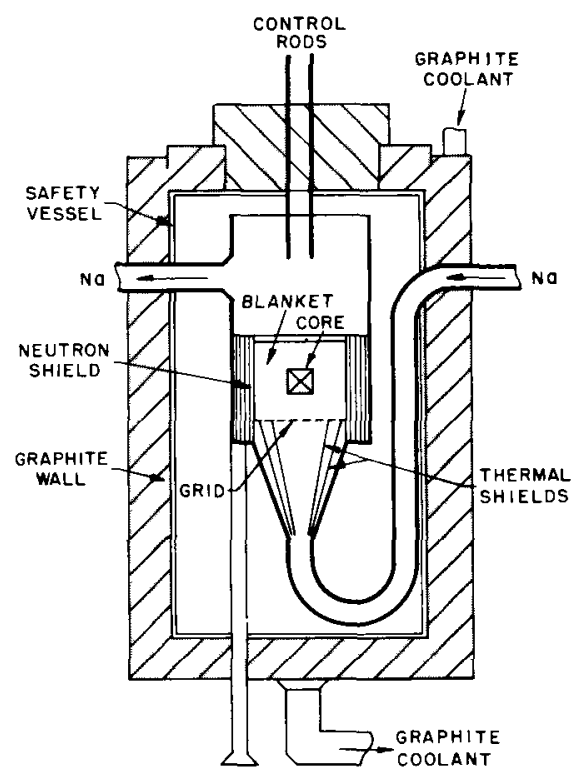

obtain data on reactor behavior at varying power level and thermal and hydraulic conditions. French plans are to investigate and develop basic information on fast reactors, including the testing of new fast reactor fuels. The present coolant system is designed for $1 \mathrm{Mw}(\mathrm{t})$; however, it can be replaced at later dates by a $10-\mathrm{Mw}(\mathrm{t})$ system and, finally, by a $20-\mathrm{Mw}(\mathrm{t})$ system. Each system includes a primary and a secondary coolant loop. The first core loading will be plutonium and enriched uranium; the plutonium will be used to control the critical dimensions of the core. Several fuels have been investigated, and a uraniumplutonium-molybdenum alloy has been irradiated in the French EL-2 and EL-3 reactors. A mixed uranium dioxide-plutonium dioxide fuel has been developed, and work on a mixed uranium carbide-plutonium carbide fuel is under way.

A full-scale mockup is a unique feature of the RAPSODIE project. The reactor core connects to a high-flow-rate sodium circuit, permitting long-term tests and thermal shocks. Also included is a circuit for test- 
ing control rods. The complete installation of 1 - and 10-Mw cooling circuits will make it possible to check a great variety of operating conditions.

\section{Los Alamos Molten Plutonium Reactor Experiment}

Investigations of means for utilizing plutonium fuels in reactors are in progress at Los Alamos Scientific Laboratory (LASL), with the major effort centered about the molten plutonium reactor experiment.

The Los Alamos Molten Plutonium Reactor Experiment No. I (LAMPRE-I), designed for 1-Mw(t) operation, utilizes a fuel loading of about $23 \mathrm{~kg}$ of plutonium in individual tantalum capsules. The fuel alloy is molten plutonium with 9.5 at.\% iron. The reactor vessel is type 304 stainless steel, and the coolant is sodium. The core tank accommodates 199 capsules; of this amount, 143 tantalum capsules contain the fuel alloy. The remaining pins, which are unfueled stainless steel, serve as a radial reflector.

One of the major objectives of the development program is the demonstration of the feasibility of the long-term containment of liquidplutonium alloy, and the LAMPRE-I itself is considered an essential step in the container-development program. A second objective is the study of the problem of accumulation of fission-product gas. The LAMPRE-I does not, however, duplicate the neutron flux and the heat flux to be expected in a molten-fuel power reactor. Hence a secondphase test reactor, the Fast Reactor Core Test Facility, with a power of $20 \mathrm{Mw}(\mathrm{t})$ is scheduled for 1964. The main objective of this program is to achieve a system of high temperature and high specific power, incorporating continuous fuel reprocessing and a blanket to exploit the potentially large breeding gains. ${ }^{19}$

The reactor first went critical with molten fuel in April 1961. Core I was operated for about $115 \mathrm{Mw}$-hr at power up to 40 percent of the designed power. The behavior of the reactor confirmed expected inherent stability, ease of control, and smooth response to power demand. However, the LAMPRE operation has disclosed a significant loss of reactivity associated with the higher power runs and to a lesser extent during shutdown periods. A thorough check for fuel leaks has been made, and none have been discovered. It is presumed that this reactivity loss is caused by gaseous fission products retained in the fuel. During the first core loading of the LAMPRE, the fuel remained molten for about $8000 \mathrm{hr}$ at temperatures from 480 to $575^{\circ} \mathrm{C}\left(896\right.$ to $1070^{\circ} \mathrm{F}$ ). Fuel capsules sectioned after exposure for this length of time disclosed no major corrosive attack. Metallographic examination, however, has shown some slight pitting of the capsule in the gas phase. Core II, now in operation, achieved a design power of $1 \mathrm{Mw}(\mathrm{t})$ in July 1962. The present LAMPRE core loading utilizes four different forms of tantalum as container ma- 
terial for the liquid fuel ( 90 at.\% plutonium and 10 at.\% high-purity 1 ron). These materials are (1) electron-beam-melted pure tantalum, (2) double-arc-melted pure tantalum, (3) tantalum plus $0.1 \mathrm{wt} . \%$ tungsten, and (4) tantalum containing $0.75 \mathrm{wt} . \%$ tungsten and $0.2 \mathrm{wt} . \%$ yttrium. Corrosion studies have recently shown that pure tantalum containers will withstand a higher temperature corrosion condition than will the tungsten-containing alloys. More detalled information on the LAMPRE operating experience is given in LASL quarterly status reports. ${ }^{20}$

\section{Reactor Programs in Preliminary Stages}

The reactor programs ${ }^{13}$ discussed in this section are considered preliminary because the major effort has been restricted to paper studies, some of which have been supported by small-scale experiments. None have as yet had any large-scale hardware built for them.

The Atomic Power Development Associates, Inc. (APDA), Detroit, Mich., has been conducting a research and development program for a paste-fuel concept. ${ }^{21}$ Many of the advantages cited for liquid fuels can be realized also for a mobile paste fuel, which is a dense slurry of a particulate solid fuel material in a liquid-metal medium. The concept avoids some of the corrosion problems of the liquid concept and allows the use of plutonium diluted with $\mathrm{U}^{238}$ in the core. The APDA paste concept differs from the settled-bed concept of the Brookhaven National Laboratory (BNL) in that fuel mobility is continuous in a gravity-flow system; in the BNL concept a stationary bed is fluidized intermittently. The APDA paste is a settled bed consisting of relatively small particles, of about 100 to $1000 \mu$ nominal diameter, which flow slowly down through the reactor under the force of gravity plus the drag of the carrier liquid. While in the reactor, the paste consists of $60 \mathrm{vol} . \%$ solids and 40 vol.\% carrier liquid, depending on particle size. The present consideration is given to metallic uranium-plutonium fuels with sodium as the carrier liquid. The APDA work has included radiation of the pastelike uranium fuel in sodium, which reveals no anomalous behavior at 0.1 percent burnup. Non-nuclear hydraulic tests of reactor components have also been very promising.

The Italian national committee on nuclear ene rgy [Comitato Nazionale per l'Energia Nucleare (CNEN)] has proposed another paste-fuel concept in a fast sodıum-cooled system known as RAPTUS (Rapıd-ThoriumUranum-Sodıum). This concept evolved when thorium-uranium cycle studies showed that the major fuel-cycle cost was the fabrication of fuel elements, irrespective of the choice of fuel. This concept is for a paste-fueled reactor, in which the paste is $\mathrm{U}^{233}$ and thorium suspended in liquid sodium. The reactor resembles a shell-and-tube heat exchanger, the fuel paste being held in the shell and the sodium coolant flowing through the tubes. The CNEN believes that this approach should 
lead to a practical power reactor with high burnup and low costs of fuel manufacture. ${ }^{22}$

A detalled study of the plutonum fuel cycle constitutes one of the major nuclear activities in Belgium at present. Belgian investigations have centered on a study of plutonlum-bearing ceramic fuels, and a process for the preparation of spherical particles of uranium dioxide and plutonium carbide has been perfected. Varıous fuel assemblies are being tested in the Belgian $B R-2$ reactor, and it is intended to extend this work in the BR-3.

Japanese authorities are interested in a concept designed around an internal breeding ratio of unity to provide a system in which the fuel need never be replaced during the lifetime of the reactor. The core size and the power output of such a reactor would need to be large, and difficult problems associated with fuel integrity are anticipated.

A settled-bed fast reactor has been proposed by BNL workers. ${ }^{23}$ They are considering fast reactor systems utilizing fuel in the form of particulate solids, in which cooling is by direct flow of sodium down through a settled bed of such fuel. The fuel is in a settled and static condition during operation; the direction of the coolant flow maintains the fuel in the settled state. After reactor shutdown the fuel may be fluidized by pumping sodium up through the bed; during this time fuel is removed, added, and mixed. The ability to operate the reactor at power with the fuel all in the core and in a static condition and yet, during transfer and redistribution operations, to handle fuel as a liquid is one of the major advantages of this system. The present effort at BNL is centered around evaluation of uranium carbide fuel spheres, studies of hydraulics in settled beds, studies of reactor physics, and determination of fuel-cycle economics.

\section{HEAVY-WATER-MODERATED REACTORS}

Interest in heavy water as a moderator for an atomic reactor was aroused very soon after the fission process was discovered because there was a possibility that graphite would not be a sufficiently good moderator to support a chain reaction. Small-scale plants for production of heavy water were built in 1943 so that a moderate supply of this material would be avalable. With the success of graphite as a moderator and the high production cost of heavy water - then $\$ 200$ per poundearly interest in it waned. Canada, however, continued to place primary emphasis on heavy-water-moderated reactors and designed the Canadian National Research Experimental Reactor (NRX) to use this material as the moderator.

Encouraged by the NRX operating experience, the United States built five large production reactors using heavy water as the modera- 
tor (the Savannah River Plant, Aiken, S. C.). Beginning in 1951 the very large amount of heavy water required for the production reactors was obtained by building a plant at Diana, Ind., and a piant at the Savannah River site, each capable of producing 500 tons per year. ${ }^{24}$ The $\mathrm{H}_{2} \mathrm{~S}-\mathrm{H}_{2} \mathrm{O}$ dual-temperature process has proved to be so superior that the cost of producing heavy water has been reduced to the point that it is now sold for $\$ 24.50$ per pound. ${ }^{25}$ In a recent study $^{26}$ it was concluded that a modern plant could be built to produce heavy water for $\$ 17$ per pound and perhaps as low as $\$ 14$ per pound.

Designers in the power-reactor field recognized that heavy-water moderation would allow sufficient excess multiplication that reactors could be fueled with natural uranium, a feature of major importance to countries without facilities for enriching natural uranium. Canada has built a 20-Mw(e) power reactor, the Nuclear Power Demonstration Reactor (NPD-2), at Chalk River ${ }^{27,28}$ and has under construction a 200$\mathrm{Mw}(\mathrm{e})$ power reactor, the CANDU, also at Chalk River. Construction will soon begin on Canada's first organic-cooled reactor, the $40-\mathrm{Mw}(\mathrm{t})$ White Shell Reactor No. 1 (WR-1). The WR-1 will be used to test fuel, coolant, and other components for organic-cooled power reactors, and it is related to Canadian interest in organic-cooled heavy-watermoderated reactors. ${ }^{29}$

In the United States operating experience is being gained with the Heavy Water Components Test Reactor (HWCTR) at the Savannah River Plant and the Plutonium Recycle Test Reactor (PRTR) at Hanford Atomic Products Operation, Richland, Wash. A prototype power reactor, the Carolinas-Virginia Tube Reactor (CVTR) at Parr, S. C., went critical on Mar. 30, 1963.

Several reactors have been built or are under construction outside the United States and Canada. Pressure-vessel reactors cooled with heavy water are under construction for power generation and district heating in Sweden, and the boiling heavy-water reactor, also a pressurevessel type, is in operation at Halden, Norway. Germany is building a heavy-water-moderated reactor, the MZFR, which is capable of generating $50 \mathrm{Mw}(\mathrm{e})$. France is building EL-4, a gas-cooled heavy-watermoderated type. ${ }^{30}$

\section{Technical Aspects}

The technology of heavy-water reactors, although not so highly developed, does not differ to any important degree from that of pressurizedwater or boiling-water reactors utilizing light water. In fact, a comparison between one of the large light-water reactors now being proposed and a large heavy-water reactor (assuming equal technological development) shows that the relative economics of these two types depends almost entirely on the relative costs of heavy water and enriched fuel. 
The heavy-water-moderated reactor is unique in that it can extract relatively high energy yields in the range of 8000 to $10,000 \mathrm{Mwd} / \mathrm{t}$. Graphite-moderated reactors fueled with natural uranium appear to have lower burnups for physics and metallurgical reasons. Although the interest in utilizing natural uranium is an overriding consideration in countries that have a limited supply of enriched uranium, the use of natural uranium for reactor operation in the United States is not a strong incentive per se; it is an incentive only insofar as it can be shown to yield net economic benefits either now or in the future. Interest in heavy-water reactors is therefore not limited to those using natural uranium. Opinion is not unanimous as to the economics of operating with natural uranium. The Canadian work seems to indicate, for example, that natural uranium can produce electricity at lower cost than enriched-uranium reactors. However, most studies in the United States have indicated that power costs from heavy-water-moderated reactors are somewhat higher than those from light-water-moderated reactors and that, even for heavy-water-moderated reactors, it may be cheaper to use slightly enriched fuel. ${ }^{31}$

The difference in moderating properties of light water and heavy water leads to some major differences in the design of large-scale power reactors. Because of the large lattice spacing of heavy-water reactors, heavy-water cores are inherently larger than light-water cores. Since a pressure vessel becomes relatively expensive for the larger reactors, both the United States and Canada have selected a pressure-tube design as the most economic. Of course, the pressuretube design is not without problems. With pressure-tube construction only the fuel element and coolant are at high pressure. The moderator could be in a separate system at nearly atmospheric pressure. This arrangement would allow the moderator temperature to be low, but the gain in reactivity would be largely offset by the use of heavy-wall zirconium pressure tubes. Another inherent difficulty with the pressuretube design is loss of generated heat to the cold moderator water. This heat loss could be as high as 10 percent. Very little operating experience exists with pressure-tube power reactors. However, with the NPD- 2 now on the line and with other reactors such as the CVTR soon to be put into operation, much will be learned about the feasibility of building large-scale pressure-tube power reactors.

Because of the high cost of heavy water, minimizing heavy-water losses becomes a primary design consideration. Experience with the Savannah River production reactors has shown that large quantities of heavy water could be circulated at moderate temperatures and pressures through heat exchangers, valves, pumps, etc., with a loss of only 3 percent of the system volume per year. For a power reactor loss rates may be higher because of the higher temperature and pressure; however, careful design may offset this factor. If a boiling heavy-water re- 
actor is to be considered, the turbine seals would be a particular problem. Tritium in the moderator presents a minor health hazard when it is spilled, but usual protective devices and clothing are generally sufficient to allow safe working in the area. Zircaloy-2 probably has the best over-all properties for cladding the fuel. Although extensive testing of prototype fuel elements is under way, much more experience will be needed with this material.

Although metal fuels and oxide fuels are both being developed, the oxide fuels seem to be the most promising because of their ability to go to higher burnups.

Maintaining heavy water at a reasonable isotopic purity will require that each reactor or reactor complex have a heavy-water purification system. Loss in the nuclear reactivity is 1.5 to 3 percent for each mole percent decrease in heavy water. Hence the reactivity loss must be balanced against the cost of isotopic purification equipment.

\section{Heavy Water Components Test Reactor}

The HWCTR, a pressure-vessel reactor cooled and moderated by heavy water, was constructed by E. I. du Pont de Nemours \& Co., Inc., for the USAEC at the Savannah River Plant. It is a $61-\mathrm{Mw}(\mathrm{t})$ facility designed to test components for a heavy-water power reactor..$^{32,33}$ The HWCTR is designed to permit simultaneous test irradiation of up to 12 full-size natural-uranıum fuel elements at power ratıngs and exposures encountered in full-scale power reactors. Both uranium metal and oxide fuel elements of various shapes and sizes will be tested. No provision for generating electric power was made, and heat will be dissipated to the atmosphere through a light-water secondary system. The operating conditions are $1000 \mathrm{psi}$ and $238^{\circ} \mathrm{C}\left(460^{\circ} \mathrm{F}\right)$. The 12 test elements are accommodated in a region near the center of the core. This region is surrounded by a ring of "driver" fuel elements of enriched uranium to furnish sufficient reactivity for operation.

Coolant flow is down through the fuel and up through the reactor tank. The normal coolant flow rate is $9600 \mathrm{gal} / \mathrm{min}$. Two in-pile experimental coolant loops have been installed. One loop is cooled with heavy water and the other with bolling heavy water. The latter loop is convertible to operation with heavy-water steam or carbon dioxide.

A driver fuel element consists of a fuel tube with a "meat" composed of an alloy, zirconium plus $9.3 \mathrm{wt} \% \%$ uranium (93 percent enriched), clad inside and outside with Zircaloy. Criticality was achieved in the HWCTR on Mar. 3, 1962, with the reactor at atmospheric pressure and room temperature. During low-power physics tests, it was noted that the nuclear reactivity was affected by the hydraulic operation of the reactor. Tests confirmed that the nuclear effects were caused by aspiration of reactor blanket gas (helium and heavy-water steam) into the core via the coolant passages for the control rods and by the forma- 
tion of gas voids in the moderator as a result of the decrease in helium solubility with decreased pressure. Design changes to minimize this problem have been described. ${ }^{33}$ In October 1962 the HWCTR reached a maximum power level of $38 \mathrm{Mw}(\mathrm{t})$ and a total reactor exposure of 258 Mwd.

\section{Plutonium Recycle Test Reactor}

The PRTR is a vertical pressure-tube reactor moderated and cooled by heavy water. ${ }^{15}$ The reactor, shown in Fig. 7 , is designed to demonstrate the feasibility of recycling plutonium as an alternative or supplement to $U^{235}$ fuel in thermal heterogeneous reactor systems. The 85 Zircaloy pressure tubes are designed for coolant temperatures and pressures of $277^{\circ} \mathrm{C}\left(530^{\circ} \mathrm{F}\right)$ and $1050 \mathrm{psig}$. The moderator is contained in a welded aluminum tank. Mode rator inlet temperature is $58^{\circ} \mathrm{C}\left(137^{\circ} \mathrm{F}\right)$, and the outlet temperature is $65^{\circ} \mathrm{C}\left(149^{\circ} \mathrm{F}\right)$. The reflector consists of heavy water in a separate annular tank, $23 \mathrm{in}$. thick, surrounding the calandria. The reflector does not extend down to the level of the calandria base. The lower $24 \mathrm{in}$. of the core is the refore without radial reflection. This space can receive moderator from the calandria very rapidly during an emergency shutdown. The initial fuel charge consists of 19 -rod clusters that are $54 \mathrm{~m}$. long. The rods are clad with $0.030-1 \mathrm{n}$.-thick Z1rcaloy-2. In about 40 percent of the fuel assemblies, the rods contain an alloy of $1.8 \mathrm{wt} . \%$ plutonium in aluminum. In the remaining 60 percent of the fuel assemblies, the rods are swaged natural uranium dioxide. Several irradiated fuel elements from the first core have been reprocessed, refabricated into new elements, and placed back into the reactor. From this and future experience, it will be possible to establish the additional cost for remote fabrication of plutonium-bearing elements.

Startup tests and initial operation of the PRTR have shown that the temperature and vold coefficients are negative. Problems of power distribution and fuel handling have been minımal, and kinetıcs and control characteristics are very satisfactory. Heat is removed from the primary heavy-water coolant in a heat exchanger that generates lightwater steam at $425 \mathrm{psi}$. The steam is condensed, monitored, and then discharged into the Columbia River.

\section{Carolinas-Virginia Tube Reactor}

The CVTR is a U.S. effort aimed specifically toward development of a heavy-water-cooled power reactor. ${ }^{34} \mathrm{~A}$ flow diagram is shown in Fig. 8. This reactor was built at Parr, S. C. Westinghouse Electric Corporation was responsible for research and development, Stone and Webster Engineering Corporation for architectural engineering, and Daniel Construction Company for construction. The reactor is cooled by liquid heavy water and will operate at a heat output of about $61.9 \mathrm{Mw}(\mathrm{t})$, 


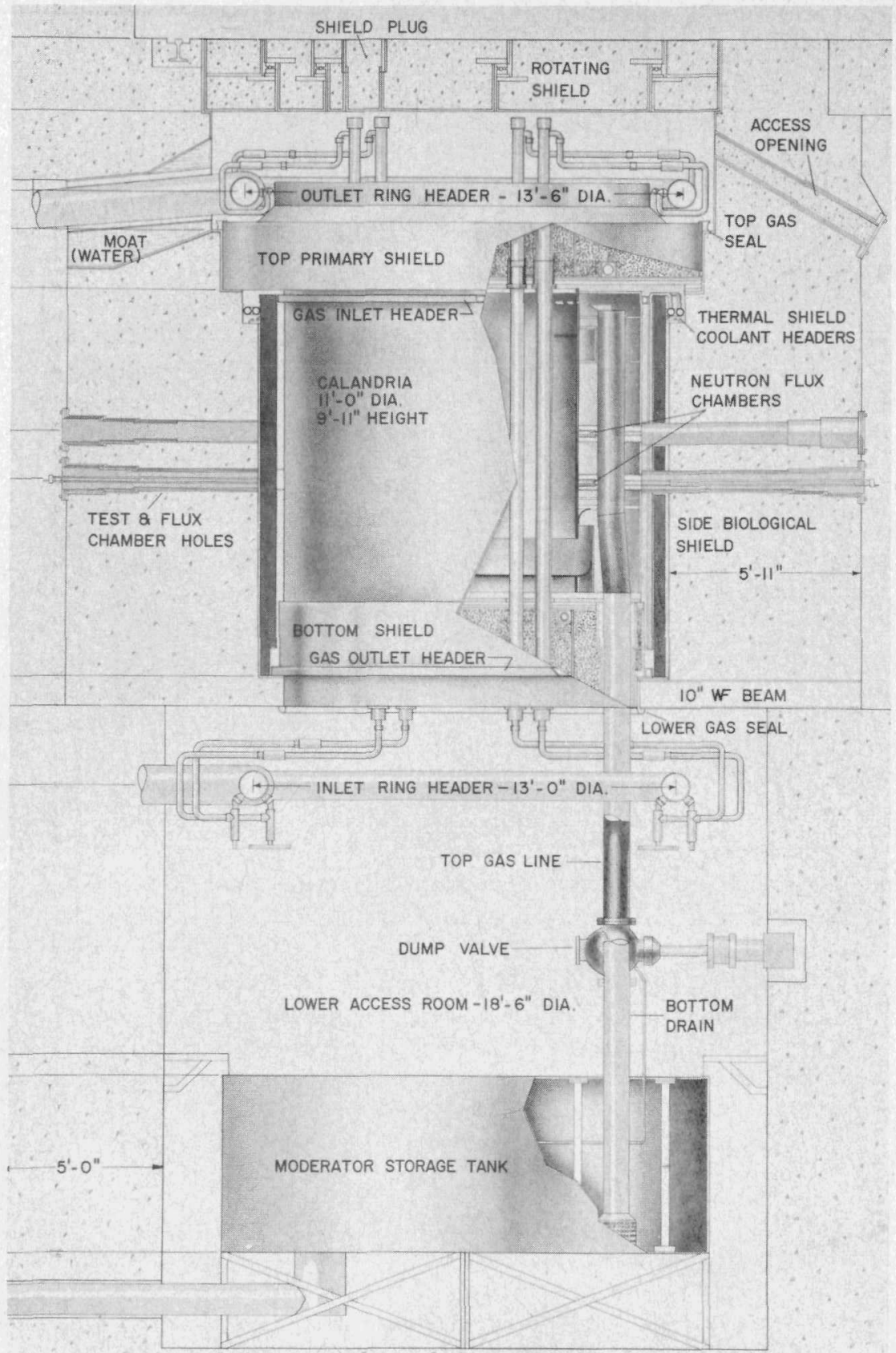

Fig. 7-Plutonium Pecycle Test Reactor. 
producing secondary steam at about $600 \mathrm{psi}$. The steam is throttled to about $400 \mathrm{psi}$ and is superheated to $385^{\circ} \mathrm{C}\left(725^{\circ} \mathrm{F}\right)$ in an oil-fired superheater to match the inlet conditions of an existing turbine.

The reactor is of the pressure-tube type employing the cold-tube concept with internal thermal insulation in the form of stagnant layers of heavy water. A unique feature of this reactor is the $\mathrm{U}$-tube arrangement of its pressure tubes. The pressure tubes are suspended in a heavy-water tank. Fuel assemblies are located in both legs of each Utube, and coolant heavy water enters the top of one leg of the tube and

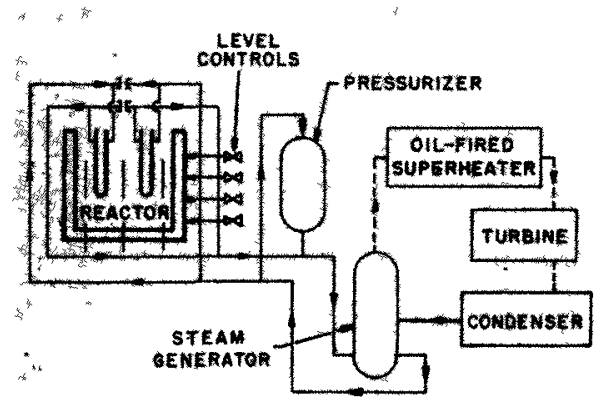

Fig. 8-Carolinas-Virginia Tube Reactor flow diagram. ${ }^{24}$

leaves at the top of the opposite leg. Thus the coolant makes a double pass through the reactor. The number of inlet and outlet connections is only one-half the number required for a straight-through design, and all inlet and outlet connections are located at the top of the reactor. Refueling requires reactor shutdown and is carried out with a shielded cask at the top of the reactor. Control rods are actuated from below. Inlet and outlet connections to the $\mathrm{U}$-tubes are made through individual connector tubes, which are collected into inlet and outlet headers. The fuel assemblies, which are of full core length, consist of 19 -rod bundles. The fuel rods consist of uranium dioxide pellets clad with 0.025 -in.-thick Zircaloy tubes, and the outside diameter of each rod $1 \mathrm{~s} 0.50 \mathrm{in}$. The rods are spaced in the bundle by helically wound spacer wires.

The $\mathrm{U}$-tube concept of the CVTR has certain obvious advantages. It also places certain restrictions on other features of the design. For example, refueling must always be from the top of the reactor. In a very large reactor, the pressure drop associated with the two-pass arrangement could lead to some performance restrictions. During 1961, radiation tests indicated that more power could be extracted from the CVTR per foot of fuel element than was originally calculated. Experiments confirm that the design power of $17 \mathrm{Mw}(\mathrm{e})$ can be achieved with 72 instead of 84 fuel elements; this permits the elimination of six pressure U-tubes. 


\section{Nuclear Power Demonstration Reactor}

The NPD- $2^{27,28,35}$ is a horizontal pressure-tube power reactor moderated and cooled with heavy water. Figure 9 is a flow diagram of this reactor. ${ }^{24}$ The NPD-2 was built for the Atomic Energy of Canada Limited (AECL) and the Hydroelectric Power Commission of Ontario by the Canadian General Electric Company. The reactor has a thermal output of $82.5 \mathrm{Mw}$ and a net electrical output of $17.5 \mathrm{Mw}$. The pressure tubes traverse a calandria that is a horizontal double-shell cylinder

Fig. 9- Nuclear Power

Demonstration Reactor flow diagram.

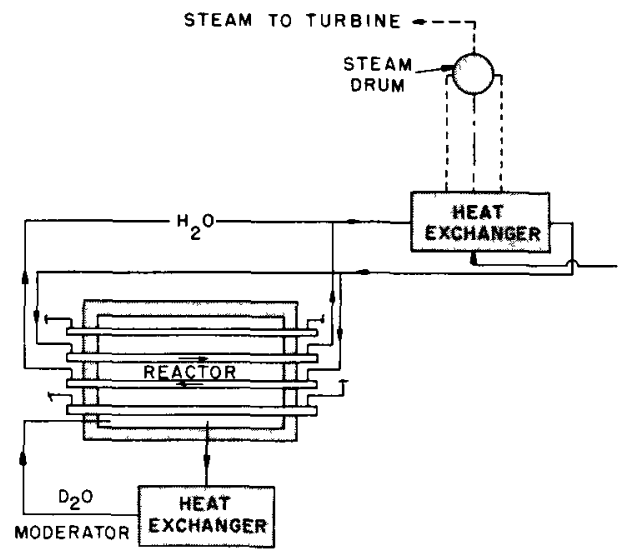

made of aluminum. The calandria is $17 \mathrm{ft}$ in diameter and $15 \mathrm{ft}$ in overall length. The reactor contains 132 Zircaloy-2 pressure tubes. The primary coolant conditions are $252^{\circ} \mathrm{C}\left(485^{\circ} \mathrm{F}\right)$ inlet and $277^{\circ} \mathrm{C}\left(530^{\circ} \mathrm{F}\right)$ outlet. Reactor inlet pressure is $1166 \mathrm{psig}$. The primary coolant in the pressure tubes is insulated by an air space between the pressure tube and the aluminum calandria tube. The moderator is kept relatively cold, between $49^{\circ} \mathrm{C}\left(120^{\circ} \mathrm{F}\right)$ and $82^{\circ} \mathrm{C}\left(180^{\circ} \mathrm{F}\right)$. Helium is used as a cover gas for the moderator system. A light-water reflector is located between the inner and outer walls of the calandria.

A unique feature of the NPD-2 design is the ability to refuel the reactor at full power. The fuel consists of uranium dioxide pellets clad in Zircaloy tubes; the tubes are clustered, typically 19 tubes to a bundle, spaced by Zircaloy wires in a helix form-welded to the Zircaloy jackets. Close approximation to uniform fuel irradiation is achieved by pushing alternate fuel channels in opposite directions through the reactor. New fuel bundles are pushed in as needed at the charging ends of the pressure tubes, displacing spent bundles, which are removed from the opposite ends of the tubes. Adjacent pressure tubes in the reactor lattice have their charge-discharge ends inverted; thus the fuel bundles progress through the core in opposite directions in adjacent tubes. This operation is performed by a charge-discharge machine at each end of 
the reactor. Coolant flow is also bidirectional, being in each tube in the direction opposite to that of fuel flow.

A special feature of the NPD-2 design is that no control rods or shutdown rods are provided. One motor-driven rod is, however, provided for shim control. Reactivity is controlled both for power regulation and rapid shutdown by the level of the heavy-water moderator. For emergency shutdown the moderator is completely evacuated from the calandria. The 12,000-gal dump tank located $20 \mathrm{ft}$ below the calandria provides the required hydrostatic head necessary to achieve the high flow rates for dumping. Moderator flow rates at dump are sufficient to reduce reactivity 0.3 percent $\Delta \mathrm{k}$ in $1 \mathrm{sec}$, and in $4 \mathrm{sec}$ reactivityreduction rate is 2 percent $\Delta \mathrm{k}$ per second.

The reactor attained criticality on Apr. 11, 1962. On June 28, 1962 , the first full-power generation of $20 \mathrm{Mw}(\mathrm{e})$ gross was attained. Before the reactor could be loaded with fuel, it was necessary to clean and dry the system thoroughly to prevent deposition of dirt on the heat-transfer surfaces and to avoid contamination of the heavy water with light-water vapor. Drying was carried out by evacuating and flushing with helium.

Because carbon steel was chosen for the primary piping system, special conditioning of the primary-system piping was required. The piping was conditioned so that it was covered with a black oxide layer. This conditioning was done by circulating water at $149^{\circ} \mathrm{C}\left(300^{\circ} \mathrm{F}\right)$ through the pipes and filtering out the red oxide while maintaining the $\mathrm{pH}$ in the range of 10 to 11 and adding hydrazine to suppress oxygen. The conditioning operation was carried out successfully in the NPD-2 in four days.

The full charge of 1190 fuel bundles was successfully loaded into the reactor with the fueling machines. This operation is equivalent to about two years of normal fueling-machine service. It was carried out, however, with the heavy water cold. The refueling machines have also been used to remove and reload irradiated fuel with the reactor pressurized but not at temperature. The total fuel charge was loaded in 19 days, which included a two-day interruption for servicing the machine heads.

No long-term loss rate for heavy water has yet been established, but early operation has given favorable results. The leak-detection system has given early warnings of several leaks and thus has provided an opportunity to minimize leakage. In the first five months of operation, the leakage was less than $1000 \mathrm{lb}$, or about 25 percent of the budgeted first-year leakage of $4000 \mathrm{lb}$. Most of these leaks occurred because of specific indicents connected with station startup, and they are not likely to be repeated. Startup tests confirm that sufficient energy would be introduced into the coolant from the main circulating pumps to raise the temperature of the system to about $149^{\circ} \mathrm{C}\left(300^{\circ} \mathrm{F}\right)$ and to produce steam in the boiler. It was found that, with the system at $149^{\circ} \mathrm{C}$ 
$\left(300^{\circ} \mathrm{F}\right)$, the reactor can be started and brought to full power and the turbine loaded in $100 \mathrm{~min}$. After a scram the reactor can be restarted against xenon poisoning in up to $33 \mathrm{~min}$ with equilibrium conditions.

\section{CANDU}

The NPD-2 is a demonstration plant, and, as such, it will not generate low-cost electricity; it was not designed to do so. Low-cost generation is, however, the a.m of the 200-Mw(e) plant, CANDU, being built at Douglas Point, Canada. ${ }^{34,36}$ Careful attention has been given in CANDU design to optimizing it for maximum fuel irradiation. As a result an average fuel exposure of $9750 \mathrm{Mwd} / \mathrm{t}$ is predicted for the equilibrium reactor. The system has been designed for rather high thermal efficiency (29 percent) within the limitations of the pressurized-water concept. A steam throttle temperature of $250^{\circ} \mathrm{C}\left(482^{\circ} \mathrm{F}\right)$ is used.

The characteristic features of CANDU are similar to those of NPD-2. The reactor has horizontal pressure tubes in a calandria tank containing cooled heavy-water moderator. The CANDU fuel consists of 19 rods per bundle, $19.5 \mathrm{in}$. long and $0.6 \mathrm{in}$. in outside diameter. The bundle slides into a pressure tube $3.25 \mathrm{in}$. in inside diameter. The Zircaloy-2 cladding is only $0.015 \mathrm{in}$. thick; thus the tubing will collapse onto the uranium dioxide pellets under the high-pressure (1100 to 1400 psi) water coolant. The primary coolant system will have carbon-steel piping. The NPD-2 should adequately demonstrate the feasibility of using carbon steel by the time CANDU is ready to go on the line. Onpower refueling will also be used with this reactor.

\section{EL-4 Reactor}

The main reactor construction project being handled by the Commissarıat à 1'Energie Atomique (CEA) is the EL-4, a prototype exper mental reactor of the gas-cooled heavy-water-moderated type. It is one of several heavy-water power reactors being bullt in Europe. ${ }^{30}$ Table 1 gives the major characteristics of these reactors. The EL-4 is a horizontal pressure-tube design with a push-through fuel system operating from both ends, as in the Canadian reactors. ${ }^{37}$ A site for this reactor has been acquired at Monts d'Arree in Finisterre. Construction was started in 1962 .

\section{Halden Reactor}

The Halden Reactor ${ }^{38,39}$ has always been of considerable interest because it is the only bolling heavy-water reactor in the world. An unusual feature is its containment in a cavern excavated into a hillside. Owned by the Institutt for Atomenergi of Norway, it achieved criticality in June 1959, and it is now operating on its second core. Operation with 
Table 1-HEAVY-WATER REACTORS IN EUROPE

\begin{tabular}{|c|c|c|c|c|}
\hline & \multicolumn{4}{|c|}{ Reactor } \\
\hline & $\mathrm{EL}-4$ & Halden* & $\mathrm{R} 3 / \mathrm{ADAM}$ & MZFR \\
\hline Location & France & Norway & Sweden & Germany \\
\hline Type & Pressure tube & $\begin{array}{l}\text { Boiling } \\
\text { water }\end{array}$ & $\begin{array}{l}\text { Pressurized } \\
\text { water }\end{array}$ & $\begin{array}{l}\text { Pressurized } \\
\text { water }\end{array}$ \\
\hline Status & $\begin{array}{l}\text { Under } \\
\text { construction }\end{array}$ & Operating & $\begin{array}{l}\text { Under } \\
\text { construction }\end{array}$ & $\begin{array}{l}\text { Under } \\
\text { construction }\end{array}$ \\
\hline \multicolumn{5}{|l|}{ Power } \\
\hline $\mathrm{Mw}(\mathrm{t})$ & 260 & 20 & 65 & 200 \\
\hline $\mathrm{Mw}(\mathrm{e})$ & 80 & & & 50 \\
\hline Fuel & $\begin{array}{l}\mathrm{UO}_{2} \text { (natural } \\
\text { or enriched) }\end{array}$ & $\begin{array}{l}\mathrm{UO}_{2} \\
\quad \text { (enriched) }\end{array}$ & $\begin{array}{l}\mathrm{UO}_{2} \\
\quad \text { (natural) }\end{array}$ & $\begin{array}{l}\mathrm{UO}_{2} \\
\quad \text { (natural) }\end{array}$ \\
\hline Fuel cladding & Be or S.S. & Zircaloy-2 & Zircaloy-2 & Zircaloy \\
\hline Moderator & $\mathrm{D}_{2} \mathrm{O}$ & $\mathrm{D}_{2} \mathrm{O}$ & $\mathrm{D}_{2} \mathrm{O}$ & $\mathrm{D}_{2} \mathrm{O}$ \\
\hline Coolant & $\mathrm{CO}_{2}$ & $\mathrm{D}_{2} \mathrm{O}$ & $\mathrm{D}_{2} \mathrm{O}$ & $\mathrm{D}_{2} \mathrm{O}$ \\
\hline $\begin{array}{l}\text { Inlet temp., } \\
{ }^{\circ} \mathrm{C}\left({ }^{\circ} \mathrm{F}\right)\end{array}$ & $240(464)$ & $185(365)$ & $204(400)$ & $250(482)$ \\
\hline $\begin{array}{l}\text { Outlet temp., } \\
{ }^{\circ} \mathrm{C}\left({ }^{\circ} \mathrm{F}\right)\end{array}$ & $500(932)$ & $230(446)$ & $221(430)$ & $282(540)$ \\
\hline Pressure, psig & 847 & 415 & 495 & 1300 \\
\hline
\end{tabular}

* Second core.

the first core seemed to be very satisfactory, although it must be remembered that the first fuel charge did not work at more than a fraction of full power. Nevertheless, with the steam-load changes up to 30 percent, the reactor power followed the change in demand smoothly without overshoot or oscillation. It is important to note that the Halden reactor achieves its easy control because it is designed and operated as an experimental process-steam reactor. The reactor power was limited mainly by the aluminum cladding material of the fuel. Fuel for the second core has Zircaloy- 2 cladding.

An evaluation of corrosion of the mild steel used in the system was made during the modification period between the first and second cores. The primary steam pipe of the reactor was of carbon steel that had been pickled in mild phosphoric acid before commissioning. It was in good condition after about $900 \mathrm{hr}$ of exposure to steam. Inspection of the main heat exchanger and subcooler also revealed no traces of corrosion or erosion on the primary side, and the austenitic tube sheet in the main heat exchanger showed no sign of stress corrosion, even though the chloride concentration varied between 20 and $40 \mathrm{ppm}$ at times. Periscopic inspection of the inside of the reactor vessel showed that nickel plating had provided efficient protection for mild-steel surfaces.

\section{Lucens Reactor}

Site work ${ }^{40}$ on the new experimental $8.5-\mathrm{Mw}(\mathrm{e})$ reactor at Lucens, Switzerland, began in August 1962. The station is being built by the 
Société Nationale pour l'Encouragement de la Technique Atomique Industrielle (SNA). The reactor is of vertical pressure-tube design, moderated with heavy water and cooled with carbon dioxide. The fuel is slightly enriched uranium metal clad with a magnesium alloy. Following Swiss practice for conventional power plants, the greater part of the station is located underground. The reactor turbogenerator and the fuel-element storage pond are contained in this way, the only outside buildings being for the switchgear, maintenance, and treatment of active effluent. The SNA envisions Lucens as the prototype of a line of pressure-tube heavy-water-moderated reactors. At a later stage the reactor may be converted to cooling by steam instead of carbon dioxide. If conditions are acceptable, the station would then go over to directcycle operation.

\section{R3/ADAM Reactor}

The Agesta power and heat station of Sweden, ${ }^{41,42}$ also referred to as $\mathrm{R} 3 / \mathrm{ADAM}$, incorporates a heavy-water power reactor designed for simultaneous generation of $10 \mathrm{Mw}$ of electric power and $55 \mathrm{Mw}$ in the form of hot water for domestic heating (see Fig. 10). The R3/ADAM is

Fig. $10-$ R3/ADAM flow diagram. ${ }^{42}$

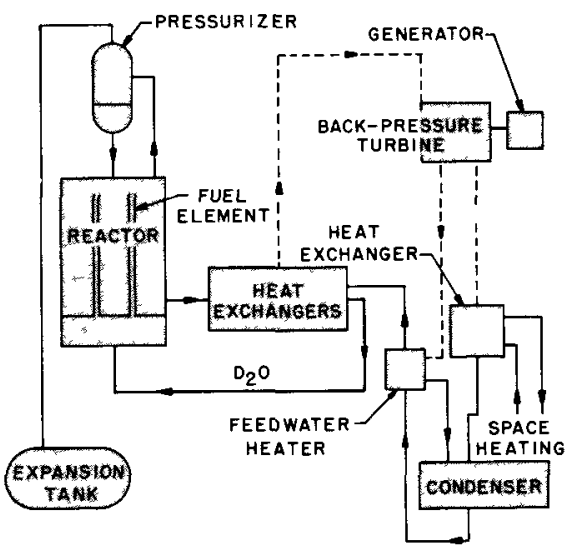

situated at Agesta, about 10 miles south of Stockholm, and it is expected to come into operation in 1963. The hot water from the plant will be used as a domestic heating source for the new suburb of Farsta, several miles away. The reactor has been planned to operate from 5000 to $6000 \mathrm{hr}$ per year and will be shut down during the summer. Although the turbines, gas and water cleaning equipment, and office are outside, the entire reactor is located in a rock cave. The R3/ADAM is a typical pressurized-water design with a vessel $8 \mathrm{ft}$ in diameter and $14 \mathrm{ft}$ high, with an electrically heated pressurizer installed outside the pressure vessel. The operating pressure is controlled by a constant spray flow of 
$1 \mathrm{lb} / \mathrm{sec}$ taken from the reactor inlet flow at 204 to $216^{\circ} \mathrm{C}\left(400\right.$ to $\left.420^{\circ} \mathrm{F}\right)$, and it is balanced by a continuously controlled group of electric heaters actuated by the pressurizer steam pressure.

\section{Spectral-shift-control Reactor}

The concept of the spectral-shift-control reactor utılizes a mixture of heavy and light water as coolant in a pressurized-water reactor. Variation of the heavy-water concentration over the lifetime of a core loading is used to change the neutron spectrum and thus control excess reactivity without wasting neutrons in poison shim control.

Spectral-shift control requires a close-packed core lattice typical of pressurized-water reactors that are somewhat undermoderated. A change in the concentration of the $\mathrm{D}_{2} \mathrm{O}-\mathrm{H}_{2} \mathrm{O}$ moderator or moderatorcoolant mixture affects the reactivity of such a core principally because the neutron slowing-down power of the heavy water $1 \mathrm{~s}$ less than that of light water. Thus the greater the concentration of heavy water in the $\mathrm{D}_{2} \mathrm{O}-\mathrm{H}_{2} \mathrm{O}$ mixture, the greater will be the intermediate- and fastneutron densities relative to the thermal-neutron densities and the greater will be the number of neutrons absorbed in the resonances of $\mathrm{U}^{238}$ relative to those causing fission of uranium.

The thorium fuel cycle is of particular interest in the spectralshift-control reactor. Because it is possible to minimize neutron losses to the control system by using the variable moderator mixture, it is possible to achieve very high conversion ratios. The Babcock \& Wilcox Company, developers of the spectral-shift-control reactor, appear to have great confidence in this concept and have announced their willingness to construct a large power reactor at a fixed price and a guaranteed cost for the first fuel cycle. In a jount Belgian-British venture, a spectral-shift reactor for ship propulsion (the Vulcain) is being studied. ${ }^{15}$ The advantages of this concept for ship propulsion are (1) small core dimensions, (2) long period between refueling due to high burnups, and (3) low fuel inventory due to high average specific power.

\section{Reactors with Coolants Other Than Heavy Water}

Coolants other than heavy water that have recelved most attention for heavy-water-moderated reactors are carbon dioxide and organic liquids. Steam cooling, cooling by light-water sprays, and cooling by bolling light water have also been considered.

Two gas-cooled reactors have been proposed: the Florida gascooled reactor in the United States and the French reactor, EL-4. These reactors have in common the use of the following: heavy water as moderator, carbon dioxide as coolant, a cold pressure-tube design with internal thermal insulation, and uranium oxide fuel in beryllium cladding. The use of a gas coolant reduces the total inventory of heavy water and 
offers the advantage of higher steam temperatures. Offsetting these advantages are low volumetric capacity and relatively poor coolant heattransfer coefficients. These disadvantages become less important as the operating pressure of the coolant is increased. In a recently completed study sponsored by the East Central Nuclear Group, St. Petersburg, Fla., and performed jointly by the American Electric Power Service Corporation, New York, and the General Nuclear Engineering Corporation, Dunedin, Fla., it was concluded that total energy costs for a gas-cooled heavy-water reactor would be 2 mills/kw-hr higher than those for pressurized-water and boiling-water heavy-water types. The proposed Florida gas-cooled reactor project was terminated in 1961 because of technical and economic uncertainties. Construction of the French EL-4 was started in 1962 and is scheduled for completion in 1964.

An organic-cooled reactor with heavy-water moderator would offer improved steam conditions stemming from higher coolant temperatures, reduced heavy-water inventory, and reduced system pressure in the reactor. The disadvantages are the poor heat-transfer characteristics of the organic coolant and the reactivity loss from neutron absorption in the coolant. This reactor would be an improvement over the all-organic type in that the rate of radiolytic decomposition of the organic coolant will be reduced because of the reduced volume of organic coolant in the reactor.

The Canadian General Electric Company is designing the Organic Cooled Deuterium Moderated Reactor Experiment for the AECL. This reactor would produce $35.1 \mathrm{Mw}(\mathrm{t})$. The decision to buld the reactor will be based on the outcome of the conceptual design and development programs now in progress and on the results of economic studies. The WR-1, an organic-cooled and -moderated reactor, will be used to test fuel, coolant, and other components that would be used for organic power reactors, but it will also be used to test other coolant systems such as steam and fog cooling.

Reactors cooled with light-water fog would use a direct steam cycle, resulting in improved thermal efficiency, elimination of steam generators, and reduction in total heavy-water inventory. With the fog coolant, problems associated with the positive coefficients are minimized. The major disadvantage of the system is related to the poor heat-transfer characteristics of the fog coolant.

\section{Economics}

For comparison of heavy-water and light-water reactors, economic factors must be considered. Since the technologies of both concepts are similar, any technological advance in one could most certainly be utilized in the other. Therefore it is important to point out the particular ways in which technological advances will economically favor heavy- 
water reactors. Obviously, for countries having no facilities for enriching uranium, consideration of the use of natural-uranium fuel is an overriding factor. However, it has been stated that, even in countries that possess stocks of enriched uranium, heavy-water reactors could be developed to produce power more cheaply than light-water reactors. ${ }^{31}$

Table 2 - POW ER COSTS FOR 300-Mw(e) HEAVY-W ATER AND LIGHT-W ATER POWER PLAATS ${ }^{31}$

\begin{tabular}{|c|c|c|}
\hline \multirow[b]{2}{*}{ Item } & \multicolumn{2}{|c|}{ Cost, mills $/ \mathrm{kw}-\mathrm{hr}$} \\
\hline & Heavy water & Light water \\
\hline Plant investment (at $14.3 /$ ) & 455 & 390 \\
\hline Heavy water ( $\$ 28$ per pound) & 073 & \\
\hline Fuel & 128 & 195 \\
\hline Operating & 062 & 060 \\
\hline Total & $\overrightarrow{7.18}$ & $\overline{645}$ \\
\hline
\end{tabular}

Possibly a $1000-\mathrm{Mw}(\mathrm{e})$ heavy-water system can produce power $0.12 \mathrm{mlll} / \mathrm{kw}-\mathrm{hr}$ cheaper than a light-water system of the same capacity with private financing rates, a 90 percent load factor, a heavy-water cost of $\$ 17$ per pound, and fuel purchased rather than leased from the USAEC. ${ }^{31}$ In a second example, it is stated that a $300-\mathrm{Mw}(\mathrm{e})$ heavywater system can produce power at $0.13 \mathrm{mill} / \mathrm{kw}-\mathrm{hr}$ cheaper than a light-water system with public financing rates, an 80 percent load factor, a heavy-water cost of $\$ 28$ per pound, and fuel leased from the USAEC. Table 2 shows a cost comparison for a $300-\mathrm{Mw}(\mathrm{e})$ plant. The figures for the light-water plant are based on the Bodega Bay reactor to be built for the Pacific Gas and Electric Company near San Francisco, Calif., by the General Electric Company, and those for the heavy-water reactor were obtained as part of a study of heavy-water reactors being performed for the USAEC by the Du Pont Company at the Savannah River Laboratory. If the present cost of heavy water ( $\$ 24.5$ per pound) were used, the power cost for the heavy-water reactor would be reduced by about $0.1 \mathrm{mlll} / \mathrm{kw}-\mathrm{hr}$.

The heavy-water reactor, being larger than a light-water reactor of equal power output, would have a higher initial capital cost, and the initial cost of heavy water would be high. However, as these plants increase in size, the differential cost begins to narrow.

The major economic advantage of the heavy-water reactor is a low fuel-cycle cost. Fuel costs are low because of good neutron economy, low burnup charges, low use charges, and the fact that the fuel will be fabricated in more massive pieces. Slight enrichment could allow longer fuel exposure and thus lower costs of fuel and reprocessing. Another 
advantage of heavy-water reactors of particular importance for reactors far from reprocessing plants and those using natura' uranium is the possibility of throwing away the fuel after irradiation.

The advantage of heavy-water-moderated reactors with potentially high neutron economy should be accentuated if plutonium is to be recycled. In the pressure-tube design, the neutron temperature can be kept low to minimize the effects of the low eta of $\mathrm{Pu}^{239}$ in the region of its $0.3-\mathrm{ev}$ resonance. The problems concerned with the use of recycled plutonium to provide the additional reactivity needed to achieve full economic potential of heavy-water reactors are being studied at Hanford. These studies include fabricating, fuel handling, and irradiating fuel containing plutonium in the PRTR.

\section{ORGANIC-MODERATED REACTORS}

As early as 1944 organic fluid as a moderator anci coolant or combination moderator-coolant in a reactor received consideration. Enrico Fermi and Leo Szilard filed one of the first basic patents in the nuclear field. It included the use of diphenyl as a moderator to be used in a reactor with slightly enriched uranium. The organic reactor concept was not actively pursued for almost 10 years, probably because this type of reactor could not operate on natural uranium and because there was a lack of knowledge concerning the degree of chemical instability of organic fluids in the combined thermal and radiation environment of a reactor core.

Interest in organic fluids was renewed in 1951, when this system was proposed for aircraft propulsion. ${ }^{43}$ The pressurized-water reactor was then being studied for this purpose, and the markedly lower pressures with the organic system made the latter attractive. Temperatures of at least $650^{\circ} \mathrm{C}\left(1200^{\circ} \mathrm{F}\right)$ were also desired. It was soon found that $540^{\circ} \mathrm{C}\left(1000^{\circ} \mathrm{F}\right)$, let alone $650^{\circ} \mathrm{C}$, was too high for the best organic fluids, even in the absence of radiation. This limitation caused interest to diminish in the organic reactor for aircraft propulsion.

In 1953 a better organized and more systematic study of the aromatic hydrocarbons began. Since then most attention has been devoted to the polyphenyls for possible use in nuclear reactors. These polyphenyls include diphenyl and terphenyı isomers as well as commercial mixtures of these compounds. The most extensive in-pile loop experiments were performed at the MTR at the NRTS in Idaho. Additional inpile work was done by the Monsanto Chemical Company at Brookhaven and by the Hanford Laboratories at Richland. The out-of-pile loop experiments have been directed primarily at measuring heat-transfer and hydrodynamic characteristics of organic coolants. This work was done both at $\mathrm{AI}$ and at Aerojet-General Corporation. 
The design and construction of the Organic Moderated Reactor Experiment (OMRE) was undertaken in mid-1955, and full-scale operation began in February 1958. The OMRE was the first large-scale test with organic fluids. The OMRE experience proved the technical feasibility of using an organic fluid as moderator, coolant, or both. It has also shown that bulk temperatures in the range of 315 to $370^{\circ} \mathrm{C}$ (600 to $700^{\circ} \mathrm{F}$ ) can be used with only negligible amounts of thermal decomposition of the organic fluid. ${ }^{44}$

Construction of an organic-moderated reactor for the city of Piqua, Ohıo, was completed. The reactor attained criticality on June 10, 1963. This plant is the first operating organic power reactor integrated into an electric utility station, and it will provide valuable data on the lifetime of metallic fuel elements and costs of fuel. As part of the USAEC organic-moderated reactor program, a number of design studies have been completed. ${ }^{44,45}$ They cover a range of plant sizes from 10 to 300 $\mathrm{Mw}_{\mathrm{w}}(\mathrm{e})$ and extend to special applications such as ship propulsion and the utilization of alternative moderators. A major design study of a heavy-water-moderated organic-cooled nuclear power plant is now in progress. This work is being performed by Combustion Engineering, Inc., for the USAEC.

In December 1962 the USAEC, after a reassessment of its organic reactor program, concluded that the concept did not hold early promise for making a significant improvement in nuclear power performance in the United States above that already achieved by other reactor concepts. Accordingly, the USAEC announced it was curtailing several activities related to the development of the organic-cooled and-moderated concept. The curtallment included deferring the installation of two test loops in the Experimental Organic Cooled Reactor (EOCR) at NRTS in Idaho and completing the test program of OMRE, underway since 1957, by mid-1963. The USAEC said it would, however, contınue its program of cooperative exchange of information with several countries (mainly Canada and Euratom) on organic reactor concepts. Canada is now bullding a test reactor for fuel coolants and other componerits that would be used with organic power reactors. This $40-\mathrm{Mw}(\mathrm{t})$ reactor, WR-1, represents the majur Canadian effort in the development of organic reactors.

Euratom is now developing its own organic-cooled reactor concept. Euratom has chosen the Organique Eau Lourde (Orgel) system, ${ }^{46}$ a heavy-water-moderated organic-cooled concept that was selected because it can utilize natural uranium as fuel. The Orgel major development effort will be a special test reactor named Essor (Essai Orgel). Besides participating in the Euratom program, Germany, Italy, Spain, and Sweden are interested in bullding organic-cooled power reactors of their own. 


\section{Technical Aspects}

The major advantages of the organic-moderated reactor system over a water-cooled and -moderated system are based on four characteristics of an organic system: (1) possible low operating pressures, (2) noncorrosiveness of organic coolants, (3) compatibility of coolant with a wide variety of nuclear fuels, and (4) low induced activity of coolant.

The excellent neutron-moderating properties of the hydrogen in hydrocarbon liquids make compact core designs possible, and, as is true with water reactors, simplicity of core design is provided by utilizing the organic fluid as both moderator and coolant. This simple and compact arrangement leads to low cost for the reactor structure. Because the diffusion length in organic moderators is more than 1.5 times that in water, there is no mechanical limitation to prevent utilizing optimum lattice spacing to achieve good nuclear performance in organic reactor cores. In addition, core operating pressures need not be high to attain temperatures that will provide high thermal efficiencies because the special liquid hydrocarbons have low vapor pressures at high temperatures. Low operating pressures raise the upper limit of size for the design of organic power reactors. Use of the organic fluid permits a wide choice of nuclear fuels. Uranium can be used in the form of metal, alloy, oxide, or carbide without introducing the potential hazard of exothermic chemical reactions.

Principal attention has been given to aluminum alloys and powdered aluminum metal (APM) for fuel cladding. The greatest limitation on fuel-element designs results from the relatively poor heat-transfer properties of the organic fluid; shapes integrally extruded with the aluminum cladding may be employed to alleviate this situation. If heat from the reactor is carried by the organic flund to the heat exchanger, the steam produced is nonradioactive and can be produced at relatively high pressure and temperature. The noncorrosive characteristics of the coolant permit the use of many conventional materials of construction. Pipıng and vessels can be of low-carbon steel, a factor that should lower initial capital investment.

\section{Organic Moderated Reactor Experiment}

The USAEC's OMRE ${ }^{44}$ has been in operation at NRTS since 1957 and is now on its third core loading. The reactor vessel is a pressure $\operatorname{tank} 4 \frac{1}{2} \mathrm{ft}$ in diameter and $28 \mathrm{ft}$ high, with a wall thickness of $1 \mathrm{in}$. The structural material is a mild alloy steel (with $0.5 \mathrm{wt} . \%$ molybdenum and 1 wt.\% chromium). Coolant is circulated from the reactor in 16-1n.diameter lines to an air-blast heat exchanger for heat rejection. The reactor operating pressure is $200 \mathrm{psig}$, the coolant inlet temperature 
is $315^{\circ} \mathrm{C}\left(600^{\circ} \mathrm{F}\right)$, and the coolant outlet temperature is $321^{\circ} \mathrm{C}\left(609^{\circ} \mathrm{F}\right)$. The reactor power level is $6 \mathrm{Mw}(\mathrm{t})$, and the coolant velocity through the core is $15 \mathrm{ft} / \mathrm{sec}$. The normal core loading consists of 31 fuel elements. The driver elements are each composed of 16 plates, the plates consisting of a cermet of enriched uranium dioxide and stainless steel, 20 mils thick, clad on each side with 5 mils of stainless steel. The present core, designated core No. 3-B, consists of 25 driver elements, four APM-clad uranium dioxide prototypes, and two aluminum-clad uranium-molybdenum prototypes. The control rods perform a double function of shim rods and safety rods. The 12 control rods consist of $1 \frac{1}{4}-1$. S . steel tubes loaded with compacted boron carbide powder. The reactor is shielded by an earth backfill surrounding the vessel and a pool of organic coolant, $14 \mathrm{ft}$ deep, above the core.

Operation of the OMRE has provided a great deal of information on the behavior of organic coolants and moderators under reactor operating conditions, and it is serving as a test apparatus to determine the performance of prototype fuel elements and other components under actual reactor operating conditions. ${ }^{47,48}$ Operation of the second cor $e^{49}$ was completed in March 1960; since then extensive investigation and testing have been performed as a result of the fouling of fuel-element surfaces encountered in operation with the No. 2 core.

Examination of many samples of deposits from the OMRE indicated that the presence of particulate matter leads to fouling of the fuel elements and plugging of some coolant passages. ${ }^{50}$ Consequently, on core No. 3, AI took steps to maintain coolant cleanliness and established a goal of $10 \mathrm{ppm}$ of particulate ash or less as acceptable. The ash content of the coolant during operation with core No. 2 was generally $10 \mathrm{ppm}$. The particle size observed was small: most particles were smaller than $5 \mu$ and many were smaller than $1 \mu$. A system of filters has been installed onstream with the reactor coolant, and these filters have been over 75 percent effective in removing particles $3 \mu$ in diameter and larger. The continuous purification system has operated well with core No. 3 , with the result that the rate of film deposition in this core is a factor of 20 less than that in core No. 2. With the installation of fullflow strainers in the reactor coolant system, which could become plugged and thus stop reactor coolant flow, it was necessary to provide an auxiliary loop to assure positive core flow at all times for removing decay heat.

The removal of heat from a reactor core through the use of an organic coolant has been successfully demonstrated by the operation of the OMRE. In this reactor, cooling by forced convection is accomplished by pumping organic coolant between fuel-bearing plates. This method of extracting heat, conventional within reactor technology, presents no unique heat-transfer or hydrodynamic problem resulting from the use of an organic coolant. However, fouling and the conditions that produce 
it must be more clearly defined to predict confidently the power capability of an organic-cooled reactor core. Fuel-element performance in core No. 3 indicated that APM-uranium dioxide elements are operating well at very near their design temperatures. Maximum cladding temperature for these elements has been $449^{\circ} \mathrm{C}\left(840^{\circ} \mathrm{F}\right)$, and a burnup of $402 \mathrm{Mwd} / \mathrm{t}$ had been reached by September 1962 (Ref. 48).

\section{Piqua Nuclear Power Facility}

The Piqua Nuclear Power Facility $(P N P F)^{51}$ is a $45.5-\mathrm{Mw}(\mathrm{t})$ reactor located near the city of Piqua, Ohio, and it will supply superheated steam to an existing power station on the opposite side of the Miami River. The plant consists of two main units: a reactor building and an auxiliary bullding. Containment for the reactor and the main heattransfer loop and its associated systems for degasification, pressurization, and removal of decay heat is provided by a domed containment shell with steel walls and a concrete lining. This containment has been designed for an internal pressure of $5 \mathrm{psig}$. A conventional insulated steel-panel bullding houses the control room and all auxiliary process systems not requiring containment, such as ventılating fans and filters, coolant purıfication and makeup, waste-disposal equipment, etc.

The reactor core consists of 85 elements. Each element basically consists of two concentric cylınders of enriched uranium-molybdenum alloy with a small amount of aluminum added as a stabilizing element. These cylinders are each clad with finned aluminum, metallurgically bonded to the fuel using an intermediate diffusion barrier of nickel $0.001 \mathrm{in}$. thick. The concentric thin tubes are enclosed between outer and inner stainless-steel tubes fastened to upper and lower end pieces that fit into the upper and lower core plates in the reactor. The main coolant flow is downward through the annulus between the two steel tubes. Orificing is used to regulate flow and to permit equalization of operating temperatures throughout the core. A stainless-steel screen at the top end of each element prevents particulate matter in the coolant from clogging the annular space. The coolant-moderator is a mixture of ortho-, meta-, and para-terphenyl in weight percentages of $10-15$, $55-70$, and 20-30, respectively. A flow diagram ${ }^{52}$ is shown in Fig. 11.

Two coolant pumps operate in parallel; each has a capacity of 6000 $\mathrm{gal} / \mathrm{min}$. The pumps are of the hor 1 ontal centrifugal type with stainlesssteel impellers and carbon-steel casings. Pump seals are mechanical types backed by a labyrunth of aluminum-bronze to minımıze leakage in case of seal fallure. Coolant flows first to the superheater and then to the boiler. The reactor inlet temperature is $270^{\circ} \mathrm{C}\left(519^{\circ} \mathrm{F}\right)$, and reactor outlet temperature is $302^{\circ} \mathrm{C}\left(575^{\circ} \mathrm{F}\right)$. Operating pressure of the primary coolant is $105 \mathrm{psig}$. The PNPF will supply steam at a flow of $150,000 \mathrm{lb} / \mathrm{hr}$ at $288^{\circ} \mathrm{C}\left(550^{\circ} \mathrm{F}\right)$ and $441 \mathrm{ps} 1 \mathrm{a}$. The pressure vessel, of 


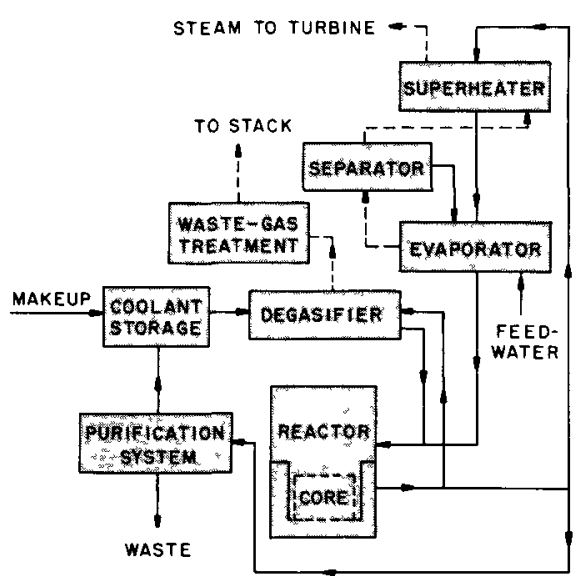

Fig. 11-Piqua Nuclear Power Faculity flow diagram. ${ }^{52}$

mild steel, has an inside diameter of $7 \mathrm{ft} 8 \mathrm{in}$. and is $27 \mathrm{ft} 3^{1 / 2}$ in. high. All the coolant piping, the superheater, and the boiler are also made of carbon steel.

The initial fuel has a relatively high excess enrichment. To limit the excess reactivity, some fuel-assembly locations will initially be filled with dummy assemblies, which will be replaced by fuel assemblies as burnup proceeds. In the equilibrium cycle approximately onefourth of the fuel assemblies will be replaced by fresh assemblies at each reloading. The core exposure between reloadings will be approximately $1000 \mathrm{Mwd} / \mathrm{t}$. Reloading of the reactor requires shutdown and removal of the pressure-vessel head. Failed fuel elements are detected by monitoring the coclant from each fuel channel. A system of 85 tubes, each $5 / 8$ in. in diameter, is used to sample coolant at the core outlet. Tubes pass through a special nozzle to the outside of the pressure vessel and then to a selector valve. It is claimed that a rupture area $1 \mathrm{~mm}^{2}$ can be detected.

Continuous purification of the coolant is proviced by the purification loop, which acts as a decontamination system, because most of the activity is contained in the high-boiling compounds removed in this system. Coolant from the return side of the pressurizing pumps is withdrawn at a controlled rate and, together with new coolant, is passed through 5- to $10-\mu$ filters to a heater where it is heated to $371^{\circ} \mathrm{C}$ $\left(700^{\circ} \mathrm{F}\right)$ before it is passed to a distillation column. The high-boiling compounds in the still bottom are pumped to decay tanks before being transferred to the waste-disposal system.

Thermal shielding of the core is provided by a series of three concentric mild-steel cylinders with a total thickness of 4 in. between the core and the vessel wall. Biological shielding is provided by $6 \mathrm{ft}$ of ordinary concrete around the core cavity liner. 
Thirteen control rods are located inside selected fuel elements. The control element proper is made up of small stainless-steel tubes filled with boron carbide, braced together to form a double ring. Magnetic jacks are provided for operating the control rods; thus raising and lowering is in small discrete steps. Scramming takes place automatically if the operating colls are deenergized. The rods drop under gravity, and shock is absorbed by springs. The entire rod mechanism is contained within the reactor vessel, the mechanism and colls being hermetically sealed in stainless-steel cans.

Three types of waste have to be considered: gaseous wastes from the degasifier and purification system. high-boiling organic wastes, and aqueous wastes from various process systems. Gaseous waste is collected under vacuum in an organic trap. The gases then flow through a steam ejector and are discharged through the stack after passing through absorbers and holdup tanks. Organic wastes are almost entirely high-boiling compounds that have been separated from the coolant. This waste is stored in a compartmented tank and is then burned. The combustion products are filtered before being discharged to the atmosphere. The compartmented tank is sized to store a six-month accumulation of wastes. Aqueous wastes are collected in a sump in each bullding and are then pumped to a settling basement. Light and heavy organics are separated for burning, and water is passed through a filter, an absorber, and then to a holdup tank. From the holdup tank the water is pumped through demmeralizers to another holdup tank, or it is discharged to the sewer.

Although criticality had been expected by early October 1960 for the PNPF, minor delays caused a rescheduling of reactor startup for 1963. One cause of the delay was insufficient insulation on the piping of the organic system and the auxiliary steam-trace heating system, which allowed parts of the building to reach $52^{\circ} \mathrm{C}\left(125^{\circ} \mathrm{F}\right)$. Another cause was leaks in the pool where fuel is stored. The last delay was due to a fire on Sept. 5, 1962. The fire probably started when coolant leaked from a thermocouple well. Smoke caused considerable damage. ${ }^{53}$

\section{Experimental Organic Cooled Reactor}

Construction of the $40-\mathrm{Mw}(\mathrm{t})$ EOCR at NRTS is essentially complete. However, owing to the curtailment of the USAEC organic-moderated reactor program, plans for startup and experımental work are highly uncertain. This reactor was designed by the Phillips Petroleum Company in collaboration with AI. The objectives of the EOCR were to supply the experimental facilities needed for testing organic-cooled power-reactor fuels and moderators. It was planned to equip the reactor with five in-plle loops for testing new coolants and fuel elements and to provide an opportunity for investigating the use of both graphite and heavy water as moderators in organic reactors. ${ }^{54}$ 


\section{Problems with Organic Coolants}

Use of organic coolants requires that the plant design incorporate provision for degasification, purification, makeup, and eventual disposal of the used organıcs. The design and operation of the equipment required for these functions appear to be straightforward but admittedly add complications. The terphenyl mixtures recommended as the virgin coolant are available in large quantities and are relatively inexpensive. However, the cost of coolant makeup is a significant factor in power-production costs.

Problems associated with decomposition of organic liquids used as reactor coolants or moderators are discussed in detail in Refs. 50 and 55. Pyrolysis and radiolysis are the two causes of damage to organics in reactors. Pyrolytic damage below $425^{\circ} \mathrm{C}\left(800^{\circ} \mathrm{F}\right)$ is considered to be small. Hence the major cause of coolant damage is by radiation particles such as alpha and beta particles, gamma rays, and neutrons. Organic liquids are damaged by all particles or energy-transfer processes that are more energetic than the dissociation bond energy ( 4 to $6 \mathrm{ev})$. Hence in an organic reactor the major radiolytic damage is due to fast electrons produced by Compton scattering of gamma radiation and by fast neutrons.

$A$ recent British report ${ }^{56}$ pointed out that the $G$ value ( $G$ equals molecules destroyed per $100 \mathrm{ev}$ of total energy absorbed) of the organics for neutrons is higher than that for fast electrons. In estimating radiation damage, workers in the United States assumed this not to be true, although the possibility has always been recognized. A recent AI report ${ }^{49}$ discusses the decomposition rate of organic coolants and makeup costs for organic-moderated and -cooled reactors. This reference updates developments in the field since 1959 and reports on recent experimental work designed to measure decomposition rates of organic coolants under a variety of conditions. Table 3 shows coolant makeup rates and costs for organic coolants for several organic-moderated reactor designs.

Fouling of heat-transfer surfaces and buldup of particulate matter in the coolant of the OMRE has caused a great deal of research to be directed in the past few years toward a solution of this problem. It is generally believed that the presence of particulate matter, specifically iron oxide corrosion products and possibly other inerganic or organic particles, will lead to fouling of fuel elements if the particles are allowed to accumulate in the organic fluid. Experience with the OMRE has demonstrated this mechanism. During the first six months of operation, the reactor vessel was never opened; examination of the fuel elements after this perıod revealed a negligible thickness of deposit on its fuel plates. Activity of the coolant remained very low and approximately constant. During a reactor shutdown the reactor vessel re- 

REAC TOR COOLANTS ${ }^{49}$

\begin{tabular}{|c|c|c|c|c|c|c|c|c|}
\hline & \multicolumn{2}{|c|}{ POPR } & \multicolumn{2}{|c|}{ PNPF } & \multicolumn{2}{|c|}{$\begin{array}{c}150-\mathrm{Mw}(\mathrm{e}) \\
\mathrm{OMR}\end{array}$} & \multicolumn{2}{|c|}{$\begin{array}{c}300-\mathrm{Vw}(\mathrm{c}) \\
\text { OVIR }\end{array}$} \\
\hline $\begin{array}{l}\text { Average in-core } \\
\text { temp., }{ }^{\circ} \mathrm{F}\end{array}$ & \multicolumn{2}{|c|}{672} & \multicolumn{2}{|c|}{547} & \multicolumn{2}{|c|}{597} & \multicolumn{2}{|c|}{653} \\
\hline $\begin{array}{l}\text { Percentage of total reacto } \\
\text { fission energy absorbed } \\
\text { in coolant }\end{array}$ & \multicolumn{2}{|c|}{2.76} & \multicolumn{2}{|c|}{2.94} & \multicolumn{2}{|c|}{2.70} & \multicolumn{2}{|c|}{2.76} \\
\hline $\begin{array}{l}f_{m} \text { fraction of absorbed } \\
\text { energy due to neutrons }\end{array}$ & \multicolumn{2}{|c|}{0.543} & \multicolumn{2}{|c|}{0.585} & \multicolumn{2}{|c|}{0.585} & \multicolumn{2}{|c|}{0.543} \\
\hline \multirow[t]{2}{*}{$\mathrm{G}_{\gamma}(-\operatorname{coolan} t)$, at $30 \% \mathrm{Hb}$} & \multicolumn{2}{|c|}{0.0796} & \multicolumn{2}{|c|}{00677} & \multicolumn{2}{|c|}{0.725} & \multicolumn{2}{|c|}{0.0778} \\
\hline & $A^{*}$ & $\mathrm{~B} \dagger$ & $A^{*}$ & $\mathrm{~B} \dagger$ & $A^{*}$ & $\mathrm{~B}_{\dagger}^{\dagger}$ & $A^{*}$ & $B \dagger$ \\
\hline $\begin{array}{l}\mathrm{G}_{\mathrm{n}} \text { (-coolant), at } 30 \% \mathrm{Hb} \\
\text { Total } \mathrm{G} \text { (coolant) }\end{array}$ & $\begin{array}{l}0.480 \\
0.297\end{array}$ & $\begin{array}{l}0.346 \\
0.224\end{array}$ & $\begin{array}{l}0.226 \\
0.160\end{array}$ & $\begin{array}{l}0.285 \\
0.195\end{array}$ & $\begin{array}{l}0.312 \\
0.213\end{array}$ & $\begin{array}{l}0.310 \\
0.211\end{array}$ & $\begin{array}{l}0.431 \\
0.270\end{array}$ & $\begin{array}{l}0.337 \\
0.219\end{array}$ \\
\hline \multicolumn{9}{|l|}{$\begin{array}{l}\text { Radiolytic decomposition } \\
\text { rate, } \mathrm{lb} / \mathrm{Al} w \mathrm{~d}(\mathrm{t})\end{array}$} \\
\hline From neutrons & 32.9 & 21.0 & 17.8 & 22.4 & 22.5 & 22.4 & 29.6 & 23.1 \\
\hline From beta and gamma & \multicolumn{2}{|c|}{4.6} & \multicolumn{2}{|c|}{3.8} & \multicolumn{2}{|c|}{3.7} & \multicolumn{2}{|c|}{4.5} \\
\hline Total & 37.5 & 25.6 & 21.6 & 26.2 & 26.3 & 26.1 & 34.0 & 27.6 \\
\hline $\begin{array}{l}\text { Pyrolytic decomposition } \\
\text { rate, ib/hr }\end{array}$ & \multicolumn{2}{|c|}{0.3} & \multicolumn{2}{|c|}{0.00008} & \multicolumn{2}{|c|}{0.02} & \multicolumn{2}{|c|}{0.6} \\
\hline $\begin{array}{l}\text { Total decomposition rate, } \\
\mathrm{lb} / \mathrm{hr} \text { at full power }\end{array}$ & 250 & 171 & 40.9 & 49.7 & 520 & 517 & 1265 & 1024 \\
\hline Thermal efficiency, $\%$ & \multicolumn{2}{|c|}{32.1} & \multicolumn{2}{|c|}{25} & \multicolumn{2}{|c|}{33.3} & \multicolumn{2}{|c|}{35} \\
\hline $\begin{array}{l}\text { Coolant makeup cost, } \\
\text { mills/kw-hr(e) } \ddagger\end{array}$ & 0.83 & 0.56 & 0.61 & 0.74 & 0.56 & 0.56 & 0.69 & 0.56 \\
\hline
\end{tabular}

*A according to $G_{n}$ values derived from in-pile experiments.

$\dagger B$ according to $G_{n}$ values derived from $P^{210}$ alpha irradiations. $\ddagger$ Coolant cost assumed to be $\$ 0.17$ per pound.

mained open a long time for fuel handling. When operation was resumed, an immediate buildup of activity of $\mathrm{Mn}^{56}$ corrosion product was observed. The presence of a high concentration of corrosion products in the coolant was confirmed when two experimental fuel elements plugged at the inlet of their coolant channels. ${ }^{50}$

It is believed that fouling can be prevented in an organic reactor system by removing particles before they can enter into the deposition process. Rigid exclusion of oxygen and water from the organic system is also necessary to prevent the formation of corrosion products and subsequent introduction of more particles. A practical method for maintaining coolant cleanliness in the organic reactor system is distillation. In addition, it is important to minimize the residence time of particles at the surface of the fuel elements by maintaining high coolant velocity, eliminating stagnation points, and minimizing the electrostatic effects at the surfaces. 
Because the organic coolant decomposes at an appreciable rate [approximately $1100 \mathrm{lb} / \mathrm{hr}$ for a $300-\mathrm{Mw}(\mathrm{e})$ plant|, polymerized high-bolling residues must be disposed of in the operation of an organicmoderated reactor power plant. Three methods of handling the waste have been proposed: (1) regenerating it to usable coolant and returning it to the reactor, (2) burying it, and (3) burning it and burying the ash. The regeneration method would appear to be the most desirable, but much development work must be done before this method can be shown to be economically feasible. Also, much additional study is necessary to establish the feasibility of burial. Most of the experimental work on disposal of high-boiling residues has been concentrated on combustion. The technical feasibility of such combustion has been fairly well established in prototype-scale equipment for the Piqua reactor. A commercial burner designed to handle asphaltic wastes appears to be suitable for this purpose. Operation of the Piqua reactor will provide additional experience on this method. In the future it might be shown that rejected coolant has value for by-products or major products, and it might be reclaimed for this purpose. ${ }^{57}$

Although thermal stability is not a problem below $425^{\circ} \mathrm{C}\left(800^{\circ} \mathrm{F}\right)$, pyrolytic damage increases rapidly above this temperature, and, with minor exceptions, apparently no organic compounds can be exposed for significant periods to temperatures above $540^{\circ} \mathrm{C}\left(1000^{\circ} \mathrm{F}\right)$. Therefore this temperature is about the upper limit for fuel surfaces in a nuclear reactor to which an organic material is exposed. Flammability is another common characteristic of the organic fluids now used which the designer must keep in mind. This danger may be reduced by choosing materials with very high boiling points, but radiolysis will usually cause breakdown and thus increase flammability.

Organıc materials are characterized by low heat-transfer coeffcients, low heat capacity, and small heats of vaporization as compared with water and liquid metals. The use of organics for forced-convection cooling or boiling conditions requires increased coolant circulation and heat-transfer area, or greater temperature differences, over those needed for water. Correspondingly the specific power of an organic reactor tends to be low. These characteristıcs, however, do not appear to be significant drawbacks in the development of organic reactors.

\section{Fuel-element Development}

The two principal fuel elements being considered for reactors of moderate to high performance are alumınum-clad uranıum - molybdenum alloys and uranium dioxide contained in high-strength aluminum (APM). Uranium alloys containing enough molybdenum to provide adequate hightemperature strength appear to be undesirably diluted with absorbing materials for good neutron economy, require development of a satisfactory diffusion barrier, and have unknown burnup capability. 
A major program is now under way in the United States on development of uranium dioxide fuel consisting of the oxide pellets held in finned APM tubes thermally bonded with helium. ${ }^{47}$ Out-of-pile tests on the uranium dioxide-APM system have demonstrated no reaction between these materials at $592^{\circ} \mathrm{C}\left(1100^{\circ} \mathrm{F}\right)$ in tests of six months' duration. Additional tests are now under way with a goal of $10,000 \mathrm{hr}$. Although no chemical reaction occurs between uranium dioxide and the organic coolant, pyrolysis can occur when the coolant comes into contact with hot fuel through a defect in the cladding; however, this process appears to be relatively slow. APM tubing of good quality has been procured, and effective methods of tube closure have been developed. Continued development, however, of fabricated APM cladding will be required to achieve quantity production of high-quality fuel elements. An in-pile test in an organic loop in the NRX reactor has shown good results with the uranium dioxide-APM fuel. In these tests the fuel cladding had a peak burnup of $2400 \mathrm{Mwd} / \mathrm{t}$, a maximum surface temperature of $459^{\circ} \mathrm{C}\left(858^{\circ} \mathrm{F}\right)$, and a maximum heat flux of $3400 \mathrm{Btu} /(\mathrm{sq} \mathrm{ft})(\mathrm{hr})$ in organıc coolants at a bulk temperature of $371^{\circ} \mathrm{C}\left(700^{\circ} \mathrm{F}\right)$ and a velocity of $30 \mathrm{ft} / \mathrm{sec}$.

\section{Organic-cooled Reactors with Moderators Other Than Organic Materials}

Heavy water, light water, beryllium, beryllium oxıde, and zirconium hydride have all been considered as moderators in conjunction with organic coolants. The system of major interest is the heavy-watermoderated organic-cooled concept. Reactors utilızing this concept have been reviewed under the section entitled "Heavy-water-moderated Reactors." Since the use of heavy water allows the use of natural uranium as fuel, the major interest in this concept has been in Canada and in Europe. The use of graphite as a moderator would probably require that the moderator blocks be clad to prevent any possible effect of organic penetration into the graphite and subsequent decomposition. The development of highly impervious graphite may make this cladding unnecessary.

Substituting heavy water or graphite as the moderator would reduce the coolant volume in the reactor, which, in turn, would reduce the coolant damage by about a factor of 10 . This reduction in coolant damage is a significant economic advantage, but it must be balanced against the added complexity of a heavy-water-moderated or graphite-moderated reactor. ${ }^{58}$

\section{Other Organic Reactor Concepts}

An organic-moderated and -cooled reactor with fuel in a fluidized bed has been under development by the Martın Company. ${ }^{59}$ The fuel is 
pellets of uranium dioxide or monocarbide suitably clad to limit the escape of fission products. A major problem with this concept was the development of fuel pellets that would resist abrasion in the highly turbulent fluid bed. Work on this concept was terminated late in 1962.

Bolling organic reactors have been considered by Marquardt Corporation. ${ }^{60}$ In this concept organic vapors are used in a direct-cycle system. A major problem is the development of turbines utılizing organic vapors.

\section{STATUS AND FUTURE DEVELOPMENT}

The SGR has the potential for achieving high temperatures and hence thermal efficiencies equal to or better than present-day fossil-fueled power plants. The fact that molten sodium absorbs lodine almost quantitatively will substantially ease the siting problem of this type of reactor by minimizing the dispersion of radioactive material in case of a reactor accident. ${ }^{61}$ Because the SGR is a low-pressure system, it has considerable promise as a large commercial power reactor, 1.e., component size will not be a limiting factor. Although the SGR is classified here as an advanced type, AI has offered to bulld a 360-Mw(e) SGR plant on a guaranteed fixed-price basis. ${ }^{62}$ The sodium-coolant technology gained from sodium-graphite reactors will also be vital to the development of sodium-cooled fast breeders utllizing plutonium and for thermal breeders utılizing thorium. The near-term success of the SGR rests heavily on the development of a satisfactory fuel, such as uranum carbide, and proved sodium components.

With five reactors either in operation or under construction, there is little doubt that fast reactors can operate at high total power. However, for a fast reactor to show economic promise, there must be avallable fuel elements which can go to high burnups and which have low fabrication and reprocessing costs. Ceramic fuels, such as uranium and plutonium oxides and carbides, show promise as high-burnup fuels. Experience with the EBR-II integrated-fuel-reprocessing plant will provide a great deal of information on reprocessing and remote fabrication of fast reactor fuels.

Heavy-water reactors will probably continue to be most attractive to countries interested in using natural uranium or slightly enriched uranium fuels. Because the moderating properties of heavy water decrease rapidly at higher temperatures, the pressure-tube design ut1lizing a "cold moderator" has been found to have the greatest potential. Heavy water may be eliminated from the coolant system by substituting an organic liquid for it. In this case enriched fuel might be considered to increase the fuel exposure. Leading the field in heavy-water development is Canada, which now has a $20-\mathrm{Mw}(\mathrm{e})$ reactor under utılity operation and a $200-\mathrm{Mw}(\mathrm{e})$ plant under construction. 
The spectral-shift reactor combines light and heavy water. In this concept the reactor startup is on a mixture of predominantly heavy water. The reactor at startup is undermoderated; and, as the fuel is used, the neutron-absorbing fission products accumulate, and the ratio of light to heavy water is increased. This procedure decreases the number of control rods required which waste neutrons and reduce fuel economy. Hence it is possible to achieve higher conversion ratios than would be possible with a light-water reactor with poison shim control.

The USAEC has decided to curtall its development program of the organic-moderated and -cooled reactor. The reason given was that the organic-moderated reactor "does not hold early promise for making a significant improvement" in performance over that already achieved by water reactors. Interest in the organic-moderated reactor is, however, continuing in Canada and in Europe. ${ }^{63}$

The present interest in large-scale power plants will undoubtedly have a strong effect on the development of these concepts. Although it now appears possible that light-water reactors capable of producing $1000 \mathrm{Mw}(\mathrm{e})$ have economic promise, the size of these reactors cannot be increased indefinitely. Design studies have shown that, when nuclear power plants are scaled up in size to the 400-Mw(e) range and higher, the costs per kilowatt go down significantly. As one approaches the $1000-\mathrm{Mw}(\mathrm{e})$ range, the fabricating and shipping of pressure vessels, pumps, and other components become more difficult. Reactors which could operate at lower pressures or which could use the pressure-tube design would not be so size limited. As fuels capable of going to higher burnups, such as the ceramics, are developed, reactor concepts that are penalized by high fabrication costs, such as the SGR and the fast reactor, will show even greater promise.

\section{REFERENCES}

1. A. M. Weinberg, Advanced Systems - A Persondl Appraisal, Vucl Eng., 5 $463-465(1960)$

2. A. W. Cramer, Atomic Energy Iround the World, Atomucs, 4 12-1\& (1962).

3. G. W. Wensch, The Sodium-Graphite Reactor Programme, Parts I and II, Nucl. Eng , 9 360-363, 10 388-392 (1962).

4. Civilian Power Reactor Program, Part III, Book 6, Status Report on Soduum Graphite Reactors as of 1959, USAFC Report TID-8518(Bk. 6), 1960.

5. C. Starr and R. W. Dickunson, Sodum Graphite Reaclors, pp. 13-28, Addison-Wesley Publishing Company Inc., Reading, Mass., 1958.

6. Pouer Reactors, USAEC Division of Fechnical Information, May 1958.

7. R. W. Dickinson, R. C. Gerber, and C. I. Larson, Atomics International, Hallam Nuclear Power Facility, Prototype for Advanced Sodium-cooled Reactors, AIEE Transactions, Vol. III, 1962.

x. Civilian Power Reactor Program, Part III, Book 1, Stulus Report on Fast Reactors as of 1959, USAEC Report TID-8518(Bk. 1), 1960. 
9. A. I. Leipunskil et al., Operational Experience with the BR-5 Reactor, Paper No. CN-15/40 presented at the Conference on Operational Exper1ence with Atomic Power Reactors, Vienna, June 4-10, 1963. USAEC Translation AEC-tr-5890.

10. B. R. T. Frost, P. G. Mardon, and L. E. Russell, Resedrch on the Fabrication Properties and Irradiation Behaviour of Plutonium Fuels for the U. K. Reactor Programme, paper presented at ANS Topical Meeting, Richland, Washington, September 13-14, 1962, USAEC Report HW-75007 (Paper 4).

11. J. M. Gerhart, The Post-Irradiation Examination of a $\mathrm{PuO}_{2}-\mathrm{UO}_{2}$ Fast Reactor Fuel, USAEC Report GEAP-3833, General Electric Company, Vallecitos Atom1c Power Laboratory, November 1961.

12. Argonne National Laboratory, Reactor Development Program, Monthly Progress Reports, April-October 1962, USAEC Reports ANL-6565, 6573, $6580,6597,6610,6619$, and 6635 .

13. Fast Reactors, A World Survey, Nucl. Pov or 7(80): 42-49 (1962).

14. E. Kovacic, Atomic Power Development Associdtes, Detrolt, Mich., private communication, February 1963.

15. International Atomic Energy Agency, Power Reactor Experiments. Proceedings of a Symposium, Viennd, 23-27 October, 1961, Report STI/PUB51 (Vols. I and II).

16. Fast Redctors Soviet Outlook, Nucl Eng., 7, 137-141 (1962).

17. A. I. Lelpunskiı, O. D. Kazachkovski1, and M. S. Pinkhasik, The Future of Fast Reactors, Soviet J. At. Energy (English Transl.), 11: 1017-1026 (1962), original pp. 370-378 (1961).

18. M. J. McNelly, K. P. Cohen, and B. Wolfe, Experımental Fast Oxide Reactor, USAEC Report GEAP-3856, General Electric Company, Atomic Power Equipment Department, Nov. 27, 1961.

19. D. B. Hall, R. P. Hammond, and R. E. Peterson (Eds.), A Preliminary Study of a Fast Redctor Core Test Facility, USAEC Report LA-2332, Los Alamos Scientific Laboratory, August 1959.

20. Los Alamos Scientific Laboratory, Quarterly Progress Reports, USAEC Reports LAMS-2681 (February), LAMS-2720 (NIay); and LAMS-2753 (August) 1962.

21. E. Kovacic, Atomic Power Development Associates, Detroit, Mich., private communcation, February 1963.

22. Italy and Euratom Agree on Joint RAP IUS Project, Form Meno to Members, pp. 18-19, Atomic Industrial Forum, Inc., July 1963.

23. W. A. Robba, Status of the Settled Bed $\Gamma$ ast Reactor, Trans Am Nucl Soc, 5(1): $127-128$ (1962).

24. Civilian Power Reactor Program, Part III, Book 4, Status Report on Heavy Water Moderated Reactors as of 1959, USAEC Report TID-851 (BK. 4).

25. USAEC News Release, Washington, D. C., Dec. 13, 1962.

26 J. F Proctor and J. R. Bayer, Economics of Heavy Water Production, Chem. Eng. Prog3., 4 53-61 (1962).

27. The World's Reactors-No. 36, NPD, Nucl. Eng, 7· 402-406 (1962).

28. Nucleonics Reactor $\Gamma i l e . .$. No. 13, Reactors on the Line, NPD, Nucleonucs, 20(11) 47-52 (November 1962).

29. News of the Month, Nucleonus, 20(12) 25 (December 1962)

30 Reactor Development in Europe- 1 comparative chart published by Nucledr Engineering, December 1962 
31. D S. St. John and J. W. Wade, Economies of Heavy-water Reactor, $N u_{-}$ cleonics, 20(12) 52-55 (December 1962).

32. Heavy-water-moderated Power Reactors. Engineering and Economic Evaluations. Volume I. Summary Report. Volume II. Engineering Studies and Technical Data, E. I. du Pont de Nemours \& Co., Inc., USAEC Reports DP-510 (June 1960) and DP-520 (December 1960).

33. E. I. du Pont de Nemours \& Co., Inc., Heavy-water-moderated Power Reactors, Progress Reports, January 1960-July 1962, USAEC Reports $\mathrm{DP}-465,475,485,495,505,515,525,535,545,555,565,575,585,595$, $605,615,625,635,645,655,665,675,685,695,705,715,725,735,745$, 755 , and 765 .

34. Heavy Water Reactors, Pouer Reactor Technology, 4(2) 62-77 (March 1961).

35. W. B. Lewis, Operating Experience with Heavy Water Nuclear Power Redctors, Paper No. 2, Nuclear Congress, June 4-7, 1962, New York, N. Y.

36. Atomic Energy of Canada Ltd, The Eighth AECL Symposium on Atomic Power, held at Chalk River, Ontarıo, September 24, 1962, Canadian Report AECL-1599, September 1962.

37. France, Broad, Self-contained Programme, Nucl Eng, 11 459-465 (1961).

38. Halden BHWR, Nucl Eng , 3 106-112 (1959).

39. Norway Reviewed, Nucl Eng, 11 453-455 (1962).

40. Lucens Switzerland's Experimental Pressure Tube Reactor, Nucl. Eng , $11 \cdot 449-451$ (1962).

41. R3/ADAM, Nucl Eng, 5 202-205 (1960).

42. International Atomic Energy Agency, Directory of Nuclear Reactors. Volume IV. Power Reactors, Report STI/PUB/53, 1962.

43. R. O. Bolt and J. G. Carroll, Research on the Radiation Stability of Organic Fluids, Summary Report for April 30, 1951-May 30, 1952, USAEC Report TID-5094(Del.), California Research Corporation, July 1, 1952.

44. Civilian Power Reactor Program, Part III, Book 7, Status Report on Organic-cooled Power Reactors as of 1959, USAEC Report TID-8518 (Bk. 7).

45. Atomies International, Prototype Organic Power Reactor Conceptual Design, USAEC Report NAA-SR-6266, 1961.

46. J. C. Leny, Orgel-A European Concept, Nucl Eng , 6 508-512 (1961).

47. U. S. Atomic Energy Commission, Status Report Coolant and Fuel Element Technology for Organic Reactors, July 1, 1961.

48. Atomies International, Annual Technical Progress Report, AEC Unclassified Programs, Fiscal Year 1962, USAEC Report NAA-SR-7400, Nov. 15, 1962.

49. R. H. J. Gercke and J. I. Zack, Jr., Coolant Decomposition Rates and Make-up Costs for Organic Reactors, USAEC Report NAA-SR-6920, Atomics International (to be published).

50. C A. Trilling, Fouling in Organic Reactors, Nucl Eng, 12 523-524 (1961).

51. E. F Weisner, Piqua Nuclear Power Tacility, Status Report, Nucl Eng, 12 515-522 (1961).

52. J. K. Pickard, F. W. Warren, W. W Lowe, Virginid Rose, and Stuart McLdin, Poutr Reactor Technology, D. Van Nostrand Company, Inc., Princeton, N. J., 1961.

53. Piqua Has Authorization, Nucl Neus, 5(10): 23 (1962). 
54. The Experimental Organic-cooled Reactor, Pouer Reactor Technology, 5(1) 88-91 (December 1961)

55. Organic Cooled Reactors, Coolant Radiolysis, Poutr Reactor Technology, 5(3) 52-59 (June 1962).

56. K. Maddock, Organic I 1quids ds Reactor Coolants, British Report AERER-3633, April 1961.

57. Argonne National Laboratory, Organic Nuclear Reactors An Evaluation of Current Development Programs, USAEC Report ANL-6360, May 1961.

58. J. R. Powell, L. Green, J. F. Black, and K. F. Hoffman (Eds.), Evaluation of Organic Cooled Reactors, USAEC Report TID-6605, Brookhaven National Laboratory, Dec. 15, 1958.

59. M. R. Scheve, Liquid Fluidized Bed Reactor Experiment, USAEC Report MND-LFBR-2337, Martın Company, April 1960.

60. Direct Cycle Diphenyl Reactor, Marquardt Corporation Proposal No. 3032, September 1960.

61. U. S. Atomic Energy Commission, Civilian Nuclear Power-A Report to the President, 1962.

62. Atomics International, Sodium-cooled Reactor Nuclear Power Plants, Brochure 525-B-25 (5/62).

63. News of the Month, Nucleonics, 123 (1963). 


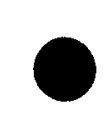

0 


\section{Boiling "Burnout"}

for Reactor Design

by

R. P. Stein and P. A. Lottes

Argonne National Laboratory 
$W_{\text {hen }}$ hen a liquid is bolled by heat from a hot surface with which it is in contact, a critical heat-transfer condition can occur. As a result the temperature of the surface necessary to transfer the required amount of heat changes, usually suddenly, from values very near the liquid bolling point to values very much larger. The importance to reactor technology of the possible occurrence of such a critical condition was recognized soon after it was decided to consider serıously the designing of a reactor cooled by water. These earliest considerations were mainly concerned with accident studies since it was not intended to allow boiling to occur during normal operating conditions. Later, serious consideration was given to the possibility of allowing some boiling to occur and thereby take advantage of possible improvements in heat transfer in operation below the critical condition. With the more recent developments in the power-reactor field, coolant bolling is now related to normal design operation as well as to accident studies. As a result quantitative knowledge of the occurrence of a critical heat-transfer condition is an important reactor-design consideration.

The purpose of this article is to report the current status of the ability both to understand and to predict the occurrence of a critical neat-transfer condition of boiling, as well as to suggest what we believe to be the most reasonable methods of attacking the problem as it occurs in reactor design today. There are many recent reports and papers in the literature with similar purposes, ${ }^{1-4}$ most of which attempt to offer something new; a few of them do so with considerable optimism. We offer nothing new except perhaps in approach, and we offer no optimism. Our evaluation of status and suggested method of attack can be briefly and generally summarized by quoting two sentences from a classic paper on the subject.

... phenomenon is technically important, and . . the literature on the subject is very considerable, quite old, obscurely located, and somewhat confused . . . For other than rough guesses, experience with the system at hand is almost essential.

These sentences are from a paper by Drew and Mueller ${ }^{5}$ published over 25 years ago. We believe that it is only slight exaggeration, if any at all, to say that they are still valid comments today.

In what follows we shall attempt to describe the state of the subject matter as it has appeared to us for many years and as it continues to appear. We anticipate criticism from many for describing too dismal a picture and perhaps exaggerating. "Why not point out all the good things," they will ask, "rather than emphasize the bad?" Aside from the need for scientific objectivity, which we believe requires emphasis of the negative, we are constantly being dismayed by what we find in the literature. For a subject matter with as intensive a research history as this one, the quantity of crude analyses, disputable arguments by 
analogy, incompletely planned experimentation, and general naiveness of approach that continues to appear in the literature seems to us to be evidence of stagnation. But what concerns us even more is the large amount of confidence, optımism, and individual breast beating, which we believe to be completely unjustified. This type of emphasis of the good seems to propagate itself through both the literature and the attitudes of the field in exponential fashion. In applied science, perhaps more than in any other field of human endeavor, "saying 1t's so doesn't make it so" is a most accurate truism. We want to say that it is not so. Perhaps we exaggerate. Even if we do, we believe we will give service by helping to provide some damping to the exponential propagation of unjustıfied confidence and its resultant stagnation of satisfactory progress in the field.

It is not the purpose of this article to provide a detailed analytical evaluation, nor is it intended to be a literature survey of any kind. The time necessary for such an effort is not avallable, and the quantity of related literature is enormous. Even if one limits himself to material generated within the nuclear-reactor field, he finds himself hard pressed to decide when to stop reading. But it is not the quantity alone that creates problems for the reader. For, as he absorbs his way through the mass of formally published papers in professional journals, meeting preprints, and company, university, and research laboratory reports, notes, and memoranda, he finds much confusing disagreement among data, interpretations, and ideas. The impression is easily formed that even the name of what we are concerned with is not generally agreed upon.

The evaluation given is a general one, illustrated occasionally by pertinent specifics. Although it has been largely formulated as a result of many years of contact with the field, most of the references listed in the bibliography have been read or reread by both of us fairly recently All the references listed, unless otherwise indicated, have been examined, at least briefly. There are also many pertinent literature references that either both or one of us had read but have not consulted recently. Although these, too, have influenced our evaluation, they have not been included in the bibliography. Many are classified documents; most are not readily avallable and are difficult to locate again

\section{THE BOILING CURVE}

Drew and Mueller ${ }^{5}$ show that as early as 1888 data existed in the Iiterature that could be interpreted to give evidence of the existence of a critical heat-transfer condition related to bolling. It appears, however, that Nukıyama ${ }^{6}$ in 1934 was the first to perform experıments and to interpret his data with the specific purpose of investigating this occurrence. 
Nukıyama bolled water from the surface of small electrically heated wires immersed in an open container (pool boiling), and he interpreted his data as characteristic of boiling when displayed as graphs of heatflux density vs. wire temperature as shown in Fig. 1 for water at $212^{\circ} \mathrm{F}$ and $1 \mathrm{~atm}$. The occurrence of a critical heat-transfer condition was revealed by the existence of a maximum heat flux at relatively low wire temperatures. When the heat flux generated within the wire was increased slightly above the maximum, the temperature of the wire would appear to jump suddenly to a very high value.

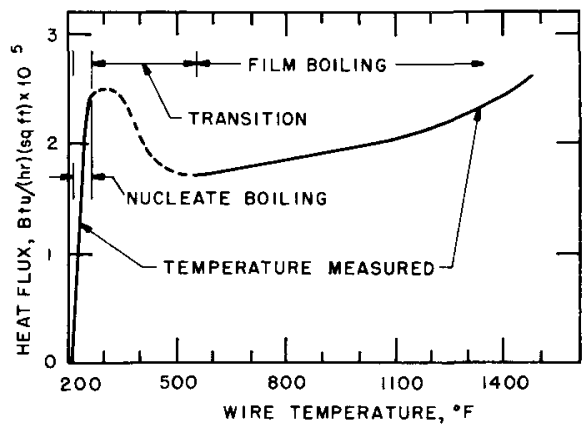

Fig. 1 - Nukiyama's boiling curve. ${ }^{6}$

Nukiyama found that, unless the wires were made of metals with melting temperatures that were high enough, the temperature jump was sufficient to cause the wire to melt. Thus his "bolling curve" interpretation could explain the data obtained earlier by Moscikı and Broder, ${ }^{7}$ who found that electrically heated wires immersed in relatively cold water would melt if the heat generation were increased beyond a certain value. Nukiyama found that, if the wire did not melt after a temperature jump occurred, reducing the heat flux resulted in higher temperatures at lower heat fluxes than were obtanned previous to the jump. A further reduction in the heat flux eventually resulted in a jump back to lower temperature operation.

The boiling curve of Nukiyama is now a classic of the literature of boiling and introduces almost every general descriptive article on the subject. It certainly assisted greatly in the interpreting of the critical heat-transfer condition as a transition from nucleate boiling to film boiling. Heat transfer with nucleate boiling takes place at relatively low surface temperatures because of the vigorous mixing action of vapor bubbles generated at the heater surface. In film bolling, heat transfer requires relatively high temperatures because of an insulating vapor film surrounding the heater surface.

The general nature of the curve has been verified many times since by a variety of experiments. They include experiments in which fluids 
of various kinds were bolled at the outer surface of tubes by condensing vapor inside the tube rather than by electrical heating. This modification made it possible to control the surface temperature instead of the heat flux, the reby allowing stable operation in the transition region of boiling. Substantiating data have also been obtained with hquids at average temperatures significantly below the bolling point, but with boiling taking place locally at the surface of the heater (subcooled pool bolling), as well as with heaters of a variety of shapes and orientations.

The concepts developed from these simple pool bolling experiments could also be used to explain the occurrence of a critical heat-transfer condition with experiments in which liquids were boiled as they flowed through heated ducts. Thus sudden melting of a heated duct or large temperature excursions in such experiments could be interpreted when a "critical heat flux," corresponding to the maximum on a hypothetical bolling curve, was exceeded. Many experıments were performed which had, at least in part, objectives related to understanding the occurrence of a crtical heat flux for subcooled forced-convection boiling. Not until 1954, however, were measured bolling curves for such systems reported. They were obtained by Ellion, ${ }^{8}$ who used a clever combination of electrical heating and simultaneous cooling by a secondary fluid.

As far as we know, bolling curves for forced-convection bolling with net steam generation (saturated or bulk boiling) have not been reported in the literature. There are, however, collections of exper1mental data that appear to indicate that, above certain values of heat flux, temperature jumps or excursions do occur when all other system variables are steady. But there are also data related to a critical heattransfer condition which do not give such indications. Thus the general correspondence of a critical heat-transfer condition in forced-convection bulk bolling to a bolling-curve maximum heat flux is uncertain. In fact, with the generation of relatively large volumes of vapor, current speculations favor other than a transition from nucleate to film boiling, as implied by Nukiyama's boiling curve, as responsible for observed critical heat-transfer conditions.

As implied above, attempts to understand or describe the physical mechanisms involved in the occurrence of a critical condition in boiling have, at least initially, relied rather heavily on extrapolating what was learned from simple pool-boiling experiments to boiling in ducts. Aided by photographic studies as well as actual bolling curves, this extrapolation appears justıfied for subcooled boiling. For bulk boiling in ducts, however, the situation is at least unclear.

\section{BURNOUT}

Although the term "burnout" is used in the title of this article, it is yet to be used in the text. The omission is intentional, for we have little 
affection for the term because of the confusion it continually seems to generate. But it is frequently used, and thus we cannot avold it entirely. We can describe a little of its past history, however, before using it.

During the period 1952 to 1954, one of the authors of this review participated in a large classified research effort related to heat transfer in the Savannah River reactors. The main purpose of this effort was to determine how much beyond normal-design power levels this type of water-cooled reactor could be pushed before heat-transfer problems became serious. Experiments were performed with full-size simulations of a fuel channel with its associated cooling flow circuits. Nuclear heat generation was simulated by electrical-resistance heating. During the course of the research, the term "burnout" evolved as a general description of fallure of the apparatus by melting of the simulated fuel rods. Eventually three types of such burnouts were acknowledged. The first, and initially the most frequent, was the result of accidental mechanical defects of the apparatus with eventual overheating and sudden melting of components. Fallures of this kind were usually quite spectacular, and the term "burnout" seemed particularly apropos. They had little to do with the purpose of the research, however, other than as a stage in the development of a satisfactory apparatus.

The second type occurred with the apparatus operating satisfactorily and with net steam generation in the simulated fuel channel. Increases of the resistance to pumping coolant flow through the channel as a result of boiling, together with the characteristics of the flow loop and pumps, would eventually cause a sudden decrease in flow rate. The simulated fuel rod would then overheat and melt as the flow decreased completely out of control. This type of fallure was called "flow-instability burnout," and the power level at which it occurred was known to depend on the pressure drop-flow rate characteristics of both simulated fuel channel and flow loop.

The third type of burnout occurred with either subcooled nucleate boiling or net steam generation in the simulated channel but with coolant flow stable and steady. With subcooled bolling, melting of the simulated fuel rod was attributed to exceeding the critical or maximum heat flux of nucleate bolling, which resulted in a sudden transition to film boiling. With net steam generation, it was not evident that a transition from nucleate to film bolling was the mechanism explaining overheating and melting. Thus, with both types of boiling, fallures of this kind were called 'boiling burnouts,' whereas, with subcooled liquid, the term was considered to imply exceeding the critical or maximum heat flux of nucleate bolling. During the same period of time, and perhaps earlier, similar terminology was being used at the Hanford Laboratories with similar classified experiments related to the Hanford reactors.

Terminology throughout the field in general was not so definite, and there were many instances of confusion resulting from lack of distinction 
between flow-instability burnouts and boiling burnouts. Attempts to correlate burnout data collections that included both types without identıfication were not unusual. Eventually, however, there appeared to be general agreement to use the term "burnout" to designate boiling burnout and to consider flow-instability burnout as an occurrence only indirectly related. This was not entirely satisfactory to all because burnout denotes physical destruction, and it was well known that the critical heat flux of nucleate boiling could be exceeded without physical destruction of the heating surface if melting temperatures were high enough. Using the term "critical or maximum heat flux" without necessarily relating it to a transition from nucleate to film boiling was suggested and adopted by many. For others this term was objectionable because it was by no means certain that, with net vapor generation in a duct, the heat flux itself was either critical or a maximum in any general sense.

For a short while the terms "burnout" and "bolling burnout" prevalled, but then the term "burnout heat flux" became most frequently used. It seems, perhaps as a result of exhaustion, that the re was tacit agreement not to consider the meaning of the words too literally. Thus "burnout" did not necessarily imply burnıng, melting, or physical destruction in general.

Soon another term began to make itself known: "departure from nucleate boiling." Because of its Iength it was abbreviated to "DNB." Initially this term had been suggested as an alternate that would not denote physical destruction and would not refer to a heat flux. But then there were claims that an actual departure from nucleate bolling could be detected experimentally before the burnout heat flux was reached and that this departure always occurred at actual heat fluxes only a few percent below the burnout value. These claims were supported, at least initially, by interpretations of boiling-curve data which suggested that, just before the maximum heat flux is reached, the rate of rise of surface temperature with heat flux increases significantly before the occurrence of an actual temperature jump. Thus, it was claimed, knowledge of the heat flux at the DNB point was just as valuable as the actual burnout heat flux, and experiments to determine DNB were much easier to perform. The term is still part of current usage even in regions of net steam generation where the occurrence of nucleate boiling is uncertain as well as in situations revealing little evidence for the existence of a maximum heat flux analogous to that of Nukiyama's boiling curve.

In the related Russian literature, which is becoming increasingly available in countries outside of the Iron Curtain, the term translated as "crisis" has appeared in a relatively consistent fashion since at least 1951. The most recent literature refers to various types of 
crises in boiling, and the use of the term has begun to appear in the technical language of boiling in the United States.

Today the term "burnout heat flux" is most often used, and its implication is understood by those most familiar with the field. The recent literature, however, continues to contain objections to its use as well as confusion as to its meaning; all other previously mentioned terms continue to appear, as well as occasional new ones. Most recent to appear is "dryout," a term applied by some to critical heat-transfer conditions occurring with the flow of vapor-liquid mixtures through heated ducts when the amount of vapor is relatively large. As was initially the case with DNB, "dryout" is meant to be somewhat descriptive of what actually happens in a specific type of critical condition. Also, it avoids the implication of physical destruction denoted by "burnout," an implication that in many cases of vapor-liquid flows containing relatively large amounts of vapor is especially inaccurate.

In many instances an experimental condition is identified as burnout when, although the rate of surface-temperature rise with heat flux has increased noticeably, the experiment indicates that a temperature jump or excursion does not occur even upon further increases of heat generation. In other cases, only small temperature excursions occur; in still others, temperature oscillations identify a burnout condition. In most of these situations, the possibility of serious overheating or actual melting would occur only at significantly larger heat-generation rates. Experiments of this type have given birth to a new term which understandably confuses the uninitiated, viz., "heat transfer beyond burnout."

\section{POOL BOILING}

The early verification of the critical condition of pool boiling as corresponding to a transition from nucleate to film bolling leads quite naturally to speculations that its occurrence is related to an overcrowding of vapor bubbles at the heat-transfer surface. Research aimed at understanding nucleate boiling in general assisted in formulating this idea in more detail.

In nucleate bolling the temperature of the heat-transfer surface is not very much above the bolling point of the liquid because vapor formation as relatively small, periodically generated bubbles results in vigorous agitation of the liquid close to the surface, thereby causing cool liquid to reach the surface and transfer heat with it directly. As the rate of vapor formation increases, however, the presence of vapor close to the heat-transfer surface can have exactly the opposite effect. Bubbles become so numerous that they tend to reduce the avallable space through which liquid must flow to reach the heat-transfer surface. Also, when this occurs, the vapor motion tends to push and drag liquid away from the surface. In experiments in which the surface tempera- 
ture is controlled, the reduction in the amount of liquid contacting the surface eventually reduces the heat flow. With experiments such as those of Nukıyama using electrical heat generation, the reduction in the amount of liquid contacting the surface eventually results in a temperature excursion to values high enough to maintain stable film boiling.

Although the preceding description of what occurs at the critical condition corresponding to a maximum heat flux in the bolling curve is generally accepted, there are many specific detalls for which agreement is hard to find. Some of these detalls concern further descriptive features, such as whether liquid-surface contact exists at all, whether the condition of the surface is important, or whether the rate at which vapor leaves the surface is determined mainly by the inherent buoyancy of vapor bubbles immersed in liquid. Other disputable details relate to the reasonableness and correctness of the application of physical principles to idealized models of the way vapor and liquid are distributed. These details are mainly concerned with rationalizing empirical prediction methods.

Agreement, though by no means unanimous, is much better with respect to the use of the prediction methods themselves. In 1945 Cichelli and Bonilla ${ }^{9}$ offered a completely empirical method that still compares quite favorably with more recent methods. In 1948 Addoms ${ }^{10}$ obtained an alternate correlation of data based partly on rational choices of dimensional groups with physical mechanisms similar to those just described. Further rationalizations of these mechanisms were attempted by Rohsenow and Grıffith. ${ }^{11}$ A variety of other relations have appeared since, and today the semiempirical correlation of Kutateladze, published in Russian ${ }^{12}$ in 1951 and appearing in English ${ }^{13}$ in 1954, is generally considered as the most accurate. Questions concerning its accuracy usually relate to applications for which the correlation has not been tested as well as to unexplained observations of the large scatter of measurements in an apparently otherwise consistent series of experiments.

Kutateladze apparently pictured the physical mechanism involved much as we have described it here and characterized its occurrence as "a purely hydrodynamic phenomenon." He used this characterization to justify considering the essential features of the interacting mechanisms to be implicit in the equations of fluid motion for each phase with appropriate boundary conditions at an imagined interface between vapor and liquid. He then put the equations with their boundary conditions into dimensionless form, eliminating various terms that he judged to be unimportant. By using various qualitative arguments, guided partly by experimental results, he was able to eliminate and combine dimensionless groups until all but one remained. The validity of this dimensionless group and its value was then demonstrated by evaluation with a variety of experimental data. 
The best-known analytical efforts of the last several years have been attempts to derive Kutateladze's equation directly from idealized physical models without the use of dimensional analysis and with a minımum of experimental data. The most publicized of these analyses are those of Zuber, ${ }^{14-17}$ who, at least initially, claimed to have derived Kutateladze's equation without the use of experimental data or empiricism. Unfortunately the initial, and still most readily available, publication of Zuber's analysis ${ }^{15}$ is rather vague, is difficult to justıfy, and has all appearances of a series of ideas presented prematurely. Neither later revisions nor attempts to clarify ${ }^{14,15}$ have been entirely convincing, although the specific qualitative physical description of the critical condition as "a purely hydrodynamic phenomenon" that resulted has given more definitive meaning to Kutateladze's description. As a result, a variety of alternate attempts to derive Kutateladze's equation have appeared in the literature and will probably continue to appear. Chang and Snyder ${ }^{18}$ offer two different derivations. A derivation similar to the "first" alternate of Chang and Snyder was, in fact, suggested by Deissler ${ }^{19}$ in 1954. A similar derivation is also offered by Bragg and Smith. ${ }^{20}$ Other published derivations are those of Berenson, ${ }^{21}$ Molssis and Berenson, ${ }^{22}$ and Adams; ${ }^{23}$ they are based on idealized physical models similar to one described by Zuber and Tribus. ${ }^{14}$

From the point of view of applied science, the utility of a detailed description of a physical phenomenon is the ability of the description to evolve, by analysis, into a prediction method not currently available or to give confidence to an existing empirical formula, thereby allowing extrapolations in specified directions. The recent attempts to justify Kutateladze's equation by entirely analytical means obviously fall into the latter category. The success of these attempts is at least disputable, if they are not completely a fallure, at this time. Verification by recent experiments of the influence of surface tension and acceleration as compared to predictions s $^{24-28}$ as well as tests for applicability to liquid metals $^{29}$ and to various types of heater-surface materials ${ }^{30,31}$ have raised many doubts as to the generality of the equation, and a variety of contrary claims can be found in the literature.

The results of experiments with heater surfaces of various orientations, shapes, and sizes are particularly difficult to reconcile with implications of current theory. Experiments with small horizontal and vertical $^{7}$ wires, horizontal tubes of much larger size, horizontal disks facing up and facing down, ${ }^{32}$ and vertical strips ${ }^{33}$ all seem to give results that, within the usual amount of scatter found with pool-boiling experiments, are nearly equivalent. Yet the details of current theory would imply large differences.

The following circumstance illustrates the kind of confusion that exists in the literature. The title of Ref. 33 refers to "a horizontal plate"; the text, however, relates that the plate was set up horizontally 
on its narrow edge. Yet the data are used to show the validity of theories applicable only to very large horizontal surfaces.

Extensions of saturated pool boiling results to include predictions of the maximum heat flux in subcooled pool boiling are avallable, notably in the semiempirical formulations of Kutateladze. ${ }^{34}$ Attempts to develop extensions to subcooled boilng by analysis alone are offered by Zuber. ${ }^{14,16,17}$ Unfortunately our analytical understanding of the maximum heat flux of subcooled bolling can be no better than that for saturated pool boiling since it is the latter that is currently used as a basis for analysis.

Experimental data for subcooled pool bolling are less plentiful than those for saturated pool boiling. This situation is due partly to the difficulty in performing such experiments in systems that can be justified as being really of general interest. Two types of systems have been reported as subcooled pool boiling. The first contains provisions for cooling the pool at some distance from the heated surface. The second consists of a pool of liquid which is not cooled but which is so large, with respect to the amount of heat added by the heat-transfer surface at which bolling occurs, that the liquid does not heat up significantly during the experiments. It is difficult to justify generalizing results from systems of these two types or from systems of the same type but of different sizes. Yet generalization is often attempted, and confusion results. Another type of system has recently been reported in the literature as being approximately equivalent, at least, to subcooled bolling. This system results from experiments performed with containers of liquid operated in centrifuges for the purpose of exploring the effect of gravity. ${ }^{27,28}$ At high accelerations a significant hydrostaticpressure gradient, with a resultant saturation-temperature gradient, occurs within the liquid. For reasons that seem difficult to defend, some experimenters apparently "correct" their data by comparison with subcooled pool boiling experiments without acceleration.

In general, the maximum or critical heat flux for saturated pool boiling for a variety of heater shapes and orientations and for various liquids can be predicted with an expected uncertainty of about 20 per cent. Much larger uncertainties should be expected with unusual heattransfer surfaces and fluids and, in general, with systems for which current prediction methods have not been sufficiently verified by experiments. Subcooled pool boiling falls into this latter category. If it is at all possible, the use of directly applicable experimental data is to be preferred.

\section{BOILING IN DUCTS}

The boiling of a liquid as it flows through a heated duct is clearly the type of boiling of most interest to reactor technology. Boiling in a 
pool occasionally may resemble certain special features of specific reactors. However, the main purposes of pool bolling experiments, as far as reactor technology is concerned, have been to obtain basic understanding with inexpensive and easily handled equipment. In addition, researchers hope that relations obtained for predicting the maximum heat flux of pool bolling can be extended to boiling in ducts, and a variety of empirical correlations of data have been suggested on this basis. ${ }^{35,36}$

\section{Mechanisms and Analysis}

A convement vehicle for describing current general understanding of the occurrence of a critical heat-transfer condition for boiling in ducts is to imagine a long, heated channel into which liquid enters at temperatures below its boiling point and exits as saturated vapor. Current ideas on how liquid and vapor are distributed in such a duct are shown schematically in Fig. 2. In this figure various possibly distinguishable regions are indicated by number.

Fig. 2-Vaporization of liquid flowing through a heated duct.

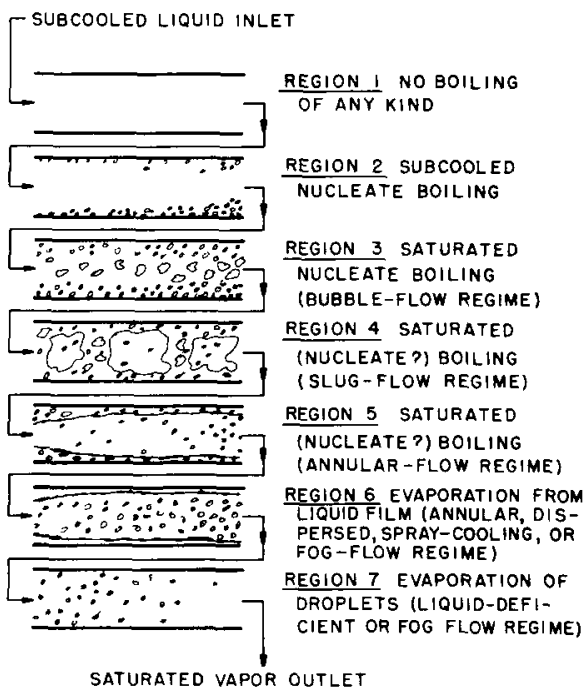

There is no boiling of any kind in region 1, although the liquid adjacent to the heat-transfer surface may be at temperatures somewhat above the local bolling point. In region 2, liquid temperatures at the surface are sufficiently above the bolling point to cause "nucleation" and vapor-bubble generation, but the liquid a short distance from the duct wall is subcooled. Vapor bubbles are swept from and along the surface and eventually condense in the cooler liquid. This region of subcooled nucleate boiling in a duct is thought to be quite similar to subcooled pool boiling. A critical condition results when the local vapor 
generation is too high, preventing sufficient cool liquid from reaching the duct wall, and a transition to film boiling occurs.

In region 3 the enthalpy of the fluid has exceeded that of saturated liquid, and net vaporization or bulk bolling begins. Vapor is generated as relatively small bubbles at the heat-transfer surface, which tend to coalesce into larger bubbles away from the surface. In region 4, coalescence, together with the larger amount of vapor present in the duct, results in the formation of separate slugs of vapor, each occupying nearly the entire cross section of the duct. These vapor slugs may contain small liquid droplets. In the parlance of "two-phase flowpattern" investigations, regions 3 and 4 are usually referred to as bubble-flow and slug-flow regimes, respectively, and are believed to be further characterized by relatively large pressure and temperature fluctuations. Speculations as to possible mechanisms for the occurrence of a critical heat-transfer condition in these regions are rarely, if ever, found in the literature, although some of the methods used to generate correlating equations based on pool-boiling relations would seem to imply similar mechanisms. One reason is that, except possibly for thermal convection flows, the bubble- and slug-flow regimes are not generally believed to persist over a significant length of the duct in which a liquid is boiled.

It is thought that the annular-flow regime of region 5 results shortly after the initiation of boiling, except possibly at pressures very near the thermodynamic critical pressure of the fluid. The annular flow of region 5 is pictured as one in which liquid flows as a thin film against the duct walls, most of the vapor being contained in a central core. It is further imagined that vapor generation occurs mainly as small bubbles within the liquid film, much as in subcooled nucleate boiling. Boiling of the liquid film and differences in interfacial shear and fluid pressure between liquid and vapor are thought to result in a continual dispersion of liquid into the vapor in the form of droplets or larger irregular masses, which eventually break up into droplets. Entrainment of liquid in the film as a result of droplet impingement from a turbulent vapor core (turbulent diffusion of droplets), which is also considered possible, acts as a source of replenishment of the liquid film. Current speculations as to mechanisms for the occurrence of a critical heat-transfer condition in region 5 are somewhat vague. An implication seems to be that, if the liquid is thick enough, vapor generation as bubbles within the liquid can result in a critical condition similar to that in pool bolling, but the idea seems somewhat forced. Another implication is that a critical condition occurs as a result of nearly complete dispersal of the liquid film, at least partially as a result of being "blown away" by the vapor generation.

Speculations as to a description of a critical condition are more definitive for region 6 . This region is also an annular-flow regime, but 
an important difference is that vapor generation is now pictured as occurring mainly as a result of evaporation directly from the liquid-film surface. Unlike region 5, vapor-bubble generation within the liquid film is insignificant. The occurrence of a critical condition corresponds to the sudden breakup or instability of the liquid film as a result of differences in shear and fluld pressure at the liquid-vapor interface, or it is a result of a gradualdispersal of the film caused by insufficient replenishment from impinging droplets by turbulent diffusion from the vapor core.

Other speculations suggest that breakup or dispersal of the liquid film does not necessarily correspond to a critical condition that would result in temperature excursions in heated ducts. The wall might be kept cool by the evaporation of droplets impinging on the heat-transfer surface as a result of turbulent diffusion from the vapor flow. Such speculations apply to region 7, where all liquid is completely dispersed as droplets in the flowing vapor, and they would appear to be most reasonable at the highest vapor-volume fractions. This region is usually referred to as a "fog flow," although the same term also appears to be used sometimes tor the higher quality annular-flow regions. The occurrence of a critical heat-transfer condition in region 7 would correspond to an insufficient rate of droplet impingement.

The current descriptive understanding of boiling in ducts just summarized has not been very successful in producing satisfactory and generally acceptable prediction methods. The complicated nature of the various mechanisms involved, as well as their interactions, would suggest that attempts at analysis would be frutless. Yet the re is always the hope that a sufficiently simple idealization can be capable of capturing the essentials.

Note that, if the term "boiling" is meant to imply the formation of vapor as bubbles within a liquid, in a strict sense vaporization in regions 6 and 7 does not occur by boiling. Thus the term is used somewhat loosely here as well as in the field in general.

So far as we know, there have been no attempts to analyze the subcooled bolling region which are comparable, for example, to the attempts by Zuber and others for pool bolling. Zenkevich ${ }^{37}$ presents a rational use of dimensional analysis similar to the attack by Kutateladze on pool bolling and indicates considerable success with correlating data empirically. Various treatments appearing in the literature are claimed to be analysis from theory, but close inspection reveals them to be nothing more than empirical correlations with much superfluous and often questionable rationales.

For bulk bolling, two rather detalled analyses based on the annularflow regime of region 6 have appeared in the literature. The first, that of Vanderwater, appeared first ${ }^{38}$ in 1956 and later in somewhat revised form ${ }^{39}$ in 1962 . The second, by Tippets, ${ }^{40}$ guided in part by photographic 
studies, appeared quite recently. In an attempt to account for all the varıous mechanısms involved, these analyses use a variety of rather crude approximations with little, if any, demonstration of applicability. These approximations also introduce empirical factors that are evaluated by fitting the final resulting equations to data. As a result they have not been generally accepted except possibly as the equivalent of fairly good empirical correlations, of which there are many others. A recent analysis by Stein et al., ${ }^{41}$ based on earlier speculations of Goldmann et al., ${ }^{42}$ uses an idealization of a fog flow as in region 7 of Fig. 2. The analysis shows promise of providing sufficient simplicity to be capable of a consistent mathematical attack, but it is possibly limited in applicability to regions of high velocity and large vaporvolume fractions.

\section{Empirical Studies}

The current descriptive understanding of boiling in ducts could be expected to give guidance to empirical studies at least. A perusal of the most recent literature convinces us that there are many cases for which this is true. In the past, however, purely empirical correlations of data based on the premise that a critical heat-transfer condition in a duct could be identified by local conditions only were, and still are, quite successful for subcooled bolling as well as for bulk boiling at moderate qualities. The local conditions consisted of a measure of the thermodynamic state of the fluid, its average velocity, and the heat flux. With bulk bolling there was, and apparently still is, much confusion in the literature with regard to the validity of such correlations. Duct length appears in many correlations of data as an additional empirical correlating variable, implying a generality of application that seems completely out of line with current understanding of the mechanisms involved except possibly for extremely short ducts. The much-publicized correlation of data of researchers at Bettıs, ${ }^{43}$ obtained primarily for studies of design safety of a particular nonbolling, water-cooled reactor, and including a "length effect," is at least partly responsible for this confusion. In $1960 \mathrm{Bell}^{44}$ showed clearly that the same data could be correlated purely on the basis of local conditions and that the length effect reported previously resulted from a peculiar method of examining the data. There are now indications that duct length as a correlating variable has been eliminated from Bettis correlations. ${ }^{45,46}$ At one time there were speculations to the effect that the fluid inlet temperature should be treated as an empirical correlating variable, ${ }^{47}$ and similar Ideas have been expressed again recently. ${ }^{48}$

What seems to us as an especially curıous way of examining data was used by the Bettis workers and continues to occur in the literature 
today. ${ }^{49}$ It consists of plotting measurements almost directly as obtained from the experiments, witn little attempt to isolate effects of single variables. From such graphs, speculations and in many cases assertions are made as to the effect of the variables; these speculations then usually influence quite strongly the form of empirical correlation of the data. If such variables as fluid inlet temperature and duct length are assumed important, it is not always possible to extract from the data the effects of all variables independent of the others because most of them become dependent upon each other by energy conservation.

But is it necessary to assume that duct length, for example, is an important variable? The simplest assumption for an initial examination of data would seem to be that only local conditions are important. This was Bell's assumption, which apparently differed from that of the Bettis researchers, and explains why the two correlations of the same data are so different. Bell was able to extract from the data graphs of the effect of a single variable on the burnout heat flux, with all other local variables fixed. Aside from a verification that channel length had no significant effect, these graphs also showed clearly that in certaiı regions the burnout heat flux decreased as the mass velocity of the fluid increased. According to the Bettis correlation, exactly the opposite occurs. There are indications in earlier reports of Bettis data ${ }^{47}$ that this dependence on mass velocity was suspected but discarded as unreasonable, apparently by analogy with previous results for subcooled nucleate bolling. This kind of reasoning eviaently led to considerations of inlet temperature and duct length as correlating variables with rationales concerning insufficient mixing of the fluid as it flowed through the duct. How an effect of such nonlocal variables could be expected to apply to reactor channels with nonuniformi lengthwise heat-generation distributions was and still is quite vague.

The readily avallable literature also contains the suggestion that, since correlation attempts based on local conditions only are not always successful, a more profitable method of attack is to correlate statist1cally in terms of independently controllable system parameters only. ${ }^{50}$ Thus burnout-heat-flux correlations are offered as functions of duct length, duct diameter, fluid inlet temperature, pressure, and flow rate. At best, such correlations are restricted in applicability to exactly the same type of system from which the original data were obtained. Application, for example, to a system with nonuniform heat generation or different duct shapes is not permissible. As a result most reactor heat-transfer engineers have silently rejected correlations based on system parameters, but perhaps too silently since serious consideration of this kind of correlation continues to appear in the literature..$^{51} 52$

In nearly all experiments having the objective of the collection of data identifying critical heat-transfer conditions in a specific system, an essentially uniform distribution of electrical heat generation is used 
along the duct. Experiments performed to test whether such data can be applied to ducts with nonuniform heat generation typical of reactors are not very plentıful. Some interpretations of these experiments conclude that direct application of uniform-heat-flux data to nonumiform cases cannot be made, ${ }^{44,53}$ whereas others conclude that the differences are not too important. ${ }^{43}$ In general, it appears that the use of unformheat-flux data, if successfully correlated in terms of local conditions, will give conservative results when applied to typical problems of reactor design. As mentioned previously, if empirical correlations of data require use of nonlocal correlating variables, such as duct length or inlet condition, the implications are not very clear.

If attempts at analysis, such as those of Vanderwater et al. ${ }^{38,39}$ and Stein et al., ${ }^{41}$ can be accepted as at least conceptually correct representations of the bulk-boiling regions to which they apply, it is clear that the traditional empirical correlations based on uniform-flux data cannot be applied to nonuniform cases. In these analyses, duct length, or, more properly, inlet conditions, serve as initial conditions, which, along with heat-flux distribution and duct geometry, must be specified before the local conditions that determine the occurrence of a critical condition within the duct can be predicted.

If the critical condition corresponds to a sudden breakup or tearing away of a liquid film, it is not clear what differences should be expected between uniform- and nonuniform-heat-flux distributions. Duct shape could be very important, as well as inlet conditions that influence the initial formation of the liquid film. Current research aimed, at least partially, at understanding the formation and behavior of liquid films as related to the occurrence of a critical heat-transfer condition could supply answers to these questions in the near future. ${ }^{54-56}$

In the past the occurrence of a critical heat-transfer condition in subcooled nucleate bolling was always attributed to operation above a definite maximum heat-flux density of nucleate boiling, resulting in a transition to film boiling. It was also recognized that in certain situations, such as bolling of a fluid flowing through extremely small ducts or generation of large amounts of vapor in a duct of any size, the occurrence of nucleate bolling as the generation of many vapor bubbles from a heat-transfer surface would not be possible. The required space would not be avallable ether in the duct itself or in the amount of liquid present. If critical heat-transfer conditions causing sudden temperature excursions occurred in such situations, they would occur for reasons other than those usually associated with a transition from nucleate to film boiling. The recent descriptive understanding of boiling in ducts as illustrated in Fig. 2 is in accord with these early speculations. Yet there is much work reported in the literature, some of it quite recent, which collects data and reports empirical correlations 
with implied generality. It completely ignores the possibility of these "unusual" situations, even though their existence is more than likely with the particular experiments or data described.

\section{Further Complications of Data Interpretation}

The possible influence of flow stability on measured values of a critical heat-transfer condition continues to appear. In most cases apparent dependence on duct length and fluid inlet conditions, as well as other peculiarities of data interpreted as of general nature, can be attributed to problems of auxiliary-equipment operation influencing stability rather than to the controlled occurrence of a critical heattransfer condition or burnout as currently understood. As a result much of the data and empirical correlations reported do not deserve the generality implied. Unfortunately, the possibility that flow stability has influence on the data is not usually easy to discover from published material alone.

Ten years ago flow-stability problems were related mainly to providing sufficient reserve pumping pressure to overcome increases in the resistance to flow through a heated duct resulting from boiling. Today sizable pressure and flow fluctuations attributable to the existence of compressible volumes in flow loops are also of concern.

Stability problems related to the existence of a gas space or other compressible volume immediately upstream of the test-section inlet were first studied extensively by Lowdermilk et al ${ }^{57}$ It was found, for example, that, with test sections of very small diameter, the presence of a gas-filled pressure-measuring transducer at the inlet could reduce the measured burnout heat flux by large amounts. A large collection of experimental data now exists which was obtained with vapor-liquid mixtures entering the test section. ${ }^{47}$ Although initially the data from these experiments were thought to be susceptible to empirical correlation and analysis for general application, they are now considered suspect because of the possibility that the liquid-vapor mixture upstream of the test section behaved as a compressible volume similar to the compressible volumes studied by Lowdermilk et al. ${ }^{57}$ One of the peculiar features of these data is that some show a maximum value of the burnout heat flux when plotted against the vapor-mass flow-rate fraction (quality) at constant mass flow rate, as well as an apparent duct-length effect. Before these data were obtained, it was generally accepted that, with bulk bolling in ducts, the heat flux at which a critical heat-transfer condition occurred decreased monotonically as the vapormass flow-rate fraction increased. Current speculations favor the interpretation that these maximum values, as well as the apparent ductlength effect, are a result of stabihty problems and, as such, are related 
to special features of the entire apparatus and method of operation. These speculations are further supported by experiments, reported by Aladyev et al. ${ }^{58}$ which relate the occurrence of uncontrolled pressure pulsations to the existence of compressible volumes immediately upstream of the test section. Experiments with compressible volumes and subcooled fluid at the inlet gave both maximum and minimum values of the burnout heat flux with bulk bolling when plotted against quality at constant flow rate. An apparent length effect was also noted. Without the compressible volume but with operating conditions otherwise the same, burnout heat fluxes were generally higher with both subcooled and bulk bolling and decreased monotonically with increasing quality; also, an apparent length effect was no longer detectable.

A particularly disturbing aspect of the experiments reported by Lowdermulk et al. ${ }^{57}$ and Aladyev et al. ${ }^{58}$ is that they suggest the possibility that significant portions of the large data collections appearing in the literature over a period of many years might also have been influenced by undetected stability problems caused by compressible volumes in the apparatus. They also suggest that reactor systems to which laboratory data are applied might contain such sources of instability. Because the experiments indicate that the occurrence of these instabilities in a reactor system would lower the safe power level, there is cause for concern and further justufication for the current practice of performing detalled simulation experiments whenever possible.

Data recently obtained at Hanford and reported by Waters et al. ${ }^{59}$ further complicate the burnout picture. These data, obtained with long, uniformly heated tubes and bulk bolling, report apparent critical heattransfer conditions at significant distances upstream of the tube outlet. If the heat flux at which a critical heat-transfer condition occurs decreases monotonically as quality increases, with uniformly heated tubes the critical condition should always occur at the tube outlet. Stability problems were carefully considered but could not be detected. The authors acknowledge that they are puzzled by these results. They offer no explanation except to note that Collier ${ }^{60}$ had previously suggested the possibility of upstream burnout but had based his speculations on accepting the existence of a minımum and a maxımum value of burnout heat flux when plotted against quality at constant flow rate as a possible general relation independent of stability considerations.

Most laboratory determinations of critical heat-transfer conditions involve some sort of burnout-detection method and electrical-resistance heating. But the detection methods are not always the same, and the electric power supply may be either alternating or direct current. Furthermore, the heat capacity of the heating element may differ significantly among various experiments. Although there is fairly general agreement that in most situations these differences in experimen- 
tation have little effect on the generality of the data obtained, it is also acknowledged that in certain "unusual" situations these differences could be important. Unfortunately, definitive specification of these unusual situations has not received much study.

As a final complicating consideration, we mention a question asked many years ago: Are data for boiling heat transfer obtained with electrical heat generation fair representations of bolling in nuclear reactors? It is now known, for example, that large voltage gradients can cause drastic changes in the occurrence of the critical heat flux of pool boiling. ${ }^{61-63}$ The possible influence of gamma radiation or neutron bombardment on nucleation properties, and hence on boiling, has been acknowledged for some time. Answers to the question are uncertain, although one experiment, a comparison of burnout in an electrically heated laboratory apparatus w1th burnout in a reactor channel, ${ }^{64}$ suggested that differences are not detectably significant, at least for the specific circumstances under test.

\section{SUMMARY AND RECOMMENDATIONS}

We have presented a variety of evidence with which we hope to have conveyed the impression that empirical data correlations, as well as the interpretation of laboratory data, should not be used to predict the occurrence of a critical heat-transfer condition, or "boiling burnout," without careful examination of applicability. In addition, implications of generality found in the literature should be viewed with skepticism. Temptation to extrapolate reported information without recognizing and allowing for large amounts of uncertainty must be resisted.

In summary, general predictions of critical heat-transfer conditions for bolling in ducts cannot be made with any reasonable certainty, except possibly for subcooled nucleate boiling and for bulk boiling with moderate qualities with the use of empirical relations based on experimental data for the particular fluid and duct geometry of interest. Recommended relations of this type which have been specifically developed for power-reactor systems relatively recently are given in Refs. 45, 46, 65, and 66. Empirical correlations that contain duct length ${ }^{67}$ and/or inlet conditions as important variables should be viewed with suspicion with respect to general applicability. If it is at all possible, direct use of experimental data is to be preferred, but caution must be exercised in the judging of applicability of such data. The possibility of stability problems, especially with bulk boiling and with very small ducts, should be considered with respect to both laboratory data and the particular system to which such data are to be applied. For other than conceptual design studies, simulation experiments and/or large safety factors, chosen more or less arbitrarily, are essential. 
It is possible that applicable data can be found from the large number of experiments reported in the literature. Appendix Tables A and $B$ are offered to assist in finding such data, but they are by no means complete. It is hoped that in the near future a more detalled, indexed collection of data sources can be assembled, perhaps on punched cards. But again it must be remarked that caution must be exercised in the use of such data. The possibility of flow instability or other special features of the experiments must be anticipated. Special features of the flow loop, such as the existence of surge tanks, ${ }^{58}$ small channel volumes, ${ }^{57}$ and methods of introducing and mixing vapor and liquid at the channel inlet, ${ }^{48,54}$ should be investigated as possibly important. Such features, if part of the reactor flow loop, may require nearly exact simulation. Systems that circulate fluid by thermal or natural convection probably always require representation by simulation experiments. In general, there is a serious lack of data for nonuniform-heat generation, for duct shapes applicable to reactors, and for fluids other than water. Furthermore, methods of accounting for these deviations are highly uncertain, especially with bulk-boiling duct flows.

\section{REFERENCES}

1 J G Collier, Burnout in Liquid Cooled Reactors - 1, Nucl Pouer, 6: 61 (1961)

2 J G Collier, Burnout in Liquid Cooled Redetors-2, Nucl Pouer 6. 64 (1961)

3 A $F$ Pexton, A Review of Data on Burnout Heat Flux for Steam-Water Vixtures in Uniformly Heated Channels, British Report DEG-Report-203, Var 10,1961

$4 \mathrm{H}$ A Roberts and $\mathrm{R} \mathrm{W}$ Bowring, Boiling Effects in Liquid-cooled Reactors Aucl Pouer, 4(34). 69 (1959) and 4(35): 96 (1959)

j T B Drew and A C Mueller, Bolling, Trans AI Ch.E., 33. 449 (1937)

$6 \mathrm{~S}$ Vukiyama, Vaximum and Vinımum Values of Heat Transmitted from Vetal to Bolling Water Under Atmospheric Pressure, J. Soc Mech Engrs Japan, $37(206) \cdot 367$ (1934) (original not seen)

7 I Moscicki and $\mathrm{J}$ Broder, Spheroiddl State of Liquids on Heated Metallic Surfaces, Rocznık (hem 6: 321-354 (1926) (original not seen)

8 I E Ellion, A Study of the Vechanism of Bolling Hedt Transfer, USAEC Report JPL-Vemo-20-88, Calıfornıa Institute of Technology, Jet Propulsion Laboratory, Var 1, 1954

9 V T Cichelli and C F Bonilla, Heat Transfer to Liquids Bolling Under Pressure, A.I.Ch.E. J, 41755 (1945)

10 J. N Addoms, Sc D Thesis in Chemical Engineering, Massachusetts Inst 1 tute of Technology, 1948 (original not seen)

11 in $V$ Rohsenow and $P$ Griffith, Correlation of Vaximum Heat Transfer Data for Bolling of Saturated Liquids, Chcm Eng Progr Symp Ser 52(18) 47 (1956) 
12 S.S. Kutdteladze, A Hydrodynamic Theory of Changes in the Bolling Process Under Free Convection Conditions, Izl. Akad. Nalk S.S.S.R., Old. Tekhn. Nauk, 4 529-536 (1951) (original not seen).

13 S S Kutateladze, A Hydrodynamic Theory of Changes in the Bolling Process Under Free Convection Conditions, USAEC Translation AEC-tr-1441

$14 \mathrm{~N}$ Zuber and M. Tribus, Further Remarks on the Stability of Boiling Heat Transfer, USAEC Report AECU-3631, University of Calıfornı at Los Angeles, January 1958

15 N. Zuber, On the Stability of Bolling Heat Transfer, Trans. ASWE, 80: 711 (1958)

$16 \mathrm{~N}$ Zuber, Hydrodynamic Aspects of Bolling Heat Transfer, USAEC Report AECU-4439, University of California at Los Angeles, June 1959

$17 \mathrm{~N}$ Zuber, $\mathrm{M}$ Tribus, and J. W. Westwater, The Hydrodynamic Crisis in Pool Bolling of Saturated and Subcooled Liquids, in International Developments in Heat Transfer. Part II, p 230, American Society of Mechanical Engineers, New York, 1961

18 Y P. Chang and N. W. Snyder, Heat Transfer in Saturated Boiling, Chem. Eng. Prog? , Symp Ser., 56(30): 25 (1960)

19 R. Cole, Photographic Study of Pool Boiling in the Region of the Critical Flux, A.I.Ch.E. J., 61533 (1960) (description of Deissler's 1954 derivation gir en)

20 S L. Bragg and E I. Smith, Dimensional Analysis of Burnout Heat Transter, Intern J. Heat Mass Transfer, 3(3): 252 (1961)

21 P J Berenson, Transition Boıling Heat Transfer from a Horizontal Surface, Report NP-8415, Massachusetts Institute of Technology, Mar 1, 1960

$22 \mathrm{R}$ Moissis and P J Berenson, On the Hydrodynamic Transitions in Nucleate Boiling, J. Heat Fransfer, 85(3): 221-229 (August 1963)

$23 \mathrm{~J} M$ Addms, An Analysis of the Critical Heat Flux in Nucleate Boiling, presented at the A I.Ch E 50th Nationdl Meeting, Buffalo, N Y, May 1963, A I Ch E Pi eprint 131 (1963)

$24 \mathrm{~J}$ V Adams, A Studv of the Critical Heat Flux in an Accelerating Pool Bolling System, Report NSF-G-19697, 1962

$25 \mathrm{C} P$ Costello and $J$ M. Adams, Burnout Heat Fluxes in Pool Boiling at High Accelerations, in International Delelopments in Heat Transfer, Part II, p 255, American Society of Mechanical Engineers, New York, 1961

$26 \mathrm{C}$ P. Costello and J. M Adams, The Interrelation of Geometry Orientation and Acceleration in the Peak Heat Flux Problem, University of Washington, Department of Vechanical engineering Report, 1962.

27 C P Costello and $W$ E. Tuthill, Eftects of Acceleration on Nucleate Bolling, Chem Eng Progr., Symp Scr, 57(32): 189 (1961)

$28 \mathrm{H}$. J Irey, Acceleration and the Critical Hedt Flux in Pool Boiling Heat Transfer, Proc Inst Hech Engrs (London), 177(1): 15 (1963)

29 R C. Noyes, An Experimental Study of Sodium Pool Bolling Heat Transfer, USALC Report NAA-SR-6769, North American Alıation, Inc, Mar 30, 1962; also J Heat Transter, 85(2): 125-131 (May 1963)

30 L K Averin, The Lffect of the Material and of the Mechanical Treatment of the Surface on the Heat Exchange in the Bolling of Water, Izl Akad Nauk S.S.S.R., Otd. T eklir. Vauk, 3 116-122 (195t), also USAEC Franslation AERE-Lib/Trans-562, 1955. 
31. H. J. Ivey and D. J. Morris, The Effect of Test Section Parameters on Saturation Pool Bollıng Burnout at Atmospheric Pressure, British Report AEEW-R-176, April 1962

32 S. Ishigal, K. Inoue, Z. Kiwakı, and T. Ina1, Bolling Heat Transfer from a Flat Surface Facing Downward, in International Developments in Heat Transfer, Part II, p. 224, American Society of Mechanical Engineers, New York, 1961

33. E. A. Kazakova, Influence of Pressure on the Production of the First Crisis in the Bolling of Water on a Horizontal Plate, in Problems of Heat Transfer During a Change of State A Collection of Arizcles, S. S. Kutateladze (Ed.), Moscow-Lenıngrad, 1953; USAEC Translation AEC-tr-3405.

34 S. S Kutdteladze, Heat Transfer in Condensation and Boiling, 2nd ed, Moscow - Lenıngrad, 1952; USAEC Translation AEC-tr-3770.

35. W. R Gambill, Generalızed Predıctıon of Burnout Heat Flux for Flowing Subcooled Wetting Liquids, Chem Eng. Progr , Symp.Ser., 59(41): 71 (1963).

36. S. Levy, Prediction of the Critical Heat Flux in Forced Convection Flow, USAEC Report GEAP-3961, General Electric Company, Atomic Power Equipment Department, June 20, 1962 .

37 B A. Zenkevich, The Generalızation of Experimental Data on Critical Heat Fluxes in Forced Convection of Subcooled Water, J. Nucl. Energy Pt. B Reaclor Technology, 1: 130 (1959).

38. R. G. Vanderwater, Ph. D. Thesis in Chemical Engineering, University of Minnesota, 1956 (original not seen).

39. H. S Isbin et al, A Model for Correlating Two-phase Stedm Water, Burnout Heat Transfer Fluxes, Trans, ASME, Ser. C J. Heat Transfer, 83: 149 (1962)

40. F. E. Tippets, Critical Heat Flux and Flow Pattern Characteristics of High Pressure Boiling Water in Forced Convection, USAEC Report GEAP-3766, General Llectric Company, Atomic Power Equipment Department, April 1962; also ASME Preprints 62-WA-161 and 62-WA-162, 1962.

41 R P Stein, H. Firstenberg, S. Israel, M. Crane, and R. Hankel, Investıgation of Wet Steam as a Reactor Coolant (CAN-2), Vol. I., USAEC Report UNC-5008-I, United Nuclear Corporation, 1962.

42 K. Goldmann, H. Firstenberg, and C. Lombardı, Burnout in Turbulent Flow A Droplet Diffusion Model, Trans. ASME, Ser. C J Heat Transfer, 83: 158 (1962).

43. R A. DeBortoh, S. J. Green, B. W. LeTourneau, M. Troy, and A. Weiss, Forced-convection Heat Transfer Burnout Studies for Water in Rectangular Channels and Round Tubes at Pressures Above 500 Psia, USAEC Report WAPD-188, Westinghouse Electric Corporation, Bettıs Plant, October 1958

44 D. W. Bell, Correlation of Burnout Heat Transfer Data, Nucl. Sc . Eng., 7: $245(1960)$.

45 Pouer Reactor Fechnol., 5(2) 15 (1962); see also PWR Project Technical Progress Reports WAPD-MRP-92 and WAPD-MRP-93.

46 Westınghouse Electric Corporatıon, Bettıs Atomic Power Laboratory, Pressurized Water Reactor (PWR) Project Technical Progress Report for Perıod Feb 24, 1963, to Aprıl 23, 1963, USAEC Report WAPD-MRP-103.

47 H. S. Jacket, J D. Roarty, and J. E. Zerbe, Investigation of Burnout Heat Flux in Rectangular Channels at 2000 Psia, Trans. ASME, 80: 391 (1958) 
48 M Silvestrı, Two Phase (Steam and Water) Flow and Heat Transfer, in International Developments in Heat Transfer, Part $\Pi, \mathrm{p}$ 341, American Soc1ety of Mechanical Engineers, New York, 1961

$49 \mathrm{~K}$ M Becker, Burnout Conditions for Flow of Bolling Water in Vertical Rod Clusters, A I Ch E J 9 (2) 216 (1963)

50 R $T$ Jacobs and J A Merrill, The Application of Statistical Methods of Analysis for Predicting Burnout Heat Flux, Nucl Scı Eng, 8480 (1960)

51 R V MacBeth, Burnout Analysis Part 1 A Burn-out Correlation for Water in Round and Rectangular Channels Uniformly Heated at Varıous Pressures with Forced Convection, British Report AEEW-R-117, Nov 9, 1961

$52 \mathrm{R} \mathrm{H}$ Wilson and $\mathrm{J} \mathrm{K}$ Ferrell, Correlation of Critical Heat Flux for Boiling Water in Forced Circulation at Elevated Pressures, USAEC Report BAW168, Babcock \& Wilcox Company, Nov 6, 1961

$53 \mathrm{~J}$ Longo, Jr, A Statistical Study of Subcooled Burnout Including the Effect of Local Hot Spots, USAEC Report KAPL-1744, Knolls Atomic Power Laboratory Oct 22,1957

54 A W Bennett, J G Collıer, and P M C Lacey, Heat Transfer to Mixtures of High Pressure Steam and Water in an Annulus Part II The Effect of Steam Quality and Mass Velocity on the "Burnout" Heat Flux for an Internally Heated Unit at 1000 Psia, Britısh Report AERE-R-3804, August 1961

55 A W Bennett, J G Collier, and P M. C Lacey, Heat Transfer to Mixtures of High Pressure Steam and Water in an Annulus Part III The Effect of System Pressure on the Burn-out Heat Flux for an Internally Heated Unit, Britısh Report AERE-R-3934, March 1963

$56 \mathrm{~J} G$ Collier and $D \mathrm{~J}$ Pulling, Heat Transfer to Two-phase Gas-Liquid Systems Part II Further Data on Steam/Water Mixtures in the Liquid Dispersed Region in an Annulus, British Report AERE-R-3809, March 1962

$57 \mathrm{~W} \mathrm{H}$ Lowdermilk et al, Investigation of Boilıng Burnout and Flow Stability for Water Flowing in Tubes, Report NASA-TN-4382, National Aeronautics and Space Administration, 1958

58 I $\mathrm{T}$ Aladyev, $\mathrm{Z}$ L Miropolsky, $\mathrm{V}$ E Doroshchuk, and M A Stryrikovich Boiling Crisis in Tubes, in International Developments in Heat Transfer, Part II, p 237, American Society of Mechanıcal Engineers New York, 1961

59 E D Waters, J K Anderson, W L Thorne, and J M Batch, Experimental Observations of Upstream Bolling Burnout, USAEC Report HW-73902(Rer ) Hanford Atomic Products Operation, November 1962

$60 \mathrm{~J}$ G Collier, The Problem of Burnout in Liquid Cooled Nuclear Reactors, Britısh Report AERE-R-3698, June 1961

$61 E$ Bonjour, $J$ Verdier, and $L$ Wek, Improvement of Heat Exchanges in Boiling Liquids Under the Influence of an Electric Field, Chem Eng Progr, $58(7) \cdot 63(1962)$

62 M Markels, Jr, $\mathrm{R}$ L Durfee, and $\mathrm{R}$ Richardson, Methods to Increase Burnout Heat Transfer, Annual Progress Report, September 1959-August 1960, USAEC Report NYO-9500, Atlantic Research Corporation, Sept 30, 1960

63 M Markels, Jr, and R L Durfee, The Effect of Applıed Voltage on Boiling Heat Transfer, Annudl Progress Report, September 1960-February 1962, USAEC Report NYO-10345, Atlantic Research Corporation, June 1962 
64. H. F. Dobel, S. J. Green, and J. E. Zerbe, In-pile Heat Transfer Burnout Tests at the MTR, USAEC Report WAPD-LSR (1M)-2, Westinghouse Electric Corporation, Atomic Power Division, Aug. 9, 1955

65. E. Janssen and J. A. Kervinen, Subcooled Burnout at High Flows, USAEC Report GEAP-3843, General Electric Company, Atomic Power Equipment Department.

66 E. Janssen and S. Levy, Burnout Limit Curves for Bolling Water Reactors, Report APED-3892, General Electric Company, Atomic Power Equipment Department, Apr. 1, 1962.

$67 \mathrm{U} H$ von Glahn, An Empirical Correlation of Critical Boiling Heat Flux in Forced Flow Upward Through Uniformly Heated Tubes, Report NASA-TN-D1285, National Aerondutics and Space Administration, 1962

68 L Bernath, A Theory of Local Boiling Burnout and Its Application to Existing Data, Chem. Eng. Progr, Symp. Ser, 56(30): 95 (1960).

\section{APPENDIX:}

\section{BOILING BURNOUT DATA}

\section{Sources of Experimental Data}

Tables A and B and the list of data sources following the tables are intended to serve as an index to specific experimental data avallable in the literature, in accordance with our recommendation to use appropriate experimental data or empirical correlation of such data whenever possible. Table A covers subcooled boiling inducts, and Table B covers bulk bolling in ducts; the data are indexed according to fluid, pressure range, detalls of duct geometry, flow rate, and inlet and outlet subcooling or quality. Other details, when pertinent, are mentioned under "Remarks."

Although most of the information recorded in the tables was obtained directly from the data sources as listed, some of the sources were not immediately avallable and thus could not be consulted directly in the tıme available. In these cases, data compilations given in Refs. 43 and 68 were relied upon. There are also various data sources that we have seen at one time or noted as referenced in the literature, for which sufficient information could not be located in time for inclusion in the tables. A more nearly complete compilation of sources for boilingburnout data is currently being prepared at Argonne National Laboratory. 


\section{Information for the Use of Tables A and B}

The following notations, indicated in Tables A and B by the symbols $*, \dagger, \ddagger, \S$, and $\pi$ (corresponding to the symbols preceding the notations), consist of information necessary to the understanding of the tables:

* Specifications of flow direction and heat-flux distribution are included. Unless otherwise indicated, test section is vertical, flow direction is up, and heat-flux distribution is uniform. The following symbols are used:

$\begin{array}{ll}\mathrm{T} & \text { tube, circular } \\ \mathrm{AI} & \text { annulus, internally heated } \\ \mathrm{AE} & \text { annulus, externally heated } \\ \mathrm{AB} & \text { annulus, both sides heated } \\ \mathrm{R} & \text { rectangular or square duct } \\ \mathrm{RB}(x) & \text { rod bundle with } x \text { rods }\end{array}$

$\begin{array}{ll}\text { V } & \text { vertical } \\ \mathrm{H} & \text { horizontal } \\ \mathrm{I}(x) & \text { inclined } x^{\circ} \\ \mathrm{D} & \text { downflow } \\ \mathrm{U} & \text { upflow } \\ \mathrm{N} & \text { nonuniform flux } \\ & \text { (see "Remarks") }\end{array}$

\section{Examples:}

" $T$ " Indicates circular tube, vertical upflow, and uniform flux distrıbution.

“ $\mathrm{T} / \mathrm{I}(45) / \mathrm{U} / \mathrm{N}$ " indicates circular tube inclined $45^{\circ}$, upflow, and nonunform flux distribution.

† The following symbols are used:

ID inside diameter of tube or annular space

OD outside diameter of tube or annular space

RD rod diameter

S spacing

$\mathrm{L}$ heated length

W width

\$ Flow rates are given as one of the following mass velocity, G, in units of $\mathrm{lbm} /(\mathrm{hr})(\mathrm{sq} \mathrm{ft}) \times 10^{-6}$; inlet velocity, $\mathrm{V}$, in $\mathrm{ft} / \mathrm{sec}$; or mass flow rate, $W$, in $\mathrm{lbm} / \mathrm{sec}$.

$\$$ In some cases values of subcooling were not conveniently avallable. In these cases either temperature, $\mathrm{T}$, in ${ }^{\circ} \mathrm{F}$, or enthalpies, $\mathrm{H}$, in $\mathrm{Btu} / \mathrm{lbm}$ are given.

I The following symbols are used:

$$
\begin{aligned}
& \text { SC subcooling, }{ }^{\circ} \mathrm{F} \quad \mathrm{T} \text { temperature, }{ }^{\circ} \mathrm{F} \\
& \mathrm{x} \text { quality, } \% \quad \mathrm{H} \text { enthalpy, Btu/lbm }
\end{aligned}
$$


Table A-SUBCOOLF D BOILING IN DUC IS

\begin{tabular}{|c|c|c|c|c|c|c|c|c|}
\hline Fluid & $\begin{array}{l}\text { Pressure } \\
\text { I ange, } \\
\text { atm }\end{array}$ & $\begin{array}{c}\text { Duct } \\
\text { geometry* }\end{array}$ & $\begin{array}{c}\text { Duct } \\
\text { dimensions, } \dagger \\
\text { in }\end{array}$ & & $\begin{array}{l}\text { Flow } \\
\text { rate } \neq\end{array}$ & $\begin{array}{c}\text { Outlet } \\
\text { subcooling, } \$ \\
{ }^{\circ} \mathrm{F}\end{array}$ & Remarks & $\begin{array}{l}\text { Ddta } \\
\text { source }\end{array}$ \\
\hline Water & 1 & AI & $\begin{array}{rll}\mathrm{S} & 0 & 25 \\
\mathrm{ID} & 0 & 25 \\
\mathrm{~L} & 5 & 5\end{array}$ & $\mathrm{~V}$ & $16-62$ & $16-28$ & $\begin{array}{l}\text { Fffect of ultrasonic } \\
\text { vibrations studied }\end{array}$ & $\mathrm{R}-2$ \\
\hline Water & 1 & Cylinder $/ \mathrm{H}$ & $\begin{array}{rll}\text { OD } & 0 & 125 \\
\text { L } & 8\end{array}$ & $\mathrm{~V}$ & $12-95$ & $\begin{array}{l}\text { Netrly satu } \\
\text { rated }\end{array}$ & $\begin{array}{l}\text { I low normal to } \\
\text { cylinder }\end{array}$ & $V-2$ \\
\hline Water & 1 & Cylinder $/ \mathrm{H}$ & 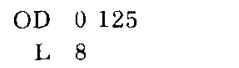 & $\mathrm{V}$ & $05-11$ & $3-100$ & $\begin{array}{l}\text { I low normil to } \\
\text { cylinder }\end{array}$ & V 3 \\
\hline Water & 1 & Wires & 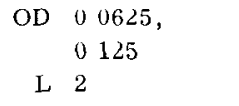 & $\mathrm{V}$ & $26-123$ & $44-164$ & Flow normal and up & w -2 \\
\hline Water & 1 & $\begin{array}{l}\text { Crossed rod } \\
\text { matrixes } / \mathrm{H}\end{array}$ & $\begin{array}{rll}\mathrm{RD} & 0 & 125 \\
\mathrm{~L} & 6 & 6\end{array}$ & G & $063-21$ & $70-180$ & Only one rod heated & $\mathrm{K}-1$ \\
\hline Water & $1-2$ & $\operatorname{Rod} / \mathrm{H}$ & 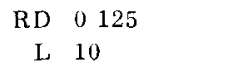 & G & $022-153$ & $80-140$ & Flow normal to rod & $\mathrm{K}-2$ \\
\hline Water & $1-4$ & $\mathrm{AI} / \mathrm{N}$ & $\begin{array}{rll}\text { ID } & 0 & 25 \\
\text { OD } & 0 & 6-25 \\
\text { L } & 3\end{array}$ & $\mathrm{~V}$ & $1-5$ & $50-100$ & $\begin{array}{l}\text { Simultaneous cooling } \\
\text { by secondary fluid }\end{array}$ & $\mathrm{E}-1$ \\
\hline Water & $1-8$ & $\Gamma$ and $\Gamma / \mathrm{N}$ & $\begin{array}{rrr}\text { ID } & 0 & 21 \\
\text { L } & 8 & 75\end{array}$ & G & $225-666$ & $10-50$ & $\begin{array}{l}\text { Includes step in- } \\
\text { cre ist of flux of } \\
\text { various magnı } \\
\text { tudes at outlet }\end{array}$ & L 4 \\
\hline Water & $1-8$ & Ribbon/H & $\begin{array}{l}0004 \times 0125 \times 6 \\
\text { (ribbon) }\end{array}$ & $\mathrm{V}$ & $5-40$ & $22-280$ & $\begin{array}{l}\text { Small ribbon in rec } \\
\text { tangulur duct }\end{array}$ & $G-6$ \\
\hline Water & $1-22$ & $\begin{array}{l}\mathrm{AI}, \mathrm{AI} / \mathrm{D} \text {, and } \\
\mathrm{AI} / \mathrm{H}\end{array}$ & $\begin{array}{rlll}\mathrm{S} & 0 & 02-0 & -022 \\
\mathrm{ID} & 0 & 06-0 & -0 \\
\mathrm{~L} & 2-2 & 4\end{array}$ & $\mathrm{~V}$ & $6-42$ & $25-250$ & Note smill sires & $\mathrm{C}-1$ \\
\hline Water & $1-37$ & $\begin{array}{l}\Gamma / \mathrm{H} \text { and } \mathrm{T} / \mathrm{H} \\
\quad(\mathrm{swirl})\end{array}$ & 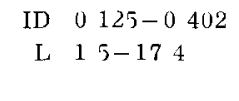 & V & $17-195$ & $0-260$ & $\begin{array}{l}\text { Internal flow guides } \\
\text { to produce swirl } \\
\text { flow }\end{array}$ & G 3 \\
\hline
\end{tabular}


I able A-- (Contmued)

\begin{tabular}{|c|c|c|c|c|c|c|c|c|}
\hline Fluid & $\begin{array}{l}\text { Pressure } \\
\text { range, } \\
\text { atm }\end{array}$ & $\begin{array}{l}\text { Duct } \\
\text { geometry* }\end{array}$ & $\begin{array}{c}\text { Duct } \\
\text { dimensions, } \dagger \\
\text { in }\end{array}$ & & $\begin{array}{l}1 \text { low } \\
\text { rateł }\end{array}$ & $\begin{array}{c}\text { Outlet } \\
\text { subcooling, } \\
{ }^{\circ} /\end{array}$ & Remarks & $\begin{array}{c}\text { Data } \\
\text { source }\end{array}$ \\
\hline Water & 1758 & $\mathrm{R} / \mathrm{D}$ and $\mathrm{AI} / \mathrm{D}$ & 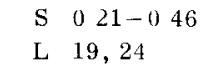 & V & $5-45$ & $11-135$ & One side heited & M-9 \\
\hline Water & $18-47$ & $\mathrm{AI} / \mathrm{D} / \mathrm{N}$ & $\begin{array}{rll}\text { S } & 0 & 25-0 \\
\text { ID } & 1 & 1 \\
\text { L } & 168\end{array}$ & v & $65-28$ & T $176-230$ & $\begin{array}{l}\text { Cosine flux distribu } \\
\text { tion }\end{array}$ & C 3 \\
\hline Water & 2 & $\Gamma / \mathrm{H}$ & 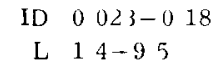 & V & $10-20$ & $30-70$ & $\begin{array}{l}\text { Note smill tube } \\
\text { drameter }\end{array}$ & B 4 \\
\hline Water & 2 & $\mathrm{RB}(4)$ & 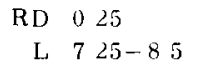 & $\mathrm{v}$ & $0-379$ & $0-11$ & $\begin{array}{l}\text { In box } 12, \times 125 \mathrm{in} \\
\text { nitural consection }\end{array}$ & J 6 \\
\hline Water & $2-6$ & AI & 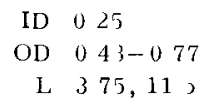 & v & $1-12$ & $20-100$ & & $M 1-6$ \\
\hline Water & $2-8$ & $\mathrm{AI} / \mathrm{D}$ and $\mathrm{AI} / \mathrm{U}$ & $\begin{array}{rll}\text { S } & 0 & 125 \\
\text { ID } & 0 & 5 \\
\text { L } & 6\end{array}$ & $\mathrm{v}$ & $5-42$ & $10-90$ & & S-1 \\
\hline Water & $24-48$ & $\mathrm{R} / \mathrm{D}$ & $\begin{array}{rlll}\mathrm{S} & 0 & 12-0 & 25 \\
\mathrm{~W} & 0 & 154 \\
\mathrm{~L} & 1,2\end{array}$ & $\mathrm{v}$ & $18-33$ & $36-70$ & $\begin{array}{l}\text { Effect of insulating } \\
\text { ribs studied, only } \\
\text { one side hedted }\end{array}$ & M 10 \\
\hline Water & 34 & $\mathrm{AI} / \mathrm{D}$ & $\begin{array}{rlll}\text { S } & 0 & 12-0 & 25 \\
\text { ID } & 0 & 5 \\
\text { L } & 24\end{array}$ & $\mathrm{~V}$ & $10-28$ & $19-70$ & $\begin{array}{l}\text { Roughing of surface } \\
\text { by knurling }\end{array}$ & D- 10 \\
\hline Water & $4-95$ & $\mathrm{R}$ & $\begin{array}{l}01 \times 25 \times 18 \\
\text { and } 36\end{array}$ & V & $6-53$ & $90-200$ & & $\mathrm{~L}-7$ \\
\hline Water & $4-82$ & $\mathrm{AI} / \mathrm{D}$ & 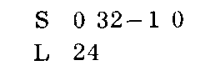 & V & $8-38$ & $45-157$ & & D-9 \\
\hline Water & 68 & $\mathrm{~T} / \mathrm{D}$ & $\begin{array}{rll}\text { ID } & 0 & 250 \\
\text { L } & 3 & 12\end{array}$ & G & $11-29$ & $193-237$ & Swirl flow studied & o-1 \\
\hline Water & $10-68$ & $\mathrm{~T} / \mathrm{D}$ & $\begin{aligned} \text { ID } & 032-087 \\
\text { L } & 24\end{aligned}$ & $\mathrm{~V}$ & $10-38$ & $40-140$ & & $\mathrm{D}-7$ \\
\hline
\end{tabular}




\begin{tabular}{|c|c|c|c|c|c|c|c|c|c|}
\hline Water & $11-39$ & $\mathrm{R} / \mathrm{D}$ & $\begin{array}{l}S \\
L\end{array}$ & $\begin{array}{l}0.043-0057 \\
12,18\end{array}$ & $\mathrm{v}$ & $10-85$ & $26-64$ & & $\mathrm{G}-1$ \\
\hline Water & 13.6 & $\mathbf{T}$ & $\begin{array}{l}\text { ID } \\
\text { L }\end{array}$ & $\begin{array}{l}0045 \\
45\end{array}$ & G & $48-118$ & $0-25$ & Stability problems & W-4 \\
\hline Water & $17-136$ & $\mathbf{T}$ & $\begin{array}{r}\text { ID } \\
\text { L }\end{array}$ & $\begin{array}{l}0.12 \\
6\end{array}$ & G & $0183-0265$ & $4-81$ & $\begin{array}{l}\text { Stability study in- } \\
\text { cluded }\end{array}$ & $\mathrm{L}-6$ \\
\hline Water & 20 & $\mathrm{AI} / \mathrm{N}$ & $\begin{array}{l}\text { S } \\
\text { ID } \\
\text { L }\end{array}$ & $\begin{array}{l}0.168 \\
0.54 \\
108\end{array}$ & $\mathrm{~W}$ & $06-1$ & $90-365$ & Cosine flux & $C-5$ \\
\hline Water & $20-200$ & $\mathrm{~T}$ & $\begin{array}{l}\text { ID } \\
\text { L }\end{array}$ & $\begin{array}{l}031 \\
1.4-52\end{array}$ & $\mathrm{~V}$ & $3-26$ & T $335-695$ & $\begin{array}{l}\text { Instability at low } \\
\text { flows and pressure }\end{array}$ & $A-4$ \\
\hline Water & $20-200$ & $\mathrm{~T}$ & $\begin{array}{r}\text { ID } \\
\mathrm{L}\end{array}$ & $\begin{array}{l}031 \\
4.7-60\end{array}$ & G & $0.3-1.6$ & & Instability studied & $A-3$ \\
\hline Water & $34-68$ & AI & $\begin{array}{r}\text { S } \\
\text { ID } \\
\text { L }\end{array}$ & $\begin{array}{l}033 \\
2.25 \\
40\end{array}$ & $\mathrm{~V}$ & $1.5-24$ & $4-61$ & $\begin{array}{l}\text { Effect of dissolved } \\
\text { He studied }\end{array}$ & $M-16$ \\
\hline Water & $34-136$ & $\mathrm{~T}$ & $\begin{array}{r}\text { ID } \\
\text { L }\end{array}$ & $\begin{array}{l}0.25 \\
25\end{array}$ & G & $096-2.65$ & $0-236$ & $\begin{array}{l}\text { Effect of dissolved } \\
\text { air studied }\end{array}$ & B-11 \\
\hline Water & $34-136$ & $\mathrm{~T}$ & $\begin{array}{r}\text { ID } \\
\text { L }\end{array}$ & $\begin{array}{l}0.226 \\
25\end{array}$ & G & $0.96-7.6$ & $6-160$ & & $T-2$ \\
\hline Water & $34-136$ & $\mathrm{~T}$ & $\begin{array}{r}\text { ID } \\
\mathrm{L}\end{array}$ & $\begin{array}{l}0.143-0226 \\
3,246\end{array}$ & G & $096-78$ & $55-163$ & & $\mathrm{~J}-8$ \\
\hline Water & $41-136$ & $\mathrm{R}$ & 0.07 & $0 \times 225 \times 72$ & G & $038-40$ & $0-15$ & & $\mathrm{~T}-6$ \\
\hline Water & 68 & AI & $\begin{array}{r}\mathrm{S} \\
\mathrm{ID} \\
\mathrm{L}\end{array}$ & $\begin{array}{l}033 \\
225 \\
40\end{array}$ & v & $10-20$ & $5-126$ & $\begin{array}{l}\text { Effect of dissolved } \\
\text { He studied }\end{array}$ & $M-15$ \\
\hline Water & 68 & $\begin{array}{l}\mathrm{AI}+\mathrm{T}(\mathrm{see} \\
\text { remarks) }\end{array}$ & $\begin{array}{r}\text { S } \\
\text { ID } \\
\text { L }\end{array}$ & $\begin{array}{l}042 \\
\sim 2 \\
77\end{array}$ & G & $05-2$ & $0-14$ & $\begin{array}{l}\text { Coolant flow through } \\
\text { Inside and outside } \\
\text { of tubular heater }\end{array}$ & $M-18$ \\
\hline Water & 68 & $\begin{array}{r}\mathrm{AI}+\mathrm{T}(\mathrm{see} \\
\text { remarks) }\end{array}$ & $\begin{array}{r}\text { S } \\
\text { ID } \\
\text { L }\end{array}$ & $\begin{array}{l}0.42 \\
\sim 2 \\
40\end{array}$ & G & $0.5-2.3$ & $0-42$ & $\begin{array}{l}\text { Coolant flow through } \\
\text { inside and outside } \\
\text { of tubular heater }\end{array}$ & $M-17$ \\
\hline Water & 68 & $\mathrm{RB}(7)$ & $\begin{array}{r}\mathrm{RD} \\
\mathrm{L}\end{array}$ & $\begin{array}{l}055 \\
37\end{array}$ & G & $0.6-1.0$ & $0-5$ & $\begin{array}{l}\text { Rods in } 199-1 n .- \text { ID } \\
\text { tube }\end{array}$ & $M-12$ \\
\hline
\end{tabular}

(Table continues on following page) 
I uble $A-$ (Continued)

\begin{tabular}{|c|c|c|c|c|c|c|c|c|c|}
\hline Fluid & $\begin{array}{l}\text { Prensure } \\
\text { inge, } \\
\text { atm }\end{array}$ & $\begin{array}{l}\text { Duct } \\
\text { stometry* }\end{array}$ & & $\begin{array}{l}\text { Duct } \\
\text { minsions, } † \\
\text { in }\end{array}$ & & $\begin{array}{l}\text { I low } \\
\text { I datef }\end{array}$ & $\begin{array}{c}\text { Outlet } \\
\text { subcoolins } \$ \\
{ }^{\circ} \mathrm{H}\end{array}$ & Remarks & $\begin{array}{l}\text { Data } \\
\text { source }\end{array}$ \\
\hline Water & $68-95$ & AI & $\begin{array}{r}\text { S } \\
\text { ID } \\
\mathrm{L}\end{array}$ & $\begin{array}{l}0125-025 \\
05 \\
29,36\end{array}$ & G & $2-6$ & $0-50$ & & $\mathrm{~J}-7$ \\
\hline Water & $68-95$ & AI & $\begin{array}{r}S \\
\text { ID } \\
L\end{array}$ & $\begin{array}{l}0125-025 \\
050 \\
29,36\end{array}$ & G & $04-6$ & $1-36$ & & W 10 \\
\hline Water & $68-204$ & $\Gamma$ & $\begin{array}{l}\text { ID } \\
\text { L }\end{array}$ & $\begin{array}{r}0143 \\
3-24\end{array}$ & G & $?-8$ & $0-150$ & & $M-8$ \\
\hline Water & $69-104$ & $\mathrm{~T}$ & $\begin{array}{c}\text { ID } \\
\mathrm{L}\end{array}$ & $\begin{array}{l}018 \\
9\end{array}$ & $\mathrm{G}$ & $189-213$ & $48-149$ & & R 1 \\
\hline Water & 82 & $\mathrm{RB}(19)$ & $\begin{array}{r}\mathrm{RD} \\
\mathrm{L}\end{array}$ & $\begin{array}{l}056-059 \\
19\end{array}$ & G & $05-4$ & $0-116$ & & $\mathrm{~B}-8$ \\
\hline W ater & 82 & RB (19) & $\begin{array}{r}\mathrm{RD} \\
\mathrm{S} \\
\mathrm{L}\end{array}$ & $\begin{array}{l}056,063 \\
0015-0074 \\
185-76\end{array}$ & $\mathrm{G}$ & $05-5$ & $0-148$ & & W -9 \\
\hline Water & $102-187$ & $\mathrm{~T}$ & $\begin{array}{c}\text { ID } \\
\text { I }\end{array}$ & $\begin{array}{l}0075 \\
6,27\end{array}$ & G & $14-312$ & $10 \quad 80$ & Note smull ID & $\mathrm{H} 2$ \\
\hline Water & 136 & $\Gamma / N$ & $\begin{array}{l}\text { ID } \\
\text { L }\end{array}$ & $\begin{array}{l}0152 \\
125\end{array}$ & G & 0215 & $0-75$ & $\begin{array}{l}\text { Heating with } \mathrm{NaK} \text {, } \\
\text { dat a at lowe } \mathrm{r} \text { pres } \\
\text { sure obtalned but } \\
\text { not reported }\end{array}$ & $\mathrm{M}-7$ \\
\hline Water & 136 & $\Gamma$ & $\begin{array}{c}\text { ID } \\
\text { L }\end{array}$ & $\begin{array}{l}03-044 \\
18\end{array}$ & G & $0126-20$ & $0-315$ & $\begin{array}{l}\text { Possible stability } \\
\text { pioblems }\end{array}$ & W 3 \\
\hline II tter & 136 & I & $\begin{array}{c}\text { II) } \\
\text { I }\end{array}$ & $\begin{array}{l}018 t \\
12\end{array}$ & $G_{1}$ & $11-21$ &, $5-110$ & $\begin{array}{l}\text { I flect of dissolied } \\
\text { hydionen }\end{array}$ & D -1 \\
\hline Water & 136 & I & $\begin{array}{c}\text { ID } \\
\text { I }\end{array}$ & $\begin{array}{l}0186 \\
12\end{array}$ & 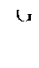 & $096-42$ & $2-19$ & & M 2 \\
\hline Wrter & 136 & $\begin{array}{l}I \text { and } I / I \\
(45) / U\end{array}$ & $\begin{array}{c}\text { ID } \\
\mathrm{L}\end{array}$ & $\begin{array}{l}0187 \\
12,\end{array}$ & $G$ & $0.377-776$ & $3-161$ & & $\mathrm{H} 2$ \\
\hline Water & 136 & I ind insert & $\begin{array}{c}\text { ID } \\
\text { I }\end{array}$ & $\begin{array}{l}031 \\
18\end{array}$ & $G$ & $0,-20$ & 07 & $\begin{array}{c}\text { Insert to produce } \\
\text { swinl flow }\end{array}$ & V 1 \\
\hline
\end{tabular}




\begin{tabular}{|c|c|c|c|c|c|c|c|c|}
\hline Water & 136 & $\mathrm{R}$ & $\begin{array}{l}0055 \times 1 \times 12 \\
0097 \times 1 \times 27\end{array}$ & $G_{3}$ & $02-15$ & $0-14$ & & $\begin{array}{l}J-3 \\
J-4\end{array}$ \\
\hline Water & 136 & $\mathrm{R}$ & $0078 \times 15 \times 54$ & $G$ & 013018 & $0-90$ & $\begin{array}{l}\text { Parallel lectangulior } \\
\text { ch annels }\end{array}$ & $W-7$ \\
\hline Water & 136 & $\mathbf{R}$ & $0087 \times 10 \times 12$ & G & 0223 & $2-21$ & & D-5 \\
\hline Water & 136 & $\mathrm{R}$ & $0097 \times 1 \times 27$ & G & $01-17$ & 1) 80 & & $\mathrm{~T}-3$ \\
\hline Water & 136 & $\mathrm{R} / \mathrm{N}$ & $0097 \times 1 \times 27$ & G & $075-1.99$ & $27-85$ & $\begin{array}{l}\text { Short step rise of } \\
\text { heat flux at exit } \\
\text { equal to } 2 \times \text { av. } \\
\text { flux }\end{array}$ & $W-6$ \\
\hline Water & 136 & $\mathrm{R} 13(9)$ & $\begin{aligned} \text { RD } & 0.413 \\
\text { L } & 9\end{aligned}$ & $G$ & $07-20$ & 0) 80 & $\begin{array}{l}\text { I ubes filled with ce- } \\
\text { ramic rods, all data } \\
\text { points below criti- } \\
\text { cal }\end{array}$ & $\mathrm{G}-5$ \\
\hline Water & $140-210$ & $\mathrm{r} / \mathrm{U}$ and $\mathrm{T} / \mathrm{D}$ & $\begin{array}{rl}\text { ID } & 016-047 \\
\mathrm{~L} & 13,26\end{array}$ & G & $06-36$ & $18-180$ & & $7-1$ \\
\hline Water & $180-210$ & $\begin{array}{l}\mathrm{RB}(7) \\
\mathrm{RB}(19)\end{array}$ & $\begin{array}{ccc}\mathrm{RD} & \sim 0 & 2 \\
\mathrm{~L} & 33\end{array}$ & V & $2-15$ & $6-22$ & & $\angle-2$ \\
\hline Ammonia & $11-87$ & $\Gamma$ & & V & $12-82$ & $0-200$ & & D-4 \\
\hline Anmonld & $11.5-124$ & 1 & $\begin{array}{rll}\text { ID } & 0 & 16,023 \\
\text { L } & 3 & 15\end{array}$ & $\mathrm{~V}$ & $3-156$ & $3-208$ & & $N-3$ \\
\hline $\begin{array}{l}\text { Ethylene } \\
\text { glycol }\end{array}$ & $14-19$ & $\begin{array}{l}1 / \mathrm{H} \text { and } \mathrm{T} / \mathrm{H} \\
\text { (swirl) }\end{array}$ & 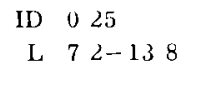 & V & $17-97$ & $77-426$ & $\begin{array}{l}\text { Internal flow guides } \\
\text { to produce suirl } \\
\text { flow }\end{array}$ & $\mathrm{G}-2$ \\
\hline Hydra/me & $2-5$ & I & & $\mathrm{V}$ & $13-120$ & $102-473$ & & $\mathrm{H}-1$ \\
\hline Hydrd/ine & 6 $8-82$ & $\Gamma$ & $\begin{array}{rll}\text { ID } & 0 & 23 \\
\text { L } & 2 & 0-435\end{array}$ & $\mathrm{~V}$ & $1-93$ & $98-506$ & $\begin{array}{c}\text { Also tests with } 90^{\prime} \\
\text { hydrd/ine }-10^{\prime} / \\
\text { ethyl'nediamine }\end{array}$ & $N-2$ \\
\hline $\begin{array}{l}\text { Hydrd/ine } \\
\text { mixture }\end{array}$ & $37-75$ & 1 & $\begin{array}{rll}\text { ID } & 0 & 23 \\
\text { L } & 3.0\end{array}$ & V & $30-90$ & I $\quad 140-200$ & & $\mathrm{~W}-8$ \\
\hline $\begin{array}{l}\text { Nitrogen } \\
\text { tctroxide }\end{array}$ & $10-41$ & $\Gamma$ & $\begin{array}{cll}\text { ID } & 0 & 18 \\
\text { L } & 3\end{array}$ & V & $10-60$ & $0-200$ & & $B-6$ \\
\hline Polyphenols & $14-27$ & Al & $\begin{array}{rll}\text { ID } & 0 & 46 \\
\mathrm{~S} & 0 & 15 \\
\mathrm{~L} & 20\end{array}$ & V & $05-17$ & $0-328$ & & $C-4$ \\
\hline
\end{tabular}


Table B-BULK IBOII ING IN DUCTS

\begin{tabular}{|c|c|c|c|c|c|c|c|c|c|c|c|}
\hline Гluıd & $\begin{array}{l}\text { Pressure } \\
\text { range } \\
\text { atm }\end{array}$ & $\begin{array}{l}\text { Duct } \\
\text { grometry* }\end{array}$ & & $\begin{array}{l}\text { Duct } \\
\text { in }\end{array}$ & & $\begin{array}{l}\text { I low } \\
\text { rate }\end{array}$ & & $\begin{array}{l}\text { Inlet } \\
\text { onditions } \pi\end{array}$ & $\begin{array}{c}\text { Outlet } \\
\text { quality } \\
\%\end{array}$ & Remarks & $\begin{array}{l}\text { Data } \\
\text { source }\end{array}$ \\
\hline Hater & $066-2$ & $\begin{array}{l}\mathrm{T} / \mathrm{H} \text { and } \mathrm{T} / \mathrm{H} \\
\quad \text { (sw1rl) }\end{array}$ & $\begin{array}{c}\text { ID } \\
\text { I }\end{array}$ & $\begin{array}{l}0125-025 \\
11-12\end{array}$ & V & $17-170$ & $\mathrm{SC}$ & & $0-17$ & $\begin{array}{l}\text { Internal flow } \\
\text { guides to pro- } \\
\text { duce swirl } \\
\text { flow }\end{array}$ & $G-3$ \\
\hline Water & 1 & $\begin{array}{l}\mathrm{T} \\
\mathrm{AI}\end{array}$ & $\begin{array}{c}\text { ID } \\
\mathrm{I} \\
\mathrm{S} \\
\mathrm{ID} \\
\mathrm{I}\end{array}$ & $\begin{array}{l}039-079 \\
42 \\
039 \\
043 \\
32\end{array}$ & V & $05-26$ & $\mathrm{SC}$ & & $0-100$ & $\begin{array}{l}\text { Effect of swirl } \\
\text { flow studied }\end{array}$ & $F-2$ \\
\hline Water & 1 & $\begin{array}{l}\mathrm{R} \text { and } \mathrm{R} / \mathrm{I} \\
(145) / \mathrm{U}\end{array}$ & I & $\begin{array}{l}0087 \\
4-40\end{array}$ & V & $01-03$ & $\mathrm{SC}$ & & $26-100$ & $\begin{array}{l}\text { Flow stratifica- } \\
\text { tion with in- } \\
\text { clined tests }\end{array}$ & $J-9$ \\
\hline Water & $1-7$ & $\mathrm{~T}$ & $\begin{array}{c}\text { ID } \\
1\end{array}$ & $\begin{array}{l}0.051-0188 \\
2.5-47\end{array}$ & V & $01-98$ & $\mathrm{SC}$ & $0-140$ & $0-100^{+}$ & $\begin{array}{l}\text { Stability study } \\
\text { included, note } \\
\text { small drame- } \\
\text { ter }\end{array}$ & $L-5$ \\
\hline Water & $1-136$ & $\mathrm{~T}$ & $\begin{array}{c}\text { ID } \\
\mathbf{I}\end{array}$ & $\begin{array}{l}004-012 \\
1-6\end{array}$ & $\mathrm{G}$ & $0 \quad 02-4.2$ & $\mathrm{SC}$ & $14-476$ & $1-93$ & $\begin{array}{l}\text { Stability study } \\
\text { included, note } \\
\text { small diame- } \\
\text { ter }\end{array}$ & $L-6$ \\
\hline Wat $\in \mathrm{r}$ & 2 & $\mathrm{~T} / \mathrm{H}$ & $\begin{array}{c}\text { ID } \\
\mathrm{L}\end{array}$ & $\begin{array}{l}0.023-018 \\
14-95\end{array}$ & $\mathrm{~V}$ & $10-20$ & $\mathrm{SC}$ & & $0-11$ & $\begin{array}{l}\text { Note small } \\
\text { didmeter }\end{array}$ & B-4 \\
\hline Wat $\in \mathbf{r}$ & 2 & $\mathrm{RB}(4)$ & $\begin{array}{c}\mathrm{RD} \\
\mathrm{L}\end{array}$ & $\begin{array}{l}025 \\
725-85\end{array}$ & V & $0-38$ & $\mathrm{SC}$ & & $0-20$ & $\begin{array}{l}\text { In box } 125 \times \\
125 \mathrm{ln}\end{array}$ & $J-6$ \\
\hline Water & $2-7$ & $\mathrm{~T} / \mathrm{H}$ & $\begin{array}{c}\text { ID } \\
\text { I }\end{array}$ & $\begin{array}{l}063 \\
39\end{array}$ & $\mathrm{~V}$ & $1-25$ & $\mathrm{SC}$ & & $\sim 0^{+}$ & & $S-5$ \\
\hline$u a t \in r$ & $2-10$ & $\mathrm{RB}(3)$ & $\begin{array}{c}\mathrm{RD} \\
1 \\
\mathrm{~S}\end{array}$ & 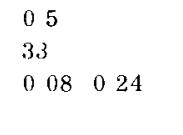 & W & $0 \quad 07-07$ & $\mathrm{~T}$ & $153-178$ & $3-52$ & $\begin{array}{l}\text { Operation with } \\
\text { constant heat } \\
\text { flux and dc- } \\
\text { creasing flow }\end{array}$ & $B-1$ \\
\hline
\end{tabular}




\begin{tabular}{|c|c|c|c|c|c|c|c|c|c|c|c|}
\hline Water & $2-42$ & $\mathrm{~T}$ & $\begin{array}{c}\text { ID } \\
\mathrm{L}\end{array}$ & $\begin{array}{l}016-039 \\
41-123\end{array}$ & G & $01-14$ & $\mathrm{SC}$ & & $0-100$ & $\begin{array}{l}\text { Operation with } \\
\text { constant heat } \\
\text { flux and de- } \\
\text { creasing flow }\end{array}$ & B-9 \\
\hline Water & $55-95$ & $\mathrm{AI}$ & $\begin{array}{l}\text { S: } \\
\text { ID } \\
\text { L }\end{array}$ & $\begin{array}{l}0.12 \\
0625 \\
40\end{array}$ & $\mathrm{G}$ & $075-1.9$ & $\mathrm{SC}$ & & $0-95$ & & $\mathrm{P}-1$ \\
\hline Water & $8-36$ & $\begin{array}{l}A I, A E \\
A B\end{array}$ & $\begin{array}{r}\text { S } \\
\text { ID } \\
\text { L }\end{array}$ & $\begin{array}{l}015 \\
0.39 \\
24\end{array}$ & G & $005-07$ & $\mathrm{SC}$ & & $10-90$ & $\begin{array}{l}\text { Operation with } \\
\text { constant heat } \\
\text { flux and de- } \\
\text { creasing flow }\end{array}$ & B- 10 \\
\hline Water & 136 & $\mathrm{~T}$ & $\begin{array}{c}\text { ID } \\
\mathrm{L}\end{array}$ & $\begin{array}{l}0.045 \\
4.5\end{array}$ & G & $48-11.8$ & $\mathrm{SC}$ & & $0-33$ & $\begin{array}{l}\text { Stability prob- } \\
\text { lems }\end{array}$ & $W-4$ \\
\hline Water & $13.6-85$ & $A I$ & $\begin{array}{r}\mathrm{S} \\
\mathrm{ID} \\
\mathrm{L}\end{array}$ & $\begin{array}{l}0085-0125 \\
0375 \\
29\end{array}$ & $\mathrm{G}$ & $05-33$ & $\mathrm{x}$ & $0-69$ & $5-85$ & $\begin{array}{l}\text { Special steam- } \\
\text { water mixing } \\
\text { drrangement } \\
\text { at inlet }\end{array}$ & B-3 \\
\hline Water & $26-180$ & $\mathrm{~T}$ & $\begin{array}{c}\text { ID } \\
\text { L }\end{array}$ & $\begin{array}{l}012 \\
1.4,6\end{array}$ & G & $063-2.2$ & $\mathrm{SC}$ & & $0-90$ & & S-3 \\
\hline Wat $\in r$ & $34-102$ & $\mathrm{~T}$ & $\begin{array}{c}\text { ID } \\
\text { L }\end{array}$ & $\begin{array}{l}018 \\
9\end{array}$ & $\mathrm{G}$ & $086-213$ & $\mathrm{SC}$ & $5-285$ & $3-47$ & & $\mathrm{R}-1$ \\
\hline Water & $34-136$ & $\mathrm{~T}$ & $\begin{array}{c}\text { ID } \\
\text { L }\end{array}$ & $\begin{array}{l}0143,0226 \\
3 \quad 246\end{array}$ & $\mathrm{G}$ & $089-52$ & $\mathrm{SC}$ & $04-434$ & $07-37$ & & $J-8$ \\
\hline Water & $34-136$ & $\mathrm{~T}$ & $\begin{array}{c}\text { ID } \\
\text { L }\end{array}$ & $\begin{array}{l}0.18 \\
9.4\end{array}$ & $\mathrm{G}$ & $002-0 \quad 075$ & $\mathrm{SC}$ & $39-540$ & $0-98$ & & C-2 \\
\hline Water & $37-136$ & $\mathrm{~T}$ & $\begin{array}{c}\text { ID } \\
\text { L }\end{array}$ & $\begin{array}{l}0.18,031 \\
116-232\end{array}$ & $\mathrm{G}$ & $0.166-634$ & $\mathrm{SC}$ & $0-361$ & $02-79$ & $\begin{array}{l}\text { Instabilities } \\
\text { noted at lower } \\
\text { pressures }\end{array}$ & $W-5$ \\
\hline Water & 40 & AI & $\begin{array}{l}\mathrm{S} \\
\mathrm{ID} \\
\mathrm{L}\end{array}$ & $\begin{array}{l}023-045 \\
03-063 \\
72\end{array}$ & G & $0.32-2.6$ & $\mathrm{SC}$ & $4-114$ & $0-35$ & $\begin{array}{l}\text { Includes tests } \\
\text { with step } \\
\text { change in ID }\end{array}$ & $\mathrm{N}-1$ \\
\hline Water & $40-82$ & $\mathrm{~T}$ & $\begin{array}{c}\text { ID } \\
\mathrm{L}\end{array}$ & $\begin{array}{l}0126-04 \\
8.3-315\end{array}$ & $\mathrm{G}$ & $07-30$ & $\mathrm{x}$ & $0-85$ & $18-94$ & $\begin{array}{l}\text { Possibility of } \\
\text { stability } \\
\text { problems }\end{array}$ & B-5 \\
\hline
\end{tabular}




\begin{tabular}{|c|c|c|c|c|c|c|c|c|c|c|}
\hline Fiuid & $\begin{array}{c}\text { Pressure } \\
\text { langr } \\
\text { dtm }\end{array}$ & $\begin{array}{l}\text { Duci } \\
\text { geometry* }\end{array}$ & $\begin{array}{c}\text { Duct } \\
\text { dımensions, } \uparrow \\
\text { in }\end{array}$ & & $\begin{array}{l}1 \text { low } \\
\text { ratet }\end{array}$ & & $\begin{array}{l}\text { Inlet } \\
\text { onditıons }\end{array}$ & $\begin{array}{l}\text { Outlet }^{+} \\
\text {quallity } \\
\text { 品 }\end{array}$ & Remarks & $\begin{array}{c}\text { Datd } \\
\text { source }\end{array}$ \\
\hline Water & $10-95$ & AI & $\begin{array}{rll}\mathrm{S} & 0 & 09-025 \\
\mathrm{ID} & 0 & 3 i 5 \\
\mathrm{~L} & 70\end{array}$ & G & $11-23$ & Sc & & $3-70$ & $\begin{array}{l}\text { Photographic } \\
\text { studies in } \\
\text { cluded }\end{array}$ & 64 \\
\hline Water & $40-127$ & $\mathrm{R}$ & $\begin{array}{l}0101 \times 1 \times 6 \\
0097 \times 1 \times 27 \\
0059 \times 1 \times 27\end{array}$ & G & $018-4$ & $\mathrm{SC}$ & $10-475$ & $3-100$ & & $T+$ \\
\hline Witer & $40-137$ & $\mathrm{AI} / \mathrm{H}$ & $\begin{array}{cll}\mathrm{S} & 0 & 19 \\
\mathrm{ID} & 181 \\
\mathrm{~L} & 252\end{array}$ & G & ) $16-17$ & $\mathrm{sC}$ & 100 & $23-14$ & & $1-1$ \\
\hline Water & $20-127$ & $\mathrm{R}$ & $0070 \times 220 \times 72$ & G & $038-10$ & $\mathrm{sC}$ & & $0-91$ & & $\Gamma-6$ \\
\hline Water & $\begin{array}{lll}565 & 83\end{array}$ & $\mathrm{R}$ & $0097 \times 1 \times 27$ & G & 0711 & so & $10-6 v$ & $26 \quad 12$ & $\begin{array}{l}\text { Sibility with } \\
\text { parillel } \\
\text { channel }\end{array}$ & j 1 \\
\hline Water & 68 & $\begin{array}{l}\mathrm{T} \text { and } \mathrm{AI} \\
\mathrm{AI}\end{array}$ & $\begin{aligned} \text { ID } & 050 \\
\text { L } & 24-43 \\
\text { S } & 025 \\
\text { L } & 24\end{aligned}$ & $\mathrm{G}$ & $025-225$ & SC & & $0-50$ & & D 11 \\
\hline Water & 68 & AI & 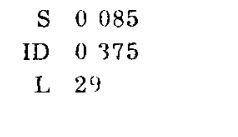 & G & $05-33$ & 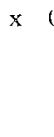 & $0 b-50$ & $5 \quad 61$ & $\begin{array}{l}\text { Spccial sicam- } \\
\text { water mixing } \\
\text { irrangement } \\
\text { dt inlet }\end{array}$ & $B-2$ \\
\hline Water & 68 & AI & $\begin{array}{rll}\text { S } & 0 & 26 \\
\text { ID } & 1 & 38 \\
\text { L } & 42\end{array}$ & G & $031-104$ & $\mathrm{sC}$ & & $5-25$ & & M 4 \\
\hline Water & 68 & $\mathrm{AF}$ & $\begin{array}{rlllll}\text { ID } & 0 & 12 & 0 & 197 \\
\text { OD } & 0 & 325 & 0 & 394 \\
\text { L } & 20 & 20 & 23 & 2\end{array}$ & & & $\mathrm{x}$ & $2-84$ & $40 \quad 85$ & $\begin{array}{l}\text { Possibility of } \\
\text { stability } \\
\text { problems }\end{array}$ & $A-1$ \\
\hline Water & 68 & $\mathrm{AI}$ and $\mathrm{AB}$ & 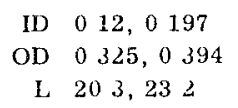 & G & $075-216$ & $x$ & & $25-79$ & $\begin{array}{l}\text { Possibiluty of } \\
\text { stability } \\
\text { problems }\end{array}$ & A 2 \\
\hline
\end{tabular}




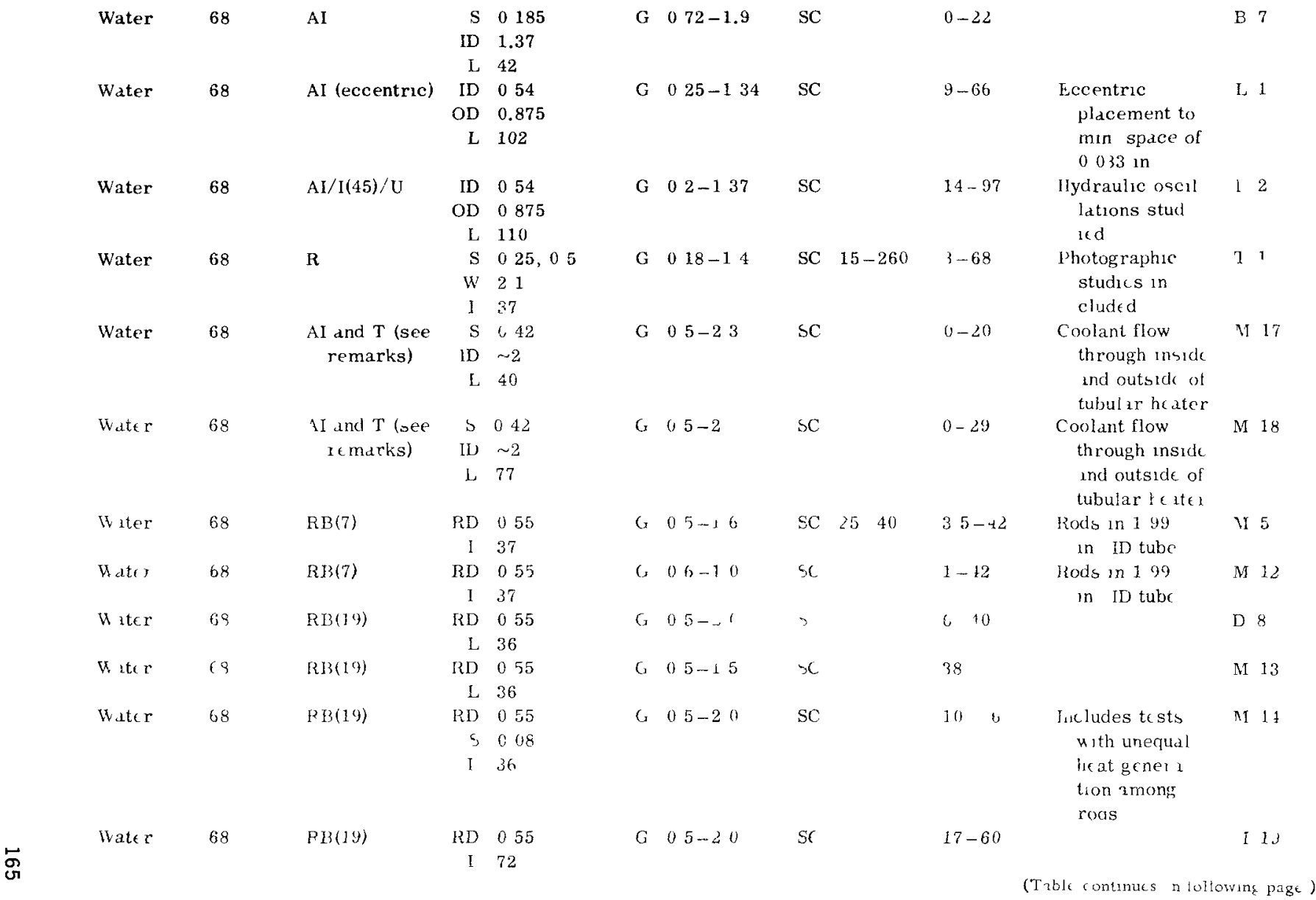


Table B-(Contınued)

\begin{tabular}{|c|c|c|c|c|c|c|c|c|c|c|c|}
\hline Fluid & $\begin{array}{c}\text { Pressure } \\
\text { range, } \\
\text { atm }\end{array}$ & $\begin{array}{c}\text { Duct } \\
\text { geometry* }\end{array}$ & & $\begin{array}{l}\text { Duct } \\
\text { mensions, } \uparrow \\
\text { in }\end{array}$ & & $\begin{array}{l}\text { Flow } \\
\text { rate }\end{array}$ & & $\begin{array}{l}\text { Inlet } \\
\text { ditions } \pi\end{array}$ & $\begin{array}{c}\text { Outlet } \\
\text { quality } \\
\%\end{array}$ & Remarks & $\begin{array}{c}\text { Data } \\
\text { source }\end{array}$ \\
\hline Water & $68-95$ & AI & $\begin{array}{r}\mathrm{S} \\
\mathrm{ID} \\
\mathrm{L}\end{array}$ & $\begin{array}{l}0125,025 \\
0.50 \\
29,36\end{array}$ & G & $04-60$ & $\mathrm{SC}$ & & $0-12$ & & W-10 \\
\hline Water & $68-109$ & AI & $\begin{array}{r}\mathrm{S} \\
\mathrm{ID} \\
\mathrm{L}\end{array}$ & $\begin{array}{l}0.125-025 \\
0.5 \\
29-36\end{array}$ & G & $2-6$ & $\mathrm{SC}$ & & $0-17$ & & $J-7$ \\
\hline Water & $68-136$ & $\begin{array}{c}\mathrm{T} \text { and } \mathrm{T} / \mathrm{I} \\
(45) / \mathrm{U}\end{array}$ & $\begin{array}{l}\text { ID } \\
\mathrm{L}\end{array}$ & $\begin{array}{l}0.187 \\
12.5\end{array}$ & G & $038-616$ & $\mathrm{SC}$ & $85-289$ & $0-42$ & & $\mathrm{H}-2$ \\
\hline Water & $80-170$ & $\mathrm{~T}$ & $\begin{array}{r}\text { ID } \\
\mathrm{L}\end{array}$ & $\begin{array}{l}0.3 \\
5-60\end{array}$ & G & $03-1.6$ & $\mathrm{SC}$ & & $0-80$ & $\begin{array}{l}\text { Instability } \\
\text { studied }\end{array}$ & $A-3$ \\
\hline Water & 82 & $\mathrm{RB}(19)$ & $\begin{array}{r}\mathrm{RD} \\
\mathrm{L}\end{array}$ & $\begin{array}{l}056 \\
18.5\end{array}$ & G & $05-3$ & $\mathrm{SC}$ & & $0-29$ & & $\mathrm{H}-3$ \\
\hline Water & 82 & $\mathrm{RB}(19)$ & $\begin{array}{r}\mathrm{RD} \\
\mathrm{L} \\
\mathrm{S}\end{array}$ & $\begin{array}{l}056-063 \\
185-76 \\
0.015-0.074\end{array}$ & G & $05-5$ & $\mathrm{SC}$ & & $0-36$ & & W-9 \\
\hline Water & 82 & $\mathrm{RB}(19)$ & $\begin{array}{r}\mathrm{RD} \\
\mathrm{L}\end{array}$ & $\begin{array}{l}056,059 \\
\sim 19\end{array}$ & G & $05-4$ & $\mathrm{SC}$ & & $0-29$ & & $B-8$ \\
\hline Water & 100 & $\mathrm{~T}$ & $\begin{array}{c}\text { ID } \\
\text { L }\end{array}$ & $\begin{array}{l}031 \\
84\end{array}$ & G & $\sim 3$ & $\mathrm{sC}$ & & $0-100$ & $\begin{array}{l}\text { Effect of com- } \\
\text { prtssible vol- } \\
\text { umes in loop } \\
\text { studied }\end{array}$ & S-6 \\
\hline Water & 102 & $\mathrm{~T}$ and $\mathrm{T} / \mathrm{H}$ & $\begin{array}{r}\text { ID } \\
\text { L }\end{array}$ & $\begin{array}{l}044 \\
144\end{array}$ & G & $05-70$ & $\mathrm{sC}$ & $5-500$ & $0-40$ & $\begin{array}{l}\text { Burnouts oc- } \\
\text { curred up- } \\
\text { stream from } \\
\text { exit for } G>4\end{array}$ & W 1 \\
\hline Water & 136 & $\mathrm{~T}$ & $\begin{array}{l}\text { ID } \\
\text { L }\end{array}$ & $\begin{array}{l}03-0.44 \\
18\end{array}$ & G & $0126-20$ & $\mathrm{sC}$ & & 070 & & $w-3$ \\
\hline
\end{tabular}




$\begin{array}{lrrrll}\text { Water } & 136 & \mathrm{~T} & \text { ID } & 0 & 186 \\ & & & \mathrm{~L} & 12 \\ \text { Water } & 136 & \mathrm{~T} & \text { ID } & 0 & 186 \\ & & & \mathrm{~L} & 12\end{array}$

G $\quad 021-352 \quad$ SC $\quad 24-242 \quad 4 \quad 4-67$

ported

Effect of dis -

$\begin{array}{llll}\text { Water } & 136 \quad \mathrm{~T} \text { and insert } \quad \text { ID } & 0 & 0 \\ & & \mathrm{~L} & 18\end{array}$

G $\quad \begin{array}{llll}0 & 5-2 & 0 & \mathrm{SC}\end{array}$

$0-53$

Insert to pro-

duce swirl

flow

$\begin{array}{lrl}\text { Water } & 136 & \mathrm{R} \\ \text { Water } & 136 & \mathrm{R} / \mathrm{V} \text { and } \mathrm{I}(45)\end{array}$

$005 \times 1 \times 12$,

G $\quad 0025-15$

SC $\quad 336-536$

$0-100$

$0097 \times 1 \times 12$

S 0050,0055 ,

G $\quad \begin{array}{llll}0 & 15 & -3 & 3\end{array}$

$\mathrm{SC}$

$0-100^{+}$ and 0097

Water $\quad 136$

$\mathrm{R}$

$\mathrm{L} \quad 12$ and 27
$0 \quad 087 \times 10 \times 12$

G $\quad 02-05$

SC $\quad 10$ and $60 \quad 48-96$

Includes special experiments with $\mathrm{x} 0$ at outlet

$\begin{array}{lll}\text { Water } & 136 & \mathrm{R} / \mathrm{I}(45) \\ \text { Water } & 136 & \mathrm{R} / \mathrm{DF} \\ & & \\ \text { Water } & 136 & \mathrm{R} \\ \text { Water } & 136 & \mathrm{R} \\ \text { Water } & 136 & \mathrm{R} \\ \text { Water } & 136 & \mathrm{R}\end{array}$

$0.05-0097 \times 1 \times$

$017-3$

SC $9-336$

$0-100^{+}$

$\mathrm{V}-1$

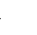$$
\begin{aligned}
& 12-27 \\
& 005-0097 \times 1 \times \quad \text { G } \quad 02-133
\end{aligned}
$$$$
\text { SC } 11-546 \quad 154-100^{+}
$$$$
12-27
$$$$
0053 \times 1 \times 1206
$$

$0059 \times 1 \times 27$

$0097 \times 1 \times 27$

G $\quad 0 \quad 18-210$

T 500

G $0176-106$

SC $11-536$

$95-94$

$28-100$

G $058-13$

SC $36-536$

$0-100$

SC $11-236 \quad 17-54$

Stability with parallel

channel 
Table B-(Contınued)

\begin{tabular}{|c|c|c|c|c|c|c|c|c|c|c|c|}
\hline Fluid & $\begin{array}{l}\text { Pressure } \\
\text { range, } \\
\text { atm }\end{array}$ & $\begin{array}{c}\text { Duct } \\
\text { geometry* }\end{array}$ & & $\begin{array}{l}\text { Duct } \\
\text { dimensions, } \dagger \\
\text { in }\end{array}$ & & $\begin{array}{l}\text { Flow } \\
\text { rate }\end{array}$ & & $\begin{array}{c}\text { Inlet } \\
\text { conditions } \Uparrow\end{array}$ & $\begin{array}{c}\text { Outlet } \\
\text { quality, } \\
\%\end{array}$ & Remarks & $\begin{array}{l}\text { Data } \\
\text { source }\end{array}$ \\
\hline Water & 136 & $\mathrm{R} / \mathrm{N}$ & 005 & $55 \times 2.12 \times 27$ & G & $0.49-2.20$ & SC & $36-538$ & $82-75$ & $\begin{array}{l}\text { Cosine flux, } \\
\text { ratio max to } \\
d v=138\end{array}$ & D-3 \\
\hline Water & 136 & $\mathrm{R} / \mathrm{N}$ & 0.09 & $97 \times 1 \times 27$ & G & $0374-20$ & $\mathrm{SC}$ & $133-533$ & $58-53$ & $\begin{array}{l}\text { Short step rise } \\
\text { of heat flux at } \\
\text { exit equal to } \\
2 \times \text { av flux }\end{array}$ & W-6 \\
\hline Water & 136 & $\mathrm{R} / \mathrm{H} / \mathrm{N}$ & 0.05 & $5 \times 0.85 \times 12$ & G & $0522-10$ & $\mathrm{sc}$ & & $68-334$ & $\begin{array}{l}\text { Nuclear heating, } \\
\text { loop in MTR }\end{array}$ & D-6 \\
\hline Water & 136 & $R$ with fins & 009 & $97 \times 1 \times 12$ & G & $0.37-1.1$ & $\mathrm{SC}$ & & $9-71$ & $\begin{array}{l}\text { Internal fins } \\
\text { parallel to } \\
\text { flow }\end{array}$ & M-11 \\
\hline Water & 136 & $\mathrm{RB}(9)$ & $\begin{array}{r}\mathrm{RD} \\
\mathrm{L}\end{array}$ & $\begin{array}{l}0.413 \\
9\end{array}$ & G & $0.7-20$ & $\mathrm{SC}$ & & $0-43$ & $\begin{array}{l}\text { Tubes filled } \\
\text { with ceramic } \\
\text { rods, only two } \\
\text { data points } \\
\text { for critical }\end{array}$ & G-5 \\
\hline Water & 150 & $\mathrm{~T}$ & $\begin{array}{r}\text { ID } \\
\text { L }\end{array}$ & $\begin{array}{l}\sim 0.3 \\
102\end{array}$ & G & $063-52$ & $\mathrm{SC}$ & & $10-65$ & & $S-4$ \\
\hline $\begin{array}{l}\text { Ethyl } \\
\quad \text { alcohol }\end{array}$ & $2-7$ & $\mathrm{~T} / \mathrm{H}$ & $\begin{array}{l}\text { ID } \\
\text { L }\end{array}$ & $\begin{array}{l}063 \\
39\end{array}$ & $\mathrm{v}$ & $1-25$ & $\mathrm{SC}$ & & $\sim 0^{+}$ & & $S-5$ \\
\hline Hydrogen & $2-5$ & $\mathrm{~T}$ & $\begin{array}{l}\text { ID } \\
\mathrm{L}\end{array}$ & $\begin{array}{l}055 \\
16\end{array}$ & G & $0003-0017$ & $\mathrm{SC}$ & & $0-100$ & & $\mathrm{~L}-3$ \\
\hline $\begin{array}{l}82 \% \text { 1so- } \\
\text { propyl } \\
\text { dlcohol }\end{array}$ & 2 & $\mathrm{~T} / \mathrm{H}$ & $\begin{array}{l}\text { ID } \\
\mathrm{L}\end{array}$ & $\begin{array}{l}063 \\
394\end{array}$ & $\mathrm{~V}$ & $065-23$ & $\mathrm{SC}$ & & $\sim 0^{+}$ & & $\mathrm{S}-2$ \\
\hline Nitrogen & $3-4$ & $\mathbf{T}$ & $\begin{array}{r}\text { ID } \\
\mathbf{L}\end{array}$ & $\begin{array}{l}055 \\
16\end{array}$ & G & $0015-0056$ & $\mathrm{SC}$ & $18-108$ & $0-100$ & $\begin{array}{l}\text { Stability prob- } \\
\text { lems }\end{array}$ & $\mathrm{L}-3$ \\
\hline
\end{tabular}




\section{Data Sources Indexed by Tables A and B}

A-1 Adornı, N, et al., Results of Wet Steam Coolıng Experıments, Pressure Drop, Heat Transfer, and Burnout Measurements in Annular Tubes with External Heatıng, USAEC Report EURAEC-44, Centro Informazıonı Studı Esperienze, December 1960

A-2 Adornı, N, et al., Results of Wet Steam Coolıng Experıments Pressure Drop, Heat Transfer, and Burnout Measurements in Annular Tubes with Internal and Bilateral Heatıng, USAEC Report EURAEC-45, Centro Informazıonı Studı Esperıenze, January 1961

A-3 Aladyev, I T, Miropolsky, Z L, Doroshchuk, V E, and Styrıkovich, M. A., Bolling Crisis in Tubes, in International Developments in Heat Transfer, Part II, p. 237, American Society of Mechanical Engineers, New York, 1961.

A-4 Aladyev, I T, Dodonov, L D, and Udalov, V S, Burnout Heat Flux for Flow of Water in Pipes, Soviet $J$ At Energy, 6(1) (January 1959), also in J Nucl Energy Pt B. Reactor Technol, 1177 (1959-1960)

B-1 Becker, K M, Burnout Conditions for Flow of Boiling Water in Vertical Rod Clusters, Swedish Report AE-74, May 1962, also in AIChE $J$, 9(2) 223 (1963)

B-2 Bennett A W, Collier, J G, and Lacey, P M C, Heat Transfer to Mixtures of High Pressure Steam and Water in an Annulus Part II The Effect of Sieam Quality and Mass Velocity on the "Burnout" Heat Flux for an Internally Heated Unit at 1000 Psia, Britısh Report AERE-R-3804 August 1961

B-3 Bennett, A W, Collier, J G, and Lacey, P M C, Heat Transfer to Mixtures of High Pressure Steam and Water in an Annulus Part III The Effect of System Pressure on the Burn-out Heat Flux for an Internally Heated Unit, British Report AERE-R-3934 March 1963

B-4 Bergles, A E, and Rohsenow, W M , Forced-convection Surface-boiling Heat Transfer and Burnout in Tubes of Small Diameter, Report NP-11831, Massachusetts Instıtute of Technology, May 25, 1962

B-5 Berkowitz, L, Bertolettı, S, Lesage, J, Peterlongo, G, Soldainı, G , and Zavattarellı, R, Results of Wet Steam Cooling Experiments Pressure Drop, Heat Transfer, and Burnout Measurements with Round Tubes USAEC Report EURAEC-42, Centro Informazionı Studi Esperienze, October 1960

B-6 Birdseye, D E, Experimental Investigation of Heat Transfer Characteristics of Liquid Nitrogen Textroxide, Report JPL-TR-32-37 Calıfornia Institute of Technology, Jet Propulsion Laboratory, 1960

B-7 Blackford, D, and Matzner, B, Basıc Experımental Studies on Boıling Fluid Flow and Heat Transfer at Elevated Pressures, Monthly Progress Report for August 1961, USAEC Report TID-13781, Columbia University Aug 31, 1961

B-8 Batch, J M , and Hesson, G M , Bolling Burnout Experiments for 19-Rod Bundle Fuel Elements, Trans Am Nucl Soc, 5 474 (1962)

B-9 Becker, K M , Measurements of Burnout Conditions for Flow of Boiling Water in Vertical Round Ducts, Swedish Report AE-87, 1962 
B-10 Becker, $\mathrm{K}$ M , and Hernborg, G, Measurements of Burnout Conditions for Flow of Bolling $W$ ater in a Vertical Annulus, Preprint 63-HT-25, American Society of Mechanical Engineers, New Yorh, 1963.

B-11 Buchberg, H Romie, F, Lipkis, R, and Greenfıeld, M, Hedt Transfer, Pressure Drop, and Burnout Studies With and Without Surface Bolling for De-aerated and Gassed Water at Elevated Pressures in a Forced $\Gamma$ low System in 1951 Heat Transfer and Fluıd Mechanus Instulute, p 177 Preprints of Papers Stanford University Press Stanford Calıf 1951

C-1 Chirkın, V S, and Iukın, V P, Critical Point in Heat Removal from Bolling Water Flowing Through an Annular Gap, $J$ Tech Physics, LSSR, 261542 (1956) and Souct Physics, 1(7): 1503 (1956)

C-2 Clark, J A, and Rohsenow, W M , Local Boiling Heat Transier to Water at Low Reynolds Numbers and High Pressure Massachusetts Institute of Technology Tech Report No 4, July 1, 1952, also Trans ASME, $76 \quad 553$ (1954)

C-3 Columbia Unversity, du Pont Sub-contract, Classified Progress Reports 1952-1954 Data tabulated by L Bernath in Chem Eng Progr, Symp. Ser , $56(30) 95$ (1960); see also Ref. 68.

C-4 Core, T C and Sato, K, Determination of Burnout Limits of Polyphenyl Coolants, USAEC Report IDO-28007, Aerojet-General Corporation Feb 141958 Data tabulated by L Bernath in Chem Eng Progr, Symp $\mathrm{Ser}, 56(30) \quad 95(1960)$

C-5 Cook, W H , Fuel Cycle Program A Bolling Water Reactor Research and Development Program Quarterly Report No 1 August 1960-September 1960, US $₫ E C$ Report GEAP-3558, General Electric Company, Atomic Pow $\in \mathrm{r}$ Equipment Department, Oct 10, 1960

D-1 D $\in$ Bortolı, R A , and Masnovi, R, Effect of Dissolved Hydrogen as Burnout for Water Flowing Vertically Upward in Round Tubes at 2000 Psia USAEC Report W APD-TH-318, Westinghoust Electric Corporation, Bettis Plant, Apr 15, 1957, see also Ref 43

D-2 DeBortoll, R A, Roarty, J D, and Troy M, Upflow Burnout Data in Vertical Rectangular Channtls at 2000 Psid, USAEC Report U APD-TH225 Westinghouse Electric Corporation, Bettıs Plant, Oct 10, 1956, see also Ref 43

D-3 DeBortolı, R A, Roarty, J D, and Weiss, A, Addıtional Burnout Data for a Rectangular Channel Having a Cosine Axial Heat Flux Distribution, USAEC Report WAPD-TH-227, Westinghouse Electric Corporation, Bettıs Plant Aug 7, 1956, see also Ref 43

D-4 Dimmock, $T$ H Heat Transfer Properties of Anhydrous Ammonia, Report RMI-124-S1, Reaction Motors, Inc , June 1957

D-5 Dingee, D 1, Epstein, H V. Chastain, J W, and Fawcett S L., Burnout Heat Flux in a Rcctangular Channel USAEC Report BMI-1065, Battelle Memorial Institute Jan 10, 1956, see also Ref 43

D-6 Dobel, H F., Green $S$ J and Zerbe, J E, In-pile Heat Transfer Burnout $T$ csts at the UTR USAEC Report $W \dashv P D-L S R(I M)-2$ Westinghouse Electric Company, Atomic Power Division, Aug. 9, 1955.

D-7 Du Pont de Nemours, F I \& Co Inc, Hedvy Water Moderated Power Reactors Progress Report September 1961, USAEC Report DP-665, November 1961 
D-8 Du Pont de Nemours, E I \& Co, Inc, Heavy Water Moderated Power Reactors Progress Report, October 1961, USAEC Report DP-675, November 1961

D-9 Du Pont de Nemours, E I \& Co, Inc, Heavy Water Moderated Power Reactors Progress Report, March 1962, USAEC Report DP-725, April 1962

D-10 Durant, W S, and Mırshak, S, Roughenıng of Hedt Transfer Surfaces as a Method of Increasing the Heat Flux at Burnout, USAEC Report DP-380, E I Du Pont de Nemours \& Co , Inc., July 1959

D-11 Du Pont de Nemours, E I \& Co, Inc, Heavy Water Moderated Power Reactors Progress Report, October 1962, USAEC Report DP-795, November 1962

E-1 Ellion, M E , A Study of the Mechanism of Bolling Heat Transfer [thesis], USAEC Report JPL-Memo-20-88, Calıfornia Institute of Technology, Jet Propulsion Laboratory, Mar 1, 1954

E-2 Epstein, H M., Chastain, J W, and Fawcett, S L, Heat Transfer and Burnout to Water at High Subcritical Pressures, USAEC Report BMI1116, Battelle Memorial Institute, July 20, 1956, see also Ref 43

F-1 Foley, D J, Batch, J. M, and MeEwen, L H, Bolling Burnout at High Pressure in Horizontal Annulı, in USAEC Report TID-7529(Pt. 2), November 1957 (Classified)

F-2 Foure, C, Rosuel, A, and Sourioux, G., Influence on Burn-out Flux of Vortices Induced in Bolling Water at Atmospheric Pressure, USAEC Report EURAEC-146, Société Nationale d'Etude et de Construction de Moteurs d Aviation, 1961

G-1 Gambill, W R, and Bundy, R. D , HFIR Heat-transfer Studies of Turbulent Water Flow in Thin Rectangular Channels, USAEC Report ORNL3079, Oak Ridge National Laboratory, June 19, 1961

G-2 Gambill, W R, and Bundy, R. D , High-flux Heat-transfer Characteristics of Pure Ethylene Glycol in Axıal and Swirl Flow, Paper No 2 presented at the A I Ch E National Meeting, Los Angeles, Calif, February 1962

G-3 Gambill, W. R, Bundy, R D, and Wansbrough, R. W., Heat Transfer, Burnout, and Pressure Drop for Water in Swirl Flow Through Tubes with Internal Twisted Tapes, USAEC Report ORNL-2911, Oak Ridge National Laboratory, Apr 11, 1960, also Chem Eng Progr, Symp Ser , 57(32) 127 (1961)

G-4 General Electric Company, Atomic Power Equipment Department $A$ Bolling Water Reactor Research and Development Program 4th Quarterly Report, April-June 1961, Fuel Cycle Program, US 4 EC Report GEAP-3781, Aug 1, 1961

G-5 Green S J, Maurer, G. W., and Weiss, A., Burnout and Pressure Drop Studies for Forced Convection Flow of Water Parallel to Rod Bundles paper presented at Nucleonics Heat Transfer Conference of the ASME held at Argonne National Laboratory April 26-27 1962 Preprint 62HT-43, American Society of Mechanical Engineers, New York, 1962

G-6 Gunther, F C , Photographic Study of Surface Bolling Heat Transfer Trans ASME, $73 \quad 115$ (1951)

H-1 Hines, W S, Forced Convection and Pedk Nucleate Bolling Heat Transfer Characteristics for Hydrazine Flowing Turbulently in a Round Tube 
at Pressures to 1000 Psia, Report R-2059, North American Aviation, Inc , 1959.

H-2 Hunt, T. W., Jacket, H. S., Roarty, J. D., and Zerbe, J. E., An Investigation of Subcooled and Quality Burnout in Circular Channels, USAEC Report WAPD-LSR(IM)-1, Westinghouse Electric Corporation, Atomic Power Division, Jan 2, 1955, see also Ref 43

H-3 Hesson, G. M, Fitzsimmons, D E, Waters, E D, and Batch, J M , Preliminary Bolling Burnout Experiments with a 19-Rod Bundle Geometry in Axial Flow, USAEC Report HW-73395, Hanford Atomic Products Operation, Apr. 17, 1962

J-1 Jacket, H. S, Lackey, J, Roarty, J D., and Sher, N C, Preliminary Investigation of Burnout and Pressure Drop at 830 and 1215 Psia with a Parallel Channel Effect, USAEC Report WAPD-TH-223, Westinghouse Electric Corporation, Atomic Power Division, Aug 17, 1956, see also Ref 43 .

J-2 Jacket, H S, Roarty, J D, and Welss, A, Prelıminary Investigation of the Effect of Vertically Downward Flow on Burnout Flux, USAEC Report WAPD-TH-183, Westinghouse Electric Corporation, Atomic Power Division, Jan 28, 1956, see also Ref 43

$\mathrm{J}-3$ Jacket, $\mathrm{H} \mathrm{S}$, Roarty, $\mathrm{J} \mathrm{D}$, and Zerbe, $\mathrm{J} \mathrm{E}$, Investigation of Burnout Heat Flux in Rectangular Channels at 2000 Psia, USAEC Report WAPDA1W(IM) -3, Westinghouse Electric Corporation, Atomic Power Division, Dec 5,1955 , see also Ref 43

J-4 Jacket, H S, Roarty, J D, and Zerbe, J E, Investigation of Burnout Heat Flux in Rectangular Channels at 2000 Psia, Trans ASME, 80391 (1958), see also Ref 43

J-5 Jacket, H S., Sonnemann, G, and Roarty, J D , Investigation of the Effect of a Parallel Channel on Flow and Burnout Flux, USAEC Report WAPDTH-162, Westınghouse Electric Corporation, Bettıs Plant, Dec 6, 1955, see also Ref 43

J-6 Janssen, E, Multrod Burnout at Low Pressure, Preprint 62-HT-26, American Society of Mechanical Engineers, New York, 1962

J-7 Janssen, E, and Kervinen, $J$ A, Subcooled Burnout at High Flows, USAEC Report GEAP-3843, General Electric Company, Atomic Power Equipment Department

J-8 Jens, W. H., and Lottes, P.A., Analysis of Heat Transfer, Burnout, Pressure Drop, and Density Data for High-pressure Water, USAEC Report ANL-4627, Argonne National Laboratory, May 1, 1951, see also Ref 43

J-9 Jens, W H, and Lottes, P A, Two-phase Pressure Drop and Burnout Using Water Flowing in Round and Rectangular Channels, USAEC Report ANL-4915, Argonne National Laboratory, Oct 1, 1952

K-1 Kezıos, S. P., Kem, T, and Rafchiek, F M., Burnout in Crossed Rod Matrices Under Forced Convection Flow of Water, in International Developments in Heat Transfer, Part II, p. 262, American Society of Mechanical Engineers, New York, 1961

K-2 Kezios, S P, and Lo, R K, Heat Transfer from Rods Normal to Subcooled Water Flow for Non-bolling and Surface-bolling Conditions Up to and Including Burn-out, USAEC Report ANL-5822, Argonne National Laboratory, January 1958 
L-1 Levy, S, Polmik, E E, Swan, C L, and McKinney, A W, Eccentric Rod Burnout at $1000 \mathrm{Lb} / \mathrm{in}^{2}$ with Net Steam Generation, Intern $J$ Heat Mass Transfer, 5 595 (1962)

L-2 Levy, S, and Swan, C L, Performance-Two-phase Pressure Drop Burnout, and Hydraulic Oscillation of an Inclined Test Section with Net Steam Generation at 1000 Psia, USAEC Report GEAP-3228(Rev 1), General Electric Company, Atomic Power Equipment Department Aug 15 1959

L-3 Lewıs, J P, Goodykoontz, J H , and Klıne, J F , Bolling Heat Transfer to Liquid Hydrogen and Nitrogen in Forced Flow, Report NASA-TN-D1314, National Aeronautics and Space Administration, September 1962

L-4 Longo, J., Jr , A Statistical Study of Subcooled Burnout Including the Effect of Local Hot Spots, USAEC Report KAPL-1744 Knolls Atomic Power Laboratory, Oct 22, 1957

L-5 Lowdermilk, W H , Lanzo, C D, and Siegel, B L, Investigation of Boiling Burnout and Flow Stability for Water Flowing in Tubes, Report NASATN-4382, National Aeronautics and Space Administration, September 1958

L-6 Lowdermik, W H , and Welland, W F, Some Measurements of Bolling Burn-out, Report NACA-RM-E54K10, Lew1s Flight Propulsion Laboratory, Feb 23, 1955, see also Ref 43

L-7 Levy, S, Fuller, R A, and Niemi, R O, Heat Transfer to Water in Thin Rectangular Channels $J$ Heat Transfer, 81(2) 129 (May 1959)

M-1 Masnovi, R, Additional 200 Psia Vertical Upflow Burnout Data for 0053 In $\times 1$ In $\times 1206$ In Long Rectangular Channels with an Inlet Water Temperature of $500^{\circ} \mathrm{F}$ USAEC Report WAPD-TH-306, Westinghouse Electric Corporation, Atomic Power Division, Mar 15 1957, see also Ref 43

M-2 Masnov1, R, and DeBortol, $R$ A Burnout Data for 0186 Inch Inside Diameter by 12 Inches Long Round Nickel Tube, USAEC Report WAPD TH-308, Westinghouse Electric Corporation, Atomic Power Division Apr 2, 1957, see also Ref 43

M-3 Masnov1, R, and Troy, M, Upflow Burnout Data for 0101 In $\times 1$ In $\times 6$ In. Vertical Rectangular Channels at 2000 Psia, USAEC Report WAPDTH-289, Westinghouse Electric Corporation, Bettıs Plant, Jan 15, 1957, see also Ref 43

M-4 Matzner, B , Basic Experimental Studies on Bolling Fluid Flow and Heat Transfer at Elevated Pressures for Month of September 1960, USAEC Report TID-6689, Columbia University, Sept 30, 1960

M-5 Matzner, B , Basic Experimental Studies on Bolling Fluıd Flow and Heat Transfer at Elevated Pressures for Month of May 1961 USAEC Report TID-12574, Columbia University, May 31, 1961

M-6 McAdams, W H , Kennel, W. E , Minden, C S , Call, R, Picornall, P M and Dew, J E, Heat Transfer at High Rates to Water with Surface Bolling, Ind Eng Chem, 411945 (1949)

M-7 McDonough, J. B , Milıch, W, and King, E C , An Experimental Study of Partial Film Bolling Regions with Water at Elevated Pressures in a Round Vertical Tube, Chem Eng Progr, Symp Ser, $57(32) 197$ (1961) 
M-8 McGill, H L, Sibbitt, W. L, Wiskind, H K, and Suciu, Spırıdon Heat Transfer and Pressure Drop of Water Flowing in a Small Tube, USAEC Report ANL-4603(Pt I), Purdue University, 1951

M-9 Mirshak, S, Durant, $\mathrm{K}$ S, and Towell, R H, Heat Flux at Burnout, USAEC Report DP-355, E. I du Pont de Nemours \& Co, Inc, February 1959

M-10 Mirshak, S., and Towell, R H, Heat Transfer Burnout of a Surface Contacted by a Spacer Rıb, US AEC Report DP-562, E I. du Pont de Nemours \& Co , Inc., April 1961

M-11 Masnov1, R, and Williams, J. S., Jr., Departure from Nucleate Bolling Data for 0.097 In. $\times 1$ In. $\times 1206$ In. Tinned Rectangular Channel Test Section, USAEC Report WAPD-TH-458, Westinghouse Electrıc Corporation, December 1958

M-12 Matzner, Bruce, Basıc Experimental Studies on Bolling Fluid Flow and Heat Transfer at Elevated Pressures, Monthly Progress Report for July 1961, USAEC Report TID-13711, Columbia University, July 31, 1961.

M-13 Matzner, Bruce, Basic Experimental Studies on Bolling Fluid Flow and Heat Transfer at Elevated Pressures, Monthly Progress Report for November 1961, USAEC Report TID-14439, Columbid University, Nov 30, 1961

M-14 Matzner, Bruce, Basıc Experımental Studies on Bolling Fluıd Flow and Heat Transfer at Elevated Pressures Monthly Progress Reports for January 1962 (USAEC Report TID-14993) and April 1962 (USAEC Report TID-15637), see also W-9

M-15 Matzner, Bruce, Basic Experimental Studies of Bolling Fluid Flow and Heat Transfer at Elevated Pressures, Monthly Progress Report for July 1962, USAEC Report TID-16451, Columbıa University July 311962

M-16 Matzner, Bruce, Basic Experimental Studies of Bolling Fluid Flow and Heat Transfer at Elevated Pressures, Monthly Progress Report for August 1962, USAEC Report TID-16813, Columbia University Aug 311962

M-17 Matzner, Bruce, Basıc Experımental Studies of Boıling Fluid Flow and Heat Transfer at Elevated Pressures, Monthly Progress Report for September 1962, USAEC Report TID-16972, Columbia University Sept. 28, 1962

M-18 Matzner, Bruce, Basic Experimental Studies of Bolling Fluid Flow and Heat Transfer at Elevated Pressures, Monthly Progress Report for December 1962, USAEC Report TID-17702, Columbia Unıversity, Dec 28, 1962

M-19 Matzner, Bruce, Basıc Experımental Studies of Bolling Fluid Flow and Heat Transfer at Elevated Pressures Monthly Progress Report for February 1963, USAEC Report TID-18296, Columbia University, Feb. 28, 1963

N-1 Neusen, K F., and Kangas, G J , Pathfinder Atomic Power Plant Single Rod Burnout Heat Flux Tests, USAEC Report ACNP-62028, AllisChalmers Manufacturing Company, Dec 21, 1962

N-2 Noel, M. B, Experimental Investigation of Heat Transfer Characteristics of Hydrazine and a Mixture of $90 \%$ Hydrazine and 10\% Ethylenediamine, Report JPL-TR-32-109, Californid Instıtute of Technology, Jet Propulsion Laboratory, June 1961 
N-3 Noel, M B, Experimental Investigation of the Forced-convection and Nucleate Boiling Heat Transfer Characteristics of Liquid Ammonia, Report JPL-TR-32-125, Callfornia Institute of Technology, Jet Propulsion Laboratory, July 1961

O-1 Oppenheimer, E, The Effect of Spinning Flow on Bolling Burnout in Tubes, USAEC Report NDA-80-1, Nuclear Development Corporation of America, July 30, 1957

P-1 Polomik, E. E, Levy, S, and Sdwochka, S G, Fılm Bolling of SteamWater Mixtures in Annular Flow at 800, 1100, and 1400 PSi, Preprint 62-W A-136, American Society of Mechanical Engineers, New York, 1962.

R-1 Reynolds, J M , Burnout in Forced Convection Nucleate Bolling of Water, Report NP-6476, Massachusetts Institute of Technology, July 1, 1957, see also Ref 43

R-2 Romie, F E, and Aronson, C A, Experimental Investigation of the Effects of Ultrasonic Vibrations on Burnout Heat Flux with Bolling Water, Final Summary Report, USAEC Report ATL-A-123, Advanced Technology Laboratories, July 31, 1961

S-1 Stein, R P., Bolling Burnout Studies with Simulated Fuel Elements, in Bolling Burnout Progress No 7, USAEC Report NDA-22, Nuclear Development Corporation of America, Nov. 7, 1955

S-2 Stcrman, L S, and Styuskin, N G , An Investigation Into the Influence of Speed of Circulation on the Values of Critical Heat Flows for Liquid Boiling in Tubes, $Z h$ Tekhn $F i z, 22(3) 446$ (1952).

S-3 Styrikovich, M A, and Faktororich, L E, Effect of Length of Pipe on Critical Heat Flux in Forced Motion of a Steam and Water Mixture, Dokl Akad Nauk, SSSR, $120(5) 1018$ (1958)

S-4 Smolin, V N, Polyakov, V K, and Esikov, V. I., Hedt Transfer Burnout in a Steam Generating Tube, At Energ (USSR), 13360 (October 1962) (in Russian).

S-5 Sterman, L S, Stıushin, N G., and Morosov, V G, An Investigation of the Dependence of Critical Heat Flow on the Rate of Circulation, Soviet Phys - Techn. Phys , 12250 (1956).

S-6 Styrikovich, M A., et al, Effects of Upstream Elements on Critical Boiling in a Vapor Generating Pipe USAEC translation AEC-TR-4740, 1960

T-1 Tippets, F E, Critical Heat Flux and Flow Pattern Characteristics of High Pressure Bolling Water in Forced Convection, USAEC Report GEAP3766, General Electric Company, April 1962; also Preprint 62-WA-162, American Society of Mechanical Engineers, New York, 1962

T-2 Tramontını, V. N., et al., Final Report on Studies in Boilıng Heat Transfer, USAEC Report COO-24, University of Calıfornı, March 1951

T-3 Troy, M, Upflow Burnout Data for Water at 2000 Psia in 0097 In $\times 1$ In. $\times 27$ In Long Rectangular Channels, USAEC Report WAPD-TH-340, Westinghouse Electric Corporation, July 18,1957, see also Ref 43

T-4 Troy, M, Upflow Burnout Data for Water in Rectangular Channels at Pressures from 600 to 1870 Psia, USAEC Report WAPD-TH-321, Westinghouse Electric Corporation, Sept. 5, 1957; see also Ref. 43.

T-5 Troy, M, and Roarty, J D, Upflow Burnout Data for 0059 In $\times 1$ In $\times$ 27 In Long Rectangular Channels at 2000 Psia, USAEC Report WAPDTH-276, Westinghouse Electric Corporation, Jan. 15, 1957, see also Ref 43 
T-6 Troy, M , Upflow Burnout Data for Water at 2000, 1200, 800, and 600 Psia in Vertical 0.070 In, $\times 225$ In $\times 72$ In Long Stainless Steel Rectangular Channels, USAEC Report WAPD-TH-408, Westınghouse Electrıc Corporation, July 1958

V-1 Viskanta, R, Critical Heat Flux for Water in Swirling Flow, Nucl SCl Eng, 10(2) 202 (1961)

V-2 Vliet, G C, and Leppert, G, Critical Heat Flux for Nearly Saturated Water Floulng Normal to a Cylinder, Preprint No 62-WA-173, American Society of Mechanical Engineers, 1962

V-3 Vliet, G. C, and Leppert, G, Critical Heat Flux for Subcooled Water Flowing Normal to a Cylınder Preprint No 62-WA-174, American Society of Mechanical Engineers, 1962

W-1 Waters, E. D., Anderson, J. K., Thorne, W. L., and Batch, J. M., Exper1mental Observation of Upstream Bolling Burnout, USAEC Report HW73902(Rev), Hanford Atomic Products Operation, November 1962

W-2 Weatherhead, R. J., Bolling Burnout Heat Fluxes for Wires in Water Cross Flow at Atmospheric Pressure, in Bolling Burnout Progress, Issue No 5, USAEC Report NDA-9, Nuclear Development Associates, Inc , 1955

W-3 Weatherhead, R J , Critical Heat Flux in Small Diameter Tubes at 2000 Psia, USAEC Report TID-12395. Data tabulated in USAEC Report ANL6675, March 1963

W-4 Weatherhead, R J, Forced Convection Heat Transfer, Local and Net Bolling, and Critical Heat Flux in Small Tubes at 200 Psia, ANL Internal Memo. Data reported in USAEC Report ANL-6715, April 1963

W-5 Weatherhead, R J , and Lottes, P A, Bollıng Burnout Newsletter No 1, Brookhaven National Laboratory, Dec 1, 1954

W-6 Weiss, A, Hot Patch Burnout Tests in 0097 In $\times 1$ In $\times 27$ In Long Rectangular Channels at 2000 Psia, USAEC Report WAPD-TH-338, Westinghouse Electric Corporation, Bettis Plant, Aug. 7, 1957, see also Ref. 43 .

W-7 Weiss, A, Emergency Cooling Tests on Electrically Heated Subassemblies with Water at 2000 Psia, USAEC Report WAPD-AD-TH-559, Westınghouse Electric Corporation, Bettis Plant, 1960, see also Ref. 43.

W-8 Witte, A. B., Experimental Investigation of Heat Flux at the Upper Limit of Nucleate Bolling for Two Mixtures of Hydrazine and Unsymmetrical Dimethyl-hydrazine, Report JPL-TR-32-78, Calıfornia Instıtute of Technology Jet Propulsion Laboratory 1961

W-9 Waters, E. D, Hesson, G M., Fitzsimmons, D. E, and Batch J M., Bolling Burnout Experiments with 19-rod Bundles in Axial Flow, USAEC Report HW-77303, Hanford Atomic Products Operation, August 1963

W-10 Weidenbaum, B, High Performance $\mathrm{UO}_{2}$ Program, Quarterly Progress Report No 2, July-September 1961, USAEC Report GEAP-3771-2 General Electric Company, Vallecitos Atomic Laboratory, Oct 1, 1961.

Z-1 Zenkevich, B A, and Subbotin, V I, Critical Heat Fluxes in Subcooled Water with Forced Convection Boiling, $J$ Nucl Energy, $\mathrm{Pt} B$ Reactor Technology, 1 134 (1959).

Z-2 Zenkevich, B A, Subbotin, V I, and Troyanov, M F, Critical Heat Fluxes for a Bundle of Tubes Cooled in Pressurized Water, $J$ Nucl Energy Pt. B: Reactor Technology, 1: $197(1960)$; original in At. Energ., 4370 (1958) 


\section{In-core Instrumentation}

by

L. R. Boyd

Atomic Products Division

General Electric Company 
When one considers the inclement environment that a nuclear-reactor core presents for instrumentation in general, he concludes that a strong incentive must be at work to foster development of in-core instrumentation. The intense radiation, high temperatures, and space-material limitations in a reactor core undoubtedly pose the most difficult problems in the application of instrumentation. The incentive for the development of in-core instrumentation has been the desire to attain economic nuclear power. Precise measurement of reactor-core parameters is recognized as a vital tool in the attainment of the full potential of reactor technology and has been given considerable attention over the past few years. ${ }^{1,2}$

In-core instrumentation is employed in several ways. It is used to supplement analysis and laboratory testing of various phases and aspects of reactor-plant operation. The results obtained in criticalassembly work and cold testing are not redundant with in-core data. Although application of more-sophisticated techniques is possible in out-of-pile tests, certain aspects of actual operation are not practical for establishment outside a reactor. Such things as realistic temperature distribution, isotopic distribution, and simulated abnormal conditions are prohibitively expensive to simulate outside an operational reactor; hence in-core instrumentation extends results of out-of-core tests.

Measurements of parameters of advanced reactor cores are essential to reactor engineering, and, here again, in-core instrumentation is a powerful tool. Complete reactor prototypes are prohibitively expensive; hence the obvious approach is to measure parameters of fully instrumented experimental core segments in an operating test reactor. In this way the same test reactor can be used to evaluate various core designs with relatively modest expenditures. The interplay between engineering design analysis and parameter measurement during operation serves to refine and extend both techniques.

Finally, in-core instrumentation is an invaluable and to reactor operations. In a tactical sense in-core instrumentation permits maximum utılization of the core under abnormal as well as under normal operating conditions.

An optimum balance point exists between measurement and other methods. From an analytical standpoint, complete coverage of all operating conditions would be, if not impossible, impractical. Similarly, complete instrumentation would not be economically feasible. A judicious mixture of analysis and measurement is the answer.

This article reviews in-core instrumentation technology, with emphasis given primarily to aspects of the technology peculiar to incore reactor measurements. Each section is devoted to a particular type of measurement, and the context of each measurement is given to assist the reader in understanding the particular method and its applications. 


\section{RADIATION MEASUREMENT}

Radiation measurement is undoubtedly the most rewarding type of measurement avallable to reactor technology. Practically every parameter of interest in a reactor core can be determined with flux-measuring techniques.

Operational power-distribution control is the most obvious application of radiation measurement. The advent of larger power reactors has been a great incentive to in-core measurement of radiation flux. The large reactors are relatively loosely coupled. That is, the average migration length of the neutrons in the core is small relative to the dimensions of the core; hence various regions of the core operate relatively independently of each other. As a consequence the indication from an external flux detector, sensing primarily the region of the core closest to it, 1s, in general, of limited value to the operator. Other regions of the core can be operating at considerably different power levels. Under these circumstances the degree of utilization of the core depends on the operator's knowledge of the power distribution in the core. The distribution can be determined by analytical methods, by measurement, or by a combination of both techniques.

The relation of neutron flux to local power (average power density in small region of the core), $\mathrm{P}_{1}$, is

$P_{1}=E \Sigma_{f_{1}}(n v)_{1}$

where $E$ is the energy per fission, $\Sigma_{f_{1}}$ is the local macroscopic fission cross section of the fuel, and (nv) is the local neutron flux.

A simplified reactor model of the power distribution in the reactor core helps to explain the application of radiation montoring to powerdistribution measurements and sources of error. ${ }^{3}$ Assume that the reactor can be divided into "n" identical volumes, each containing a flux monitor. Further assume that within each volume the flux is uniform. Thus, if the flux can be accurately sensed, the following relation strictly applies:

$\frac{S_{1}}{S_{j}}=\frac{p_{2}}{p_{j}}$

where $p_{1}$ is the power generated in $1 / h$ volume and $S_{1}$ is the signal from the 1 th detector. That is, the signals provide the relative power distribution of the core.

The power distribution can be absolutely determined by application of a normalizing factor, $\mathrm{C}$, obtained as follows:

$$
\text { C } \frac{P}{\sum_{1} S_{1}}
$$


where $P$ is the total reactor power. Therefore

$P_{1}=C S_{1}$

In a practical system, of course, these conditions do not exist. Monitored volumes are not isotopically identical, flux distribution within each monitored volume is not unform, and the volumes are not necessarily of equal size. Corrections must be applied to relate the average power in the monitored volume to the flux at the detector and to relate the flux at the detector to the signal from the detector.

The preceding analysis applies equally well to a system employing gamma-flux-level monitors when the reactor has operated in a steady state for a considerable length of time. During perıods after power transients, however, the gamma-level distribution does not precisely correspond to power-level distribution. The gamma activities of the fission products, each of which has its characteristic half-life, compose a delayed component of gamma flux that is a function of the operating history of the fuel. The delayed component accounts for approximately 40 percent of the total gamma level under equilibrium conditions. Under transient conditions this component has roughly a 1.2-day half-life after the first $10 \mathrm{sec}$; hence the appropriateness of a gamma-monitoring system depends on its application. Only where significant variations need be monitored is the delayed gamma component of concern.

Postoperational determination of both integrated and quasiinstantaneous power distribution that existed immediately before reactor shutdown is possible by use of gamma-sensitive ion chambers to scan the fuel elements. Selected elements are removed from the core to a remote location in the pressure vessel. Axial scans of gamma activity can reveal both power distribution before shutdown and burnup or integrated flux. The gross gamma activity shortly after shutdown indicates the former, and the activity of the longer half-infe isotopes after several days indicates the latter.

The locating of falled fuel elements is another interesting application of in-core ion chambers. In large reactor cores the emission of short-lived fission products from a ruptured element can be modulated by perturbation of the power level in the region of the fallure. If the overall reactor power is maintained constant, correlation of the effluent activity in the power distribution as revealed by the in-core fluxmonitoring system can define the location of the fallure to within a few fuel bundles.

The use of ion chambers to detect boiling within a reactor core has been demonstrated experimentally. Vapor bubble formation super1 mposes on the frequency spectrum of the signal from a local neutronflux monitor a frequency spectrum dependent on the bubble-formation 
rate at various nucleation centers on the adjacent heat-transfer surface. By electronic means the change in signal spectrum can be indicated. The detection of boiling is of interest in the operation of pressurizedwater reactors.

A method of protection against burnup based on neutron-flux monitoring suggests itself. Although it has not been verified by test, there is good reason to believe that the onset of transition boiling, because of its distinct character, would cause a characteristic change in frequency spectrum of the neutron-flux signal; thus a safety system might be devised to protect a reactor against burnout. By rapid reduction of power when the transition bolling stage is indicated, burnout due to the more advanced stage, known as film boiling, could be avolded.

A number of highly sophisticated measurements have been suggested, for which a relatively high-frequency in-core reactivity oscillator $(>1 \mathrm{cycle} / \mathrm{sec}$ ) would be used and the spatial dependence of the amplitude and phase of the flux oscillation would be determined with ion chambers. From this information diffusion lengths and migration lengths might be determined. ${ }^{5}$

\section{Material Activation}

The classical method of neutron-flux measurement is by material activation. Basically the method involves exposing an activation material to a neutron flux for a fixed amount of time, withdrawing the material, and determining the activation at a known time after withdrawal. Based on the assumptions that the irradiation time is short relative to the decay time and that the neutron flux is constant, the relation of the activity of the material, $\mathrm{A}$, to the flux level, $\phi$, seen by the material is as follows (for a single activity):

$$
\mathrm{A}=\frac{0.69}{\mathrm{~T}} \Sigma_{\mathrm{a}} \phi\left(1-\mathrm{e}^{-069 \mathrm{t}_{1} / \mathrm{T}}\right) \mathrm{e}^{-069 \mathrm{t}_{2} \mathrm{~T}}
$$

where $\mathrm{T}=$ half-life of the isotope of interest

$$
\begin{aligned}
\Sigma_{\mathrm{a}} & =\text { macroscopic cross section of the material } \\
\phi & =\text { neutron-flux level } \\
t_{1} & - \text { irradiation time } \\
t_{2} & - \text { decay time (time between removal and counting) }
\end{aligned}
$$

The validity of the preceding relation depends on the correctness of the assumptions and on the preciseness of the times involved. Furthermore, the value of the neutron microscopic cross section used in tive calculation of the macroscopic cross section must be based on the same neutron-energy spectrum as that being measured. Otherwise, analytical corrections are required because of the general dependence of neutron cross sections on neutron energy. 
Practically, an element or isotope is chosen to give an appropriate activity for the flux range of interest and a reasonable irradiation time. Complications arise owing to extraneous activities from other nuclear reactions in the element or matrix material. An extensive technology exists in the field of activation analyses. ${ }^{6}$

A wire-activation system is a valuable part of most in-core instrumentation systems. It can be the primary source of in-core power-distribution data, or it can be a calibration means for a fixed in-core detector system. The simplest way to accomplish wire activation is to insert a wire manually into a dry thimble, withdraw it after irradiation, and scan it with a crystal-photomultiplier scanning head. The Yankee pressurized-water reactor employs an elaborate system, which includes remotely controlled insertion, irradiation time, withdrawal, and activation scanning. ${ }^{7}$ The flux profile is immediately plotted by an $x-y$ recorder and an indexing device in the reactor control room. Multistrand carbon-steel zctivation wires are used. The outer strand on this wire is in the form of an open helix that permits the motors to drive it by a geared drive wheel. The normal $\mathrm{Mn}^{55}$ content of the carbon steel, which is activated to $\mathrm{Mn}^{56}(2.56-\mathrm{hr}$ half-life), serves as the activation isotope.

Eight wire drives serve 22 thimbles through the Yankee core. Special solenoid-activated switches route the activation wires to the chosen core thimble or to a thimble running past the scanning head.

Flowing argon gas (1.83-hr half-hfe) as an activation medium has been used in the Oak Ridge Research Reactor. ${ }^{8}$ The system provides a continuous indication of flux. It has the advantage of a simple gas line in the core, but it has a rather complicated system for handling gas outside the core. Gas flows into and out of a capsule, the volume of which is large compared with that of the tubing; hence the average residence time of the gas in the position chosen for the capsule is long compared with its transit time.

Average irradiation time, $t$, is then taken to be

$\mathrm{t}=\frac{\mathrm{V}}{\mathrm{F}}$

where $\mathrm{V}$ is the volume of the capsule and $\mathrm{F}$ is the flow rate. Of course, a correction for temperature of the capsule must be used.

Activation techniques promise to be a valuable tool in the foreseeable future. The ease and economy with which a minimum experiment can be performed and the precision which can be attained are strong arguments for this method. In addition, the integrating ability and the information on spectral energy obtanable through the use of isotopes with threshold reactions are unique characteristics of this approach. 


\section{Ion Chambers}

Ion chambers are by far the most widely used type of radiation detector for in-core flux measurement. They are strongly recommended because of their small size, linearity of response, and high tolerance to in-core ambients. The entire flux range of present-day cores, from startup to the upper power limits, can be monitored by ion chambers.

In brief, an ion chamber consists of two electrode surfaces separated by a gas gap, across which a d-c electric potential is applied. Energetic charged particles traversing the gas gap form ion pairs. The ions and electrons formed are attracted to the electrodes of opposite polarity, respectively; thus current flow is detected in the external circuit by a standard ammeter. The voltage, $V$, required to eliminate space-charge effects in a plane electrode chamber and, hence, collect all the charge is ${ }^{g}$

$\mathrm{V}=\mathrm{c}\left(\frac{\mathrm{Ne}}{\mu_{+}}\right)^{1 / 2} \mathrm{~d}^{2}$

where $\mathrm{c}=$ constant

$\mathrm{N}=$ volume rate of ion-pair formation

$\mathrm{e}=$ electronic charge

$\mu_{+}=$mobility of the positive ion

$\mathrm{d}=$ distance between electrodes

The desirability of close electrode spacing and high ionic mobility to avoid a high saturation voltage dictates the design of the chamber.

Any ion chamber is gamma sensitive by virtue of the direct photoionization of the gas; but, primarily, it is gamma sensitive by virtue of the photoelectrons ejected from the walls, which have a much higher electron density than the gas itself.

Neutron sensitivity is imparted to a chamber by including an isotope which undergoes a neutron reaction [i.e., $\mathrm{B}^{10}(\mathrm{n}, \alpha) \mathrm{Li}^{7}, \mathrm{U}^{235}(\mathrm{n}, \mathrm{f}) \mathrm{fp}$ ] which releases ionized particles. For fast neutrons recoil protons can be utilized as the charged particles.

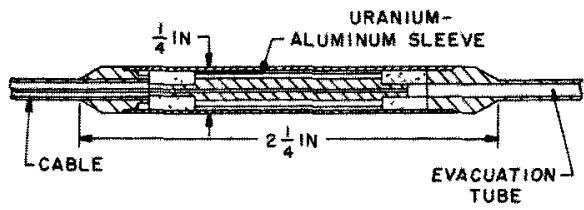

Fig. 1-Dresden in-core fission chamber. ${ }^{10}$

Fixed-position in-core ion chambers, primarily, have been used thus far to monitor in-core power distribution. Typical of these is the type used in the Dresden reactor shown in Fig. 1. These ion chambers 
are $1 / 4 \mathrm{in}$. in diameter and $2 \frac{1}{4} \mathrm{in}$. long. They have an active length of 1 in. with a $1 / 8-1 n$. coaxial alumina-insulated cable. Alumina insulation, argon gas, and type 304 stainless steel are used exclusively in the pressure vessel with the exception of the $\mathrm{Al}-20 \mathrm{wt} \% \mathrm{U}$ alloy sleeve in the chamber, which provides the neutron sensitivity.

The alloy-sleeve technique is used rather than an electrodeposited $\mathrm{U}_{3} \mathrm{O}_{8}$ coating because it provides greater control of the chamber sensitivity. Electrodeposited oxide coatings tend to vary in both point-topoint thickness and total amount. The alloy, however, is highly uniform; hence the sensitivity becomes simply a matter of maintaining dimensional tolerances and gas density. In addition, the alloy promises high tolerance to neutron irradiation because of the low atomic percent of fissionable isotope (one-tenth of the oxide coating); therefore the atomic percent burnup of the alloy after a given neutron dose (nvt) is low relative to an oxide coating.

Bolling water at $542^{\circ} \mathrm{F}$ and 1000 psi is the operating medium for this chamber. In bolling-water reactors no gas seal is required between the chamber and the cable because the temperature along the chamber and the cable is essentially uniform except for the small fraction of the assembly outside the pressure vessel. In situations in which the chamber temperature varies, a gas seal is needed. Changes in gas density in the chamber which result from gas flow due to temperature gradient in the assembly would otherwise cause sensitivity changes.

The neutron sensitivity of these chambers is approximately $5 \times 10^{-18}$ $\mathrm{amp} /$ neutron $/ \mathrm{cm}^{2} / \mathrm{sec}$, whereas the gamma sensitivity is $3 \times 10^{-14}$ $\mathrm{amp} / \mathrm{r} / \mathrm{hr}$. In the power range $10^{12}$ to $10^{14}$ neutrons $/ \mathrm{cm}^{2} / \mathrm{sec}$, the gamma contribution to the signal is quite small, of the order of 1 percent.

Barring mechanical damage due to handling, these chambers have demonstrated high reliability. Many of them continue to operate well beyond $10^{21}$ neutrons $/ \mathrm{cm}^{2}$, which is equivalent to about one year of reactor operation. Ultimately, the decrease in neutron sensitivity due to uranium burnup limits the useful life of the chamber.

The Dresden in-core power-monitoring array consists of 16 assemblies, each of which includes 4 ion chambers and a dry thimble to accept an activation wire for calibration purposes. The 64 chambers are distributed 16 each at 4 elevations in the core.

The chambers are calibrated immediately after installation to correct for variations in the as-built sensitivity by the irradiation of wires in the dry thimbles of each of the 16 assemblies. Periodically thereafter they are calıbrated to correct for uranium burnup. By the method previously described, the normalization factor is obtained which permits indication in terms of rated power. By periodic adjustment of the gain of the signal amplifier to account for these correction factors, 
the chambers are made to indicate percentage of full power in the vicinity of the respective detectors.

The adjusted signals are displayed in the control room in a special console. The positioning of the indicators on the console is such as to preserve the spatial relations of the assemblies to each other and to the control rods that run parallel to the assemblies in the core. Electronically, the highest of the four indications from each assembly is selected and displayed. The chamber whose signal is selected is indicated by a light. Manual means are also avallable for monitoring the other outputs.

Traversing ion chambers can also be used to monitor reactor cores. A system that utılizes flux wires for low-power operations and ion chambers for high-power operation is planned for the Experimental Gas Cooled Reactor at Oak Ridge National Laboratory. The ion chambers can be used as the primary means of monitoring the power distribution in the core, or they can be used to calibrate fixed in-core detectors. The chamber-cable probes are inserted into a total of 18 thimbles, which are sealed to the reactor atmosphere and open to the air. The chambers are positioned by a flexible, multiple-strand cable, the core of which is a triaxial electrical lead. The outer-wire strand of the cable is an open helix, which meshes with a geared drive wheel. The cable can be driven manually or electrically.

The chamber and the wires of the cable are of commercially pure titanium. Quartz fiber is used as electrical insulation in the cable, and Forsterite is used as insulation in the chamber. The cable and chamber must operate in air-filled thimbles, which are at $1075^{\circ} \mathrm{F}$. Gamma and neutron heating raises the temperature of the chambers to about $1200^{\circ} \mathrm{F}$. This temperature permits the use of titanium, which has low activation; temperatures of $1300^{\circ} \mathrm{F}$ or more, however, would preclude the use of titanium in air because of rapid deterioration of the metal due to gas absorption and chemical combination with air, with subsequent embrittlement.

The chambers are lined with $\mathrm{B}^{10}$ to provide the required neutron sensitivity. Boron is chosen in this instance to minimize the radioactivity of the chamber, which is withdrawn into an accessible area when it is switched between thimbles. The relatively rapid burnup of the boron ( 33 percent at $10^{20}$ neutrons $/ \mathrm{cm}^{2}$ ) is acceptable because it is planned to use the probes for periodic traverses only. This system provides simultaneous sensing and indicates the flux along the axes of the thimbles. Two-pen recorders in the control room plot flux against position along the respective lines of travel through the core. The continuous flux plots produced by this system make it particularly valuable for reactor operational tests.

The cables are switched from thimble to thimble in much the same way as the wire in the wire-1rradiation system previously described. 
Switching devices permit 6 cables to be used in 18 thimbles. Cross calibration is made possible by sequential insertion of each of the 6 chambers into a common thimble.

The capabilities of ion chambers are impressive. Chambers are currently avalable which will operate at $1500^{\circ} \mathrm{F}$ for extended periods of tıme. ${ }^{11}$ Nickel-based alloys, such as Nimonic-75, have been used successfully at these temperatures; however, problems due to temperature-induced electrical leakage in the cables can be limiting at much lower temperatures, particularly with chambers using coaxial cables. The effect of temperature on the resistance of $20 \mathrm{ft}$ of cable is shown in Fig. 2. The cable leakage, which is indistınguishable from the signal, is reduced by employment of a triaxial cable, which uses the inner conductor as an electric guard. The voltage across the cable producing the extraneous signal is then primarily due to the contact potentials, which, in general, exceed the drop across the ammeter, particularly if used with a feedback amplifier, which has a very low $d-c$ input impedance. An ion chamber and an electrically guarded cable are shown in Fig. 3.

In a reactor the long-life fission products give rise to a signal from in-core ion chambers which is not related to the instantaneous flux level. This gamma current and cableleakage current determine the

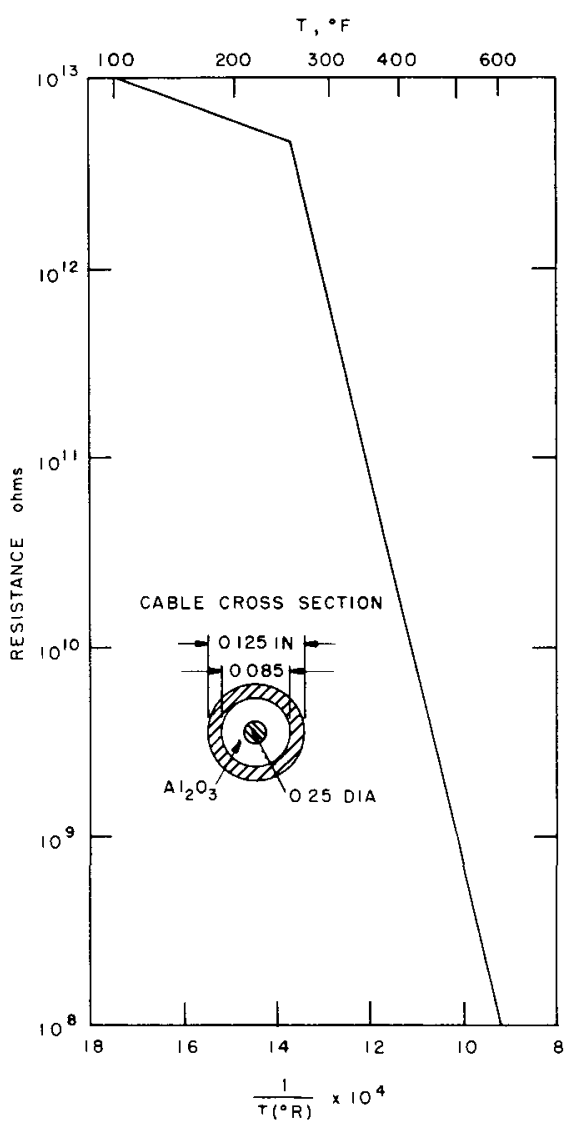

I 1g. 2- Lffect of temperature on cable resistance lower operating range of a neutron chamber. These currents also preclude the use of low-cross-section threshold reactions [1.e., $\left.\mathrm{Np}^{237}(\mathrm{n}, \mathrm{f}) \mathrm{fp}\right]$ that provide low sensitivity and, hence, small d-c signals.

An ingenious method of discriminating against extraneous signals has recently been given considerable attention. The neutron-induced 
current in an ion chamber is due to large numbers of individual current pulses occurring essentially randomly in time. The current can be represented as the sum of a $d-c$ component and a varying, or noise, component. The average mean-square deviation of the noise component can be expressed as follows:

$\overline{(y-\bar{y}})^{2}-N \int_{0}^{\infty} f(t)^{2} d t$

where $\mathrm{N}$ is the average rate of pulses, $\mathrm{f}(\mathrm{t})$ is the time-dependent amplitude function of the individual pulse, and $y-\bar{y}$ is the deviation. It follows that the noise power is proportional to the flux, and the average deviation is proportional to the square root of flux. ${ }^{12,13}$ Meters, such as the Ballantıne RMS meter, model No. 320, measure true root-meansquare voltage.

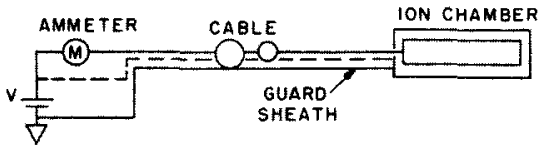

rig 3 - Ion chamber and electrically guarded cable

The preferential weighing of the neutron signal results from the quared amplitude factor. Neutron pulses, from either (n, $\alpha)$ or $(\mathrm{N}, \mathrm{f})$ reactions, are far larger than gamma pulses and tremendously larger than the electronic events that cause cable leakage; hence it is possible in this manner to measure neutron signals that would be entirely swamped by cable leakage or gamma signals in the d-c mode.

With this technique the capabilities of ion chambers are significantly increased. A practical limitation on operating temperatures of an ion chamber becomes the current capacity of the power supply. A current of the order of $1 \mathrm{amp}$ might be drawn from the supply owing to cable conduction at the voltage required to saturate the chamber.

Because of their wide range of linearity and their tolerance of the most severe reactor environments, neutron-sensitive ion chambers will continue to be valuable sensors for in-core reactor measurements. Current ion-chamber development is aimed at greater lifetımes in the reactor and also at increased uniformity of sensitivity from chamber to chamber. It would be highly desirable to install flux monitors in the permanent core structure and have them operate accurately with a predetermined sensitivity for the infetime of the reactor plant, e.g., 20 years.

Gamma chambers have a sensitivity that is independent of integrated neutron exposure; however, long-term effects such as gas absorption or gas liberation from the chamber materials have not been evaluated. In addition, the common structural materials, such as stainless steel and titanium, might undergo appreciable transmutation and might suffer severe physical changes under very prolonged irradiation. 
Currently, effort is being devoted to breeder or regenerating detectors. ${ }^{14,15}$ In these detectors a mixture of fertile and fissile isotopes is utilized to effect a sensitivity that is relatively stable in comparison to pure $\mathrm{U}^{235}$. As the fissile atoms burn up, fertile atoms are converted to fissile atoms.

The comparatively low absorption cross sections of the fertile isotopes relative to the fissile isotopes require a large preponderance of the former; hence the detector sensitivity is low. A typical composition is 98.10 percent $\mathrm{U}^{238}, 0.75 \mathrm{Pu}^{239}, 0.85 \mathrm{Pu}^{240}$, and $0.30 \mathrm{Pu}^{241}$.

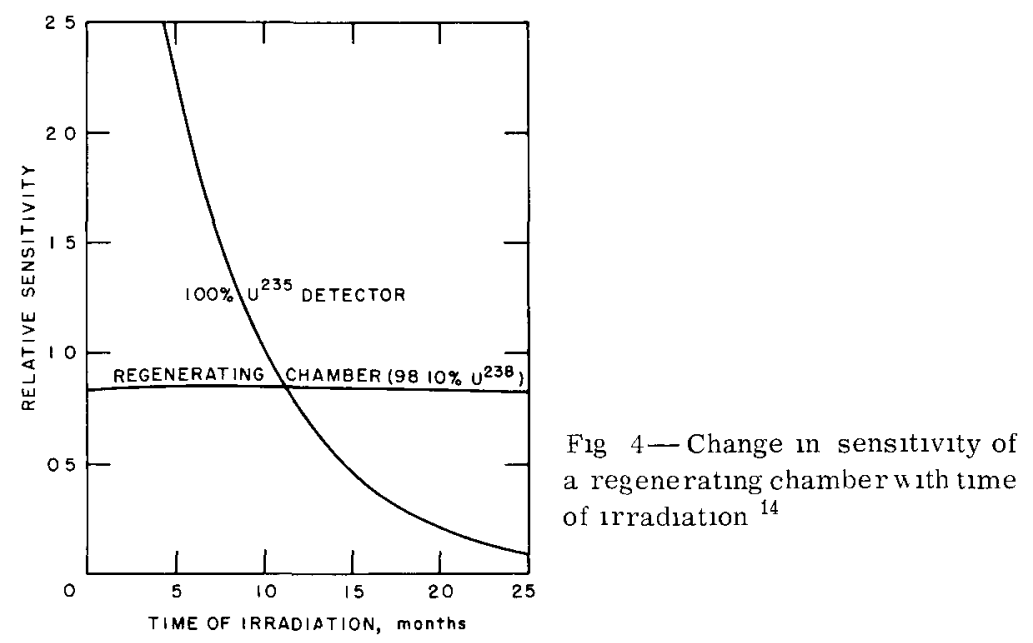

Regenerating detectors are sensitive to changes in both the ep1thermal fraction and the "temperature" of the neutrons; hence their application to situations wherein the thermal temperatures and consequently the neutron temperatures vary or wherein the epithermal fraction varies spatially (1.e., bolling-water reactors) would present problems. The value of this type of detector would depend on the care with which the detector is applied and on the degree of variation in the flux spectrum with time and location. The change in sensitivity of a regenerating chamber of the preceding composition with time is shown in Fig. 4. The thermal flux is $2.5 \times 10^{13}$ neutrons $/ \mathrm{cm}^{2} / \mathrm{sec}$. For comparison, the change for a detector with 100 percent $\mathrm{U}^{235}$ is also shown.

\section{Thermopiles}

The ease of construction and the ease of readout of thermocouples has fostered a considerable effort in the development of thermopiles utilizing this device. Thermocouples are low-impedance low-voltage 
devices; hence the insulation resistance required for the electrical leads and readout system of thermopiles is low relative to that required for ion chambers.

The basis of thermopile operation is the temperature rise of an element above ambient temperature caused by either fission or gamma heating. A simple illustration of this principle is the neutron thermopile shown in Fig. 5. The junctions are connected in series externally so as to give an output that is proportional to the temperature rise of the heat source above ambient. Ideally, the signal is proportional to the rate of

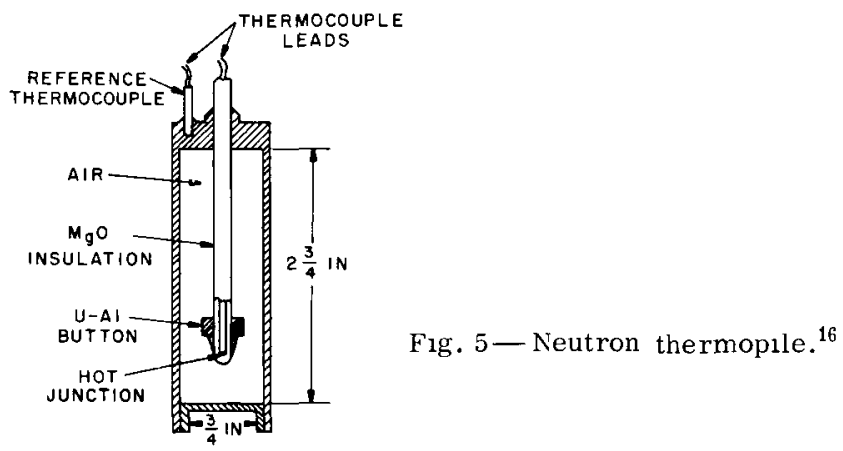

heat generation in the heat source. One junction senses the temperature of the uranium at the end of a slender column, and the second junction senses the case temperature. If all generated heat were from fission and all heat flow were conductive, the following relations would hold:

$\mathrm{Q}=\mathrm{C} \Delta \mathrm{T}=\Sigma \phi \mathrm{E}$

and

$\phi=\frac{\mathrm{C}}{\sum_{\mathrm{f}} \mathrm{E}} \Delta \mathrm{T}=\mathrm{K} \Delta \mathrm{T}$

where $\mathrm{C}=$ constant of proportionality

$\mathrm{K}=$ constant of proportionality

$\Delta \mathrm{T}=$ temperature rise

$\Sigma_{f}=$ total fission cross section of heating element

$\mathrm{E}=$ energy per fission

The facts that the gamma heating exists in a reactor and that convective and radiative heat losses occur complicate the situation. In addition, temperature dependence of the thermal conductivities adds another extraneous factor.

The thermopile described previously has a thermal time constant of about $30 \mathrm{sec}$ and a dynamic range of one decade, which is limited by 
fission-product heating in the uranium alloy. If natural uranium is used for a heat source, as it is in this case, the sensitivity becomes a complex function of integrated neutron flux because some of the $U^{238}$ will be converted to plutonium.

In an attempt to eliminate nonlinearities caused by convective and radiative heat losses and the temperature dependence of thermal conductivities, a thermopile was developed which uses electric power to nullify the temperature differential between two junctions heated by elements containing uranium of different enrichments (see Fig. 6). The electric heating is caused by the flow of current through the lowenrichment uranium element itself. Considerable skill was displayed in the development of a $\mathrm{UO}_{2}$-containing ceramic that would also serve as a heating element.

Fig. 6-- Null type thermopile. ${ }^{17}$

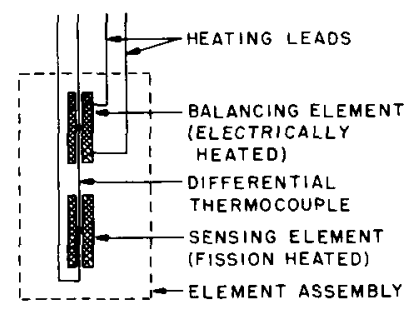

By means of a servo system, the temperature differential is automatically nullified. The power necessary to accomplish this is then proportional to the local flux; thus the dial of the wattmeter that measures this power can be calibrated in terms of neutron flux.

The thermopile neatly eliminates the sources of inaccuracy, such as stray heat losses and temperature dependence, at the expense of a rather complex detector and readout system. A system requiring a large number of such channels would be quite complex because of the readout requirements. A scanning system might be of value for large numbers of such detectors. A balance would need to be maintained between the scanning-cycle time and the amount of readout equipment.

In a prototype test of this thermopile device, fallure due to opening up of the heater circuit occurred, a common problern with in-core heaters. The measured response time was about $1 \frac{1}{2} \mathrm{~min}$.

The possibility of alternating hot and cold junctions is an attractive feature of thermopile devices. With alternating hot and cold junctions, a larger signal, in general, can be realized; however, complications due to heat transfer between junctions arise when compactness of the detector is desired.

Heating devices continue to be an alluring though somewhat elusive type of detector. The obvious advantages of basic simplicity, ease of 
construction, and ease of readout are coupled with the possibility of making a detector that physically resembles a fuel element.

It is feasible to utilize uranium in a thermopile in the form of the reactor fuel that is often of low enrichment. The possibility of a fuelelement type of detector suggests a "true power monitor" in contrast to a flux monitor. The problem of analytically and experimentally relating signal to local power is eliminated if the detector has the same configuration and isotopic content as the fuel itself; however, attempts to accomplish this have not been particularly successful owing to problems associated with the measurement of fuel-element temperatures, which are discussed later.

\section{Solid-state Devices}

Solıd-state, diode, charged-partıcle detectors are extremely attractive devices for measuring radiation. They are small, inexpensive, and extremely versatile. Their fast pulse rise time $\left(\sim 10^{-7} \mathrm{sec}\right)$ and their excellent energy-resolution capabilities (20 to $50 \mathrm{kev}$ full width-half maximum) make these sensors powerful tools in nuclear research.

Unfortunately the application of these devices thus far is limited to situations of low temperature and low radiation. Limited applications to test reactors are possible; but application to power reactors at present is impossible. Easing of the temperature limitations would certainly result in widespread application of semiconductor devices to power reactors. High-temperature materials are currently being investigated. Silicon carbide is being investigated ${ }^{18}$ for use at $500^{\circ} \mathrm{C}$. Since high radiation tolerance usually accompanies high temperature tolerance, silicon carbide detectors would be expected to have a much wider area of application.

A solid-state diode detector may be thought of as an ion chamber. When an external voltage is applied across the junction such that the potential drop is in the nonconducting direction (reversed biased), a strong field gradient is established in the region of the junction. Energetic charged particles traversing this region create free electrons and holes, which rapidly move toward the electrodes of opposite polarity, respectively.

Junctions can be formed by two methods. One method is to diffuse a doping material, such as phosphorus, into a $P$ type material from one side. The phosphorus makes the base material $n$ type, thus forming a junction. A simpler technique is to form an oxidized layer on $n$ type silicon. The oxidized layer forms a p-layer in a manner not completely understood. A conductive coating is then evaporated on both surfaces to form electrodes. The surface-barrier type of junction results in a very thin inactive layer, a "window," between the surface and the active volume. A thin window is essential to particle spectroscopy 
since energy dissipated by the particle traversing the window causes a distortion of the measured energy spectrum.

A basic surface-barrier detector can be used in a number of ways. If a thin layer of $\mathrm{U}^{235}$ is coated on the conductive coating nearest the junction, a fission detector is obtained. By use of a hydrogenous or $\mathrm{He}^{3}$ gas covering, a fast-neutron detector is realized. With two detectors

Fig. 7-Solid-state detector.

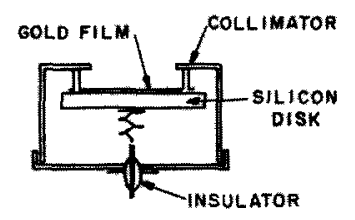

separated by a $\mathrm{He}^{3}$ volume, a simple neutron spectrometer can be realized. ${ }^{19}$ The energies of both charged particles from the $\mathrm{He}^{3}(\mathrm{n}, \mathrm{p}) \mathrm{H}^{3}$ can be electronically summed. The sum then equals the $Q$ of the reaction plus the kinetic energy of the impinging neutron. A simple solidstate detector is shown in Fig. 7.

\section{PRESSURE MEASUREMENT}

Pressure measurements have several important in-core instrumentation applications. First and foremost is the determination of flow. Although, in general, flow is predetermined by design parameters and is not controllable, it is important that it be experimentally determined in order that the design can be evaluated and safe operating limits set.

Steady-state flow conditions are, to a considerable degree, amenable to analysis; however, transient-flow analysis is extremely complex since the behavior of the entire reactor system enters into the problem. Particularly in two-phase systems, the flow is interrelated with the power response of the reactor. An increase in power results in an increase of the void fraction; consequently the pressure differential across the core available for flow increases.

In pressurized-water reactors the rate of flow coastdown after pump failure is an important figure. The flow behavior in the case of pump failures becomes of critical importance in the specification of safe modes of reactor operation.

The monitoring of the internal pressure buildup of fuel elements is another pressure measurement of interest to reactor designers. The internal gas pressure can be related to the rate of fission-product release of the fuel. Also, the pressure buildup has important mechanical ramifications. On thin-walled elements particularly, internal pressure can be an important consideration in the calculation of cladding stress and strain and ultimate life of the fuel elements. 


\section{Pressure Differential}

Differential pressure is the time-honored method of determining fludd flow. Bernoullı's equation gives rise to the basic relation between flow and differential pressure across a primary flow element:

$\mathrm{q}=\mathrm{KD}^{2} \sqrt{\mathrm{H}}$

where $D=$ diameter of primary flow element

$\mathrm{H}=$ differential pressure

$q=$ flow rate

$\mathrm{K}=$ constant

With a pair of pressure taps, one immediately upstream of the orifice and the other downstream, one can determine the flow from the differential-pressure measurement. Several types of orifices are commonly used: the Venturi tube, the primary flow element, and the orifice plate. The choice of restriction depends on the space avallable. the pressure differential desired, and the amount of permanent pressure loss that can be tolerated.

In a reactor core special conditions prevall that present restrictions on measurement of flow. Avallable space along the line of flow, as well as the space in a radial direction, is usually severely restricted; hence provision of sufficient length of straight flow path to establish laminar flow upstream of the orifice is a problem, as is the run of the pressure tap lines.

The pressure drop that can be introduced is still another important consideration. Since the measured channel is normally in parallel with other unperturbed channels, induced pressure drop that is significant relative to the total drop across the core is prohibited. Redistribution of flow as a result of sensor installations can invalidate flow measurements. This consideration is pertinent in boiling-water reactors, particularly natural-circulation reactors, where low total pressure drops across the core are to be found. Permanent loss of pressure due to a flow nozzle can be as low as 10 percent or as high as 50 percent of the measured differential. Usually tolerable pressure drop and axial distance avallable are conflicting limitations.

Long leads are a fact of life for in-core measurements. With flow measurement long leads become an important consideration in the determination of the speed of response of the system.

Error in indication due to gas in the pressure tubes can also be a problem in reactors. In bolling-water reactors the tubes normally traverse a saturated portion of the core; hence vapor formation in the lines is a definite possibility. By thermal lagging and periodic purging of the lines, this problem can be alleviated. The ability to purge also permits the removal of gas in the lines due to radiolysis. 
The proper design of a differential-pressure channel requires analysis of the entire system as a unit. Tubing length and diameter, as well as the volume and spring constant of the differential-pressure transducer, are important parameters of the system. Since the water flow in the tubes is involved in transient measurements, flow characteristics of the water must be considered.

The mathematical description of the motion of the diaphragm takes the form of a second-order differential equation: ${ }^{20}$

$M \frac{d^{2} x}{d t^{2}}+C \frac{d x}{d t}+k x=x(t)$

where $M=$ effective mass of the system

C - damping coefficient (primarily viscous-flow pressure drop)

$k=$ restoring force of the transducer diaphragm

$X(t)=$ forcing term due to the flow

Some interesting results are obtained from the complete analysis of the system. Throttling the tubing at some point has a negligible effect on the natural frequency of the system, for the effective mass is increased only slightly. However, the damping coefficient is increased, and the deviations from true response due to oscillation are thus greatly decreased.

The effect of increased tube diameter is also somewhat surprising. As long as the transducer-diaphragm diameter is larger than the tubing diameter, increasing the tubing diameter increases the frequency response of the system. This increase is due to the fact that the effective mass of the system is a function of the square of the ratio of the area of the diaphragm to the tubing.

A system with 20-ft lead tubes of $0.150 \mathrm{in}$. inside diameter and a commercially avallable transducer gives a system resonant frequency of about 45 radians/sec.

\section{Absolute Pressure}

The measurement of absolute pressure, such as is needed for internal measurement of fuel elements, requires a local transducer. Additional volume that would be added by a pressure tube to an external transducer would severely alter the system. The pressure, and hence the expansion and distortion of the system, would also be modified.

To employ a completely electrical transducer in a reactor core requires extremely careful design. To employ an electromechanical transducer compounds the problem. Simplicity becomes an essential design feature.

In an attempt to meet these requirements, an in-core pressure transducer has been designed to monitor gas-pressure buildup in an 
oxide fuel element. The principle of operation is as follows: A slack diaphragm in the transducer is exposed to the gas pressure to be measured on one side and a variable gas pressure on the other side. The variable pressure is controlled externally. With an inbalance of pressure in one direction, the diaphragm provides contact between two electrodes. With a reversal of pressure differential, electrical continuity is broken; thus, by the varying and monitoring of the external pressure and the electrical circuit continuity, the internal pressure can be determined with essentially zero variation in the monitored volume. The usual mode of operation is to vary the controlled pressure in a sawtooth fashion over a suitable range. The fraction of the cycle during which electrical continuity is maintained is then an indication of pressure level of the montored volume.

Severe overpressure can be tolerated by the diaphragm because its maximum displacement is very slight and at either end of its travel it is supported across practically its whole area. Electrical contact surfaces of precious metal are used to minimize erosion of contact points.

\section{VELOCITY MEASUREMENT}

Velocity measurement in some instances serves the same purpose as pressure measurement. ${ }^{21}$ In a homogeneous stream a velocity measurement determines mass flow rate through the relation

$\mathbf{F}=\rho \mathrm{AV}$

where $\mathrm{A}=$ cross-sectional area of inlet and outlet

$\mathrm{F}=$ mass flow rate

$\rho=$ density of material

$\mathrm{V}=$ velocity of flow

Velocity measurement can determine another parameter besides flow rate that is of great interest in the investigations of the operation of bolling-water reactors-void fraction in the core. The margin between operating conditions and burnout is strongly dependent on the void fraction. By comparison of the inlet velocity, $V_{1}$, and the outlet velocity, $V_{\circ}$, of a channel, a measurement of the vold fraction at the exit can be obtained. A simplified continuity equation for the coolant can be written as follows:

$\mathrm{V}_{1} \rho \mathrm{A}=\mathrm{V}_{\mathrm{o}} \rho(1-\mathrm{X}) \mathrm{A}$

$\mathrm{X}=1-\frac{\mathrm{V}_{1}}{\mathrm{~V}_{0}}$ 
where $\rho$ is the water density and $X$ is the void fraction at the exit. It is assumed that the inlet and outlet areas are equal, that the vaporfraction density is zero, and that the inlet and outlet water densities are identical. The measurement of vord fraction is shown in Fig. 8.

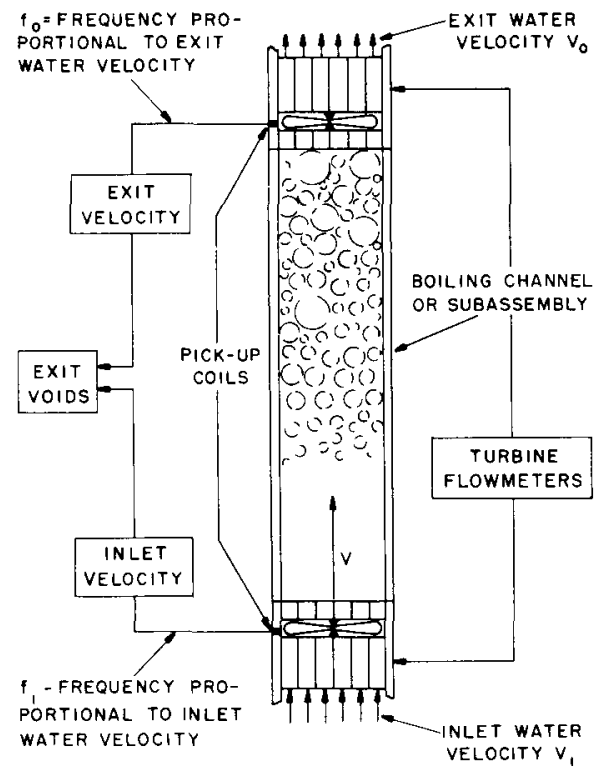

Fig. 8-Measurement of vold fraction

\section{Rotating Vane Meters}

A rotating vane meter $1 \mathrm{~s}$, in concept, ideally suited to the measurement of velocity. A vane meter consists of a multiple-blade rotor mounted on a shaft that is parallel to the axis of the line of flow. The rotor is housed in a cylinder that directs all the flow in the channel of interest past the blades. A means of sensing the rotational velocity is then provided.

An elementary analysis of the rotating vane meter results in the following relations between velocity and rotational speed of the rotor:

$\omega=\mathrm{V} \frac{\tan \beta}{2 \pi \mathrm{r}}$

where $\omega=$ angular velocity of rotor

$\beta=$ angle blade formed wath direction of flow

$\mathrm{V}=$ flow velocity

$r=$ mean radius of rotor blades 
The relation is shown in Fig. 9. The result is obvious if one considers a particle of water in contact with the vane moving past the vane with zero deflection from its initial direction.

For water reactors the rotor and housing are usually of stainless steel or Inconel for chemical compatibility. Several types of bearings, both journal bearıngs and ball bearings, have been used in vane flow-

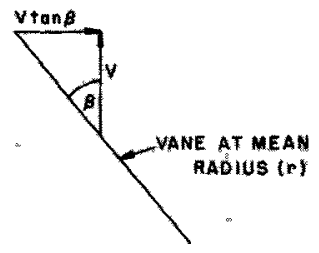

Fig. 9- Relation between

flow and rotational velocity

in a rotating vane meter.

meters. Experience with journal bearings has not been consistent. Argonne National Laboratory $(\mathrm{ANL})^{22}$ has found that Graphitar-30 is very successful and that meters using this type of bearing journal have lasted in excess of $3000 \mathrm{hr}$. Experience at General Electric Company at San Jose, Calif., however, has shown poor results with Graphitar-30. After a few hours in a test loop, the journal surface was found to be elliptical and, in some cases, generally disintegrated. Nitrided Inconel shafts in Stellite journals are now being used with fair success. Evidently results with bearings are very dependent on the specific details of application.

A coil is used to sense the speed of rotor rotation. Several variations of the general method of detecting rotational speed exist. Permanent magnets can be embedded in the rotor blades. A passive coil in the housing will then detect the passing of the individual blades owing to the variation in the magnet flux at the coil caused by the varying reluctance of the path to the magnet. Another approach is to use an active coil to detect a variation of the reluctance of the magnetic-flux path caused by rotor rotation. A splined permeable member is attached to the rotor to accomplish this. Here again results vary. Argonne $\mathrm{Na}-$ tional Laboratory reports no deterioration of the in-core signal. General Electric Company at San Jose, however, reported a 10 to 1 decrease in signal strength. Since the signal at ANL did not depend on a permeable link in the magnetic-flux path, it is conjectured that the permeability of the flux link decreased considerably at General Electric. The digital output can either be handled in its original form or be converted to analog form by a counting-rate-meter circuit.

\section{Standing-wave Measurement}

Another type of device that might be of value for measuring in-core flow, particularly of fast transients, is described in a U. S. patent. ${ }^{23}$ 
In brief, a resonant cavity is provided in the flow channel. The discontinuities of the channel geometry or other protuberance are used to provide turbulent flow. The resultant turbulence supplies energy to maintain a standing wave in the resonant cavity. The cavity itself can be either in line or in the form of a stub perpendicular to the line of flow. The technique applies in principle to either gas or fluid flow. The frequency of the standing wave, under constant conditions of temperature and pressure, is determined solely by the dimensions of the resonant cavity. The amplitude, however, is a function of the flow velocity. Therefore, if the amplitude of the standing wave is measured, the flow velocity is monitored.

The wave amplitude can be sensed either by monitoring of the water pressure or, perhaps more conveniently, by strain gauges on the walls of the resonant cavity. Strain gauges are desirable because of their small size. In addition, the application of strain gauges is a welldeveloped technology.

An interesting feature of the resonant-cavity method of flow measurement is its ability to measure fast flow transients. If the resonant frequency is looked upon as a carrier, then flow transients are indicated as amplitude modulations of the carrier. By means of an electronic demodulation system, the fast transients can be indirectly indicated.

\section{TEMPERATURE MEASUREMENT}

Except for fuei-element integrity, temperature is the most important parameter in a reactor core; therefore temperature distribution is valuable information regarding core conditions. Information on temperature distribution in fuel sheathing aids in the protection against metallurgical changes in the fuel due to chemical reactions that have threshold temperatures. Likewise, loss of strength due to excess temperature can be forestalled by temperature monitoring.

Axial center-line temperature monitoring of the fuel elements is of great help in precluding mechanical and isotopic distribution changes in the fuel, particularly in oxide-fuel cores in which center-line fuel temperatures often approach $4000^{\circ} \mathrm{F}$.

In spite of the importance of temperature data to both the reactor designer and the reactor operator, there has been only a limited amount of temperature monitoring of specific points in reactors. This applies to analytical measurements as well as control measurements. The reasons are many and varied. Contrary to popular opinion, except for a few notable instances, valid measurement of temperature is a difficult operation. ${ }^{24}$ Some of the reasons for this situation are discussed in this section. 


\section{Thermocouples}

The most successful applications of thermocouples are those in which the temperature is sampled in an essentially isothermal environment. Examples of this type of measurement are inlet and outlet coolant temperatures and temperatures of such massive structural elements as pressure-vessel and core-support members.

The use of thermocouples for this type of measurement is a welldeveloped technique. An in-core thermocouple for water reactors has a metal tubing sheath that is welded shut at the tip to form a hermetic jacket. The junction can be either fused into the tubing closure bead or isolated. In the latter configuration the time response is longer, but problems due to induced mechanical strains in the leads are minimized. Inorganic insulation, usually aluminum oxide, is used to insulate the leads from themselves and from the tubing sheath. Magnesium oxide can also be used; however, if the sheath falls and moisture leaks into the magnesium oxide, the sheath can be completely destroyed. Magnesium oxide under the proper conditions of temperature absorbs moisture and expands. As a result the sheath is grossly ruptured, and the insulation is released into the coolant.

The main fabrication problem has been sheath integrity. The integrity requirements for thermocouple sheaths are as stringent as those for fuel cladding. Any leakage of moisture into the insulation, even aluninum oxide, eventually lowers the resistance of the sheaths to the point at which the thermocouple becomes inoperative. Electrolytic action or corrosion shorts the leads in a relatively short time. Fortunately this problem, at least for stainless-steel-clad thermocouples having sheath outside diameters of $1 / 8 \mathrm{in}$. or larger, has been solved. Conformance with military specification MIL-T-22300 for thermocouples and MIL-T-18063 for tubing essentially precludes integrity problems in bolling- or pressurized-water reactors. Smaller thermocouples with thinner sheaths or thermocouples in other ambient conditions, however, undoubtedly present new problems.

The most common lead configuration is simply two wires; some advantages are claimed, however, for a coaxial configuration of the thermoelectric materials. The coaxial configuration allows leads of larger cross section for a given sheath size than do two wires; thus the effects of inhomogeneities in the thermoelectric materials are reduced, and the resistance of the leads is reduced.

Neutron radiation, as an ambient condition in reactors, has sigmificant effects on the behavior of thermocouples. Couples utilizing materials with significant neutron-absorption cross sections would be expected to undergo change as a result of transmutation, and this effect has been confirmed. ${ }^{25}$ Fortunately Chromel and Alumel are relativels unaffected by exposure to neutron flux. Chromel-Alumel junctions are 
generally applicable for monitoring temperatures up to $1800^{\circ} \mathrm{F}$ and, with certain restrictions, to $2200^{\circ} \mathrm{F}$. For monitoring temperatures characteristic of oxide fuel elements and advanced reactors, materials such as platınum, rhodium, tungsten, and rhenium are required. For these materials transmutation becomes a significant effect. In junctions of platinum to platinum-10 wt. $\%$ rhodrum alloy, the change is due mainly to the transmutation of rhodium to palladium. The absolute error, $\Delta \mathrm{T}$, in terms of the integrated exposure and the temperature, $\mathrm{T}$, is measured as follows:

$$
\Delta \mathrm{T}=\left(0.15+0.25 \times 10^{-3} \mathrm{~T}\right) \mathrm{T} \times 10^{-22} \phi \mathrm{t} \sigma(\mathrm{T})
$$

where $\phi=$ neutron flux

$\mathrm{t}=\mathrm{t}$ ime

$\mathrm{T}=$ temperature, ${ }^{\circ} \mathrm{C}$

$\sigma(T)=$ cross section of rhodium at temperature $T /$ cross section of rhodium at $150^{\circ} \mathrm{F}$

For example, the error at $1000^{\circ} \mathrm{C}$ after $10^{21}$ neutrons $/ \mathrm{cm}^{2}$, where the flux temperature is $150^{\circ} \mathrm{F}$, is $45^{\circ} \mathrm{C}$, a sizable error.

Likewise, the error in indication of a platinum resistance thermometer can be written as follows:

$\Delta \mathrm{T}=49 \times 10^{-22} \circ \mathrm{t} \sigma(\mathrm{T})$

Under similar conditions the error would be $4.9^{\circ} \mathrm{C}$.

An entirely new set of problems arises when attempts are made to measure the temperature of a given point in a region of high temperature gradient, e.g., the surface temperature of a fuel element. Any attempt to measure surface temperature usually perturbs conditions to the degree that the measurement does little to refine the estımate of the true temperature. An internal couple replaces fuel and reduces heat flux. An external couple can, by varying the coolant flow and increasing the area of heat transfer, either increase the temperature or decrease it at the point of measurement.

Various techniques are used to minimize the perturbation. In gascooled reactors where bare wires can be used at the junction, the error can be minimized by spot welding the junction to the fuel cladding, and the thickness of the junction can thus be reduced to a minımum. ${ }^{26}$

Another technique used in a water environment is to embed a thermocouple in the fuel-element cladding. ${ }^{27}$ The magnitude of the perturbation resulting from this configuration depends on the net disturbance of normal heat flow. With some cladding materials it is possible to reduce the net effect to a reasonable size by choosing a thermocouple sheath that has a total thermoconductivity equal to that 
of the displaced cladding material. Cladding of sufficient thickness to permit the use of this technique is unusual, however. Use of thermocouples to measure fuel-cladding temperatures is shown in Fig. 10.

Finally, and this reservation applies to measurements of both internal fuel temperatures and surface temperature, it is virtually impossible to determine whether or not the particular point at which the temperature is measured is representative of the temperature in the vicinity. Dimensional variations in fuel-element and core structure, both macroscopic and microscopic, can cause significant deviations in the temperature distribution.

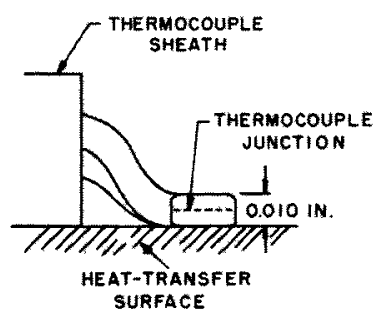

Fig. 10-Measurement of fuel-cladding temperature with thermocouples.

Thermocouples, because of their conveniently small size and relative ease of application, will continue to be employed in and around reactors in large numbers for bulk-temperature measurements; however, their use for measuring temperature distributions continues to pose very difficult problems. Other methods of temperature measurement might well be given increased attention because of the limitations in thermocouple methods.

\section{Sonic Flow Orifices}

One alternate method of measuring gas temperature will be used in the Experimental Gas Cooled Reactor. This reactor is graphite moderated and gas cooled. Objectives of its temperature-measuring system are that the system indicates the exit gas temperature of the individual channels accurately, within \pm 1.2 percent, for a period of 10 to 20 years without maintenance. It would be very difficult to realize these objectives with a thermocouple system. Long-term calibration drift due to transmutation by neutron absorption and metallurgical changes due to corrosion would most probably result in calibration drift considerably in excess of this specified amount. In addition, a significant incidence of failure would be expected.

The proposed system is based on the temperature dependence of sonic flow through an orifice. ${ }^{28}$ The relation of sonic flow rate to nozzle temperature is

$\mathrm{W}=\mathrm{CA} \frac{\mathrm{P}}{\sqrt{\mathrm{T}}}$ 
where $\mathrm{A}=$ throat area of nozzle

$\mathrm{P}=$ absolute pressure upstream

$\mathrm{C}=$ constant

$\mathrm{T}=$ absolute temperature

$\mathrm{W}=$ mass flow rate

If two nozzles are put in series, both of which have sonic flow through them, by the temperature control of one, the temperature of the second can be determined by a pressure-ratio measurement. Since the mass flow through both nozzles is identical, the temperature of the first nozzle, in terms of its upstream pressure, and the upstream pressure and temperature at the second nozzle are

$\mathrm{T}_{1}=\mathrm{KT}_{2}\left(\frac{\mathrm{A}_{1}}{\mathrm{~A}_{2}}\right)^{2}\left(\frac{\mathrm{P}_{1}}{\mathrm{P}_{2}}\right)^{2}$

where symbols are as before and $\mathrm{K}$ is the calibration constant.

Numerous sources of error are present in the system. Some are due to variation in controllable conditions, and others are due to unavordable and uncontrollable conditions. Among the latter are gas leakage in the pressure lines and changes in the nozzle areas due to corrosion or erosion.

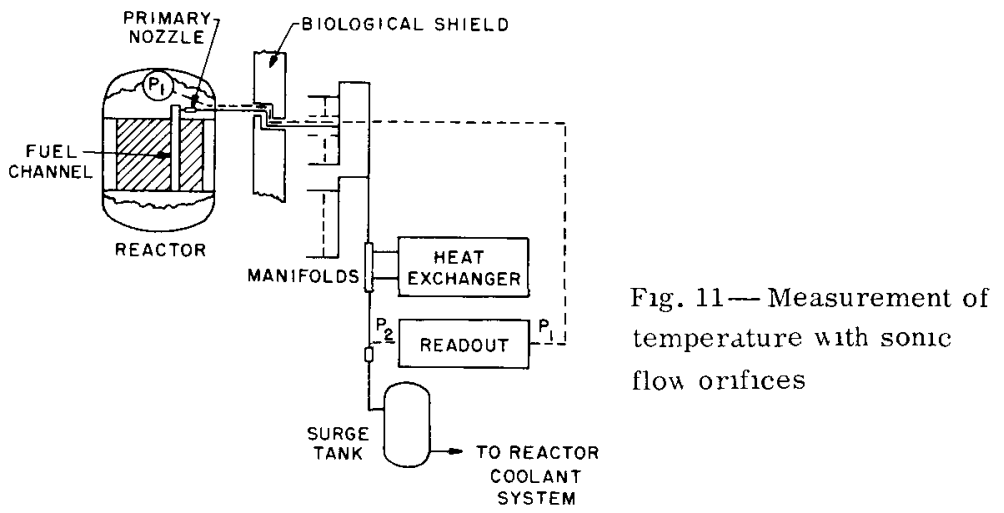

A considerable price must be paid for the simplicity of the in-core components in terms of complexity of the system external to the reactor. Figure 11 illustrates the entıre system.

\section{Capacitance Temperature Sensors}

The dependence of dielectric constant on temperature is the basis of another technique of temperature measurement. ${ }^{29}$ By the use of such 
refractory materials as alumina or beryllia, a compact probe is possible which is capable of high-temperature operation and which is tolerant of contaminating environments. In addition, if the probe is in the form of a capacitor in an oscillator circuit, the temperaturedependent frequency is in a convenient form for digital recording. The dielectric constant for beryllia has nearly a linear relation to temperature in the ranges of 1800 to $2000^{\circ} \mathrm{F}$ and 2500 to $2700^{\circ} \mathrm{F}$ with a change of slope at about $2500^{\circ} \mathrm{F}$. Of course, this linear relation is desirable. It is easy to conceive various small coaxial probes of this type that would be similar in configuration to thermocouples. Fortunately these temperature ranges are just those which are both currently of interest and difficult to measure with thermocouples.

\section{FISSION-PRODUCT DETECTION}

Safety is the prime concern in the operation of a nuclear-reactor plant as it is with any other type of industrial plant. In nuclear power plants the most serious safety hazard is the uncontrolled release of large quantities of fission products to the environs. Elaborate precautions are taken to preclude this situation, and, in the United States, the U. S. Atomic Energy Commission must approve the specified precautions for each reactor as being adequate.

\section{Coolant-activity Monitoring}

In water-cooled reactors a number of different monitoring techniques are commonly used to monitor the coolant activity. ${ }^{30}$ The simplest measurement is to monitor gross gamma activity of each coolant sample.

Sensitivity can be increased by accounting for spurious indications due to power changes. This is done by energy-spectrum analysis of the total gamma activity. Gamma activity of fission products is mainly in the 2- to $4-\mathrm{Mev}$ range. The $\mathrm{N}^{16}$ gamma activity, which is proportional to power, is in the $6-$ to $7-\mathrm{Mev}$ range. An increase in the ratio of activity in the energy range of the fission products to the high-energy gamma radiation is a more positive and sensitive indication of fuelelement fallure than gross activity.

Delayed neutrons can also be used as an indication of fuel-element fallure. The fission-produced delayed-neutron precursors $\mathrm{Br}^{87}$ and $\mathrm{I}^{137}$, the longest lived of the precursor isotopes, are the main contributors. Although the detection of delayed neutrons avolds the problem of contamination buildup in the monitoring-station chambers because there are no long half-life groups, it has its own problems. Other sources of neutrons in the coolant, such as the photoneutrons from deuterium oxide in the water, reduce the sensitivity of this method. 
A combination of reducing background radiation and concentrating the isotope of interest is used in a radioactive-iodine isotopes-detection system. The coolant water is run through a particle filter and then passed through a cation bed to remove all metal-like ions. Finally, the $\mathrm{I}^{137}(1.27 \mathrm{Mev}, 6.7 \mathrm{hr}$ half-life) is either monitored in the sample stream or collected on an anion bed and monitored.

\section{Fission-product Precipitation}

A method particularly well suited to gas reactors depends on detecting beta activity. ${ }^{31}$ Basically this system is designed to collect solid daughters of gaseous fission products (krypton and xenon) and to measure their beta activity.

Gas samples from each of the fuel channels are individually sampled by a selector valve and then filtered to remove radioactive particulate matter. The filtered gas is cooled to a fixed temperature to maintain constant temperature and hence constant density. The solid daughters of the gaseous fission products are next collected in a precipitation chamber. The chamber consists of a shell maintained at a high positive potential and a grounded collector electrode in the form of a wire or tape. Radioactive cesium and rubidium ions under the influence of the high field are deposited on the collector. After a predetermined collection time, the loaded section of the collector is advanced so as to be scanned by a scintillation counter. The solid fission-product daughters are the main contributors to the beta activity. The precipitation system is shown in Fig. 12.

With this system, improved sensitivity can again be realized by considering the ratio of an individual reading to a group. This technique tends to eliminate systematic errors in the system. With a slight modification the fission-product-precipitation method can also be applied to water reactors. Each water sample is degassed in a "scrubber," which consists of a water fountain in a chamber through which a noble gas flows. The low-solubility gaseous fission products are carried away by the noble gas, and the mixture is conducted to the precipitator unit.

The Dresden boiling-water reactor uses a hybrid system for detecting and locating fuel rupture. The rupture-location system is activated only after the off-gas radiation monitor indicates the existence of a defective fuel element. During plant operation a core-flux-tilting procedure is used in conjunction with the off-gas monitoring system to determine the general core location of ruptured assemblies. A signif $1-$ cant local depression of neutron flux by insertion of a control rod will reduce the operating heat flux of a ruptured assembly and thus reduce the release rate of fission products from a cladding break. This results in a reduction in off-gas activity continuously monitored by the 
off-gas monitoring system. Typically, the control rods in the north half of the reactor are inserted while the control rods in the south half are withdrawn to maintain reactor power at whatever level is permitted by activity in the off-gas system and burnup level of the fuel in the core. The process is repeated with control rods in the east and west halves of the reactor. The quadrant where insertion of control rods reduces fission-product activity is thus identified. Insertion of individual control rods within this quadrant further narrows the search area.

The temperature rise and the resultant increase in gas pressure that follow a power rise in an element ald in the detection process. As the gas pressure in the faulty fuel rod increases, the expulsion of radioactive gas increases; this results in considerably more change in activity level at the off-gas monitor than in the power level in the faulty element.

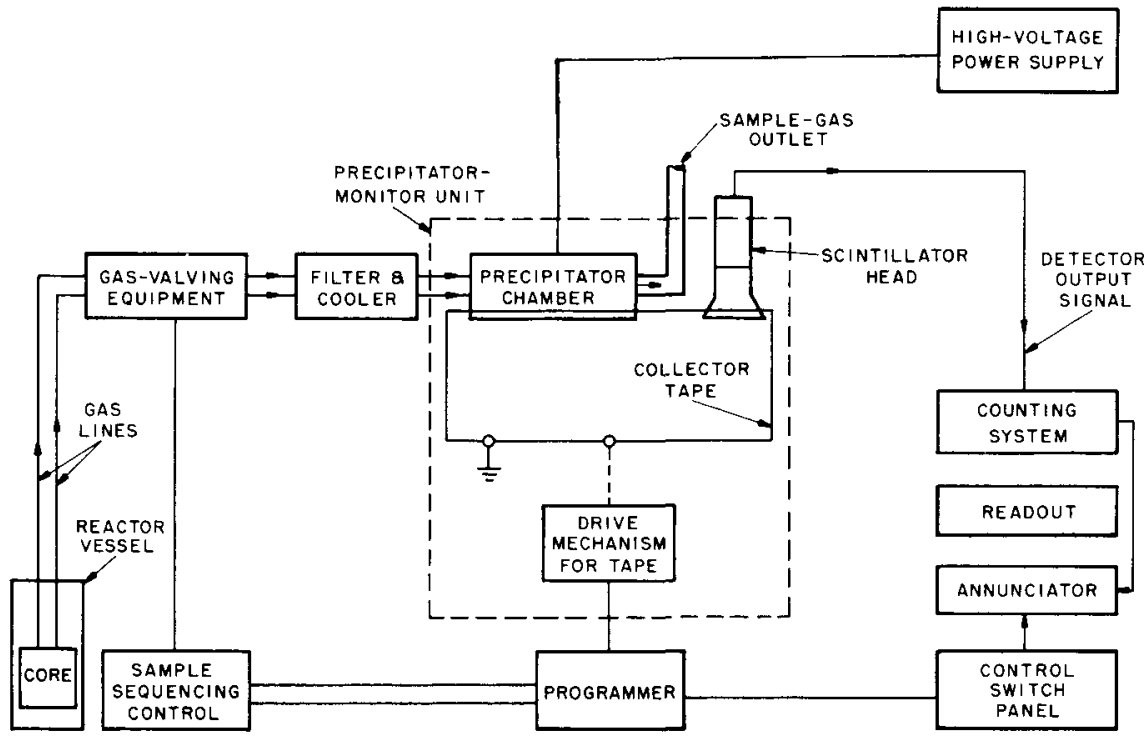

Fig. 12-Precipitation system for detecting tuel rupture

After plant shutdown the reactor vessel head is removed, and a channel-plugging and sampling device (sipper) is used to remove a water sample from individual suspect fuel assemblies. The sampling device is positioned, with the use of the refueling grapple, to cap the top of a suspect fuel channel in the core. Continuous anr flow into the cap establishes an air pocket above the fuel which prevents watersample contamination by cross-mixing from surrounding fuel channels. After a short wart to allow for buildup of concentration of fissionproduct iodine, a water sample is withdrawn for laboratory analysis. 
The sample from a channel with a defect will have a higher counting rate than samples from channels containing sound fuel.

Instrumentation for environmental protection will certainly continue to be an important portion of reactor instrumentation in the future. Investigation of novel methods of locating ruptures is not now being carried on with vigor; however, the considerable cost of present systems as well as their requirements of careful operation and intensive maintenance would appear to be a considerable incentive. The flux-perturbation method as well as other truly in-core methods might well be pursued.

\section{TELEMETERING}

One factor common to all present-day in-core instrumentation is the careful consideration given to the leads that transmit information to the outside of the pressure vessel. Each sensing element requires one or more leads, two in the case of differential pressure orifices. The length of run can be 40 to $60 \mathrm{ft}$ from the sensor to the nearest accessible location. If the leads are electrical, mineral-insulated cable is used for its high tolerance to radiation and temperature.

From the point of access to the control room, conventional organic insulation cable is used. This cable run is usually several hundred feet. In their course the cables must be protected from moisture, excessive temperature, and mechanical damage. At the wall of the containment vessel, each cable must have its own penetration, which has stringent requirements in regard to electrical insulation and leaktightness.

In-core problems with transducer cables are equally difficult. The many pressure-vessel penetrations require the attention of the pressure-vessel designer to avold stress problems, as do all other discontinuities in the vessel. In addition, in-core cable runs must be accommodated, usually at the expense of uncomfortable compromises. In the light of the foregoing requirements and difficulties, multiplied perhaps several hundred times, the concept of in-core telemetering appears very worthwhile.

Recently effort has been applied to the development of means for in-core telemetering. ${ }^{32}$ Although telemetering is a well-developed technology, the totality of conditions under which it must be performed in the case of in-core measurements is unique. High temperatures and intense radiation preclude most accepted methods. Electronic components in general are not usable in this environment.

\section{Mechanical Scanning}

Of the methods investigated, both an electromechanical system and a purely electronic system appear to have promise. The simplest approach is a motor-driven commutating switch with the required number 
of contacts. A limited number of materials are utılized in such a system; ceramic-insulated wire, inorgamc insulation, and inorganic lubricants are the main ingredients. Degradation of the motor torque due to radiation-induced effects on the permeability of the parts can be compensated for by derating the original power capacity of the motor. At the readout end a synchronized switch is used to feed the signals back into their respective channels. Standard methods can be employed to maintain synchronism. To assure operation for long periods of time, as slow a scanning rate as practıcal would be used to minimize wear. A slow speed switching would also help reduce noise levels. For noncontrol functions a high repetition rate of sampling individual points is not necessary.

\section{Electronic Multiplexing}

The avallability of ceramic-metal vacuum tubes and other electronic-circuit elements permits the consideration of purely electronic multiplexing. These tubes can operate for long periods at temperatures up to $500^{\circ} \mathrm{C}$ and at integrated neutron dosages of up to $10^{19}$ neutrons $/ \mathrm{cm}^{2}$. In fact, in one mode of operation, the tubes are in an enclosure at a temperature sufficiently high to provide the required amount of cathode emission. In applications of these tubes in circumstances of the kind found inside reactor pressure vessels, a considerable simplification is achieved by using this mode of operation. The need for filament power supply and a large number of electrical connections is eliminated. A relatively simple temperature controller suffices. The power dissipated in the circuit components themselves contributes to the heating required.

Because reliability sufficiently high to assure long-term operation without maintenance is essential, a frequency-sharing multiplexing system is indicated. In a time-sharing system, any fallure in the sequencing system destroys the usefulness of the remainder of the entire system. Situations can be easily imagined, however, in which only short-term operation would be required, e.g., nuclear rockets.

One possible type of electronic multiplexer is a frequency-modulated type of circuit module. With this circuit a linearly related frequency shift is obtained from an input-voltage change. In a system an oscillator is used for each input. The signals are mixed onto the transmission line. At the recelving end of the line, band-pass filters are used to retrieve the individual modulated signals. The individual modulated signals can then be reconverted to analog signals by low-pass filters. The information density is quite low, perhaps 20 channels per transmission line. A considerably higher information density would be necessary in a typical reactor to permit the use of a single transmission line. 
A system that is improved in regard to information density is one based on amplitude modulation. A fixed-frequency and fixed-amplitude oscillator is part of each channel. A fixed resistor and another resistor, the value of which is dependent on signal level, are placed in series across the oscillator output. The a-c signal across the variable resistor is then transmitted to the receiver. The frequency-distributed signals from the total number of channels are superimposed on the transmission line. The signal frequencies are separated at the receiver by filtering and monitored.

If the high information-density potential of this approach to telemetering is to be realized, a fairly sophisticated readout system is necessary. A phase-locked demodulation circuit is needed for the readout. The drift in frequency of the sending oscillator is compensated for by a phase-error-correction circuit in the recelver, which acts as a very steep-walled band-pass filter. Another circuit then converts the modulated carrier back to an analog signal.

Another problem peculiar to telemetering in-core data, besides the environment, is the limitation of the configuration of the system in the pressure vessel. To be of value, components must be accessible and replaceable. Furthermore, the cable runs and other components must not interfere with reactor-servicing operations.

In water reactors the multiplexing unit can be located on the inside of the pressure vessel where it can be reached when the pressurevessel head is removed.

The link between the sensors themselves and the multiplexing unit poses a more difficult problem. First, the connections must be such that the electrical-insulation resistances between conductors are adequate. In general, this means a hermetic connection to preserve a lowhumidity environment. Second, if a difficult job of cable routing is to be avolded every time a detector is replaced, the cable and detector assembly must be connected at the top of the core. An operator is thus faced with a problem of making a dry connection under about $25 \mathrm{ft}$ of water.

One possible solution to the problem of making the dry connection might be a diving-bell type of connector which, in the proper position, would carry entrapped air from above the surface of the water to the submerged connection. The connection would be so constructed that the water would be displaced from around it as the mating connector with its entrapped air was lowered over it. Proper positioning having been attained, the waterline would need to be below the seal joint so that the intervals of the connector would contain water vapor but no liquid water. The reactor having risen to power, the temperature of the connector would increase, and the relative humidity would drop to a value at which insulation resistances would be adequately high. 


\section{INSTRUMENTED FUEL ASSEMBLIES}

An instrumented fuel assembly is designed to give comprehensive measurement data on the in-core performance of a particular fuelelement design. These data allow a detailed appraisal of the design and analytical techniques used to arrive at the design. In turn the refined techniques can be used to produce improved designs. The interplay between analysis and measurement requires, to be rewarding, simultaneous refinement of the in-core measurement techniques as well as the analytical techniques.

Requirements for instrumented fuel assemblies are as follows:

1. The dimensions will allow the instrument assembly to replace a regular assembly with a minimum of accommodation.

2. The fission energy available will be equivalent, in amount and distribution, to the normal element.

3 . The instrumented assembly will not significantly perturb the over-all core flow by reason of pressure drop due to instruments.

4. Sensors with a degree of precision and accuracy consistent with the analytical needs will detect at a chosen number of points - neutron flux, pressure, temperature, and coolant velocity.

In addition to the problems associated with the individual measurements, which have been discussed previously, a multitude of engineering problems - such as those involving routing of signal leads and pressure taps, pressure-vessel penetrations, and readout - are associated with a highly instrumented assembly. A complex and sophisticated system for indicating and recording data is needed to maximize the usefulness of the information. The time and spatial relations in the information must be preserved, or the value of the information will be severely reduced.

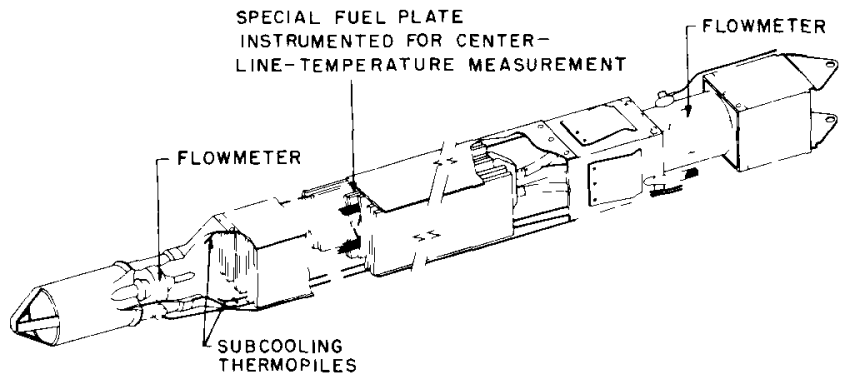

Fig. 13-Instrumented fuel subassembly for EBWR. ${ }^{33}$

Recently a design has been evolved for an instrumented fuel bundle that permits the fuel and the instrument to be handled as separate entities. For accomplishment of this, the lower flowmeter and other 
sensors at the bottom of the assembly are positioned before the fuel is put in place. After the fuel is positioned, the upper flowmeter and other sensors that are either at the top or distributed along the length of the element are positioned from the top. With this design, exposed fuel can be disposed of, and the instrumentation can be used on a new fuel bundle. For short test periods the savings in instrument costs can be important. An instrumented fuel subassembly for the Experimental Boiling Water Reactor is shown in Fig. 13.

Instrumented fuel bundles are representative of the current stateof-the-art of most aspects of in-core instrumentation and are the result of integrating the various related in-core measurements.

\section{REFERENCES}

1 Proceedings of the Power Reactor In-core Instrumentation Meeting, Washington, D C , April 28-30, 1960 USAEC Report TID-7598, March 1961

$2 \mathrm{R}$ W Bowring ( $\mathrm{Ld}$ ), Proceedings of the Boiling Water Reactor In-core Instrumentation Meeting at Halden, May 15-18, 1961, Norwegian Report HPR-16 December 1961

3 R A DuBridge, In-core Power Monitoring of Nuclear Reactors, USAEC Report GEAP-3914, General Electric Company Atomic Power Equipment Department, Apr 15, 1962

4 L R Boyd, Ion Chambers Can Detect Nuclear Bolling, Nucleonıcs, 17(3): 96 (March 1959)

5 L G Barrett, Applications of Pile Modulation Measurement Techniques, USAEC Report KAPL-M-LGB-13, Knolls Atomic Power Laboratory, May 22, 1957

6 R C Koch, Activation Analyses Handbook, Academıc Press, Inc, New York and London, 1960

7 A J Kompanek, Jr, and E C Tarnuzzer, Neutron-actıvated Wires Plot Fluxes in Yankee Core, Nucleoncs, 20(2): 44-46 (February 1962)

8 R M Carroll, Argon Activation Measures Irradiation Flux Continuously, Nucleonucs, 20(2): 42-43 (February 1962)

9 J Sharpe, Nuclear Radıation Detectors, John Wiley \& Sons, Inc, New York

10 L R Boyd, In-core Ion Chambers for Reactor Safety and Control, AIEE Fall General Meetıng, October 11-16, 1959, Paper No. CP 59-1141

11 W Abson, W R. Loosemore, and P G Salmon, New Developments in Fission Chamber Detectors for Neutron Flux Measurement, Paper 2 presented at Fifth International Instruments and Measurements Conference, September $13-16,1960$

12 D A. Guinn and W A Trenholme, A Log N and Perıod Amplifier Utılizing Statistical Fluctuations from a Neutron Detector, presented at Ninth Annual Meeting IRE-PGNS, October 15-19, 1962

13 N R Campbell, Proc Phil Soc, 15: 177, 310, and 513 (1909)

14 D E Hegberg, Feasibility Study of In-core Neutron Flux Monitoring with Regenerating Detectors, USAEC Report HW-73335, Hanford Atomic Products Operation, June 1962

15 E E Goodale and D H Morley, General Electric Company Report No 59GLG3, Mar 5, 1959 
16 A C Lapsley and R R Ingham, Internal Flux Medsurements, in Proceedings of the Sixth Tripartite Instrumentation Conference, Held at Chalk River, Ontarıo, Apr 20-24, 1959, Canadian Report AECL-801(p 55-60), Dec 5, 1960

17 C K Smith C V Weaver, J W Chastain, and S L Fancett, The Development of a Thermal-neutron-flux Measuring Instrument, USAEC Report BMI1083, Battelle Memorial Institute, Apr 12, 1956

$18 \mathrm{~J}$ Weisman (Ed), Development of Miniature SiC Neutron Detectors, Quarterly Progress Report for Perıod Ending December 31, 1961, USAEC Report WCAP-1929, Westinghouse Electric Corp, Atomic Power Department, January 1962

19 G Dearnaley and A B Whitehead, The Solid-state Surface Barrier Charged Particle Detector, British Report AERE-R-3437, August 1960

$20 \mathrm{H}$ Paitchell, An Analysis of the Mode of Response of a Liquid Filled Differential Pressure Transducer System, USAEC Report KAPL-M-HOP-1, Knolls Atomıc Power Laboratory, Jan 8, 1957

21 G. F. Popper, Lecture Notes on In-core Instrumentation for the Measurement of Hydrodynamic Parameters in Water Cooled Reactors, USAEC Report ANL-6752

22 G F Popper, Argonne National Laboratory, private communication

23 G S November and F Schute, U S Patent 3,021,708

$24 \mathrm{~J}$ A McCann, Temperature Measurement Theory, USAEC Rcport KAPL2067-2, Knolls Atomic Power Laboratory, Apr 1, 1962

$25 \mathrm{C}$ W Ross Effect of Thermal Neutron Irradiation on Thermocouples and Resistance Thermometers, Transactions of Joint Nuclear Instrumentation Symposium, P/110, 1961

$26 \mathrm{~W}$ E Browning and $\mathrm{H}$ L Hemphill, Thermocouples for Measurement of Temperatures of Gas-cooled Surfaces, USAEC Report TID-7586(Pt 1)(pp 100-109), Oct 5, 1960

27 A Byszuski, Temperature Measurement of the Fuel Element Shell of the WWP-S Reactor, Nukleonlka, 5(11): 736 (1960)

28 L L Kinter, D A Lampe, and A Armstrong, Pneumatic Temperature Probes for Gas Cooled Reactors, Nucl Scl Eng, 11: 318 (1961)

29 Reactor Instrumentation and Control Progress Report, No 71, Dec 1, 1961Mar 1, 1962, USAEC Report GEMP-71, General Electric Company, Mar 21, 1962

30 H W Georg1, Survey of Fission Product Detectors for Nuclear Reactors, USAEC Report GAMD-1221, General Atomic Div , General Dynamics Corp , Jan 27,1960

31 K W Cunningham, G V Hough, and D Aliaga-Kelly, The Detection of Burst Fuel Elements in Nuclear Reactors, in Proceedings of the Second Unuted Nations International Conference on the Peaceful Uses of Atomic Energy, Gener a, 1958, Vol T, pp 478-485, United Nations, New York, 1958

32 A C Duckart, In-core Instrumentation Development, Task II, Phase ITelemetering, USAEC Report GEAP-4026, General Electric Company, Atomic Power Equipment Department, Mar 15, 1962

$33 \mathrm{~W}$ A Sutherland, Development of In-core Instrumentation for the EBWR, Argonne National Laboratory, April 1959 


\section{0}

0 


\section{Behavior of Cladding}

Materials in Water and Steam Environments

edited by

Sherman Greenberg

Argonne National Laboratory 
The fuel cladding in heterogeneous reactors isolates the fuel from the moderator or coolant. This primary function automatically establishes several necessary characteristics of the cladding material-compatibility with fuel and coolant (or moderator) and mechanical properties adequate to maintain core integrity at the conditions of reactor operation. In addition, it is desirable that the cladding material be cheap, be easily fabricable, have a low cross section for thermal-neutron absorption, and not result in excessively complicated or expensive fuelrecovery processes. The "necessary characteristics" relate to the technical feasibility of a given system. The degree to which a given cladding possesses the other desirable characteristics influences the economic attractiveness of the reactor system.

Consideration of these various requirements in a more or less rational manner has resulted in the domination of the cladding-material field (for aqueous power reactors) by two groups of materials: austenitıc stainless steels and Zircaloy-2. Aluminum alloys have universally been used in low-temperature research and production reactors and are, from the economic point of view, probably the most attractive materials for water-cooled power reactors (not restricted to naturaluranıum fuel). However, technical difficulties, real and imagined, have prevented their widespread use in such applications.

Stainless steels are subject to chloride stress corrosion and other forms of nonuniform attack as well as to relatively rapid general corrosion in the high-temperature superheated-steam environments that are technically desirable. The Zircaloys are vulnerable to unacceptable hydrogen damage under certain conditions. These and other shortcomings generate efforts to replace the presently used or accepted materials with superior alloys. Among these alloys are aluminum, iron, nickel, and niobıum alloys for liquid-water systems and zirconium and nickel alloys and ferritic stainless steels for superheated steam.

These materials are discussed in this review. The emphasis is on power-reactor applications and consideration of corrosion behavior. Problems more or less characteristic of the individual reactor system, such as deposition of transported corrosion products (crud) and interactions between the various system components, are not considered. Proposed directions for future development as well as an evaluation of current status are included. Continuing progress in these fields is convenient to follow in two quarterly summary journals published by the U. S. Atomic Energy Commission: Reactor Haterals (formerly Ruactor Core Iaterals) and Pouci Rcaclor Tcchnologl.

The corrosion literature concerning materials useful, or potentially useful, in water-cooled nuclear reactors has recently (through the latter part of 1961 ) been reviewed by Wanklyn and Jones. ${ }^{1}$ 


\section{ALUMINUM ALLOYS}

by Joseph E. Draley and Westley E. Ruther Argonne National Laboratory

Aluminum has been used for cladding nuclear fuel since the inception of the atomic energy program. Its low thermal-neutron cross section, ease of fabrication, good heat-transfer characteristics, and low cost, combined with the good corrosion resistance of its alloys, have made it a leading cladding contender in the low-temperature aqueous reactor field. Alloys specifically designed for high-temperature-water service have been avallable since 1955. However, increased corrosion in rapidly flowing water and the relatively poor high-temperature mechanical properties of these alloys have limited their application to relatively few high-temperature bolling-water reactors.

\section{Corrosion}

LOW TEMPERATURE The reaction of aluminum alloys with pure water is characteristically rapid at the beginning of the exposure, and it thereafter diminishes. During exposure some of the products of the corrosion reaction enter the water. Under some circumstances corrosion behavior appears to be sensitive to traces of these corrosion products in the solution Thus the rate of water refreshment as well as the usual experimental parameters can influence the kinetics of the reaction. At low temperatures $\left(30\right.$ to $\left.100^{\circ} \mathrm{C}\right)$ and with all normal refreshment rates, the average corrosion rate in static water is low enough to be only of academic interest after the first few weeks. For example, as shown in Fig. 1, the penetration rate of 1100 alloy at one year of exposure in oxygen-saturated water at $70^{\circ} \mathrm{C}$ is about $0.002 \mathrm{mil}$ per year. ${ }^{2}$

At such temperatures the effect of the velocity of flow past the metal on the rate of corrosion in pure water is minor ${ }^{3}$ up to at least $20 \mathrm{ft} / \mathrm{sec}$. Acceleration by high flow rates is observed if the water is too acid and, particularly, if it is alkaline.

HIGH TEMPERATURE High-purity aluminum begins to suffer a penetrating intergranular attack below $100^{\circ} \mathrm{C}$, but most of the common commercial alloys can withstand the corrosive effects of water up through 150 to $200^{\circ} \mathrm{C}$ without accelerated attack Above about $200^{\circ} \mathrm{C}$ it is necessary to use one of the alloys developed for high-temperature aqueous service. The nominal compositions of these alloys are shown in Table 1. The more recent aluminum-nickel-1ron alloys with controlled impurity content have improved corrosion resistance in the 310 to $370^{\circ} \mathrm{C}$ range compared with the older $\times 8001$ alloy, ${ }^{4-6}$ as illustrated for static conditions in Fig. 2.

The corrosion behavior of such low-silicon alloys is essentially identical to that of $\mathrm{X} 8001$ below about $300^{\circ} \mathrm{C}$. At some temperature 


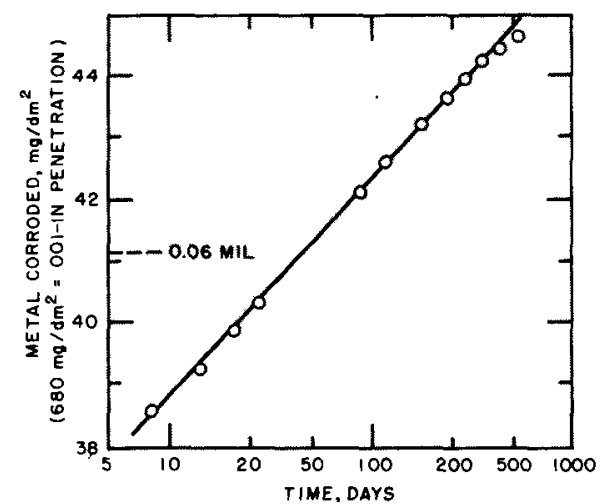

Fig. 1- Long-term kinetic behavior of aluminum alloy 1100 in water at $70^{\circ} \mathrm{C}$.

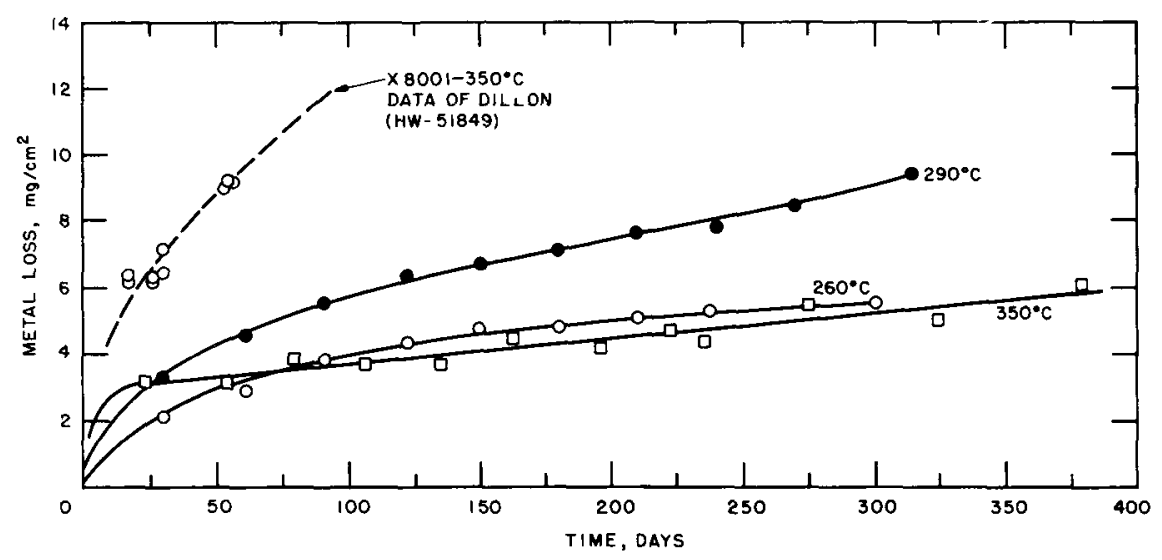

Fig. 2- Aqueous corrosion ${ }^{7}$ of aluminum alloy A288.

Table 1-SPECIAL ALUMINUM ALLOYS FOR HIGH-TEMPERATURE WATER SERVICE

Composition,* wt.\%

\begin{tabular}{|c|c|c|c|c|c|c|}
\hline Type & Designation & Nickel & Iron & Silicon & Titanium & Others \\
\hline $\begin{array}{l}\text { Based on } \\
1100 \text { alloy }\end{array}$ & X8001 & 1 & 0.5 & 0.1 to 0.3 & & $\sim 0.05$ \\
\hline Based on & X8003 & 1.5 & 1.5 & 0.003 & & 0.01 \\
\hline high-purity & Argonne A288 & 1 & 0.5 & 0,003 & 0.1 & 0.01 \\
\hline aluminum & $\begin{array}{l}\text { Hanford } \\
\quad \text { experimental }\end{array}$ & 1.2 & 1.8 & 0.002 & & 0.01 \\
\hline
\end{tabular}

*The remainder is aluminum. 
above $300^{\circ} \mathrm{C}$, an inversion occurs in the dependence of the corrosion rate of the newer alloys upon temperature, whlle the rate of $\times 8001$ continues to increase.

When high water flow rates are used, corrosion rates are usually observed to increase. Extreme variability in results is obtained, depending upon the particular equipment used and its history, the number of specimens or other aluminum area employed, and the rate of refreshment of water. Figure 3 shows the corrosion occurring in two dynamic tests performed (in "pure" water) in one laboratory as compared with typical static corrosion at $260^{\circ} \mathrm{C}$. During the short exposures employed, rates were about 1.3 and 29 mils per year; even higher rates have sometimes been obtained.

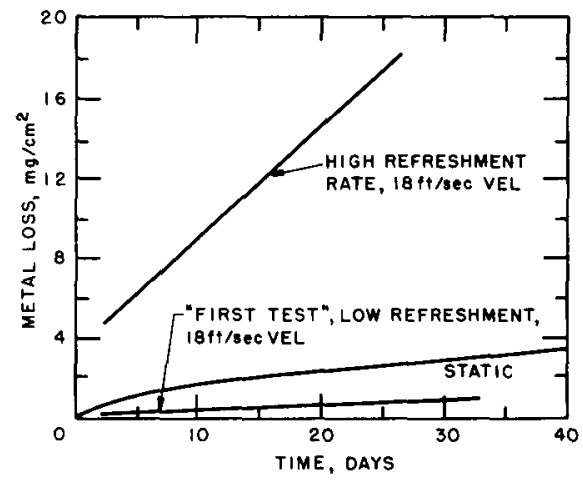

Fig 3 - Aqueous corrosion ${ }^{6}$ of aluminum alloy X8001 at $260^{\circ} \mathrm{C}$

Such variability makes it diff 1 cult to evaluate individual effects. Increasing the velocity generally increases the corrosion rate. The re is a beneficial influence in the use of a larger aluminum area, which is particularly noticeable immediately downstream of the high area; the continuous addition of fresh water at a high rate opposes the high-area effect. A temperature differential through the corrosion-product layer during heat transfer increases the corrosion rate, at least for $\mathrm{X} 8001$ alloy. It is not certain whether this increase occurs simply because the metal is at a higher temperature than the bulk water or if there is an additional effect of the temperature difference.

Many of these observations have been qualitatively explained on the basis of the dependence of dynamic corrosion rate on the dissolution of the protective corrosion product. ${ }^{8}$ However, the complexity of these interrelations makes it quite difficult to predict power-reactor performance. In bolling reactor systems, the factors seem generally favorable (high aluminum areas, low "refreshment rates," sometimes relatively low flow rates, and apparently no transport of corrosion product through the oxide surface coating because liquid water cannot exist above bulk water temperature). In pressurized-water systems it 
seems more difficult to estımate the over-all effect of the favorable and unfavorable factors.

Of the possible inhibitors tested in high-temperature water (217 to $350^{\circ} \mathrm{C}$ ), dilute phosphoric acid had the most beneficial effect on corrosion resistance of aluminum. ${ }^{9}$ If the corrosion of other reactor materials, the deposition of transported corrosion products (crud), and the spread of radioactive phosphorus were all tolerable, the use of this inhibitor would make the prospect of aluminum-jacketed fuel seem much more promising for power reactors. None of the three potential problems has been completely evaluated, but it is clear that such a system would be more difficult to manage than a pure (or alkaline) water system.

STEAM The corrosion behavior of some aluminum alloys in steam at various temperatures and pressures has been reported..$^{10-12}$ The results can be summarized in the following fashion:

At relatively low temperatures (up to $370^{\circ} \mathrm{C}$ ) and with the vapor only slightly superheated, the general appearance and over-all corrosion are roughly those obtained in water at the same temperature. The corrosion by steam tends to be more agressive, accentuating the corrosion of alloys of marginal resistance. After a few days' exposure, the corrosion coatings are relatively heavy $\left(10^{3}\right.$ to $\left.10^{4} \mu \mathrm{g} / \mathrm{cm}^{2}\right)$ and are multilayered, as with corrosion in water.

As the temperature $\left(400\right.$ to $\left.540^{\circ} \mathrm{C}\right)$ and the degree of superheat of the steam are increased, resistant alloys acquire a thin temper film ( 5 to $50 \mu \mathrm{g} / \mathrm{cm}^{2}$ ), which grows only slowly with time. The nonresistant alloys fail rapidly by a penetrating corrosion attack. This type of attack usually starts at one or more spots on the sample and rapidly spreads to consume the entire specimen. A serious lack of reproducibility in corrosion results has been noted, particularly for the higher temperatures $\left(500\right.$ to $\left.540^{\circ} \mathrm{C}\right)$. The differences appear to be partly a result of small variations in methods of starting and running the tests. ${ }^{12}$

Because of their poor mechanical properties at the higher temperatures $\left(500\right.$ to $540^{\circ} \mathrm{C}$ ), wrought alloys have a corrosion behavior that is of academic interest only. Some tests made with alloy-powder products $^{13}$ suggest improved corrosion resistance and useful mechanical properties for these materials in high-temperature steam.

IN REACTOR In common with a number of other corrosion-resistant metals, aluminum alloys depend on the continuous maintenance of a thin protective oxide coating. The limited published data for aqueous corrosion experiments in reactor environments indicate that the protective nature of the oxide film on aluminum is not significantly altered by the radiation present. Most comparison experiments show a slightly lower corrosion rate ${ }^{14,15}$ for the in-reactor specimens. Increased corrosion has occurred on occasion in the radiation zone. ${ }^{15}$ 

cally require fuel assemblies with narrow, dimensionally stable coolant channels. At modest temperatures (below about $450^{\circ} \mathrm{F}$ ) aluminum alloys provide adequate mechanical strength and creep resistance for both cladding and structural applications. Unfortunately the mechanical properties of wrought alloys, particularly the creep resistance, decrease significantly with increasing temperature. ${ }^{16}$ This decrease is the major reason for the active interest in substituting the stronger aluminum-powder products in high-temperature applications.

Many aluminum-alloy-powder product samples develop blisters and areas of accelerated attack upon long exposure to high-temperature water However, it appears to be possible to manufacture alloy-powderproduct shapes that have corrosion resistance equivalent to that of a wrought alloy of similar composition, judging from results obtained on some small extruded rods. Attempts to increase greatly the mechanical strength by ball-milling powder have in most cases reduced the corrosion resistance of the finished product. Modest increases in hot tensile strengths and more than proportionately higher creep resistance have been obtained in some instances without loss of corrosion resistance.

It appears that extensive refinement of current commercial ballmilling and compaction techniques is required to produce good powder products consistently. The most serious problems appear to be associated with the entrapment of gas and various milling and die lubricants in the basic billet. Once a sound billet is obtained, it can be extruded by most of the normal aluminum extrusion techniques into the desired shapes

\section{REACTOR EXPERIENCE}

Production and Research Reactors Little has been published in the unclassified literature on corrosion problems in water-cooled reactors used for the production of fissionable materials. The successful use of aluminum-clad fuel indicates that under suitable operating conditions the corrosion resistance is satisfactory.

The corrosion problems encountered in low-temperature research reactors are usually associated with (1) tramp inclusions (accidental impurities) in the aluminum surface, (2) stagnant or crevice areas, and (3) poor water cleanup, particularly of halogen and heavy-metal rons. Recently the trend toward high-flux reactors, such as the High Flux Isotope Reactor (HFIR) at Oak Ridge National Laboratory, has introduced the high-temperature high-velocity corrosion problems discussed previously. Water treatment by acidification ${ }^{17}$ has decreased these problems for the HFIR.

The fuel used in research and production reactors varies in type and sophistication from simple cylindrical clad slugs of uranium to 
involute-shaped plates with internal fuel gradients. A good metallurgical bond between the cladding and the fuel alloy is generally felt to be required to prevent local fuel hot spots. The bond also minimizes blistering of the cladding in the event of a pinhole penetration to the more reactive fuel alloy.

Power Reactors Aluminum alloys have been used in several boilingwater reactors designed to produce power. They have served as cladding for water temperatures up to $217^{\circ} \mathrm{C}$ and as structural components up to $252^{\circ} \mathrm{C}$.

Bolling Reactor Experiment No. 3 (BORAX-3) was the first power reactor to use aluminum (1100 alloy) cladding. The intentionally short Iife of this experimental reactor at $300 \mathrm{psig}$ and $217^{\circ} \mathrm{C}$ did not seriously test the capabilities of the cladding, and no corrosion difficulty was experienced.

The next reactor in this series, BORAX-4, had a core made from ceramic pellets of fuel placed in "tube plates" of X8001 aluminum. Heat was conducted from fuel to jacket through lead. The operating temperature and pressure were the same as those for the BORAX-3 reactor. The cladding operated initially in a satisfactory fashion, but, after a long period of inactivity, it suffered many mechanically induced corrosion fallures. The weak metal-tubing wall had crept away from high-stress points inadvertently designed into the fuel plate, and corrosion penetrated these weak points during the long inactive period. Recent experience with a pellet type ceramic fuel in an aluminum tube indicates that this type of fallure can be prevented by proper design. ${ }^{18}$

The fuel plates of the SL-1 reactor (water at $217^{\circ} \mathrm{C}$ ) provided the longest test of the use of X8001 aluminum alloy as a cladding material. The aluminum-uranium-nickel alloy fuel was bonded to the cladding with a silicon eutectic-forming process. An examination of the fuel elements prior to a nuclear incident showed the cladding to be in excellent condition. Heat-transfer tests indicated that the thin corrosion product on the fuel plates offered no significant impediment to heat flow. Thin burnable poison strips fabricated from aluminum-alloy powder and boron powder had inadequate corrosion resistance in this reactor environment.

In the Halden Boiling Water Reactor, an aluminum alloy approximately equivalent to 1100 aluminum was used for cladding cylindrical fuel elements and providing water channels. Pittıng of the aluminum was noted at the end of five months of intermittent operation at very low power (about 250 watts and $20^{\circ} \mathrm{C}$ ). During that period the waterpurification unit was not operating. The fuel elements were then repaired, and they operated satisfactorily at the design temperature of $150^{\circ} \mathrm{C}$.

In the Experimental Bolling Water Reactor (EBWR) at Argonne, X8001 alloy was used for dummy fuel assemblies within the reactor to 
control the water-flow characteristics of the core. These assemblies had received exposures of up to one year at operating temperatures of $252^{\circ} \mathrm{C}$ (two years total exposure) before they were removed. For those plates examined, the estimated uniform corrosion attack was about $0.003 \mathrm{in}$. No serious galvanic effect was found for the junction of the aluminum and the stainless steel in the reactor exposure. However, the presence of these dummy fuel assemblies increased the normal problems of corrosion-product deposition in the reactor significantly.

In the $\mathrm{BORAX}-5$ reactor $\left(252^{\circ} \mathrm{C}\right), \mathrm{X} 8001$ aluminum is also used for some structural parts of the reactor core, but no information is yet avallable as to its performance.

It has been observed that the normal careful control of water purity under operatıng conditions is sometımes abandoned during reactor downtimes. If allowed to continue for long periods, harmful impurities can build up and cause pitting of the aluminum within the reactor. Aluminum is more susceptible to pitting at low temperatures than at reactor operating temperatures of 150 to $250^{\circ} \mathrm{C}$.

\section{Applicability}

The incentive to use aluminum in water-cooled reactors is the potential for lower cost than for the alternative materials, Zircaloy and stainless steel. Its advantage over Zircaloy is direct and indirect cost saving. It offers better neutron economy than stainless steel. Aluminum alloys are at a disadvantage with respect to the alternative materials in corrosion resistance and in mechanical properties. Their neutron absorption is also slightly greater than that of Zircaloy.

In order to achieve the economies $p^{\prime}$ "sntially avaslable through the use of aluminum alloys, designs should be optimized for all materials involved. Such design considerations might influence parts of the power system other than the reactor core. For example, aluminum corrosion is unsatisfactory in the alkaline water currently preferred in pressurized reactors to control the deposition of transported steelcorrosion products. The use of aluminum in such systems would require the use of different water treatment and the development of an acceptable method for controlling crud. For the fuel elements employed, the limited strength and creep resistance of aluminum jacketing and its compatibility with the fuel material would have to be satisfactory. It is perhaps feasible to meet these requirements with either a uranium alloy or uranium dioxide fuel.

Assuming that either good design can accommodate the relatively weak wrought alloys or satisfactory sintered-powder products can be developed, the applicability of aluminum alloys depends upon their corrosion resistance. At metal temperatures below perhaps $175^{\circ} \mathrm{C}$, there is little doubt that corrosion rates can be made adequately low 
in neutral or slightly acidified pure water. For natural-convection bolling-water reactors producing 300 psi steam, the corrosion behavior of such alloys as X8001 can be expected to be excellent, judged by the results of examination of the fuel elements of the SL-1.

There has been no full loading of aluminum-clad fuel in powerproducing reactors at higher water flow rates or higher temperatures. In view of the dependence of corrosion rate on the area of aluminum alloy exposed in a given system and on the system characteristics, it is not considered possible to predict with confidence the performance to be expected in a reactor. If the feasibility of using aluminum fuel jacketing for power reactors is to be determined, it is believed that a full reactor test is required. Such a test, in an experimental power reactor, is strongly recommended.

In the absence of demonstration tests, the corrosion behavior of aluminum alloys under conditions leading to the production of economic power can only be estimated. Extrapolation of the results of corrosionrate experiments to operating reactor conditions has not been possible on a purely empirical basis. The reasons for the importance of some experimental parameters, such as relative surface areas, temperatures and temperature differences, and type and rate of water cleanup, have been obscure, and it has been necessary to hypothesize corrosion mechanisms in order to estimate in-reactor performance. For this reason, the necessary extrapolation has been done differently by different people.

In the belief that corrosion rate varies with the concentration of dissolved aluminum oxide corrosion product in otherwise pure water, Ayres $^{19}$ has concluded that corrosion would be unacceptably rapid in such an environment in pressurized-water reactors. He apparently felt that there would be a reasonable chance of the successful application of aluminum alloys if phosphoric acid could be added as an inhibitor. He took no position regarding the use of aluminum in boiling-water reactors. Draley and Ruther ${ }^{7}$ have speculated that it is not dissolved, but suspended (in the water) particulate corrosion product that assists in maintaining corrosion resistance. For bolling-water reactors they have felt that there is a good chance that aluminum would be adequately corrosion resistant, especially if newer alloys ${ }^{6}$ were used. For pressurized-water reactors they have expressed no opinion, being unwlling to conclude that aluminum could not be used.

There is no water temperature above which aluminum obviously could not be used. With optimum treatment of "pure" water, it seems possible and perhaps likely that corrosion rates would be acceptable (several mils per year) at temperatures as high as those which can be used in water-cooled reactors (1.e., not to exceed the critical temperature of water). It is important to remember that considerable care in controlling water conditions and perhaps flow patterns might be re- 
quired. With increasing temperature, design would also become more critical owing to decreasing mechanical properties.

\title{
STAINLESS STEELS AND RELATED ALLOYS FOR USE IN WATER
}

\author{
by Thomas J. Pashos \\ General Electric Company \\ Atomuc Pouer Equipment Department
}

The cladding materials that best meet the requirements of, and are used in, current water-cooled power reactors are the austenitic stainless steels and the zirconium alloys. Although stainless steel has a higher cross section for thermal-neutron absorption than do the zirconium alloys, its good corrosion resistance, high strength, low cost, and ease of fabrication make it a strong competitor as a fuel-cladding material for water-cooled power reactors.

The high-nickel alloys, such as Inconel, and the ferritic alloys, such as type 406 stainless steel, may meet the performance requirements of water-cooled power reactors. They have not yet, however, been fully explored and evaluated as to either performance or economics relative to stainless steel and the zirconium alloys. Inconel, Incoloy, and AISI type 406 stainless steel are being investigated as fuel-cladding materials for superheated-steam applications. ${ }^{20,21}$ It is expected that many of the results of these tests will be applicable to the evaluation of these materials for use in water-cooled reactors. It is doubtful that Inconel, because of its high thermal-neutron cross section, will be economically feasible for fuel cladding in water-cooled power reactors in the foreseeable future. However, Incoloy and AISI 406 have more-favorable neutron economies and may eventually be competitive with austenitic stainless steel and the zirconium alloys.

Water-cooled nuclear power plants now in operation contain many fuel rods, clad with zirconium alloys and stainless steels, which are operating at the rather conservative performance conditions typical of first-generation reactor-design concepts. The experience gained in the design, fabrication, and operation of fuel in the existing reactors provides a basis of reference from which future technical and economic improvements can be made. However, reactor operating experience has not been extensive enough to provide needed statistical information as to the lifetime capabilities of fuel elements clad with either zirconium alloy or stainless steel. Inasmuch as fuel-cycle costs are highly sensitive to fuel lifetime, a firm economic comparison of the two materials based on actual operating experience cannot be made at this time. Until current fuel-irradiation test programs and continued 
large-scale reactor operations provide data on actual fuel lifetime, fuel economic analyses by necessity will continue to be made on the basis of predicted fuel lufetimes. Whether one cladding material ult1mately will be economically more attractive than the other will depend upon such factors as fabrication costs, thermal performance capabilities, and fuel lifetimes, as well as neutron economy. It is expected that in the future, as in the past, the choice between the two materials may vary from one reactor to another, depending upon differences in design, physics, and coolant-system requirements.

Unlike the zirconium alloys, which were developed especially for nuclear fuel cladding in order to take advantage of their low thermalneutron cross section, austentıc stainless steels have had a previous history of non-nuclear investigations and applications as structural materials in high-temperature water and steam service. However, the consideration of stainless steel for water-cooled nuclear applications required extension of the knowledge of general corrosion and localized stress corrosion which had been developed in non-nuclear applications. In addition, the effects of radiation on changes in structural properties and the much more severe requirements of reliablity had to be considered.

\section{Corrosion of Stainless Steel}

Early work performed in the corrosion-testing and screening of materials for applications to pressurized-water reactors led to the choice of the austemitic stainless steels as the principal structural materials for nuclear components. ${ }^{22,23}$ Investigations were conducted in water at 500 and $600^{\circ} \mathrm{F}$ to determine the effects of $\mathrm{pH}$ and impurities, the erosive effects of flowing water, and the influence of hydrogen and oxygen on the corrosion of stainless steel. Although the uniform corrosion rate of stainless steel in water up to $650^{\circ} \mathrm{F}$ was found to be extremely low, less than $10 \mathrm{mg} / \mathrm{dm}^{2} /$ month, it was recognized that the release of soluble and insoluble corrosion products into the primary coolant stream constituted a potential problem in the reactivity buildup in the coolant system and in the deposition of transported corrosion products (crud) on heat-transfer surfaces. ${ }^{24-26}$ In addition to the consideration of general corrosion, the use of stainless steel as a fuelcladding material introduced the added consideration of localized corrosion attack, such as stress corrosion or crevice corrosion, which may result in cracking of the cladding and subsequent release of fue] or fission products into the primary coolant.

In the early applications of stainless steel as a reactor structura] material, niobium-stabilized AISI type 347 was used because of its low susceptibility to intergranular corrosion cracking. Subsequent tests of sensitized AISI type 304 stainless steel exposed to high-purity water a 
$500^{\circ} \mathrm{F}$ indicated no susceptibility to intergranular corrosion. ${ }^{24}$ On the basis of these results, the use of type 304 stanless steel in water reactors was initiated.

Since the initial use of stainless steel as a cladding material, there has been close surveillance of the coolant systems of operating boilingwater and pressurized-water reactors with regard to the potentral problems associated with general or localized corrosion of the cladding. The most extensive reactor operating experience with fuel clad with stainless steel has been that associated with the Vallecitos Boiling Water Reactor (VBWR), the Yankee reactor, and the army compact reactors, such as the SM-1 and the PM-2A.

Operating experience thus far with the $\mathrm{VBWR}^{27,28}$ and the Yankee reacto ${ }^{28,29}$ has revealed no problems relating to the buldup of activity levels of primary loops from corrosion products of stainless-steel cladding or other components. Extensive studies conducted during the lifetıme of core I of the SM-1 reactor (June 3, 1957, to Apr. 28, 1960) indicated a gradual buldup in primary-coolant-loop activity level. ${ }^{30,31}$ The major contributor was indicated to be $\mathrm{Co}^{60}$ activity released from the cobalt in the Haynes 25 alloy flux suppressors and the cobalt $1 \mathrm{~m}$ purity in stainless steel. As a corrective measure, cobalt-free flux suppressors and cladding of low-cobalt stanless steel were used in core II of the SM-1 and in the cores of the SM-1A and PM-2A reactors. It was reported subsequently ${ }^{32}$ that the analysis of the PM- $2 \mathrm{~A}$ radiation levels after shutdown indicated that mechanisms other than the release of nuclides from core cladding materials contributed significantly to the long-lived activity levels. Preliminary evaluations indicated that the use of stainless steel of low cobalt impurity would not significantly reduce the primary-system activity levels.

In another measure to reduce the activity bulldup in the SM-1 primary loop, it was decided to increase the operating $\mathrm{pH}$ from neutral to approximately 10 by the addition of lithium hydroxide. ${ }^{32}$ Operation of the SM-1 at high pH was initiated in November 1961. As indicated in Ref. 32, there had not been sufficient operating experience to evaluate the effects of high $\mathrm{pH}$ on system activity buildup.

Some foulng of heat-transfer surfaces of fuel cladding has been observed in in-pile loop tests. ${ }^{24}$ However, there have been no reported instances of fouling of heat-transfer surfaces of stainless-steel fuel cladding in water-cooled reactors. In the loop tests the deposits on Zircaloy surfaces were found to be thicker than those on stainless steel. Investigation of the factors affecting crud formation and deposition on fuel-cladding surfaces indicated that deposition is decreased by increasing the $\mathrm{pH}$ and decreasing the oxygen content of the coolant.

STRESS CORROSION An important consideration and potential problem in the use of stainless-steel cladding in a high-temperature water 
environment is its susceptibility to stress-corrosion attack. This phenomenon, which usually manifests itself as localized intergranular or transgranular cracking, has been investigated for many years in relation to the use of stainless steel in non-nuclear applications. With the use of stainless steel as a structural and cladding material in reactors, many investigations have been made to extend the existing knowledge to reactor-coolant temperature and chemistry conditions. Recent comprehensive reviews and discussions of the problem of stress-corrosion cracking of stainless steels by Wanklyn and Jones ${ }^{33}$ have been published, and a literature search by Feldman ${ }^{34}$ has been published.

Although the general corrosion of stainless steel in a reactor core is of concern in the buldup of radioactivity in the primary coolant system, the susceptibility of stainless-steel cladding to stress-corrosion cracking is the more serious problem from the standpoint of cladding performance. Stress-corrosion cracking may result in the loss of cladding integrity and the release of fission products into the coolant system. Depending upon the degree of cracking and the capacity of the cleanup system for the reactor coolant to remove fission products, the occurrence of stress-corrosion cracking of the cladding may mean the end of the useful life of the fuel element.

The transgranular type is usually considered the classical form of stress-corrosion cracking, and it is associated with the combined effects of stress and chlorides or caustics. Until very recent years the intergranular mode of cracking had generally been believed to occur only in stainless steels that had been sensitized by the precipitation of carbides in the grain boundaries. It was generally believed, and usually proved by experience, that intergranular cracking could be prevented by the use of stabilized steels or by suitable postfabrication heat treatment. Accordingly, most of the occurrences and investigations of causes and methods of prevention of stress-corrosion cracking have been of the transgranular mode of fallure.

The occurrence of intergranular cracking in nonsensitized stainless steels is discussed in recent reports. Wanklyn and Jones ${ }^{33}$ and Snowden $^{35}$ report the intergranular cracking of stabilized austenitic stainless steels in caustic solutions containing sodium hydroxide and potassium hydroxide. The concentration of the caustic solution was found to determine whether cracking would be intergranular or transgranular. Exposure to solutions containing up to 50 percent potassium hydroxide or sodium hydroxide resulted entirely in intergranular cracking. At concentrations of 75 percent, the potassium hydroxide solution caused only intergranular cracks, but the sodium hydroxide solution produced mixed intergranular and transgranular cracking.

The normal bulk concentrations of caustic in reactor water of high $\mathrm{pH}$ are much lower than those reported to cause stress-corrosion crackıng. However, Wanklyn and Jones ${ }^{33}$ observed that the localized 
concentration of the caustic can be increased in crevices of heattransfer surfaces. The concentration of caustic was found to increase from about $50 \mathrm{ppm}$ in the coolant solution to about $50 \mathrm{wt}$. \% in heattransfer-surface crevices, with resultant intergranular cracking of the specimens. Thus crevices or pits on a fuel-cladding surface can be nucleation points for cladding cracks if mechanisms for concentration of chlorides or caustics are operative.

Snowden ${ }^{35}$ observed that the mode of cracking in caustic is affected by the carbon content of the steel. Alloys containing about 0.03 percent carbon falled transgranularly, whereas, under similar test conditions, alloys containing 0.07 to 0.11 percent carbon falled intergranularly; this suggests that the presence of a submicroscopic grain-boundary carbide phase or its associated effects resulted in the intergranular attack.

Both transgranular and intergranular crackıng of type 304 stainless steel have been observed in high-purity-water reactor coolants. Intergranular cracking of type 304 stainless steel has been reported in both pressurized-water ${ }^{36-38}$ and bolling-water ${ }^{39}$ reactor coolants. These phenomena are discussed in greater detail in subsequent sections.

There is fairly good agreement among investigators as to the qualitative effects of the various factors that influence the susceptibility of austenitic stainless steels to stress-corrosion cracking. Stresscorrosion attack is influenced by alloy composition, metallurgical condition, residual and applied stresses, temperature, time, and coolant chemistry. The effects of many of these factors are interdependent. Strain-cycling fatigue and irradiation effects may accelerate the onset of stress-corrosion cracking. However, the quantitative interrelations of the various factors that influence stress-corrosion cracking are not very well understood, particularly in applications to high-purity reactor coolant water.

All the austenitic stainless steels are considered susceptible to stress-corrosion attack. However, changes in composition have been found to improve resistance to attack. The use of higher nickel content to improve resistance to stress-corrosion attack was investigated by Copson. ${ }^{40}$ Test results indicated that alloys containing more than 45 to 50 percent nickel were immune to stress-corrosion cracking. However, Corrou et al., ${ }^{41}$ Cheng and Tymchyn, ${ }^{42}$ and others have reported the stress-corrosion cracking of Inconel, which contains approximately 78 percent nickel. Uhlig and White ${ }^{43}$ showed that lowering the nitrogen and carbon contents to below 0.01 and 0.02 percent, respectively, significantly increased the resistance to stress-corrosion cracking. In tests of stress-corrosion cracking conducted in bolling 42 percent magnesium chloride at $154^{\circ} \mathrm{C}$, specimens of commercial type 304 stainless steel falled within 0.2 to $1.4 \mathrm{hr}$, whereas alloys low in carbon and nitrogen did not fall within exposure times of 200 to $260 \mathrm{hr}$. Typical 
Table 2-EFFECT OF NITROGEN AND CARBON ON SUSCEPTIBILITY OF AUSTENITIC STAINLESS STEELS TO STRESS-CORROSION CRACKING ${ }^{44}$ IN BOILING 42 PERCENT $\mathrm{MgCl}_{2}$ AT $154^{\circ} \mathrm{C}$

\begin{tabular}{|c|c|c|c|c|c|c|c|c|c|}
\hline \multirow[b]{2}{*}{$\begin{array}{l}\text { Phase as } \\
\text { quenched }\end{array}$} & \multirow[b]{2}{*}{$\begin{array}{c}\text { Chromium, } \\
\text { wt } \%\end{array}$} & \multirow[b]{2}{*}{$\begin{array}{c}\text { Nickel, } \\
\text { wt } \%\end{array}$} & \multirow[b]{2}{*}{$\begin{array}{c}\text { Carbon, } \\
\text { wt } \%\end{array}$} & \multirow[b]{2}{*}{$\begin{array}{l}\text { Nitrogen, } \\
\text { wt \% }\end{array}$} & \multicolumn{2}{|c|}{ Annealed and sheared } & \multicolumn{3}{|c|}{ Cold rolled and sheared } \\
\hline & & & & & $\begin{array}{l}\text { No of } \\
\text { specimens } \\
\text { tested }\end{array}$ & $\begin{array}{l}\text { Crackıng } \\
\text { tıme, hr }\end{array}$ & $\begin{array}{l}\text { Reduction of } \\
\text { thickness, } \%\end{array}$ & $\begin{array}{c}\text { No of } \\
\text { specimens } \\
\text { tested }\end{array}$ & $\begin{array}{l}\text { Cracking } \\
\text { time, hr }\end{array}$ \\
\hline \multicolumn{10}{|c|}{ 18-8 and Type 304} \\
\hline Alpha & 184 & 87 & 0012 & $<0001$ & 2 & $>260$ & 80 & 2 & $>260$ \\
\hline Alpha & 184 & 81 & 0004 & 0005 & 3 & $>260$ & 80 & 3 & $>260$ \\
\hline Gamma & 185 & 85 & 0013 & 015 & 13 & $12 \pm 03$ & & & \\
\hline Gamma & 186 & 80 & 015 & 0002 & 4 & $24 \pm 04$ & 80 & 3 & $08 \pm 04$ \\
\hline Gamma & 184 & 86 & 008 & 004 & 37 & $14 \pm 04$ & 35 & 11 & $07 \pm 02$ \\
\hline Gamma & 188 & 92 & 006 & 005 & 4 & $02 \pm 01$ & 35 & 4 & $03 \pm 01$ \\
\hline \multicolumn{10}{|c|}{$20-20$ and Type 310} \\
\hline Gamma & 187 & 206 & 001 & 0002 & 3 & $>200$ & 80 & 3 & $>200$ \\
\hline Gamma & 213 & 175 & $\begin{array}{ll}0 & 01\end{array}$ & 0115 & 5 & $149 \pm 49$ & 80 & 3 & $59 \pm 16$ \\
\hline Gamma & 182 & 204 & 017 & 0005 & 2 & $>300$ & 80 & 2 & $>300$ \\
\hline Gamma & 247 & 214 & 005 & 004 & 5 & $20 \pm 3$ & 80 & 13 & $53 \pm 15$ \\
\hline Gamma & 248 & 195 & 003 & 005 & 4 & $55 \pm 18$ & 30 & 4 & $52 \pm 12$ \\
\hline
\end{tabular}


results of these tests are shown in Table 2. The increased resistance to stress-corrosion cracking is attributed to the predominantly ferritic structure resulting from the lower nitrogen and carbon content.

Lang $^{45}$ observed a significant increase in time to fallure of highpurity austenitic stainless steel (20 percent nickel and 18 percent chromium) compared with material of commercial purity when tested in boiling magnesium chloride solution. Additions of nitrogen, phosphorus, arsenıc, antimony, bismuth, ruthenıum, and aluminum greatly reduced the time to fallure of the test specimens. Additions of carbon and silicon were beneficial.

The fabrication history and finished metallurgical condition as affected by heat treatment, microstructure, degree of cold work, surface finish, and surface impurities can influence the resistance of the material to stress-corrosion cracking. If the material is sensitized during fabrication, small grains will result in more widely dispersed carbide precipitates in the grain boundaries and will reduce the susceptibility to cracking. Surface treatments, such as acid etching or abrasive polishing, can leave residual acids or impurities that may lead to localızed attack.

The stress level is a significant factor with regard to stresscorrosion cracking of stainless steels in relatively high-purity water in which the bulk concentrations of chloride and caustics are very low. As previously discussed, tensile stresses are considered necessary for transgranular stress-corrosion cracking to occur. In normal, wellcontrolled reactor-coolant environments, the average levels of oxygen, chlorides, and caustics (if used for $\mathrm{pH}$ control) are very low. Therefore it is expected that relatively high stress levels applied over a long perıod of tıme are necessary for stress-corrosion crackıng to occur in high-purity water. Such factors as the fueldesign, method of fabricatıon, and degree of cold work will determine the claddıng stresses during operation, which will in turn determine the degree of susceptibility of the cladding to stress-corrosion cracking. Quantitative knowledge of the effects of variations in stress on corrosion cracking of stainless steel in high-purity reactor water environments is not avallable to the fuel designer at this time. Essentially all the investigations of transgranular and intergranular attack on stainless steel have been conducted in environments more severe than those of water-cooled reactors. However, the experience thus far in and out of reactors provides an understanding of the factors that lead to optımum fuel performance in a water-cooled reactor.

There have been many investigations of the threshold stress levels below which stress-corrosion cracking does not occur for various conditions of cold work. Hines and Hoar ${ }^{46}$ observed that the threshold stress for cracking is high for fully annealed material, decreasing with increasing cold work and then increasıng again for heavily cold-worked 
material. It was suggested that fully softened material is barely susceptible to stress-corrosion cracking at applied stresses of less than about $25,000 \mathrm{psi}$ and that heavily cold-worked material has an apparent threshold stress of 5 percent of the yleld stress. However, these extreme conditions are rarely present throughout a fabricated structure because of changes introduced locally or more widely during welding or mechanical treatments. Intermediate conditions of cold work can cause stress-corrosion cracking with little or no applied stress. In Fig. 4 results by Lees ${ }^{47}$ of time to fallure are plotted as a function of measured residual stresses for commercial type 304 stainless-steel tubing in boiling magnesium chloride solution. Also plotted are results of similar

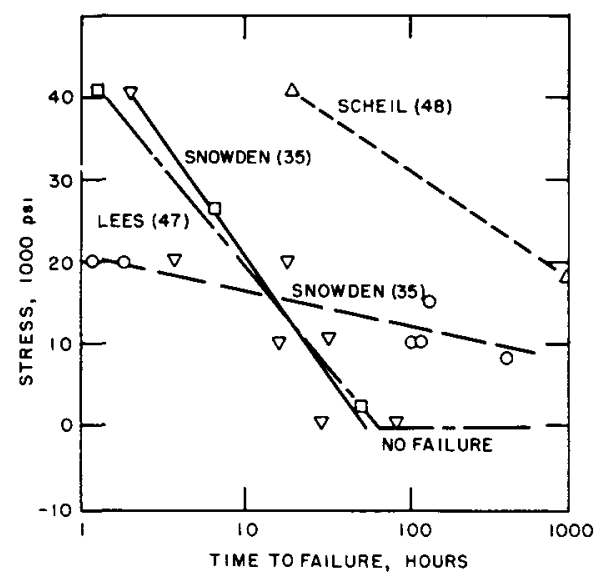

Fig. 4-Time to fallure by stress corrosion as a function of applied stresses.

tests reported by Schell ${ }^{48}$ and Snowden ${ }^{35}$ for time to fallure as a function of applied stresses for fully annealed laboratory specimens of types 347 and 321 stainless steels. As shown, some fallures occurred at essentially zero applied and residual stresses.

The preceding observations indicate that the normal commercial "annealed" tubing is not in the fully softened condition. Lees ${ }^{47}$ measured residual stresses as high as 20,000 psi in the outer fibers of commercrally procured annealed material.

Effective means have been demonstrated for reducing or eliminating susceptibility to cracking by putting the outer fibers of the material in compression. Suss ${ }^{49}$ reported that, in eight weeks of exposure, no specimens of AISI 410 that had been shot peened falled whereas the same material falled in one week or less in the as-received condition.

The mechanical cold-swaging techniques used in the fabrication of fuel rods of compacted uranium dioxide powder impose compressive 
stresses on the outer fibers of the cladding. Lees ${ }^{47}$ investigated the residual stresses in the outer fibers of stainless-steel-clad fuel rods fabricated by various mechanical reduction processes. The results shown in Table 3 indicate that compressive stresses as high as 39,500 psi were imparted to the outer fibers of cladding of swaged fuel rods. Time to fallure in a test with boiling $42 \mathrm{wt} . \% \mathrm{MgCl}_{2}$ solution varied from $45 \mathrm{~min}$ for as-recelved cold-worked tubing to $2400 \mathrm{~min}$ for swaged specimens.

In normal reactor service the initial compressive stresses most likely will be canceled by greater applied tensile stresses imposed on the cladding by thermal expansion of the uranium dioxide. However, the net tensile stresses will be appreciably lower. Whether this cladding treatment will result in improved cladding performance will be indicated by the results of current irradiation tests in the VBWR of fuel rods made by various fabrication processes. ${ }^{39}$

\section{Application to Reactors}

The first use of stainless steel as a fuel-cladding material was in the army Stationary Medium Power Plant 1 (SM-1) at Ft. Belvoir, Va., which started initial operations in April 1957. There has since been a steadily increasing number of applications of austenitic stainless steel as a fuel-cladding material in water-cooled power reactors. The reactor applications have been supported by extensive development efforts, which have included (1) in-reactor proof tests of prototypes of firstcore fuel elements and (2) investigations in and out of reactors to explore technical and economic advances over initial designs.

The SM-1 reactor was the forerunner of a large family of similar army reactor power plants utilizing plate fuel consisting of a dispersion of uranium dioxide and stainless-steel cermet clad with type 304 stainless steel. The SM-1 type of plate fuel also was used in the initial core of the VBWR, which achieved criticality in August 1957. Subsequently the VBWR plate fuel was replaced by rod fuel elements, clad with stainless steel and zirconium alloys, being tested as prototypes for commercial reactors.

In contrast to the plate fuel elements in the military compact reactors, the commercial water-cooled power reactors use rod fuel elements consisting of stainless-steel tubes containing high-density uranium dioxide or a mixture of uranium dioxide and thorium dioxide. The first full-scale application of stainless-steel-clad rod fuel elements in a commercial power reactor was in the Yankee Nuclear Power Station. The Yankee reactor uses type 348 stainless-steel fuel cladding. Subsequently the use of rod fuel elements clad with type 304 stainless steel has been initiated in large power reactors, such as the N. S. Sal amah, Indian Point, Elk River, Big Rock Point, and Humboldt Bay reactors. In addition to the preceding fuel-core applications, type 
rable 3 - RESIDUAL ST RESS IN OUTER FIBERS OF SAMPLES CLAD WITH STAINLESS STEEL ${ }^{47,50}$

\begin{tabular}{|c|c|c|c|c|c|}
\hline $\begin{array}{l}\text { Fabrication } \\
\text { process }\end{array}$ & $\begin{array}{l}\text { Reduction } \\
\text { in area, \% }\end{array}$ & $\begin{array}{c}\text { Outside } \\
\text { diameter, in. }\end{array}$ & $\begin{array}{l}\text { Wall thick- } \\
\text { ness, in }\end{array}$ & $\begin{array}{l}\text { Cırcumferentıal* } \\
\text { stress, } 1000 \mathrm{ps} 1\end{array}$ & $\begin{array}{c}\text { Time to } \\
\text { fallure in } \\
\text { boiling } \\
42 \mathrm{wt} . \% \mathrm{MgCl}{ }_{2} \text {, } \\
\text { min }\end{array}$ \\
\hline Swaged powder & 22 & 0.380 & 0.011 & 11.5 & 60 \\
\hline Swaged powder & 22 & 0.380 & 0.011 & 16.6 & 60 \\
\hline Swaged powder & 39 & 0.488 & 0.019 & -39.5 & $360 \dagger$ \\
\hline Swaged powder & 39 & 0488 & 0.019 & -35.1 & $360 \dagger$ \\
\hline Swaged powder & 24 & 0.428 & 0016 & -2.02 & 2400 \\
\hline Swaged powder & 24 & 0.428 & 0.016 & -1.25 & 2400 \\
\hline Tandem rolled & 36 & 0409 & 0.016 & 1.17 & 180 \\
\hline Tandem rolled & 36 & 0.409 & 0016 & 0.360 & 180 \\
\hline As receivedt & & 0.403 & 0.012 & 42.1 & 75 \\
\hline Cold worked $\ddagger$ & & 0.403 & 0.012 & 39.0 & 75 \\
\hline Tubing $\ddagger$ & & 0.363 & 0.014 & 34.3 & 330 \\
\hline \multicolumn{6}{|l|}{$95,000-$ psi yield } \\
\hline strength + & & 0.363 & 0014 & 305 & 330 \\
\hline Swaged pellet $\ddagger$ & 1 & 0359 & 0.014 & -0.280 & 2420 \\
\hline Swaged pellet $\neq$ & 1 & 0.359 & 0.014 & -0.260 & 2420 \\
\hline Swaged pellet & 1.7 & 0.396 & 0.012 & -17.96 & 1000 \\
\hline As recelved & & 0363 & 0.014 & 20.6 & 790 \\
\hline Annealed tubing & & 0.363 & 0.014 & 18.7 & 790 \\
\hline
\end{tabular}

*Negative values indicate compressive stress, and positive values indicate tensile stresses.

$†$ †ailed at vibratooled identification mark.

‡Samples are all from the same tubing. 
304 stainless-steel cladding was used in the partial refueling of the Dresden reactor made in late 1962 for approximately 100 fuel assemblies.

The current applications of stainless steel as fuel cladding in watercooled power reactors are Iisted in Tables 4 and 5 . As shown, the principal austenitic stainless steels used as fuel cladding thus far are types 304,347 , and 348 , being used in pressurized-water and bolling-water reactors at peak cladding-surface temperatures in excess of $650^{\circ} \mathrm{F}$.

REQUIREMENTS The principal requirements of stanless-steel cladding in the coolant environments of water-cooled power reactors are as follows:

1. The general corrosion rate should be low enough so as not to cause a problem in buildup of coolant activity level. This requirement is related to such long-term considerations as release of products of cladding corrosion into the coolant, buldup of crud on fuel heat-transfer surfaces, release of activated crud into the coolant system, and the eventual release of fuel and fission products into the coolant system by loss of cladding material through long-term general corrosion.

2. The cladding should maintain sufficient dimensional and structural integrity over the life of the fuel element so as not to release large amounts of fuel or fission products into the coolant system. This requirement is related to both short-term and long-term considerations, such as localized stress-corrosion attack, effects of radiation damage, steady-state and cyclic mechanical effects of interactions between fuel and cladding, and overheating of cladding resulting from fouling of heat-transfer surfaces.

REACTOR-COOLANT CONDITIONS As shown in 'Tables 4 and 5, stainless-steel-clad fuel elements in current pressurized-water and boilingwater power reactors are designed to operate at coolant pressures of up to $2100 \mathrm{psia}$ and at peak cladding-surface temperatures in excess of $650^{\circ} \mathrm{F}$. Although both bolling-water and pressurized-water reactors use high-purity coolant water, there are differences in chemical compositions of the two coolant systems. In pressurized-water reactors, hydrogen additions are made to suppress oxygen formed from radiolytic dissociation of coolant water. In addition, the $\mathrm{pH}$ of the coolant is in some applications maintained in the range of 9 to 10.5 by additions of lithium hydroxide. Bolling-water reactors normally operate at neutral $\mathrm{pH}$ and with up to $0.3 \mathrm{ppm}$ oxygen from radiolytic decomposition of the coolant. Typical coolant-chemistry conditions for currently operating boiling-water and pressurized-water reactors utılizing stainless-steelclad fuel are given in Table 6.

FUEL LIFETIME In discussing fuel lifetimes, one must differentiate between the physics or design lifetime and the metallurgical or me- 
Table 4-STAINLESS-STEEL CLADDING IN PRESSURIZED-WATER POWER REACTORS ${ }^{5 t}$

\begin{tabular}{|c|c|c|c|c|c|c|c|c|c|}
\hline \multirow[b]{3}{*}{ Reactor } & \multirow{3}{*}{$\begin{array}{l}\text { Rated } \\
\text { power } \\
\text { level, } \\
\text { gross } \mathrm{Mw}(\mathrm{t})\end{array}$} & \multirow[b]{3}{*}{ Fuel } & \multirow[b]{3}{*}{ Claddıng } & \multicolumn{3}{|c|}{ Coolant-water conditions } & \multirow{3}{*}{$\begin{array}{l}\text { Maxımum } \\
\text { claddıng } \\
\text { temperdture, } \\
{ }^{\circ} \mathrm{F}\end{array}$} & \multirow{2}{*}{\multicolumn{2}{|c|}{$\begin{array}{c}\text { Fuel-surface } \\
\text { hedt flux, } \\
1000 \mathrm{Btu} /(\mathrm{hr})(\mathrm{sq} \mathrm{ft})\end{array}$}} \\
\hline & & & & \multirow{2}{*}{$\begin{array}{l}\text { Inlet } \\
\text { temperature, } \\
{ }^{\circ} \mathrm{F}\end{array}$} & \multirow{2}{*}{$\begin{array}{c}\text { Outlet } \\
\text { temperature, } \\
{ }^{\circ} \mathbf{F}\end{array}$} & \multirow{2}{*}{$\begin{array}{l}\text { Pressure, } \\
\text { psia }\end{array}$} & & & \\
\hline & & & & & & & & Average & Maximum \\
\hline $\begin{array}{l}\text { Stationary Medium } \\
\text { Power Plant No. } 1\end{array}$ & 10 & $\begin{array}{l}\mathrm{UO}_{2}-\mathrm{S} . \mathrm{S} \\
\text { cermet } \\
\text { plates }\end{array}$ & $\begin{array}{l}0.005-1 \mathrm{n} .- \text { thick } \\
\text { type } 304 \mathrm{~S} . \mathrm{S} .\end{array}$ & 428 & 448 & 1200 & 550 & 61 & $\sim 185$ \\
\hline $\begin{array}{l}\text { Stationary Medium } \\
\text { Power Plant No. 1A }\end{array}$ & 20.2 & $\begin{array}{l}\mathrm{UO}_{2}-\mathrm{S} . \mathrm{S} \\
\text { cermet } \\
\text { plates }\end{array}$ & $\begin{array}{l}0.005-1 \mathrm{n} .- \text { thick } \\
\text { type } 304 \text { S.S.* }\end{array}$ & & & & $\sim 550$ & 124 & \\
\hline $\begin{array}{l}\text { Portable Medium } \\
\quad \text { Power Plant }{ }^{52} \text { No. } 2 \mathrm{~A}\end{array}$ & 10 & $\begin{array}{c}\mathrm{UO}_{2}-\mathrm{S} . \mathrm{S} . \\
\text { cermet } \\
\text { plates }\end{array}$ & $\begin{array}{l}0.005-1 \mathrm{n}-\text { thick } \\
\quad \text { type } 304 \text { L S.S.* }\end{array}$ & 500 & 518 & 1750 & 612 & 72.3 & \\
\hline $\begin{array}{l}\text { Portable Medium } \\
\quad \text { Power Plant No. } 1^{53}\end{array}$ & 937 & $\begin{array}{l}\mathrm{UO}_{2}-\mathrm{S} . \mathrm{S} \\
\text { cermet } \\
\text { tubes }\end{array}$ & $\begin{array}{l}0.0085-\text { in.-thick } \\
\text { type } 347 \mathrm{~S} . \mathrm{S} \text { modi- } \\
\text { fred with } 0.05 \mathrm{wt} \% \\
\text { Co (max.), } 0.15 \\
\text { wt.\% Co plus Ta } \\
\text { (max.) }\end{array}$ & 447 & 479 & 1300 & 580 & 72 & 286 \\
\hline $\begin{array}{l}\text { Yankee Nuclear } \\
\text { Power Station }^{54}\end{array}$ & 485 & $\begin{array}{l}\mathrm{UO}_{2} \\
\text { pellet } \\
\text { rods }\end{array}$ & $\begin{array}{l}0.021-\text { in. }- \text { thick } \\
\text { type } 348 \text { S.S. }\end{array}$ & 496 & 533 & 2000 & 653 & 106.8 & 446 \\
\hline $\begin{array}{l}\text { Saxton Nuclear } \\
\text { Experımental } \\
\text { Reactor }\end{array}$ & 20 & $\begin{array}{l}\mathrm{UO}_{2} \\
\text { pellet } \\
\text { rods }\end{array}$ & $\begin{array}{c}0015-1 n .- \text { thick } \\
\text { type } 304 \text { S.S. }\end{array}$ & 520 & 540 & 2000 & 642 & 137 & 444 \\
\hline
\end{tabular}




\begin{tabular}{|c|c|c|c|c|c|c|c|c|c|}
\hline $\begin{array}{l}\text { Portable Medium } \\
\text { Power Plant No. 3A }\end{array}$ & 9.37 & $\begin{array}{c}\mathrm{UO}_{2}-\mathrm{S} . \mathrm{S} \\
\text { cermet } \\
\text { tubes } \\
\end{array}$ & $\begin{array}{l}0.0075-1 n .- \text { thick } \\
\text { type } 347 \text { S.S. modi- } \\
\text { fled with } 0.01 \text { wt. } \\
\text { Co (max.), } 0.03 \\
\text { wt. } \% \text { Co plus Ta } \\
\text { (max.) }\end{array}$ & 447 & 479 & 1300 & & 72.8 & 290 \\
\hline $\begin{array}{l}\text { Consolidated Edison } \\
\text { Thorlum Reactor }\end{array}$ & 585 & $\begin{array}{c}\mathrm{ThO}_{2}-\mathrm{UO}_{2} \\
\text { pellet } \\
\text { rods }\end{array}$ & $\begin{array}{l}0.0205-1 \mathrm{n} .- \text { thick } \\
\text { type } 304 \mathrm{~S} . \mathrm{S} . \text { con- } \\
\text { taining approxi- } \\
\text { mately } 300 \mathrm{ppm} \\
\text { boron }\end{array}$ & 486.5 & 519 & 1500 & 605 & 128 & 560 \\
\hline $\begin{array}{l}\text { Belgian Thermal } \\
\text { Reactor BR- } 3^{55}\end{array}$ & 40.9 & $\begin{array}{l}\mathrm{UO}_{2} \\
\text { pellet } \\
\text { rods }\end{array}$ & $\begin{array}{l}0.020-1 \mathrm{n} .- \text { thick } \\
\text { type } 348 \mathrm{~S} . \mathrm{S}\end{array}$ & 491 & 514 & 2000 & 680 & 94.2 & 441.8 \\
\hline $\begin{array}{l}\text { N. S. Savannah } \\
\text { Reactor }\end{array}$ & 70 & $\begin{array}{l}\mathrm{UO}_{2} \\
\text { pellet } \\
\text { rods }\end{array}$ & $\begin{array}{c}0.035-1 \mathrm{n} .- \text { thick } \\
\text { type } 304 \text { S.S. }\end{array}$ & 497 & 519 & 1750 & 626 & 63.5 & 277 \\
\hline $\begin{array}{l}\text { First Atomic Power } \\
\text { Plant of the USSR }\end{array}$ & 30 & $\begin{array}{l}\text { Hollow } \\
\text { uranium } \\
\text { cylinders }\end{array}$ & $\begin{array}{l}\text { Clad with } 0 \text { 0152- } \\
\text { in.-thick S.S. on } \\
\text { inside and } 0.0076- \\
\text { in.-thick S.S. on } \\
\text { outside }\end{array}$ & 374 & 588 & 1430 & & & \\
\hline SELNI Reactor ${ }^{58}$ & 835 & $\begin{array}{l}\mathrm{UO}_{2} \\
\quad \text { pellets }\end{array}$ & $\begin{array}{l}0.015-1 \mathrm{n} .- \text { thick } \\
\text { type } 304 \text { S.S. }\end{array}$ & & & & & & \\
\hline
\end{tabular}

*Second core clad with type 347 stainless steel with low cobalt and low tantalum. 
Table 5-STAINLESS-STEEL CLADDING IN BOILING-WATER POWER REACTORS ${ }^{51}$

\begin{tabular}{|c|c|c|c|c|c|c|c|c|c|}
\hline \multirow[b]{3}{*}{ Reactor } & \multirow{3}{*}{$\begin{array}{l}\text { Rated } \\
\text { power } \\
\text { level, } \\
\text { gross } M w(t)\end{array}$} & \multirow[b]{3}{*}{ Fuel } & \multirow[b]{3}{*}{ Cladding } & \multicolumn{3}{|c|}{ Coolant-water conditions } & \multirow{3}{*}{$\begin{array}{c}\text { Maximum } \\
\text { claddıng } \\
\text { temperature, } \\
{ }^{\circ}\end{array}$} & \multirow{2}{*}{\multicolumn{2}{|c|}{$\begin{array}{c}\text { Fuel-surface } \\
\text { heat flux, } \\
1000 \mathrm{Btu} /(\mathrm{hr})(\mathrm{sq} \mathrm{ft})\end{array}$}} \\
\hline & & & & \multirow{2}{*}{$\begin{array}{c}\text { Inlet } \\
\text { temperature, } \\
{ }^{\circ} \mathrm{F}\end{array}$} & \multirow{2}{*}{$\begin{array}{l}\text { Outlet } \\
\text { temperature, } \\
{ }^{\circ} \mathrm{F}\end{array}$} & \multirow{2}{*}{$\begin{array}{l}\text { Pressure, } \\
\text { psia }\end{array}$} & & & \\
\hline & & & & & & & & Average & Maximum \\
\hline $\begin{array}{l}\text { Vallecitos Boiling } \\
\text { Water Redctor }\end{array}$ & 50 & $\begin{array}{l}\mathrm{UO}_{2} \\
\quad \text { pellets }\end{array}$ & $\begin{array}{l}\text { 7ircaloy-2 } \\
\text { Zircaloy-4, and } \\
\text { type } 304 \mathrm{~S} \mathrm{S.}\end{array}$ & 542 & 5466 & 1017 & $\sim 600$ & $\sim 150$ & 535 \\
\hline $\begin{array}{l}\text { Dresden Nuclear } \\
\quad \text { Power Station }\end{array}$ & 626 & $\begin{array}{l}\mathrm{UO}_{2} \\
\quad \text { pellets }\end{array}$ & $\begin{array}{l}\text { Zircaloy-2, } \\
\text { Z1rcaloy-4, and } \\
\text { type } 304 \mathrm{~S} \mathrm{~S}\end{array}$ & 504 & 5466 & 1017 & 561 & 942 & 276 \\
\hline Elk River Reactor & 73 & $\begin{array}{c}\mathrm{ThO}_{2}-\mathrm{UO}_{2} \\
\text { pellets }\end{array}$ & $\begin{array}{l}0020-\text { in -thick } \\
\text { type } 304 \mathrm{~S} \mathrm{~S} \text { con- } \\
\text { tainıng } 600 \mathrm{ppm} \\
\text { natural boron }\end{array}$ & 450 & 536 & 935 & 611 & 91 & 313 \\
\hline $\begin{array}{l}\text { Humboldt Bay } \\
\text { Power Plant }\end{array}$ & 165 & $\begin{array}{l}\mathrm{UO}_{2} \\
\text { pellets }\end{array}$ & $\begin{array}{l}0019-1 \mathrm{n}-\text { thick } \\
\text { type } 304 \mathrm{~S} \mathrm{~S}\end{array}$ & 5366 & 549 & 1035 & 575 & 806 & 3651 \\
\hline $\begin{array}{l}\text { Big Rock Point } \\
\text { Reactor }\end{array}$ & 157 & $\begin{array}{l}\mathrm{UO}_{2} \\
\quad \text { pellets }\end{array}$ & $\begin{array}{c}0019-1 n \text {-thick } \\
\text { type } 304 \mathrm{~S} \mathrm{~S}\end{array}$ & 5387 & 5506 & 1050 & 575 & 110 & 350 \\
\hline $\begin{array}{l}\text { Urals Atomic } \\
\text { Power Station }\end{array}$ & 285 & $\begin{array}{l}\text { Hollow } \\
\text { uranium } \\
\text { cylinders }\end{array}$ & $\begin{array}{l}\text { S S on inside and } \\
\text { outside of hollow } \\
\text { cylinders }\end{array}$ & 572 & 644 & 2140 & 671 & 196 & \\
\hline
\end{tabular}


Table 6-TYPICAL PRIMARY COOLANT CONDITIONS IN BOILING-WATER AND PRESSURIZED-WATER REACTORS UTILIZING STAINLESS-STEEL-CLAD FUEL ELEMENTS

\begin{tabular}{|c|c|c|c|c|c|c|}
\hline Reactor & $\mathrm{pH}$ & $\begin{array}{l}\text { Resistivity, } \\
\text { megohm-cm }\end{array}$ & $\begin{array}{l}\text { Total } \\
\text { solids, } \\
\text { ppm }\end{array}$ & $\begin{array}{c}\text { Chlorides, } \\
\text { ppm }\end{array}$ & $\begin{array}{l}\text { Oxygen, } \\
\text { ppm }\end{array}$ & Hydrogen \\
\hline \multicolumn{7}{|c|}{ Boiling-water Reactors } \\
\hline $\begin{array}{l}\text { Vallecitos Bolling } \\
\text { Water Reactor }\end{array}$ & $\sim 7$ & 1.0 & 1 to 12 & $\sim 0.02$ & 0.2 to 0.3 & Stoichiometric \\
\hline $\begin{array}{l}\text { Dresden Nuclear } \\
\text { Power Station } 20,59\end{array}$ & $\sim 7$ & 1.0 & 0.6 & $<0.03$ & 0.2 to 0.3 & Stoichiometric \\
\hline \multicolumn{7}{|c|}{ Pressurized-water Reactors } \\
\hline $\begin{array}{l}\text { Stationary Medium } \\
\text { Power Plant } \\
\text { No. } 1^{* 30,31}\end{array}$ & 7.5 to 8.5 & 1.0 to 1.5 & $\sim 0.5$ & $<0,1$ & $<0.01$ & $\begin{array}{l}30 \text { to } 40 \mathrm{~cm}^{3} / \\
\text { liter (S.T.P.) }\end{array}$ \\
\hline $\begin{array}{l}\text { Yankee Nuclear } \\
\text { Power Station } t^{54}\end{array}$ & $7.5 \pm 1$ & 0.5 & $\sim 2$ & $<0.1$ & $<0.1$ & $\begin{array}{l}25 \text { to } 45 \mathrm{~cm}^{3} / \\
\text { liter (S.T.P.) }\end{array}$ \\
\hline
\end{tabular}

*The pH of SNI-1 prumary coolant system was increased recently to approximately 10 by adding lithum hydroxide. 32

†Boric acid is added to coolant for auxiliary control during reactor shutdown.

chanical lifetime. The fuel design lifetime, based on reactivity considerations, is a function of core excess reactivity available for burnup. The metallurgical or mechanical lifetime is a function of cladding performance as related to maintaining its dimensional and mechanical integrity. This discussion is concerned with the factors that affect the metallurgical or mechanical lifetime of the fuel.

The fuel lifetimes reported for the various commercial power reactors listed in Tables 4 and 5 indicate burnup targets of up to 18,000 $\mathrm{Mwd} / \mathrm{t}$ (average) and $50,000 \mathrm{Mwd} / \mathrm{t}$ (maximum). ${ }^{51}$ The reported values are considered design or reactivity lifetimes.

The most extensive fuel-lifetime experience thus far in the use of stainless-steel-clad fuel in water-cooled commercial power reactors has been associated with the rod fuel elements in the first cores of the Yankee, Humboldt Bay, and Big Rock Point reactors and in the reload fuel of the Dresden reactor. The Yankee reactor is clad with type 348 stainless steel. All other commercial power reactors utilizing stainlesssteel cladding use type 304 stainless steel. The performance analysis of the Yankee first core, which was replaced in 1962 for reactivity reasons after an average core burnup of approximately $8000 \mathrm{Mwd} / \mathrm{t}$, is now being conducted. ${ }^{60} \mathrm{Up}$ to the present time, there have been no reported fuel-performance problems relating to potential metallurgical lifetime limits. Coe et al. ${ }^{29}$ reported that, during the lifetime of Yankee core I, there was indication of only minor fission-product activity in the primary coolant loop. The second core of the Yankee reactor is identical with the first core; it consists of $\mathrm{UO}_{2}$-pellet fuel rods clad with type 348 stainless steel. 
REACTOR EXPERIENCE The significant irradiation experience with stainless-steel-clad fuel elements has been obtained in the power reactors listed in Tables 4 and 5 and in the irradiation testing of prototypic or advanced fuel concepts in experimental or test reactors listed in Tables 7 to 16 .

The Yankee reactor is the only commercial power reactor utilizing stainless-steel cladding which has operated lorg enough to have its first core replaced. As previously mentioned, the fuel was clad with type 348 stainless steel, and the performance of the first core is now being evaluated. Thus far there have been no reported indications of any problems associated with the performance of the Yankee first core. In all subsequent applications of stainless-steel-clad fuel in commercial power reactors, type 304 stamless steel has been used. Reactor operating experience with fuel with this cladding is being obtained currently in bolling-water reactors, such as the Dresden, Humboldt Bay, and Big Rock Point, and in pressurized-water reactors, such as the Indian Point and N. S. Sar annah

Reactor applications, up to the present time, have been successful for both the plate fuel elements used in the military reactors and the conservatively designed, freestanding, rod fuel elements used in large power reactors. However, there have been some reported occurrences of both intergranular and transgranular cracking of highly stressed stainless-steel cladding in pressurized-water reactors and of intergranular cracking in boiling-water-reactor (VBWR) fuel tests.

Stress-corrosion cracking of some of the type 304L stainlesssteel fuel plates of the SM-1 core I was reported. ${ }^{36}$ Postirradiation examination of a fuel element (S-72) after $10.5 \mathrm{Mw}$-years of operation in the SM-1 core I indicated localized corrosion of brazed joints and some intergranular cracking of the type 304L stainless-steel cladding. Examination of SM-1 core I fuel element (S-79), which had operated for the full design life of $16.4 \mathrm{Mw}$-years, indicated severe corrosion of the brazed joint and both intergranular and transgranular cracking of the type 304L cladding. The intergranular cracking was believed to be related to the fuel-assembly fabrication process, which resulted in carburization, sensitization, and formation of coarse grains in the cladding. The observed transgranular cracking was believed to be caused by a stress-corrosion mechanism.

Beaver et al. ${ }^{37}$ had previously reported the sensitization of the type $304 \mathrm{~L}$ cladding by diffusion of the carbon from the fuel matrix during fabrication, and they had indicated that the use of type 347 stainlesssteel cladding would eliminate the problem of sensitization during fabrication. Type 347 cladding has been used in subsequent cores. There appear to have been no other performance problems reported for fuel elements in the army compact water-cooled reactors. The expected life of the SM-1 core III, which is clad with type 347 stainless steel, is 
Table 7 - PARAMETERS OF VBWR IRRADIATION TESTS OF FUEL RODS CLAD WITH TYPE 304 STAINLESS STEEL

Cladding
Claddıng thickness
Rod outsıde diameter
Cladding strength*
Diametral gap between
cladding and pellets
Method of fuel-rod
fabrication

Peak surface heat fluxes of fuel rods

Thermal ratungs of fuel rods
Temperature and pressure of reactor coolant

Coolant flow

Active fuel length in test rods
Type 304 stannless steel

Freestanding 0014 to $0045 \mathrm{in}$ Thin wall 0005 to 0012 in

0250 to $1375 \mathrm{in}$

Variations in degree of initial cold work of clad tubing from 40,000 psi (fully annealed) to $110,000 \mathrm{psi}$ (cold worked) room-temperature yleld strength

0 to $0010 \mathrm{in}$

Pressed and sintered $\mathrm{UO}_{2}$ pellets

Extruded and sintered $\mathrm{UO}_{2}$ pellets

Compacted $\mathrm{UO}_{2}$ powder

Cold swaged

Hot swaged

Vibrationally compacted

Tandem rolled

Coextruded $\left(\mathrm{UO}_{2}\right.$ in stainless steel)

isostatic-gas-pressure bonded

Up to approximately $535,000 \mathrm{Btu} /(\mathrm{hr})(\mathrm{sq} \mathrm{ft})$

$\int_{T_{S}}^{T_{0}} k(T) d T$ values of up to 132 watts $/ \mathrm{cm}$

$\left(T_{s}\right.$ and $\Gamma_{0}$ are temperatures at the pellet surface and pellet center, respectively)

Inlet, water at $535^{\circ} \mathrm{F}$, outlet, steam-water mixture at $545^{\circ} \mathrm{F}$ and $1000 \mathrm{ps}$

Up to $15 \mathrm{ft} / \mathrm{sec}$

$\sim 36$ in

* Of the 1400 stanless-steel-clad fuel rods under test in the VBWR, approximately one-third were fabricated with fully annealed cladding having a roomtemperature yield strength of 44,000 psi, one-third with a cladding roomtemperature yreld strength between 50,000 and $85,000 \mathrm{ps}$, and the remainder with a cladding room-temperature yield strength greater than $90,000 \mathrm{ps}$ 
rable 8 - VBWR IRRAIIA TION TESTS OF UO ${ }_{2}$-PEI IF $\Gamma$ FUEI RODS CLAD WITII

TYPF 304 STAINI FSS STFEL

\begin{tabular}{|c|c|c|c|c|c|c|c|}
\hline $\begin{array}{l}\text { No } \\
\text { rods }\end{array}$ & $\begin{array}{l}\text { Cladding } \\
\text { OD, in. }\end{array}$ & $\begin{array}{c}\text { Cladding } \\
\text { wall } \\
\text { thick- } \\
\text { ness, } \\
\text { in }\end{array}$ & $\begin{array}{l}\mathrm{UO}_{2} \text { cladding } \\
\text { didmetral } \\
\text { gap, in }\end{array}$ & $\begin{array}{l}\text { Pedk surface } \\
\text { heat flux, } 1000 \\
\text { Btu/(hr) }(\mathrm{sq} f \mathrm{ft})\end{array}$ & $\begin{array}{l}\text { Averdge } \\
\text { burnup } \\
\text { of rods } \\
\text { in leading } \\
\text { dssembly, } \\
\text { Mwd/t* }\end{array}$ & $\begin{array}{c}\text { Cladding } \\
\text { room-temperature } \\
\text { yreld strength, } \\
1000 \mathrm{ps} \text {. }\end{array}$ & $\begin{array}{l}\text { Reference } \\
\text { No }\end{array}$ \\
\hline \multicolumn{8}{|c|}{ F reestandıng Cladding } \\
\hline 6 & 0567 & 0046 & 00035 & 286 & 3300 & 65 to 85 & 63,64 \\
\hline 9 & 0555 & 0025 & $0002-0008$ & 316 & 6800 & $\sim 35$ & $63 \quad 64$ \\
\hline 74 & 0568 & 0033 & $0003-0007$ & 356 & 4300 & 35 to 85 & 63,64 \\
\hline 18 & 0555 & 0025 & $0003-0013$ & 505 & 1900 & $\sim 35$ & 65,66 \\
\hline 2 & 0250 & 0028 & $\sim 0008$ & 220 & 5600 & $\sim 45$ & $67,68,69$ \\
\hline 8 & 0515 & 0020 & $0004-0008$ & 535 & 4075 & 85 & 70,71 \\
\hline 16 & 0500 & 0035 & 0005 & 240 & 1980 & & 72 \\
\hline 48 & 0500 & 0035 & $0002-0007$ & 333 & $\sim 4400$ & & 73 \\
\hline 224 & 0410 & 0020 & $0004-0008$ & 426 & 5700 & 44 & $70,71,74,76$ \\
\hline 100 & 0400 & 0017 & $0002-0005$ & 410 & 4400 & 44,90 & 50,75 \\
\hline 252 & 0410 & 0015 & $0004-0006$ & 419 & 5500 & 85 & $70,71,74$ \\
\hline 200 & 0360 & 0014 & $0004-0006$ & 489 & 7800 & 44,90 & 74,75 \\
\hline 100 & 0360 & 0014 & $0000-0002$ & 500 & 7800 & 44,90 & 74,75 \\
\hline $12 \uparrow$ & 0540 & 0022 & $\sim 0011$ & 262 & $\sim 200$ & 87 & $76,77,78$ \\
\hline 1 & 1375 & 0065 & $0004-0010$ & $\sim 535$ & $\sim 200$ & 90 & 79,38 \\
\hline \multicolumn{8}{|c|}{ Thın-wall Claddıng } \\
\hline 100 & 0400 & 0012 & $0000-0003$ & 441 & 4950 & 94 & $39,75,80$ \\
\hline 25 & 0400 & $0 \quad 012$ & $0000-0003$ & 441 & 4950 & 94 & $39,75,80$ \\
\hline 15 & 0400 & 0010 & $0000-0001$ & 408 & 4950 & 44 & $39, / 5,80$ \\
\hline 12 & 0400 & 0008 & $0000-0001$ & 408 & 4950 & 44 & $39,75,80$ \\
\hline 12 & $0 \quad 385$ & (1) 005 & $0000-0001$ & 488 & 2550 & 110 & $39,70,78$ \\
\hline $5 t$ & 0445 & 0011 & $0003-0004$ & $\sim 250$ & $\sim 150$ & 45,70 & 38 \\
\hline
\end{tabular}

*as of Mar 15, 1963, megawatt days per ton of uranium

† I uel rods containing $\mathrm{UO}_{2}$ extrusions up to 6 in long

tOne rod contains $500 \mathrm{ppm}$ boron in cladding and one rod contains $750 \mathrm{ppm}$ boron in cladding 
Iable 9-VBUR IRRADIA IION IESIS OI CONPAC IF D-UO 2 -POWDLR F UL L RODS CLAD WITH TYI I 101 SI AINI I SS STEEL

\begin{tabular}{|c|c|c|c|c|c|c|c|c|c|c|}
\hline $\begin{array}{l}\text { No } \\
\text { 10lu }\end{array}$ & $\begin{array}{l}\text { (1) lling } \\
\text { (Oi) in }\end{array}$ & 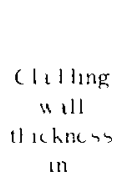 & Method of librication & $\begin{array}{c}\text { I inil } \mathrm{UO}_{2} \\
\text { density altet } \\
\text { compiction } \\
T \text { D }\end{array}$ & $\begin{array}{l}\text { Peal suifice } \\
\text { he it flux } 10000 \\
B t u /(h t)(s q f t)\end{array}$ & $\begin{array}{l}\text { Ales lge } \\
\text { burnup of } \\
\text { rods in } \\
\text { ledding } \\
\text { issc mbly } \\
\text { Vudd } / t^{*}\end{array}$ & $\begin{array}{c}\text { Cld lding } \\
\text { loom-temperature } \\
\text { ylcld itrength } \\
\text { after rod fabri- } \\
\text { cation } 1000 \mathrm{ps} 1\end{array}$ & Ref & $\mathrm{Fo}$ & \\
\hline \multicolumn{11}{|c|}{ Frecutanding Cltalding } \\
\hline 12 & 1) $: 03$ & 001 , & Coextruded & $x$ to $)$ & +1 & +200 & 10 & -0 & -1 & 91 \\
\hline 13 & 0100 & 0011 & Cold sw iged ( 3 pdsses) & 93 to 91 & Y, & $\pm 4,0$ & 9 & 80 & $\times 2$ & \\
\hline 12 & $11+00$ & 0014 & (old swaged (2 passes) & 90 to 92 & 10 & 3400 & 90 & 40 & 42 & \\
\hline 10 & 11400 & $(1) 01$ & Hot swuged & 11 to 96 & +26 & 3400 & 7 & 40 & $\$ 2$ & \\
\hline 1 & $11+100$ & 0011 & I in lem rolled & $\times 10 \times 9$ & 22 & 42,0 & 112 & 42 & 83 & \\
\hline 3 & $03)^{7}$ & 001 & $\begin{array}{l}\text { Inout bitic-g is pichsu e } \\
\text { bonded }\end{array}$ & $\sim$ if & $i$ & 316 & $\sim 10$ & 70 & 348 & 85 \\
\hline $3: 2$ & 11100 & 0010 & Cold iwaged (2 passes) & 301092 & 140 & 3200 & 10 & 42 & 81 & \\
\hline 12 & $11+2$, & 0010 & cold swaged ( 2 passes) & 49 to 92 & +20 & 1400 & 10 & 42 & 86 & \\
\hline 13 & $11+00$ & 0012 & Ibrationally compacted & $x 3$ to $8 x$ & $3 \times 1$ & 3400 & 10 & $r_{0}$ & 42 & \\
\hline 11 & $11: 100$ & (1) ola & Cold swaged ( 2 pdises $s)$ & $=$ to 90 & +2 & 3400 & 10 & 42 & 46 & \\
\hline 17 & 11100 & 0010 & Cold swaged (3 passcs) & $1110 \quad 13$ & "4 & $4 \quad 00$ & 15 & 0 & 42 & \\
\hline \multirow[t]{2}{*}{ 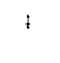 } & $(1), 3$ & (1) 01 & Vibtation illy compicted & 47 to 90 & 27) & 124 & $\mathrm{NA} \ddagger$ & 47 & & \\
\hline & 11 , 3 & 0010 & vibritionally compacted & $4710 \quad 10$ & 27 & $1,2+5$ & $\mathrm{NA}$ & 47 & & \\
\hline 2 & $11+3$ & $0110 \mathrm{n}$ & Vibr at ionally compacted & $x+1090$ & 279 & 1215 & $\mathrm{NA} \pm$ & $x_{1}$ & & \\
\hline It & & 0100 & libidtonaliy compicted & $\rightarrow 3$ to 43 & 2,0 & -100 & 1110102 & -0 & -8 & \\
\hline$\S$ & 1103 & 0011 & Wbi thonally compreted & , & 20 & 10 & 10) to 0 & $m$ & & \\
\hline
\end{tabular}

* Is of Mar l lif 3 meg iw itt days per ton of uranium

tRods contain a ppm boron in the $\mathrm{UO}_{2}$ a b burnable poson

†Not « tilable

sOne sod cont tums 00 ppm boron in alding one 1 od contans, 0 ppm boron in clideling and three tods contuin 0 ppm bor on in the UO, 
Table 10-VBWR IRRADIATION TESTS OF INTENTIONALLY DEFECTED STAINLESS-STEEL-CLAD UO 2 FUEL RODS

\begin{tabular}{|c|c|c|c|c|c|c|c|}
\hline $\begin{array}{l}\text { No. } \\
\text { rods }\end{array}$ & $\begin{array}{c}\text { Cladding } \\
\text { OD, in. }\end{array}$ & $\begin{array}{c}\text { Cladding } \\
\text { wall } \\
\text { thick- } \\
\text { ness, in. }\end{array}$ & $\begin{array}{c}\text { Defect } \\
\text { diameter, } \\
\text { in. }\end{array}$ & $\begin{array}{l}\text { Defect } \\
\text { location }\end{array}$ & $\begin{array}{c}\text { Peak } \\
\text { surface } \\
\text { heat flux, } \\
1000 \mathrm{Btu} / \\
(\mathrm{hr}) \text { (sq ft) }\end{array}$ & $\begin{array}{l}\text { Average } \\
\text { rod } \\
\text { burnup, } \\
\text { Mwd/t* }\end{array}$ & $\begin{array}{c}\text { Activity } \\
\text { release } \\
\text { at steady } \\
\text { state, } \\
\mu \mathrm{c} / \mathrm{sec}\end{array}$ \\
\hline \multicolumn{8}{|c|}{ Pellet Fuel } \\
\hline 1 & 0.385 & 0.005 & 0.013 & Plenum & 488 & 2000 & 5 \\
\hline 1 & 0.410 & 0.015 & 0.010 & Plenum & 400 & 1200 & 5 \\
\hline 1 & 0.410 & 0.015 & 0.020 & Fuel & 400 & 1000 & 5 \\
\hline 1 & 0.515 & 0.020 & 0.013 & Plenum & 460 & 800 & 3 \\
\hline 1 & 0.400 & 0.012 & 0.020 & Fuel & 350 & 100 & 5 \\
\hline \multicolumn{8}{|c|}{ Compacted-powder Fuel } \\
\hline 1 & $0.400^{\dagger}$ & 0.015 & 0.013 & Plenum & 270 & 300 & 8 \\
\hline 1 & $0.400 \ddagger$ & 0.015 & 0.015 & Fuel & 100 & 1200 & 5 \\
\hline 1 & $0.400 \ddagger$ & 0.010 & 0.020 & Fuel & 250 & 100 & 5 \\
\hline 1 & $0.400 \ddagger$ & 0.015 & $\begin{array}{l}0.5-\text { by } \\
0.020-\text { in. } \\
\text { slit }\end{array}$ & Fuel & 350 & 1000 & 20 \\
\hline 1 & 0.4008 & 0.015 & $\begin{array}{l}0.5-\text { by } \\
0.020-\text { in. } \\
\text { slit }\end{array}$ & Fuel & 380 & 1000 & 20 \\
\hline
\end{tabular}

*As of Mar. 15, 1963, megawatt days per ton of uranium.

†Coextruded rod.

\$Cold-swaged rod.

$\S$ Hot-swaged rod. 
Table 11 - SUMMARY OF FA ILURES OF STAINLESS-STEEL-CLAD

$\mathrm{UO}_{2}$ FUEL RODS IN THE VBWR

\begin{tabular}{|c|c|c|c|c|c|c|c|}
\hline $\begin{array}{l}\text { No } \\
\text { rods }\end{array}$ & $\begin{array}{l}\text { Cladding } \\
\text { OD, in }\end{array}$ & $\begin{array}{l}\text { Cladding } \\
\text { wall } \\
\text { thick- } \\
\text { ness, } \\
\text { in }\end{array}$ & $\begin{array}{l}\mathrm{UO}_{2} \text { cladding } \\
\text { gap, in }\end{array}$ & $\begin{array}{c}\text { Peak } \\
\text { surface } \\
\text { heat flux, } \\
1000 \mathrm{Btu} / \\
(\mathrm{hr})(\mathrm{sq} \mathrm{ft})\end{array}$ & $\begin{array}{c}\text { Peak } \\
\text { fuel-rod } \\
\text { burnup, } \\
\text { Mwd/t* }\end{array}$ & $\begin{array}{c}\text { Initıal } \\
\text { cladding } \\
\text { rcom-temp } \\
\text { yield } \\
\text { strength, } \\
1000 \mathrm{ps} 1\end{array}$ & $\begin{array}{l}\text { Ref } \\
\text { No. }\end{array}$ \\
\hline \multicolumn{8}{|c|}{ Intergranular Longitudinal Crack } \\
\hline $2 \dagger$ & 0360 & 0014 & $\begin{array}{c}0001 \text { to } \\
0003\end{array}$ & 480 & 8,500 & 90 & 39 \\
\hline 3 & 0360 & 0014 & $\begin{array}{c}0001 \text { to } \\
0003\end{array}$ & 460 & 11,603 & 90 & 88 \\
\hline 1 & 0360 & 0014 & $\begin{array}{c}0001 \text { to } \\
0003\end{array}$ & 480 & 9,600 & 90 & 39,50 \\
\hline 1 & 0363 & 0014 & $\begin{array}{c}0004 \text { to } \\
0006\end{array}$ & 470 & 9,900 & 90 & 39,50 \\
\hline 1 & 0398 & 0012 & $\begin{array}{c}0001 \text { to } \\
0003\end{array}$ & 400 & 8,000 & 94 & 39,50 \\
\hline 1 & 0398 & 0012 & $\begin{array}{c}0001 \text { to } \\
0003\end{array}$ & 400 & 6,600 & 94 & 39,50 \\
\hline 1 & 0398 & 0012 & $\begin{array}{r}0.001 \text { to } \\
0003\end{array}$ & 380 & 6,200 & 94 & 39,50 \\
\hline 1 & 0398 & 0012 & $\begin{array}{c}0001 \text { to } \\
0003\end{array}$ & 390 & 6,860 & 94 & 88 \\
\hline \multicolumn{8}{|c|}{ Transgranular Mechanical Fracture } \\
\hline 3 & 0380 & 0005 & $\sim 0001$ & 488 & 4,100 & 115 & 70,78 \\
\hline \multicolumn{8}{|c|}{ Defect Hole in End-plug Weld } \\
\hline 1 & 0398 & 0012 & $\begin{array}{l}\sim 0001 \\
\quad \text { to } 0003\end{array}$ & 400 & 2,800 & 94 & 89 \\
\hline \multicolumn{8}{|c|}{ Intergranular Crack } \\
\hline $1 \bar{t}$ & 0400 & 0010 & 0000 & 380 & 7,100 & $\sim 94$ & 88 \\
\hline 1f & 0400 & 0016 & 0000 & 380 & 7,100 & $\sim 94$ & 88 \\
\hline
\end{tabular}

*As of May 1, 1963, megawatt days per ton of uranium Except as otherwise noted, all rods are clad with type 304 stainless steel and contain about 95 percent dense $\mathrm{UO}_{2}$ pellets.

tAfter the detection of cladding cracks, these fuel rods were reinserted into the VBWR and operated for one additional cycle to obtain data on fission-product release The release rates as measured by an in-pile sampling device were of the order of $180 \mu \mathrm{c} / \mathrm{sec}$

$\ddagger$ These rods are compacted-powder fuel rods clad with type 304 stainless steel and cold swaged to 93 percent of theoretical density 
Table 12-POWER-CYCLING TESTS OF UO ${ }_{2}$ CLAD WITH THIN-WALL STAINLESS STEEL IN THE GETR TRAIL CABLE FACILITY*

\begin{tabular}{|c|c|c|c|c|c|c|c|}
\hline $\begin{array}{l}\text { No } \\
\text { rods }\end{array}$ & $\begin{array}{l}\text { Cladding } \\
\mathrm{OD}, \text { in }\end{array}$ & $\begin{array}{l}\text { Wall } \\
\text { thick- } \\
\text { ness, } \\
\text { in }\end{array}$ & $\begin{array}{l}\text { Method of } \\
\text { fabrication }\end{array}$ & $\begin{array}{c}\mathrm{UO}_{2} \\
\text { density, } \\
\% \mathrm{~T} \mathrm{D}\end{array}$ & $\begin{array}{c}\text { Diametral } \\
\text { cold gap, } \\
\text { in. }\end{array}$ & $\begin{array}{l}\text { Measured } \\
\text { increase } \\
\text { in diameter } \\
\text { at end of } \\
\text { cycling, in. }\end{array}$ & $\begin{array}{l}\text { Maximum } \\
\text { surface } \\
\text { heat flux, } \\
1000 \mathrm{Btu} / \\
\text { (hr)(sq ft) }\end{array}$ \\
\hline 4 & $\sim 0482$ & 0011 & Pellets & 94 to 97 & $\begin{array}{c}0000 \text { to } \\
0006\end{array}$ & $\begin{array}{c}0000 \text { to } \\
0003\end{array}$ & 430 \\
\hline 1 & 0396 & 0010 & Pellets & 95 & 0000 & 0001 & 445 \\
\hline 1 & 0403 & 0010 & $\begin{array}{l}\text { Swaged } \\
\text { powder } \dagger\end{array}$ & 92 & 0000 & 0000 & 475 \\
\hline 1 & 0404 & 0010 & $\begin{array}{l}\text { Swaged } \\
\text { powder } \ddagger\end{array}$ & 91 & 0000 & 0000 & 500 \\
\hline 2 & $\sim 0493$ & 0008 & Pellets & 94 to 97 & $\begin{array}{l}0000 \\
\quad 0001\end{array}$ & $\begin{array}{c}0001 \text { to } \\
0003\end{array}$ & 410 \\
\hline
\end{tabular}

${ }^{*} \mathrm{UO}_{2}$ fuel specimens, approximately $7 \mathrm{in}$ long, clad with type 304 stainless steel. Each specimen was subjected to 3000 power cycles over a surface-heatflux range of $50,000 \mathrm{Btu} /(\mathrm{hr})(\mathrm{sq} \mathrm{ft})$ to the maximum value indicated Duration of each cycle was $2 \mathrm{~min}$ Specimens were cooled by bolling water at $1000 \mathrm{ps} 1$

$\dagger$ Fabricated by cold swaging

$\ddagger$ Cold swaged and annealed

Table 13 -IRRADIATIONS IN THE EBWR OF FUEL RODS CLAD WTTH TYPE 304 STAINLESS STEEL*

\begin{tabular}{|c|c|c|c|c|c|c|}
\hline $\begin{array}{l}\text { No } \\
\text { rods }\end{array}$ & $\begin{array}{l}\text { Fuel-rod } \\
\text { length, } \\
\text { in }\end{array}$ & $\begin{array}{c}\text { Fuel-rod } \\
\text { OD, in }\end{array}$ & $\begin{array}{c}\text { Cladding } \\
\text { thickness } \\
\text { in }\end{array}$ & $\begin{array}{c}\text { Diametral } \\
\text { pellet-to-claddıng } \\
\text { gap, in }\end{array}$ & $\begin{array}{c}\text { Peak } \\
\text { surface } \\
\text { heat flux, } \\
1000 \mathrm{Btu} / \\
(\mathrm{hr})(\mathrm{sq} \mathrm{ft})\end{array}$ & $\begin{array}{l}\text { Average } \\
\text { burnup } \\
\text { Mwd/t }\end{array}$ \\
\hline \multicolumn{7}{|c|}{$90 \mathrm{Wt} \% \mathrm{ThO}_{2}-10 \mathrm{Wt} \% \mathrm{UO}_{2}$ Pellets $\dagger^{98}$} \\
\hline 1 & 31 & 0374 & 0035 & 0004 & 165 & 787 \\
\hline 1 & 48 & 0372 & 0025 & 0010 & 152 & 2017 \\
\hline \multicolumn{7}{|c|}{$97 \mathrm{Wt} \% \mathrm{ThO}_{2}-3 \mathrm{Wt} \% \mathrm{uO}_{2}$ Pellets $^{62}$} \\
\hline 25 & 48 & 0453 & 0020 & 00015 to 00085 & 85 & 570 \\
\hline
\end{tabular}

*All tests terminated at indıcated burnup values

†Cladding intentionally defected for studies of fission-gas release 
Table 14-IRRADIATIONS IN ORR PRESSURIZED-WATER LOOP OF COMPACTED UO ${ }_{2}$ POWDER FUEL CLAD WITH STAINLESS STEE L ${ }^{\mathbf{9 3}, 94,99}$

\begin{tabular}{llccc}
\hline No & Fabrication method & $\begin{array}{c}\mathrm{UO}_{2} \\
\text { density } \\
\text { \% T D }\end{array}$ & $\begin{array}{c}\text { Peak } \\
\text { surface heat flux, } \\
1000 \mathrm{Btu} / \\
(\mathrm{hr})(\mathrm{sq} \mathrm{ft})\end{array}$ & $\begin{array}{c}\text { Average } \\
\text { burnup, } \\
\mathrm{Mwd} / \mathrm{t}\end{array}$ \\
\hline 2 & Cold swaged & 90 & 90 & 820 \\
2 & Cold swaged & 88 & 95 & 910 \\
2 & Hot swaged & 90 & 115 & 955 \\
2 & Cold swaged & 90 & $>90$ & $\sim 1,640$ \\
2 & Cold swaged & 88 & $>95$ & $\sim 1,820$ \\
2 & Hot swaged & 90 & $>115$ & $\sim 1,910$ \\
1 & Cold swaged & 89 & 200 & 2,270 \\
2 & Vibrationally compacted & 89 & 275 & 3180 \\
1 & Cold swaged & 89 & 200 & $7,000 \dagger$ \\
2 & Vibrationally compacted & 89 & 275 & $10,000 \dagger$ \\
3 & Vibrationally compacted & 89 & 400 & $5,000 \dagger$ \\
6 & Vibrationally compacted & 89 & 550 & $6,800 \dagger$ \\
$1 \neq$ & Vibrationally compacted & $\sim 89$ & 330 to 400 & $<1,000$
\end{tabular}

* Loop routinely operates at $500^{\circ} \mathrm{F}$ with $1750 \mathrm{psi}$ water flowing at $10 \mathrm{ft} / \mathrm{sec}$ Fuel rods are $19 \mathrm{in}$ long by $05 \mathrm{in}$ in outside diameter, with $0035-$ in -thick type $304 \mathrm{~L}$ cladding

†Calculated burnup values

$\$$ Fuel rod removed from ORR loop as a result of fallure of Zircaloy-2clad fuel rod in same assembly

Table $15-\mathrm{NRX}$ AND MTR IRRADIATIONS OF $\mathrm{ThO}_{2}-\mathrm{UO}_{2}$ COMPACTEDPOWDER FUEL RODS CLAD WITH TYPE 304 STAINLESS STEEL*94

( $\mathrm{ThO}_{2}-\mathrm{UO}_{2}$ Solıd Solution)

\begin{tabular}{cccccccc}
\hline & Fuel- & Cladding & Fuel- & Peak & Average & \\
rod & thick- & rod & surface heat flux, & Cladding & burnup, & Fuel \\
No & OD, & ness, & length, & $1000 \mathrm{Btu} /$ & tempera- & 1000 & density, \\
rods & in & in & in & $(\mathrm{hr})(\mathrm{sq} \mathrm{ft})$ & ture, ${ }^{\circ} \mathrm{F}$ & $\mathrm{Mwd} / \mathrm{t}$ & $\% \mathrm{~T} \mathrm{D}$ \\
\hline
\end{tabular}

NRX (Capsules Irradıated in Reactor Process Water at $70^{\circ} \mathrm{C}$ )

\begin{tabular}{|c|c|c|c|c|c|c|c|}
\hline 8 & 0312 & 0025 & 11 & $\sim 300$ & $\sim 200$ & Up to 15 & $\sim 78$ \\
\hline 4 & $0 \quad 312$ & 0025 & 225 & $\sim 250$ & $\sim 200$ & & 75 to 79 \\
\hline 6 & 0312 & $0 \quad 025$ & 39 & $\sim 370$ & $\sim 200$ & & \\
\hline
\end{tabular}

MTR (Capsules Irradiated in Reactor Process Water)
$7 \quad 0 \quad 312$
0025
1125
Up to 520
$\sim 200 \quad$ Up to $14 \quad 78$ to 80

* Capsule tests conducted to determine relative performance characteristics of vibrationally compacted thoria-base fuels containing powders made by such processes as sol gel and arc fusion 


\begin{tabular}{|c|c|c|c|c|c|c|c|c|c|c|}
\hline Loop facility & $\begin{array}{l}\text { No } \\
\text { rods }\end{array}$ & $\begin{array}{c}\text { Type } \\
\text { of cladding }\end{array}$ & $\begin{array}{l}\text { Fuel- } \\
\text { rod } \\
\text { OD, } \\
\text { in }\end{array}$ & $\begin{array}{l}\text { Cladding } \\
\text { thick- } \\
\text { ness, } \\
\text { in }\end{array}$ & $\begin{array}{l}\text { Fuel- } \\
\text { rod } \\
\text { length, } \\
\text { in }\end{array}$ & Type of fuel & $\begin{array}{l}\text { Fuel- } \\
\text { claddıng } \\
\text { dıametral } \\
\text { gap, ın }\end{array}$ & $\begin{array}{l}\text { Peak surface } \\
\text { heat flux, } \\
1000 \mathrm{Btu} / \\
(\mathrm{hr})(\mathrm{sq} \mathrm{ft})\end{array}$ & $\begin{array}{l}\text { Average } \\
\text { burnup, } \\
\mathrm{Mwd} / \mathrm{t}\end{array}$ & $\begin{array}{l}\text { Ref } \\
\text { No }\end{array}$ \\
\hline \multirow[t]{3}{*}{$\begin{array}{l}\text { ETR pressurized- } \\
\text { water loop }\end{array}$} & 3 & Annealed & 0336 & 0021 & 308 & $\mathrm{UO}_{2}$ pellets & $\begin{array}{r}00005- \\
00015\end{array}$ & 157 & & 92 \\
\hline & 3 & $\begin{array}{l}\text { Annealed type } \\
304 \mathrm{~L}\end{array}$ & 0323 & 0015 & 227 & $\begin{array}{l}\mathrm{UO}_{2} \text { pellets clad- } \\
\text { ding stretch- } \\
\text { formed onto } \\
\text { pellets }\end{array}$ & & 296 & & 92 \\
\hline & $7^{*}$ & $304 \mathrm{~L}$ & 0906 & 0035 & 36 & $\begin{array}{l}\text { Cold-swaged } \mathrm{UO}_{2} \\
\quad \sim 87 \% \text { T D }\end{array}$ & & & & 87 \\
\hline $\begin{array}{l}\text { Hanford reactor } \\
\text { high-temperature- } \\
\text { water loop }\end{array}$ & 7 & 304 & & & 96 & Cold-swaged $\mathrm{UO}_{2}$ & & $\begin{array}{c}\text { Not } \\
\text { avaılable }\end{array}$ & $\begin{array}{c}\text { Not } \\
\text { avall- } \\
\text { able }\end{array}$ & 87 \\
\hline \multirow[t]{5}{*}{$\begin{array}{l}\text { GETR pressurized- } \\
\text { water loop }\end{array}$} & 9 & $\begin{array}{l}\text { Type } 304 \mathrm{~S} \mathrm{~S} \\
\text { contaınıng } 300 \\
\text { ppm natural } \\
\text { boron }\end{array}$ & 0304 & 0205 & 36 & $\mathrm{ThO}_{2}-\mathrm{UO}_{2}$ pellets & & 560 & 1180 & 90 \\
\hline & $1 \dagger$ & 304 & 0412 & 0010 & 36 & $\mathrm{UO}_{2}$ pellets & 0 & 540 & 773 & 96 \\
\hline & 2 & 304 & 0415 & 0010 & 36 & $\mathrm{UO}_{2}$ pellets & 0 & 410 & 617 & 96 \\
\hline & 1 & 304 & 0480 & 0010 & 36 & $\mathrm{UO}_{2}$ pellets & 0 & 340 & 255 & 96 \\
\hline & 2 & 304 & 0480 & $\begin{array}{lll}0 & 0 & 10\end{array}$ & 36 & $\begin{array}{c}\mathrm{ThO}_{2}-\mathrm{UO}_{2} \\
\text { pellets }\end{array}$ & 0 & 340 & 255 & 96 \\
\hline $\begin{array}{l}\text { GETR bolling- } \\
\text { water loop }\end{array}$ & 9 & 304 & 0500 & 0035 & 38 & $\mathrm{UO}_{2}$ pellets & $\begin{array}{r}0002- \\
0006\end{array}$ & 223 & 5360 & 100 \\
\hline
\end{tabular}

*Four out of seven rods falled shortly after going to power Localized swelling of rods occurred in fallure region $\dagger$ Intentionally defected rod 
$27 \mathrm{Mw}$-years, as compared with the design life of $16.4 \mathrm{Mw}$-years for the original core. ${ }^{61}$

The most extensıve experımental testing of stainless-steel-clad rod fuel elements for commercial reactors ${ }^{39}$ has been in the VBWR. The VBWR tests have included studies of new fabrication processes, thermal limits of fuel rods, and operation of fuel rods clad with thinwall stainless-steel tubing. The fuel characteristics and the performance test parameters for the fuel rods tested in the VBWR are shown in Tables 7 to 11 . Other irradiation tests of stainless-steel fuel elements in water-cooled environments have been conducted in the $\mathrm{EBWR}^{61}$ and in loops in the General Electric Test Reactor (GETR), ${ }^{90}$ Engineering Test Reactor (ETR), ${ }^{91,92}$ Materials Testing Reactor (MTR), ${ }^{93,94}$ Oak Ridge Research Reactor (ORR), ${ }^{93}$ and the Hanford ${ }^{91}$ reactors. These tests are summarized in Tables 12 to 16.

Power-cycling tests were conducted on thin-wall clad fuel rods containing both pellets and compacted powder. ${ }^{95}$ As shown in Table 12 , the fuel specimens containing lower density, compacted $\mathrm{UO}_{2}$ powder exhibited no measurable growth in diameter, whereas the pellet-filled assemblies exhibited finite increases in diameter. Preliminary interpretation of these results indicates that the use of a lower density $\mathrm{UO}_{2}$ may result in less plastic deformation and lower stress levels in the cladding and potentially longer lifetıme for a fuel rod operating at a given power output.

Intentionally defected fuel rods of both the pellet type and the compacted-powder type were irradiated in varıous test facilities as shown in Tables 10 and 13. The VBWR tests of intentionally defected fuel rods with cladding thicknesses as low as 0.005 in. showed no evidence of water-logging effects. Of particular significance were the defected-cladding tests of compacted-powder fuel rods listed in Table 10. Two fuel rods containing $0.5-$ by $0.020-1 n$. slits in the cladding were irradiated in the VBWR with no detectable loss of powder and with relatively low levels of activity release into the coolant system. ${ }^{89,96,97}$ The slotted fuel rods after an exposure of $1000 \mathrm{Mwd} / \mathrm{t}$ are shown in Fig. 5.

As discussed by Baroch and Porembka, ${ }^{85}$ three fuel rods fabricated by the isostatic gas-pressure-bonding process falled as a result of sensitization and intergranular cracking of the cladding. The fuel rods, which had achieved an average burnup of $316 \mathrm{Mwd} / \mathrm{t}$ in the VBWR, falled during storage in the reactor pool. Fallure was attributed ${ }^{70,85}$ to intergranular cracking of the type 304 cladding, which had been sensitized during fuel-rod fabrication by migration of carbon from the residual binder in the $\mathrm{UO}_{2}$.

Sensitization and intergranular cracking were observed in a fuel rod clad with $0.015 \mathrm{in}$. annealed type 304L stainless steel after loss of coolant in an ETR loop experiment (see Table 16). The fuel rod, which 


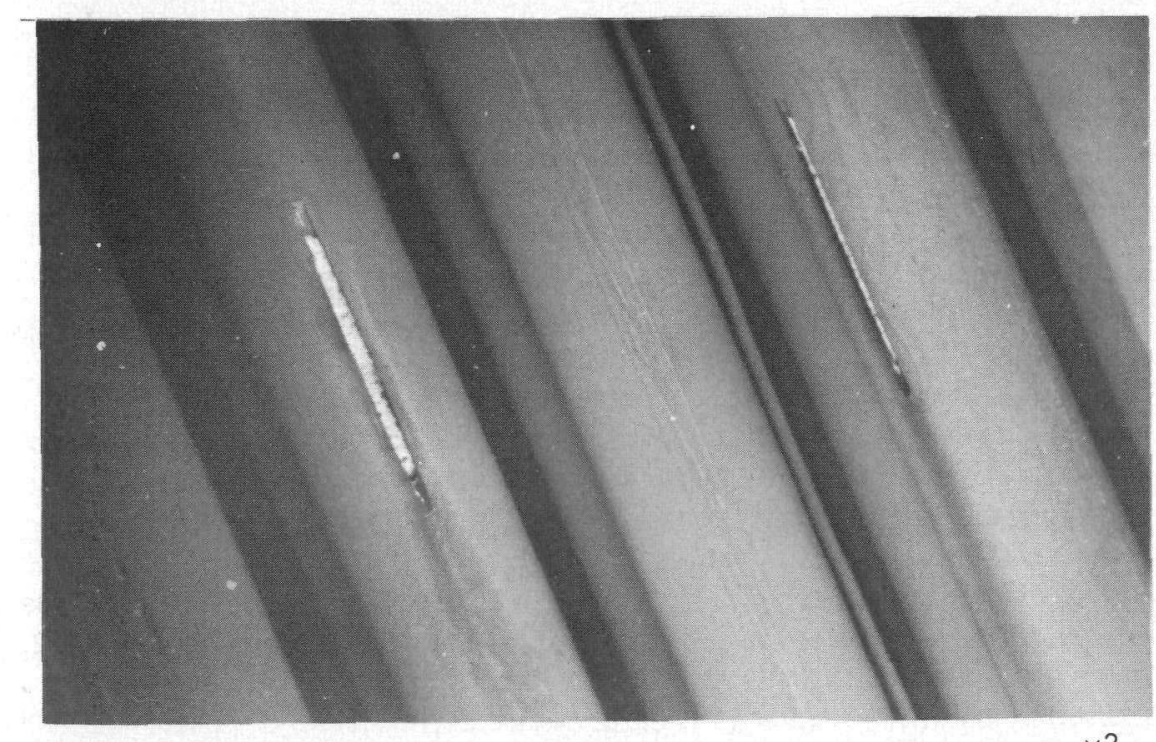

$\times 2$

Fig. 5- Intentional slit defects in cold- and hot-swaged compacted- $\mathrm{UO}_{2}$-powder fuel rods after exposure of 1000 $\mathrm{Mwd} / \mathrm{t}$ in the VBWR.

had been fabricated by a stretch-forming technique to reduce the diametral gap to approximately 0.001 in., had operated for 76 days in $600^{\circ} \mathrm{F}$ pressurized water at a peak surface heat flux of 296,000 Btu/ (hr) (sq ft). A rod clad with a 0.021-in.-wall tube of the same material was operating in the loop at the same time. Although there was significant distortion of the second rod, there was no cracking of the cladding. Failure of the 0.015-in.-wall cladding was attributed to the severe thermal stresses and temperature that resulted from the loss of coolant.

In-pile failures of three out of fifteen stainless-steel-clad annular fuel rods in a Savannah River Plant reactor were reported by G. R. Caskey et al. ${ }^{101}$ The rod dimensions were $1.5 \mathrm{in}$. inside diameter, 2 in. outside diameter, and $24 \mathrm{in}$. long. They were clad with $0.020 \mathrm{in}$. of the steel. The fuel was cold-swaged $\mathrm{UO}_{2}, 90$ percent of theoretical density (T. D.). The outer sheath of one of the fuel specimens was split longitudinally, and defects were found in the welded end closure. Examination of the sheath split and the end-closure defects showed branching transgranular, stress-corrosion cracks. It was postulated that the stress-corrosion cracking may have been due to chloride impurities introduced during degreasing operations in fabrication.

Intergranular cracking of nonsensitized type 304 stainless steel was reported to have occurred during irradiation in a high-temperature 
pressurized-water environment during operation at stresses in excess of the yield point. ${ }^{38}$ These cracks appear to be identical with some of the fuel-cladding cracks that have occurred in the VBWR.

Four out of sixteen fuel rods containing $\mathrm{UO}_{2}$ pellets clad with 0.005-1n.-thick type 304 stainless steel falled after a burnup of 2550 Mwd/t in the VBWR. ${ }^{70}$ Three of the fallures were mechanical, primarily in the form of cladding wrinkles and short longitudinal transgranular cracks. One rod apparently contained a small cladding defect that could not be located by visual examination (in the hot cell). The fuel rods had operated at a peak surface heat flux of $488,000 \mathrm{Btu} /(\mathrm{hr})$ (sq ft) for a short period during the irradiation span. It was postulated that the rods had falled after radial plastic straining of the cladding by the thermal expansion of the $\mathrm{UO}_{2}$ at the high power level. Radial deformation of the cladding is believed to have enlarged the gap between the $\mathrm{UO}_{2}$ and the cladding. Upon subsequent cooling and contraction of the $\mathrm{UO}_{2}$, the coolant external pressure caused the cladding to collapse against the $\mathrm{UO}_{2}$, resulting in the wrinkling of the cladding. A cross section of a wrinkled and falled rod and the appearance of the cladding at a crack are shown in Fig. 6.

Of the approximately 1400 stainless-steel-clad fuel rods under irradiation in the VBWR, about one-third were fabricated with annealed cladding, one-third with slightly cold-worked cladding, and the remainder with cladding cold worked to more than 90,000 psi roomtemperature tensile strength. Eleven pellet fuel rods and two compactedpowder fuel rods (Table 11) have falled owing to longitudinal cracking of the cladding. A typical cracked fuel rod is shown in Fig. 7.

Preliminary examinations of the falled fuel rods indicate the following conditions:

1. The cracks are predominantly intergranular, starting at the outer surface and progressing inward through the cladding. The progressive nature of the cracking is shown in the sequence of five photographs in Fig. 8, prepared from varıous sections of a cracked rod.

2. No grain-boundary precipitates or other evidence of sensitization has been detected by either optical or electron microscopy.

3 . Most of the fallures occurred in cold-worked, type 304 stainlesssteel cladding having an initial room-temperature yield strength of 90,000 to $95,000 \mathrm{ps} 1$. Some fallures occurred in fuel rods clad with annealed tubing but fabricated with essentially zero cold gap between fuel and cladding.

4. The nature of the fallures indicates that the high cladding stresses or strain-cycling effects imposed on the cladding by the $\mathrm{UO}_{2}$ may contribute significantly to causing the cracking.

5. None of the fuel rods clad with initially annealed material and fabricated with a nominal cold gap (4 to 6 mils) has falled thus far. Rods with annealed cladding have operated in the same fuel assembly, 


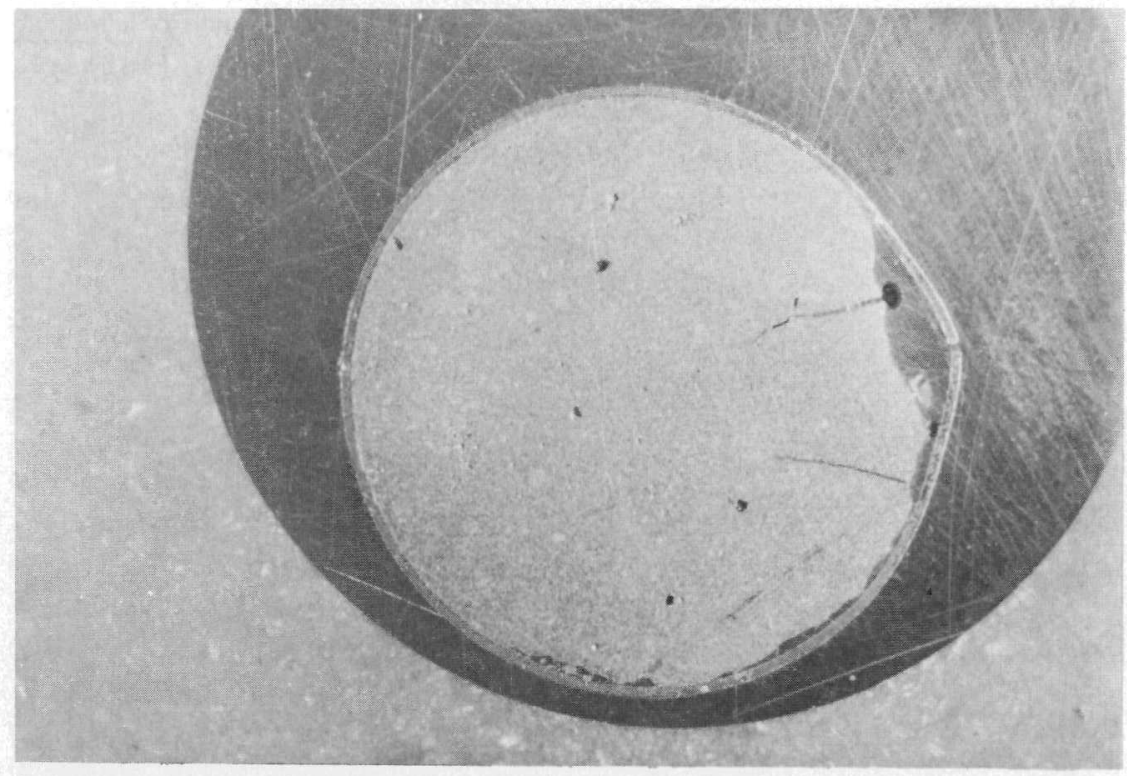

$\times 5$

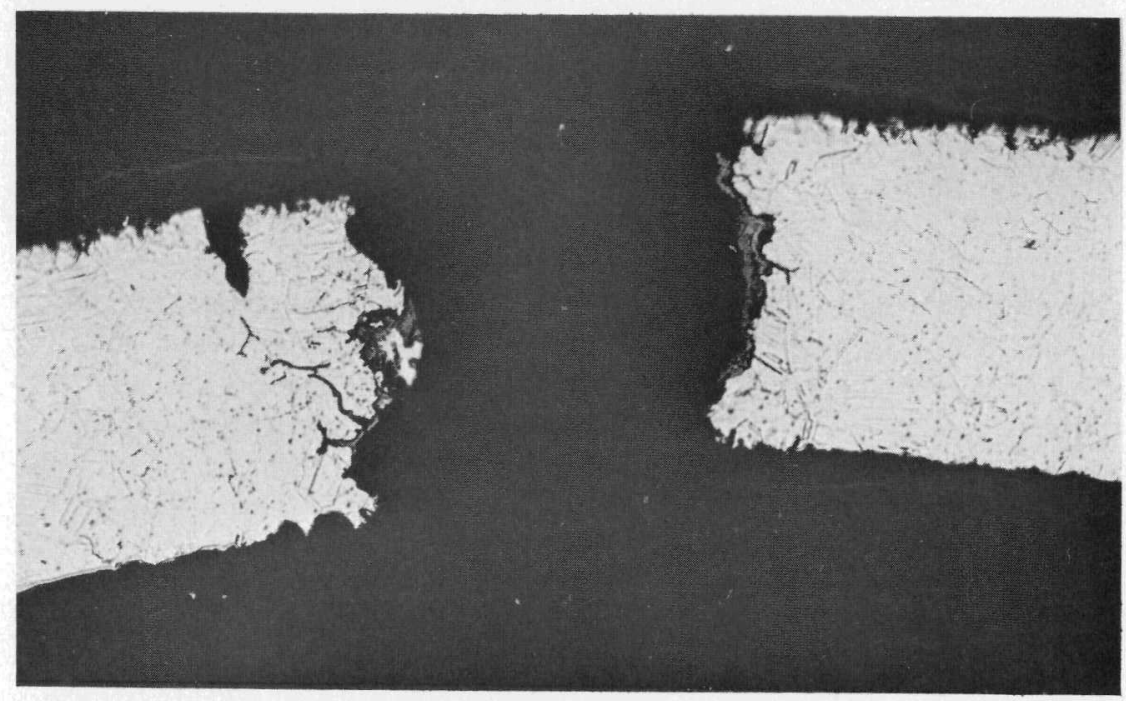

$\times 250$

Fig. 6-Wrinkled fuel rod clad with 0.005-in.-thick stainless steel. Top, cross section. Bottom, cladding in region of crack. 

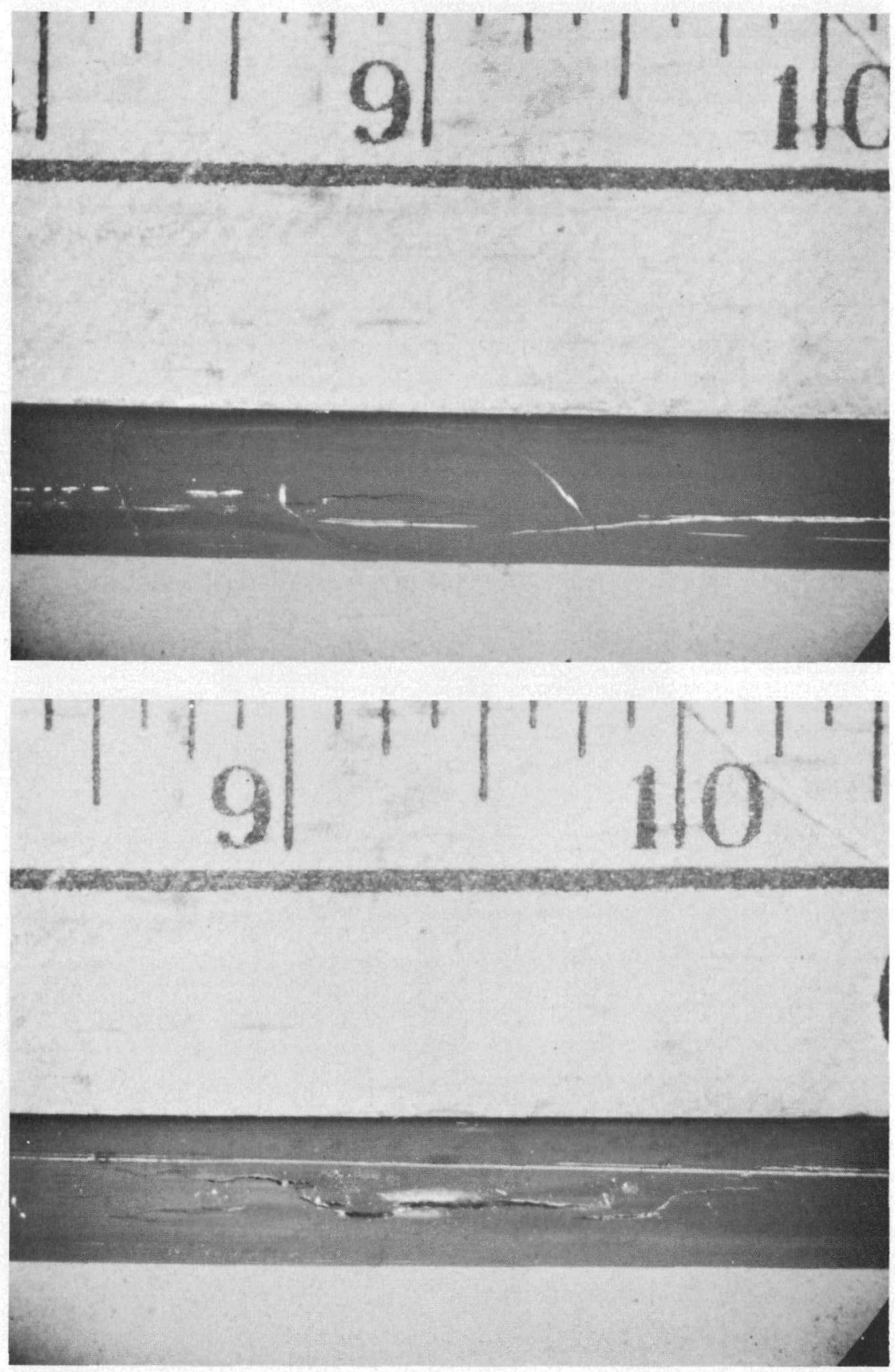

Fig. 7-Cracks in cladding of fuel rods clad with coldworked type 304 stainless steel. 

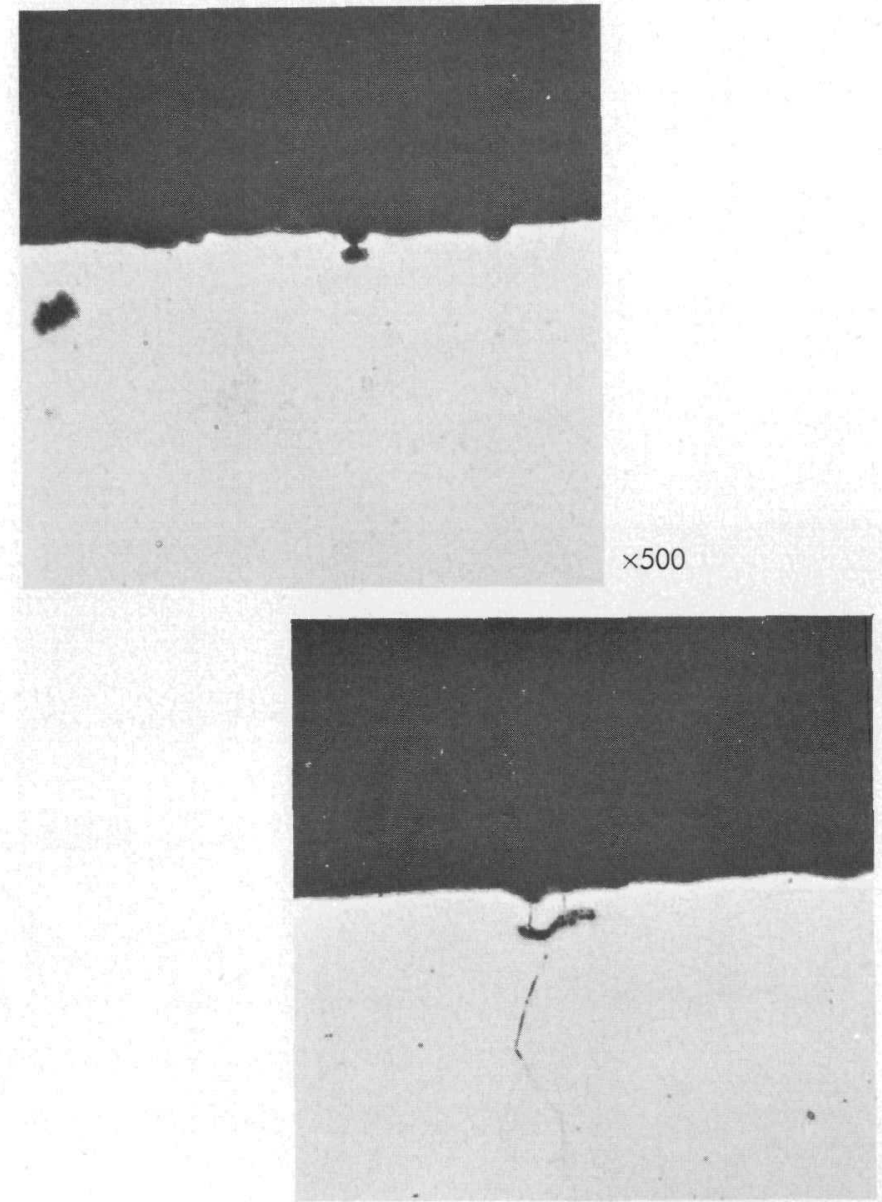

$\times 500$

Fig. 8-Stages in cracking of cladding of failed fuel rod.

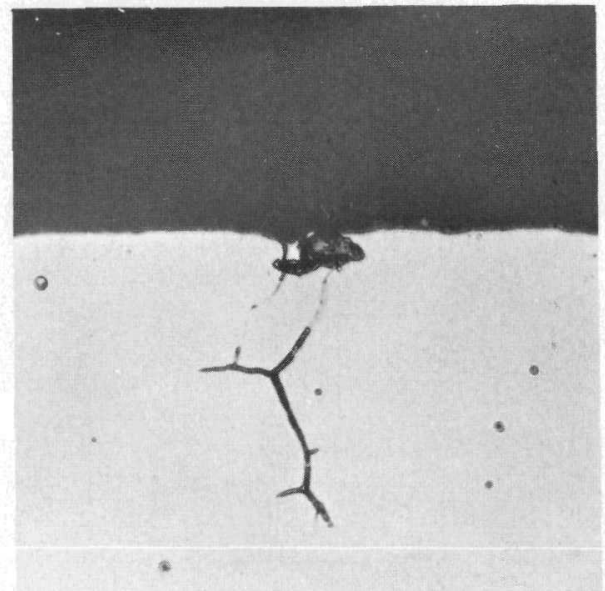



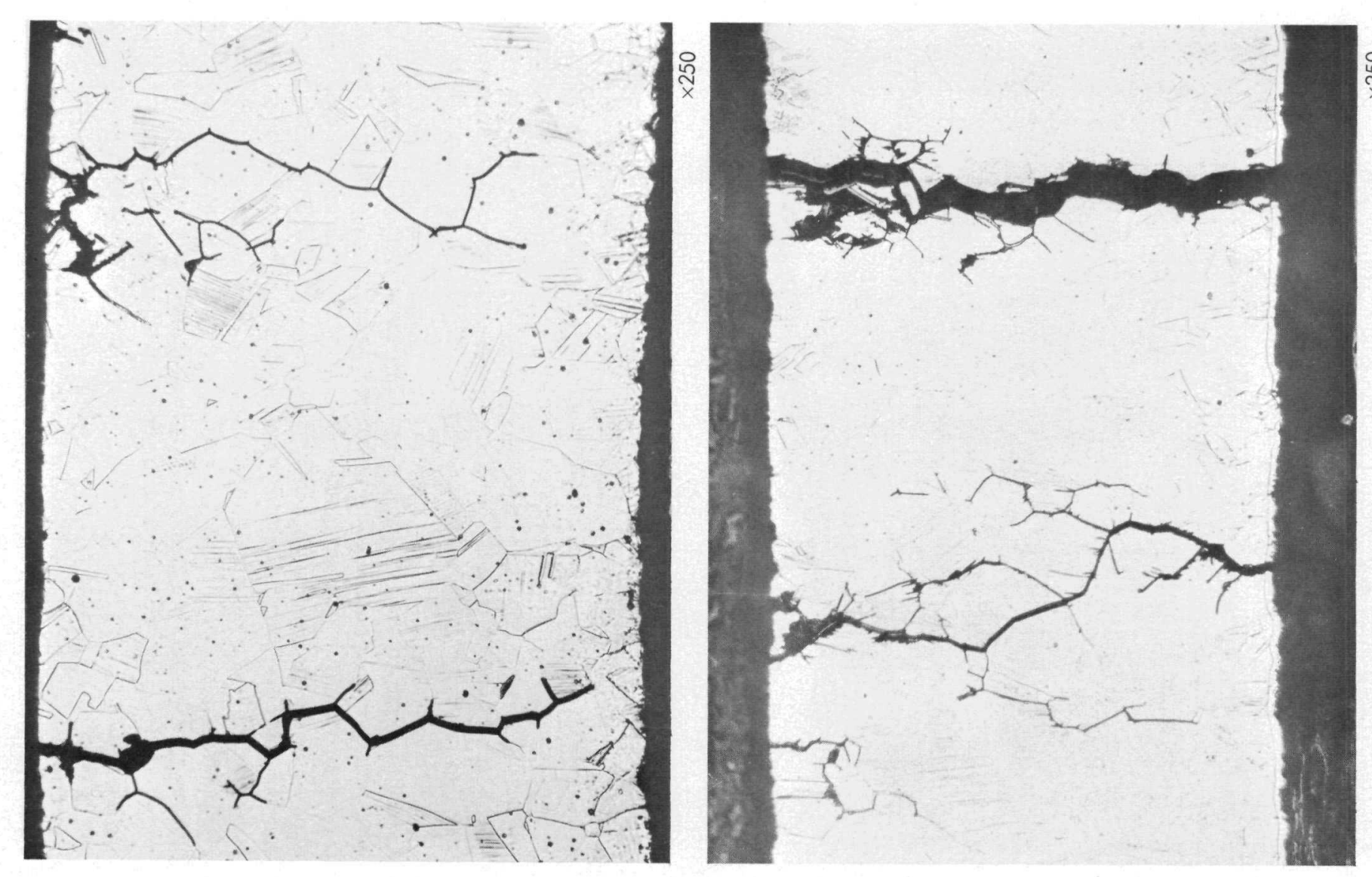
under identical environmental conditions, and to the same exposure levels as the cold-worked rods that have failed. This is another indication of the significance of differences in operating stress levels in determining time to failure.

6. Essentially all the cracks have occurred in the peak heat-flux region of the fuel rods, which corresponds to the region of peak burnup and maximum mechanical interaction between $\mathrm{UO}_{2}$ and the cladding. Examination of various portions of the failed rods indicates the occurrence of numerous longitudinal cracks in the peak heat-flux region and no detectable cracks in the lower heat-flux portion of the same rod. This suggests that, although the various portions of the cladding are exposed to essentially identical coolant environmental effects, the cracking is concentrated at the region of highest exposure and highest applied cladding stress.

7. All the intergranular cracks occurred in fuel rods that had operated at peak surface heat fluxes in excess of $380,000 \mathrm{Btu} /(\mathrm{hr})$ (sq ft) and to peak local exposures in excess of $6200 \mathrm{Mwd} / \mathrm{t}$. This suggests an incubation time before the corrosion and stress-accelerated cracking occurs. The surfaces of annealed fuel rods having the same radiation exposures were checked in the hot laboratory by ultrasonic techniques for evidence of detectable crack initiation. There was no evidence of crack initiation either in the annealed rods or in the lower power portions of the failed rods.

8. As listed in Table 17 , the cladding hardness in the failure region had increased from 255 to $400 \mathrm{DPH}$ (diamond pyramid hardness).

Table $17-$ HARDNESS OF IRRADIATED FUEL CLADDING ${ }^{50}$

\begin{tabular}{lccc}
\hline Cladding condition & $\begin{array}{c}\text { Fuel burnup } \\
\text { at point of } \\
\text { measurement, } \\
\text { Mwd/t }\end{array}$ & $\begin{array}{c}\text { Exposure, } \\
\text { neutrons } / \mathrm{cm}^{2} \\
\left(1 \mathrm{Mev} \times 10^{-21}\right)\end{array}$ & $\begin{array}{c}\text { Over-all } \\
\text { DPH }\end{array}$ \\
\hline Cold worked, as received & & & 255 \\
Cold worked, irradiated & 6600 & $\sim 0.7$ & 400 \\
Cold worked, irradiated & 8500 & $\sim 0.6$ & 400 \\
Cold worked, irradiated & 9600 & 1.0 & 306 \\
Annealed, irradiated & 9500 & 1.0 & 288 \\
\hline
\end{tabular}

9. High-temperature $\left(650^{\circ} \mathrm{F}\right)$ tensile properties of tubing from one of the failed rods are listed in Table 18. In some specimens the elongation at yield was found to be as low as 1.4 percent. These data are preliminary and were obtained by newly developed techniques. The error range has not yet been established.

There appears to be no previous observation of intergranular cracking of apparently nonsensitized type 304 stainless steel in a 
Table 18 - TENSILE PROPERTIES OF IRRADIATED TYPE 304 STAINLESS-STEEL FUEL CLADDING AT $625^{\circ} \mathrm{F}$

\begin{tabular}{|c|c|c|c|c|c|}
\hline Sample* & $\begin{array}{c}\text { Initıal } \\
\text { claddıng } \\
\text { condition }\end{array}$ & $\begin{array}{c}\text { Cladding } \\
\text { exposure, } \\
\text { neutrons } / \mathrm{cm}^{2} \\
\left(1 \mathrm{Mev} \times 10^{-2 \mathrm{t}}\right)\end{array}$ & $\begin{array}{c}\text { Yleld strength } \\
(02 \% \text { offset }) \\
\text { psi }\end{array}$ & $\begin{array}{l}\text { Ultumate } \\
\text { tensile } \\
\text { strength, } \\
\text { ps } 1\end{array}$ & Elongation $\dagger$ \\
\hline B-3 & Annealed & 10 & 90,900 & 97,400 & .80 \\
\hline B-3 & Annealed & 10 & 104,000 & 104,000 & 61 \\
\hline$B-1 C$ & Annealed & & 75,000 & 84,000 & 66 \\
\hline$B-1 C$ & Annealed & & 71,200 & 85,500 & 68 \\
\hline$W-3$ & Annealed & 10 & 99,000 & 99,400 & 44 \\
\hline$W-3$ & Annealed & 10 & 107,200 & 108,300 & 28 \\
\hline$W-1$ & Annealed & & 76,300 & 81,700 & 55 \\
\hline$W-1$ & Annealed & & 76,200 & 87,500 & 78 \\
\hline$Q-5$ & Cold worked & 10 & 117,000 & 118,000 & 14 \\
\hline$Q-5$ & Cold worked & 10 & 120,000 & 121,000 & 23 \\
\hline$Q-2$ & Cold worked & & 91,100 & 98,600 & 40 \\
\hline$Q-2$ & Cold worked & & 111,900 & 118,700 & 39 \\
\hline $\mathrm{R}-5 \ddagger$ & Cold worked & 10 & 72,500 & 72,500 & 25 \\
\hline$R-5 t$ & Cold worked & 10 & 39,700 & 40,900 & 38 \\
\hline $\mathrm{R}-1$ & Cold worked & & 112,408 & 115,000 & 40 \\
\hline$R-1$ & Cold worked & & 104,300 & 108,000 & 38 \\
\hline Control & Cold worked & None & 62,500 & 86,500 & 135 \\
\hline Control & Cold worked & None & 60,100 & 83,500 & 125 \\
\hline Control & Cold worked & None & 72,700 & 85,000 & 65 \\
\hline Control & Cold worked & None & 77,000 & 86,400 & 98 \\
\hline
\end{tabular}

* Letter indicates fuel-rod designation \$Samples contained longitudinal cracks + Percent in 0 8-in gauge length

high-purity reactor coolant water. In a preliminary evaluation the intergranular cracking is postulated by Lees ${ }^{47}$ to be initially caused by an electrochemical corrosion attack and to be accelerated by the effects of high stress levels and strain cycling. As discussed by Coffin, ${ }^{102}$ stainless steel can be subjected to many plastic-strain cycles before fallure due to fatigue. With the combined effects of strain cycling and the coolant environmental effects, the number of cycies to fallure can be reduced significantly. Strain-cycling fallures, however, normally are transgranular at the cladding temperatures $\left(600^{\circ} \mathrm{F}\right)$ at which the fallures have occurred.

With no evidence of sensitization (the usual explanation for intergranular cracking), identifying and evaluating causes of the observed intergranular cracks are unsolved complex problems typical of the usual difficulties involved in interpreting the combined effects of corrosion and stress. Many mechanisms to explain the mode of crack propagation along grain boundaries have been proposed. Significant among them is electrochemical corrosion occurring at points or planes 
of high stress concentration in the matrix. There may be significance in the change in mode of cracking from intergranular to transgranular with increase in potassium hydroxide concentration reported by Wanklyn and Jones ${ }^{33}$ and by Snowden. ${ }^{35}$ In these experiments, with no change in composition of the original specimens, the only change occurring from one mode of cracking to the other was the concentration of the corrosive medium. Increasing the concentration of potassium hydroxide changed the electrochemical characteristics of the solution.

Understanding the causes of these localized fallures is a formidable problem facing investigators. The continued irradiation of different types of fuel elements in the VBWR to higher exposures is expected to provide valuable information about fuel-rod lifetime as a function of such variables as cladding condition and thickness, pellet-cladding gap, $\mathrm{UO}_{2}$ density, and thermal power level. These data will supplement the performance information on fuel rods operating in large power reactors. These rods represent the more conservative design, fabrication, and performance conditions of the fuel concepts being tested in the VBWR and in other test irradiation facilities.

In addition to the tests described previously, there have been numerous capsule-irradiation tests of stainless-steel-clad fuel segments. These tests are usually performed in a sodium-potassium or sodium environment. Capsule tests constitute excellent means of operating fuel at high thermal ratings and to high burnups to obtain needed information as to the irradiation behavior of fuel materials and the effects of fuel-cladding interactions. However, they do not provide information as to cladding performance in high-temperature water. These tests, therefore, are not discussed here.

\section{Mechanical Properties of Stainless Steel}

The mechanical properties of unirradiated stannless steels as a function of temperature are fairly well known. Unfortunately the avallable information on the properties as a function of radiation exposure at high temperature is somewhat meager. As discussed by Porter, ${ }^{103}$ correlation of the available data is made difficult by the fact that the levels and temperatures of exposure are rather scattered. In addition, the well-recognized problem of accurate neutron dosimetry sometimes introduces errors of \pm 50 percent in exposure values.

Figure 9 shows the effect of neutron irradiation on tensile strength of austenitic stainless steels as a function of fast-neutron exposure at various exposure temperatures.

Table 19 shows that there is no apparent relation between increase in yield strength and neutron exposure.

A more detailed treatment of the effects of radiation on mechanical properties is given in the following section. 


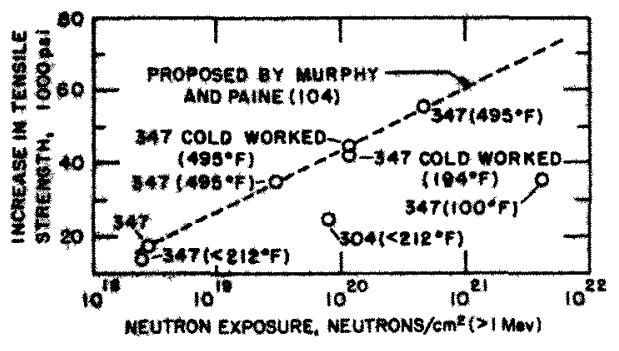

Table $19-$ CHANGE OF YIELD STRENGTH WITH NEUTRON IRRADIATION
Fig. 9-Effect of neutron ir radiation on tensile strength of austenitic stainless steels. ${ }^{103}$

\begin{tabular}{cccc}
\hline & \multicolumn{2}{c}{ Irradiation conditions } & \\
\cline { 2 - 3 } $\begin{array}{c}\text { Material } \\
\text { (AISI type) }\end{array}$ & $\begin{array}{c}\text { Temperature, } \\
{ }^{\circ} \mathrm{F}\end{array}$ & $\begin{array}{c}\text { Exposure, neu- } \\
\text { trons } / \mathrm{cm}^{2}(>1 \mathrm{Mev})\end{array}$ & $\begin{array}{c}\text { Increase in tensile } \\
\text { strength, ps } 1\end{array}$ \\
\hline 321 & $<212$ & $7.8 \times 10^{19}$ & 59,400 \\
304 & $<212$ & $7.8 \times 10^{19}$ & 51,200 \\
305 & $<212$ & $39 \times 10^{19}$ & 39,300 \\
$347 *$ & 194 & $1.2 \times 10^{20}$ & 41,300 \\
347 & 100 & $24 \times 10^{20}$ & 41,100 \\
347 & 100 & $72 \times 10^{20}$ & 40,400 \\
347 & 100 & $26 \times 10^{21}$ & 43,900 \\
347 & 100 & $3 \times \times 10^{21}$ & 50,000 \\
\hline
\end{tabular}

*Cold worked.

\section{Use of Other Cladding Materials}

As mentioned in the introduction, higher nickel alloys, such as Inconel or Incoloy, and the ferritic stainless steel, AISI 406, could be useful as fuel-cladding materials. There have been very few investigations of these materials as fuel cladding for water-cooled reactors. They have, however, been extensively studied with respect to nuclearsuperheat applications, and they are discussed from this point of view in the following section. In addition, Inconel has been investigated as a potential structural material for pressurized-water reactors. ${ }^{105-108}$

Two fuel rods clad with AISI 406 stainless steel were irradiated in an ETR pressurized-water loop. ${ }^{87}$ However, there was indication of activity release after $20 \mathrm{hr}$ of operation. Subsequent examination failed to reveal a cladding defect.

Inconel was tested with types 304 and 347 stannless steel for susceptibility to caustic cracking at $636^{\circ} \mathrm{F}$ and 2000 psi. Powers and Tymchyn $^{109}$ report that the stainless steels are more susceptible than Inconel to cracking in 1-molal sodium hydroxide solution, although intergranular cracking of Inconel was observed to occur after extended exposure. 


\section{Development Efforts}

An extensive program is under way to investigate the maximum capabilities of fuel elements clad with stainless steel and other promising materials.

\section{REDUCTION OF FUEL-FABRICATION COSTS Some of the processes un-} der investigation for reducing the fabrication costs of stainless-steelclad fuel rods are as follows:

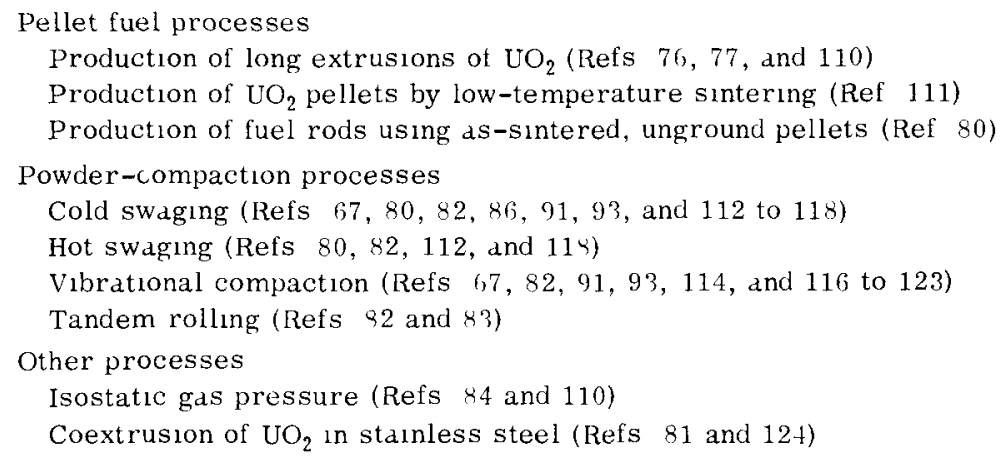

Fuel rods made by all these fabrication processes either have been or are now under irradiation testing in the VBWR. Some of the fuel-rod characteristics, performance conditions, burnup values, and results of the VBWR tests are given in Tables 7 to 11. Additional irradiation tests performed by Hanford Atomic Products Operation, Oak Ridge National Laboratory, and others are shown in Tables 12 to 16. The dependence of fuel performance upon methods of fabrication cannot be overemphasized.

\section{INCREASE IN FUEL POWER OUTPUT}

Stainless-steel-clad fuel rods have been irradiated in various water-cooled reactor and loop facilities at peak surface heat fluxes of up to $540,000 \mathrm{Btu} /(\mathrm{hr}$ ) (sq ft); see Tables 7 to 16 . The tests ${ }^{70-72}$ have included the successful operation of fuel rods with gross central melting of the $\mathrm{UO}_{2}$.

IMPROVEMENT OF THE NEUTRON ECONOMY BY THINNING THE CLADDING Out-of-reactor and in-reactor investigations have been conducted to determine the performance characteristics of the thin-wall clad fuel. As shown in Tables 7 to 9 , both pellet and compacted-powder rods with cladding thicknesses as low as $0.005 \mathrm{in}$. have been irradiated at peak surface heat fluxes of up to $488,000 \mathrm{Btu} /(\mathrm{hr})(\mathrm{sq} \mathrm{ft})$.

EXTENSION OF FUEL LIFETIME The ultimate objectıves of the fueldevelopment programs currently being conducted are to determine the relations between fuel lifetıme and such variables as method of fabrication, type of cladding material, cladding thickness, and fuel power 
output. Experience shows that a change in any one of these factors may affect the performance of the cladding and either increase or decrease the lifetime of the fuel element. The effects of these interrelated factors must be made avallable to the reactor designer, who will then optimize the combination of parameters for a specific reactor application.

Fuel lifetime is important in the economics of a specific reactor. It is usually determined by factors other than reactivity. A change in any one of the factors, such as cladding material, fuel density, fuelcladding gap, cladding thickness, or power rating, will probably have an effect on the lifetime of the fuel rod in a specific reactor environment. $\mathrm{Th}_{\mathrm{i}} \mathrm{e}$ objective of the various current fuel-development programs is to determine the effects of these parameters on fuel lifetime. Achrevement of this objective is necessary for the development of the optimum fuel element.

\section{Conclusions}

Exposures of up to $20,000 \mathrm{Mwd} / \mathrm{t}$ have been attained in conservatively designed stainless-steel-clad fuel rods tested in the VBWR. Many such fuel rods, utilizing conservative cladding designs typical of design philosophies of first-core reactors, are currently operating successfully in large power reactors. The Yankee reactor, in which the first core was replaced for reactivity reasons after an average exposure of approximately $8000 \mathrm{Mwd} / \mathrm{t}$, utılizes fuel clad with type 348 stainless steel. All the subsequent power-reactor applications of stainless-steel-clad rod fuel elements use type 304 stainless steel. Operating experience with fuel with this cladding is currently being obtained in bolling-water reactors, such as the Dresden, Humboldt Bay, Big Rock Point, and Elk River, and in pressurized-water reactors, such as the N. S. Salamal, Indian Point, and Saxton.

Irradiation tests currently are being conducted in test reactors and loops to explore improvements and cost reductions in fuel designs, methods of fabrication, and thermal performance levels relative to first-core-application philosophies. Some of the tests are designed to explore actual limits. such as fuel-rod power levels and thinning of cladding walls. The most extensive irradiation testing of fuel rods clad with type 304 stainless steel has been performed in the VBWR.

On the basis of the fuel-irradiation experience up to the present, several observations can be made:

Fuel-irradiation experience indicates that the performance of stainless-steel cladding in a water reactor environment is influenced by the combined residual, thermal, and mechanical stresses resulting from fuel-design characteristıcs, thermal power level of the fuel rods, and method of fabrication. Intergranular cracking of highly stressed type 304 stainless steel has occurred in both pressurized-water and 
boiling-water reactors. In contrast, conservatively designed fuel rods operating at relatively low levels of cladding stress have been irradiated successfully to $20,000 \mathrm{Mwd} / \mathrm{t}$ in the $\mathrm{VBWR}$.

The qualitative and quantitative effects of time, temperature, stress level, coolant environment, and radiation exposure on intergranular cracking of stainless steel have not yet been determined. Preliminary evaluations indicate that the operating stress level is a significant factor.

Although the feasibility of operation of fuel rods with thin-wall stainless-steel cladding has been demonstrated in the VBWR tests, high stresses imparted to the cladding by thermal expansion of the uranium dioxide appears to increase the susceptibility to failure by intergranular cracking. The important questions to be answered in evaluating the full potential of the thin-wall cladding concept concern the interrelations of fuel lifetime, method of fabrication, fuel density, cladding thickness, and fuel-rod power level.

There are indications that the use of lower density uranium dioxide results in lower cladding stress levels and potentially longer fuel lifetimes. This may result in a change in the previous philosophy of striving for as high a fuel density as possible.

Although the occurrences of failures of test or prototype fuels appear to unnerve some of the casual observers, the point of failure is the much-desired metallurgical lifetime of a particular fuel. The performance of tests to determine the point of failure of a fuel element as a function of design, fabrication, and performance parameters is necessary in order to explore, evaluate, and exploit the full technical and economic potentials of stainless-steel-clad fuel elements.

\title{
STAINLESS STEELS AND HIGH-NICKEL ALLOYS FOR USE IN SUPERHEATED STEAM
}

\author{
by Costas N. Spalaris \\ General Electric Company \\ Atomic Pouer Equipment Department
}

Economic studies show that the performance of present-day directcycle boiling-water reactors can be improved by the addition of superheat. Nuclear supercritical steam plants have also been considered as a possible route to improving the efficiencies of today's water-cooled plants. The materials required for such service have not as yet been specified because of the lack of the basic information needed for such specifications.

At present, high-temperature superheat steam or supercritical steam plants are reliable and economically proved systems for power 
generation from fossil fuels. Their successful operation is due primarily to the reliability of commercially available materials, which have adequate corrosion resistance as well as satisfactory mechanical and metallurgical properties. Equally important factors contributing to satisfactory power-plant service are (1) control of coolant chemistry during operation and (2) judicious component design based upon knowledge of material limitations. During the last decade considerable work was done to explore and develop new materials for use in superheatedsteam environments and to extend the knowledge to materials readily avallable in commercial quantities.

The environments anticipated in nuclear plants are in many respects similar to those found in conventional power plants, but with the addition of two very important factors: (1) the presence of neutron flux and (2) the high oxygen content in the steam coolant. Both cond1tions profoundly affect the material behavior in long-term service at high pressures and temperatures. In addition to the basic material properties usually required for service in high-temperature steam, neutron economy dictates the use of fuel-cladding materials having low, or relatively low, neutron-absorption cross sections. The requirement can be satisfied by using materials of low cross section or designs for thin-wall material of relatively high cross section. A higher degree of reliability is also required. With the exception of certain experimental work in the United States, the Union of Soviet Socialist Republics, and Canada, no nuclear superheat power system has yet been operated, although several are being constructed.

The following environmental conditions are expected for fuel elements in nuclear steam-cooled plants:

$\begin{array}{ll}\text { Metal temperatures } & \text { Up to } 1350^{\circ} \mathrm{F} \\ \text { Steam temperatures } & \text { Up to } 1200^{\circ} \mathrm{F} \\ \text { Steam pressures } & 1000 \text { psi for superheat; 4000 ps } \\ & \text { for supercritical } \\ \text { Oxygen in steam } & 20 \text { ppm for superheat; not known } \\ & \text { for supercritical } \\ \text { Sheath stresses } & \text { High, in some cases near yield point }\end{array}$

The selection of materials for use in fabricating nuclear plants must be based initially upon the data and practical experience avaslable from conventional power plants. Only a limited amount of this information can be applied directly to the selection of materials for nuclear superheat systems. Typical operating conditions for conventional superheat and supercritical plants are given in Table 20.

Owing to its relatively good corrosion resistance, radiation stability, and over-all compatıbility, uranium dioxide has received the most consideration for steam-cooled plants. ${ }^{128,129}$ The fuel elements considered in this section, unless otherwise specified, will be those containing uranium dioxide in pressed and sintered or swaged forms. 
Table 20-ENVIRONMENTAL CONDITIONS IN TYPICAL MODERN STEAM POWER PLANTS ${ }^{125-127}$

\begin{tabular}{|c|c|c|c|}
\hline Conditions & $\begin{array}{c}\text { Twin Branch } \\
\text { (1949) }\end{array}$ & $\begin{array}{l}\text { Philo } \\
\text { (1957) }\end{array}$ & $\begin{array}{c}\text { Eddystone } \\
(1958)\end{array}$ \\
\hline Steam temperature, ${ }^{\circ} \mathrm{F}$ & 1050 & 1150 & 1200 \\
\hline Pressure, psı & 2400 & 4500 & 5000 \\
\hline Steam reheat, ${ }^{\circ} \mathrm{F}$ & 1000 & 1050 & 1050 \\
\hline Water, $\mathrm{pH}$ & 95 & 95 & 95 \\
\hline Oxygen, ppm & & 0005 & 0005 \\
\hline Solıds, ppb & & 500 & 100 \\
\hline \multicolumn{4}{|l|}{ Materials } \\
\hline Turbıne pıpıng & & 347 & 316 \\
\hline Plant pipıng & Ferritics & 347 & $316, \mathrm{G} 18 \mathrm{~B}$ \\
\hline Main steam lines & 347 & 347 & 316 \\
\hline Reheat lines & Ferritics & Ferritics & $2 \frac{1}{2} \mathrm{Cr}, 1_{\mathrm{C}}^{\mathrm{C}} \mathrm{Mo}$ \\
\hline Tube dirnensions & & $\begin{array}{l}1 \% / 16 \text { in OD; } \\
034 \text { in thick }\end{array}$ & $1 \frac{1}{2}$ in $O D$ \\
\hline
\end{tabular}

\section{Corrosion}

Prior to 1940 structural materials in steam plants operated below $950^{\circ} \mathrm{F}$. Chromium, in amounts up to 5 percent, was added to iron-base alloys during the early 1930's, followed by additions of molybdenum up to 1 percent, to overcome certain brittle behavior, "temper embrittlement," in long-term high-temperature applications. The chromium improved corrosion resistance in high-temperature air and steam. ${ }^{130}$ The percentage of chromium increased steadily to 9 percent, with 1 percent molybdenum, and the resulting alloys were adequate up to 1050 to $1100^{\circ} \mathrm{F}$. The use of nickel, which inaugurated the era of the austenitics, increased the alloy strength at high temperatures. By the end of 1956, austenitic type stainless steel had replaced the ferritic alloys in hightemperature high-pressure parts of the power plants. ${ }^{131}$

A systematic approach was directed toward increasing corrosion resistance of iron-base and nickel-base alloys in air or oxygen. ${ }^{130}$ Increasing the amounts of chromium, aluminum up to 4 percent, and silicon up to 2 percent, along with nickel concentrations above 6 percent, improved corrosion resistance in air or oxygen. ${ }^{132}$ The most effective of the additions is chromium above 17 percent, which affords increased oxidation resistance through the formation of an $\mathrm{FeO}-\mathrm{Cr}_{2} \mathrm{O}_{3}$ spinel. ${ }^{133}$ Molybdenum additions do not improve oxidation resistance of ironchromium-nickel alloys under conditions of restricted circulation in oxygen-containing atmospheres. ${ }^{134}$

Corrosion behavior of alloys in pure steam containing low oxygen impurities was studied by several investigators..$^{135-138}$ In general, the greater part of this work has been directed to the evaluation of commercially avallable materials, notably the $300-$ series austenitic stain- 
Table 21 - CORROSION OF SOME AUSTENITIC ALLOYS IN SUPERHEATED STEAM

\begin{tabular}{|c|c|c|c|c|}
\hline \multirow[b]{2}{*}{ Alloy } & \multirow{2}{*}{$\begin{array}{c}\text { Tempera- } \\
\text { ture, }{ }^{\circ} \mathrm{F}\end{array}$} & \multicolumn{3}{|c|}{ Corrosion rate, mils/year } \\
\hline & & 290 days & 305 days & 595 days \\
\hline 304 & 1258 & 15 & & 09 \\
\hline 304 & 1288 & & 095 & \\
\hline 347 & 1292 & 04 & & 05 \\
\hline 321 & 1255 & 15 & & 05 \\
\hline 321 & 1292 & & 22 & \\
\hline 316 & 1288 & 60 & & 28 \\
\hline 318 & 1326 & 05 & & 085 \\
\hline $16-25-6$ & 1326 & 05 & & 085 \\
\hline $15-15 \mathrm{~N}$ & 1332 & & 32 & \\
\hline 17-14 CuMo & 1332 & 065 & & 25 \\
\hline
\end{tabular}

less steels. It was found that at $1100^{\circ} \mathrm{F}$ unstabilized grades, such as type 304, had lower corrosion resistance than stabilized alloys, such as type 347 , but that at higher temperatures, up to $1700^{\circ} \mathrm{F}$, only types high in chromium, such as type $310(25 \mathrm{Cr}-20 \mathrm{Ni})$ and $25 \mathrm{Cr}-15$ $\mathrm{N} 1-2$ W exhibited satisfactory corrosion resistance. Ferritic alloys that contained less than 2 percent chromium formed excessively thick, nonadherent scales. Hoke and Eberle ${ }^{136}$ studied several austenitic alloys in pure steam at 1250 to $1350^{\circ} \mathrm{F}$ for up to 595 days. The alloys tested were of the austenitic type, including the more common 300 series as well as 15-15 $\mathrm{N}$ and 17-14 CuMo. The corrosion behavior is given in Table 21, and compositions of some alloys that are not as well known as those of the type 300 series are presented in Table 22 .

In general, types 316, 17-14 CuMo, and 15-15 $\mathrm{N}$ exhibited the least resistance to corrosion. After 595 days the rates of metal penetration of types $304,347,321,318$, and $16-25-6$ were found to be more or less equal.

Eberle and Anderson ${ }^{139}$ studied the scaling behavior of ferritic, nickel-base, and austenitic alloys in 1100 to $1500^{\circ} \mathrm{F}$ steam for periods up to 18 months. With the exception of type 310 , the corrosion products of all austenitics, including types 321, 316, 347, 304, 17-14 CuMo, 16-25-6, and 15-15 N, and of all $\mathrm{Cr}-$ Mo ferritics displayed varying degrees of exfoliation, but over-all corrosion behavior was satisfactory for service in conventional plants. The tendency toward exfoliation increased with increasing temperature. Incoloy and Inconel did not exfollate but behaved as well as type 310 . Of the ferritics tested, $9 \mathrm{Cr}-\mathrm{Mo}$ formed the thinnest scale in steam at $1200^{\circ} \mathrm{F}$. Scale thickness was about 7 mils after one year of exposure, compared with less than $0.5 \mathrm{mil}$ for type 310 stanless steel and Inconel and $1.0 \mathrm{mll}$ for Incoloy and types 347 and 304 stainless steel. 
Table 22-ALLOY COMPOSITIONS

\begin{tabular}{|c|c|c|c|c|c|c|c|c|c|c|}
\hline \multirow[b]{2}{*}{ Alloy } & \multicolumn{10}{|c|}{ Components, wt $\%$} \\
\hline & $\mathrm{C}$ & $\mathrm{Mn}$ & S1 & $\mathrm{Cr}$ & $\mathrm{N} 1$ & Mo & $w$ & $\mathrm{Nb}$ & $\mathrm{T}_{1}$ & Others \\
\hline $16-25-6$ & 06 & 135 & 07 & 160 & 250 & 60 & & & & $015 \mathrm{~N}$ \\
\hline 17-14 CuMo & 012 & 075 & 05 & 160 & 140 & 25 & & 04 & 03 & $30 \mathrm{Cu}$ \\
\hline $15-15 \mathrm{~N}$ & $\begin{array}{l}015 \\
\max \end{array}$ & $\begin{array}{l}200 \\
\max \end{array}$ & $\begin{array}{l}075 \\
\max \end{array}$ & $\begin{array}{l}1475 \\
\text { to } \\
1800\end{array}$ & $\begin{array}{c}135 \\
\text { to } \\
165\end{array}$ & $\begin{array}{c}125 \\
\text { to } \\
185\end{array}$ & $\begin{array}{c}10 \\
\text { to } \\
185\end{array}$ & $\begin{array}{l}080 \\
\text { to } \\
130 \\
(+\mathrm{Ta})\end{array}$ & & $\begin{array}{l}015 \mathrm{~N} \\
\max \end{array}$ \\
\hline
\end{tabular}

CORROSION IN OXYGENATED STEAM

Materials of interest have been exposed to steam, in the temperature range 1050 to $1300^{\circ} \mathrm{F}$, containing 15 to $20 \mathrm{ppm}$ oxygen and the stoichiometric amount of hydrogen to simulate the in-reactor radiolytic decomposition of water. ${ }^{140}$ Type 304 stainless steel exposed isothermally at $1050^{\circ} \mathrm{F}$ for up to 210 days suffered rapid initial (up to 42 days) weight gains followed by a period of slower corrosion, undergoing a total weight gain of about $350 \mathrm{mg} / \mathrm{dm}^{2}$ after 192 days.

The scales formed were adherent and of uniform thickness and showed no evidence of intergranular attack, although sensitization of the specimens was evident. The outer layer was of a metallic luster, and the inner oxide was a mottled, green-blue oxide typical of chromium oxide. ${ }^{141}$ The frlm thicknesses on annealed, unstressed samples were of the order of $0.5 \mathrm{mul}$ after 42 days at $1050^{\circ} \mathrm{F}$.

Under steady-state heat-transfer conditions at surface temperatures up to $1300^{\circ} \mathrm{F}$ and steam velocities up to $100 \mathrm{ft} / \mathrm{sec}$, tubular specimens of type 304 stainless steel exhibited weight gains up to $452 \mathrm{mg} / \mathrm{dm}^{2}$, equivalent to about $0.23 \mathrm{mil}$ metal loss after about 200 days. The oxide films were adherent, having a duplex structure similar to that observed by Eberle and Anderson in low-oxygen steam environments. A spinel structure was found in these films, but no attempt was made to determine exact chemical composition. Electron-probe analysis of the metal immediately adjacent to the oxide film showed changes in composition. There was enrichment with respect to iron at the outermost edge, whereas the next layer contained higher percentages of chromium and nickel than did the unexposed metal. No known significance can be attached to this behavior at this time.

Film thicknesses measured on the samples tested at temperatures up to $1300^{\circ} \mathrm{F}$ under heat-transfer conditions did not agree with those reported by Greenberg ${ }^{142}$ for 1 sothermal tests that were carried out in oxygenated steam containing no hydrogen at $1200^{\circ} \mathrm{F}$. Greenberg observed a somewhat erratic behavior, and in numerous cases films up to 6 mils thick were formed withın $1000 \mathrm{hr}$ for both $304 \mathrm{~L}$ and 304 . 
Incoloy underwent relatively little corrosion, as indicated by the low weight gain of about $8.5 \mathrm{mg} / \mathrm{dm}^{2}$ after 42 days at $1050^{\circ} \mathrm{F}(20 \mathrm{ppm}$ $\mathrm{O}_{2}$ plus stoichiometric $\mathrm{H}_{2}$ ) and a scale thickness of $0.2 \mathrm{mil}$ at the deepest penetration. ${ }^{141}$ More-recent data show Incoloy and Inconel to have weight gains of 32 and $18 \mathrm{mg} / \mathrm{dm}^{2}$, respectively, after 167 days of exposure in steam. The appearance of an Incoloy sample after 216 days in oxygenated steam is illustrated in Fig. 10. The specimen was ex-

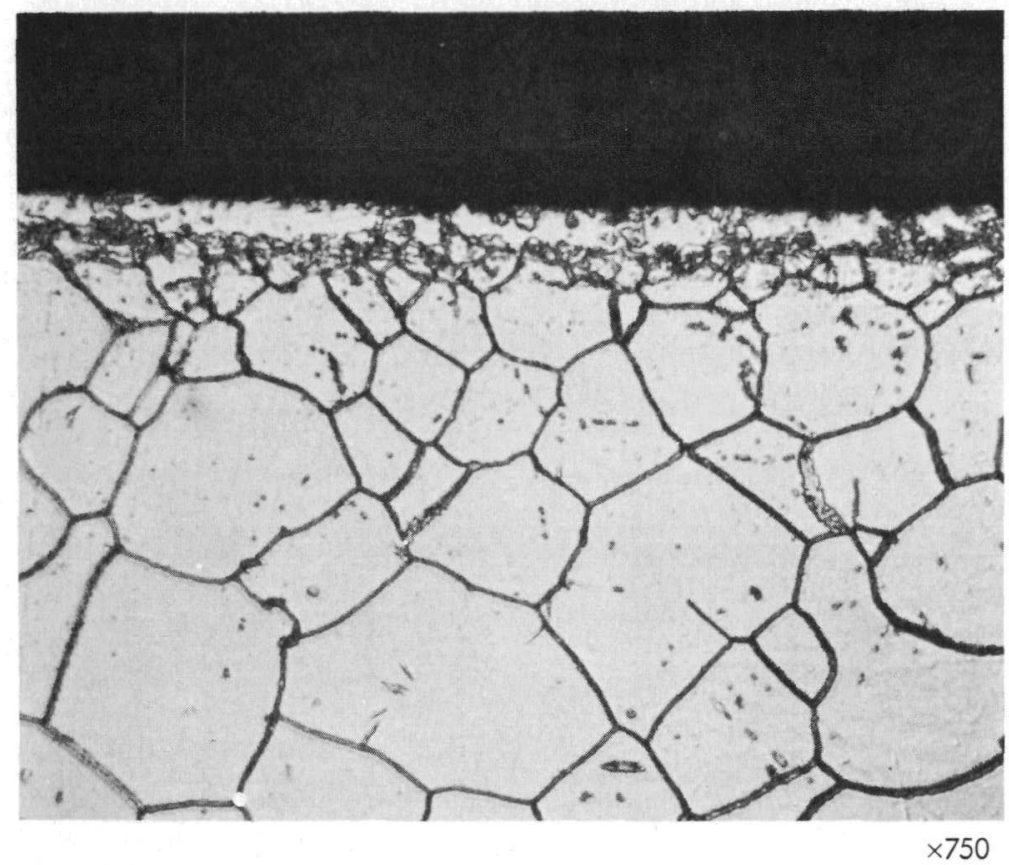

Fig. 10-Uniform corrosion of Incoloy after 216 days in oxygenated steam. ${ }^{143}$

posed without stress at $1050^{\circ} \mathrm{F}$ and $1000 \mathrm{psi}$. The weight gain was 28 $\mathrm{mg} / \mathrm{dm}^{2}$, and the descaled weight loss was $140 \mathrm{mg} / \mathrm{dm}^{2}$. The surface layer is noticeable.

The corrosion data obtained by various investigators in hightemperature, oxygenated steam have been compared, and the results are shown in Fig. 11. With one possible exception, the data are shown to be consistent. ${ }^{129,142,144}$ Additional data are presented in Table 23 for Incoloy, Inconel, Hastelloy $\mathrm{X}$, and type 304 alloys.

General corrosion rates of the alloys studied in oxygenated steam appear to be sufficiently low to permit reasonable fuel-element design without the risk of failure due to material loss resulting from general uniform corrosion. In general, the corrosion rates found in oxygenated 

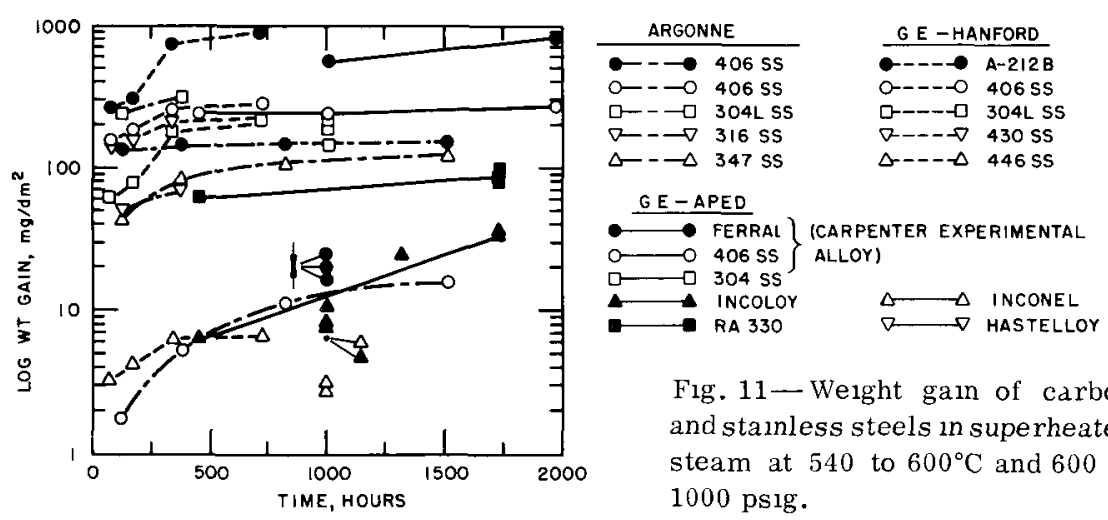

Fig. 11-Weight gain of carbon and stanless steels in superheated steam at 540 to $600^{\circ} \mathrm{C}$ and 600 to $1000 \mathrm{psig}$.

Table 23 - UNIFORM CORROSION OF HIGH-NICKEL ALLOYS ${ }^{143}$

Heat-transfer Surfaces of Heated Tubes*

\begin{tabular}{lccc}
\hline Alloy & Time, days & $\begin{array}{c}\text { Descaled welght } \\
\text { loss, mg/dm }\end{array}$ & $\begin{array}{c}\text { Metal to system } \\
\text { loss, mg/ } \mathrm{dm}^{2}\end{array}$ \\
\hline Type 304 S S & 43 & 284 & 62 \\
& 40 & 452 & 120 \\
Incoloy & 103 & 354 & 74 \\
Hastelloy X & 40 & 165 & 31 \\
Inconel & 41 & 151 & 34 \\
\hline
\end{tabular}

Coupons Exposed to $1050^{\circ} \mathrm{F}$ Superheated Steam

\begin{tabular}{|c|c|c|c|c|c|}
\hline \multirow[b]{2}{*}{ Alloy } & \multicolumn{4}{|c|}{ Welght gain, $\dagger \mathrm{mg} / \mathrm{dm}^{2}$} & \multirow{2}{*}{$\begin{array}{c}\text { Descaled weight } \\
\text { loss in } 83 \text { days, } \\
\mathrm{mg} / \mathrm{dm}^{2}\end{array}$} \\
\hline & 42 days & 83 days & 125 days & 167 days & \\
\hline Type 304 S S & 85 & $\begin{array}{c}95 \\
\text { (103 days) }\end{array}$ & & $\begin{array}{c}116 \\
\text { (188 days) }\end{array}$ & $\begin{array}{c}276 \\
\text { (103 days) }\end{array}$ \\
\hline Incoloy & 9 & 23 & 30 & 32 & 115 \\
\hline Hastelloy $\mathrm{X}$ & 20 & 31 & 38 & 44 & 85 \\
\hline Inconel & 2 & 11 & 16 & 18 & 33 \\
\hline
\end{tabular}

*Calculated metal temperature of 1100 to $1300^{\circ} \mathrm{F}$ Stress applied to glve 01 percent creep in $1000 \mathrm{hr}$ at $1300^{\circ} \mathrm{F}$

+ For time specified unless otherwise noted

steam are comparable to those found in conventional-plant steam. The loss of corrosion products to the system is lower for the high-nickel alloys. However, as will be shown in a subsequent section, in-reactor experiments reveal that rapid, highly localized attack (attributed to stress corrosion) is the leading mode of the fuel-cladding failures.

Out-of-reactor loops have been constructed and operated to simulate reactor environments (except, of course, for the nuclear radia- 
tion). Cyclic operation of these loops is intended to provide the necessary temperature and pressure conditions responsible for crud deposition upon the tubular heaters used for corrosion specimens. ${ }^{143}$ Moisture, believed by many investigators to be necessary for cracking to occur in materials under stress, is generated during such cyclic operating conditions.

In these cycling tests the heater sheath was stressed longitudinally. The water from which steam was generated contained $1.5 \mathrm{ppm}$ chloride, added as sodium chloride, resulting in a deposit upon the test sheath. Oxygen and hydrogen were maintained in the water at a level such that the steam phase contained $20 \mathrm{ppm}$ oxygen and the storchometric quantity of hydrogen. The $\mathrm{pH}$ of the water was neutral. The applied stress was sufficient to cause 0.1 percent creep in $1000 \mathrm{hr}$ at the temperature of the steam. The temperature of the metal coupons was about $200^{\circ} \mathrm{F}$ higher than that of the steam. Steam temperatures and duration of tests were as follows:

$\begin{array}{ccc}\begin{array}{c}\text { Inlet saturated, } \\ { }^{\circ} \mathrm{F}\end{array} & \begin{array}{c}\text { Outlet superheated. } \\ { }^{\circ} \mathrm{F}\end{array} & \begin{array}{c}\text { Time, } \\ \text { days }\end{array} \\ 350 & 360 & 4 \\ 546 & 550 & 3 \\ 546 & 1050 & 2 \\ 350 & 360 & 3 \\ 546 & 550 & 2\end{array}$

The following results for some austenitic stamless steels and nickelbase alloys tested were obtained:

$$
\text { Alloy Condition after cycling }
$$

Type 304 stainless steel Cracking, transgranular and intergranular

Type $347 / 348$

Type $310 \mathrm{VM}^{*}$

Type 304 VM*

Type 406

Inconel

Incoloy

Hastelloy $\mathrm{X}$
Cracking, transgranular

No crackıng

Cracking, transgranular

No cracking

No crackıng

No cracking

No crackıng

*Vacuum melted

The $310 \mathrm{VM}$ and $304 \mathrm{VM}$ steels were vacuum melted to reduce the $\mathrm{m}-$ trogen to less than $100 \mathrm{ppm}$.

These results are regarded as only relative, but they are believed to be a useful guide for the selection of materials. Typical cross sections of the heater sheaths tested are shown in Figs. 12 to 14. 

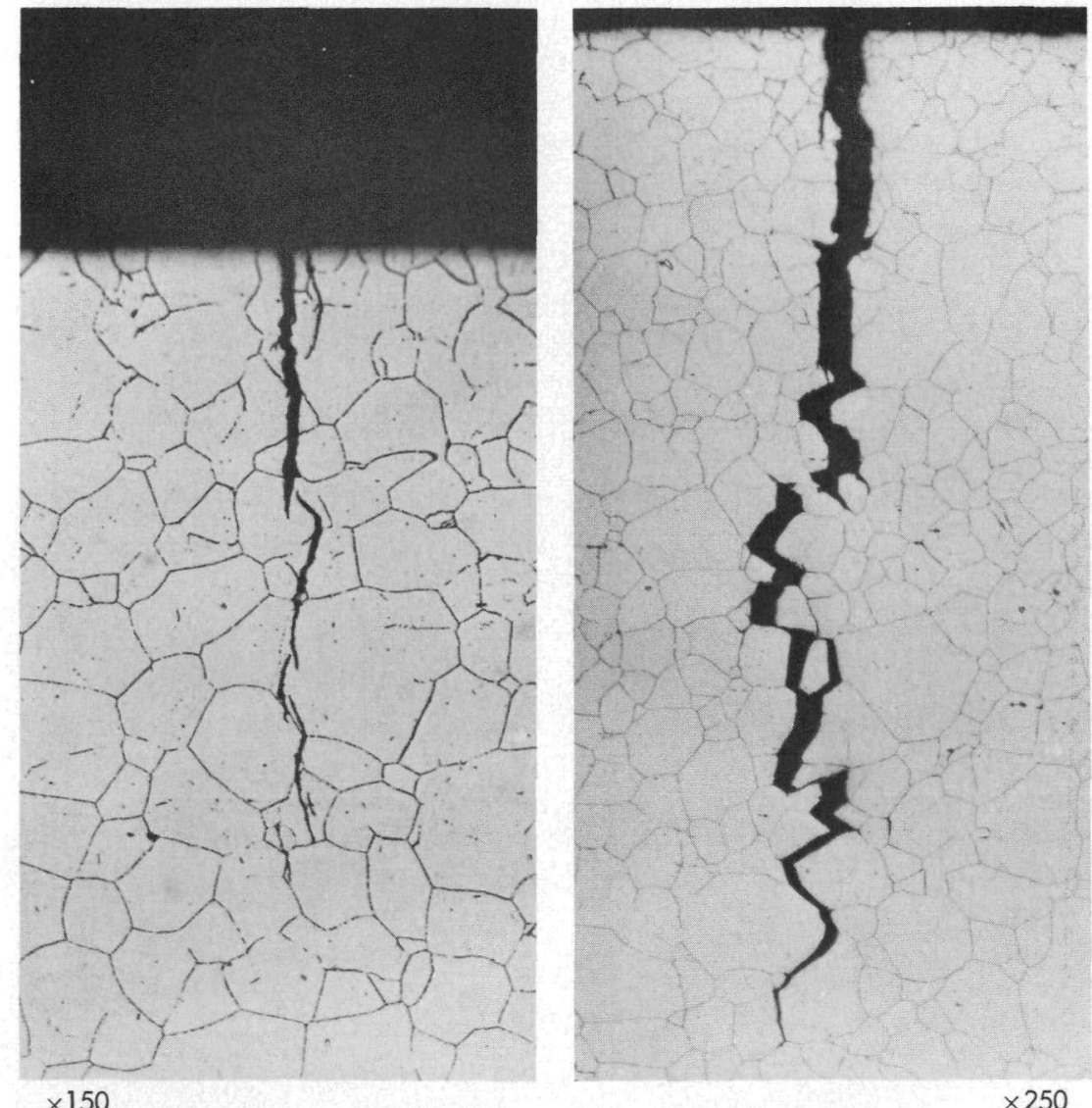

Fig. 12-Transgranular and intergranular cracks in type 304 stainless-steel heater sheath after cyclic corrosion test (specimens descaled of surface oxide).

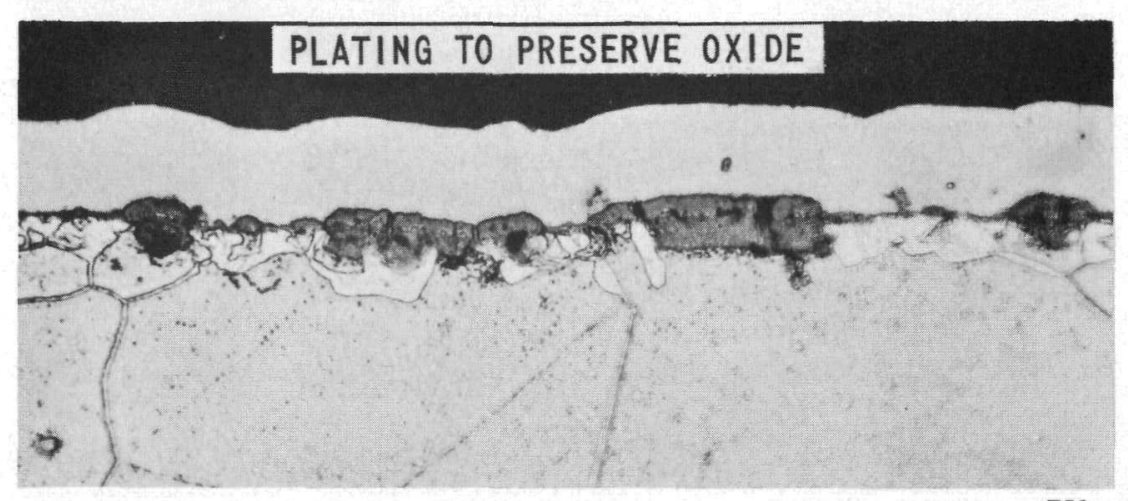

Fig. 13- Inconel heater sheath after cyclic corrosion test. 


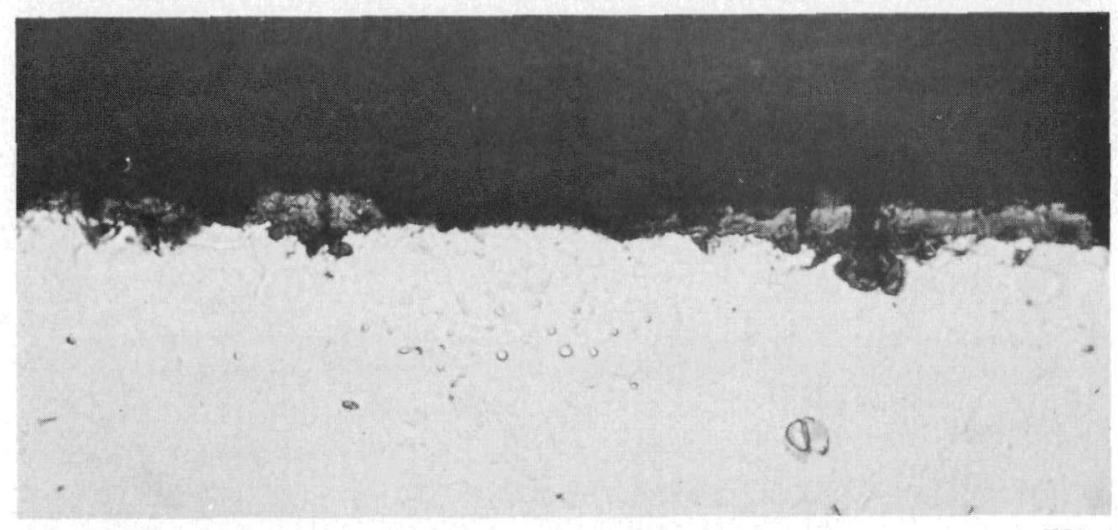

$\times 750$

Fig. 14-Incoloy heater sheath after cyclic corrosion test.

Table 24-ANALYSES OF COMPOSITIONALLY DISTURBED LAYERS ${ }^{143}$

\begin{tabular}{|c|c|c|c|c|c|}
\hline \multirow[b]{2}{*}{ Alloy } & \multirow{2}{*}{$\begin{array}{c}\text { Temperature } \\
\text { of exposure, } \\
{ }^{\circ} \mathrm{F}\end{array}$} & \multirow{2}{*}{$\begin{array}{l}\text { Depth of } \\
\text { layer, } \mu\end{array}$} & \multicolumn{3}{|c|}{ Components, * wt. $\%$} \\
\hline & & & $\mathrm{Fe}$ & $\mathrm{Cr}$ & $\mathrm{Ni}$ \\
\hline \multirow{3}{*}{ Inconel } & & & (6) & $(16)$ & $(78)$ \\
\hline & 1100 & 25 & 4.5 & 11.5 & 84.5 \\
\hline & 1300 & 8 & 5.0 & 12.5 & 85.0 \\
\hline \multirow{3}{*}{ Incoloy } & & & $(42)$ & (20) & (31) \\
\hline & 1300 & 9 & 46 & 14 & 36 \\
\hline & & & (18) & (21) & $(50)$ \\
\hline Hastelloy $\mathrm{X}$ & 1300 & 32 & 20 & 10 & 60 \\
\hline
\end{tabular}

*Numbers in parentheses, matrix values; others, surface values.

After long times at high temperatures, all materials exhibited a diffusion layer between the surface oxide and the base material. This layer has been found in materials that have been tested under isothermal as well as under heat-transfer conditions, and it has been identified by means of electron-probe analysis to have a composition different from that of the base metal. Typical analyses are given in Table 24 for the matrix surface. For Hastelloy $\mathrm{X}$ and Incoloy, the growth of this layer has been shown to be time and temperature dependent. For example, Incoloy exposed to $1100^{\circ} \mathrm{F}$ steam for 42 days exhibited a diffusion zone of about $1 \mu$ in thickness between the oxide and the metal surface, in addition to the normal metal oxide, as shown in Fig. 15. At $1300^{\circ} \mathrm{F}$ the diffusion-layer depth was $9 \mu$ after the sametime. This layer has neither been reported for material exposed to nonoxygenated steam nor found in type 304 stainless steel or Inconel-X fuel sheaths exposed in in-reactor loops for 42 days. 
Surface condition has been reported to be a significant factor in corrosion rates of stainless steels and high-nickel alloys. Ruther ${ }^{145}$ reported that Incoloy lost $830 \mathrm{mg} / \mathrm{dm}^{2}$ (defilmed metal loss) when an electropolished specimen was exposed, as compared with only $21 \mathrm{mg} /$ $\mathrm{dm}^{2}$ for a wet-ground sample. Samples were exposed for seven days to steam, at $1200^{\circ} \mathrm{F}$ and $600 \mathrm{psig}$, containing $30 \mathrm{ppm}$ oxygen but no hydrogen.

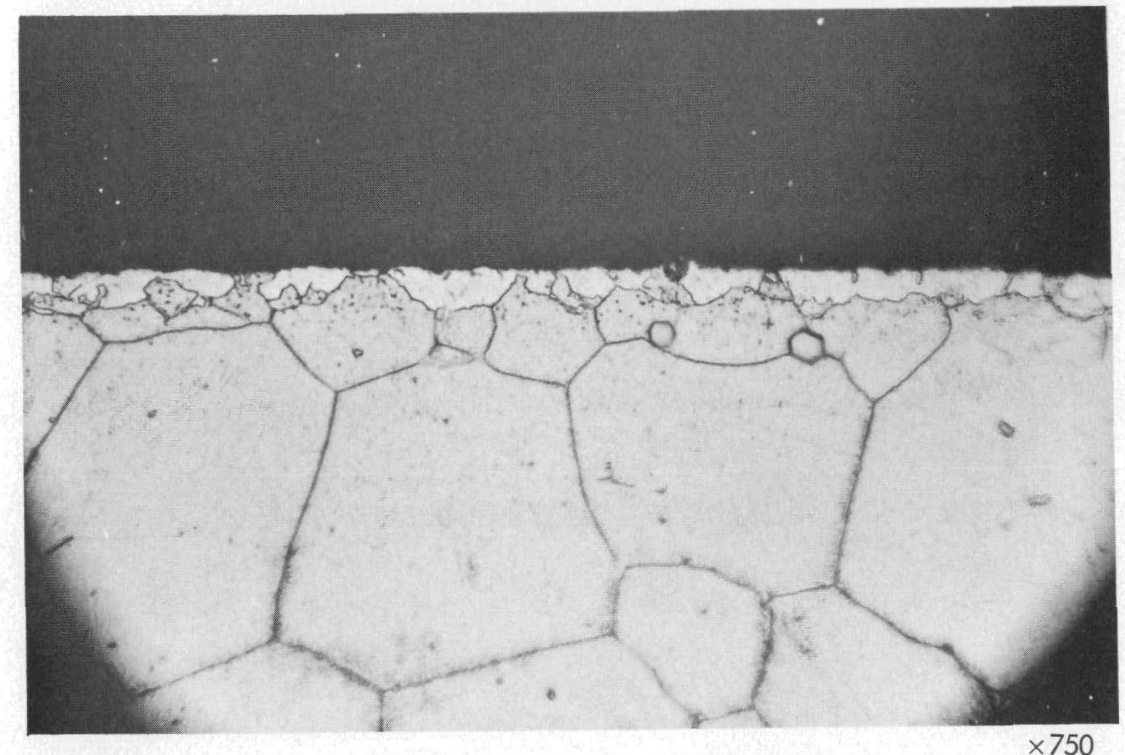

Fig. 15-Inconel tubing specimen tested at 1200 to $1300^{\circ} \mathrm{F}$ for $1000 \mathrm{hr}$ in steam (normal oxide descaled chemically; 3 percent nital etch.)

Similar one-week exposures for type 304 stainless steel have resulted in defilmed metal losses of $230 \mathrm{mg} / \mathrm{dm}^{2}$ for grit-blasted surfaces, 360 for machined surfaces, 840 for 80 -grit wet-ground surfaces, and 1280 for pickled surfaces. Similar effects of surface treatment have been reported by Ulmer. ${ }^{138}$ Surface condition has not been a variable in the studies conducted by the General Electric Company workers. In all cases, including in-reactor tests discussed in a subsequent section, samples were exposed as pickled and acetone cleaned.

It has been reported that impurities such as nitrogen, aluminum, or phosphorus have an adverse effect upon the resistance of the 300-series stainless steels to cracking under stress in magnesium chloride solution. Nitrogen in particular was observed by Uhlig and White ${ }^{146}$ and by Lang $^{147}$ to be a cracking-promoting impurity. Nitrogen is said to diffuse to lattice imperfection sites forming cathodic areas, resulting in 
crack-sensitive paths (by means of elactrochemical or electrochemicalmechanical mechanısms). Other impurities or alloying constituents ald crack resistance.

Low-nitrogen ( 20 to $40 \mathrm{ppm}$ ) types 304 and 310 stainless-steel tubing of low ( 0.02 percent) and high ( 0.06 percent) carbon levels has been tested in magnesium chloride solution and in superheated steam under the cycle conditions previously described. ${ }^{148}$ The low-nitrogen stainless steel is produced by vacuum melting, which is referred to as "VM." Improved crack resistance was noted in both environments. Type $304 \mathrm{VM}$ was found to be 10 times better than commercial-grade type 304, in terms of time to crack initiation in magnesium chloride solution. However, a loop cyclic run revealed cracking within 14 days as compared with 3 to 4 days for commercial grades. ${ }^{143}$ Type $310 \mathrm{VM}$ exhibited no cracking during a 14-day cyclic run. Additional study of $310 \mathrm{VM}$ appears to be worthwhlle.

EFFECT OF REACTOR ENVIRONMENT Relatively few studies have been made in environments simulating those of a nuclear reactor. Irradiation of fuel elements, if carried out for long enough perıods of time, permits simultaneous study of corrosion and radiation effects. Exploratory studies conducted by Spalaris and associates ${ }^{149-151}$ to evaluate type 304 stainless steel showed that this material was subject to severe localized attack. Three prototype elements falled after short periods of exposure, largely because of intergranular attack. Some transgranular attack occurred at areas of relatively low heat generation (cladding surfaces located over $\mathrm{ZrO}_{2}$ spacer pellets). The Superheater Advance Demonstration Experiment (SADE) facility is shown in Fig. 16. In this facility the experimental elements are cooled by reactor-produced steam. It was enlarged to accommodate nine fuel elements and was therefore renamed Expanded Superheater Advance Demonstration Experiment (E$\mathrm{SADE})$. The two types of fallure are illustrated in Figs, 17 and 18.

Fallure occurred in both annealed and slightly cold-worked material. Results from the first two tests were somewhat clouded by abnormal conditions of operation, i.e., high moisture carryover in the steam and a relatively high chloride content in the reactor water. Normal conditions are about 0.1 percent moisture, 0.03 ppm chloride in the water, 20 ppm oxygen, and stolchiometric amounts of hydrogen. In addition, gasketed flanges allowed leakage of chloride-contaminated water into the fuel compartment. A welded flange prevented leakage in the third test.

Postirradiation examination of the falled elements revealed large deposits of chloride impurities on the fuel-cladding surfaces. ${ }^{152}$ This evidence, plus the morphology of the crack as revealed under careful metallographic examination, indicated that the jacket fallures were due to stress-corrosion attack. Consideration of present knowledge concerning stress corrosion of austenitic alloys, together with the condi- 


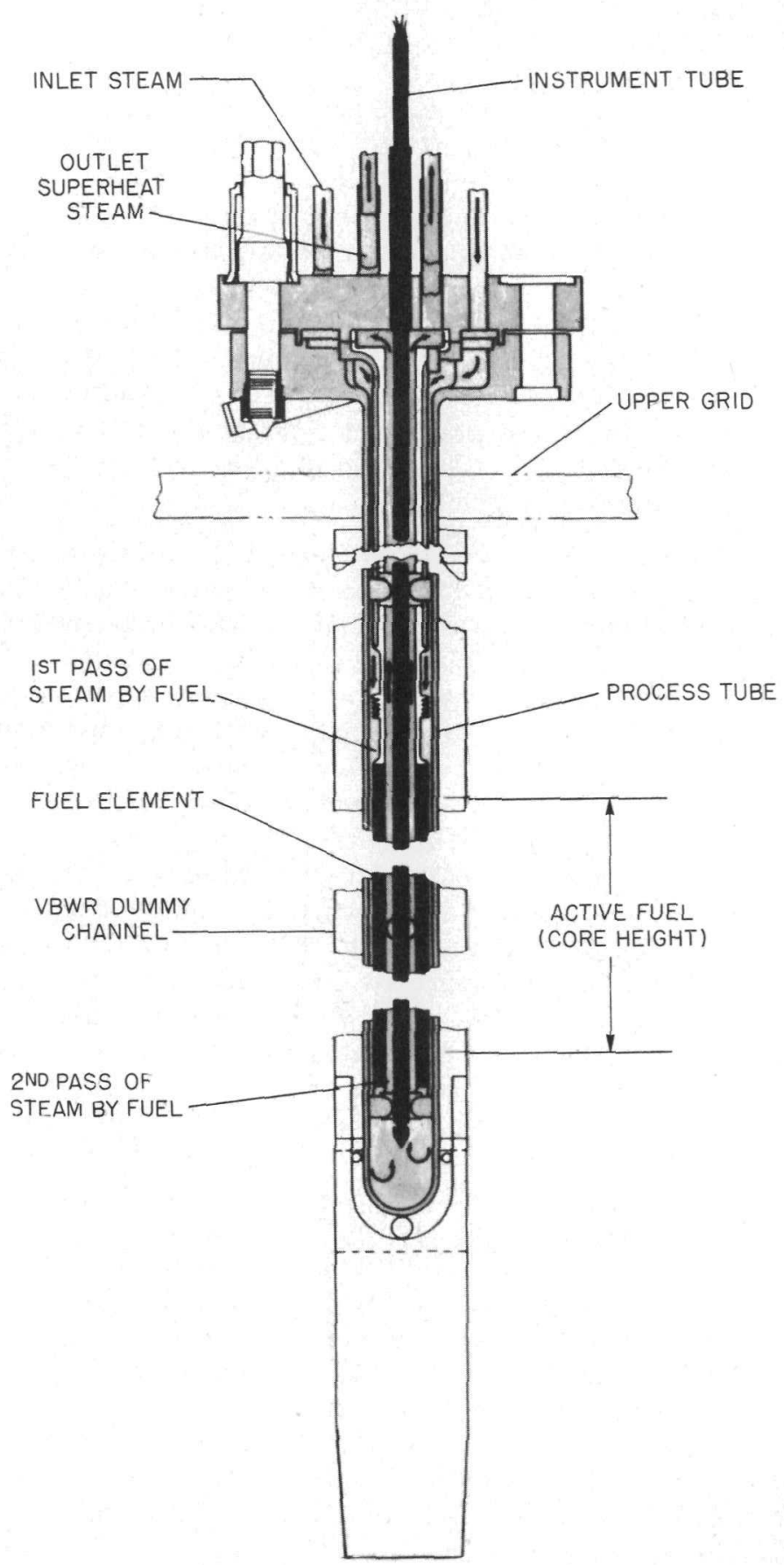

Fig. 16-SADE loop in the VBWR. 


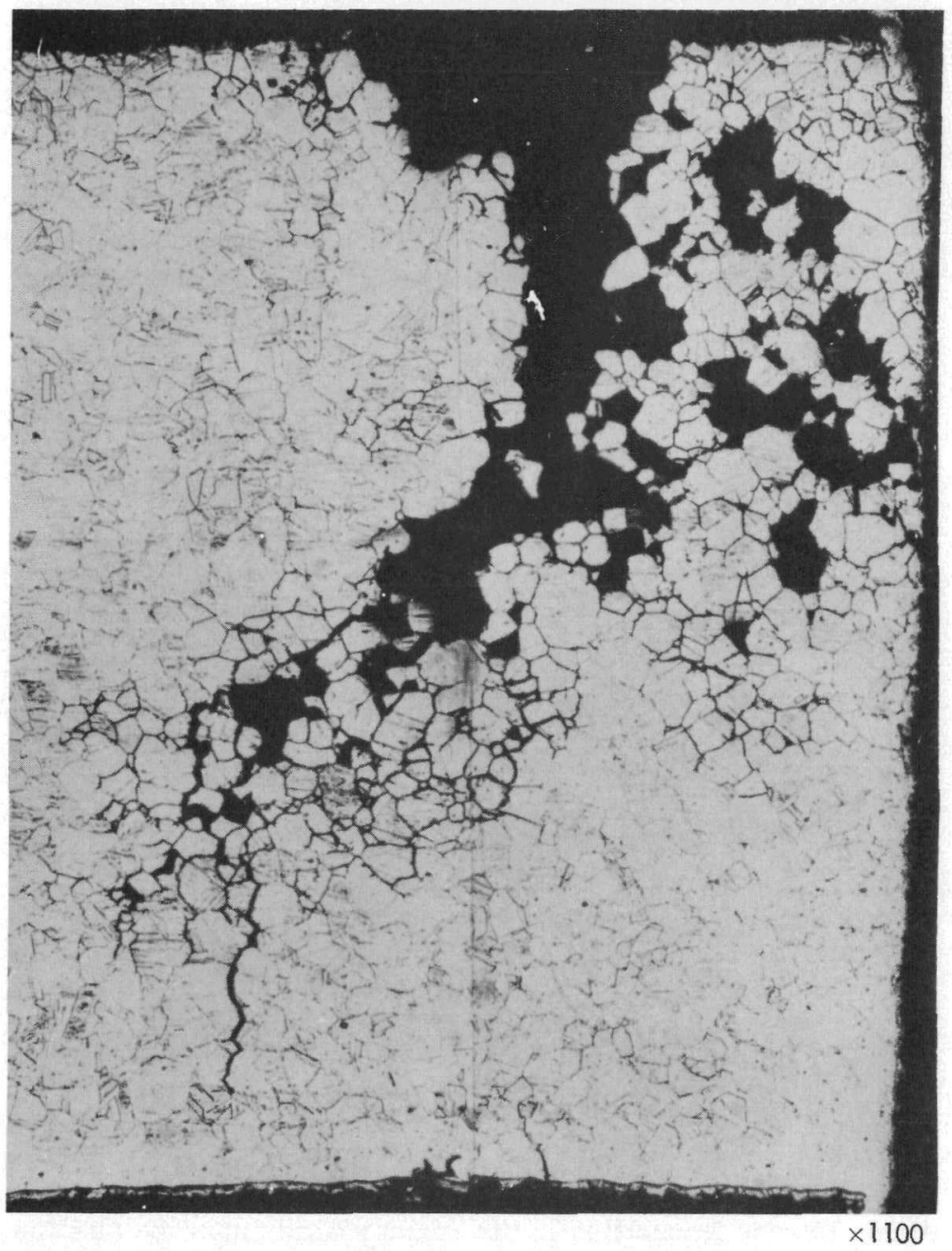

Fig. 17-Crack in type 304 stainless steel. 


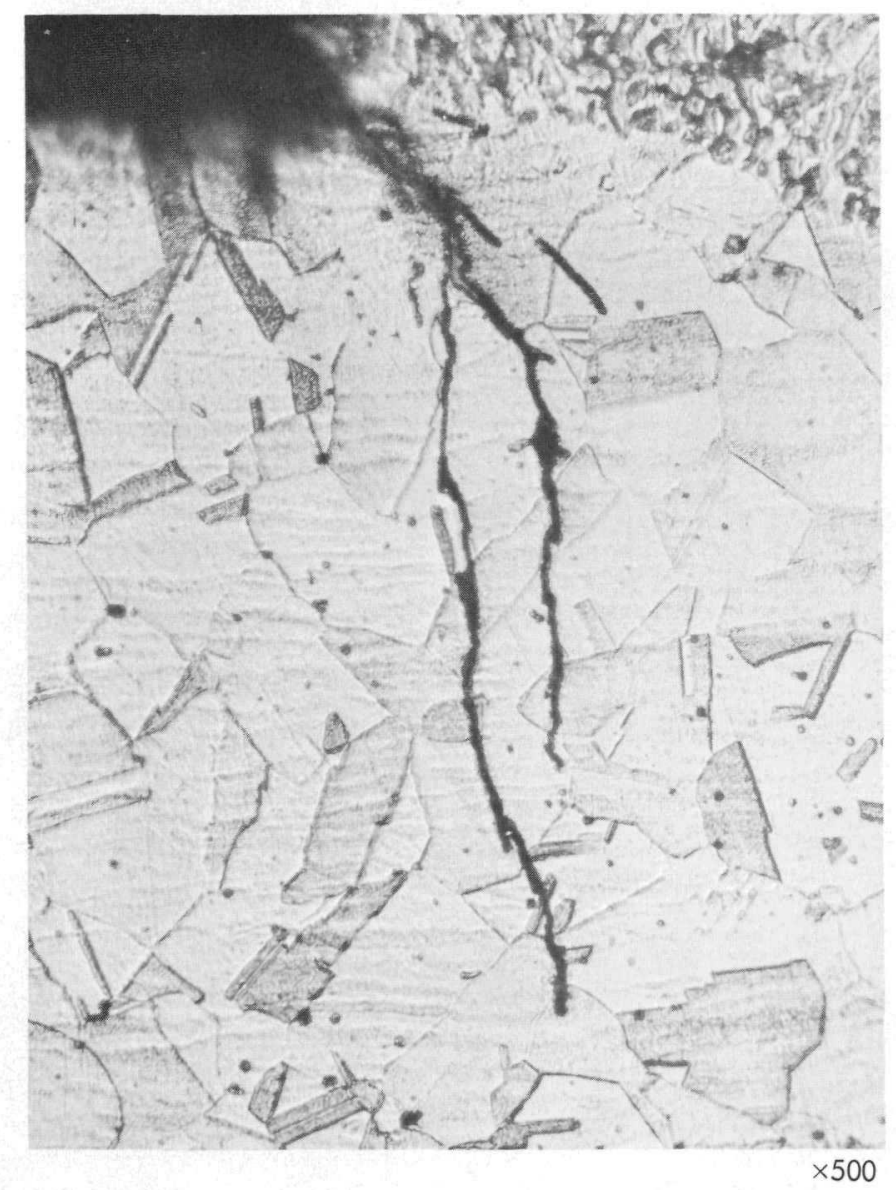

Fig. 18-Transgranular crack in type 304 stainless steel.

tions prevailing in the $\mathrm{SADE}$ environment, indicated three possible approaches to the solution of the problem:

1. Residual or operating stresses, or both, in fuel elements must be minimized through judicious design.

2. Moisture content must be reduced in the steam, and improved control of chloride impurities in the reactor water must be introduced.

3. Alternative materials must be selected which are less susceptible to stress corrosion or other types of rapid failure.

Relatively short irradiations (less than 60 days) indicate that Inconel, Inconel-X, and Incoloy are not subject to localized corrosion attack. However, much longer experiments are necessary to determine if these materials are capable of the long life necessary for commercial 
power reactors. The results of the SADE and E-SADE radiations are summarized in Table 25.

Much remains to be done in the area of understanding corrosion behavior of stainless steel and high-nickel alloys in the environments of superheated-steam nuclear reactors. Impurities in the steam carryover present in reactor systems are considered to play an important role. A recent study of the system for one of the superheat reactors under construction illustrated the complexity of the environmental problems presented in such systems. ${ }^{153}$ Impurities such as chlorides or oxides may themselves attack fuel cladding at high temperatures independently of the role played by steam, moisture, or oxygen. Stresses, which are present in varying degrees, can contribute to or cause localized corrosion attack, depending upon the material used. Residual impurities in the alloys may be altered to improve corrosion resistance. Only in reactors, however, can the proper environment for valid exper mental investigation and evaluation of all pertinent variables be found. It is expected that the superheat reactors now under construction will provide such necessary testing environments.

\section{Mechanical and Metallurgical Properties}

The previous discussion concerning the behavior of prototype fuel elements demonstrates the relation netween corrosion behavior and mechanical properties. It the refore seems reasonable to discuss in some detail the effects of high temperature, radiation, and othe $r$ condltions of service, e.g., cyclic stresses, on the performance of the materials considered as fuel-element cladding. This discussion should serve to emphasize that the final selection of a cladding material must be based on many factors in addition to corrosion behavior.

The qualities necessary for adequate performance at high temperatures for prolonged periods in conventional plants a re equally desirable in materials for service in nuclear plants. The conventional materials, therefore, are given first consideratıon. Exceptions are cobaltcontaining alloys, which, because of neutron economy and the need to minimize the degree of downstream component activation, are eliminated from consideration. ${ }^{154}$

EFFECT OF TEMPERATURE AND FATIGUE Fuel-element cladding is subjected to high stresses during reactor operation because of the rmal expansion of the fuel, reactor pressure, and buldup of internal pressure from release of fission gas and adsorbed residual gases from the fuel. ${ }^{155}$

Cladding materials for fuel elements must have adequate hightemperature ductility and strength. When a nuclear reactor is brought to power, the fission process heats the fuel column. Because the average fuel temperature is much greater than the average cladding tem- 
Iable 25-IRRADIATION TESTING OF NUCLI AR SUPI RHEAI TUEL ELEMHNIS IN SADE LOOP (VBWR) ${ }^{149,150}$ 152

\begin{tabular}{|c|c|c|c|c|c|c|c|c|c|}
\hline & SH 2 & SH 1 & SH $4 B$ & $\mathrm{SH}-4$ & $\mathrm{SH} 4 \mathrm{C}$ & SH $5 A^{*}$ & SH $4 \mathrm{D}$ & NUSU & ESH 1 (ESADE loop) \\
\hline \multicolumn{10}{|l|}{ Cladding miteridl } \\
\hline Outcr & $304 \mathrm{~S} \mathrm{~S}$ & $304 \mathrm{SS}$ & $304 \mathrm{~S} \mathrm{~S}$ & 304 S S & $304 \mathrm{~S} \mathrm{~S}$ & $304 \mathrm{~S} \mathrm{~S}$ & Inconel & $\begin{array}{l}347 \mathrm{~S} \mathrm{~S} \\
\text { (boilung water) }\end{array}$ & $\begin{array}{l}3 \text { Incoloy (annular) } \\
1304 \mathrm{~S} \mathrm{~S} \text { (annular) }\end{array}$ \\
\hline \multicolumn{10}{|l|}{$\begin{array}{l}\left.\mathrm{C}\right|_{\text {Idding dimensions }} \\
\text { in }\end{array}$} \\
\hline Inner OD by wall & $07 \times 0$ by 003, & 0750 by 0035 & 0750 by 0028 & 0750 by 0028 & 0750 by 0028 & 0750 by 0016 & 0750 by 0028 & 1072 by 0025 & 0750 by 0028 \\
\hline Outcr OD by wall & 12501 ,y 0019 & 12,0 by 0019 & 12,0 by 0028 & 12.00 by 0028 & 1250 by 0028 & 1230 by 0016 & 1250 by 0028 & 1500 by 0028 & 1250 by 0028 \\
\hline \multicolumn{10}{|l|}{ I uel pellets } \\
\hline $\begin{array}{l}\mathrm{LO}_{2} \Gamma \mathrm{D} \\
\mathrm{U}^{235}\end{array}$ wt $\pi$ & $\begin{array}{l}95 \\
23\end{array}$ & $\begin{array}{l}95 \\
23\end{array}$ & $\begin{array}{l}94 \\
+3\end{array}$ & $\begin{array}{l}94 \\
35\end{array}$ & $\begin{array}{l}94 \\
35\end{array}$ & $\begin{array}{l}95 \\
40\end{array}$ & $\begin{array}{l}95 \\
35\end{array}$ & $\begin{array}{l}95 \\
35\end{array}$ & $\begin{array}{l}94 \\
6 \text { to } 10\end{array}$ \\
\hline $\begin{array}{l}\text { In adration time } \\
\text { diys }\end{array}$ & 60 & 45 & 130 & 77 & 30 & 60 & 21 & 54 & 55 \\
\hline $\begin{array}{l}\text { In adiation cxpo } \\
\text { sure (maximum) } \\
\text { Mud } / \mathrm{t}\end{array}$ & 440 & 440 & 327 & 570 & 371 & 710 & $\begin{array}{l}18 \mathrm{~s} \\
\text { (hedt } \\
\text { balance) }\end{array}$ & $\begin{array}{l}920 \\
\text { (heat } \\
\text { balance) }\end{array}$ & \\
\hline $\begin{array}{l}\text { Power (miximum) } \\
k w\end{array}$ & 34 & 44 & 94 & 68 & 64 & 807 & 62 & 114 & 90 \\
\hline $\begin{array}{l}\text { Exit steam tem } \\
\text { peraturc (maxi } \\
\text { mun), }{ }^{\circ} \mathrm{F}\end{array}$ & 820 & 820 & 900 & 875 & 830 & 845 & 850 & 780 & 830 \\
\hline Defects & $\begin{array}{l}\text { Crach in } \\
\text { bellows } \\
\text { convolution }\end{array}$ & $\begin{array}{l}\text { No visible } \\
\text { flaws }\end{array}$ & $\begin{array}{l}\text { Inter, ranuldr } \\
\text { and trans } \\
\text { granular } \\
\text { cracks and } \\
\text { pinhole de- } \\
\text { fects }\end{array}$ & $\begin{array}{l}\text { lo visible } \\
\text { defects }\end{array}$ & $\begin{array}{l}\text { Circum- } \\
\text { ferential } \\
\text { crack, } \\
\text { grain } \\
\text { boundary } \\
\text { corrosion }\end{array}$ & $\begin{array}{l}\text { Many inter } \\
\text { granular } \\
\text { cracks } \\
\text { especially } \\
\text { in the } \\
\text { bottom oD } \\
\text { position }\end{array}$ & $\begin{array}{l}\text { Slight fission } \\
\text { gas release } \\
\text { during reac } \\
\text { tor exposure, } \\
\text { none detected } \\
\text { at the hot } \\
\text { cclls }\end{array}$ & $\begin{array}{l}\text { Fiscion } \\
\text { product gas } \\
\text { released } \\
\text { during reac } \\
\text { tor exposure, } \\
\text { none detected } \\
\text { at the hot } \\
\text { cells }\end{array}$ & $\begin{array}{l}\text { Sone detected during } \\
\text { reactor operation }\end{array}$ \\
\hline
\end{tabular}


$\mathrm{Cl}^{-}$excursion
to $3 \mathrm{ppm}$ for
$861 \mathrm{Cl}^{-}$at
$8 \mathrm{hr}, 20 \mathrm{ppm}$,
$\quad 18 \mathrm{ppm} \mathrm{O}_{2}$

$\mathrm{O}_{2}$

Diametral gap, in 0010

v 010

Comments

Stress-cor-
Uniform

f $11 \mathrm{~m}$$$
\text { ros }
$$
rosion
cracks due
to high-

water seep-

dge in loop

and chlo-

ride ion

concentra-

tion, high

stresses

evidenced

by collapse

of claddung

over $\mathrm{UO}_{2}$

(non-self-

supporting

geometry)

\section{$\mathrm{Cl}^{-}$rose to \\ Chloride de-}

above 0 ;

ppm for 9

hr while

reactor was

at $30 \mathrm{Mw}$,

$18 \mathrm{ppm} \mathrm{O}_{2}$

posits found

on fuel-

element sur-

face espec1-

dliy at the

defected

region

of $507 \mu \mathrm{g} \mathrm{W}$
found on ID

0009 to 0011 then swaged

$$
\text { to } 0001
$$

$\begin{array}{ll}\text { No sıgmifl- } & \text { Intergranular } \\ \text { cant release } & \text { attack } \\ \text { of fission } & \text { caused fdil- } \\ \text { gas, chloride } & \text { ure, brittle } \\ \text { deposits } & \text { fracture due } \\ \text { found on sur- } & \text { to tensile } \\ \text { face cladding } & \text { stress, } \\ & \text { flange water } \\ & \text { leakage of } \\ & \text { lb } / \mathrm{hr}\end{array}$

Interg ranu

attack

caused fall-

No

ure, stress

corrosion

mechanısm

was probably

responsible

for fallure,

wear of

cladding at

spacer con-

tact, also

crackıng at

spacer con-

tact up to $8 \mu \mathrm{g}$ /

rud

was found on

OD, total $\mathrm{Cl}^{-}$

0

attack foun

Reactor water steady at $003 \mathrm{ppm} \mathrm{Cl}^{-}$

$2 \mu \mathrm{g}$ were

found in 31

$\mathrm{mg}$ of $\mathrm{crud}$

on Inconel- $X$

steam side

\section{Not given}

corrosion

at tack found

on Inconel- $X$

steam side

(Results re-

ported in

USAEC Re-

port GEAP-

4153)
Type 304 claddıng

falled after 29 days

in reactor, failure

similar to that ob-

served for the SH-4B,

the SH-4C, and the

SH-5A (Results re-

ported in USAEC Re-

port GEAP-4153)

*Flange welded to eliminate water leakage during reactor exposure 
perature, the fuel column will expand to make contact with the cladding. As the temperature increases, the fuel will continue to expand faster and will permanently deform the cladding when the combined stresses exceed the yield strength of the material. High-temperature ductility, therefore, is important because it is needed to allow significant amounts of strain deformation to occur without rupture. A low modulus of elasticity is also desirable to permit a sizable deformation without consequent high stress. High ductility is important throughout the temperature range from room-temperature machining to hightemperature forging for ease of fabrication. Large ductility variations over short temperature ranges or sudden changes in ductility in the heat-affected zones near a weld are undesirable because they may lead to premature failures. Resistance to fatigue failure, especially low cycle fatigue, is also an important criterion of material selection. ${ }^{155}$

Mechanical properties of alloys are influenced by microscopic metallurgical changes that can result from exposure to neutron flux as well as from other factors in the environment. In general, microscopic changes in an alloy, such as grain-boundary precipitation or precipitation of discontinuous intermetallic phases in grains, reduce ductility and increase yield and tensile strengths. Increasing neutron flux also decreases ductility. All types of alloys display microscopic changes due to prolonged high-temperature exposures. Typical mechanical properties for the 300-series stainless steels are shown in Fig. 19 as a function of time at high temperature. ${ }^{156}$ The original values of these properties were as follows:

Tensile strength, $1000 \mathrm{psi}$

$\begin{array}{ccc} & \begin{array}{c}\text { At } \\ \text { room } \\ \text { temp. }\end{array} & \begin{array}{c}\text { At } \\ 1350^{\circ} \mathrm{F}\end{array} \\ \text { Type } & & \\ 304 & 82 & 35.5 \\ 316 & 80.6 & 38.3 \\ 318 & 86.3 & 45.1 \\ 321 & 80.1 & 34.9 \\ 347 & 91.8 & 37.6\end{array}$

Elongation in $1.5 \mathrm{in.} \%$

$\begin{array}{lcc}\begin{array}{c}\text { At } \\ \text { room } \\ \text { temp. }\end{array} & \begin{array}{c}\text { At } \\ 1350^{\circ} \mathrm{F}\end{array} & \begin{array}{c}\text { Charpy impact } \\ \text { at room temp., } \\ \text { ft-lb }\end{array} \\ 66 & 60 & 94 \\ 63.3 & 60 & 88.5 \\ 52.6 & 40.7 & 83.5 \\ 57.3 & 58 & 92 \\ 46 & 78 & 42^{*}\end{array}$

${ }^{*}$ Half-width specimen.

No changes in mechanical properties drastic enough to exclude any of the 300-series stainless steels from consideration as a material for fuel-element cladding have been experienced. Type 310 alloy is particularly subject to formation of sigma phase, a hard, brittle, complex iron-chromium intermetallic compound. ${ }^{157}$ This phase precipitates at 1100 to $1600^{\circ} \mathrm{F}$. Clark ${ }^{158}$ and his coworkers found that, at the exposure temperatures of $1300^{\circ} \mathrm{F}$, sigma formation had no adverse effects upon 

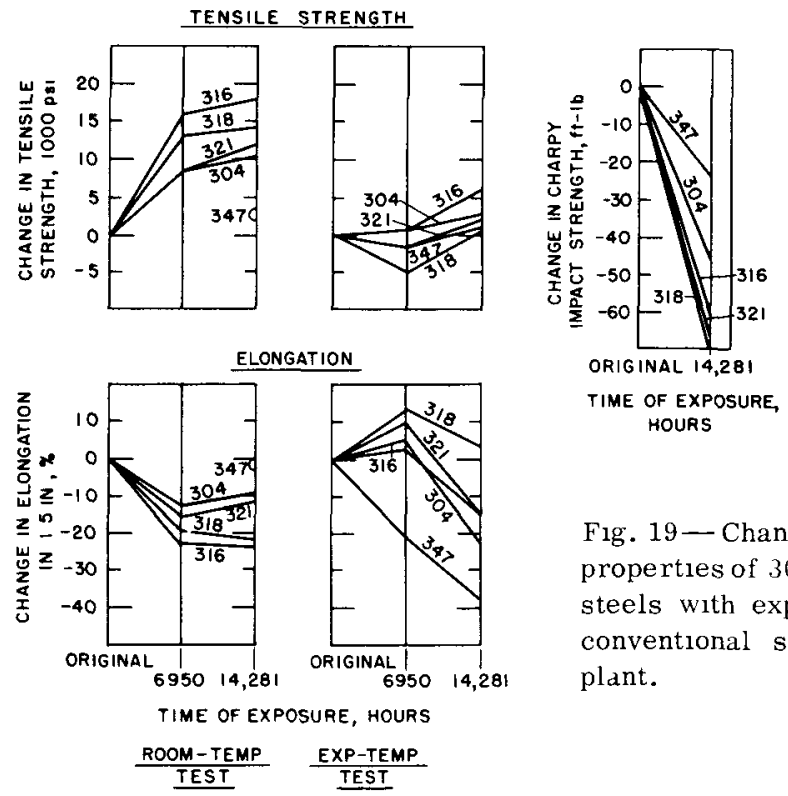

Fig. 19-Changes in mechanical properties of 300-series stainless steels with exposure to steam in conventional superheat power plant.

the elongation or impact properties of type 310 , and room-temperature tests show this alloy to have adequate ductility. Foley and Krivobok ${ }^{159}$ recently reported that, after long exposure (125 days and longer) at $1200^{\circ} \mathrm{F}$, ferrous alloys containing 15 to 30 percent chromium together with 20 to 35 percent nickel transform in some degree to sigma phase. The largest amount of sigma and the lowest impact values occur in the alloys with the highest chromium and the lowest nickel. Increasing the nickel content appears to decrease the temperature at which sigma forms and to narrow the range of temperature in which it is stable.

Carbide precipitation at the grain boundaries is rapid at 1150 to $1250^{\circ} \mathrm{F}$ for all austenitıc alloys. The mobium or titanium in the socalled "stabilized" grades prevents carbide precipitation at the grain or twin boundaries during rapid temperature rise followed by rapid quenching. Thus sensitization during welding is prevented. For longterm high-temperature applications, however, stabilization with niobium or other similar alloy additions is not totally effective. Long-term diffusion mechanisms due to high temperatures are operative in fuel applications in superheat environments. Thus some degree of carbide precipitation in all austemitic or nickel-base alloys is to be expected. It is possible to control carbide morphology to optimize the performance of an alloy, but, unless specific precipitate morphologies manifest themselves as being optımum, the metallurgist cannot design alloys for a specific use. It is considered prudent to select alloys of simple compositions, 1.e., stable within wide limits of solid solubility in the 
temperature range $\left(1100\right.$ to $\left.1350^{\circ} \mathrm{F}\right)$ useful in nuclear superheat plants. Precipitation-hardening alloys are relatively complex, and it is therefore more difficult to predict performance in nuclear-superheat environments.

Because of their satisfactory corrosion properties, Incoloy, Inconel, and Hastelloy $\mathrm{X}$ have been given wide consideration for hightemperature fuel applications. In Great Britain a $20 \mathrm{wt} . \% \mathrm{Cr}-25 \mathrm{wt} . \%$ $\mathrm{Ni}-0.25 \mathrm{wt} . \% \mathrm{Nb}$ alloy has been considered for the fuel cladding for the Advanced Gas Reactor on the basis of satisfactory Charpy impact strength after periods of up to $10,000 \mathrm{hr}$ at $1472^{\circ} \mathrm{F}$ and satisfactory corrosion resistance in a carbon dioxide atmosphere containing 5 percent carbon monoxide. ${ }^{160}$ The 20 wt. $\% \mathrm{Cr}-25$ wt. $\% \mathrm{Nl}-0.25$ wt. $\% \mathrm{Nb}$ alloy was found to be free of sigma formation even after long times at high temperatures.

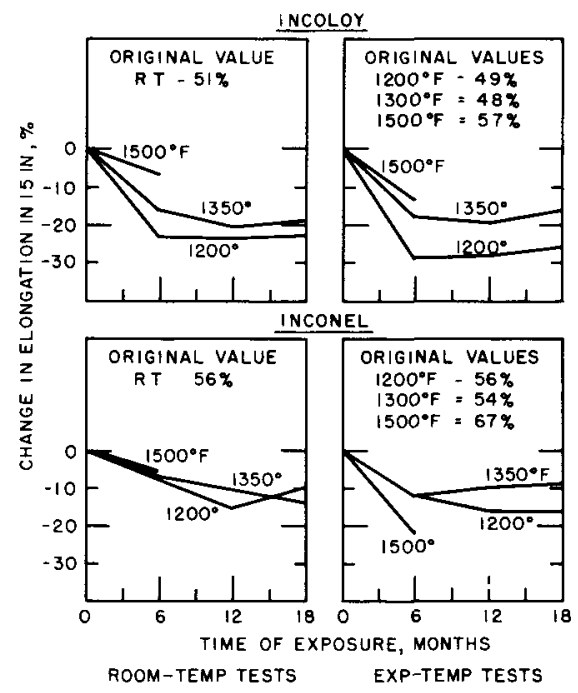

Fig. 20-Changes in elongation of Incoloy and Inconel wath exposure to steam of conventional superheat power plants.

Long exposures of Inconel and Incoloy to superheated steam (conventional low oxygen content) have been reported. ${ }^{158}$ After s1x moiths of exposure, the elongation and impact properties of Incoloy remained unchanged after initial drops to values considered acceptable for fuelelement cladding. Impact and elongation properties of Inconel changed even less than those of Incoloy. The changes in elongations are shown in Fig. 20.

More-recent work indicates similar behavior for Incoloy, Inconel,

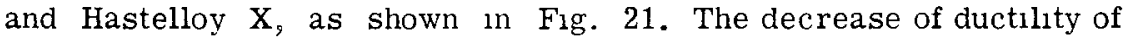
Hastelloy $\mathrm{X}$ as a function of time at high temperatures can be explained 
in terms of intermetallic complexes formed by the molybdenum. Beat$\mathrm{t}_{1} \mathrm{e}^{161}$ showed that the molybdenum intermetallic in Incoloy 901 (molybdenum-containing alloy) is an $\mathrm{M}_{2} \mathrm{Mo}$ precipitate that promotes age hardening. Watanabe and associates ${ }^{162}$ have identified a precipitate believed to be $\mathrm{Fe}_{2} \mathrm{Mo}$ after exposure at $1400^{\circ} \mathrm{F}$ for $6415 \mathrm{hr}$.

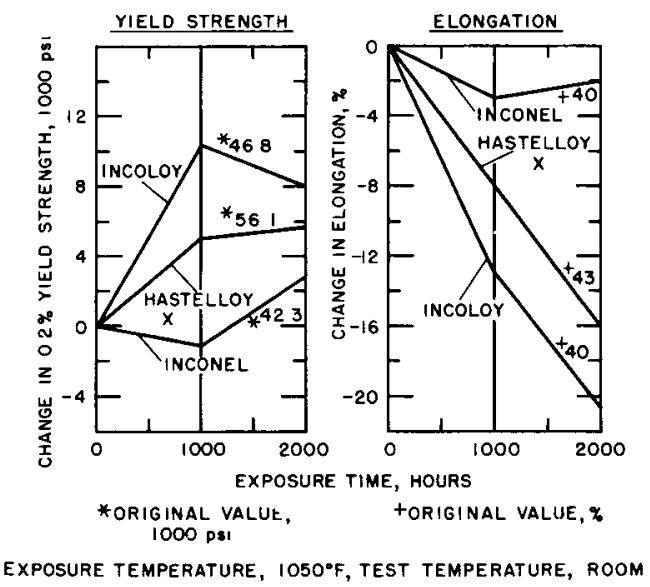

Fig. 21 - Yield strength and elongation of alloys tested in oxygenated $(20 \mathrm{ppm})$ steam. ${ }^{148}$

The drop in elongation for Incoloy has been attributed to small amounts of aluminum and titanium, 4000 and $1000 \mathrm{ppm}$, respectively. ${ }^{148}$ Controlled experiments showed that elongation "recovery" was obtained when the material was solution annealed at $2050^{\circ} \mathrm{F}$ followed by age hardening at $1150^{\circ} \mathrm{F}$. Although no changes in microstructure could be detected by ordinary metallog raphy, electron microscopy revealed precipitate formation at the grain boundaries as a function of time at temperature. This formation is illustrated in Fig. 22. This alloy nominally contains 0.20 percent titanium and 0.1 percent alumınum. The vendor's analysis shows 0.4 percent titanium and 0.4 percent aluminum. It is suspected that the decrease in ductility and elongation with exposure at 1200 to $1300^{\circ} \mathrm{F}$ reported by Clark et al..$^{158}$ may be due to increased quantitıes of aluminum and titanıum.

Stress-rupture and creep properties of materials may be critical in applications for which long fuel infe is desired. At operating levels and during power cycling, the sheath is subjected to significant plastic strains and high levels of stress. The relative amounts of strain will depend on a given geometry, mode of reactor operation, and amount of stress relaxation. Complete information for all materials presently considered for superheat-fuel applications is not avallable. Furthermore, results are often a function of material-fabrication history and 


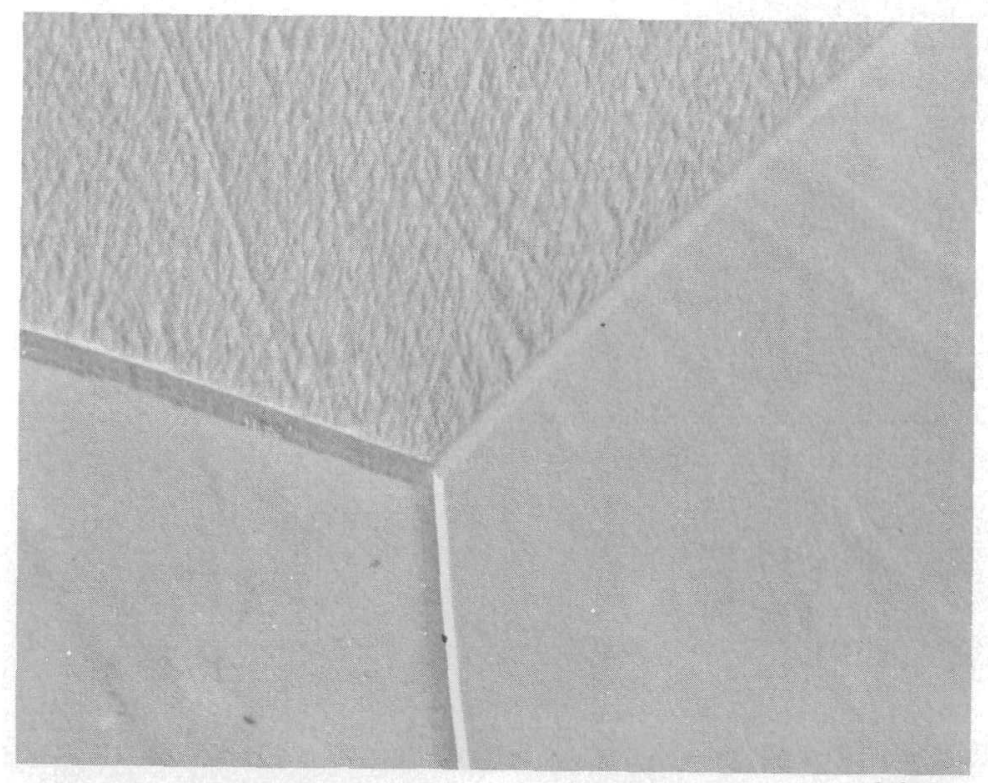

$\times 8,000$

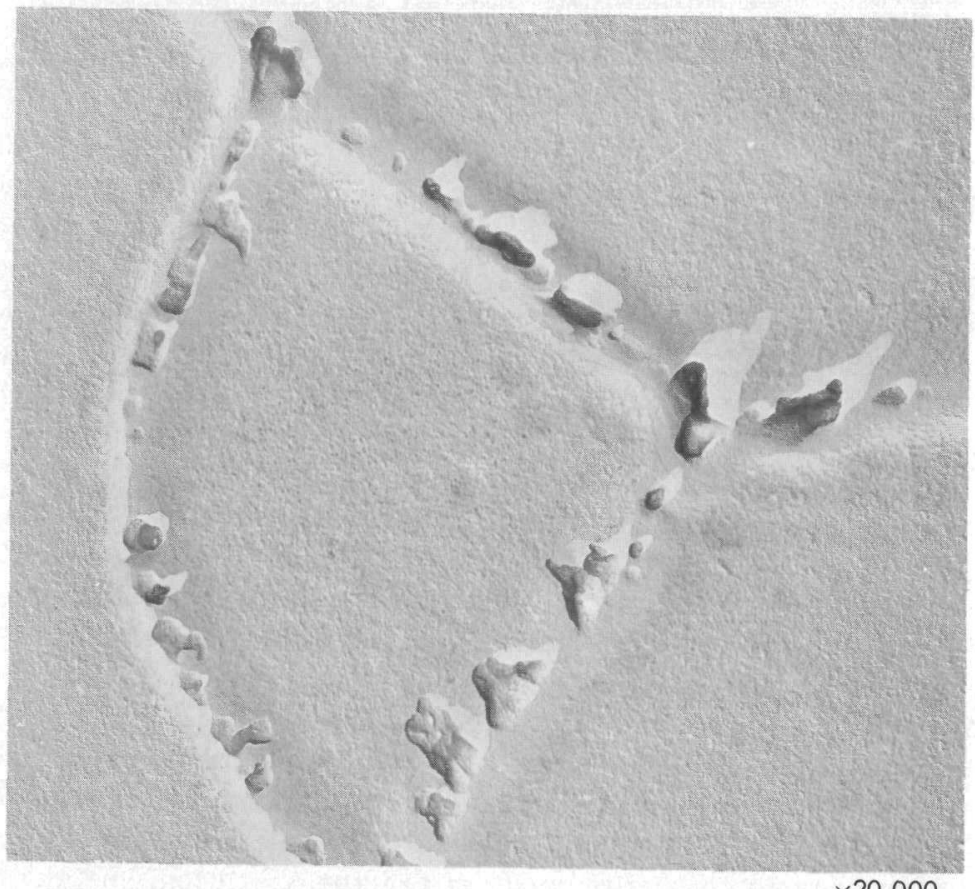

$\times 20,000$

Fig. 22- Formation of precipitate at grain boundaries in Incoloy. Top specimen was heat-treated at $1150^{\circ} \mathrm{C}$ for $1 \mathrm{hr}$. Bottom specimen is same as top specimen, aged at $1050^{\circ} \mathrm{C}$ for about 42 days. 
are therefore difficult to apply to specific designs. Swindeman and Douglass ${ }^{163}$ reported that certain heat treatments that produce finegrain structures result in improved stress-rupture strengths at $1300^{\circ} \mathrm{F}$, as compared with treatments that produce coarse-grain structures. Also, chemical treatments, such as carburizing, reduced the creep rate of Inconel at $1300^{\circ} \mathrm{F}$ by a factor of 10 and more than tripled the rupture life. Hastelloy $X$ exhibited high creep-rupture strength in an atmosphere of 99.5 percent nitrogen and 0.5 percent oxygen at $1750^{\circ} \mathrm{F}$, but it is doubtful that these properties will remain unaffected under longterm exposure since intermetallic precipitation increases with time at high temperatures.

Major variations of reactor power and fiuctuations of reactor pressure will result in low-frequency fatigue. Owing to the low frequency, the crystal structure of an alloy has time to rearrange and allow movement of dislocations and point defects. These lattice imperfections will position themselves in an array favorable for fracture.

Low-frequency fatigue with relatively long hold time at a given stress has been studied for the 300-series stainless steels and other materials. Long hold times were found to be a significant factor in the results of low-frequency faligue tests for type 347 stainless steel. ${ }^{164}$ Studies of this nature are important for systems in which components are subjected to infrequent reversals in loading, such as those occurring in power reactors under steady-state operation.

Although many materials obey Coffin's relations, $\mathrm{N}^{12} \Delta \mathrm{E}_{\mathrm{p}}=\mathrm{C}$, regardless of temperature and time of testıng, experımental work of Swindeman and Douglass ${ }^{163}$ with Inconel shows that relaxation or other time-dependent processes are operative. The exponent was found to vary from 0.58 to 0.81 . This significantly affects the number of cycles $(\mathrm{N})$ to fallure at a given strain range $\left(\Delta \mathrm{E}_{p}\right)$ per cycle.

The grain size had a definite effect upon the isothermal strain cycling of Inconel at $1500^{\circ} \mathrm{F}$, whereas at $1300^{\circ} \mathrm{F}$ little effect was noted. Specimen geometry and small variations in alloy composition did not noticeably affect the cycling properties at $1500^{\circ} \mathrm{F}$.

Extensive testing at 1300 to $1600^{\circ} \mathrm{F}$ shows that there is no major change in fracture behavior as a function cf temperature. This can be expected because Inconel is metallurgically stable and no grain growth occurs throughout this temperature span. The influence of stress-cycle frequency, however, was significant above $1300^{\circ} \mathrm{F}$, especially at lower frequencies, where creep or relaxation may become active. Figure 23 presents the data from a series of tests at 1300,1500 , and $1650^{\circ} \mathrm{F}$ at 2 and $30 \mathrm{~min}$ per cycle. At the high percentages of plastic strain per cycle at 1500 and $1650^{\circ} \mathrm{F}$ and $30 \mathrm{~min}$ per cycle, good correlation exists, but a significant deviation is clearly shown for the low strain values. At $1300^{\circ} \mathrm{F}$ the only test point that falls outside of the $2 \mathrm{~min}$ per cycle data occurs below 1 percent strain, and the deviation is minor. 
More-recent information regarding strain-cycle fatigue of type 304 stainless steel, Incoloy, Hastelloy $\mathrm{X}$, and Inconel has been determined by Reynolds. ${ }^{165}$ The results are summarized in Fig. 24.

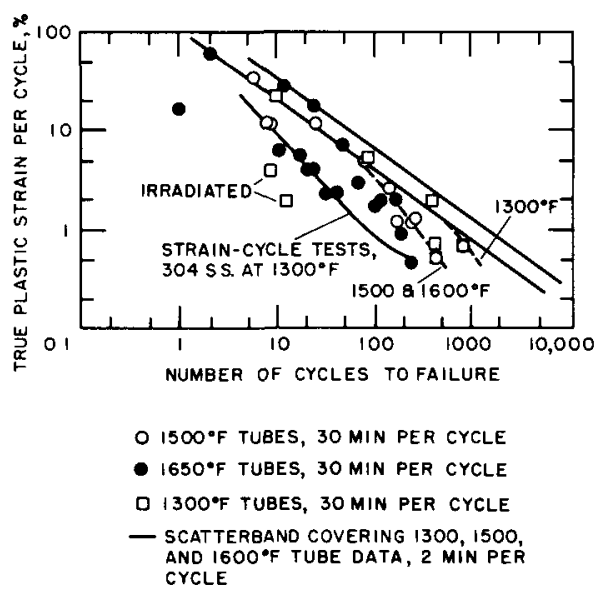

Fig 23--Elfect of temperature and frequency on strain-cycling properties of Inconel 128,165

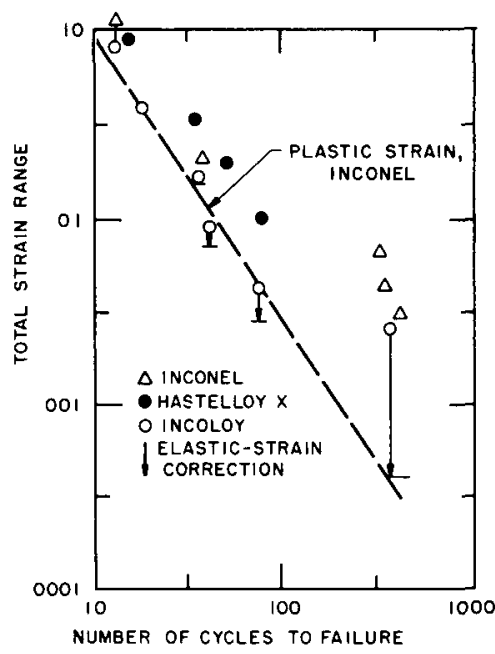

Fig. 24- Life of mickel allovs under slow-cycle fatigue strain at $1300^{\circ} \mathrm{F}$.

EFFECT OF RADIATION The mechanical and physical properties of a solid are exceedingly sensitive to its defect structure, i.e., the deviations from perfection in its crystal structure. Changes in mechanical and physical properties that occur in solids under energetic particulate irradiation are due almost entirely to changes in the defect structure resulting from atomic displacements. ${ }^{64}$ The effect of foreign atoms generated by nuclear transmutation is usually negligible in comparison with the effect of displaced atoms.

The group of alloys that has recelved the widest attention with respect to radiation effects is the 300 series of stainless steels, type 304 in particular. In general, it is observed that austenitic alloys increase in ultimate strength and significantly decrease in ductility at exposures of up to $10^{21}$ neutrons $/ \mathrm{cm}^{2}$ for neutron energies greater than 1 Mev. In most investigations, irradiation was at low temperatures; only data obtained at high temperatures are considered in this review.

Hinkle ${ }^{166}$ has carried out stress-rupture experiments on type 304 stainless-steel tubes under fast-neutron radiation. Data at $1300^{\circ} \mathrm{F}$ show that, for a given stress level, the life to rupture for this steel is not affected by irradiation up to about $4 \times 10^{20}$ neutrons $/ \mathrm{cm}^{2}$. On the other hand, the tangential strain at rupture decreases by a factor of about 4 owing to irradiation, in many cases to values less than 1 percent. In- 
conel has also been the subject of the tube-burst stress-rupture experiments reported by Hinkle and others. These tests showed the stressrupture life of Inconel at $1500^{\circ} \mathrm{F}$ to be reduced by a factor of 3 to 5 as a result of irradiation. This effect was attributed by Hinkle and associates to the presence of boron in the alloy since the type of grainboundary rupture observed could be explained on a basis of helium segregation at grain boundaries. These investigators proposed to test this hypothesis by irradiating alloys containing boron of varying $\mathrm{B}^{10}$ content.

Cupp $^{167}$ investigated the properties of Inconel after irradiation to $7.5 \times 10^{19}$ neutrons $/ \mathrm{cm}^{2}$ at 527 to $600^{\circ} \mathrm{F}$, as well as after postirradiation annealing to $1292^{\circ} \mathrm{F}$. The results show no reduction in elongation properties due to irradiation, but yield and ultımate strengths, as well as Rockwell $\left(R_{B}\right)$ hardness, increased about 20 to 30 percent over their as-received annealed values. Postirradiation heating reduced the mechanical properties essentially to their as-received values.

Recent studies by Robertshaw and Collins ${ }^{168}$ show that substantial reduction in the stress-rupture strength of Inconel-X at 1000 and $1200^{\circ} \mathrm{F}$ results from a neutron exposure of $2.8 \times 10^{18}$ neutrons $/ \mathrm{cm}^{2}$ or greater. In addition, the notch sensitivity increased, with signs of brittle behavior at fracture. Similar experiments show stress-rupture strength of Hastelloy $X$ to decrease when the alloy is irradiated at $1600^{\circ} \mathrm{F}$ to dosages between $4 \times 10^{19}$ and $7 \times 10^{19}$ neutrons $/ \mathrm{cm}^{2}$. For example, at $7 \times 10^{19}$ neutrons $/ \mathrm{cm}^{2}$ and $1600^{\circ} \mathrm{F}$, the $100-\mathrm{hr}$ stress-torupture strength for solution heat-treated Hastelloy $\mathrm{X}$ decreased from $9500 \mathrm{psi}$ to $6500 \mathrm{psi}$, a 30 percent reduction. At lower temperatures $\left(1200^{\circ} \mathrm{F}\right)$, only a 10 percent reduction in stress to rupture was noted.

Reynolds $^{148,165}$ has observed a reduction in the number of cycles to fallure at a given strain rate for type 304 stainless steel irradiated at 1200 to $1300^{\circ} \mathrm{F}$. A flux of $1.5 \times 10^{14}$ neutrons $/ \mathrm{cm}^{2} / \mathrm{sec}(>1 \mathrm{Mev})$ reduced the number of cycles to fallure to about two-thirds of the value for unirradiated samples.

Effects of neutron irradiation upon the mechanical properties of nickel-base alloys were determined by Pessl. ${ }^{144}$ Tensile specimens irradiated in a helium environment at $1200^{\circ} \mathrm{F}$ to integrated exposures of $2.53 \times 10^{20}$ and $1.21 \times 10^{21}$ neutrons $/ \mathrm{cm}^{2}$ suffered severe losses in elongation with increasing neutron exposure Results for Inconel and Hastelloy $X$ are shown in Figs. 25 and 26.

Irradiation test results such as those discussed in this section which may be applied to fuel-cladding design for nuclear superheat reactors are very fragmentary. It is apparent, however, that ductility in general decreases and that yield strength, tensile strength, and notch sensitivity increase. For the materials investigated, stress to rupture as well as the number of cycles to fallure during strain cycling decrease. 

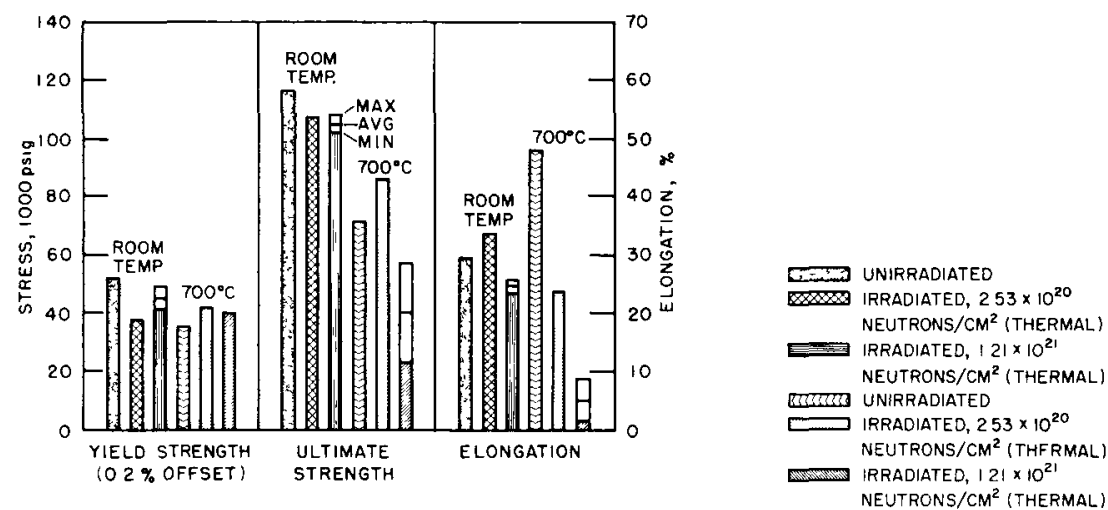

Fig. 25-Effects of neutron radiation in helium at $650^{\circ} \mathrm{C}$ maximum on tensile properties of Inconel.

Fig. 26-Effects of neutron radiation in helium at $650^{\circ} \mathrm{C}$ maximum on tensile properties of Hastelloy X.

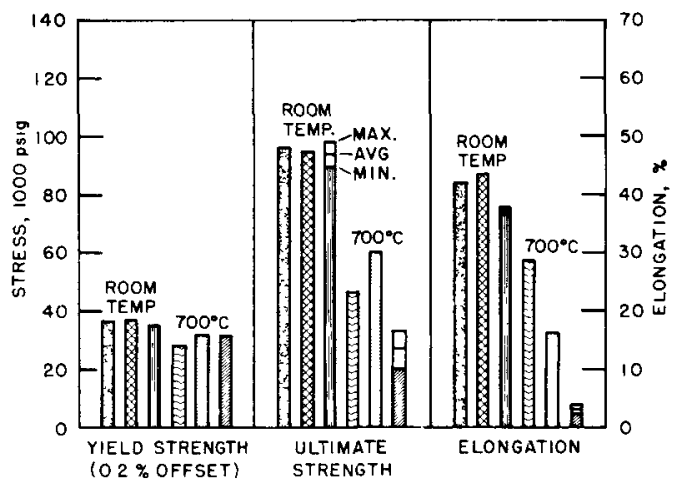

\section{Application to Reactors}

Nuclear superheat reactors under construction include three in the continental United States, one in Puerto Rico, and one in the Soviet Union. These plants are considered vital for the understanding of system characteristics as well as fuel and materials behavior. In addition to supplying operating and maintenance data, these plants will provide excellent testing facilities for advanced fuel concepts.

The status of the Beloyarsk (URAL) Reactor has been discussed in a report issued by Hanford. ${ }^{169}$ No definitive information has yet been published as to its construction status or operating history. The remaining four superheat reactor plants are (1) ESADA Vallecitos Experimental Superheat Reactor (VESR), ${ }^{170}$ a separate superheat concept; (2) BORAX -5; ${ }^{171}$ (3) Pathfinder; ${ }^{172}$ and (4) Boiling Nuclear Superheater (BONUS), ${ }^{173}$ all integral superheat reactor concepts. In the separate reactor design, steam is taken from a boiling-water reactor or an 
auxiliary fossil-fired boller and superheated in the superheat core. Some additional steam is produced in the water moderator surrounding the fuel elements. In the integral superheat concept, steam is directed through a core section designed for steam cooling. The superheat section may be in the center or at the periphery of the core. The exit steam is used to drive either a turbine for commercial power production (as in the BONUS and Pathfinder plants) or a turbine for experimental purposes (as in BORAX-5).

The maximum design steam-exit temperature for all plants ranges from $750^{\circ} \mathrm{F}$ initially to $1100^{\circ} \mathrm{F}$ at later dates. The heat-transfer coefficient at the metal-steam interface is such as to give an estimated drop of $200^{\circ} \mathrm{F}$. Surface temperatures of fuel cladding will thus range from 950 to $1300^{\circ} \mathrm{F}$. A drop of $50^{\circ} \mathrm{F}$ is estimated across the thickness of the cladding. Process tubes are used in the BONUS and the ESADA VESR to insulate the bolling-water moderator from the steam to minimize heat losses at the exit side. Initial fuel design for BORAX-5 calls for flat-plate fuel elements, and the Pathfinder fuel is essentially a plate fuel made into a tubular shape The BONUS fuel elements are cylindrical rods placed in series of four successive steam passes. The ESADA fuel is of annular two-pass design. The incoming steam enters from the outer diameter at the top and exits through the inner annulus at the top. Other detalls of fuel design for the superheat reactor plants are given in Table 26. Only details pertinent to the selection of materials for fuel are included.

\section{Conclusion}

The selection of materials for cladding nuclear superheat fuel must be preceded by considerable experimentation in environments closely simulating those expected in future power plants. Avallable technology from conventional superheat power plants is not directly applicable to nuclear superheat plants because of basic differences in environment. The presence of oxygen in nuclear-plant steam, structural consideratıons, and neutron-flux effects require a broad-basis development program. Such a program is now under way, with reactor experimental facilities being designed and constructed.

Problems connected with cladding are at present a limiting factor in the designing of fuel elements that have an economic advantage. These limitations have been defined by in-reactor experiments. Localized stress-corrosion attack in type 304 stainless steel takes place rapidly and has been the predominant mode of fuel-element fallure during inreactor experıments. Prelıminary out-of-reactor experıments indicated that high-nickel alloys are superior to 300-series stainless steels at 1100 to $1300^{\circ} \mathrm{F}$; recent irradiation experiments appear to confirm this superiority. 
Table 26 - SELEC IION OF FUEL MATERIALS F OR SUPERHEAT REACTORS UNDER CONSTRUCTION

\begin{tabular}{|c|c|c|c|c|}
\hline Reactor & Fuel geometry & Fissionable material & Fuel cladding & Cladding thickness, in \\
\hline $\begin{array}{l}\text { Beloyarsk* } \\
\text { (Ural) }\end{array}$ & 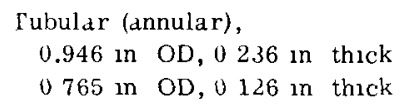 & $\begin{array}{l}\mathrm{U} \text { metal in } \mathrm{Mg} \\
\text { matrix }(12 \% \mathrm{Mg}) \text {, } \\
\text { later, } 9 \% \mathrm{Mo}-\mathrm{U}\end{array}$ & $\begin{array}{l}\text { AISI- } 321 \\
\quad\left(18 \mathrm{Cr}, 9 \mathrm{~N} 1,1 \Gamma_{1}\right)\end{array}$ & 0008 \\
\hline $\begin{array}{l}\text { BONUS } \\
\text { Puerto Rico }\end{array}$ & Rod, 0542 in OD & $\begin{array}{l}\mathrm{UO}_{2} \text { sintered } \\
\text { pellets }\end{array}$ & $\begin{array}{l}348 \mathrm{H} \text {, later changed } \\
\text { to Inconel }\end{array}$ & $\begin{array}{l}0018 \text { for } 348 \mathrm{H}, \\
\text { not known for } \\
\text { Inconel }\end{array}$ \\
\hline $\begin{array}{l}\text { BORAX-5 } \\
\text { Idaho Falls, } \\
\text { Idaho }\end{array}$ & $\begin{array}{l}\text { Plates, each } 0030 \mathrm{in} \text { thick, } \\
373 \mathrm{in} \text { wide, and } 24 \mathrm{in} \text { long }\end{array}$ & $\begin{array}{l}\mathrm{UO}_{2} \text { in } 304 \text { matrix } \\
\text { (cermet), } 0010 \text { in } \\
\text { thick }\end{array}$ & $304 \mathrm{~L}$ & 0010 \\
\hline $\begin{array}{l}\text { ESADA VESR } \\
\text { Pleasanton, } \\
\text { Callf }\end{array}$ & $\begin{array}{l}\text { Annular, } 128 \text { in } O D \text {, } \\
075 \text { in ID }\end{array}$ & Annular $\mathrm{UO}_{2}$ pellets & $\begin{array}{l}\text { Incoloy, } 16 \text { assemblies } \\
\text { Inconel, } 8 \text { assemblies } \\
310 \mathrm{VM} \dagger 4 \text { assemblies } \\
304 \mathrm{VM}, \dagger 3 \text { assemblies } \\
304 \text { com } \dagger 1 \text { assembly }\end{array}$ & $\begin{array}{l}0028 \text { (both sides } \\
\text { of annulus) }\end{array}$ \\
\hline $\begin{array}{l}\text { Pathfinder, } \\
\text { Sioux Falls, } \\
\text { S Dak }\end{array}$ & $\begin{array}{l}\text { Two tubular plates } \\
\text { (concentric), outer, } \\
0750 \text { in OD, } 0624 \text { in ID, } \\
\text { inner, } 0470 \text { in OD, } \\
0374 \text { in ID }\end{array}$ & $\begin{array}{l}\mathrm{UO}_{2} \text { in } 316 \text { matrix } \\
\text { (cermet), } 0016 \text { in } \\
\text { thick, } 15 \% \mathrm{UO}_{2}\end{array}$ & $316 \mathrm{~L}$ & $\begin{array}{l}0016 \text { (outer } \\
\text { and inner) }\end{array}$ \\
\hline
\end{tabular}

* Temperatures cladding surface, $1050^{\circ} \mathrm{F}$, fuel $1100^{\circ} \mathrm{F}$, steam outlet $950^{\circ} \mathrm{F}$

$\dagger \mathrm{VM}$, vacuum melted, com, commercial 


\section{ZIRCONIUM ALLOYS}

by Sherman Greenberg

Argonne National Laboratory

Zirconium became of interest to designers of power reactors because of its low thermal-neutron absorption cross section of 0.18 barn. Preliminary investigations also indicated that the necessary recovery and fabrication processes would not result in excessively high costs. In addition, corrosion behavior in high-temperature water $\left(315^{\circ} \mathrm{C}\right.$ and higher) appeared to be promising.

However, the corrosion behavior of the first readily avallable materıal, high-purity Van Arkel crystal bar, was extremely varıable. In addition, the cheaper Kroll-process zirconıum was generally unacceptable in high-temperature water. The desire for a dependably corrosionresistant and cheap material for the Naval Reactors Program led to an intensive development program in the United States. This program, described by Kass, ${ }^{174}$ led to the development of the zirconium-tin alloys known as the Zircaloys. The compositions of these alloys are given in Table 27. Only Zircaloy-2 and Zircaloy-4 are of practical importance.

Table 27-COMPOSITIONS OF ZIRCALOYS

\begin{tabular}{|c|c|c|c|c|}
\hline \multirow[b]{2}{*}{ Element } & \multirow{2}{*}{ Zircaloy-1 } & \multicolumn{2}{|c|}{ Content, wt \%* } & \multirow[b]{2}{*}{ Zircaloy-4 } \\
\hline & & Zircaloy-2 & Zircaloy-3 & \\
\hline Tin & 250 & 120 to 170 & 020 to 050 & 12 to 170 \\
\hline Iront & & 007 to 020 & 020 to 040 & 018 to 024 \\
\hline Chromiumt & & 005 to 015 & 500 ppm $\max$ & 007 to 013 \\
\hline Nickel† & & 003 to 008 & 500 ppm max & $0007 \max$ \\
\hline Nitrogen & & $80 \mathrm{ppm} \max$ & $80 \mathrm{ppm} \max$ & 80 ppm max \\
\hline
\end{tabular}

*Values are in weight percent unless otherwise noted

$\dagger$ The sum of iron, chromium, and nickel for Zircaloy- 2 must be in the range 0.18 to 0.38 wt. \%. For Zircaloy -4 the sum of iron plus chromium is $0.28 \mathrm{wt} . \%$ minimum.

The initial Zircaloy development was based on the fact that tin increased the tolerance for nitrogen and carbon to workable levels. Iron, chromium, and nickel also increased the corrosion resistance of the alloy (nickel particularly, in high-temperature steam), but quantities of these elements were kept relatıvely low for the sake of good fabricability.

Zircaloy-2 has been the subject of intensive study and has gained widespread use in Canada, France, Great Britain, and the United States. Subsequent development work has had the twin objectives of improving corrosion resistance and reducing hydrogen absorption. Zircaloy -4 is 
the latest result of this work and has found reactor application, as will be discussed in a subsequent section.

In addition to the complex Zircaloy type of alloys, zirconiumnıobium binary alloys and complex alloys containing tin. 1ron, nickel, and niobium (Ozhennites) have been developed in the Soviet Union. ${ }^{175}$ The successful application of these alloys has led to further study of the zirconıum-niobium system in the United States, in Canada, and in Great Britain, as well.

General discussions of the metallurgy of zirconium and its alloys are found in a review by Loevenstein and Gilbert, ${ }^{176}$ in books by Lustman and $\mathrm{Kerze}^{177}$ and Miller, ${ }^{178}$ and in Volume 1 of the Reaclor Handbook. ${ }^{179}$ Recent developments and directions for future research efforts are discussed in the Proceedings of the November 1962 USAEC Zirconium Symposium. Papers presented at this symposium are cited individually. Recent developments (up to about 1960) in the field of zirconium corrosion have been reviewed by Cox. ${ }^{180}$

\section{Corrosion}

True corrosion rates can be measured with the use of ethyl acetatebromine solution to dissolve the metal from the corrosion product, which is insoluble in this reagent. However, corrosion behavior is usually expressed in terms of sample weight gain. Under conditions of technological importance, the corrosion product is adherent, and there is a direct relation between weight gain and metal corroded under conditions of no pickup from the system. If the corrosion product is assumed to be zirconium dioxide $\left(\mathrm{ZrO}_{2}\right)$, weight gain, expressed as milligrams per square decimeter per day, may be converted to mils per year penetration by multiplying the weight-gain figure by about 0.6.

\section{HIGH-TEMPERATURE WATER}

Pure Zirconium The corrosion behavior of lodide zirconium has been described by Thomas ${ }^{181,182}$ and Kass. ${ }^{174}$ Material of reasonably good quality exhibits a temper film upon initial exposure. With continued exposure the film becomes dark and eventually is converted to a loosely adherent or spalling white product. During the initial period, corrosion proceeds at a decreasing rate. Meaningful measurements are difficult during the second period, known as breakaway or transition, because of the nature of the corrosion product. However, the material loses (rathe $\mathbf{r}$ than gains) weight, and corrosion apparently proceeds at a constant or an accelerating rate. In any event the material is no longer technically useful. The time to transition (or breakaway) is variable, depending upon material purity and temperature, and can vary from a few hours to longer than a year. 
During the initial period the kinetics of the corrosion process can be described by the empirical equation 181,182

$\mathrm{W}=\mathbf{k t} \mathrm{t}^{\mathrm{n}}$

where $W$ is in milligrams per square decimeter and $t$ is in days. The constants for this equation for various temperatures and pressures are as follows: ${ }^{177}$

$\begin{array}{cccc}\text { Temperature, }{ }^{\circ} \mathrm{C} & \text { Pressure, psi } & \mathrm{k} & \mathrm{n} \\ & & & \\ 260 & 2000 & 1.5 & 0.264 \\ 288 & 1048 & 2.4 & 0.270 \\ 316 & 2000 & 2.6 & 0.315 \\ 316 & 1553 & 3.5 & 0.301 \\ 360 & 2705 & 5.9 & 0.330\end{array}$

Both pretransition and posttransition corrosion producis have been identıfied as monoclinic zirconıum oxide, with some evidence for a small amount of the tetragonal form in the early stages. ${ }^{183}$

Many common elements, partıcularly nitrogen and carbon, are deleterious to the corrosion resistance of zirconium when present as impurities. Nitrogen is probably the most important because of the magnitude of its effect at low concentration and the ease with which it may be introduced in many stages of processing. Concentrations as low as 95 to $130 \mathrm{ppm}$ reduce the time to breakaway to as little as four days at $316^{\circ} \mathrm{C}$. Slightly higher concentrations result in complete disintegration. Carbon contents above about $400 \mathrm{ppm}$ result in accelerated localized attack, apparently at carbide sites. Mechanical treatments that disperse the carbide phase improve corrosion resistance of material of a given carbon content. ${ }^{181}$

Surface treatments that result in severely disturbed surface layers produce material with poor corrosion resistance. This behavior may be caused by nitrogen contamination of the surface. At the surface temperatures that can be reached in such treatments, zirconium will react with atmospheric nitrogen. Another probable cause is the entrapment of harmful contaminants in the fragmented surface. In addition, such a surface may not be conducive to the formation of an adherent corrosion product and may provide an additional source of lattice vacancies, thus accelerating diffusion in the oxide. It is necessary to remove about $2 \mathrm{mils}$ from the surface by pickling at 30 to $45^{\circ} \mathrm{C}$ to ensure maximum corrosion resistance. The pickling solution contains 50 percent distilled water, 45 percent concentrated nitric acid, and 5 percent of 48 percent hydrofluoric acid. Thorough rinsing is necessary to remove all fluoride. ${ }^{181}$ 
Common chemical impurities (in dilute solution), with the exception of fluoride, have no appreciable effect on the corrosion of zirconium in high-temperature water. Fluoride (as $20 \mathrm{ppm}$ sodium fluoride) causes catastrophic attack in crevices. Lithium hydroxide in concentrations above $5 \times 10^{-3} M$ and, to less extent, other alkaline additions have deleterious effects on the corrosion of the Zircaloys (as discussed in a subsequent section). ${ }^{184}$ Similar effects would probably be observed for pure zirconium. Dissolved hydrogen, oxygen, or nitrogen in concentrations up to several hundred cubic centimeters per kilogram do not appreciably affect the corrosion behavior. Much greater amounts of nitrogen result in accelerated attack. ${ }^{181}$ Heat treatment and mechanical work have little, if any, effect on the corrosion resistance of pure zirconium. ${ }^{181}$ The effect on material containing carbon has already been discussed.

Marker experiments indicate that corrosion proceeds by the inward diffusion of oxygen anions by means of an anion-vacancy mechanism. One explanation of breakaway correlates the change in corrosion rate with a critical oxide thickness. Nitrogen, because it can exist in the -3 valence state, increases the number of anion vacancies and hence the diffusion rate of oxygen anions and the corrosion rate. Thus the time to reach the critical oxide thickness, and hence to breakaway, is decreased. ${ }^{181}$

An alternate mechanısm, proposed by Schwartz, Vaughan, and Cocks, ${ }^{183}$ postulates that the tetragonal form of zirconium oxide is the protective film and that fallure is determined by the rate of change of the tetragonal to monoclinic forms of the oxide. The tetragonal form of the oxide has not been reported by other observers.

The preceding mechanisms do not account for all observations relating to the corrosion of zirconium and its alloys. For instance, the effect of hydrogen is not considered. Some of the present work, which is concerned with applications in high-temperature superheated steam, proceeds along different lines. These ideas are discussed in a subsequent section.

Complex Tin Alloys (Zircaloys) As indicated at the beginning of this section, Zircaloy-2 and Zircaloy-4 are the most important of this group. Zircaloy-1 has erratic corrosion behavior. Zircaloy-3 was the result of efforts to improve the corrosion resistance and fabricability of Zircaloy-2. This material has corrosion properties similar to Zircaloy-2. However, Zircaloy-3 is subject to localized corrosion (stringer corrosion) caused by segregation of grain-boundary precipltate. The stringer effect can be minimized by beta quenching. It was subsequently learned that Zircaloy-2 is also subject to stringer corrosion, though to much less a degree. In Zircaloy-2 the stringers are caused by gas volds formed during melting; their occurrence can be reduced to acceptable limits by vacuum melting. Since the water cor- 
rosion of Zircaloy-2 is equal to that of Zircaloy-3 and since acceptable material can be produced by simpler techniques, Zircaloy-3 has not become technically important. ${ }^{174}$

The impetus for the development of $\mathrm{Z}_{1}$ rcaloy-4 was the desire for a material less susceptible to hydrogen damage (embrittlement) than Zircaloy-2. It was known that nickel could increase the absorption of hydrogen. Hence the nickel was removed from Zircaloy-2. Zircaloy-4 is essentially nickel-free Zircaloy-2 with an increase in the iron content to compensate for the removal of the nickel. The development of Zircaloy -4 , its corrosion and irradiation behavior, its physical and mechanical properties, and its methods of fabrication have been described in detail by Kass ${ }^{174}$ and by Chirigos and associates. ${ }^{185}$

The qualitative description of the behavior of pure zirconium applies, in a general way, to Zircaloy-2 and Zircaloy-4. The notable exceptions are the relative lack of sensitivity to nitrogen and carbon and the maintenance of an adherent film after transition.

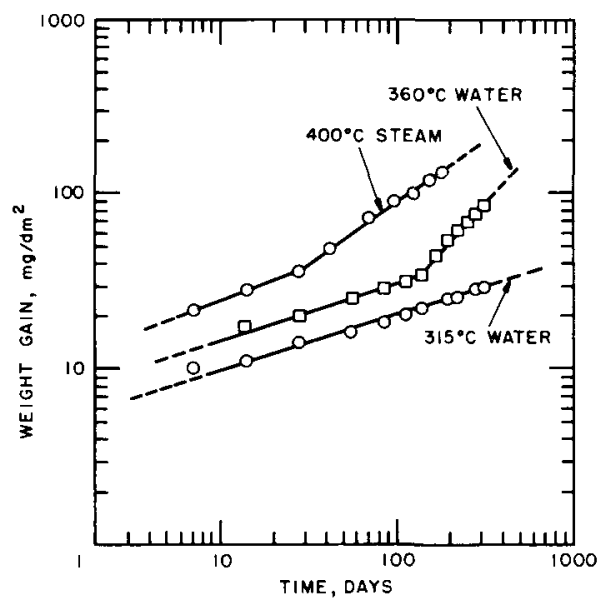

rig. 27-Corrosion of betaquenched Zircaloy-2. ${ }^{174}$

The corrosion behavior of Zircaloy-2 is illustrated in Figs. 27 and 28. The corrosion behavior in water is not very sensitive to heat treatment. ${ }^{174}$ In steam at $400^{\circ} \mathrm{C}$ and above, however, corrosion behavior is adversely affected by heat treatments in the alpha-plus-beta region or by slow cooling through this region. ${ }^{174,186}$ The sample that was alpha and beta annealed falled in steam at $454^{\circ} \mathrm{C}$ after about two days. Another sample that was alpha or alpha and beta annealed falled almost immed1ately in steam at $510^{\circ} \mathrm{C}$. It is believed that this effect is related to the size and distribution of a precipitated phase (or phases).

The corrosion behavior ${ }^{174,187}$ of Zircaloy-4 is similar to that of Zircaloy-2. There is some evidence ${ }^{174}$ that Zircaloy-2 is superior to Zircaloy-4 in steam at $510^{\circ} \mathrm{C}$. Significantly, nickel-free Zircaloy-2 is 
Fig. 28-Corrosion of Zircaloy-2 in hightemperature water and steam. ${ }^{174,185}$

C, alpha hot rolled

$\Delta$, alpha annealed

$\nabla$, oeta quenched

$[$, beta quenched
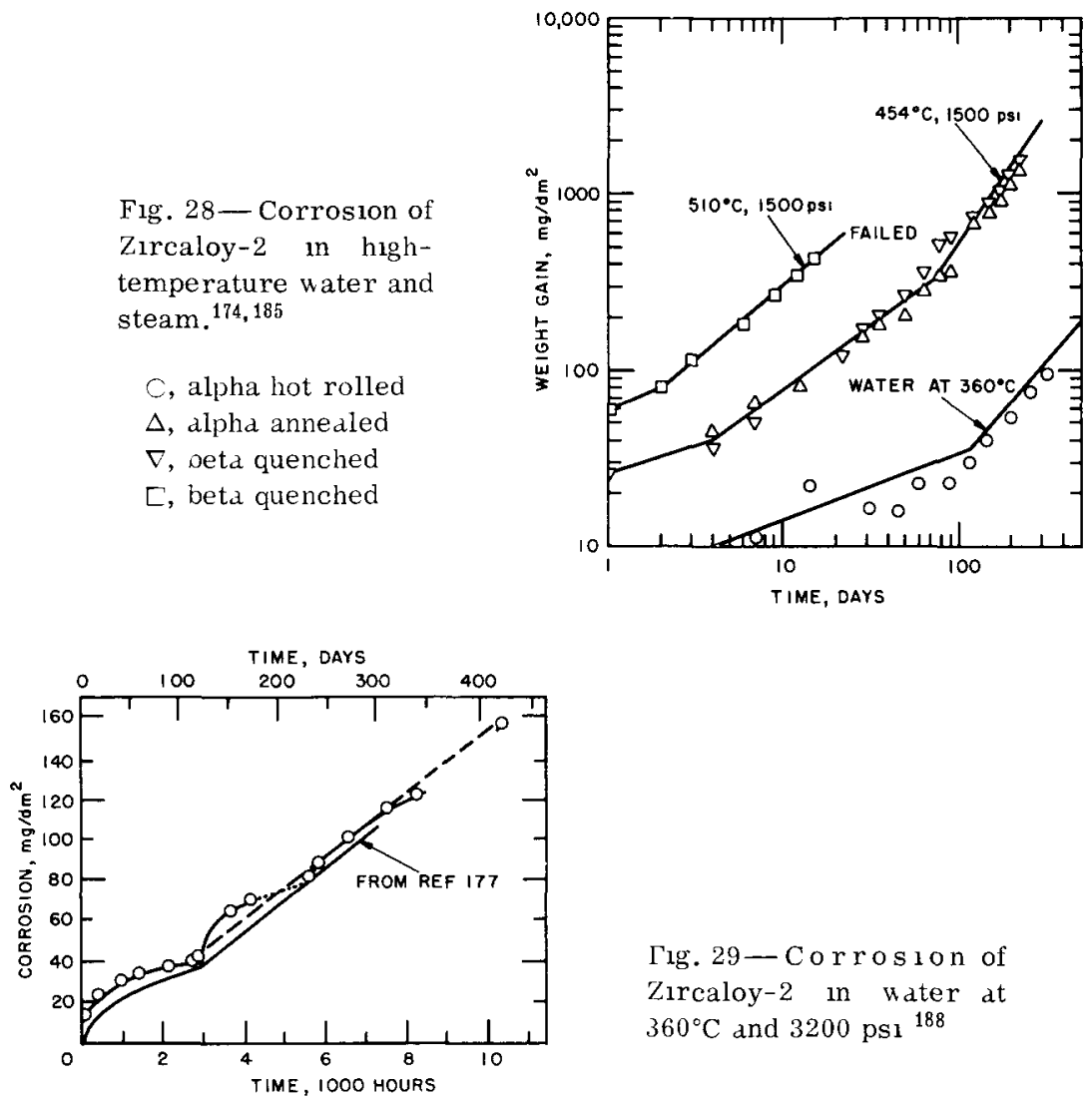

Гig. $29-$ Corrosion of Zircaloy-2 in water at $360^{\circ} \mathrm{C}$ and 3200 psi ${ }^{188}$

greatly inferior to these alloys in steam at high temperatures $\left(400^{\circ} \mathrm{C}\right.$ and higher).

There is evidence ${ }^{188}$ that the usual description of the corrosion kinetics of the Zircaloys, including linear behavior in the posttransition period, is an oversimplification. Careful measurements on individual samples indicate that the weight gain vs. time curves consist of at least two more or less repetitive curves similar to the initial "cubic" portion.

Because all cycles for all samples are not identical, the averaging of many samples results in the linear kinetics usually described. Moreover, because each grain corrodes with its own kinetics, the results for one sample represent the average behavior of many grains. The results for an individual sample thus eventually approach linearity. This behavior is illustrated in Fig. 29.

The sample, which is represented by the points on the graph, was autoclaved for $51 \mathrm{hr}$ at $400^{\circ} \mathrm{C}$ in $1500 \mathrm{psi}$ steam as pretreatment. The refreshment rate of the water was 8 liters/hr. 


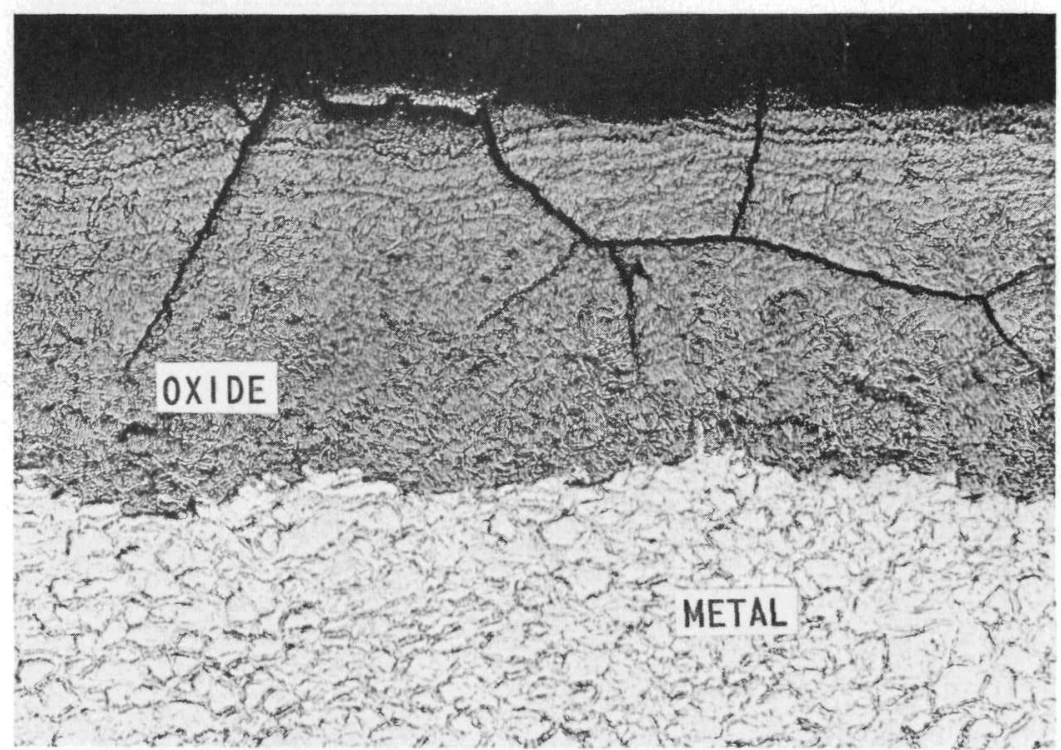

$\times 125$

Fig. 30-Oxide formed on low-nickel Zircaloy-2 after exposure for 129 days to steam at $400^{\circ} \mathrm{C}$ and 1500 psi..$^{188}$ (Polishing angle $20^{\circ}$ to oxide surface; cathodic etch; bright field.)

These data are consistent with, but do not exclusively define, a mechanism of corrosion based on mechanical stresses in the film which periodically cause the film to break away from the metal. The film grows until stresses are relieved by microcracks parallel to the corroding surface. These "parallel" cracks are connected to the surface by larger transverse cracks, effectively rendering the bulk of the oxide porous and therefore not protective. At the time the bulk of the oxide becomes porous, the effective diffusion path is shortened and the corrosion rate increases, initiating a new cycle. When the periods for the various grains making up a given sample become sufficiently out of phase, the corrosion kinetics of the individual sample becomes linear. An example of the crack network is shown in Fig. 30.

Figure 31 compares the hydrogen absorption of the two alloys, ${ }^{185}$ using different bases of comparison. It indicates that Zircaloy-4 absorbs only about 30 to 50 percent as much hydrogen as Zircaloy-2.

There is also evidence that absorption of hydrogen by Zircaloy-4 is less sensitive to water chemistry (including hydrogen overpressure) than is Zircaloy-2. An in-reactor test, ${ }^{174,185,187}$ designed to produce rapid failure by hydrogen embrittlement, confirmed the superiority of Zircaloy-4. 
Fig. 31- Absorption of hydrogen $^{175,185}$ by Zircaloy-2 and Zircaloy- 4 exposed to water at $360^{\circ} \mathrm{C}$.
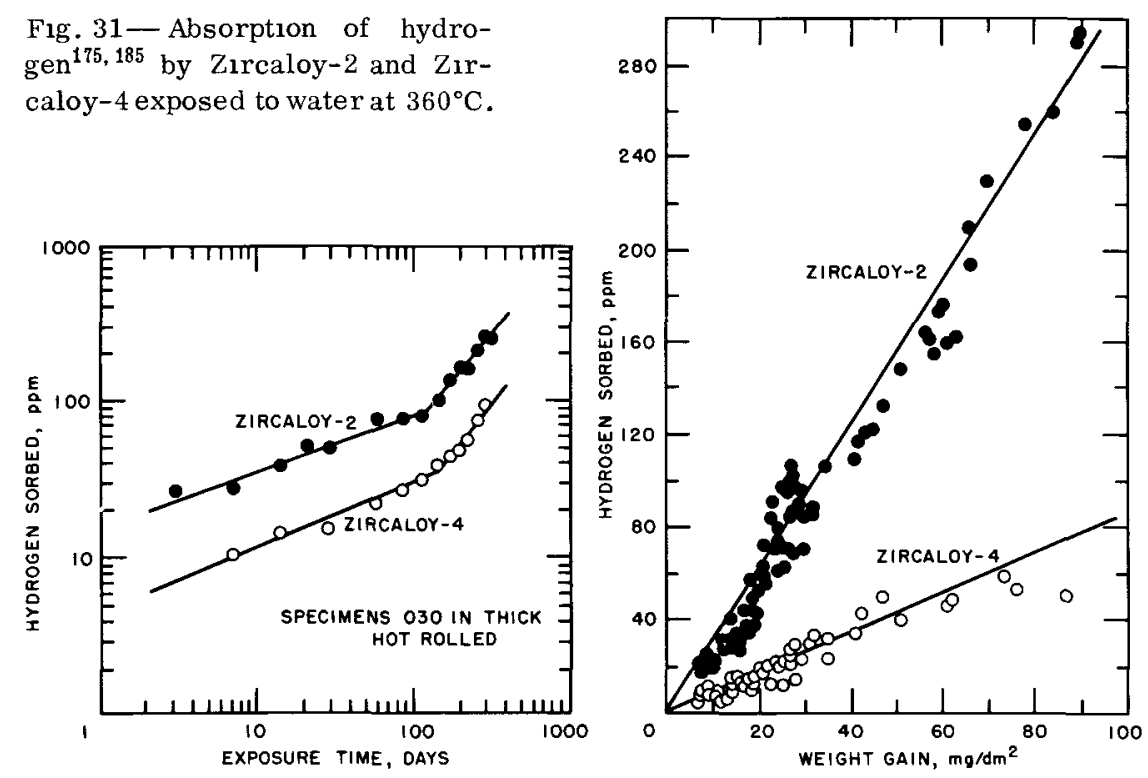

However, there is evidence $184,189,190$ that both Z1rcaloy-2 and Zircaloy-4 are severely attacked and embrittled in water containing lithium hydroxide at 308 and $360^{\circ} \mathrm{C}$. The attack on Zircaloy-4 appeared to be the more severe. There is a threshold concentration, but it varies with temperature and disposition of samples; e.g., crevices suffer severe attack in a lithium hydroxide solution of $\mathrm{pH} 11$. Solutions containing ammonium, sodium, or potassium hydroxide are considerably less corrosive.

Oxidizing additives decrease the hydrogen pickup of Zircaloy-2 exposed to water at $360^{\circ} \mathrm{C}$; reducing additives may increase it. $^{191}$

Additions of up to $0.5 \mathrm{wt} . \%$ antimony, arsenic, bismuth, or tellurium to Zircaloy-2 did not decrease the absorption of hydrogen. ${ }^{192}$ These additions were selected because of their ability to poison nickel hydrogenation catalysts.

Other aspects of hydrogen absorption are considered in subsequent sections devoted to zirconium-nioblum alloys, steam corrosion, effects of radiation, and mechanical properties. Shannon ${ }^{193}$ and Biefer et al. ${ }^{194}$ have reviewed and interpreted the literature of the field. However, the mechanism of hydrogen absorption (apparently different in water and steam) is not understood. Consequently there is considerable disagreement in the evaluation of the significant variables.

Based on satisfactory performance in many reactors and test loops and on the experience with corrosion-resistant unalloyed zirconium, ${ }^{177}$ it may be stated with reasonable assurance that water velocities up to 
at least $30 \mathrm{ft} / \mathrm{sec}$ have no effect on the corrosion behavior of the Zircaloys or other corrosion-resistant zirconıum alloys.

Fretting corrosion may be defined as the damage occurring to metal surfaces in rubbing contact in a corrosive environment. Great damage may result, even when the amplitude of motion is very small. Apparently the protective film is continuously removed by mechanical means, resulting in extremely high rates of corrosion.

Zircaloys are potentially susceptible to catastroph1c damage due to fretting or impact corrosion under certain conditions. However, there have apparently been no serious reactor incidents resulting from this phenomenon. The results of exposure to conditions of fretting corrosion are very erratic, depending on such factors as vibration frequency, amplitude, and impact loading, which are difficult to control. The extent of damage is also very sensitive to temperature. ${ }^{195}$

For example, in an investigation to determine the consequences of a loose spacer wire on a process tube [Z1rcaloy- 2 components of the Plutonium Recycle Test Reactor (PRTR)], fretted areas 5 mils deep resulted after 18 days in lithiated water ( $\mathrm{pH}$ of 10$)$ at $300^{\circ} \mathrm{C}$ and 67 $\mathrm{ft} / \mathrm{sec}$ velocity. There was a concentration of hydride in the fretted area. Under conditions that were identical except that the temperature was reduced to $260^{\circ} \mathrm{C}$, the only evidence of fretting after 208 days was a small "polished" area. Rotating-rod and disk tests conducted in water at 100 and $300^{\circ} \mathrm{C}$ indicated similar effects of temperature.

Heat transfer through the metal and corrosion film results in increased corrosion rates for both unalloyed zirconium ${ }^{177}$ and Zircaloy2. ${ }^{196}$ However, there is no evidence that this increase is the result of anything but the increased temperature of the metal surface.

Zirconium-Niobium Alloys Ambortsumyan et al. ${ }^{175,197}$ and Ivanov and Grigorovich ${ }^{198}$ have described the development, corrosion and other properties, and application of these alloys. Complex alloys, containing small percentages of other elements in addition to niobium (Ozhennite), as well as zirconium-niobium binary alloys, are included. The behavior of these alloys in water and steam is shown in Figs. 32 and 33.

The water was at saturation pressure and the steam at $300 \mathrm{~atm}$ in the tests reported in both ingures. Figure 33 shows that at 350 and $450^{\circ} \mathrm{C}$ corrosion varies to a negligible extent with small changes in composition. At $450^{\circ} \mathrm{C}$ the lower points are chiefly for the Ozhennite0.5 alloy $(0.2$ wt. $\% \mathrm{Sn}, 0.1$ wt. $\% \mathrm{Fe}, 0.1$ wt. $\% \mathrm{Nb}$, and $0.1 \mathrm{wt} . \% \mathrm{N1})$, and the upper points are for the Ozhennite-1 alloy, in which the additions total 1 wt.\%.

The favorable experience of the Russians with the zirconiumnobium alloys has resulted in further development work on this system. ${ }^{199-203}$ It was hoped that these alloys would have adequate corrosion resistance and significantly reduced, or greater tolerance for, 


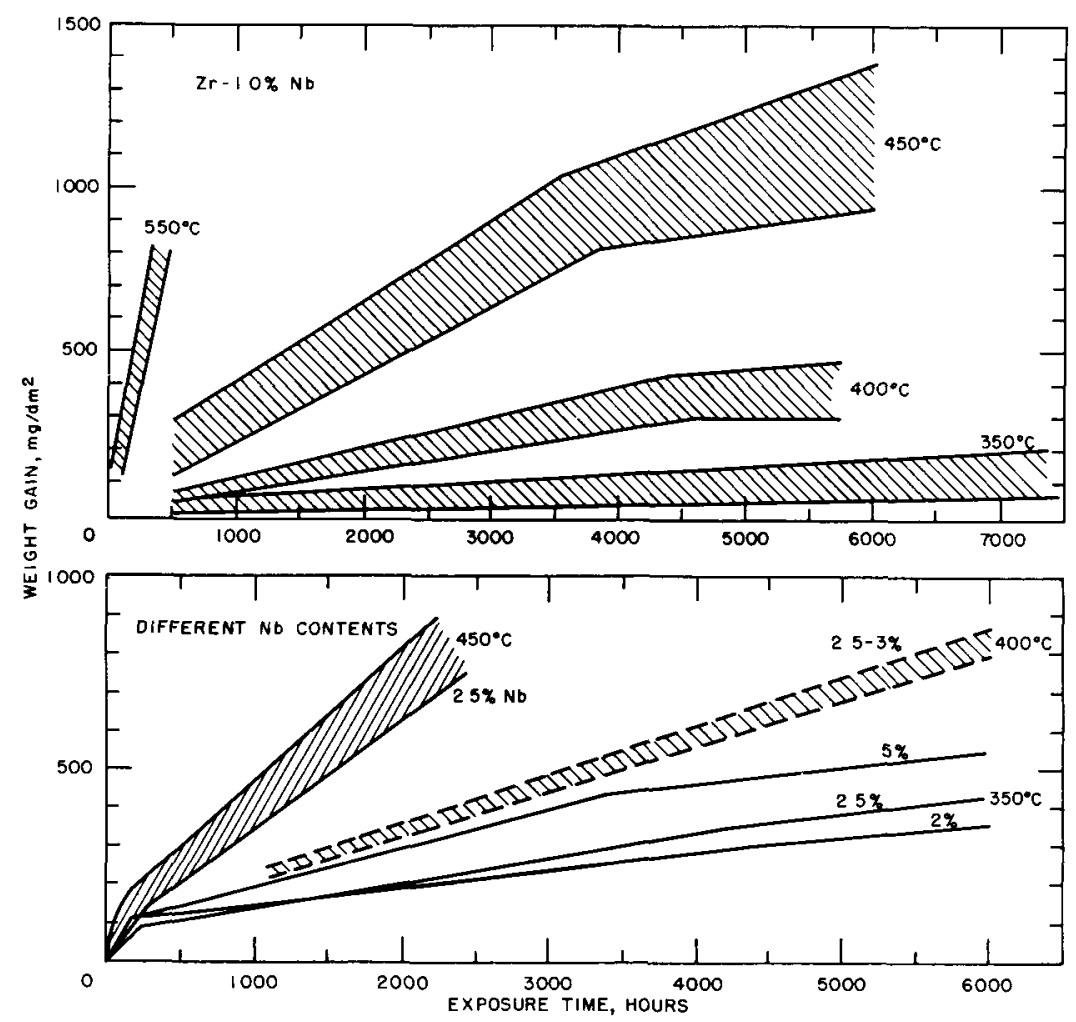

Fig. 32-Corrosion of zirconium-niobium alloys in water and superheated steam. ${ }^{175}$

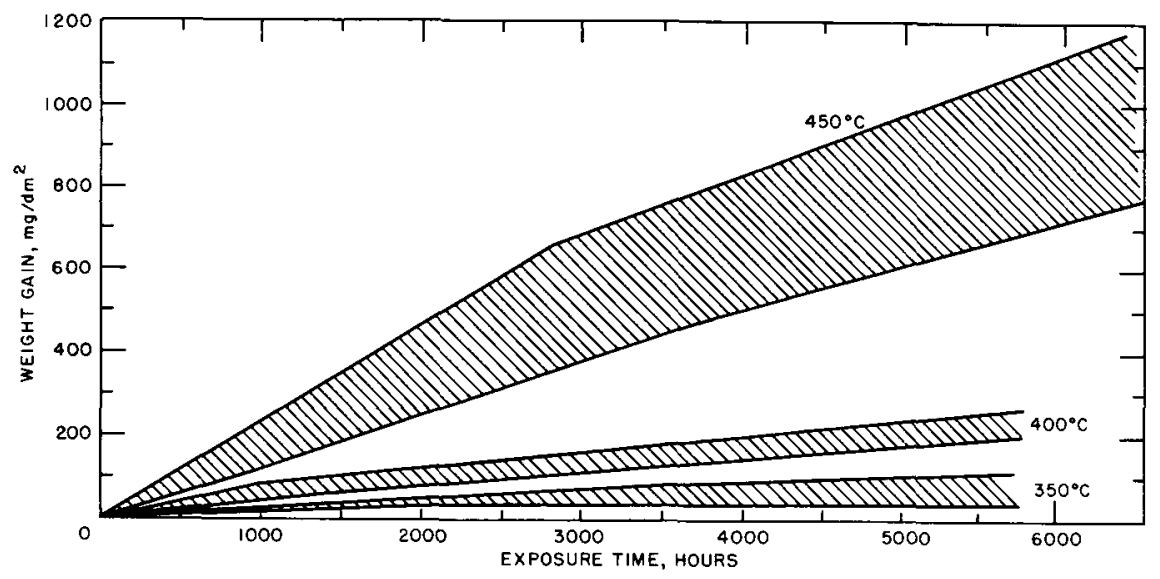

Fig. 33-Corrosion of Ozhennite alloys in water and superheated steam. ${ }^{175}$ 
hydrogen absorption. ${ }^{199,203,204}$ Improved high-temperature mechanical properties, as compared with Zircaloy-2, could reasonably be expected.

The niobium alloys absorb a lower percentage of the total corrosionproduct hydrogen than Zircaloy-2 and, in addition, are much less sensitive to hydrogen damage. ${ }^{201}$ This lower sensitivity of the niobium alloys is apparently due to the high solubility of hydrogen in the alpha-treated alloys. Corrosion rates under favorable conditions are probably acceptable (about 2 to 3 times the rate of $\left.\mathrm{z}_{1 \mathrm{rcaloy}-2}\right)^{199,200}$ but are more sensitive than Zircaloy-2 to heat treatment, nitrogen contamination, heat flux, and other factors present in a reactor environment. ${ }^{200,205}$ The addition of tin adversely affects both corrosion and hydriding rates, particularly at higher temperatures. ${ }^{199}$ The mechanical properties of the niobium alloys are superior to those of Zircaloy. ${ }^{175,179}$

Effect of Radiation There is apparently no effect ${ }^{196}$ of radiation on corrosion of pure zirconium in water at $280^{\circ} \mathrm{C}$ at an integrated thermai flux of $10^{18}$ neutrons $/ \mathrm{cm}^{2}$. Galonian (as reported by Coriou) ${ }^{196}$ indicates little effect on the pretransition corrosion of Zircaloy-2 in neutral water at $316^{\circ} \mathrm{C}$ up to an integrated flux of $10^{21}$ neutrons $/ \mathrm{cm}^{2}$. Asher and $\mathrm{Cox}^{206}$ report that there is a negligible effect of gamma radiation on the corrosion of Zircaloy- 2 below $400^{\circ} \mathrm{C}$.

High fast fluxes ( $>1 \mathrm{Mev}$ ), however, do have an appreciable effect on the corrosion behavior. Exposure to fluxes ${ }^{20 ?}$ of $1.7 \times 10^{13}$ to $1.6 \times$ $10^{14}$ neutrons $/ \mathrm{cm}^{2} / \mathrm{sec}$ (total integrated exposure of $3.5 \times 10^{19}$ to $4.5 \times$ $10^{20}$ neutrons $/ \mathrm{cm}^{2}$ ) cause an increase of an order of magnitude in the corrosion rate of Zircaloy -2 in pH 10 water at $280^{\circ} \mathrm{C}$. The percentage of corrosion-product hydrogen absorbed is not appreciably affected.

STEAM At relatively low temperatures, $1 . e .$, up to about $400^{\circ} \mathrm{C}$, the corrosion behavior of zirconium and its alloys in steam is not very different from that in water. In fact, short exposures in steam can, with some risk, be used to predict the behavior in water for rough determinations of material quality. The behaviors of the alloys previously discussed are summarized in Figs. 27, 28, 32, and 33. The behavior of nominally pure zirconium is very erratic, depending on purity. In this section, however, we are mainly concerned with efforts to develop alloys suitable for use at about 480 to $650^{\circ} \mathrm{C}$.

Pemsler ${ }^{208}$ showed that tin is a harmful alloying addition at 482 and $540^{\circ} \mathrm{C}$; 1.e., the Zircaloys showed generally poor performance. Small additions of nickel, iron, and chromium were of great benefit. Morerecent work of Klepfer ${ }^{200}$ has shown that proper heat treatment, 1.e., low-temperature alpha annealing, greatly improves the performance of Zircaloy-2. This alloy is still, however, not suitable for long-time use at the temperatures of interest.

Greenberg and Youngdahl ${ }^{209,210}$ also found that nickel, copper, and Iron were beneficial. For example, a laboratory-produced alloy of $\mathrm{Zr}-$ 
3 wt. $\% \mathrm{Ni}-0.5 \mathrm{wt} . \% \mathrm{Fe}$ had a weight-gain rate of 1 to $2 \mathrm{mg} / \mathrm{dm}^{2} /$ day $\mathrm{in}$ steam at $540^{\circ} \mathrm{C}$ and $600 \mathrm{psi}$. However, such low rates have not been achieved in commercially produced alloys of the same nominal compositions. The behaviors of some commercial alloys at 540 and $650^{\circ} \mathrm{C}$ are shown in Figs. 34 and 35. Wanklyn and associates ${ }^{211}$ have produced copper-containing alloys of comparable corrosion behavior.

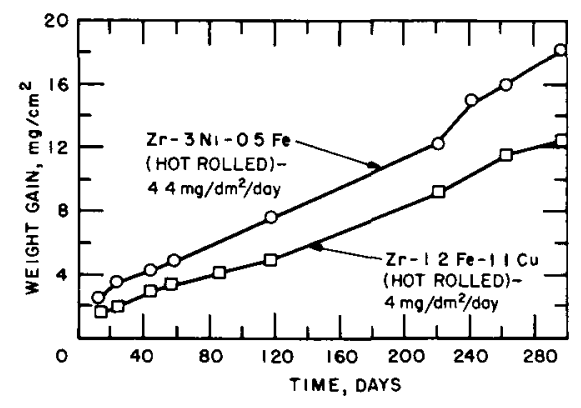

Fig. 34-Corrosion of zirconium alloys in steam at $540^{\circ} \mathrm{C}$ and $600 \mathrm{psig}^{210}$

Fig. $35-$ Corrosion of zirconium alloys in superheated steam at $650^{\circ} \mathrm{C}$ and 600 psi. $^{210}$

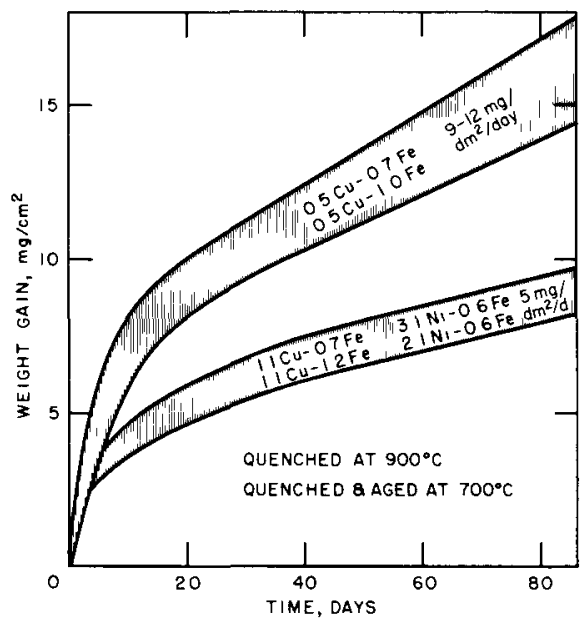

Cox and associates, ${ }^{212}$ Dalgaard, ${ }^{199}$ and Klepfer ${ }^{200,201}$ have investigated niobium-containing alloys for use in high-temperature steam. Many alloys superior to Zircaloy- 2 have been developed, but, in general, the niobium-containing alloys are inferior to those containing nickel and iron or iron and copper. Rösler ${ }^{213}$ has studied the effect of ternary additions to zirconium-niobium binary alloys between 400 and $600^{\circ} \mathrm{C}$ at 1 atm. Small additions of copper and iron and trace amounts of calcium appear to be beneficial.

Britton and Wanklyn ${ }^{214}$ have shown that boric acid greatly reduces the corrosion rate of pure zirconium in steam at $500^{\circ} \mathrm{C}$ and $1000 \mathrm{psi}$. 
A smaller reduction was found for Zircaloy-2, but there was no appreciable reduction for $\mathrm{Zr}-0.5 \mathrm{wt} . \% \mathrm{Cu}-0.5 \mathrm{wt} . \% \mathrm{~W}$, a material that is more corrosion resistant. Although these results are of no technological importance, they may have important theoretical significance and thus are discussed in the following section, "New Theoretical Approaches to Alloy Development."

None of the programs discussed has produced alloys with acceptable corrosion rates above $540^{\circ} \mathrm{C}$. However, it is probable that the limitation on the usefulness of these alloys will not be corrosion rate but, rather, the impairment of physical properties as the result of exposure to the corrosive environment. In particular, absorption of corrosion-product hydrogen and dissolution of oxygen (from the oxide) can lead to severe embrittlement. The problem of hydrogen absorption has been considered an integral part of alloy development and is discussed in many of the references previously cited.

Wanklyn and associates ${ }^{215}$ noted that hydrogen absorption (expressed as percentage of corrosion product absorbed) can increase markedly (up to quantitative absorption) with exposure time. They also noted that the $\mathrm{Zr}-0.5 \mathrm{wt} . \% \mathrm{Cu}-0.5 \mathrm{wt} \% \mathrm{~W}$ has a particularly low uptake. The increase in hydrogen absorption with corrosion has also been noted by Cox. ${ }^{216}$ This behavior, in apparent contrast to that in liquid water, must be considered when results of laboratory corrosion test are used to predict in-reactor behavior.

Rösler ${ }^{213}$ and Weinsteın ${ }^{217}$ have studied the effect of ternary additions on hydrogen absorption as well as on corrosion. The work of Rösler showed that the additives previously mentioned, copper, iron, and calcium, are also useful in reducing hydrogen absorption. Weinstein has observed that small additions of tellurium, germanium, chromium, or iron reduce the hydrogen absorption of binary alloys based on antimony, niobium, or tin.

The presence of oxygen in the corroding medium or as a surface film can materially affect hydrogen absorption. Krenz ${ }^{218}$ has reported that the addition of $1.5 \mathrm{vol} \%$ oxygen to steam reduces the corrosion rate and hydrogen pickup. Gulbransen and Andrew ${ }^{219,220}$ and Marshall and Louthan ${ }^{221}$ have shown that thin, intact, preformed $\mathrm{ZrO}_{2}$ films offer substantial resistance to hydrogen penetration, as determined in gaseous hydriding experiments. However, the effect can be maintained only under oxidizing conditions that enable the film to be continually renewed. ${ }^{222-224}$

Shannon $^{224}$ has suggested a correlation between the electrical properties of the film and its permeability to hydrogen. It would be expected that, in an environment not sufficiently oxidizing, the number of defects (anion vacancies) would be increased, resulting in increased conductivity. There is, in fact, a difference of a factor of $10^{6}$ in the conductivities of the film measured in oxidizing and nonoxidizing 
atmospheres-greater conductivity is observed in the nonoxidizing atmosphere. The fact that increased permeability to hydrogen and increased electrical conductivity occur concurrently indicates a possible relation between the rate of hydrogen diffusion and the concentration of anion vacancies.

The effect of hydrogen absorption on mechanical properties depends on several factors in addition to the quantity absorbed. They are discussed under "Mechanical and Physical Properties." This problem would, or course, disappear if alloys with extremely low corrosion rates were developed.

It has been suggested by Cox and by Douglass that $600^{\circ} \mathrm{C}$ represents the useful upper ilmit for employment of zirconum in oxidizing atmospheres. ${ }^{225}$ Above about $600^{\circ} \mathrm{C}$ diffusion of oxygen in zirconium is so rapid that oxide would be dissolved as fast as it was formed, leading to early embrittlement as well as extremely high corrosion rates because there would be no protective film. However, before it can be stated that oxygen diffusion in fact sets a real limit on the useful upper temperature for zirconium alloys, more must be known concerning the factors, including alloying, which could influence the transport of oxygen from oxide to metal and the diffusion rates through the metal. Preliminary data of Greenberg and Youngdahl ${ }^{210}$ indicate no increase in hardness after about 88 days' exposure at $650^{\circ} \mathrm{C}$.

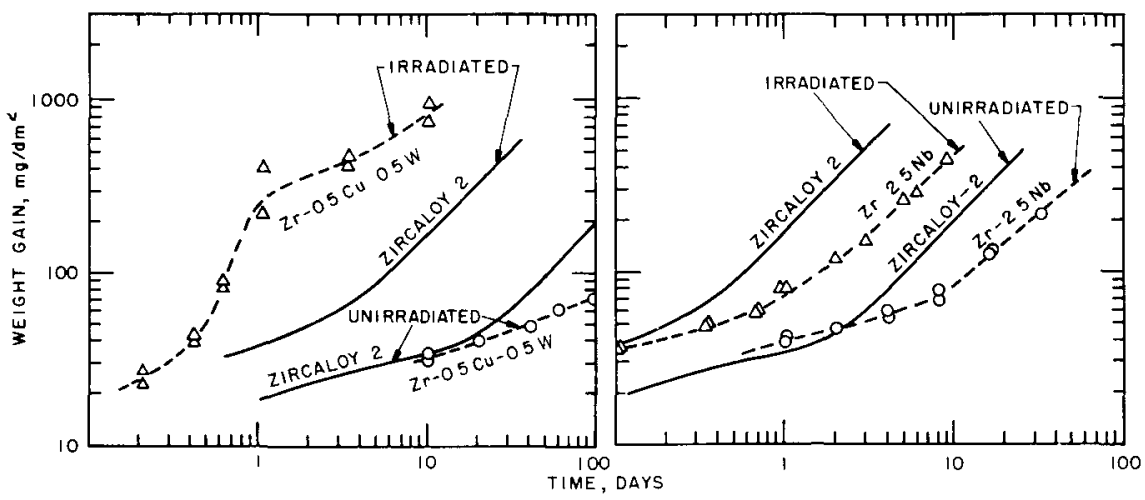

Fig. $36-$ Effect of radiation on corrosion of $\angle 1$ rconium alloys in steam at $500^{\circ} \mathrm{C}$.

The effect of radiation on corrosion of zirconium alloys in steam has been investigated. The time to transition is decreased, and the postransition rate is increased ${ }^{206}$ for $\mathrm{Z}$ ircaloy $-2, \mathrm{Zr}-2.5 \mathrm{wt} . \% \mathrm{Nb}$, and $\mathrm{Zr}-0.5 \mathrm{wt} .{ }^{\circ} \mathrm{C} \mathrm{Cu}-0.5 \mathrm{wt} . \% \mathrm{~W}$ in steam at fast-flux levels greater than $10^{11}$ neutrons $/ \mathrm{cm}^{2} / \mathrm{sec}$. The fast-neutron effect is dependent upon temperature. For the preceding alloys, in the range 400 to $600^{\circ} \mathrm{C}$, there is a maximum at 450 to $500^{\circ} \mathrm{C}$. The magnitude of the effect ${ }^{206}$ is shown in Fig. 36. The percentage of corrosion-product hydrogen absorbed is 
not appreciably affected, but the absolute rate of hydrogen absorption is greater in proportion to the increased corrosion rate. ${ }^{190,206}$

NEW THEORETICAL APPROACHES TO ALLOY DEVELOPMENT The fallure to produce zirconium alloys that are satisfactory at the high temperatures of interest to present reactor technology may be taken as an indication of the failure of current theories - of course, the problem may be insoluble. With this idea in mind, R. D. Misch has contributed the following discussion, which suggests new approaches to the problem of alloy development.

The need for new approaches to an understanding of the mechanism has been brought home forcefully by the unexpected difficulties in analyzing the many variables that affect oxidation. The analysis of observed effects has generally been based on the Wagner-Hauffe theory or on oxide stabilization, and each of these viewpoints will be briefly considered.

The Wagner-Hauffe theory is based on the assumption of lattice diffusion. The intrinsic point defects of the reaction-product layer are assumed to be modified by the presence of foreign elements whose ions require a readjustment of the defect equilibrium in order to maintain electrical neutrality.

The difficulty with this approach is that ions such as $\mathrm{Fe}^{2+}$ and $\mathrm{Ni}^{2+}$ are required to be in interstitial positions if the formation of anion vacancies is to be repressed. However, the radil of these ions are too large to fulfill this condition. Also, the effect of tin in compensating for nitrogen and retarding breakaway requires association of tin and nitrogen in the zirconium dioxide lattıce. There is no independent evidence for such a phenomenon.

According to Kofstad and Ruzicka, ${ }^{226}$ the prevalling picture of oxygen anions migrating via anion vacancies may require modification. From their data on conductivity in zirconium dioxide as a function of oxygen pressure, they concluded that both interstitial oxygen and anion vacancies participate in ion migration and that the basic step in ion transport may be a coupled interchange. It may or may not be possible to reconcile the Wagner-Hauffe theory with known data by taking account of this mechanism.

The possibility of oxide stabilization or changes in the zirconium dioxide lattice during oxıde growth has been suggested to account for the effect of alloying elements in retarding or promoting breakaway. The obvious procedure of adding elements that stabilize cubic zirconium dioxide has demonstrated only that such additıves are generally deleterious. Calcium, which serves both to stabilize cubic zirconium dioxide and to essentially eliminate electronic conductivaty, would seem to be an ideal choice from the standpoint of eliminating structural changes (which could cause cracking) as well as eliminating electronic conductivity (which is necessary to the scaling reaction). However, zir- 
conium binary alloys with calcium or yttrium, which has a similar effect, have very poor oxidation resistance.

Nioblum has some tendency to stabilize cubic zirconium dioxide, and this stabilization may be a factor in the improved corrosion resistance of zırconıum-nıobıum alloys. Rösler ${ }^{213}$ has reported that small amounts of calcium confer additional oxidation resistance, and a synergistic effect of the type suggested by Misch and Van Drunen ${ }^{227}$ may be operative. In general, the existing evidence does not support any approach to alloy improvement based solely on the stabilization of cubic zirconium dioxide.

Recent experimental evidence of Wanklyn et al. ${ }^{215}$ and of $\operatorname{Cox}^{228}$ supports a picture of intercrystalline diffusion in the posttransition period for Zircaloy-2. This evidence is based on the response of an oxidizing specimen to changes in pressure. The results of Britton and Wanklyn ${ }^{214}$ on the effect of boric oxide are most easily explained on the basis of an intercrystalline network that the boric oxide is able to fill or to bridge over.

It is concervable that much of the difficulty in explaining the oxidation behavior of zirconium or zirconium alloys is associated with certain characteristics of the zirconium dioxide layer which are far from the idealized models usually postulated. The oxide layer may consist of a fine mosaic of interlocked crystallites, with ionic migration taking place in grain boundaries of molecular dimensions. The effect of increasing steam pressure may be to force molecules of water into this network, with consequent disruption and breakaway. Deleterious elements such as nitrogen and aluminum may promote this process, whereas other elements retard it.

If the preceding viewpoint is correct, many of the complexities of zirconium oxidation are related to the surface chemistry of zirconium dioxide and to the effect of additives on surface properties. As an example, fluoride ion might act to break chemical bonds between neighboring crystallites of zirconium dioxide by forming new bonds with zirconium. The separation of the crystallites would give rise to white oxide. Such elements as boron may act as bonding agents by forming oxyboron linkages. Elements of partıcular interest in alloy development, such as iron and nickel, may act by modifying the growth characteristics of zirconium dioxide crystallites in such a way as to form an interlocked network. This network would have sufficient strength to resist disruption under the influence of compressive stresses and water and hydrogen penetration.

This line of speculation indicates the importance of examining the oxide layer in much more detall than heretofore as well as the importance of measuring its tensile strength. Except for the work of Bradhurst and associates, ${ }^{229}$ these approaches are not being followed at present. 
The lack of understanding of basic effects is becoming more troublesome as the need for alloys serviceable at higher temperatures increases. It is hoped that further acknowledgment of the fallure of existing theories may help to focus attention on additional important factors and lead to a better understanding of the mechanisms that determine zirconium oxidation.

\section{Mechanical and Physical Properties}

Detaled compilations of mechanical properties are avallable in many of the references previously cited, ${ }^{175-179,184}$ most of which are readily available. In addition, Meham and Wiesınger ${ }^{230}$ have presented a very detalled report of the properties of Zircaloy-2. At this point it is sufficient to state that the as-fabricated properties of the commercial zirconium alloys do not limit their employment in water-cooled reactors.

Embrittlement by absorbed hydrogen, resulting from exposure to the reactor environment, is potentially a serious problem and warrants discussion here. Factors influencing hydrogen absorption have been discussed in previous sections. In this section the consequence of hydrogen absorption will be evaluated.

Markowitz ${ }^{231,232}$ has shown that hydrogen diffuses in Zircaloy-2 under a thermal gradient, concentrating in the region of low temperature. In reactor applications involving relatively thick cladding, it wouid be expected that the bulk of the hydrogen would be close to the surface.

Marshall and Louthan $221,233,234$ have shown that the orientation of the hydride determines the effect of absorbed hydrogen on the mechanical properties of Zircaloy. In addition, they have shown that the state of the Zircaloy with regard to stress, prior deformation, and crystallographic orientation (texture) greatly influences the type and degree of hydride orientation.

Hydride platelets tend to be aligned parallel to the direction of metal flow during prior deformation (e.g., in fabrication processes). Applied stresses during hydriding tend to cause the platelets to be oriented perpendicular to tensile stresses and parallel to compressive stresses.

However, the effect of applied stress during hydriding is greatly influenced by texture, which is defined by the texture coefficient of the $(0001)$ poles. If the texture coefficient in the stress direction is greater than 3 , the material is very susceptible to stress orientation. For random orientation (coefficient of approximately 1), there is no stress or entation below 15,000 psi. For a coefficient near zero (in the stress direction), there is no stress orientation below $22,000 \mathrm{ps} 1$, the upper limit of testing. The effect of applied stress on hydride orientation is also influenced by the prior deformation, as shown in Fig. 37.

Fawrication processes thus greatly influence the orientation of hydride. For example, extruded and drawn tubing is very susceptıble to 
radial orientation of hydride. This condition could be somewhat alleviated by a tube-expanding operation. Tubing fabricated by extrusion, drawing, and roll forming would be much less susceptible to radial hydriding.

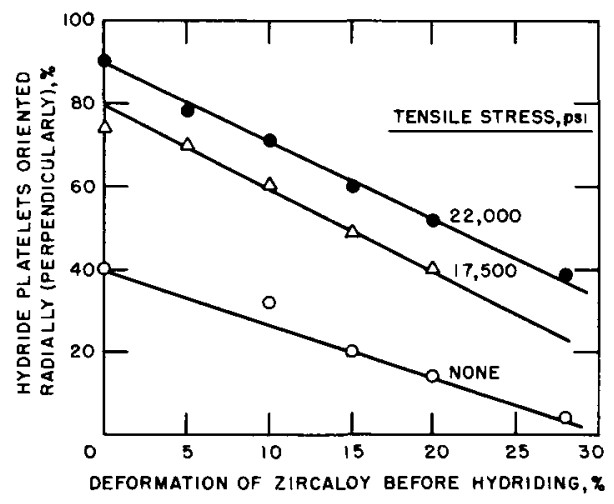

Fig. 37-Effect of deformation on stress orientation of zirconium hydride platelets. ${ }^{221}$

Hydride aligned nearly parallel to the deforming tensile stress has little effect on room-temperature mechanical properties. However, hydride aligned nearly perpendicular to the tensile stress markedly reduces strength and ductility. Above 50 ppm hydrogen as "perpendicular" hydride, there is no macroscopic ductility.

Klepfer ${ }^{201}$ has found that zirconium-nioblum binary alloys are less susceptible to hydrogen embrittlement, as measured by impact tests, than the Zircaloys, presumably because of the greater solubility of hydrogen in the niobium-containing alloys. In this group of alloys, the alpha-treated material is superior to the beta-quenched material. The important factors include greater hydrogen solubility, the grain structure and size, and the hydride structure and distribution (clustered rather than angular distribution of platelets).

The previous discussion indicates that only hydrogen present as hydride platelets results in impairment of mechanical properties. Because the solubility of hydrogen varies with (decreases with an increase in) temperature, the degree of impairment is also temperature sensitive; 1.e., no hydrogen would be precipitated as hydride until the solubility of hydrogen is exceeded.

The previous discussion has been based on results of studies of short-time effects. The results of a recent investigation, ${ }^{235}$ employing hydrogen-hydrided samples, indicate that unalloyed zirconium and Zircaloy-2 are not subject to delayed fallure (static fatigue). However, $\mathrm{Zr}-\mathbf{2 . 5} \mathrm{wt} . \% \mathrm{Nb}$ containing $500 \mathrm{ppm}$ hydrogen is slightly susceptible to static fatigue at room temperature, and the degree of sensitivity is greatly increased at $2000 \mathrm{ppm}$ hydrogen. 


\section{Reactor Experience}

Zirconium-base alloys have been used as the fuel cladding for two full-scale central-station power plants in the United States and at least one in the Soviet Union.

The Shippingport reactor ${ }^{236-238}$ is of the pressurized-water type and has two regions, core-seed and blanket. The seed elements are plates of $\mathrm{Zr}-6.7$ wt.\% U (highly enriched) alloy clad with Zircaloy-2. The blanket consists of cylindrical pellets of $\mathrm{UO}_{2}$ (natural) clad with Zircaloy-2. The maximum reactor outlet temperature is $280^{\circ} \mathrm{C}$.

Reactor operation has, in general, been satisfactory. ${ }^{239,240}$ There were no fuel fallures. As expected, exposure to radiation resulted in greatly increased tensile and yield strengths but only a slight decrease in notch ductility. It is planned to continue the use of Zircaloy in core 2 , but the blanket, as well as the seed elements, will be of the plate type because superior heat-transfer performance permits higher power density.

The Dresden reactor is of the dual-cycle bolling-water design. ${ }^{241}$ The fue ${ }^{242}$ consists of slightly enriched $\mathrm{UO}_{2}$ pellets clad with Zircaloy-2. The maximum reactor outlet temperature $1 \mathrm{~s} 285^{\circ} \mathrm{C}$. Procurement of Zircaloy tubing of adequate quality presented difficulties, which could probably be eliminated by improved definition of inspection methods. Small defects in the cladding have not, however, interfered with reactor operation. ${ }^{240}$

Ambortsumyan and associates ${ }^{197}$ have reported that uranium oxide fuel elements clad with $\mathrm{Zr}-1 \mathrm{wt} . \% \mathrm{Nb}$ have performed satisfactorily in high-temperature-water reactors.

Zircaloy-clad fuel elements are apparently satısfactory in watercooled naval power plants. Detalls, however, are classıfied.

In addition to the reactors just described, two fairly large exper mental bolling-water reactors, $\mathrm{EBWR}^{238,243}$ and VBWR, ${ }^{238,244,245}$ have successfully used Zircaloy-2 as fuel cladding at water temperatures of about 250 and $290^{\circ} \mathrm{C}$, respectively. Examination of an EBWR element after a burnup of 0.39 at.\% revealed the element to be in good condition. ${ }^{246}$

The PRTR is a pressure-tube reactor cooled and moderated with heavy water. ${ }^{247}$ The pressure tubes are $\mathrm{Z} 1$ rcaloy-2, and the fuel cladding is Zircaloy-2 or Zircaloy-4. Exit water temperature is $277^{\circ} \mathrm{C}$.

The experimental power station at Kahl (Main, West Germany) is a bolling-water reactor. ${ }^{238}$ The fuel is slightly enriched uranium oxide pellets clad with Zircaloy-2. Exit coolant temperature is $286^{\circ} \mathrm{C}$.

The generally acceptable properties of Zircaloy, combined with the history of satisfactory performances, have led to the specification of Zircaloy for several power reactors now in the planning or construction stages, including those discussed in the remainder of this section. 
SENN, a dual-cycle bolling-water reactor, is being constructed in Italy. The fuel ${ }^{248}$ consists of rods of uranium oxide pellets clad with Zircaloy-2. Exit coolant temperature is $282^{\circ} \mathrm{C}$.

R-3/Adam, a dual-purpose pressurized heavy-water reactor, is being constructed near Stockholm. ${ }^{238}$ The fuel is natural uranium oxide rods clad with Zircaloy. Exit coolant temperature is $220^{\circ} \mathrm{C}$.

CANDU, a pressure-tube reactor cooled and moderated with heavy water and reflected and shielded with light water, is to be built at Douglas Point, Ontario, Canada. The fuel is uranium dioxide pellets clad with Zircaloy-4. The design exit coolant temperature is $293^{\circ} \mathrm{C}$. A smaller version, the Nuclear Power Demonstration (NPD) reactor, which is to serve as a pilot plant, is in operation, using fuel with Zircaloy-2 cladding. ${ }^{238,249,250}$ Exit coolant temperature of the NPD is $277^{\circ} \mathrm{C}$.

The New Production Reactor (NPR), ${ }^{251}$ at Hanford Laboratories, is a large dual-purpose (produces both plutonium and electric power) graphite-moderated light-water-cooled pressure-tube reactor. Pressure tubes are of Zircaloy-2, and the fuel is slightly enriched metallic uranium clad with Zircaloy.

The Carolinas-Virginia Tube Reactor, ${ }^{238,252}$ a heavy-water-cooled and -moderated reactor with an oil-fired superheater, is located at Parr, S. C. The fuel is slightly enriched $\mathrm{UO}_{2}$ clad with Zircaloy-4. Pressure tubes are Zircaloy. Exit coolant temperature is $301^{\circ} \mathrm{C}$.

The Japan Power Demonstration Reactor is a bolling light-water reactor. ${ }^{238}$ The fuel is pellets of slightly enriched uranium oxide clad with Zircaloy-2. Exit coolant temperature is $277^{\circ} \mathrm{C}$.

\section{Evaluation}

WATER-COOLED REACTORS Continued use of zirconium alloys in water-cooled central-station reactors depends upon satisfactory performance at competitive costs.

Corrosion resistance is satisfactory for properly produced material under present operating conditions. Exposure to radiation does not severely impair mechanical properties. ${ }^{239,249}$ Susceptibility to hydrogen embrittlement has been thoroughly discussed and probably will be the limiting technical factor. Although, thus far, there apparently has been no fallure of fuel elements in production or power reactors which is entirely attributable to hydrogen embrittlement, the problem remains a potential one. It may become increasingly important as operating conditions become more severe and the pressure for lower costs results in more economical manufacturing techniques, e.g., less-rigorous inspection of fuel elements. Fallures caused by hydrogen embrittlement 
have occurred in deliberately defected fuel elements 185,239 and in apparently sound test elements. ${ }^{253}$ The latter fallure was attributed to hydrogen generated by the reaction between the Zircaloy cladding and the water vapor adsorbed on the oxide-powder fuel.

Zirconum is inherently a relatively expensive material, and the decision to use it, assuming satisfactory physical, chemical, and other properties, must be justıfied economically. The basic material cost is further increased by difficulties in fabrication. For example, the yield of satisfactory material for the first Shıppingport core was only 45 percent. $^{239}$ Difficulty has been experienced in procuring satisfactory tubing for the Dresden ${ }^{240}$ and the Canadian $\mathrm{NPD}^{254}$ reactor cores. However, it may be expected that with increased experience these difficulties will be eliminated, or at least greatly reduced. For example, tubing required for the SENN reactor core was obtained without difficulty and with an insignificant rejection rate. ${ }^{255}$ If fuel is not restricted to natural uranium, the use of stainless steel or aluminum can result in more economical reactor power plants. In particular, if satisfactory aluminum alloys could be produced at no great increase in material cost (ncluding fabrication) and parasitic-absorption cross section, it would appear that the use of such alloys could result in lower power-generation costs.

REACTORS FOR SUPERHEATED STEAM Based upon nuclear consideratıons, zirconium alloys are clearly superior to the stainless steels and high-nickel alloys now being considered as fuel cladding for nuclearpowered superheated-steam reactors. Several of the alloys discussed in the preceding sections are probably adequate to about $500^{\circ} \mathrm{C}$, but such a low temperature limitation is not attractive for economic power generation.

For use at higher temperatures, zirconium alloys must have greatly reduced corrosion rates and must not suffer severe deterioration of mechanical properties as a result of exposure to the corrosive environment. The latter can be the result of absorption of hydrogen and oxygen. As has been indicated, the effect of hydrogen depends on many factors, more or less controllable, in addition to the quantity absorbed. This problem would, of course, disappear if alloys with extremely low corrosion rates could be produced.

Corrosion rates and oxygen diffusion, and the refore the change in properties produced by oxygen, are of course intimately related. The effect of alloying and other pertinent variables on oxygen diffusion and the effect of oxygen content on physical properties must be studied in greater detall. Because the potential rewards are great, it is to be hoped that such studies and alloy-development programs will be vigorously pursued, perhaps along the newer lines suggested by Misch in a preceding section. 


\section{OTHER METALS}

by Sherman Greenberg

Argonnc Nalional Laboralory

The desire for cheaper nuclear power is translated, in some degree, to a contınuing search for more suitable cladding materials. In this context "more suitable" refers to materials capable of reliable operation under the increasingly severe conditions that the achievement of economic nuclear power appears to impose. Preferably these materials would also be cheaper than those now used.

The unique characteristics of thermal nuclear reactors impose the additional requirement of relatively low cross section for thermalneutron sorption. This requirement limits potential cladding materials to only a very few metals. Those which have found some degree of application have been considered. Here we shall discuss the few remaining metals that could be suitable as cladding material in steam-or water-cooled reactors for central-station power plants. These metals are probably limited to magnesium, beryllium, chromıum, molybdenum, and iron (carbon and low-alloy steel) alloys. The discussion will emphasize corrosion behavior and will be limited to materials for which reasonable data are avallable.

\section{In Water}

Assuming that materials now used are technically satisfactory, only magnesium and iron (carbon or low-alloy steel) alloys merit consideration as alternatives owing to their low cost. The use of magnesium would require a major advance in the understanding of the corrosion process. Even in fluoride-inhibited solutions at $150^{\circ} \mathrm{C}$, the rate of attack (about $1 \mathrm{mll} / \mathrm{day}$ ) for some of the better alloys warrants the term "dissolution rate" rather than "corrosion rate."256

Untıl recently the corrosion behavior of ferrous alloys had been studied in detail mainly under conditions of low oxygen content. These studies lead to operating conditions for conventional steam power plants of very low (less than $0.01 \mathrm{ppm}$ ) oxygen concentration and high $\mathrm{pH}$ (greater than 10). The specifications result in corrosion rates low enough for adequate performance of relatively thick-wall pipe and tubing.

However, corrosion rates are not low enough to warrant consideration of these materials for use as nuclear-fuel cladding. Moreover, because of radiolytic decomposition, it is not ilkely that reactor operation would result in the extremely low oxygen concentrations thought to be optimal. The assumption, unsound on the basis of conflicting data, that high $\mathrm{pH}$ is necessary for optimum behavior with regard to corrosion rate and crud deposition, is responsible for the myth that mild steel 
and aluminum alloys are incompatible in aqueous reactor systems.

More recently, studies have been conducted by Vreeland, Gaul, and Pearl $1^{257,258}$ and Ruther and Hart ${ }^{259}$ to determine the behavior of carbon and low-alloy steels under conditions of the relatively high oxygen content typical of reactor environments. Vreeland et al. have compared the liquid-water corrosion rates and "iron-to-system" values obtained un-

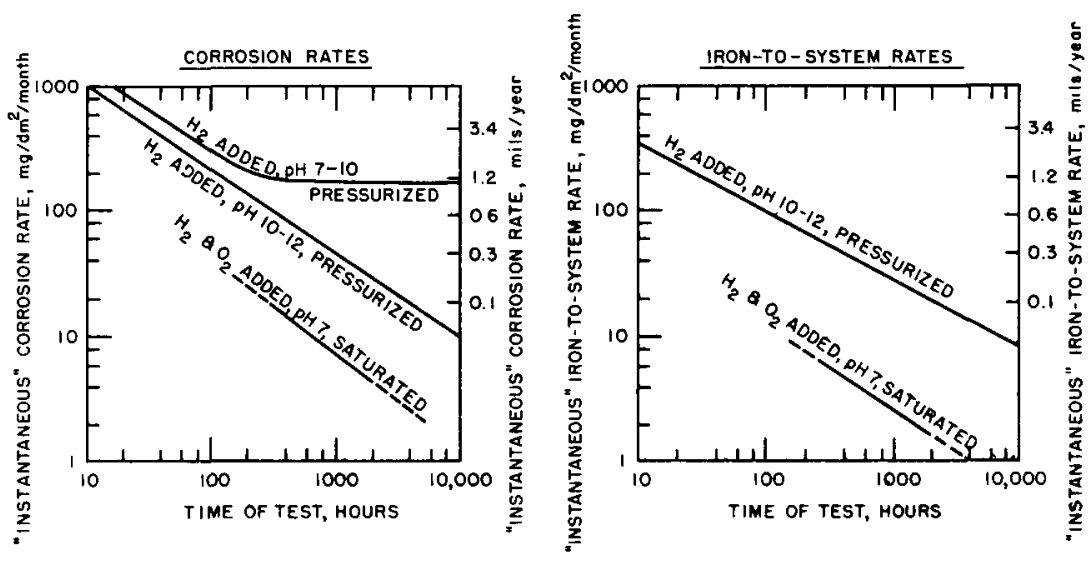

Fig. 38-Effect of oxygen ${ }^{257}$ on corrosion rate and deposition of low-alloy steels in water at $290^{\circ} \mathrm{C}$.

der oxygenated and "standard" conditions. The results are shown in Fig. 38. The terms "instantaneous corrosion rate" and "instantaneous iron-to-system rate" are used in these measurements because they refer to rates at a specific time, not to rates integrated over any period. The oxygenated tests were run in a boiling-water loop at $290^{\circ} \mathrm{C}$. Oxygen content of the steam was controlled at about $15 \mathrm{ppm}$, and the stoichiometric amount of hydrogen was added to simulate reactor conditions. Oxygen content of the saturated water was about $0.1 \mathrm{ppm}$, and that of the pressurized water was about $1 \mathrm{ppm}$.

Ruther and Hart ${ }^{259}$ studied the effect of oxygen content and temperature on corrosion. In general, the oxygen content required for formation of a temper film decreased as the temperature increased. These results are summarized in Table 28.

Krenz $z^{260}$ has shown that the operation of a carbon-steel in-pile loop at $270^{\circ} \mathrm{C}$ with deliberate addition of oxygen (10 to $20 \mathrm{ppm}$ ) does not result in crud deposit on heat-generating surfaces. The total crud in the system may be increased under these conditions.

It seems apparent that carbon steel should not be ruled out as a primary material of construction for aqueous reactors. Among the problems to be solved before widespread use could be recommended is 
Table 28-CORROSION BEHAVIOR OF PURE IRON IN W ATER CONTAINING OXYGEN ${ }^{259}$

\begin{tabular}{|c|c|c|c|c|}
\hline \multirow{2}{*}{$\begin{array}{c}\text { Tempera- } \\
\text { ture, }{ }^{\circ} \mathrm{C}\end{array}$} & \multicolumn{4}{|c|}{ Oxygen content } \\
\hline & $35 \mathrm{ppm}$ & $50 \mathrm{ppm}$ & $290 \mathrm{ppm}$ & $540 \mathrm{ppm}$ \\
\hline 50 & $\begin{array}{c}P^{*}\left(\begin{array}{ll}(0 & 08\end{array}\right) \dagger \\
\left(\begin{array}{ll}0 & 08\end{array}\right)\end{array}$ & $\begin{array}{r}P\left(\begin{array}{ll}0 & 12\end{array}\right) \\
\left(\begin{array}{ll}0 & 11\end{array}\right)\end{array}$ & & $\begin{array}{r}P\left(\begin{array}{ll}0 & 03\end{array}\right) \\
\left(\begin{array}{ll}0 & 04\end{array}\right)\end{array}$ \\
\hline 100 & & $P\left(\begin{array}{ll}0 & 08\end{array}\right)$ & $\begin{array}{r}P\left(\begin{array}{ll}0 & 05\end{array}\right) \\
\left(\begin{array}{ll}0 & 06\end{array}\right)\end{array}$ & 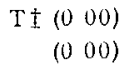 \\
\hline 150 & $\begin{array}{r}P(052) \\
(055)\end{array}$ & 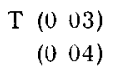 & $T\left(\begin{array}{ll}0 & 03\end{array}\right)$ & $T\left(\begin{array}{ll}0 & 08\end{array}\right)$ \\
\hline 200 & $P\left(\begin{array}{ll}3 & 34\end{array}\right)$ & $\begin{array}{r}T\left(\begin{array}{ll}0 & 05\end{array}\right) \\
\left(\begin{array}{ll}0 & 0\end{array}\right)\end{array}$ & & $T\left(\begin{array}{ll}0 & 06\end{array}\right)$ \\
\hline 260 & $\mathrm{P}$ & $\begin{array}{r}P\left(\begin{array}{ll}0 & 71\end{array}\right) \\
\left(\begin{array}{ll}0 & 65\end{array}\right)\end{array}$ & 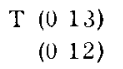 & $\begin{array}{r}\mathrm{T}\left(\begin{array}{ll}0 & 15\end{array}\right) \\
(0 \\
(014)\end{array}$ \\
\hline 315 & 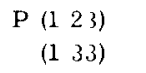 & $\begin{array}{r}P\left(\begin{array}{ll}0 & 46\end{array}\right) \\
\left(\begin{array}{ll}0 & 46\end{array}\right)\end{array}$ & $\begin{array}{r}T\left(\begin{array}{ll}0 & 34\end{array}\right) \\
\left(\begin{array}{ll}0 & 47\end{array}\right)\end{array}$ & $\begin{array}{r}\Gamma\left(\begin{array}{ll}0 & 43\end{array}\right) \\
(04\end{array}$ \\
\hline
\end{tabular}

*P refers to pitting noticed in three-day test

†Numbers in parentheses are defilmed weight losses in mill1grams per square centımeter

$\$ \mathrm{~T}$ refers to temper film in three-day test

inhibition during downtime and other low-temperature periods when the required oxygen concentration is prohibitively high. Oxygen depletion in crevices and other stagnant locations is also a problem.

If operating conditions or other factors justıfy a more costly cladding material, niobium-base alloys would probably be more than adequate. Berry and associates ${ }^{261-263}$ have shown that many nioblum-base alloys have lower corrosion rates than Zircaloy-2 in water at $360^{\circ} \mathrm{C}$ and in steam at $400^{\circ} \mathrm{C}$. In addition, these alloys apparently do not suffer breakaway (or transition) and are not affected by oxygen or hydrogen absorption. Two of the more corrosion-resistant alloys are $\mathrm{Nb}-12.6$ at. $\% \mathrm{~V}$ and $\mathrm{Nb}-28.2$ at. $\% \mathrm{~T} 1-6.1$ at. $\% \mathrm{Cr}$.

\section{In Superheated Steam}

Spalaris and associates ${ }^{20}$ have surveyed the field and have concluded that the only alternatives to the austenitic stainless steels which show promise for service in the near future are the high-nıckel alloys, e.g., Incoloy. Development efforts concerned with other systems are in progress, however.

The work on zirconium alloys has been described. Beryllium is attractive, in spite of its high cost, because of its very low absorption cross section (about 0.01 barn) for thermal neutrons. However, the properties of beryllium are profoundly affected, in a manner that is only very inadequately understood, by minor variations in impurity level and fabrication technique. Thus an alloy-development program is very difficult to undertake. The literature has been reviewed by Darwin and 
Buddery. ${ }^{264}$ There is conflicting evidence 264,265 regarding the effect of cathodic metals. An approach, which may be promising, to alloying for corrosion resistance relies on the hypothesis of analogous behavior of the aluminum and beryllium systems. Aylmore and associates ${ }^{266}$ have shown that water vapor, at least at low partial pressures, does not affect the oxidation of electrolytic flake beryllium up to about $600^{\circ} \mathrm{C}$. Protective films are formed under these conditions. Above about $650^{\circ} \mathrm{C}$, breakaway occurs. These results suggest that it is not unreasonable to expect to be able to produce corrosion-resistant alloys in the temperature range of interest, 1.e., up to about $650^{\circ} \mathrm{C}$ and perhaps higher.

Niobium-base alloys are of interest because of reasonably low $a b-$ sorption cross section and very good high-temperature mechanical properties. ${ }^{261}$ Although the unalloyed metal is not very corrosion resistant, considerable improvement can be accomplished by alloying. Fisch and associates ${ }^{267}$ found decreasing corrosion rate with time for niobium-vanadium alloys at 360 to $482^{\circ} \mathrm{C}$. Corrosion rate decreased with the vanadium content up to 8.9 percent vanadium, the maximum studied. Douglass ${ }^{268}$ found nobium alloys of little promise for super heat application. DeMastry and associates, ${ }^{269}$ however, report very promising results for at least three alloys: $\mathrm{Nb}-15$ at. $\% \mathrm{~T}_{1}-12$ at.\% $\mathrm{V}-6$ at.\% $\mathrm{Cr} ; \mathrm{Nb}-18$ at. $\% \mathrm{~T} 1-4$ at. $\% \mathrm{~V}-9$ at. $\% \mathrm{Cr}$; and $\mathrm{Nb}-21$ at.\% $\mathrm{T}_{1}-12$ at. $\% \mathrm{~V}-9$ at. $\% \mathrm{Cr}$. Strongly adherent blue-black tarnish films are formed after about two months in steam at $540^{\circ} \mathrm{C}$ and $1500 \mathrm{ps}$. Corrosion resistance is sensitive to sample condition; cold working increases the corrosion resistance of annealed material. This program is continuing.

\section{ACKNOWLEDGMENT}

The authors and editor express their appreciation to Messrs, Hugh E. Voress and Theodore F. Davis of the USAEC Division of Technical Information Extension, Oak Ridge, Tenn., for their painstaking and thorough literature search in the field of fuel-element cladding.

This initial sifting and screening was of great value to us and reduced to a considerable degree the tediousness of this phase of our effort. 


\section{REFERENCES}

1. J. N. Wanklyn and P. J. Jones, The Aqueous Corrosion of Reactor Metals, J. Nucl. Mater., 6: 291 (1962).

2 J. E. Draley, S. Morı, and R. E. Loess, The Corrosion of 1100 Aluminum in Oxygen Saturated Water at $70^{\circ} \mathrm{C}$, paper presented at the Second International Symposium on Passivity, Toronto, September 3-7, 1962, J. Electrochem. Soc., 110: 622 (1963).

3. J. E. Draley and W. E. Ruther, Corrosion Resistant Aluminum Above $200^{\circ} \mathrm{C}$, Corrosion, 12: 441t (1956).

4 M. H. Brown, R. H. Brown, and W. II. Binger, Aluminum Alloys for Handling High Temperature Water, Alcoa Report, presented at the March 1960 NACE Conference.

5. J. E. Draley, W. E. Ruther, and S. Greenberg, Alumınum Alloys with Improved High Temperature Aqueous Corrosion Resistance, J. Nucl. Mater., b: $157-171$ (1962).

6. R. L. Dillon and H. C. Bowen, A Basis tor Design of Aluminum Alloys for High Temperature Water Service, Corrosion, 18: 406t-416t (1962).

7. J. E. Draley and W. E. Ruther, The Corrosion of Aluminum Alloys in High Temperature Water, in Corrosion of Reactor Materials, Vol. I, p. 477, International Atomic Energy Agency, Vienna, 1962.

8. R. L. Dillon, Dissolution of Aluminum Oxide as a Regulating Factor in Aqueous Aluminum Corrosion, USAEC Report HW-61089, Hanford Atomic Products Operation, August 1959.

9. J. E. Draley, S. Greenberg, and W. E. Ruther, Corrosion of Some Reactor Materials in Dilute Phosphoric Acid, USAEC Report ANL-6206, Argonne National Laboratory, April 1961.

10. N. J. M. Wilkins and J. N. Wanklyn, The Corrosion of Aluminum and Its Alloys in High Pressure Steam, J. Inst. Metals, 88(3): 134-140 (1959-1960).

11. H. Corlou et al., Al-Fe-Ni Alloys Corrosion Resistant in Hot Water and Steam, in Proceedings of the Second Unted Nalions International Conference on the Peaceful Uses of Atomic Energy, Geneva, 1958, Vol. 5, pp. 128-152, United Nations, New York, 1958.

12. J. E. Draley, W. E. Ruther, and S. Greenberg, Corrosion of Aluminum and Its Alloys in Superheated Steam, USAEC Report ANL-6207, Argonne National Laboratory, April 1961.

13. J. N. Wanklyn and N. J. M. Wilkins, The Corrosion of Aluminum, Its Alloys and S.A.P. in High Pressure Steam, British Report AERE-M-529, 1959.

14. E. L. Martinec, Corrosion of an Aluminum-Nickel Alloy in a Reactor Test Loop, USAEC Report ANL-5783, Argonne National Laboratory, September 1957.

15. R. J. Lobsinger, Summary Report on the Corrosion of Aluminum in High Temperature Dynamic Water Systems, USAEC Report HW-59778(Rev.), Hanford Atomic Products Operation, Feb. 1, 1961.

16. K. Videm, Corrosion of Aluminum Alloys in High Temperature Water, $J$. Nucl. Mater., 2: 145-153 (1959).

17. J. C. Griess et al., Effect of Heat Flux on the Corrosion of Aluminum by Water, Part III. Final Report on Tests Relative to the High-flux Isotope Reactor, USAEC Report ORNL-3230, Oak Ridge National Laboratory, Dec. 20, 1961. 
18. J. H. Kittel, Argonne National Laboratory, private communication, 1962.

19. J. A. Ayres, Evaluation of Aluminum for Use in Reactors Cooled by Hightemperature Recirculating Water, USAEC Report HW-61757(Rev.), Hanford Atomic Products Operation, Feb. 10, 1960.

20. C. N. Spalaris, F. A. Comprell, D. L. Douglass, and M. B. Reynolds, Materials for Nucledr Superheat Applications, A Literature Survey, USAEC Report GEAP-3875, General Electric Company, Atomic Power Equipment Department, Jan. 5, 1962.

21. Argonne National Laboratory, Reactor Development Program Progress Report, USAEC Report ANL-6619, Oct. 15, 1962.

22. C. R. Breden et al, Water Corrosion of Structural Materials, October $1948-$ June 1951, USAEC Report ANL-4519, Argonne National Laboratory, July 15, 1951.

23. S. C. Datsko and C. R. Breden, Corrosion of Metals in High Temperature Water at $500^{\circ} \mathrm{F}$ and $600^{\circ} \mathrm{F}$, USAEC Report ANL-5354, Argonne National Laboratory, Oct. 6, 1954.

24. D. J. DePaul (Ed.), Corrosion and Wear Handbook for Water Cooled Reactors, USAEC Report TID-7006, Westinghouse Electric Corporation, Bettıs Plant, March 1957.

25. C. R. Breden, Behavior of Reactor Structural Materials from the Standpoint of Corrosion and Crud Formation, in AEC-Euratom Conference on Aqueous Corrosion of Reactor Materials, Brussels, Belgium, October 14-17, 1959, USAEC Report TID-7587, pp. 48-70, July 1960.

26. W. E. Berry, Corrosion Behavior of Cladding Materials in High-temperature Water, in AEC-Euratom Conference on Aqueous Corrosion of Reactor $\mathrm{Ma}$ terials, Brussels, Belgium, October 14-17, 1959, USAEC Report TID-7587, pp. 71-95, July 1960 .

27. F. J. Brutschy, R. S. Gilbert, and R. N. Osborne, The Behavior of Corrosion Products in Bolling Water Redctors, in Corrosion of Reactor Materials, Vol. 1, pp. 133-159, International Atomic Energy Agency, Vienna, 1962.

28. C. R. Breden, Bolling Water Reactor Technology Status of the Art Report. Volume II. Water Chemistry and Corrosion, USAEC Report ANL-6562, Argonne National Laboratory, February 1963.

29. R. J. Coe, W. J. Miller, L. E. Minnick, and G. A. Reed, Yankee Plant and Reactor Performance, Trans Am Nucl Soc, 5: 116-117 (1962).

30. C. A. Bergmann, SM-1 Research and Development Program, Long-lived Induced Actıvity Buldup During SM-1 Core I Lifetıme, Task XVIII-Phase I, USAEC Report APAE-77, Alco Products, Inc., Nov. 30, 1960.

31. R. J. Clark and A. L. Medin, Corrosion and Water Purity Control for the Army Package Power Reactor, Corrosion, 14: 419t (1958).

32. Alco Products, Inc., Army PWR Support and Development Program SIX Months Summary Report, October 1, 1961-March 31, 1962, USAEC Report APAE-113, May 25, 1962.

33. J. N. Wanklyn and D. Jones, The Corrosion of Austenitic Stainless Steels Under Heat Transfer in High Temperature Water, J Nucl Mater, 1:154 (1959).

34. M. S. Feldman, Stress-corrosion Cracking of Stainless Steel. A Literature Search, USAEC Report DP-683, E. I. du Pont de Nemours \& Co., Inc., February 1962.

35. P. P. Snowden, Stress Corrosion of Austenitic Stainless Steel by High Tem- 
perature Solutions and Contammated Steam, $J$ Iron Steel Inst (London), 194: 181 (1960).

36. L. D. Schafter, Army Reactors Program Progress Report, USAEC Report ORNL-3231, Oak Ridge National Laboratory, Feb. 14, 1962.

37. R. J. Bedier, R. C. Waugh, C. F. Leitten, Jr., and W. R. Burt, Jr., Investigation of the Factors Affecting Sensitization of Army Pachage Power Redctor (APPR-1) Fuel Elements, USAEC Report ORNL-2312, Oak Ridge National Laboratory, Oct. 8, 1957.

38. C. F. Lacy, Knolls Atomic Power Laboratory, private communication, 1963.

39. J. W. Lingafelter and T. J. Pashos, Irradiation Testing of Staınless Steel Clad, $\mathrm{UO}_{2}$ Rod Type Fuel Elements, Trans Am. Vucl. Soc., 5: 469 (1962).

40. H. R. Copson, Effect of Composition on Stress Corrosion Craching of Some Allovs Containing Nichel in Physical Metallurgy of Stress Corrosion Fracture, pp. 247-267, Interscience Publishers, Inc., New Yorh, 1959.

41. H. Coriou et al., Stress Corrosion Cracking of Inconel in High Temperature Water, in Third Colloqunm of Metallurgy and Corrosion, Centre d'Etudes Nucleares de Saclay, North Holland Publıshing Company, Amsterdam, 1960.

42. C. F. Cheng and H. L. Tymchyn, Stress Corrosion of Inconel $1.1550^{\circ} \mathrm{F}$ Aerated Sea Water, USAEC Report KAPL- II-CC-2, Knolls Atomic Power Laboratory, February 1961.

43. H H Uhlig New Perspective in the Stress Corrosion Problem, in Phy 4 acal rosion Craching of Austenitic Stanless Steels, Trans. Am. Soc. Metals, 52: 830 (1960).

44. H. H. Uhlig, New Perspective in the Stress Corrosion Problem, in Physical Metallurgy of Stress Corrosion Fracture, Interscience Publishers, Inc., New York, 1959.

45. F. S. Lang, Effects of Trace Elements on Stress-corrosion Craching of Austenitic Stainless Steels in Chloride Solutions, Corrosion, 18: 378t-382t (October 1962).

46. J. G. Hines and T. P. Hoar, The Stress Corrosion Craching of Austenitic Staınless Steels. II. Fully Softened, Stram-hardened and Retrigerated Material, J Iron Steel Inst (London), 184: 166 (1956).

47. E. A. Lees, Residual Stresses and Stress-corrosion Craching of Type 304 Stainless Steel, General Electric Company, Atomıc Power Equipment Department (to be published).

48. II. A. Scheil, Some Obseriations of Stress-corıosion Craching in Austentic Stanless Alloys, in Symposium on Stress Corrosion Craching of Mletals, American Society for Testing and Naterials and American Institute of Chemical Engineers, 1944.

49. H. Suss, Shot Peening of Metals for Protection Aganst Stress Corrosion Cracking, Corrasion, 18: 17t-20t (1962).

50. R. L. Holladay (Comp.), High Power Density Development Project, Eleventh Quarterly Progress Report, October-December 1962, USAEC Report GEAP-4155, General Electric Company, Atomıc Power Equipment Department, Jan. 1, 1963.

51. Directory of Nuclear Reactors, Vol. IV, Pouer Reactors, International Atomic Energy Agency, Vienna, 1962.

52. Alco Products, Inc., Army PWR Support and Development Program, MidYedr Summary Report, Uctober 1, 1960-March 31, 1961, USAEC Report APAE-86, June 2, 1961. 
53. Nucleonics Reactor File No. 12, Reactors on the Line, PM-1 (Sundance), Nucleonics, 20 (9): 37 (1962).

54. Design Practice: Yankee Nuclear Power Station, Pouer Reactor Technol, 4 (3) (June 1961).

55. Progress on Specilıc Reactor Types, The Belgian BR-3, Pouer Reactor Technol, 3(1) (December 1959).

56. Desıgn Practice: The N. S. Savannah, Pouer Reactor Technol., 6(1) (December 1962).

57. Nucleonics Reactor File No. 11, Reactors on the Line, Savannah, Nucleonics, 20(7): 37 (1962).

58. F. Costell, Improvements in the Design of the SELNI Nuclear Power Station, Nucl. Poter, 1: 69 (1962).

59. F. J. Brutschy, H. S. Dreyer, and W. L. Pearl, Vallecitos Bolling Water Reactor Coolant Technology, Ind. Eng. Chem., 51: 1262 (1959).

60. Hestinghouse Electric Corporation, Atomic Power Division, Yankee Core Eialuation Program Quarterly Progress Report for Period June 20, 1962, to September 30,1962, USAEC Report WCAP-6052, Oct. 26, 1962.

61. J. N. Inglima, R. H. Beam, S. L. Davidson, and E. C. Edgar, Preliminary Technical Report, SM-1 Core III with Type 3 Elements, USAEC Report APAE114, Alco Products, Ine., VIar. 30, 1962.

62. L. 4 . Neimark, Exammation of an Irradiated Prototype Fuel Element for the Elh River Reactor, US $4 E C$ Report ANL-6160, Argonne National Laboratory, January 1961.

63. R. G. Cochran, Pre-irradiation Data on N. S. Savannah Core II-4, -5 , and -6) Prototype Fuel Assemblies to be Tested in VBWR, N. S. Savannah Fuel Design and Derelopment Program, USAEC Report GEAP-3.376, General Electric Compan, Atomic Power Equipment Department, tpr. 26, 1960.

64. E. Manglum, Jx., and F. H. Megerth, N. S. Salannah Fuel Design and Development Program, Pre-1rradiation Data on N. S. Savannah Core II-4, -5, and -6 Prototype I uel Assemblies to be Tested in VBWR, USAEC Report GEAP-3376(Add.), General Electric Company, Atomic Power Equipment Department, Sept. 1, 1960.

65. R. K. Baird, J. O. trterburn, F. A. Brandt, and C. N. Spalai is, N. S. Savannah Tuel Design and Development Program, Pieliminary Summary of Irradiation Tests Conducted on N. S. Salannah Core II Type Assemblies II-2 and II-3 in VBWR, USAEC Report GEAP-3248, General Electric Company, Atomic Power Equipment Department, Sept. 25, 1959

66. F. A. Brandt et al., Iriadiation Results, N. S. Salannah Core II Prototype Fuel Assemblies (Assemblies Sar II-2 and Sar II-3), LSAEC Report GEAP3559, General Electı1c Company, Vallecitos Atomic Laboratory, Nov. 7, 1960 .

67. E. A. Lees, M. E. Snyder, and R. A. Duncan, The Fabrication of the Fuel Elements for the $\mathrm{UO}_{2}$ High Burn-up Program, USAEC Report GEAP-3108 (Pt. 1), General Electric Companv, Vallecitos Atomic Laborator, Jan. 12 , $195 \%$.

68. T. J. Sloseh and B. Il eidenbaum, Irradiation and E\amınation of Vibratory Pached $\mathrm{UO}_{2}$ High Burnup Program Fuel Elements, USAEC Report GEAP3108(Pt. 2), General Electric Company, Vallecitos Atomic Laboratory, Feb. 26, 1960 .

69. F. A. Brandt, T. J. Sloseh, and B. Weidenbaum, Irradiation and Examina- 
tion of $\mathrm{UO}_{2}$ High Burnup Program Fuel Elements, USAEC Report GEAP3108(Pt. 3), General Electric Company, Vallecitos Atomic Laboratory, January 1962.

70. C. L. Howard (Comp.), Fuel Cycle Program, A Bolling Water Redctor Research and Derelopment Program, Tenth Quarteily Progress Report, October-December 1962, USAEC Report GEAP-4159, General Electric Company, Atomic Power Equipment Department, Jan. 14, 1963.

71. J. A. Hodde, Fuel Cycle Program, A Bolling Water Reactor Research and Development Program, Fourth Quarterly Report, USAEC Report GEAP3781, General Electric Company, Atomic Power Equipment Department, Aug. 1, 1961.

72. D. L. Zimmerman, Irradiation and Post-irradiation Examination of N.S. Savannah Test Fuel Element S1-a, Report GEAP-3342, General Electric Company, Atomic Power Equipment Department, January 1960.

73. D. L. Zimmerman, General Electric Company, Atomic Power Equipment Department, private communication.

74. C. J. Baroch, J. P. Hollmann, and W. C. Rous, AEC Fuel Cycle Program, Design and Fabrication of the Basic Fuel Assemblies, USAEC Report GEAP-3653, General Electric Company, Atomic Power Equipment Department, Mar. 15, 1963.

75. W. D. Fowler and J. W. Lingatelter, High Power Density Development Project, Design and Fabrication of High Power Density Fuel Assemblies for VBW R Irradiation Testıng, USAEC Report GEAP-3609, General Electric Compan, Atomic Power Equipment Department, Nov. 1, 1960.

76. K. J. O'Leary and R. S. Miller, Extrusion of $\mathrm{UO}_{2}$ and $\mathrm{ThO}_{2}-\mathrm{UO}_{2}$ Nuclear Fuels, in Symposıum on Powder Pached Uramum Dioxide Fuel Elements, November 30-December 1, 1961, USAEC Report CEND-153(Vol. II), pp. 135-154, Combustion Engineering, Inc.

77. R. Hauser, The Extrusion of Uranium Dioxide; Technique of Extrusion, in Symposium on Powder Packed Uranum Dioxide Fuel Elements, November 30 -December 1, 1961 USAEC Report CEND-153(Vol. II), pp. 115-129, Combustion Engineering, Inc.

78. C. L. Howard (Comp.), Fuel Cycle Program, A Bolling Water Reactor Research and Derelopment Program, Ninth Quarterly Progress Report, JulySeptember 1962, LS $+E C$ Report GE $+P-4094$, General Electric Company, Atomic Power Equipment Department, Oct. 25, 1962.

79. H. E. Williamson and J. P. Hoffmann, The In radiation Performance of $\mathrm{UO}_{2}$ with Central Melting, paper presented at the American Ceramic Society Pacilıc Coast Northwest 15th Regional Meetıng, Seattle, Washungton, October 17-19, 1962.

80. E. A. Lees, Fabrication of Fuel Elements by Swaging, USAEC Report GEAP-3918, General Electric Company, Vallecitos Atomic Laboratory, May 21, 1962.

81. J. G. Hunt, D. F. Kautman, and P. Loewenstem, Hot Extrusion of $\mathrm{UO}_{2}$ Fuel Elements, Fundamental and Applied Resedrch and Development in Metallurgy, Final Report for the Period July 1, 1960, through June 30, 1961, USAEC Report AMII-1245, Nucleal Metals, Inc., Oct. 31, 1961.

82. J. II. Lingafelter, The Pertormance Eraluation of Compacted Powder $\mathrm{UO}_{2}$ Fuel Rods, in Symposium on Ponder Packed Uramum Dioxide Fuel Elements, November 30-December 1, 1961, USAEC Report CEND-153(Vol. I1), pp. 67-76, Combustion Engineering, Inc 
83. J. W. Lingafelter, Fabrication of Fuel Rods by Tandem Rolling, USAEC Report GEAP-3775, General Electrıc Company, Atomıc Power Equipment Department, July 1961.

84. S. W. Porembka and C. B. Boyer, Consolıdatıon of Uranıum Dioxıde by Gaspressure Bonding, in Symposium on Powder Packed Uranium Dioxide Fuel Elements, November 30-December 1, 1961, USAEC Report CEND-153 (Vol. II), pp. 155-162, Combustion Engineering, Inc.

85. C. J. Baroch, S. W. Porembka, and C. B. Boyer, Evaluation of Falled Hot Gas Isostatic Pressed Fuel Rods, USAEC Report GEAP-4206, General Electric Company, Atomic Power Equipment Department, and Battelle Memorial Institute, Mar. 20, 1963.

86. C. M. Ryer, Powder Fuel Processing by Two-pass Swaging, The Effect of Particle Size and Distribution, USAEC Report GEAP-3891, General Electric Company, Atomic Power Equipment Department, Apr. 10, 1962.

87. G. R. Horn, General Electric Company, Hanford Laboratories, private communication, Apr. 3, 1963.

88. R. L. Holladay, High Power Density Development Project, Eighth Quarterly Progress Report, January-March 1962, USAEC Report GEAP-3947, General Electric Company, Atomıc Power Equipment Department, Apr. 1, 1962.

89. S. R. Vandenbeı, General Electrıc Company, Atomic Power Equipment Department, private communication, 1962.

90. R. F. Boyle, Final Report of Pre- and Post-irradiation Examination of Consolidated Edison Fuel, USAEC Report GEAP-3351, General Electric Company, Atomic Power Equipment Department, February 1960.

91. E. A. Evans, Irradiation Testing of Powder-containing Fuel Elements, in Symposium on Powder Packed Uranium Dioxide Fuel Elements, November 30-December 1, 1961, USAEC Report CEND-153(Vol. II), pp. 3-38, Combustion Engineering, Inc.

92. D. C. Bullington, Yankee Irradiation Program. Summary Report, Part 1, Yankee Inpile Loop Irradiation Test, USAEC Report YAEC-182(Pt. 1), Westinghouse Electric Corporation, Atomic Power Department, January 1962.

93. W. C. Thurber, Compacted Powder Fuel Irradıatıon Studıes at the Oak Ridge National Laboratory, in Symposium on Powder Packed Uranium D1oxide Fuel Elements, November 30-December 1, 1961, USAEC Report CEND-153(Vol. II), pp. 39-65, Combustion Engineering, Inc.

94. W. C. Thurber, Oak Ridge National Laboratory, pritate communication.

95. T. C. Rowland and J. S. Atkınson, Power Cyclıng of High Power Density Fuel Specimens Clad With 10-mil IIall Stanless Steel, USAEC Report GEAP-4069, General Electric Company, Vallecitos Atomic Laboratory, October 1962 .

96. J. W. Lingafelter et al., Results of Irradiation Tests of Thm-wall Stainless Steel Clad, $\mathrm{UO}_{2}$ Fuel Rods, paper piesented at 8th Annual Meeting of the American Nuclear Society, Boston, Massachusetts, June 18-21, 1962.

97. J. W. Lingafelter, E. A. Lees, and R. J. Seely, Erosion Flow Testing of Purposely Defected Stainless Steel Clad Compacted $\mathrm{UO}_{2}$, Powder Fuel, USAEC Report GEAP-4020, General Electric Companv, Atomic Power Equipment Department, February 1962.

98. Pouer Reactor Technol, 4(1): 52-56 (December 1960).

99. P. M. Mathay, Post-ırradiation Esammation of ORNL Maritime Fuel As- 
semblies $1 \mathrm{~A} 1$ and 1A2, USAEC Report GEAP-3797, General Electric Company, Atomic Power Equipment Department, December 1961.

100. P. M. Mathay, General Electric Company, Atomic Power Equipment Department, private communication, 1962.

101. G. R. Caskey, Jr., G. R. Cole, and W. G. Holmes, Fallures of $\mathrm{UO}_{2}$ Fuel Tubes by Internal Hydriding of Zircaloy-2 Sheaths, in Symposium on Powder Packed Uranıum Dioxide Fuel Elements, November 30-December 1, 1961, USAEC Report CEND-153(Vol. II), pp. 77-99, Combustion Engineering, Ine.

102. L. F. Coffin, Jr., Low Cycle Fatigue - A Review, Report 62-RL-3069M, General Electric Company, June 13, 1962.

103. L. F. Porter, Radiation Effects in Steel, Materials in Nuclear Applications, Am. Soc. Testing Mater., Spec. Tech Publ., 276 (June 1960).

104. W. F. Murphy and S. H. Paine, Fast Neutron Eftects on Tensile and Hardness Properties of Type 347 Stainless Steel, in Symposium on Radiation Effects on Materials, Vol. 1, Am. Soc. Testing Mater., Spec. Tech. Publ., 208 (1956).

105. H. R. Copson and W. E. Berry, Qualifications of Inconel for Nuclear Power Plant Applications, Corrosion, 16: 79 t (1960).

106. D. E. White and E. G. Johnson, Stress Corrosion Screening Tests of Materials for Steam Generatıng Tubıng in Nuclear Power Plants, Corrosion, 16: $320 \mathrm{t}$ (1960).

107. H. R. Copson and W. E. Berry, Corrosion of Inconel Nickel-Chromium Alloy in Primary Coolants of Pressurized Water Reactors, Corrosion, 18: 21t (1962).

108. I. C. Mayes and J. McGrew, ANPP Corrosion Program, Final Summary Report, Report MND-E-2727, Martın Companv, February 1962.

109. M. A. Powers and H. L. Tymehyn, Corrosion of Inconel in High-temperature Water, in Reactor Technology Report No. 14-Chemistry, USAEC Report KAPL-2000-11, pp. IV-3-IV-6, Knolls Atomic Power Laboratory, Nov. 28, 1960 .

110. A. Porneuf, The Extrusion of Uranium Dioxide. Physico-chemical Properties of Extruded Uranium Dioxide, USAEC Report CEND-153(Vol. II), pp. 131-134, Combustion Engineering, Inc.

111. Fuel Cycle Development Program, Quarterly Progress Report, April 1, 1962, to June 30, 1962, USAEC Report UNC-5033, Unted Nuclear Corporation, Aug. 31, 1962.

112. F. Hofmarn, H. Kroll, and B. Leibmann, Fuel Element Fabrication by Cold and Hot Swaging of Specially Prepared $\mathrm{UO}_{2}$ Powders, in Symposium on Powder Packed Uramum Dioxıde Fuel Elements, November 30-December 1, 1961, USAEC Report CEND-153(Vol. I), pp. 125-135, Combustion Eng1neering, Inc.

113. E. I. Veil and R. H. Gale, Fabrication of $\mathrm{UO}_{2}$ Fuel Elements by the "Vibswage" Process, in Symposium on Powder Packed Uranıum Dioxide Fuel Elements, Norember 30-December 1, 1961, USAEC Report CEND-153 (Vol. I), pp. 137-147, Combustion Engineering, Inc.

114. R. L. E1chinger, Vibratory and Swage Compaction of Small Diameter Stainless Steel Clad Fuel Rods, in Symposium on Pow der Packed Uranium Dioxude Fuel Elements, November 30-December 1, 1961, USAEC Report CEND-153(Vol. I), pp. 149-162, Combustion Engineering, Inc. 
115. G. Frigerio, Cold Swaging of Uranium Dioxide, in Symposium on Powder Packed Uranuum Dionde Fuel Elements, November 30 -December 1, 1961, USAEC Report CEND-153(Vol. I), pp. 163-169, Combustion Engineering, Inc.

116. J. J. Hauth, Fabrication Techniques for Packed-pow der Fuel Elements, in Symposium on Powder Packed Uranium Diovide Fuel Elements, November 30 -December 1, 1961, USAEC Report CEND-153(Vol. I), pp. 11-21, Combustion Engineering, Ine.

117. Babcoch and Wilcos Company, Development and Testing of Low Cost Fuel Elements for Power Reactor Service, Report BAW-156, June 2, 1961.

118. Hanford Atomic Products Operation, Novel Ceramic Fuel Fabrication Processes, USAEC Report HW-64629, Apr. 15, 1960.

119. R. C. Brayer and B E. Murtha, Pneumatic Vibratory Compaction of $\mathrm{UO}_{2}$, in Symposium on Powder Packed Uranium Dioside Fuel Elements, November 30-December 1, 1961 USAEC Report CEND-153(Vol. I), pp. 45-59, Combustion Engineering, Inc.

120. W. S. Ernst, Jr., and R. L. Beatts, Vibiatory-compaction Studies at the Oak Ridge National Laboratory, in Symposium on Powder Packed Uranium Dioxide Fuel Elements, November 30-December 1, 1961, USAEC Report CEND-153(Vol. I), pp. 61-74, Combustion Engmeering, Inc.

121. W. R, DeHollander, Particle Size Reldtionships in the Paching of $\mathrm{UO}_{2}$, in Symposium on Powder Packed Uranum Dioside Fuel Elements, November 30 -December 1, 1961, USAEC Report CEND-153(Vol. 1), pp. 75-83, Combustion Engineering, Inc.

122. U. R. DeHollander, Vibratıonal Compaction of Uramum Dioxide, USAEC Report GEAP-4032, General Electrıc Company, Vallecitos Atomic Laboratory, Mar. 1, 1962.

123. W. B. Tarpley and R. Phedsant, Ultrasonic Filling of Tubular Cladding with Ceramic Fuel Powders, in Symposium on Powder Packed Uranium Dioxide Fuel Elements, November 30-December 1, 1961, USAEC Report CEND-153 (Vol. II), pp. 163-194, Combustion Engineering, Inc.

124. F. S. Galdner and J. G. Hunt, The Fabrication of Clad Massive $\mathrm{UO}_{2}$ Fuel Elements by Coestrusion. Second Quarterly Report, USAEC Report NMI2505, Nuclear Metals, Ine., Jan, 14, 1960.

125. Phllip Sporn, The $2000 \mathrm{ps}, 1050^{\circ} \mathrm{F}$, and $1000^{\circ} \mathrm{F}$ Reheat Cycle at the Philıp Sporn and Twin Branch Steam-Electric Stations, Trans ASME, 70: 287 (1948).

126. S. N. Fiala, First Commercial Supercritical Pressure Steam-Electric Generating Unit tor Philo Plant, Trans ASME, 79: 389 (1957).

127. J. H. Harlow, Engmeering the Eddystone Plant for 5000 Lb., 1200 Deg. Steam, Trans ASME, 79:1410 (1957).

128. C. N. Spalaris, F. A. Comprelli, and M. Siegler, Erosion Experiments of Powder Compacted $\mathrm{UO}_{2}$ Under Dynamıc Steam $\mathrm{F}$ low, USAEC Report GEAP3698, General Electric Company, Atomic Power Equipment Department, Mar. 21, 1961.

129. C. N. Spalarıs, Materials for Superheat Reactors, Trans AIME, Spec Rept Ser No 11, 191-208 (1962).

130. G. H. Hawhms, H. L. Solverg, T. J. Agnew, and A. A. Porter, Corrosion of Unstressed Specimens of Alloy Steel by Steam at Temperatures Up to $1800^{\circ} \mathrm{F}$, Trans ASME, 65: 301 (1943). 
131. H. S. Blumberg, Eight Years of Experience with Austenitic Steel Piping Materials at Elerated Stedm Conditions, Trans ASME, 79: 1371 (1957).

132. E. Scheil and K. Kiwit, Arch Elsenhuttenu, 9: 405 (1936).

133. H. M. McCullough, M. G. Fontana, and H. F. Beck, Formation of Oxides on Some Stamless Steels at High Temperatures, Trans ASME, 43: 404 (1951).

134. W. C. Leslie and M. G. Fontana, Mechanism of the Rapıd Oxidation of High Temperature, High Strength Alloys Contamng Molybdenum, Trans ASME, 41: 1213 (1949).

135. I. David and A. J. E. Welch, Oxidation of Magnetite and Related Spinels, Trans Faraday Soc, 52: 1642 (1956).

136. H. Hohe and F. Eberle, Experimental Superheater for Steam at 2000 psi and $1250^{\circ} \mathrm{F}$-Report Atter 14,281 Hours of Operation, Trans ASME, 79: 307 (1957).

137 W. K. Boyd and H. A. Pray, Corrosion of Stannless Steels in Supercritical W ater, Corrosion, 13: 375t (1957).

138. R. C. Ulmer, Corrosion Study of Metals for Supercritical Pressure Power Plants, presented at the National Association of Corrosion Engineers 15th Conference, San Francisco, Cahifornia, March 14-18, 1960.

139. F. Eberle and C. H. Anderson, Scaling Behavior of Superheater Tube Alloys in ASME High Temperature Steam Research Tests at $1100-1500^{\circ} \mathrm{F}$, ASME Paper 61-Pwr-3, San Francisco National Power Conference, September 2527, 1961, Trans ASME, Ser A[3], 84: 223 (1962).

140. G. G. Gaul and W. L. Pearl, Corrosion of Type 304 Stamless Steel in Simulated Superheat Reactor Enuronments, USAEC Report GEAP-3779, General Electric Company, Vallecitos Atomic Laboratory, Oct. 16, 1961.

141. L. I. Van Torne, R. F. Kirby, and C. N. Spdarıs, Materials Evaluation for Nuclear Superheat Reactor Seruce, Task C, in Nuclear Superheat Project, Eighth Quarterly Report, Apri1-June 1961, USAEC Report GEAP-3785, General Electric Company, Atomic Power Equpment Department.

142. S. Greenberg, in Proceedings of the Nuclear Superheat Meeting No. 6, March 7, 8, and 9, 1962, Windsor, Connecticut, USAEC Report TID-7634 (COO-265), Chicago Operatiors Office, Mar. 30, 1962.

143. W. L. Pearl and G. G. Gaul, General and Stress Corrosion of High Nickel Alloys in Simulated Superheat Reactor Environment, USAEC Report GEAP4165, General Electric Company, Atomic Power Equipment Department, January 1963.

144. H. J. Pessl, in Proceedings of the Nuclear Superheat Meeting No. 7, September 12, 13, and 14, 1962, Sioux Falls, South Dakota, USAEC Report TID-7658 (COO-266), Chicago Operations Office, Oct. 30, 1962.

145. W. E. Ruther, in Proceedings of the Nuclear Superheat Meeting No. 7, September 12,13, and 14, 1962, Sioux Falls, South Dakota, USAEC Report TID-7658 (COO-266), Chicago Operations Office, Oct 30, 1962

146. H. H. Uhlig and R. A. White, Some Metallurgical Factors Attecting Stress Corrosion Cracking of Austemtic Stamless Steels, Trans Am Soc Metals, 52: $830(1960)$.

147. F. S. Lang, Effects of Trace Elements on Stress Corrosion Cracking of Austenitic Stainless Steels in Chloride Solutions, Corrosion, 18: 378t (1962).

148. General Electric Company, Atomic Power Equipment Department, Nuclear Superheat Project Thirteenth Quarterly Report, July-September 1962, USAEC Report GEAP-4126, 4.1 
149. E. A. Lees, R. F. Boyle, and C. N. Spalaris, Nuclear Superheat Project, Fabrication, Irradiation, and Evaluation of Superheat Fuel Element SH-1 and SH-2, USAEC Report GEAP-3387, General Electric Company, Atomic Power Equipment Department, April 1960.

150. C. N. Spalaris, R. F. Boyle, T. F. Evans, and E. L. Esch, Design, Fabrication, and Irradiation of Superheat Fuel Element SH-4B in VBWR, USAEC Report GEAP-3796, General Electrie Company, Atomic Power Equipment Department, Sept. 1, 1961.

151. R. T. Pennington, Nuclear Superheat Project, Ninth Quarterly Progress Report, July-September 1961, Fuel Development Task B, USAEC Report GEAP-3877, General Electric Company, Atomıc Power Equipment Department.

152. General Electric Company, Atomic Power Equipment Department, Nuclear Superheat Project, Tenth Quarterly Report, Fuel Development Task B, USAEC Report GEAP-4240, October-December 1961.

153. John C. Griess et al., BONUS Bollng Water Nuclear Superheat Reactor Project. Tash Force Report on Chloride Stress Corrosion Cracking of Austenitic Stainless Steel, USAEC Report TID-16888, October 1962.

154. K. C. Antony et al., Remarks Concerning Material for Nuclear Fuel Cladding, USAEC Report GEAP-4060, General Electric Companv, Vallecitos Atomic Laboratory, Sept. 4, 1962.

155. M. F. Lyons, F. A. Comprell, V. E. Hazel, and H. E. Townsend, Plastic Strain in Thin Fuel Element Cladding Due to $\mathrm{UO}_{2}$ Thermal Expansion, USAEC Report GEAP-3739, General Electric Company, Atomic Power Equipment Department, July 7, 1961.

156. J. H. Hoke and F. E. Eberle, Experimental Superheater for Steam at 2000 psi and $1250^{\circ} \mathrm{F}$, Report After 14,281 Hours of Operation, contributed by the Resedrch Committee on High Temperature Steam Generation and presented at a joint session with the Power Division, Diamond Jubilee Annual Meeting, Chicago, Illinois, November 13-18, 1955, of the American Society of Mechanical Engineers, ASME Paper No. 55-A-102, Trans ASME, 79: 307317 (February 1957).

157. M. T. Simnad, The Stabılity and Properties of Alloy Steels at Elevated Temperatures, A Literature Survey, USAEC Report GAMD-1769, General Atomic Division, General Dynamics Corporation, Nov. 21, 1960.

158 C. L. Clark, J. J. B. Rutherford, A. B. Wilder, and M. H. Cordovi, Metallurgical Evaluation of Superheater Tube Alloys After 12 and 18 Months' Exposure to Steam at 1200,1300 , and $1500^{\circ} \mathrm{F}$, ASME Paper 61-Pwr-4, San Francisco National Power Conference, September 25-27, 1961, Trans. ASME, Ser A J Eng Pouer, 84: 258-288 (1962).

159. F. B. Foley and V. N. Krivobok, Sigma Formation in Commercial $\mathrm{Nl}-\mathrm{Cr}-$ Fe Alloys, Metal Progr, 71: 81 (1957).

160 G. B. Greenough and P. Murray, Fuel Elements for U.K. Gas Cooled Reactors, Trans AIME, Spec Rept Ser, No 11, 83-107 (1962).

161. H.S. Beattie, Phase Changes in Precipitation Hardening Nickel-Chromium Iron Alloys During Prolonged Heating, Discussions, Trans AIME, 218: 368 (1960).

162. H. T. Watanabe, G. T. Geering, and J S. Brunhouse, Trans Am Nucl Soc, 5: 484 (1962); also Semiannual Progress Report for Army Gas Cooled Reactor Systems Program, USAEC Report IDO-28590, August 1962. 
163. R. W. Swindeman and D. A. Douglass, The Fallure of Structural Metals Subjected to Strain Cycling Conditions, Trans ASME, Ser D J Basic Eng, 81: 203 (1959).

164. J. F. Tavernellı and L. F. Coff 1 , Jr., A. Compilation and Interpretation of Cyclic Strain Fatigue Tests on Metals, Trans Am Soc Metals, 51: 438 (1959).

165. M. B. Reynolds, in Nuclear Superheat Project Fourteenth Quarterly Report, October-December 1962, USAEC Report GEAP-4153, 4.26, General Electric Company, Atom1c Power Equipment Department, Jan. 15, 1963.

166. N. E. Hinkle, Solıd State Division Annual Report, for Period Ending August 31, 1959, USAEC Report ORNL-2829, Oak Ridge National Laboratory, Dec. 11,1959 .

167. C. R. Cupp, The Effect of Neutron Irradiation on the Mechanical Properties of Inconel X and Inconel-Nickel Chromium Alloys, Report CRMet-870 (AECL-948), International Nickel Company, Inc., September 1959.

168. R. C Robertshaw and C G Colluns, The Effect of Neutron Irradiation on the Stress Rupture Strength of A-286 and Inconel X, Trans Am Soc Metals, 55565 (1962).

169 Hanford Atomic Products Operation, Steam Cooled Power Reactor Evaluation-Beloyarsk (URAL) Reactor, USAEC Report HW-67473, April 1961.

170. J Barnard, The Reactor and Plant Design for the ESADA EVESR, Preprint Paper 61-W A-223, Winter Annual Meeting, Nov. 26-Dec 1, 1961, Amer1can Society of Mechanical Engineers, New York, 1962, also D H Imhoff and R T. Pennington, Nuclear Superheat for Bolling Reactors, Nucl. Eng., $7330(1960)$.

171. Design and Hazards Report, Bolling Reactor Experıment V (BORAX-V), USAEC Report ANL-6302, Argonne National Laboratory, May 1961, also Nucl Eng, 7 90 (1962).

172. Superheat for BW R, Pathfınder CRBR Project, Nucl Eng , 5397 (1960), also Allis Chalmers Critical Facility, Final Safeguards Report, USAEC Report ACNP-5910, May 1, 1959

173. BONUS Superheat Reactor Off to Good Start, Nucleonus, 19(7): 90 (July 1961); also Development of BONUS Type Superhedter Fuel Assembly, USAEC Report GNEC-197, Oct 31, 1961, and BONUS Zero Power Critical Experiments and Applications to the Reactor Design, USAEC Report GNEC198, Feb 10, 1962

174 Stanley Kass, The Development of the Zircaloys, in Proceedings of the USAEC Symposium on Zirconium Alloy Development, Held in Castlewood, Pleasanton, California, November 12-14, 1962 USAEC Report GEAP-4089, General Electric Company, Vallecitos Atomic Laboratory Nov. 30, 1962

175 R. S Ambortsumyan et al, Mechanical properties and Corrosion Resistance of Zirconium and Its Alloys in Water, Steam and Gases at High Temperatures, in Proceedings of the Sccond Lnted Nations International Conference on the Pcaceful Uses of Alomu Energy, Geneva, 1958, Vol. $5 \mathrm{pp}$ 12-33, United Nations, New York, 1958

176 H. Loevenstein and H. L Gilbert, Zirconium \& Review and Summary of Published Data, USAEC Report AECU-3818, Harvey Aluminum Company, October 1958.

177. Benjamin Lustman and Frank Kerze, Jr. (Eds.), The Vetallitgy of Lirconum, MeGraw-H1ll Book Company, Inc, New York, 1955. 
178. G. L. Miller, Zırconıum, 2nd ed., Academic Press Inc., New York, 1957.

179 B. Lustman and J G. Goodwin, Zirconium and Its Alloys, Chap. 32, Reactor Handbook, 2nd ed., Vol. 1, Materials, Interscience Publishers, Inc., New York, 1960.

180. Brian Cox, Recent Developments in Zirconium Alloy Corrosion Technology, Progr Nucl. Energy, Ser. IV, Vol IV, 166-188 (1961)

181. D. E. Thomas, Corrosion of Zirconium in High-temperature Water, Nuclear Engineering, Part II, pp. 16-22, American Institute of Chemical Engineers, New York, 1954.

182. D. E Thomas, Aqueous Corrosion of Zirconium and Its Alloys at Elevated Temperatures, in Proceedings of the United Nations International Conference on the Peaceful Uses of Atomic Energy, Geneva, 1955, Vol. 9, pp. 407-413, United Nations, New York, 1956.

183 C M Schwartz, D. A. Vaughan, and C G. Cocks, Identıficatıon and Growth of Oxide Films on Zirconıum in High-temperature Water, USAEC Report BMI-793, Battelle Memorial Institute, Dec 17, 1952

184. E. Hillner and J. N. Chirigos, The Effect of Lithium Hydroxide and Related Solutions on the Corrosion Rate of Zircaloy in $680^{\circ} \mathrm{F}$ Water, USAEC Report WAPP-TM-307, Westinghouse Electric Corporation, Bettis Atomic Power Laboratory, August 1962

$185 \mathrm{~J}$ N. Chırıgos, S Kass, W W. Kırk, and G. J. Salvaggıo, Development of Zircaloy-4, in Fuel Element Fabrication uith Special Emphasis on Cladding Mater lals, Academic Press Inc., New York, 1961

186. H. S Kalish and H. M. Cobb, Investigations of the Effects of Fabrication Variables on the Corrosion Resistance of Zircaloy-2, Am Soc Metals, Trans Quart, 54247 (1961), see also discussion by S. L. Ames and J Preston, Am Soc Metals, Trans Quart, 54781 (1961).

187 S. Kass and W. W. Kırk, Corrosion and Hydrogen Absorption of Nickelfree Zircaloy-2 and Zircaloy-4, Am Soc Vetals, Trans Quart, 5577 (1962).

188. B Griggs, H. P. Maffel, and D. W. Shannon, Multiple Rate Transitions in the Aqueous Corrosion of Zircaloy, $J$ Electrochem Soc, 109665 (1962).

189. W K Anderson and M. J. McGoff, Corrosion of Zircaloy in Crevices Under Nucleate Boiling Conditions, USAEC Report KAPL-2203, Knolls Atomic Power Laboratory, Apr. 13, 1962.

190. H. Corıou, L. Grall, J Meunier, M Pelids, and H Willrmoz, Corrosion des zircaloy dans devers nickeleux alcalıns à haute temperature, Corrosion of Reactor Materials, Vol. II. pp. 193-208, International Atomic Energy Agency, Vienna, 1962

191 F. H Krenz, The Steam and Water Corrosion of Zirconium Alloys, in Firsl International Congress Metallic Corrosion, Butterworth \& Co., London, 1962.

192 W E Berry, E L White, and F W. Fink, Effect of Additions to Zircaloy on Hydrogen Pickup During Aqueous Corrosion, USAEC Report BMI-1402, Battelle Memorial Institute, Dec. 29, 1959

193 D W Shannon, Conditıons for the Hydriding of Zirconıum and Zircaloy An Interpretive Literature Survey, USAEC Report HW-55460, Hanford Atomic Products Operation, Apr. 7, 1958.

194 G J Biefer, L M. Howe, A. Sawatsky, and F H Krenz, Hydrogen Pick-up in Zirconium Alloys, A Review of Data Up to June 1, 1959, Canadıdn Report CRMet-849 (AECL-919), September 1959. 
195. A. P. Larrick, Fretting Corrosion of PRTR Fuel Elements and Process Tubes, USAEC Report HW-68613, Hanford Atomic Products Operation, Mar. 14, 1961.

196. H. Coriou, Less Problèmes de corrosion aqueuse dans le domaine de l'energie nucléaire, Corrosion Sci., 1. 132 (1961). (Based on work of G. E Galonian, NACE Publication 60-13, 1960, and G. E. Galonian, E. J. Callahan, and R. F. Koenig, USA EC Report KAPL-M-GEG-4, 1955.)

197. R. S. Ambortsumyan et al., Fuel Elements for Water-cooled Water Moderated Reactors of Atomic Power Plants, in Proceedings of the Second Unuled Nations International Conference on the Peaceful Uses of Atomic Energy, Geneva, 1958, Vol. 6, pp. 645-654, United Nations, New York, 1958.

198. O. S. Ivanov and V. K. Grigorovich, Structure and Properties of Zirconium Alloys, in Proceedings of the Second United Nations International Conference on the Peaceful Uses of Atomac Energy, Geneva, 1958, Vol. 5, pp. 3451, United Nations, New York, 1958.

199. S. B. Dalgaard, Corrosion and Hydriding Behavior of Some $\mathrm{Zr}-2.5$ wt.\% $\mathrm{Nb}$ Alloys in Water, Steam, and Various Gases at High Temperatures, in Corrosion of Reactor Materials, Vol. II, pp. 159-191, International Atomic Energy Agency, Vienna, 1962.

200. H. H. Klepfer, Zirconium-Columbium Binary Alloys for Boiling Water Reactor Use, Part I, Corrosion Resistance, J. Nucl. Mater., 9. 65 (1963).

201. H. H. Klepfer, Zirconium -Columbium Binary Alloys for Boiling Water Reactor Use, Part II, Corrosion Hydrogen Embrittlement, J. Nucl. Mater, 9. 77 (1963).

202. D. L. Douglass and B. E. Dearing, Effect of Heat-treatment on the Corrosion of Zirconium-2 at.\% Tin -2 at.\% Niobium, USAEC Report KAPL-2071, Knolls Atomic Power Laboratory, Jan. 20, 1960.

203. H. A. Fisch, Hydrogen Absorption by Zirconium -2 at. $\%$ Tin -2 at. $\%$ Niobium Alloy During Corrosion, USAEC Report KAPL-2149, Knolls Atomic Power Laboratory, Jan. 19, 1961.

204. H. H. Klepfer, W. V. Cummings, and R. E. Blood, The Effect of Heat Treatment on the Corrosion Resistance and Corrosion Hydrogen Embrittlement of Some $\mathrm{Zr}-\mathrm{Nb}$ Alloys, USAEC Report GEAP-3729, General Electric Company, Vallecitos Atomic Laboratory, May 22, 1961.

205. C. J. Baroch and W. C. Rous, Evaluation of Zirconium, $1.5 \mathrm{wt} \%$ Niobium Cladding for Use in Boiling Water Reactor Environments. USAEC Report GEAP-4098, General Electric Company, Atomic Power Equipment Department, October 1962.

206. R. C. Asher and B. Cox, The Effects of Irradiation on the Oxidation of Zirconium Alloys, Corrosion of Reactor Materials, Vol. II, pp. 209-221. International Atomic Energy Agency, Vienna, 1962.

207. W. A. Burns and H. P. Maffei (Hanford), Neutron Irradiation and Cold Work Effects on Zircaloy-2 Corrosion and Hydrogen Pickup. paper presented at Twelfth Annual USAEC Corrosion Symposium, May 1963. (Some of the data are also reported in Interim Hanford Report HW-76636, December 1962.)

208. J. Paul Pemsler, Corrosion of Zirconium Alloys in 900 and $1000^{\circ} \mathrm{F}$ Steam, USAEC Report NMI-1235, Nuclear Metals, Inc., Mar. 15, 1960.

209. S. Greenberg, Zirconium Alloys for Use in Superheated Steam, J. Nucl. Mater., 4. 334 (1961). 
210. S Greenberg and C. A. Youngdahl, Development of Zirconıum Alloys for Use in Supercritical Steam at $600 \mathrm{Psl}$, presented at the 19th Conference and Corrosion Show, National Association of Corrosion Engineers, New York, Mar. 11-15, 1963 (to be published in Corrosion)

211. J N. Wanklyn, J. T. Demant, and D. Jones, The Corrosion of Zirconium and Its Alloys by High Temperature Steam, General Introduction and Part I. The Effect of Alloy Composition, British Report AERE-R-3655, March 1961.

212. B Cox, M. J. Davies, and T. Johnston, The Oxidation and Corrosion of Zirconium and Its Alloys. XI. The Oxidation Kinetics of Zirconium-Niobium Alloys in Steam at $300-500^{\circ} \mathrm{C}$, Britısh Report AERE-R-3257, June 1960.

213. V. Rösler, Corrosion Resistance of Improved Zirconium Alloys in High Temperature Steam, in Proceedings of the USAEC Symposium on Zirconium Alloy Development, Held in Castlewood, Pleasanton, California November 12-14, 1962, USAEC Report GEAP-4089, General Electric Company, Vallecitos Atomic Laboratory, Nov. 30, 1962

214. C F Britton and J. N Wanklyn, Inhibition by Boric teid of the Oxidation of Zırconıum in High Pressure Steam, $J$ Nucl Mater, 5326 (1962)

215. J N Wanklyn, D R Silvester, J. Dalton, and N J M Wilkins, The Corrosion of Zirconium and Its Alloys in High Temperature Steam Part II The Uptake of Hydrogen During Corrosion, Britısh Report AERE-R-3768, July 1961

216. B Cox, The Oxidation and Corrosion of Zirconium and Its Alloys YII Hydrogen Absorption by Zircaloy-2 and Some Other Alloys During Corrosion in Steam, British Report AERE-R-3556, January 1961

217 D. Weinstein, Development of Improved Zırconıum Alloys for Use in Suptrheated Water and Steam, in Proceedings of the USAEC Symposium on Zirconıum Alloy Development, Held in Castlewood, Pledsanton, Calıfornia, November 12-14,1962, USAEC Report GEAP-4089, General Electric Company, Vallecitos Atomic Laboratory, Nov. 30, 1962

218 F. H. Krenz, Can Hydrogen Pick-up in Zircaloy be Prevented? Canadian Report CRGM-1081 (AECL-1626), October 1962

219 E A Gulbransen and K F Andrew, Reaction of Hydrogen with Preoxidized Zircaloy -2 at 300 to $400^{\circ} \mathrm{C}$, J Electrochem Soc, 104709 (1957)

220 E A Gulbransen and K F Andrew, Nature and Properties of the Thin OxIde Film Formed on Zirconum and Zircaloy, Rtactıє Vetals, Interscience Publishers, Ine, New York, 1959

221 R. R Hood and L Isakoff (Comps.) Heavy Water Moderated Power Reactors, Progress Report, June 1962, USAEC Report DP-755 E I Du Pont de Nemours and Co, Inc, July 1962

$222 \mathrm{R} F$ Boyle and $\mathrm{T} J$ Kisiel Hydrogen Permeation of Zircaloy-2 Corrosion Films, USAEC Report WAPD-BT-10, pp 31-48, Westınghouse Electric Corporation, Bettis Plant, October 1958

223 D. W Shannon, The Role of the Oxidation Rate on the Hydriding of Zircaloy2 by Gaseous Hydrogen Interım Report No 3, USAEC Report HW-67811 Hanford Atomic Products Operation Dec. 15, 1960

224 D W Shannon, Effect of Oxıdation Rate on Hydriding of Zirconium Alloys in Gas Mixtures Containing Hydrogen USAEC Report HW-76562, February 1963 presented at the 19th Conference and Corrosion Show, National Association of Corrosion Engineers New York, Mar 11-15 1963; Comosion, $19414 \mathrm{t}-420 \mathrm{t}(1963)$ 
225 Personal communications and discussion with Brian Cox, Atomic Energy Research Establishment, and with D L. Douglass, Vallecitos Atomic Power Laboratory

$226 \mathrm{P}$ Kofstad and D J Ruzickd, Note on the Defect Structure of $\mathrm{ZrO}_{2}$ and $\mathrm{HfO}_{2}$, in Proceedings of the USAEC Symposium on Zirconium Alloy Deve1opment, Held in Castlewood, Pleasanton, California, November 12-14, 1962, USAEC Report GEAP-4089 (Vol. II), Paper 20; also $J$ Electrochem Soc, 110: 181 and 1285 (1963).

227 R D Misch and C J Van Drunen, Corrosion Studies of Ternary Zirconium Alloys in High-temperdture Water and Steam, USAEC Report ANL-6370, Argonne National Laboratory, July 1961

228 Brian Cox, Some Effects of Pressure on the Oxidation of Zircaloy-2 in Steam and Oxygen, in Proceedings of the USAEC Symposium on Zirconium Alloy Development, Held at Castlewood, Pledsanton, Calıfornia, November 12-14, 1962, USAEC Report GEAP-4089 (Vol. II), Paper 16, General Electric Company, Vallecitos Atomic Laboratory, Nov. 30, 1962

229 D H. Bradhurst, H.S Isaacs, and $J \mathrm{~S}$ Llewelyn Leach, Fundamental Studies in Corrosion, A Report to the Central Electricity Generating Board, Imperial College of Science and Technology, London, April 1962

230 R. L Mehan and $F$ W Wresinger, Mechanical Properties of Zircaloy-2, USAEC Report KAPL-2110, Knolls Atomic Power Laboratory, Feb 1, 1961

231 J. M. Markowitz, The Thermal Diffusion of Hydrogen in Zircaloy-2, in Proceedings of the Second Unted Nations International Conference on the Peaceful Uses of Atomic Energy, Genera, 1908, Vol 6 pp. 235-239 United Nations, New York, 1958

232 J. M Markowitz, The Thermal Diffusion of Hydrogen in Alpha-Delta Zircaloy-2, Trans AIME, 221819 (1961)

233 R R Hood (Comp.), Heavy Water Moderated Power Reactors, Progress Report, March 1962, USAEC Report DP-725, E I. Du Pont de Nemours and Co , Inc , April 1962

234 R P. Marshall and M R Louthan, Jr., Tensile Properties of Zircaloy with Oriented Hydrides, in Proceedings of the USAEC Symposium on Zirconium Alloy Development, Held in Castlewood, Pleasanton, Calıfornia, November $12-14,1962$, USAEC Report GEAP-4089 (Vol. II), Paper 14,General Electric Company, Vallecitos Atomic Laboratory, Nov 30, 1962

235 D Weinstein and Fred C Holtz, Susceptibility of Zirconium and Zirconium Alloys to Delayed Fallure of Hydrogen Embrittlement (to be published by American Society for Metals)

236 H F Turnball, W J. Hurford, i B Brus, and A. W Klein, Manufacture of the Seed Fuel Elements for PWR, in Proceedings of the Second Unuted Nations International Conference on the Peaceful Uses of Atomic Energy, Geneva, 1958, Vol 6, pp. 481-485, United Nations, New York, 1958

237. J. Glatter et al., The Manufacture of PWR Blanket Fuel Elements Containing High-density Uranium Dioxide, in Proceedings of the Second United Nations International Conference on the Peaceful Uses of Atomic Energy, Geneva, 1958, Vol. 6, pp. 630-644, United Nations, New York, 1958.

238. Directory of Nuclear Reactors, Vol. IV, Pouer Reactors, International Atomic Energy Agency, Vienna, 1962.

239 B Lustman et al , Zircalcy Cladding Performs Well in PWR, Nucleonics, 19 58(1961). 
240 F K Pittman, Power Reactor Experience, Combustion, 3433 (1962)

241 N A Kershaw, G L. Redman, and A F Veras, Dresden Nuclear Plant Reports on Operation and Maintenance, Elec World, 158 42(1962).

242 C N Spalarıs, Fuel Elements for Dresden, Nucl Eng, 4254 (1959)

243. Argonne National Laboratory, The Experimental Boiling Water Reactor (EBWR), USAEC Report ANL-5607, Argonne National Laboratory, May 1957

244 C. N Spalaris, Fabrication of Zircaloy-2 Channels for Vallecitos Boiling Water Reactor Fuel Assemblies, Nucl Scl Eng , 637 (1959).

245 D H Imhoff, W. H Cook, R. T Pennington, and C N Spalaris, Experimental Programs in the Vallecitos Bouling Water Reactor, Report GER-1600, General Electric Company, presented at American Nuclear Society Meetıng, June 17, 1959.

246 C F Reinke and R. Carlander, Examination of Irradiation EBWR Core-I Fuel Elements, USAEC Report ANL-6091, Argonne National Laboratory, July 1960

247 R. M. Fryar, The Design of the Experimental Reactor for the Plutonium Recycle Program, in Proceedings of the Second United Nations International Conference on the Peaceful Uses of Atomic Energy, Geneva, 1958, Vol 9, pp 221-235, United Natıons, New York, 1958

248 V. A Ellott and G J Stathakıs, The SENN Nuclear Power Station-Europe's First Full-scale BWR, Nucl Power, 487 (October 1959)

249 W R. Thomas, Zırconıum Alloys for Water-cooled Power Reactors, in Fuel Element Fabrication with Special Emphasis on Cladding Materials, Academic Press Inc, New York, 1961

250 I N. MacKay, General Description of the Nuclear Power Demonstration Plant, presented at November 1962 Meeting of the American Nuclear Soc1ety

251 W H Zinn (Ed), The New Production Reactor, Power Reactor Technol, 375 (September 1960)

252 R G McGrath and Mayhue A Bell, CVTR Criticality, Nucl News, 615 (June 1963)

253 R. R Hood and L Isakoff (Comps.), Heavy Water Moderated Power Reactors, Progress Report, April 1961, USAEC Report DP-615, E I. Du Pont de Nemours and Co, Inc., June 1961.

254. G H Chalder, Problems in the Use of Thin Zircaloy Cladding for Uranium Dioxide Fuel, in Fuel Element Fabrication with Special Emphasis on Cladding Materials, Academic Press Ine, New York, 1961

255. C N. Spalarıs, General Electrıc Company, Atomıc Power Equipment Department, personal communication

256 S. Greenberg and W E Ruther, Aqueous Corrosion of Magnesium Alloys, USAEC Report ANL-6070, Argonne National Laboratory, May 1960.

257 D C Vreeland, G. G Gaul, and W L. Pearl, Corrosion of Carbon and Lowalloy Steels in Out-of-plle Bolling-water Reactor Environment, Corrosıon, 17 269t (1961)

258 D C Vreeland, G G Gaul, and W L. Pearl, Corrosion of Carbon Steel and Other Steels in Simulated Bolling-water Reactor Environment Phase II, Corrosion, 18 368t (1962)

259 W. E Ruther and R. K. Hart, The Influence of Oxygen on the High Temperature Aqueous Corrosion of Iron, Corrosion, 19 127t (1963). 
260. F. H. Krenz, Atomic Energy of Canada, Limited, personal communication.

261. D. J. Maykuth, W. D. Klopp, R. I. Jaffee, W. E. Berry, and F. W. Fink, Development of Corrosion-resistant Niobium-base Alloys, USAEC Report BMI-1437, Brookhaven National Laboratory, May 12, 1960.

262. W. D. Klopp, W. E Berry, and D. J. Maykuth, The Hot Water Corrosion Resistance of Columbium and Columbium Alloys, Columbnum Metallurgy, Interscience Publishers, Inc., New York, 1961.

263. W. E. Berry, Le comportement à la corrosion de l'alliàge nickel-chrome Inconel et de alliàges de niobıum dans un réacteur à l'eau presseurısée: II Etude du niobium et de ses alliàges, Energie Nucl., 4: 204 (1962).

264. G. E. Darwin and J. H. Buddery, Beryllium, Butterworth \& Co., London, 1960.

265. D. S. Kneppel, Corrosion of Beryllium in $600^{\circ} \mathrm{F}$ Water, USAEC Report NMI1190, Nuclear Metals, Inc., Sept. 10, 1957.

266. D. W. Aylmore, S. J. Gregg, and W. B. Jepson, The High Temperature Oxidation of Beryllium - Part IV -in Water Vapour and in Moist Oxygen, J. Nucl. Mater., 3: 190 (1961).

267. H. A. Fisch, D. L. Douglass, and B. E. Dearing, The High Temperature Steam Corrosion of Columbium - Vanadium Alloys, Columbıum Metallurgy, Interscience Publishers, Inc., New York, 1961.

268. D. L Douglass, The Kinetics and Mechanism of Columbium Alloy Corrosion in Superheat Steam, Report APED-3964, General Electric Company, Atomic Power Equipment Department, June 1962.

269. J. A. DeMastry, A. A. Bauer, and F. A. Rough, Development of Niobiumbase Alloys for Use in a Nuclear Superheater, Quarterly Progress Report, October-December 1962, USAEC Report BMI-X-10030 (EURAEC-546), Battelle Memorial Institute, Jan. 1, 1963. 


\section{Metallic Fuels}

by

Stanley F. Pugh and

Benjamin R. Butcher

United Kingdom Atomic Energy Authority Atomic Energy Research Establishment Harwell, England 


\section{-}

$T$ his article describes the present state of knowledge of the physical metallurgy and in-pile behavior of metallic fuel materials for power reactors. An indication of the technological status of each type of fuel is also given.

In the first, and largest, section are discussed "pure" uranium and very dilute alloys, 1.e., alloys with less than a total of about $1 / 4$ wt. $\%$ of alloying elements and impurities. The principal alloying elements, iron, silicon, aluminum, and chromium, were originally added to achieve grain refinement by some form of beta heat treatment; but, in power reactors with fuel temperatures in the high alpha range, some alloying elements have been found to have important effects on other properties, such as creep, recrystallization, and swelling. This group of allcys accounts for the major use of metallic fuel in power reactors, and, although many of the higher alloys have improved properties, they suffer from economic competition with dilute alloys on the one hand and ceramic fuels on the other.

Subsequent sections are devoted to uranium-molybdenum alloys, other uranium alloys, and thorium-metal fuels. Plutonium-bearing uranium-base fuels are only briefly discussed.

Cladding materials are not included in this article (see review entitled "Behavior of Cladding Materials in Water and Steam Environments"). The behavior of complete fuel elements, which depends as much on the cladding material as on the fuel material, is referred to only briefly.

\section{URANIUM AND ITS VERY DILUTE ALLOYS}

Under reactor conditions uranum and its dilute alloys undergo several changes that affect their use as fuel-growth, creep, swelling, and cracking. The mechanisms of these changes are frequently complex, and in many areas agreement has not been reached.

\section{Properties}

The properties that affect the dimensional and other changes that uranium fuels undergo include thermal conductivity, diffusion, and compatibility.

THERMAL CONDUCTIVITY At the temperatures in a power reactor, the phonon wavelength in uranium would be about equal to the ionic diameter. Thus a given concentration of impurity atoms or displaced atoms would have the greatest effect on heat transport in uranum at reactor temperatures, whether transport is by electronic or lattice conduction, when the impurities or defects are dispersed on an atomic scale. 
Displaced atoms and vacancies formed on 1 rradiation will be clustered from room temperature up to about $500^{\circ} \mathrm{C}$; at higher temperatures they will anneal away altogether. The decrease in thermal conductivity that is due to these defects alone will therefore be small or zero, and the conductivity will reach equilibrium after a few hours in pile. The effect of the solid fission products and the impurity or alloying elements originally present will depend on their state of aggregation. This changes markedly over the fuel-temperature range in a gas-cooled reactor owing to variation in solubility and rates of precipitation plus dissolution caused by fission fragments. From 300 to $600^{\circ} \mathrm{C}$, the state of aggregation of all foreign atoms is a more $1 \mathrm{~m}$ portant variable than the total content of impurities. Because of its impurities, unirradiated reactor-grade uranium has a thermal conductivity of only about 90 percent of that of pure uranium.

An additional factor, however, the formation of fission-product gas bubbles, decreases thermal conductivity during irradiation. The conductivity of porous aggregates has been calculated with the assumption that the bubbles do not conduct heat. ${ }^{1}$ The calculation is approximate, but, when the volume increase is small so that the distortions of the isotherms of neighboring bubbles do not overlap, the result is valid. The proportional decrease in conductivity is given by

$$
1-\frac{1-p_{v}}{1+\left(p_{v} / 2\right)}
$$

where $p_{y}$ is the volume fraction of voids. Thus, if the volume fraction of fission-gas voids is 3 percent, the decrease in conductivity is about 5 percent. Total decreases in thermal conductivity measured on irradiated bars range from about 5 to 15 percent, as might be expected from the temperature variation possible in each of the factors. ${ }^{2-4}$

DIFFUSION Diffusion occurs in uranium and its alloys during recovery, precipitation, phase transformation, solution, bonding, swelling, and degassing. Because all can occur in and out of pile, the study of diffusion is important for the nuclear metallurgist. It also has an interest for the physicist since both alpha and beta uranium might be expected to show anisotropic diffusion effects and gamma uranium shows diffusion constants differing from those expected. Rothman ${ }^{5}$ has critically reviewed the diffusion experiments up to late 1961, including methods, theory, and application.

The self-diffusion rates in gamma uranum are now known with some certainty since three independent sets of results agree remarkably well. The diffusion rates are rapid compared with those in beta and alpha uranium, showing a distinct jump at the beta-gamma phase boundary, and both the activation energy and the $D_{0}$ value are low. The diffusion mechanısm in gamma uranium is, therefore, a matter for 
debate. Chemical diffusion studies have not so far helped to resolve this debate because the diffusion constants approach more normal values, and Kirkendall effects that have been observed seem to prove that chemical diffusion occurs by a vacancy mechanism. Adda and Kirianenk $0^{6}$ have studied the self-diffusion of uranium in alloys containing 10 at.\% of molybdenum, niobium, or zirconium. Molybdenum increased the activation energy for self-diffusion, zirconium reduced it, and niobium left it comparatively unaffected. $D_{0}$ was increased slightly by molybdenum and decreased by both zirconium and niobium. The theoretical significance of these results is not clear.

Practically, the interdiffusion at high temperatures of uranium with most of the simple high-temperature cladding materials has been sufficiently investigated, but the need for information on ternary systems may arise.

There is also good agreement on self-diffusion in beta uranium. There has been no absolute proof of the anisotropy of diffusion because it is impossible, without the most elaborate techniques, to arrange and verify that diffusion will take place in a beta-phase single crystal. Yet, diffusion effects that have arisen in small specimens could be very well explained by supposing that anisotropic diffusion took place in only one or two crystals. The diffusion of solutes in beta uranium has been somewhat neglected, and it is therefore very doubtful that sufficient information exists to correlate with the kinetics of precipitate formation in the beta phase, especially in ternary systems.

Earlier measurements of self-diffusion in alpha uranium showed very little evidence of anisotropy, considering the possible errors involved in the methods applied. Later and more refined work by Rothman et al., ${ }^{7}$ however, has shown that at $625^{\circ} \mathrm{C}$ the diffusion rates in the $\left[\begin{array}{lll}1 & 0 & 0\end{array}\right]$ and $\left[\begin{array}{lll}0 & 0 & 1\end{array}\right]$ directions are equal and are much greater than diffusion rates in the $\left[\begin{array}{lll}0 & 1 & 0\end{array}\right]$ direction. Thus diffusion along the closely packed planes of alpha uranium is much easier than diffusion perpendicular to them. The connection between this anisotropic diffusion and radiation growth is tenuous. This experiment at a temperature high in the alpha range presumably measured diffusion by means of thermally created vacancies. Ir radiation growth, however, is thought to involve the diffusion, below $500^{\circ} \mathrm{C}$, of vacancies and interstitials formed by irradiation, and it may involve different diffusion mechanisms.

The interdiffusion of alpha uranium with ordinary metals usually leads to the formation of intermetallic layers; because this problem affects bonding and compatibility tests, it has been closely studied. Earlier work disclosed some peculıar facts, such as "negatıve actıvation energies" occurring on diffusion under pressure. Kidson ${ }^{8}$ has given mathematical expressions for layer formation, and from them he has suggested a possible explanation for negative activation energies. 
The diffusion of hydrogen in uranium is now known in detail. Recent work $^{9}$ has shown that the diffusion rates are influenced by the concentration of hydrogen and carbon in the beta and alpha phases of uranium, but not in the gamma phase.

Information on the diffusion of rare gases in uranium would be useful in the evaluating of swelling data, but the fact that uranium swells by precipitation of small bubbles of the gas makes it practically impossible to measure the diffusion rates in irradiated material.

Thus the directly applicable aspects of diffusion seem to have been well covered, but the theoretical aspects and those that are less directly applicable need more work.

COMPATIBILITY Uranium or dilute alloys cannot be considered compatible with oxidizing coolants; thus the philosophy of their use in reactors cooled by carbon dioxide or water is different from that for use in fully compatible systems, such as uranium dioxide in water. The use of noncompatible fuels relies on an efficient system for detecting and removing perforated clad fuel elements, and it is important that the extent of disruption shall not be excessive in the time taken to unload defective fuel. Various schemes are avallable to reduce time to unload perforated elements. They include on-power refueling, and great ingenuity has been displayed in the developing of systems for detecting perforations.

The corrosion and oxidation behavior of uranium probably arises from the ease with which extra oxygen is accommodated in the $\mathrm{UO}_{2}$ lattice and the rapid diffusion of interstitial oxygen in $\mathrm{UO}_{2}$. Also, the large volume expansion occurring when uranium metal oxidizes to $\mathrm{UO}_{2}$ generates considerable stress at the oxide-metal interface. The oxide therefore normally forms rapidly and fractures to produce a nonadherent, nonprotective layer. ${ }^{10}$

In water corrosion the hydrogen released by the corrosion appears to accelerate the corrosion, but the mechanism is not known. The acceleration could be due to an altering of the properties of the oxide film by protons in the $\mathrm{f}_{1} \mathrm{~lm} ;^{11}$ to forming of a hydride under tne film, causing film disruption; ${ }^{12}$ or to diffusing of hydrogen into the metal, forming hydride and disrupting the metal. ${ }^{13}$ Corrosion of uranium in water is appreciable at room temperature, and the rate increases with increase in temperature. The corrosion rate is linear with time after an initial slower rate; the preliminary stage is prolonged by the presence of oxygen or hydrogen peroxide but is reduced by hydrogen. ${ }^{14}$ At $300^{\circ} \mathrm{C}$ the corrosion rate of uranium in water is very rapid, but it is reduced considerably by alloying the uranium with molybdenum, niobium, and zirconium separately or in combination. ${ }^{14}$ One of the best alloys is uranium with $5 \mathrm{wt} . \%$ zirconium and $1.5 \mathrm{wt} . \%$ nioblum, but the special heat treatment required to confer corrosion resistance does not confer dimensional stability. ${ }^{15}$ 
Corrosion of a fuel element under conditions of a pressurized-water reactor when the cladding is perforated may be quite different from the behavior of specimens of the uranium fuel tested separately. In the perforated fuel element, the corrosion hydrogen formed inside the cladding is less likely to escape; it may, therefore, combine with either the fuel or the cladding, or with both, and in any case the effect can be deleterious.

A description has been published ${ }^{16}$ of typical behavior of uranium in a bonded coextruded Zircaloy cladding (the cladding having a small hole drilled through it) when exposed to water at $300^{\circ} \mathrm{C}$. The attack appears to be most rap1d along the uranium-Zircaloy interface; a blister is formed, which eventually splits the cladding. This sequence is repeated as the attack spreads along the element on the other hand, an alloy of uranium plus 2 wt.\% zirconium, clad in Zircaloy and diffusion bonded, is claimed to have considerable corrosion resistance at a defect. There is no rapid attack along the $Z_{\text {ircaloy - uranium interface. }}{ }^{17}$ The protection in this case could also be due to the preferential takeup of hydrogen in the cladding rather than in the uranium, to restraint of the uranium opposing its cracking and disintegration, or to plugging of the perforation with dense corrosion product. It should be possible to arrange for the initial corrosion rate, though low, to be adequate to indicate the presence of a perforation.

Uranium temperatures are higher in gas-cooled reactors than in water-cooled reactors. In carbon dioxide the oxidation rate of uranium again follows a linear-rate law and increases with temperature up to a temperature at which the oxide film sinters, ${ }^{18}$ which in the absence of alloying additions is about $900^{\circ} \mathrm{C}$. Several alloying elements, such as molybdenum, niobium, titanium, and copper, lower the reaction rate at high temperatures (higher than $700^{\circ} \mathrm{C}$ ), but they have little effect at reactor-operating temperatures. With copper the effect has been shown to be due to the formation of a layer of $\mathrm{UCu}_{5}$ at the metal-oxide interface, but the beneficial effects produced by the other alloying elements are not now fully understood. In oxygen or air molybdenum is particularly effective in reducing the attack by increasing the plasticity and sintering properties of the oxide. ${ }^{19}$

The behavior of clad uranuum-metal fuel elements when there is a small cladding defect is complicated, and it depends considerably upon the size of the hole in limiting the supply of gaseous reactant to the fuel and the formation of gaseous reaction products. If the gas reacts In one or two stages to form only solid products and if the temperature of the uranium is high enough to allow rapid reaction with the carbon dioxide, a partial vacuum is created inside the cladding. The low pressure increases gas flow through the defect into the cladding interior, which prevents escape of gaseous fission products. Thus detection of the leak is difficult. ${ }^{20}$ The volume expansion associated 
with the oxidation after a certain time splits the cladding at the site of the oxide mound to expose a large area of the fuel. The time depends upon the oxidation and the ductility of the cladding. At this stage a large signal is given by the equipment for detecting burst slugs. Use of special techniques now allows defects to be detected in the early stages.

Radiation has little effect on oxiciation rates of uranium because, even in the absence of irradiation, the oxide film is not protective. With badly swollen irradiated specimens, reactivity increases because of an increase in surface area. If such specimens are porous, the specific surface may be so great that spontaneous combustion ensues when the specimens are exposed to air. ${ }^{21}$

Except with magnesium-alloy cladding, there are compatibility problems with uranium-metal fuel. For service below $500^{\circ} \mathrm{C}$. both alumirum and magnesıum are attractive cladding materials that show different compatibility with uranium. Uranium does not react or alloy with magnesium in the solid or the liquid state, whereas it reacts readily with aluminum above about $250^{\circ} \mathrm{C}$ if the surfaces are clean. ${ }^{5}$ Thus with aluminum cladding an interlayer is necessary. For service much above $500^{\circ} \mathrm{C}$, one of the problems with uranium-metal or -alloy fuel is selection of a compatible cladding material. Iron and nickel form eutectics that melt at about $700^{\circ} \mathrm{C}$. Nioblum, vanadium, and molybdenum react only slowly but are not themselves oxidation resistant.

\section{Mechanism of Irradiation Growth}

Dimensional changes in uranium fuel during irradiation arise from several phenomena. The furst phenomenon to be discussed is that occurring in irradiation growth in unalloyed alpha uranium. Since the Berkeley (England) Conference ${ }^{22}$ in 1961, there have been significant developments in this field.

Study of irradiation growth in alpha uranium has two aims. The first is to elucidate the complete atomic mechanism of growth to eliminate or reduce the incidence of growth in fuel elements. The second is to collect empirical data, such as preferred orientation, grain size, conditions of irradiation, and certain other composition and structural variables. These data are sought in order to relate the magnitude of growth in individual grains to growth and wrinkling in polycrystalline fuel bars.

This section is mainly concerned with the mechanism and the extent and temperature dependence of growth in single crystals and highly textured material. Secondary phenomena arising from irradiation growth which are of direct technological importance are discussed in later sections.

Investigators have so far agreed that irradiation growth in alpha uranium consists of an increase in length in the [0 10$]$ direction and a decrease in the $\left[\begin{array}{lll}1 & 0 & 0\end{array}\right]$ direction with no change in volume, ${ }^{23,24}$ but few 
experiments have been devoted specifically to this topic. Experiments in which a change in the length of wires with the $\left[\begin{array}{lll}0 & 1 & 0\end{array}\right]$ texture is

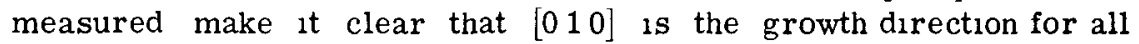
irradiation temperatures. These experiments, however, do not reveal the shrinkage direction. When irradiation takes place at room temperature or higher, the growth rate of single crystals does not change with degree of burnup over a very wide range, 1.e., from $10^{-1}$ to $3 \times$ $10^{-1}$ fissions of all atoms. Where increase in length, dl, is small compared with the original length,

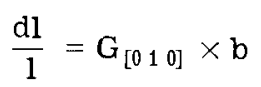

where $\mathrm{G}_{[010]}$ is a constant for a given temperature of irradiation and represents the growth factor for the [010] direction and b is the proportion of all the uranium atoms that have undergone fission.

$G$ has been measured for highly textured rods or wires formed at about $300^{\circ} \mathrm{C}$, in which most grains tend to lie with the $\left[\begin{array}{lll}0 & 1 & 0\end{array}\right]$ direction close to the rod axis. For such rods a value of $G$ for growth along the rod axis of about 850 has been obtained by many independent workers $^{24-26}$ for irradiation in the range 50 to $250^{\circ} \mathrm{C}$. Careful mea-

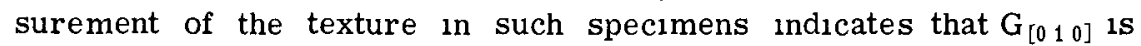
about 1100. For single crystals there is a much less consistent picture. After a series of careful experiments in which burnup was checked by fission-product analysis, Buckley ${ }^{27}$ claimed that $G_{[010]}$ for single crystals is 1100. This finding is in agreement with the value for highly textured polycrystalline material, but it does not agree with the earlier reported ${ }^{23}$ value of $420 \pm 20$.

There has been considerable disagreement in reported data concerning the temperature variation of irradiation growth in alpha uranum. This disagreement is to be expected when the data require accurate assessments of burnup, degree of preferred orientation, and temperature of irradiation, all of which present considerable experimental difficulties. The general picture that now emerges is indicated in Fig. 1. The principal features are (1) a tenfold increase in growth rate when the temperature is decreased from room temperature to about $77^{\circ} \mathrm{K}\left(-196^{\circ} \mathrm{C}\right),{ }^{27,28}$ (2) a plateau between room temperature and $573^{\circ} \mathrm{K}\left(300^{\circ} \mathrm{C}\right)$, and $(3)$ a sharp drop to zero growth at $773^{\circ} \mathrm{K}\left(500^{\circ} \mathrm{C}\right) .^{24,26}$ There are some indications that the position of the sharp drops may be dose-rate dependent, and the exact form of the curve may also depend on whether single crystals or highly textured wire specimens are used. $^{26,29}$

With the thin-film-transmission technique in electron microscopy, it has been shown that dislocation loops are formed profusely in alpha uranium during fission, the loops being clustered about two main 


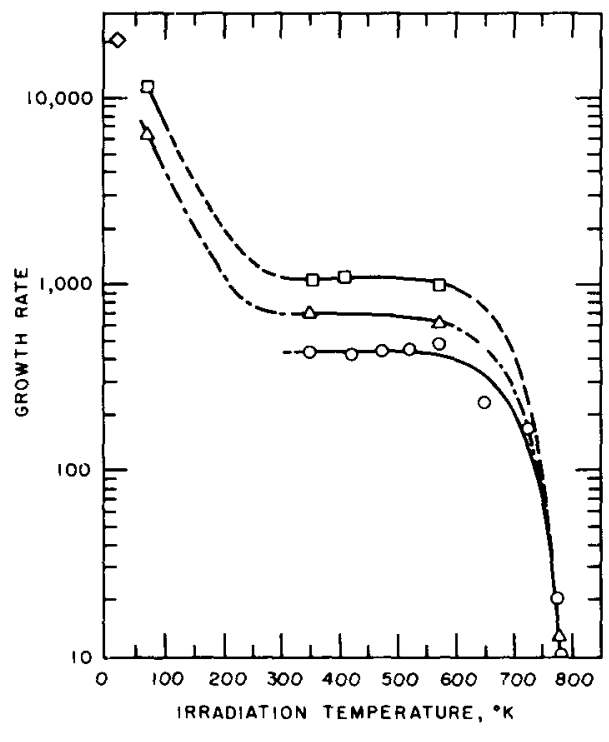

C polycrystalline uranium 58 percent deformation at $300^{\circ} \mathrm{C}$ Each point is the mean of 23 specimens Burnup 003 to 006 percent in 100 days (DIDO) determined from fission yield of $\mathrm{Cs}^{137}$

$\triangle$ polycrystalline uranium 85 percent deformation at $20^{\circ} \mathrm{C}$ Each point is the mean of four spec1mens Burnup $4 \quad 10^{-6}$ percent in 14 days (BEPO), cobalt flux monitor

¿ monocrystal, measured parallel to $\{010\}$ Each point is the mean of two specimens Burnup, $2 \times$ $10^{-6}$ percent (BEPO), cobalt flux monitor

strongly textured polycrystal ${ }^{28}$

Fig 1-Variation in growth of alpha uranium with iriadiation temperature

crystallographic orientations. ${ }^{30}$ Typical loops in uranium foll about 250 A thick are shown in Fig. 2. The specimen was irradiated to $1.2 \times 10^{8}$ neutrons $/ \mathrm{cm}^{2}$ and then annealed for three weeks at $273^{\circ} \mathrm{C}$. Dislocation loops lying on two planes can be seen. If it is assumed that the loops of one orientation consist of clusters of vacancies and the other of interstitial clusters, the growth can be accounted for to within a factor of 2 or 3 by integrating the loop areas per unit volume of specimen for a given burnup. In addition, the number of loops formed per fission event as a function of irradiation temperature agrees well with the change in growth rate with temperature. Loops formed at lower temperatures anneal rapidly above $500^{\circ} \mathrm{C}$, where growth no longer occurs. These findings have since been confirmed and augmented. Thus the mechanism of growth in alpha uranium appears to be the building up of extra planes of interstitial atoms with $\left[\begin{array}{lll}1 & 1 & 0\end{array}\right]$ and $\left[\begin{array}{lll}1 & \overline{1} & 0\end{array}\right]$ Burgers vectors, with a resultant strain in the $\left[\begin{array}{lll}0 & 10\end{array}\right]$ direction and removal of planes by accumulation of vacancy loops with Burgers vector in the $\left[\begin{array}{lll}1 & 0 & 0\end{array}\right]$ direction. The nature of the elastic forces between the loops must account for the rare occurrence of mutual annihilation of loops of interstitials and vacancies. ${ }^{31,32}$

Realization that irradiation growth is due to the nucleation and growth of loops helps to account for the characteristics and incidence of growth in various materials under various conditions of irradiation.

Thus bombardment of alpha uranium with $4-\mathrm{Mev}$ protons did not cause significant growth under conditions at which it might be expected 


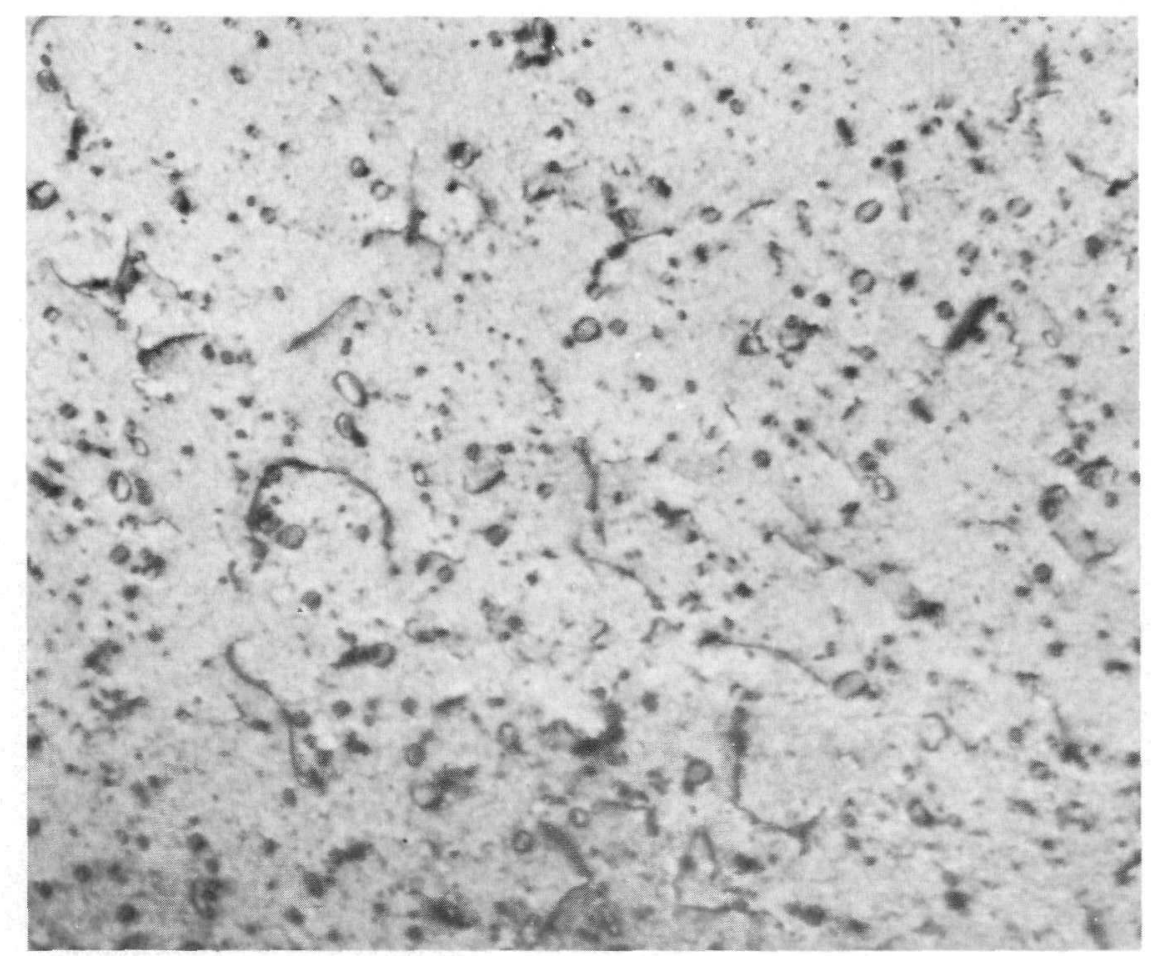

$\times 460,000$

Fig, 2-Dislocation loops in uranium foil.

to do so because sufficient displaced atoms are produced. ${ }^{33}$ This bombardment ${ }^{34}$ did not, however, cause loop formation in uranium either at $-196^{\circ} \mathrm{C}$ or at about $50^{\circ} \mathrm{C}$. Thus absence of growth at low doses was apparently due simply to the failure to nucleate and grow point-defect clusters, presumably because mutual annihilation of interstitials and vacancies removes most of the damage.

A later study by S. N. Buckley* showed that bombardment of uranium foils with $50-\mathrm{kv}$ protons produced dislocation loops and caused growth. The lack of measurable growth in the earlier results ${ }^{33}$ may have been due to the much lower collision cross section of uranium for the high-energy irradiation particles. Thus bombardment with both protons and heavy fission fragments can cause clustering of point defects, and thermal spikes are not a necessary accompaniment of cluster formation.

The behavior of alpha uranium is closely analogous to that of copper. Radiation of copper with 4-Mev electrons does not cause cluster for-

*Unpublished work. 
mation, although interstitials and vacancies are produced at a very high rate. Bombardment with heavier, more energetic particles such as $2-\mathrm{Mev}$ neutrons or 4-Mev protons, however, does cause loop formation. ${ }^{34}$ The formation of collision cascades large enough to leave behind defect clusters thus appears to require a higher energy of incident particle for uranium than for copper. The difference may be due to a smaller energy transfer in primary collisions caused by the greater mass of the uranium 10n. These observations support Brinkman's original suggestion that during irradiation vacancy clusters form in the region that has lost atoms owing to a closely spaced series of collisions with a primary knocked-on ion at the end of its track. ${ }^{35}$ The displaced atoms travel as interstitials or interstitialcies into the surrounding region, where they diffuse and agglomerate into clusters in regions with an excess of interstitial atoms. To account for the low proportion of interstitial-vacancy recombinations, it is necessary to assume only that the vacancy clusters are not able to collect interstitials from distances that are long, compared with their initial separation. ${ }^{34}$ According to this mechanism a large local release of energy accompanies loop formation unless there is an over-all excess of one type of defect, e.g., vacancies produced by quenching or interstitials by certain types of $10 \mathrm{n}$ bombardment. ${ }^{36}$ This is significant when some of the possible growth mechanisms are considered in detall.

If it is assumed that the energy of the dislocation loop is entirely that stored in the long-range stress field, then interstitial and vacancy clusters of the same size on the same plane will have the same energy. Consistent with this assumption, both interstitial and vacancy loops lie on the same type of crystal plane in irradiated cubic metals. The difficulty in the case of anisotropic metals is to explain why, on irradiation with fission fragments, the interstitial and vacancy loops form on different planes. This differentiation could arise from the different interaction of interstitial and vacancy loops with the anisotropic thermal stress due to the fission spike. ${ }^{27}$ Because the thermal expansion of alpha uranium is very anisotropic, ${ }^{37}$ the local heating in the fission spikes causes a tensile stress to develop along [0 10$]$. This stress

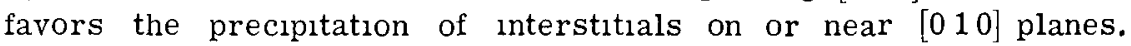
Although the largest compressive stress is in the $\left[\begin{array}{lll}1 & 0 & 0\end{array}\right]$ direction, that in the $\left[\begin{array}{lll}0 & 0 & 1\end{array}\right]$ direction is also large, and the choice of plane for the vacancy loops is probably determined by the absence of a short Burgers vector for a complete dislocation in the $\left[\begin{array}{lll}0 & 0 & 1\end{array}\right]$ direction. The vacancy loops therefore form with the $\left[\begin{array}{lll}1 & 0 & 0\end{array}\right]$ Burgers vector.

The idea that the thermal stress in the fission spike may be important led Buckley to measure the growth of a number of hexagonal metals during bombardment with fission fragments from uranium and to correlate the magnitude of growth with the degree of anisotropy of thermal expansion. There was a marked positive correlation. ${ }^{27}$ 
In all the metals in which growth occurred, loops were formed; ${ }^{26}$ loops in zirconium are shown in Fig. 3. The sample had been irradiated with $1.7 \times 10^{14}$ fission fragments per square centimeter at about $500^{\circ} \mathrm{C}$. In spite of the excellent correlation, the role of the thermal-expansion stress cannot yet be regarded as established because both thermal expansion and loop orientation may depend on something deeper, related to the nature of the interatomic forces. The difference in core energy of the interstitial and the vacancy loops might be the cause of their lying on different planes.

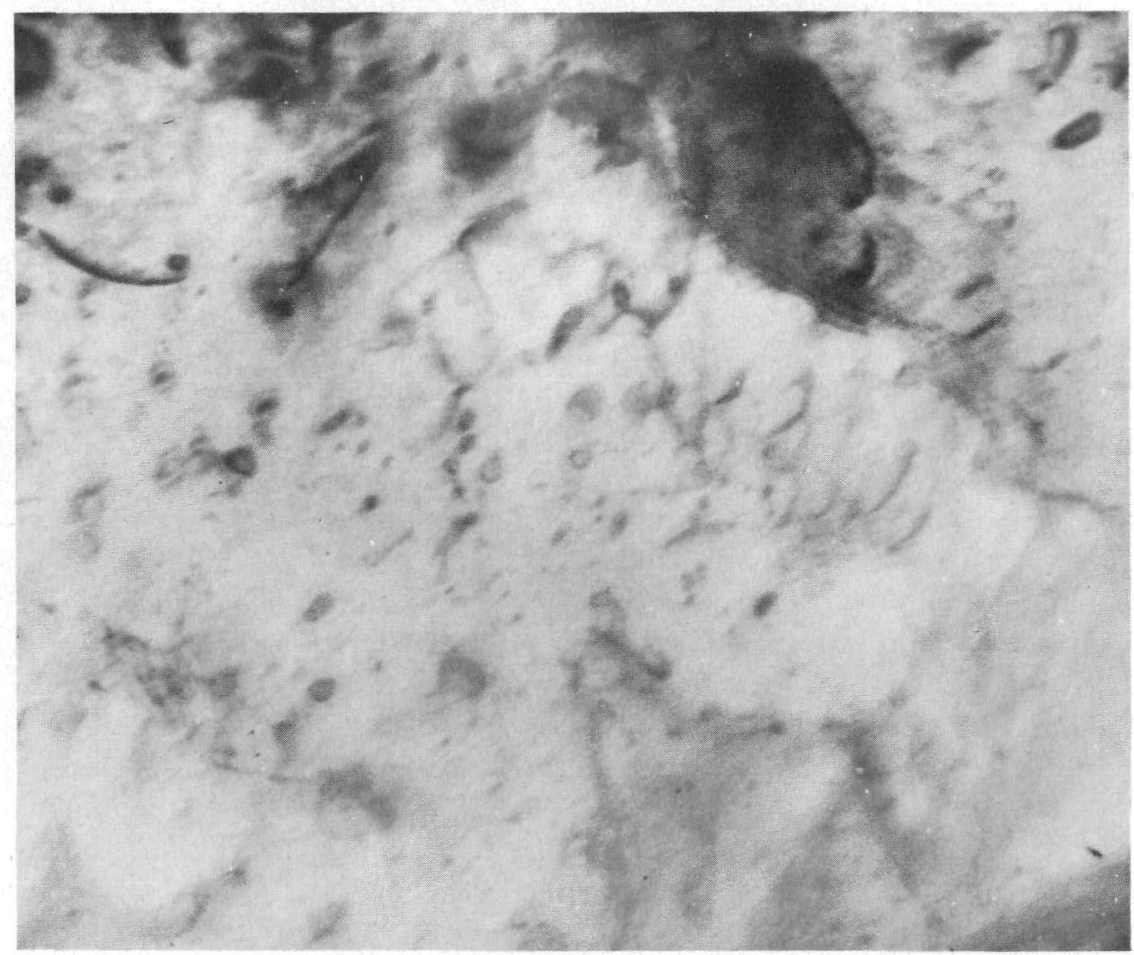

$\times 73,000$

Fig. 3-Dislocation loops in irradiated alpha zirconium.

The observation that growth rates in uranium are higher at $80^{\circ} \mathrm{K}$ than at room temperature, and even higher at about $20^{\circ} \mathrm{K}$, requires further comment in view of the probably very low mobility of vacancies and interstitials at these low temperatures. Because collision cascades leave vacancies in loose clusters, some diffusion may be required for the vacancies to form flat loops. The interstitials are probably dispersed; thus their loop formation definitely requires diffusion. One 
possible mechanism was given by Brinkman, ${ }^{35}$ who suggested that in some metals the vacancy cluster may form a loop by mechanical collapse or by diffusion in the thermal spike. The interstitial loop formation might be feasible by normal thermally activated diffusion at $80^{\circ} \mathrm{K}$, but it is unlikely at $20^{\circ} \mathrm{K}$. At $20^{\circ} \mathrm{K}$ it is possible that the loop formation, and hence growth, occurs in two stages. The first stage, at $20^{\circ} \mathrm{K}$, is the formation of loose clusters, which cause a volume increase. The second, which takes place when the specimen is warmed, is the collapse of the clusters into loops on preferred planes.

The characteristics of growth at low temperatures are not expected to be the same as those at ambient or higher temperatures. In particular, growth at $80^{\circ} \mathrm{K}$ appears to saturate at an elongation of about 15 percent. This behavior could be taken as evidence of the fallure of vacancies to form into loops.

Neither focused collisions ${ }^{38-41}$ nor anisotropic diffusion of point defects $^{7,42}$ appear to be necessary to explain growth, but both phenomena must play some part in determining the details of the growth mechanism, and they perhaps affect the magnitude of growth under any given conditions of irradiation. For example, owing to focused-collision processes, the number of displaced atoms decreases because of the dissipation of energy in nonbranching collision sequences, but the distance separating interstitials and vacancies increases. Because of thermal scattering these effects are less important at higher irradiation temperatures. ${ }^{43}$

A complete description of the growth process would start with details of collision processes with fission fragments and knocked-on atoms, leading to a picture of the initial distribution of interstitials and vacancies. It would continue with a description of the subsequent behavior of the defects in terms of the nucleation and growth of loops, possibility of mechanical collapse of vacancy clusters, role of thermalspike stresses, anisotropic diffusion, thermal stability of loops, and coalescence of loops. These factors must be related to the properties of uranium and their variation with temperature, the temperature dependence of growth, the dependence of growth on the nature of the bombarding particle, the crystallography of growth, and the occurrence of growth in a range of anisotropic materials. Many of the contributions in this field have emphasized one aspect of the problem. It is now necessary to assess the relative importance of each of the factors for various conditions of irradiation.

Clearly, more experimental data are required before a complete description of the growth mechanism is possible.

The difference between a grain of alpha uranium growing freely and one embedded in a polycrystalline matrıx has been demonstrated by examination of the microstructures after irradiation. The single crystal showed no changes due to irradiation when viewed with an optical 
microscope, ${ }^{44}$ whereas the embedded crystal was covered with wavy twins owing to accommodation of the growth strains by subsequent reversed plastic deformation. ${ }^{45}$ Buckley ${ }^{46}$ has since shown that the growth process contınues at an undimınished rate even when the stress resisting the change in shape approaches the yleld stress at room temperature, the external change of shape of the grains is, however, diminished owing to reversed plastic deformation. Growth of grains in a polycrystalline specimen is not, however, completely restrained, for bars with a slight preferred orientation undergo marked irradiation growth. The relation between texture and growth of near-random matrixes is complex, and, in practice, it can be determined only empirically

In addition, in the attempt to predict the dimensional changes of fuel elements from knowledge of the growth behavior of single crystals and highly textured material, several effects must be considered. Not only the mutual internal restraint of grains but also the effects of external restraints and other sources of dimensional instability must be considered. These effects and secondary phenomena due to growth wrinkling, irradiation creep, and changes in texture due to growth and to restraint of growth-are discussed further in the following sections.

\section{Grain Size and Wrinkling}

Wrinkling of a uranıum fuel element depends on many factors, of which grain size is one. The aim of measuring the grain size is to determine whether the grains in an element are small enough to ensure that wrinkling will not occur in the element. Careful investigation of the working and annealing used is necessary to attain desired grain size and to give the desired orientation. Although wrinkling problems have diminished sharply, further study may be warranted to improve understanding of the mechanısms of growth in fuel elements.

MEASUREMENT OF GRAIN SIZE Although it is known that wrinkling depends upon grain size and temperature and, it is suspected, on many other factors, no wrinkling parameter has ever been measured or even suggested. This is, perhaps, as well because no satisfactory method exists for measuring the grain size of beta-quenched alpha uranium. What is wanted is a measure of the largest grains, to give some idea of the worst wrinkles, and the average grain size, to indicate the average behavior of the surface of an element. The maximum grain size can be measured, but a representative figure for the average grain size is more difficult to decide. An initial decision can be made that grain size, in this case, is to be a measure of the whole grain, disregarding twins and polygonization. This assumption can be made because, under conditions that produce irradiation growth, the grain will probably act as a whole in producing wrinkling during irradiation. 
Metallographic methods using polarized light suffer from the wellknown disadvantage of coincidental extinctions; however, new etches have been developed for revealing the grain boundaries of uranium. ${ }^{4}$ Linear counts of the metallographs would not give a representative average size because of the many reentrant grain boundaries, but point counting might be considered a suitable method for development.

Another possibility is to use $\mathrm{X}$-ray analysis and to study the statistical variation in intensity that occurs on counting any one diffraction from alpha uranium when the oscillating sample is rotated to a different position in the beam. ${ }^{48}$ Adjusting the angle of oscillation would permit this method to ignore polygon size. It would be fairly accurate if the twin content of the uranium were 5 percent or less.

Such quantitative methods could be consistent in themselves for a given material. They would not, however, allow comparison of betaquenched material, partially annealed material, and fully annealed material with polygonal grains because of the large proportion of small grains that appear within larger grains in any cross section of betaquenched material. Cheney, Bauer, and Dickerson ${ }^{49}$ investigated the form of these small grains by successively removing layers from a polished uranium surface. They proved to their own satisfaction that the small grains were all parts of large grains. They therefore considered that beta-quenched uranium has a uniform grain size, and they optimistically suggested that an accurate estimation of this size would be obtained by averaging the sizes of the three to five largest grains visible in any one section. Further studies of this problem to establish these conclusions were promised, but they have not so far appeared.

The situation is such that, at the Savannah River Laboratory, for instance, grain sizes are not measured but large photographs are taken for comparison purposes of every specimen in which the grain size is considered important.

One problem that has been solved in grain-size measurements is the nondestructive monitoring of cylindrical fuel rods to detect coarse grains resulting from inadequate heat treatments. In Sharpe and Aveyard's ${ }^{50}$ apparatus, an ultrasonic transmitter and detector are placed on opposite sides of a horizontal uranium rod just above the diametral plane, the whole being immersed in water. The transmitter and detector are made to traverse the length of the rod while it is being rotated. Multipath transmission of the signal is achieved, and signals from different paths can be continuously recorded to give the attenuation from both core and rim regions of the rod. By use of a facsimile recorder, the attenuation can be associated with a particular azımuthal angle as well as a particular distance along the rod. Although absolute measurements of grain size are not possible, coarse-grained regions can be easily detected, and the detalled distribution of large grains can be found. 

uranium can be easily achieved by some combination of working and annealing the alpha phase, the working inevitably leads to preferred orientation in the material. Therefore, if the material must not be taken out of the alpha phase, the working and annealing schedules must be carefully investigated to arrive at a combination that gives a preferred orientation such that the uranium does not grow on irradiation below $450^{\circ} \mathrm{C}$. However, both worked and cast uranum of production quality undergo grain refinement if quenched from the temperature range of the beta phase, and this treatment has the advantage that it largely rids worked material of its preferred orientation.

Thus beta quenching is the normal method for achieving fine grain size in uranium, and this quenching is usually followed by an annealing treatment to remove quenching and transformation stresses. As the purity of production-quality uranium improved, it was realized that small alloy additions had to be made to the uranium for grain refinement to be achieved by this process. Normal American practice is to add 100 to $500 \mathrm{ppm}$ of 1 ron and 100 to $300 \mathrm{ppm}$ of silicon to ingot uranum, whereas British practice is to add 200 to $500 \mathrm{ppm}$ of 1 ron and 500 to $1200 \mathrm{ppm}$ of aluminum to magnesium-reduced billet. ${ }^{51}$ Such small additions markedly affect the beta $\rightarrow$ alpha transformationtemperature-time characteristics, both delaying and lowering the temperature of transformation. It is not known whether this effect is due to the effects of precipitation or solution on the nucleation or growth rates of the alpha phase separating from the beta phase. Nor is it known whether the conditions prior to the preceding alpha $\rightarrow$ beta transformation play a part in controlling beta grain size and solution rates in the beta phase.

Boland, Kloepper, and Neumann ${ }^{52}$ have claimed that the mechanism of grain refinement with the iron-silicon addition was connected with the size and distribution of the precipitate. Preliminary experiments showed that the fine precipitate in the worked metal dissolved in the beta phase in 4 to $6 \mathrm{hr}$, although a large proportion of it dissolved after $15 \mathrm{~min}$. They then annealed the worked material in the alpha phase and showed that increasing the time and raising the temperature led to increasing size of precipitate and a larger alpha grain size. After beta treatment the alpha grain size depended only on the initial dispersion of the precipitate and not on the time at beta-phase temperatures. A suggested explanation was that the precipitate alded beta nucleation and hindered beta grain growth and that the alpha grain size after the beta treatment depended largely on beta grain size. It is most remarkable that beta annealing times ranging from $6 \mathrm{~min}$ to $82 \mathrm{hr}$ had no effect on alpha grain size. It might be expected that the precipitate would dissolve, removing many obstacles to beta grairi growth and affecting the kinetics of the beta - alpha transformation markedly. 
The basic reason for the necessity of ternary additions is also completely unknown. Aluminum alone, in concentrations up to 1200 $\mathrm{ppm}$, does not promote good refinement. When iron alone is added, although the refinement is satisfactory, the uranium tends to crack after or during severe quenching. Together, these solutes promote good grain refinement with no cracking. It might be speculated that the precipitate that promotes cracking in the binary iron alloy is inhibited by the addition of aluminum. The fact that good grain refinement occurs, however, must mean either that the iron is taken into solution or that the identity or distribution of the precipitate associated with aluminum is affected. (See p. 367.)

The laboratory-scale experiment, which decides the alloy compositions warranting industrial-scale investigation by maintaining the alloy at beta-phase temperatures for several minutes before quenching, does not exactly correspond with the production process for grain-refining British uranium. The fuel bar is at beta-phase temperatures for approximately $15 \mathrm{sec}$ in the traverse quenching process, and thus little solution of the coarser precipitates can occur. The cast uranium contains fine intermetallic precipitates, mainly at beta and alpha grain and polygon boundaries. Judging by optical microscopy, however, the matrix mist pe supersaturated with one or both solutes since further slight precipitation becomes visible on alpha annealing. Furthermore, during the heat treatment that inevitably accompanies the cladding being pressurized onto the fuel bar, volume changes occur that strongly suggest that some solutes are coming out of solution as precipitates. If the alpha-annealed cast bar $\left(625^{\circ} \mathrm{C}\right.$ for two weeks) is heated rapidly at $725^{\circ} \mathrm{C}$, left for periods ranging from $2 \mathrm{~min}$ to $48 \mathrm{hr}$, and then quenched at a constant rate, the grain size is roughly the same for all times. If, however, it is quenched immediately, it attains the beta-annealing temperature; its grain size is twice the grain size of all the other specimens. ${ }^{53}$ All these facts point to grain refinement's being a most complex aspect of transformation behavior, and the present belief is that the effect of precipitates on alpha and beta nucleation and growth rates, the effect of solution on beta $\rightarrow$ alpha transformation kinetics, and the time precipitates take to dissolve in the beta phase, which would in turn affect the first two factors, are all involved.

There is no doubt that, although beta quenching produces a fme grain, it also leaves a small amount of preferred orientation in the fuel element. Consequently there has been a resurgence of interest in dilute alloys that can be allowed to transform isothermally after beta treatment to give a fine grain size and, it is hoped, no preferred orientation. Typical of these alloys is uranium containing $1000 \mathrm{ppm}$ chromium. Aubert ${ }^{54}$ studied this alloy after isothermal transformation from the beta phase at temperatures ranging from 450 to $640^{\circ} \mathrm{C}$. He showed that the grain size obtaned was independent of the specimen size in 
bars up to $4 \mathrm{~cm}$ in diameter and of the temperature in the beta phase. He confirmed earlier results showing that the finest grain size was obtained after transformation at $500^{\circ} \mathrm{C}$, and further studies showed that this treatment could be carried out on full-size bars with no bowing if suitable precautions were taken. This grain size was stable after annealing at temperatures up to $575^{\circ} \mathrm{C}$, and specimens ir radiated for $550 \mathrm{Mwd} / \mathrm{t}$ at low temperatures showed no signs of wrinkling or bowing. There is some suspicion, however, that the transformation mechanısm at $500^{\circ} \mathrm{C}$ may be orientation dependent and give small amounts of preferred orientation. Aubert quoted no measurements to prove the presence or absence of growth.

Minty and Butcher ${ }^{55}$ have suggested that, instead of the normal isothermal treatment, continuous cooling could be used with this type of alloy to achieve grain refinement. They cooled small samples at different rates from beta-phase temperatures and plotted the beta $\rightarrow$ alpha transformation temperatures and alpha grain sizes as functions of cooling rate. From this information they showed that, with an alloy containing $700 \mathrm{ppm}$ chromium, it was possible to produce a fine grain size at a transformation temperature at which the transformation mechanism was thought to be non-orientation dependent. They did so by cooling at a rate of approximately $450^{\circ} \mathrm{C} / \mathrm{min}$, which is comparable to the rate of cooling of a 1.2-1n.-diameter uranium bar removed from a salt bath at $730^{\circ} \mathrm{C}$ and air cooled.

Although uranium-chromium alloys were first investigated more than 10 years ago, no fuel charge for a power reactor has ever been made of this alloy. Two other desirable properties in a fuel material are good creep resistance and good swelling resistance, and the swelling resistance of uranium-chromium alloys is suspect. With the new understanding of the swelling mechanism, however, there seems to be no reason why a ternary or quarternary alloy based on uraniumchromium should not be developed to give good resistance to swelling and creep.

RECRYSTALLIZATION OF BETA-QUENCHED MATERIAL Recrystallization of beta-quenched material is important in two ways: it has been investigated in the United States as part of the grain-refining process; and recrystallization during irradiation in the high alpha range is thought to be one of the causes of enhanced swelling.

The principles of annealing beta-quenched material were laid down by Gardner and Riches. ${ }^{56}$ For any particular grade of uranum, the ease of recrystallization increases both with increasing amount of strain induced by beta quenching and with increasing annealing temperature. The amount of recrystallization increases with increasing annealing time and decreases with increasing precipitate content. ${ }^{57}$ The latter is a conflicting factor in the grain-refinement process because the an- 
nealed alpha grain size depends, among other things, on the as-quenched alpha grain size, and a certain amount of alloying addition is necessary to ensure a fine as-quenched structure. The optimum addition of solute to give the minimum recrystallized alpha grain size in practicable annealing times has not been worked out; but recrystallization rates depend so strongly on differences of tens of parts per million of solute that such a close control of composition probably could not be realized in practice.

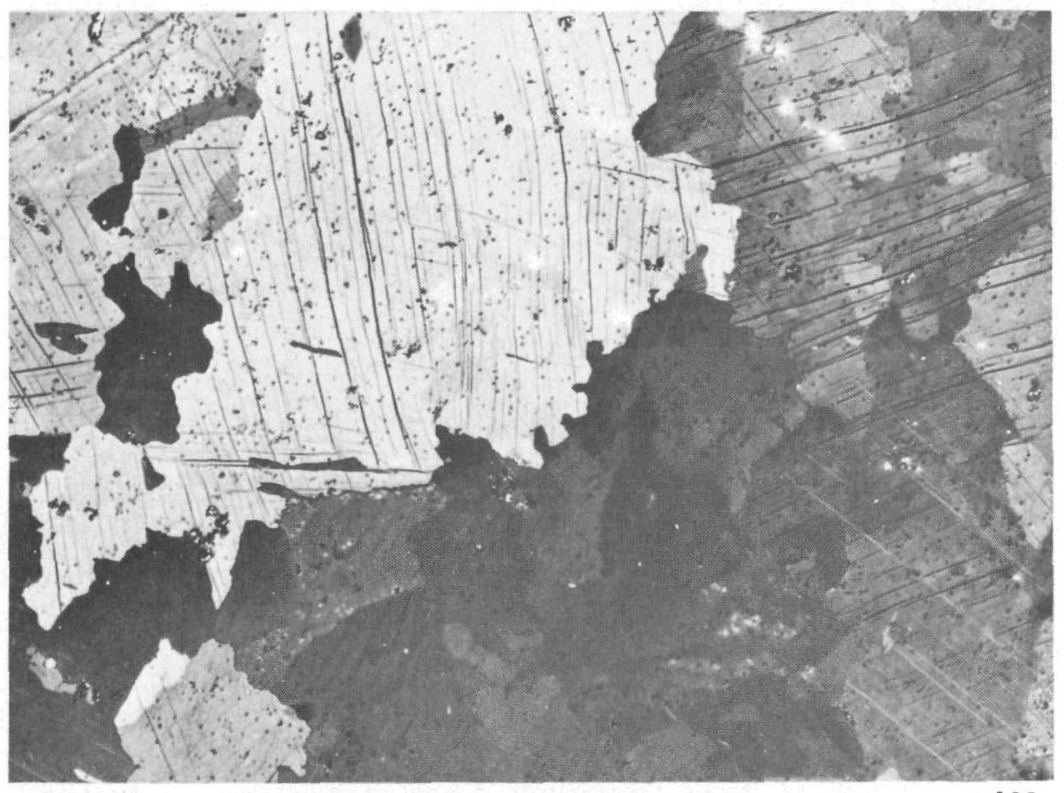

$\times 100$

Fig. 4- Grain boundaries in uranium after beta quenching and annealing (polarized light).

The grain size attained on annealing, if true recrystallization has taken place, always seems to be smaller than the as-queriched alpha grain size. This difference may be a practical criterion for distinguishing true recrystallization from a type of recovery. Figure 4 shows boundaries in the interior of a uranium specimen from a magnesiumreduced billet after beta quenching and subsequent annealing for $1 \mathrm{hr}$ at $620^{\circ} \mathrm{C}$. The recovery is characteristic in its early stages, shown in the figure, as the sharply angled alpha grain boundaries become slowly rounded. In later stages of recovery, however, the grain boundaries straighten out, and the structure looks like a recrystallized specimen. The grain size is, for all practical purposes, the same as that of the as-quenched structure, but normal methods of measurement would show a larger grain size except, perhaps, for the method of Cheney et al. ${ }^{49}$ 
Recrystallization and recovery can occur in the same specimen: recrystallization at the $\mathrm{rim}$, where quenching is most rapid; and recovery in the core.

Although this sort of experiment is useful in the laying down of principles, because of irradiation effects it is no guide to what can happen in the reactor. The most important of these processes is irradiation growth, which in effect puts cold work into the uranium, as evidenced by the large numbers of highly distorted twins seen in microstructures of irradiated uranium. This cold work, however, is not enough to cause recrystallization of production-grade uranium irradiated up to $2100 \mathrm{Mwd} / \mathrm{t}$ at low temperatures when it is subsequently annealed for long periods at up to $650^{\circ} \mathrm{C}$, even though plastically deformed unirradiated uranium thought to contain the same amount of cold work recrystallizes readily. ${ }^{58}$ Super-pure uranium does, however, recrystallize on annealing after irradiation at low temperatures. (See p. 366.)

Irradiation growth is important only below $500^{\circ} \mathrm{C}$, and thus for the higher irradiation temperatures recrystallization might be thought to be more predictable. So many more factors arise, however, that can vary with temperature, total irradiation, or rating, or all three, that no predictions can be made. Examples are the generation of vacancies, the presence of gas bubbles, and the precipitation or solution of other phases associated either with the original constituents of the uranium or with the solid fission products. Until more basic work is done and some general principles are laid down, no real progress will be made in this subject.

WRINKLING Wrinkling has not been a major subject of research for many years, probably because it is no longer a technological problem. It is a particularly intractable problem to tackle basically. No wrinkling parameter has ever been suggested except for visual comparisons. If one were suggested, it would have to take into account the different restraints imposed by different environments even at a free surface, the influence of subsurface grains on surface wrinkling, and the accidental juxtaposition of grains having one growth direction almost on a common line.

Formerly the maximum in the wrinkling effect found around $250^{\circ} \mathrm{C}$ was taken to be an indication of a maximum in irradiation growth at the same temperature. Since Buckley ${ }^{26}$ has shown that the irradiation growth rate increases with decreasing temperature, at least one other mechanism must also enter into wrinkling. This mechanism is presumably a thermally activated process, such as the relaxation of the mutual restraint between grains by a creep process, so that the increase in the growth rate of individual grains is balanced by the decrease in thermal activation as the temperature decreases. 
Wrinkling is no longer a problem with metallic fuels because of the development of grain-refinement methods and alloys. Research on wrinkling may be well worthwhile, however, because it may lead to an understanding of the mechanism of mutual restraint between adjoining grains, which is an important feature of the general growth mechanism. The understanding of the basic mechanism of grain refinement in uranium alloys has not kept pace with the technological development of these alloys, and much work remains to be done on the role of precipitates and solutes in the grain-refining process.

\section{Preferred Orientation and the Growth of Fuel Elements}

On the assumption that preferred orientation is undesirable in a fuel element, this section will be confined to discussion of beta-treated material. This treatment, as well as being a standard method of grain refinement, is also a standard method of reducing preferred orientation in wrought materials. Unfortunately beta treatment introduces a small amount of preferred orientation into cast material and apparently leaves small amounts of texture in worked material. Beta-treated fuel rods in the NRX reactor decrease in length and increase in diameter slightly, owing to the slight texture left by the beta-quenching process. An attempt has been made to counteract this shrinkage by introducing a small amount of working texture by cold drawing the rods with small reductions. ${ }^{59}$ The beta-quenched texture in rods may vary both radially, as a necessary consequence of the production process, and axially, as a result of production vagaries. The question then arises regarding whether it is valid to talk about preferred orientation, a statistical quantity, as continually varying, as is done when preferred orientation is measured as a function of the radius of a cross section of a rod. Salesse ${ }^{60}$ has answered this in part by calculating the probabilities that a given number of grains of randomly orlented uranium would have an excess of one of the major axes within a solid angle $2 \pi / 4$ (1.e., within approximately $411^{\circ}$ of a chosendirection). He found that the probability that the grains would have 20 percent excess axes within this angle was $1.5 \times 10^{-1}$ for 100 grains but approximately $10^{-9}$ for 10,000 grains. For 5 percent excess these probabilities were increased, being approximately $2 \times 10^{-2}$ for 10,000 grains and $8 \times 10^{-5}$ for 100,000 grains. If there were a grain size of $1 / 3 \mathrm{~mm}$ in an annulus one grain wide at a radius of $1 \mathrm{~cm}$ in a fuel rod $25 \mathrm{~cm}$ long, there would be approximately 75,000 grains. Thus, if there is no longitudinal variation of preferred orıentation, talking about a radial varıation is justıfıed. Measuring this variation satısfactorily, however, is very difficult.

Another implication of Salesse's work which should be considered is that aggregates of 100 to 1000 grains may have a significant amount 
of coorientation, which might lead to bumps or wrinkles on the surface of an irradiated rod purely as a chance effect.

MEASUREMENT OF TEXTURE BY DIFFRACTION Neutron diffraction will not be considered here because it is not a normal metallurgical laboratory tool and because the resolution of a neutron diffractometer is usually very poor. X-ray methods are of two main types, one for measuring the spatial distribution of a few selected crystallographic directions and the other for measuring the relative numbers of all the diffracting planes parallel to the specimen surface. The first method, giving "pole figures, is not frequently used with uranium, mainly because the diffractions from some of the principal planes lie so close to other diffractions that the resolution becomes very poor when the specimen is tilted to find the spatial distribution of a particular pole. Use of a spherical specimen will eliminate this defocusing effect, and it has been claimed that suitable choice of slits for the diffractometer will reduce it to insignificance. ${ }^{61}$ But for beta-quenched material, in which the preferred orientation varies radially, the method produces results of uncertain meaning because of the geometry of reflection. ${ }^{62}$

The other method produces inverse pole figures, in which $\mathrm{p}$ values are given for the reflecting planes, where

$p(h, k, 1)=\frac{I_{(h k 1)}}{I_{o(h, k, 1)}} / \frac{1}{n} \sum_{c}^{n} \frac{I_{(h k l)}}{I_{o(h, k, 1)}}$

and $I_{(h k l)}$ is the measured intensity from the $(h, k, 1)$ plane, $I_{o(h, k, l)}$ is the intensity from the same plane of the specimen with random orientation, and $\mathrm{n}$ is the number of planes studied.

Since $I_{\circ}$ cannot be determined experimentally for uranium, $p$ depends on the accuracy of calculation of $\mathrm{I}_{\mathrm{o}}$, and the latest determination is probably accurate only to 5 percent. ${ }^{63}$ Furthermore, $\mathrm{p}$ also depends on the accuracy of the determination of $I$, and, with the assumption that the diffractometer and counting techniques are adequate, this accuracy depends on the statistics of sampling and on the sample itself. If a random specimen contains $\mathrm{N}(\mathrm{h}, \mathrm{k}, \mathrm{l})$ planes and $\mathrm{s}$ is the ideal proportion that can diffract, then the fractional standard deviation of the number that actually diffract ${ }^{64}$ is $(t / N s)^{1 / 2}$, where $t=1-s$. The proportion, $s$, depends on the geometry of the diffractometer, the rocking angle of the uranium crystals, and the scanning arrangement. Translational scanning will have no effect, but rotational scanning will increase s, the increase being greatest when the center of rotation coincides with the center of the irradiated area of the specimen. If every crystal with its normal within $3^{\circ}$ of the ideal position can reflect, which is probably a large overestimate, $\mathrm{s} 0.0088$, and the fractional standard deviation $\approx 10 /(N)^{1 / 2}$. For an $(h, k, 1)$ reflection, $N=4 n$, where $n$ is the 
number of grains; thus for an accuracy in I comparable to the accuracy of $I_{\circ}$, at least 10,000 grains must be irradiated if the specimen has only a little preferred orientation. Because the absorption of $X$ rays in uranium is so high, these 10,000 grains must lie on the surface of the sample so that an area of at least $10 \mathrm{~cm}^{2}$ must be irradiated. It is evident in some work that this precaution has not been taken, although Sturcken, ${ }^{65}$ when starting development of this method, pointed out that he needed to examine $90 \mathrm{~cm}^{2}$ of metal for reproducible results.

The sample itself may affect the results in two ways. One factor is thai, with some samples and some diffractions, $p_{(h, k l)}$ does not equal $\mathrm{p}_{(2 \mathrm{~h} n \mathrm{k} 21)}$. This effect is normally attributed to secondary extinction and can be allowed for. The other factor is the surface condition of the sample. It has been found that different etchants give slightly different p values. ${ }^{66}$

Values of $p$ are used to calculate a growth index, G.I. The history and applications of this calculation can be found in Refs. 63 and 65 to 68 . The principle is to convert the relative abundances of planes parallel to the specimen surface, as shown in the $\mathrm{p}$ values, to effective relative numbers of $\left[\begin{array}{lll}1 & 0 & 0\end{array}\right]$ and $\left[\begin{array}{lll}0 & 1 & 0\end{array}\right]$ axes perpendicular to the surface. By subtracting the number of $\left[\begin{array}{lll}1 & 0 & 0\end{array}\right]$ directions from the number of $\left[\begin{array}{lll}0 & 1 & 0\end{array}\right]$ directions, a growth index is obtained. This method began as simple arithmetic, but the latest refined method of calculation requires a computer program. ${ }^{69}$ Although the latest method does not employ $p$ values as such, it still depends on the accuracy of $I$ and $I_{c}$.

The growth-1ndex method works well with small irradiated spec1mens of uranium having a unform, reasonable amount of preferred orientation, but there are many difficulties in applying it to a fuel element. Most of these will be discussed later, for they apply to any method of texture measurement. One difficulty that applies only to this method is that the $p$ values measured for beta-quenched material often show a variation from unity ( $\mathrm{p}=1$ for random material) that is of the same order as the accuracy of determination of $p$.

With beta-quenched material the growth-index method allows an informed guess to be made at the magnitude of growth rather than an accurate prediction; thus methods requiring the use of computers for calculating growth index appear to be far more elaborate than necessary for this application.

OTHER METHODS OF TEXTURE MEASUREMENT Some simple method for predicting growth is obviously desirable. Thermal cycling in the alpha phase, measurement of ultrasonic velocity, and metallography, although all useful, have been rejected as means of quantitative measurement of preferred orientation. The most promising method would seem to be that proposed by Stobo and Pawelski ${ }^{70}$ and developed by Raraty. ${ }^{71}$ Table 1 shows some properties of uranum from measurements on single crystals. 
Table 1-URANIUM PROPERTIES

\begin{tabular}{|c|c|c|c|}
\hline Crystal axis & Growth & $\begin{array}{l}\text { Thermal expansion } \\
\text { coefficient }(20 \text { to } \\
\left.100^{\circ} \mathrm{C}\right), 10^{-6} /{ }^{\circ} \mathrm{C}\end{array}$ & $\begin{array}{l}\text { Electrical } \\
\text { resistance, } \\
\text { microhms } / \mathrm{cm}^{3}\end{array}$ \\
\hline$\left[\begin{array}{lll}1 & 0 & 0\end{array}\right]$ & $-g$ & 216 to $253(20)$ & $422(42)$ \\
\hline$\left[\begin{array}{lll}0 & 1 & 0\end{array}\right]$ & $+g$ & -02 to $+01(0)$ & $273(28)$ \\
\hline$\left[\begin{array}{lll}0 & 0 & 1\end{array}\right]$ & 0 & 179 to $220(20)$ & $280(28)$ \\
\hline
\end{tabular}

For the accuracy required, the figures can be approximated to those shown in parentheses. If $y$ is the effective percentage of $\left[\begin{array}{ll}0 & 1\end{array}\right]$ directions in a polycrystalline specimen aligned in the direction of measurement, when $y=100$, the specimen is a single crystal, and the thermalexpansion coefficient, e, will equal 0 . When $y=33.3$, the specimen will be random as long as $x$, the percentage of $\left[\begin{array}{lll}1 & 0 & 0\end{array}\right]$ directions, also equals 33.3 ; thus $e=\bar{e}$, the coefficient of expansion for random material. It will be assumed, therefore, that in a specimen with a preferred orien-

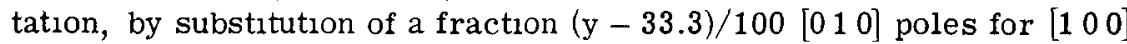
and [ $\left.\begin{array}{ll}0 & 0\end{array}\right]$ poles, the expansion coefficient is lowered by an amount equal to the product of the fraction and the difference in expansion coeff 1 cients

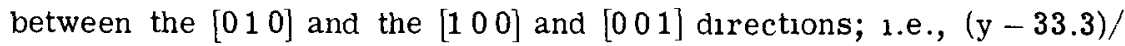
$100=(\bar{e}-e) /(20-0)$. Simllarly $(x-33.3) / 100=(r-\bar{r}) /(42-28)$, where $r$ and $\bar{r}$ are the experimentally found and average electrical resistances.

The measurements for this method can be made as accurate as is necessary by refinements to apparatus. If the specimens cut from bars are $6 \mathrm{~mm}$ in diameter and $5 \mathrm{~cm}$ long, they will contain approximately 10,000 grains; thus the chances of 5 percent random fluctuation of orientation $^{60}$ will be $2 \times 10^{-2}$. The principal difficulty with this method 1s deciding on values for $\bar{e}$ and $\bar{r}$. The decision on $\bar{e}$ is easier because it is not particularly structure sensitive and small differences of composition will not affect it markedly. The value for $\bar{r}$ is much harder to decide on because it is structure sensitive. Whatever value is chosen, even if it is in error, comparisons between different specimens obtained through identical routes should stıll be possible. Preliminary results have shown qualitative agreement with the type of preferred orientation thought to exist in British fuel rods, and it is hoped to make the method quantitative. $^{71}$

If it succeeds, this method will be much less elaborate and time consuming than the $\mathrm{p}$-value method. It is, however, a destructive test, and there are the same difficulties in applying the results to the growth of fuel elements. No certain nondestructive test for monitoring fuels has been found; the best that can be done is to record diametral ultrasonic velocities and reject rods with values outside certain limits. 
There seems no doubt that the origin of the textures in cast bars that have been beta quenched lies in the quenching; with cast material the textures apparently depend mainly on the contours of the isotherms during quenching. ${ }^{71}$ From this conclusion it is a natural step to associate the texture with the mode of transformation and state that the stresses involved in quenching and in the phase transformation favor the formation of certain orientations of martensite plates at the expense of others. There is, however, no proof of this idea, and remanent textures have been observed in worked material that has been beta treated and slow-cooled, during which treatment there was presumably no martensitic transformation. On the other hand, cast bars of dilute alloys that have been isothermally transformed by a nonmartensitic mechanism show effectively no texture. ${ }^{71}$

A distinction should be drawn, however, between remanent textures caused by inefficient heat treatment and those resulting from proper heat treatment. McDone11 ${ }^{72}$ showed that the disappearance of preferred orientation of worked material depended on both time and temperature of beta treatment if the temperature was below $690^{\circ} \mathrm{C}$, and Barwood and Butcher ${ }^{73}$ have indicated that this dependency is due to the sluggishness of the final stages of the alpha $\rightarrow$ beta transformation at low temperatures. Neveriheless, the possibility exists that alpha uranium has preferred growth directions, whatever the transformation mechanism, possibly being independent of it. Stobo ${ }^{74}$ grew lineage crystals from cast samples of pure, adjusted (see p. 362) and unadjusted uranum by passing them slowly through a steep temperature gradient; and In 49 out of 53 samples, the $\left[\begin{array}{lll}0 & 1 & 0\end{array}\right]$ direction was within $45^{\circ}$ of the growth direction, and the $\left[\begin{array}{lll}1 & 0 & 0\end{array}\right]$ was more than $75^{\circ}$ from it.

Remanent textures do exist in worked materials that have been heated to temperatures high in the beta range and then quenched. For instance, rolled material that has been traverse beta quenched has a texture similar to that of cast bar that has recelved the same treatment, but there is much less radial variation of texture. ${ }^{71}$ There is very little quantitative evidence from worked bars that have been slowly cooled from beta-phase temperatures, but single crystals that were grown from rolled sheet via the alpha $\rightarrow$ beta $\rightarrow$ alphatransformation displayed a strong tendency to have their [1 000$]$ directions from 50 to $90^{\circ}$ away from the growth direction, agreeing with Stobo's results. In contrast to Stobo's work, however, their [0 10$]$ directions were distributed from 10 to $90^{\circ}$ away from the growth direction. ${ }^{62}$ Thus the original texture has some influence on the final texture. It has yet to be proved whether these remanent textures are truly remnants of the original texture of the worked material or if they are modified textures that coincidentally give an effect similar to a small remnant of the original texture. Whichever is true, both the alpha $\rightarrow$ beta and the 
beta $\rightarrow$ alpha transformations must be orientation dependent in some degree for the remanent textures to occur.

According to Burke and Dixon's theoretical analysis, ${ }^{75}$ the alpha $\rightarrow$ beta transformation can never be martensitic, and it must occur through diffusion processes. Donzé ${ }^{76}$ has explained remanent textures by the apparently thermodynamically impossible idea that nucles of the alpha phase are retained through the transformation to temperatures high in the beta phase. Burke and Dixon prefer to believe that there is a slight orientation dependence in the nucleation of the beta phase from the alpha.

In summary, two things are known to affect the textures of betatreated uranium, namely, the quenching conditions and previous preferred orientation, but it is not known why. Secondary factors, such as minor compositional variations, might affect the amount and type of texture. It seems likely, however, that no production process involving beta quenching will give a material free from preferred orientation. On the other hand, the texture is slight, and it has caused no serious problems in reactors. If, however, there were a demand for fuel materials without texture, larger additions of alloying elements and a different heat-treatment schedule would be required. An alloy containing $1 / 2$ to $1 \frac{1}{2}$ at. $\%$ solute, according to the 1 dentity of the solute, could be used. ${ }^{71}$

GROWTH OF FUEL ELEMENTS The application of preferred-orientation data to growth of fuel elements is complicated by several factors.

The variation of growth rate with temperature and burnup rate is not yet well known. Nevertheless, fuel-element temperatures vary both radially and longitudinally, imposing growth restraints and different plastic properties in various parts of the element. According to Thomas, ${ }^{77}$ however, for worked rods the rate of growth of the whole rod is controlled by the rate of growth of the portion of the rod at the lowest temperature.

The restraint between individual contiguous grains is not known. Formerly it was assumed that the growth rate was directly related to the amount of preferred orientation, but Buckley ${ }^{46}$ has shown that this is not true. For strong textures the growth was more than that predicted by a linear relation, and for weak textures it was less, as shown in Fig. 5. This situation is fortunate because fuel elements are weakly textured. Buckley, however, worked with specimens in which the preferred orientation, induced by mechanical working, was uniformly distributed throughout each specimen. He made the same assumption as that inherent in the Stobo-Pawelski method of measuring preferred orientation, that the $\left[\begin{array}{lll}0 & 1 & 0\end{array}\right]$ texture is linearly related to the thermalexpansion coefficient of the uranium. This assumption is not necessarily true, and the textures and grain size of fuel rods vary radially. 


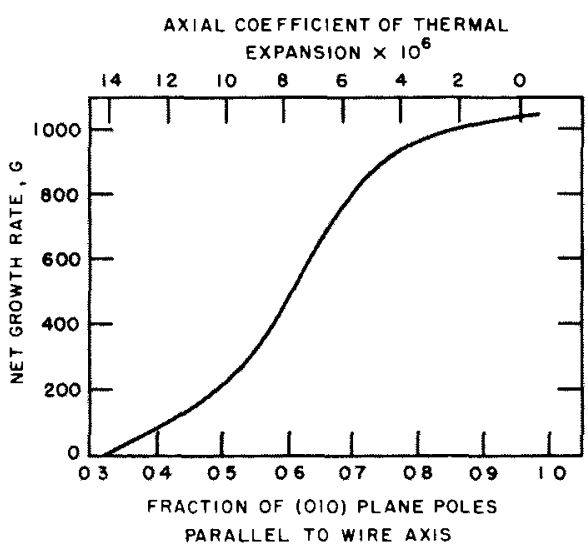

Fig 5-Effect of pıeferred orıentation on net ir radiation growth in polycrystalline wiles

Thus, for fuel rods, Buckley's curve can be used only as an approximation, albeit a much better one than any previous.

The restraint between regions having different preferred orientations is unknown. Equations that neglect temperature gradients and plastic deformations have been found for dimensional changes of certain fuel elements, ${ }^{78}$ but the situation is not so simple. For instance, the preferred orientation of Calder Hall fuel rods is such that the core should undergo a small axial contraction and the rim a small expansion. In the channel position in which growth is expected to be maximum, the ends of the rods did show dishing. Over the end inch, however, some exhibited a percentage of expansion that was often an order of magnitude greater than the over-all percentage contraction. ${ }^{71}$ The only explanation that has been put forward for this fact is that the ends of the bars are unrestrained by surrounding uranium. Since alteration in dimensions of the end inch might be associated with the development of grain-boundary leak paths across the cladding near the ends, this growth is very important. The plotted results, however, show both positive and negative deviations from an average zero value which have not been correlated quantitatively with preferred orientation.

The influence of the restraint imposed by cladding and other external factors is unknown. Buckley ${ }^{46}$ has shown that the growth rate after restraint has been imposed in the initial stages of growth is considerably diminished. This decrease occurs because, in effect, the plastic strains caused by restraining growth alter the preferred orientation of the material so as to diminish total growth. Such a phenomenon must be invoked to explain the growth of Experimental Breeder Reactor No. I (EBR-I) fuel elements, which first expanded and then shrank again with increasing burnup. ${ }^{79}$ The fuel elements were under compressive loading from a spring and were thus subject to irradiation creep. It is suggested that the spring loading was suffi- 
cient to alter the texture of the uranium gradually as irradiation progressed, until eventually the texture was such that no irradiation growth occurred. Thereafter irradiation creep under the compressive loading shortened the elements.

Other dimensional changes affect the fuel elements. They include ir radiation creep, thermal-cycling creep, bowing, swelling, and solution effects. Most of these can be either calculated or independently measured; taken together with the uncertainties of growth, however, they make the comparison of predicted and calculated values of growth extremely difficult. For example, LeGeros ${ }^{80}$ initially examined the correlation of length changes in nearly 1000 fuel elements with the physical characteristics of the fuel elements, including preferred orientation measurements, and the reactor geometry and operating characteristics. The only apparently significant correlation he found was between growth and the temperature of the coolant surrounding the fuel elements.

Thus, in contrast to wrinkling, the growth of fuel rods remains a nuisance, if nothing more. The extent to which it has been controlled technologically can be realized by contrasting the growths observed in fuel rods of fractions of a percent at burnups up to $3000 \mathrm{Mwd} / \mathrm{t}$ with the growth of 400 percent that would be expected under similar cond1tions for a highly textured bar. The extent of the mutual restraint between grains that accounts for this reduction can also be realized. The slight preferred orientations can be measured with reasonable accuracy. Yet far more work remains to be done before these results can be used to predict growth accurately on full-size rods and before the different mechanisms producing preferred orientation and restraint of growth are understood. The Stobo-Pawelski method can be applied only to very dilute alloys of uranıum containing a constant amount of solute in the form of a standard distribution of second phases. The effect that an appreciable amount of a solute such as molybdenum in solution in the alpha phase has on the anisotropy of electrical resistance is unknown.

\section{In-pile Creep of Alpha Uranium}

With uranium clad with a weak material such as aluminum or a magnesium alloy, the in-pile creep behavior of the uranium determines the way in which the fuel element will react to external stresses. These stresses include those due to stacking of fuel elements in vertical columns or that due to coolant pressure in the case of a hollow-rod fuel element. When the uranium is clad with a strong material, such as steel, beryllium, or a zirconium alloy, the in-pile creep strength of the fuel will be important in determining fuel-cladding interactions. However, the in-pile creep behavior of alpha uranium can be quite different from that deduced from isothermal creep tests. 
Postirradiation tests show that most metals, with the exception of heavily cold-worked metals, when subjected to fast-neutronirradiation, increase in yield stress and in hardness. Alpha uranium shows such effects, particularly if the irradiation temperature is below $350^{\circ} \mathrm{C}$; the effects are, however, due mainly to fission-fragment damage and accumulation of fission products. ${ }^{81}$ Nevertheless, the behavior in reactors under certain circumstances indicates that the deformation rates under a given stress are higher than those found outside the reactor. ${ }^{82}$

In polycrystalline alpha uranium the main cause of irradiation creep is development of internal stresses. These stresses are due to irradiation growth, to anisotropic expansion of the grains during thermal cycling, ${ }^{83}$ or to the large volume changes during phase transformations. Because strain is a higher-than-linear function of stress in the plastic range, an increase of internal stress causes an increase in net external deformation when a given external stress is applied, owing to an increase in the average amount of plastic yielding in all the grains. The external strain is increased because, in grains in which the internal and external stresses oppose, there is only a relatively small decrease in elastic strain, whereas, in grains in which the stresses are in the same direction and sign, there is a large increase in plastic strain.

For the estimation of the magnitude of in-pile creep due to irradiation, it is necessary to adopt a simplified model that includes a simple yield criterion, neglects primary creep and work hardening, and makes some assumption of the distribution of stress or strain among the individual grains. ${ }^{84}$ Owing to the approximate nature of these models, some of the finer points of the radiation-creep behavior due to the internal stress mechanisms will be missed.

In the original treatment using a discontinuous model, ${ }^{85}$ it was argued that, if $\mathrm{Y}$ is the yield stress, $\dot{\mathrm{e}}_{\mathrm{g}}$ is the growth rate under 1 rradiation, and $E$ is an elastic modulus, the yield point in every grain would be reached in time $t_{m}$, given by

$\mathrm{t}_{\mathrm{m}} \approx \frac{\mathrm{Y}}{\mathrm{E}} \dot{\mathrm{e}}_{\mathrm{g}}$

If at this time a tensile stress, $\sigma$, is applied, the strain will be of the order of $\sigma / \mathrm{E}$, and in many grains the strain is plastic. If the stress is removed, it will take time $t_{m}$ to bring the internal stresses back to the y1eld stress, and, if stress, $\sigma$, is again applied, a further strain of $\sigma / \mathrm{E}$ will occur. Thus the strain rate $\dot{\mathrm{e}}_{\mathrm{m}} \approx \sigma / \mathrm{E} \mathrm{t}_{\mathrm{m}} \approx(\sigma / \mathrm{Y}) \dot{\mathrm{e}}_{\mathrm{g}}$.

Anderson and Bishop, ${ }^{86}$ using a continuous deformation model and assuming that each grain undergoes the same over-all deformation as 
the aggregate, deduced that in-pile creep due to irradiation growth in alpha uranium occurs at a rate given by

$\dot{\mathrm{e}}_{\mathrm{z}}=\frac{5}{2 \sqrt{3}} \frac{\bar{\sigma}_{\mathrm{z}}}{\mathrm{Y}} \dot{\mathrm{e}}_{\mathrm{g}}$

where $\dot{e}_{g}$ is the growth rate of a free grain due to irradiation, $\bar{\sigma}_{z}$ is the applied tensile stress, and $\mathrm{Y}$ is the yield stress. This result corresponds closely to the earlier estimate and to experimental results. In this calculation it was assumed that the rmal creep did not significantly relax the internal stresses. Because irradiation growth occurs at a decreasing rate above $300^{\circ} \mathrm{C}$ and thermal-creep rates increase, irradiation creep of this type is unimportant above about $400^{\circ} \mathrm{C}$. Experiments $^{87}$ have confirmed that the steady-state creep of uranium is unchanged during irradiation at $500^{\circ} \mathrm{C}$.

Some experimental results published by Konobeevskil indicate the existence of another type of irradiation creep not due to internal stresses. ${ }^{88}$ A large stress relaxation was found in a gamma-phase uranium-molybdenum alloy which, being cubic, neither underwent irradiation growth nor developed stresses on thermal cycling. The strains due to this creep were almost completely recoverable on subsequent annealing at 10 to $400^{\circ} \mathrm{C}$. A mechanısm has been proposed based on the preferred survival of irradiation-created dislocation loops of one Burgers vector under the action of the external stress. ${ }^{89}$

Analytically, two types of creep due to thermal cycling in the alpha range can be distinguished.

In the first, the cycles are of large amplitude, and the yield stress of the grains is exceeded. When an external stress is applied, the external strain, owing to plastic-yıelding processes, is greater than it would be if no internal stress existed.

In the second type with only small thermal cycles, true creep is involved. The isothermal creep rate of uranium is given by $\dot{\mathrm{e}}=\mathrm{A} \sigma^{2.6}$, where $\dot{\mathrm{e}}$ is the creep rate, $\mathrm{A}$ is a constant, and $\sigma$ is the applied stress. When small thermal cycles are imposed, although the mean stress in the grains is unaltered, there is a larger range of stresses in the grains. Also, because the strain rate increases at a greater-thanlinear rate with stress, the mean strain rate is increased, and hence creep occurs at an acceierated rate. ${ }^{86}$ The cycling is more effective if the rate of cycling is high enough to maintain the internal stresses during a high proportion of the period of each cycle. In the high alpha range, where this type of creep is likely to be important, stress relaxation is rapid. Thus the practical importance and magnitude of this type of thermal-cycling creep depends on both the amplitude and the frequency of cycling. It is likely to be more important above the growth range, 1.e., from 400 to $650^{\circ} \mathrm{C}$. In base-load power stations, 
however, it is not likely to add significantly to creep rates because the rate and amplitude of cycling is low.

The possibility of cycling uranium fuel bars into the beta phase is of practical interest because, if it is feasible, thermal ratings mignt be increased. Such cycling causes both swelling and enhanced creep due to the large local strains accompanying the phase change.

When alpha $\rightleftharpoons$ beta cycling occurs with externally applied small stresses, there is a linear relation between the applied stress and the strain per alpha $\rightleftharpoons$ beta cycle. The strain for one complete alpha $\rightarrow$ beta $\rightarrow$ alpha cycle with an externally applied stress of $1 / 3 \mathrm{~kg} / \mathrm{mm}^{2}$ is about 1 percent. Johnson and Greenwood ${ }^{90}$ have proposed a quantitative theory and derived an equation,

$\frac{\mathrm{e}_{\mathrm{n}}}{\mathrm{n}} \approx \frac{4}{3} \frac{\sigma}{\mathrm{Y}} \frac{\Delta \mathrm{V}}{\mathrm{V}}+\left(\frac{\Delta \mathrm{V}}{\mathrm{V}}\right)_{\mathrm{T}}$

where $\mathrm{Y}=$ yield stress

$\sigma=$ applied stress

$\Delta \mathrm{V} / \mathrm{V}=$ volume change on transformation

$\mathrm{e}_{\mathrm{n}}=$ elongation after $\mathrm{n}$ cycles

$(\Delta \mathrm{V} / \mathrm{V})_{\mathrm{T}}=$ the volume change per unit volume caused by cycling with out an externally applied load (found experimentally to be $\approx(\Delta \mathrm{V} / \mathrm{V}) / 5)$

The magnitude of all the effects found on alpha $\rightleftharpoons$ beta cycling ind cates that cycling of a complete fuel rod into the beta phase is not likely to be tolerable but that cycling of the core of a fuel rod into the beta phase may be acceptable under some conditions.

Thermal cycling of alpha uranium in the alpha range will, in the absence of external stresses, cause growth if preferred orientation is present, as well as wrinkling. The main features of these processes have been described and mechanısms discussed. ${ }^{91,92}$

The most important manifestation of creep in vertically stacked fuel rods is in bowing, and the bowing behavior of the lower fuel rods in the Calder Hall reactors appears to be largely due to ereep induced by 1 rradiation growth. ${ }^{20}$ The scatter in bowing rates and the occurrence of bowing in unstressed rods during irradiation ${ }^{93}$ point to another source of bowing that is random in its incidence and is unrelated to the applied stress. This phenomenon is probably due to circumferential variations in texture or burnup causing different longitudinal growth rates around the rods.

Changes of length in vertically stacked fuel rods are due to swelling, irradiation growth, thermal-cycling growth, the rmal-cycling creep, thermal creep, and bowing. The relative amounts depend on the stress, temperature, rate of burnup, degree of burnup, and composition of the uranium. 


\section{Swelling in Alpha Uranium}

The rate of volume increase of uranium when irradiated at temperatures up to about $400^{\circ} \mathrm{C}$ is acceptable for the chief present applcations. For power reactors most interest has therefore been directed to study of behavior in the range 400 to $650^{\circ} \mathrm{C}$, wherein volume increases are both large and of variable incidence. ${ }^{94}$ The large distortion and swelling caused by continued cycling into the beta range ${ }^{95}$ are considered by many to set an upper limit to the use of low alloys of uranium at about $650^{\circ} \mathrm{C}$.

MECHANISM OF SWELLING Three main phenomena are responsible for swelling. First, the solid fission products in uranium occupy about four times the volume of the uranium from which they formed. This source of volume increase will not be discussed further because it is not structure sensitive and the volume increase is linear with burnup. One source of variation in swelling behavior of alpha uranium is related to large differences in distributions of fission-gas bubbles, ${ }^{94}$ discussed in this section. Grain-boundary cracking, which also contributes to swelling, especially on 1 rradiation at about $450^{\circ} \mathrm{C}$, is discussed separately in the next section.

Probably the major recent development in the study of swelling from the practical standpoint is the demonstration of the importance of minor variations in composition and structure in swelling behavior. ${ }^{96}$ This influence has helped to explain the large scatter in swelling results reported hitherto, in which, among nominally similar uranium specimens, large quantitative and qualitative differences in swelling behavior have been found. For example, in fairly pure uranium at about 0.3 percent burnup of all atoms, swelling increases markedly with temperature of 1 rradiation at 450 to $600^{\circ} \mathrm{C}$. At about 0.45 percent burnup in the same temperature range, breakaway swelling, in which volume increases are greater than 100 percent of the original volume, is occasionally observed. In marked contrast to this behavior, in betaquenched uranium containing a few hundred parts per million iron and aluminum ("adjusted" uranium), the volume increase at 0.3 percent burnup is only about 3 percent and does not increase ${ }^{96}$ with temperature of irradiation at 450 to $600^{\circ} \mathrm{C}$.

Fission-gas bubbles are so small before breakaway that the pressure, $p$, in them is balanced by surface tension, $\gamma$, so that $p=2 \gamma / \mathrm{r}$, where $r$ is the bubble radius. The parameter that determines the volume increase due to gas bubbles, therefore, is $N$, the number of bubbles per cubic centimeter of uranium. When $N$ is large, $r$ is small; thus $p$ is large. Therefore, when $N$ is large, the fission gas is held at a high pressure, and the volume increase is small. In fact, for a given burnup and temperature, volume increase due to bubbles is inversely proportional to $\sqrt{\mathrm{N}}$. Thus one source of large differences in swelling 
behavior can be related to differences in $\mathrm{N}$. If $\mathrm{N}$ remains constant with burnup, $b$, then theoretically the volume increase varies as $b^{3 / 2}$. At up to $1 / 2$ percent burnup, the scatter in results is so large that a linear relation fits equally well.

The earlier work on bubble distributions in adjusted uranium used replica techniques. It indicated that, in adjusted beta-quenched uranium irradiated at 500 to $600^{\circ} \mathrm{C}$, fission-gas bubbles on a scale of $10^{13}$ per cubic centimeter accounted for a volume increase of about 3 percent at 0.3 percent burnup. ${ }^{97}$ A similar bubble distribution has more recently been found at a higher burnup, 0.7 percent in adjusted material in which the net volume increase was about 10 percent. ${ }^{96}$ The stabllity of the bubbles on a scale of $10^{13}$ per cubic centımeter at $600^{\circ} \mathrm{C}$ must be related to some structural feature of the adjusted uranium, such as particles of uranium-aluminum-1ron intermetallic compounds, which are distributed on about the right scale. These precipitate particles could act as fission-gas collectors from the start of irradiation ${ }^{98}$ and provide some protection against dissolution of bubbles, due to traverse by fission fragments, in the early stages of their formation. Replica work also indicates that the number of the bubbles of about $1000 \mathrm{~A}$ diameter is essentially constant at about $10^{13}$ per cubic centimeter during irradıation between 500 and $600^{\circ} \mathrm{C}$ in adjusted uramum and that the bubbles merely grow larger during irradiation. Because they are uniformly distributed, the larger bubbles would begin to touch at a volume increase of about 25 percent and a burnup of about 2 percent; once the bubbles begin to join, swelling accelerates.

There has always been some doubt of the validity of the bubble distributions deduced from replica studies of polished sections. A further significant extension of knowledge of swelling has been provided by examination of thin films of irradiated adjusted uranium in the electron microscope. Thus far most specimens exammed have been ırradıated below $450^{\circ} \mathrm{C}$ and showed bubbles distributed on a much finer scale than were those formed between 500 and $600^{\circ} \mathrm{C}$. After irradiation at or below $450^{\circ} \mathrm{C}$, there are more than $10^{15}$ bubbles per cubic centimeter, each of about $100 \mathrm{~A}$ diameter. Use of improved replica techniques has revealed the smaller bubbles with both etched and fractured surfaces. Figure 6 shows transmission-electron micrographs of a uranium foll about $200 \mathrm{~A}$ thick. The specimen was 1rradiated to a burnup of $1120 \mathrm{Mwd} / \mathrm{t}$ at a surface temperature of $330^{\circ} \mathrm{C}$. The bubbles, $3 \times 10^{15}$ per cubic centimeter, produced a volume increase of 0.6 percent (Fig. 6a). They are about $100 \mathrm{~A}$ in diameter. The same irradiated specimen polished and cathodically etched is shown in Fig. 6b. The shadowed replica shows bubbles having the same size and distribution as in the original. The larger features are not due to irradiation. A shadowed replica of a transgranular cleavage surface from the same irradiated sample is shown in Fig. 6c. These bubbles 


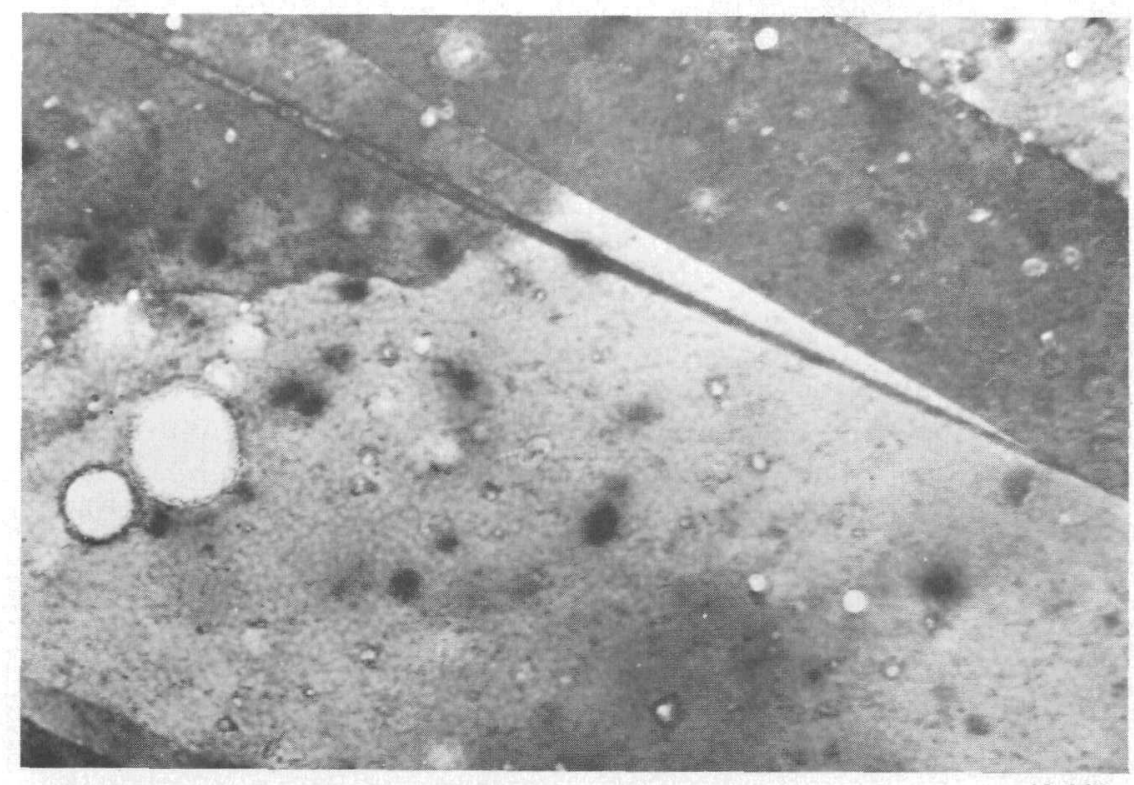

$\times 60,000$

Fig. 6a-Distribution of bubbles on surface of original irradiated uranium-foil specimen.

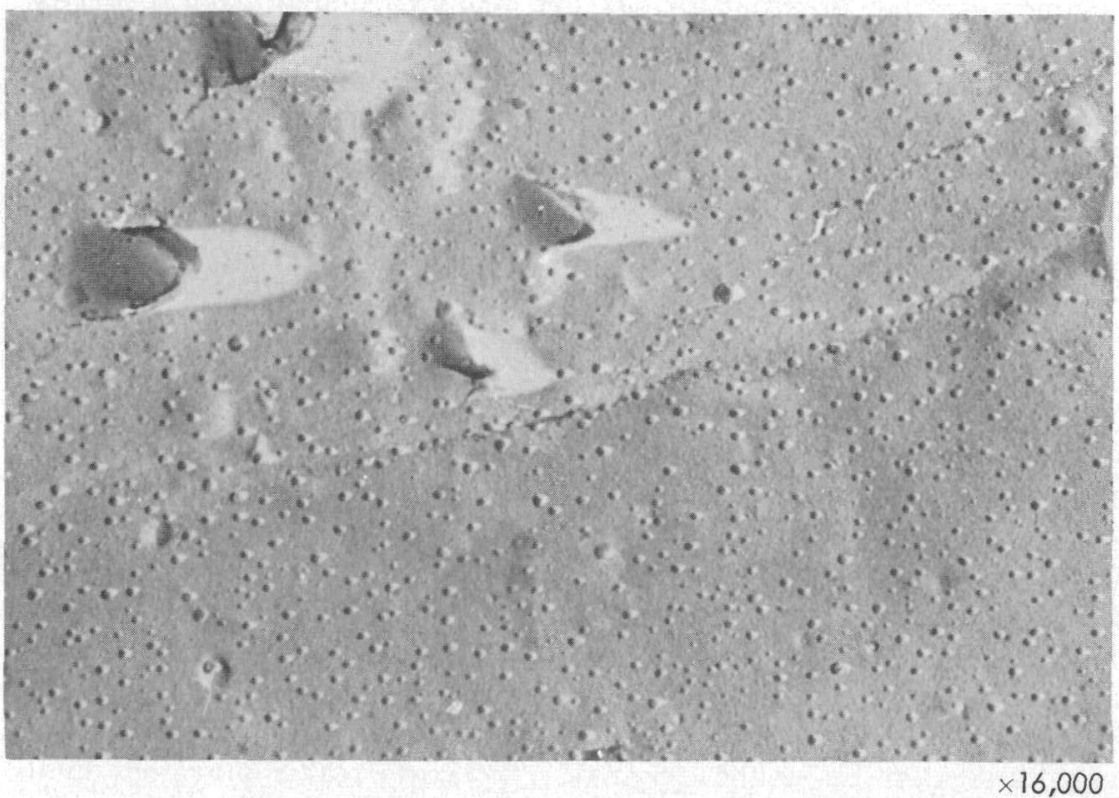

Fig. $6 b-$ Distribution of bubbles on surface of original irradiated uranium-foil specimen after being polished and cathodically etched. 


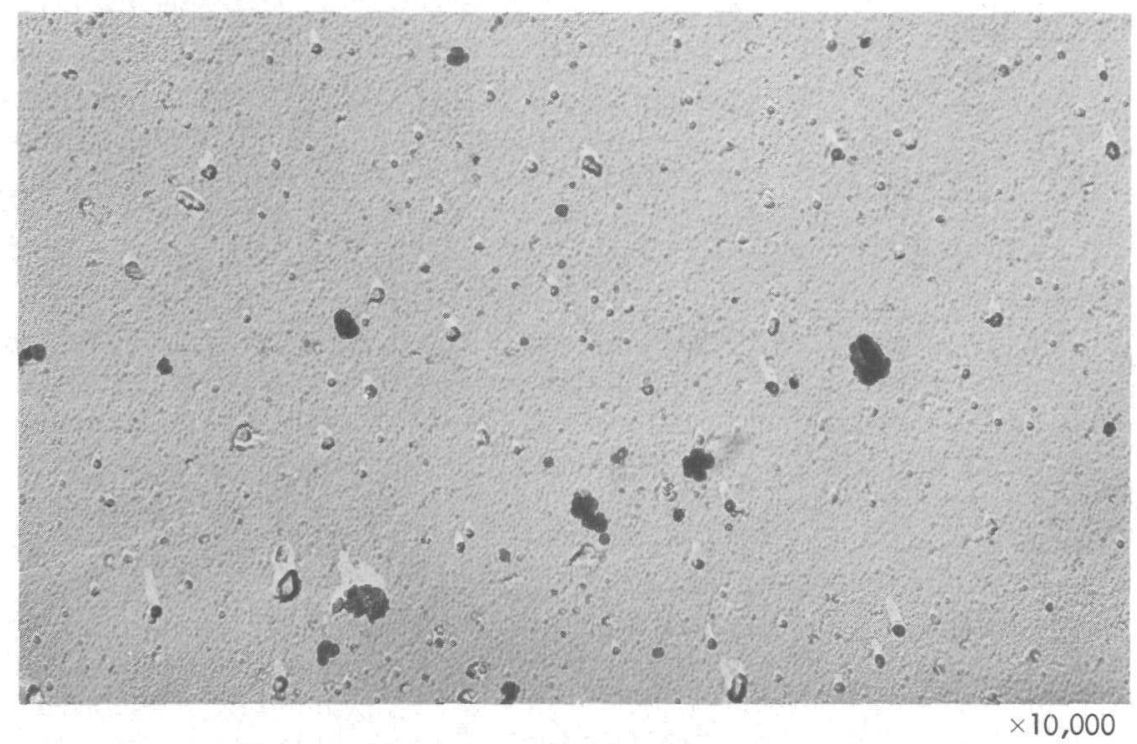

Fig. 6c-Distribution of bubbles on shadowed replica from transgranular cleavage surface (same irradiated sample).

formed by irradiation below $450^{\circ} \mathrm{C}$ might be nucleated homogeneously or on vacancy clusters. Unfortunately thin-film techniques cannot be used to study bubbles of more than about $150 \mathrm{~A}$ diameter because the films are only of that thickness.

In contrast to the behavior of adjusted uranium in the high alpha range, the swelling of pure uranium increases steeply with temperature $\mathrm{e}^{101}$ of irradiation in the range 500 to $650^{\circ} \mathrm{C}$, and breakaway swelling at 0.7 percent is observed..$^{96}$ Presumably the number of bubbles per cubic centimeter of uranium decreases as the irradiation temperature is raised in the range 500 to $650^{\circ} \mathrm{C}$. A similar result is obtained with adjusted material, however, in the fully annealed condition.

Irradiation at high temperatures does not favor buildup of a high degree of supersaturation of fission-product gases because long-range diffusion is possible and therefore precipitation of gas on pre-existing nuclei rather than by homogeneous nucleation is more probable. The coarse bubble dispersions in pure uranium irradiated between 500 and $650^{\circ} \mathrm{C}$ point, therefore, to a lack of centers for bubble nucleation. There is, however, a contrary view that in pure uranium the bubbles form on a fine scale and then coalesce by movement of the bubbles in the way demonstrated with helium bubbles in copper ${ }^{102}$ or by grainboundary sweeping processes. ${ }^{103}$ Transfer of gas by solution is not a possible process for bubble coarsening in the alpha range in the absence of radiation. 
Results of postirradiation annealing of uranium irradiated up to about $500^{\circ} \mathrm{C}$ show many points of similarity with experiments in which irradiation is at a high temperature in the alpha range. Thus, in adjusted uranium irradiated at about $450^{\circ} \mathrm{C}$ and containıng $10^{15}$ bubbles per cubic centimeter, the bubbles survive postirradiation annealing treatments ${ }^{99}$ of up to $100 \mathrm{hr}$ at $600^{\circ} \mathrm{C}$, and the only volume increase, of about 0.2 percent, is due to a small amount of grain-boundary cracking.

On the other hand, pure uranium irradiated initially at $500^{\circ} \mathrm{C}$ and then at lower temperatures swelled markedly ${ }^{101}$ on annealing at 600 and $650^{\circ} \mathrm{C}$. Swelling was rapid and essentially complete in an hour, and It was accompanied by coarsening of the bubbles and decrease in $\mathrm{N}$. The physical process reducing the number of gas bubbles is not known; but, in pure uranum after irradiation at about $500^{\circ} \mathrm{C}$, the bubbles are distributed very inhomogeneously, and there are regions in which the local swelling is much greater than the over-all swelling of the specimen. ${ }^{96,104}$ Because with pure uranium the average volume increases are high, 5 to 50 percent, it is reasonable to suppose that a significant contribution to bubble coarsening is from thermal expansion of the gas causing the bubbles to touch and coalesce. Furthermore, uranium irradiated at a low temperature is severely distorted owing to growth. Recrystallization occurs readily in pure uranium on postirradiation annealing at $600^{\circ} \mathrm{C}$, and the accompanying grain-boundary movements may cause some bubble coarsening.

Recent work in which very pure uranium was irradiated to a burnup of 0.3 at.\% at approximately $275^{\circ} \mathrm{C}$ and subsequently annealed for up to $75 \mathrm{hr}$ at a series of higher temperatures has demonstrated the $1 \mathrm{~m}$ portance of recrystallization in the swelling of alpha uranium. ${ }^{105} \mathrm{With}^{\text {th }}$ postirradiation heat treatments up to $550^{\circ} \mathrm{C}$, volume increases were only up to 1 percent. But, in a specimen annealed at $618^{\circ} \mathrm{C}$, a volume increase of 18 percent was obtained, and large pores were observed in the recrystallized areas at the boundaries of new grains. In unrecrystallized areas of the same specimen, however, the bubbles remained small.

The exact mechanism of stabilization of the dispersions of fine bubbles in adjusted uranium is not yet known. The precipitates might act as bubble nucleators or stabilizers, or they might prevent bubble coarsening by inhibiting grain-boundary movements. The alloying elements might, however, act in solid solution in some entirely different way, by changing the diffusion and homogeneous bubblenucleation conditions of fission-product gases. The lattice strain around a large gas atom can be relaxed if the xenon or krypton atom associates with a vacancy, and the diffusion of the gas will be facilitated by the presence of these vacancy-gas atom pairs. If, however, the large gas atom were to associate with a small atom, such as beryllium, 
In solid solution, rather than with a vacancy, the diffusion rate would be reduced, each bubble would collect gas from a smaller volume, and the bubble size would be reduced. ${ }^{106}$ In addition, the early stage of bubble nucleation involves the formation of a complex xenon-vacancyxenon configuration. A large atom, such as cerium, could replace one of the xenon atoms in this nucleus. ${ }^{106}$ Thus the presence of large solute atoms might increase the rate of bubble nucleation, and again swelling would be reduced.

In connection with fission-gas bubbles, thermal-cycling effects have not been discussed except in their role of facilitating grain-boundary movements. An experiment ${ }^{96}$ has shown that 60,000 cycles of $\pm 5^{\circ} \mathrm{C}$ and $\pm 15^{\circ} \mathrm{C}$ at $575^{\circ} \mathrm{C}$ did not affect the swelling behavior or bubble distribution. This result is to be expected because there is thought to be no stress around the bubbles. ${ }^{97}$ The effect of large thermal cycles is again not relevant to bubble behavior but is relevant to cracking. Irradiation hardening in uranium, if not simply due to interstitial or vacancy clusters, must be related to fission-gas distribution on a scale finer than that of precipitates of alloying elements. Hardening in uranium has been observed ${ }^{81}$ after irradiation below $300^{\circ} \mathrm{C}$. Such hardening and the embrittlement that accompanies it are resistant to annealing, and it has been suggested that it is due to fission-gas bubbles. The recently discovered bubbles on a scale of $10^{15}$ per cubic centimeter are of about the right size and scale to cause hardening. ${ }^{99}$

The discussion has been confined to uranium and its very dilute alloys. The principles involved apply, of course, to more highly alloyed uranium.

INTERMETALLIC PRECIPITATES The success of uranium with small amounts of alloying elements in resisting swelling has concentrated attention on the solubilities of the added elements, the identity of the intermetallic phases formed, and the morphology of these phases. This interest has resulted because, although the exact mechanism whereby these alloys resist swelling is unknown, Bellamy's ${ }^{96}$ results make it clear that a critical dispersion of precipitate must be initially present for this mechanism to operate.

The equilibrium phases present in most binary alloys are well established, although the solubilities are less so. In ternary alloys, however, neither kind of information is well known. Three relevant alloys are uranium-1ron-silicon and uramum-iron-aluminum, both of which are in use as reactor fuels, and uranium-silicon-aluminum, which has been proposed as an experimental fuel. Most is known about uranium-silicon-aluminum. Petzow and Kvernes ${ }^{107}$ have studied the ternary equilibrium. They have shown that no ternary compounds are formed in this system and that there is very little solid solubility of either silicon or aluminum in the compounds of uranium with aluminum 
and silicon, respectively. Solubilities in the gamma phase are shown to be greater than those in the beta phase, which are in turn greater than those in the alpha phase. These findings are borne out by American work which shows that $0.3 \mathrm{wt} \%$ aluminum is soluble in the gamma phase, that with this concentration of aluminum the solubility of silicon is about $0.25 \mathrm{wt} . \%$, but that with this content precipitates form in the alpha phase. ${ }^{108}$

Uranium with $150 \mathrm{ppm}$ iron and $100 \mathrm{ppm}$ silicon shows a single precipitate that was originally attributed to a ternary compound..$^{52}$ Later studies showed that there was no ternary compound below $650^{\circ} \mathrm{C}$, but there was extensive solubility of silicon in $\mathrm{U}_{6} \mathrm{Fe}$; thus the precipitate was attributed to $\mathrm{U}_{6}$ (1ron, silicon). ${ }^{109}$

Not enough is known about ternary equilibrium in uranium-ironaluminum, but some speculation may be fruitful. A redetermination of the binary uranum-rich diagrams, using super-pure uranium, has shown that the solubilities of iron in uranium at $650,700,750$, and $790^{\circ} \mathrm{C}$ are $20,470,750$, and $2520 \mathrm{ppm}$, respectively, and that the solubilities of aluminum in uranium at 640,760 , and $950^{\circ} \mathrm{C}$ are 100 to 200,400 to 600 , and 4000 ppm, respectively. ${ }^{110}$ Petzow, Steeb, and $\mathrm{Tank}^{111}$ have shown that, in the quasi-binary system $\mathrm{UFe}_{2}-\mathrm{UAl}_{2}$, there is extensive solubility of aluminum in $\mathrm{UFe}_{2}$ and iron in $\mathrm{UAl}_{2}$ but that a ternary compound, UFeAl, having an extended range of composition also forms. The melting point of this compound is approximately 1000 to $1050^{\circ} \mathrm{C}$, as opposed to 815,1235 , and $1590^{\circ} \mathrm{C}$ for the meltung points of $\mathrm{U}_{6} \mathrm{Fe}, \mathrm{UFe}_{2}$, and $\mathrm{UAl}_{2}$, respectively. The ternary compound therefore seems unlikely to dominate the system. In addition to forming the pseudobinary fields with $\mathrm{UFe}_{2}$ and $\mathrm{UAl}_{2}$, the ternary compound may form a pseudobinary field with $\mathrm{U}_{6} \mathrm{Fe}$ rather than with uranium. The solubility of aluminum in $\mathrm{U}_{6} \mathrm{Fe}$ is unknown, but below $700^{\circ} \mathrm{C}$ the solubility of aluminum in $\mathrm{UFe}_{2}$ is lower than the solubility of iron in $\mathrm{UAl}_{2}$. Thus the solubility of aluminum in $\mathrm{U}_{6} \mathrm{Fe}$ is likely to be appreciable but not excessive. If it is assumed that the se speculations have some worth, the ternary sections in $\mathrm{F}_{1} \mathrm{~g} .7$ can pe drawn. ${ }^{*} \mathrm{UAl}_{2}$ containing varying amounts of dissolved iron has been identıfied by electron diffraction in extraction replicas from simulated adjusted uranium that had undergone various heat treatments, ${ }^{112}$ and thus some credence is given to the postulated equilibrium.

The study of the morphology of the precipitates is very difficult, especially if the alloy is in a nonequilibrium state, because their

*Phase relations in the ternary us anium-ıron-aluminum equilibrium diagiam are now known and have been discussed in a paper entitled "The Equilibrium Phases in the Uranıum-Alumınum-Iron Alloys in the Partial Domain Uranium $-\mathrm{UAl}_{2}-\mathrm{NFe}_{2}$," by G. Petzow and R Tank, which appears in $Z$ Wetallk, 54: 91 (1963) 


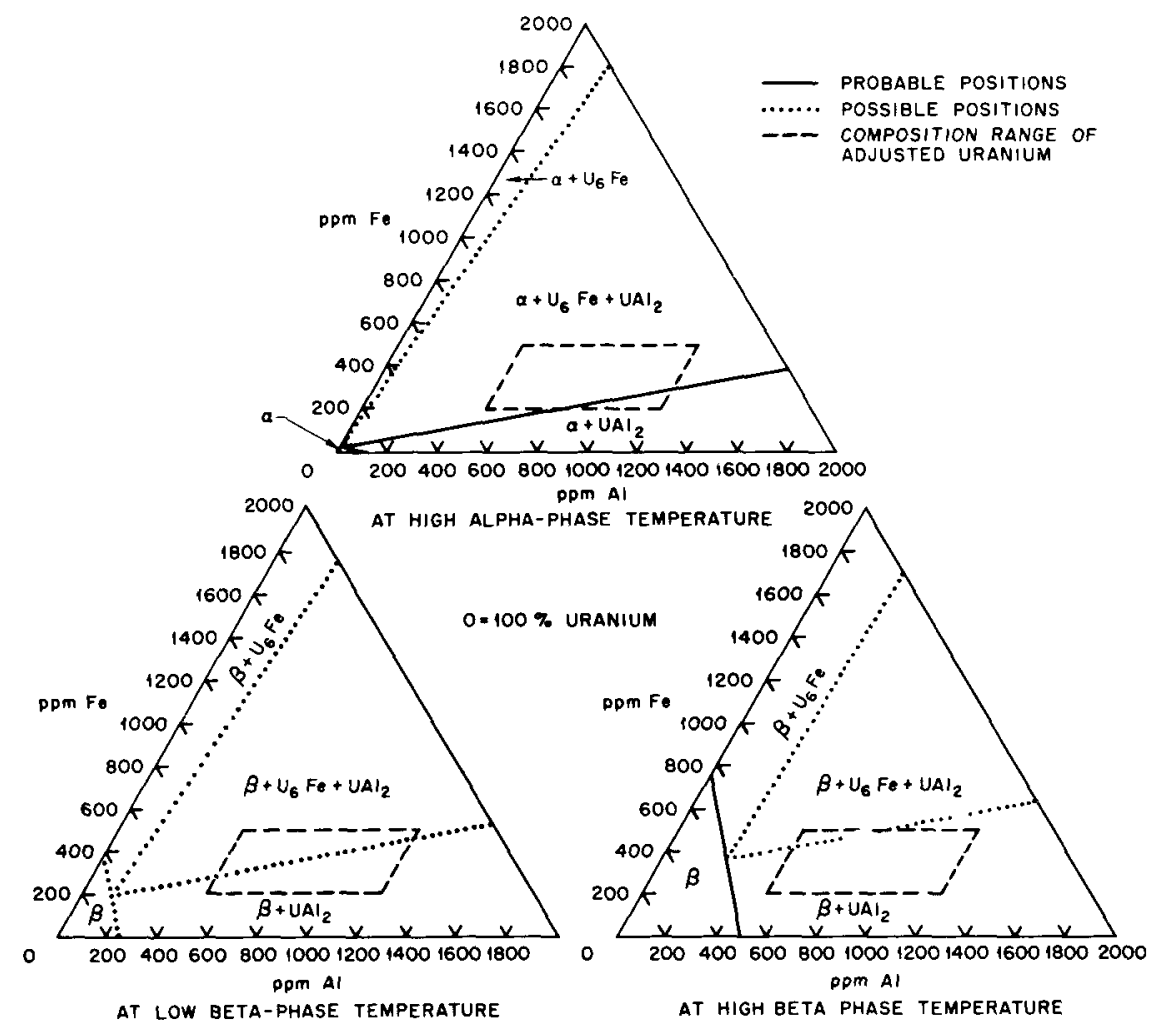

Fig. 7-Possible 1sothermal sections of the uranium-rich end of the uranıum-iron-aluminum equilibrium diagram

particle sizes range from a few microns down to $100 \mathrm{~A}$, 1.e., from particles just optically visible to those which can be seen only by transmission-electron microscopy of thin films of uranium.

A cast rod of adjusted uranium, after suitable heat treatment, resists swelling. If such a rod is cooled slowly, iron and aluminum will be in solid solution in the gamma phase. As further cooling occurs, however, the beta phase will separate until the remaining gamma phase undergoes a eutectoldal decomposition. Over most of the range of composition, the eutectoid will be beta $+\mathrm{UAl}_{2}$, and this will lead to a network of $\mathrm{UAl}_{2}$ containing dissolved iron at beta grain and polygon boundaries. As the beta phase cools, however, it will become supersaturated, and further precipitation, mainly of $\mathrm{UAl}_{2}$ but possibly also of $\mathrm{U}_{6} \mathrm{Fe}$, will take place. When the beta phase transforms to alpha, precipitation of $\mathrm{U}_{6} \mathrm{Fe}$ and $\mathrm{UAl}_{2}$ will occur at the alpha grain and polygon boundaries. Finally there will be a very small amount of precipitation as the alpha phase cools. 


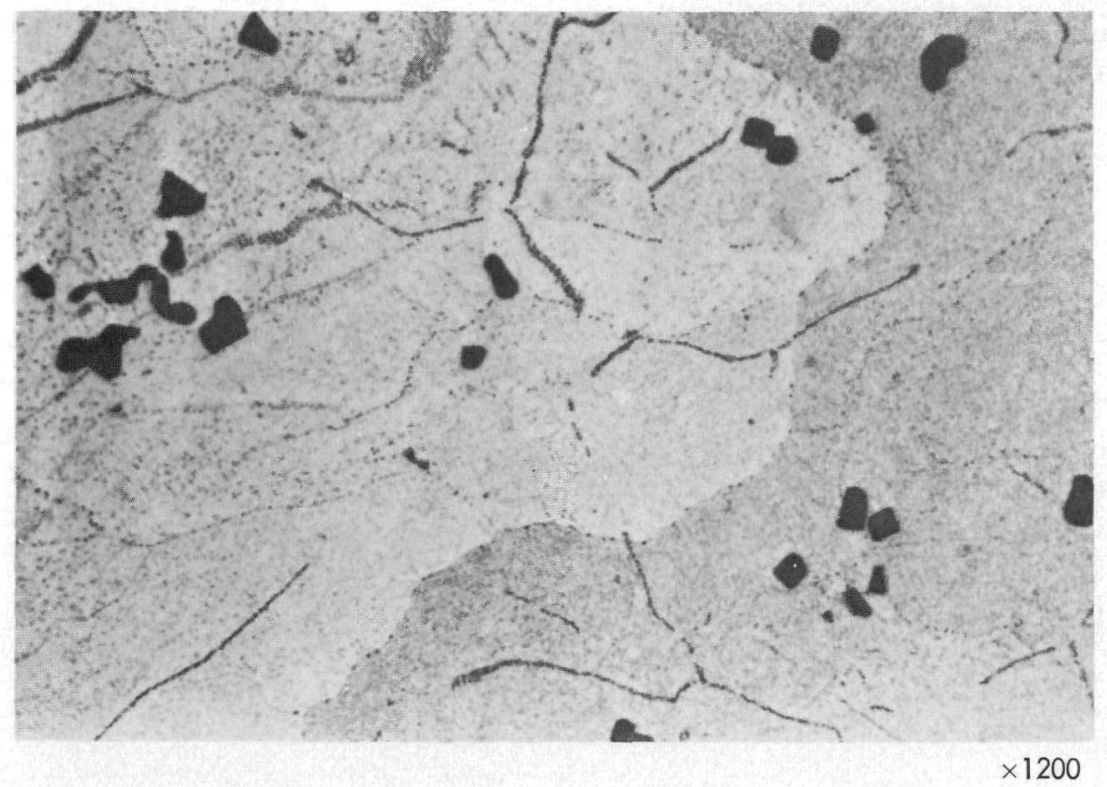

Fig. 8- Precipitation in area from rim of cast adjusted aluminum bar (attack polished and electrolytically etched in citric acid orthophosphoric acid-water solution; bright field).

Figure 8 shows three forms of precipitation. There are heavy black lines of precipitate that cross the alpha grain boundaries, strings of precipitates along the alpha grain and polygon boundaries, and a general background of precipitates. The heavy black lines have been examined at greater magnifications by electron microscopy of extraction replicas, and their morphology is consistent with a eutectoidal decomposition. ${ }^{113}$ Judging from the annealing experiments mentioned in the section on grain refinement, however, some of the solute either remains in supersaturated solution or exists as a very fine precipitate.

After beta treatment ranging from $15 \mathrm{sec}$ to $15 \mathrm{~min}$ or gamma treatment lasting up to a few minutes, the precipitates partially redissolve, and the solutes are held in supersaturated solution on severe quenching. Annealing at alpha-phase temperatures then gives a dispersion of fine precipitates of sizes down to $100 \mathrm{~A}$ within the grains without diminishing the networks of larger precipitate. ${ }^{114}$ The average particle concentration in this state is $10^{13}$ per cubic centimeter. ${ }^{115} \mathrm{~A}$ gamma treatment for longer periods, followed by quenching and alpha annealing, leads to more re-solution of the precipitates and consequently a finer dispersion, with populations up to $3.5 \times 10^{15}$ per cubic centimeter. ${ }^{116}$

Thus this type of heat treatment can give dispersions of precipitate of the same order as the dispersion of bubbles of fission gas, and the 
dispersion does not seem to be markedly affected ${ }^{115}$ by alpha-annealing temperatures of 400 to $600^{\circ} \mathrm{C}$. The type of dispersion is not, of course, restricted to this alloy. It has been produced in uranium-aluminumsilicon alloys 117 and in "modified" adjusted uranium to which small amounts of silicon and chromium have been added. ${ }^{115}$

This raises questions as to the ideal qualities, dispersion, and concentration of the precipitate which are required to prevent swelling. The fine precipitate should remain fine and should not coalesce. The ideal precipitate should therefore have no effective solub:lity in the alpha phase. Thus a nonmetallic compound would serve very well, but production of the required dispersion would be extremely difficult. The solute, therefore, should have the minimum possible solubility in the alpha phase, ensuring not only the minımum mass transfer between particles but also the reprecipitation of any solute knocked into supersaturated solution by fission. It should have a higher solubility in either the beta or the gamma phase so that the dispersion can be achieved by heat treatment. If reasonable nuclear properties and easy addition in melting are added to this list, the choice for uranium compounds is reduced to iron, aluminum, silicon, and possibly nickel. If, in addition, much precipitate is required for a small addition of solute, iron and nickel have obvious advantages.

The ideal dispersion of precipitate is not known. Despite the variability of swelling results, however, the best result obtained by Bellamy with adjusted uranium was with the simulated cast specimen. This result may suggest that the gamma-quenched specimen had too much fine precipitate and that the others, because of the slow cooling in the zone-melting operation, had too little. The ideal dispersion in any case does not depend only on antiswelling behavior. For instance, it must not be so dense that the fuel element is seriously embrittled, nor must it need so much solute in solution at high temperatures that either the beta phase is retained on quenching or the beta $\rightarrow$ alpha transformation is at such a low temperature that cracks form.

The ideal concentration of solute to produce the ideal dispersion will depend on the heat treatment used; but this same concentration must also give grain refinement, or at least it must not react with other grain-refining elements. Untıl more is known about the grainrefining mechanism and the part played in it by precipitates, it may be difficult to define an optimum concentratıon. The possibility exists, however, that, if the concentrations of iron and aluminum in adjusted uranium are reduced and the beta-treatment time is increased enough to allow all the precipitate to be in solution before quenching, both grain refinement and the ideal dispersion could be achieved without producing the larger precipitates that lie on the alpha grain boundaries and seem to weaken them. (See section on grain-boundary cracking.) 
Finally, is there any virtue, apart from its grain-refining properties, in a ternary addition for antiswelling purposes, or does one compound uniquely decide this? The theoretical answer must lie in determining the exact mechanism whereby the precipitates prevent formation of large bubbles, but by practical experiment this question could be answered comparatively easily.

Thus it has been shown (1) that the precipitates that prevent swelling are those which are almost insoluble in the alpha phase, (2) that they exist as fine dispersions on a scale comparable to the bubble dispersions, and (3) that there may be other successful ones in addition to those already found. The next few years should bring great advances in the knowledge of both swelling mechanisms and precipitates.

\section{Grain-boundary Cracking}

The tensile properties of unirradiated uranium may have a direct bearing on the cracking of fuel elements. Although the factors affecting these properties have long been known, few have been studied systematically. Irradiation results in stresses that result in fallures at grain boundaries.

\section{TENSILE PROPERTIES OF UNIRRADIATED URANIUM}

It has long been known that the tensile properties of uranium, particularly elongation, are affected by grain size, preferred orientation, previous working, heat treatment, content and distribution of impurities and inclusions, and testing temperature. Many of these variables are, of course, interdependent. Few have been studied systematically. One exception is the hydrogen content, the effects of which have been recently reviewed by Owen. ${ }^{118} \mathrm{He}$ has quoted work showing that the roomtemperature ductility of uranum could be reduced from over 30 percent to below 10 percent by a hydrogen content of as little as $0.3 \mathrm{ppm}$. The hydrogen content also affected the temperature range of the ductile-brittle transition that occurs between 0 and $100^{\circ} \mathrm{C}$. No satisfactory explanation exists for these effects.

Studies on the fractograpny of tensile fallure are slowly beginning to build up a systematic picture of the fallure mechanisms. Davies, ${ }^{119}$ and Davies and Martın, ${ }^{120}$ working mainly with cast uranium containing about $750 \mathrm{ppm}$ carbon and a total of 400 ppm iron, aluminum, and silicon, showed that the fracture at room temperature was initiated by the larger inclusions, mainly of carbide cuboids but sometimes of oxide, cracking or parting from the matrix. The cracked inclusions lay both on grain boundaries and within the grains. There were four types of fracture surface.

1. Smooth surfaces containing many fine inclusions, associated with grain-boundary parting in the initial stages of fracture and with the fibrous part of the fracture surface. 
2. Irregular surfaces containing many cubold inclusions, associated with transgranular cracks propagating via inclusions and with fibrous fracture.

3. Smooth surfaces, containing steps but very few inclusions; these were associated with bright facets on the fracture surface, and with transgranular cleavage formed in the last stages of fracture parallel to twin traces.

4. Surfaces on which small cusps were seen, the node of each cusp containing a fine precipitate particle. These were found only in spec1mens that had been quenched from the gamma phase into oll to give a fine dispersion of intermetallic precipitates within the grains, and they were associated with heavy local shear in the later stages of fracture.

Thus cracks initiated at the larger inclusions spread either along grain boundaries or transgranularly from cubold to cubold. Final stages of fracture could be due to this transgranular tearing or to cleavage, depending perhaps on grain orieniation, or to heavy local shear associated with the fine inclusions.

Adjusted uranium specimens had a much higher ratio of intergranular cracks to transgranular cracks than the unadjusted material; of these intergranular cracks, most did not contain cubolds but were associated with fine intermetallic precipitates at the grain boundaries.

Testing just below room temperature increased the proportion of bright facets on the fracture surface, but fracture was still initiated at the cuboid inclusions. At lower temperatures, however, cleavage fracture predominated. At $100^{\circ} \mathrm{C}$ the fracture was entirely fibrous. Above $400^{\circ} \mathrm{C}$ the fracture was no longer initiated by cracking at these inclusions but by vold formation at inclusions, followed by plastic necking both internally and externally. There was strong suspicion that, in the beta range, the fracture was intergranular and unaffected by the inclusions. The cracks were initiated by the formation of voids, possibly caused by vacancy condensation at grain boundaries. In the gamma range the fracture was very similar to fracture in the high alpha range but was in a more extreme form.

Loy ${ }^{121}$ has largely confirmed these fractographic observations in uranium containing about $250 \mathrm{ppm}$ carbon and a total of about $130 \mathrm{ppm}$ iron, aluminum, and silicon, and he, too, found grain-boundary cracks at room temperature. However, Daniel et al. ${ }^{122}$ with uranium containing $630 \mathrm{ppm}$ carbon and a total of approximately $180 \mathrm{ppm}$ iron, nickel, and silicon, found no evidence of intergranular cracking at room temperature and above, although the fracture was initiated at the carbide particles. Taplin and Martin, ${ }^{123}$ working with the same quality of uranium as Davies and Martin, found that intergranular cracking was a feature only of the transition zone from brittle to ductile fallure.

Loy has suggested that the Owen-Petch relation between yield stress and grain size might hold for uranium. However, achieving a 
range of grain sizes adequate to test this theory while preserving a constant preferred orientation, grain shape, and precipitate distributıon is difficult. Taplin and Martın have studied specimens that were beta quenched and annealed at different temperatures in the alpha range to give approximately the same grain size and precipitate distribution but different grain shapes. They showed that, with these specimens, the temperature of the ductile-brittle transition was increased with increasing irregularity of grain shape. At first sight this is qualitatively inconsistent with the ideas on the phenomenon of brittle fracture because increasing grain-boundary area should lower the ductile-brittle transition temperature; there may, however, be alternative explanations.

Uranium in reactors undergoes grain-boundary cracking at about $450^{\circ} \mathrm{C}$. It is difficult to relate the in-pile to the out-of-pile grainboundary cracking because of the difference in temperature of about $400^{\circ} \mathrm{C}$. From the foregoing experiments, it is even difficult to ascribe a basic reason for grain-boundary cracking since in none of the experiments except those of Owen ${ }^{118}$ was the hydrogen content known or controlled. Cracking might be prevented by the empirical addition of various solutes, as has been done with non-nuclear materials. These solutes, however, must not adversely affect the grain-refining properties or precipitate distributions of the small additions of alloying elements already made. Grain-boundary cracking in uranium will never be understood, however, untıl cracking and the ductıle-brittle transition are studied first in super-pure uranium, then in uranium with only one precipitate, and finally in commercially pure uranium; with all these materials the hydrogen content must be known and controlled. The research could then be extended to irradiated specimens.

CRACKING DURING IRRADIATION Replication of fractured surfaces and optical metallography have shown that irradiation of alpha uranium to 0.2 percent burnup or more in the growth range, 1.e., below $500^{\circ} \mathrm{C}$, causes the formation of large ragged grain-boundary voids, as shown in Fig. 9. The figure shows two areas on a specimen of $300 \mu$ grain size irradiated to 0.56 percent burnup at about $400^{\circ} \mathrm{C}$ and a burnup rate of 0.83 percent per year. If irradiation is in a very narrow range of temperature near $450^{\circ} \mathrm{C}$, the volds may become very large, up to about $0.1 \mathrm{~mm}$ in diameter at 0.5 percent burnup. ${ }^{124}$ This phenomenon may cause an appreciable increase in volume in addition to that caused by the solid and gaseous fission products; hence there is a narrow peak in the curve of swelling plotted against temperature. The position of the peak has been variously reported as being from 390 to $470^{\circ} \mathrm{C}$. The exact position may be influenced by the rate of burnup, possibly because higher internal stresses are developed by higher growth rates or because growth itself may depend on rate of burnup 

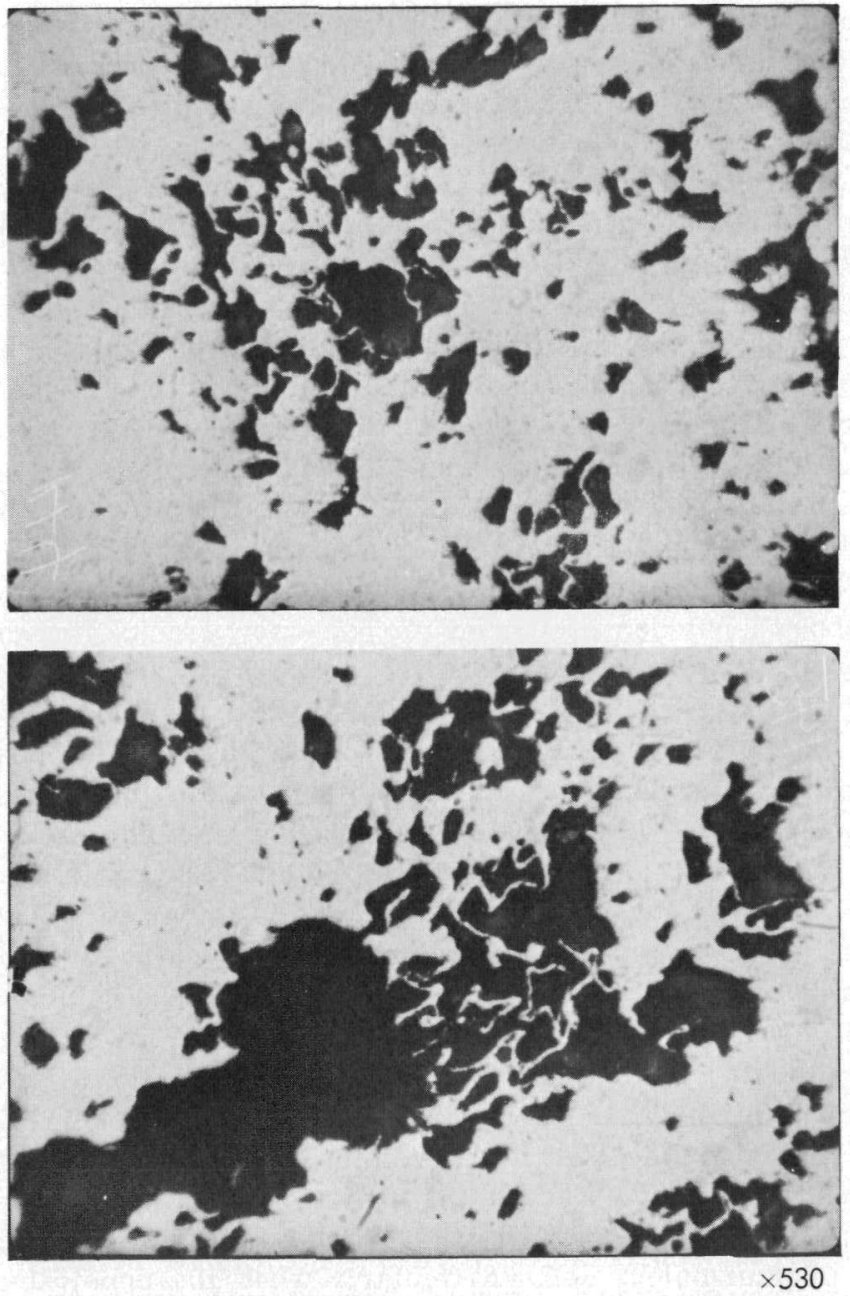

Fig. 9-Grain-boundary cracking in irradiated alpha uranium (bright field). 
in this temperature range. At very low rates of burnup, the peak may be absent altogether.

It is thought that this type of cracking is due to the internal stresses set up by irradiation growth. These stresses decrease with increase in temperature since growth rate decreases and stress relaxation in the grains increases. Yet the occurrence of grain-boundary fallure at the higher temperature points to an increase in the ease of grain-boundary fracture with increase in temperature in the growth range. The occurrence of such fallure is typically confined to a narrow temperature range. Consistent with the supposed role of irradiation growth, swelling of this type cannot be produced by postirradiation annealing in the critical temperature range near $450^{\circ} \mathrm{C}$. Because it is likely that the volds do not contain gas under high pressure, it might be expected that external restraint would effectively reduce this type of swelling. Thus, in a fuel element subjected to a temperature gradient from surface to center, the phenomenon may not appear if the volume subject to the critical temperature is near the center where it is restrained by the cooler outer layers. In addition, the pressure of the coolant may be sufficient to reduce the volume increase markedly.

A second source of internal stress in polycrystalline alpha-uranium aggregates is from the anisotropic thermal expansion of the individual grains. Specimens irradiated to about 0.3 percent burnup at 450 to $600^{\circ} \mathrm{C}$ showed patches of fine grain-boundary cracks in a third of the specimens, ${ }^{94}$ mainly those irradiated above $575^{\circ} \mathrm{C}$. It is believed that these cracks were caused by internal stress cycling due to occasional cooling of the specimens by about $200^{\circ} \mathrm{C}$ during reactor shutdowns. The grain-boundary nature of the cracks indicates that they formed at a high temperature in the cycle. The absence of such cracks in spec1mens irradiated at lower temperature could be due to the lower strain involved in each thermal cycle. With the number of thermal cycles found in most irradiation experiments, this form of fallure is not appreciable and contributes less than 1 percent to the volume increase. It could, however, be important. For example, in a fuel running at $600^{\circ} \mathrm{C}$ and cooled dally to room temperature, this form of fallure might be dominant in the absence of external restraint. Also, if the cracks should collect fission-product gas, volume could increase significantly. ${ }^{94}$

Postirradiation annealing in the high-alpha range also causes cracking due to thermal stresses, the extent of which increases with the number of thermal cycles, particularly when the upper temperature is above $575^{\circ} \mathrm{C}$ and cooling is below $100^{\circ} \mathrm{C}$. Since thermal cycling of unirradiated uranium would not cause cracking, irradiation embrittlement is important in this type of cracking.

The extent and kind of embrittlement change with burnup and irradiation temperature. For example, the part of the embrittlement due to small clusters of displaced atoms is important only for very 
low irradiation doses at low temperatures of irradiation. Thus for irradiation below $35^{\circ} \mathrm{C}$ significant changes in mechanical properties were detected at a dose of $2.9 \times 10^{15}$ neutrons $/ \mathrm{cm}^{2}$, and there was a 90 percent increase in yield strength and a 60 percent decrease in elongation at a dose of $6.6 \times 10^{17}$ neutrons $/ \mathrm{cm}^{2}$. Almost complete recovery ${ }^{125}$ of all specimens exposed to less than $6.6 \times 10^{17}$ neutrons/ $\mathrm{cm}^{2}$ was achieved by annealing at $300^{\circ} \mathrm{C}$ for $25 \mathrm{hr}$. At a burnup of 0.02 at.\%, only slight recovery of ductility was achieved by annealing in the alpha range. ${ }^{81}$ At the higher burnup in fuel elements, the fission products, the gas bubbles, and the internal distortion due to irradiation growth are likely to be the main causes of embrittlement. Embrittlement due to the fission-gas bubbles is probably much less if irradiation is above $450^{\circ} \mathrm{C}$, where the bubbles form on a coarser scale. Grain-boundary weakening due to solid fission products, however, would probably increase with increase in temperature because the diffusion distances would be greater. Thus postirradiation thermal cycling of uranium irradiated at a low temperature is likely to involve different effects from those occurring during high-temperature irradiation with occasional cooling to room temperature.

\section{Status}

The superior nuclear characteristics of unalloyed uranium metal and the relative ease of fabrication compared with alternative fuels led to its choice for production reactors. Later these characteristics led to its adoption for a series of gas-cooled graphite-moderated power reactors burning natural-uranium fuel in the United Kingdom and in France. Uranum fuels have also been developed for pressurizedwater power reactors and fast reactors in the United States.

In the United Kingdom several difficulties that appeared early in the operation of power reactors have been eliminated or minimized. In these reactors the bowing of fuel rods was recognized in the early stages as a problem in vertically stacked fuel rods. It was controlled by the use of braces to prop the element against the wall of the fuel channel. ${ }^{20}$

At the lower temperatures of the coolant inlet end of the fuel channels, fuel fallures were due to dimensional changes in the rod. The changes were caused by irradiation growth combined with low ductility in the lower temperature range of the Magnox first used.

Under slow straining conditions, leak paths developed at the grain boundaries of the Magnox owing to cavitation, 1.e., formation of grainboundary creep volds. ${ }^{126}$ A major improvement was achieved by using a finer-grained Magnox that had greater ductility in the lower temperature range. ${ }^{127}$ Owing to the low metal temperature in the lower fuel elements, perforation was not followed by oxidation of the uranium rod. The 
leaks developed slowly and were readily detected, and leaking elements could remain in the reactor for many weeks without deterioration. ${ }^{128}$

It was originally considered that, because of the higher temperatures at the middle and top of the fuel channels, swelling of the uranium might be excessive. A volume increase of 20 percent was taken as the initial design criterion, but occasional test specimens had shown larger volume increases within the planned temperature and burnup range. The incidence of large volume increases was spasmodic, unexpected, and unexplained untıl it was demonstrated that minor compositional variations were responsible and that, with adjusted uranium, volume increases at the target burnup would be less than 10 percent. ${ }^{96}$ Magnox has more than ample ductility at the higher temperature to accommodate the dimensional changes of the fuel rods. Cladding perforations, when they occurred, were found to be due to manufacturing defects that had escaped detection. Although such fallures were rare, they at first proved difficult to detect in pile. ${ }^{20}$ It was necessary to remove leaking fuel elements because of the possibility of excessive oxidation of the fuel at the higher temperatures. It now seems likely that with this reactor system the channel average of $3000 \mathrm{Mwd} / \mathrm{t}$ can be reached without an undue number of systematic fallures. ${ }^{129}$ The expected output of uranium fuel elements clad in Magnox in the United Kingdom is about 250,000 per annum. ${ }^{130}$

A similar development has been followed in France, with a different magnesium alloy for the cladding. ${ }^{131,132}$ There is, however, considerable interest in the development of a fuel element for reaching 10,000 $\mathrm{Mwd} / \mathrm{t}$, and therefore the use of pure or adjusted uranium might later have to be abandoned. (See section on dilute uranium-molybdenum alloys.)

The use of uranium-metal fuel in pressurized-water reactors is being developed in the United States. ${ }^{133}$ The status cannot be assessed until a fair number of fuel-element tests at full burnup have indicated that the fallure rate is reasonably low and that burst slugs can be efficiently detected.

For fast reactors uranum metal has been used as fuel with stainless-steel cladding in EBR-I, and in the Dounreay Fast Reactor (DFR) a U-1/4 wt.\% $\mathrm{Cr}$ alloy was used with nioblum and vanadium outer and inner cladding, respectively. For high burnup with uraniummetal fuel, a weak-fuel strong-cladding design was tested to 2 percent burnup and was successful on a small scale. Thus the concept of a weak fuel was shown to be of potential interest. ${ }^{134}$

The use of uranium fuel in fast reactors is probably only a passing phase, for eventually the fuel will be enriched with plutonium. Although metal fuel lends itself to pyrometallurgical reprocessing, many think in terms of cermet and ceramic fuels for fast reactors because with them it might be possible to achieve higher burnup. 


\section{URANIUM-MOLYBDENUM ALLOY FUELS}

Both dılute uranıum - molybdenum alloys and "gamma" alloys (5 to 16 percent molybdenum) have had application in reactors.

\section{Dilute Uranium-Molybdenum Alloy Fuels}

Dilute uranium-molybdenum alloys have been used as fuel elements in the French EL-3 reactor, and under reactor conditions they have shown remarkable resistance to wrinkling and growth at comparatively low temperatures. ${ }^{135}$ The alloy used contaned $1 \frac{1}{2}$ wt. $\%$ molybdenum and was cast so that it cooled slowly. The structure consisted of "pseudo-alpha" grains, each of these containing fine parallel lamellae of the alpha and gamma phases, with the alpha lamellae in any one grain possessing the same orientation, judging from their reaction to polarized light. Thus this alloy's resistance to irradiation effects at low temperatures might be ascribed to these fine and randomly oriented pseudo-alpha grains. No truly comparative experiments to show what part the gamma phase lamellae play in this resistance have been performed.

The resistance of this type of alloy to swelling is considerably more suspect. Three separate serıes of experıments have given widely differing results.

Smith ${ }^{136}$ irradiated a $2 \frac{1}{2}$ wt. $\%$ molybdenum alloy in three conditions: (1) as cast (into graphite molds), (2) wrought and furnace cooled from $850^{\circ} \mathrm{C}$, and $(3)$ wrought and water quenched from $850^{\circ} \mathrm{C}$. The irradiation temperatures were calculated. They ranged from 468 to $854^{\circ} \mathrm{C}$ (1.e., apparent temperatures at which the stable phases would be alpha plus gamma', alpha plus gamma, beta plus gamma, and gamma) and averaged $666^{\circ} \mathrm{C}$; the burnups ranged from 0.40 to 0.56 total at. \%. Uncertainties of temperature make these results of doubtful value; nevertheless, the swelling index for the quenched specimens averaged 40 , and for the others, 4.

French workers ${ }^{137}$ have irradiated uranium alloys containing 1, 2, and 3 wt. $\%$ molybdenum. These alloys were oll quenched from $1000^{\circ} \mathrm{C}$ and then tempered at $450,500,550$, and $600^{\circ} \mathrm{C}$ for six days. The three lowest tempering temperatures led to a fine pearlitic alpha-plusgamma' structure, and the highest temperature, to a coarser pearlitic alpha-plus-gamma structure for all alloys. Irradiation temperatures for these specimens varied with the tempering temperature, being 410 to 430 for the $450^{\circ} \mathrm{C}$ temper, through 460 to 480 and 488 to 500 , to 490 to 495 for the $600^{\circ} \mathrm{C}$ temper. The specimens tempered at $450^{\circ} \mathrm{C}$ showed small swellings and all the others large swellings. Postirradiation examinations disclosed a duplex mottled structure of alpha-plus-gamma phases, in which the molybdenum content of the 
gamma phase was about $11 \frac{1}{2} \mathrm{wt} . \%$; the equilibrium value for the molybdenum content of the gamma' phase is about $16 \mathrm{wt} . \%$.

Bellamy ${ }^{138}$ has 1 rradiated a series of samples containing $2 \frac{1}{2}$ wt. $\%$ molybdenum. Heat treatments were as follows:

1. Slow cooling from $950^{\circ} \mathrm{C}$ (analogous to cast structures).

2. Isothermal transformation from the gamma phase at $620^{\circ} \mathrm{C}$.

3. Isothermal transformation at $650^{\circ} \mathrm{C}$ (in the beta-plus-gamma phase field) and then furnace cooling.

4. Water quenching from $950^{\circ} \mathrm{C}$ and then tempering for $2 \mathrm{hr}$ at $450^{\circ} \mathrm{C}$.

Irradiation temperatures were 560 to $585^{\circ} \mathrm{C}$, and burnups ranged from 0.4 to 0.6 percent. Swelling on all specimens was small.

At first sight the three sets of results are obviously anomalous. With pure and adjusted uranium, the good swelling properties of the adjusted uranium are believed to be due to the bubbles' being kept as a fine dispersion by fine intermetallic precipitates. From experience with these metals, the question arises as to whether uraniummolybdenum alloys have any inherent resistance to swelling in their own right or whether the resistance of some of the specimens was due to unnoted variations of impurity content. These variations might, with suitable heat treatment, lead to a fine dispersion of precipitates. However, it must be a most peculiar precipitate that will form a satisfactory distribution both on casting and on prolonged isothermal transformation, but not on tempering for long periods at varying temperatures. Yet the results cannot be sorted into good and bad either in terms of phases present or lamellar spacing. Another consideration is that the preirradiation testing and the early stages of irradiation constitute an extension of the heat treatment. Bellamy took precautions against disturbing the structures or phases present in his specimens by testing at $400^{\circ} \mathrm{C}$ or below. He also carried out the initial irradiation at $400^{\circ} \mathrm{C}$ for $36 \mathrm{hr}$. Very little is known about these conditions in the other experiments, but in the French work the phases were thermally stable.

There may be a connection between swelling and the detailed kınetics and morphology at transformation. Howlett et al. ${ }^{139}$ showed there were three stages in the kinetics of isothermal decomposition of a $2 \frac{1}{2}$ wt. $\%$ alloy. From 645 to $600^{\circ} \mathrm{C}$, there was a lamellar decomposition to a roughly equiaxed pseudo-alpha structure. From 600 to $400-$ $450^{\circ} \mathrm{C}$ there was initially a little grain-boundary decomposition to a pseudo-alpha structure, which was rapidly followed by the complete transformation of the remaining gamma phase to a granular supersaturated alpha phase; this phase decomposed to a very fine lamellar alpha-plus-gamma mixture. Between 400 and $450^{\circ} \mathrm{C}$ there was a martensitic transformation to the alpha ${ }_{b}^{\prime}$ phase; the martensite tempered to a very fine lamellar alpha-plus-gamma phase mixture. Only at long 
transformation times was gamma' formed. R. G. Bellamy has given an explanation for the anomalous swelling results on dilute uraniummolybdenum alloys. The alloys giving large swelling were all irradiated in the temperature range in which swelling occurs by grain-boundary cracking in pure and adjusted uranium. It is possible that analogous grain-boundary cracking because of irradiation growth also occurs in the uranıum-molybdenum alloys.

There were also three forms of the final product. The first was the result of the lamellar decomposition between 645 and $600^{\circ} \mathrm{C}$. Between 600 and $500-450^{\circ} \mathrm{C}$, the granular alpha phase decomposed to an acıcular-lookıng lamellar structure, and below 500 to $450^{\circ} \mathrm{C}$ both the granular and the martensitic alpha phase decomposed to nodules of lamellae.

There is also the possibility of a martensitic reversal if the quenched alloy is heated again above $450^{\circ} \mathrm{C}$, depending upon heating rate. Fizott $1^{140}$ found that between 450 and $550^{\circ} \mathrm{C}$ a quenched 5 at.\% molybdenum alloy decomposed much more rapidly than both 2 and 3 at. $\%$ molybdenum quenched alloys. At $600^{\circ} \mathrm{C}$ the 5 and 3 at. $\%$ alloys decomposed at roughly the same rate, faster than the 2 at. $\%$ alloy at the same temperature. The $M_{s}$ (martensite transformation) temperature, and consequently the $A_{s}$ temperature, of molybdenum alloys, in common with many others, decrease with increasing molybdenum content. Fizottı's ${ }^{140}$ curves of hardness against tempering temperature for the 5 at. $\%$ alloy are remarkably similar to the curves of Howlett et al. ${ }^{139}$ for the isothermal decomposition of the $2 \frac{1}{2}$ wt. $\%$ ( 6 at. ${ }^{\circ}$ ) alloy.

One other fact that might be relevant is the identity of the continuous phase, if any, in the lamellar structure. Johnson and Kench ${ }^{141}$ measured the creep rates of specimens of $2 \frac{1}{2}$ wt. ${ }^{C} \mathrm{c}$ molybdenum alloy which were elther slowly cooled from the gamma phase or quenched from the gamma phase and tempered at $500^{\circ} \mathrm{C}$, the creep-testing temperature, prior to testing. The secondary creep rate of the slowcooled specimens was $1 / 100$ of that of the tempered specimens. They considered this good evidence, in conjunction with the microstructure, that the gamma phase was the matrix of the slow-cooled alloy, and the alpha phase, the matrix of the tempered alloy.

Thus all the slow-cooled, or isothermally transformed, alloys, which consisted of alpha phase in a gamma matrix, gave good results. Of the quenched alloys that performed poorly, three out of four underwent a phase transformation in pile, either alpha plus gamma' to alpha plus gamma or alpha' to alpha plus gamma. The specimen consisting of alpha plus gamma formed by tempering at $600^{\circ} \mathrm{C}$ swelled badly, however. The two that performed well were tempered at $450^{\circ} \mathrm{C}$, one producing alpha plus gamma and the other alpha plus gamma'.

All tempering processes up to $600^{\circ} \mathrm{C}$ probably produce initially a dispersion of gamma phase in the alpha phase. ${ }^{142}$ Two differences 
occur, however, except perhaps in the $1 \mathrm{wt} . \%$ alloy. The first is that, between 500 and $600^{\circ} \mathrm{C}$, it is possible that a martensitic reversion to the gamma phase occurs, which then decomposes via the granular alpha structure. The second is that there is a change in morphology of the decomposition product above and below the 450 to $500^{\circ} \mathrm{C}$ range, although whether there is a change in the detailed disposition of the lamellae is unknown. A direct relation between these observations and swelling may seem somewhat unlkely, but at present they seem to provide a consistent scheme for correlating the results. It would be possible to test which, if either, is true by irradiating specimens of $2 \frac{1}{2}$ wt. $\%$ alloy transformed isothermally from the gamma phase at 450 and $550^{\circ} \mathrm{C}$.

\section{"Gamma" Uranium-Molybdenum Alloys}

Uranium alloys containing 5 to 16 wt.\% molybdenum, or more, retain a metastable gamma phase to room temperature when cooled from this phase at anything but very slow rates. At the lower contents (from approximately 5 to 9 wt.\% molybdenum) the phase at room temperature is not truly random body-centered cubic but contains a shortrange tetragonal order, not directly related to the ordering of the gamma' phase. ${ }^{143}$ This order is itself metastable in that the critical temperature for ordering is below the temperature at which the gamma phase decomposes to the equilibrium phases. It is thought that ordering can occur in two ways, either by annealing at subcritical temperatures for periods too short for decomposition to start or by quenching. ${ }^{144}$ With quenching, order is believed to occur by the diffusion of vacancies along preferential paths. At 10 to $16 \mathrm{wt} . \%$ molybdenum, very little order seems to be present in the retained gamma phase.

All these alloys transform comparatively slowly, and with increasing molybdenum content the transformation times also increase. Thus their use as reactor fuels was projected since Konobeevskıl et al. ${ }^{145}$ and Bleıberg et al. ${ }^{146}$ had independently shown that alpha-plus-gamma' phase mixtures would revert to a homogeneous gamma phase under certain conditions of irradiation. Also, it was known that the homogeneous gamma phase of this alloy did not show large dimensional changes up to relatively large burnups. All gamma-phase alloys have advantages over the alpha-phase alloys in that they are not subject to irradiation growth and hence there are no associated effects such as irradiation creep and bowing. Of the swelling effects, swelling due to solid fission products will inevitably occur. Grain-boundary cracking is probably reduced because one source of stress is removed. Thus the main cause of dimensional change will be fission-gas bubbles. Gamma-phase uranium-molybdenum alloys containing more than a certain percentage of molybdenum resist this type of swelling well, but the reason for the 
fine bubble dispersion, which is associated with small swelling, is unknown.

A 10 wt.\% alloy was chosen for use in the Enrico Fermi reactor; it was felt that this composition represented the best compromise between using an alloy slow to transform and suffering a loss in reactivity of the fuel through the parasitic and diluent effects of the molybdenum. It was predicted, however, that a critical flux existed for each irradiation temperature and, should the flux fall below this critical value, the metastable gamma phase would transform either to alpha plus gamma or alpha plus gamma', depending on temperature and flux. Shoudy, McHugh, and Silliman have confirmed this prediction $^{147}$ and found that there were serious consequences in allowing the phase change to occur, for it was accompanied by greatly enhanced swelling that depended strongly on the total burnup. They proved that the swelling was connected with the phase transformation by showing that, between 480 and $570^{\circ} \mathrm{C}$, the specimens transformed and swelled at a certain fission rate and burnup and that, above and below these temperatures at the same fission rate and burnup, the specimens did not transform and did not swell badly.

At $525^{\circ} \mathrm{C}$ and below the critical flux, the swelling at a given burnup of 1 percent appeared to be a linear function of fission rate, the line having a negative slope. It was suggested that the enhanced swelling was associated with the presence of the alpha phase. It may have been associated with the action of the grain boundaries of the transforming phases, in which the boundaries sweep the matrix and disturb the conditions (as yet not understood), whereby the gamma phase holds the bubbles as a very fine dispersion.

Untıl the mechanism of swelling in these alloys is better understood, it will be difficult to propose effective remedies while retaining a metallic fuel. The fact that the swelling was associated with the phase transformation, however, allows empirical remedies to be suggested. The obvious remedy is to increase the transformation times; they can be increased by increasing the molybdenum content, although this means that a heavy price has to be paid in loss of reactivity of the fuel. Early American work, however, showed that ternary additions could be made to the alloy which effectively delayed the transformation, although there is no guarantee that the gamma phase of the ternary alloys will resist swelling as well as the gamma phase of the binary alloy. Cabane and Donzé ${ }^{-148}$ made a more systematic approach in that they studied a series of alloys with constant atomic content of solute of 14,16 , and 18 percent. By this means they were able to find the powers of substitution for molybdenum of the other solutes, some of which are given in Table 2. For example, if two atoms of ruthenium are substituted for two atoms of molybdenum in an alloy containing a total of 14 at.\% solute, the alloy will behave on transforma- 
Table 2-POWERS OF SUBSTITUTION OF METALS FOR MOLYBDENUM

\begin{tabular}{|c|c|c|c|c|c|c|}
\hline \multirow{2}{*}{$\begin{array}{l}\text { Total addition } \\
\text { of solute, at }\end{array}$} & \multicolumn{2}{|c|}{ Ruthensum } & \multicolumn{2}{|c|}{ Chromium } & \multicolumn{2}{|c|}{ Niobium } \\
\hline & 2 at ${ }_{c}^{c}$ & 4 at & 2 at & $4 \mathrm{at}^{\mathrm{7}}$ & 2 at ${ }_{C}$ & 4 at $^{n}$ \\
\hline 14 & 24 & 17 & 22 & & 20 & 14 \\
\hline 16 & 18 & 15 & 15 & & 11 & 11 \\
\hline 18 & 17 & 13 & 12 & $\ll 1$ & 08 & 08 \\
\hline
\end{tabular}

tion as if it contained $[12+(2.4 \times 2)]=16.8$ at.\% molybdenum.

Two things are obvious from Table 2. The first is that the effectiveness of the ternary addition decreases with total atomic percentage of alloying elements. The second is that above certain concentrations a ternary addition can accelerate the transformation.

Despite this earlier work, Justusson ${ }^{149}$ concentrated on ternary uranıum-molybdenum-moblum alloys. In fact, he confirmed that there was no advantage in adding niobium to uranium-molybdenum alloys with higher concentrations. For instance, at $500^{\circ} \mathrm{C}$ the transformation was initiated in $16 \mathrm{hr}$ for an alloy containing $9.37 \mathrm{wt} . \%$ molybdenum, but the corresponding time for alloys containıng $8.63 \mathrm{wt} . \%$ molybdenum plus 2.85 wt.\% noblum and $10.50 \mathrm{wt} . \%$ molybdenum plus 1.61 wt.\% nioblum was only $20 \mathrm{hr}$. He also found that, with more than certain concentrations of solute, the stability of the alloys decreased; he attributed this to the two-phase structure of these alloys at high temperatures.

Thus, although transformation times can be increased by ternary additions, the benefit may be only marginal. Nevertheless, small additions of ruthenium to uranium containing about $10 \mathrm{wt}$. \% molybdenum have still to be investigated.

The possibility exists that the transformation mechanism can be changed. Bostrom and Halteman ${ }^{150}$ originally resolved some of the anomalies of earlier equilibrium diagrams by pointing out that the alpha-plus-gamma' phase field could be divided into two regions by a temperature-composition line, as shown in Fig. 10. On the left of the Bostrom - Halteman line, the alpha phase precipitated before the gamma phase ordered to gamma'; on the right of 1 t, the gamma phase ordered to gamma' before the alpha phase precipitated. Donzé and Cabane ${ }^{151}$ studied the decomposition of a $\mathrm{U}-8 \mathrm{wt} \% \mathrm{Mo}$ alloy at 530 and $480^{\circ} \mathrm{C}$. They found that, as the alpha phase precipitated, the gamma phase increased in average molybdenum content up to a limit of $11.8 \mathrm{wt} . \%$ at $530^{\circ} \mathrm{C}$ and $12.9 \mathrm{wt} . \%$ at $480^{\circ} \mathrm{C}$, when the pearlitic decomposition was complete. Thereafter the gamma phase ordered to gamma', the parameters of the gamma' phase remaining constant as its volume increased. These results proved that the ordering process was not homogeneous but involved nucleation and growth of the ordered domains and the diffusion of molybdenum atoms to increase the molyb- 
denum content of the gamma phase to the molybdenum content of the gamma' phase. From considerations of the thermodynamics of alloys, and from the maximum molybdenum contents of the gamma phase, they thought that Bostrom and Halteman's line should be moved to the right, to become an extension of the alpha-alpha-plus-gamma phase boundary.

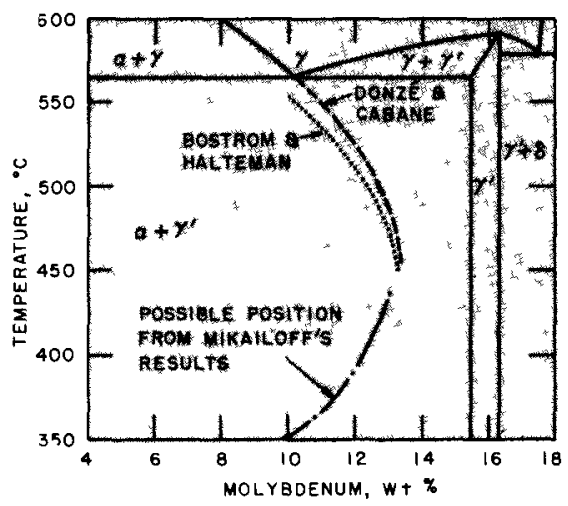

Fig. 10-Part of the uraniummolybdenum equilibrium diagram.

Ivanov and Virgliev, ${ }^{152}$ however, found that, with a 9 wt.\% molybdenum alloy which was quenched and then repeatedly tempered at successively higher temperatures, the parameter of the gamma phase slowly decreased, to become the parameter of the gamma' phase. Coincidentally with the start of this decrease at $410^{\circ} \mathrm{C}$, a "c" parameter of the gamma' phase appeared, which altered with each successive annealing. Moreover, Mikailoff ${ }^{153}$ with a $10 \mathrm{wt} . \%$ alloy found that tempering at $350^{\circ} \mathrm{C}$ led to the direct formation of the gamma' phase whereas at $400^{\circ} \mathrm{C}$ there was a little pearlitic decomposition at the grain boundaries, the bulk of the grains, however, transforming again directly to the gamma' phase. At $450^{\circ} \mathrm{C}$ and above, however, there was a pearlitic decomposition to the alpha-plus-gamma phase. An explanation of these discrepancies may be found in the quenching treatment: ${ }^{144}$ Donzé and Cabane's specımens were air cooled in evacuated capsules, whereas all the others were quenched from the gamma phase. Quenching could lead to the retention of vacancies or to the introduction of a certain amount of order, or both, and either of these could lead to an easier transformation of the gamma to the gamma' phase at lower molybdenum contents. Mikalloff's results can be compared directly with Bostrom and Halteman's and can be explained by saying that at low temperatures the short-range diffusion of vacancies to form order 
is easier than the long-range diffusion of molybdenum atoms necessary to form the alpha phase. The Russian results ${ }^{152}$ are not directly comparable with the others, but, before any changes in lattice parameters were noted, their specimen had been at $410^{\circ} \mathrm{C}$ or below for a total of $150 \mathrm{hr}$. This condition could contribute considerably to ordering by vacancy diffusion and, as suggested by these authors, to coherent precipitation of the gamma' phase at higher temperatures.

Objections to this idea on thermodynamic grounds may be met qualitatively by saying that the system after quenching is a metastable ternary one of uranium, molybdenum, and vacancies. Some proof for the idea of vacancy retention can be found in the behavior ${ }^{151}$ of a uranium-molybdenum-ruthenıum alloy, which, when quenched from $900^{\circ} \mathrm{C}$, behaved very differently from when it was quenched from $650^{\circ} \mathrm{C}$.

Thus, on the uranium-molybdenum diagram, it is possible in the field of the alpha-plus-gamma' phase to draw a line whose position depends on prior heat treatment but which probably does not pass $13 \frac{1}{2}$ wt. $\%$. For compositions to the right of this line, it has been presumed that ordering takes place from nucle1, that some molybdenum diffuses to these nucle1, and that not until the molybdenum content of the remaining gamma phase falls below $13 \frac{1}{2}$ wt. $\%$ will the alpha phase be precipitated. It is probably easier to prevent the ordering of the gamma phase by irradiation than it is to prevent the precipitation of the alpha phase. ${ }^{147}$ Moreover, the gamma' phase does not possess grain boundaries in the normal sense because it probably forms coherently with the gamma phase. ${ }^{152}$ Thus there is a range of alloys containing from $13^{1 / 2}$ to $16 \mathrm{wt} . \%$ molybdenum which not only transform extremely slowly but probably also transform by a different mechanism. This mechanism may not be so deleterious to the swelling properties of the alloy as the mechanism involving the primary separation of the alpha phase. The molybdenum content may be very high, and tne alloys may be susceptible to grain-boundary cracking, ${ }^{154}$ but the effect of ternary additions, such as ruthenium, on the kınetıcs and mechanism of decomposition of these alloys have still to be investigated.

All this treatment presumes that the mechanism of phase decomposition is as stated. In samples of 14 and $16 \mathrm{wt} . \%$ molybdenum alloys, however, both quenched and tempered ${ }^{155}$ and isothermally transformed $d^{156}$ from the gamma phase, a fine precipitate has been seen in the early stages of transformation. The precipitate reached a maximum and then slowly redissolved. It has been identified by X-ray diffraction as alpha uranium. This is inexplicable either on thermodynamic groundsDonzé and Cabane's curve does not extrapolate to $16 \mathrm{wt} . \%$ molybdenum above $350^{\circ} \mathrm{C}$ - or in the light of other experimental evidence on the mechanism of transformation. Further work is required to resolve this anomaly. 


\section{Compatibility}

The oxidation rates of uranıum-molybdenum alloys in air and in carbon dioxide have been determined as a function of temperature and molybdenum content. ${ }^{19,157}$ Considerable protection is afforded by adding 5 wt.\% molybdenum. The higher the temperature of oxidation, the more marked is the improvement, and protection is more effective in oxygen than in carben dioxide. The main effect is probably to improve the sinterability and plasticity of the corrosion product and thus to form a more coherent oxide scale. Molybdenum confers corrosion resistance in pressurized water up to $300^{\circ} \mathrm{C}$, and specimens containing 10 to 12 wt.\% molybdenum will survive about a month with very low rates of corrosion after perforation of the cladding. The initial rates are so low, however, that detection of the leak by monitoring the coolant is likely to be difficult. When final fallure occurs, it is very rapid owing, it is thought, to disruption of the specimen by formation of uranium hydride. ${ }^{158,159}$ For gamma-phase alloys, however, it has been suggested that the strains engendered by the lattice mismatch between the metal and an epitaxial oxide layer might play a part in the development of cracks. ${ }^{160}$

\section{Status}

Uranium containing about 1 wt.\% molybdenum shows excellent dlmensional stability at the lower temperatures of irradiation, and it is under consideration for use as a high-burnup fuel in gas-cooled graphite-moderated reactors. ${ }^{161}$ The main difficulty ${ }^{136,137}$ is associated with swelling in the range 500 to $600^{\circ} \mathrm{C}$.

Uranium alloys containing about 9 to $12 \mathrm{wt} . \%$ molybdenum have been investigated with a view to their use in pressurized-water reactors in the United States. ${ }^{162}$ In thermal reactors, however, they have poor neutron economy compared with alternative fuels.

Uranium with 10 to $14 \mathrm{wt} . \%$ molybdenum is attractive as a fuel for fast reactors, in which the absorption cross section of the molybdenum is very low. Use of alloys in this range has been under consideration for some time tor use in the $\mathrm{DFR}^{163}$ and in the Enrico Fermi reactors. ${ }^{164}$ There 1s, however, difficulty in achieving the high burnup required for economic operation, which in fast reactors is at least 2 percent of all fissile and fertıle atoms per cycle at a nominal maximum fuel-surface temperature of at least $650^{\circ} \mathrm{C}$. Choice of a cladding material compatible with both metal fuel and sodium coolant is difficult. Stainless steels and nickel-chromium alloys are compatible with sodium containing a few parts per million oxygen and thus might be obvious choices for cladding material in sodium-cooled fast reactors. Uranium alloys are not, however, compatible ${ }^{165}$ with such cladding materials above about $700^{\circ} \mathrm{C}$. 


\section{OTHER URANIUM ALLOYS}

In addition to the uranium-molybdenum alloys, others containing zirconium, niobium, or aluminum have reached at least the development stage. Several additional ones, such as ternary alloys with molybdenum and silicon, have been suggested, as has modification of heat treatment to improve properties.

\section{Uranium-Zirconium Alloys}

Uranum-zirconum alloys are remarkable for being dimensionally stable below $350^{\circ} \mathrm{C}$ and having very poor resistance to swelling above this temperature. Despite this behavior, interest continues in this alloy because of its corrosion resistance and because of the low capture cross section of zirconium for neutrons. The latest concept to be applied to this material is that of "weak fuel-strong cladding"; in restrained and voided specimens of a uranium alloy containing $2 \mathrm{wt} . \%$ zirconium, very high burnups have been achieved without container distortion. ${ }^{166}$ The fuel in most cases had expanded to fill the void and looked like a sponge, with gas bubbles easily visible at a magnification of $50 \times$.

The reason for this poor resistance to swelling, as opposed, for example, to the better results from uranium-molybdenum alloys, is unknown. With the same alloy it was found that lamellae of a second phase dispersed in an alpha-phase matrix were broken up into globules after irradiation and that the bubbles after small irradiation doses lay in bands resembling the original lamellae of the second phase. ${ }^{167}$ Thus the positional instability of the second phase, which was not positively identified as delta $\left(\mathrm{UZr}_{2}\right)$, may have something to do with swelling.

For want of a better lead, dilute uranium-zirconium will be compared with dilute uranium-molybdenum alloys that have successfully resisted swelling. In most of the latter, the alpha phase forms a pearlitic structure with lamellae of the metastable gamma phase, which may well be the continuous matrix and be stable under irradiation. The equilibrium diagram of the uranium-zirconıum system shows complete miscibility of the body-centered-cubic phases of uranium and zirconium at high temperature. At lower temperatures a beta-plusgamma $_{1}$ phase field exists up to $4.5 \mathrm{wt} \%$ zirconium, and a gamma g $^{-}$ plus-gamma 2 phase field, from 4.5 to 24 wt. $\%$ zirconium. ${ }^{168}$ With decreasing temperatures the phase fields are beta plus gamma ${ }_{2}$, alpha plus gamma $a_{2}$, and finally the stable phases below $590^{\circ} \mathrm{C}$ with up to 50 wt.\% zirconıum, alpha uranium and delta phase, a compound existing over a range of composition but roughly equivalent to $\mathrm{UZr}_{2}$. The exact detalls of the diagram depend on the oxygen and nitrogen content of the alloy, ${ }^{168}$ but it is clear that at low temperatures, unless the gamma 
phase can be retained to room temperature, the amount of metastable gamma phase, or any allied phase, will be much less than in a uraniummolybdenum alloy of the same composition. The alpha phase will exist as a continuous matrix and the major phase for zirconium contents up to, and probably over, $2 \mathrm{wt} . \%$.

The second point about these alloys, which cannot be found from the equilibrium diagram, is the identity of the second phase. The gamma phase cannot be retained to room temperature. ${ }^{169}$ Alloys containing from 20 to $80 \mathrm{wt} . \%$ zirconium behave more like zirconium alloys than uranium alloys, when quenched from high temperatures, in that only at the most rapid quenching rates is the gamma phase retained. Slower quenching rates, or tempering in the retained gamma phase, lead to the formation of the omega phase. ${ }^{170}$

This optically invisible, embrittling phase is formed as a metastable constituent in many zirconium alloys. In this case it can be considered as a metastable form of the delta phase which can be supersaturated with zirconium or uranium, depending on composition, and which is disordered. ${ }^{170}$ Because it plays a prominent part in the decomposition of uranium alloys with the stated zirconium content, it may also play a part in the decomposition of the gamma ${ }_{2} \mathrm{n} \mathrm{mixtures}$ of the beta-plusgamma $_{2}$ and alpha-plus-gamma 2 phases.

Thus, whatever the mode of decomposition, dilute uraniumzirconium alloys of a given composition contain about half the quantity of second phase that a uranium-molybdenum alloy of the same composition does. Also, the second phase is likely to be dispersed in an alpha-phase matrix, and, unless a deliberate attempt has been made to attain equilibrium conditions, the second phase may be in a metastable, brittle condition.

There have been surprisingly few studies of the mechanism of decomposition of these alloys. Lagerberg ${ }^{169}$ studied the isothermal transformation from the gamma phase of a uranium alloy containing 2 wt. $\%$ zirconium. He found that, above $700^{\circ} \mathrm{C}$ in the beta-plus-gamma field, the beta phase appeared as islands whereas, below $690^{\circ} \mathrm{C}$ in the alpha-plus-gamma ${ }_{2}$ and alpha-plus-delta fields, transformation took place by the consumption of the matrix by Widmanstätten-like plates of alpha phase, which then precipitated a second phase. Neither the beta nor the gamma ${ }_{1}$ phase could be retained to room temperature by quenching; both underwent decompositions that were probably martensitic. The second phase precipitating from the alpha-phase plates was not definitely identified.

Virot ${ }^{171}$ has studied the decomposition of a $\mathrm{U}-6 \mathrm{wt} . \% \mathrm{Zr}$ alloy both on continuous cooling and on isothermal transformation at temperatures of $650^{\circ} \mathrm{C}$ and below. Cooling rates from 25 to $350^{\circ} \mathrm{C} / \mathrm{min}$ gave pearlitic structures of alpha phase and a second phase, which could not be identıfied uniquely by $X$ rays. Isothermal transformation between 650 and 
$550^{\circ} \mathrm{C}$ gave pearlitic structures similar to the continuously cooled ones. From 550 to $500^{\circ} \mathrm{C}$ the decomposition strongly resembled the granular decomposition in $\mathrm{U}-2 \frac{1}{2}$ wt. \% Mo alloys. ${ }^{139}$ Presumably no separation in the gamma 1 -plus-gamma 2 loop occurred after either type of heat treatment.

Apparently, if structures in a uranium-zirconium alloy similar to those of a U-2 $\frac{1}{2} / 2$ wt. $\%$ Mo alloy are to be obtained, at least $6 \mathrm{wt} . \%$ zirconium must be used. Even then the thermal and irradiation stability of the matrix phase may be suspect.

\section{Uranium-Niobium Alloys}

Other things being equal, niobium would be preferred to molybdenum as an alloying element in uranium because it has the smaller cross section for the capture of thermal neutrons. The two alloys are very similar. The equilibrium diagrams are somewhat different in that molybdenum forms $\mathrm{U}_{2}$ Mo whereas the uranium-niobrum diagram has no compounds but contains a gamma ${ }_{1}$-plus-gamma ${ }_{2}$ loop. However, the transformation behavior and structures formed in both alloys are very similar at the uranium-rich end. On quenching of these alloys, a series of metastable alpha and gamma phases are formed, which are identical in structure for both systems. At slower cooling rates the gamma $\rightarrow$ beta transformation is easily suppressed, and the direct transformatıon of gamma $\rightarrow$ alpha-plus-gamma pearlitic structure occurs. About three atoms of niobium are required to produce the same effect as two atoms of molybdenum.

The alloys have good resistance to water corrosion, and they would presumably be suitable, with or without a ternary addition of zirconium, for use in a bolling-water reactor in which the fuel temperature never rises above the growth range. In this respect, however, niobium alloys must compete with uranium-zirconium and ternaries based on 1 .

For gas-cooled reactors nobuum alloys have never been considered because the dilute alloys swell considerably at higher temperatures. ${ }^{172}$ Even the alloys containing enough niobium to stabilize the gamma phase swell badly. The reason for the poor swelling resistance is unknown. It may be connected with grain-boundary weakness and cracking. It may possibly be connected with a puzzle which was set a few years ago but which has not yet been solved. Peterson and Oglvie, ${ }^{173}$ while studying diffusion couples of uranum and niobium, found a compound they called " $\delta . "$ The limits of composition of this compound, as given by these authors, are plotted on the accepted diagram in Fig. 11. The compound straddles the boundary of the gamma 1 -plus-gamma field and has a peculiarly sloping range of composition that peaks at about the top of the gamma ${ }_{1}$-plus-gamma 2 loop. The compound cannot be dismissed as an impurity or a pressure effect. It may possibly be 
Fig. 11- Part of the uraniumniobium equilibrium diagram.

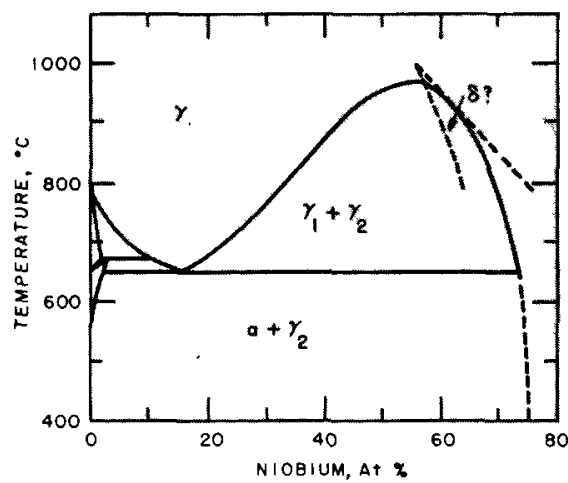

connected with the factor of 100 difference between the diffusion coefficients for uranium and niobium. This would mean that the re would be a large number of vacancies in the diffusion zone, and the ternary system uranium-niobium-vacancies might give rise to a phase not found in equilibrium. On irradiation, also, the re will be a large number of vacancies.

\section{Aluminum-base Uranium Alloys}

If slowly cooled from the melt, aluminum-uranium alloys containing up to $68.8 \mathrm{wt} \%$ uranium consist of $\mathrm{UAl}_{4}$ in an aluminum matrix. Morerapid cooling may suppress the peritectic formation of $\mathrm{UAl}_{4}$; the alloy ${ }^{174}$ would then consist of aluminum and $\mathrm{UAl}_{3}$. The principle use hitherto of aluminum-uranium alloys as fuel in water-cooled research reactors is well known, and these alloys have given excellent service at surface temperatures of up to about $120^{\circ} \mathrm{C}$. The alloy is roll bonded to an aluminum cladding and contains 20 to $25 \mathrm{wt}$. $/ \mathrm{h}$ uranium. The fabrication of fuels containing higher proportions of uranium has been studied. ${ }^{175}$ The intermetallic compounds usually have a range of particle sizes from about 5 to $200 \mu$ diameter. The compounds have high melting points, and their behavior on irradiation is more akin to that of a ceramic fuel than that of a metal. More than 50 percent burnup of all uranium atoms is achievable without deterioration. Optical microscopy reveals no apparent change in the structure of these fuels during irradiation. Postirradiation annealing indicates that swelling does not occur $^{176}$ up to about $500^{\circ} \mathrm{C}$ and that fission products in lightly irradiated material are retained ${ }^{177}$ during annealing of up to three weeks at temperatures up to the eutectic temperature of $640^{\circ} \mathrm{C}$.

Use of these fuels in pressurized-water reactors is limited by the rather high corrosion rate of the aluminum cladding at the higher temperatures and perhaps by the lower strength. In view of the relative ease of fabrication, there is interest in the analogous aluminumplutonium fuels for recycling plutonium in pressurized-water reactors. 
Zircaloy cladding has been used to add corrosion resistance and strength. ${ }^{178}$

\section{Fuels for Beta-phase Operation}

Two questions of operation of beta-phase fuel elements have arisen recently. The first concerns operating existing power reactors with the cores of the fuel rods in the beta phase (beta-core operation) so that thermal efficiency can be improved. The second is the development of a metastable beta-phase fuel that could be irradiated and remain in this phase.

Problems of irradiation in beta-core operation come under two main headings, mechanical behavior and enhanced swelling. Both must be considered in the light of an alpha-beta boundary that fluctuates with fluctuations of reactor temperature. Because of the hysteresis of the alpha $\rightarrow$ beta $\rightarrow$ alpha transformation, however, the re will be a limiting temperature cycle that will not move the alpha-beta boundary.

This cycle will depend on the individual alloy, but, as an example of the worst possible conditions, pure uranium will be considered because no uranium alloy transforms faster than the pure metal. Blumenthal ${ }^{179}$ has given the beta $\rightarrow$ alpha transformation temperatures of uranium at various slow cooling rates; for instance, at $1 / 2{ }^{\circ} \mathrm{C} / \mathrm{min}$ the transformation temperature was $660^{\circ} \mathrm{C}$. Barwood and Butcher ${ }^{73}$ have shown that the alpha $\rightarrow$ beta transformation $1 \mathrm{~s}$ extremely slow below $669^{\circ} \mathrm{C}$. Thus, at first sight, a cycle of $\pm 41 / 2{ }^{\circ} \mathrm{C}$ every $36 \mathrm{~min}$ would not inove the phase boundary. However, the effect of pre-existing alphaphase nucle1 has not been taken into effect. Donzé ${ }^{76}$ has shown that the beta $\rightarrow$ alpha transformation temperature of uranium taken to low beta-phase temperatures is 6 to $8^{\circ} \mathrm{C}$ higher than that of uranium taken to high beta-phase temperatures; this evidence is capable of two or three different interpretations. More convincingly perhaps, Barwood ${ }^{180}$ found thal, for pure uranium heated at $672^{\circ} \mathrm{C}$ and cooled at $450^{\circ} \mathrm{C} / \mathrm{min}$, the transformation temperature for specimens heated up to $4 \mathrm{hr}$ was $657.5 \pm 0.5^{\circ} \mathrm{C}$ whereas, for specimens heated over $4 \mathrm{hr}$, it was $652 \pm$ $1^{\circ} \mathrm{C}$. Because this difference is also associated with the disappearance of preferred orientation, it is thought that remnants of alpha phase are in the beta phase up to $4 \mathrm{hr}$ at $672^{\circ} \mathrm{C}$ and that these remnants serve as nuclei to trigger the beta $\rightarrow$ alpha transformation. Thus any work on the hysteresis of alpha-beta boundary movement in a particular alloy should include work on specimens containing these boundaries rather than simple measurements of alpha $\rightleftharpoons$ beta cycling hysteresis.

Assessing the extra swelling and mechanical damage is more difficult. Enhanced swelling may occur from two causes. The fine precipitates limiting swelling in the alpha phase probably dissolve to a large extent in the beta phase, and the gas either may be collected and deposited by the moving phase boundary or may diffuse much more 
rapidly through the disturbed lattice. Scott and Buddery ${ }^{181}$ have shown that, when irradiated uranium is wholly cycled through the alpha $\rightarrow$ beta $\rightarrow$ gamma phase changes out of pile, a small burst of fission gas is released every time the specimen passes from the alpha phase to the beta. Such factors may lead to the deposition of annuli of bubbles in the fluctuating region and larger bubbles in the beta core.

Two ways in which the mechanical properties can be affected have been mentioned already, enhanced creep and distortion. Buckley et al. ${ }^{95}$ have given a formula relating the beta-core radius, the fuel-element radius, and the mechanical properties of the material for conditions that do not cause plastic deformation of the alpha-phase envelope at its surface. Greenwood and Johnson ${ }^{182}$ have studied the creep of fuel elements with a beta core; the problem here is to determine what values are to be taken for the mechanical properties of uranium during irradiation at temperature. If it is supposed, however, that no distortion resulted, there is still the possibility that the fluctuating hoop stresses would cause radial cracks to appear in the alpha phase. This crackıng would not affect the thermal conductivity or the compression strength markedly, but, if these cracks spread along the circumferential annuli of any bubbles that might form or along grain boundaries, the thermal conductivity would be seriously affected.

There are so many unknown factors that any development must be empirical. Very few specimens have been irradiated in the beta-phase range; thus an irradiation program is imperative. Meanwhile, measurement of the hysteresis of the various fuel materials and development of alloys with a large hysteresis could proceed. The other possibility in alloy development is to investigate alloys, such as the dilute uranium-molybdenum alloys, in which it is possible that the gamma phase may remain the stable matrix during cycling. Unfortunately most solutes lower the alpha $\rightarrow$ beta transformation temperature, and the width of the alpha-plus-beta annulus between the alpha and the beta phases will be increased. Thus the total volume affected by beta-grain-boundary movements will be increased.

Interest in the development of a metastable beta-phase fuel is based on a belief that is not now generally held, namely, that, because beta uranium is mechanically stronger than alpha uranium, it will withstand swelling better. On this premise, Kehoe ${ }^{183}$ did some approximate calculations that showed that, if the beta $\rightarrow$ alpha induction period was 5 min or more, the beta phase might remain in the metastable state in a power-producing reactor. It would do so because the local heating around the fission spikes would raise very small amounts of alpha phase to high temperature and the resulting quenching by the conduction of heat to the mass of surrounding material would again stabilize the beta phase. On this basis, Geary and Nerses, ${ }^{184}$ after an exhaustive search of binary alloys and after testing several ternary alloys, found 
three that they considered might fulf 1 ll the required stability condition. Of these, two (uranium containing $0.3 \mathrm{wt} . \%$ chromium and uranium

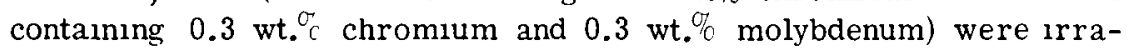
diated to small burnups. ${ }^{185}$ The results were somewhat inconclusive in that metallographic examinations did not show anything interpretable and $\mathrm{X}$-ray examination showed only two or three diffraction lines from each specimen. Density measurements, however, suggested that most of the specimens that had entered the plle as beta-phase alloys had, in fact, transformed to the alpha phase. A suggestion was made that this might be a way of reducing total dimensional changes of fuel elements. What it would do to the heat transfer through the cladding was not considered.

Use of a metastable beta-phase fuel does not seem to be a serious possibility for power reactors. Nevertheless, the irradiation of metastable beta-phase uranium is interesting because it would provide information on irradiation damage in fissile material of a different lattice structure. The other interesting point from this work is that, after an exhaustive search, the best binary alloy that could be suggested was one $f_{1} r s t$ worked on over ten years ago.

The influence of a solute on beta-phase stability seems very complex. Very few attempts have been made to relate this property to other properties of the solute. Deighton ${ }^{186}$ has measured the hot hardness of several dilute alloys in the alpha and beta phases and the depression of the beta - alpha transformation temperature of the same alloys at different cooling rates. He concluded that the depression of the transformation temperature was directly related to the hardness of the beta phase at the transformation temperature. This conclusion only led to another problem since the hardening produced by the solute could not be related to any simple property of the solute, such as its atomic diameter. It is perhaps not surprising, in view of the empirical state of knowledge of this subject, that no attempt has been made to examine systematically the effect of ternary additions on beta-phase stability.

\section{Alloys Recently Investigated}

So far this article has discussed uranium fuels on which major research is being or has been done. Other alloys have been proposed from time to tıme; some are only suggestions. Others have been subject to considerable investigations, but irradiation results have only recently been made avallable.

The simplest approach, perhaps, is to improve an existing alloy by modifying the heat treatment to give superior properties. Craik et al..$^{187}$ took a U -2 wt.\% Mo alloy into the gamma phase and then annealed it at $675^{\circ} \mathrm{C}$ in the beta-plus-gamma phase field so that the gamma phase precipitated islands of beta phase containing about $0.4 \mathrm{wt} . \%$ molybdenum. The gamma-phase matrix was enriched in molybdenum up to 
approximately $4 \mathrm{wt}$. $c$. The alloy was then cooled slowly to room temperature. The beta-phase islands became alpha uranium containing a very fine precipitate of gamma phase, and the gamma-phase matrix transformed to a lamellar structure of alpha plus gamma. The matrix should thus withstand swelling because of its high molybdenum content, while the swelling of the uranium-rich islands might either be confined by the matrix or influenced by the fine precipitate of gamma phase. The few results that are avallable, however, show that this treatment does not give the alloy properties superior to those of the simple alpha-plus-gamma lamellar structure. ${ }^{138}$

In a similar manner, carbon has been added to uranium-molybdenum alloys. ${ }^{187}$ Streets and Stobo ${ }^{188}$ have shown that all the carbon forms uranium carbide, in which the maximum solubility of molybdenum is about 0.7 wt. \% . Thus the alloys consist of a uranium-molybdenum matrix, enriched in molybdenum far beyond the nominal content, containing discrete pieces of uranium carbide. Both matrix and precipitate should withstand swelling. Unfortunately the density of the fuel is decreased considerably by the carbon additions. ${ }^{189}$ This decrease, together with the parasitic effect of the molybdenum additions, makes its use as a fuel for a thermal reactor unlikely.

The second approach is to take an existing fuel material and add to it a solute that will form an intermetallic compound, in the hope of improving its properties. This approach was taken originally to improve the mechanical properties, ${ }^{190,191}$ but later work was concentrated on producing a fine dispersion of precipitate by heat treatment to $1 \mathrm{~m}$ prove swelling resistance. ${ }^{192}$

In the first type of 1nvestigation, ${ }^{191}$ the base alloy was uranium containing from 3.5 to $10 \mathrm{wt} . \%$ molybdenum with ternary additions of aluminum and silicon. Cast samples have been irradiated; the first results on $3.5 \mathrm{wt} . \%$ molybdenum alloy, normalized to approximately 0.3 percent burnup at $650^{\circ} \mathrm{C}$, showed that $0.5 \mathrm{wt} . \%$ silicon or $0.1 \mathrm{wt} \%$ aluminum had an effect equivalent to an extra 1 wt. $\%$ molybdenum in preventing swelling. ${ }^{193}$ Later results ${ }^{194}$ on specimens taken to approximately 1 percent burnup at $500^{\circ} \mathrm{C}$ showed that the $3.5 \mathrm{wt} \%$ molybdenum alloy with $2 \mathrm{wt. \%}$ aluminum, 0.1 to $2 \mathrm{wt} . \%$ silicon, or a quaternary addition of $0.1 \mathrm{wt} . \%$ aluminum and $0.5 \mathrm{wt} . \%$ silicon had an ave rage swelling of approximately 10 percent. All these samples contained coarse precipitates of the intermetallic phases.

In the second type of work, ternary uranium-molybdenum-silicon alloys, heat treated to produce coarse and fine dispersions of the intermetallic phase, were irradiated at $300^{\circ} \mathrm{C}$ to 0.4 at. $\%$ burnup. Subsequent examination showed that as a result of irradiation the precipitate had been redistributed in a very fine form in both types of sample, and there was strong evidence of solution from the large particles. ${ }^{195}$ Postirradiation annealing at $650^{\circ} \mathrm{C}$ produced encouragingly 
low swelling, especially when compared with the binary uraniummolybdenum base alloy. ${ }^{196}$ Although there is no real analogy between low-temperature irradiation plus postirradiation annealing and hightemperature irradiation, the results from the earlier work ${ }^{193}$ suggest that at least some of these effects might be retained in the same alloy at higher irradiation temperatures. No bubbles were detected in the specimen that originally contained fine precipitates, but in the other type of specimen bubbles were detected in bands around, but separated from, large precipitate particles. The bubbles appeared to have nucleated on the fine precipitates produced by irradiation. ${ }^{197}$ These experiments strongly confirm the influence of fine precipitates on swelling.

The idea of dispersion hardening lies behind a third approach, which is in the preliminary stages only. ${ }^{198,199}$ The work has consisted of attempts to emulate dispersion-hardened aluminum by the hot extrusion of uranium powder that has been oxidized by a controlled amount. Alpha $\approx$ beta thermal-cycling tests showed that the product behaved better than ordinary uranium but the quality control must be improved for a consistent product.

The fourth idea is having uranium as the minor constituent of a binary alloy. These alloys are intended for use as fuels either in fast reactors or when such considerations as safety and integrity override any economic considerations. Three alloys are niobium-uranium, zirconium-uranium, and yttrium-uranium. They might be said to range over a complete spectrum since niobium dissolves up to $45 \mathrm{wt} \%$ uranium at low temperatures; zirconıum-uranıum alloys exist as a mixture of the delta and epsilon (alpha-zirconium) phases; yttrium and uranium are completely immiscible in the solid state; and an $1 \mathrm{mmisci-}$ bility gap exists in the liquid state.

Nioblum-uranium alloys containing up to $20 \mathrm{wt} \%$ uranium have been cast and forged successfully and have shown good mechanical properties and corrosion resistance in tests. ${ }^{200}$ They possess a body-centeredcubic structure and are not subject to irradiation growth. Ir radiation of specimens to 1 percent total burnup at 650 to $870^{\circ} \mathrm{C}$ and to 0.6 percent total burnup at $980^{\circ} \mathrm{C}$ has shown that alloys containing up to $20 \mathrm{wt} . \%$ uranium had very low density decreases. If, however, the uranum content is increased to 30 percent or zirconium was added to form a ternary alloy, swelling is considerable. ${ }^{201}$

Zirconium-uranıum alloys carry a dispersion of delta phase in the close-packed-hexagonal structure of zirconium, which has very small solubility for uranium. They are intended for use in water-cooled reactors. They are remarkable in that the rolled fuel rods grow under irradiation. Although the fissionable material is carried mainly in the precipitate, the scale of the precipitate distribution compared with the recoil range of the fission fragments is usually such that the radiation damage in the zirconium matrix is homogeneous. ${ }^{202}$ The same phenom- 
enon was observed and explained in the fission-fragment irradiation of z1rconıum folls by Buckley. ${ }^{26}$

The usual mechanical and chemical tests have been carried out on yttrium-uranium alloys, and irradiation tests are in progress. ${ }^{203}$ The material is noteworthy as being the only proposed metallic fuel that must be fabricated by powder-metallurgical techniques.

Any metallic fuel must possess good corrosion, creep, irradiationgrowth, and swelling resistance. For power production it must be economic. The economic factor is very subtle: it includes the costs of production and enrichment, neutron economy, postirradiation processing, average life of the fuel, and percentage of fuel-element fallures. For thermal reactors using metal fuels, the first three of these considerations favor natural-uranium fuel; only if the last two outweigh the others should an alloy fuel be considered.

The last two economic factors depend on the properties previously mentioned. Adjusted uranium has good swelling resistance; indeed, it is much better than that of most of the alloys tested so far. Its creep properties are marginally adequate, even under thermal cycling and irradiation. Its corrosion resistance is poor but can be controlled by rigorous inspection of cladding. Only in growth is it slightly suspect because of the preferred orientation introduced by beta quenching. This growth may lead to the fallure of some cladding in the low-temperature positions in the reactor.

It is questionable whether it would be economic to replace natural uranium by an alloy fuel in thermal reactors for electric power production. If it is, the replacement would have to be by a dilute alloy containing not more than a few atomic percent of solute. Unless a duplex charge is adopted, such an alloy has yet to be developed, for dilute alloys tested so far possess inferior swelling properties to those of adjusted uranium. French experience with uranium alloys containing $1 \frac{1}{2}$ wt. \% molybdenum has shown that this alloy can withstand irradiation in excess of $10,000 \mathrm{Mwd} / \mathrm{t}$ in a water-cooled reactor. Further investigation of the swelling properties of these materials is needed, however, before they can be used at higher temperatures.

One economic factor that has not been mentioned is specific power rating. If, for any reason, while a metallic fuel is being retained, the rating has to be increased so that core temperatures go above $650^{\circ} \mathrm{C}$, then it is possible that higher-alloy fuel will possess advantages. Only by the use of an alloy will it be possible either to avoid the beta phase and its attendant temperature-cycling problems or to control the distribution of this phase and minimize the problem. Compatibility and swelling problems make the use of a metallic fuel in this application very doubtful, however.

For the economic production of power by thermal reactors using metallic fuels, the last few years have produced increasing disappoint- 
ment in dilute alloy fuels and further confirmation of the capabilities of adjusted uranuum.

\section{THORIUM-METAL FUEL}

Thorium is a fertile material that might allow near breeding in a thermal system and hence improve the utılization of $\mathrm{U}^{235}$ reserves. The place of thorium-based metallic fuels in future fuel cycles is, however, difficult to predict. ${ }^{204}$ Although the majority view is that, by the time thorium cycles become established, ceramic fuels will have completely replaced metallic fuels, there are still a few proponents of meiallic-thorıum fuel cycles with uranium or plutonium enrichment.

Because of 1 ts high melting point of $1755 \pm 10^{\circ} \mathrm{C}$, the fabrication of thorium is difficult. Powder metallurgy and arc melting have, however, been successfully employed. ${ }^{205}$ Powder metallurgy involves handling a radioactive and chemically active powder, and arc melting poses refractory difficulties also. In spite of its very high melting point, thorum does not behave as a refractory metal; in the range 500 to $800^{\circ} \mathrm{C}$, its creep strength is not noticeably higher than that of uranium. ${ }^{206} \mathrm{~A}$ search has been made for creep-resistant alloys. ${ }^{207,208}$

Thorium metal is not significantly denser than its oxide or carbide, nor is it easier to fabricate. Choice of the metal must therefore rest on its mechanical integrity under irradiation allowing it to be used with weak cladding and on its thermal conductivity.

Compared with uranium metal, thorium metal has the advantage that from room temperature to the phase transformation at $1360 \pm 10^{\circ} \mathrm{C}$ there are no phase transformations. It has a cubic structure and so does not suffer from radiation growth or phenomena resulting from growth, and it does not have anisotropic thermal expansion. A creepresistant thorium alloy should therefore be suitable for service at temperatures above those possible for uranium.

Since natural thorium is fertile but not fissile, a thorium fuel needs enrichment with fissile isotopes of uranium or plutonium. Thoriumuranıum alloys were developed for a sodıum-graphite reactor ${ }^{209}$ but were found to undergo severe swellıng ${ }^{210}$ above $600^{\circ} \mathrm{C}$. Thor plutomum is known to be stable $e^{211}$ up to $450^{\circ} \mathrm{C}$, but an alloy containing $15 \mathrm{wt} . \%$ plutonium increased in volume by 14 percent when irradiated at $500^{\circ} \mathrm{C}$ to 0.54 percent burnup of all atoms. ${ }^{212}$

On the other hand, thorium-uranium alloys containing up to $20 \mathrm{wt} \%$ uranium in the form of a fine dispersion have been shown to resist swelling and other dimensional changes. ${ }^{213}$ The swelling rate increased slowly from 1 percent per atomic percent burnup at $100^{\circ} \mathrm{C}$ to 2.5 percent per atomic percent burnup at $650^{\circ} \mathrm{C}$. More significantly perhaps, this resistance was maintained to high burnups. For example, samples containıng $20 \mathrm{wt}$. \% uranıum ir radiated at approximately $650^{\circ} \mathrm{C}$ to about 
4 percent burnup of all atoms swelled only about 10 percent. According to these results, this alloy would make a very attractive fuel material, and renewed interest in fuels based on metallic thorıum is justified.

\section{ACKNOWLEDGMENTS}

This article must end with an expression of the authors' gratitude to all the authors who allowed their results to be quoted prior to publication and to the many members of the Atomic Energy Research Establishment staff who have helped in the preparation of the article. This help has taken many forms, from the preparation of micrographs to the detailed discussion of theoretical points. While it is impossible to list all those who have helped, mention must be made of M. B. Waldron, S. N. Buckley, R. G. Bellamy, M. J. Makin, B. Hudson, B. W. Howlett, and S. J. Rothman (on attachment from Argonne National Laboratory) for their special contributions.

\section{REFERENCES}

1. J. C. Maxwell, Electracty and Magnetısm, 3rd ed., Vol. 1, p. 440, Oxiord University Press, London, 1904.

2. D. S. Billington, Radiation Damage in Reactor Materials, in Proceedings of the United Nations International Conference on the Peaceful Uses of Atomic Energy, Geneva, 1955, Vol. 7, pp. 421-432, United Nations, New York, 1956.

3. J. C. Bates, A Comparison of the Thermal Conductivity of Irradiated and Unırradiated Uranum, Britısh Report RDB(W)/TN-78, July 1953.

4. A. N. Holden, The Physical Metallurgy of Uranum, p. 175, Addison-Wesley Publıshing Company, Inc., Reading, Mass., 1958.

5. S.J. Rothman, Dilfusion in Uranum, Its Alloys and Compounds, in Advances in Nuclear Science and Technology, Vol. 1, p.111, Academic Press Inc., New York, 1962.

6. Y. Adda and A. Kirianenko, Abaissement des Coefficients d'Autodiffusion de l'Uranium en Phase $\gamma$ par des Additıons de Molybdène, de Zirconıum, ou de Niobium, J. Nucl. Mater., 6: 135 (1962).

7. S. J. Rothman, J. J. Hines, J. Gray, Jr., and A. L. Harkness, Anısotropy of Self-diffusion in Alpha Uranium, J. Appl. Phys., 33: 2113 (1962).

8. G. V. Kidson, Some Aspects of the Growth of Diffusion Layers in Binary Systems, J. Nucl. Mater., 3: 31 (1961).

9. J. A. Fellows, Alpha Phase Vacuum Outgassing of Dingot Uranium, USAEC Report MCW-1467, Mallinckrodt Chemical Works, Aug. 21, 1961.

10. O. Kubaschewski and B. E. Hophins, Oxidation of Melals and Alloys, p. 64, Butterworth \& Co., London, 1962.

11. J. S. Ll. Leach, Some Properties of Surface Oxide Films on Metals, in Propertzes of Reactor Materials and the Effects of Radiation Damage, D. J. Littler (Ed.), p. 383, Butterworth \& Co., London, 1962.

12. J. E. Draley and J. W. McWhirter, Effects of Metal Purity and Heat-treatment on the Corrosion of Uranium in Bolling Water, USAEC Report ANL5029, Argonne National Laboratory, Apr. 14, 1953. 
13. J. T. Waber, Aqueous Corrosion of Uranium and Its Alloys, in AECEuratom Conference on Aqueous Corrosion of Reactor Materıals, Brussels, Belg1um, Oct. 14-17, 1959, USAEC Report TID-7587, p. 307, July 1960.

14. F. G. Foote, Physical Metallurgy of Uranium and Its Alloys, in Proceedings of the Unuted Nations International Conference on the Peaceful Uses of Atomic Energy, Geneva, 1955, Vol. 9, p. 68, United Nations, New York, 1956.

15. J. E. Draley, High Temperature Aqueous Corrosion of Uranium Alloys Containing Minor Amounts of Alloying Elements, in AEC-Euratom Conference on Aqueous Corrosion of Reactor Materials, Brussels, Belgium, Oct. 14-17, 1959, USAEC Report TID-7587, p 390, July 1960.

16. V. H. Troutner, Mechanisms and Kinetics of Uranium Corrosion and Uranuum Core Fuel Element Ruptures in Water and Steam, USAEC Report HW67370, Hanford Atomic Products Operation, July 21, 1960.

17. S. Isserow and R. G. Jenkins, Aqueous Corrosion of Zircaloy Clad Fuel Elements with High Uranium Cores, in AEC-Euratom Conference on Aqueous Corrosion of Reactor Materials, Brussels, Belgium, Oct. 14-17, 1959, USAEC Report TID-7587, p. 437, July 1960.

18. J. E. Antıll and K. A. Peakall, Kineties of the Oxidation of Uranium by Carbon Dioxide, J Less-Common Metals, 1: 227 (1959).

19. J. E. Antill and K. A. Peakall, Oxidation of Uranium Alloys in Carbon D1oxide and Air, $J$ Less-Common Metals, 3: 239 (1961).

20 L Grainger, Fuel Elements for Clvil Reactors, Nucl Eng, 6102 (1961)

$21 \mathrm{~J}$ H Kittel, Spontaneous Ignition of Highly Irradiated Fuel, in Nuclear Scrence and Technology, Volume 1A, Issue 3, December 1955, USAEC Report TID-2508(Del) p 513

22 D L. Littler (Ed.) Properties of Reactor Materials and the Effects of Radiatıon Damage, Butterworth \& Co., London, 1962

23 S H. Paine and J H Kittel, Preliminary Analysis of Fission-1nduced D1mensional Changes in Single Crystals of Uranium USAEC Report ANL5676, Argonne National Laboratory, October 1958

24 S F. Pugh, Damage Occurring in Uranium During Burn-up, in Proceedings of the United Nations International Conference on the Peaceful Uses of Atomic Energy, Geneva, 1955, Vol 7, pp 441-444, United Nations, New York, 1956

25 F. G. Foote, Physical Metallurgy of Uranium and Its Alloys, in Proceedings of the United Nations International Conference on the Peaceful Uses of Atomuc Energy, Geneva, 1955, Vol 9, pp 33-68, United Nations, New York, 1956

26 S N. Buckley, The Temperature Coefficient of Radiatıon Growth, United Kingdom Atomic Energy Authority, to be published.

27 S. N Buckley, Irradiation Growth, in Properties of Reactor Materials and the Effects of Radiation Damage, D J. Littler (Ed.), p 143, Butterworth \& Co , London, 1962

28 Y Quéré and J Doulat, Deformation Under Irradiatıon of Uranıum at Low Temperature, Compt. Rend, 2521305 (1961)

29 S. H Paine and J H Kittel, Irradiatıon Effects in Uranıum and Its Alloys, in Proceedings of the United Nations International Conference on the Peaceful Uses of Atomic Energy, Geneva, 1955, Vol 7, pp 445-454, United Nations, New York, 1956 
30 B Hudson, $\mathrm{K}$ H. Westmacott, and $\mathrm{M} J$ Makin, Dislocation Loops and Irradiation Growth in $\alpha$-Uranium, Phıl Mag., 7377 (1962)

31 A J E Foreman and J D Eshelby, Elastic Interaction Energy of Dislocation Loops, British Report AERE-R-4170, 1962

32 K H Westmacott, A C Roberts, and R S Barnes, The Growth of Dislocation Loops During the Irradiation of Aluminium, Britısh Report AERE-R4096, July 1962

33 M W Thompson, An Experiment to Clarify the Role of Point Defects in the Radiation Growth of $\alpha$-Uranium, J. Nucl. Mater, 3354 (1961)

34 M. J. Makin, A D Whapham, and F J Minter, The Formation of Dislocation Loops in Copper During Neutron Irradiation, Phil Mag , 7285 (1962).

$35 \mathrm{~J}$ A Brinkman, On the Nature of Radiation Damage in Metals, J. Appl. Phys , 25961 (1954)

36 A $J$ Baker, Defects Produced in Platınum by Ion Bombardment, in Proceedings of Regular Conference on Electron Microscopy at the Universaty of Nottingham, England, Institute of Physics and the Physical Society, London, 1961

37 L T Lloyd, Thermal Expansion of Alpha-uranium Single Crystals, USAEC Report ANL-5972, Argonne National Laboratory, June 1959

$38 \mathrm{R} H$ Silsbee, Focusing in Collision Problems in Solids $J$ Appl Phys., 28 1246 (1957)

39 G Leibfried, Correlated Collisions in a Displacement Spıke, J. Appl. Phys , 301388 (1959).

$40 \mathrm{~J}$ B. Gibson, A $\mathrm{N}$ Goland, $M$ Milgram, and $\mathrm{G} H$ Vineyard, Dynamics of Radiation Damage, Phys Rev., 1201229 (1960)

41 M. W Thompson and R S Nelson, Atomic Collision Sequences in Crystals of Copper, Silver and Gold Revealed by Sputterıng in Energetıc Ionıc Beams, Proc Roy Soc, A, 259458 (1961)

42. $\mathrm{R}$ Resnick, L S Castleman, and L Seıgle, Dimensional Instability of Uranium-IV, Final Progress Report, USAEC Report SEP-255, Sylvania Electric Products, Inc, February 1960

43 R S Nelson, $M$ W Thompson, and H Montgomery, The Influence of Thermal Vibration on Focused Collision Sequences in Gold, Phıl Mag, 71385 (1962)

$44 \mathrm{~V} J$ Haddrell and E C Sykes, The Metallographic Examınation of Some Single Crystals of Uranium Irradiated at $200^{\circ} \mathrm{C}$ and $500^{\circ} \mathrm{C}$, British Report AERE-M/R-1518A, November 1958

$45 \mathrm{~J}$ Bloch, A Micrographic Examination of Irradiated Uranium, Ret. Met, 55339 (1958)

46 S N Buckley, The Relationship Between Irradiation Growth in Mono- and Polycrystalline $\alpha$-Uranium, in Uranıum and Graphite, $\mathrm{p} 41$ Institute of Metals, London, 1962

47 J $F \quad R$ Ambler and G F. Slattery New Metallographic Techniques for the Examination of Uranium, Uranıum Alloys, and Uranıum Dioxide, J. Nucl Mater, 490 (1961)

48 B E Warren, X-ray Measurement of Grain Size, USAEC Report NYO4836, Massachusetts Institute of Technology, July 20, 1960

49 D M Cheney, A A Bauer, and R F Dicherson, A Metallographic Study of the Structure in Beta-quenched Uranium, USAEC Report NMI-4949(Pt II), p 6, Nuclear Metals, Inc, May 12, 1961 
50 R S. Sharpe and S Aveyard, The Visualisation of an Ultrasonic Extinction Network in Coarse-grained Uranium, Appl Mater Res , 170 (1962)

51. M D. Jepson and G. Slattery, Improvements in or Relating to the Production of Uranıum Metal, British Patent No. 863,492, 1961

52. J. F Boland, H. C Kloepper, Jr., and N F Neumann, The Alloying Influence of Iron and Silicon on the Grain Size of Beta-heat-treated Dingot Uranium, USAEC Report MCW-1465, p 31, Mallınckrodt Chemıcal Works, Aug 1, 1961

53 D. C. Minty, Atomıc Energy Research Establıshment, Harwell, unpublıshed work

54 H. Aubert, Uranium-0.1\% Chromium Alloy, Mem Scı Rev Met., 58276 11961)

55. D C Minty and B. R Butcher, Grain Refinement of Uranıum-Chromium Alloys by Contınuous Cooling, J.Nucl.Energy Pt. $A$ \& B, 16369 (1962)

56 H. R Gardner and J. W Riches, The Effect of Transformation Cooling Rate on the Activation Energy Required for Recrystallization of Beta-quenched Uranium, presented at Nuclear Engineering and Science Conference, Chicago, March 17 to 21, 1958, Preprint 17, Session 9, American Institute of Chemical Engineers, New York, 1958

57 R. R. Guyer and N. F. Neumann, Recrystallization of Beta-heat-treated Dingot-Uranıum Cores, USAEC Report MCW-1460, Mallınckrodt Chemical Works, Aug. 24, 1962.

$58 \mathrm{~J}$ Bloch, J P. Mustelier, D Tardivon, P Bussy, and J Blın, Examens d'Echantillon d'Uranıum de la Barre N R.X No 683, French Report CEA271 (NAA-SR-Memo-4135)

59. G G. Garrow, Summary of the Fabrication and Behaviour of Standard Uranium Rods in the NRX Reactor, 1947 to 1960, Canadian Report IOI-210 (AECL-1298), February 1961

60. M. Salesse, Textures Statistiques, Compt Rend, 2531331 (1961)

61 M Möller, Quantıtative Determination of Pole Figures with a Texture Gonsometer by the Reflection Method, Swedish Report AE-68, March 1962

62 B R. Butcher, Grain Size and Preferred Orientation of Uranum, in Uranum and Graphite, $\mathrm{p} \mathrm{1,} \mathrm{Institute} \mathrm{of} \mathrm{Metals,} \mathrm{London,} 1962$

63 R. D Arnell and J. Clayworth, The "p" Value Method of Determining Preferred Orientation in Uranium Fuel Rods, and Its Extension to the Prediction of Irradiation Growth, Britısh Report DEG-Report-292, July 17, 1961

64 L Alexander, H P. Klug, and E Kammer, Statistıcal Factors Affecting the Intensity of X Rays Diffracted by Crystalline Powders, J. Appl Phys., 19 742 (1948).

65 E. F Sturcken, An X-ray Method for Predicting the Stability of Natural Uranium at Low Burnup, USAEC Report DP-251(Del), E I du Pont de Nemours \& Co., Inc., November 1957

66. N Crank and R N Thudıum, Effects of Etchıng on Preferred Orientation Measurements, in Papers and Proceedings of the X-ray Preferred Orientation Meeting Held at HAPO June 29 and 30,1961, USAEC Report HW-74429, p. 41, Hanford Atomic Products Operation, August 1962

67 P. R. Morris (Ed), Papers Presented at the X-ray Preferred Orientation Meeting Held at National Lead Company of Ohı November 9 and 10, 1959 USAE C Report NLCO-804, National Lead Company of Ohio, July 15, 1960

68 M H Mueller (Ed), Papers and Discussion from the X-ray Preferred 
Orientation Meeting Held at Argonne National Laboratory December 15 and 16, 1960, USAEC Report ANL-6359, Argonne National Laboratory May 1960

69 E. F Sturcken, A Generalized Growth Index Formalism, in Papers Presented at the X-ray Preferred Orientation Meeting Held at National Lead Company of Ohio November 9 and 10 1959, USAEC Report NLCO-804 p 9, National Lead Company of Ohıo, July 151960

$70 \mathrm{~J} \mathrm{~J}$ Stobo and B Pawelskı, The Relationship Between Irradiation Growth and Other Properties of $\alpha$-Uranium, $J$ Nucl Mater, 4109 (1961)

71 J H Gittus, V W Eldred A Stuttard, L. E Raraty G Slattery and F Chatterley Dimensional Stability of Uranium Under Irradiation presented at IAEA $S_{y}$ mposium on Radiation Damoge in Sollds and Reactor Mater ials, Venice, Italy, Way 7 to 11, 1962, IAEA Preprint No SM-25/83 International Atomic Energy Agency, Vienna, 1962

72 W R McDonell Kinetics of Structural Changes During $\beta$-transformation of Uranuum, Nucl Sc Eng, 12325 (1962)

73 I F Barwood and B R Butcher, The $\alpha \rightarrow \beta$ Phase Transformation in Uranum, to be published in Journal of Nuclear Materials

$74 \mathrm{~J} \mathrm{~J}$ Stobo, International Research and Development Company, Ltd, Newcastlc-upon Tyne, England, to be published

75. J Burke and P $\mathrm{H}$ Dixon, The $\alpha \rightleftharpoons \beta$ Phase Transition in Pure Uranium, $J$ Nucl Mater, 738 (1962)

76 G. Donzé, Nature de Ia Transformation $\alpha \rightleftharpoons \beta$ de l'Uranium au Voisınage de l'Equilibre, $J$ vucl Hater, 5150 (1962)

77. $\mathrm{W} R$ Thomas, The Effect of Cold Work on the Irradiation Stability of Beta Heat-treated Uranum, Canadian Report CRMet-766 June 1958

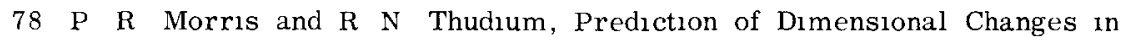
Uranium Fuel Elements Durıng Irradiation - The Elastıc Solution, Interim Report, in Papers and Discussion from the X-ray Preferred Orientation Meeting Held at Argonne National Laboratory December 15 and 16, 1960, USAEC Report ANL-6359, Argonne National Laboratory May 1960

79 W F Murphy, A C Klank, and S H Paine, Examınation of Uranium from the First Core of the EBR-I, USAEC Report ANL-6113, Argonne National Laboratory, September 1961

80 J P LeGeros, Empirica: Approach to Fuel Element Irradiation Growth Prediction, in Papers and Discussion from the X-ray Preferred Orientation Meeting Held at Argonne National Laboratory December 15 and 16 1960 USAEC Report ANL-6359, p 41, Argonne National Laboratory May 1960

$81 \mathrm{~S} \mathrm{H}$ Bush, Irradiation Effects in Uranum, in Fuel Elements Conference, Paris, November 18-23, 1957, USAEC Report TID-7546, p. 591, 1958

82 S T Konobeevskil, N F Pravdiuk, and V I Kutaitsev, Effects of Irradiation on Structure and Properties of Fissionable Materials, in Proceedings of the United Nations International Conference on the Peaceful Uses of Atomac Energy, Geneva, 1955, Vol 7, pp 433-440 United Nations New York, 1956

83 A H Cottrell, Creep of Alpha Uranium During Irradiation or Thermal Cycling British Report AERE-M/M-102 November 1955

84 W S Blackburn, The Effect of Internal Stresses Due to Irradiation Growth and Thermal Cycling on the Creep of Uranium in the Cases of Both Elastic 
and Plastic Behaviour, J.Nucl. Energy Pt. A\& B, 14107 (1961)

85 A. C Roberts and A H Cottrell, Creep of $\alpha$-Uranium During Irradiation with Neutrons, Phil. Mag., 1(Series 8) 711 (1956)

86 R G Anderson and J. F W Bishop, The Effect of Neutron Irradiation and Thermal Cycling on Permanent Deformations in Uranium Under Load, in Uranium and Graphıte, p. 17, Institute of Metals, London, 1962

87 H C Rose, A Compressive Creep Test of $\alpha$-Uranium Under Neutron Irradiation, J. Inst Metals, 86122 (1957)

$88 \mathrm{~S}$ T Konobeevski1, Relaxation of Elastıc Stresses Under Neutron Irradiation, At. Energ., 9194 (1960)

89 R. V Hesketh, A Possible Mechanısm of Irradiation Creep and Its Reference to Uranium, Phal. Mag , 71417 (1962)

90. R. H. Johnson and G W. Greenwood, Deformation of Uranıum During $\alpha / \beta$ Cycles Under Small Stresses and a Qualitative Interpretation of the Mechanical Weakness of Metals Undergoing Phase Transformations, Nature, 195138 (1962)

91. S, F Pugh, The Mechanısm of Growth of Uranium on Thermal Cycling in the Alpha Range, J. Brit. Nucl Energy Conf., 4: 27 (1959).

$92 \mathrm{H} H$ Chiswik, The Plastic Deformation of Uranium on Thermal Cycling, Trans. Am. Soc. Metals, 49622 (1957).

93 A. N. Holden, The Physical Metallurgy of Uranıum, p 165, Addison-Wesley Publıshıng Company, Inc , Reading, Mass., 1958

94 S F Pugh, Swelling in Alpha Uranium Due to Irradiation, J. Nucl Mater., 4177 (1961)

95 S N Buckley, A. G Harding, and M B Waldron, Physical Damage Brought About by Thermally Cycling Uranium Through Its Phase Changes $J$ Inst Metals, 87150 (1959).

96 R G Bellamy, The Swelling of $\alpha$-Uranium Under Neutron Irradiation to $07 \%$ Burn-up, in Uranıum and Graphite, p 53, Institute of Metals, London, 1962

97 G W Greenwood, A J. E Foreman, and D E Rimmer The Role of Vacancies and Dislocations in the Nucleation and Growth of Gas Bubbles in Irradiated Fissile Materıals, J Nucl Mater., 1305 (1959)

98 P C L Pfeil, Atomic Energy Research Establishment, Harwell, original suggestion (circa 1952).

99. B Hudson, Atomic Energy Research Establishment, Harwell, to be published

$100 \mathrm{~J}$ E Bainbridge and R G Bellamy, Atomıc Energy Research Establishment, Harwell, to be published

101. T K Bierlein, R D Leggett, B. Mastel, and J W Weber, Swelling in Uranium A Comparison of the Effects of Irradiation and Postirradiation Annealıng, USAEC Report HW-69393, Hanford Atomic Products Operation, April 1961.

102 R S. Barnes and D J Mazey, The Migration and Coalescence of Inert Gas Bubbles in Metals, Britısh Report AERE-R-4223, January 1963

$103 \mathrm{R}$ S Barnes, Contribution to the Discussion of Swelling in Uranium, $J$. Inst. Metals, 89310 (1961).

104 T. K Bierlein, B Mastel, and R D Leggett, Metallographic Observations of Swelling in Uranum. Interim Report, USAEC Report HW-63848, Hanford Atomic Products Operation, June 1, 1960 
105 B A Loomıs and D W Pracht, Swelling of Uranium on Post-irradiation Annealing, to be published in Journal of Nuclear Materials

$106 \mathrm{~J}$ A Brinkman, Fundamentals of Fission Damage, in Nuclear Metallurgy, Vol 6, p 1, Metallurgical Society of American Institute of Minıng, Metallurgical and Petroleum Engineers, New York, 1959

107 G Petzow and I Kvernes, Zur Konstitution der Uranreichen Uran-Silızium Alumınıum-Legierungen, $Z$ Metallk , 53248 (1962)

108 S Isserow, R W Anderson A B Bremer and W L Larson, Power Reactor Program Progress Report to Savannah River Operations Office, USAEC, for the Period Feb 1-28, 1962, USAEC Report NMI-7248, Nuclear Metals, Inc , May 10, 1962

109 D Randolph and N F Neumann, Metallographic Studies of the UraniumIron-Silıcon System, USAEC Report MCW-1475, p 35 Mallinckrodt Chemical Works, Aug 1, 1962

110 N Swindells and P J Bowles, A E I Laboratories, Aldermaston, England, to be published

111 G Petzow, $S$ Steeb, and $R$ Tank, Das Quasıbınäe System $\mathrm{UFe}_{2}-\mathrm{UAl}_{2}$, $Z$ Metallk, 53526 (1962)

112. I S Brammar, M A P Dewey, and G W Briers, in Uranıum and Graphite, given in the discussion, $\mathrm{p} 98$ Institute of Metals, London, 1962

113 M J Makın, W H Chatwin, J H. Evans, B Hudson, dnd E D. Hyam, The Study of Irradiation Damage in Uranium by Electron Microscopy, in Uranium and Graphate, $\mathrm{p} 45$, Institute of Metals, London, 1962

$114 \mathrm{P}$ Ryder and $\mathrm{J}$ Nutting, in Uranium and Graphite, given in the discussion, p 98, Institute of Metals, London, 1962

115 D F Babcock, $R \quad R$ Hood, and L Isakoff (Comps), Heavy Water Moderated Power Reactors Progress Report, June 1962, USAEC Report DP755, E I du Pont de Nemours \& Co, Inc. July 1962

116 D. F Babcock, $R$ R Hood, and L Isakoff (Comps), Heavy Water Moderated Power Reactors Progress Report, July 1962, USAEC Report DP765, E I du Pont de Nemours \& Co, Inc , August 1962

117 D F Babcock, $R$ R Hood, and L Isakoff (Comps), Heavy Water Moderated Power Reactors Progress Report, September 1962 USAEC Report DP-785, E I du Pont de Nemours \& Co , Inc , October 1962

$118 \mathrm{~W} L \mathrm{~L}$ Owen, Effect of Hydrogen on Mechanical Properties of Uranium, Metallurgia, 66(393) 3 (1962)

119 D M Davies, The Fracture Characteristics of Uranium, Ph D. Thesis, Oxford University, 1961

120 D M Davies and J W Martin, The Effect of Inclusions on the Fracture of Uranium, $J$ Nucl Mater, 3156 (1961)

121 B Loy, The Influence of Temperature and Grain Size on the Fracture of Alpha Uranium Britısh Report NRC-62-54

$122 \mathrm{~N}$ E Daniel, F R Shober, E L Foster, Jr, and R F. Dickerson, Crack Initiation and Propagation in Uranium at Elevated Temperatures, USAEC Report BMI-X-10011, Battelle Memorial Institute, Aug 1, 1962

123 D Taplın and J W Martın, Metallurgy Department, The Oxford Unıversity, London, England to be published

$124 \mathrm{R}$ G Bellamy The Cracking of Irradiated Uranıum, presented at IAEA Symposium on Radiation Damage in Solids and Reactor Materials, Venzce, Italy, May 7 to 11, 1962, International Atomic Energy Agency, Vienna, 1962. 
125 A L. Bement, The Effect of Low Neutron Exposures at Low Temperatures on the Hardness and Tensile Properties of Natural Uranium, USAEC Report HW-60326, Hanford Atomic Products Operation, June 2, 1959

126 P E Brookes, N Kirby, and W T. Burke, The Creep and High Temperature Fatigue Properties of the Magnesium-base Canning Alloy, Magnox A12, J Inst. Metals, $88500(1960)$

127. G. B Greenough and P Murray, Fuel Elements for UK Gas-cooled Reactors, in Nuclear Metallurgy, Vol. 8, p. 83, Metallurgical Society of Amerıcan Institute of Mining, Metallurgical, and Petroleum Engıneers, New York, 1962

128. V W Eldred, Changes in Calder Hall Fuel Elements Under Irradiation, address to the EAES Symposium on Redctor Materials, Stockholm, 1959

129 H K. Hardy, J F W. Bishop, D O. Pickman, and V W. Eldred, The Development of Uranium-Mdgnox Fuel Elements for an Average Irradiation Life of $3000 \mathrm{MWD} / \mathrm{te}, \mathrm{J}$. Brit. Nucl Energy Soc., 233 (1963)

130 Sır Leonard Owen, Nuclear Fuel Manufacture - A New Industry Atom, 65 31 (March 1962)

131 M. Salesse, Metallurgy and Atomic Energy - Difficulties and Results Acquired, Nukleonik, 278 (1960)

132. J A Stohr, M. Englander, and M Gauthron, The Fuel Elements in Pressurized-gas Reactors, in Proceedings of the Second United Nations International Conference on the Peaceful Uses of Atomic Energy, Geneva, 1958, Vol 6, pp 324-342, United Nations New York 1958

133 Heavy Water Component Testing Reactor, USAEC DP Series of Progress Reports, such as Refs 115, 116, and 117 and DP-795, E I du Pont de Nemours \& Co, Inc

134 L R Blake, Irradiation of Uranum Metal and Uramum Oxide Fuel Pins to High Burn-up at High Temperature, J. Nucl. Energy Pt. A \& B, 15140 (1961).

135. J. A Stohr and $M$ Englander, Fuel Elements of the First Charge of the E L3 Reactor, Bull. Inform. Sc2. Tech. (Parls), 422 (1960).

136. K. F. Smith, The Irradiation of Uranium-Fissium Alloys and Related Compositions, USAEC Report ANL-5736, Argonne National Laboratory, September 1957

137 J P. Mustelier, H. Mikaıloff, J L Ratier, D Gondol, and J Bloch, The Effects of Irradiation on Uranium Alloys with Small Molybdenum Contents, in Properties of Reactor Materials and the Effects of Radiation Damage, D J. Littler (Ed.), p. 505, Butterworth \& Co , London, 1962

138 R. G. Bellamy, Atomic Energy Resedrch Establishment, Harwell, to be published.

139 B W. Howlett, A. J Eycott, I K. Kang, and D R F West, The Kinetics of the Isothermal Dccomposition of a $\gamma$-Phase Uranium-6 At \% Molybdenum Alloy, to be published in Journal of Luclear Vateruals.

140. C. Fizottı, Transformation of Metastable Phases in the 2, 3, and 5 At $\%$ Uranıum-Molybdenum Alloys, Itahan Report RT/MET(62)4, September 1962

$141 \mathrm{M}$ P. Johnson and $J \mathrm{R}$ Kench, to be published in Journal of Nuclear Vaterials.

142 G. H May, The Annealing of a Quenched Uranıum-5 At \% Molybdenum Alloy, J. Nucl. Mater., 77 (1963) 
143. $\mathrm{K}$ Tangrı, Les Phases $\gamma$ Métastables dans les Allıges d'Uranıum Contenant du Molybdène, Mem Scı Rev Met, 58469 (1960)

144. B. W. Howlett, AERE, Harwell, to be published.

145 S. T Konobeevskı, N F Pravduuk, and V I Kutaitsev, Effects of Irradiation on Structure and Properties of Fissiondble Materials, in Proceedings of the United Nations International Conference on the Peaceful Uses of Atomic Energy, Geneva, 1955, Vol 7, pp 433-440, United Nations, New York, 1956

146 M L Bleiberg, L J. Jones, and B Lustman, Phase Changes in Plle Irradiated Uranum-base Alloys, $J$ Appl Phys., 27 1270 (1956)

147 A A. Shoudy, W. E McHugh, and M. A Silliman, The Effect of Irradiation Temperature and Fission Rate on the Radiation Stability of Uranium$10 \mathrm{Wt} \%$ Molybdenum Alloy, presented at IAEA Symposium on Radiation Damage in Soluds and Reactor Materials, Venice, Italy, May 7 to 11, 1962, International Atomic Energy Agency Vienna, 1962

148 G Cabane and G. Donzé, Stabılısatıon de la Phase $\gamma$ dans les Alliages Ternaıres à Base d'Uranum-Molybdène, J. Nucl. Mater , 4364 (1959)

149 W. M Justusson, Transformation Kinetics of Gamma-phase UraniumMolybdenum-Niobium Alloys, J. Nucl. Mater., 437 (1961)

150 W A Bostrom and E K Halteman, The Metastable Gamma Phase in Uranuum Base Molybdenum Alloys, Advan. Nucl Eng., 2184 (1957).

151. G Donzé and G. Cabane, Mécanısme de la Décompositıon de la Phase $\gamma$ des Allıages Uranıum-Molybdène et Uranıum-Molybdène-Ruthénıum, Mem. Scr Rev. Met, 57450 (1960).

152. O. S Ivanov and Yu S Virgiliev, The Decomposition of the $\gamma$-Uranum Base Solid Solutions as Revealed by X-Ray Investigations, $J$ Nucl Mater., 6 199 (1962).

153 H Mikalloff, Etude des Transformations par Revenu de la Phase $\gamma$ Cubique Centrée des Allıage Uranum Molybdène, French Report CEA-1270 (AECtr-4273), June 23, 1959

154 R F Hills, B R Butcher, and B. W Howlett, The Mechanical Properties of Quenched Uranium-Molybdenum Alloys Pt I Tensile Tests on Polycrystalline Specimens, British Report AERE-R-4208 December 1962

155 W A Holland, Isothermal Transformation of Uranum-14 and Uranium$16 \mathrm{Wt} \%$ Molybdenum Alloys at $550^{\circ} \mathrm{C}$. Interim Report, USAEC Report NAA-SR-6125, North American Aviation, Ine, Dec 1, 1961

156 D Kramer and C G Rhodes, The Precipitation of Metastable Alpha Phase During the Gamma to Gamma Prime Transformation in Uranıum-16 Wt \% Molybdenum, Trans. AIME, 2241015 (1962)

157 J Gioseff , Oxıdation Rates of U-10 Wt \% Mo Alloy in Aır, US4EC Report NAA-SR-Memo-4845, North American Aviation, Inc, Sept 16, 1960

158 M W Burkart (Ed), Development and Properties of Uranium-base Alloys Corrosion Resistant in High Temperature Water, USAEC Report WAPD127(Pt III), Westinghouse Electric Corporation, Bettis Plant, July 1956

159 M. W Burkart and B Lustman, Corrosion Mechanısm of Uranium-base Alloys in High Temperature Water, Trans AIME, 21226 (1958)

160. J N Chirigos, The Role of Lattice Mismatch Between Oxide and Metal in the Corrosion Behaviour of Gamma Uranium Alloys, in Physical Metallurgy of Stress Corrosion Fracture, $\mathrm{T} N$ Rhodin (Ed.), p. 70, Interscience Publishers, Inc., New York, 1959 
161. M Englander and J A Stohr, The Characteristics of Varıous Metallic Nuclear Fuels and Their Behaviour Under Irradiation, in Properties of Reactor Materials and the Effects of Radiation Damage, D. J. Littler (Ed.), p. 483, Butterworth \& Co., London, 1962

162. B. Lustman, Resumé of Uranium Alloy Data - VIII, USAEC Report WAPDPMM-15, Westunghouse Electric Corporation, Bettis Plant, Feb 25, 1955

163 C R Tottle, D S Oliver, and K Q. Bagley, Dounreay Fast Reactor Metallurgical Problems, J. Brit Nucl. Energy Conf., 6211 (1961)

164 J R Dietrich and W H Zinn, in Solvd Fuel Reactors, p. 239, AddisonWesley Publıshıng Company, Inc, Reading, Mass, 1958

165 R. Weil and S. H Paine, Effect of Irradiation upon Interdiffusion of Stainless Steel and Uranıum, USAEC Report ANL-5346, Argonne Natıonal Laboratory, July 15, 1953.

166 J. A. Horak, J H Kittel, and F L Yaggee, Irradiation Behavior of Restrained and Vented Uranium-2 Wt \% Zirconium Alloy, USAEC Report ANL-6431, Argonne National Laboratory, June 1962

$167 \mathrm{C}$ L Angerman and W R McDonell, Metallography of U-2 Wt \% Zr Alloy Before and After Irradiation, USAEC Report DP-589, E I du Pont de Nemours \& Co., Inc., July 1961

168 S. T Zegler, The Uranıum-rıch End of the Uranıum-Zirconıum System, USAEC Report ANL-6055, Argonne National Laboratory, February 1962

169 G Lagerberg, Phase Transformations in a Uranium-Zirconium Alloy Containıng 2 Wt \% Zirconıum, Swedish Report AE-50, Aprıl 1961.

170 B H. Hatt, G I Williams, and D Stewart Fulmer Research Institute, Stoke Poges, England, to be published

171. A. Virot, Caracterıstıques de 1'Allıage Uranıum-Zirconıum à $6 \%$ en Poids de Zirconium, J Nucl Mater, 5 I09 (1962)

172 D E Thomas, $R$ H Fillnow, $K$ M Goldman, J Hino, $R$ J Van Thyne F C Holtz, and D J McPherson, Properties of Gamma-phase Alloys of Uranium, in Proceedings of the Second United Nations International Conference on the Peaceful Uses of Atomic Energy, Geneva, 1958, Vol 5, pp. 611-618, United Nations, New York, 1958

173 N. L Peterson and R E Ogilvie, Diffusion Studies in the Uranium - Niobium (Columbium) System, Trans. AIME, 218439 (1960)

174. $\mathrm{R} F$ Hills, Some Observations on the Identification of Compounds in the System Uranium-Aluminium, J Inst Metals, 86438 (1957-1958)

$175 \mathrm{H}$ A. Saller, J R Keeler, and N S Eddy, Control of Particles Size in Aluminum-Uranium Alloys, USAEC Report BMI-T-16, Battelle Memorial Institute, Nov 15, 1949

176 J H Evans, Atomic Energy Research Establishment, Harwell, to be published.

177 M B Reynolds, Fission Gas Behavior in the Uranıum-Aluminıum System, Nucl Scı. Eng, 3428 (1958)

178 O J Wick, $\mathrm{T}$ C Nelson, and M D Freshley, Plutonium Fuels Development, in Proceedings of the Second Unted Nations International Conference on the Peaceful Uses of Atomic Energy, Geneva, 1958, Vol 6, pp. 700-709, United Nations, New York, 1958

179 B Blumenthal, The Transformation Temperatures of High Purity Uranium, J Nucl. Mater., 223 (1960)

180. I. F. Baru ood, AERE, Harwell, unpublished work. 
181 K T Scott and J H. Buddery, The Release of Krypton 85 from Irradiated Uranium on Thermal Cycling Through the Phase Changes, J. Nucl. Mater., $5 \quad 94$ (1962)

182. G W Greenwood and R. H Johnson, An Analysis of Stress-1nduced Permanent Dimensional Changes in Uranium Fuel Bars with a $\beta$-Core, J. Nucl. Energy Pt. A \& B, 16473 (1962)

183 R B. Kehoe, Non Equilıbrıum Beta Retention in Fuel Elements, Britısh Report IGR-TN/C-855, 1958

184 A. L. Geary and V Nerses, Retention of Uranium Beta Phase, USAEC Report NMI-1237, Nuclear Metals, Inc., Sept. 7, 1960

$185 \mathrm{H}$ M. Green and W. B Nowak, Irradiation Behavior of Metastable Beta Phase Uranum-base Alloys, USAEC Report NMI-1249, Nuclear Metals, Inc, Aug 18, 1961

186. M Deighton, Fulmer Research Institute, Stoke Poges, England, to be published.

187 R L Craık, D Birch, C Fizzottı, and F. Saraceno, Phase Equilıbria in Uranıum-rich Binary Alloys Contaıning Molybdenum and Zirconıum and the Effect of Ternary Additions of Carbon, J. Nucl. Mater., 613 (1962)

188. F G Streets and J Stobo, The Uranum-Molybdenum-Carbon Equalibrium Diagram, to be published in Journal of Instutute of Metals.

$189 \mathrm{C}$ Fizzottı and F Saraceno, Metallurgical Examination of Uranium-rich Ternary Alloys Containıng Molybdenum and Carbon, Italıan Report CNEN113, April 1962

190 British Patent Specification No 912,960 to USAEC, 1962.

191 W H Friske, Some Properties of Uranium-Molybdenum Alloy Fuels for Organic Moderated Reactors, USAEC Report NAA-SR-4646, North American Aviation, Inc , Apr. 1, 1960

192 D Kramer, Finely Dispersed Phases in Uramum-Molybdenum Ternary Alloys, J. Nucl. Mater., 4281 (1961)

193 W. A Holland, Irradiation Properties of Uranum-Molybdenum Alloys, Trans. Am. Nucl. Soc., 4337 (1961)

194. M Kangllaskı, J E Gates, and R F Dickerson, Irradiation Studies of Uranium-Molybdenum Alloys with Minor Additions, in Progress Relating to Civilıan Applications During July 1962, USAEC Report BMI-1589(Del.), p. B-9, Battelle Memorial Institute, Aug 1, 1962

195 D. Kramer, C. G Rhodes, and W. V. Johnston, Irradiation Induced Precipıtation in a Uranium-Molybdenum-Silicon Alloy, to be published in Journal of Applied Physics.

196 D. Kramer and W. V Johnston, Post Irradiation Annealing of Uranium Molybdenum Ternary Alloys, presented at the Annual Meeting of the Metallurgical Society of American Institute of Mining, Metallurgical, and Petroleum Engineers, 1963.

197 C G Rhodes and D. Kramer, Irradiation Effects and Fission Gas Bubble Formation in Uranıum-Molybdenum Ternary Alloys Containıng Fine Precipitates, presented at the Annual Meeting of the Metallurgical Society of American Institute of Mining, Metallurgical, and Petroleum Engineers, 1963

$198 \mathrm{~J}$ Paix and G Cizeron, Comparison du Comportement au Cyclage Thermique en Phase $\alpha$ de l'Uranium Fritté par Extrusion et de l'Uranium Massif, Mem.Sct Rev. Met, 59769 (1962) 
199 W Arbiter, The Preparation and Properties of Dispersion-hardened Uranuum Powder Products, USAEC Report NDA-2119-1, Nuclear Development Corporation of America, Feb 21, 1961

200 J A DeMastry, D P Moak, S G Epstein, A A Bauer, and R F Dickerson, Development of Niobıum-Uranum Alloys for Elevated Temperature Fuel Applications, USAEC Report BMI-1536, Battelle Memorial Institute Aug 9, 1961

201 J. A DeMastry, A A Bauer, and R F Dickerson, Irradiation Studies of Niobium-Uranium Alloys, in Progress Relating to Civilian Applications During May 1962, USAEC Report BMI-1581(Del ) p. B1, Battelle Memorial Institute, June 1, 1962

202 A H Willis and A. E Bibb, The Dimensional Instability of Fissionable Materıals Durıng Reactor Irradıation, Reactor Technology Report No $12-$ Metallurgy, USAEC Report KAPL-2000-9 p C 1, Knolls Atomic Power Laboratory, Sept 8, 1960

203 S D Strauss and $J$ L Zambrow Irradiation of Uranıum-Yttrium Alloys USAEC Report SCNC-329 Sylvanıa Electric Products, Inc , August 1961

204 Oak Ridge National Laboratory and American Nuclear Society Proceedings of the Thorium Fuel Cycle Symposium, Gatlınburg, Tennessee, December $5-7,1962$, USAEC Report TID-7650

$205 \mathrm{H}$ L Lloyd and A E Symonds, The Isostatic Pressing, Vacuum Sintering and Swaging of Thorium Powder, Powder Met , 6170 (1960)

206 A D Schwope, G T Muehlenkamp and L L Marsh Mechanical and Metallurgical Properties of Thorıum, USAEC Report BMI-784, Battelle Memorlal Institute, Nov. 18, 1952

207 G. H Bannister and J R Murray, Age-hardening of Thorıum-Aluminum and Thorium - Uranum Alloys, British Report AERE-R-2951, June 1959

208 M S Farkas, A A Bauer, and R F Dickerson, The Development of Thorıum-Uranium-base Fuel Alloys, USAEC Report BMI-1428, Battelle Memorial Institute, Mar 18, 1960

209 B R Hayward and P Corzıne, Thorıum-Uranıum Fuel Elements for SRE, in Proceedings of the Second Untted Nations International Conference on the Peaceful Uses of Atomic Energy, Geneva, 1958, Vol 6, pp 438-442 United Nations, New York, 1958

210. J E Gates, G E Lamale, and R F Dickerson The Examination and Evaluation of Irradiated Thorium-11 Wt \% Uranium Specimens, USAEC Report BMI-1334, Battelle Memorial Institute Apr 16, 1959

$211 \mathrm{~J}$ A Horak, J. $\mathrm{H}$ Kittel, and $\mathrm{H} \mathrm{V}$ Rhude, The Effects of Irradiation on Some Binary Alloys of Thorium-Plutonium and Zirconium-Plutonium USAEC Report ANL-6428 Argonne National Laboratory July 1962

212 M B Waldron, A G Adwıck, H Lloyd, M J Notley D M Poole, L E Russell, and J B. Sayers, Plutonium Technology for Reactor Systems in Proceedings of the Second United Nations International Conference on the Peaceful Uses of Atomic Energy, Geneva, 1958, Vol 6 pp 690-696 United Nations, New York, 1958

213 J H. Kittel, J A Horak, W F Murphy, S H Paine, Effects of Irradiation on Thorium and Thorium-Uranium Alloys USAEC Report ANL-5674 Argonne National Laboratory, April 1963 


\section{Pyroprocessing of Reactor Fuels}

by

R. Dean Pierce and Leslie Burris, Jr. Argonne National Laboratory 
The possibility of applying pyroprocesses, such as those which have long been utilized in the metallurgical industry in refining metals, to reactor-fuel materials has interested engineers and chemists for several years. These high-temperature processes include pyrometallurgical processes and certain other processes in which high temperatures are used to effect desirable chemical reactions. Not included in this article are fluoride-volatility processes, which are based upon the relative volatility of fluorides. Two attractive features of pyroprocesses are the small number of chemical steps as compared with conventional aqueous processes and the absence of radiation-sensitive reagents such as organic extractants. Metallurgical processes can handle fuels shortly after their discharge from a reactor, thus avoiding costly inventories of fissionable materials awaiting radioactive decay of the shorter lived fission products. The elimination of extended decay times is especially desirable for fast reactor fuels. These fuels have high contents of fissionable material, and, therefore, large out-of-reactor fuel inventories would result in high inventory charges. Other advantages of these processes are that criticality problems in the chemical plant are reduced because of the absence of neutron moderators and that process volumes are small because the fuel materials are maintained in relatively concentrated form. This concentrated fuel will permit the plants to be compact, and the volume that must be shielded will therefore be reduced. A practical plant size may be small enough to permit a single reactor to have its own processing plant.

Because pyroprocesses do not, in general, provide high decontamination from fission products, their development must be accompanied by the design and development of reactor fuel elements that can be remotely refabricated from the recovered materials. However, semiremote refabrication may be necessary even for conventionally processed fuel, inasmuch as the high burnups desired for power reactors result in the accumulation of significant concentrations of certain higher 1sotopes, such as $\mathrm{Pu}^{240}, \mathrm{U}^{237}, \mathrm{Th}^{228}$, and $\mathrm{U}^{232}$, whose radiations may preclude direct fabrication of recovered fissionable material.

A major handicap to successful pyroprocesses has been the unavalability of suitable materials for the containment of certain molten metals at high temperatures. Recent developments with refractory metals have offered encouraging solutions to many of the containment problems, as has the avallability of improved ceramic materials.

The pyroprocessing art as applied to irradiated fuels is not sufficiently mature to permit a really significant evaluation of its economic potential, but the current projects may soon make economic projections meaningful. Research in pyroprocessing of irradiated nuclear fuels did not become active untıl about 1952; but by 1954 wide interest had developed in the field, and a symposium was devoted to presenting many of the research results. ${ }^{1}$ Since that time an increasing 
number of publications in this field have appeared. Currently a pyroprocessing plant with remote fuel fabrication is nearing completion and will be employed in a closed fuel cycle for the Experimental Breeder Reactor No. II (EBR-II) at the USAEC National Reactor Testing Station in Idaho.

Perıodically, reviews of pyroprocesses have been published, ${ }^{2-7}$ and the progress of the various development programs is reviewed in Reactor Fuel Processing, a quarterly journal. In this article we shall review the status of the art as reflected in publications through 1962 , accenting the most promising concepts and reflecting trends as they now appear.

The major development of pyroprocesses in the nuclear field has been for application to irradiated materials. Nuclear fuels must be reprocessed to restore physical integrity, to restore reactivity by the addition of fissionable material and the removal of fission products, and to recover fissionable material. Many of the fission products, especially the rare-earth elements, are reactor poisons that capture and waste a signif 4 cant portion of the neutrons in a thermal reactor. Also, many of the fission products, in addition to diluting the fuel and capturing neutrons, can produce adverse physical or mechanical properties if retained in fuel that is refabricated. Often, before a fuel would require processing to remove fission products or to increase its fissionable constituents, it must be removed from a reactor to maintain dimensional tolerances or to prevent fallure of cladding as a -result of excessive radiation damage. Such fuel must be processed to repair radiation damage and to prepare it for reuse. Fertile material irradiated in a reactor blanket is processed principally to recover the bred fissile elements for utilization in a reactor core. These processes for the separation of relatively small amounts of $\mathrm{Pu}^{239}$ from $\mathrm{U}^{238}$ or $\mathrm{U}^{233}$ from $\mathrm{Th}^{232}$ will probably require relatively high recoveries of these fissionable elements but little or no removal of fission products when remote fabrication is employed.

Suggestions for other applications of pyrochemistry are becoming common. These include uses in ore treatments, scrap recovery, metal reductions, and production of compounds.

\section{REVIEW OF UNIT OPERATIONS}

A brief discussion of several unit operations that are frequently employed may be useful before the status of development programs is reviewed. For convenience, these unit operations are categorized as physical and chemical operations, although the distinction between these two is not always well defined. 


\section{Separations Based on Differences in Physical Properties}

Many separation schemes have been envisioned which take advantage of the differences in physical properties of various materials. The properties most frequently considered are vapor pressure, solubility, and equilibrium distribution between immiscible phases. The use of various molten metals or alloys as solvents introduces many systems in which these property differences may be utilized.

CRYSTALLIZATION Fractional crystallization is employed as a processing step in many of the processes under consideration. Such processes have been reviewed by Feder and Teitel. ${ }^{8}$ Generally, these procedures involve the crystallization of a major constituent from a solution, the minor constituent being left in solution. The behavior of a solute in a pure solvent is not necessarily the same as its behavior in the presence of other solutes. Two metals, if added below their individual solubility limits, may interact to form an insoluble phase if they form a stable intermetallic compound; or one element may increase or suppress the solubility of the other. A solute in a saturated solution of another solute may coprecipitate with the saturated element when the solution is cooled even though its own solubility in the pure solvent is not exceeded. Because solubility data alone are not enough to predict accurately the behavior of a system during crystallization, data on the cobehavior of elements are also required in support of process studies.

Purification by crystallization is also possible without added solvent, for impurities frequently distribute preferentially in either the solid or the liquid phase of a metal. An application of this principle is zone melting, in which so.ute elements are concentrated in the ends of a bar of material by repeated unidirectional passage of a small molten zone through the material. ${ }^{9}$ Studies of the application of zone melting to reactor fuels were reported earlier. ${ }^{2}$ These studies have been largely abandoned because of unfavorable distribution coefficients, slow processing rate, and the necessity of a complementary process for the recovery of fissionable material from the cropped ends.

LIQUID-LIQUID EXTRACTION Because there are many immiscible liquid-metal combinations, the possibility exists of separating reactor materials by liquid-liquid partitioning. The success of these separations depends on the finding of immiscible solvents that provide favorable equilibrium solute distributions. Extractions have been effected with molten fuel as one phase in contact with a suitable immiscible solvent and also between two processing solvents in which fuel is dissolved. Although multistage extractions have not yet been employed, the possibility of achieving large decontamination factors by this technique does exist. The two immiscible phases generally have some 
mutual solubility, and the removal of the small amount of one solvent from the other can be important, especially when the fuel itself serves as one of the phases.

EVAPORATION Every pyroprocess for irradiated reactor fuel incorporates evaporation to some degree. A simple example is the removal of the fission gases or other highly volatile fission products when fuel is melted or dissolved. Table 1 presents atmospheric boiling temperatures and melting points of several elements of interest in reactor-materials processing. The vapor pressure of uranium is low compared with many of the fission products. The possibility of volatilizing plutonium for recovery from the uranium is apparent. The major developments and studies of vaporization for high-temperature processing have been for the removal or recovery of solvent metals from other processing steps. The data for several solvents are included in Table 1. Frequently in these operations the thermal decomposition of an intermetallic compound, such as $\mathrm{U}_{2} \mathrm{Zn}_{17}$, is effected, as well as the volatilization of excess solvent. This process, and also the simple evaporation of residual solvent remaining after transfer of a depleted solution from a precipitated product, is generally called retorting. Thus retorting is distinguished from distillation, which is the evaporation of a large amount of solvent or solute.

Table 1-ME LTING AND BOILING POINTS OF SELECTED MATERIALS ${ }^{10}$

\begin{tabular}{|c|c|c|c|c|c|}
\hline Element & $\begin{array}{l}\text { Melting } \\
\text { point } \\
{ }^{\circ} \mathrm{C}\end{array}$ & $\begin{array}{c}\text { Boiling } \\
\text { point } \\
\text { at } 760 \\
\mathrm{~mm} \mathrm{Hg} \\
{ }^{\circ} \mathrm{C}\end{array}$ & Element & $\begin{array}{l}\text { Melting } \\
\text { point } \\
{ }^{\circ} \mathrm{C}\end{array}$ & $\begin{array}{c}\text { Boiling } \\
\text { point } \\
\text { at } 760 \\
\mathrm{~mm} \mathrm{Hg} \text {, } \\
{ }^{\circ} \mathrm{C}\end{array}$ \\
\hline \multicolumn{3}{|c|}{ Fissile or Fertile Materials } & \multicolumn{3}{|c|}{ Representative Potentıal Solvents } \\
\hline Uranıum & 1132 & 3813 & Alumınum & 660 & 2450 \\
\hline Thorium & 1750 & 4200 & Bismuth & 271 & 1627 \\
\hline Plutonium & 640 & 3235 & Cadmium & 321 & 767 \\
\hline \multirow{2}{*}{\multicolumn{3}{|c|}{ Representative Fission Products }} & Calcium & 851 & 1482 \\
\hline & & & Lead & 327 & 1737 \\
\hline Barıum & 710 & 1500 & Magnesium & 651 & 1103 \\
\hline Cerium & 795 & 3468 & Manganese & 1244 & 2097 \\
\hline Cesium & 28 & 705 & Mercury & -39 & 357 \\
\hline Praseodymium & 935 & 3127 & Silver & 960 & 2212 \\
\hline Strontium & 770 & 1380 & Sodıum & 98 & 883 \\
\hline Yttrium & 1509 & 3200 & Zine & 420 & 906 \\
\hline Zirconium & 1852 & 3580 & & & \\
\hline
\end{tabular}

\section{Chemical Separations}

In most of the early pyroprocessing concepts, the major fuel constituent was maintained in its original metallic state throughout the 
process. The avoidance of chemical transitions was considered a major advantage of these processes. Subsequent demonstrations of the ease of oxidizing and reducing various metals and their compounds by pyroprocessing have tended to place less emphasis on the need to avold chemical conversion in these processes. Processing possibilities have, therefore, been greatly broadened. Most of these processes take some advantage of differences in the chemical stabilities of compounds of the elements of interest. Conditions are selected in which certain elements will react whereas others will not.

SELECTIVE OXIDATION One element can often be removed from another by selective oxidation of one into a dross or slag out of a liquid-metal phase. Generally, the minor constituent is oxidized from a bulk phase. The term "oxidation," as used here and frequently throughout this review, is used in the broad sense to include reactions to form halides, carbides, or perhaps other compounds as well as oxides.

CHEMICAL EXTRACTIONS BETWEEN TWO PHASES In one attractive processing technique, a molten metal and a molten flux are employed so that reduced elements dissolve in the metal and oxidized elements in the flux. Such systems can often provide unusually good kinetics because of the resulting increased mobility of the reactants and products, which thereby prevents formation of solid diffusion barriers. The composition of the two phases can, in theory at least, be adjusted to give any oxidation or reduction potential within a rather wide range, limited only by the potentials of the reagents available. As an example, if the metallic phase is zinc and the flux phase is magnesium chloride, reduction of solute element, $M$, from the flux phase into the metal phase can be accomplished by the addition of magnesium to zinc if the reaction

$\frac{1}{\mathrm{x}} \mathrm{MCl}_{\mathrm{x}_{\left(\mathrm{MgCl}_{2}\right)}}+\frac{1}{2} \mathrm{Mg}_{(\mathrm{Zn})} \rightarrow \frac{1}{2} \mathrm{MgCl}_{(1, \mathrm{q})}+\frac{1}{\mathrm{x}} \mathrm{M}_{(\mathrm{Zn})}$

occurs. Since magnesium is a relatively strong reducing agent, many elements can be reduced in this manner. Conversely, an element can be extracted from the zinc into the flux phase by the addition of zinc chloride to the flux in accordance with the reaction

$\frac{1}{\mathrm{x}} \mathrm{M}_{(\mathrm{Zn})}+\frac{1}{2} \mathrm{ZnCl}_{2\left(\mathrm{MgCl}_{2}\right)} \rightarrow \frac{1}{2} \mathrm{Zn}_{(1, \mathrm{q})}+\frac{1}{\mathrm{x}} \mathrm{MCl}_{\left(\mathrm{MgCl}_{2}\right)}$

If its chloride is more stable than zinc chloride. These are actually equilibrium reactions; thus the ultimate concentrations can be repre- 
sented by equilibrium constants

$K_{1}=\frac{a_{M}^{1 / x} a_{M g C l}^{1 / 2}}{a_{M C l_{x}}^{1 / x} a_{M g}^{1 / 2}}$

and

$\mathrm{K}_{2}=\frac{\mathrm{a}_{\mathrm{MCl} \mathrm{x}_{\mathrm{Z}}}^{1 / \mathrm{x}} \mathrm{a}_{\mathrm{Zn}}^{1 / \mathrm{s}}}{\mathrm{a}_{\mathrm{M}}^{1 / \mathrm{x}} \mathrm{a}_{\mathrm{ZnCl}}^{1 / 2}}$

where a is the thermodynamic activity of the appropriate component and is the product of the molar concentration and an activity coefficient. For dilute systems the activity is approximately proportional to concentration. The oxidation or reduction potential of these systems is established largely by the amount of magnesium or zinc chloride added. Further control could be exercised in the first reaction if the magnesium chloride were diluted with, for example, a sodium chloride-magnesium chloride mixture as the flux or, similarly, in the second reaction if the zinc were diluted with another metal.

An important effect in solutions is the interaction of solvents with solutes to lower the activities and thus disturb the chemical equilibrium. The activity coefficient, which relates activity to concentration, is often highly sensitive to solvent composition. This provides another variable that is employed in controlling equilibrium distributions.

Because of the reactive nature of many of the reactor fuels and reagents employed in pyroprocessing, a controlled predominantly inert atmosphere is desirable in the application of these processes. The atmosphere can be especially critical when precise oxidation-reduction potentials are required since small amounts of air, for example, can alter the potential. Most of the presently concelved processes are designed either to tolerate slight changes in potential or to have the potential buffered by certain constituents that are present in large amounts

ELECTROCHEMICAL REACTIONS Electrochemical processing separations, exactly analogous to the chemical extractions, can be performed. In these systems potentials are imposed electrically to establish desired chemical equilibria. A wide variety of electrode arrangement is possible in the presence of suitable molten fluxes, which serve as electrolytes. A simple approach is to make the material to be processed, e.g., irradiated uranium, a consumable anode and to establish a potential such that materials more noble than the uranium are not transferred into the electrolyte. Purified uranium is deposited at the cathode. As long as sufficient uranium is in the flux solution, little of the fission products more reactive than uranium will deposit at the 
cathode. Theoretically, uranium can be separated from both materials of greater and less chemical reactivity in one cell. More-sophisticated concepts, utılizing liquid electrodes, contınuous operation, multiple stages, and recycle, may permit good recovery of high-purity products.

\section{RECENT BASIC INVESTIGATIONS}

The pyrochemical processes under development at several laboratories are supported by fundamental investigations to determine needed data on phase relations, coprecipitation phenomena, vapor pressures, densities, viscosities, diffusivities, activity coefficients, and thermodynamic functions. Because the data are oriented toward the processing with liquid-metal and fused-salt solutions, much of the information relates to the potential solvents. The basic data on the chemistry of the high-temperature systems are the foundation for processing schemes and for the evolution of theoretical treatments of liquid-metal and fused-salt systems.

\section{Phase Relations}

In 1957 Hansen $^{11}$ made an extremely valuable compilation of all available phase diagrams for binary metallic systems. Since this publication, several notable phase studies have been reported. Recently reported diagrams for thorıum, plutonium, and uranium with zinc are particularly pertinent since zinc is one of the solvents receiving considerable processing attention.

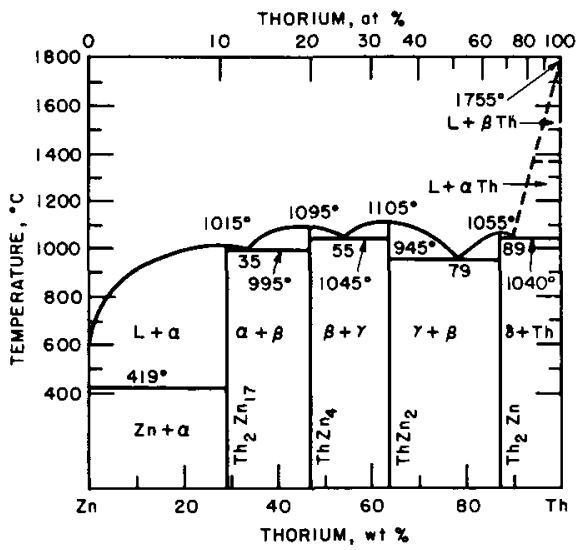

Fig 1 - Thorlum-zınc system.

The thorıum-zinc phase diagram, determined by Chiottı and Gill ${ }^{12}$ at the Ames Laboratory, is shown in F1g. 1. Albrecht ${ }^{13}$ has reported the plutonuum-rich region of the plutonium-zinc binary system, presented in Fig. 2. The uranium-rich region of the uranium-zinc 
system, which was reported earlier by Chiottı, Klepfer, and Gill of Ames Laboratory ${ }^{14}$ and is included by Hansen, ${ }^{11}$ has been under further study at Argonne National Laboratory. ${ }^{15,16}$ The phase originally believed to be $\mathrm{UZn}_{\mathrm{g}}$ was shown to be $\mathrm{U}_{2} \mathrm{Zn}_{17}$ by Makarov and Vinogradov. ${ }^{17}$ Veleckıs ${ }^{15}$ and Martın $^{16}$ have identıfied an additional phase, which has the approximate composition $\mathrm{U}_{2} \mathrm{Zn}_{23}$.

Other binary systems that have been recently reported are yttriumzınc, ${ }^{18}$ cadmium-uranium, ${ }^{19}$ calcium-zinc, ${ }^{20}$ and yttrium-aluminum. ${ }^{21}$

In a review of liquid-metal solvents by Feder and Teitel, ${ }^{8}$ the solubilities of elements in bismuth, zinc, mercury, lead, and aluminum are summarized, along with related data avallable on equilibrium solid phases and thermodynamic properties. Since their review the solubilties of elements in cadmium have been studied extensively at Argonne, ${ }^{22-27}$ and additional data have become avallable for solutes in zinc, ${ }^{28,29}$ mercury, ${ }^{30}$ bismuth, ${ }^{31}$ and aluminum. ${ }^{32}$ The solubilities of uranıum, plutonıum, and thorıum in several solvents of interest are presented in Fig. 3.

Knowledge of the solubility of individual solutes in pure solvent is not enough to permit design of processes because various solutes may affect behavior of one another. In metal solutions the coprecipitation of solute elements on carrier precipitates has been found to be correlated by the Doerner and Hoskins distribution law, ${ }^{8,38}$ which is based on an assumption of dynamic equilibrium of each layer of precipitate with the remaining solution. The Doerner-Hoskins coefficient, $\lambda$, is defined by

$\log \frac{\text { element in solution }}{\text { total element }}=\lambda \log \frac{\text { carrier in solution }}{\text { carrier }}$

Table 2 summarizes several coprecipitation coefficients determined at Argonne.

The solubilities of elements in a solvent may be affected greatly by the presence of other solutes. Data for several complex systems have been reported. The cosolubilities of uranum and magnesium in zinc, which have been reported by Argonne, ${ }^{45,46}$ are presented in Fig. 4. Isothermal and peak solubility lines are shown. The influence of zinc, magnesium, palladium, and zirconium on the solubility of uranium in cadmium has also been determined at Argonne. ${ }^{47,48}$ Similar data for bismuth-base alloys have been reported by Brookhaven National Laboratory $^{49}$ and Armour Research Foundation, ${ }^{50}$ and for mercury solutions, by Oak Ridge National Laboratory (ORNL). ${ }^{30}$

\section{Thermodynamic Properties}

If the thermodynamic properties of the systems of interest in pyrochemical processes were well known, many phenomena could be ac- 


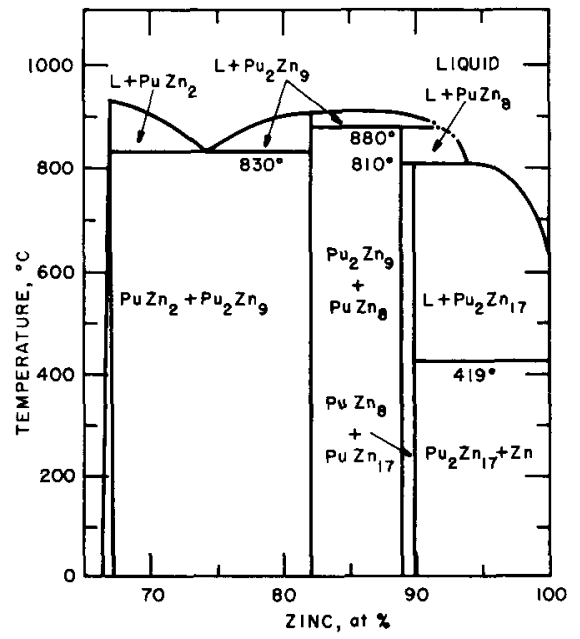

Fig. 2-Plutonium-zinc system.

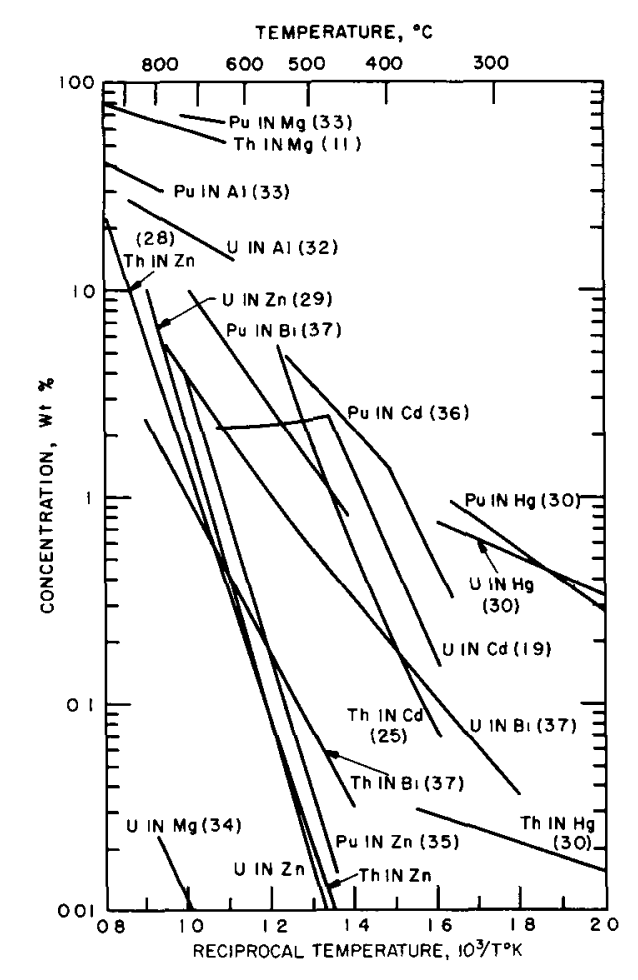

Fig. 3-Solubilities of uranium, plutonium, and thorium in selected metal solvents. (References from which data are taken are given in parentheses.) 


\begin{tabular}{|c|c|c|c|c|c|}
\hline Carrier & Solvent & Element & $\begin{array}{c}\text { Temper- } \\
\text { ature, } \\
{ }^{\circ} \mathrm{C}\end{array}$ & $\begin{array}{c}\text { Doerner-Hoskins } \\
\text { coefficient }(\lambda)\end{array}$ & $\begin{array}{l}\text { Ref } \\
\text { No }\end{array}$ \\
\hline \multirow[t]{9}{*}{$\mathrm{U}_{2} \mathrm{Zn}_{17}$} & \multirow[t]{9}{*}{ Zinc } & Ruthenuum & \multirow[t]{9}{*}{500 to 700} & 000 & \multirow[t]{9}{*}{39} \\
\hline & & Hafnıum & & 000 & \\
\hline & & Niobium & & 000 & \\
\hline & & Zirconium & & 000 & \\
\hline & & Cerium & & 066 & \\
\hline & & \multirow{2}{*}{ Lanthanum } & & $043^{*}$ & \\
\hline & & & & $057 \dagger$ & \\
\hline & & Plutonıum & & 067 & \\
\hline & & Thorıum & & $\sim 1$ & \\
\hline \multirow[t]{4}{*}{ Uranıum } & \multirow{4}{*}{$\begin{array}{l}\text { Zinc- } \\
\text { magnesium }\end{array}$} & Ruthenium & 752 & 03 & 40 \\
\hline & & Ruthenıum & 810 & 08 & 40 \\
\hline & & Plutonium & 800 & 0 & 41 \\
\hline & & Cerium & 797 & 0 & 42 \\
\hline $\mathrm{UCd}_{11}$ & Cadmium & Plutonium & 450 to 326 & 067 & 43 \\
\hline Uranium & $\begin{array}{l}\text { Cadmium - } \\
\text { magnesium }\end{array}$ & Plutonium & & 0 & 43 \\
\hline \multirow[t]{6}{*}{$\mathrm{CeCd}_{11}$} & \multirow[t]{6}{*}{ Cadmium } & Yttrium & & 0 & \multirow[t]{6}{*}{44} \\
\hline & & Thorium & & 11 & \\
\hline & & Lanthanum & & 15 & \\
\hline & & Praseodymium & & 063 & \\
\hline & & Uranium & & 013 & \\
\hline & & Zirconium & & 004 & \\
\hline
\end{tabular}

* Slow cooling † Fast coolıng

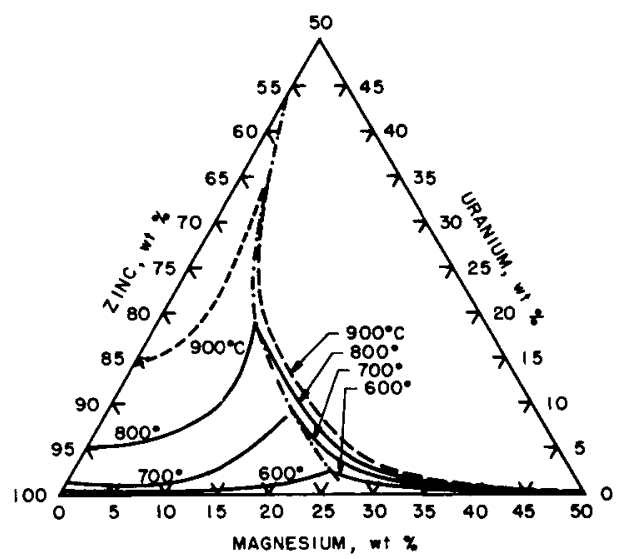

Fig. 4-Solubility of uranium in zinc-magnesium melts. 
curately predicted. Considerable standard-state data have been compiled for compounds of process interest. Glassner's compilation of data for oxides, fluorides, and chlorides ${ }^{51}$ is a convenient reference. Since estimations of data were required in the preparation of the compilation, certain values may not be reliable, but the compilation is valuable for indicating the probable direction and extent of a reaction. An errata sheet was issued to correct errors in the equations presented in Glassner's report, and some portions of Table 3 of the report are out of order. The plots of free-energy data as originally printed are satisfactory. Free energies of formation, in kilocalories per gram atom of oxygen, of selected oxides at $1500^{\circ} \mathrm{K}$ are as follows: ${ }^{51}$

\begin{tabular}{|c|c|c|c|c|c|c|c|}
\hline Compound & $-\Delta \Gamma$ & Compound & $-\Delta \Gamma$ & Compound & $-\Delta F$ & Compound & $-\Delta F$ \\
\hline $\mathrm{CaO}$ & 116 & $\mathrm{Y}_{2} \mathrm{O}_{3}$ & 109 & $\mathrm{Al}_{2} \mathrm{O}_{3}$ & 95 & $\mathrm{IcO}_{2}$ & 20 \\
\hline $\mathrm{ThO}_{2}$ & 112 & $\mathrm{BeO}$ & 108 & $\mathrm{PaO}_{2}$ & 90 & $\mathrm{Bl}_{2} \mathrm{O}_{3}$ & 13 \\
\hline $\mathrm{Pr}_{2} \mathrm{O}_{3}$ & 112 & SrO & 106 & $\mathrm{NbO}$ & 68 & $\mathrm{Rb}_{2} \mathrm{O}$ & 12 \\
\hline $\mathrm{Ce}_{2} \mathrm{O}_{3}$ & 112 & $\mathrm{MgO}$ & 102 & $\mathrm{CO}$ & 58 & $\mathrm{Cs}_{2} \mathrm{O}$ & 8 \\
\hline $\mathrm{La}_{2} \mathrm{O}_{3}$ & 112 & $\mathrm{Pu}_{2} \mathrm{O}_{3}$ & 100 & $/ \mathrm{nO}$ & 39 & $\mathrm{TeO}_{2}$ & $\vec{s}$ \\
\hline $\mathrm{Ba}_{2} \mathrm{O}$ & 112 & $\mathrm{UO}_{2}$ & 99 & $\mathrm{Nd}_{2} \mathrm{O}$ & 38 & $\mathrm{Rh}_{2} \mathrm{O}$ & -4 \\
\hline $\mathrm{Nd}_{2} \mathrm{O}_{3}$ & 111 & $7 \mathrm{rO}_{2}$ & 97 & $\mathrm{MoO}_{2}$ & 36 & $\mathrm{RuO}_{2}$ & $(-5)$ \\
\hline
\end{tabular}

For some chlorides at $1000^{\circ} \mathrm{K}$, the free energies, in kilocalories per gram atom of chlorine, are as follows: ${ }^{51}$

\begin{tabular}{|c|c|c|c|c|c|c|c|}
\hline Compound & $-\Delta F$ & Compound & $-\Delta \Gamma$ & Compound & $-\Delta \mathrm{I}^{\top}$ & Compound & $-\Delta \mathrm{F}$ \\
\hline $\mathrm{BaCl}_{2}$ & 83 & $\mathrm{LaCl}_{3}$ & 68 & $\mathrm{PuCl}_{3}$ & 59 & $/ \mathrm{nCl}_{2}$ & 34 \\
\hline $\mathrm{CsCl}$ & 82 & $\mathrm{PrCl}_{3}$ & 65 & $\Gamma \mathrm{hCl}_{3}$ & 59 & $\mathrm{CdCl}_{2}$ & 29 \\
\hline $\mathrm{SrCl}_{2}$ & 82 & $\mathrm{CeCl}_{3}$ & 65 & $\mathrm{MgCl}_{2}$ & 58 & $\mathrm{FeCl}_{2}$ & 27 \\
\hline $\mathrm{RbCl}$ & 81 & $\mathrm{PaCl}_{3}$ & 64 & $7 \mathrm{rCl}_{2}$ & 55 & $\mathrm{BiCl}_{3}$ & 18 \\
\hline $\mathrm{LiCl}$ & 79 & $\mathrm{NdCl}_{3}$ & 63 & $\mathrm{UCl}_{3}$ & 54 & $\mathrm{\Gamma eCl}_{2}$ & 17 \\
\hline $\mathrm{CaCl}_{2}$ & 78 & $\mathrm{YCl}_{3}$ & 62 & $\mathrm{AlCl}_{3}$ & 46 & $\mathrm{MoCl}_{2}$ & 8 \\
\hline $\mathrm{NaCl}$ & 77 & & & & & & \\
\hline
\end{tabular}

These data will be referred to in later discussions of process developments. Table 3 lists standard free-energy data recently reported by Brookhaven for four chlorides of special interest in fuel processing $\left(\mathrm{UCl}_{3}, \mathrm{ThCl}_{4}, \mathrm{MgCl}_{2}\right.$, ana $\left.\mathrm{CeCl}_{3}\right) .{ }^{52}$ The standard free energies of formation of several carbides, which were reported by Krikorian ${ }^{53}$ and by Huber and Holley, ${ }^{54}$ are summarized in Table 4.

The interatomic forces operative in liquid-metal solutions strongly influence the properties of solutes. The nature of the solid phase in equilibrium with saturated solutions must be known if these forces are to be evaluated. It would be desirable to know the way in which the forces vary with the basic properties of the solute and solvent atoms, but, at present, chemical activities must be experimentally determined. Activities have been measured at several laboratories. Galvanic cells 
Table 3-STANDARD FREE ENERGIES OF FORMATION OF FOUR CHLORIDES ${ }^{52}$

\begin{tabular}{ccccc}
\hline & \multicolumn{4}{c}{$\Delta \mathrm{F}$, kcal/gram atom of chlorine } \\
\cline { 2 - 5 } Chloride & $400^{\circ} \mathrm{C}$ & $450^{\circ} \mathrm{C}$ & $500^{\circ} \mathrm{C}$ & $600^{\circ} \mathrm{C}$ \\
\hline $\mathrm{MgCl}_{2}$ & -6390 & -6309 & -6228 & \\
$\mathrm{CeCl}_{3}$ & -7042 & & -6886 & -6734 \\
$\mathrm{ThCl}_{4}$ & -581 & & -561 & -542 \\
$\mathrm{UCl}_{3}$ & -561 & & -544 & -528 \\
\hline
\end{tabular}

Table 4 - FREE ENERGIES OF FORMATION OF CARBIDES AT $298^{\circ} \mathrm{K}$

\begin{tabular}{|c|c|c|c|}
\hline Carbide* & $\begin{array}{c}\Delta \mathrm{F}, \mathrm{kcal} / \mathrm{gram} \text { atom } \\
\text { of carbon } \dagger\end{array}$ & Carbide* & $\begin{array}{c}\Delta \mathrm{F} \quad \mathrm{kcal} / \mathrm{gram} \text { atom } \\
\text { of carbon } \dagger\end{array}$ \\
\hline $\mathrm{HfC}$ & $(-458 \pm 5)$ & $w_{2} C$ & $(-117 \pm 4)$ \\
\hline $\mathrm{Ta}_{2} \mathrm{C}$ & $-449 \pm 6$ & $\mathrm{Al}_{4} \mathrm{C}_{3}$ & $-114 \pm 3$ \\
\hline $\mathrm{ZrC}$ & $-436 \pm 11$ & $\mathrm{Cr}_{9} \mathrm{C}_{2}$ & $-106 \pm 02$ \\
\hline $\mathrm{T} 1 \mathrm{C}$ & $-430 \pm 04$ & $\mathrm{UC}_{1.86}$ & $-100 \pm 3$ \\
\hline $\mathrm{TaC}$ & $-381 \pm 06$ & $\mathrm{CaC}_{2}$ & $-87 \pm 07$ \\
\hline $\mathrm{Nb}_{2} \mathrm{C}$ & $(-377 \pm 8)$ & WC & $-86 \pm 04$ \\
\hline $\mathrm{NbC}$ & $-333 \pm 07$ & $\mathrm{Mg}_{3} \mathrm{C}_{2}$ & $(-84 \pm 5)$ \\
\hline $\mathrm{CeC}$ & $(-308 \pm 10)$ & $\mathrm{Li}_{2} \mathrm{C}_{2}$ & $-67 \pm 4$ \\
\hline $\mathrm{Ce}_{2} \mathrm{C}_{3}$ & $(-243 \pm 5)$ & ThC & $-64 \pm 6$ \\
\hline $\mathrm{UC}$ & $-201 \pm 10$ & $\mathrm{Mo}_{2} \mathrm{C}$ & $-51 \pm 15$ \\
\hline $\mathrm{V}_{2} \mathrm{C}$ & $-184 \pm 6$ & $\mathrm{SrC}_{2}$ & $(-46 \pm 4)$ \\
\hline $\mathrm{Cr}_{23} \mathrm{C}_{6}$ & $-167 \pm 05$ & $\mathrm{BaC}_{2}$ & $(-35 \pm 4)$ \\
\hline $\mathrm{ThC}_{2}$ & $-164 \pm 40$ & $\mathrm{Mn}_{3} \mathrm{C}$ & $-34 \pm 1$ \\
\hline $\mathrm{U}_{2} \mathrm{C}_{3}$ & $-160 \pm 2$ & $\mathrm{MgC}_{2}$ & $(-33 \pm 5)$ \\
\hline $\mathrm{CeC}_{2}$ & $(-157 \pm 5)$ & $\mathrm{PuC}_{0.77}$ & $-32 \pm 5$ \\
\hline $\mathrm{Cr}_{7} \mathrm{C}_{3}$ & $-146 \pm 03$ & MoC & $-20 \pm 07$ \\
\hline $\mathrm{VC}$ & $(-145 \pm 8)$ & $\mathrm{Na}_{2} \mathrm{C}_{2}$ & $-05 \pm 20$ \\
\hline $\mathrm{UC}_{2}$ & $-139 \pm 40$ & $\mathrm{Pu}_{2} \mathrm{C}_{3}$ & $\left(\begin{array}{ll}0 & 3\end{array}\right)$ \\
\hline $\mathrm{B}_{4} \mathrm{C}$ & $-137 \pm 27$ & $\mathrm{Co}_{3} \mathrm{C}$ & $46 \pm 15$ \\
\hline $\mathrm{SIC}$ & $-124 \pm 10$ & $\mathrm{Fe}_{3} \mathrm{C}$ & $483 \pm 10$ \\
\hline $\mathrm{Be}_{2} \mathrm{C}$ & $(-124 \pm 5)$ & $\mathrm{N}_{1}{ }_{3} \mathrm{C}$ & $(57 \pm 2)$ \\
\hline
\end{tabular}

* Data are taken from Ref 53 for all but $\mathrm{six}$ of the carbides Data for UC $\mathrm{U}_{2} \mathrm{C}_{3} \quad \mathrm{UC}_{1.86} \quad \mathrm{ThC}_{\mathrm{PuC}} \mathrm{Pu}_{77}$, and $\mathrm{Pu}_{2} \mathrm{C}_{3}$ are taken from Ref 54 $\dagger$ Parentheses indıcate estimate 
and effusion apparatus have been used at Argonne to determine thermodynamic propertıes of solutes in zinc, cadmium, gallium, indium, thallium, tin, and lead, ${ }^{5-58}$ and similar cells were used at Brookhaven to determine values for solutes in molten bismuth. ${ }^{37,59}$ Thermodynamic values for uranıum-bismuth were determined at the University of

Table 5-ACTIVITY COEFFICIENTS IN SELECTED METAL SYSTEMS

\begin{tabular}{|c|c|c|c|c|c|c|c|}
\hline Solute & $\begin{array}{c}\text { Temper- } \\
\text { ature, } \\
{ }^{\circ} \mathrm{C}\end{array}$ & $\begin{array}{c}\text { Activity } \\
\text { coefficient }\end{array}$ & $\begin{array}{l}\text { Ref } \\
\text { No }\end{array}$ & Solute & $\begin{array}{c}\text { Temper- } \\
\text { ature, } \\
{ }^{\circ} \mathrm{C}\end{array}$ & $\begin{array}{c}\text { Activity } \\
\text { coefficient }\end{array}$ & $\begin{array}{l}\text { Ref } \\
\text { No }\end{array}$ \\
\hline \multicolumn{8}{|c|}{ Bismuth Solvent } \\
\hline Cerium & 500 & $30 \times 10^{-14}$ & 59 & \multirow{3}{*}{$\begin{array}{l}\text { Sodıum } \\
\text { Uranıum }\end{array}$} & 500 & $85 \times 10^{-5}$ & 59 \\
\hline Magnesıum & 500 & $30 \times 10^{-13}$ & 59 & & 500 & $20 \times 10^{-5}$ & 60 \\
\hline Lithium & 450 & $10 \times 10^{-5}$ & 59 & & 700 & $08 \times 10^{-3}$ & 60 \\
\hline \multicolumn{8}{|c|}{ Cadmıum Solvent } \\
\hline \multirow[t]{2}{*}{ Uranium } & 300 & 10 & 63 & \multirow[t]{2}{*}{ Uranıum } & \multirow[t]{2}{*}{450} & \multirow[t]{2}{*}{74} & \multirow[t]{2}{*}{63} \\
\hline & 400 & 43 & 63 & & & & \\
\hline \multicolumn{8}{|c|}{ Zinc Solvent } \\
\hline \multirow[t]{3}{*}{ Uranıum } & 500 & $22 \times 10^{-3}$ & 56 & \multirow[t]{3}{*}{ Cerium } & 500 & $27 \times 10^{-11}$ & 64 \\
\hline & 600 & $12 \times 10^{-2}$ & 56 & & 600 & $14 \times 10^{-9}$ & 64 \\
\hline & & & & & 700 & $40 \times 10^{-8}$ & 64 \\
\hline
\end{tabular}

Table 6-FREE ENERGIES OF FORMATION OF SOME INTERMETALLIC COMPOUNDS

\begin{tabular}{|c|c|c|c|c|c|c|}
\hline \multirow[b]{2}{*}{ Compound } & \multicolumn{5}{|c|}{$\Delta \mathrm{F}, \mathrm{kcal} / \mathrm{gram}$ mole } & \multirow{2}{*}{$\begin{array}{l}\text { Ref } \\
\text { No }\end{array}$} \\
\hline & $300^{\circ} \mathrm{C}$ & $400^{\circ} \mathrm{C}$ & $500^{\circ} \mathrm{C}$ & $600^{\circ} \mathrm{C}$ & $700^{\circ} \mathrm{C}$ & \\
\hline $\mathrm{CeZn}_{11}$ & & & -530 & -486 & -439 & 64 \\
\hline $\mathrm{UZn}_{\sim 12}$ & & & -246 & -208 & -170 & 56 \\
\hline $\mathrm{UZn}_{8.5}$ & & & -270 & & -190 & 65 \\
\hline $\mathrm{UCd}_{\mathrm{t} 1}$ & -64 & -28 & & & & 56 \\
\hline UBı & -98 & -94 & -89 & -85 & -80 & 60 \\
\hline $\mathrm{Th}_{2} \mathrm{Zn}_{17}$ & & & -890 & & -750 & 12 \\
\hline $\mathrm{YZn}_{11}$ & & & -540 & & & 66 \\
\hline
\end{tabular}

Michigan by an optical absorption technique used for measuring vapor pressure. ${ }^{60}$ Measurements of both electromotive force and vapor pressure were employed at Ames Laboratory to determine thermodynamic properties of intermetallic compounds of zinc. ${ }^{14,61,62}$ Table 5 lists a few data for activity coefficients of solutes in zinc, cadmium, and bismuth, and Table 6 presents the free energies of formation of some intermetallic compounds. 


\section{Physical Properties}

Diffusion coefficients of uranium in cadmium, zinc, and bismuth have been determined by Hesson and Hootman, ${ }^{67-69}$ and those of uranium in bismuth, by Bonilla at Columbia. ${ }^{70}$ The values of these coefficients at $650^{\circ} \mathrm{C}$ are $2.3 \times 10^{-5} \mathrm{~cm}^{2} / \mathrm{sec}$ in cadmium, $1.7 \times 10^{-5}$ $\mathrm{cm}^{2} / \mathrm{sec}$ in $\mathrm{zinc}$, and $3.3 \times 10^{-5} \mathrm{~cm}^{2} / \mathrm{sec}$ in bismuth. These values are all lower than those which would be predictedfrom the Einstein-Stokes equation with use of the ionic diameter, $2.842 \mathrm{~A}$, in the calculation. Good agreement is obtained with these experimental results and with unpublished results for uranium in aluminum when a diameter of $4.0 \mathrm{~A}$ is used in the Einstein-Stokes equation.

A program is in progress at Mound Laboratory for determining physical properties of systems of interest in reactor-fuel technology. The densities of both liquid uranium and liquid plutonium have been reported. The density (in grams per cubic centimeter) of liquid uranium from its melting point, $1406^{\circ} \mathrm{K}$, to $1900^{\circ} \mathrm{K}$ may be represented by

$\mathrm{D}_{\mathrm{l1q}}=19.356-10.328 \times 10^{-4} \mathrm{~T}\left({ }^{\circ} \mathrm{K}\right)$

with a probable error of \pm 0.078 percent. ${ }^{71}$ It was concluded that the density of uranium is a straight-line function of temperature far beyond the metal's normal bolling point. From the tabulated data, liquid densities of pure $\mathrm{U}^{233}, \mathrm{U}^{235}$, and $\mathrm{U}^{238}$ can be calculated. ${ }^{71}$ The density (in grams per cubic centimeter) of liquid plutonium, determined by pycnometric technique, ${ }^{72}$ may be represented by

$\mathrm{D}_{\mathrm{lqq}}=17.63-1.52 \times 10^{-3} \mathrm{~T}\left({ }^{\circ} \mathrm{C}\right)$

with an accuracy of $\pm 0.04 \mathrm{~g} / \mathrm{cm}^{3}$.

\section{Distribution Between Immiscible Metal Phases}

Extractions of solutes from uranium and from $\mathrm{U}-5 \mathrm{wt} . \% \mathrm{Cr}$ with several lighter metal phases have been studied by Voigt at the Ames Laboratory. ${ }^{73}$ The distribution coefficients for the extraction of plutonium from uranium that originally contained up to 0.2 percent plutonium by cerıum, lanthanum, and silver are summarized in Table 7. Similar experiments were performed earlier by McKenzie, who used silver ${ }^{74}$ and some rare-earth metals as extractants. ${ }^{75}$ The silver data of the two investigations are not in agreement, but the Ames Laboratory authors believe that the difference is a result of McKenzie's neglecting the effect of an insoluble dross containing plutonium. This dross results in a difference between the percentage of metal removed and that extracted. Better agreement exists for the data with rare-earth ex- 
Table 7-DISTRIBUTION OF PLUTONIUM BETWEEN MOLTEN URANIUM AND SILVER, LANTHANUM, AND CERIU $M^{13}$

\begin{tabular}{lccc}
\hline Extractant & $\begin{array}{c}\text { Temper- } \\
\text { ature, } \\
{ }^{\circ} \mathrm{C}\end{array}$ & $\begin{array}{c}\text { Initial } \\
\text { plutonium in } \\
\text { uranium, } \%\end{array}$ & $\left.\begin{array}{c}\text { Distribution coefficient } \\
\text { g of Pu/mole of extractant } \\
\text { g of Pu/mole of uranium }\end{array}\right)$ \\
\hline Silver & 1175 to 1380 & $18 \times 10^{-3}$ & 21 \\
Lanthanum & 1230 to 1375 & $18 \times 10^{-3}$ & 140 \\
Cerium & & 02 & 038 to 040 \\
& 1225 & $18 \times 10^{-3}$ & 056 \\
& & 02 & 051 \\
\hline
\end{tabular}

tractants, in which any drossing effects were minimized because of the protective action of the more reactive solvents.

The distributions of plutonium and various fission products between $\mathrm{U}-5 \mathrm{wt} . \% \mathrm{Cr}$ and approximately equal volumes of alloys of silver and magnesium were determined by Voigt ${ }^{76,77}$ at Ames Laboratory, and the results are listed in Table 8 . The difference between extracted and removed solute reflects additional removal of a solute element by drossing or vaporizing. The interphase solubility of uranium in the extractant is about $4 \mathrm{wt} . \% \mathrm{in}$ suver and decreases to $0.03 \mathrm{wt} . \% \mathrm{in}$ magnesium. The solubility of silver in the uranium phase is $3\left(10^{-2}\right)$ wt. $\%$ at $1000^{\circ} \mathrm{C}$, but the equilibrium silver concentration is only $4\left(10^{-4}\right)$ wt. $\%$ in the uranium phase in contact with $\mathrm{Mg}-6 \mathrm{wt} . \% \mathrm{Ag}$. The interphase solubilities for chromium and magnesium were very small.

Argonne has reported metal-metal extraction results for the leadzinc $^{78-80}$ and cadmium-aluminum ${ }^{81}$ systems. Figure 5 presents the miscibility gap for the lead-zinc system, and Table 9 lists some distribution coefficients. Similar data for the cadmium-aluminum system are shown in Fig. 6 and Table 9.

\section{Distribution Between Liquid Metal and Fused Salt}

Lıquid-metal and fused-salt systems are attractive for extractions because they can, theoretically at least, be adjusted so that conditions favoring almost any desired distribution of a solute can be obtained. Salt-metal extractions are equilibrium reactions for which equilibrium is determined by an appropriate adjustment of oxidizing and reducing agents. In a system employing a chloride salt phase, which is the general choice, a solute is extracted into the salt phase if the solute reacts to form its chloride salt or into the metal phase if it is present in the reduced state. Frequently good separation of two solutes can be achieved in only one equilibrium stage.

The equilibrium conditions can be predicted when the thermodynamic properties of the system are known, but, in general, the actual 
Table 8-EXTRACTION OF METALS ${ }^{\mathbf{7 8}}$ " ${ }^{7}$ FROM AN IRRADIATED U-5 WT $\%$ Cr ALLOY WITH MAGNESIUM-SILVER ALLOYS AT $1000^{\circ} \mathrm{C}$

\begin{tabular}{|c|c|c|c|c|c|c|c|c|c|c|}
\hline \multirow[b]{3}{*}{ Element } & \multicolumn{10}{|c|}{ Magnesium in extractant } \\
\hline & \multicolumn{2}{|c|}{$100 \mathrm{wt} \%$} & \multicolumn{2}{|c|}{$515 \mathrm{wt} \%$} & \multicolumn{2}{|c|}{$335 \mathrm{wt} \%$} & \multicolumn{2}{|c|}{$106 \mathrm{wt} \%$} & \multicolumn{2}{|c|}{$0 \mathrm{wt} / \mathrm{g}$} \\
\hline & $\begin{array}{c}\text { Removed, } \\
\%\end{array}$ & $\begin{array}{c}\text { Extracted, } \\
\%\end{array}$ & $\begin{array}{c}\text { Removed, } \\
\%\end{array}$ & $\begin{array}{c}\text { Extracted } \\
\%\end{array}$ & $\begin{array}{c}\text { Removed, } \\
\%\end{array}$ & $\begin{array}{c}\text { Extracted, } \\
\%\end{array}$ & $\begin{array}{c}\text { Removed, } \\
\%\end{array}$ & $\begin{array}{c}\text { Extracted } \\
\%\end{array}$ & $\begin{array}{c}\text { Removed, } \\
\%\end{array}$ & $\begin{array}{c}\text { Extracted, } \\
\%\end{array}$ \\
\hline Plutonıum & 26 & 12 & 26 & 17 & 28 & 20 & 75 & 73 & 986 & 96 \\
\hline Cerıum & 9982 & 93 & $\sim 998$ & 88 & 997 & 82 & 992 & 85 & 98 & 47 \\
\hline Lanthanum & & & 99 & 73 & & & 99 & & & \\
\hline Yttrıum & 982 & 82 & 998 & 78 & 997 & 70 & 989 & 78 & 965 & 37 \\
\hline Strontium & 88 & 55 & 96 & $\sim 55$ & 98 & 56 & 95 & 67 & 88 & 68 \\
\hline Barıum & 88 & 58 & 97 & $\sim 48$ & & & 95 & 39 & 90 & \\
\hline Cesium & & & 96 & $\sim 10$ & & & 97 & 62 & 74 & \\
\hline Zirconium & 36 & 25 & 57 & $\sim 8$ & 26 & 15 & 38 & 15 & 31 & 18 \\
\hline Nioblum & & & $\sim 9$ & $\sim 2$ & & & & & & \\
\hline Ruthenıum & & & $\sim 25$ & $\sim 1$ & & & & 2 & 17 & \\
\hline Tellurium & & & 993 & 58 & & & & & 33 & \\
\hline
\end{tabular}




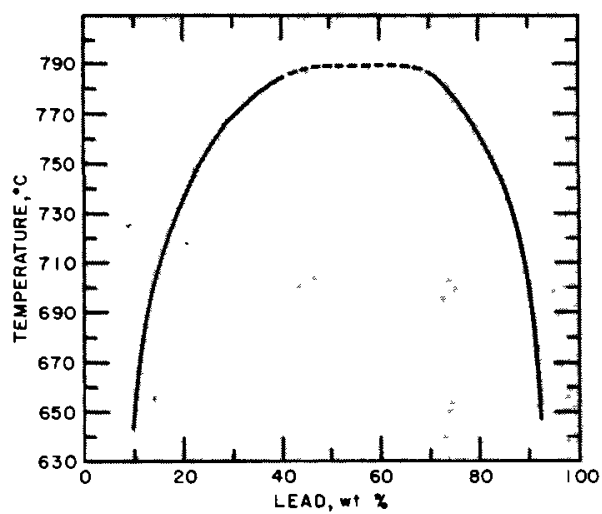

Fig. 5- Miscibility gap in lead-zinc syste ${ }^{78}$ above $650^{\circ} \mathrm{C}$.

Table 9-PARTITION COEFFICIENTS IN THE LEAD-ZINC AND ALUMINUM-CADMIUM SYSTEMS ${ }^{78-81}$

\begin{tabular}{lcc}
\hline Solute & $\begin{array}{c}\text { Temper- } \\
\text { ature, } \\
{ }^{\circ} \mathrm{C}\end{array}$ & $\begin{array}{c}\text { Partition coefficient, K } \\
\left(\frac{\text { wt.\% in upper layer }}{\text { wt. \% in lower layer }}\right)\end{array}$ \\
\hline Uranium & Lead-Zinc System \\
& 701 & 52.0 \\
Plutonium* & 755 & 120 \\
Cerium & 700 & 180 \\
& 760 & 5.0 \\
Zirconium & 701 & 9.0 \\
& 755 & 3.8 \\
Ruthenium & 701 & $5.3 \times 10^{2}$ \\
Strontium & 755 & $1.1 \times 10^{2}$ \\
Palladium & 701 & $2.1 \times 10^{3}$ \\
& 755 & $1.6 \times 10^{2}$ \\
& 736 & 0.14 \\
Palladium & 737 & 1500 \\
Lanthanum & Aluminum-Cadmium System \\
Cerium & 680 & $59 \times 10^{3}$ \\
Praseodymium & 686 & $4.6 \times 10^{2}$ \\
Uranium & 680 & $1.9 \times 10^{2}$ \\
\hline
\end{tabular}

*In codistribution with other components of irradiated uranium. 


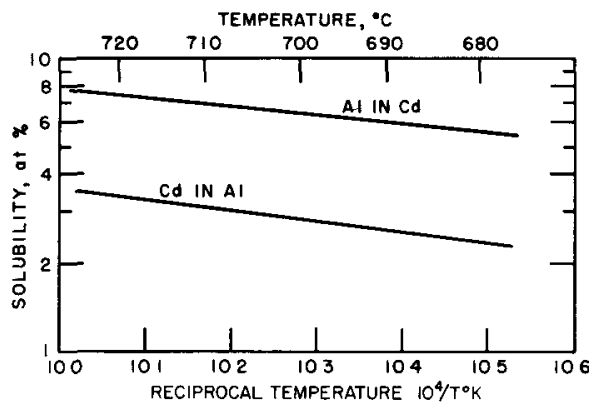

F1g 6-Mutual solubilities of aluminum and cadmium ${ }^{81}$

distributions have been determired experimentally before the necessary activity data were avallable Nevertheless, the standard free energies of formation of chlorides (see p. 422) have given considerable insight into the potentiality of given separations.

Brookhaven pioneered the use of molten-salt extraction for the purification of fuel from the Liquid Metal Fuel Reactor, a reactor that would utilize a solution of uranium in bismuth as fuel. The behavior of the actinide metals in aluminum-aluminum chlor ${ }_{\perp}$ de systems has been investigated at Hanford Laboratories. Salt-metal systems are under study at Ames and Argonne for several processing applications.

Brookhaven demonstrated two techniques, stolchiometry and buffering, for controlling distributions of uranium and fission products between bismuth and $\mathrm{MgCl}_{2}-\mathrm{KCl}-\mathrm{NaCl}$ eutectic. In the stolchiometric technique an oxidant, $\mathrm{UCl}_{3}$ or $\mathrm{BiCl}_{3}$, was added to the salt, or a reductant, magnesium, was added to the bismuth to promote a selective extraction. In the buffering technique the salt-metal oxidation potential is buffered by the relative concentrations of $\mathrm{MgCl}_{2}$ and magnesium in the two phases.

Moore and Lyon ${ }^{85}$ at Hanford Laboratories have studied the distribution of actinide elements between aluminum and aluminum chloride potassium chloride at $725^{\circ} \mathrm{C}$. The distributions expressed as the ratio of weight percent solute in metal to weight percent solute in salt for thorıum, plutonium, americium, and curıum are of the same order, ranging from about 0.2 to 0.5 . Those for neptunium are approximately an order of magnitude larger, and those for uranium and protactinium are larger by factors of 100 and 200 to 300 , respectively. In all cases the distributions strongly depended upon the aluminum chloridepotassium chloride ratio and were most favorable for distribution to the aluminum phase at a mole ratio of 1.0 . The influence of the $\mathrm{AlCl}_{3}$ to $\mathrm{KCl}$ ratio is illustrated in Fig. 7 , which presents distribution data for uranium as a function of the flux composition. Complexes that form between $\mathrm{AlCl}_{3}$ and $\mathrm{KCl}$ strongly influence the equilibrium distribution ${ }^{86,87}$ of solutes between aluminum and various solutions of $\mathrm{KCl}$ and $\mathrm{AlCl}_{3}$. Because complexing of the $\mathrm{AlCl}_{3}$ reduces the activity of this compound, 
which is a product of the reduction of the actinide chlorides by aluminum, the reductions become more favorable as the complexing becomes stronger. The effect of concentration ratios of $\mathrm{KCl}$ and $\mathrm{AlCl}_{3}$ and the effects on complexing in the salt phase which were caused by substitution of $\mathrm{NaCl}$ or $\mathrm{CsCl}$ for $\mathrm{KCl}$ and by substitution of $\mathrm{Br}^{-}$for all or part of the $\mathrm{Cl}^{-}$were studied through the influence of the anions and cations on the distribution of uranium between the aluminum and the

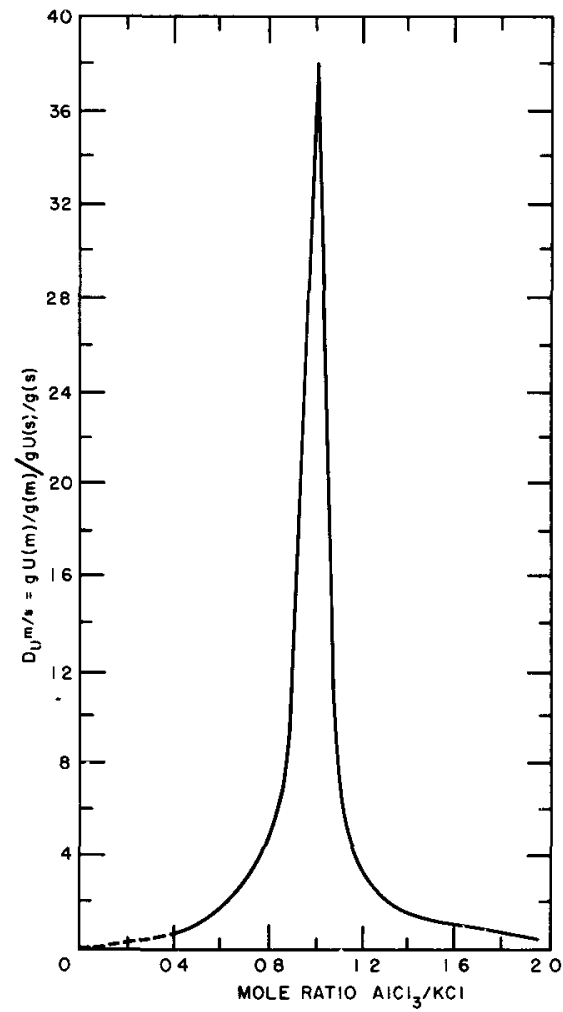

Fig. 7-Distribution of uranium between aluminum and aluminum chloride-potassium chloride solutions at $725^{\circ} \mathrm{C}$ (Ref. 85).

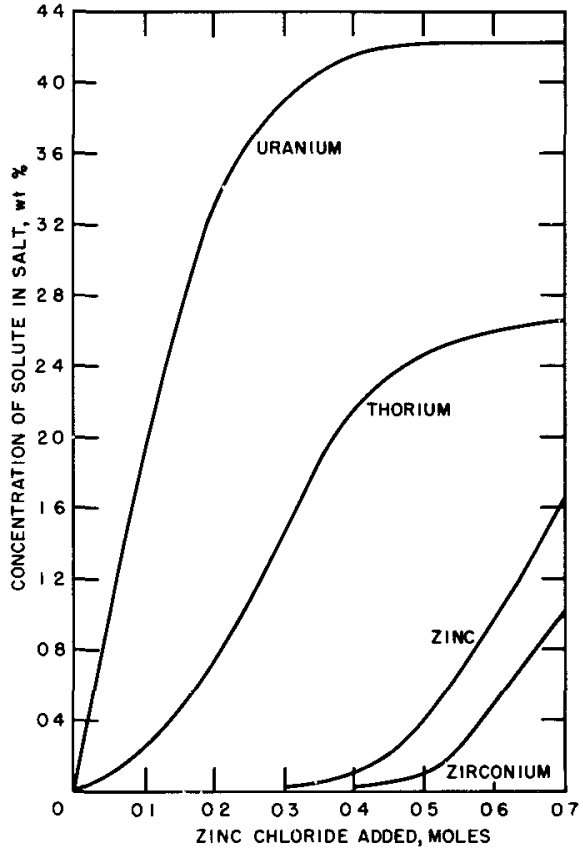

Fig. 8- Transfer of uranium, thorium, and zirconium from liquid zine to a flux by incremental add1tion of zinc chloride. ${ }^{89}$

flux. ${ }^{87,88}$ The substitution of sodium for potassium hinders the reduction of uranium chloride, and the substitution of cesium for potassium enhances the reaction. Complete substitution of bromides for the chlorides decreases the reduction of uranium chloride, but a substitution for only 5 to 10 percent of the chlorides markedly enhanced the reduction. These results are all explained in terms of the compounds and complexes formed. ${ }^{88}$ 
An extensive study of the separation of components by oxidation and reduction reactions in a system of zinc and lithium chloride-potassium chloride eutectic at 500 and $700{ }^{\circ} \mathrm{C}$ has been reported by Chiotti and Parry. ${ }^{89}$ They employed magnesium and zinc chloride as the reductant and the oxidant, respectively, and iron, molybdenum, niobium, chromium, yttrium, zirconium, tho rium, uranium, protactinium, and cerium as solutes. Their objective was to obtain basic information that would be helpful in the design of processes. Values of $\mathrm{K}_{\mathrm{N}}$, the ratio of the mole fraction of products and reactants with each mole fraction raised to the appropriate power, are presented in Table 10 for some separation reactions. At $500^{\circ} \mathrm{C}$, in a system containing all these elements, the expected sequence of transfer from the zinc to salt phase is cerium, uranium with yttrium, thorium, protactinium, zirconium, and chromium.

\begin{tabular}{|c|c|c|}
\hline Reaction & $\begin{array}{c}\mathrm{K}_{\mathrm{N}}^{*} \text { at } \\
500^{\circ} \mathrm{C}\end{array}$ & $\begin{array}{c}\mathrm{K}_{\mathrm{N}}^{*} \text { at } \\
700^{\circ} \mathrm{C}\end{array}$ \\
\hline $\mathrm{U}+\mathrm{ThCl}_{3} \rightarrow \mathrm{UCl}_{3}+\mathrm{Th}$ & 20 & 90 \\
\hline $\mathrm{Cr}+\mathrm{ZnCl}_{2} \rightarrow \mathrm{CrCl}_{2}+\mathrm{Zn}$ & 33 & 75 \\
\hline $\mathrm{Zr}+3 / 2 \mathrm{ZnCl}_{2} \rightarrow \mathrm{ZrCl}_{3}+3 / 2 \mathrm{Zn}$ & $19 \times 10^{3}$ & $15 \times 10^{3}$ \\
\hline $\mathrm{Zr}+3 / 2 \mathrm{CrCl}_{2} \rightarrow \mathrm{ZrCl}_{3}+3 / 2 \mathrm{Cr}$ & $32 \times 10^{2}$ & 730 \\
\hline $\mathrm{U}+\mathrm{ZrCl}_{3} \rightarrow \mathrm{UCl}_{3}+\mathrm{Zr}$ & $69 \times 10^{3}$ & $67 \times 10^{2}$ \\
\hline $\mathrm{Th}+\mathrm{ZrCl}_{3} \rightarrow \mathrm{ThCl}_{3}+\mathrm{Zr}$ & $34 \times 10^{3}$ & $07 \times 10^{2}$ \\
\hline $\mathrm{U}+3 / 2 \mathrm{CrCl}_{2}-\mathrm{UCl}_{3}+3 / 2 \mathrm{Cr}$ & $22 \times 10^{6}$ & $49 \times 10^{4}$ \\
\hline $\mathrm{Th}+3 / 2 \mathrm{ZnCl}_{2} \rightarrow \mathrm{ThCl}_{3}+3 / 2 \mathrm{Zn}$ & $66 \times 10^{6}$ & $11 \times 10^{5}$ \\
\hline $\mathrm{Y}+\mathrm{UCl}_{\mathbf{3}} \rightarrow \mathrm{YCl}_{\mathbf{3}}+\mathrm{U}$ & 10 & \\
\hline $\mathrm{U}+\mathrm{PaCl}_{3} \rightarrow \mathrm{UCl}_{3}+\mathrm{Pa}$ & 200 & \\
\hline $\mathrm{Ce}+\mathrm{UCl}_{3} \rightarrow \mathrm{CeCl}_{3}+\mathrm{U}$ & 180 & 10 to 100 \\
\hline
\end{tabular}

* Mole-fraction ratio of products and reactants, each mole fraction being raised to the appropriate power.

Nioblum, molybdenum, and iron are not oxidized by zinc chloride. The reverse of this sequence occurs on reduction of these elements from a flux phase. The results were found to be fairly consistent with avallable thermodynamic data. Representative results are presented in Fig. 8 for the sequential transfer of uranium, thorium, and zirconium from solution in zinc into the flux by the incremental addition of zinc chloride to the flux.

The distributions of several solutes between metal and salt phases have been measured by Knighton. ${ }^{90-92}$ The variables examined are magnesium concentration in a zinc metal phase, substitution of cadmium for zinc as metal phase, flux composition, solute concentration, and temperature of extraction. The distribution of some solutes between magnesium chloride and zinc-magnesium at $800^{\circ} \mathrm{C}$ is presented in 


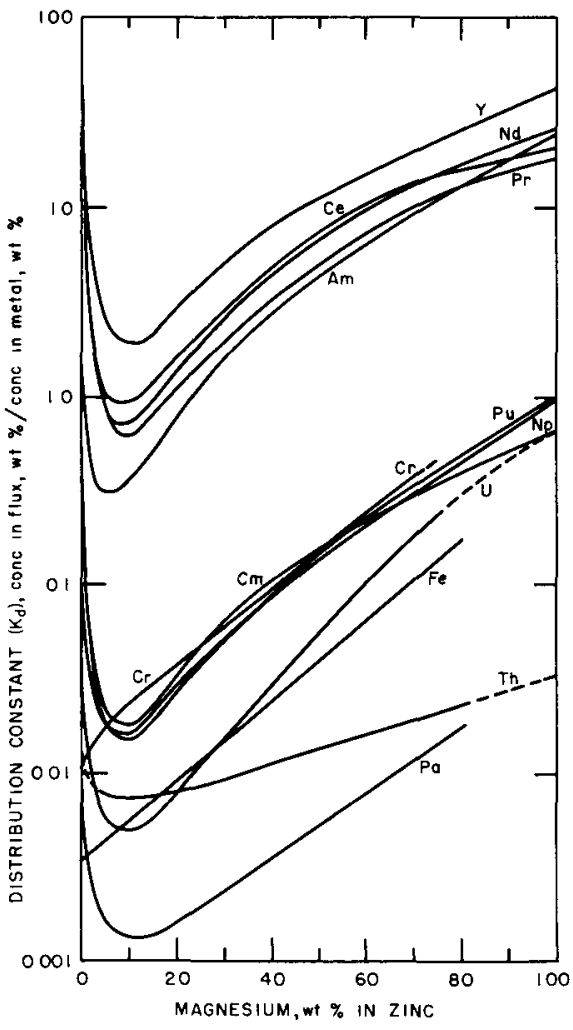

Fig. 9-Distribution of selected elements between $\mathrm{z} ı \mathrm{nc}$ - magnesium alloy and magnesium chloride ${ }^{90-92}$

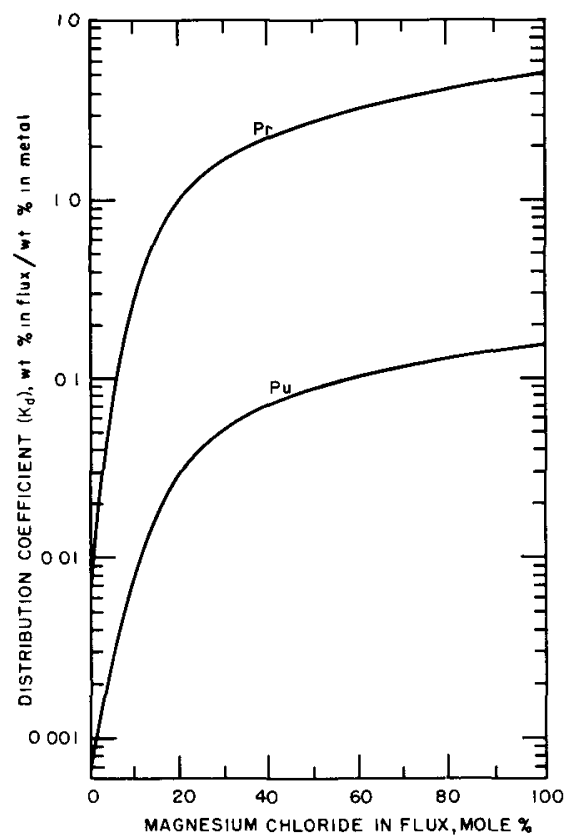

Fig. 10-Distribution of praseodymium and plutonium between $\mathrm{Zn}-50$ wt.\% $\mathrm{Mg}$ and $11 \mathrm{thlum}$ chloride-magnesium chloride flux. ${ }^{92}$

Fig. 9 as a function of the metal-phase composition. The feasibility of separating uranium and plutonium from rare earths is revealed by these data. The effect of varying the magnesium chloride composition of the flux is presented in Fig. 10 for distribution of plutonium and praseodymium between $\mathrm{Zn}-50 \mathrm{wt} . \% \mathrm{Mg}$ and a lithium chloridemagnesium chloride flux. For Figs. 9 and 10, the conditions of the measurements were an $800^{\circ} \mathrm{C}$ temperature, a $300-\mathrm{rpm}$ mixing rate, a tantalum crucible, and an argon atmosphere. Since the results in Fig. 10 show that the separation factor (the ratios of distribution coefficients) is nearly constant above 30 mole $\%$ magnesium chloride, sufficient other chlorides can be added to lower the melting point of the flux phase.

In addition to single-element distribution studies, the codistribution behavior of uranium, plutonium, and praseodymium has been examined. The codistribution data agreed with the single-element results within 
the accuracy of the determinations. ${ }^{92}$ The distribution factors for plutonium and praseodymum did not change appreciably ${ }^{92}$ when cadmium-magnesium was substituted for zinc-magnesium at $650^{\circ} \mathrm{C}$.

Table 11 -EFFECT OF TEMPERATURE ON THE DISTRIBUTION

COEF FICIENTS OF PLUTONIUM AND PRASEODYMIUM

IN A $\mathrm{Zn}-\mathrm{Mg}$ AND $\mathrm{L} l \mathrm{Cl}-\mathrm{MgCl}_{2}$ SYSTEM $^{92}$

\begin{tabular}{|c|c|c|c|}
\hline \multirow{2}{*}{$\begin{array}{l}\text { Temper- } \\
\text { ature, } \\
{ }^{\circ} \mathrm{C}\end{array}$} & \multicolumn{2}{|c|}{$\mathrm{K}_{\mathrm{d}}=\frac{\mathrm{wt} \% \text { in flux }}{\mathrm{wt} \% \text { in metal }}$} & \multirow[b]{2}{*}{$\mathrm{SF}=\frac{\mathrm{K}_{\mathrm{d}}(\mathrm{Pr})}{\mathrm{K}_{\mathrm{d}}(\mathrm{Pu})}$} \\
\hline & Plutonıum & $\begin{array}{l}\text { Praseo- } \\
\text { dymium }\end{array}$ & \\
\hline 850 & 0179 & 450 & 251 \\
\hline 800 & 0143 & 400 & 281 \\
\hline 700 & 0116 & 412 & 365 \\
\hline 620 & 00885 & 413 & 467 \\
\hline
\end{tabular}

A lower-melting lithium chloride-magnesium chloride flux was substituted for magnesium chloride in a study of temperature effects. The effect of temperature on plutonium and prasecdymium distributions is shown in Table 11. The conditions and the composition of the charge were as follows:

Conditions

$\begin{array}{ll}\text { Mixing rate } & \sim 300 \mathrm{rpm} \\ \text { Atmosphere } & \text { Argon }\end{array}$

Crucible

Tantalum

$\begin{array}{ll} & \text { Charge } \\ \text { Znnc } & 150 \mathrm{~g} \\ \text { Mdgnesium } & 150 \mathrm{~g} \text { (chemical analysis } \\ & \text { indicated } 48.5 \mathrm{wt} . \% \\ & \text { magnesium in the metal } \\ & \text { phase) } \\ & 300 \mathrm{~g}(50 \mathrm{~mole} \% \mathrm{LiCl}- \\ \mathrm{LlCl}-\mathrm{MgCl}_{2} & 50 \text { mole } \% \mathrm{MgCl}_{2} \text { ) } \\ & 088 \mathrm{~g} \\ \text { Praseodymium } & 2.29 \mathrm{~g} \\ \text { Plutonium } & \end{array}$

Since the separation factor increases with decreasing temperature, higher values could be expected with an even lower melting flux.

\section{Metal Preparation}

The rapid chemical reactions that have been employed to achieve chemical separations in liquid metal-fused salt systems are also attractive for production of metals. A detalled study of the reduction of uranium and thorium oxides from suspension in a chloride flux into liquid zinc-magnesium has been conducted at Argonne ${ }^{93,94}$ The fluxes aid in the control of the reaction rate, scavenge the magnesium oxide reaction product, and permit operation in an a1r atmosphere. Table 12 shows the effect of salt-flux composition on the reduction of $\mathrm{U}_{3} \mathrm{O}_{8}$. 
Table $12-$ EFFECT OF FLUX COMPOSITION ${ }^{93}$ ON THE

REDUCTION OF $\mathrm{U}_{3} \mathrm{O}_{8}$ BY $\mathrm{Zn}-5 \mathrm{WT} \% \mathrm{Mg}$

\begin{tabular}{|c|c|c|c|c|c|c|c|}
\hline \multicolumn{3}{|c|}{ Flux composition } & \multicolumn{5}{|c|}{ Percent reduction at time } \\
\hline $\begin{array}{c}475 \\
\text { mole } \%\end{array}$ & $\begin{array}{c}475 \\
\text { mole } \%\end{array}$ & $\begin{array}{c}50 \\
\text { mole } \%\end{array}$ & $\begin{array}{c}10 \\
\mathrm{~min}\end{array}$ & $\begin{array}{c}20 \\
\min \end{array}$ & $\begin{array}{c}30 \\
\min \end{array}$ & $\begin{array}{c}60 \\
\min \end{array}$ & $\begin{array}{l}120 \\
\mathrm{~min}\end{array}$ \\
\hline $\mathrm{LiCl}$ & $\mathrm{MgCl}_{2}$ & $\mathrm{MgF}_{2}$ & $999+$ & $999+$ & $999+$ & $999+$ & $999+$ \\
\hline $\mathrm{NaCl}$ & $\mathrm{MgCl}_{2}$ & $\mathrm{MgF}_{2}$ & 860 & 994 & 994 & 994 & 994 \\
\hline $\mathrm{KCl}$ & $\mathrm{MgCl}_{2}$ & $\mathrm{MgF}_{2}$ & 705 & 909 & 978 & 970 & 980 \\
\hline $\mathrm{LlCl}$ & $\mathrm{CaCl}_{2}$ & $\mathrm{MgF}_{2}$ & 267 & 440 & 560 & 860 & 998 \\
\hline $\mathrm{LiCl}$ & $\mathrm{SrCl}_{2}$ & $\mathrm{MgF}_{2}$ & 251 & 420 & 594 & 950 & 960 \\
\hline $\mathrm{LiCl}$ & $\mathrm{BaCl}_{2}$ & $\mathrm{MgF}_{2}$ & 125 & 216 & 260 & 520 & 850 \\
\hline $\mathrm{LiCl}$ & $\mathrm{NaCl}$ & $\mathrm{MgF}_{2}$ & 57 & 90 & 88 & 133 & 234 \\
\hline $\mathrm{CaCl}_{2}$ & $\mathrm{MgCl}_{2}$ & $\mathrm{MgF}_{2}$ & 970 & $990+$ & $990+$ & $990+$ & $990+$ \\
\hline $\mathrm{MgCl}_{2}$ & $\mathrm{MgCl}_{2}$ & $\mathrm{MgF}_{2}$ & 975 & $999+$ & $999+$ & $999+$ & $999+$ \\
\hline
\end{tabular}

The conditions were as follows:

$\begin{array}{llll}\text { Metal phase } & 400 \mathrm{~g} \mathrm{Zn}-5 \mathrm{wt} . \% \mathrm{Mg} & \text { Temperature } & 750^{\circ} \mathrm{C} \\ \text { Flux phase } & 200 \mathrm{~g} \mathrm{(as} \mathrm{indicated)} & \text { Muxing rate } & 800 \mathrm{rpm} \\ \text { Oxide } & 4.7 \mathrm{~g} \mathrm{U} \mathrm{O}_{8},-325 \mathrm{mesh} & \text { Crucible } & \text { Alumina } \\ \text { Atmosphere } & \text { Alr } & \text { Agitator } & \text { Quartz }\end{array}$

Theoretical uranium concentration in metal phase at 100 percent reduction $10 \mathrm{wt} \%$

The flux composition markedly influenced the reaction rate. An alkaline-earth salt appears necessary for the reduction, and magnesium chloride is the most effective. Rapid and complete reductions of $\mathrm{U}_{3} \mathrm{O}_{8}$ were achieved in simple equipment. The variables influencing thorium oxide reductions have also been studied, and a range of flux compositions that promote complete reduction was defined. ${ }^{94}$ Plutonium oxide was also reduced readily, but the variables were not examined in detail. ${ }^{93}$

In a similar manner, Raleigh has reduced thorium oxide from molten cryolite by aluminum in graphite crucibles with nearly quantitative yields to make $\mathrm{Al}-20 \mathrm{wt} \% \mathrm{Th}$ alloys. ${ }^{95}$ The reaction, which was complete in $30 \mathrm{~min}$ at $1050^{\circ} \mathrm{C}$, is presumably driven by the large negatıve free energy of formation of $\mathrm{ThAl}_{3}$, estımated at $36.5 \mathrm{kcal} / \mathrm{mole}$. Several fluoride-salt mixtures were investigated for this reduction, but cryolite was selected as the most promising.

The reduction at $500^{\circ} \mathrm{C}$ of uranium trichloride from a $30 \mathrm{wt} . \% \mathrm{con}-$ centration in potassium chloride-lithium chloride eutectic by $\mathrm{Cd}-$ $0.5 \mathrm{wt} \% \mathrm{Mg}$ solutions has been performed at Harwell. ${ }^{96}$ Reductions were essentially complete in $5 \mathrm{~min}$; final uranium concentrations in the 
salt phase were only $0.015 \mathrm{wt} . \%$ The reduced uranium dissolved in the cadmium to a final concentration of $2.25 \mathrm{wt} . \%$, which is about the saturation concentration. Uranıum trichloride was reduced in Germany by a sodium amalgam. With good mixing the reaction was over 90 percent complete after $4 \mathrm{hr}$ at $300^{\circ} \mathrm{C}$. Uranium products containing less than $7 \mathrm{ppm}$ mercury have been obtained after filtering off excess mercury and retorting. ${ }^{97,98}$

These reductions have been successful on very stable compounds; thus the technique would be applicable to many other compounds that have not yet been studied.

\section{Engineering Studies}

Several engineering investigations of liquid-metal systems have been reported. Included in these investigations are fundamental eng1neering studies and the development of experimental engineering equipment.

Brookhaven has reported prelimmary mass-transfer resuits on a study of mixing and mass-transfer phenomena in a fused salt-liquid metal extraction column. ${ }^{99}$ The column is a 4-in.-diameter cylinder containing a series of disk and doughnut trays such that the fluid passing through must flow alternately around the disk and inside the doughnuts. Cerium was employed as the distributing solute between a $\mathrm{NaCl}-$ $\mathrm{KCl}-\mathrm{MgCl}_{2}$ eutectic and bismuth containing small concentrations of magnesium and zirconium. Another multistage countercurrent extractor for use with fused salt and molten metal was developed at Iowa State University. ${ }^{100}$ This unit, a modıfied disk-and-doughnut column, was used to extract cadmium from bismuth into a potassium chloridezinc chloride eutectic.

Argonne has presented preliminary data on mixing of liquid metals. ${ }^{101}$ A high-temperature mixing dynamometer, which permits operation with melts under an inert atmosphere, was constructed and operated with mercury, cadmium, and water. The results show that, in mixing geometries for which good correlations exist for aqueous and organic systems, these correlations can be accurately applied to liquid metals. The apparatus will be used in the evaluation of special systems encountered in the solvent processes under study.

Mass transfer in liquid metals and fused salts was discussed in 1955 by Bonilla. ${ }^{70}$ Currently the mass-transfer coefficient for the dissolution of uranium into cadmium is being measured at Argonne in two systems. The first is for many particles in a conventional stirred, baffled vessel, ${ }^{102}$ and the other is for a single sphere suspended in a flowing stream.

Experience in techniques for handling liquid metals is being gained at Argonne through long-term operation of a large cadmium distillation unit. $^{103}$ Information, in addition to that on metal distillation, has been 
obtained on liquid-metal transfer, liquid-level detection, pressure and temperature measurement and control, and control of metal vapors in processing equipment. Distillation temperatures and rates have ranged from 455 to $620^{\circ} \mathrm{C}$ and 12 to $102 \mathrm{~kg} / \mathrm{hr}$, respectively, with corresponding heating efficiencies of 31 to 77 percent. ${ }^{104,105}$

A study of the mechanisms of liquid-metal boiling and entrainment is under way at Argonne. ${ }^{106,10 ?}$ The nature and magnitude of entrainment in liquid metals may differ greatly from those of conventional liquids as a result of the larger densities, thermal conductivities, and surface tensions of the liquid metals. As a first step in this program, the vaporization of mercury from a mercury surface without bubble formation is under investigation.

\section{PROCESS APPLICATIONS}

The processing programs at the various research centers generally originate from a specific processing requirement or are oriented to a special application.

\section{EBR-II Fuel Processing}

The first large-scale pyroprocessing of a reactor fue $1^{108}$ will be of fuel from Argonne's EBR-II. Construction of this reactor and an adjacent fuel-cycle facility is nearing completion at the National Reactor Testing Station in Idaho. Figure 11 is an artist's cutaway view of the processing cells. The annular cell will contain an argon atmosphere,

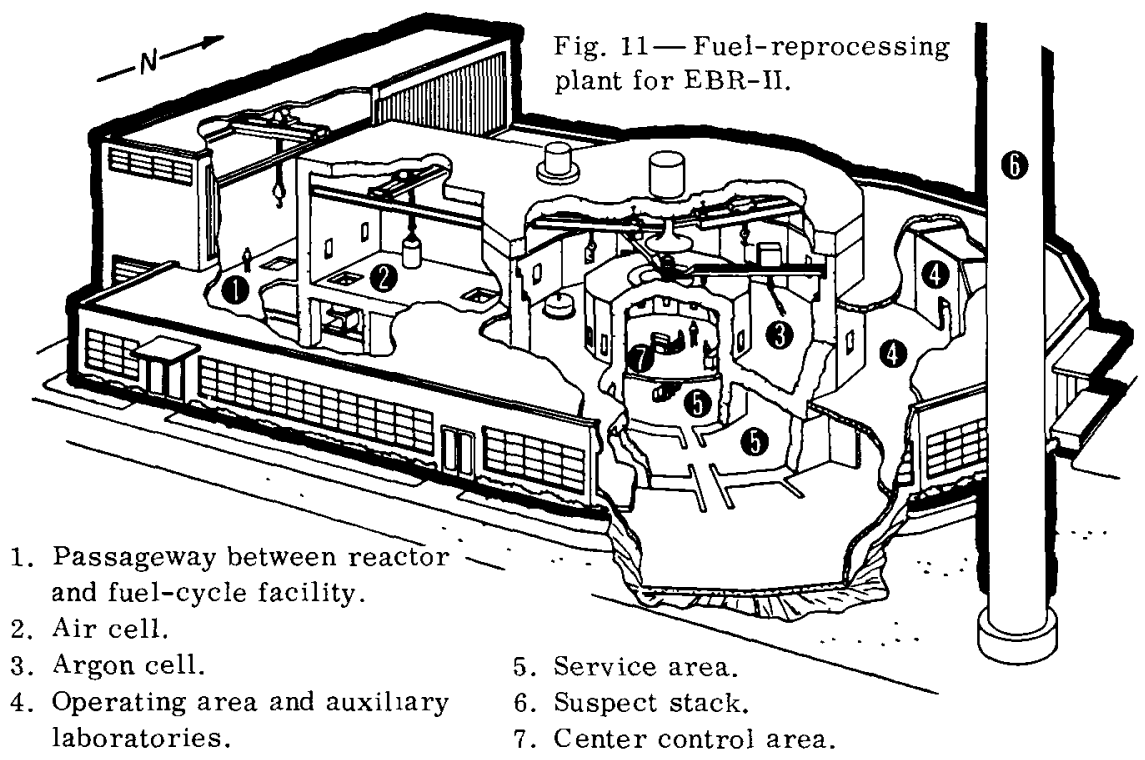


and the rectangular cell will contain air. Because decay heating would result in excessive oxidation of the highly irradiated fuel if the fueI were handled in air, all operations in which the alloy must be exposed directly to the atmosphere will be performed in the argon cell.

The fuel elements for this reactor are subassemblies of 0.144-in.diameter uranium-alloy rods, which are sealed in stainless-steel tubes with the narrow annuli filled with sodium to ensure good heat transfer. ${ }^{109}$ The fuel alloy for the first core loading is 48 percent enriched uranium containing 5 percent fissium, a mixture of several fissionproduct elements. The term "fissium" is used at Argonne to describe a mixture of relatively noble metals having the following composition: 110 49.4 percent molybdenum; 39.2 percent ruthenium; 5.6 percent rhodium; 3.6 percent palladium; 2.0 percent zirconium; and 0.2 percent niobium. Remote refabrication of these fuel assemblies will be demonstrated to permit operation of a complete fuel cycle. Remote fabrication techniques were used to prepare the first core loading for the reactor. ${ }^{11-113}$

MELT REFINING The EBR-II fuel cycle, which is represented schematically in Fig. 12, is built around a melt-refining process. In melt refining, as developed at Argonne, the fuel is melted and held at $1400^{\circ} \mathrm{C}$ for 1 to $4 \mathrm{hr}$ in a zirconium oxide crucible. In this step gases are released, volatile elements are vaporized, and reactive fission products are oxidized into a reaction layer that forms along the crucible walls. Oxygen for the selective oxidation and drossing of rare earths

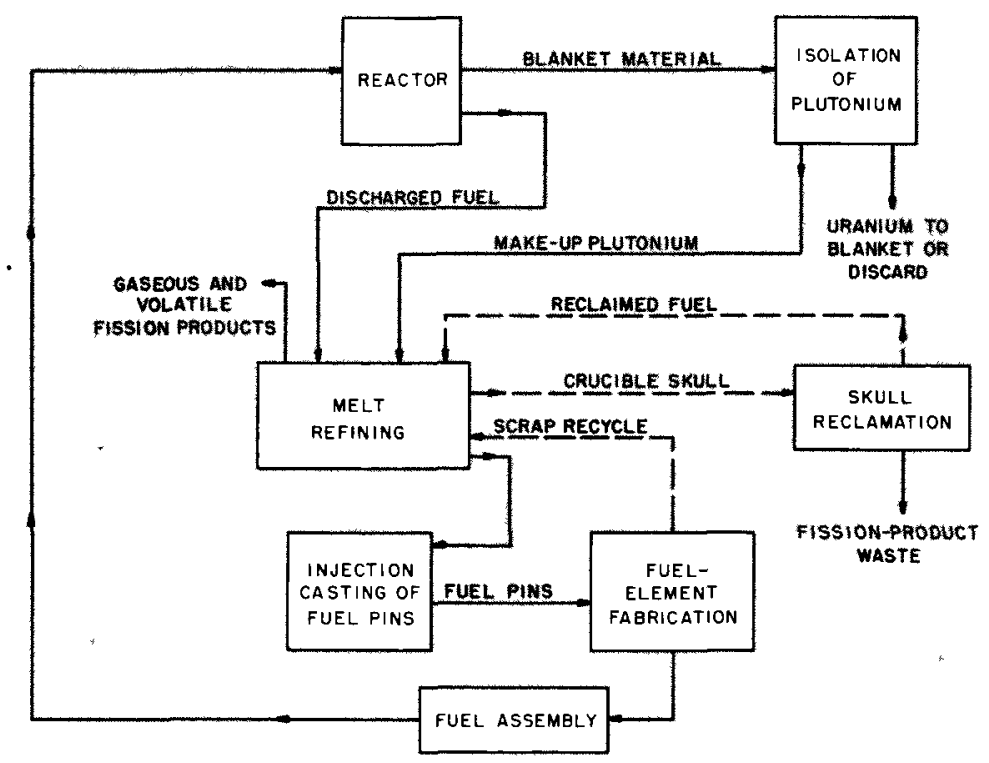

Fig. 12-EBR-II fuel cycle. 
and other reactive fission products is provided by the zirconia crucibles, which reduce only to a zirconium suboxide and thus do not introduce zirconium into the melt. Fission-product elements that form oxides more stable than zirconium oxide are removed in the reaction layer, or "skull." The free energies of formation of oxides of some elements of interest are given on p. 422. As would be expected from their high free energies of formation, the alkaline-earth, yttrium, and rare-earth elements are removed. A slight amount of uranium is also oxidized in this step. Plutonium at tracer levels and at 20 percent concentration in uranium displayed a small but significant preferential concentration in the skull as compared to uranium. At 20 percent plutonium, the plutonium concentration dropped 0.3 percent after melt refining. ${ }^{114}$ The alkalı metals, halogens, and inert gases volatilize, and the relatively noble (less reactive) elements remain in solution in the uranium. The preferential removal of zirconium by the addition of carbon to the melt has been demonstrated, ${ }^{114}$ but there are no plans to incorporate this procedure in the EBR-II melt-refining process.

The fissionable material is replenished during melt refining to replace that lost in process and consumed in the reactor. After liquation the melt is poured and the resultant ingot is reused in casting new pins. Much of the development of this process has been reported. ${ }^{110,114}$

Demonstration of melt refining at the full plant scale of $10 \mathrm{~kg}$ of simulated fuel under remote conditions ${ }^{113,115}$ and small-scale demonstrations with highly irradiated fuels ${ }^{116}$ have recently been completed. The process equipment for melt refining was developed and demonstrated in a full-scale mockup of a segment of the annular argon cell. ${ }^{113}$ The melt-refining furnace developed in the mockup facility is shown in Fig. 13. The upper photograph shows the furnace in the argon cell of the fuel-cycle facility. The lower photograph shows the crucible in a partially tilted position.

Five melt-refining experiments at high activity levels were conducted at Argonne on a $400-\mathrm{g}$ scale to permit final evaluation of the process prior to its installation in the fuel-cycle facility. ${ }^{117,118}$ The fuel alloy for these experiments was 10 percent enriched uranium containing 5 percent fissium that was irradiated to a burnup between 0.2 and 1.8 percent. The physical properties of the irradiated material were of special interest because of handling operations necessary in decladding, cutting, and charging it to a crucible. Although the pins were brittle and shattered when clamped in a vise or struck a sharp blow, no particular difficulty was encountered in handling them for the process.

The five melt-refining runs were made at $1400^{\circ} \mathrm{C}$. In the first two, the liquation time was $3 \mathrm{hr}$ at this temperature, and in the other three, $1 \mathrm{hr}$. The fission-product removals were in agreement with earlier 

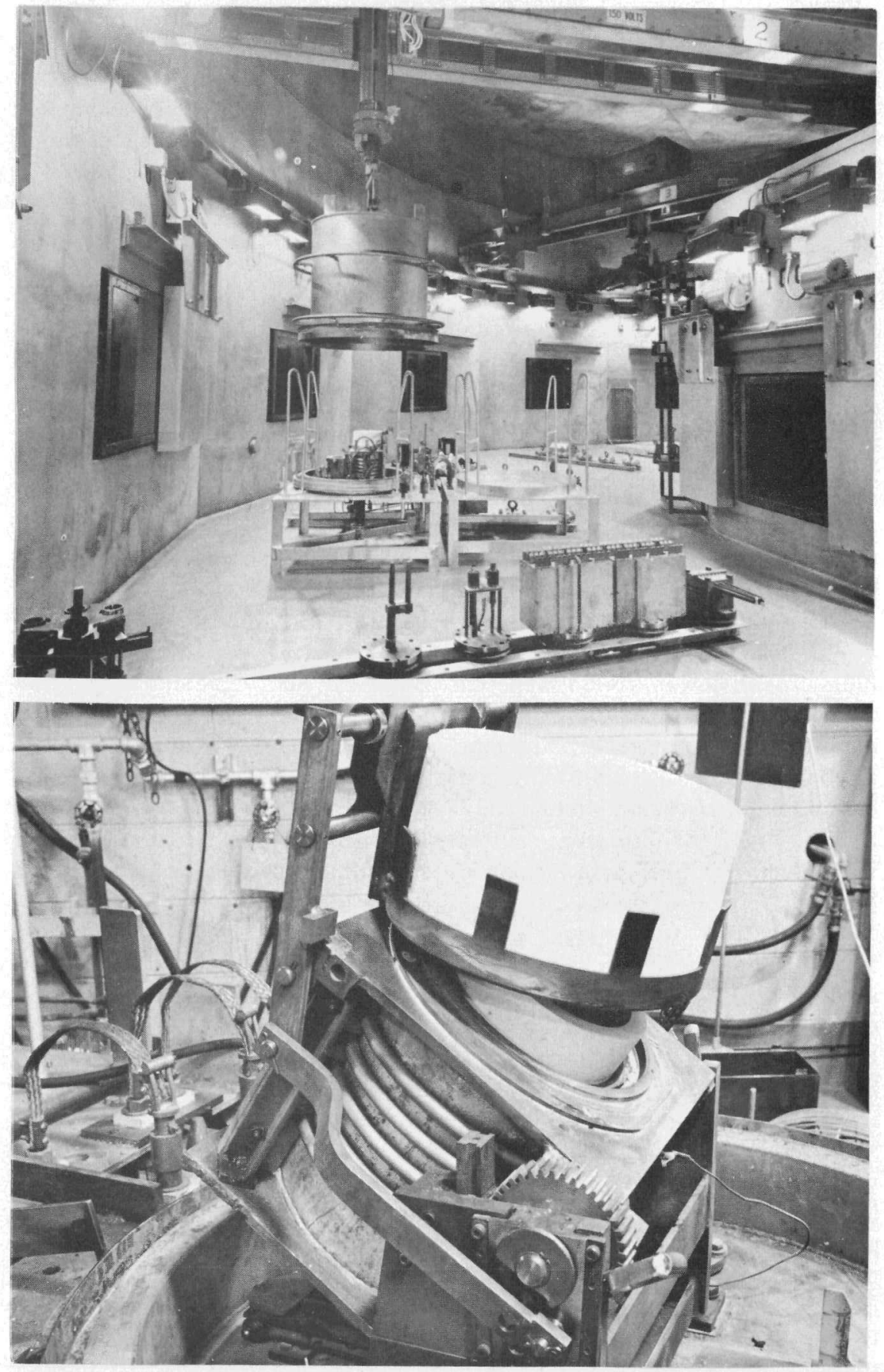

Fig. 13-Melt-refining furnace in EBR-II facility. 
experiments with inactive or low-activity fuel. The results showed no significant effect of burnup and radiation level, and on this scale a liquation time of $1 \mathrm{hr}$ was adequate. As shown in the following tabulation (data for which were obtained by radiochemical analyses except for molybdenum), yttrium, rare earths, tellurium, iodine, cesium, barium, and strontium were completely removed. ${ }^{118}$

\begin{tabular}{lc||lc}
\multicolumn{1}{c|}{ Element } & Removal, $\%$ & \multicolumn{1}{c}{ Element } & Removal, $\%$ \\
Rare earths and ytţrium & & & \\
$\quad$ (Group IIIB elements) & 97 to $99+$ & Cesium & Barium and strontium \\
Tellurium & 95 to $99+$ & (Group IIA elements) & $99+$ \\
Zirconium & 9 to 28 & Ruthenium & 0 \\
Iodine & $99+$ & Molybdenum & 0
\end{tabular}

As expected, the less reactive metals, ruthenium and molybdenum, were not removed. Radioactive zirconium was partially removed as a result of isotopic exchange with inactive zirconium from the zirconia crucible. Although this exchange resulted in no reduction in the total zirconium, small amounts of zirconium were removed as the carbide because of traces of carbon contamination in the fuel.

The yields in experiments with highly irradiated alloy were lower by 15 to 30 percent than those in control experiments with unirradiated fuel. These lower yields were the result of less-efficient separation of purified metal because of the presence of a surface dross, which hindered top pouring. The formation of a surface layer appeared to be a consequence of oxidation of the pins during handling of the highly irradiated, self-heated fuel in air. The oxide floated to the surface as a dross when the pins were melted. It is not expected that the problem will be encountered with fuel processed in the argon cell of the EBR-II facility.

Analysis of the product ingots, the skull, and the crucible showed that the rare earths, yttrium, and tellurium had concentrated in the skull but that barium and strontium had migrated extensively into the crucible wall. Cesium and iodine, which are vaporized from the liquid metal during melt refining, collected principally on surfaces that were between 450 and $700^{\circ} \mathrm{C}$. The iodine was present either as cesium iodide or as the iodide of some non radioactive element. A small but significant amount of the iodine will be present in the skull after melt refining. ${ }^{118}$ A similar iodine behavior was found in a study at Brookhaven to determine the chemical and physical form in which fission products would be released from a reactor fuel element under accident conditions. ${ }^{119}$ Fission-product iodine, released from a molten uranium molybdenum alloy that had been lightly irradiated, condensed from a flowing helium stream on surfaces at temperatures above $200^{\circ} \mathrm{C}$. In the same study the behavior of other fission products was also determined. ${ }^{119}$ 
Swelling of the pins on heating was of concern because of the possibility of resultant cracking of the zircoma crucible used in melt refining. These experiments indicate that notable expansion of the pins did occur but that the forces generated are not sufficient to harm the crucible. Measurements were made on unrestrained single pins during heating. The pins expanded diametrically about 47 percent between 650 and $900^{\circ} \mathrm{C}$, but there was little longitudinal change. The pins were soft during the expansion, and therefore the entrapped fission gases were completely released. ${ }^{120}$ These observations make it apparent that fuel temperatures should not be allowed to reach $650^{\circ} \mathrm{C}$ in the reactor.

The argon atmosphere in the EBR-II argon cell may be allowed to contain as much as 5 percent nitrogen. Therefore the possibility of nitriding of irradiated material that is hot as a result of decay heating had to be considered. Nitridation studies indicated that below $500^{\circ} \mathrm{C}$ less than 0.5 percent of the uranium in a pin would be nitrided. Rate studies ${ }^{121}$ made with fuel irradiated to 1.2 percent burnup and cooled 80 days showed no large effect of radiation on the nitridation rate at $500^{\circ} \mathrm{C}$. No significant effect on melt-refining yields was noted with unirradiated pins stored in argon-5 percent nitrogen for $2 \mathrm{hr}$ at 350 or $650^{\circ} \mathrm{C}$. These exposures bracket those expected in the EBR-II argon cell. Nevertheless, current plans are to restrict the pin temperatures to $300^{\circ} \mathrm{C}$ and to consider reducing the nitrogen content of the fuel-cell atmosphere.

The application of fluxes during melt refining has been considered attractive to enhance slagging kinetics and to suspend or dissolve the oxidized fission products and thereby improve pouring yields. ${ }^{117,122}$ Severe container problems were encountered with oxide fluxes that were tried. Beryllia crucibles were successfully employed in preliminary runs with the use of calcium chloride fluxes containing a uranium chloride or a magnesium chloride oxidant to melt-refine $700 \mathrm{~g}$ of uranium containing simulated fission products. ${ }^{91}$ Good removal of rare earths and high ( 95.7 and 97.6 percent) yıelds of metal ingots were achieved.

SKULL RECLAMATION The scoria or skull material in a zirconia crucible after melt refining can be expected to contain about 10 percent of the original uranium charge. The bulk of this uranium will be present as unpoured metal. A skull-recovery process is under development to recover this uranium and to dispose of accompanying fission products. Because only 10 percent of the fuel will be treated, a uranium recovery in this process of 95 percent is considered adequate. The less reactive fission elements that are not removed in melt refining are removed in this process, as are the rare earths that are concentrated in the scoria from melt refining. 
The skull-recovery process has been demonstrated on unirradiated skulls on a 100 - to 150 -g-uranium scale, ${ }^{123}$ and equipment for $2 \frac{1}{2}-\mathrm{kg}$ runs has been built and is in shakedown testing. The development of features required to perform the process remotely is also under way in a mockup facility. The small-scale runs are intended to test process variables and to determine optimum process conditions as well as to reveal any unexpected difficulties prior to the operation of the larger equipment.

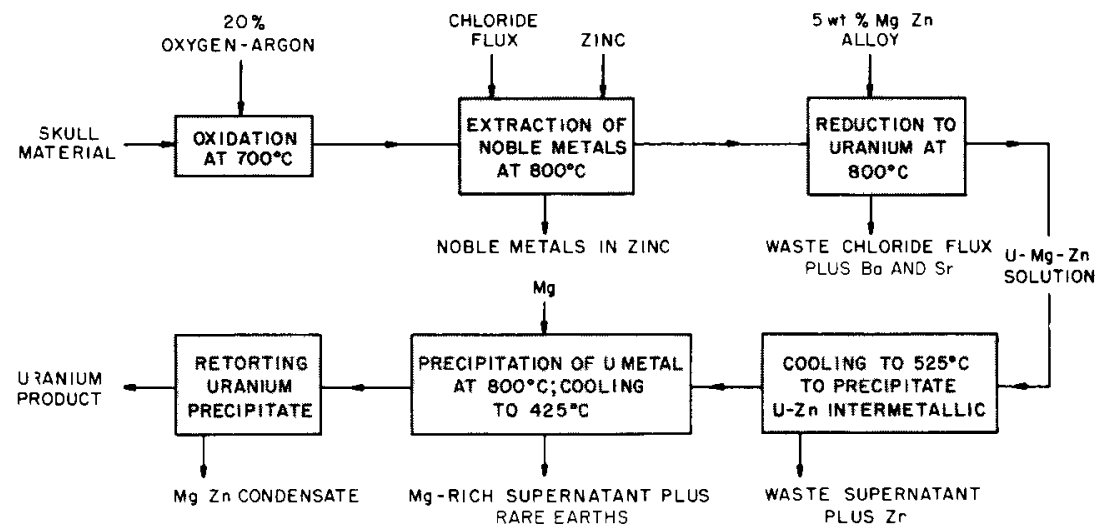

Fig. 14-Reclamation of melt-refining skulls in EBR-II.

The process flow sheet currently under study is presented in Fig. 14. The steps are (1) oxidation of the skull to transform it to a powder that can be poured out of the melt-refining crucible; (2) extraction of "noble" elements into zinc, leaving the uranium and the reactive elements suspended as oxides in a flux; (3) reduction and extraction of uranium into a zinc-magnesium phase; (4) crystallization of uranium as a uranium-zinc intermetallic compound; (5) decomposition of the iranium-zinc compound by the addition of magnesium, leaving a uranium precipitate; and (6) retorting to remove residual zin: and magnesium solvent from the uranium product.

At the conclusion of a skull oxidation, 98 to 99 percent of the uranium will pour freely from the crucible when the crucible is inverted. ${ }^{124}$ A skull-oxidation furnace for the EBR-II facility has been built and is in test. Even though the remainder of the skull-recovery process will not be installed untıl later, the present plans are to oxidize the skulls immediately to permit disposal of the crucibles and to facilitate storage of skull material.

The flux used for the recovery procrss was selected as a result of the reduction studies already mentior ed ${ }^{93}$ (see p. 433) and has the composition 47.5 mole ${ }^{c} c$ magnesium chloride, 47.5 mole $/ c$ calcium 
chloride, and 5.0 mole $\%$ magnesium fluoride. To prevent loss of any unoxidized metallic uranium in the charge material, 2 to $10 \mathrm{wt} . \% \mathrm{zinc}$ chloride is added with the flux to ensure transfer of all uranium into the flux. Four parts, by weight, of flux and sixteen parts of zinc are charged to one part of skull oxide for the noble-metal extraction step, which is performed in a tungsten crucible. The noble-metal extractions can be expected to remove 60 to 100 percent of the ruthenium and molybdenum. ${ }^{125}$ This range of removal is adequate for this process. After an extraction is completed at $800^{\circ} \mathrm{C}$, which requires about $1 \mathrm{hr}$ with vigorous agitation, the melt is cooled to $525^{\circ} \mathrm{C}$ to freeze the flux, and the zinc is removed by pressure siphoning. The zinc is agitated gently during the transfer to keep the molybdenum and ruthenium in suspension because they are both very insoluble at this temperature. These elements suspend readily and transfer with the zinc. Uranium losses in the transferred waste zinc phase have been low (about 0.01 percent of the charge).

Sufficient $\mathrm{Zn}-5$ wt.\% $\mathrm{Mg}$ is added to the slurry of flux and skull oxide remaining in the crucible to form a solution containing about $4 \mathrm{wt} . \%$ uranium in zinc after reduction of the uranium is complete. The reduction proceeds rapidly at $800^{\circ} \mathrm{C}$ and is complete in about $15 \mathrm{~min}$ under the conditions employed. Reduction of 99.6 percent of the uranium is typical for this step. At the conclusion of the reaction, the flux phase is transferred to waste, and the metal phase is transferred to an adjacent beryllia crucıble. A semiautomatic separating techmique has been devised and demonstrated for these phase transfers. ${ }^{126}$ An alternative procedure, in which the two precipitation steps after the uranium reduction are also performed in the reduction crucible, has also been exammed. In this procedure the only transfer at the conclusion of the uranium-reduction step is for flux removal.

The zinc solution from the reduction step contains zirconium and rare earths as well as uranium. These elements are removed from the uranium in two successive crystallization steps. In the first precipitation, uranum-zinc intermetallic phases are crystallized by cooling the solution from $800^{\circ} \mathrm{C}$ to $525^{\circ} \mathrm{C}$. Zirconium remains in solution in the supernatant phase, which is discarded. The coprecipitation of zirconium with uranium-zinc intermetallic compound has been shown to be low, but the rare earths coprecipitate extensively (see Table 2). The removal of zirconium in this step is limited by its solubility at the transfer temperature. At $525^{\circ} \mathrm{C}$ the solubility is about 0.2 wt. \% in $\mathrm{Zn}-5$ wt. ${ }^{\circ} \mathrm{C} \mathrm{Mg}$. The uranium solubility is $0.032 \mathrm{wt} . \%$ in the supernatant phase and results in a loss of about 0.5 percent of the uranium charge. The behavior of zirconium in these runs is critical because some zirconium, in addition to that present in the fuel, will be introduced as crucible fragments from the reaction zone of the meltrefining crucible. A typical oxıdized skull contains about 1 percent 
zirconium from the reaction zone of the crucible wall, but the content has been as high as 10 percent.

Japanese investigators, ${ }^{127}$ who have also reported some results with the separation of zirconium from uranium by crystallization of intermetallic compound, report decontamination from zirconium by factors of between 2.2 and 9.5 .

The cake of intermetallic compound remaining after the zinc solution has been pressure siphoned off is treated with additional magnesium to increase the weight ratio of magnesium to zinc to about 1 . This increase results in the decomposition of the intermetallic compound, and metallic uranium is left as an insoluble phase. During the decomposition the rare earths return to solution and are removed with the supernatant phase. The solubility of uranium in this waste stream results in a loss of about 0.6 percent of the uranium charge at a transfer temperature of $425^{\circ} \mathrm{C}$.

After this decomposition step the uranium product remains as a cake consisting of about 40 to 60 percent uranium, the remainder being residual magnesium-zinc solution. This residual solvent is removed by retorting in smaller beryllia crucibles, which requires a transfer of the uranium from the precipitation crucible to the retort crucible. When beryllia crucibles are used for the precipitation steps, the uraniumsolvent cake does not wet the crucible and can be removed and transferred as a solid. In the alternative one-crucible procedure, in which the precipitation steps are performed in the tungsten crucible, the cake sticks to the crucible. The uranium can be redissolved in a solvent of $\mathrm{Zn}-12 \mathrm{wt} . \% \mathrm{Mg}$ and transferred to the retorting crucible as a solution containing about 15 percent uranıum (see Fig. 4). The greater evaporation load in this latter alternatıve is not a particular problem.

In the small-scale demonstration runs, the product was retorted under vacuum and recovered as a dense sponge. However, for the larger scale experiments, the retorting is terminated by melting the uranium.

The results of the demonstration runs indicate that a uranium recovery of 95 percent will be readily obtained. Removal of 75 to 90 percent of the noble elements, molybdenum and ruthenum, and over 99 percent of the palladium is typical. Zirconium removal in excess of 75 percent can be expected; greater removals are possible when the skull oxide contains no more than 2 or 3 percent of zirconia crucible fragments. The removal of rare earths is limited only by the efficiency of the phase separation after the second crystallization step. More than 90 percent of the cerium has been removed; even more could be removed by washing the uranum precipitate. All these results are considered entirely satisfactory for a reactor of the EBR-II type.

Preliminary experiments were made to examine the feasibility of direct processing of uranium fuel clad with stainless steel by slight modification of the existing skull-recovery process. ${ }^{128,129}$ The ability to 
handle clad pins could be useful in treating any EBR-II pins that are too badly distorted for removal of cladding. The only modification that would be made in the existing process is in the extraction of noble metals. Because the charge would be in its metallic state rather than as oxide, sufficient zinc chloride would be added to oxidize all the uranium into the flux. The noble metals would remain in the zinc phase. In preliminary experiments, iron and nickel from the stainless steel were extracted with the noble elements, but about one-fourth of the chromium transferred to the flux along with the uranium. ${ }^{128}$ Techniques for better removal of chromium are being explored.

BLANKET PROCESS The EBR-II fuel-cycle program will also demonstrate pyrometallurgical processing to recover bred plutonium from blanket elements. The objective of the blanket process is to increase the concentration of plutonium in discharged blanket material from an initial concentration of $1 \mathrm{wt} . \%$ in uranium to at least 40 percent so that it may be used for enrichment of core materials. The processes under investigation are based on the high solubility of plutonium in magnesiumrich zinc alloys and the contrasting low solubility of uranium in these alloys.

The process currently under investigation is presented in Fig. 15. Blanket material is first dissolved in a $\mathrm{Zn}-12 \mathrm{wt} \% \mathrm{Mg}$ alloy, which was selected because it has a maximum uranium solubility (see Fig. 4). Subsequent addition of magnesium to a concentration of about 50 percent precipitates uranium away from the plutonium. The supernatant solution containing the plutonium is separated from the uranium precipitate and boiled down to give a plutonium concentrate suitable for feeding into

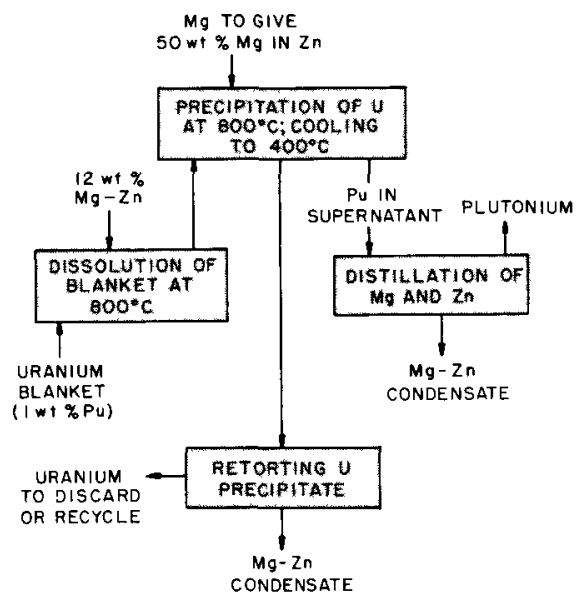

Fig. 15- Recovery of plutonium from uranium blanket in EBR-II. ${ }^{41}$ 
the core cycle. If necessary, a wash step may be employed to reduce the plutonıum content of the uranium cake, but this markedly increases the distillation load.

Results of five demonstration runs of the blanket process have been compiled from five reports and are presented in Table 13. All these

\begin{tabular}{|c|c|c|c|}
\hline \multirow[b]{2}{*}{$\begin{array}{l}\text { Run } \\
\text { No }\end{array}$} & \multicolumn{3}{|c|}{ Scale of operation: $500 \mathrm{~g}$ of $1 \mathrm{wt} \% \mathrm{Pu}-\mathrm{U}$ alloy } \\
\hline & $\begin{array}{c}\text { Pu recovery, } \\
\%\end{array}$ & $\begin{array}{l}\mathrm{Pu} /(\mathrm{Pu}+\mathrm{U}) \\
\text { in product }\end{array}$ & $\begin{array}{c}\text { Separation } \\
\text { factor }\end{array}$ \\
\hline 1 & 92 & 065 & 1680 \\
\hline 2 & 95 & 065 & 1690 \\
\hline 3 & 93 & 061 & 1570 \\
\hline 4 & 100 & 044 & 775 \\
\hline 5 & 92 & 070 & 2300 \\
\hline
\end{tabular}

runs were characterized by rapid dissolution of the uranium, good material balances for plutonıum and uranıum, and good separation of plutonium from uranium. Table 13 lists separation factors, defined as plutonum to uranium ratio in the product divided by the same ratio in the feed material. A separation factor of $2401 \mathrm{~s}$ about the maximum that could be realized in the plutonium-product supernatant solution. In all runs except run 5, the uranium precipitate was washed with $2 \mathrm{~kg}$ of $50 \mathrm{wt} . \% \mathrm{Mg}-\mathrm{Zn}$ alloy. The use of a wash, while increasing the percentage of plutonium recovered, reduces the separation factor because additional uranium is dissolved in the wash solution. The low separation factor in run 4 is the result of an unusually high physical carryover of uranium in the magnesium wash solution.

Direct dissolution of elements clad with stainless steel in the blanket process would be allowable if the steel constituents do not affect plutonium recovery and can be separated from plutonium. Results of a demonstration run ${ }^{130}$ indicate that stainless steel and fission elements, which were added in appropriate amounts, would have no effect on plutonium behavior. However, although chromium and iron would be precipitated with the uranium and thus be separated from the plutonium, nickel would quantitatively follow the plutonıum unless the process were modified.

The process requires distillation of large amounts of solvent to recover plutonium from a dilute solution (about 0.08 percent plutonium). A new still is in operation to demonstrate this step. Alternative procedures to recover plutonium in a more concentrated form are also under consideration.

DEVELOPMENT OF ENGINEERING PROCEDURES The major engineering procedures required in the skull and blanket processes are (1) mate- 
rials handling, (2) mixing of metal and flux phases, (3) separation and transfer of molten metal and flux phases, (4) retorting of uranium product, and (5) distillation for recovery of plutonium.

Materials handling has not received much attention except in connection with liquid transfers. Principal attention will be given to this subject when equipment is mocked up for remote operation.

Mixing has been satisfactorily accomplished by conventional mechanical mixers operating in baffled vessels. Inductive mixing is currently being investıgated as an alternative that may have advantages over mechanical mixing for remote operation. ${ }^{134}$

The method that has been adopted for the transfer of liquids is called "pressure siphoning." It consists of transferring fluids by pressure through overhead pipes from one vessel to another. In this manner 90 to 95 percent of the zinc extract of the noble-metal extraction step is transferred to waste from beneath a solidified flux. ${ }^{135}$ A system of two transfer tubes has been developed for effecting an essentially automatic separation of flux and metal phases at $800^{\circ} \mathrm{C}$ after reduction of uranium oxides. ${ }^{126}$ Perfect separation of the two molten phases has been demonstrated repeatedly at practıcal transfer rates. The transfer of about 80 percent of the supernatant solution from a precipitated uranıum-zinc intermetallic phase has been achieved without difficulty. The removal of $50 \mathrm{wt} ._{0}^{\odot} \mathrm{Mg}-\mathrm{Zn}$ solution from precipitated uranium metal is a phase separation common to both the blanket and skullreclamation processes. On a 500-g-uranium scale, 95 percent removal of supernatant is readily achieved. ${ }^{131}$

The vaporization of residual magnesium and zinc from the uranium product can be carried out above $700^{\circ} \mathrm{C}$ at whatever pressure and corresponding temperature are desired. Both vacuum and atmospheric pressure retorting are under investigation at Argonne. More important than the selection of retorting conditions is the selection of a container material. The use of a material that will release the uranium product is of prime importance. Metals are unsatisfactory. Of the ceramics, beryllia has been most successful because it is not wet by the metal systems and is not highly susceptible to thermal shock. ${ }^{136}$ Large beryllia crucibles of sufficiently low permeability, hitherto unavallable, are being prepared for this purpose by industry.

A pilot-scale still has been recently placed in operation for demonstrating the distillation of $50 \mathrm{wt} . \% \mathrm{Mg}-\mathrm{Zn}$ solvent from dilute solutions of plutonium. Vapor baffles are employed above the bolling metal to prevent entrainment of the plutonium in the vapor because in smallscale stılls entrainment of plutonium has been a major problem.

FUTURE EBR-II FUELS Future EBR-II fuels, as well as other fuels for fast reactors, will contain plutonium. The nature of these fuels, e.g., whether metal, oxide, or carbide, is uncertain. Although melt refining 
can be used for metal fuels, the present skull-reclamation process cannot be used because plutonium would be extracted into a waste stream along with the rare earths.

Two approaches are currently under investigation for processing plutonium-bearing fuels. The first utılizes separations by selective partitioning between molten magnesium - zinc alloy and a saltflux, such as magnesium chloride. ${ }^{90}$ The experimental distribution coefficients presented in Fig. 9 indicate that plutonium and uranium can be separated from rare earths, although more than one equilibrium stage will be necessary to achieve both high plutomum recovery and good cerium removal.

The insolubility of uranium and plutonium in calcium as compared with relatively high solubility of rare earths has been examined for application to separation of these fuel materials from the rare earths. ${ }^{137}$ In one run in which uranium, plutonium, and cerium were coprecipitated from zinc solution and the resulting cake was digested with enough calcium to give a $64 \mathrm{wt} \% \mathrm{Ca}-\mathrm{Zn}$ solution, more than 97 percent of the plutonium and virtually all the uranium in the intermetallic cake remained insoluble after the calcium addition, whereas over 94 percent of the cerium went into solution. Better plutonıum recovery must be achieved before this procedure can be useful.

OTHER PROCESS APPLICATIONS The liquid-metal and liquid-salt solvent processes under development at Argonne for use on the EBR-II fuel are also being considered for their more general application. The application of these processes to oxide fuels appears attractive, although a preliminary oxidation-reduction cycle to pulverize the fuel might be beneficial. The application of the processing techniques to the recovery and reduction of ores is under study. Carbide or nitride fuels could readily be converted to oxides or chlorides for processing by liquid metal-salt processes. At the conclusion of the purification, the carbide can be formed from liquid-metal solution by reaction with carbon. Kilogram batches of uranium monocarbide have been produced by reacting uranium dissolved in a magnesium-zinc solution with finely divided carbon. ${ }^{138-140}$

Several refractory compounds of actinide elements also have been prepared by precipitation reactions in liquid-metal media. These processes are attractive because they show the possibility of integrating the procedures into present liquid-metal processes and may provide a technique for preparing high-purity compounds. The general procedure is to dissolve the element to be reacted in a suitable liquid-metal solvent and to react it with an appropriate reagent. The compound is isolated by decanting supernatant solvent and vaporizing the residual solvent metal. Six compound $\mathbf{s}^{141}$ have been formed in liquid-metal reaction media: $\mathrm{UC}, \mathrm{Pu}_{2} \mathrm{C}_{3}, \mathrm{Ce}_{2} \mathrm{C}_{3}, \mathrm{USI}_{3}, \mathrm{U}_{3} \mathrm{Si}_{2}$, and $\mathrm{UB}_{2}$. 


\section{Magnesium Processes for Thorium-Uranium Fuels}

Chrotti and coworkers at the Ames Laboratory have been working on the chemistry of processes for thorium-uranium fuels. ${ }^{66,142}$ A process proposed to separate uranium from thorium and to separate impurities from these two metals is diagramed in Fig. 16. The first step is dissolution of thorium blanket elements in magnesium to form a $\mathrm{Th}-\mathrm{Mg}$ eutectıc containing about $40 \mathrm{wt} . \%$ thorium (melting point, $585^{\circ} \mathrm{C}$ )

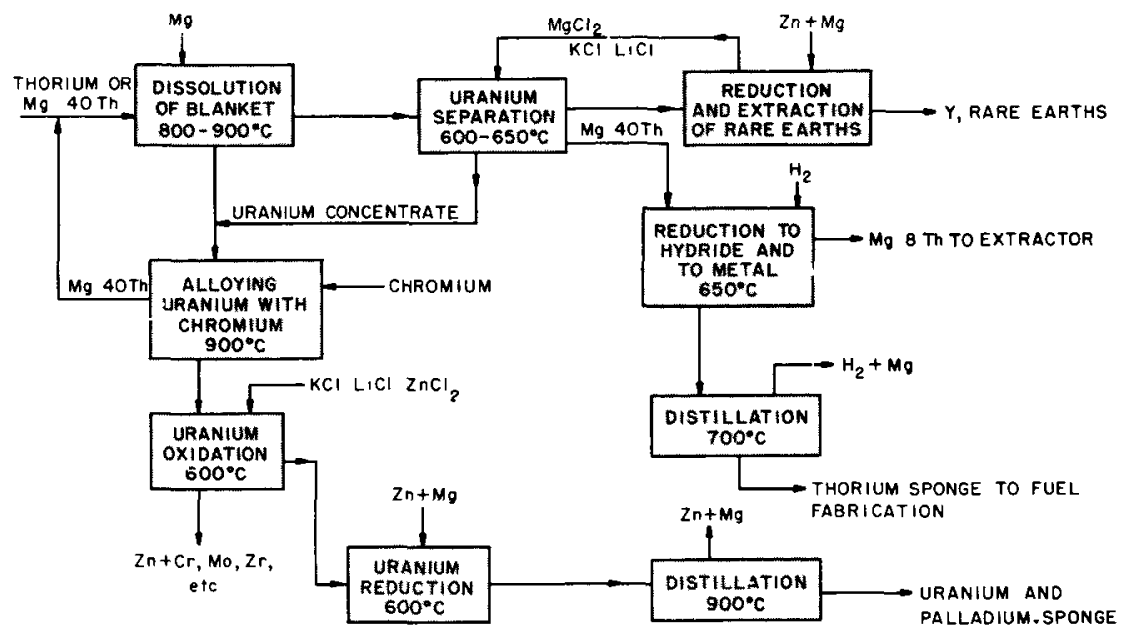

Fig. 16-Reprocessing of thorium-uranium fuel. ${ }^{66}$

and a uranium precipitate. After the supernatant phase is removed, the uranium phase is removed as a concentrated slurry and consolidated in a second vessel by alloying it with chromium to form a eutectic of $\mathrm{U}-5$ wt. \% $\mathrm{Cr}$ (melting point, $860^{\circ} \mathrm{C}$ ). This alloy can be frozen to simplify decantation of excess thorium-magnesium solution.

The relatively noble metal fission products will precipitate with uranium. They, together with about 0.5 percent thorium, will be present in the chromium-uranium alloy. The uranium is recovered from the alloy by selective oxidation and reduction reactions. First, the uranium is separated from the more noble elements and the chromium by oxidizing the uranium into a $\mathrm{KCl}-\mathrm{LlCl}$ salt phase with $\mathrm{ZnCl}_{2}$, leaving the noble metals in the zinc phase. The salt phase is then treated with a magnesium-zinc solution to reduce the uranium, which crystallizes from a saturated solution in the zinc phase as an intermetallic compound. After the zinc and intermetallic compound are separated from the flux, the zinc and magnesium can be evaporated away, leaving a uranium sponge that can then be used to prepare reactor fuel. The protactınıum has been shown to follow uranium through this process. 
The magnesium-thorium phase from the magnesium extractor is treated with a salt flux, which extracts yttrium and rare earths. The flux is transferred to another vessel, in which these fission products are reduced by magnesium and extracted into a zinc phase for disposal. The refined magnesium-thorium solution is then contacted with hydrogen at 1 atm pressure to precipitate thorium hydride $\left(\mathrm{ThH}_{2}\right)$. The magnesium and residual thorium are recycled to the extractor. The thorium hydride is decomposed and the residual magnesium driven off under reduced pressure at $700^{\circ} \mathrm{C}$, leaving a thorium sponge for refabrication.

The uranium solubility in the thorium-magnesium eutectic is 0.19 wt. $\%$ at $1132^{\circ} \mathrm{C}$ and only $0.008 \mathrm{wt} . \%$ at $650^{\circ} \mathrm{C}$. Thus additional uranium may be precipitated from the eutectic by cooling it to $650^{\circ} \mathrm{C}$. If the second separation of uranium is made (as indicated in the flow diagram), 98 percent of the uranium contained initially in a $1 \mathrm{wt} . \% \mathrm{U}-\mathrm{Th}$ alloy can be separated from the thorium. The second uranium precipitation could be avoided by cooling the solution to $650^{\circ} \mathrm{C}$ in the dissolver before transferring the supernatant eutectic phase. The settled volume of the uranium has not been determined, but the transferred slurry is expected to contain at least $0.6 \mathrm{vol} \%$ uranium.

The studies supporting the salt-extraction steps have been mentioned previously, and the results of equilibrium extraction data are summarized in Table 11.

The possibility of precipitating various elements from solution as hydrides was investigated by contacting solutions with hydrogen at 1 atm. Magnesium is an attractive solvent for these reactions. It does not exhibit the strong interactions with solutes encountered with many other liquid solvents, and the resultant higher activity of the solutes in magnesium makes the formation of the hydrides more likely.

Solubility results for the hydrogen equilibrations are presented in Table 14. Because of the much greater concentration of thorium compared with that of the fission products, some further separation of these elements should be obtainable in the hydriding step of the flow sheet (Fig. 16). The extent to which solutes may coprecipitate with thorium hydride has not been investigated.

\begin{tabular}{|c|c|c|c|c|}
\hline \multirow[b]{2}{*}{ Element } & \multicolumn{4}{|c|}{ Concentration, wt. $\%$} \\
\hline & $650^{\circ} \mathrm{C}$ & $700^{\circ} \mathrm{C}$ & $800^{\circ} \mathrm{C}$ & $900^{\circ} \mathrm{C}$ \\
\hline Calcium & 894 & 11.8 & 19.3 & 28.3 \\
\hline Yttrium & 0.13 & 0.37 & 2.38 & 10.5 \\
\hline Lanthanum & 14.7 & 21.9 & 39.8 & 59.2 \\
\hline Cerium & 16.3 & 18.8 & 24.2 & 29.5 \\
\hline Thorium & 6.01 & 10.4 & 24.7 & 44.3 \\
\hline
\end{tabular}


Chilton and coworkers at Atomics International have reported research on a similar process for the separation of thorium and uranium by molten-magnesium extraction. ${ }^{143}$ The process is shown in Fig. 17. The supernatant thorium solution was removed from precipitated uranuum by filtration, and the uranum residue was further concentrated by vaporization of the magnesium and then consolidated by arc melting.

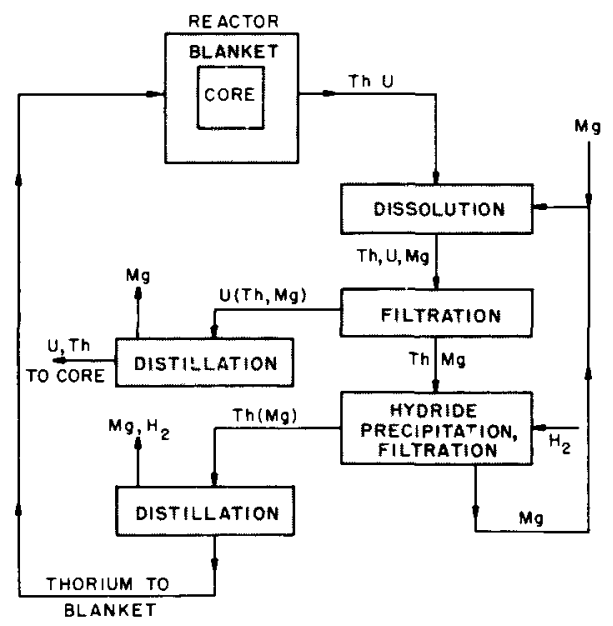

Fig 17-Separation of uranium from thorium by magnesium extraction ${ }^{143}$

Most of the thorium in the filtrate was precipitated as the hydride, which was decomposed after removal of the supernatant solution by filtration, and the thorium was recovered in the same manner as that used for the uranum fraction. The supernatant solution from the thorium hydride precipitation step, which contained about 25 percent of the thorium, was recycled to the dissolution step.

Uranium recoveries in a thorium-uranium concentrate in excess of 90 percent were shown, but most of the recoveries ranged between 70 and 90 percent. The unrecovered uranium would not be lost, however, because it would be recycled with either the thorium or the magnesium. Thorium to uranium ratios of around 1:1 were realized in the best experiments. Fission-product behavior was discussed. A silvermagnesium alloy was also briefly investigated as a processing medium and showed some promise, but the removal of silver, which has farly low volatılity, from the product phases gave problems.

\section{Hanford Salt-cycle Process}

A pyrochemical process for ceramic fuels of mixed oxides of uranuum, plutonium, and thorium is under development at Hanford as part 
of the plutonium recycle program. ${ }^{144,145}$ This process is being developed principally for ceramic fuels consisting of mixtures of uranium and plutonium dioxides. It is hoped to achieve economies in the fuel cycle by adjusting composition in a few simple steps that yield oxide products requiring minimal handling during remote refabrication into fuel elements. The mixed oxides are first dissolved in a molten chlorine salt by sparging the mixture with chloride or hydrogen chloride. Uranium or plutonium is recovered as oxides either by electrolytic reduction or by appropriate chemical reduction. The fused salt can be reused and an equilibrium fission-product concentration maintained by discarding a fraction of the salt after each cycle or by scavenging the fission products from it. Electrolytic reductions are favored and have received principal attention. Conditions of the electrolysis may be adjusted for the deposition of uranium dioxide essentially free from plutonium or for the codeposition of a mixture of uranium and plutonium dıoxides at a plutonıum to uranıum ratio equal to or slightly greater than that in the melt. Various alternative procedures for processing uranium, plutonıum, and thorium oxide fuels are also being examined.

CHEMISTRY OF PROCESS The principal molten-salt systems under study are $\mathrm{NaCl}-\mathrm{KCl}, \mathrm{KCl}-\mathrm{LlCl}, \mathrm{KCl}-\mathrm{MgCl}_{2}, \mathrm{NaCl}-\mathrm{MgCl}_{2}$, and $\mathrm{KCl}-\mathrm{PbCl}_{2}$. The most important characteristics required of a suitable flux are reasonable liquid range, ease of drying, proper chloride activity, and ability to promote formation of suitable uranium dioxide deposits during electrolytic reduction.

Soluble uranium species have been produced by reaction of chlorine with $\mathrm{UO}_{2}, \mathrm{UO}_{3}$, and $\mathrm{U}_{3} \mathrm{O}_{8}$ in various fused-salt systems. Uranium dioxide dissolution rates have been measured in several fused salts sparged with chlorine. ${ }^{146,147}$ With the use of large single specimens, a rate of $0.25 \mathrm{mg}$ of uranium per cubic centimeter per minute was measured in 10-min exposures in $\mathrm{KCl}-\mathrm{PbCl}_{2}$ (mole ratio, 2.5 to 1 ) at 600 and $700^{\circ} \mathrm{C}$. The rate was somewhat lower when the proportion of potassium chloride was decreased. Lorger term measurements show increasing rates, probably as a result of catalysis by an increasing uranyl chloride concentration. The rate appears to be proportional to the one-half power of the uranyl chloride concentration. The dissolution rates were increased by factors of 30 to 80 by the addition of 0.5 to 3 mole \% thallous chloride, cuprous chloride, or ferrous chloride to molten $\mathrm{KCl}-\mathrm{NaCl}$, $\mathrm{KCl}-\mathrm{PbCl}_{2}$, or $\mathrm{KCl}-\mathrm{ZnCl}_{2}$ flux. Similar acceleration of the dissolution of $\mathrm{U}_{3} \mathrm{O}_{8}$ was also observed.

The solubilities of chlorine and hydrogen chloride in molten chloride systems have been determined, and the results are presented in Table 15. In each case the chlorme solubility increased with temperature. The potassium chloride-lead chloride system showed the least tendency to dissolve chlorine. The removal of chlorine or hydrogen 
Table 15 - SOLUBILITIES OF CH LORINE AND HYDROGEN CHLORIDE IN SELECTED MOLTEN SALTS ${ }^{147}$

\begin{tabular}{lcccccc}
\hline & & $\begin{array}{c}\text { Approximate } \\
\text { Salt system }\end{array}$ & $\begin{array}{c}\text { Mole } \\
\text { ratio }\end{array}$ & $\begin{array}{c}\text { Temper- } \\
\text { melting point, } \\
{ }^{\circ} \mathrm{C}\end{array}$ & $\begin{array}{c}\text { Solubility, } \\
\text { ature, } \\
{ }^{\circ} \mathrm{C}\end{array}$ & $\begin{array}{c}\mathrm{Cl}_{2} \\
\mathrm{HCl}\end{array}$ \\
\hline $\mathrm{KCl}-\mathrm{NaCl}$ & 1 & 1 & 667 & 800 & 63 & 50 \\
& & & & 700 & 53 & 79 \\
$\mathrm{KCl}-\mathrm{MgCl}_{2}$ & 3 & 2 & 450 & 600 & 35 & 101 \\
& & & & 500 & 28 & 135 \\
$\mathrm{KCl}-\mathrm{PbCl}_{2}$ & 25 & 1 & 585 & 700 & 20 & \\
& & & & 600 & 14 & \\
\hline
\end{tabular}

chloride by helium sparging was considerably slower in the potassium chloride-magnesium chloride melt; this suggests that some type of bonding with the magnesium chloride occurred.

In the dissolution of plutonium dioxide in potassium chloride-lead chloride and potassium chloride-magnesium chloride at $750^{\circ} \mathrm{C}, \mathrm{Pu}$ (III) was formed with hydrogen chloride sparging, and partial conversion of $\mathrm{Pu}$ (III) to $\mathrm{Pu}(\mathrm{IV})$ was observed with chlorine sparging.

The principal goals of the reduction studies are to achieve production of ceramic-grade oxides and to establish conditions for the precipitation or coprecipitation of the desired oxide or oxides from a manycomponent solution. Systematic studies have been made of variables affecting the bulk density, oxygen to uranium ratio, purity, and other pertinent properties of oxide deposits.

Time-lapse infrared photography has been employed to study the accumulation of crystals on a cathode during the course of an electrolytic reduction. ${ }^{148}$ After the first few minutes of reduction, existing crystals tend to grow uniformly in preference to the formation of new crystals. A prime requirement for growing large, ceramic-grade uranium dioxide crystals is a dry, oxygen-free system. Single crystals werghıng as much as $4 \mathrm{~g}$ and having densitıes as high as 99.5 percent of theoretical have been grown. The crystal size seems to depend on the uranium concentration in the melt. In an experiment in which the uranium concentration was reduced continuously from 20 percent to 1 percent, crystal growth was good in the early stages, but the deposit at the end of the run was a fine powder. ${ }^{146,149}$ Typical crystal analyses show oxygen to uranium ratios of between 2.0006 and 2.005 and lead, potasslum, and chloride contents of 500 to 1000,100 to 200 , and 100 to 200 ppm, respectively. These impurity levels can be substantially reduced by a simple nitric acid leach.

Conditions of the electrolysis may be adjusted to give either selective deposition of uranium dioxide from a salt bath containing dissolved uranium and plutonium or codeposition of a mixture of uranium and plutonium dioxides. The condition required for the selective deposition 
of $\mathrm{UO}_{2}$ is electrolysis under a moisture-free oxygen-free atmosphere, generally achieved by electrolyzing under an atmosphere of anodegenerated chlorine. ${ }^{145}$ Under this condition, a dense, adherent deposit of $\mathrm{UO}_{2}$ is formed. In hot-cell studies, the $\mathrm{UO}_{2}$ was purified from plutonium and rare earths by decontamination factors of 200 and more than 1000 , respectively. For codeposition of uranium and plutonium dioxides, the electrolysis must be performed in an atmosphere containing moisture or oxygen, or both. ${ }^{145}$ In the codeposition of uranium dioxide and plutonium dioxide from a sodium chloride-potassium chloride melt, the product has consisted of mixed crystals rather than solid solutions. Separation factors of only 1 to 2 for cerium and 6 to 8 for other rare earths have been realized. ${ }^{144}$ As yet no satısfactory means has been reported for achieving a good rare-earth separation during electrolytic codeposition of uranium dioxide and plutonium dioxide.

Results have shown that plutonium dioxide can be precipitated from a molten-salt solution of uranium and rare earths by sparging the melt with a mixture of oxygen and chlorine. ${ }^{150}$ Under these conditions, a good separation of plutonium from both uranium and rare earths is possible because these elements remain in solution. The plutonium precipitation is affected strongly by the compositions of the melt and the sparge gas. Decontamination factors based on plutonium of 370 for promethum and 1500 for uranium have been demonstrated. ${ }^{150}$ Plutonium dioxide has also been precipitated from a chloride media by metathesis of plutonium chloride and stannic oxide. ${ }^{151}$

Chemical techniques for precipitating mixed oxides from molten chloride systems have also been examıned. ${ }^{151}$ Mixed plutonium-uranium oxides and mixed uranium - thorium oxides have been precipitated by sparging a chloride melt with moist helium. Plutonium - thorium oxide mixtures were precipitated from a chloride solution by a chlorineoxygen sparge.

Electrolytic procedures for the codeposition of uranium dioxide and thorium dioxide from salt melts containing uranyl chloride and thorium chloride are also under consideration at Hanford. ${ }^{150}$ It was concluded that solid solutions of 48 percent thorlum dioxide in uranium dioxide can be formed as polycrystalline deposits. The deposit can be enriched in thorium, as compared with the melt, by factors at least as high as 2.5. The degree of enrichment decreases with increasing thorium content of the melt. The incorporation of thorium dioxide in the oxide deposit is believed to occur through reaction of thorium tetrachloride with the uranium dioxide as the uranium deposits at the cathode. ${ }^{150}$ The higher thorlum dioxide concentrations (more than $14 \mathrm{wt} . \%$ ) required the use of chlorine or hydrogen chloride sparging during the electrolysis, chlorine being somewhat more effective. ${ }^{151}$

ENGINEERING-SCALE STUDIES Pllot-plant investigations have been conducted on the salt-cycle process at Hanford. ${ }^{151}$ A 24-hr dissolution test 
was made to determine the minımum time required to dissolve $\mathrm{U}_{3} \mathrm{O}_{8}$ in the melt $\left(60 \mathrm{wt} . \% \mathrm{KCl}-40 \mathrm{wt} . \% \mathrm{LiCl}\right.$ ) with chlorine sparging. The $\mathrm{U}_{3} \mathrm{O}_{8}$ was added in two 30-1b increments at zero and $8 \mathrm{hr}$, followed by a $20-1 \mathrm{~b}$ increment at $16 \mathrm{hr}$. The melt was c1rculated through a gas lift by means of 4.4 liters of chlorine per minute, and another 3 liters of chlorine per minute was added through a sparge tube. A total of $81 \mathrm{lb}$ (fourfold excess) of chlorine was added. A maximum dissolution rate occurred after each $\mathrm{U}_{3} \mathrm{O}_{8}$ addition, and it was concluded that with properly timed additions the dissolution could be completed in about $12 \mathrm{hr}$, followed by $2 \mathrm{hr}$ of drying with hydrogen chloride gas.

Electrolytic reductions have been conducted in a $60 \mathrm{wt} \% \mathrm{KCl}-40$ wt.\% LiCl melt in an 80-liter quartz vessel. The $\mathrm{U}_{3} \mathrm{O}_{8}$ feed to the process was dissolved by chlorine sparging at $600^{\circ} \mathrm{C}$, and the resulting solution was dried by chlorine and hydrogen chloride sparging at $535^{\circ} \mathrm{C}$. Several batches of uranium dioxide which varied from about 45 to $85 \mathrm{lb}$ each were produced. In general, the reference potentials were about 0.45 to 0.8 volt, and the current densities were 0.5 to $1.0 \mathrm{amp} / \mathrm{sq} 1 \mathrm{n}$. The oxygen to uranium ratios of the products fell between 2.0006 and 2.005 , and the bulk densities were higher than 95 percent of theoretical. The product was generally of excellent quality and, after a preliminary water rinse, contained lithium and potassium impurities of less than 100 ppm.

\section{Low-decontamination Processes}

Atomics International has a program for the study of lowdecontamination reprocessing of reactor fuel. In low-decontamination processing, fuel is recovered with little removal of fission products. The goals of the program are to generate fuel material that can be refabricated for recycle to a reactor and to reenrich the fuel with fissionable isotopes. In the processing, additional benefits should accrue from repair of radiation damage.

OXIDE.FUEL PROCESSING In a low-decontamination process under development for uranium dioxide fuels, irradiated uranium dioxide is alternately oxidized by air or oxygen at 200 to $600^{\circ} \mathrm{C}$ and reduced by hydrogen at $600^{\circ} \mathrm{C}$ until the particle size is sufficiently small that the material is suitable for refabrication by remote cold pressing and sintering. The oxidation-reduction cycle is used both to remove the oxide fuel from stanless-steel cladding and to produce the particle sizes required for refabrication. Although the procedure removes some fission products (mainly cesium, ruthenium, tellurium, lodine, and the noble gases), the primary goal of the process is to facilitate reenrichment and refabrication of fuel elements for recycle to the reactor.

The processing of $100-\mathrm{g}$ quantities of uranium dioxide 1 rradiated to $15,000 \mathrm{Mwd} / \mathrm{t}$ ky gas-phase oxidation-reduction has been demon- 
strated. ${ }^{152}$ The irradiation had no detrimental effect on the process. The optımum decladdıng rate was at $465^{\circ} \mathrm{C}$ and had an oxygen pressure of $0.5 \mathrm{~atm}$. The rate was increased eightfold to tenfold by perforating the stainless-steel cladding.

Experiments on irradiated oxide with remotely operated pressing and sintering equipment have been started. Pellets pressed from the reprocessed irradiated uranium dioxide appeared sound on the basis of examination through a cave window. ${ }^{153}$

CARBIDE-FUEL PROCESSING Two low-decontamination py rochemical processes for uranium carbide reactor fuels are under investigation at Atomics International. ${ }^{153}$ The major effort is being applied to a carbideoxide-carbide cycle. The carbide is first oxidized by oxygen or carbon dioxide at about $400^{\circ} \mathrm{C}$ to form uranium oxide, which is then converted to the carbide by reduction with carbon at or above $1300^{\circ} \mathrm{C}$. The carbide product is arc melted to form a solid surtable for use as a fuel. A second process for carbide fuels involves a somewhat similar cycle in which the carbide is converted to uranium nitride by reaction with nitrogen; then the reaction is reversed by heating the uranium nitride and carbon under vacuum.

An oxidation-resistant form of uranium monocarbide has been encountered occasionally in material that has been freshly melted. Its oxidation rate is insignificant below $600^{\circ} \mathrm{C}$, in contrast to the usual ignition temperature of 250 to $400^{\circ} \mathrm{C}$, which depends mainly on particle size. The oxidation-resistant form is converted to the reactive form by aging or by exposure to moist a1r. ${ }^{154,155}$

The oxidation of uranium carbide has presented more difficulty in kilogram-scale experiments than was encountered in the oxidation of uranium dioxide fuels. Reaction-rate control and dissipation of heat are more severe problems, and the reaction product, carbon dioxide, must be removed. Rapid oxidation of arc-melted uranium monocarbide is initiated at about $300^{\circ} \mathrm{C}$ in oxygen and produces an oxide with an oxygen to uranium ratio of 2.00 to 2.33 . A second, slower reaction then takes place to produce $\mathrm{U}_{3} \mathrm{O}_{8}$. The oxidation can be controlled by limiting the oxygen pressure or by diluting the oxygen with an inert gas. ${ }^{156}$

Scale-up of air oxidation of uranium monocarbide to kilogram quantities has been initiated. ${ }^{157}$ The operating temperature can be regulated by the air input, and the practical conversion rate is therefore controlied by the heat-removal capacity of the equipment. A rotary-kiln type of furnace with a capacity of about $10 \mathrm{~kg}$ is under consideration. The use of a fluidized bed of alumina in the air oxidation of uranium carbide has also been considered.

Rate measurements made of the oxidation of uranıum monocarbide with carbon dioxide over a temperature range of 375 to $500^{\circ} \mathrm{C}$ indicate first-order kinetics in accordance with the equation ${ }^{158}$ 
$\ln \frac{1}{1-\mathrm{x}}=\mathrm{kt}$

where $\mathrm{x}$ is the fraction of the carbide reacted at time $\mathrm{t}$. Above $550^{\circ} \mathrm{C}$ the first-order rate law does not apply. The rate has also been found to be proportional to the 0.7 power of the carbon dioxide pressure. The oxidation of uranium monocarbide by carbon dioxide, oxygen, nitrogen, and carbon monoxide has been investigated also at Harwell. ${ }^{155,159}$ With all four gases the exten $\mathrm{f}$ of reaction proved to be linear with time. This difference in reaction behavior as compared with the Atomics International experience may be related to the use of sintered compacts of uranium carbide by Harwell and arc-melted material by Atomics International.

Kinetic studies have also been made at Atomics International on the reduction of uranium dioxide with carbon in accordance with the reaction $^{160}$

$\mathrm{UO}_{2}+3 \mathrm{C} \rightarrow 2 \mathrm{CO}+\mathrm{UC}$

The reaction showed a behavior consistent with the second-order equation

$\frac{\mathrm{x}}{1-\mathrm{x}}=\mathrm{kt}$

where $\mathrm{x}$ is the fraction of the total carbon monoxide evolved in time $t$.

The carbothermic reduction of uranium dioxide is being investigated on a kılogram scale. ${ }^{153}$ The first phase of the program involves the reaction of uranium dioxide and carbon in a vacuum induction furnace. Preliminary experiments with half-kılogram quantities of material utilized furnaces with graphite susceptors and lampblack or alumina insulation. The reactants were agglomerated with a binder and water, oven dried at $80^{\circ} \mathrm{C}$, and then heated under vacuum at $900^{\circ} \mathrm{C}$ to remove the binder and residual moisture. The charge was then heated to the reaction temperature $\left(1600\right.$ and $\left.1750^{\circ} \mathrm{C}\right)$ The products thus far, however, proved to be somewhat inhomogeneous, with carbon contents ranging from 5.0 to $5.2 \mathrm{wt} \%$ carbon in one experiment and 4.7 to $5.6 \mathrm{wt} \%$ in the other. The theoretical carbon content for uranum monocarbide is $4.8 \mathrm{wt} . \%$.

For the nitride-cycle treatment of reactive uranium carbide, it has been found that the nitridation rate is maximum between 850 and $900^{\circ} \mathrm{C}$. The particle size has a relatively small effect on the rate. Table 16 presents the results of 10 experiments for regeneration of uranium monocarbide in which uranium nitride has been reacted with carbon by heating a mixture in a vacuum. ${ }^{155}$ At temperatures above $1500^{\circ} \mathrm{C}$, the product sintered, and at $2000^{\circ} \mathrm{C}$ it adhered to the graphite crucible. 
Table 16-REGENERATION OF URANIUM MONOCARBIDE

BY HEATING URANIUM NITRIDE-CARBON

MIXTURES IN VACUUM

\begin{tabular}{rccc}
\hline $\begin{array}{c}\text { Time, } \\
\mathrm{hr}\end{array}$ & $\begin{array}{c}\text { Temper- } \\
\text { ature, } \\
{ }^{\circ} \mathrm{C}\end{array}$ & $\begin{array}{c}\text { Initial nitrogen } \\
\text { content, wt } \%\end{array}$ & $\begin{array}{c}\text { Final nitrogen } \\
\text { content, wt } \%\end{array}$ \\
\hline 10 & 1300 & 77 & 263 \\
8 & 1400 & 69 & 149 \\
10 & 1500 & 73 & 110 \\
5 & 1600 & 82 & 040 \\
5 & 1600 & 67 & 028 \\
10 & 1600 & 73 & 025 \\
5 & 1800 & 80 & 020 \\
5 & 1850 & 73 & 023 \\
4 & 1900 & 80 & 02036 \\
4 & 2000 & 73 & 0045 \\
\hline
\end{tabular}

\section{Mercury Process for Uranium (Hermex Process)}

A process for the removal of impurities from natural and irradiated uranium by solution in and recovery from mercury has been described by Dean of ORNL. ${ }^{161} \mathrm{~A}$ major a1m of the process was to provide an economic means of returning fabrication scrap to required purity for reuse. Sclution rates and solubilities of uranium in mercury and amalgams were determined.

The process that has been demonstrated is shown in Fig. 18. In the first step, uranium is dissolved and withdrawn from beneath a floating dross, which contains any elements and compounds such as the oxides and nitrides of uranium and reactive impurities. The mercury-uranium solution is cooled to precipitate the uranium as an intermetallic compound, which is recovered by filtration. The mercury filtrate is re-

Fig 18- Amalgam processing of uranium metal ${ }^{161}$

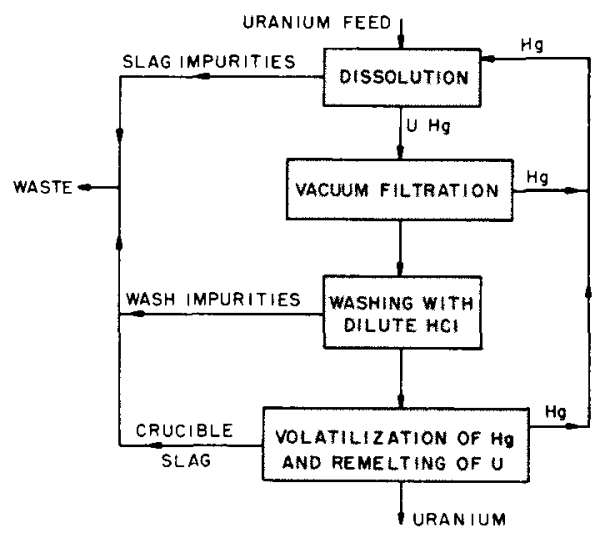


cycled. The uranium-amalgam cake includes the dross, which is removed by acid washing. The washed intermetallic compound is vacuum retorted to remove the mercury, and the resultant uranium is coalesced by melting.

The results of a run with irradiated uranium are presented in Table 17. Interaction of the product and the retort crucible resulted in

\begin{tabular}{|c|c|c|c|}
\hline \multirow[b]{2}{*}{ Step } & \multicolumn{3}{|c|}{ Component removal, $\%$ of total } \\
\hline & Uranıum & $\begin{array}{l}\text { Gross } \\
\text { gamma }\end{array}$ & $\begin{array}{c}\text { Gross } \\
\text { beta }\end{array}$ \\
\hline Solution (dross) & 23 & 442 & 139 \\
\hline Cold filtration & 01 & 16 & 27 \\
\hline Amalgam washing & 40 & 233 & 195 \\
\hline \multicolumn{4}{|l|}{ Mercury distillation } \\
\hline Crucible slag & 136 & 164 & 266 \\
\hline Volatılızed mercury & 01 & 02 & 01 \\
\hline Product & 799 & 48 & 25 \\
\hline
\end{tabular}

Table 18-REMOVAL OF METAL IMPURITIES FROM URANIUM BY MERCURY PROCESSING ${ }^{161}$

\begin{tabular}{|c|c|c|c|c|}
\hline \multirow[b]{2}{*}{ Impurity } & \multicolumn{2}{|c|}{ Run 1} & \multicolumn{2}{|c|}{ Run 2} \\
\hline & $\begin{array}{l}\text { Initral metal, } \\
\text { ppm }\end{array}$ & $\begin{array}{l}\text { Product, } \\
\text { ppm }\end{array}$ & $\begin{array}{l}\text { Initial metal, } \\
\text { ppm }\end{array}$ & $\begin{array}{l}\text { Product, } \\
\text { ppm }\end{array}$ \\
\hline Aluminum & 338 & 41 & 77 & 6 \\
\hline Boron & 00 & 9 & 5 & 6 \\
\hline Calcium & 590 & 10 & 42 & 5 \\
\hline Chromium & 130 & 21 & 20 & 1 \\
\hline Copper & 160 & 5 & 34 & 14 \\
\hline Iron & 270 & 96 & 104 & 7 \\
\hline Magnesium & 6 & 02 & 6 & 0007 \\
\hline Manganese & 20 & 00 & 12 & 003 \\
\hline Nickel & 00 & 51 & 0 & 4 \\
\hline Silıcon & 00 & 65 & 277 & 150 \\
\hline
\end{tabular}

uranium loss, further fission-product removal, and some introduction of crucible elements into the product. Gross beta and gamma, cesium, strontium, and rare-earth decontamination factors of $10^{2}$ to $10^{4}$ were realized for irradiated uranium cooled three years. Gross decontamination factors were poorer on material cooled for shorter times.

Data for the removal of impurities from uranium reduction wastes are given in Table 18 . The boron and silicon impurities in the product probably were introduced from the glass apparatus. 
The process, which shows some promise for purıfication of uranium, particularly scrap material, has the advantages over most other pyroprocesses that steel equipment may be used and that temperatures are low. Two difficulties in the process are the pyrophoricity of uranium quasi-amalgams and the colloidal nature of the $\mathrm{UHg}_{4}$ intermetallic compound in mercury.

Prelimmary development of a process for high-fired uranium dioxide fuels employing reduction, extraction with mercury, and oxidation with steam has also been reported by ORNL. ${ }^{162}$ Uranium dioxide pellets have been reduced at $1000^{\circ} \mathrm{C}$ by magnesium in the presence of a magnesium chloride flux with yields as high as 93 percent. The uranium product was dissolved in bolling mercury, and the resultant solution was filtered hot to remove insoluble material. The filtered solution was cooled to $25^{\circ} \mathrm{C}$ and filtered again to isolate uranium mercuride. The cake was redissolved, crystallized, and filtered again to enhance the purity. The uranum mercuride was then decomposed by steam at $200^{\circ} \mathrm{C}$, which converted the uranium to uranium oxide. The oxide was washed with bolling mercury to remove noble metals and then heated to $900^{\circ} \mathrm{C}$ under vacuum to vaporize the residual mercury.

The uranium product has an oxygen to uranium ratio of 2.43 . It was decontaminated from ruthenium, cesium, and samarium, which had been added to concentrations equivalent to a burnup of $30,000 \mathrm{Mwd} / \mathrm{t}$, by factors of more than 1000,220 , and 75 , respectively.

\section{Aluminum Process for Uranium}

Teitel and Layne ${ }^{32}$ of the Dow Chemical Company reported an investigation of an aluminum pyrometallurgical process for reactor fuel. This process consists in dissolving uranium in molten aluminum, precipitating the uranium as $\mathrm{UAl}_{3}$ by the addition of magnesium, separating the $\mathrm{UAl}_{3}$ and dissociating it by treatment with zinc or magnesium, and retorting to vaporize the residual zinc or magnesium to enable recovery of a uranium-metal product. Fission-product removals are effected by several mechanısms: volatility, insolubility in aluminum, and solubility in supernatant metal phases. This process and various modifications were evaluated in terms of application to the fuel cycle for the EBR-II fast breeder reactor. The behavior of uranium, plutonium, and fission products in the various process systems was discussed. Graphite was generally employed as the container material.

The process has two serious limitations: (1) limited ability to handle molybdenum and ruthenium without significant sacrifice of uranium and (2) difficulty in removing aluminum. This removal required extensive washing operations with magnesium or zinc, with associated uranium losses. Without washing, uranium products with residual aluminum contents of about 1 percent result. The effect of aluminum on radiation stability of the EBR-II alloy has not been tested. 
A second suggested application of the aluminum process is as a head-end step in the processing of low uranium-zirconıum fuel alloys. ${ }^{32}$ In molten aluminum, zirconium is converted by a process of exfoliation to an insoluble compound, $\mathrm{ZrAl}_{3}$, and the uranium goes into solution in the aluminum. Nearly quantitative removal of zirconium may be effected, and uranium losses can be made small. Uranium may be subsequently precipitated from the aluminum solution as $\mathrm{UAl}_{3}$ by the addition of magnesium, and, after separation, the $\mathrm{UAl}_{3}$ may be dissolved in mitric acid to provide a feed solution to the Purex process, the aqueous process currently in general use.

\section{LMFR Processing}

The Brookhaven National Laboratory has developed processes for short-cycle purification of fuel from the proposed Liquid Metal Fuel Reactor (LMFR). The fuel would consist of dilute solutions of uranium, magnesium, and zirconium in bismuth. The fission products are considered in groups according to their chemical and physical behavior. Typical steady-state operating conditions and fuel composition for a two-region (fuel and blanket) LMFR are as follows:

\begin{tabular}{|c|c|c|c|}
\hline Total-core heat rate & $500 \mathrm{Mw}$ & Fission products & \\
\hline Total uranium - bismuth fuel & & FPS & $18 \mathrm{ppm}$ \\
\hline Inventory & 150 tons & Zirconıum & $250 \mathrm{ppm}$ \\
\hline Fuel temperature & & FPN-I & $4.5 \mathrm{ppm} *$ \\
\hline Reactor inlet & $400^{\circ} \mathrm{C}$ & FPN-II & $3.29 \mathrm{ppm}$ \\
\hline Reactor outlet & $550^{\circ} \mathrm{C}$ & FPN-III & 78.6 ppm* \\
\hline Fuel composition & & FPV & $0.016 \mathrm{ppm}$ \\
\hline Bismuth & $99.8 \%$ & $\mathrm{Po}^{210}$ & $26 \mathrm{ppm}$ \\
\hline $\mathrm{U}^{235}$ & $1000 \mathrm{ppm}$ & Corrosion products & \\
\hline Uranıum total & $1500 \mathrm{ppm}$ & Iron & $10 \mathrm{ppm}$ \\
\hline Magnesium & $300 \mathrm{ppm}$ & Chromium & $30 \mathrm{ppm}$ \\
\hline
\end{tabular}

*After $10^{6} \mathrm{sec}$ (1157 days) of full-power operation and with no removal.

The abbreviations "FPS" and "FPN" were selected by Brookhaven to designate the fission products that formed chlorides more stable and less stable, respectively, than uranium chloride. Zirconium was not included with the FPS group because the stability of its chloride is close to that of uranium chloride. The nobler group of fission products, the FPN elements, have been further subdivided. The FPN-I group are fission products that form chlorides of stability intermediate between $\mathrm{UCl}_{3}$ and $\mathrm{BlCl}_{3}$. The FPS, zirconium, and FPN-I groups can theoret1cally be removed from the fuel by proper manipulation of salt-metal extractions; however, the incentive for removal of the FPN-I elements is low because they are of low yield. The proposed salt-extraction process, which is based on the principles and supported by experiments 
mentioned earlier, was described several years ago ${ }^{82}$ and will not be reviewed.

The FPN-II and FPN-III groups of fission products are those which form chlorides less stable than bismuth chloride. The FPN-II group consists of molybdenum, ruthenuum, rhodium, and tellurium, each of which is soluble only to about $1 \mathrm{ppm}$ in the bismuth fuel solution. The solubilities of the last three of these elements are higher than this in pure bismuth but are suppressed by zirconium present in the fuel as a corrosion inhibitor. It has been proposed to remove the FPN-II elements on a cold surface immersed in the fuel. ${ }^{163}$

The FPN-III group of elements, consisting of selenium, niobium, technetrum, and palladium, can be removed, as can residual FPN-II elements, by precipitation with zinc. ${ }^{163}$ In the proposed process the bismuth containing the residual FPN-II and FPN-III elements is treated in large batches with about $0.5 \mathrm{wt} \%$ zinc at $500^{\circ} \mathrm{C}$. The FPN elements form intermetallic compounds with the zinc which, upon cooling and liquating, float as a sludge. The sludge can be separated from the solution by skimming the surface, draining away the bismuth, or filtering. The excess zinc can be removed from the bismuth solution by sparging with chlorine.

The other fission products, the FPV group, are volatile and would be removed continuously from an LMFR fuel stream. ${ }^{164}$ The solubility of xenon is only about $10^{-9} \mathrm{~mole} /\left(\mathrm{cm}^{3}\right)(\mathrm{atm})$ in the fuel, which would indicate that effective removal of the severe neutron poison $\mathrm{Xe}^{135}$ can be expected. Only small amounts of the halogens lodine and bromine are expected in the FPV group, the balance reacting, probably with alkalı and alkaline earths to form lodides, which will extract into flix with the FPS group.

\section{Electrolytic Processes}

A technique for electrorefining thorium into molten zinc at $600^{\circ} \mathrm{C}$ has been reported by Atomics International. ${ }^{165,166}$ It was suggested that such an electrorefining step might constitute the initial step in lowdecontamination processing of nuclear fuels or reactor breeder blankets containing thorium. The use of a molten-zinc cathode eliminates the difficulties of loosely adherent, salt-laden, dendritic deposits encountered with solid inert electrodes. The zinc may be subsequently removed from the thorium-zinc alloy by vaporization.

The current efficiencies of cells were markedly improved by stirring the zinc. ${ }^{165}$ Current efficiencies of essentially 100 percent were obtained with a lithium chloride-potassium chloride salt batch containing $15 \mathrm{wt} . \%$ thorium tetrachloride. The practical limit for the deposition of thorium into zinc at $600^{\circ} \mathrm{C}$ is about $15 \mathrm{wt} . \%$ thorium, at which concentration the alloy becomes paste-like and difficult to stir. It is pos- 
sible to obtain this high concentration, even though the solubility of thorium in zinc is only of the order of 1 percent, as a suspension of $\mathrm{Th}_{2} \mathrm{Zn}_{17}$ crystals.

Los Alamos Scientific Laboratory has developed an electrorefining process to provide high-purity high-density plutonium metal. The products, which have been prepared on $500-\mathrm{g}$ and $3.5-\mathrm{kg}$ scales, have been superior to those produced by high-purity bomb-reduction techniques. ${ }^{167}$ An equimolar solution of sodium chloride-potassium chloride was selected as an electrolyte because these salts are less hygroscopic than alternative chlorides. In the $3.5-\mathrm{kg}$ runs, Pu(III) chloride was added to this electrolyte to a concentration of $10 \mathrm{wt} . \%$. Impure plutonium was located in an anode cup and electrolyzed at about $700^{\circ} \mathrm{C}$ to a tungsten cathode and collected as a liquid in an alumina-yttria cell. The electrolyte was stirred to prevent polarization. Products containing less than $200 \mathrm{ppm}$ detectable metal impurities were produced from a charge containing $2300 \mathrm{ppm}$ impurities at a collection efficiency of greater than 93 percent. Even better results were obtained in the $500-\mathrm{g}$ runs.

A preliminary cost analysis for the recycle of plutonium scrap indicates that electrorefining is considerably cheaper than conventional aqueous methods. ${ }^{167}$

Workers at Atomics International have investigated a procedure for electrolytic dissolution of uranium carbide in a lithium chloridepotassium chloride salt bath, which deposits the uranium as metal on a molybdenum cathode. ${ }^{154,168}$ The metallic uranium deposit is dissolved in mercury and then converted to carbide with propane as the mercury is removed by distillation. Uranium monocarbide clad with 10-mil stainless steel was subjected to anodic dissolution in a lithium chloridepotassium chloride-uranium tetrafluoride salt bath. The cladding material was corroded through, and some carbide was dissolved with a current efficiency near 100 percent. Some fission-product decontamination data are available:

$\begin{array}{lc}\begin{array}{c}\text { Fission-product } \\ \text { element }\end{array} & \begin{array}{c}\text { Decontamination } \\ \text { factor (average } \\ \text { of six experiments) }\end{array} \\ \text { Barium } & 3000 \\ \text { Strontium } & 5000 \\ \text { Rare earths } & 700 \\ \text { Cerium } & 66 \\ \text { Ruthenium } & 500 \\ \text { Zirconium } & 2\end{array}$

These decontamination factors, with the exception of the ruthenium factor, are the ratios of the fission-product concentrations in the salt bath to those in the final uranium monocarbide product. Because sig- 
nificant ruthenum removal occurs at the anode, the over-all value is given.

\section{MATERIALS OF CONSTRUCTION}

The containment of the solvent metals employed in the pyroprocesses is a major problem. Commonly employed solvents, such as zinc and magnesium, dissolve or react with most common container materials (e.g., iron alloys) at processing temperatures. Other materials, such as graphite, that could contain the solvents are unusable because they react with uranium or plutonum solutes, causing irretrievable loss of these fissionable materials.

Corrosion problems are particularly severe in the zinc-molten salt systems employed in the skull-reclamation and blanket processes of the EBR-II fuel cycle. A development program on materials and equipment in support of these processes is under way at Argonne. ${ }^{169,170}$ Special attention is being given to the development of plant-size containers of "production-run" reliability. All materials considered for process use are subjected to corrosion and solution compatibility testing.

Thus far the only materials found with adequate corrosion resistance to molten-zinc and fused-salt media are tungsten, certain alloys of tungsten, and very stable ceramic oxides such as beryllia. These are not common engineering materials, and a fairly extensive program, in cooperation with industry, has been required to develop the necessary technology, e.g., fabrication, for use of these materials in practical engineering equipment.

The corrosion resistance of tungsten to attack by zinc-molten salt systems has been found to be very good. ${ }^{169}$ No corrosion of tungsten could be detected after $500-\mathrm{hr}$ tests at $800^{\circ} \mathrm{C}$ in process systems. The mechanical properties of tungsten were, in fact, improved considerably by the annealing that occurred. Small pressed-and-sintered crucibles have not been visibly affected by over $1000 \mathrm{hr}$ of process use and can withstand repeated freezing and remelting of the contained material. A large (12-1n.-OD by 20-1n.-high) pressed-and-sintered tungsten crucible that is in use in a pilot-plant installation is shown in Fig. 19. The crucible was fabricated with integral mixing baffles on the walls. A similar $5 \frac{1}{4}$-in.-OD tungsten crucible with integral bafiles has been used in more than 40 runs of an average duration of $4 \mathrm{hr}$ at $800^{\circ} \mathrm{C}$ for containment of molten zinc and flux solutions. The crucible is still in use and apparently in perfect condition.

Tungsten can be fabricated into simple, monolithic shapes, such as crucibles, but it cannot readily be fabricated into more complex shapes such as pipes and agitators. A Mo-30 wt. $\mathrm{W}$ alloy has been found satisfactory for these purposes. This material is machinable. Its cor- 


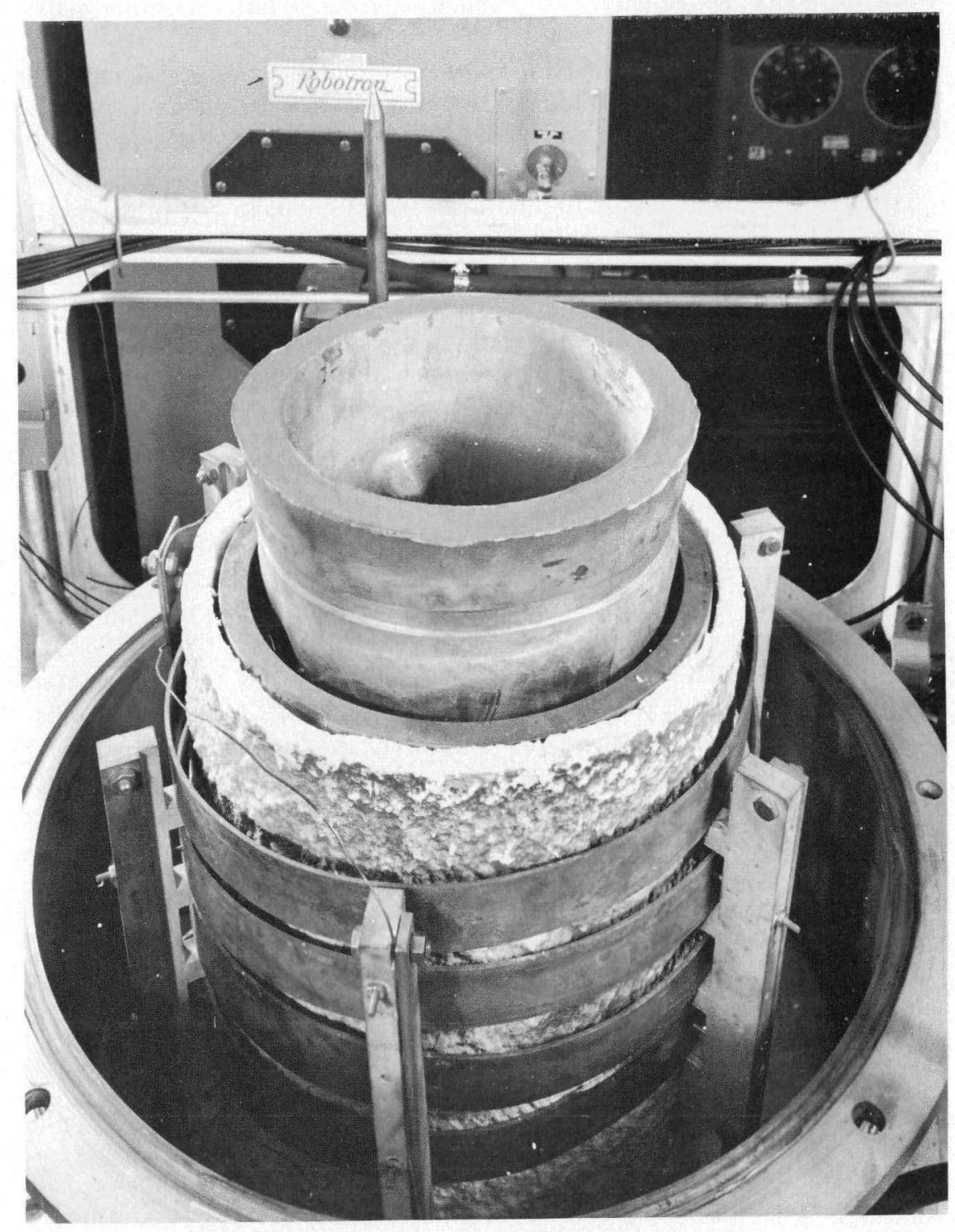

Fig. 19-Tungsten crucible. 
rosion resistance to process systems is not so good as that of pure tungsten because molybdenum is slowly dissolved out, but it is sufficient to permit several thousand hours of process use for items manufactured from it.

Tantalum, once regarded as a potential container material, has been found to undergo intergranular corrosion and embrittlement, especially in the heat-affected zones near welds. Salt fluxes containing zinc chloride cannot be contained in tantalum.

Beryllia is not wet by the metal systems encountered in the skullreclamation and blanket processes. As a result, metal-product phases may be readily removed from beryllia crucibles. Beryllia crucibles, however, are often somewhat porous to the salt fluxes employed. ${ }^{170}$ Therefore beryllia crucibles have been proposed for the steps of the skull-reclamation and blanket processes in which only metal phases are present. Because beryllia crucibles were avallable only in small sizes, it was necessary to develop in cooperation with industry a method of fabricating large crucibles. A method known as "thixotropic casting" shows considerable promise. A small (4-1n.-OD by 9-1n.-high) thixotropically cast beryllia crucible performed well for about $450 \mathrm{hr}$ of repetitive process operations (about 25 runs) before fallure occurred. Large process-size beryllia crucibles have been made by thixotropic casting, but their performance has not been evaluated.

Although stanless steels are severely attacked by molten zinc, they are more resistant to zinc vapor. After $500 \mathrm{hr}$ of exposure to zinc vapor at $900^{\circ} \mathrm{C}$, two 400 -series stamless steels (types 405 and 440 ) showed good resistance to attack, but two austenitic steels (types 304 and 347 ) were severely attacked. ${ }^{169}$ Because of the high vapor pressure of zinc at the processing temperatures, all high-temperature regions of processing equipment using zinc must be able to withstand zinc vapor. It appears that type 400 stainless steel may be used where the only exposure is to vapor, as in vapor-transfer lines in stills or for high-temperature structural supports. Regions in which zinc can condense as a liquid are especially susceptible to corrosion, however.

Similar corrosion problems resulting from the use of zinc chloride, which is both volatile and highly corrosive, have been minimized by maintaining relatively low temperatures (up to $650^{\circ} \mathrm{C}$ ). In most applications, zinc chloride reduces almost immediately when the runs are started, but the effects of long-term operation must still be assessed.

Brookhaven did extensive corrosion testing of materials for the salt-extraction processing of uranium-bismuth fuel. ${ }^{171}$ Several of the most common steels had satisfactory corrosion resistance to the eutectic $\left(\mathrm{MgCl}_{2}-\mathrm{NaCl}-\mathrm{KCl}\right)$, but none of these could tole rate even small amounts of bismuth trichloride in the flux. Corrosion by the two-phase system of bismuth-fuel solution and ternary eutectic salt resembled that expected in fuel alone. The selection of a material appears to de- 
pend on the selection of a container material for the fuel. The most probable materuals appear to be type 1020 mild steel or steels containing $1 \frac{1}{4}$ wt. $\% \mathrm{Cr}-1 / 2 \mathrm{wt} . \% \mathrm{Mo}$ or $2 \frac{1}{4}$ wt.\% $\mathrm{Cr}-1$ wt.\% Mo.

The development of tantalum and tantalum-base alloys has recelved considerable attention for application to the containment of plutonium1ron eutectic reactor fuel. ${ }^{172,173}$ The corrosion resistance of various alloys to mercury is under study at Aerojet-General Corporation ${ }^{174}$ and Brookhaven. ${ }^{175}$ A paper discussing liquid-metal corrosion mechanisms has been presented. ${ }^{176}$

\section{CONCLUSION}

Pyroprocessing concepts are avallable for nearly all the separations required in the processing of nuclear-fuel materials, e.g., separation of fission products and alloying elements from uranium, thorium, or plutunium, separation of plutonium from uranium, and the separation of uranium from thorium. A variety of fuel materials (metal, oxide, and carbide) can be handled by many of the processes. Many of these processes remove fission products sufficien'ly for reactor operation or restoration of desired fuel properties. The molten metal-molten salt extraction systems, however, offer potential for efficient separations and high recoveries in multistage applications.

An outgrowth of the development of pyroprocesses for purification of irradiated fuel materials has been the realization that the processes, often in simplified form, can be used in processing ores, recovering scrap, producing compounds, and reducing compounds to metals. A notable example of an application for production of nuclear raw materials is the use of an electrorefining technique for preparation of highdensity high-purity plutonium on a production scale at Los Alamos.

Considerable progress has been made toward utilization of pyrometallurgical processes for recovery of irradiated fuel materials. Because of the low decontamination generally realized in pyroprocesses, remote fuel-refabrication procedures are being developed and demonstrated as an integral part of these processes. Much of the engineering development has been associated with the intent to use pyrometallurgical processes in the EBR-II fuel cycle. For the purpose of demonstrating these processes, a plant has been built adjacent to the EBR-II reactor. Use of the EBR-II processes for production type operations in this plant will provide much-needed information on the technological and $\epsilon$ conomic capabilities of pyrometallurgical processes.

The accumulation of fundamental data for metal and salt systems has continued at an impressive level. The ever-increasing fund of fundamental data is a valuable resource for origination of new process concepts and the assessment of their feasibility. 
The ability to develop process concepts far outstrips present capabilities of expanding these concepts to a practical, engineering scale. The high temperatures and the scarcity of practical engineering materials for containment of highly corrosive metal and salt systems are formidable engineering problems that must be solved before widespread use of pyrometallurgical processes can be expected. Nevertheless, considerable progress has been made in the developing and testing of engineering materials and in the fabricating of these materials into processing equipment. Many of these materials, which are presently regarded as somewhat exotic, e.g., tungsten and beryllia, may, because of developments in their technology, become regarded as common engineering materials.

Although advances have been made in pyroprocessing, full recognltion of their potential awaits demonstration of one or more on an eng1neering scale. Such demonstrations are in the offing and, if successful, will provide considerable impetus for acceleration of the development of other processes in the pyroprocessing area.

\section{REFERENCES}

1. Argonne National Laboratory, Symposium on High Temperature Fuel Processing, January 19-21, 1955.

2. H M. Feder and I G. Dillon, Pyrometallurgical Processes, Chap. 7, Reactor Handbook, pp. 313-341, Vol. 2, Fuel Reprocessing, pp. 313-341, Interscience Publishers, Inc., New York, 1961.

3 M Gazith, Literature Survey on Pyrometallurgical Purification of Metals 1. Liquid Metal Extraction. 2 Precipitation in Moiten Metal, Israeli Report LS/93, January 1961.

4 E Motta et al., Pyrometallurgical Processes Process and Equipment Development, Symposium on the Reprocessing of Irradıated Fuels, Held at Brussels, Belgium, May 20-25, 1957, USAEC Report TID-7534(Bk 2), pp $719-747,1957$

5 J. H. Schraidt and M. Levenson, Developments in Pyrometallurgical Processing, Progr Nucl Energy, Ser III, 3 329-339 (1960).

6. F. S. Martin and G L. Miles, The Principles of High Temperature Fuel Processing, Progr Nucl Energy, Ser III, 1 291-300 (1956)

7. L. Burris, M Levenson, J. H. Schraidt, and R K Steunenberg, Recent Advances in Pyrometallurgical Processes, Trans. Am. Nucl. Soc., 4(2) 192194 (1961)

8 M. Feder and R. J Teitel, Purification of Reactor Fuels and Blankets by Crystallization from Liquid Metal Solvents, Prog. Nucl. Energy, Ser. III, $3 \quad 355-390(1960)$

9 William G Pfann, Zone Melting, John Wiley \& Sons, Inc, New York, 1958

10 C. A. Hampel (Ed.), Rare Metals Handbook, Reınhold Publıshing Corporation, New York, 1961

11. Max Hansen and K. Anderko, Constztution of Bınary Alloys, McGraw-Hill Book Company, Inc., New York, 1958. 
12. Premo Chıottı and K J. Gill, Phase Diagram and Thermodynamic Properties of the Thorium-Zinc System, Trans Met Soc AIME, 221 573-580 (1961).

13. E. Daniel Albrecht, The Plutonium-Zinc Phase Diagram from 65 to 100 Atomic Percent Zinc, MS Thesis, USAEC Report TID-12630, Los Alamos Scientific Laboratory, 1961

14. P. Chıottı, H H Klepfer, and K. J Gill, Uranıum-Zinc System, J Metals, Trans AIME, 209 51-57 (1957)

15. Argonne National Laboratory, Chemical Engineerıng Divisıon Summary Report, October, November, December 1960, USAEC Report ANL-6287, pp. 102-104, March 1961.

16 Argonne Nationdl Laboratory, Chemical Engineering Division Summary Report, April-June 1962, USAEC Report ANL-6569, pp 80-81, August 1962

17 E S. Makaror and S. I. Vınogradov, Crystal Structure of $\mathrm{Th}_{2} \mathrm{Zn}_{17}$ and $\mathrm{U}_{2} \mathrm{Zn}_{17}$, Kristallogratiya, 1 634-643 (1956)

18 Ames Laboratory, Annual Summary Research Report in Chemistry Eng1neering Metallurgy and Physics, July 1, 1961, to June 30, 1962, USAEC Report IS-500, pp. M-22-30, September 1962

19 A E Martın, I Johnson, and H M Feder, The Cadmium-Uranium Phase Diagram, Trans liet Soc AIME, 221 789-791 (1961)

20 Argonne National Laboratory, Chemical Engineering Division Summary Report, October-December 1962, USAEC Report ANL-6648, pp. 80-83, May 1963.

$21 \mathrm{C}$ E. Lundin, Jr, and $\mathrm{D} \mathrm{T}$ Klodt, Phase Equilibria in the YttriumAluminum System, Trans Am Soc Metals, 54 168-175 (1961)

22 M. G Chasanov, P D Hunt, I. Johnson, and H M Feder, Solubility of 3-d Transition Metals in Liquid Cadmium, Trans. Met. Soc. AIME, 224 935938 (1962)

23. Argonne National Laboratory, Chemical Engineering Division Summary Report, January, February, March 1961, USAEC Report ANL-6333, pp. 101109,1961

24 Argonne National Laboratory, Chemical Engineering Division Summary Report, Aprll, May, June 1960, USAEC Report ANL-6183, pp 66-69, Jan. 12, 1961.

25 Argonne National Laboratory, Chemical Engineering Division Summary Report, January, February, March 1960, USAEC Report ANL-6145, p. 70, Aug 31,1960

26 Argonne National Laboratory, Chemical Engineerıng Division Summary Report, April, May, June 1959, USAEC Report ANL-6029, pp. 48-60, September 1959

27 Argonne National Laboratory, Chemical Engineering Division Summary Report, January, February, March 1959, USAEC Report ANL-5996, pp. $92-$ 105, June 1959

28 A. E Martin, Solubilities in Liquid Zinc, J Chem Eng Data, 6(4) 596 (1961)

29 J B Knighton L Burris, Jr , and H M. Feder, Purification of Reactor Fuels Using Liquid Zınc, USAEC Report ANL-6223, Argonne National Laboratory, January 1961.

30 A F. Messing and O C Dean, Solubilities of Selected Metals in Mercury Hermex Process, USAEC Report ORNL-2871, Oak Ridge National Laboratory, June 29, 1960 
31 D G. Schweitzer and J. R. Weeks, Liquid-metal Fuel Constitutions-III. Liquidus Curve of the Bismuth Fission-product System, Trans. Am Soc. Metals, 54 185-200 (1961).

32. R. J Teitel and G. S. Layne, The Dow Aluminum Pyrometallurgical Process, USAEC Report TID-11692, Dow Chemical Company, Aug. 19, 1960

33. A S. Coffinberry and W. Miner, The Metal Plutonum, University of Chicago Press, Chicago, 111., 1961.

34. P. Chiottı, G A Tracy, and H. A Wilhelm, Magnesium-Uranium System, Trans. ALME, 206 562-567 (1956).

35 Argonne National Laboratory, Chemical Engineering Division Summary Report, July, August, September 1957, USAEC Report ANL-5789, pp. 89-95, December 1957.

36. Argonne National Laboratory, Chemical Engineering Division Summary Report, October, November, December 1958, USAEC Report ANL-5959, pp. 120-121, March 1959.

37. R. H. Wiswall, Jr., and J. J. Egan, Thermodynamic Properties of Solutions of the Actinides and the Principal Fission Products in Bismuth, in Thermodynamics of Nuclear Materials, pp. 345-364, International Atomic Energy Agency, Vienna, 1962.

38. H A. Doerner and W M. Hoskins, Co-precipitation of Radium and Barium Sulfates, $J$ Am Chem Soc., 47 662-675 (1925).

39. Argonne National Laboratory, Chemical Engineering Division Summary Report, July, August, September 1958, USAEC Report ANL-5924, pp. 135-136, December 1958.

40 Argonne National Laboratory, Chemical Engineering Division Summary Report, January - March 1962, USAEC Report ANL-6543, pp. 94-96, June 1962

41. Argonne National Laboratory, Chemical Engineering Division Summary Report, October, November, December 1961, USAEC Report ANL-6477, pp. 47-52, March 1962.

42. Reference 41, pp 9497

43. Reference 27, pp. 111-114.

44. Reference 23, pp. 110-112.

45. Reference 41, pp. 93-94.

46. Reference 16, pp. 83-85.

47. Argonne National Laboratory, Chemical Engineerıng Divisıon Summary Report, July, August, September 1959, USAEC Report, ANL-6068, pp. 72-74, 1959.

48. Reference 27, pp. 97-103.

49. D. G. Schweitzer and J. R. Weeks, Liquid-metal Fuel Constitution-II. Liquidus Curves of the Uranium-Zirconium-Bismuth System, Trans. Am. Soc. Metals, 53 259-264 (1960).

50. A. F. Weinberg, R. J. VanThyne, and R E Steiner, Uranium Solubility in Bismuth-base Liquid Solutions, Trans Met. Soc AIME, 221 83-90 (1961).

51. A Glassner, The Thermochemical Properties of the Oxides, Fluorides, and Chlorides to $2500^{\circ} \mathrm{K}$, USAEC Report ANL-5750, Argonne National Laboratory, 1957.

52. J J Egan, W. McCoy, and J Bracker, The Standard Molar-free Energy of Formation of Some Chlorides of Magnesium, Cerlum, Uranium, and Thorium by Solıd-state EMF Techniques, in Thermodynamics of Nuclear Materials, pp. 163-172, International Atomic Energy Agency, Vienna, 1962 
53 O H Krıkorıan, Hıgh-temperature Studıes, USAEC Report UCRL-2888, University of Calıfornia Radiation Laboratory, April 1955

54 E J Huber and C E. Holley, Jr., The Thermodynamic Properties of the Actinide Carbides Including New Measurements of the Heats of Formation of Some Thorium, Uranium, and Plutonium Carbides, in Thermodynamics of Nuclear Materials, pp. 163-172, International Atomic Energy Agency, Vienna, 1962

55. Reference 36 , pp. 124-126

56 I Johnson and $\mathrm{H}$ M. Feder, Thermodynamics of the Binary Systems of Uranum with $\mathrm{Zn}, \mathrm{Cd}, \mathrm{Ga}, \mathrm{In}, \mathrm{Tl}, \mathrm{Sn}$, and $\mathrm{Pb}$, in Thermodynamics of Nuclear Materials, pp. 319-329, International Atomic Energy Agency, Vienna, 1962

57. Reference 24, pp. 72-75

58 I Johnson and H. M. Feder, Thermodynamics of the Uranıum-Cadmium System, Trans Met Soc AIME, 224 468-473 (1962).

59. J. J. Egan and R. H. Wiswall, Jr., Applying Thermodynamics to Liquidmetal-fuel Reactor Technology, Nucleonics, 15(7) 104-106 (1957).

60. P A. Rice, R. E. Balzhiser, and D V. Ragone, Thermodynamics of the Uranium-Bismuth System, in Thermodynamics of Nuclear Maternals, pp. 331-344, International Atomic Energy Agency, Vienna, 1962.

61. J. F. Smith, Determination of Thermodynamic Functions for the Formation of Binary Intermetallic Phases from Vapor Pressure Measurements, USAEC Report IS-440, Ames Laboratory, March 1962

62 Ames Laboratory, Annual Summary Research Report in Metallurgy, July 1959 -June 1960, USAEC Report IS-193, pp. 32-35, December 1960.

63. Reference 27, pp. 116-122.

64. Argonne National Laboratory, Chemical Engineering Division Summary Report, July, August, September 1960, USAEC Report ANL-6231, pp. 78-80, 1960

$65 \mathrm{P}$ Chlotti and G. R K1lp, Vapor Pressures and Thermodynamic Properties of $\mathrm{Zn}-\mathrm{Zr}$ and $\mathrm{Zn}-\mathrm{U}$ Alloys, Trans AIME, 218 41-46 (1960).

66. P Chiottı, Separation of Impurities from Thorium by Extraction with Magnesium and by Oxidation-Reduction Reactions in a Zine - Salt System, Proceedings of the Thorium Fuel Cycle Symposium, Gatlınburg, Tennessee, Dec 5-7, 1962, USAEC Report TID-7650(Bk. 1), pp. 436-453, 1963.

67 Reference 16, pp. 60-62

68 Reference 41, pp. 69-74

69. Argonne National Laboratory, Chemical Engineering Division Summary Report, July-September 1962, USAEC Report ANL-6596, pp. 87-90

70 C. F. Bonilla, Mass Transfer in Molten Metal and Salt Systems, in Proceedings of the Unted Nations International Conference on the Peaceful Uses of Atomic Energy, Geneva, 1955, Vol. 9, pp. 331-340, United Nations, New York, 1956.

71 A V Grosse, J. A. Cahill, and A D. Kirshenbaum, Density of Liquid Uranium, $J$ Am. Chem. Soc, 83 4665-4666 (1961).

72. C. Z Serpan and L. J. Wittenberg, The Density of Liquid Plutonium Metal, Trans AIME, 221 1017-1020 (1961).

73. A. F. Voigt, R G. Clark, J. G. Gonser, D L. Haes, G. J. Lutz, and K. L. Malaby, Removal of Plutonium from Uranium by Molten Metal Extraction, USAEC Report IS-470, Ames Laboratory, May 1962

74. D. E. McKenzie, Distribution of Plutonium in the Systems of UraniumSilver and Uranium - Silver-Gold, Can J Chem, 34 749-756 (1956) 
75 D E. McKenzie, $\mathrm{W}$ M. Jenkinson, and A S Denovan, Limiting Heat of Solution of Plutonium in Some Rare Earth Metals, Can J Chem, 34 11761181 (1956)

76. Reference 18, pp. C-54-57.

77 Ames Laboratory, Annual Summary Research Report in Chemistry July 1, 1960, to June 30, 1961, USAEC Report IS-350, pp. 61-66, September 1961

78. Reference 16 , pp. $86-87$

79. Reference 40, pp. $97-99$

80. Reference 64 , pp. $74-76$

81. F. A. Cafasso, H. M Feder, and I. Johnson, Partition of Solutes Between Liquid Metals, I. The Aluminum-Cadmium System $J$ Phis Chem 66 1028-1030 (1962).

82. O. E. Dwyer, Process for Fission Product Removal from Uranium-Bismuth Reactor Fuels by Use of Fused Salt Extraction, A I Ch $E \quad J, 2$ 163-168 (1956).

83 W. S Ginell, Oxidation Extraction of Lanthanide Metals from Molten Bismuth by Fused Salts, Ind Eng Chem, 51 185-188 (1959).

84 F. J Salzano and F B Hill, Distribution of Uranium and Cerium Between Liquid Bismuth-Magnesium Alloy and Liquid $\mathrm{NaCl}-\mathrm{KCl}-\mathrm{MgCl}_{2}$ Eutectic, USAEC Report BNL-639, Brookhaven National Laboratory, June 1962

85 R. H. Moore and $W$ L Lyon, Distribution of the Actinide Elements in the Molten System $\mathrm{KCl}-\mathrm{AlCl}_{3}-\mathrm{AI}$, USAEC Report HW-59147, Hanford 4tomic Products Operation, October 1959

86. J R Morrey and R H Moore, Thermodynamic Evidence for Complex Formation by Actinide Elements in Fused $\mathrm{KCl}-\mathrm{AlCl}_{3}$ Solvents $J$ Phys Chem, 67 748-752 (April 1963).

87. $\mathrm{R}$ H. Moore, J R Morrey, and E E Volland, The Equilibrium Controlled Reduction of Uranium Chloride by Molten Aluminum in a Fused Salt Solvent $J$ Phys Chem, 67 744-747 (April 1963).

88. R. H Moore, Cation and Anion Effects on the Distribution of Uranium in the System Aluminum-Aluminum Halide-AIkalı Halide, USAEC Report HWSA-2537, Hanford Atomic Products Operation, Apr 13, 1962.

89. P. Chiotti and S F. S Parry, Separation of Various Components from Uranium by Oxidation-Reduction Reactions in a Liquid Potassium ChlorideLithium Chloride/Zinc System, $J$ Less-Common Metals, 4 315-337 (1962)

90. Reference 16, pp. 39-43.

91 Reference 20, pp 46-53.

92 Reference 69, pp. 59-66

93. J. B. Knighton and R. K Steunenberg, Effect of Flux Composition on the Reduction of Uramum, Thorium, and Plutonium Oxides by Zinc-Magnesium Alloy, Trans. Am. Nucl. Soc , 4(2): 352-353 (November 1961).

94. A. V Harıharan, J B. Knighton, and R K. Steunenberg, Direct Reduction of Thorium Dioxide, Trans Am Nucl Soc, 5(2) 461-462 (November 1962).

95. D O Raleigh, Preparation of Thorium-Aluminum Alloys by Direct Thorla Reduction, USAEC Report NAA-SR-5689, Atomics International, Dec. 1, 1960

$96 \mathrm{~B}$ A Partridge and $\mathrm{R} \mathrm{J}$. Moulton, The Reduction of $\mathrm{UCl}_{3}$ in $\mathrm{LlCl}-\mathrm{KCl}$ Eutectic by $\mathrm{Mg}$ in Cd, Britısh Report AERE-R-3607, November 1961

97 G Jangg, Metallic Nuclear Fuel Obtained with Amalgam Metallurgy, Atompraxis, 8 87-89 (March 1962) (in German). 
98 W. Stoll, Industrial and Economic Aspects of Obtainung Uranium with the Amalgam Process, Atompraxis, 8 87-92 (March 1962) (1n German)

99. J. H Reynold (Ed), Nuclear Engineering Department Progress Report, January 1-April 30, 1962, USAEC Report BNL-731, pp. 40-41, Brookhaven National Laboratory, 1962.

100. P R Josephson and L. E Burkhart, A Countercurrent Multistage, Fused Salt-Molten Metal Extractor, Trans Am Nucl Soc, 4352 (November 1961).

101. Reference 69, pp. 84-87.

102 Reference 20, pp. 86-88.

103 Argonne National Laboratory, Chemical Engineering Division Summary Report, April, May, June 1961, USAEC Report ANL-6379, pp. 94-99, October 1961

104. Reference $16, \mathrm{pp} .57-58$

105 Argonne National Laboratory, Chemical Engineering Division Summary Report, July, August, September 1961, USAEC Report ANL-6413, pp. 72-74, 1961

106 Reference 20, pp. 84-86.

107 Reference 69 , pp. $80-83$

108. L J Koch, H. O Monson, D Okrent, M Levenson, W R Simmons, J R Humphreys, J Haugsnes, V C. Jankus, and W B. Loewensteın, Experımental Breeder Reactor II (EBR-II), Hazard Summary Report, USAEC Report ANL-5719, Argonne National Laboratory May 1957.

109 A B Shuck and $J$ E. Ayer, Engineering Considerations for Remote Fabrication of EBR-II Fuel Elements, Nucl Scl Eng, 12 398-404 (1962)

110. The Melt Refining of Irradiated Uranium Application to EBR-II Fast Reactor Fuel, Sections I-V, Nucl Scl Eng, 6(6) 493-513 (December 1959).

111. H F Jelinek, N J Carson, Jr, and A. B Shuck, Fabrication of EBR-II Core-I Fuel Pins, USAEC Report ANL-6274 Argonne Natıonal Laboratory, June 1962.

112 H F Jelinek and G. M. Iverson, Equipment for Remote Injection Casting of EBR-II Fuel, Nucl Scl Eng, 12 405-411 (1962).

113. D. C. Hampson, Preparation of Alloy for First Core Loading of EBR-II, USAEC Report ANL-6290, Argonne National Laboratory, August 1961.

114 The Melt Refining of Irradiated Uranıum Application to EBR-II Fast Reactor Fuel, Sections VI-XII, Nucl Scl Eng, 9(1) 55-90 (January 1961).

115. Reference 15, pp. 89-94

116 Reference 41, pp. 29-33

117 Reference 20, pp. 32-38.

118. V. G. Trice, Jr, and $R$ K Steunenberg, Small-scale Demonstration of the Melt Refining of Highly Irradiated Uranium-Fissium Alloy, USAEC Report ANL-6696, Argonne National Laboratory, August 1963.

119 A W Castleman, Jr., The Chemical and Physical Behavior of Released Fission Products, USAEC Report BNL-6415, Brookhaven National Laboratory, 1962

120 N. R. Chellew and R. K. Steunenberg, Fission Gas Release and Swelling During Heatıng of Irradiated EBR-II Type Fuel, Nucl Scı. Eng , 14(1) 1-7 (September 1962).

121. J P LaPlante and $\mathrm{R} \mathrm{K}$ Steunenberg, The Nitridation Rates of UraniumFissium Alloys, USAEC Report ANL-6642, Argonne National Laboratory November 1962 
122 L. J Mullins, J A Leary, and W. J Maraman, Removal of Fission Product Elements by Slagging, Ind Eng Chem, 52 227-230 (1960).

123. Reference $40, \mathrm{pp} 32-35$

124 Reference 64 , pp 55-56

125 Reference 20, pp. 40-43

126 Reference $40, \mathrm{pp} .37-43$

127 Masayoshı Kanno and Sanya Kokubo, Pyrometallurgical Processing of $\mathrm{Nu}-$ clear Fuels by Molten Zinc, $J$ At Energy Soc Japan, 4 30-36 (January 1962) (in Japanese).

128. Reference 16 , pp. 36-39

129 Reference 105, pp. 52-53.

130. Reference 16 , pp. 43-50.

131. Reference 69, pp. 66-69.

132 Reference 103, pp. 75-79

133 Reference 105, pp. 56-59.

134. Reference 69, pp. 104-107.

135. Reference 69 , pp. 55-57

136. Reference 69, pp. 50-55.

137 Reference 40, pp 51-55

138. Reference $16, \mathrm{pp} .63-65$

139 Reference 40, pp. 62-63

140. T R Johnson, G D White, J H Handwerk, and R. K. Steunenberg, Sintering of Uranium Monocarbide Precipitated from Liquid Metal Media, Trans Am Nucl Soc, 5 243 (June 1962).

141. A. Schneider, L Burris, Jr., and S Lawroskı, The Synthesis of Refractory Nuclear Feed Materials in Liquid Metal Media, Trans Am Nucl Soc, 4 345-346 (November 1961).

142. P. Chiottı, P. F. Woerner, and S. J. S Parry, Pyrometallurgical Reprocessing of Thorium-Uranium Fuel, in Il Ciclo Combustıble U-Th, $\mathrm{p}$ 405432, Comitato Nationale Energia Nucleare, Rome, Italy, 1961

143. J. D. Chilton, L A Hanson, E. W. Murbach, and F. W Hodge, Separation of Uranium from Thorium by Liquid Metal Extraction, Thorium Recovery and Fission Product Distribution, USAEC Report NAA-SR-6666, North American Aviation, Inc., Feb. 1, 1962.

144. S. Goldsmith (Ed.), Plutonium Recycle Program Annual Report, Fiscal Year 1961, USAEC Report HW-70000, Hanford Atomic Products Operation, Aug. 11, 1961.

145 K M. Harmon, The Salt Cycle Process Concept, Trans Am Nucl. Soc, 4(2) 183-184 (November 1961).

146. S. Lawroski et al, Pyrometallurgical Processes, Reactor Fuel Process, 5(2) 34-36 (April 1962).

147. M C. Lambert and R. L. Braun, Catalytic Increase in Dissolution Rate of Uranium Oxides by $\mathrm{Cl}_{2}$ in Molten Salts, USAEC Report HW-SA-2636, Hanford Atomic Products Operation, June 11, 1962

148. S Lawroskı and associates, Pyrometallurgical Processes, Reactor Fuel Process , 5(1) 44-45 (January 1962).

149. F A Scott and L K. Mudge, The Electrolytic Preparation of Single Crystals of Uranium Dioxide, USAEC Report HW-SA-2645, Hanford Atomic Products Operation, June 18, 1962.

150. S Lawroski and associates, Pyrometallurgical Processes, Reactor Fuel Process , 5(3) 34-36 (July 1962). 
151. S. Lawroski and associates, Pyrometallurgical Processes, Reactor Fuel Process., 5(4): 46-49 (October 1962).

152. J. Guon, J. E. Bodine, R. J. Sullivan, F. W. Gandolfo, Low Decontamination Reprocessing Studies on Irradiated Uranium Dioxide Reactor Fuel, USAEC Report NAA-SR-7136, North American Aviation, Inc., Nov. 30, 1962.

153. Reference 151, pp. 49-50.

154. Reference 146, pp. 35-37.

155. Reference 150, pp. 37-39.

156. E. W. Murbach, The Oxidation of "Reactive" Uranium Carbide, USAEC Report NAA-SR-6331, North American Aviation, Inc., July 15, 1961.

157. Reference 148, pp. 46-47.

158. E. W. Murbach and W. D. Turner, Oxidation of Uranium Carbide by Carbon Dioxide, USAEC Report NAA-SR-7482, North American Aviation, Inc., Dec. $30,1962$.

159. K. A. Peakall and J. E. Antill, Oxidation of Uranium Monocarbide, British Report AERE-R-3834, August 1962.

160. W. G. Smiley, Oxidation-Reduction Reprocessing of Uranium Carbide Reactor Fuel I. Carbothermic Reduction of $\mathrm{UO}_{2}$, USAEC Report NAA-SR-6976, North American Aviation, Ine., Mar. 15, 1962.

161. O. C. Dean, Mercury Processing of Uranium and Its Alloys, Progr. Nucl. Energy, Ser. III, 2: 412-419 (1958).

162. A. F. Messing and O. C. Dean, Processing of High-fired Uranium Dioxide Fuels by a Reduction-Mercury Extraction-Oxidation Process, USAEC Report ORNL-2909, Oak Ridge National Laboratory, Aug. 12, 1960.

163. O. E. Dwyer, H. E. Howe, and E. R. Avrutk, Removal of the More Noble Nonvolatile Fission Products from Uranium-Bismuth Fuels, Nucl. Sci. Eng., 12(1): 15-22 (January 1962).

164. O. E. Dwyer and A. M. Eshaya, On the Removal of Volatile Fission Products from Uranium-Bismuth Reactor Fuels, Nucl. Sci. Eng., 6(4): 350-360 (October 1959).

165. R. E. Johnson, Electrodeposition of Thorium from Fused Salts into a Molten Zinc Cathode, J. Electrochem. Soc., 109: 989-991 (October 1962).

166. W. N. Hansen, Decontamination of Thorium by Electrolysis: A Theoretical Discussion, USAEC Report NAA-SR-4885, North American Aviation, Inc., June $15,1960$.

167. L. J. Mullins, J. A. Leary, A. N. Morgan, and W. J. Maraman, Plutonium Electrorefining, USAEC Report LA-2666, Los Alamos Scientific Laboratory, Feb. 2, 1962.

168. W. N. Hansen, Reprocessing of Uranium Carbide by Molten Salt Electrolysis, USAEC Report NAA-SR-7660, North American Aviation, Inc., Mar. 15, 1963.

169. Reference 20, pp. 65-76.

170. Reference 69 , pp. 69-78,

171. H. Susskind, F. B. Hill, L. Green, S. Kalish, L. E. Kukacka, W. E. McNutty, and E. Wirsing, Jr., Corrosion Studies for a Fused Salt-Liquid Metal Extraction Process for the Liquid Metal Fuel Reactor, USAEC Report BNL585, Brookhaven National Laboratory, June 30, 1960.

172. Los Alamos Scientific Laboratory, Quarterly Status Report on LAMPRE Program for Period Ending August 20, 1962, USAEC Report LAMS-2753, p. 8, September 1962 . 
173. B. J. Thamer, Corrosion Tests with Molten Plutonium Fuels, in Corrosion of Reactor Materials, Vol. 2, pp. 285-318, International Atomic Energy Agency, Vienna, 1962.

174. Aerojet-General Corporation, Mercury Corrosion Loop Testing Program, Third Quarterly Report, Aprll 1-June 30, 1962 AGC-0584-04-3, August 1962.

175. Reference 99, pp. 56-69.

176. J. R. Weeks and C. J. Klamut, Liquid Metal Corrosion Mechanısms, in Corrosion of Reactor Materials, Vol. 1, pp. 105-132, International Atomic Energy Agency, Vienna, 1962. 


\section{Reactor By-products}

A. F. Rupp

Oak Ridge Nationai Laboratory 
he original Atomic Energy Act recognized that large quantities of radioactive materials would be produced as a result of the operation of nuclear reactors, and these materials are identified and described in the Feder al Regislel: ${ }^{1}$

"By product materıal" means any radıoactıve materıal (except special nuclear material*) yielded in or made radioactive by exposure to the radiation incident to the process of producing or utilizing special nuclear material

This definition 1s, of course, primarily for legal purposes and indicates that atomic energy by-products include all the radioisotopes produced by interactions of radiation from reactions with matter (almost exclusively neutron reactions) and, most clearly, the fission products resulting from the chain reaction itself. Primordial natural radioactivities, such as radium and $\mathrm{K}^{40}$, cyclotron-produced radioisotopes, cosmic-ray-produced radioisotopes in nature, and fission products from bomb explosions in the atmosphere, are not covered and are therefore exempt from the regulations of the Atomic Energy Act. The regulations would appear not to cover nonradioactive by-products of reactors, e.g., stable fission-product isotopes or the stable products of decay of neutron-produced radioisotopes.

All the by-products are by definition radioisotopes, and three categories are fairly obvious: (1) neutron-produced light radioisotopes from hydrogen to uranium, (2) fission products, and (3) neutronproduced heavy transuranium isotopes. Of these by-products the only ones that fall within the usual understanding of the term "by-product" are the fission products, which are an unavoidable product of the nuclear chain reaction; uranium; and transuranium elements formed in natural-uranium reactors. To obtain the other radioisotopes, one must deliberately irradiate materials for the purpose. For this reason the discussion of by-products in this article is directed mainly toward fission products.

In the programs for processing spent fuel, attention has been directed almost entirely toward recovering uranium and plutonium cheaply and efficiently; the by-product fission elements were regarded as dross for which the cheapest, most expeditious acceptable safe disposal method was all that was required. Not until 1948 did interest develop in separating, purıfying, and distributing certain fission products for research and development. During that year, work was begun on this problem by the radioisotope development group at the Oak Ridge National Laboratory (ORNL). The program remained small, but work on fission-products separations progressed steadily through the various stages. The feasibility of producing pure fission products on a multıkılocurie scale was demonstrated ${ }^{2-5}$ in 1957.

\footnotetext{
*Uranıum or plutonıum.
} 
The first uses were for gamma-radiation sources; these were mainly $\mathrm{Cs}^{137}$ for medical work and industrial radiography. Small amounts of $\mathrm{Sr}^{90}$ and $\mathrm{Pm}^{147}$ were also sold for special medical applications and industrial gauges. A slow, steady climb in demand to millions of curies of $\mathrm{Cs}^{137}$ per year was foreseen, with a continuing demand for smaller quantities of $\mathrm{Sr}^{90}, \mathrm{Pm}^{147}, \mathrm{Ce}^{144}$, and minor fission products. The eventual demand for very large sources was expected to be for large industrial irradiators. The heavy demand for heat sources to produce small amourits of power for special purposes such as satellites, though not unforeseen, developed unexpectedly fast. In the last few years, the heat-source requirements have been the controlling factor in the fission-product program.

There has been growing interest in the recovery of fission products from wastes and increasing appreciation of the importance of fissionproduct recovery as related to waste management during the past seven or eight years. In the annual reports of the U. S. Atomic Energy Commission up to 1959 , little mention is made of recovering fission products or otherwise concentrating high-level wastes in wastemanagement programs. However, the steady progress in separation and purification of fission products is noted in the radioisotope development section, and one significant comment was made in the section on liquid radioactive waste in the 1956 report: ${ }^{6}$

Another approach is to separate chemically from the liquid wastes the especially hazardous and long-lıved beta-emitting strontıum-90 and gamma ray emitting cesium-137 The cost of removing cesium and strontium might be offset in part by revenues from sale of these materials for industrial, medical, or experimental use With these two separated for special confınement or practical use, the remainder of the wastes would be at least a hundred tımes less hazardous and possibly could be disposed of to the environment

This statement is extracted from some of the material presented before the Joint Congressional Subcommittee on Industrial Radioactive Waste Disposal. ${ }^{7}$

Nevertheless, this view did not carry much weight, as is evidenced in the summary of these hearings: ${ }^{8}$

It was generally agreed that separation of specific fission products (In particular $\mathrm{Sr}^{90}$ and $\mathrm{Cs}^{137}$ ) only for their industrial utilization would not affect appreciably the waste disposal problem nor significantly aid in its solution

Notwithstanding these expressions of skepticism and lack of interest in the USAEC annual report for 1959 under the waste-management section were the following remarks: ${ }^{9}$

The major objective of waste management in atomic energy operation is control over the radiation hazard that might be produced by these 
wastes, either in storage or in nature

Two basic disposal concepts are applied:

Concentrate and Contain The radioactive materials may be confined or isolated within permanently maintained reservations, away from people and useful resources Highly active liquid wastes originating from the chemical processing of irradiated fuels from reactors must be reduced to a suitable concentrated form* and contained indefinitely in this way

*For example, total weight of all fission products of a 1000 megawatt (thermal) power reactor for one year is about $750 \mathrm{lbs}$ If the elements were to be separated and converted into chemicdl compounds, then dried and compressed into a density of $3 \mathrm{grams} / \mathrm{cc}$, they would occupy a volume of about 5 cubic feet The compounds of the two important long-lived radioisotopes, $\mathrm{Cs}^{137}$ and $\mathrm{Sr}^{90}$, could occupy less than one cubic foot Since the total volume of waste from which the fission products were removed would be about 540,000 gals $(73,000 \mathrm{cu} \mathrm{ft})$ for natural uranium process waste, this would represent a volume concentration bv a factor of 100,000

[Note: These estimates assume $1000 \mathrm{Mwd} / \mathrm{t}$, which of course is low for power reactors.]

Meanwhlle, as a result of the demands for heat sources for unique electric-power-generation purposes, the need to separate fission products (particularly $\mathrm{Sr}^{90}, \mathrm{Ce}^{144}, \mathrm{Pm}^{147}$, and $\mathrm{Cs}^{137}$ ) for their own value became apparent. In a cooperative program of ORNL and Hanford begun in 1959, megacurie quantities of $\mathrm{Sr}^{90}, \mathrm{Ce}^{144}$, and $\mathrm{Cs}^{137}$ have been separated at Hanford; packaged in tested and approved containers; and shipped 3000 miles by rail to the Fission Products Development Laboratory at ORNL, where the materials were fabricated into heat-power sources. The largest of these, a 225,000-curie $\mathrm{Sr}^{90} \mathrm{~T}_{1} \mathrm{O}_{3}$ heat-power source was used by the Martin Company in a remote weather station at sea; other smaller $\mathrm{Sr}^{90} \mathrm{TlO}_{3}$ sources are serving at remote weather stations at both poles. Similarly, $\mathrm{Cs}^{137}$ has been made as a cesium-glass heat source, and $\mathrm{Ce}^{144}$ has been formed as the sintered oxide.

Primary interest in fission-product recovery in the United States has been at ORNL and Hanford; closely related work on the concentration of gross high-level wastes has been done at Brookhaven National Laboratory, at Argonne National Laboratory in cooperation with the Idaho Chemical Processing Plant, and at the Savannah River Plant. The Britısh have done much work on waste treatment, but only a relatively minor amount on the separation of fission products; their program has been reviewed. ${ }^{10}$ The French also have an active research and development program on the separation of fission products, principally $\mathrm{Cs}^{137}$. Little is known of the Russian program in separating fission products except that it is proceeding on a fairly large scale with heavy emphasis on solvent-extraction processes. 
The most prominent of the neutron-produced radioisotopes is $\mathrm{Co}^{60}$, which is produced and used on a kilocurie scale for gamma-irradiation purposes. Cobalt-60 is the gamma-1rradiation source most used at present. It can be produced on a scale comparable with that of the major fission products and at competitive cost.

The transplutonium isotopes, particularly americium and curium, are also of great interest for special heat-power sources and for neutron generation. However, as in the case of $\mathrm{Co}^{60}$, neutrons that might theoretically have gone to make plutonium or other fissile material are used up. Costs are not likely to be competitive with fission products, but the special properties of $\mathrm{Cm}^{242}$ and $\mathrm{Cm}^{244}$ - primarily alpha radiation and high power density - make them of particular interest for unique applications, such as power sources in space vehicles. The possible uses of transcurium isotopes, such as the spectacular neutronemitting $\mathrm{Cf}^{252}$, remain to be determined.

\section{OUTPUT}

A vast supply of fission products is produced currently; enormous supplies of the longer lived species such as $\mathrm{Sr}^{90}$ and $\mathrm{Cs}^{137}$ are held in storage tanks; and a still greater supply can be projected for the future. The sources of $f_{1}$ ssion products in the United States are (1) the production reactors at Hanford and Savannah River; (2) the storage tanks at the production sites; (3) the research and test reactors at Idaho and the many government and private nuclear laboratories now in operation; (4) military reactors, the most important of which are those for propulsion of navy vessels; (5) special reactors, as nuclear rocket engines, etc.; (6) civilian electric-power-generating reactors; and (7) civilian process-heat reactors.

Information can be made available on only a few of these sources of supply, the most important being the reactors in central electricpower-generating stations. The projections given by Lane ${ }^{11}$ are shown in Fig. 1. From the curve for predicted growth of nuclear power and Table 1, which gives the production per 1000 megawatt days (with six months' cooling) for most of the important fission products, the probable supply from this source can be calculated.

Some unclassified information has been made avallable by the USAEC Division of Isotope Development ${ }^{12}$ on the avallability of fission products and several neutron-produced isotopes under consideration for large-scale production of isotopic power sources. These data are given in Tables 2 to 5 . The figures for production and cost represent the best avallable when the tables were compiled. Several assumptions were made in arriving at these estimates. The assumptions include establishment of a fission-product separation plant at Hanford and an increase in facilities at ORNL, Savannah River, and Mound Laboratory 


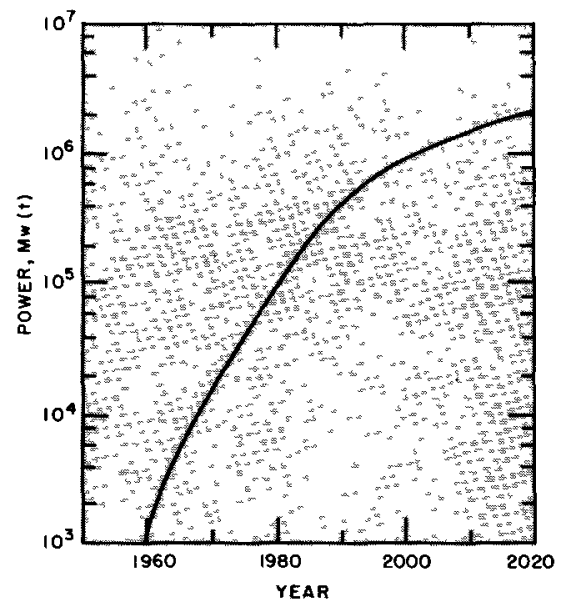

Fig. 1-Growth of U.S. central-station nuclear power.

Table 1-FISSION-PRODUCT PRODUCTION

(1000-Mwd Irradiation, Six Months' Cooling)

\begin{tabular}{ccccccc}
\hline Nuclide & Half-lıfe & Kilocuries & $\begin{array}{c}\text { Gamma } \\
\text { watts } \\
\text { kilocurie }\end{array}$ & $\begin{array}{c}\text { Total } \\
\text { gamma } \\
\text { watts }\end{array}$ & $\begin{array}{c}\text { Total } \\
\text { watts/ } \\
\text { klocurie }\end{array}$ & $\begin{array}{c}\text { Total } \\
\text { watts }\end{array}$ \\
\hline $\mathrm{Nb}^{95}$ & $35 \mathrm{~d}$ & 120 & 4.4 & 528 & 4.6 & 553 \\
$* \mathrm{Ce}^{144}$ & $290 \mathrm{~d}$ & 71 & 0.34 & 24 & 7.4 & 504 \\
$\mathrm{Zr}^{95}$ & $63 \mathrm{~d}$ & 64 & 4.5 & 288 & 5.0 & 320 \\
$\mathrm{Y}^{91}$ & $58 \mathrm{~d}$ & 53 & 0.02 & 1 & 3.5 & 185 \\
$\mathrm{Sr}^{89}$ & $53 \mathrm{~d}$ & 39 & & & 3.3 & 133 \\
$\mathrm{Ru}^{103}$ & $41 \mathrm{~d}$ & 14 & 2.7 & 38 & 3.3 & 46 \\
$* \mathrm{Ru}^{106}$ & $1 \mathrm{y}$ & 4.2 & 1.1 & 5 & 9.0 & 25 \\
$\mathrm{Ce}^{141}$ & $33 \mathrm{~d}$ & 14.3 & 0.5 & 7 & 1.7 & 24 \\
$* \mathrm{Sr}^{90}$ & $28 \mathrm{y}$ & 3.3 & & & 6.3 & 17 \\
$* \mathrm{Cs}^{137}$ & $30 \mathrm{y}$ & 3.2 & 3.3 & 10.6 & 5.0 & 16 \\
$\mathrm{Pm}^{147}$ & $2.67 \mathrm{y}$ & 13 & & & $0.37 \dagger$ & 5 \\
$\mathrm{Kr}^{85}$ & $10.3 \mathrm{y}$ & 3.4 & & & 1.35 & 4.6 \\
$\mathrm{Sm}^{151}$ & $100 \mathrm{y}$ & 0.1 & & & & \\
\hline
\end{tabular}

*Including short-lived daughters.

$\dagger$ Hanford has recently suggested 0.38 watt/kılocurie for $\mathrm{Pm}^{147}$. ORNL has also recently found 0.414 watt/kilocurie for $\mathrm{Pm}^{147}$. 
Table 2-PRODUCTION CAPABILITY OF RADIOISOTOPES FOR ISOTOPIC POWER APPLICATIONS

\begin{tabular}{|c|c|c|c|c|c|c|c|c|c|c|}
\hline \multirow[b]{2}{*}{ Isotope } & \multicolumn{10}{|c|}{ Year } \\
\hline & 1963 & 1964 & 1965 & 1966 & 1967 & 1968 & 1969 & 1970 & 1971 & 1972 \\
\hline & \multicolumn{10}{|c|}{ Megacuries } \\
\hline $\mathrm{Sr}^{90}$ & 3 & 5 & 5 & 5 & 10 & 10 & 10 & 10 & 10 & 10 \\
\hline $\mathrm{Cs}^{137}$ & 1 & 3.5 & 3.5 & 3.5 & 10 & 10 & 10 & 10 & 10 & 10 \\
\hline $\mathrm{Ce}^{144}$ & 3.5 & 3.5 & 3.5 & 3.5 & 100 & 100 & 100 & 100 & 100 & 100 \\
\hline \multirow[t]{2}{*}{$\mathrm{Pm}^{147}$} & 0.02 & 0.5 & 0.5 & 0.5 & 30 & 30 & 30 & 30 & 30 & 30 \\
\hline & \multicolumn{10}{|c|}{ Kllograms } \\
\hline $\mathrm{Pu}^{238}$ & 3 & 6 & 13 & 18 & 24 & 32 & 36 & 42 & 47 & 51 \\
\hline \multirow[t]{2}{*}{$\mathrm{Cm}^{244}$} & & 0.05 & 0.1 & 6 & 18 & 40 & 56 & 56 & 58 & 58 \\
\hline & \multicolumn{10}{|c|}{ Grams } \\
\hline $\mathrm{Cm}^{242}$ & & 12 & 80 & 1000 & 1000 & 1000 & 1000 & 1000 & 1000 & 1000 \\
\hline $\mathrm{Po}^{210}$ & 20 & 50 & 100 & 100 & 1000 & 1000 & 1000 & 1000 & 1000 & 1000 \\
\hline
\end{tabular}

Table 3-THERMAL POWER AVAILABLE FROM RADIOISOTOPES*

(Kilowatts/year at Fuel-fabrication Time)

\begin{tabular}{lllllllllll}
\hline & \multicolumn{10}{c}{ Frscal year } \\
\cline { 2 - 11 } Isotope & 1963 & 1964 & 1965 & 1966 & 1967 & 1968 & 1969 & 1970 & 1971 & 1972 \\
\hline $\mathrm{Sr}^{90}$ & 19 & 32 & 32 & 32 & 63 & 63 & 63 & 63 & 63 & 63 \\
$\mathrm{Cs}^{137}$ & 5 & 17 & 17 & 17 & 48 & 48 & 48 & 48 & 48 & 48 \\
$\mathrm{Ce}^{144}$ & 25 & 25 & 25 & 25 & 700 & 700 & 700 & 700 & 700 & 700 \\
$\mathrm{Pm}^{147}$ & 0.01 & 0.2 & 0.2 & 0.2 & 14 & 14 & 14 & 14 & 14 & 14 \\
$\mathrm{Pu}^{238}$ & 1.5 & 3.0 & 6.0 & 0.5 & 11.5 & 15 & 17 & 20 & 23 & 25 \\
$\mathrm{Cm}^{244}$ & & 0.1 & 0.2 & 14 & 41 & 92 & 129 & 129 & 134 & 134 \\
$\mathrm{Cm}^{242}$ & & 1.5 & 9.5 & 120 & 120 & 120 & 120 & 120 & 120 & 120 \\
$\mathrm{Po}^{210}$ & 3.0 & 7.0 & 14 & 14 & 140 & 140 & 140 & 140 & 140 & 140 \\
\hline
\end{tabular}

* Based on quantities of material in Table 2 . 
Table 4-ELECTRIC POWER AVAILABLE FROM RADIOISOTOPES*

(Kilowatts/year Based on Indicated Mission Time and 5 Percent Conversion Efficiency)

\begin{tabular}{|c|c|c|c|c|c|c|c|c|c|c|c|}
\hline \multirow{2}{*}{$\begin{array}{l}\text { Iso- } \\
\text { tope }\end{array}$} & \multirow{2}{*}{$\begin{array}{c}\text { Mission } \\
\text { time, } \\
\text { years }\end{array}$} & \multicolumn{10}{|c|}{ Year } \\
\hline & & 1963 & 1964 & 1965 & 1966 & 1967 & 1968 & 1969 & 1970 & 1971 & 1972 \\
\hline $\mathrm{Sr}^{90}$ & 10 & 0.75 & 1.2 & 1.2 & 1.2 & 2.5 & 2.5 & 2.5 & 2.5 & 2.5 & 2.5 \\
\hline $\mathrm{Cs}^{13 ?}$ & 10 & 0.2 & 0.6 & 0.6 & 0.6 & 1.8 & 1.8 & 1.8 & 1.8 & 1.8 & 1.8 \\
\hline$C e^{144}$ & 1 & 0.5 & 0.5 & 0.5 & 0.5 & 14.0 & 14.0 & 14.0 & 14.0 & 14.0 & 14.0 \\
\hline $\mathrm{Pm}^{147}$ & 2.6 & & 0.007 & 0.007 & 0.007 & 0.5 & 0.5 & 0.5 & 0.5 & 0.5 & 0.5 \\
\hline $\mathrm{Pu}^{238}$ & 10 & 0.07 & 0.13 & 0.29 & 0.4 & 0.53 & 0.7 & 0.79 & 0.92 & 1.03 & 1.12 \\
\hline $\mathrm{Cm}^{244}$ & 10 & & & & 0.47 & 1.4 & 3.1 & 4.4 & 4.4 & 4.5 & 4.5 \\
\hline $\mathrm{Cm}^{242}$ & 0.5 & & 0.03 & 0.22 & 2.8 & 2.8 & 2.8 & 2.8 & 2.8 & 2.8 & 2.8 \\
\hline $\mathrm{Po}^{210}$ & 0.5 & 0.04 & 0.14 & 0.28 & 0.28 & 2.8 & 2.8 & 2.8 & 2.8 & 2.8 & 2.8 \\
\hline
\end{tabular}

*Based on quantities of material in Table 2.

Table 5-ISOTOPIC POWER COSTS*

\begin{tabular}{lllllll}
\hline & & & \multicolumn{3}{c}{ Electric power } \\
\cline { 5 - 6 } & $\begin{array}{c}\text { Material } \\
\text { cost } \\
\text { Isotope }\end{array}$ & $\begin{array}{c}\text { Yearly } \\
\text { production } \\
\text { rate }\end{array}$ & $\begin{array}{c}\text { Thermal } \\
\text { power, } \\
\$ / \text { watt }\end{array}$ & $\begin{array}{c}\text { Mission } \\
\text { time, } \\
\text { years }\end{array}$ & $\begin{array}{c}\text { Cost, } \\
\$ / \text { watt }\end{array}$ & $\begin{array}{c}\text { Cost, } \\
\$ / \text { watt-hr }\end{array}$ \\
\hline $\mathrm{Sr}^{90}$ & $0.50 /$ curie & $10 \mathrm{Mc}$ & 77 & 10 & 2,000 & 0.023 \\
$\mathrm{Cs}^{137}$ & $0.50 /$ curle & $10 \mathrm{Mc}$ & 104 & 10 & 2,750 & 0.031 \\
$\mathrm{Ce}^{144}$ & $0.04 /$ curle & $100 \mathrm{Mc}$ & 5 & 1 & 280 & 0.032 \\
$\mathrm{Pm}^{147}$ & $0.18 /$ curie & $10 \mathrm{Mc} \dagger$ & 485 & 2.6 & 19,500 & 0.86 \\
$\mathrm{Pu}^{238}$ & $500 / \mathrm{g}$ & $50 \mathrm{~kg}$ & 1040 & 10 & 22,500 & 0.26 \\
$\mathrm{Cm}^{244}$ & $1000 / \mathrm{g}$ & $50 \mathrm{~kg}$ & 435 & 10 & 12,700 & 0.15 \\
$\mathrm{Cm}^{242}$ & $19,800 / \mathrm{g}$ & $80 \mathrm{~g}$ & 165 & 0.5 & 7,160 & 1.64 \\
$\mathrm{Po}^{210}$ & $26,500 / \mathrm{g}$ & $100 \mathrm{~g}$ & 190 & 0.5 & 9,300 & 2.12 \\
\hline
\end{tabular}

*These are estimated costs as of January 1962. Changing conditions could markedly affect costs.

$\dagger$ Recent Hanford data indicate that this figure can probably be increased by a factor of 3 , with a concomitant reduction in cost. 
to purify fission products and the alpha emitters and to fabricate heatpower sources.

The supply of $\mathrm{Sr}^{90}, \mathrm{Cs}^{137}, \mathrm{Ce}^{144}$, and $\mathrm{Pm}^{147}$ that will be avalable from power-reactor fuels in the future and the amounts suggested by the data in Tables 2 to 5 on 1sotopic fuels for the more immediate future are large indeed. The enormous supply of fission products in storage tanks at the production sites and the outpouring of fission products in current operations cannot be disclosed; the figures are, however, extremely large.

For practical purposes the basic supply of the important long-lived fission products is essentially unlimited when considered from the standpoint of possible use in the future. Large gamma irradiators are the only other possible use for radioactive by-products at present, and for practical purposes one can confine the isotopes for this purpose to $\mathrm{Cs}^{137}$ and $\mathrm{Co}^{60}$.

The potential basic supply of $\mathrm{Cs}^{137}$ is practically unlimited, although the cost of putting it into usable form will perhaps be a limiting factor.

Cobalt- 60 can be produced in amounts limited only by the number of neutrons and amount of reactor space devoted to its production. Production of the order of megacuries per year is possible, but here again no unclassified figures are avallable. The probable production of $\mathrm{Co}^{60}$ in power reactors is an open question. Although on the surface it appears that much $\mathrm{Co}^{60}$ could be produced by using cobalt metal as flux flatteners and control rods at almost no cost, it is not likely to be so simple. A major part of the world's supply of $\mathrm{Co}^{60}$ is now being produced in the British power reactors, but good cost data are not avallable. A large power reactor might produce as much as a megacurie of $\mathrm{Co}^{60}$ per year. It is reasonable to believe that the supply of $\mathrm{Co}^{60}$ can keep up with the probable demand; here again cost is most likely to be the controlling factor.

The total probable demand for other radioactive by-products, e.g., radioisotopes for medical therapy, instruments, tracing, and research, in the light of the figures just discussed for power and radiation, is completely insignificant. Power reactors are not particularly well suited for producing miscellaneous radioisotopes, and many research reactors are avallable throughout the world which can easily produce more radioisotopes than can be used. This situation is clearly illustrated by Table 6 , which gives the distribution of radioisotopes from ORNL, the principal production center. This table excludes several thousand curies of radioisotopes produced and distributed directly from other USAEC facilities, such as Mound Laboratory and Brookhaven, radiolsotopes from reactors owned by private industrial firms and universities, and radioisotopes made in other countries and imported into the United States. 
Table 6 - DISTRIBUTION OF RADIOISOTOPES FROM ORNL

\begin{tabular}{|c|c|c|c|c|c|c|}
\hline \multirow[b]{2}{*}{$\begin{array}{l}\text { Radic- } \\
\text { Isotopes }\end{array}$} & \multicolumn{2}{|c|}{$\begin{array}{l}\text { Aug. } 2,1946, \text { to } \\
\text { Dec. } 31,1959\end{array}$} & \multicolumn{2}{|c|}{$\begin{array}{l}\text { Jan. } 1,1960 \text {, to } \\
\text { Nov. } 30,1960\end{array}$} & \multicolumn{2}{|c|}{$\begin{array}{c}\text { Total as of } \\
\text { Nov. } 30,1960\end{array}$} \\
\hline & $\begin{array}{l}\text { Activity, } \\
\text { curies }\end{array}$ & Shipments & $\begin{array}{l}\text { Activity, } \\
\text { curies }\end{array}$ & Shipments & $\begin{array}{l}\text { Activity, } \\
\text { curies }\end{array}$ & Shupments \\
\hline $\mathrm{C}^{14}$ & 85 & 3,135 & 23 & 300 & 108 & 3,435 \\
\hline $\mathrm{Cs}^{137}$ & 93,239 & 1,306 & 29,626 & 202 & 122,865 & 1,508 \\
\hline $\mathrm{Co}^{60}$ & 678,565 & 2,038 & 141,037 & 146 & 819,602 & 2,184 \\
\hline $\mathrm{H}^{3}$ & 92,900 & 1,008 & 5,203 & 115 & 98,103 & 1,123 \\
\hline$I^{131}$ & 6,590 & 44,031 & 503 & 2,327 & 7,093 & 46,358 \\
\hline $\operatorname{Ir}^{192}$ & 30,862 & 763 & 8,538 & 109 & 39,400 & 872 \\
\hline $\mathrm{Kr} \mathrm{r}^{85}$ & 6,636 & 284 & 3,290 & 116 & 9,926 & 400 \\
\hline $\mathrm{P}^{32}$ & 1,656 & 26,453 & 141 & 1,957 & 1,797 & 28,410 \\
\hline $\mathrm{Pm}^{147}$ & 1,270 & 332 & 2,285 & 64 & 3,555 & 396 \\
\hline $\mathrm{Sr}^{90}$ & 561 & 745 & 302 & 107 & 863 & 852 \\
\hline All others & 1,541 & 51,510 & 173 & 6,330 & 1,714 & 57,840 \\
\hline Total & 913,905 & 131,605 & 191,121 & 11,773 & $1,105,026$ & 143,378 \\
\hline
\end{tabular}

\section{GENERAL CHARACTERISTICS}

In the preceding sections, main attention has been directed toward several important fission products, transuranium elements, and $\mathrm{Co}^{60}$. Several other nuclides are also interesting. Table 7 lists some of the important characteristics of the radioisotopes that are most likely to have some significance as reactor by-products. A few may be conspicuous by their absence, e.g., tritium.

Much work remains to be done in getting more accurate information on many radioisotopes, particularly good experimental data; this applies in large measure to the nuclides given in Table 7. Fox example, we are not really sure of the half-life of the important radioisotopes $\mathrm{Cs}^{137}$; there is much evidence indicating that the half-life is about 28 years, but other data suggest that it should be conservatively shown as $30 \pm 3$ years. Measurements on large amounts of pure material will improve these values. In this review it is not practical to comment on each of the nuclides, but the characteristics and uses of some of the more important radioisotopes will be discussed.

Americium-241 is used in the form of the oxide as a target material for the production of transamericium 1sotopes and as an alpha source; it is also combined with beryllium or boron as a neutron source.

Cerium-144* has been separated and purified in kilocurie amounts

\footnotetext{
*When reference is made to $\mathrm{Ce}^{144}$, the $\mathrm{Pr}^{144}$ daughter is always included unless otherwise stated.
} 
at ORNL and made into refractory, sintered, ceric oxide pellets for power sources. Cerium silicide and cerium glasses can also be made, but the oxide appears to be the preferred form at present. About equal weights of $\mathrm{Ce}^{140}$ and $\mathrm{Ce}^{142}$ result from fission and subsequent decay chains; the fast-decaying $\mathrm{Ce}^{144}$ therefore rapidly loses in specific activity after discharge from the reactor. Cerium-144 is the most plentiful and potentially the cheapest radioisotope, considering its relative amount after about one year of decay of the fission products discharged from the reactor. It is of somewhat limited use, however, owing to its comparatively short half-life and to its unusual mixture of hard beta radiation and some hard gamma radiation.

Cesium-137 is considered by many to be the most important fission product. It is the only long-lived gamma-emitting fission product that occurs in large amount. Unfortunately it is accompanied by like amounts of fission-product $\mathrm{Cs}^{133}$ and $\mathrm{Cs}^{135}$, which reduce the specific activity. Worse still, the $\mathrm{Cs}^{133}$ captures a neutron to produce 2.3 -year $\mathrm{Cs}^{134}$, a harder gamma emitter than $\mathrm{Cs}^{137}$. This complicates the calculations on gamma output and greatly increases the necessary shielding. The fission-product cesium is usually comprised of about 1 to 8 percent $\mathrm{Cs}^{134}$, and nothing can be done about it except to wait for it to decay out. For teletherapy sources, pressed pellets of cesium chloride are used; for power sources and gamma irradiators, cesium glasses are used.

The characteristics of $\mathrm{Co}^{60}$ are fairly well known. Cobalt-60 is irradiated as the metal in the form of disks, rods, and strips, and after encapsulation in the same metallic form it is used as irradiation sources. Cobalt-60 is a very powerful gamma emitter, having two hard gamma rays. The first irradiation units for food pasteurization will contain $\mathrm{Co}^{60}$ at a specific activity of about 50 to 100 curies/g. Largescale experiments are under way at Brookhaven to determine the optimum specifications for $\mathrm{Co}^{60}$ sources for irradiators.

The curium sources will be used primarily for heat and auxiliary power generation in space vehicles.

Iridium-192 is made by irradiating iridium metal, much in the same way as cobalt. The primary use is for radiographic sources. The metal is an ideal form both for irradiation and as source material.

Krypton-85 is a most important gaseous fission product. It is separated as the fairly pure gas, sometimes with added helium carrier, but it contains other krypton isotopes, as shown in the following typical analysis:

$\begin{array}{cccc}\text { Mass } & \text { Percent } & \text { Mass } & \text { Percent } \\ 78 & 0.03 & 84 & 32.73 \\ 80 & 0.42 & 85 & 5.06 \\ 82 & 2.17 & 86 & 46.08 \\ 83 & 13.49 & & \end{array}$


Table 7 - PROPERTIES OF SELECTED RADIOISOTOPES

\begin{tabular}{|c|c|c|c|c|c|c|c|c|c|c|c|c|}
\hline \multirow[b]{2}{*}{ Source } & \multirow[b]{2}{*}{ Half-life } & \multirow{2}{*}{$\begin{array}{l}\text { Calculated } \\
\text { specific } \\
\text { activity of the } \\
\text { pure nuclide, } \\
\text { curies } / g\end{array}$} & \multirow{2}{*}{$\begin{array}{l}\text { Practical } \\
\text { specific } \\
\text { activity, } \\
\text { curies/g }\end{array}$} & \multicolumn{3}{|c|}{$\begin{array}{l}\text { Maximum energy } \\
\text { radiations, Mev }\end{array}$} & \multicolumn{3}{|c|}{$\begin{array}{l}\text { Radiation output, } \\
\text { watts/kilocurie }\end{array}$} & \multicolumn{3}{|c|}{ Power density of source compound } \\
\hline & & & & $\beta$ & $\gamma$ & $\alpha$ & $\alpha-\beta$ & $\gamma$ & Total & Material & Watts $/ \mathrm{cm}^{3}$ & Watts/g \\
\hline $\mathrm{Am}^{241}$ & $458 \mathrm{y}$ & 3.21 & 3.1 & & 0.06 & 5.48 & 32.5 & 0.4 & 32.9 & $\mathrm{AmO}_{2}$ & 0.90 & 0.090 \\
\hline$C e^{144}, \operatorname{Pr}^{144}$ & $285 \mathrm{~d}$ & 3,190 & $600^{*}$ & 2.98 & 2.18 & & 7.2 & 0,18 & 7.3 & $\mathrm{CeO}_{2}$ & 22 & 3.6 \\
\hline $\mathrm{C}^{137}, \mathrm{Ba}^{137 \mathrm{~m}}$ & $30 \mathrm{y}$ & 86.9 & 32 & 1.17 & 0.66 & & 1.6 & 3.2 & 4.8 & $\begin{array}{c}43 \% \text { Cs glass } \\
(43 \text { wt. } \%)\end{array}$ & 0.21 & 0.066 \\
\hline$C s^{134}$ & $2.3 \mathrm{y}$ & 1,160 & 90 & 065 & 1.36 & & 0.87 & 9.3 & 10.2 & $\begin{array}{l}437 \text { Cs glass } \\
\text { (43 wt.\%) }\end{array}$ & 1.2 & 0.39 \\
\hline $\mathrm{Co}^{60}$ & $5.27 \mathrm{y}$ & 1,130 & $100^{*}$ & 0.31 & 1.33 & & 0.55 & 14.8 & 15.4 & Metal & 130 & 1.5 \\
\hline $\mathrm{Cm}^{242}$ & $162 \mathrm{~d}$ & 3,330 & & & & 6.1 & 36.2 & & 36.2 & $\mathrm{CmO}_{2}$ & 1,170 & 120 \\
\hline $\mathrm{C} \mathrm{m}^{244}$ & $18.4 \mathrm{y}$ & 797 & & & & 5.8 & 34.4 & & 34.4 & $\mathrm{CmO}_{2}$ & 22 & 2.8 \\
\hline $\mathrm{Ir}^{192}$ & $74.5 \mathrm{~d}$ & 9,110 & 440 & 0.67 & 1.16 & & 5.07 & 1.14 & 6.2 & Metal & 59 & 2.7 \\
\hline $\mathrm{Kr} \mathrm{r}^{\mathrm{B}}$ & $10.3 \mathrm{y}$ & 409 & $31 *$ & 0.7 & 054 & & 1.35 & $\mathrm{~N}_{1} \mathrm{l}$ & 1.35 & Liq. Kr & 0.10 & 0.042 \\
\hline $\mathrm{Pu}^{238}$ & $89.6 \mathrm{y}$ & 16.8 & 16 & & 0.04 & 5.5 & 32.5 & $\mathrm{~N}_{11}$ & 32.5 & Metal & 9.3 & 0.48 \\
\hline $\mathrm{Po}_{0}^{210}$ & $138 \mathrm{~d}$ & 4,520 & 4,500 & & 0.8 & 5.3 & 31.4 & Nol & 31.4 & Metal & 1,300 & 140 \\
\hline $\mathrm{Pm}^{147}$ & $2.5 \mathrm{y}$ & 974 & 970 & 0.23 & & & 038 & & 0.38 & $\mathrm{Pm}_{2} \mathrm{O}_{3}$ & 2.2 & 0.32 \\
\hline $\mathrm{Ru}^{106}, \mathrm{Rh}^{106}$ & $1.0 \mathrm{y}$ & 3,370 & $70^{*}$ & 3.54 & 2.42 & & 8.65 & 1.2 & 9.85 & Metal & 8.3 & 0.69 \\
\hline $\mathrm{Sr}^{90}, \mathrm{Y}^{90}$ & $28 \mathrm{y}$ & 142 & 76 & 2.81 & & & $6.6 \dagger$ & & 6.3 & $\mathrm{SrTlO}_{3}$ & 0.81 & 0.23 \\
\hline$T \mathrm{c}^{99^{3}}$ & $2.1 \times 10^{5} \mathrm{y}$ & 0.0172 & 0.017 & 0.29 & & & 0.51 & & 0.51 & $\mathrm{TcO}_{2}$ & $6.5 \times 10^{-6}$ & $4.5 \times 10^{-5}$ \\
\hline $\mathrm{T} 1^{296}$ & $4.1 \mathrm{y}$ & 428 & 12 & 0.76 & & & 1.45 & & 1.45 & Metdl & 0.210 & 0.018 \\
\hline $\mathrm{Th}^{228}$ & $1.9 \mathrm{y}$ & 825 & 800 & $2.25 \ddagger$ & $289+$ & $8.78 t$ & 31.8 & 0.14 & $223 \ddagger$ & Metal & $1,610 \ddagger$ & $161 \ddagger$ \\
\hline $\mathrm{U}^{232}$ & $73.6 \mathrm{y}$ & 20.9 & 20 & $2.25 \hbar$ & $2.20 \ddagger$ & $8.78 t$ & 31.4 & 0.36 & $220 \ddagger$ & Metal & $84 \ddagger$ & $44 \ddagger$ \\
\hline$Y^{90}$ & $2.67 \mathrm{~d}$ & 543,000 & 540,000 & 2.27 & & & 5.4 & & 5.4 & $\mathrm{Y}_{2} \mathrm{O}_{3}$ & 11,000 & 2,300 \\
\hline$/ \mathrm{r}^{95}, \mathrm{Nb}^{95}$ & $63.3 \mathrm{~d}$ & 21,700 & 130 & 0.89 & 0.76 & & 0.99 & 8.8 & 9.79 & $\mathrm{Z \textrm {rO } _ { 2 }}$ & 4.7 & 0.95 \\
\hline
\end{tabular}

*Calculated values, which depend on several variables, 1.e., tume in reactor, time cooled, and neutron flux.

$\dagger$ Measured value, $6.3 \pm 03$, used

$\ddagger$ Includes daughter activities. 
Promethium-147 is unusual in that it has no natural stable isotopes and its specific activity is independent of the time between discharge from the reactor and separation. It is the most plentiful low-energy pure beta emitter. The oxide is the usual chemical form for sources; it has been fabricated as the sintered oxide and also as a glass. It also may be fixed in ceramic microspheres, as can most of the radioisotopes discussed in this section.

Strontium-90 is the most plentiful highly energetic pure beta emitter available. A problem similar to that mentioned for $\mathrm{Cs}^{134}$ contamination in $\mathrm{Cs}^{137}$ also exists for $\mathrm{Sr}^{90}$, which contains a large fraction of 50.5 -day $\mathrm{Sr}^{89}$ when it is discharged from the reactor. Fortunately $\mathrm{Sr}^{89}$ does not have gamma radiation, but its energetic beta emission and high decay rate make it the controlling factor in heat production in young fission-product strontium. Table 1 shows that even six months after discharge almost 90 percent of the total strontium heat power is coming from $\mathrm{Sr}^{89}$. The $\mathrm{Sr}^{89}-\mathrm{Sr}^{90}$ mixture must therefore be cooled for as long as feasible to reduce the $\mathrm{Sr}^{89}$ content to about 5 to 10 percent.

An additional complication is that, although $\mathrm{Sr}^{90}-\mathrm{Y}^{90}$ has only beta emission (some investigators have also stated that there is 0.03 percent gamma emission), the bremsstrahlung is troublesome and is an important factor in space applications. This condition is illustrated in Figs. 2 and 3.

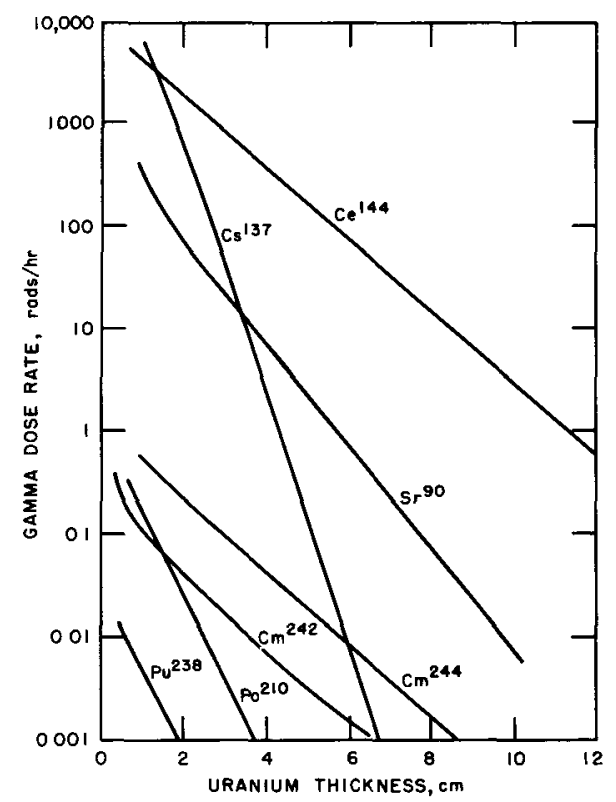

Fig. 2- Effect of uranium thickness on prirnary gamma dose rate. 


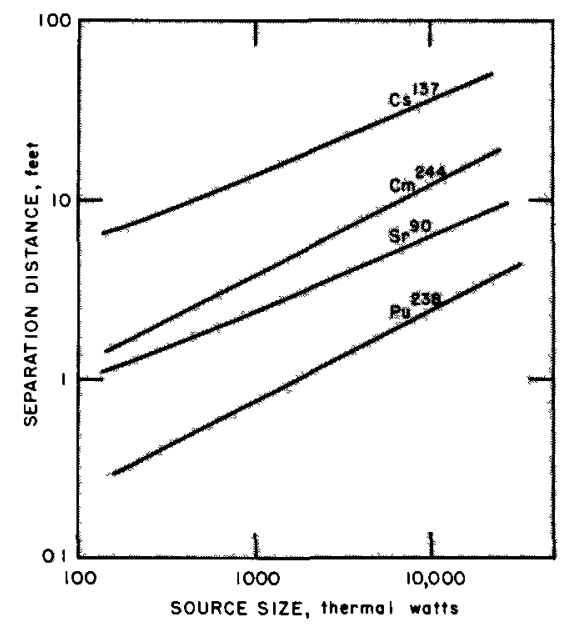

Fig. 3-Effect of source size on source-receptor separation.

Strontium-90 may be used eventually as a beta-irradiation source, but the primary use is for heat-power sources. It is usually formed as sintered strontium titanate, a refractory ceramic material that is highly insoluble. Strontium oxide, sintered with a binder, is also being considered. The stable isotopes $\mathrm{Sr}^{86}, \mathrm{Sr}^{87}$, and $\mathrm{Sr}^{88}$ also occur with the fission-product $\mathrm{Sr}^{90}$, reducing the specific activity; contamination with natural strontium during chemical processing also occurs in many cases. Attempts to produce durable ceramic coatings containing high concentrations of $\mathrm{Sr}^{90}$, for use as beta irradiators, have not been successful.

Technetium-99 is very mildly radioactive and is mainly considered for its possible chemical uses. Technetium has been suggested for use in superconducting alloys and as a corrosion inhibitor in pure-water systems, but thus far no developments have been made in these areas.

Thorlum-228 and uranium-232 have been suggested as power-source materials by Rohrmann. ${ }^{13}$ As shown in Table 7, $\mathrm{Th}^{228}$ and $\mathrm{U}^{232}$ (starting material, $\mathrm{Th}^{230}$ ) have very high heat-power density, but the gamma radiation from decay products may limit their use where low radiation background is required.

Yttrium-90, the daughter of $\mathrm{Sr}^{90}$, appears to be out of place in Table 7 because it has a very short half-life. However, this $\mathrm{Sr}^{90}$ daughter may be extracted from $\mathrm{Sr}^{90}$ to give a tremendously powerful source of short-lived beta radiation. Advantage will probably be taken of this property eventually.

Zirconium-95-niobium-95, though relatively short lived, appears to be the only other radioisotope that is plentiful enough and has the quantity and quality of gamma radiation to be interesting as a gamma- 
irradiator source material. The radiation quality closely resembles that from $\mathrm{Cs}^{137}$, and $\mathrm{Zr}^{95}-\mathrm{Nb}^{95}$ may therefore be useful as an auxiliary "buttıng" source material. Zirconıum-95-nıobium-95 is easily separated on silica gel and can be made into the refractory oxides. Sources can also be made by adsorbing $\mathrm{Zr}^{95}-\mathrm{Nb}^{95}$ on silica gel or other ceramic porous material and firing it to fix it in place.

Ruthenum-106 (one-year half-life) is also potentıally useful because it occurs in high fission yield, has very hard beta radiation (up to $3.53 \mathrm{Mev}$ from $\mathrm{Rh}^{106}$ daughter), and can be electroplated to form plate sources. Unfortunately it is not a pure beta emitter, the $\mathrm{Rh}^{106}$ daughter having gamma radiation up to $2.41 \mathrm{Mev}$.

\section{MAJOR APPLICATIONS}

Two applications of radioisotopes that are of major current interest are as radiation sources and as compact heat sources. Radioisotopes have unique advantages in supplying high-energy radiations for such fields as industry and medicine. The SNAP (Systems for Nuclear Auxiliary Power) program has included most of the development of heat-power sources from these isotopes.

\section{Radiation Sources}

Even though current interest is highest in the use of radiossotopes as compact heat-power sources, the most interesting characteristic of the radioisotopes is their emission of high-energy radiations that otherwise can be obtained only with complex high-voltage machines. Radioisotopes, in addition to their unique uses as tracers, are used for industrial and medical radiography, in research irradiation machines, in thickness gauges, for food irradiation, and as catalytic agents in chemical processing. In most of these applications, radioisotopes compete mainly with $\mathrm{X}$-ray machines, ranging all the way from small radiographic $X$-ray units to giant supervoltage machines used for deep irradiation of cancerous tissue. Cobalt-60 and cesium-137 have developed a place in medical therapy; but, in diagnostıc work, virtually no in roads have been made on the regular X-ray machines. The field in which competition is likely to be great is industrial radiation, i.e., food pasteurization, chemical processing, sterilization of medical supplies, etc. The choice will more than likely be based on economics, and it is still too early to tell what the result will be. Machines have the advantage of high intensity, on-off operation, lower initial capital cost, relatively uniform output, and freedom from possible radioactive contamination. On the other hand, radiossotopes involve little machinery, require no electric power, can be arranged in an infunite variety of geometric configurations, emit relatively pure radiation to produce 
large uniform radiation fields, and probably have lower operational and maintenance costs.

Cobalt-60 is the unquestioned leader as a radiossotope source for gamma radiation at present. It is now being made in megacurie quantıties by irradiating encapsulated cobalt metal strips, disks, and pellets in high-flux production reactors, a relatıvely simple process. Cobalt60 production is very large in Canada, where the NRX and NRU reactors have many excess neutrons available, and in Britain, where $\mathrm{Co}^{60}$ is being used as a neutron-flux flattener in the large power reactors. The prices on this 5.3-year isotope have become low, with Canada marketing it at about $\$ 1$ per curie; however, the price varies greatly with the specific activity and the amount sold per order.

Cesium-137 is the main fission product used as a source of gamma radiation. Cesium-137 has weaker radiations than $\mathrm{Co}^{60}(0.667 \mathrm{Mev}$ vs. $1.2 \mathrm{Mev}$ ), and the dose rate per curie is about one-fourth that of $\mathrm{Co}^{60}$. It requires much less shielding, however, and it has found growing acceptance in radiography and teletherapy. Now priced at $\$ 0.50$ per curie, it is competitive with $\mathrm{Co}^{60}$ at $\$ 0.35$ per curie if the longer useful life is considered:

$$
\$ 0.50 \times 4 \text { (dose-rate factor) } \times \frac{5.3 \text { years }}{30 \text { years }}=\$ 0.35
$$

Cesium-137 may eventually drop in price, with large-scale production, to $\$ 0.10$ per curie or less, at which time it would be difficult for $\mathrm{Co}^{60}$ or $\mathrm{X}$-ray machines to compete. For example, it is difficult to imagine an $\mathrm{X}$-ray machine operating day and night for 30 years with practically no attention and no maintenance; yet, during such a period, $\mathrm{Cs}^{137}$ would lose only one-half its original irradiating power. Radioisotopes should have future applications in all types of radiation uses, including industrial irradiation. Table 8 gives possible uses of $\mathrm{Cs}^{137}$ for industrial radiation.

Sources have been fabricated from the separated fission products for uses calling for gamma radiation, fairly pure beta radiation, and bremsstrahlung ( $X$ radiation). The only fission product given serious consideration as a material for fairly large gamma sources is Cs ${ }^{137}$. Cerıum-144 and ruthenium-106 also have considerable gamma-radiation power, but the quality and quantity of the gamma radiation are unsuitable for most applications.

The principal beta emitter is $\mathrm{Sr}^{90}$, which has energetic beta radiation from its $\mathrm{Y}^{90}$ daughter; the emission is free from gamma radiation, although bremsstrahlung is troublesome. Promethium-147 is useful as an emitter of soft, pure beta radiation; it is virtually alone in this field. Cerium-144 and ruthenum-106 are also powerful beta-radiation emitters; however, not only are they fairly short lived but also they emit a 
Table 8-POSSIBLE FISSION-PRODUCT USAGE FOR INDUSTRIAL IRRADIATION PROCESSING, 1968*†

\begin{tabular}{|c|c|c|}
\hline & $\mathrm{s}^{137}$, megacuries & $\mathrm{Sr}^{90}$, megacuries \\
\hline \multicolumn{3}{|l|}{ Industrial radiation processing } \\
\hline Medical supplies & 5 & \\
\hline Special polymeric materials & 1 & \\
\hline Wood-plastic combinations & 20 & \\
\hline B10-degradable detergents & 50 & \\
\hline Chemicals (intermediates) & 4 & 2 \\
\hline Research & 1 & 0.50 \\
\hline Bulk polymers & 10 & 0.20 \\
\hline Hydracarbon fuels from coal & 5 & 10 \\
\hline \multirow[t]{2}{*}{ Sewage treatment } & 5 & \\
\hline & 101 & 12.7 \\
\hline \multicolumn{3}{|l|}{ Food irradıatıon } \\
\hline 0.15 billion pounds of irradiated food & $250 \ddagger$ & \\
\hline Total & 351 & 12.7 \\
\hline
\end{tabular}

*[From Nucl. News, 7(4): 31 (April 1964).]

$\left\lceil\right.$ Based on prices of $\$ 0.10$ percurie for $\mathrm{Cs}^{137}$ and $\$ 0.13$ per eurie of $\mathrm{Sr}^{90}$. Only 1968 requirements shown.

$\ddagger$ This amount could increase by 500 megacuries/year for annual replacement.

considerable amount of gamma radiation which contaminates their radiation fields.

For $\mathrm{X}$-ray production, only $\mathrm{Sr}^{90}$ and $\mathrm{Pm}^{147}$ appear to be of interest.

Applications of gamma-radiation sources for industrial purposes are such that the minimum dose rate required within the target is about $2 \times 10^{5} \mathrm{rads} / \mathrm{hr}$, with rates as high as $2 \times 10^{6} \mathrm{rads} / \mathrm{hr}$ being desirable for some applications.

Data on practical activity concentrations obtainable are given in Table 7. It appears that, if the possible contribution of bremsstrahlung is neglected, $\mathrm{Ru}^{106}$ would be practical for only low-gamma-dose-rate applications; $\mathrm{Ce}^{144}$ could be useful for gamma irradiation if proper source design were provided to handle the principal radiation, 2.97Mev beta radiation from the $\operatorname{Pr}^{144}$ daughter.

For medical teletherapy, only $\mathrm{Cs}^{137}$ has high enough activity concentration (though this is marginal), long enough half-life, and the essential radiation characteristics to be useful. There are problems with the $\mathrm{Cs}^{134}$ contamination, which ranges from about 1 to 8 percent of the radiations, depending upon the reactor flux and the age of the discharged fission products.

Cesium-137 is also the only fission product that has found much use in radiography. Here again, as for teletherapy, it would be desirable 
to have a higher activity concentration to come closer to achieving an intense point source. Cesium is already obtained in very high chemical purity; thus the mass -137 cesium must be separated from the rest of the isotopes to enhance activity concentration. Work on this problem has been under way at ORNL for some time, but it is not yet possible to predict whether the isotope separations will be practical on a fairly large scale.

In applications using beta radiation, minimum dose rates at the surface of the target of $10^{6} \mathrm{rads} / \mathrm{hr}$ are required, and $10^{7} \mathrm{rads} / \mathrm{hr}$ and even higher are desirable.

To be at all useful, $\mathrm{Pm}^{147}$ must be as pure as possible. Strontium90 with specific activities as low as about 5 curies/g may find some use, but it would be much more useful at the highest possible purity. Cerium-144 at about 44 curies/g may have uses; $\mathrm{Ce}^{144}$, however, has the disadvantages of a relatively short half-life and associated gamma radiation. The same considerations would apply to the use of $\mathrm{Ru}^{106}$.

\section{Heat-power Sources}

The use of radioactive materials for heat-electric-power sources is one of the most interesting developments in nuclear energy in recent years (see Table 9). The uses in remote weather stations, in unattended buoys at sea, in satellites, and for special heating devices are important not only in their service function but also in their economic function because they offer the first market for relatively large amounts of radioactive materials. Although well-established devices such as chemical batteries, fuel cells, solar cells, and internal-combustion engines serve for many of these uses, it is now apparent that, for the low power range up to about $5 \mathrm{kw}(\mathrm{t})$, radioisotope power generators will certainly find extensive use and that, in some applications, radioisotope power is the only possible answer to the power problem. Radioactive materials can generate heat in a completely predictable manner over long periods of time without being attended, with no outside connections, with no great changes in physical or chemical state, and with no elaborate controls. For higher power levels, particularly in certain space applications, small nuclear reactors will be required. Radioisotope power is therefore complementary to other forms of power generation and can fill needs where there is essentially no other way of obtaining power.

Radiolsotope power sources fall into four general categories:

1. Sources to produce small amounts of heat for special purposes, such as warming instruments in space vehicles, underseas, and at remote locations.

2. Sources to generate electric power for special purposes in which economic factors are unimportant but reliability, low weight, long life, 
etc., are important. Electricity at high voltage (essentially static electricity) can be generated with charge collectors. Thermoelectric and thermionic devices and special bollers to produce vapors to run turbogenerators are used to produce electricity at ordinary voltages.

3. Sources for small amounts of mechanical power, e.g., heat engines and jets.

4. Sources for uses in which unique characteristics such as long life and great reliability result in actual economies over other power systems.

The development of heat-power sources has for the most part been a part of the SNAP (Systems for Nuclear Auxiliary Power) program, and a review of this program will best give the present status of radio1sotope power.

The SNAP program (see Table 10) was started in 1956 with the awarding of a contract to the Martin Company for the development of a radioisotope-fueled space power unit. ${ }^{14,15}$ Many of the programs listed in Table 10 are research and development programs. Thus the devices may or may not be used eventually in operating missions. The SNAP programs using radioisotopes were numbered with odd numbers to distinguish them from a parallel program (having even numbers) using nuclear reactors as the power source. ${ }^{16}$

A variety of radioisotope SNAP sources have been produced in cooperative effort by commercial laboratories and the USAEC laboratories and production facilities. The first SNAP-1 generator designed for an electrical output of 500 watts, using $\mathrm{Ce}^{144}$ for its power source, was canceled owing to the complexity of the systems and the gamma-radiation problems. Succeeding units, such as SNAP-7 $\left(\mathrm{Sr}^{90}\right)$ and SNAP-9A $\left(\mathrm{Pu}^{238}\right)$, have been tested successfully as far as the radio1sotope fuel parts are concerned. The advanced models designated as SNAP-11 and SNAP-13 are in the hardware stage, and production of $\mathrm{Cm}^{242}$ will commence at ORNL in the near future.

The emphasis in the SNAP development program has been placed on producing an operating unit with the highest power density (watts per cubic centimeter), the minimum shielding requirements, and suitable half-life for missions requiring reliable operations for periods ranging from 100 days to 5 years. Three types of generators have been developed for the program to transform the heat of radioactive decay to usable electric power. The first unit (SNAP-1) used a mercury boiler to drive a turbine that converted the decay heat to electric power. Thermoelectric units (SNAP-3, 7, 9,11) used the well-known principle that an electric current is produced when two dissimilar metals are joined and the two junctions are kept at different temperatures. An advanced model (SNAP-13) will use a direct energy-conversion systemthermionic emission. This system operates on the principle that an electric current can be obtained by collecting electrons emitted by an 
incandescent substance. The thermionic generators will reduce the size and weight of future generators, and a conversion efficiency of 8 percent vs the 5 percent obtained in the thermoelectric unit is envisioned. A future unit combining the thermoelectric and thermionic generators into a "cascade" may possibly increase the conversion efficiency to 12 percent.

The conceptual design of the SNAP-1 generator called for an output of 500 electrical watts from a mercury-boller turbine supplied by an output of 7400 thermal watts from a 1 -megacurie source of $\mathrm{Ce}^{144}$ oxide. The $\mathrm{Ce}^{144}$ was to be recovered by ORNL from spent-fuel-element recovery solutions and converted to $\mathrm{Ce}^{144}$ oxide in the form of sintered pellets The pellets were to be encapsulated in Hastelloy and loaded into the generator for a power-output demonstration. This program was abandoned in 1959 in favor of work on the thermoelectric generators, but ORNL produced 100,000 curies of $\mathrm{Ce}^{144}$ oxide pellets as proof that $\mathrm{Ce}^{144}$ is a feasible fuel form for heat sources.

Table 9-POTENTIAL REQUIREMENTS FOR FISSION-PRODUCT HEAT SOURCES*

\begin{tabular}{|c|c|c|c|c|}
\hline Application & $\begin{array}{l}\text { Approximate } \\
\text { generator } \\
\text { power } \\
\text { watts }(\mathrm{e}) \dagger\end{array}$ & $\begin{array}{l}\text { No. of } \\
\text { potential } \\
\text { generators } \\
(1964-1968)\end{array}$ & $\begin{array}{l}\text { Total } \\
\text { requirements, } \\
\text { watts (e) }\end{array}$ & Comments \\
\hline \multicolumn{5}{|l|}{ Military applications } \\
\hline Navigational aids & 10 & 260 & 2,600 & $\begin{array}{l}\text { Decided ad- } \\
\text { vantage, } \\
\text { high prob- } \\
\text { ability }\end{array}$ \\
\hline \multicolumn{5}{|l|}{$\begin{array}{l}\text { Oceanographic and } \\
\text { weather } \\
\text { monitors }\end{array}$} \\
\hline East coast & $20-120$ & $40-150$ & 18,800 & $\begin{array}{l}\text { Price depen- } \\
\text { dent }\end{array}$ \\
\hline West coast & $20-120$ & $60-130$ & 16,800 & $\begin{array}{l}\text { Price depen- } \\
\text { dent }\end{array}$ \\
\hline Seagoing & 60 & 17 & 1,020 & $\begin{array}{l}\text { Price depen- } \\
\text { dent }\end{array}$ \\
\hline $\begin{array}{l}\text { Miscellaneous } \\
\text { military pro- } \\
\text { grams }\end{array}$ & 100 & $\ddagger$ & + & $\begin{array}{l}\text { Decided ad- } \\
\text { vantage }\end{array}$ \\
\hline $\begin{array}{l}\text { Military com- } \\
\text { munications } \\
\text { satellite }\end{array}$ & 30 & \pm & $\ddagger$ & $\begin{array}{l}\text { Decided ad- } \\
\text { vantage }\end{array}$ \\
\hline
\end{tabular}


Table $9-$ (Continued)

\begin{tabular}{|c|c|c|c|c|}
\hline Application & $\begin{array}{l}\text { Approximate } \\
\text { generator } \\
\text { power } \\
\text { watts }(e) \dagger\end{array}$ & $\begin{array}{c}\text { No. of } \\
\text { potential } \\
\text { generators } \\
(1964-1968)\end{array}$ & $\begin{array}{l}\text { Total } \\
\text { requirements, } \\
\text { watts }(e)\end{array}$ & Comments \\
\hline \multicolumn{5}{|l|}{$\begin{array}{l}\text { Other government } \\
\text { and civilian ap- } \\
\text { plications }\end{array}$} \\
\hline $\begin{array}{c}\text { Weather stations, } \\
\text { interagency }\end{array}$ & 10 & 10 & 100 & $\begin{array}{l}\text { Price depen- } \\
\text { dent }\end{array}$ \\
\hline \multicolumn{5}{|l|}{ Navigational aids } \\
\hline $\begin{array}{l}\text { Alaska and } \\
\text { Aleutian } \\
\text { shore lights }\end{array}$ & 10 & 68 & 680 & $\begin{array}{l}\text { Price depen- } \\
\text { dent }\end{array}$ \\
\hline $\begin{array}{l}\text { Buoys, Alaskan } \\
\text { waters }\end{array}$ & 10 & 88 & 880 & $\begin{array}{l}\text { Price depen- } \\
\text { dent }\end{array}$ \\
\hline $\begin{array}{l}\text { Other beacons } \\
\text { and buoys, } \\
\text { U. S. Codst } \\
\text { Guard }\end{array}$ & 50 & 27 & 1,350 & $\begin{array}{l}\text { Price depen- } \\
\text { dent }\end{array}$ \\
\hline $\begin{array}{l}\text { Gulf of Mexico } \\
\text { oil-well } \\
\text { buoys, civilian }\end{array}$ & 50 & 100 & 5,000 & $\begin{array}{l}\text { Price depen- } \\
\quad \text { dent }\end{array}$ \\
\hline $\begin{array}{l}\text { Unattended seis- } \\
\text { mic stations }\end{array}$ & 60 & 50 & 3,000 & $\begin{array}{l}\text { Decided ad- } \\
\text { vantage; } \\
\text { high prob- } \\
\text { ability }\end{array}$ \\
\hline $\begin{array}{l}\text { Missile-range un- } \\
\text { derwater splash } \\
\text { detectors and } \\
\text { tracking-ship- } \\
\text { position fixers }\end{array}$ & 10 & 262 & 2,620 & $\begin{array}{l}\text { Price depen- } \\
\text { dent }\end{array}$ \\
\hline Weatner stations & 20 & 30 & 600 & $\begin{array}{l}\text { Price depen- } \\
\text { dent }\end{array}$ \\
\hline $\begin{array}{l}\text { Underwater cable } \\
\text { repeaters }\end{array}$ & 1 & 12 & 12 & $\begin{array}{l}\text { Price depen- } \\
\text { dent }\end{array}$ \\
\hline Manned spacecraft & $\ddagger$ & 本 & $\ddagger$ & $\begin{array}{l}\text { Not price } \\
\text { dependent }\end{array}$ \\
\hline Possible total & equirements fo & or $1964-1968$ & 100,000 & \\
\hline \multicolumn{5}{|c|}{$\begin{array}{l}\text { If all systems are assumed to operate at an energy conversion effi- } \\
\text { ciency of } 5 \text { percent, their total fuel inventory at the end of the design } \\
\text { mission lives ls } 320 \text { megacuries of } \mathrm{Sr}^{90} \text { equivalent. (This is not to be } \\
\text { construed to mean that each system described would be fueled neees- } \\
\text { sarily with Sr }{ }^{90} \text { since other fission products may be more sultable in } \\
\text { specific applications.) }\end{array}$} \\
\hline
\end{tabular}

*[From Nucl. News, 7(4): 30 (April 1964).] †Classified.

†At end of mission life. 
Table 10 - ISOTOPIC POWER PROGRAM

\begin{tabular}{|c|c|c|c|c|c|c|c|c|}
\hline $\begin{array}{l}\text { Power } \\
\text { source }\end{array}$ & Isotope & $\begin{array}{c}\text { Fuel } \\
\text { processing }\end{array}$ & $\begin{array}{c}\text { Generator } \\
\text { fueling }\end{array}$ & $\begin{array}{c}\text { Total } \\
\text { activity, } \\
\text { kilocuries }\end{array}$ & $\begin{array}{c}\text { Thermal } \\
\text { output, } \\
\text { watts }\end{array}$ & $\begin{array}{c}\text { Electrical } \\
\text { output, } \\
\text { watts }\end{array}$ & $\begin{array}{c}\text { Type of } \\
\text { generator }\end{array}$ & Mission \\
\hline SNAP-1 & $C e^{144}$ & ORNL & ORNL & 1000 & 7400 & 500.0 & Mercury boller & Alr force (space) \\
\hline SNAP-1A & $\mathrm{Ce}^{144}$ & ORNL & ORNL & 1000 & 7400 & 500.0 & & Air force (space) \\
\hline SNAP-3 & $\mathrm{Po}^{210}$ & Mound & $3 \mathrm{M}$ & 2 & 64 & 2.5 & Thermoelectric & Prototype \\
\hline * & $\mathrm{Pu}^{238}$ & Savannah-Mound & $3 \mathrm{M}$ & $\sim 2$ & & 2.7 & Thermoelectric & Transit \\
\hline * & $\mathrm{Pu}^{238}$ & Savannah-Mound & $3 \mathrm{M}$ & $\sim 2$ & & 2.7 & Thermoelectric & Transit \\
\hline SNAP-5 & $\mathrm{Pm}^{147}$ & ORNL & ORNL & 37 & 14 & & Experimental & \\
\hline$*$ & $\mathrm{Sr}^{90}$ & Hanford-ORNL & ORNL & 17.5 & 110 & 5.0 & Thermoelectric & Weather bureau \\
\hline SNAP-7A & $\mathrm{Sr}^{90}$ & Hanford-ORNL & Martın & 41 & 250 & 10.0 & Thermoelectric & Coast guard \\
\hline SNAP-7B & $\mathrm{Sr}^{90}$ & Hanford-Martın & Martın & 220 & 1400 & 60.0 & Thermoelectric & Coast guard \\
\hline SNAP-7C & $\mathrm{Sr}^{90}$ & Hanford-ORNL & Martın & 41 & 250 & 10.0 & Thermoelectric & Navy \\
\hline SNAP-7D & $\mathrm{Sr}^{90}$ & Hanford-ORNL & ORNL & 225 & 1400 & 60.0 & Thermoelectric & Navy \\
\hline SNAP-7E & $\mathrm{Sr}^{90}$ & Hanford-ORNL & ORNL & 30 & 180 & 7.5 & Thermoelectric & Navy \\
\hline$*$ & $\mathrm{Cs}^{137}$ & ORNL & $\begin{array}{l}\text { Royal } \\
\text { Research }\end{array}$ & 27 & 125 & 5.0 & Thermoelectric & $\begin{array}{l}\text { Lamont } \\
\text { Observatory }\end{array}$ \\
\hline SNAP-9A & $\mathrm{Pu}^{238}$ & Savannah-Mound & Martın & & & 25.0 & Thermoelectric & Transit \\
\hline SNAP-11 & $\mathrm{Cm}^{242}$ & ORNL & Martin & & & 25.0 & Thermoelectric & Surveyor \\
\hline SNAP-13 & $\mathrm{Cm}^{242}$ & ORNL & ORNL & & & 12.0 & Thermionic & Prototype \\
\hline
\end{tabular}

*Undesignated. 
The SNAP-3 generator, designed by Minnesota Mining and Manufacturing Company $(3 \mathrm{M})$, was a prototype thermoelectric generator that required 2000 curies of $\mathrm{Po}^{210}$ metal for the heat source. This unit was fueled by Mound Laboratory with a 64-watt thermal output that was converted to 2.5 watts of usable electric power. This unit, which was delivered in January 1959, became the proof-of-principle demonstration device. It is commonly referred to as the "atomic battery."

The conceptual design for the SNAP-5 unit required a $\mathrm{Pm}^{147}$ source of 37,000 curies to produce the heat source. This program was canceled because it did not appear possible to meet the extremely rigorous gamma-ray specifications placed on the source. ORNL was responsible for producing the $\mathrm{Pm}^{147}$ source from spent-fuel-element recovery solutions and succeeded in separating kilocurie quantities of extremely pure $\mathrm{Pm}^{147}$, aged to become relatively free of the 42-day gamma-emitting $\mathrm{Pm}^{148}$. This $\mathrm{Pm}^{147}$ probably could meet the gammaradiation specifications for heat sources or for lower power electrical sources to be used in experiments in which the radiation background must be kept very low. Hanford has also recently produced kilocurie amounts of highly purified $\mathrm{Pm}^{147}$ that would meet specifications for space applications.

The SNAP-7 program yielded the greatest number of operating generators and proved the feasibility of encapsulating $\mathrm{Sr}^{90}$ in a safe form. Four SNAP-7 generators have been made through the coordinated efforts of Hanford Laboratories, ORNL, and the Martin Company. A fifth unit has recently been finished by the Martin Company and has been put into operation.

The $\mathrm{Sr}^{90}$ cortent of the units varied from 30,000 to 225,000 curies. The $\mathrm{Sr}^{90}$ was recovered from the Hanford fuel-processing system, purified by solvent extraction, and shipped as strontium carbonate to ORNL. The purified $\mathrm{Sr}^{90}$ carbonate was converted to strontium titanate, calcined, pelletized, sintered, and loaded into Hastelloy capsules. The capsules were remotely welded, leak tested, and loaded into a thermoelectric generator; the generator unit was also sealed and tested.

The SNAP-7A generator is intended to power an experimental coast-guard buoy in Chesapeake Bay; SNAP-7C is supplying power to an automatic weather station in the Antarctica; SNAP-7D is being used by the navy in an unmanned floating weather station; SNAP-7E is for an experimental navigational beacon for the navy.

SNAP-9A is a thermoelectric generator using $\mathrm{Pu}^{238}$ as heat supply. The mission for the SNAP-9A on a Transit satellite requires an operational lifetime of 5 to 10 years; the low gamma radiation and the long half-life of $\mathrm{Pu}^{238}$ make it ideal for this type of mission. The unit will give a usable electric-power output of 25 watts. Two smaller versions of the modified SNAP-3 that have been placed in orbit on the Transit$4 \mathrm{~A}$ and $4 \mathrm{~B}$ satellites have operated successfully. 
A thermoelectric generator fueled with $\mathrm{Cm}^{242}$ will be used for the SNAP-11 project. This unit may be used by the National Aeronautics and Space Admunistration (NASA) for supplying an electric-power output of 25 watts for the "Surveyor" (moon shots) project and possibly for other space vehicles.

ORNL has recently installed facilities for the production of $\mathrm{Am}^{241}$ fuel elements, the solvent-extraction separation of $\mathrm{Am}^{241}-\mathrm{Cm}^{242}$ from the fission products, and fabrication of curium heat sources. Amer1cium-241 will be pelletized, encapsulated, and irradiated in a highflux reactor, such as the Oak Ridge Research Reactor or the Idaho Materials Testıng Reactor. The irradiated materıal will be dissolved and the fission products removed by solvent extraction, but the amer1clum probably will not be separated.

The SNAP-11 generator probably will use about $8 \mathrm{~g}$ of $\mathrm{Cm}^{242}$ to give a thermal output of 975 watts, which will be converted to about 25 watts of usable electric power.

A small test thermionic generator, SNAP-13, was fabricated by the Martin Company in 1963 to demonstrate proof of principle; this device will be fueled by ORNL with $\mathrm{Cm}^{242}$. For a high conversion efficiency, the transfer of radioactive decay heat from the radioactive pellet to the thermionic device must be very efficient. The SNAP-13 generator is expected to produce 12 watts of electricity and weigh only about $4 \mathrm{lb}$. The thermionic system will use a diode filled with cesium vapor. The generator is designed for a 90-day mission.

Development programs are under way using radiousotopes, such as $\mathrm{Cs}^{137}$, to produce operating power sources for specialized equipment in which gamma activity and heavy shielding are not limiting factors. The $\mathrm{Cs}^{137}$ is prepared in the form of glass rods or pellets that allow operation at fairly high temperatures.

Other materials being actively considered are $\mathrm{Cm}^{244}$, for fairly long missions; $\mathrm{Co}^{60}$, for use where heat production in gamma-absorption shields is desirable; and $\operatorname{Ir}^{192}$, for short missions in which a gamma radiation background is permissible.

\section{RECOVERY}

A program for the processing and recovering of fission products, transuranium elements, and other by-products would have many advantages, some of them obvious. Fission products are the most $1 \mathrm{~m}$ portant, and the greatest amount of work has been done with them.

Recovered products would have uses that would result in income to offset some of the added ultımate waste-disposal costs. Most of these uses have been discussed - national defense applications, research and medicine, commercial radiation, unique heat-energy applications, and 
the use of rare chemicals that are separated, e.g., technetium, stable xenon, rubidium, and rare earths.

A program on processing could result in improved storage of fission products in concentrated form in double-jacketed containers or in a maximum-safety form, e.g., $\mathrm{Sr}^{90} \mathrm{~T}_{1} \mathrm{O}_{3}$ ceramic. Products so stored could be maintained in storage or retrieved for use or for treatment by methods yet undeveloped or unknown for disposal. Such methods might include destruction of radionuclides by thermonuclear reactions or transportation of extremely dangerous nuclides, e.g., $\mathrm{Sr}^{90}$, into deep space in maximum-safety forms.

There are, of course, political advantages in safely disposing of wastes to reduce possible contamination.

\section{Fission Products}

Recovery of fission products, both as related to disposal methods and as a source of elements, has been extensively investıgated. At present, processes for separating fission products are chiefly aimed at maximum recovery of the chief products, uranium and plutonium, and improved waste disposal.

RELATION OF FISSION-PRODUCT RECOVERY TO DISPOSAL METHODS Permanent tank storage for high-level waste is a practıcal, economical, and relatively safe method of disposal. This method, however, is now being critically examined in comparison with other possible procedures, such as pot calcination, from the standpoint of economy and safety. Bradshaw et al. ${ }^{17}$ and Perona et al. ${ }^{18}$ reported the economics of tank storage, taking into account not only the capital costs but also the interest on investment, a sinking fund for new tanks as needed, and the operating and maintenance costs. The costs vary with the interim storage period, which is defined as the tank-filling time plus the inactive storage time. Cost information for Purex waste from a 56,000 $\mathrm{Mw}(\mathrm{t})$ (1500 metric tons of uranium converter fuel per year) plant is summarized in Table 11.

Further studies have been made at ORNL on the probable cost of pot calcination (drying and calcination in 10-ft-long stainless-steel pots, 6 to $24 \mathrm{in}$. in diameter); these costs are estumated as $\$ 13$ per gallon for the 6-1n.-diameter pot and $\$ 5.70$ per gallon for the 24-1n.diameter pot.

The main effect of aging is to allow larger pot diameter; seven years of interim storage is required for use of a 24-1n.-diameter pot.

The probable characteristics of one of the calcining pots filled with waste are as follows: 
Fuel

Waste used

Pot size

Amount per pot

Beta radiation

$\mathrm{Sr}^{20}$

$\mathrm{Cs}^{\mathrm{t37}}$
$10,000 \mathrm{Mwd} /$ metric ton; flux, $3 \times 10^{13}$ neutrons $/ \mathrm{cm}^{2} / \mathrm{sec}$; one year irradiation

Purex acid waste calcined to 7.1 gal of solids per metric ton

Diameter, 6 in.; length, $10 \mathrm{ft}$; filled depth, $8 \mathrm{ft}$

Equivalent to 1.62 metric tons of fuel

$=11.4 \mathrm{gal}$ of waste

$=143 \mathrm{lb}=64,800 \mathrm{~g}$

$5.8 \times 10^{6}$ curies at about four months' decay

53,500 curies

51,800 curies

The total weight of the fission-product elements in the pot is about $17,000 \mathrm{~g}$. With the use of the estimated amounts of iron and sodium for a typical Purex waste, it is estimated that the pot contains about $5000 \mathrm{~g}$ of each of these elements. Using the estimated total weight of pot material of $64,800 \mathrm{~g}$ gives the following distribution:

\begin{tabular}{lr} 
Fission products & $17,000 \mathrm{~g}$ \\
Iron & $5,000 \mathrm{~g}$ \\
Sodium & $5,000 \mathrm{~g}$ \\
Other solids & $37,800 \mathrm{~g}$ \\
\multicolumn{1}{c}{ Total in pot } & $64,800 \mathrm{~g}$
\end{tabular}

The example being used is for fuel irradiated to $10,000 \mathrm{Mwd} /$ metric ton. Presumably for shorter irradiations, for example, 1000 Mwd, the amount of inert solids with the fission products would increase tenfold. There would also be differences in the kind of residues.

With the 10,000 - Mwd fuel, the pot containing 64,800 $\mathrm{g}$ of solids will contain approximately $1000 \mathrm{~g}$ of strontium and $1800 \mathrm{~g}$ of cesium $\left(\mathrm{Sr}^{90}\right.$ and $\mathrm{Cs}^{137}$ plus their accompanying isotopes), constituting about $4 \mathrm{wt} \%$ of the mixture. With $1000-\mathrm{M}$ wd fuel the strontium-cesium may be less: than 1 wt.\% of the mixture. Plant and equipment of relatively small size could apparently be used to remove the bulk chemical contaminants from the fission-product stream to produce concentrated fractions of strontium, cesium, and most of the other fission products. If the amount of low-level-waste solids produced is no greater than that put into the plant, a savings would result from storage as relatively low-level calcined waste in large-diameter steel containers. The concentrated fission products could be used, stored, or transported more easily and cheaply than the 10-ft-long containers.

Sources of pure $\mathrm{Sr}^{90}$ titanate of about 41,000-curie size (about the amount as in the preceding example) have been made at ORNL and appear to be quite manageable; this quantity of $\mathrm{Sr}^{90}$ as the titanate occupiea a volume of only about $300 \mathrm{~cm}^{3}$. Cesium as the borosilicate would have a slightly larger volume. The rest of the separated fission 
Table 11 - ANNUAL COSTS FOR STORAGE OF PUREX WASTE ${ }^{17}$

$(75,000$ Gallons of High-level Wastes per Year)

\begin{tabular}{|c|c|c|c|c|c|}
\hline \multirow[b]{2}{*}{ Cost item } & \multicolumn{5}{|c|}{ Interım storage tıme, years } \\
\hline & 0.5 & 1 & 3 & 10 & 30 \\
\hline \multicolumn{6}{|c|}{ Acid Purex } \\
\hline Capital costs & $\$ 85,000$ & $\$ 117,000$ & $\$ 202,000$ & $\$ 342,000$ & $\$ 527,000$ \\
\hline Water & 3,200 & 4,600 & 7,000 & 9,500 & 13,600 \\
\hline Power & 14,500 & 20,300 & 29,000 & 40,600 & 55,000 \\
\hline Labor & 75,000 & 75,000 & 75,000 & 75,000 & 75,000 \\
\hline Total & $\$ 177,000$ & $\$ 216,900$ & $\$ 313,000$ & $\$ 467,000$ & $\$ 670,600$ \\
\hline Cost per gallon & $\$ 2.36$ & $\$ 2.88$ & $\$ 4.18$ & $\$ 6.22$ & $\$ 9.03$ \\
\hline \multicolumn{6}{|c|}{ Neutralized Purex } \\
\hline Capital costs & $\$ 44,000$ & $\$ 57,000$ & $\$ 89,000$ & $\$ 140,000$ & $\$ 207,000$ \\
\hline Water & 3,200 & 4,600 & 7,000 & 9,500 & 13,600 \\
\hline Power & 14,500 & 20,300 & 29,000 & 40,600 & 55,000 \\
\hline Labor & 75,000 & 75,000 & 75,000 & 75,000 & 75,000 \\
\hline Total & $\$ 136,700$ & $\$ 156,900$ & $\$ 200,000$ & $\$ 265,100$ & $\$ 350,600$ \\
\hline Cost per gallon & $\$ 1.83$ & $\$ 2.09$ & $\$ 2.67$ & $\$ 3.53$ & $\$ 4.68$ \\
\hline \multicolumn{6}{|c|}{ Acid and Neutralized Purex } \\
\hline $\begin{array}{l}\text { Capital costs (per } \\
\text { year) other than } \\
\text { those for tanks } \\
\text { (e.g., cooling } \\
\text { equipment) }\end{array}$ & $\$ 10,900$ & $\$ 14,000$ & $\$ 20,000$ & $\$ 26,800$ & $\$ 37,400$ \\
\hline
\end{tabular}


products would have a volume of about $1 \mathrm{gal}$ (as borosilicate) and could be stored in a container designed for convection air cooling or used as a shorter term heat source if the handling and shipping costs were not prohibitive.

From the standpoint of operability and economy, it appears to be difficult to improve the present tank method of handling high-level wastes, particularly at Hanford and Savannah River. Although this storage method may not be the safest possible, it appears to be safe in a practical sense in that only disasters such as earthquakes or warfare would be likely to affect the tanks enough to create an emergency. Varıous schemes for ultımate waste disposal are being advocated, including continuous calcining, pot calcination, sorption on clays, injection into wells, pumping into the sea, and solidification in glass or concrete.

The cost figures for permanent tank or calcined waste storage show that none of these methods promises an outstanding economic advantage over processing separated fission products for use or uit1mate disposal in highly concentrated form, provided the wastes from the fission-product processing plant itself can be handled cheaply and effectively. Recovery of fission products appears to merit attention in connection with waste-management planning; and indeed this is now being done at Hanford. The Hanford approach to waste management has been discussed in detall in a recent paper by Tomlinson. ${ }^{19}$ The byproduct fission elements (or a portion of them) can be sold for useful purposes, thereby recovering some of the possible additional costs of improved ultimate disposal. It is by no means definite, however, that handling waste this way would actually cost more.

Future work will be directed toward development of fission-product processes that produce a relatively low weight of low-level chemical waste and development of economical methods for dealing with these contaminated chemicals.

PROCESSING As previously pointed out, the recovery of fission products is intimately tied up with the waste-management policies and practices at the present time and probably will be until such time as the demand for fission products is large enough to use a major amount of the fission products being produced. For this reason fission-product separations processes are not optimized for fission-product production but, rather, for the main products (uranium and plutonium) and for waste disposal. Progress has been made toward integrating fissionproduct recovery with waste management at Hanford, and a three-phase program is under way that will result in the annual production of $\mathrm{Sr}^{90}$, $\mathrm{Cs}^{137}, \mathrm{Ce}^{144}$, and $\mathrm{Pm}^{147}$ indicated in Table 2.

Also, the USAEC has encouraged private companies to bulld plants to process fission products from Hanford high-level waste. 
If large-scale recovery, purification, and fabrication of fission products into useful forms is decided upon, the location and kind of plant and process to use will depend upon many variables:

1 . Whether the demand for fission products is based upon compet1tive commercial use or upon a national defense use on which a real money value cannot be placed.

2. How many of the products are needed and how much of each kind at what rate.

3. The kind of high-level waste avallable.

4. The combination of waste handling and recovery that is appro priate.

5. The specifications for the final products.

6. Whether the plant for separating products can be contiguous to the production plant.

7. If all processing is done at a production site, whether the final products can be conveniently shipped.

8. If processing is done away from a production site, whether the raw fission-product material can be shipped safely and economically.

9. What transportation facilities are avaliable.

Many other minor questions undoubtedly would arise because of the many ways in which the major factors can be combined. Because of the many possible combinations of schemes for processing fission products for integration with fuel-processing plants, only a few of the most general cases can be discussed.

Short-lived fission products will no doubt be handled by allowing them to decay in special tanks where the heat can be removed by cooling coils or by self-bolling and evaporation. An exception may be $\mathrm{Zr}^{95}-\mathrm{Nb}^{95}$, which can be removed in simple head-end steps (e.g., adsorption on silica gel).

If the various head-end treatment steps and the back-feeding of such chemicals as ferrous sulfamate and sodium nitrite are avolded in the separation of fission products from uranium and plutonium, a rather pure acid waste should be obtained. If the acid waste is evaporated in tantalum or titanium vessels, the corrosion products could be greatly reduced. Treatment with formaldehyde or similar chemicals might be used to reduce the nitric acid concentration further. One of the objectives would be to accumulate as concentrated a mixture of fission products as possible in order to reduce the plant and equipment size. Some limitation would be encountered because of the heating effects of the accumulated products.

Several precipitation, solvent-extraction, or ion-exchange procedures that have been developed or are now under active development could be combined to design a reasonably good fission-product recovery system. Solvent-extraction procedures are favorable for $\mathrm{Sr}^{90}$, 
$\mathrm{Ce}^{144}, \mathrm{Pm}^{147}$, and, in certain cases, $\mathrm{Cs}^{137}$; precipitation-Decalso (a synthetic zeolite) ion-exchange processes also appear good for $\mathrm{Cs}^{137}$. The main deterrent to going ahead with large-scale separations of fission products is that a large assured market cannot be guaranteed. However, a large assured market seldom exists for any new product; but, for any commodity with the unique properties possessed by certain fission products, a market will eventually be developed if a supply becomes available.

Many recovery methods for individual fission products and over-all schemes designed to fit the wastes from certain processes have been proposed by workers at the varıous USAEC sites and at foreign atomicenergy installations. Private companies and technical institutions have also studied such processes under contract with the USAEC.

The processes fall into the general categories of precipitation, crystallization, solvent extraction, and ion exchange. There are, of course, many possible subcategories and combinations of processes. The different processes must be evaluated on the basis of the feed material avallable and the required product specifications, as well as on the characteristics of the process, plant, and equipment with which the fission-product process is to be coordinated. ${ }^{2-4,20}$

Precipitation processes were studied first, most of this work being done in connection with the radiolsotope program at ORNL. Workers at Hanford have studied the precipitation of cesium as the complex ferrocyanide and have precipitated strontium as the sulfate and carbonate and the rare earths as the double sulfates. British and French investigators have used direct precipitation of cesium from highly concentrated waste as the phosphotungstate. Most of the potential precipitation processes (except cesium ferrocyanide and phosphotungstate processes) have been studied on a pilot-plant scale at ORNL. Most of the precipitation processes in the first flow sheets have been supplemented or supplanted by solvent-extraction processes. However, many of the precipitation processes retain their value as intermediate or feed-preparation steps for solvent extraction or ion exchange.

The 1on-exchange processes have been used infrequently in the primary stages of processes for fission-product recovery, although they have proved to be of great value for intermediate- or purificationstage steps. Schemes for complete ion-exchange separations of fission products have been unsuccessful up to now, and they have not been advocated by many investigators Ion-exchange work has been done principally at ORNL and Hanford.

Solvent extraction is the most promising kind of process for supplementing precipitation and ion-exchange or possibly for supplanting these processes completely. Interest is now centered on in-line solvent-extraction processes to provide compatibility with the existing plutonum solvent-extraction processes for contınuous removal and 
separation of fission products. Completely continuous processes may not be necessary or desirable at this stage of fission-product production since the market for the products is not very firm and producers will therefore be subjected to demands for products with widely varying specifications. Solvent extraction will be used at several points in semicontinuous, mixed-technique processes. Solvent extraction of fission products is being studied at more sites than any other method; it is being studied by British and Russian investigators, as well as by those at Brookhaven, Savannah River, ORNL, and Hanford.

The first small amounts of $\mathrm{Cs}^{137}$ were recovered in the ORNL radioisotope program by ion exchange with the use of organic ionexchange resins that have a special selectivity for cesium. Ion exchange can be adapted to large-scale processing by utilizing the continuous type of ion-exchange equipment, such as the Higgins column. The method may be limited by the large volume of low-level waste fractions produced, by radiation damage to resin, and by the amount and complexity of large equipment required for a plant installation. A highly successful method of first-stage separation of $\mathrm{Cs}^{137}$ puts the alkaline waste-tank supernatant through Decalso inorganic ion exchanger, which selectively takes up cesium. This method simultaneously provides a safe method of shipping cesium when the Decalso bed is placed in a shielded transfer tank (the ORNL STT). About 50,000 curies of $\mathrm{Cs}^{137}$ is taken up on 500 gal of Decalso at Hanford. This is then stripped with ammonium mitrate solution in the Fission Product Development Laboratory at ORNL, and the eluted material is fed into the cesium alum crystallizers for concentration and purification. This method, however, is limited by the requirement that only alkaline feed material be used with the Decalso beds, and there is an undesirably large amount of low-level waste produced by the ammonium nitrate elution and alum crystallizations.

The ORNL alum crystallization process takes advantage of the very low solubility of cesium alum to effect separations. With this process, cesium can be separated in very high yield from large amounts of intèrfering chemicals, even the highly salted (aluminum) Redox waste or waste from proposed processes containing dissolved stainless steel. Relatively simple equipment that can easily be scaled up is used. A disadvantage is that a large amount of slightly contaminated aluminum ammonium sulfate waste is produced. The process appears to be adapted to purification stages rather than to primary separations.

A Brookhaven process for extracting cesium as the lodide into nitrobenzene has been proposed for incorporation into a solventextraction scheme for fission products. British and Russian investigators are also said to be working on a similar process, possibly using the bromide instead of the lodide. The Russians have been interested 
in using nitromethane and a complexing agent in several of their solvent-extraction processes, possibly including those for cesium. ORNL and Hanford also have actıve development programs for solvent extraction of cesium with the use of BAMBP [4-sec-butyl-2-( $\alpha-$ methylbenzyl)phenol].

The direct precipitation methods (by phosphotungstate) advocated by the British and the French depend upon having very pure waste that can be evaporated to a highly concentrated solution of fission products. These methods are fundamentally simple. They have been used so far by the British and the French on batches of a maximum of about 1000 curies. Hanford has recently precipitated batches as large as 30,000 curies successfully. Phosphotungstate cesium precipitation is only one of several possible direct precipitation methods. The important feature of this type of recovery is the use of relatively pure, highly concentrated solutions of fission products.

Precipitation of cesium in alkaline solution as complex ferrocyanides has been investigated, principally by Hanford workers. Although this process has been considered as a method of recovering cesium for production of radiation sources, the original idea was to remove cesium from the supernatant tank liquor to allow the liquid to be discarded, giving more tank space. ${ }^{21}$ The cesium ferrocyanide can be calcined and leached or chemically treated to yield cesium chloride. Simple crossover processes to the ORNL Decalso-alum process have also been developed. ${ }^{22-24}$

Strontium occurs in fission-product solutions with varying amounts of closely related barium (from fission) and calcium (from water, chemicals, etc.). For separation of strontium from the bulk of the chemicals and other fission products in the waste stream, precipitation methods utilize the insolubility of the carbonate, oxalate, and sulfate (with lead carrier) along with the relative solubility of the hydroxides. Precipitation processes have been used for purıfying alkalineearth fractions, principally by precipitating strontium and barium nitrates in concentrated (83 percent) nitric acid, leaving calcium, rare earths, iron, and most other impurities in the filtrate. This method, a classical one for separating barium and strontium from other elements, has been used on a fairly large (1000-curie) scale at ORNL with some success. It is, however, a difficult procedure, involving handling of dangerous fuming $\mathrm{HNO}_{3}$, and it has now been replaced by a highly superior solvent-extraction process. The varying amounts of barlum that may be present have been separated by the precipitation of barlum chromate, which leaves the more-soluble strontium chromate in solution. The selective precipitation of $\mathrm{BaCl}_{2}$ in $13 M$ hydrochloric acid or in $\mathrm{HCl}$-ether solution has also been used, but it has been avoided in large-scale operations because of the corrosion problems with chloride systems. 
The British have also experimented with the precipitation of barıum and strontium nitrates in concentrated $\mathrm{HNO}_{3}$ as a primary separation step, again takıng advantage of their relatıvely pure, highly concentrated waste feed material. Precipitation processes (carbonate, oxalate, titanate, etc.) are used in the finishing operations. Ion exchange was used in all the early small-scale work at ORNL on extraction of alkaline earths, but it was not considered as a primary separation method for large-scale work because of the large volume of low-level waste produced and the loading effect of the many chemicals in the input waste stream. As with other fission products, ion exchange appears to have a more important role in intermediate- or finishingstage operations for strontium. A combination of precipitation $\left(\mathrm{PbSO}_{4}\right.$ $\mathrm{SrSO}_{4}$ ) and ion exchange [ethylenediaminetetraacetic acid (EDTA) complexing on calcium-form ion-exchange column] for strontium production has been worked out by Hanford, although ion exchange has now been replaced by a solvent-extraction process.

Solvent extraction, both for primary separations and for finishing stages, appears to be the method of cholce, and work is going on at all the locations doing work on fission products. Solvent extraction will probably be the main method used for strontium, but undoubtedly there are situations in which both precipitation and ion exchange will be used for either presolvent or postsolvent extraction steps. ${ }^{25,26}$

The original ORNL pilot-plant process called for group precipitation of the rare earths as hydroxides with the use of ammonia gas $1_{1}$ jected into an essentially carbonate-free solution as the precipitating agent. Iron and other gross impurities that have insoluble hydroxides in $\mathrm{NH}_{4} \mathrm{OH}$ solution were previously precipitated. In actual practice on Purex waste at ORNL, this separation has worked fairly well in producing crude rare-earth fractions. In the solvent-extraction process [dl-2-ethylhexyl phosphoric acid (D2EHPA)], cerium is separated cleanly from promethium and the other rare earths and from the short-lived $\mathrm{Y}^{91}$ (yttrium closely resembles the rare earths in most chemical properties). The cholce of solvent extraction for these steps is clear. Precipitation of the oxalate is used in the finishing stages, affording extra purification from casual impurities, such as iron, and producing a filterable solid that can be fired to the final $\mathrm{CeO}_{2}$ form.

Hanford has developed a process for separating the rare-earth fraction in which advantage is taken of the low solubility of the rareearth double sulfates. Tartaric acid is used as a complexing agent to minimize the interference from iron. The double sulfate form is stable enough for shipment as a filter cake; kllocurıe amounts of rare earths have been shipped from Hanford to ORNL for further separation, purification, and packaging.

Promethium is of main interest in the rare earths-minus-cerium cut. Hanford has developed a peroxyacetate process to separate cerum 
from the other rare-earth elements. Promethium can be further separated from the other rare earths and casual impurities by ion exchange or solvent extraction (or a combination); feed-preparation steps, such as precipitation of the rare-earth oxalates, also can be used to advantage. Several variations of the con-exchange process for promethium separation and purification are avallable. Continuous solvent-extraction processes appear to be well suited to large-scale promethium work. ${ }^{27-33}$

Of all the major fairly long-lived fission products, the least amount of development work has been done on ruthenium. In the original ORNL process, ruthenium is coprecipitated with a special form of hydrated magnetic 1ron oxide at a $\mathrm{pH}$ of 2.5 ; the rest of the fission products are passed into the filtrate. A similar step has been in use at Savannah River for several years, 1.e., coprecipitating ruthenium with manganese dioxide directly from the dissolver solution as a feed-preparation step. Although ruthenum can be fairly successfully processed by precipitation, anion exchange, or solvent extraction, the usual method of further refinement is distillation of the volatile tetroxide. Electrolytic methods have also been proposed. Few of the methods directed at actual recovery of ruthenum have been tested on a kilocurie scale. Much more development is evidently required before the probable best method becomes apparent.

The gases krypton and xenon, discharged in large amounts from the dissolvers of the large production plants, can be removed by lowtemperature adsorption on charcoal or other adsorbents, by extraction in liquid oxygen in an adaptation of the Claude process, or by extraction by solvents. The adsorption process has been thoroughly tested at the Idaho Chemical Processing Plant and at ORNL for separation and purification of both krypton and xenon. Thousands of curies of $\mathrm{Kr}^{85}$ have been produced, as well as many liters of liquefied fission-product stable xenon. This process is well developed and could be installed on a large scale, although the first-stage processing would probably be done by the modified Claude process or a solvent-extraction process rather than by direct adsorption on charcoal. ${ }^{34}$

Fission-product $\mathrm{I}^{131}$ (8.3-day half-life) also occurs in the dissolver off-gases and has recelved the major share of the attention because it must be removed to reduce atmospheric pollution. It is too short lived to be of interest in a large-scale program of fission-product recovery, but the accompanying $\mathrm{I}^{129}$ (having a half-life of $1.6 \times 10^{7}$ years) could possibly be of interest. Methods of recovering $\mathrm{I}^{129}$ from the silvercoated beds used to capture lodine in the off-gas stream have been worked out. ${ }^{35,36}$

Certain shorter lived and minor fission products should be mentioned. Strontium-89 (54-day half-life) goes along with $\mathrm{Sr}^{90}$. It can be produced in greater proportion by short uranium irradiation. 
Yttrium-91 (59.5-day half-lıfe) and $\mathrm{Y}^{90}\left(\mathrm{Sr}^{90}\right.$ daughter having a 2.7day half-life) can be separated in the solvent-extraction process described for cerium.

Zirconıum-95-niobium-95 (with half-lives of 65 and 35 days, respectively) is most conveniently separated from fresh dissolver solution by percolating through silica-gel columns. The zirconiumniobium is removed periodically as the oxalate complex. It is also carried down with fresh manganese dioxide precipitates. Several precipitation processes are also avarlable.

Ruthenum-103 (39.8-day half-11fe) follows $\mathrm{Ru}^{106}$ and is always associatec with an appreciable amount of $\mathrm{Ru}^{106}$ unless the irradiation is quite short.

Cerrum-141 (32.5-day half-life) accompanies $C e^{144}$ and can be handled easily by solvent extraction.

Technetium-99 (having a half-life of $2.12 \times 10^{5}$ years) is a practically stable element that can be separated by any of several combinations of precipitation, anion-exchange or solvent-extraction processes. Large amounts are stored in the waste tanks at the production sites, from which it can be recovered by an anion-exchange process on the supernatant liquor; however, the most readily avallable source of supply is from residues in the gaseous-diffusion reprocessing plants. ORNL has a well-developed solvent-extraction process that has been used to produce several kılograms of pure technetium as the pertechnetate salt. It can also be easily converted to the metal. ${ }^{37}$

STABLE FISSION-PRODUCT ELEMENTS In about 1990 there may be $10^{6}$ $\mathrm{Mw}(\mathbf{t})$ of central-station nuclear power being produced; and, unavoidably, over a ton of fission products will be produced daily by these reactors alone. As previously pointed out, the most important characteristic of these by-products is that they are radioactive; however, a few of the fission products are stable, and many more decay fairly rapidly to stable elements several atomic numbers away from the primary fission element. Examination of the list of fission elements shows that they are among the scarcest of the earth's elements, as may be noted in Table 12. In this table, element abundance in the earth's crust and atmosphere is shown to illustrate the relative scarc1ty of some of these materials. Thus the decayed fission products might be an important source of supply of certain elements. Most of the stable elements manufactured in fission and subsequent decay processes have deranged isotopic compositions, as compared with those found in nature. They therefore potentially have value as enriched isotopes for direct use or as enriched feed for calutrons or other isotopeseparations machines. 
Table 12 - FISSION-PRODUCT ELEMENTS PRODUCED AT $10^{6}$ MW(T) IN A YEAR AFTER APPROXIMATELY 30 YEARS' DECAY

\begin{tabular}{|c|c|c|c|c|c|}
\hline $\begin{array}{l}\text { Fission- } \\
\text { product } \\
\text { element }\end{array}$ & $\begin{array}{c}\text { Produc- } \\
\text { tion, lb }\end{array}$ & $\begin{array}{c}\text { Natural } \\
\text { occurrence, } \\
\text { parts per } \\
10^{6} \text { parts } \\
\text { of silicon }\end{array}$ & $\begin{array}{l}\text { Fission- } \\
\text { product } \\
\text { element }\end{array}$ & $\begin{array}{l}\text { Produc- } \\
\text { tion, lb }\end{array}$ & $\begin{array}{c}\text { Natural } \\
\text { occurrence, } \\
\text { parts per } \\
10^{6} \text { parts } \\
\text { of silicon }\end{array}$ \\
\hline Xenon & 117,000 & $0.05 *$ & Iodine & 5,450 & 0.238 \\
\hline Neodymium & 110,000 & 17.0 & Selenium & 1,090 & 0.1 \\
\hline Zirconium & 109,500 & 173.0 & Europium & 920 & 0.72 \\
\hline Molybdenum & 85,000 & 1.0 & Gadolınıum & 312 & 4.0 \\
\hline Cerium & 58,300 & 33.0 & Tin & 304 & 1.7 \\
\hline Cesium & 46,400 & 3.8 & Cadmium & 224 & 0.14 \\
\hline Barıum & 41,700 & 73.0 & Antımony & 121 & 0.2 \\
\hline Ruthenıum & 38,300 & 0.001 & Silver & 101 & 0.09 \\
\hline Lanthanum & 28,000 & 13.0 & Bromine & 57 & 3.9 \\
\hline Praseodymium & 28,000 & 4.0 & Indium & 37 & 0.1 \\
\hline Samarium & 24,600 & 4.4 & Germanium & 6 & 1.5 \\
\hline Technetium & 20,600 & 0.0 & Promethium & $\sim 2$ & 0.0 \\
\hline Strontıum & 19,100 & 520.0 & Terbium & 6 & 58.0 \\
\hline Yttrium & 14,200 & 32.0 & Arsenic & $\mathrm{N} 1 \mathrm{l}$ & 2.7 \\
\hline Rubidium & 12,100 & 137.0 & Dysprosium & Nil & 2.8 \\
\hline Tellurıum & 11,600 & 0.001 & Gallium & Nil & 27.0 \\
\hline Krypton & 10,800 & $1.0^{*}$ & Nioblum & Nil & 26.0 \\
\hline Rhodlum & 10,200 & 0.001 & Zine & $\mathrm{N}_{1} 1$ & 62.0 \\
\hline Palladium & 5,750 & 0.036 & & & \\
\hline
\end{tabular}

*Parts per $10^{6}$ parts of air.

\section{Transuranium Isotopes}

by E. Lamb, S. J. Rimshaw, S. D. Clinton, R. E. Leuze, and R. W. Schaich Oak Ridge National Laboratory

Except for the transuranium elements formed during the operation of some reactors, producing such elements requires irradiation of other elements. The transuranium elements are formed by irradiation of either reactor products or reactor targets. As with the fission products, extensive chemical research has been done on separating and purifying the transuranium elements.

PRODUCTION FROM REACTORS Ullmann ${ }^{38}$ and Arnold ${ }^{39}$ have shown the undesirability of buildup of $\mathrm{U}^{236}$ with the recycle of $\mathrm{U}^{235}$ fuel; however, the $\mathrm{U}^{236}$ can be further irradiated to produce $\mathrm{Np}^{237}$, which is the initial nuclide in the production scheme for $\mathrm{Pu}^{238}$. In reactors fueled with 
natural uranium, the $(n, 2 n)$ reaction with $U^{238}$ is important as a source of $\mathrm{Np}^{237}$; however, at higher enrichments and longer burnups, the successive captures in $\mathrm{U}^{235}$ and $\mathrm{U}^{236}$ predominate in the production of $\mathrm{Np}^{237}$ and $\mathrm{Pu}^{238}$. The production scheme is

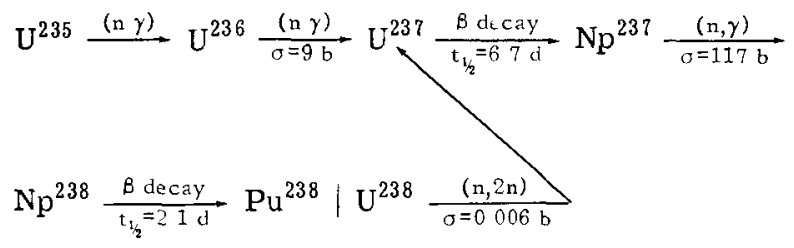

Schuman and Tromp ${ }^{40}$ have calculated that, because of the low capture cross section ( 9 barns) of $U^{236}$, an integrated flux of $1 \times 10^{22}$ neutrons/ $\mathrm{cm}^{2}$ (580 days at a flux of $2 \times 10^{14}$ neutrons $/ \mathrm{cm}^{2} / \mathrm{sec}$ ) is required to obtain a 10 percent maximum conversion of $\mathrm{U}^{236}$ to $\mathrm{Np}^{237}$. Analog computations show that a maximum conversion of 18 percent of the initial $\mathrm{Np}^{237}$ to $\mathrm{Pu}^{238}$ is achieved at an integrated flux of $3.81 \times 10^{20}$ neutrons/ $\mathrm{cm}^{2}$. The buldup of transplutonium isotopes has been described by Brauer, ${ }^{41}$ Bentley, ${ }^{42}$ and Barrett. ${ }^{43}$ Curium-242 is produced by 1 rradiation of $\mathrm{Am}^{241}$, which is obtained by the following production system:

$\mathrm{Pu}^{239} \frac{(\mathrm{n}, \gamma)}{\sigma=303 \mathrm{~b}} \mathrm{Pu}^{240} \frac{(\mathrm{n} \gamma)}{\sigma=250 \mathrm{~b}} \mathrm{Pu}^{241} \frac{(\beta \text { decay })}{\mathrm{t}_{1 / 2}=132 \mathrm{y}} \mathrm{Am}^{241}$

Plutonium-239 is also irradiated to obtain $\mathrm{Pu}^{242}, \mathrm{Am}^{243}$, and $\mathrm{Cm}^{244}$. The $\mathrm{Cm}^{244}$ is recovered as product, and the $\mathrm{Pu}^{242}$ and $\mathrm{Am}^{243}$ are inserted in the reactor for further irradiation to produce additional $\mathrm{Cm}^{244}$. The reactions are

$\mathrm{Pu}^{241} \underset{\sigma=390 \mathrm{~b}}{\stackrel{(\mathrm{n}, \gamma)}{\longrightarrow}} \mathrm{Pu}^{242} \underset{\sigma=52 \mathrm{~b}}{\stackrel{(\mathrm{n}, \gamma)}{\longrightarrow}} \mathrm{Pu}^{243} \frac{(\text { B decay })}{\mathrm{t}_{1 / 2}=498 \mathrm{~h}}$

$\operatorname{Am}^{243} \frac{(\mathrm{n}, \gamma)}{\sigma=138 \mathrm{~b}} \mathrm{Am}^{244} \frac{(\beta \text { decay })}{\mathrm{t}_{1 / 2}=26 \mathrm{~m}} \mathrm{Cm}^{244}$

The capture cross sections given for the even-numbered isotopes are average values for reactor irradiations and are dependent on neutron energy.

PRODUCTION FROM REACTOR TARGETS Irradiating targets for producing transuranium elements involves five problems:

1. Removal of fission heat at rates consistent with safe heat fluxes at the surface of the irradiation capsule, the thermal conductivity of the target material, and the maximum utilization of reactor space.

2. Remote fabrication of target elements.

3. High concentration of alpha activity and the attendant formation of helium gas in the capsule. 
4. Containment of alpha and fission-product activity within the target element during reactor irradiation.

5. Effect of high flux perturbation on the target element and surrounding reactor envıronment.

Two target materials of current interest are (1) $\mathrm{Pu}^{242}$ to produce gram quantities of $\mathrm{Am}^{243}$ and $\mathrm{Cm}^{244}$ and (2) $\mathrm{Am}^{241}$ to produce gram quantities of $\mathrm{Cm}^{242}$. Plutonium-242 target material is produced by longterm irradiation of $\mathrm{Pu}^{239}$ in Savannah River reactors. ${ }^{44} \mathrm{The} \mathrm{Pu}^{242}$ will be fabricated into $\mathrm{PuO}_{2}-\mathrm{Al}$ cermet pellets for irradiation in the ORNL High Flux Isotope Reactor (HFIR) at an effective thermal neutron flux of about $3 \times 10^{15}$ neutrons $/ \mathrm{cm}^{2} / \mathrm{sec}$ for 1.4 years. Each HFIR target will contain $10 \mathrm{~g}$ of plutonium in a capsule with an active fuel length of $20 \mathrm{in}$. and an outside diameter of $0.370 \mathrm{in}$.

The irradiated $\mathrm{PuO}_{2}$ target $\mathrm{w} 1 \mathrm{ll}$ be processed in the ORNL Transuranium Processing Facility to recover curıum, berkelium, californuum, and einsteinium. The curium, consisting of approximately equal quantities of the 1sotopes $\mathrm{Cm}^{244}, \mathrm{Cm}^{246}$, and $\mathrm{Cm}^{248}$, will be encapsulated for further irradiation in the HFIR to produce greater quantities of the transplutonium elements berkelium through fermium.

Americium-241 is irradiated as $\mathrm{AmO}_{2}-\mathrm{Al}$ pellets at an effective thermal neutron flux of about $2 \times 10^{14}$ neutrons $/ \mathrm{cm}^{2} / \mathrm{sec}$ for 45 days. Each americium target will contain $3 \mathrm{~g}$ of $\mathrm{Am}^{241}$ in a capsule with an active length of $6.5 \mathrm{in}$. and an outside diameter of $0.500 \mathrm{in}$.

The total loading in each target is limited by the ability to remove heat from the capsule. The initial heat-generation rate in the HFIR $\mathrm{PuO}_{2}$ element is primarily due to fissioning of the 1 percent residual $\mathrm{Pu}^{241}$ in the $\mathrm{Pu}^{242}$, which contributes $2.4 \mathrm{kw}$ per gram of plutonium. The average capsule-surface heat flux at reactor startup will be approximately $600,000 \mathrm{Btu} /(\mathrm{hr})(\mathrm{sq} \mathrm{ft})$. The problem for the $\mathrm{Am}^{241}$ target element is slightly different in that the peak heat generation occurs 9 to 10 days after reactor startup owing to fissioning of the two $\mathrm{Am}^{242}$ isomers. At the estimated effective flux, the heat-generation rate from fissioning should not exceed $2.6 \mathrm{kw}$ per initial gram of $\mathrm{Am}^{241}$, and the estımated average capsule-surface heat flux will be $420,000 \mathrm{Btu} /(\mathrm{hr})$ (sq ft).

Pellets will be fabricated for both $\mathrm{Pu}^{242}$ and $\mathrm{Am}^{241}$ targets by blending actinide oxide powder with aluminum powder and pressing to a density of about 89 percent of theoretical. The amount of $\mathrm{PuO}_{2}$ in the pellets will be about 17 vol.\%, whereas the $\mathrm{AmO}_{2}$ will be present as 4 vol.\%. Both pellet types will be surrounded by pure aluminum sleeves and end caps, which will and in controlling the spread of alpha contamination. Although both fabrication processes must be done in a glove box because of high specific alpha activities, only the $\mathrm{Am}^{241} \operatorname{tar}$ gets will require shielding for gamma radiation. 
Aluminum was selected as the matrix material for both actinide oxide targets because of its high thermal conductivity and its chem1cal dissolution properties. Aluminum-base pellets containing up to 25 vol. $\% \mathrm{Gd}_{2} \mathrm{O}_{3}$ have exhibited unexpectedly low thermal conductivities because the oxide rather than the aluminum was the continuous phase. ${ }^{45}$ Although the decreased conductivity should not significantly affect the predicted central temperature in the americium targets, the temperature within the $\mathrm{PuO}_{2}-\mathrm{Al}$ pellets can reach 1100 to $1200^{\circ} \mathrm{F}$ if no resistance to heat flow between the pellets and the jacket is assumed. The aluminum cladding must be collapsed tightly around the pellets by hydrostatic pressure to prevent center melting in the $\mathrm{PuO}_{2}-\mathrm{Al}$ pellets. ${ }^{46}$ Owing to the lower percertage of oxide in the americium pellets and accompanying increased thermal conductivity, a gap of 1 to 2 mils is allowable between the pellets and the cladding.

In the $\mathrm{PuO}_{2}$ targets approximately 80 percent of the original actınide will undergo fission, which can generate significant pressures within the pellets. ${ }^{47}$ A fission-gas plenum is provided at each end of the target rod to reduce the hazard of capsule fallure. The aluminum end caps on each pellet are porous to permit the fission gases to escape and thus prevent pellet swelling. Pressure due to fission gases should not be a serious problem in the americium targets.

CHEMICAL PROCESSING Neptunium exists in all valence states from $\mathrm{Np}$ (III) to $\mathrm{Np}$ (VI). The stability of $\mathrm{Np}$ (V), the most stable valence state, distinguishes neptunium irom the other transuranium elements. The $\mathrm{Np}(\mathrm{IV})$ and $\mathrm{Np}(\mathrm{VI})$ states are extracted by organic solvents, such as tributylphosphate (TBP) and trissooctylamine. But, because it is more aifficult to maintain the $\mathrm{Np}(\mathrm{VI})$ state in cortact with organic material, neptunium is usually reduced to $\mathrm{Np}(\mathrm{IV})$ and extracted as $\mathrm{Np}(\mathrm{IV})$. Thus Flanary and Goode ${ }^{48}$ reduce neptunium to $\mathrm{Np}(\mathrm{IV})$ with $0.01 \mathrm{M}$ to $0.02 \mathrm{M}$ ferrous sulfamate and coextract $\mathrm{Np}(\mathrm{IV})$ with $\mathrm{U}(\mathrm{VI})$ in 15 percent TBP. The $\mathrm{Np}(\mathrm{IV})$, along with some $\mathrm{U}(\mathrm{VI})$, is back-extracted into $1.0 \mathrm{~N} \mathrm{HNO}_{3}$. Further processing by ion exchange or solvent extraction is required to obtain a pure neptunium product. Schneider ${ }^{49}$ extracted $\mathrm{Np}(\mathrm{IV})$ into trisooctylamine dissolved in xylene from a nitric acid reducing solution. Alimarin and Zolotov ${ }^{50}$ have reviewed the oxidation states of neptunium and separation methods based on coprecipitaion, ion exchange, and solvent extraction.

Neptunium can be reduced to $\mathrm{Np}(\mathrm{IV})$ in $6 \mathrm{~N} \mathrm{HNO}_{3}$ with a mixture of ferrous sulfamate and hydrazine as a reducing agent; $\mathrm{Np}$ (IV) is then sorbed strongly by a Dowex I anion exchanger. ${ }^{51}$ The chemistry of $\mathrm{Np}(\mathrm{IV})$ and $\mathrm{Pu}(\mathrm{IV})$ is very similar under these conditions. With the use of a strong reducing agent such as hydrazine, however, Pu(IV) can be reduced to $\mathrm{Pu}(\mathrm{III})$, and neptunium can be separated from plutonium. Roberts $^{52}$ sorbs $\mathrm{Np}(\mathrm{IV})$ and $\mathrm{Pu}(\mathrm{IV})$ on an anion exchanger and separates 
$\mathrm{Np}(\mathrm{IV})$ from $\mathrm{Pu}(\mathrm{IV})$ by elution with $0.005 \mathrm{M}$ ceric sulfate in $0.25 \mathrm{~N} \mathrm{HNO}_{3}$; $\mathrm{Np}$ (IV) is oxidized to $\mathrm{Np}(\mathrm{V})$ and is rapidly eluted from the anion column. Neptunium recoveries of 95 percent have been obtained with a plutonium decontamination factor of $5 \times 10^{4}$.

Americium and curium are difficult to recover and purify from irradiation targets because their chemical behavior is similar to that of the rare-earth fission products. Several good summaries of amer1 cium and curium chemistry, and procedures for their purification, have been prepared. ${ }^{53-56}$ In most cases the separation methods discussed are for recoveries of small quantities of transplutonium elements.

Americium-241 is probably the easiest transplutonium isotope to obtain in pure form because it is the daughter of 13.2-year $\mathrm{Pu}^{241}$ and can be periodically extracted from purified plutonium containing appreciable quantities of the $\mathrm{Pu}^{241}$ isotope. The plutonium anion-exchange procedure of Ryan and Wheelwright ${ }^{30}$ can be adapted for separation of pure americium from plutonium nitrate solutions. In this process, $\mathrm{Pu}^{4+}$ as a nitrate complex is strongly sorbed on anion exchange resin from 7.5M $\mathrm{HNO}_{3}$, but americium does not load. A procedure of this type was suggested by Nairn et al. ${ }^{57}$ in which plutonium is stored on anionexchange resin and the $\mathrm{Am}^{241}$ daughter is eluted with $6 \mathrm{M} \mathrm{HNO}_{3}$. Continuous storage of plutonium on the resin may not be desirable because of column gassing and resin degradation resulting from prolonged exposure to nitric acid and alpha radiation.

When purified plutonium is processed to convertit to metal or other chemical forms, $\mathrm{Am}^{241}$ is often concentrated in waste streams. Several methods have been used for recovering americium from these wastes. Keenan ${ }^{58}$ used an adaptation of a thlocyanate-anion exchanger process $^{33,34}$ for purifying $200 \mathrm{mg} \mathrm{Am}{ }^{241}$ to more than 99.8 percent chemical purity. This purification included separation from non radioactive rare earths. Application of this method to $\mathrm{Cm}^{242}$ purification was not successful because the high alpha-radiation density on the resin caused sufficient gas-bubble formation and thiocyanate degradation to prevent establishment of equilibrium. This method should not be considered for high-activity-level processing because of thiocyanate instabihty.

A method based on $\mathrm{Am}^{241}$ extraction into 100 percent tributyl pnosphate from $17 \mathrm{M} \mathrm{HNO}_{3}$ was described by Lewis. ${ }^{59}$ The feed for this process contained about $600 \mathrm{~g}$ of lanthanum (plus cerium) per gram of americium. Americium recoveries were 99.5 percent, and product contained less than 1 percent of the rare earths in the feed. Final purification was made by 1on-exchange methods based on citrate complexıng to selectively elute americium from cation-exchange resin. ${ }^{60}$ This solvent-extraction process is limited because light-element impurities, such as aluminum, iron, and calcium, which have only limited solubilities in concentrated nitric acid, must first be removed. Also, 
this procedure cannot be used to separate fission-product neodymium from americium because their extractabilities are nearly the same. ${ }^{61}$

Processes for recovering $\mathrm{Cm}^{242}$ from irradiated $\mathrm{Am}^{241}$ and for recovering $\mathrm{Am}^{243}$ and $\mathrm{Cm}^{244}$ from highly irradiated plutonium must be carried out in shielded facilities. Special chemical separation methods based on complex formation are necessary for separating americium and curium from fission products, especially the rare earths. Several procedures have been used for purifying small amounts of these materials. Higgins and $\mathrm{Crane}^{62}$ reported a process for purifying $100-\mathrm{mg}$ quantities of $\mathrm{Cm}^{242}$ which consists of loading $\mathrm{Am}^{241}$ and $\mathrm{Cm}^{242}$ on anionexchange resin from $10 . M \mathrm{LiCl}$ solution, washing with $11 . W \mathrm{LiCl}$ to remove rare earths, and eluting the americium and curium with $13 . \mathrm{M} \mathrm{HCl}$. Final purification was obtained by selective elution of the $\mathrm{Am}^{241}$ and $\mathrm{Cm}^{242}$ from cation-exchange resin with solutions of lactic acid.

The procedure using anion exchange with concentrated lithium chloride solutions has been used to make complete separation of the trivalent lanthanides from the trivalent actinides. Hulet et al ${ }^{63}$ discuss the variables affecting separation. This method was used by Fried to recover actinides from irradiated curıum. The procedure gives excellent separations for the small quantities processed. It is doubtful that it can be used for significantly large $r$ quantities because of resin damage and column gassing at sites of highly concentrated activity.

Marcus and Nelson ${ }^{64}$ reported that actinides and lanthanides can be loaded on anion-exchange resin from concentrated $\mathrm{LiNO}_{3}$ solutions at low acidity. Unfortunately actinide and lanthanide group separation cannot be readily made from nitrate systems. However, Lloyd and Leuze ${ }^{65}$ suggested a process to recover americium and curıum from plutonium process wastes based on loading anion resin with americium, curium, and rare-earth fission products from neutral nitrate solution and then selectively eluting the rare-earth fission products with $10 \mathrm{M} \mathrm{LiCl}$. In addition to the limitations of the process described by Hulet et al., ${ }^{63}$ the alternate use of nitrate and chloride on the same resin results in increased gassing problems. Lloyd has described a process for recovering americium and curium contaminated with all the rare-earth fission products which consists of loading an anion-exchange resin from $2.6 \mathrm{II} \mathrm{Al}\left(\mathrm{NO}_{3}\right)_{3}$, washing the resin with $8 \mathrm{~W} \mathrm{LiNO}_{3}$, and eluting the product with dilute nitric acid. Although this process has limitations imposed by resin degradation, multigram scale processing was successfully accomplished at ORNL by frequent resin replacement. A moderate amount of gassing in the column can be tolerated because this separation does not depend upon a chromatographic elution.

The most significant recent advancement in process methods for recovering transplutonium elements is selective extraction of trivalent transplutonum elements into a tertiary amine solvent from concentrated lithium chloride solutions. ${ }^{66-68}$ Separation factors of 100 between 
curium, the least extractable actinide, and europium, the most extractable lanthanide, can be obtained. It is a liquid anion-exchange process similar to that in which anion-exchange resin is used, but it has the advantage of being readily scaled up into a plant-scale contınuous process. Furthermore, the activity concentration can be regulated to decrease radiation damage to process solutions.

The solvent-extraction process ${ }^{69,70}$ (Tramex) consists of (1) actinide extraction from $10 \mathrm{MLCl}-0.1 \mathrm{MACl} \mathrm{AlCl}_{3}-0.02 \mathrm{M} \mathrm{HCl}$ into $0.6 \mathrm{~W}$ Alamine $336 \cdot \mathrm{HCl}$ in diethylbenzene, (2) solvent scrubbing with $11 M \mathrm{LiCl}-0.02 \mathrm{M}$ $\mathrm{HCl}$, (3) actinide stripping into $8 . \mathrm{H} \mathrm{HCl}$, and (4) strip-product washing with freshly prepared $0.6 \mathrm{M}$ Alamine $336 \cdot \mathrm{HNO}_{2}$ in diethylbenzene. This process is useful for recovering all the known transplutonium elements as a group. Results of laboratory tests in Minimixer settlers with synthetic feed and of high-activity-level batch extraction on a 1 - to $2-\mathrm{ml}$ scale indicate that the Tramex process is satisfactory for separating the transplutonium elements from all probable contaminants except nickel. Americium and curium recoveries of greater than 99.9 percent have been demonstrated, and decontamination factors were equal to or greater than $10^{4}$ for gross gamma activity, rare earths, zirconium, and ruthenium and equal to or greater than $10^{3}$ for 1 ron, chromium, and aluminum. No radiation-induced difficulties were detected at activity levels of 10 watts/liter and at total solvent exposures of 300 watt-hr/ liter.

Corrosion is the most serious problem connected with application of the Tramex process. Special equipment bull from materials that can handle chloride solutions is required. Close control and adjustment of Tramex feed is required because slight changes in variables often cause considerable changes in actinide extractability.

Another significant advance is the use of amine extraction to easily convert from nitrate systems to chloride systems. ${ }^{71}$ As with anionexchange resin, americium, curlum, and rare-earth fission products can be extracted into the $\mathrm{HNO}_{3}$ salt of tertiary amine from neutral nitrate salt systems. Because little excess nitrate is extracted, the solvent can be stripped with $\mathrm{HCl}$ solution, and traces of $\mathrm{HNO}_{3}$ in the strip product are removed with washes of fresh tertiary amine. The $\mathrm{HCl}$ solution of americium, curlum, and rare earths can then be adjusted to Tramex feed.

Several methods are avallable for separating americium and curium. Limited amounts can be separated by chromatographic elution from cation-exchange resin ${ }^{72}$ with alpha-hydroxyisobutyrate or by chromatographic elution from amon-exchange resin ${ }^{73}$ with $4 . / \mathrm{L}_{1} \mathrm{NO}_{3}$. Complete separation is not obtained in one pass with either system, but the $\mathrm{LiNO}_{3}$ elution gives better separation. The activity level that can be handled by either of these methods is limited, for even slight disturbance of the resin bed by gassing results in poor separation. A 
precipitation method for separating americium and curium was discussed by Penneman and Asprey. ${ }^{54}$ This separation is based upon the fact that americium dissolved in $3 \mathrm{M} \mathrm{K}_{2} \mathrm{CO}_{3}$ can be oxidized with $0.1 \mathrm{M}$ $\mathrm{NaOCl}$ to the pentavalent state, which forms an insoluble double carbonate, $\mathrm{KAm}_{2} \mathrm{CO}_{3}$. Curium remains in the trivalent state and stays in solution. The activity level is also important in this method because $\mathrm{H}_{2} \mathrm{O}_{2}$ formed by radiolysis reduces the americium and makes it soluble.

A good separation between $\mathrm{Am}^{241}$ and $\mathrm{Cm}^{242}$ has been demonstrated by sorbing $100 \mathrm{mc}$ of $\mathrm{Cm}^{242}$ plus $\mathrm{Am}^{241}$ and fission products on a Dowex $50-$ WX 4 column and eluting with 0.5 percent diethylenetriaminepentaacetic acid (DTPA). There is virtually no separation of $\mathrm{Cm}^{242}$ from the rare earths by this method.

\section{Other By-products}

The major by-products other than fission products and the several transplutonium isotopes are $\mathrm{Po}^{210}$ and $\mathrm{Co}^{60}$. Little or no processing is involved with $\mathrm{Co}^{60}$. The pure-metal shapes are sometimes plated with nickel or enclosed in aluminum before irradiation. The major problem is in irradiating in the most efficient array to get maximum production. The remaining procedures are handling, assaying, and source fabricating of the finıshed $\mathrm{Co}^{60}$, which are accomplished for the most part with remote-control manipulators in cells equipped with viewing windows.

Little can be said about the production and processing of $\mathrm{Po}^{210}$. It is produced by neutron irradiation of bismuth metal (see Ref. 74).

Although any of the more than 200 radioisotopes produced and distributed by ORNL could be produced in the large power reactors, it is highly unlikely that many of these would have any significance econom1cally. This situation is clear from Table 6, which shows the amounts distributed in the radioisotope program. Whereas a significant byproduct program would involve megacurie quantities, the amounts of most radioisotopes distributed are counted in curies, millicuries, or, with some, even in microcuries. Thus no further discussion of the many other radiolsotopes is made here, although a particular isotope can come into great demand almost overnight as the directions of technical programs change.

\section{TRANSPORTATION}

by E. E. Beauchamp

Oak Ridge National Laboratory

If by-products are to have any use, they will have to be packaged and shipped from the plant site as spent fuel, radioactive waste, or 
intermediates of one kind or another. Transportation of radioactive materials is therefore a vital part of the utilization of reactor byproducts and must be carefully considered in any by-product program.

Fortunately the transportation of radioactive materials thus far has been quite successful. There have been very few accidents or incidents with any significant problems involved. ${ }^{75,76}$

In the maintaining of the proper perspective concerning the statistics on the shipment of radioactive materials, two factors are $1 \mathrm{~m}$ portant. The total number of shipments would be increased by including the shipments from secondary radioisotope suppliers (ORNL being the primary supplier) engaged in private business in the radioisotope industry; in that case the over-all statıstıcs would be even better than those cited. Also, probably more than 90 percent of the individual shipments of radioactivity originate from the radioisotope-distribution program. More than 80 percent of the shipments in the radioisotopedistribution program involve less than 2.7 curies of radioactivity, and an average for this segment would probably be less than 1 curie. If quantities of radioactivity of only this magnitude were involved in an incident, a troublesome situation might be created but, with few exceptions, hardly a major hazard.

Thus the shipping of radioisotopes is a relatively minor problem statistics show this - and the shipment of large sources, irradiated fuel, etc., wherein the potential hazards are the greatest, should be the major concern. Any radioactivity incident, no matter how minor, may result in a public-relations problem. This aspect of the problem will continue until the general public accepts the fact that radioactivity in most cases presents no greater hazard than many other hazardous articles of commerce, such as toxic chemicals, explosives, and dangerous biological preparations that are accepted as a part of everyday life.

The basic regulations for shipping radioactive materials commercrally were prescribed under the Act of June 25, 1948 (62 Stat. 738; 18 U.S.C.A. 831-835). This basic law is carried out domestically under three agencies:

1. Interstate Commerce Commission (ICC) through the Bureau of Explosives for rall-freight and motor-vehicle service.

2. Civil Aeronautics Board through the Federal Aviation Authority for articles carried by air.

3. U. S. Coast Guard for service by water.

When radioactive materials become involved in international shipping, other agencies also have pertinent regulations: (1) the International Air Transport Association provides rules for air transport; (2) the International Atomic Energy Agency (IAEA) provides regulations for their own operations. Several IAEA member countries have adopted these rules for regulations within their own country. 
Although the USAEC is exempt from the ICC regulations for its own operations, its stated policy is to follow these regulations. The USAEC has, however, great influence on the requirements through its licensing operations, from which broad regulations are published through the Federal Regisler. Particularly noteworthy at present is AEC Manual Chapter 0527,* which is proposed in the Federal Register as Part 72, and is concerned with irradiated fuel elements. Likewise, ALC Manual Chapter $0529, *$ which is to be proposed for the Federal Regisles, is concerned with "large sources"

Shipping containers used at ORNL in the radioisotope program are representative of the kinds of containers used for millicurie to kilocurie quantities. Approximately 80 percent of the shipments are made in a disposable package made up of an inner-molded lead shield, paper absorbent material, crimp-sealed steel ("tın") can, and heavy pasteboard outer box. Normally, 2.7 curies is the maximum amount allowed in the disposable container. Experience with many thousands of shipments has been excellent; there has been no significant loss of radioactivity during shipment.

The returnable containers are much more sturdy. The lead shield is encased in stainless steel, and it is enclosed in a wooden box to simpliny handling. These containers have up to $3 \mathrm{~m}$. of lead shielding and a maximum weight of $350 \mathrm{lb}$, which is about the maximum weight that can be handled without hoisting equipment. A further refinement to this container is a stainless-steel insert in which extra-hazardous materials, such as $\mathrm{Sr}^{90}$, can be sealed during shipment.

Another group of shipping containers of lead-filled stainless-steel construction weigh from 300 to $6800 \mathrm{lb}$ each. They are used to ship curie amounts of $\mathrm{Co}^{60}, \mathrm{Cs}^{137}$, and $\mathrm{Ir}^{192}$.

The first large transport container for fission products was the STT (Shielded Transfer Tank). These containers are used to ship 50,000 -curie quantities of $\mathrm{Cs}^{137}$ from Hanford to ORNL by special railroad car. The special car is a heavily trussed gondola car that affords protection from impact in possible train wrecks; extra thermal shields are included around the casks for protection in case of fire.

Hanford has designed and procured containers in which up to 170,000 curies of $\mathrm{Sr}^{90}$ are shipped as a dry carbonate filter cake. The cask is provided with fins for air cooling, and the unit is enclosed in a rubbersteel bumper for protection against impact or fire. Two larger containers of similar design are avallable for the shipment of up to 1 megacurie of $\mathrm{Ce}^{144}$ as the double sulfate or up to 500,000 curies of $\mathrm{Sr}^{90}$ as the carbonate salt. ${ }^{77}$

There is currently a trend for more stringent standards, apparently for the following reasons: (1) the realization that the shipments

*Applicable only to USAEC contractors 
of irradiated fuel and large sources will increase; (2) a desire to ship irradiated fuel and large sources by regular commercial transportation; (3) moves by the IAEA to prepare regulations that may in some cases be more restrictive than current U. S. regulations.

The issuance of the proposed rules making up Part 72 in the Federal Registe concerning specifications for containers to ship 1rradiated fuel started a search for contamers that would withstand a maximum credible incident and yet not be prohibitively costly. The shipment of irradiated fuel is a very complex problem because of the multiple problems of criticality, heat removal, and large quantities of radioactivity involved.

Furthermore, there has been a desire to modify the ICC regulations to more nearly approach the regulations established by the IAEA so that ultimately there will be truly international shipping-regulation container specifications. As a result the Interagency Committee on Transport of Radioactive Materials has prepared some revisions, updating, and modifications that they have recommended to the ICC for adoption. At present this report is awaiting ICC action.

The IAEA continues to try to improve and enlarge the scope of their regulations. At an IAEA meeting held in March 1963, consideration was given to the adoption of a series of standard tests for containers. These tests have been prepared by the United Kingdom. Some of the proposed tests, such as the fire test, have merit; however, a document will have to first be prepared containing design criteria and specifications for containers. Then containers can be designed and built with reasonable expectations that they will meet the tests that simulate transport conditions and the tests of actual usage.

Currently the main problems in the testing of containers for shipment of radioactive materials appear to be:

1. Fire testing of containers. Both the United Kingdom and the United States are concerned with establishing a standard fire test. ${ }^{78}$ The British approach appears to be somewhat less stringent, but it has the advantage of simplicity. ${ }^{79}$ The British have introduced the concept of using hardwood as insulating material for the container to withstand a fire.

2. Shock resistance of containers. The British apparently have confined their efforts to a physical drop test, whereas the United States is exploring three methods. The United States is exploring prototype drop tests, methods of calculation to determine acceptability, and the use of scale models for the physical tests in order to reduce the costs involved in producing full-scale prototypes. ${ }^{80}$

3. Resistance to piercing or penetration. The British ${ }^{81}$ have placed less emphasis in this test than the United States has. In the U.S. tests, a 15-G drop on a 6-1n.-diameter object has been used as the criterion. 
However, this test appears rather stringent, and some other test that is probably more representative of an actual accident may be devised.

\section{CONCLUSION}

By-product operations will be of significance in the nuclear industry in the future. On a quantity basis fission products and $\mathrm{Co}^{60}$ are the most important; heat-power uses will call for the production of transuranium elements. Considering the vast present-day production operations and the future projection for central-station nuclear power, the basic supply of fission products is well-nigh inexhaustible. The over-all neutron economy places restrictions on production of $\mathrm{Co}^{60}$, transplutonium elements, and other neutron-produced materials, but the potential supply, without cost consideration, also can probably meet the demand.

Separation and utilization of fission products are closely related to waste management, and fission-product recovery will be governed by waste-management requirements in the foreseeable future. Ideas on waste management are changing with the realization that high-level wastes must be concentrated, contained, immoblized, and stored permanently in a safe manner. Work on the gross high-level wastes is being given most attention at present, but separation of fission products is now being started on a megacurie scale at Hanford. In my opinion this irend will grow so that eventually the main part of the really hot long-lived fission-product waste will be stored or used (at least, most of it) in the form of high-integrity radiolsotope packages. This practice will leave the relatively lower activity waste to be dealt with as the main waste-management problem. The demand for fission products at prices that will cover production costs will, however, be the controlling factor. The most important demand for fission products now comes from special heat-power applications, but radiation uses will probably eventually be the controlling factor in the use of fission products, particularly $\mathrm{Cs}^{137}$.

I regard transuranium radioisotopes, $\mathrm{Co}^{60}$, and other neutronproduced materials as by-products only in a special sense; the neutrons consumed for their production probably could be used more profitably for fuel production, except where reactors fueled with uranium not completely enriched or with plutonium unavoldably build up some transuranium radiolsotopes. The $\mathrm{U}^{236}$ buldup in highly enriched reactors is another exception. The special radioisotopes produced by using "excess" neutrons are very important at present and undoubtedly will continue to be. Nevertheless, the fission products are clearly nuclearreactor by-products; it is therefore problematical whether neutrons will continue to be spent to produce $\mathrm{Co}^{60}$ for gamma radiation when $\mathrm{Cs}^{137}$ is produced whether it is wanted or not, or to produce $\mathrm{Pu}^{238}$ and 
$\mathrm{Cm}^{244}$ for heat-power sources when there is an inexhaustible supply of $\mathrm{Sr}^{90}$ and $\mathrm{Ce}^{144}$.

\section{REFERENCES}

1. Federal Register, Part 30, Document 57-8536, Oct. 16, 1957.

2. A. F. Rupp, Large-scale Production of Radioisotopes, in Proceedings of the United Nations International Conference on the Peaceful Uses of Atomic Energy, Geneva, 1955, Vol. 14, pp. 68-84, United Nations, New York, 1956.

3. E. Lamb, H. E. Seagren, and E. E. Beauchamp, Fission Product Pilot Plant and Other Developments in the Radioisotope Program at the Oak Ridge National Laboratory, in Proceedings of the Second Unted Nations International Conference on the Peaceful Uses of Atomic Energy, Geneva, 1958, Vol. 20, pp. 38-44, United Nations, New York, 1958.

4. A. F. Rupp, Avallability and Economics of By-product Sources, Atome Industrial Forum Report No. 12, Vol. II, pp. 271-276, 1956.

5. A. F. Rupp, Factors Influencing Costs of Fission Products, University of Michigan Symposium Report 1P157, pp. 205-219, 1956.

6. Radiatzon Safety and Major Activitzes in the Atome Energy Programs, JulyDecember 1956, p. 304, U. S. Government Printıng Offıce, Washıngton, D.C., January 1957.

7. Hearings Before the Special Subcommuttee of the Jount Commuttee on Atomuc Energy, 86th Congress, Vol. 3, p. 2341, U. S. Government Prıntıng Office, Washington, D. C., 1959.

8. Summary-Analysis of Hearings on Industrial Radioactive Waste Disposal, 86th Congress, 1st Session Joint Committee Print, August 1959.

9. Major Activities in the Atomic Energy Programs, Januury-December 1959, p. 304, U. S. Government Printing Office, Washington, D. C., January 1960.

10. E. Gleuckauf (Ed.), Atomic Energy Waste, Interscience Publishers, Inc., New York, 1961.

11. J. A. Lane, Future Needs for Nuclear Power, ORNL unpublished committee report, November 1961 .

12. A. Berman and W. Eıster, reports prepared for SN 4 P program reviews, 1963.

13. C. A. Rohrmann, Special Radioisotopes for Power: Avallability and Applications of Thorlum-230 (Ionıum) from Uranium Ore Mills, USAEC Report HW -71319(Rev.), Hanford Atomic Products Operation, Oet. 16, 1961.

14. J. G. Morse and D. G. Harvey, Radionuchide Power for Space Missions, Nucleonics, 19(4): 69-72 (1961).

15. E. H. Smith et al., Isotopic Power Sources-A Compendium, USAEC Report MND-P-2581, Parts I and IIl, Martin Company, 1962.

16. Review of SNAP Program, Nucl Neus, 5(8): 14-15 (August 1962).

17. R. L. Bradshaw, Evaluation of Ultimate Disposal Method for Liquid and Solid Radioactive Wastes. Part I. Interım Liquid Storage, USAEC Report ORNL3128, Oak Ridge Natıonal Laboratory, Aug. 22, 1961.

18. J. J. Perona, R. L. Bradshaw, J. O. Blomeke, and J. T. Roberts, Evaluation of Ultimate Disposal Methods for Liquid and Solıd Wastes. IV. Shipment of Calcıned Solıds, USAEC Report ORNL-3356, Oak Ridge Natıonal Laboratory, Oct. 18,1962 . 
19. R. E. Tomlinson, The Hanford Program for Management of High-level Waste, USAEC Report HW-SA-2515(Rev.), Hanford Atomic Products Operation, Feb. 4, 1963.

20. S. J. Rimshaw, Decontamination of Fission Product Waste with Separation of Kllocurie Quantities of Cs, Sr, Ru and Rare Earths, in USAEC Report TID-7517(Pt. Ia).

21. R. E. Burns and M. J. Stedwell, Volume Reduction of Wastes by Carrier Precipitation, Chem. Eng. Progr., 53: 93F (1957).

22. H. H. Van Tuyl and L. A. Bray, Recovery of Cesıum from Purex Tank Farm Supernatant Solution by Ferrocyanide Precipitation and Absorption on Decalso, USAEC Report HW-70874, Hanford Atomic Products Operation, Oct. $18,1961$.

23. G. B. Barton et al., Cesium Recovery by Complex Ferrocyanide Precipitation, Ind. Eng Chem, 50: 212-216 (1958).

24. H. H. Van Tuyl, Report of Invention. The Methathesis of Cesium Ferrocyanides, Ferrıcyanıdes and Cobaltıcyanıdes with Silver Carbonate, Report HW57228, Hanford Atomic Products Operation, 1958.

25. W. W. Schulz, J. E. Mendel, and G. L. Richardson, Solvent Extraction Recovery and Purıfication of Strontıum-90, USAEC Report HW-SA-2396, Hanford Atomic Products Operation, Dec. 13, 1961.

26. R. E. McHenry and J. C. Posey, Separation of $\mathrm{Sr}^{90}$ from Calcium by Solvent Extraction, Ind. Eng. Chem., 53: 647-650 (1961).

27. R. S. Pressly, Production and Separation of Rare Earths, in Rare Earths in Blochemical and Medical Research, USAEC Report ORINS-12, Oak Ridge Institute of Nuclear Studies, 1955.

28. R. S. Pressly, Preparation of Fission Rare-earth Isotopes, USAEC Report ORNL-2252, Oak Ridge National Laboratory, May 27, 1957.

29. R. S. Pressly, Separation of Americium and Promethium, USAEC Report ORNL-2202, Oak Ridge National Laboratory, Mar. 27, 1957.

30. R. S. Pressly, E. E. Beauchamp, P. B. Orr, and C. L. Ottinger, Purification of Kilocurie Quantities of $\mathrm{Pm}^{147}$ by Ion Exchange, USAEC Report ORNL2928, Oak Ridge National Laboratory, July 19, 1960.

31. R. S. Pressly, Purification of $\mathrm{Pm}^{147}$ from Fission-produced Rare Earths, USAEC Report ORNL-2843, Oak Ridge Natıonal Laboratory, Mar. 15, 1960.

32. P. B. Orr, Ion Exchange Purification of $\mathrm{Pm}^{147}$ and Its Separation from $\mathrm{Am}^{241}$ with Diethylenetriaminepentaacetic Acid as the Eluant, USAEC Report ORNL-3271, Oak Ridge National Laboratory, July 6, 1962.

33. R. E. McHenry and B. Lopez-Perez, Solvent Extraction Separation of Neodymium and Promethium Using Di(2-ethylhexyl)orthophosphoric Acid as Extractant, USAEC Report ORNL-TM-184, Oak Ridge National Laboratory, July $6,1962$.

34. R. E. McHenry, Multikilocurie Production of Krypton-85, USAEC Report ORNL-2976, Oak Ridge National Laboratory, Apr. 25, 1961.

35. H. T. Russell, Recovery and Half-life Determination of $I^{129}$, USAEC Report ORNL-2293, Oak Ridge National Laboratory, May 24, 1957.

36. H. A. O'Brien and J. M. Sullivan, A Process for Recovering Iodine-129, USAEC Report ORNL-TM-469, Oak Ridge Natıonal Laboratory, 1963.

37. S. J. Rimshaw and G. F. Malling, Solvent Extraction of Technetium and Rhenıum with Pyridine or Methyl-substituted Pyridine Derivatives from Alkalıne Medıa, Anal. Chem., 33: 751-754 (1961). 
38. J. W. Ullmann, Heavy Element Isotopic Bulldup, in Symposium on the Reprocessing of Irradiated Fuels Held at Brussels, Belgium, May 20-25, 1957, USAEC Report TID-7534(Bk.3), pp. 1080-1107, 1957.

39. E. D. Arnold, Effect of Uranıum Recycle on Transuranic Element Buldup, Nucl Scr Eng., 3: 707-725 (1958).

40. R. P. Schuman and R. L. Tromp, Calculation of the Composition of Reactorirradiated Heavy Nuclides, USAEC Report IDO-16571, Phillips Petroleum Company, Dec. 17, 1959.

41. F. P. Brauer and H. H. Burley, Transplutonlum Isotope Bulldup by Neutron Irradiation of Plutonium, USAEC Report HW-58596, Hanford Atomic Products Operation, Dec. 15, 1958.

42. W. C. Bentley et al., The Formation of Higher Isotopes and Higher Elements by Reactor Irradiation of $\mathrm{Pu}^{239}$; Some Nuclear Properties of the Heavier Elements, in Proceedings of the Unted Nations International Conference on the Peaceful Uses of Atomic Energy, Geneva, 1955, Vol. 7, pp. 261-273, United Nations, New York, 1956.

43. R. J. Barrett, J. Killeen, J. O. Rasmussen, Jr.. and S. G. Thompson, Pile Neutron Production Yield Curves Calculated Using the UCRL Differential Analyzer, USAEC Report UCRL-2387, University of California Radiation Laboratory, Oct. 30, 1953.

44. W. D. Burch et al., Production of the Transuranium Elements, Trans Am. rucl Soc, 5(1): 14-15 (June 1962).

45. D. L. MeElroy et al., The Thermal Conductivity at $75^{\circ} \mathrm{C}$ of Cold-pressed $\mathrm{Al}-\mathrm{Gd}_{2} \mathrm{O}_{3}$ Pellets, USAEC Report ORNL-CF-62-7-21, Oak Ridge National Laboratory, Aug. 20, 1962.

46. W. C. Thurber et al., Development of Procedures and Equipment for Fabrication of the High-flux Isotope Reactor Target Rods, Trans Am. Nucl. Soc., $5(2)$ : 298-299 (November 1962).

47. W. E. Unger et al., Design of the TRU-HFIR Target, USAEC Report ORNLCF-62-1-31, Oak Ridge National Laboratory, Jan. 22, 1962.

48. J. R. Flanary and J. H. Goode, Recovery of Neptunium-237 from Process Residues by Solvent Extraction, Ind Eng Chem 51: 55-57 (1959).

49. R. A. Schneider, Analytical Extraction of Neptunium Using Tri-1sooctylamıne and Thenoyltrifluoroacetone, Anal. Chem , 34. 522-525 (1962).

50. I. P. Alimarin and Yu. A. Zolotov, Analytical Chemistry of Neptunium, Usp. Khım, 26: 625-639 (1957).

51. J. L. Ryan, Concentration and Final Purification of Neptunium by Anion Exchange, USAEC Report HW-59193(Rev.), Hanford Atomic Products Operation, Sept. 3, 1959.

52. F. P. Roberts, An Analytical Method for $\mathrm{Np}^{237}$ Using Anıon Exchange, USAEC Report HW-59032, Hanford Atomic Products Operation, Jan. 28, 1959.

53. J J. Katz and G. T. Seaborg, The Chemistry of the Actunide Elements, Methuen \& Company, Ltd., London, 1957.

54. R. A. Penneman and L. B. Asprey, A Review of Americium and Curlum Chemistry, in Proceedings of the United Nations International Conference on the Peaceful Uses of Atomuc Energy, Geneva, 1955, Vol. 7, pp. 355-362, United Nations, New York, 1956.

55. R. A. Penneman and T. K. Keenan, The Radiochemistry of Americium and Curıum, USAEC Report NAS-NS-3006, National Academy of SciencesNational Research Counc1l, Januery 1960. 
56. Darleane C. Hoffman, Recent Advances in the Separation and Analysis of the Transuranium Elements, Progr. Nucl. Energy, Ser. IX, 2: 157 (1961).

57. J. S. Nairn et al., The Extraction of Actinide Elements from Wastes, in Proceedings of the Second Unted Nations International Conference on the Peaceful Uses of Atomic Energy, Geneva, 1958, Vol. 17, p. 233, United Natrons, New York, 1958.

58. T. K. Keenan, Rapid and Efficient Purification of Americium, J. Inorg. Nucl. Chem., 20: 185-188 (1961).

59. W. H. Lewis, Americium and Neptunium Recovery Processes, in Proceedings of the Second Unted Nations International Conference on the Peaceful Uses of Atomic Energy, Geneva, 1958, Vol. 17, pp. 236-244, United Nations, New York, 1958.

60. D. O. Campbell, The Isolation and Purification of Americium, USAEC Report ORN'.-1855, Oak Ridge National Laboratory, Apr. 7, 1956.

61. G. F. Best, E. Hesford, and H. A. C. McKay, Trı-n-Butyl Phosphate as an Extracting Agent for Inorganic Nitrates. VII. The Trivalent Actinide N1trates, J. Inorg. Nucl. Chem., 12: 136-140 (1959).

62. G. H. Higgins and W. W. T. Crane, The Production and Chemical Isolation of Curium-242 in Thousand-curie Quantities, in Proceedings of the Second Untted Nations International Conference on the Peaceful Uses of Atomic Energy, Geneva, 1958, Vol. 17, pp. 245-251, United Nations, New York, 1958.

63. E. K. Hulet, R. G. Gutmacher, and M. S. Coops, Group Separations of the Actinides from the Lanthanides by Anıon Exchange, J. Inorg. Nucl. Chem., 17: 350-360 (1961).

64. Y. Marcus and F. Nelson, J. Phys, Chem., 63: 77 (1959).

65. M. H. Lloyd and R. E. Leuze, Anıon Exchange Separation of Trivalent Actinides and Lanthanides, Nucl. Scr. Eng., 11: 274 (1961).

66. Fletcher L. Moore, New Technique for the Separation of Trivalent Actinide Elements from Lanthanide Elements, Anal. Chem., 33: 748 (May 1961).

67. R. D. Baybarz and B. Weaver, Separation of Transplutoniums from Lanthanides by Tertiary Amine Extraction, USAEC Report ORNL-3185, Oak Ridge National Laboratory, Dec. 20, 1961.

68. R. D. Baybarz and H. B. Kinser, Separation of Transplutonuums and Lanthanides by Tertiary Amine Extraction. II. Contaminations, USAEC Report ORNL-3244, Oak Ridge National Laboratory, Feb. 20, 1962.

69. R. D. Baybarz, B. S. Weaver, and H. B. Kınser, Separation of Transuranium Elements from Rare Earths by Tertiary Amine Extraction, to be published in Nuclear Scuence and Engineering.

70. R. E. Leuze, R. D. Baybar $\angle$, and B. S. Weaver, The Application of Amine and Phosphonate Extractants to Transplutonium Element Production, to be published in Nuclear Science and Engineering.

71. D. E. Ferguson, Transuranium Quarterly Progress Report for Perıod Ending August 31, 1962, USAEC Report ORNL-3375, p. 11, Oak Ridge National Laboratory, Feb. 1, 1963.

72. H. Lourse Smith and Darleane C. Hoffman, Ion Exchange Separation of the Lanthanides and Actinides by Elution with Ammonium Alpha-hydroxyısobutyrate, J. Inorg. Nucl. Chem., 3: 243 (1956).

73. S. Adar, R. K. Sjoblom, R. F. Barnes, P. R. Fields, E. K. Hulet, and H. Wilson, Ion-exchange Behavior of the Transuranium Elements in $\mathrm{LiNO}_{3}$ Solutions, USAEC Report TID-16595, May 1962; to be published in Journal of Inorganic and Nuclear Chemistry. 
74. H. V. Moyer (Ed.), Polonıum, USAEC Report TID-5221, Mound Laboratory, 1955.

75. D. E. Patterson and V. P. DeFatta, A Summary of Incidents Involving USAEC Shipments of Radioactive Materıal, 1957-1961, USAEC Report TID-16764.

76. USAEC Division of Organization and Personnel, A Summary of Transportation Incidents in Atomic Energy Activities, 1949-1956, USAEC Report AECU-3613, December 1957.

77. C. W. Smith, Strontium-90 Shipping Cask, Design Criteria and Hazards Evaluation, USAEC Report HW-68081, Hanford Atomic Products Operation, Jan. 13, 1961.

78. L. H. Horn, Fire Tests of Shipping Containers and Cobalt-60 Teletherapy Head, USAEC Report COO-274, Underwriters' Labs., Inc., Chıcago, Mar. 31, 1963.

79. F. E. Dixon, The Design of Shielded Containers to IAEA Standards, in AEC Symposium on Packaging and Regulatory Standards for Shipping Radioactive Materials, Held in Germantown, Maryland, Dec, 3-5, 1962, USAEC Report TID-7651, pp. 331-393, December 1962; British Report TCAP/P 64

80. AEC Symposium on Packaging and Regulatory Standards for Shipping Radioactive Materials, Held in Germantown, Maryland, Dec. 3-5, 1962, USAEC Report TID-7651, December 1962.

81. W. de L. M. Messenger and A. Faurbairn, The Transport of Radioactive Materıal, Apperidix N, Part D, Britısh Report AHSB(S) R.19. 


\section{Reactor-physics Data for Water-moderated \\ Lattices of Slightly Enriched Uranium}

by

Robert L. Hellens and Glenn A. Price Brookhaven National Laboratory 
he important role that light-water-moderated reactors assumed at an early date in the development of civilian power reactors has led to extensive experimental and theoretical studies of their nuclear characteristics. In this work most attention has been given to uranium fuel of enrichment from just above natural to about 5 percent $U^{235}$ as a result of appraisals of the economic potential of this type of reactor. Early work indicated that methods for both theoretical and experimental reactor physics required for the study of water lattices fueled with slightly enriched uranıum would be different in many ways from those appropriate to other types of reactors. Subsequent work has shown this to be true.

The principal features of the theory currently in vogue for watermoderated lattices have been reviewed in a series of papers presented at a recent panel sponsored by the International Atomic Energy Agency (IAEA). ${ }^{1}$ However, the experimental work in the same area is widely scattered; much of it is unpublished, and previous reviews of the data have, of necessity, been fragmentary. ${ }^{2-4}$ Now that much of the new experimental work is being applied to other fuels, a review of the apparently definitive data on slightly enriched uranium appears to be appropriate and is the subject of this article.

The principal purpose of this compilation of measurements is to provide a guide, for both the reactor theorist and the nuclear design engineer, to the variety of experimental data that can be invoked to support the continually changing theoretical models and cross-section estimates used in reactor design. Because the lattice data have been obtained in many different ways, it has been necessary to give some attention in the first section of this review, "Experimental Measurements of Lattice Characteristics," to the methods of interpreting the varıous types of lattice measurements. In doing so, we have made use of theoretical models to show some of the more common sources of systematic error, particularly those encountered in exponential experiments. These theoretical results are presented only to show the trends which could presumably be observed in very precise data but which are usually obscured in practice by experimental uncertainties.

The lattice measurements are described, and the results are tabulated in the second section, "Summary of Experimental Results." The great variety of data collected from water-lattice experiments during the last 12 years makes it difficult to classify the experiments in any precise way. However, from the viewpoint of assessing the accuracy of theoretical methods, the characteristic of principal importance is the degree of complexity in geometry or neutron spectrum of the assembly studied. We have used this characteristic of complexity, or rather simplicity, as the main criterion in choosing the experiments to be included in this compilation. On this basis a sequence of experimental situations can be distinguished which provide increasingly diffi- 
cult problems for the theory to describe. The simplest situation in this series is represented by the homogeneous critical assemblies of the Oak Ridge National Laboratory (ORNL). They are free of all laticice effects, and they provide a direct test of neutron-cross-section and leakage estimates. The next step of increasing complexity, made by including heterogeneous effects in a uniform lattice, provides the greatest bulk of the experimental information avallable on slightly enriched uranium fuel, and most of our discussion is devoted to experiments of this typa.

Of somewhat greater complexity are assemblies that exhibit simple energy-spectrum transients between several regions of differing lattice characteristics. The most common effect of this type occurs near a lattice-reflector interface, but of greater practical importance in design of power reactors are the similar spatial transients that occur in multiregion lattices. Effects of this type have been the subject of several series of experuments, which we shall describe.

A further step in complexity is produced in uniform lattices by introducing thin regions of altered characteristics such as water slots, plane sheets of aluminum, gold, cadmium, and various types of neutron-absorbing materials of engineering interest. Because much of the best work of this sort with simple control elements has been done with highly enriched uranium fuel, we have chosen to exclude such measurements rather than to provide a fragmentary listing of them.

The final stage of experimental complexity is reached by the traditional power-reactor-core mock-up, sometimes constructed with remarkable detail and frequently bult in an even more complex fashion than the actual reactor core to achieve some degree of flexibility. Many experiments of this type have been performed in connection with particular reactor-construction projects, and, although not intended for this purpose, some of this work can undoubtedly be useful in testing the basic capability of theoretical methods. However, we have made no attempt to review the information avallable from mock-up experiments. We have done so primarily because the analysis of such experiments is notoriously troublesome in that the approximate representation of geometrical detall frequently introduces errors that are comparable to those in the basic theoretical description of the physical processes. The resulting confusion between errors in theory and uncertainties in application Iimits the usefulness of mock-up experiments for the evaluation of the basic theory, although they can still be useful as an over-all test of reactor - design calculations.

The range and distribution of uniform lattıces that have been explored are indicated in the condensed Table 1 for uranium-metal fuel and in Table 2 for uranium dioxide fuel. In Table 1 the rods range in diameter from 0.175 to $1.660 \mathrm{ln}$., and the plates are $0.122 \mathrm{~m}$. thick. In Table 2 the rods range in diameter from 0.297 to $1.436 \mathrm{~m}$. The principal 
Table 1 - UNIFORM LATTICES FUELED WITH URANIUM METAL

\begin{tabular}{|c|c|c|c|}
\hline $\begin{array}{c}\mathrm{U}^{235} \\
\text { enrichment, } \sigma_{c}\end{array}$ & $\begin{array}{c}\text { No. of } \\
\text { fuel-element sizes }\end{array}$ & Cladding & $\begin{array}{c}\text { No of } \\
\text { lattices } \\
\text { measured }\end{array}$ \\
\hline 0.26 & $1 \mathrm{rod}$ & Aluminum & 3 \\
\hline 071 & 8 rods & $\begin{array}{l}\text { Aluminum, plastic, } \\
\text { none }\end{array}$ & 27 \\
\hline 0.93 & 2 rods & Aluminum, steel & 8 \\
\hline 094 & 1 annulus & Plastic & 2 \\
\hline 0.95 & $1 \mathrm{rod}$ & Aluminum, iron & 8 \\
\hline 1.01 & 2 rods, 1 annulus & Alumınum & 25 \\
\hline 1.03 & 4 rods & Alumınum & 44 \\
\hline 114 & 4 rods & Alumınum & 59 \\
\hline 125 & 1 annulus, 1 plate & Aluminum, none & 15 \\
\hline 1.30 & 2 rods & Aluminum & 23 \\
\hline 144 & 1 rod, 1 annulus & Alumınum & 15 \\
\hline 1.47 & 1 annulus & Aluminum & 5 \\
\hline 160 & 1 annulus & Aluminum & 10 \\
\hline 200 & 2 rods & Plastic & 11 \\
\hline \multirow[t]{2}{*}{306} & 4 rods & Plastic & 22 \\
\hline & & Total & 277 \\
\hline
\end{tabular}

Table 2-UNIFORM LATTICES FUELED WITH URANIUM DIOXIDE

\begin{tabular}{cclc}
\hline $\begin{array}{c}\mathrm{U}^{235} \\
\text { enrichment, } 7\end{array}$ & $\begin{array}{c}\text { No. of } \\
\text { fuel-element sizes }\end{array}$ & \multicolumn{1}{c}{ Cladding } & $\begin{array}{c}\text { No. of } \\
\text { lattices } \\
\text { measured }\end{array}$ \\
\hline 131 & 3 rods & Aluminum & 8 \\
185 & 1 rod & Aluminum & 2 \\
246 & 1 rod & Aluminum & 1 \\
2.55 & 1 annulus & Steel & 1 \\
260 & 1 annulus & Plastic & 6 \\
270 & 1 rod & Steel & 11 \\
3.01 & 1 rod & Steel & 20 \\
302 & 1 rod & Steel & 3 \\
304 & 1 rod & Aluminum, steel & 4 \\
340 & 1 annulus & Steel & 8 \\
370 & 1 rod & Steel & 7 \\
402 & 1 rod & Steel & 7 \\
443 & 1 rod & Steel & 2 \\
495 & 1 rod & Steel & 2 \\
& & & 85 \\
\hline
\end{tabular}


experimental results for the simple lattices can be summarized by the material buckling and cell parameters. Many of the cell-parameter data are given in the second section along with a brief indication of the experimental methods used. Bucklings and critical dimensions are tabulated in the appendix to this review. The results of the multiregionlattice experiments, outlined in Table 3 and described in the second section, are not readily summarized, so that little more than an idea of the type of data available can be given here. The interested reader should consult the references provided for critical loadings, fission distributions, and other detailed experimental information.

Table 3-MULTIREGION LATTICES FUELED WITH URANIUุM DIOXIDE

\begin{tabular}{|c|c|c|c|c|}
\hline \multicolumn{4}{|c|}{$\begin{array}{c}\text { Uranium enrichments } \\
\text { by region, } \%\end{array}$} & \multirow{2}{*}{$\begin{array}{c}\begin{array}{c}\text { No. of } \\
\text { lattices } \\
\text { measured }\end{array} \\
2\end{array}$} \\
\hline 1.6 & 3.7 & & & \\
\hline 2.7 & 3.7 & & & 1 \\
\hline 1.6 & 2.7 & & & 2 \\
\hline 1.6 & 2.7 & 3.7 & $"$ & 10 \\
\hline \multirow[t]{2}{*}{2.7} & 4.4 & & & 4 \\
\hline & & & Total & 19 \\
\hline
\end{tabular}

\section{EXPERIMENTAL MEASUREMENTS OF LATTICE CHARACTERISTICS}

In principle any lattice experiment in which either a steady or a time-dependent chain reaction is observed can be compared directly with the theory by computing the neutron behavior in the entire experimental arrangement of lattices, reflectors, sources, detectors, and all other surroundings exposed to an appreciable neutron flux. Such an analysis is obviously lengthy, and the influence of errors in the theoret1cal description of components other than the lattıce under investigation can effectively mask the properties of the lattice. Several different techniques have been evolved for use in exponential and critical experiments to avold this confusion of the lattice with its casual surroundings. As might be expected, each technique introduces the possibility of systematic error into the interpretation of the measurement.

The principal, and by far the simplest, measure of agreement between theory and measurements of uniform lattice characteristics is the material buckling. There are two reasons for this: first, material buckling is the only measurable quantity that characterizes the chainreacting properties of the lattice alone, and, second, it is relatively 
easy to carry out rather exact calculations of the entıre neutron spectrum in the lattice for the simple spatial distribution implied by the existence of an asymptotic region. Both exponential and critical experiments have been extensively used to provide this type of data.

Aside from the measurement of the material buckling, which yields data of direct physical significance concerning the lattice alone, criticalloadıng measurements are frequently made both by the critical-approach method and by critical experiments. If the surrounding reflector is well defined, these experiments can be quite useful, although for small assemblies they must be analyzed as two-region systems. In that case they do not provide information concerning the lattice characteristics as unambiguously as do the buckling measurements.

In addition to these two types of criticality measurements, a substantial amount of experimental work has been done to infer the neutron behavior in a lattice cell by measurement of detalled neutron-activation traverses within a unit cell and by measurements of the relative activation of folls by various materials in the fuel and moderator. Because these so-called "lattıce-cell-parameter" measurements normally require rather high flux levels, they are usually performed in critical assemblies or in miniature lattices irradiated by a strong external source of neutrons.

\section{Inference of Material Buckling from Exponential Experiments}

Exponential experiments are normally performed with a thermal column at one end of the exponential assembly, which provides an essentrally plane source of thermal neutrons, structural material and void at the other end, and a water reflector on the sides. The two experimental techniques in common use for measuring buckling in exponential assemblies are intended to eliminate the effect of these peripheral regions and to measure properties of the asymptotic lattice region only, 1.e., the region of the lattice in which the neutron spectrum is presumably independent of position and dependent only on the characteristics of the lattice.

In this discussion we shall overlook the lattice-cell fine structure and suppose that it does no more than superimpose a perıdıc ripple on the fundamental spatial mode shape

In the most common type of buckling measurement used in exponential experiments, the curvature of the activation distribution for a given absorber is measured along the principal directions of flux variation. These curvatures lead directly to the material buckling when combined with the assumption that the flux variation is separable in space and energy. For brevity we shall refer to this technique as the "flux-shape" method. 
Another type of buckling measurement that has been extensively used requires measurement of the activation distribution in one direction only, 1.e., normal to the plane of the thermal-neutron source. The relaxation length that results from fitting this distribution to an exponential is then measured for a sequence of many loadings of the lattice with different radiı. The material buckling is taken to be the sum of the axial and radial bucklings, the former being the negative inverse square of the axial relaxation length, $L$, and the latter being obtained from the known core radil and an unknown radial-reflector savings. The material buckling and reflector savings are obtained fr $m$ the usual buckling equation by subjecting all the data for a given lattice, 1.e., concurrent values of core radius and relaxation length, to a twoparameter least-squares fit Implicit in the procedure, which we shall call the "variable-loadıng" method, is again the assumption of separability of the neutron flux in space and energy

The main difficulty in applying both of these techniques to watermoderated exponential experiments arises from the fact that, to obtain axial relaxation lengths that can be measured with adequate precision (10 $\mathrm{cm} \leq \mathrm{L} \leq 40 \mathrm{~cm})$, the radial buckling, $\mathrm{B}_{\mathrm{r}}^{2}$, must often be large $\left(50 \mathrm{~m}^{-2} \leq \mathrm{B}_{\mathrm{r}}^{2} \leq 150 \mathrm{~m}^{-2}\right.$ ). Consequently the radil of the assemblies are sometimes so small that the radial-flux transients produced in the lattice by the reflector distort the neutron spectrum appreciably everywhere in the lattice. This behavior introduces systematic errors into any simple method of determining the material buckling; the magnitude of these errors, of course, depends on the particular lattice and the method of measurement being used.

A general idea of the effect of these radial-flux transients on the results of exponential experiments can be gained from a theoretical study of radially reflected, one-dimensional assemblies made critical by a search for the proper axial exponential flux shape. The results of such calculations are shown in Figs. 1 to 5 for a uranium dioxide fueled lattice chosen from a recent series of Brookhaven National Laboratory (BNL) exponential experiments. They lllustrate the essential characteristics of the two methods of analysis in common use.

In the measurements the fuel rods were loaded into an approximately circular pattern in a hexagonal lattice plate. The fuel, in the example discussed in tnis section, was 3.006 percent enriched uranium dioxide of $9.28 \mathrm{~g} / \mathrm{cm}^{3}$ density contained in type 304 stainless-steel tubes of $0.499 \mathrm{in}$. outside diameter and $0.029 \mathrm{in}$. wall thickness. The volume ratio of water to uranium dioxide was 2.86 . In the radial direction the assembly was surrounded by an effectively infinite water reflector.

In the theoretical study of the radial-reflector effects made for comparison with these experiments, the neutron spectrum was represented by four groups, with the group end points at $10 \mathrm{Mev}, 0.821 \mathrm{Mev}$, $5.53 \mathrm{kev}, 0.625 \mathrm{ev}$, and zero ene rgy. The few-group constants for the fast 


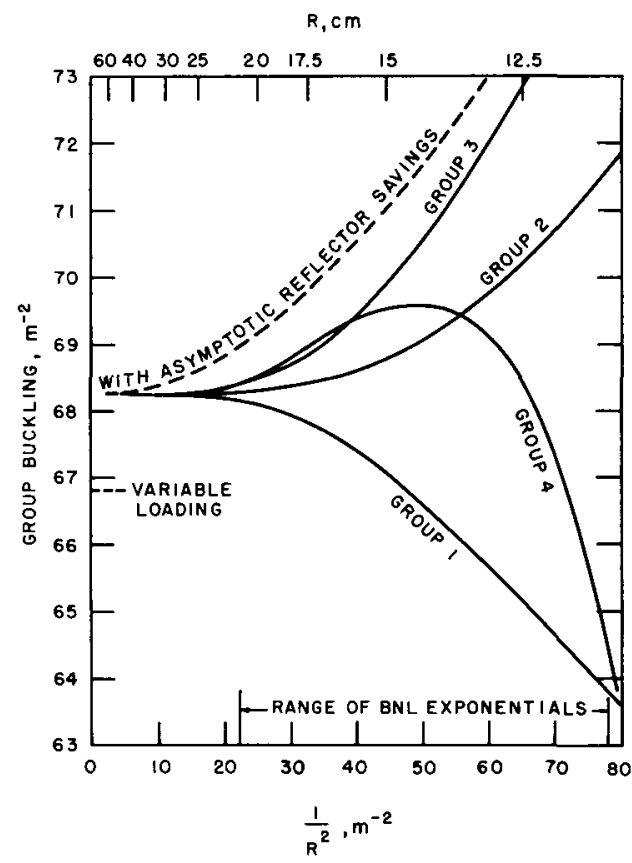

Fig. 1-Group-dependent buckling at core center as a function of core size for a uranium dioxide rod lattice.

Fig. 2-Group-dependent reflector savings from inferred core-center flux shapes as a function of core size.

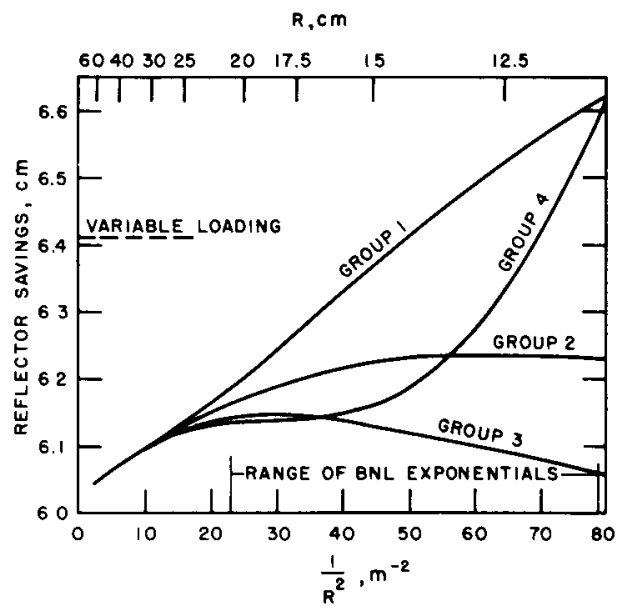


F1g. 3-Group-dependent reflector savings obtained by fitting of $J_{0}(\alpha r)$ to computed radial-flux shapes.
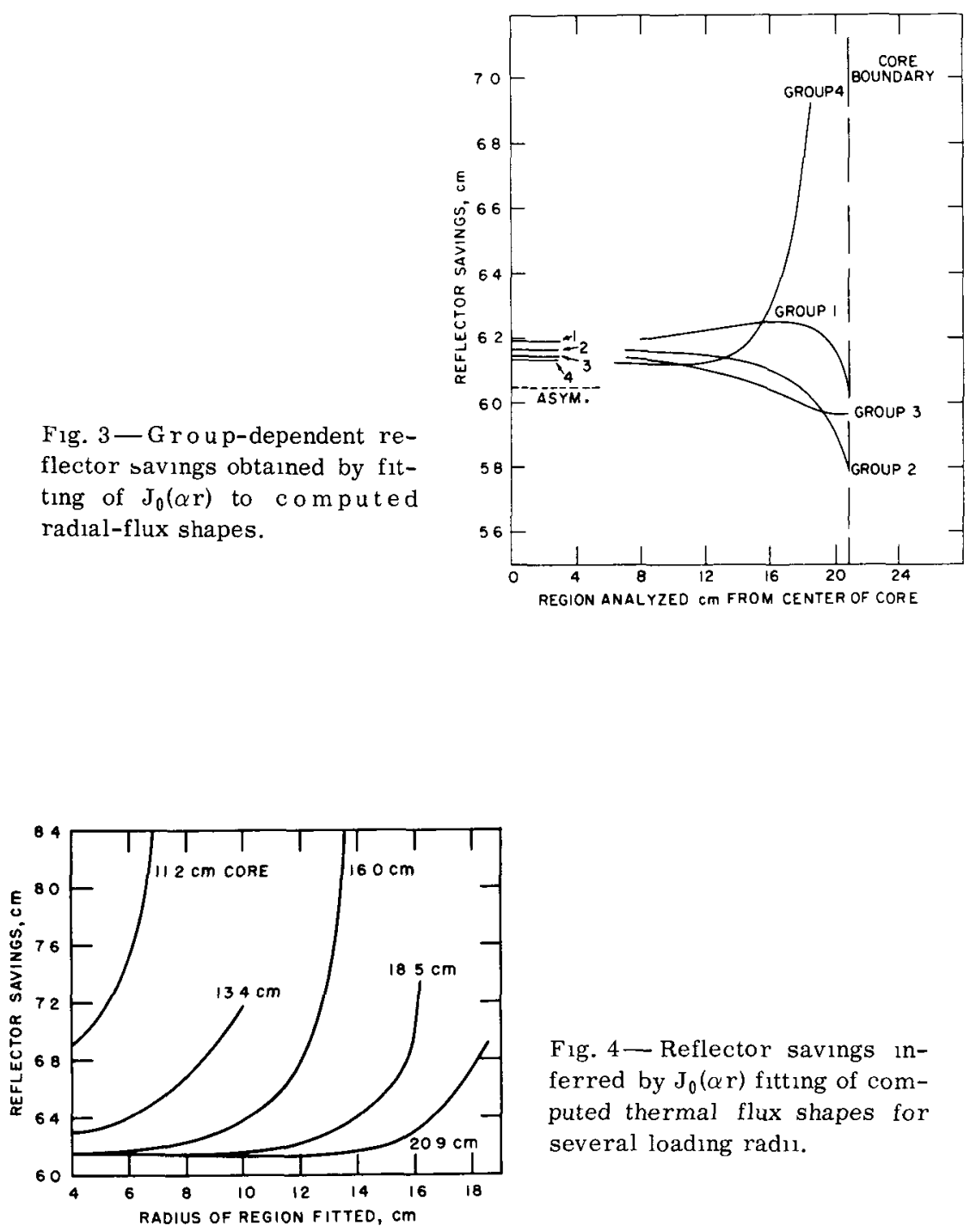

Fig. 4-Reflector savings inferred by $J_{0}(\alpha r)$ fitting of computed thermal flux shapes for several loading radı. 


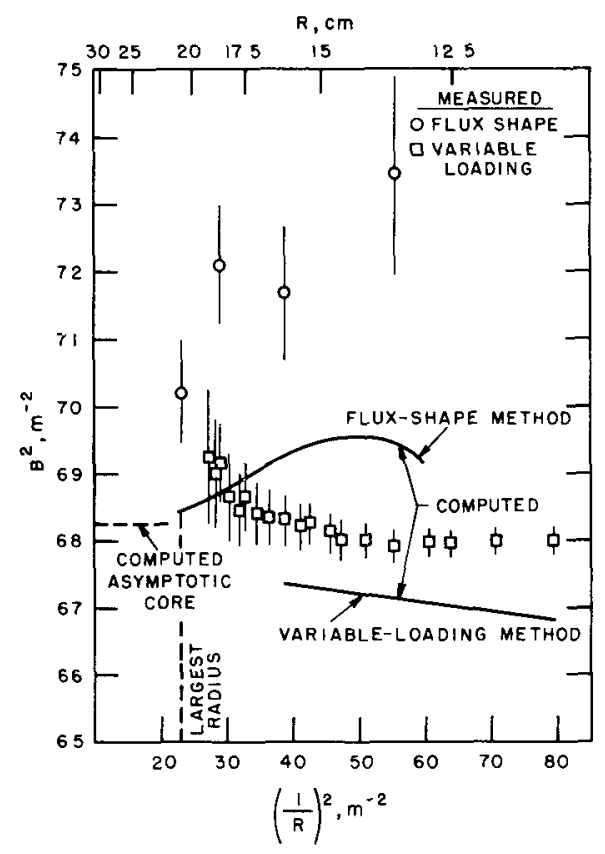

Fig. 5-Flux-shape and variable-loading results for measured and computed exponential assemblies.

neutrons were edited by MUFT-IV from B-1 multigroup-spectrum calculations corresponding to the measured material buckling of the lattice studied. ${ }^{5}$ Averaged cross sections for thermal-neutron groups were taken from THERMOS multigroup calculations of the lattice cell. ${ }^{6}$ The principal features of these lattice calculations are given in two papers ${ }^{7,8}$ contributed to the IAEA panel mentioned earlier.

The one-dimensional four-group calculations provide a piecewise continuous representation of the space-dependent neutron spectrum, which becomes identical with the multigroup spectrum when the bucklings in all groups are equal to the buckling used in the multigroup MUF'T calculation. The generation of an asymptotic spectrum at some point in a reflected lattice is indicated by the constancy of the radial buckling, $\mathrm{B}_{\mathrm{r} 1}^{2}=-\left(\nabla_{\mathrm{r}}^{2} \phi_{1}\right) / \phi_{1}$, with group index 1 at that point. In Fig. 1 the total buckling in each group, $\mathrm{B}_{1}^{2}=\mathrm{B}_{\mathrm{r} 1}^{2}-1 / \mathrm{L}^{2}$, at the core center where the expectation of an asymptotic spectrum is greatest, is shown as a function of the loading radius of the exponential assembly. The dashed curve shows the buckling that results from using the asymptotic reflector savings, $6.04 \mathrm{~cm}$, the loading radı, and the computed critical relaxation lengths. 
In the actual experiments the axial relaxation length was measured for 24 loadings of this lattice with radil in the range $11.2 \mathrm{~cm} \leq \mathrm{R} \leq$ $20.9 \mathrm{~cm}$. It is apparent from Fig. 1 that the radial-flux shape of the high-energy neutrons (group 1) is so much flatter than that of the ep1thermal and thermal neutrons (groups 3 and 4 ) that the neutron spectrum generated cannot be characterized by any single buckling value. However, it is clear that, for the large loading at least, the increased leakage in the lower three neutron groups tends to compensate to some extent for the reduced leakage of neutrons in the first group.

In view of these deviations from a simple neutron spectrum in the lattice, the question of primary importance is whether or not the characteristics of the asymptotic lattice can be inferred from an analysis of a sequence of nonasymptotic exponential assemblies. Let us consider, first, the results that would be obtained by applying the flux-shape method to these computed "experıments." If we were to measure the radial thermal-neutron shape in a small region near the center of the core and fit it to an appropriate Bessel function, $J_{0}(\alpha r)$, the material buckling inferred would follow the group 4 curve in $F_{1 g}$. 1 . This effect would appear in the measurements as a size dependence of the radialreflector savings, and, if corresponding measurements could be made for each of the four neutron-energy groups, the reflector savings shown in Fig. 2 would be found. These results clearly show that appreciable errors can be made if the flux-shape method is used with assemblies that are too small.

So far we have discussed the application of the flux-shape method only in a very small region at the center of the assembly. In practice, however, it is necessary to fit an appreciable segment of the radialflux shape to determine the second derivative with adequate precision. As the outer part of this segment is extended to include more measured points, the influence of the unwanted radial transients becomes more pronounced. In Fig. 3 the reflector savings for the various neutronenergy groups are shown for the largest lattice $(R=20.9 \mathrm{~cm})$ as a function of the radius of the region containing the data used in the $\mathrm{J}_{0}$ fit Since these "data" originated from calculations, the curves are all quite smooth and show that, for an assembly this large, one would expect the thermal-activation shape to fit a single $\mathrm{J}_{0}(\alpha \mathrm{r})$ function to within about $8 \mathrm{~cm}$ of the reflector boundary. In this case the flux-shape method yields a reflector savings of $6.13 \mathrm{~cm}$ and a material buckling of $68.48 \mathrm{~m}^{-2}$, which is in quite satisfactory agreement with the buckling, $68.26 \mathrm{~m}^{-2}$, of the computed asymptotic core.

Although fitting the thermal flux in the largest assembly to $J_{0}(\alpha r)$ yrelds a clearly defined reflector savings, applying the same method to the computed thermal-flux shapes in smaller assemblies results, as shown in Fig. 4, in a rapidly decreasing region within which an adequate $\mathrm{J}_{0}$ can be obtained. In addition, any error in the inferred reflector 
savings affects the material buckling more seriously in the smaller cores. Consequently it is clear that flux-shape measurements should be employed in only the largest loadings, and the results are convincing only if an adequate "plateau" in the reflector savings can be found.

Corresponding measurements at BNL of the buckling by the fluxshape method are not in disagreement with these computed results, although the error in the measurements obscures the trend one would expect from Fig. 4. The results of $\mathrm{J}_{0}$ fitting of indium-activation

Table 4-MATERIAL BUCKLING FROM FLUX-SHAPE MEASUREMENTS*

\begin{tabular}{ccccrc}
\hline $\begin{array}{c}\text { Loading } \\
\text { radius, cm }\end{array}$ & $\begin{array}{c}\text { Reflector } \\
\text { savings, cm }\end{array}$ & $\begin{array}{l}\text { Relaxation } \\
\text { length, cm }\end{array}$ & \multicolumn{1}{c}{$\mathrm{B}_{\mathrm{r}}^{2}, \mathrm{~m}^{-2}$} & \multicolumn{1}{c}{$\mathrm{B}_{\mathrm{z}}^{2}, \mathrm{~m}^{-2}$} & $\mathrm{~B}_{\mathrm{m}}^{2}, \mathrm{~m}^{-2}$ \\
\hline 20.91 & $6.69 \pm 0.09$ & $41.94 \pm 0.21$ & $75.88 \pm 0.52$ & $5.68 \pm 0.06$ & $70.20 \pm 0.52$ \\
18.54 & $6.45 \pm 0.08$ & $22.10 \pm 0.07$ & $92.58 \pm 0.57$ & $20.48 \pm 0.12$ & $72.10 \pm 0.58$ \\
16.07 & $6.69 \pm 0.08$ & $15.82 \pm 0.01$ & $111.65 \pm 0.76$ & $39.97 \pm 0.04$ & $71.68 \pm 0.77$ \\
13.43 & $6.74 \pm 0.08$ & $12.06 \pm 0.12$ & $142.15 \pm 1.18$ & $68.71 \pm 1.36$ & $73.44 \pm 1.80$ \\
\hline
\end{tabular}

*Uranium dioxide rod lattice of 0.499 in. diameter, 3.006 percent enrichment, and 2.86 water to uranium dioxide ratio.

traverses in the uranium dioxide lattice previously described are shown in Table 4 and Fig. 5. In Fig. $5, R_{S}$ is either the loading radius for flux-shape results or the radius of the smallest loading included in the variable-loading sequence. In this figure the two curves are for the flux-shape and variable-loading methods applied to calculated assemblies. As we shall see shortly, the material buckling inferred from the flux-shape measurements is appreciably larger than that given by application of the variable-loading method.

Before discussion of the other type of buckling measurement, it is worth observing to what extent the constancy of the cadmium ratio of an absorber within a lattice can be taken as an indication of the presence of an asymptotic spectrum. Examination of the results of the reflected uranium dioxide lattice calculations covering the experimental range of $11.2 \mathrm{~cm} \leq \mathrm{R} \leq 20.9 \mathrm{~cm}$ shows that the ratio of epithermal to thermal flux at the center of the lattice is the same for all. It remains within 2 percent of this value over a central region that excludes in each case the outer $6 \mathrm{~cm}$ of the assembly. This close coupling between the thermal and the epithermal flux is suggested by the behavior of the bucklings shown in Fig. 1 since neutron groups 3 and 4 show much the same dependence of group buckling on core size until the radius is smaller than about $15 \mathrm{~cm}$. Consequently a constant cadmium ratio of $\mathrm{U}^{235}$, indium, boron, etc., over the interior of the assembly does not, in general, provide a good measure of whether or not an asymptotic spectrum has been generated. 
The same conclusion applies to measurements of the reflector savings by the flux-shape method with bare and cadmium-covered folls, Fig. 2 shows that the bare and cadmium-covered results for the reflector savings would agree in assemblies as small as those with $15 \mathrm{~cm}$ radius. This $1 \mathrm{~s}$ a characteristic of light-water-moderated lattices, which is not so pronounced in heavy-water-moderated systems, and it apparently results from the short duffusion length between epithermal and thermal neutron energies. A better means of detecting departures from an asymptotic spectrum would be the $\mathrm{U}^{238}$ to $\mathrm{U}^{235}$ fission-activity ratio, but the flux level in an exponential experiment is usually not adequate for the use of high neutron-energy detectors.

We consider next the application of the variable-loading method $^{9}$ to the same sequence of computed exponential assemblies as shown in Fig. 1. The variable-loading method uses the measured axial relaxation lengths, $L_{j}$, tor a given loading radius, $R_{j}$, with a one-group formula for the material buckling to obtain the radial reflector savings by a least-squares $f_{1} t$. The formula to be fitted is

$\mathrm{B}^{2}=$ constant $=\mathrm{B}_{\mathrm{rJ}}^{2}-\frac{1}{\mathrm{~L}_{\mathrm{j}}^{2}}$

where, for cylinders, the radial buckling is given by

$\mathrm{B}_{\mathrm{rj}}^{2}=\left(\frac{2.405}{\mathrm{R}_{\mathrm{j}}+\lambda}\right)^{2}$

and $\lambda$ is the reflector savings which is usually assumed to be constant

As in measurements in which the flux-shape method is used, the results of the variable-loading method are affected by the range of the radial loading sizes employed. The largest loading that can be used in the exponential sequence is limited by the material buckling of the lattice being studied and by the maximum relaxation length that can be permitted. In the BNL experiments the latter is taken to be $40 \mathrm{~cm}$. The loading radius is usually then reduced in roughly twenty steps until the minimum relaxation length that can be measured accurately is reached; this lower limit on $\mathrm{L}$ is about $10 \mathrm{~cm}$. If the material buckling is large, e.g., $60 \mathrm{~m}^{-2}$, the loading radius required to reach the lower limit of $L$ is very small, as it is in the lattice used here for illustrative purposes. As a consequence in such cases, systematic errors in the buckling inferred by the variable-loading method are to be expected owing to the nonasymptotic neutron spectrum generated in the small assemblies.

One rather direct way of examining the data for such systematic errors is by progressively deleting the small assemblies from the 
data used in the least-squares fit. This procedure can also be applied to the sequence of computed assemblies, and the results, shown in Fig. 5, indicate similar trends from both measured and computed data, although the probable error in the fit of the experimental data increases rapidly with deletion so that the apparent trend may not be significant.

Judging from the analysis of the computed assemblies, the variableloading analysis in which the entire range of sizes is used results in a material buckling lower than the correct value by $1.45 \mathrm{~m}^{-2}$. The flux-shape method applied to the largest loading yields a value only $0.25 \mathrm{~m}^{-2}$ larger than the correct value. Thus in this case the two methods should yield results that are discrepant by $1.7 \mathrm{~m}^{-2}$. Similar results from the measured data indicate a discrepancy of $2.2 \pm 0.7 \mathrm{~m}^{-2}$. Thus it appears that these rather large discrepancies between the results obtained from the measurements by these two methods of analysis can be given a theoretical explanation.

The usual comparison between theory and experiment would be made between the computed asymptotic buckling, $68.26 \mathrm{~m}^{-2}$, and the variable-loading fit to all the experimental data, $67.98 \mathrm{~m}^{-2}$, which would indicate a slight overestimate of the buckling by the theory. Examination of the computed and experimental variable-loading curves in Fig. 5 indicates, however, that the theory probably underestimates the buckling by about $1 \mathrm{~m}^{-2}$.

This isolated example of the analysis of a sequence of exponential loadings does not provide a basis for general conclusions concerning the relative worth of the flux-shape and variable-loading methods, nor does it provide a measure of the precision with which measurements by the two methods can be made. Other lattices of lower material buckling have been studied, and the discrepancies found in both the measurements and the calculations have been smaller than those in the present example. A more detailed discussion of the problem is given in Ref. 10. Some attempts have been made, particularly at BNL, to infer lattice anisotropy from the variable-loading measurements, but they have not met with much success because the deviations from the asymptotic lattice already discussed produce appreciable and spurious symptoms of anisotropy.

From the calculations discussed here and from similar results for other water-moderated lattices, several conclusions can be inierred. It should be emphasized that these comments are pertinent only to water-moderated and -reflected assemblies, although similar situations may arise in other systems.

1. The variable-loading method of inferring the material buckling is subject to small, but nonetheless appreciable, systematic errors. In the example given, this error is 3 percent of the buckling and thus is an order of magnitude larger than the probable error inferred from the measurements. 
2. The use of radial activation traverses for measuring buckings by the flux-shape method should be limited to relatively large assemblies.

3. Cadmium ratios of $1 / \mathrm{v}$ or resonance absorbers that are act1vated principally by neutrons below, say, $5 \mathrm{kev}$ are of limited value in demonstrating that an asymptotic spectrum has been established in a water-moderated lattice.

Some attention should be given to the systematic errors that can affect the measurement of the relaxation length in the direction normal to the neutron source plane. There are two principal sources of such errors: the presence of axial-flux transients introduced by the bottom thermal column and the top reflector and the presence of distributed primary neutron sources in the exponential assembly itself. Small errors of these types are frequently difficult to identify because they produce only slight perturbations of the flux pattern, which still retains its exponential shape but with an erroneous relaxation length.

The analysis of end effects or axial-flux transients in exponential experiments is well known, ${ }^{11}$ and the length of fuel elements is generally chosen to be so large, e.g., $120 \mathrm{~cm}$, that a sizable axial region exists that is essentially free from these perturbations. In general, the influence of axial transients becomes less important as the assembly is loaded closer to critical. Attempts have been made in some experiments to extend the flux-distribution measurements into regions of the lattice containing appreciable transient components, with a subsequent subtraction of the assumed transient shape, but this procedure seems to have little merit.

The second type of systematic error, that introduced by spurious neutron sources in the assembly, is more difficult to detect and eliminate. Experiments containing large inventories of $\mathrm{U}^{238}$ or appreciable amounts of heavy water can have relatively strong internal sources from the spontaneous fission of $\mathrm{U}^{238}$ and the photodisintegration of deuterium. In a typical exponential experiment, the neutron flux caused by spontaneous fission can range from 2 to 40 neutrons $/ \mathrm{cm}^{2} / \mathrm{sec}$, depending upon the neutron multiplication of the lattice. The effect can be made negligible by increasing the external thermal-neutron source strength to, say, $10^{7}$ neutrons $/ \mathrm{cm}^{2} / \mathrm{sec}$.

Measurements in the uranium dioxide fueled exponential experiments at BNL indicated the presence of a large photoneutron source, presumably caused by the action of high-energy gamma rays on uranium. The gamma rays are suspected to originate from neutron capture in or about the thermal column, possibly from iron or silicon in the heavy concrete. These gammas are of sufficient energy to cause both photoneutron and photofission reactions in uranium. The gamma radiation and the resultant photoneutrons have sufficient intensities to increase the observed relaxation length by as much as $0.5 \mathrm{~cm}$, which 
is particularly noticeable at short relaxation lengths and which can contribute an error of as much as $10 \mathrm{~m}^{-2}$ in the observed buckling. The effects of both spontaneous fission neutrons and photoneutron sources can be observed by the insertion of a neutron shutter between the exponential assembly and the neutron thermal column. The spurious effects are then eliminated by taking the difference between neutron activations with and without the neutron shutter.

\section{Approach-to-critical-loading Experiments}

The approach-to-critical technique utilizes the change of neutron multiplication with assembly size to yield an extrapolation of subcritical data to the condition of infinite multiplication, at which size the assembly would be critical. Since only the critical loading is inferred from these measurements, the interpretation problems, discussed in connection with exponential experiments, do not arise.

The commonly accepted procedure is to place a sensitive neutron detector and a neutron source near the center of a subcritical assembly of fissionable and moderating materials. The counting rate in the neutron detector is then observed as a function of the size of the assembly as more fissionable material is added. The loading process stops while the system is substantially subcritical, and there is no need for the complicated control system of a critical assembly.

The approach-to-critical technique has been used extensively by both the Hanford Laboratories, Richland, Wash., and the United Kingdom Atomic Energy Research Establishment (AERE), Harwell, to measure critical sizes of reactor assemblies. The techniques employed by the two laboratories differ somewhat. Both methods have been used to predict the critical size of a particular assembly with good precision after corrections are made for the reactivity effects of the neutron detectors, source, and control-rod channels. As mentioned previously, only the critical loading with a particular reflector arrangement is directly obtained in these experiments, and it is necessary to utilize additional information from other sources about the reflector savings in the radial and axial directions to infer the buckling.

The Hanford experiments utilize a radium-beryllium neutron source placed at the center of the assembly and a boron trifluoride neutron detector, also near the center. As the assembly is increased from 85 to 96 percent of its critical mass, the quantity $\sqrt{\mathrm{N}} / \mathrm{CR}$ is found to be a very nearly linear function of $N$, where $N$ is the number of fuel rods and $C R$ is the counting rate observed in the neutron detector. This quasi-linear relation is expected from a simple one-group reactor model at loadings between 85 and 100 percent of the critical mass

Figure 6 shows a typical Hanford approach-to-critical measurement. In addition to the central neutron detector, it shows data from a 


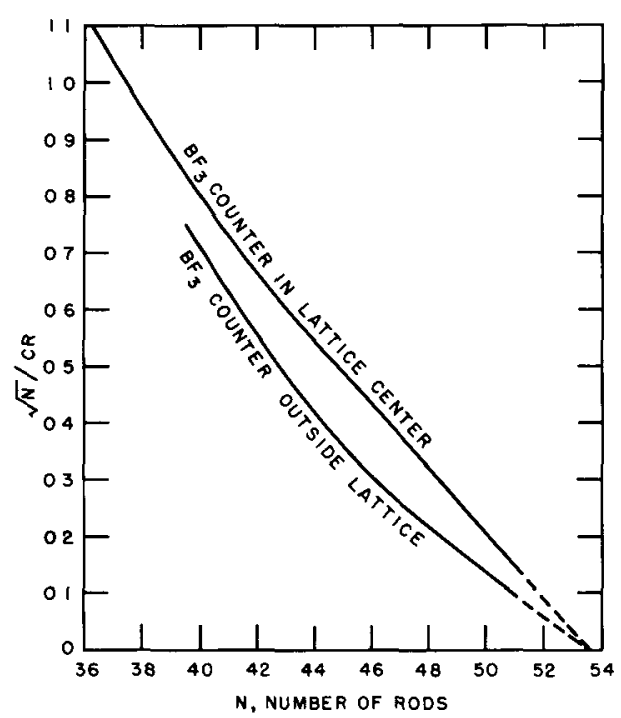

Fig 6-Critical-approach curves for 3063 percent enriched uranıum metal rods.

neutron detector in the reflector. The rods are $0.925 \mathrm{in}$. in diameter and $1.6 \mathrm{in}$. long. The lattice pitch is $1.6 \mathrm{~m}$. The curvature in the data from the latter detector may be attributed to the effects of spatial harmonics and the movement of the reflector peak with changes in the loading of the assembly. Consequently it is advantageous to locate the neutron detector at the center of the assembly to facilitate extrapolation of the data to critical.

The presence of the neutron detector in the assembly obviously affects the critical size. The effect can be measured by inserting two detectors of identical dimensions in symmetrical locations and measuring the critical size with and without the second detector. By an extrapolation of the data, the critical size of the assembly with no detector can be obtained if the effects are assumed to be linear and additive. In a similar fashion the worth of a control-rod channel, or other perturbations of the assembly, can be measured. Of course, each perturbation introduces an uncertainty in the deduced critical size, and consequently neutron detectors and control-rod channels should be kept to a minimum commensurate with necessary counting rates and nuclear safety. In the Hanford experiments the presence of the neutron detector decreased the critıcal mass by about 1 percent. The Harwell results indicate a similar, but much larger, detector effect of up to 18 percent in the critical mass.

The Harwell approach-to-critical experiments utilize the spontaneous fission neutrons from $\mathrm{U}^{238}$ in the normal or slightly enriched uranium 
lattices. The neutron detector is a large boron trifluoride neutron detector at the center of the lattice. The spontaneous fission source is by nature distributed uniformly throughout the assembly and thus produces less spatial harmonic effect than would a point source. The Harwell measurements indicate a linear dependence (see Fig. 20) of the quantity $\mathrm{N} / \mathrm{CR}$ on the number of fuel rods throughout the entire range of loadings from 10 to 80 percent of the critical size. This behavior indicates the possibility of measuring critical masses with a relatively small amount of fissionable material although, of course, the accuracy should increase as the maximum size approaches critical. Unfortunately the corrections to the critical mass due to the neutron detector are unusually large, presumably because of the size of detector.

The principal advantage of the approach-to-critical technique lies in the ability to survey the criticality conditions of many reactor assemblies quickly without the intricate control system of a critical assembly and without the strong neutron source and multiple neutronflux traverses required by an exponential experiment.

\section{Measurements in Critical Assemblies}

The critical experiment is the most obvious and probably the most widely used method of measuring the critical size, buckling, and cell parameters of a reactor lattice. Many of the remarks already made concerning exponential experiments with uniform lattices can be applied with only quantitative modification to critical assemblies. In general, critical assemblies are less subject to size-dependent errors because the reflector is usually less important and because the neutron source plays little or no role. These and other important advantages derived from the great sensitivity of the critical conditions to small reactivity effects are obtained at the price of a much smaller observable buckling range than can be studied in exponential experiments and a more complex nuclear control system and operating procedure.

CRITICAL-LOADING AND BUCKLING MEASUREMENTS Critical-loading experiments are carried out very simply; the assembly is bult up with sufficient fissionable material to approach very nearly a self-sustaining chain reaction with infinite multiplication of source neutrons. For precision measurements it is eventually necessary to remove the source or to operate at such a high neutron-flux level that the source makes a negligible contribution. Of course, in the latter case the assembly is slightly subcritical at a constant flux level.

One consequence of the higher flux level and its constancy in time when criticality has been achieved is that the neutron detectors can be removed from the assembly and the corrections for the reactivity effect of detectors that are required in approach-to-critical measurements are unnecessary. The most significant corrections in critical 
experiments with uniform lattices, particularly when the lattice pitch is small, arise from the effects of the control-rod channels and followers required for control and safety.

In some experiments, such as the Yankee critical experiments (see p. 587), loading measurements have been made with different numbers of symmetrically placed control-rodfollowers in the assembly, which provide a basis for extrapolation to an unperturbed lattice. In other experiments the presence of the control rods is not permitted to distort the lattice; in the TRX experiments by the Westinghouse Electric Corporation, Bettis Atomic Power Laboratory (BAPL), the control rods themselves have been shaped to fit between the fuel elements so that no additional channel is needed. Another technique uses control-rod followers made of fuel rods on the same pitch as the lattice being studied. By these means the perturbations of the lattice can be eliminated if the reduced uncertainties are deemed worth the added cost.

The measurement of the buckling of a uniform critical lattice is almost invariably made by the flux-shape method described in connection with exponential experiments. The variable-loading method can also be used; but it is more time consuming, and the range of axial bucklings obtainable with a normal inventory of fuel is usually smaller than that in an exponential experiment. In the exponential experiment the usable range of relaxation lengths, $10 \mathrm{~cm} \leq \mathrm{L} \leq 40 \mathrm{~cm}$, results in values for negative axial buckling between 100 and $6 \mathrm{~m}^{-2}$, whereas the normal range of the positive axial buckling in critical experiments is roughly one-half as great. Consequently the incentive to use the variable-loading method is usually not present in critical experiments.

Attempts have been made in the Bettis critical experiments ${ }^{12}$ to measure the reflector savings of both fast and thermal neutrons by fitting a $J_{0}(\alpha r)$ function to the radial fission activation shapes of highly depleted uranium (5 ppm $\mathrm{U}^{235}$ ) and 1.3 percent enriched uranium foils. The depleted uranium foil should respond almost exclusively to neutrons above about $1 \mathrm{Mev}$ (group 1 neutrons in Fig. 2), whereas the 1.3 percent foils should primarily detect thermal and epithermal neutrons (groups 3 and 4). The lattices were constructed of 0.387-in.diameter rods, 1.3 percent enriched, with water to uranium volume ratios of 2 and 3. Analysis of the foil data indicated no difference in the reflector savings exceeding the estimated error of $\pm 0.2 \mathrm{~cm}$ on each measurement. This finding is essentially in agreement with what one would expect from the theory (Fig. 2) because of the large radii of the critical assemblies used.

In many single-region and multiregion critical experiments, the axial, but not the radial, activation shape is measured. This is done because the axial reflectors are complicated even at full moderator height by the top and bottom lattice plates that support and position the 
fuel, whereas the radial reflector is usually well defined and is essentially infinite. An even more ill-defined situation arises when the lattice is made critical by adjustment of the moderator height for observation of temperature or moderator void effects, for the axial-reflector savings is then found to be a function of the amount of water or dry core that lies above the immersed part of the lattice. The errors entailed in the neglect of these effects can be large, as has been shown by Harris ${ }^{13}$ and, more recently, by the General Electric Company Atomic Power Equipment Department (GEAP) group. ${ }^{14}$ GEAP inferred the change in top-reflector savings by progressively dropping the moderator height while increasing the radial loading of the assembly. By assuming a constant radial- and bottom-reflector savings, they obtained the unknown top-reflector savings shown for one lattice pitch of superheater fuel elements (see p.581) in Fig. 7. In addition to generating errors in static water-height measurements, the variability of the top-reflector savings can introduce errors of 30 percent or so in the reactivity change inferred from the kinetic measurements discussed in the next section.

Fig. 7-Variation of the measured top-reflector savings with moderator height in a uranium dioxide superheat fuel lattice.

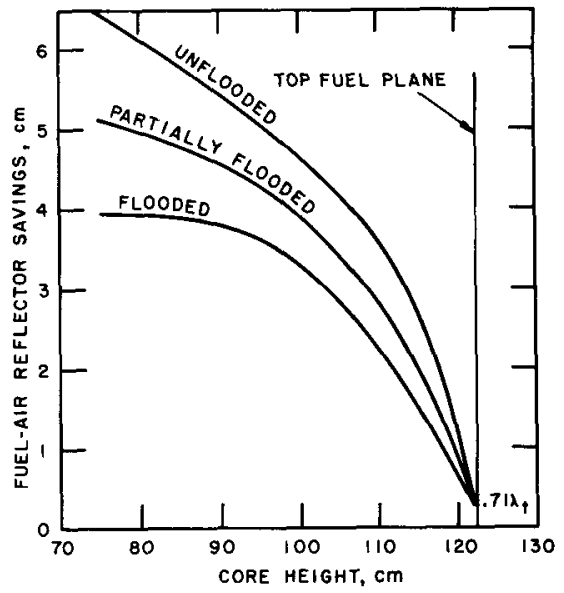

MEASUREMENTS BY KINETIC RESPONSE One of the unique advantages of critical experiments comes from the inherent ability to measure very small reactivity effects by kinetic experiments. In the study of temperature coefficients, control-rod worth, void coefficients, and the other small reactivity effects of practical importance, this feature provides the means for simple and rather precise measurements by the observation of relatively long reactor periods.

In experiments with clean uniform lattices, kinetic measurements have been used principally to determine the temperature coefficient of reactivity and the reactivity effect of changes in the reactor size. 
The latter type of measurement is important since it is related to the neutron leakage from the system and thereby provides a means for gaining information about the neutron migration area in the reactor lattice.

Two problems are encountered in using kinetic measurements in the study of slightly enriched uranium lattices. The first problem, which has been recognized for some time, ${ }^{15}$ involves the adaptation of the simple inhour formula into a form that not only describes properly the difference in fast capture, fission, and leakage between delayed and prompt neutrons but also accounts for the difference in delayed-neutron yield between $U^{235}$ and $U^{238}$. In addition, it must be compatible with the criticality equation being used in the theoretical analysis of the experiment. In some applications the reactivity errors that can arise from the neglect of these effects are quoted to be from 10 to 25 percent. ${ }^{3,16,17}$ The features of this problem are sufficiently well known that they need no elaboration here.

The second problem arises in the interpretation of $\partial \rho / \partial \mathrm{B}^{2}$ measurements, or the buckling coefficient of reactivity. In a thermal reactor described by the four-factor formula, this type of experiment has a simple interpretation in terms of the spatial moments of the slowingdown distribution of neutrons from a point fission source. In a watermoderated, slightly enriched uranium lattice, however, the epithermal fission in both $U^{235}$ and $U^{238}$ is too large to be treated as a small correction, and the four-factor formula is no longer accurate. The replacement of the four-factor formula by a multigroup or few-group criticality equation changes the interpretation of the slowing-down probability in a way that depends on how the elgenvalue appears in the criticality equation. Because measurements of this type are valuable, the remainder of this section is devoted to a discussion of the interpretation of $\partial \rho / \partial B^{2}$ measurements, although space does not permit a collection of this type of datum in this review

In the following example, again taken from calculations of the BNL metal-rod lattices, we will use the moment form of the critical equation to show some of the relationships between the buckling dependence of the multigroup eigenvalue, the moments of the slowing-down distribution in the lattice, and some simple forms of the criticality equation. For convenience of notation the multigroup eigenvalue equation for an asymptotic lattice with buckling $\mathrm{B}^{2}$,

$\left(\mathrm{D}_{1} \mathrm{~B}^{2}+\Sigma_{1}\right) \phi_{1}=\frac{\chi_{1}}{\lambda} \sum_{\mathrm{k}} \nu_{\mathrm{k}} \Sigma_{\mathrm{fk}} \phi_{\mathrm{k}}+\sum_{\mathrm{k}} \Sigma_{\mathrm{sk} 1} \phi_{\mathrm{k}}$

can be reduced exactly to the two-group equation,

$\lambda=\left[\frac{(\eta \mathrm{f})_{1}\left(1-\mathrm{p}_{1}\right)}{\mathrm{p}_{1}}+\frac{(\eta \mathrm{f})_{2}}{1+\mathrm{L}^{2} \mathrm{~B}^{2}}\right] \underset{1+\tau \overline{\mathrm{B}}^{2}}{\mathrm{p}_{1}}$ 
with suitable definitions of the group constants in terms of cross section and the actual reactor spectrum. Here $(\eta \mathrm{f})_{1}$ and $(\eta \mathrm{f})_{2}$ are the number of fission neutrons produced per neutron absorbed in the fastand thermal-neutron energy ranges, respectively. The quantity (1$\left.\mathrm{p}_{1}\right) / \mathrm{p}_{1}$ is the fast-neutron absorption per neutron slowing down into the thermal region, and $p_{1} /\left(1+\tau B^{2}\right)$ is the number of neutrons slowing down into the thermal region per fission neutron produced. Since the fast-neutron group constants are obtained from multigroup-spectrum calculations, not all the buckling dependence is explicit in the two-group equation, but $\left(\eta \mathrm{f}_{1}, \mathrm{p}_{1}\right.$, and $\tau$ are also weak functions of buckling.

The buckling dependence of Eq. 2 becomes clearer when the equation is trarsscribed into the moment form. ${ }^{18}$ If the production of neutrons by fast fission in $\mathrm{U}^{235}$ and $\mathrm{U}^{238}$ is, for the moment, neglected in Eq. 2, the usual thermal reactor critical equation results:

$\lambda=\frac{(\eta f)_{2}}{1+L^{2} B^{2}} P_{\infty}\left(B^{2}\right)$

where

$P_{\infty}\left(B^{2}\right)=\frac{p_{1}}{1+\tau_{1} B^{2}}$

is the probability of a fission neutron's reaching the thermal-neutron group. The expansion of $\mathrm{P}_{\infty}\left(\mathrm{B}^{2}\right)$ as a power series in $\mathrm{B}^{2}$,

$\mathrm{P}_{\infty}\left(\mathrm{B}^{2}\right)=\sum_{\mathrm{j}=0}^{\infty}(1)^{2 \mathrm{~J}} \mathrm{a}_{2 \mathrm{j}} \mathrm{B}^{2 \mathrm{~J}}$

contains as expansion coefficients quantities that are related to the spatial moments $\mathrm{r}^{2 J}$ of the distribution of neutrons reaching the thermal group from a point source of fission neutrons in an infinite medium,

$\overline{r^{23}}=(2 j+1) ! \frac{a_{2 j}}{a_{0}}$

If the production of neutrons by fast fission is now included, the same form of the critical equation (Eq. 3) can be retained by choosing the slowing-down probability from Eq. 2 to be

$\mathrm{P}_{\infty}\left(\mathrm{B}^{2}\right)=\frac{\mathrm{p}_{1}}{1+\tau \mathrm{B}^{2}}\left[1+\frac{(\eta \mathrm{f})_{1}\left(1-\mathrm{p}_{1}\right)}{(\eta \mathrm{f})_{2} \mathrm{p}_{1}}\left(1+\mathrm{L}^{2} \mathrm{~B}^{2}\right)\right]$

in which the second factor is just the ratio of total fission-neutron production to that produced by thermal fission alone. When Eq. 7 is expanded in a power series, the inclusion of fast fission decreases the 
expansion-coefficient ratios, $a_{2 j} / a_{0}$ (see Table 5). At first sight this decrease in the coefficients is surprising because fast fission is known to increase the moments of the slowing-down distribution from a point fission source. ${ }^{19}$ Inspection of Eq. 1 shows, however, that this equation does not contain the description of a simple point-source slowing-down problem except when production of fast-fission neutrons is neglected. Consequently the usual physical interpretation of the expansion coefficients does not apply to this form of the critical equation.

The eigenvalue equation (Eq. 1) can be slightly modified, however, to preserve the interpretation of the slowing-down probability in terms of the spatial moments of a physical problem. This modification is made by altering the fission-source term so that $1 / \lambda$ multiplies only the thermal-neutron contribution. The critical equation (Eq. 3) is again obtained but with

$P_{\infty}\left(B^{2}\right)=\frac{p_{1}}{1+\tau B^{2}}\left[1-\frac{(\eta f)_{1}\left(1-p_{1}\right)}{1+\tau B^{2}}\right]^{-1}$

The expansion coefficients obtained from this form of the escape probability function, given in the last line of Table 5, show the substantial increase, compared with the first line, which results from the fission cycling during the slowing-down process.

Table 5-COEFFICIENTS OF THE SLOWING-DOW PROBABILITY OF FISSION NEUTRONS IN A LATTICE*

\begin{tabular}{|c|c|c|c|c|}
\hline $\begin{array}{l}\text { Slowing-down } \\
\text { probability function }\end{array}$ & $a_{0}$ & $\mathrm{a}_{2} / \mathrm{a}_{0}\left(\mathrm{~cm}^{2}\right)$ & $a_{4} / a_{0}\left(\mathrm{~cm}^{4}\right)$ & $a_{6} / a_{0}\left(\mathrm{~cm}^{6}\right)$ \\
\hline Eq 4 & 0628 & 3243 & 808 & $177 \times 10^{4}$ \\
\hline $\mathrm{Eq} 7$ & 0811 & 300 & 751 & $170 \times 10^{4}$ \\
\hline $\mathrm{Eq} 8$ & 0840 & 4044 & 1327 & $372 \times 10^{4}$ \\
\hline
\end{tabular}

The expansion coefficients of Eqs. 7 and 8 show that the eigenvalues and their buckling dependence are markedly different for these two critical equations. This difference does not, however, $1 \mathrm{mply}$ that the kinetic response of the reactor to changes in buckling predicted by the two forms of the slowing-down probability function will differ but, rather, that each criticality equation has an appropriate inhour formula associated with it to relate reactor period to reactivity. In the analysis of $\partial \rho / \partial B^{2}$ measurements, Eq. 7 is almost invariably used.

Having obtained the critical equation in a form that shows the buckling dependence explicitly, we can write the formula for $\partial \rho / \partial B^{2}$ 
Fig. 8-Dependence of $1 / \lambda$ and $\partial(1 / \lambda) / \partial B^{2}$ on buckling.

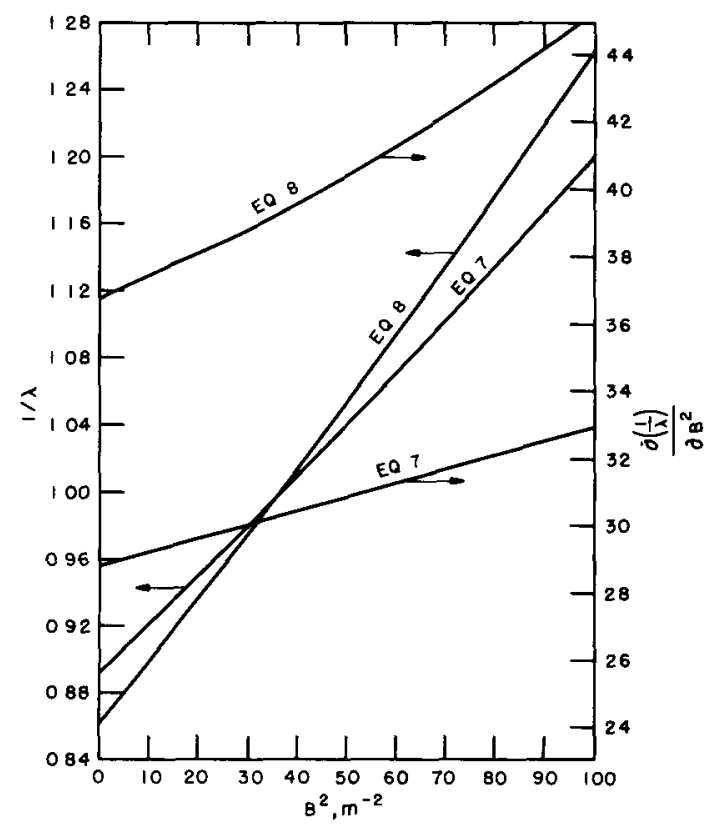

directly in the equation

$$
\frac{\partial \rho}{\partial \mathrm{B}^{2}}=-\frac{\partial(1 / \lambda)}{\partial \mathrm{B}^{2}}=-\frac{1}{\lambda}\left[\frac{\mathrm{L}^{2}}{1+\mathrm{L}^{2} \mathrm{~B}^{2}}-\frac{\mathrm{P}_{\infty}^{\prime}\left(\mathrm{B}^{2}\right)}{\mathrm{P}_{\infty}\left(\mathrm{B}^{2}\right)}\right]
$$

For small bucklings we can approximate this expression by

$$
-\frac{\partial \rho}{\partial B^{2}} \cong \frac{1}{\lambda(0)}\left[L^{2}+a_{20}-2\left(a_{40}-a_{20}^{2}-a_{20} L^{2}\right) B^{2}+\ldots\right]
$$

in which the notation $a_{20}=a_{2} / a_{0}$, etc., and $\lambda(0)=a_{0}(\eta f)_{2}$ has been used. In Fig. 8 both $1 / \lambda$ and $\partial(1 / \lambda) / \partial B^{2}$ are shown as functions of buckling from B-1 multigroup slowing-down calculations for a typical lattice of 0.600 -in.-diameter metal rods with a water to uranium ratio of 1.5 and an enrichment of 1.15 percent.

The principal difficulty in using this general expansion for the derivative $\partial \rho / \partial B^{2}$ is that at least two or three expansion coefficients need to be determined to obtain either the spatial moments or results of value at bucklings other than the one used in the measurements. This problem is often avoided by making some estimate of the relation between the second and all the higher expansion coefficients. For example, if we choose $a_{\left(2_{j}\right) 0}=a_{20}$, the one-group approximation results:

$P_{\infty}\left(B^{2}\right)=\frac{a_{0}}{1+a_{20} B^{2}}$ 
If, instead, we choose $a_{(2 \mathrm{j})_{0}}=a_{20}^{(j)} /(\mathrm{j})$ !, the exponential approximation of the slowing-down probability results:

$$
P_{\infty}\left(B^{2}\right)=a_{0} \exp \left(-a_{20} B^{2}\right)
$$

The multigroup results in Table 5 appear to favor the one-group approximation, but it should be recalled that B-1 theory, on which the calculations are based, gives only an approximate result for the coefficients beyond $a_{20}$; thus, until more-exact calculations have been made for lattices, there is no clear reason for choosing the one-group rather than the exponential approximation.

In the limit of pure water as the moderating medium, exact calculations ${ }^{20}$ indicate that the one-group slowing-down model is superior to the exponential kernel even though its moment sequence diverges progressively from the exact results. In Table 6 a comparison is given of the exact expansion coefficients of the slowing-down probability of fission neutrons with the sequence implied by both the onegroup and the exponential models having the same second moment as the exact calculation.

Table 6-COEF FICIENTS OF THE SLOWING-DOW $N$ PROBABILITY OF FISSION NEUTRONS IN PURE WATER

\begin{tabular}{lccc}
\hline Slowing-down model & $a_{20}\left(\mathrm{~cm}^{2}\right)$ & $a_{\mathbf{4 0}}\left(\mathrm{cm}^{4}\right)$ & $a_{60}\left(\mathrm{~cm}^{6}\right)$ \\
\hline Exact & 257 & 816 & $384 \times 10^{4}$ \\
One group & $(257)$ & 659 & $169 \times 10^{4}$ \\
Exponential & $(257)$ & 330 & $0281 \times 10^{4}$
\end{tabular}

\section{Cell-parameter Measurements}

Studies of the reaction rates of various absorbers in a lattice cell have formed an important part of the experimental work on watermoderated lattices. The bulk of this work has been devoted to the measurement of quantities that describe fast-fission and resonance capture in $\mathrm{U}^{238}$ and the detalled shape of the thermal-neutron flux in the cell. These quantities can be related, at least intuitively, to the components of the four-factor formula, and the results of early measurements were frequently given in this way. As the theory has developed, however, the tendency to define cell parameters that can be used directly in simple critical equations has dimınished since the more exact theory has shown that such an approach can be expected to achieve limited success at best. The fallure of the simple neutron-cycle models can be attributed largely to the interaction between the various fastneutron reaction rates and the leakage. As a result the comparison of measurements with theory is now customarily made in terms of the 
measured reaction rates, rather than the familiar derived quantities $\epsilon, p$, and $f$.

The definitions of the most commonly measured cell parameters follow. The first three make use of average reaction rates in the fuel alone; the fourth is the usual thermal disadvantage factor and involves activations in both fuel and moderator.

$\delta_{25}^{28}=\frac{\text { fission rate in } \mathrm{U}^{238}}{\text { fission rate in } \mathrm{U}^{235}}$

$\rho_{c}^{28}=\frac{\text { epicadmium capture in } \mathrm{U}^{238}}{\text { subcadmium capture in } \mathrm{U}^{238}}$

$\rho_{f}^{25}=\frac{\text { epicadmium fission in } U^{235}}{\text { subcadmium fission in } U^{235}}$

$\zeta^{x}=\frac{\text { average activation of isotope } \mathrm{x} \text { in the moderator }}{\text { average activation of isotope } \mathrm{x} \text { in the fuel }}$

The notation adopted here departs somewhat from the traditional form and is chosen to designate general categories of reaction-rate ratios that can be applied to plutonium and $U^{233}$ fuel in uranium and thorium as well as to the more common slightly enriched uranium lattices. The ratio of fission rates in two different isotopes is represented by $\delta$, the superscript and the subscript indicating the particular 1sotopes involved; in uranium lattices the subscript for $U^{235}$ can usually be omitted without confusion. The ratio of epicadmium to subcadmium reaction rates in a single isotope is designated by $\rho$, the superscript giving the isotope and the subscript indicating the measured reaction, either capture (c) or fission (f). Notation for the disadvantage factor, $\zeta$, is complicated by the fact that some measurements give the total, some give the subcadmium activation ratios in the cell. The convention we have followed is to designate by superscript the foll material and, If necessary, to indicate by the subscript, $\mathrm{Cd}$, the fact that the measured disadvantage factor represents the subcadmium activation alone.

In addition to these traditional cell parameters, measurements have recently been made of the so-called "modified conversion ratio," which we shall refer to as MCR and define as

$\operatorname{MCR}=\frac{\text { captures in } U^{238}}{\text { fissions in } U^{235}}$

The MCR avolds the use of cadmium filters, which may be a source of trouble in the $\rho_{c}^{28}$ measurements, and provides a quantity that is related to the normal conversion ratio by a properly spectrum-averaged factor $1 /\left(1+\alpha^{25}\right)$, where $\alpha$ is the capture to fission ratio. 
In cell-parameter measurements involving cadmium covers, and particularly for $\rho_{\mathrm{f}}^{25}$, the thickness of the covers has a significant influence on the values obtained. The intercomparison and analysis of this type of data are facilitated by the concept of an ideal neutron filter which yields the same neutron activation in the detector foll as a given cadmium filter but which transmits all neutrons above a certain cutoff energy, $E_{C}$, and none below. The effective cutoff energy of folls irradiated in the fuel of a reactor lattice is, in general, a function of the energy-dependent cross sections of the detector foll, the surrounding fuel, the filter or cover material, which may be cadmium, boron, etc., and the flux spectrum and angular distribution incident on the fuel.

Clearly the most direct and unambiguous method of analysis is to compute the foll activation in each case by a high-order multigroup transport approximation with the filter explicitly represented. Codes such as THERMOS (Ref. 6) or the various thermal-neutron Monte Carlo cell treatments are capable of carrying this admittedly complex calculation through. For quantities such as $\rho_{c}^{28}$, such an elaborate analysis is probably not necessary, and use can be made of the tables of Hickman and Leng ${ }^{21}$ or Stoughton et al. ${ }^{22}$ For thin cadmium covers ( $<30 \mathrm{mils}$ ), these tables show that an appreciable contribution to the presumably epicadmium activation can come from well-thermalized neutrons, and the use of an ideal filter cutoff becomes a rather artıficial description of the physical situation. Many cell-parameter measurements have been made with cadmum covers of 20 mils or less, and in these cases the effect of filter transmission of low-energy neutrons can be appreciable if the lattice thermal-neutron spectrum is sufficiently strong.

Before we leave the subject of neutron filters, the series of measurements by Volpe and $\mathrm{Kleln}^{23}$ should be mentioned. They have attempted to provide a measure of the neutron-energy spectrum in a lattice by employing a range of boron, gadolınium, and cadmium filters of various thicknesses (see Fig. 14). The fission activation in $U^{235}$ was used for detection, and, according to their analysis, the ideal filter cutoff ranged from 0.04 to $25 \mathrm{ev}$.

Cell parameters have been measured in critical assemblies with uniform or multiregion lattıces and in small subcritıcal assemblies, often called miniature lattices, irradiated with neutrons from a large reactor. If a critical assembly is used, there are certain practical advantages in making the measurements in a multiregion lattice composed of a small central region of the lattice under study driven by a surrounding lattice chosen for convenience. For example, changes in the central lattice can be made quickly without altering the large driving lattice. Central-region lattıce configurations can be studied which alone would not go critical or which would have unacceptably large positive temperature coefficients. In addition, only a relatively 
small inventory of fuel is needed to construct the central lattice. These same three advantages also make the miniature-lattice experiments attractive.

The principal question raised by the use of miniature lattices in both types of experiments mentioned regards how large the lattice must be to ensure that the measured cell parameters are indicative of the reaction rates in the asymptotic lattice. The Bettis group has studied this question ${ }^{24}$ for a two-region critical assembly by varying the radius of the central region in both calculations and measurements of the cell parameters. The results, of course, depend on the characteristics of both the central and the driving lattice, so that general conclusions valid for all combinations of lattices cannot be made. Both calculations and measurements, however, do show that the errors to be expected in the cell parameters are sufficiently small that theoretical corrections for the nonasymptotic flux spectrum can be made with some confidence. For example, a $37-$ rod sublattıce of $5.8 \mathrm{~cm}$ radius yields values of $\delta^{28}$ that are high by less than 1 percent and values of $\rho_{c}^{28}$ that are about 6 percent higher than those in the asymptotic lattice. This is a much smaller central region than is normally used in cellparameter measurements, and the corrections are large. However, since the size of the corrections is strongly influenced by the degree of dissimilarity between the neutron spectra in the two regions, it should not be inferred that larger central regions will always produce smaller corrections than these.

Before summarizing the experimental data, we shall describe briefly the methods and some of the experimental difficulties encountered in measuring cell parameters.

FISSION RATIO OF $\mathbf{U}^{238}$ AND $\mathbf{U}^{235}$ In a slightly enriched uranium lattice, the quantity $\partial_{25}^{28}$ is defined to be the ratio of the average fission rate of $\mathrm{U}^{238}$ to the average fission rate of $\mathrm{U}^{235}$. Untermyer ${ }^{25}$ has used small fission chambers containing separated isotopes of $U^{238}$ and $U^{235}$ to measure fission ratios directly as a function of position within a large uranium rod in a graphite-moderated assembly. This direct technique is unfortunately, not applicable to the small fuel elements that are characteristic of water-moderated reactors because of the large perturbation caused by the insertion of the fission chamber in the rod.

The most widely used method of measuring $\delta_{25}^{28}$ is by counting the beta or gamma activity of the fission products of $U^{238}$ and $U^{235}$. This method, first used by $\mathrm{H}_{111^{26}}$ in measurements of the fast effect in a graphite-moderated assembly, utılizes two folls of different uranium isotopic compositions. Because the fission rate of $U^{235}$ is so much greater than that of $\mathrm{U}^{238}$, it is important to use the highest purity $\mathrm{U}^{238}$ that is obtaunable. If the uranium contains more than a few parts per million of $\mathrm{U}^{235}$, the counting rates must be corrected for the $\mathrm{U}^{235}$ concentration. 
In one technique thin inert "catcher" folls are placed in contact with the uranium foils inside a typical fuel rod of the lattice to absorb fission fragments from the surface of the uranium. After an appropriate irradiation in the lattice, the fission-product activity on the catcher foils is measured by a beta detector. If gamma detectors are used, it is possible to count the uranium foils directly with the use of a discriminator setting that biases out the low-energy natural-uranium gamma activity and bremsstrahlung from $\mathrm{U}^{239}$ and its daughter products. However, the ratio of fission-product activities from the two uranium isotopes is not necessarily equal to the ratio of fissions because of differences in the fission-product yields. The method of correcting the data for this effect is given in several forms by Kouts et al. ${ }^{2}$ and by Klein et al. ${ }^{27}$ In essence the conversion from the catcher-activity ratio to the fission ratio requires a separate measurement of the function $P\left(t^{\prime}, t\right)$, as defined by

$\mathrm{P}\left(\mathrm{t}^{\prime}, \mathrm{t}\right)=\frac{\text { activity per fission in } \mathrm{U}^{235}}{\text { activity per fission in } \mathrm{U}^{238}}$

in which $t^{\prime}$ is the time of exposure to neutrons and $t$ is the time elapsed between the end of the exposure and measurements of the activity. A measurement of $P\left(t^{\prime}, t\right)$ can be made utilizing calıbrated fission counters containing known amounts of $\mathrm{U}^{235}$ and $\mathrm{U}^{238}$. The ratio of $\mathrm{U}^{238}$ fissions to $\mathrm{U}^{235}$ fissions, as observed with the fission counters, is compared with the ratio of fission catcher activities after exposure in the same neutron spectrum for a time $t^{\prime}$. Any subsequently measured ratio of fissionproduct activities can be converted to fission ratio if multiplied by $\mathrm{P}\left(\mathrm{t}^{\prime}, \mathrm{t}\right)$.

Figure 9 shows plots of $\mathrm{P}\left(\mathrm{t}^{\prime}, \mathrm{t}\right)$ that have been measured at several laboratories under various conditions of exposure time and detection methods. Hill, ${ }^{26}$ Price, ${ }^{28}$ and Erdik $^{29}$ used beta counters and catcher folls, whereas Klein et al., ${ }^{27}$ Futch, ${ }^{30}$ and Grob et al. ${ }^{31}$ used gamma counters with a discriminator level of $1.2 \mathrm{Mev}$. It is apparent that the type of detector, whether beta or gamma, has a pronounced effect upon $P\left(t^{\prime}, t\right)$. In addition, the exposure time, $t^{\prime}$, also affects the magnitude and slope of $\mathbf{P}\left(t^{\prime}, t\right)$ although the correlation here is not as conclusive as it might be. The probable errors, as quoted by the authors, are indicated by one flagged point on each curve, except for the curves for Hill's data. The solid curves represent the best fit through the experimental data points, which are not shown in the figure. The original data of Hill, Price, and Erdik extend to times up to $4000 \mathrm{~min}$, although the region beyond $180 \mathrm{~min}$ is not of any great practical consideration because of the relatively low fission-product activity.

The major source of error in the $\delta_{25}^{28}$ values probably arises from uncertainties in the value of $\mathrm{P}\left(\mathrm{t}^{\prime}, \mathrm{t}\right)$, which can be as much as \pm 5 percent. The curves in $F$ ig. 9 indicate that enough variation in $P\left(t^{\prime}, t\right)$ occurs under 


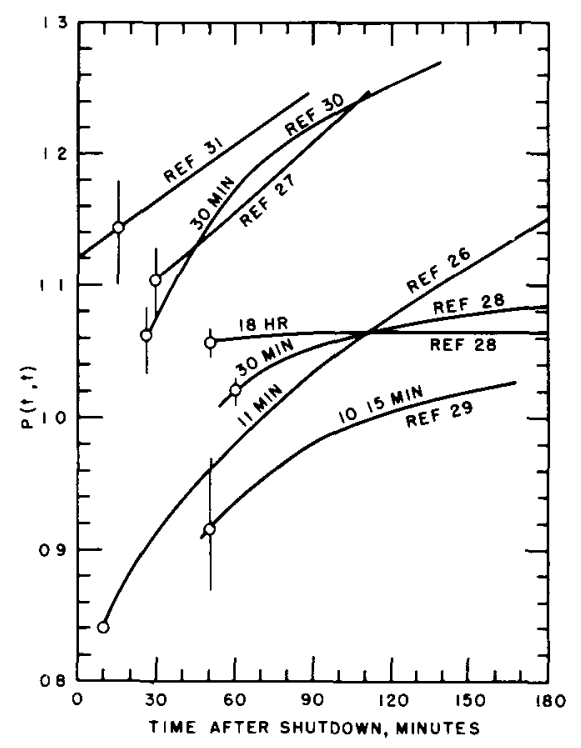

Fig. 9- Ratio of the measured activity per $\mathrm{f}$ is $\mathrm{s}$ ion in $\mathrm{U}^{235}$ to that in $\mathrm{U}^{238}$.

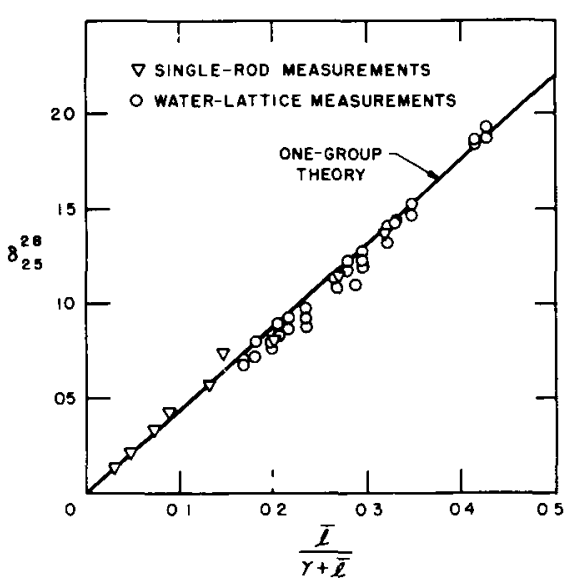

Fig. 10-Measurements of $\delta_{25}^{28}$ for single uranium rods and watermoderated uranium-metal lattıces as a function of $\bar{l} /(\gamma+\bar{l})$.

different conditions of exposure time and fission-product detection methods to warrant remeasurement of this function when new measurements of $\delta_{25}^{28}$ are carried out.

The fission ratio $\delta_{25}^{28}$ is one of the few quantities in light-water lattices that is amenable to a rather simple correlation with the lattice geometry. In Fig. 10 measured values of $\delta_{25}^{28}$ for single rods and lattices are shown as a function of $\bar{l} /(\gamma+\bar{l})$, where $\vec{l}$ is the effective average chord length in the lattice fuel and $\gamma$ is the fast-neutron mean free path in the fuel. This correlation has been given by Hellens and Honeck ${ }^{7}$ for metal-fueled lattices, but similar behavior should be observed in uranium dioxide systems as well.

\section{MEASUREMENTS BY CADMIUM RATIO OF U ${ }^{238}$ CAPTURES AND U ${ }^{235}$ FISSIONS} The lattice-cell parameter, $\rho_{c}^{28}$, is defined as the ratio of epicadmium to subcadmium neutron captures in $\mathrm{U}^{238}$. Despite intensive efforts at several laboratories, the measurements of $\rho_{c}^{28}$ have more doubts and uncertainties connected with them than those of any of the other cell parameters. A wide variety of techniques has been developed and used at BNL, BAPD, Babcock \& Wilcox Company (B\&W), and Westinghouse Electric Corporation, Atomic Power Division (WAPD), but there is as yet no conclusive evidence as to which technique or combination of techniques for the measurement of $\rho_{c}^{28}$ is entirely satisfactory.

As the definition of $\rho_{c}^{28}$ impiles, the experimental method requires the measurement of rates of neutron capture in $U^{238} w_{1}$ th and without 
cadmium covers. This can be done by observing the decay rate of either $\mathrm{U}^{239}$ or $\mathrm{Np}^{239}$, which is the daughter product in the reaction

$$
\mathrm{U}^{238}(\mathrm{n}, \gamma) \rightarrow \mathrm{U}^{239} \frac{\overline{\mathrm{E}}, \gamma}{23 \mathrm{~m} \mathrm{ln}} \mathrm{Np}^{239} \frac{\overline{\bar{B}, \gamma}}{56 \mathrm{hr}} \mathrm{Pu}^{239}
$$

Kouts and Sher ${ }^{32}$ devised a technique for exposing a uranium foil in a fuel rod enclosed in a cadmium pillbox with 0.100-1n.-thick uranlum spacer disks adjacent to the foll to eliminate the streaming of epicadmium neutrons through the cadmium into the foll. Another uranium foll exposed in a symmetrical position, but without the cadmium pillbox, will capture neutrons in both the subcadmium and epicadmium regions. Klein et al. ${ }^{27}$ reported the variation of $\rho$ vs. spacer-disk thickness and concluded that spacer disks $0.050 \mathrm{in}$. or more in thickness are required to attain a consistent value of the cadmium ratio. The pillbox used in the BNL measurements did not displace any of the water surrounding the fuel element because the 0.015-in. cadmium filter was an integral part of the fuel-rod cladding. The measurements, as done by Klein et al., ${ }^{27}$ Grob et al., ${ }^{31}$ and Engelder et al., ${ }^{33}$ required cadmium wrappers that displaced some water around the fuel rod and consequently affected the neighboring neutron source somewhat.

One of the disadvantages of using thin uranium folls for observing epicadmium neutron capture is that a slight displacement of the foll increases the effective surface area for resonance neutron capture. For example, a 0.001-1n. gap between the 0.007-1n. $\mathrm{U}^{238}$ foll and the 0.100-1n. spacer disk could increase the apparent value of $\rho$ by 7 percent. The measurements at $B \& W$ avoid this problem by utilizing a section of fuel rod about $2 \mathrm{in}$. long to minimize the edge effects.

There appears to be no a prior reason for observing the $\mathrm{Np}^{239}$ activity in preference to the $\mathrm{U}^{239}$ activity. Sher ${ }^{34}$ quotes cadmum ratios as observed from both the $\mathbf{U}^{239}$ and $\mathrm{Np}^{239}$ activities, and there is no observable difference within the quoted probable errors. If one observes the $\mathrm{U}^{239}$ beta activity, it is necessary to separate the fission products from the sample before counting. Kouts and Sher ${ }^{32}$ and Engelder et al. ${ }^{33}$ report chemical separation methods that can be successfully performed in the short time allowed before observation of the $23-\mathrm{min}$ beta decay of $\mathrm{U}^{239}$. If one observes gamma activity, it is possible to take advantage of either a coincidence between the 106-kev and 283-kev gamma rays of $\mathrm{Np}^{239}$ or a coincidence between the 103-kev internal conversion line of $\mathrm{Pu}^{239}$ and the $106 \mathrm{-kev} \mathrm{Np^{239 }}$ line to reduce the effect of unwanted fission-product activities. The use of high-purity $\mathrm{U}^{238}$ folls reduces the fission-product activity to essentially that of $\mathrm{U}^{238}$ alone, but the limited avallability of this material restricts the number of measurements that can be done. 
One of the difficulties in the $\rho$ measurement arises from the fact that the cadmium ratio, $C R$, may be close to unity. Since the value of $\rho$ depends upon the difference between the cadmium ratio and unity, $\rho_{\mathrm{c}}^{28}=\frac{1}{\mathrm{CR}-1}$

it follows that a small error in the cadmium ratio is amplified in the corresponding error in $\rho_{c}^{28}$. Engelder et al. ${ }^{33}$ have circumvented this problem somewhat by the thermal-activation method. This method compares the activation of dysprosium with that of $U^{238}$, first in a lattıce and then in a well-thermalized neutron spectrum. The technique has the advantage of reducing probable errors in tight-packed lattıces since no cadmium covers are used in the primary exposure. It is necessary to make a second exposure with cadmium covers to correct the results for the small epicadmium activation of dysprosium. Although the use of cadmium covers may require a correction of up to 15 percent in a directly observed cadmium-ratio measurement, the results of the thermal-activation method are only slightly affected by perturbations caused by the cadmium covers in the lattice. Moreover, this correction which itself makes use of a cadmium-ratio measurement in the lattice becomes quite small in tight-packed lattices as the cadmium ratio approaches unity. This technique has been carefully studied and extensively exploited at $B \& W$, and it seems to provide consistent results even in situations in which direct $\rho$ measurements become very uncertain.

Arcipianı et al. ${ }^{35}$ and more recently Lutz and Hachiya ${ }^{36}$ have reported a source of error in $\rho_{c}^{28}$ which is attributed to the mode of radioactive counting. The spatial distributions of subcadmium and epicadmium neutron captures in the $\mathrm{U}^{238}$ foll differ because of the resonance cross section in the epicadmium region. The epicadmium capture has a strong surface component, whereas the subcadmum capture has a more unform distribution in the foll. Therefore it is possible that, when the beta or gamma activity from an intact uranium foll is observed, self-shielding and counter-geometry effects may influence, to a different extent, the apparent subcadmium and ep1cadmium induced activities. Lutz and Hachiya correlated values of $\rho$, as obtained by several investigators, with either dissolved or undissolved uranium folls. Presumably, dissolving the folls homogenizes the subcadmium and epicadmium induced activities, whereas they remain segregated if the folls are not dissolved. These authors observed, in a typical water-moderated lattıce, a difference of 25 percent in $\rho_{c}^{28}$, which is attributed to differential absorption of surface and volume activities in the solid undissolved uranium foil. If this reasoning is accepted, it is clear that, if the correct value of $\rho$ is to be obtained, the $\mathrm{U}^{238}$ foll should be homogenized before counting is done. 
The measurement of the epicadmium to subcadmium fission ratio, $\rho_{\mathrm{f}}^{25}$, in $\mathrm{U}^{235}$ can be made by use of the fission-product gamma-activity counting discussed in connection with $\delta_{25}^{28}$ with and without cadmium covers. Two of the principal sources of error in $\delta_{25}^{28}$ and $\rho_{c}^{28}$ are of little or no consequence in the measurement of $\rho_{\mathrm{f}}^{25}$. The first 1s, of course, the fact that, since the same source of gamma activity is present in both the bare and the cadmium-covered $\mathrm{U}^{235}$ folls, the ratio of fissions produced in the foils can be taken as simply equal at all times to the ratio of gamma activities. The more-serious source of error, which is apparentiy quite pronounced in $\rho_{c}^{28}$ measurements and which arises from the large surface to volume capture ratio, is much less important in measurements of $\rho_{f}^{25}$ because of the greater dilution and weaker resonance cross-section structure of $\mathrm{U}^{235}$ in the fuel. The reduced influence of these two sources of error in measurements of $\rho_{\mathrm{f}}^{25}$ probably accounts to a large extent for the rather satisfactory agreement frequently found between the measured values and the theoretical predictions.

The principal difficulty encountered with $\rho_{f}^{25}$ measurements is one of interpreting the precise effect of the cadmium filter on the fission rate. The ratio of thermal cross section to resonance integral for the $\mathrm{U}^{235}$ in the lattice is roughly a factor of 10 greater than that for $\mathrm{U}^{238}$. As a result, an appreciable amount of fission can be induced by the few thermal neutrons that penetrate a thin cadmium filter. In addition, a substantial contribution to the fission rate of the cadmium-covered foils is induced by neutrons in the neighborhood of the so-called effective cadmium cutoff, where the cross-section dependence of $\mathrm{U}^{235}$ is quite different from $1 / v$. These difficulties are more theoretical than experimental, and they are mentioned only to indicate that the use of $\rho_{f}^{25}$ to support the theory is not entirely free from suspicion when the computed results are based on the choice of a simple cadmium cutoff energy.

MODIFIED CONVERSION RATIO Since the neutron economy in light-watermoderated lattices is such that the conversion of $\mathrm{U}^{238}$ to plutonium compensates at least partially for the loss of $\mathrm{U}^{235}$, there has been considerable interest in measuring the conversion ratio or, failing that, quantities closely related to it. Direct measurements of the conversion ratio have not been made in any of the experiments reviewed here because of the difficulty of finding the total $U^{235}$ destruction. In operating power reactors the loss of $\mathrm{U}^{235}$ is large enough to permit measurements $^{37,38}$ of the conversion ratio by mass spectrographic methods. In low-power critical and exponential experiments, however, the so-called "modified conversion ratio," or MCR, is usually taken as an easily measurable alternate quantity. In addition, the MCR provides a measure of the resonance capture in $\mathrm{U}^{238}$ without the uncertaint 1 es attendant on 
the use of cadmium covers which are encountered in the $\rho_{c}^{28}$ measurements.

BAPL ${ }^{39}$ WAPD,${ }^{40}$ and GEAP $^{14}$ have all reported measurements of MCR in natural or slightly enriched lattices. The methods and difficulties of observing the relative fissions in $U^{235}$ and relative captures in $\mathrm{U}^{238}$ have been discussed above in connection with $\delta_{25}^{28}$ and the cadmiumratio measurements. A normalization of the counting rates from the two activities at time $t$ after an exposure of duration $t^{\prime}$ is necessary in a well-thermalized flux spectrum such as that avalable in the thermal column of the BNL Graphite Research Reactor, in which it is assumed that the capture in $\mathrm{U}^{238}$ to fission in $\mathrm{U}^{235}$ ratio is known. The desired quantity is then

$\operatorname{MCR}=\frac{N^{28} \sigma_{c}^{28}}{N^{25} \overline{\sigma_{c}^{25}}} \frac{\left[G_{L}^{28}\left(t^{\prime}, t\right) / G_{0}^{28}\left(t^{\prime}, t\right)\right]}{\left[G_{L}^{25}\left(t^{\prime}, t\right) / G_{0}^{25}\left(t^{\prime}, t\right)\right]}$

where $\mathrm{N}$ represents the isotopic atom density in the fuel, the cross sections are spectrum averages in the normalized spectrum, and the subscripts 0 and $L$ on the gamma activity $G$ designate irradiation in the thermal and the lattice spectrum, respectively.

\section{THERMAL-NEUTRON DISADVANTAGE FACTOR}

Two te chniques have been developed for measuring the thermal-neutron disadvantage factor, $\zeta$, in a lattice cell which are usually designated as the "sector foll" and the "cell traverse" methods.

The sector-foil method makes use of two large, but thin, detector folls, one of which covers a representative area of a fuel cell and the other a representative area of a moderator cell. The disadvantage factor, $\zeta^{x}$, is simply the ratio of the neutron-induced specific activity of the two foils of material $x$. If $\zeta$ is to be defined as the subcadmium activity, it is necessary to make a cadmium-ratio measurement and to correct the bare-foll activities accordingly. If this is done, the cadmium ratio is usually measured only in the moderator, and the assumption is made that the epicadmum neutron flux is identical in moderator and fuel. This practice is not unversal, however, and in some WAPD measurements $^{41-43}$ cadmium ratios were measured in both fuel and moderator.

The cell-traverse method of measuring $\zeta$ requires the use of detector folls or wires that are much smaller than the unit lattice cell. With these small detectors the neutron flux can be mapped out throughout a lattice cell. Suitable neutron-flux averages are then obtained by appropriate smoothing and averaging of the individual points. The celltraverse method is obviously more tedious and time consuming than the sector-foll method, but it provides more information about the detalled neutron-flux shapes. 
In both methods of measuring $\zeta$, it is necessary to minimize the effect that the detector folls and their holders can have on the neutron flux and to prevent fission-product contamination from the fuel on the detector folls. An early systematic error in $\zeta$ values, as measured at $\mathrm{BNL},{ }^{44}$ was traced to the use of aluminum-foll holders in the moderator region, which noticeably affected the neutron flux. Subsequent measurements indicated that Lucite is a better material to use in the water as a foll holder although it does not simulate water exactly and the quantity of material used should be minimized. Obviously the detector foils must be kept to a minimum, consistent with measurable induced activity, to avoid distortion of the neutron distribution by the detector itself.

\section{SUMMARY OF EXPERIMENTAL RESULTS}

In reviewing the experimental data on light-water-moderated lattices, we have attempted to extract only the results of buckling, critical-loading, and cell-parameter measurements and have made no systematic effort to mention or tabulate the results of less-common measurements. Thus, for example, the indications of the lattice neutron spectrum obtained from the activation of various resonance absorbers have not been reviewed, even though the results are certainly of value. The experimental work done at each of the various laboratories that have contributed to the field has been summarized, and we have included in these sections tables of the measured cell parameters. The data on material buckling, critical size, and specifications of the fuel elements and lattice arrangement are given in the appendix.

To provide a readily interpreted identification for each uniform lattice, we have used a four-component "lattıce index" made up as in the following example. The first pair oi letıers in MA-130-387-150 designates the fuel material and cladding or tubing ( $\mathbf{M}$, uranium metal; O, uranıum dioxide; A, alumınum; S, steel; F, ıron; and U, unclad). The first three figures give the enrichment in $U^{235}$ as weight percent of uranium times $10^{2}$ (130 is 1.30 percent); the next three give the diameter of the fuel slug or pellet in inches times $10^{3}$ (387 is $0.387 \mathrm{in}$.); and the last three specify the water to fuel slug or water to pellet volume ratio times $10^{2}$ ( 150 is water to uranium ratio of 1.50$)$. This lattice index is sufficient to distinguish most of the fuel elements employed in the various experiments. A few annular and superheat fuel elements, however, require a more detalled description; these are set apart by an asterısk over the first hyphen, and their specifications are given separately in Table $\mathrm{F}$ of the appendix. The third component of the index for these complex fuel elements represents the outer diameter of the fuel slug or pellet. The one set of unclad uranium-plate fuel elements in the collection is indicated by a footnote. 
This summary of data would not be complete if the many measurt ments of natural-uranium fuel in light water were excluded. However, one cannot avoid having misgivings about the precision of some of the early experimental results because they were obtained in an apparently extempore fashion, and the reports that do exist are incomplete. At this late date it is dufficult to evaluate the merits of these various measurements, and we have simply included in the tables all the data available to us for seemingly well-defined lattıces.

\section{Argonne National Laboratory}

Measurements in clean, water-moderated lattıces of slightly enriched fuel have been started only recently at Argonne National Laboratory (ANL) because of the earlier orientation of the laboratory program toward more practical problems and more-advanced types of reactors. As a result few measurements have yet been completed; the results given here have not been published and should be viewed as tentative. Because the principal interest expressed in these experiments lies in the conversion ratio, both cell parameters and material buckling will eventually be measured.

Two uniform lattices have been built in the Zero Power Reactor (ZPR-VII) with the use of fuel made of 4.95 percent enriched uranium dioxide pellets contained in stainless-steel tubing of $0.015 \mathrm{in}$. wall thickness. The cell parameters given in Table 7 were measured, but neither the radial-reflector savings nor the axial buckling are given, although presumably these quantities will be measured later.

Table 7 -- PRELIMINARY VALUES OF CELL PARAMETERS AND BUCKLINGS (ANL)

\begin{tabular}{|c|c|c|c|c|}
\hline Lattice index & $\mathrm{B}^{2}, \mathrm{~m}^{-2}$ & $\delta_{25}^{28}$ & $\rho_{f}^{25}$ & $\zeta$ \\
\hline $\mathrm{OA}-304-365 \quad 076$ & $5538 \pm 024$ & & & \\
\hline 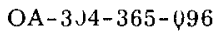 & $7076+071$ & & & \\
\hline OS-304-365-096 & $4747 \div 027$ & $01014 \pm 00007$ & $0278+0008$ & $123+006$ \\
\hline OS- $304-365-128$ & $6199+039$ & & & \\
\hline OS- $304-365-170$ & $7427+029$ & & & \\
\hline OS- $495-343-114$ & & $0119+001$ & 0.345 & 114 \\
\hline OS $-495-343-150$ & & $0065 \pm 0006$ & 0254 & 117 \\
\hline
\end{tabular}

A large amount of uranium dioxide fuel of 3.04 percent enrichment is available for these experiments in both aluminum and stainless-steel tubes. So that the range of the water to uranium dioxide volume ratio can be extended without additional lattice plates, it is planned to measure bucklings by the flux-shape method in nonuniform arrays with, for example, $7 / 8$ or $3 / 4$, etc., of the lattice positions fueled. Cell parameters will be measured only in the uniform lattices. 
Since these data ${ }^{45}$ are so recent, they are not included in the summary tables in the appendix. A few of the values obtained so far are given in Table 7.

\section{Atomic Energy of Canada Limited}

A series of material-buckling and fine-structure measurements has been made at Atomic Energy of Canada Limited (AECL) in lattices of both natural and depleted uranium metal rods moderated by light water. $^{46,47}$ This series is unique in that it not only adds to the data avallable on natural uranium (Fig. 11) but also provides the only data on depleted uranium $\left(0.26\right.$ percent $\left.\mathrm{U}^{235}\right)$. For the depleted uranium, large negative bucklings are found over the full range of water to uranium volume ratios.

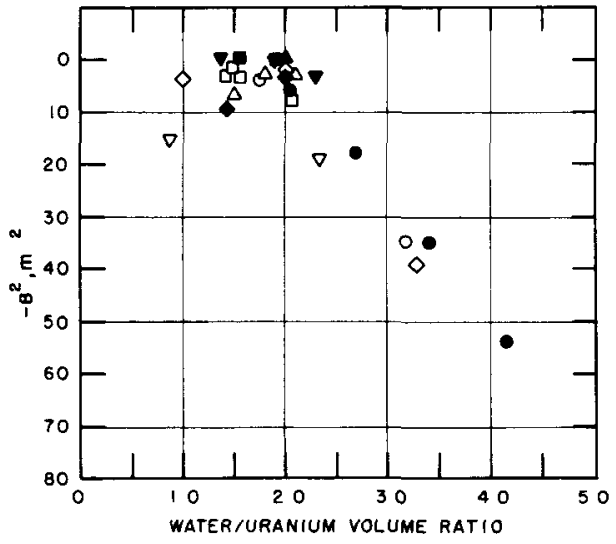

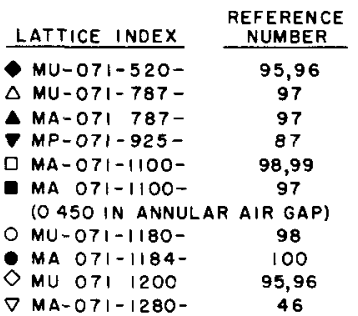

Fig $11-$ Relation between material buckling and water to uranum volume ratio for natural uranium in light water

The lattices in these experiments were composed of uranium-metal rods, 1.28 in. in diameter, clad in aluminum jackets and arranged in a square lattice pitch at water to uranium volume ratios of $0.859,2.33$, and 6.83. Bucklings were measured by foll activations along the three major axes of the rectangular exponential assembly.

The lattices were surrounded on five sides by cadmium, paraffin, and various amounts of structural material. Hence the measured reflector savings cannot be compared with the results of fully waterreflected lattices employed by other laboratories. Nonetheless, if the assembly is large enough to achieve an asymptotic neutron spectrum in the central region, the measured material buckling is independent of these particular reflector properties. As we have pointed out before, the use of cadmium ratios to confirm an asymptotic neutron spectrum, as is done at Chalk River with indium folls, is not really decisive although the assemblies in question were undoubtedly large enough for the type of buckling measurement used. Activation shapes were mea- 
sured with bare and cadmum-covered folls of copper, manganese, gold, and indium. There was no significant difference between the bucklings inferred from bare and cadmium-covered folls, and the quoted values are simply the average of both types of measurements.

The thermal-neutron disadvantage factor, $\zeta$, was measured for one depleted uranium lattice with 6.83 water to uranium ratio with the use of small manganese pins, both bare and cadmium covered. The results are:

$\begin{array}{ccc}\text { Lattice index } & \zeta_{\mathrm{Cd}}^{\mathrm{Mn}} & \zeta_{\mathrm{ep} \mathrm{p}^{\mathrm{M}}-\mathrm{Cd}}^{\mathrm{Mn}} \\ \mathrm{MA}-026-1280-683 & 1.724 & 1205\end{array}$

Many cadmium-ratio measurements using thick and thin indium, gold, and manganese folls in the moderator of lattices fueled with natural uranium were made with the intent of providing a basis for evaluating the slowing-down density per unit thermal flux. Fast-fission measurements in these lattices are to be published. ${ }^{48}$

\section{Babcock \& Wilcox Company, Atomic Energy Division}

B \&W has carried on an extensive and varied program of exper1mental reactor-physics work ${ }^{49-53}$ in connection with the N.S. Savamah reactor, a central-station power reactor fueled with uranium-thorium, and general studies of the spectral-shift concept. Particular emphasis has been placed on measurements of resonance integrals in single rods and Iattices, the age in thorium oxide lattices with mixtures of lightand heavy-water moderator, and buckling, reflector savings, and cell parameiers in a variety of critical and exponential experiments with slightly enriched uranium and thorium fuel. Only a few of the experiments in this program fall within the narrow limits of this review, but one of them is of unusual interest because it provides buckling measurements for a single lattice from 66 to $406^{\circ} \mathrm{F}$. In addition to these high-temperature exponential experiments, critical experiments have been used to provide buckling, reflector savings, and cell parameters in three lattices at very low water to uranium dioxide volume ratios.

The high-temperature exponential assembly was irradiated in a pressure vessel, $3 \mathrm{ft}$ in internal diameter and $9 \mathrm{ft}$ long, fabricated of 1-in.-thick carbon steel and clad on the inside with stainless steel. A swimining-pool reactor provided the source of thermal neutrons. Neutron activations with bare and cadmium-covered gold wires in the axial and radial directions were used to obtain the material buckling. As a check the material buckling of the same lattice was measured in a clean critical array at room temperature and found to be $88.0 \pm 0.4 \mathrm{~m}^{-2}$. The value found agreed very well with the value from the exponential ex- 
periment of $88.24 \pm 0.87 \mathrm{~m}^{-2}$. At elevated temperatures only the cadmium-covered gold wires were used because these activation shapes are not susceptible to the local intracellular variations of the thermalneutron flux. Hence a misalignment of the gold wires due to nonuniform expansion of the assembly has little effect upon the observed flux shape.

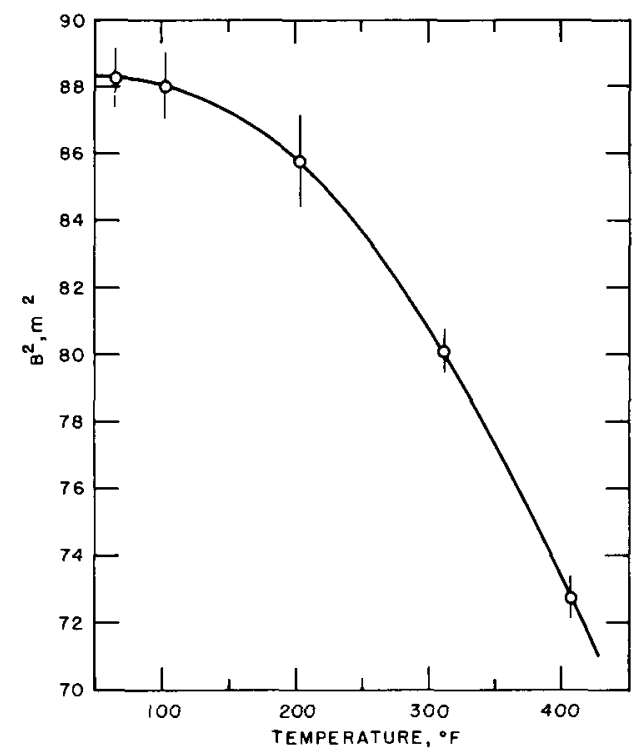

Fig. 12- Material buckling as a function of temperature for a lattice fueled with 4.02 percent enriched uranium dioxide

Figure 12 shows the material buckling as a function of temperature for a lattice of 4.02 percent enriched uranium dioxide rods clad in stainless steel. The fuel rod is $0.444 \mathrm{in}$. in diameter. These data are given in Table 8 , and the details of the lattice are given in Table $B$ of the appendix. The exponential lattice contained 368 fuel rods and had a water reflector of about $28 \mathrm{~cm}$ between the fuel and the pressure-vessel wall. The maximum temperature drop across the assembly was $4^{\circ} \mathrm{F}$, so that a reasonably uniform temperature was 2ssured at all times.

In addition to these exponential experiments, measurements of the usual cell parameters were performed in the lattıce mentioned above and in two others as well. The results are of particular interest in that the lattices were unusually undermoderated and, consequently, exhibited strong resonance capture and fission in $\mathrm{U}^{238}$. Besides the cell parameters given in Table 9, activation measurements were made with rhodium, gold, tungsten, cobalt, manganese, and selenıum as indicators of the epicadmium neutron spectrum. ${ }^{3 s}$ 
Table 8-MATLRIAL BUCKLING AS A FUNCTION OF TEMPERATURE

FOR A LATTICE FUELED WITH 402 PERCENT ENRICHED

URANIUM DIOXIDE (OS-402-444-114)

\begin{tabular}{rrrrr}
\hline $\begin{array}{c}\text { Temp } \\
{ }^{\circ} \mathrm{F}\end{array}$ & $\begin{array}{c}\text { Radial } \\
\text { buckling, } \mathrm{m}^{-2}\end{array}$ & $\begin{array}{c}\text { Axidl } \\
\text { buckling, } \mathrm{m}^{-2}\end{array}$ & $\begin{array}{c}\text { Material } \\
\text { buckling, } \mathrm{m}^{-2}\end{array}$ & $\begin{array}{c}\text { Reflector } \\
\text { savings, } \mathrm{cm}\end{array}$ \\
\hline 66 & $10282 \pm 071$ & $-1458 \pm 051$ & $8824 \pm 087$ & $736 \pm 008$ \\
103 & $10262 \pm 095$ & $-1459 \pm 010$ & $8803 \pm 096$ & $738 \pm 011$ \\
203 & $10161 \pm 137$ & $-1585 \pm 008$ & $8576 \pm 137$ & $750 \pm 016$ \\
308 & $9809 \pm 065$ & $-1797 \pm 011$ & $80.12+0.66$ & $792 \pm 008$ \\
406 & $9444 \pm 064$ & $-2172 \pm 010$ & $72.72+0.65$ & $839 \pm 008$ \\
\hline
\end{tabular}

Table 9 - LATTICE-CELL PARAMETERS $(B \& W)^{54}$

\begin{tabular}{ccccc}
\hline Lattice index & \multicolumn{1}{c}{$\rho_{\mathrm{c}}^{28}$} & $\rho_{\mathrm{f}}^{25}$ & \multicolumn{1}{c}{$\zeta^{\mathrm{Dy}}$} \\
\hline OA-246-405-137 & $228 \pm 003$ & $0151 \pm 0002$ & $1191 \pm 0007$ \\
OS-402-144-096 & $508 \pm 010$ & $0.307 \pm 0003$ & $124 \pm 001$ \\
OS-402-444-114 & $412 \pm 031$ & $0.266 \pm 0003$ & $1,27 \pm 002$ \\
\hline
\end{tabular}

The experimental work on the spectral-shift reactor, utilizing mixtures of light and heavy water, provides an extensive series of measurements for comparison with theory as well as some careful studies of the consistency of various methods of measuring the lattice-cell parameters. Although it is outside the scope of this review, much of this work contributes to the physics of light-water lattices, particularly the studies of various methods for the measurement of cell parameters.

\section{Westinghouse Electric Corporation, Bettis Atomic Power Laboratory}

The interest in slightly enriched uranium lattices at BAPL was a result of development work on the Shippingport reactor, and it led to a cooperative experimental program between BAPL and BNL, which made use of the uranium-metal fuel described here in connection with the BNL experiments. The TRX facility ${ }^{12}$ was constructed at BAPL for both critical experiments and measurements of lattice-cell parameters. The initial experimental work was intended to show that the bucklings and cell parameters measured in a full critical assembly were the same as those inferred by different methods at BNL from exponential and miniature lattıce experiments.

Shortly after the start of this work, considerable interest in uranium dioxide as a reactor fuel developed at BAPL. As a result three lots of 
uranium dioxide fuel elements, contained in aluminum tubes, were obtained, and the subsequent experimental program has been primarily concerned with uranium dioxide rather than with metal fuel. Although both bucklings and reflector savings have been measured, the principal contributions of the BAPL group are an extensive set of cell-parameter measurements in both metal-and oxide-fueled lattices and a series of related, but unusual, experimental studies of lattice effects.

The early experiments carried out in the TRX with the uraniummetal fuel provided independent measurements of the buckling in only two lattices, temperature coefficients at two temperatures in six lattices, and some determinations of the change of reactivity with radial buckling and water height. The water-height measurements were analyzed for anisotropy in the migration area, but the results were inconclusive. The buckling measurements differed from the BNL results by about $1 \mathrm{~m}^{-2}$, which is roughly the combined probable error of the two measurements.

The uranium dioxide fuel, all 1.311 percent enriched and contained in 0.028-in.-thick aluminum tubing, was fabricated in essentially two rod sizes and two fuel densities:

$\begin{array}{cc}\text { Pellet diameter, in. } & \text { Pellet density, } \mathrm{g} / \mathrm{cm}^{3} \\ 0.601 & 7.53 \\ 0.388 & 7.52 \\ 0.383 & 10.53\end{array}$

The lattice indexes we have used do not explicitly incluae the fuel density; the reader must therefore distinguish the small rods of high and low fuel density by the slight difference in pellet diameter. In general, the basic experimental techniques that had been developed for the uranium-metal fuel were found to be applicable to the uranium dioxide fuel without major changes. Bucklings were measured in eight uranium dioxide lattices in addition to temperature coefficients and $\partial \rho / \partial B^{2}$. The search for anisotropic effects in these $\partial \rho / \partial B^{2}$ measurements appeared to yield a systematic ratio of $M_{\| /}^{2} / M_{\perp}^{2}=1.04 \pm 0.03$; thus, although the results are again not conclusive, the indication of anisotropy is more pronounced than that observed from the metalfuel data.

The lattice-cell parameters given in Table 10 for both metal and oxide fuel include a few recently published results ${ }^{55}$ in addition to those of an earlier compilation of Klein et al. ${ }^{27}$ It is interesting to compare the results from the metal-fueled lattices with the corresponding BNL values in Table 11 because the experimental techniques were somewhat different in each case. The thermal disadvantage factors, $\zeta_{\mathrm{Cd}}^{25}$, were measured at BAPL by the sector-foil method, whereas the BNL experiments utilized small bare dysprosium foils. At BAPL neutron 
Table $10-$ LATTICE-CELL PARAMETERS (BAPL)

\begin{tabular}{|c|c|c|c|c|}
\hline Lattice index & $\delta_{25}^{28}$ & $\rho_{c}^{28}$ & $\rho_{\mathfrak{f}}^{25}$ & $\zeta_{C d}^{25}$ \\
\hline$M A-114-600-202$ & $0104 \pm 001$ & $120 \pm 003$ & & $145 \pm 004$ \\
\hline 301 & $0081 \pm 0008$ & $093 \pm 004$ & & $145 \pm 004$ \\
\hline $\mathrm{MA}-130-387-100$ & 0183 & $313 \pm 020$ & $0254 \pm 0004$ & $118 \pm 001$ \\
\hline 202 & $0099 \pm 001$ & $159 \pm 003$ & $015 \pm 001$ & $121 \pm 004$ \\
\hline 235 & $0099 \pm 001$ & $141 \pm 006$ & $0101 \pm 0001$ & $123 \pm 001$ \\
\hline 302 & $0078 \pm 0008$ & $118 \pm 003$ & $0099 \pm 0003$ & $131 \pm 004$ \\
\hline 800 & & 0.484 & & $145 \pm 003$ \\
\hline MA-130-600-151 & & $180 \pm 018$ & & $139 \pm 004$ \\
\hline 202 & & $124 \pm 012$ & & $145 \pm 004$ \\
\hline 301 & & $089 \pm 009$ & & $149 \pm 004$ \\
\hline$O A-131-383-143$ & $0078 \pm 0004$ & $143 \pm 001$ & $0089 \pm 0002$ & $110 \pm 001$ \\
\hline 178 & $0070 \pm 0004$ & $115 \pm 001$ & $0072 \pm 0001$ & $113 \pm 001$ \\
\hline 240 & $0057 \pm 0003$ & $0934 \pm 001$ & $0055 \pm 0001$ & $113 \pm 001$ \\
\hline OA-131-388-139 & $0063 \pm 0003$ & $104 \pm 005$ & $0078 \pm 0001$ & $1095 \pm 0008$ \\
\hline 173 & $0054 \pm 0003$ & $090 \pm 002$ & $0063 \pm 0001$ & $110 \pm 001$ \\
\hline OA-131-601-107 & $0071 \pm 0007$ & $119 \pm 004$ & $0080 \pm 0003$ & $109 \pm 003$ \\
\hline $14 Q$ & $0059 \pm 0006$ & $0994 \pm 0013$ & $0077 \pm 0002$ & $114 \pm 003$ \\
\hline 176 & $0051 \pm 0004$ & $0807 \pm 0014$ & $0072 \pm 0002$ & $116 \pm 003$ \\
\hline
\end{tabular}

Table 11 - LATTICE-CELL PARAMETERS (BNL)

\begin{tabular}{|c|c|c|c|c|}
\hline Lattice index & $\delta_{25}^{28}$ & $\rho_{\mathrm{c}}^{28 *}$ & $\rho_{\mathrm{f}}^{25 *}$ & $\zeta^{D y}$ \\
\hline $\mathrm{MA}-071-1100-149$ & & & & 1718 \\
\hline$M A-103-250-150$ & 0.129 & $204 \pm 003$ & 0.14 & 1105 \\
\hline 200 & 0.102 & $156 \pm 001$ & 0.095 & 1.091 \\
\hline 300 & 0.077 & & 0056 & 1.114 \\
\hline 400 & 0.066 & & 0050 & 1131 \\
\hline $\mathrm{MA}-103-387-100$ & 0.187 & $244 \pm 010$ & 024 & 1101 \\
\hline 150 & 0.136 & $161 \pm 005$ & 0096 & 1149 \\
\hline 200 & 0.109 & $135 \pm 0.05$ & & 1183 \\
\hline 300 & 0081 & $093 \pm 0.03$ & 0.053 & 1. 249 \\
\hline 400 & 0.068 & $073 \pm 003$ & 0.037 & 1251 \\
\hline MA-103-600-100 & 0.180 & $200 \pm 020$ & & 1278 \\
\hline 150 & 0.144 & & & 1321 \\
\hline 200 & 0116 & $101 \pm 002$ & & 1356 \\
\hline 300 & 0081 & $079 \pm 0.02$ & & 1448 \\
\hline 400 & 0.072 & $060 \pm 002$ & & 1.519 \\
\hline $\mathrm{MA}-103-750-133$ & $0.145 \pm 0007$ & & & \\
\hline 383 & $0.092 \pm 0090$ & & & \\
\hline $\mathrm{MA}-114-250-150$ & 0.126 & & & 1083 \\
\hline 200 & 0.103 & & & 1087 \\
\hline 300 & 0.077 & & & 1128 \\
\hline 400 & 0.061 & & & 1146 \\
\hline
\end{tabular}


Table 11 - (Contınued)

\begin{tabular}{|c|c|c|c|c|c|}
\hline \multicolumn{2}{|c|}{ Lattice index } & $\delta_{25}^{28}$ & $\rho_{\mathrm{c}}^{28 *}$ & $\rho_{\mathrm{f}}^{25 *}$ & $\varphi^{\mathrm{Dy}}$ \\
\hline \multirow[t]{5}{*}{$\mathrm{M}+114-387$} & 100 & 0177 & & 022 & 1122 \\
\hline & 150 & 0138 & & 015 & 1182 \\
\hline & 200 & 0106 & & 010 & 1185 \\
\hline & 300 & 0081 & & 0089 & 1232 \\
\hline & 400 & 0064 & & & 1266 \\
\hline \multicolumn{2}{|c|}{ MA $114-600-100$} & 0179 & & & 1270 \\
\hline & 150 & 0142 & & & 1289 \\
\hline & 200 & 0113 & & & 1383 \\
\hline & 300 & 0086 & & & I 449 \\
\hline & 400 & 0070 & & & 1514 \\
\hline \multicolumn{2}{|c|}{ MA $130-387-100$} & 0176 & & 024 & 1150 \\
\hline & 150 & 0127 & & 017 & 1173 \\
\hline & 200 & 0108 & & 012 & 1222 \\
\hline & 300 & 0077 & & 0073 & 1258 \\
\hline & 400 & 0066 & & 0052 & 1303 \\
\hline \multicolumn{2}{|c|}{ M А $130-600-100$} & 0177 & & & 1285 \\
\hline & 150 & 0126 & & & 1354 \\
\hline & 200 & 0106 & & & 1427 \\
\hline & 300 & 0084 & & & 1482 \\
\hline & 400 & 0071 & & & 1582 \\
\hline \multirow[t]{5}{*}{ OS $301-441$} & 132 & 0065 & $292 \pm 009$ & & I $213 \pm 0005$ \\
\hline & 163 & 0056 & $241 \pm 004$ & & $1249 \neq 0007$ \\
\hline & 209 & 0048 & $181 \pm 006$ & & $1278 \pm 0008$ \\
\hline & 286 & 0037 & $141 \pm 002$ & & $1326 \pm 0009$ \\
\hline & 407 & 0031 & $104 \pm 002$ & & $1357 \pm 0006$ \\
\hline \multicolumn{3}{|c|}{$M U-125-122-102 \dagger$} & & & 1108 \\
\hline \multicolumn{2}{|c|}{154} & & & & 1135 \\
\hline & 205 & & & & 1150 \\
\hline & 307 & & & & 1211 \\
\hline & 410 & & & & 1258 \\
\hline
\end{tabular}

* Cadmium cover thickness $20 \mathrm{mlls}$

†Uranium-metal-plate fuel elements

capture in $\mathrm{U}^{238}$ was inferred from the $103-\mathrm{kev} \mathrm{X}$-ray emission, which is associated with the decay of $\mathrm{Np}^{239}$, whereas the beta emission from $\mathrm{U}^{239}$ was utilized at BNL. The fission ratios, $\delta_{25}^{28}$ and $\rho_{\mathrm{f}}^{25}$, were obtained from measurements of the gross fission-product gamma activity above $12 \mathrm{Mev}$ at BADL and from the beta activity of catcher folls at BNL.

In the choice of lattice pitch for cell-parameter measurements, an arrangement providing greater flexibility than that permitted by a uniform critical lattice was needed. Theoretical and experimental studies were made of two-region lattices to explore the errors resulting from the use of a small, changeable central test region surrounded by a fixed driver region. The main points of this work ${ }^{24}$ have already been mentioned; the method is particularly useful for mea- 
surements at extreme lattice pitches such as that shown under MA130-387-800 in Table 10 (water to uranium ratio of 8 ).

An important part of the more recent experimental program at BAPL has centered on the study of resonance-capture phenomena in both lattices and single fuel rods. Klein et al ${ }^{56}$ measured the spatial distribution of $U^{238}$ resonance capture in a $0.387-1 n$.-diameter uraniummetal rod; their results, along with some later measurements, are

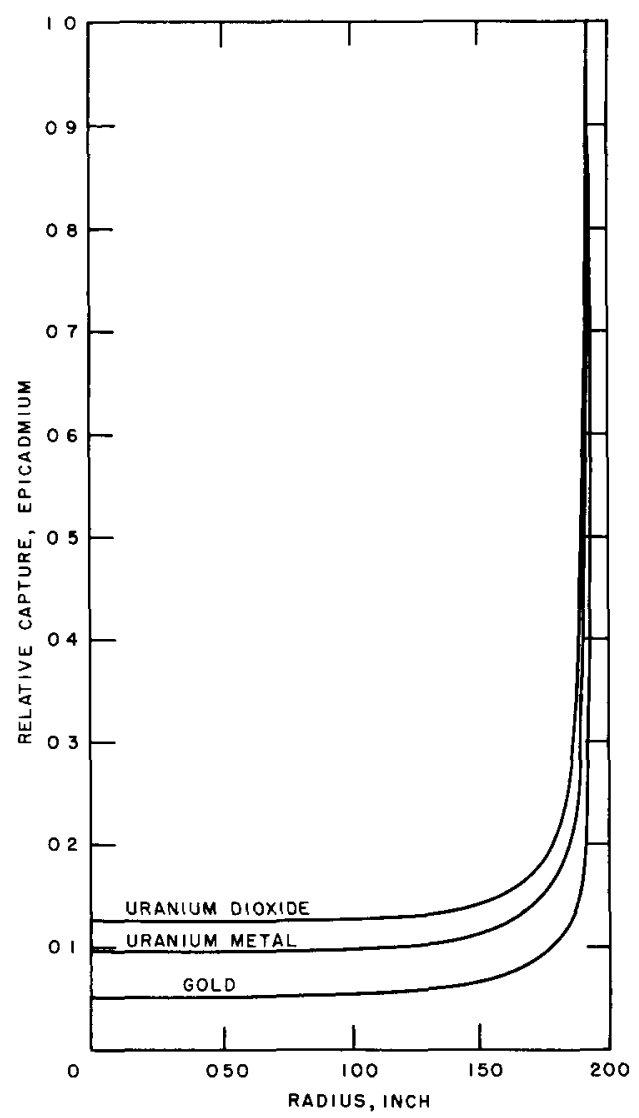

Fig. 13- Spatial distribution of resonance neutron capture in rods of gold, uranium metal, and uranium diox1de

shown in F1g. 13. Smith et al. ${ }^{5 ?}$ have compared these measurements with the spatial distribution computed by Monte Carlo methods in a metal rod. After volume absorption is added, based on estimated integrals over the unresolved resonances, ${ }^{\mathbf{5 8}}$ the calculations appear to agree very well with the measured spatial distribution of captures. To test the theoretical methods for a simple resonance absorber other 
than uranium, Hardy et al..$^{59}$ have measured the spatial distribution of captures in a 0.387 -in.-diameter gold rod. Comparison of these results with Monte Carlo calculations again indicated the necessity of adding, as a volume term, from 20 to 30 percent of the Monte Carlo resonance integral, presumably to account for relatively unshielded capture at neutron energies above the $250-\mathrm{ev}$ starting energy of the Monte Carlo calculations.

Smith et al. ${ }^{60}$ continued this work with similar measurements in uranium dioxide, uranium-zirconium, and uranium-aluminum rods of the same diameter. All the fuel rods employed in these measurements had the same $\mathrm{U}^{238}$ atom density; this provided data on the effect of neutron moderation and $\mathrm{U}^{238}$ dilution in the fuel rod. The measured change of resonance integral with dilution by zirconium is smaller than that given by Hellstrand' ${ }^{61}$ metal-rod formula, and the ratio of the resonance integral of a 1-cm-diameter oxide rod to that of a similar metal rod is also about 8 percent smaller than one would infer from Hellstrand's metal and oxide formulas.

A series of single-rod resonance-capture measurements has been reported by Hardy et al. ${ }^{62}$ for nine uranium metal and oxide rod diameters. Multigroup calculations were made in an attempt to account and correct for the departure of the hydrogen-moderated spectrum from a $1 / \mathrm{E}$ dependence. The results for the uranium dioxide rods agree closely with Hellstrand's measurements, but the BAPL metal-rod data are systematically higher. These BAPL resonance integral curves predict essentially the same effect of dilution and oxygen scattering as was measured earlier.

As a step toward relating these single-rod results with the lattice measurements of $\rho_{c}^{28}$, Hardy et al.$^{63}$ have measured the Dancoff correction by observing the surface to volume capture ratio in $\mathrm{U}^{238}$ for two lattices loaded in sequence with three different fuel rods of the same diameter but with different uranium densities.

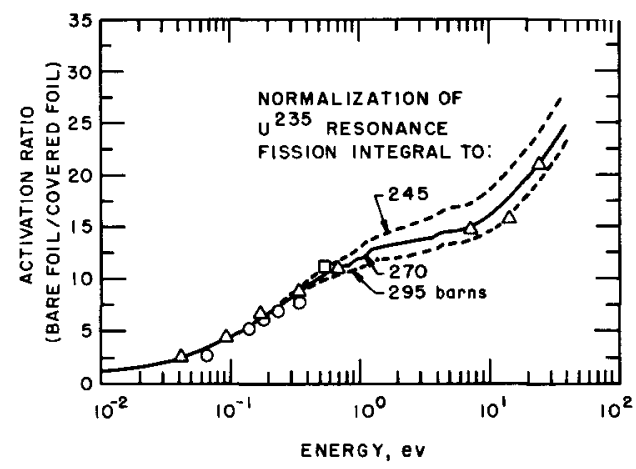

Fig. 14-Experimental and theoretical $U^{235}$ fission activation ratios as a function of filter cutoff energy.

$O$, gadolinium shields

$\triangle$, boron shields

$\square$, cadmium shields 
In a series of measurements on the properties of the important fissile isotopes, Klein ${ }^{64}$ has obtained the $\mathrm{Pu}^{239}$ and $\mathrm{Pu}^{241}$ fission rates relative to $\mathrm{U}^{235}$ in two lattices of $0.387-1$.-diameter metal rods enriched to 1.3 percent in $\mathrm{U}^{235}$. Ratios of the fission rate in $\mathrm{Pu}^{240}$ to those in $\mathrm{Pu}^{239}$ and $\mathrm{Pu}^{241}$ have been given by Volpe and Klein ${ }^{65}$ for the same two lattices. The measurements by Volpe and $\mathrm{Kle}^{23}$ of the fission rates of $\mathrm{U}^{235}$ folls, bare as well as covered by varıous thicknesses of boron, gadolinium, and cadmium filters, have been discussed previously. These fission ratios are compared with calculated values in Fig. 14. This unusual method of using variable neutron filters can probably be exploited with other fissile and fertile isotopes to gain a better understanding of resonance-absorption effects.

\section{Brookhaven National Laboratory}

During the past 12 years, a continuing program of measurements on slightly enriched uranium, water-moderated lattices has been under way at BNL. The principal emphasis of this work has been on the determination of the basic lattice properties, such as the buckling and cell parameters, over a range of configurations. Consequently many other quantities of less general, but more practical, significance in reactor design have been, of necessity, neglected. The initial experiments were performed with uranum-metal fuel rods of large diameter, and, although shortly thereafter uranium dioxide began to develop its present popularity as a reactor fuel, the choice was made to continue measurements with the metal fuel to cover a parametric mesh of four rod diameters, three enrichments, and five water to uranium volume ratios. Two later series of measurements provided similar information on lattices constructed of uranium-metal fuel in the form of flat plates and lattices of uranium dioxide fuel rods.

All of the BNL buckling measurements have been made in exponential assemblies by either the flux-shape or the variable-loading method. In the most recent measurements, both methods have been used, and they have been found to yield slightly, but systematically, different results. Attempts have been made, without much success, to reconcile the results of both methods by introducing anisotropy into the migration area, As was mentioned earlier, an alternate explanation provided by the theory indicates that differenres of the type observed are to be expected and can be traced to the influence of radial-flux transients; whether or not the magnitude of the differences in buckling can be explained on this basis can be settled only by a detailed analysis of the more recent measurements in which these differences have been carefully determined. The comparison of buckling measurements shown in Fig. 21 for the 3.006 percent enriched uranium dioxide fuel used at both BNL in exponentials and B\&W in criticals is typical of the discrepancy found in the data. 
In addition to studies of clean uniform lattices, many measurements of bucklings in assemblies poisoned with boric acid in the moderator have been made. The boron capture of neutrons in the thermal and near-epithermal energy range is compensated for by a change in the neutron leakage that occurs principally in the high-energy range. These poison experiments thus provide a good measure of consistency between two almost completely uncoupled parts of the theoretical description. It is in these measurements that one of the unique advantages of exponential experiments is exploited, for the system can be poisoned down to zero buckling, and the prediction of the infinite medium multiplication can be tested if enough fuel is avallable to provide reasonable relaxation lengths.

The BNL cell-parameter measurements were carried out in a miniature lattice, $12 \mathrm{ln}$. in diameter by $18 \mathrm{ln}$. high, which was surrounded by paraffin and which could be irradiated in a tunnel under the Brookhaven Graphite Research Reactor. The neutron spectrum in these lattices is probably sufficiently close to that of the asymptotic lattice for cell-parameter measurements. The main problem introduced by the small size of the miniature lattice is the short relaxation length $(6$ to $8 \mathrm{~cm}$ ) of the neutron distribution in the direction of the fuel elements, which makes the precise positioning of folls in the assembly very important. In these miniature lattices measurements have been made of the thermal-neutron disadvantage factor with dysprosium foils, the cadmium ratio of $\mathrm{U}^{235}$ and $\mathrm{U}^{238}$ in the fuel, and the fission ratio of $\mathrm{U}^{238}$ to $\mathrm{U}^{235}$. No direct measurements of the modified conversion ratio have been attempted. Instead, values of the conversion ratio itself have been given ${ }^{3}$ which were obtained from the measured $\rho_{c}^{28}$ and $\rho_{f}^{25}$ combined with assumed values of $\alpha^{25}$; these results are probably not as reliable as those which could be obtaned from a direct measurement of MCR and are not included here. The results of the cellparameter measurements are listed in Table 11.

The exponential experiments with uranium-metal fuel were initiated with 0.750-1n.-diameter rods of 1.027 percent enrichment, clad in 0.030-1n.-thick aluminum tubes. Bucklıng and reflector savings ${ }^{9}$ were measured at six water to uranium volume ratios by the variableloading method. A few radial activation shapes, measured with indium folls, gave reflector savings that showed agreement between the two methods within the experimental uncertainty of about $0.5 \mathrm{~cm}$. The next set of fuel elements was of smaller diameter, $0.600 \mathrm{in}$., and included two higher enrichments, 1.143 and 1.299 percent, in addition to the enrichment already used. ${ }^{32}$ This fuel ${ }^{3}$ was subsequently reduced in diameter to $0.387 \mathrm{in}$. and finally to $0.250 \mathrm{in}$. Because some fuel was withdrawn at each step for miniature lattice work, the amount finally avallable for the $0.250-\mathrm{m}$. fueled exponentials was less than that needed to obtain a full range of relaxation lengths. Consequently this last series 
Table 12 - IEASURED RADIAL-REFLECTOR SAVIAGS FOR

UNPOISONED BNL METAL-ROD LATTICES

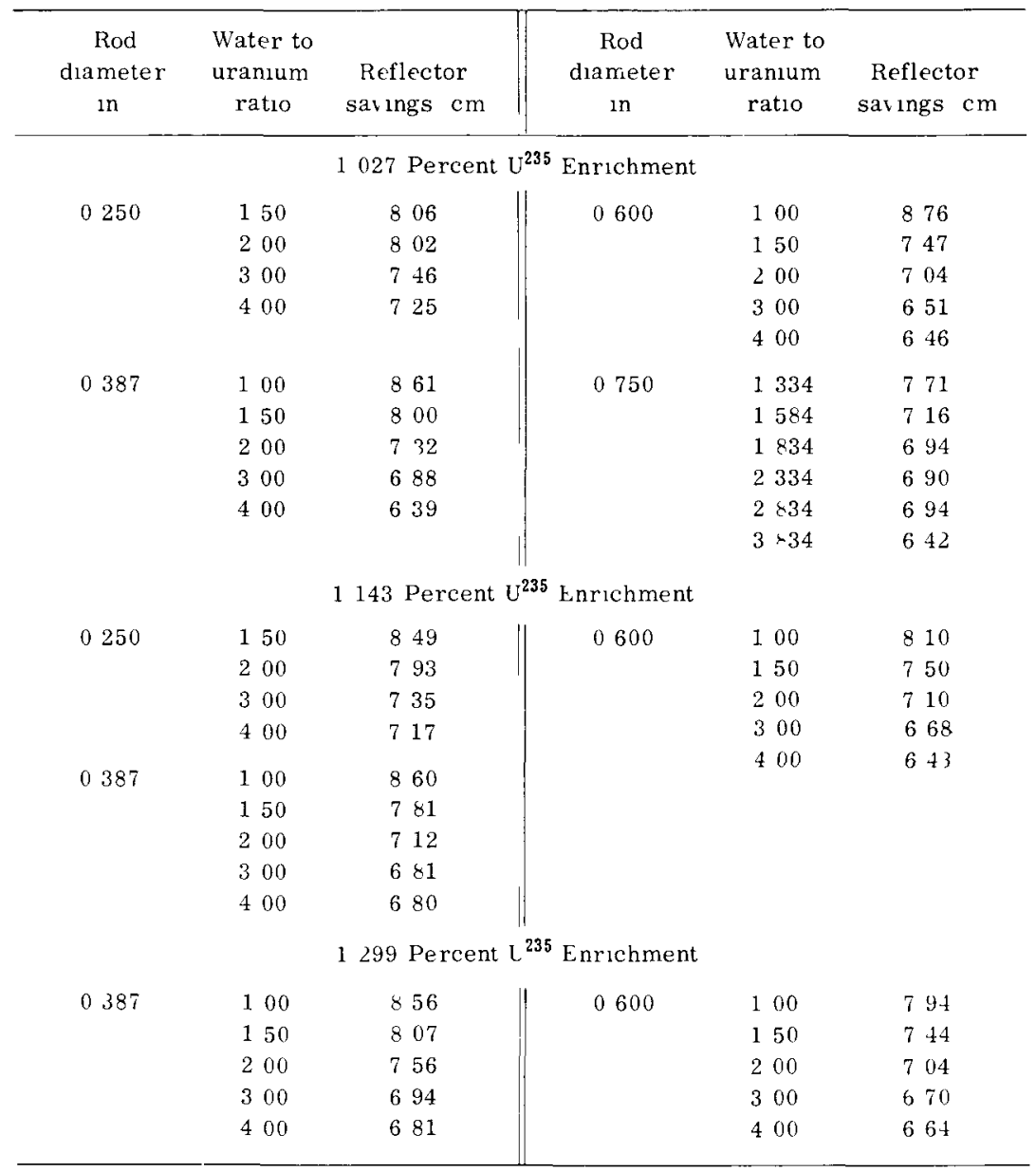

of measurements is believed to be less precise than the earlier measurements at larger fuel-rod sizes. In all the exponential experiments, a general pattern was established of measuring the low buckling lattices by radial activation snapes but of treating the high buckling lattices by the variable-loading method. However, the shortage of fuel rods for the $0.250-\mathrm{in}$. lattices resulted in the use of the variable-loading method exclusively and the elimination of the 1 to 1 volume ratio from this final set. It will be noticed in the summary table (Table 12) that the 1.299 percent enriched fuel was not reduced beyond $0.387 \mathrm{in}$. in diameter.

Results of the buckling measurements for the lowest $(1.027 \%)$ enrichment and four rod sizes are shown in Fig. 15, and the reflector- 


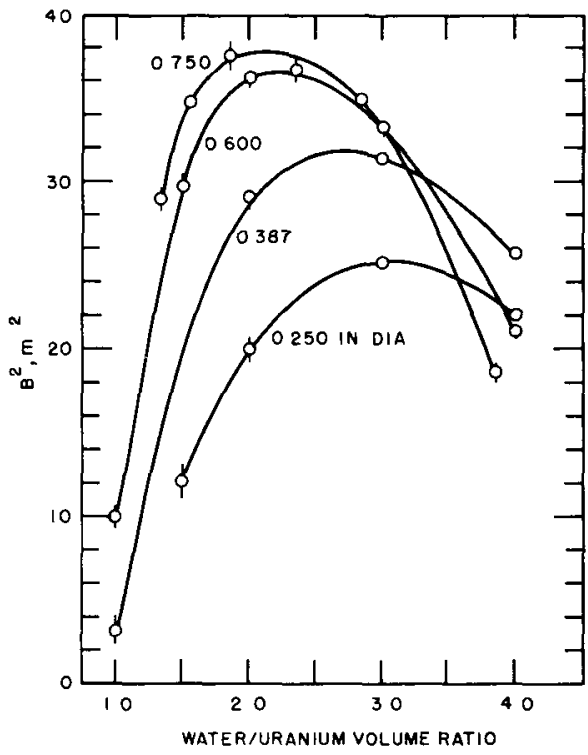

Fig. 15-Material bucklıngs as a function of water to uranium volume ratio for rods of 1.027 percent enriched uranıum metal.

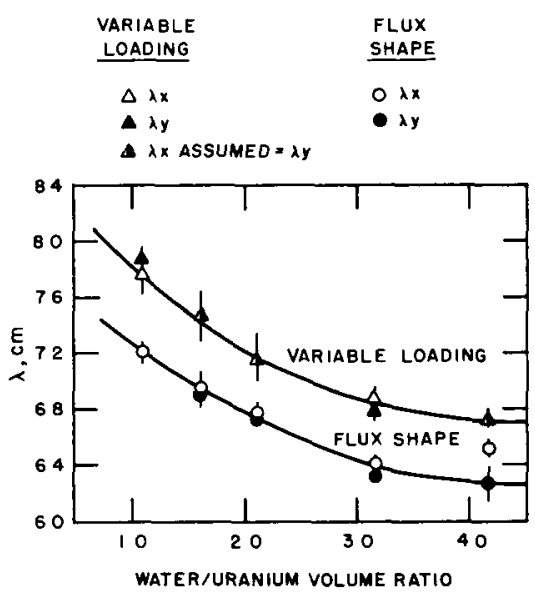

Fig 16- Reflector savings inferred by the variable-loading and flux-shape methods for BNL flat-plate uranummetal lattices.

savings results, without error indications, for all the metal-rod lattices are shown in Table 12. Estımates of errors for Table 12 are given in Table A of the appendix.

After the experiments with uranium-metal rods, a shorter series of measurements was undertaken with unclad flat plates of uranium metal. ${ }^{66}$ These plates were arranged in slab lattices with adjacent plates touching at the edges. Because the lack of cladding made the use of boric acid poison undesirable, the study was limited to clean moderator. The fuel plates used in these measurements were enriched to 1.25 percent and had the linear dimensions of 0.122 by 2 by $48 \mathrm{in}$. Both the variable-loading and flux-shape methods were used with considerable care. The differences in the inferred reflector savings shown in Fig. 16 are thought to be significant, and they result in a difference of 5 to 10 percent in material buckling. Consequently these experiments provide probably the best opportunity to explore the peculiarities of the exponential measurement techniques. In Fig. 16 all reflector savings were calculated with the assumption that the lattice boundaries were the edge of the metal in the $x$, or parallel to the fuel, direction and half a water gap outside the fuel in the $y$ direction.

Another series of exponential experiments with uranium dioxide fuel (3.006 percent enriched) was carried out in parallel with the metalplate work. This fuel, contained in stainless-steel tubes of $0.029 \mathrm{in}$. wall 
thickness, was originally used by the B\&W group in critıcal experiments for the N.S. Savannah reactor. As in the bulk of the metal lattice work, bucklings and reflector savings were measured at five water to uranium ratios (the results are shown in Figs. 21 and 22 along with data from other sources). The differences in fuel dimensions given for this fuel in Table $B$ of the appendix result from different estimates of the average tube thickness, rod diameter, etc., made by $\mathrm{B} \& W$ and BNL. Several difficulties encountered in the analysis of these measurements were eventually traced to two sources: (1) the presence of a spurious source of neutrons in the lattıce, apparently due to photoneutron production in uranium, and (2) in the poisoned lattices a slow variation of boron content in the moderator with time. When these effects were taken into account, a systematic difference was again found between the results of the flux-shape and the variable-loading method (see Fig. 22). The bucklings shown in Tables $B$ and $C$ of the appendix and in Fig. 21 are those inferred by the variable-loading method

\section{Combustion Engineering, Inc., Nuclear Division}

The Nuclear Division of Combustion Engineering, Inc. (CEND), has carried out, under AEC contract, a series of critical experiments with four types of complex uranium dioxide fuel elements intended for use in reactors generating superheated steam. These experiments derive their value from the opportunity they provide to evaluate the capabilities of the theory in treating lattices of multiregion fuel elements containing both internal voids and moderator. The experimental work was divided into two parts comprising first a series of clean one- and two-region cores which were then followed by mock-up experıments on a proposed reactor design. From the first series a group of 12 different lattice configurations can be found which meet the requirements of simplicity we have chosen to follow in this review. The large quantity of data on more complex lattices is not easily summarized, and the reader with particular interests in this type of fuel should consult the original reports. ${ }^{67-72}$

The four types of superheat fuel elements used in the CEND experiments are shown in Fig. 17 and are described in Table $E$ of the appendix. The uranium dioxide fuel of 3.41 (a) and 1.85 (b) enrichment was formed into sintered pellets, whereas the annular (c) and multıtube (d) elements were loaded by vibratory compaction of fused uranium dioxide powder, 2.55 percent enriched. Since the quantity of 3.41 percent enriched fuel was insufficient to achieve criticality as a singleregion system, a three-region rectangular assembly was constructed with outer rows of 1.85 percent enriched fuel driving the central region of 3.41 percent enriched fuel. With the other three fuel elements, criticality measurements were made on single-region uniform lattıces. 

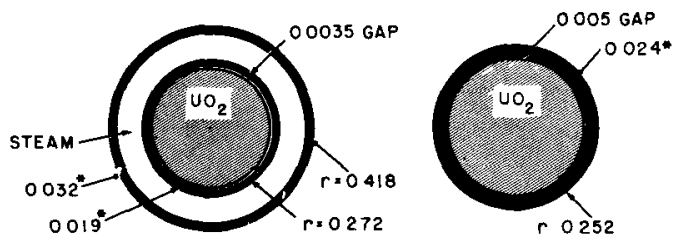

- TUBE THICKNESS

ENRICHMENT, $\% \quad 341$
TUBING $\quad 316 \mathrm{SS}$

(a)
185

$1616 \mathrm{Al}$

(b)

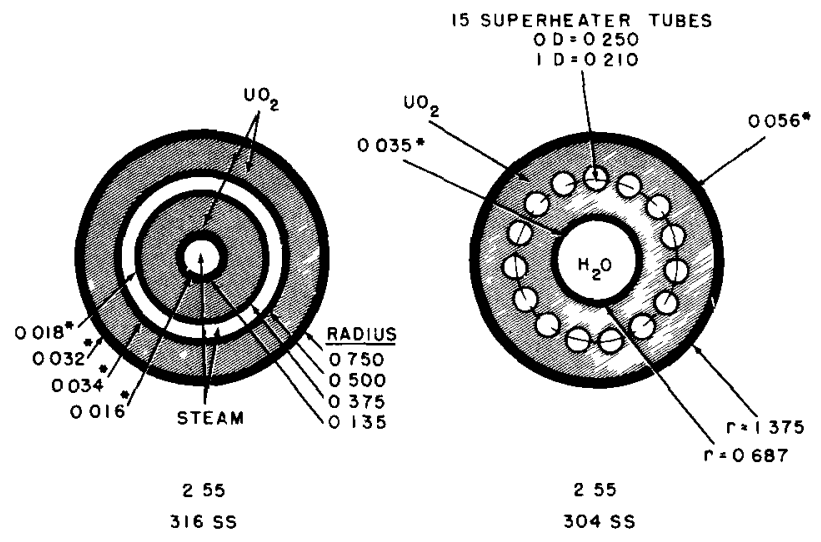

(c)

(d)

ALL DIMENSIONS IN INCHES

Fig. 17 - Fuel-element geometry for the CEND superheat lattıces. 
In all lattices only the axial buckling was measured, so that the worth of the transverse reflector must be computed in any analysis of the experiments.

The clean-lattice measurements can be summarized as follows: Criticality and the cell parameters, $\zeta^{\mathrm{Dy}}$ and $\rho_{\mathrm{c}}^{28}$, were measured for two square lattice pitches with the 1.85 percent enriched fuel. The same cell parameters and the three-region criticality mentioned previously were measured with the 3.41 percent enriched fuel for one square lattice pitch, but with the steam region in both wet and dry conditions. Both the double annular and the annular multitube 2.55 percent enriched fuels were used with two lattice pitches, again with the steam regions wet or dry; at one pitch values of $\xi^{\text {Dy }}$ were measured. The double annular fuel was loaded in a rectangular array on a square lattice; the annular multıtube fuel was loaded into a large hexagonal array on a triangular lattıce.

Table 13 - LATTICE-CELL PARAMETERS (CEND)

\begin{tabular}{|c|c|c|}
\hline Lattice index & $\rho_{c}^{28}$ & $\zeta^{\mathrm{Dy}}$ \\
\hline OA-185-445-123 & $191 \pm 011$ & $117 \pm 005$ \\
\hline 374 & $0780 \pm 0034$ & $130 \pm 004$ \\
\hline $\mathrm{OS}^{*}-341-500-330$ & $135 \pm 013$ & $160 \pm 005$ \\
\hline 450 & $117 \pm 007$ & $167 \pm 004$ \\
\hline
\end{tabular}

Measurements of $\rho_{\mathrm{c}}^{28}$ were attempted in the vibratory-compacted fuel by making test sections of uranium dioxide powder impregnated with Loctite, a polymer of indefinite stoichiometric composition. ${ }^{69}$ However, it is estımated ${ }^{72}$ that this addition of carbon, hydrogen, and oxygen could increase the value of $\rho_{c}^{28}$ in the multitube fuel element by as much as 14 percent. Because rather large deviations from the expected values were found and little time was avallable to develop alternate methods, the measurements of $\rho_{\mathrm{c}}^{28}$ were discontinued. The parameters are shown in Table 13.

\section{General Electric Company, Atomic Power Equipment Department}

The GEAP has recently completed critical experiments ${ }^{14}$ on one type of superheat reactor fuel element as a part of the same USAEC program that sponsored the CEND measurements mentioned earlier. The fuel elements studied at GEAP were constructed of single annular uranium droxide fuel pellets contained between inner and outer tubes of type 304 stainless steel, each element being surrounded by a third concentric steel process tube. The fuel dimensions and arrangement of moderator 


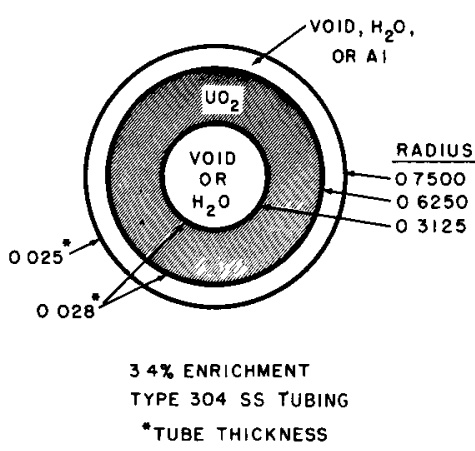

ALL DIMENSIONS IN INCHES
Fig. 18-Fuel-element geometry for the GEAP superheat lattices.

and steam regions are shown in Fig. 18 and are described in Table E of the appendix. The uranium dioxide was enriched to 3.4 percent $U^{235}$, and the pellets were fabricated by adhesive-bonding techniques ${ }^{73}$ to yield a density of $10.2 \mathrm{~g} / \mathrm{cm}^{3}$. Measurements were made in three square lattices of pitch $1.800,1.900$, and 2.00 in., which provided water to fuel ratios of $1.858,2.324$, and 2.816 , respectively, for the unflooded fuel element and $2.713,3.180$, and 3.672 for the completely flooded lattices.

It was apparently not possible to carry out many critical measurements with both steam regions voided because of nuclear safety requirements. An approximation to the voided situation was made by filling the outer steam channel, between the fuel cladding and the process tube, with an aluminum annulus, which would provide heat transfer in case of an excursion without introducing much neutron moderation. The effect of introducing voids into the lattice was observed by inserting thinwalled (0.016 in.) aluminum tubes of 0.252 in. outer diameter in a regular pattern at either of two locations in the lattice cell, i.e., at the interstices of the cell boundary or in the central coolant channel of the fuel element.

The experiments provided critical data on thirteen fully reflected cores, a series of critical and $\partial \rho / \partial \mathrm{h}$ measurements at reduced water height, and measurements of the effect of moderator temperature and voids on the critical moderator height. Axial manganese activation shapes were measured in four lattices and are given in detail in Ref. 14, but the axial-reflector savings were inferred, not from these shapes, but from criticality at reduced moderator height. These measurements have already been mentioned in the discussion of critical experiments as an example of the dependence of axial-reflector savings on the amount of exposed dry core. Results are given for the 1.800-in.-pitch lattice only, but all the measurements of the temperature and void effects have apparently been evaluated by the use of $\partial \rho / \partial \mathrm{h}$ from kinetic experiments rather than by axial buckling. 
Because the thermal-neutron disadvantage factors are so important in these lattices, measurements of the activation of manganese-copper or copper in various regions of the cell were made in four lattices. Because of the many fuel-element regions involved, the results are presented in Table 14 and in Table $E$ of the appendix. The error in the individual activations shown in Table 14 is estimated to be \pm 2 percent. These lattices, in their various flooded and voided configurations, provide an unusually severe test of theoretical methods for computing the space-energy distribition of thermal neutrons.

Table 14 - ANNULAR FUEL DISADVANTAGE FACTORS (GEAP)

\begin{tabular}{|c|c|c|c|c|c|c|c|}
\hline \multirow[b]{2}{*}{ Lattice index } & \multirow[b]{2}{*}{$\mathrm{H}_{2} \mathrm{O}$} & \multicolumn{5}{|c|}{ Specific activity by region (from center) } & \multirow[b]{2}{*}{$\mathrm{H}_{2} \mathrm{O}$} \\
\hline & & $\mathrm{S} \mathrm{S} \dagger$ & $\mathrm{UO}_{2}$ & $\mathrm{~s} \mathbf{s} \dagger$ & $\mathrm{H}_{2} \mathrm{O}$ & $\mathrm{s} \mathrm{s} \dagger$ & \\
\hline OS $-340-1194-186$ & & 0913 & 1000 & 1257 & & 1257 & 1821 \\
\hline $\mathrm{OS}^{*}-340-1194-271$ & 1340 & 1073 & 1000 & 1142 & 1348 & 1540 & 1976 \\
\hline$O S^{*}-340-1194-282$ & & 0910 & 1000 & 1184 & & 1184 & 1912 \\
\hline $\mathrm{OS}^{*}-340-1194-367$ & 1233 & 1047 & 1000 & 1182 & 1427 & 1649 & $211 t$ \\
\hline
\end{tabular}

+Stainless steel

Table 15 - MODIFIED CONVERSION RATIO (GEAP)

\begin{tabular}{cc} 
Lattice index & $\begin{array}{r}\text { Ratio of captures in } \mathrm{U}^{238} \\
\text { to fissions in } \mathrm{U}^{235}\end{array}$ \\
\hline OS-340-1194-186 $^{*}$ & $0399 \pm 0013$ \\
OS $^{*} 340-1194271$ & $0361 \pm 0007$ \\
OS-340-1194-282 & $0332 \pm 0005$ \\
OS*340-1194367 & $0309 \pm 0004$ \\
\hline
\end{tabular}

Instead of measuring $\rho_{c}^{28}$ as an indication of the resonance capture in $\mathrm{U}^{238}$, GEAP has measured the modified conversion ratio at two lattice pitches for both voided and flooded conditions of the fuel element. The results are listed in Table 15. The quoted errors represent the 95 percent confidence range.

\section{General Electric Company, Hanford Laboratories}

An unusually extensive series of experiments has been conducted at the Hanford Laboratories to obtain the critical size of natural and slightly enriched uranium rod lattices moderated by light water. The purpose of the experiments was not primarily to gather data of interest in reactor physics but rather to provide a basis for establishing safe conditions for storing and processing these and similar fuel elements. However, the range of rod sizes and uranium enrichments investigated 
makes them of unusual interest, even though the avallable data concerning any individual lattice are limited and the uncertainties in some of the measurements are larger than they would have been had the original intent of the experiments been the collection of physics information. The results of measurements on 127 lattices with uranium-metal fuel and 6 lattices with uranium dioxide fuel have been reported thus far by the Hanford group.

For the most part the data have consisted of a single measurement of the relaxation length in an exponential experiment at one loading, sometimes coupled with a critical-loading determination from a criticalapproach experiment. The assemblies were fully reflected by water on the sides and top; the bottom reflector was separated from the assembly by an aluminum plate. The neutron source in both types of measurements consisted of from one to four $1 / 2-\mathrm{g}$ radium-beryllium sources.

In the exponential experiments a small boron trifluoride neutron detector was usually used to measure the axial neutron-flux distribution; in some cases indium and gold folls were used in addition to verify these shapes. The radium-berylluum sources were placed at one end of the assembly. The measured relaxation lengths ranged from about 10 to $50 \mathrm{~cm}$ for various lattices. In the cases in which the relaxation length was large, the axial leakage contributed little to the over-all leakage, and the measurements provide the same quality of information as that obtained from critical experiments in which only the axial buckling is measured. The exponential measurements with shorter relaxation lengths require greater precision in the measurement of axial-flux shape because the axial leakage of neutrons into the assembly becomes a more dominant contributor to the neutron cycle.

Approach-to-critical measurements were done with the radiumberyllium neutron source and a $\mathrm{BF}_{3}$ counter, both located near the center of the assembly. Reciprocal counting rates were observed as the number of fuel rods was increased from 85 to 96 percent of the critical size. The critical size was then obtained from an extrapolation of the reciprocal counting rate vs. the number of fuel rods.

For reporting of the data, reflector savings were frequently obtained from approach-to-critical measurements at two values of axial buckling or from a combination of exponential and approach-to-critical measurements. In these measurements one would expect that, although the critical size is well known, there may be a sizable uncertainty in the inferred reflector savings and material bucklings.

Figure 6 shows the reciprocal counting rate in a typical approachto-critical experiment. In addition to showing the response of the central $\mathrm{BF}_{3}$ counter, Fig. 6 indicates the results of a $\mathrm{BF}_{3}$ counte $r$ located outside the assembly. As would be expected, the central $\mathrm{BF}_{3}$ counter gives a more nearly linear approach to the critical loading. 
A typical set of Hanford data 1s shown in Fig. 19, in which buckling values for 3.063 percent enriched uranium-metal rods, clad with plastic, in water are shown for a wide range of water to uranium ratios and various rod sizes. This figure indicates the normal transition of the buckling vs. water to uranium curves, with a peak buckling occurring at a rod diameter of $0.300 \mathrm{in}$. The extremely large values of water to uranium ratios are useful in the evaluation of criticality problems that may be encountered in storing and processing fuel rods rather than in power reactors.

Fig 19- Material buckling as a function of water to uranium volume ratio for metal-rod sizes of 3063 percent enriched uranium fuel

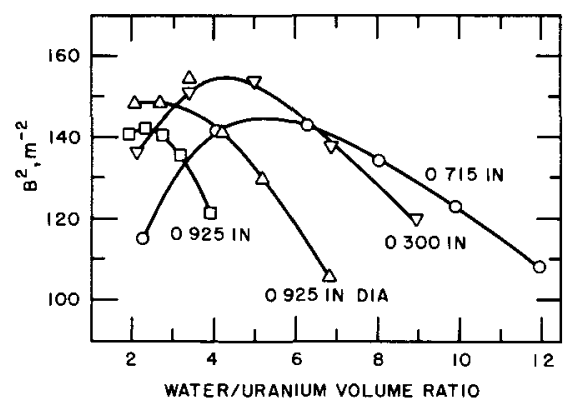

Because of the originally limited purpose of these experiments, no attempts were made to measure cell parameters in any of these lattices.

The Hanford results have been primarily published in quarterly progress reports from 1956 to the present. ${ }^{74-92}$ In addition, one report ${ }^{93}$ lists most of the data avallable.

\section{United Kingdom Atomic Energy Research}

\section{Establishment, Harwell}

An experimental study of slightly enriched uranium lattices moderated with light water was conducted by the AERE between 1953 and 1957 , primarily to develop reactor-physics information. Measurements were made in a series of 21 lattices in which the following parameters were varıed: uranium enrichment, rod diameter, moderator to uranium volume ratio, sheathing material, sheath thickness, moderator density, and temperature. The measurements consisted largely of thermalneutron disadvantage factors and of material bucklings by exponential techniques. In addition, there were some approach-to-critical measurements that are unique in that they extend from about 10 to about 80 percent of the critical mass.

The approach-to-critical technique was employed at Harwel1 $1^{94}$ to ensure safety in constructing the exponential assemblies by estimating not only the critical size but also an appropriate "exponential size" for the material-buckling measurements. Although they were not intended to 
yield precise results, the approach-to-critical experiments indicate the possibility of inferring critical size from very small assemblies with less effort than is required in the exponential experiments described earlier. A typical approach-to-critical curve is shown in Fig. 20. The curve is for a fuel rod $1.2 \mathrm{in}$. in diameter and 1.14 percent enriched. The pitch was 1.85 in., the water to uranium ratio was 1.93, and a spontaneous fission neutron source was used. The curve indicates that $\mathrm{N} / \mathrm{CR}$ is relatively linear with respect to $\mathrm{N}$, where $\mathrm{N}$ is the number of fuel rods and $C R$ is the counting rate of a centrally located $B F_{3}$ counter. An attempt was made to measure the temperature coefficient of reactivity by observing changes in neutron multiplication as the temperature was increased by about $50^{\circ} \mathrm{C}$. The temperature-coefficient measurements ${ }^{94}$ were not satisfactory, however, since the principle change in counting rate was due to the temperature coefficient of the neutron counter.

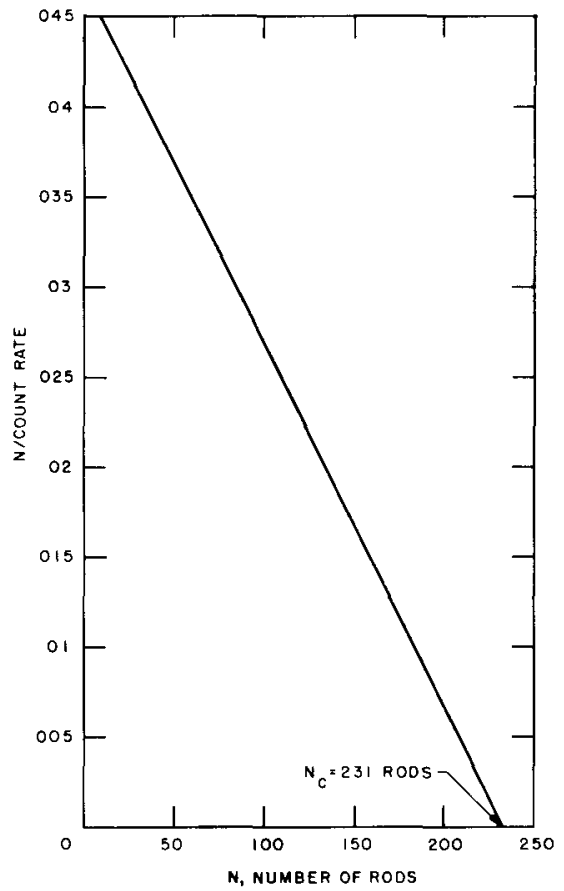

Fig. 20-Typical approach-to-critical curve for uranium-metal-rod lattice.

The material bucklings were obtained from neutron-flux traverses in the exponential experiments along the three major axes of the rectangular parallelepiped assemblies by using either an external antimony-beryllium source or neutrons from a thermal column. These buckling values are recorded in Table $\mathrm{A}$ of the appendix.

The thermal-neutron disadvantage factor was measured by irradiating a $0.020-$ in. manganese wire in a lattice cell and by subsequently 
scanning the wire with a Geiger counter arrangement. ${ }^{95}$ The resulting disadvantage factors are as follows:

\begin{tabular}{cc||cc} 
Lattice index & $\zeta^{\mathrm{Mn}}$ & Lattice index & $\zeta^{\mathrm{Mn}}$ \\
MU-071-0520-142 & 1.158 & MA-093-1200-090 & 1.706 \\
MU-071-0520-199 & 1.181 & MA-093-1200-140 & 1.847 \\
MU-071-0520-367 & 1.268 & MA-093-1200-193 & 1.976 \\
MU-071-1200-099 & 1.571 & MA-114-1200-090 & 1.817 \\
MU-071-1200-201 & 1.804 & MA-114-1200-141 & 1.982 \\
MA-093-0750-085 & 1.323 & MA-114-1200-194 & 2.132 \\
MA-093-0750-184 & 1.425 & &
\end{tabular}

The wires passed through uranium metal, aluminum sheath, and moderator in two directions so that the distribution could be properly averaged over the complete unit cell.

\section{Oak Ridge National Laboratory}

Although homogeneous mixtures of slightly enriched uranium with a hydrogenous moderator are of little practical interest for power reactors, the experiments of this type done at ORNL ${ }^{96}$ are of considerable value in appraising the errors and uncertainties of the theory. Some of the principal uncertaincies in the theoretical description of watermoderated lattices arise from the heterogeneous lattice effects on fast fission, resonance capture, and the thermal-neutron distribution, so that the basic cross-section errors are effectively masked. These lattice effects are avoided in the ORNL experiments while, at the same time, the neutron spectrum is not markedly different from that produced in a heterogeneous assembly.

The only objectionable feature of these homogeneous experiments is the high concentration in the fuel-moderator mixture of fluorine, which is not a normal constituent of the heterogeneous counterparts of these critical assemblies. Thus the analysis of the homogeneous experiments does not provide an entirely unambiguous measure of the heterogeneous lattice effects but, instead, trades these theoretical uncertainties for those of the fluorine neutron cross sections.

The critical assemblies in the ORNL experiments were built of blocks of five different uranium tetrafluoride-paraffin mixtures with the uranium fuel enriched to 2 and 3 percent $\mathrm{U}^{235}$. The hydrogen to uranium atom ratio covers the same range as that of uranium-metal lattices with water to uranium volume ratio between 2.9 and 7.3 . In the mixture with the largest fuel concentration, the atom density of fluorine is a trifle greater than that of hydrogen.

The extrapolation lengths of the unreflected, parallelepipedal assemblies were inferred from the spatial fission-rate distribution mea- 
sured with miniature $\mathrm{U}^{238}$ fission chambers. From these and the assembly dimensions, the bucklings shown in Table 16 were computed.

Table 16 - CRITICAL DATA FOR $\mathrm{UF}_{4}$ - PARAFFIN MIYTURES (ORNL)

\begin{tabular}{lccccc}
\hline $\mathrm{U}^{235}$ enrichment, $\%$ & 2 & 2 & 2 & 2 & 3 \\
Mixture density $\mathrm{g} / \mathrm{cm}^{3}$ & 45 & 393 & 345 & 316 & 446 \\
$\mathrm{UF}_{4}, \mathrm{wt} \%$ & 9213 & 886 & 848 & 820 & 9195 \\
$\mathrm{~N}\left(\mathrm{U}^{235}\right)$, stated value $\times 10^{20}$ & 1613 & 1355 & 1139 & 1009 & 2391 \\
$\mathrm{~N}$ (hydrogen), stated & & & & & \\
$\quad$ value $\times 10^{22}$ & 315 & 398 & 460 & 505 & 319 \\
Hydrogen to $\mathrm{U}^{238}$ ratio & 404 & 608 & 835 & 1034 & 413 \\
Extrapolation distance cm & 272 & 268 & 264 & 260 & 251 \\
Reflector savings cm & 55 & 48 & 42 & 41 & 57 \\
Buckling * m ${ }^{-2}$ & 4344 & 5849 & 6462 & 6466 & 6413 \\
\hline
\end{tabular}

* The total error in buckling is 15 percent

The reflector savings listed represent the change in critical height when 6 in. of paraffin reflector was placed on top of a nearly cubic assembly. Some of the entries in Table 16 are slightly different from those of Ref. 96; we are indebted to J. T. Mihalczo for these recent revisions.

\section{Westinghouse Electric Corporation, Atomic Power Division}

Probably the most extensive series of water-moderated critical experiments with uranium dioxide fuel has been performed by WAPD as an original part and a later outgrowth of work on the Yankee reactor project. The simplicity of the Yankee reactor core design permitted the mock-up experiments to be simple uniform lattice assemblies, perturbed only by the presence of a few cross control rods or their aluminum followers. As a consequence it was possible during the Yankee experiments ${ }^{41}$ to measure buckling and reflector savings in cylindrical assemblies at three water to uranium ratios, in addition to making some measurements of the cell parameters $\xi, \delta_{25}^{28}$, and $\rho_{c}^{28}$. Kinetic experiments were done to yield the change of reactivity with buckling. In all these experiments the uranium dioxide fuel rods of 2.7 percent enrichment were loaded in a square unit cell Beyond these measurements, which are of principal interest here and which are summarized in Tables 17 and 18, a substantial number of other measurements were intended to support the reactor-design activity more directly. These measurements included temperature coefficients; control-rod worth; the intercomparison of the effectiveness of different control-rod materials; the reactivity effect of voids; and the influence of water slots on local power distribution. 
After the Yankee measurements the same fuel was used in a series of buckling, reflector-savings, and cell-parameter measurements in three more widely spaced uniform lattices. This so-called "looselattice" series extended the data with fuel of the Yankee enrichment and rod size as far as a water to uranium dioxide ratio of 5.0. Although this extension is probably well beyond dilutions of practical interest, it is of considerable theoretical value because, at such great fuel-element separation, the neutron spectrum becomes more strongly thermal, and fast-neutron effects become of less importance. As in the earlier measurements, the critical loading for the uniform lattice was extrapolated from two measurements with first two and then four control-rod followers in the core. Both the axial- and radial-reflector savings were obtained from activation shapes of gold foils and fuel rods. Unfortunately, in the loose-lattice experiments, no measurements were made of the change of reactivity with buckling.

Work on the Belgian thermal reactor BR-3 made a loading of uranium dioxide fuel avallable at an enrichment of 4.43 percent. The fuel tubes were again of stannless steel nearly the same diameter as the Yankee fuel tubes, so that the same lattice plates could be used. Singleregion uniform-lattice measurements were made, at two lattice pitches, of critical size, buckling, reflector savings, and cell parameters with the 4.43 percent enriched fuel. ${ }^{42}$ Two-region experiments then followed $^{31}$ which made use of both the BR-3 fuel and the 2.7 percent enriched Yankee fuel to provide critical moderator heights, radial activation plots using gold and depleted uranium foils, and radial power distributions based on measurements of the fission-product activity in the fuel itself.

In the next serıes of experiments, the Multiregion Lattıce Program, the Yankee fuel was again used at two intermediate water to uranum volume ratios, and two additional sets of fuel rods were procured, one set having a higher ( 3.7 percent) and the other a lower ( 1.6 percent) enrichment than the original fuel. The stated purpose of this program was to provide an experimental basis for the evaluation of the theory when applied to clean, multiregion assemblies. It included the study of not only systems with two and three separate zones of enrichment but also single-region systems with absorber sheets of various materials and water slots. No experiments were done in this series in which the assembly contained zones of different water to uranium ratio. One $1 \mathrm{~m}$ portant feature of these experiments was the elimination of aluminum control-rod followers in favor of follower sections that were loaded with fuel of the proper enrichment and lattice pitch so that, on withdrawal of the control rod, the lattice became uniform.

Interest in methods of soluble poison control led to a short series of experiments following the Multiregion Lattice Program to provide information on the change of material buckling and reflector savings 
with the boron content of the moderator. Measurements were made of the critical loading in a lattice having a water to uranium dioxide ratio of 2.2 and fuel of either 2.7 or 3.7 percent enrichment at eight boron concentrations. The axial buckling was measured in each case, but the radial-reflector savings shown in the summary table (Table $\mathrm{C}$ of the appendix) are the results of calculations.

To show the type of data avallable on uranıum dioxide fuel in stainless-steel tubes, we have combined in Fig. 21 the results of WAPD, BNL, B\&W, and ANL measurements of the buckling and in Fig. 22 some of the corresponding reflector savings. Differences in steel-tube wall thickness and rod diameter do not permit simple quantitative intercomparison of the various series of measurements, but the figure is rather instructive, nonetheless. The WAPD bucklings for 2.7 percent enriched fuel are very similar to the BNL data for 3 percent enrichment, but the WAPD data show a peculiar variation with water to uranium dioxide volume ratio, which is probably related to the rise of the WAPD reflector savings at large water to uranium dioxide ratios. The apparent crossing of the WAPD 4.43 percent bucklings with the 3.7 percent data from the same laboratory (curves 4 and 7 of Fig. 21) is odd, but it should be noted that the 4.43 percent bucklings were measured with two aluminum control-rod followers in the core, which probably decrease the buckling by 1 to $3 \mathrm{~m}^{-2}$. In addition, the steel
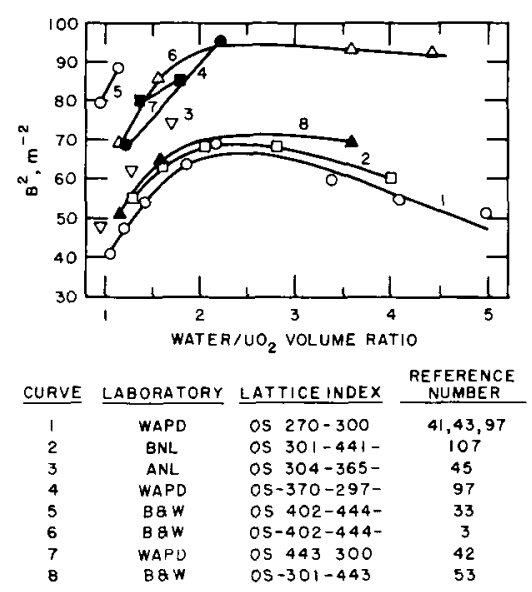

Fig 21-Material buckling as a function of water to uranium dioxide volume ratio for stainlesssteel-clad fuel of various enrichments.

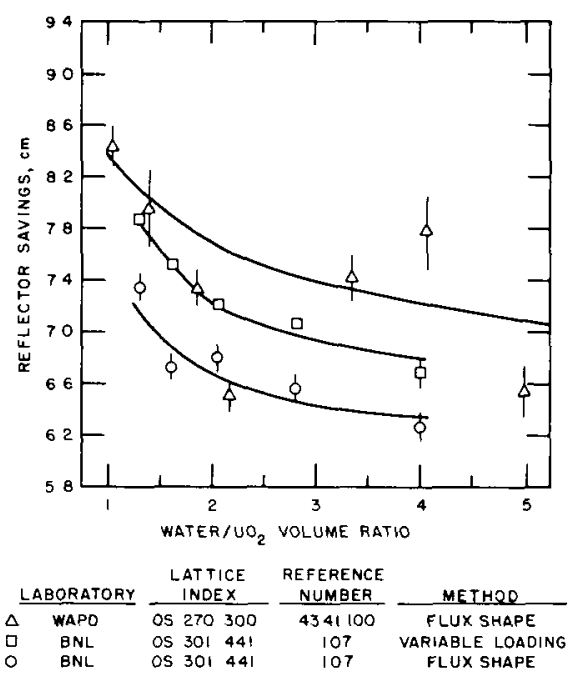

Fig. 22- Reflector savings as a function of water to uranium dioxide volume ratio for uranium dioxide rods in steel tubes. 
Table 17 - LATTICE-CELL PARAMETERS (WAPD)

\begin{tabular}{|c|c|c|c|c|c|c|}
\hline \multicolumn{2}{|c|}{ Lattice index } & $\delta_{25}^{28}$ & $\rho_{\mathrm{c}}^{28}$ & $\rho_{\mathrm{f}}^{25}$ & $\zeta^{25}$ & MCR \\
\hline \multicolumn{2}{|c|}{ OS $-160-297-123$} & $0107 \pm 0006$ & $208 \pm 009 *$ & $0144 \pm 0003 \dagger$ & & $0854 \pm 008$ \\
\hline & 221 & $0072 \pm 0001$ & $125 \pm 001^{*}$ & $0080 \pm 0002 \dagger$ & & $0668 \pm 0018$ \\
\hline \multirow{8}{*}{ OS $270-300$} & 105 & & $277 \pm 008^{\dagger}$ & & $111 \pm 002$ & \\
\hline & 120 & $0097 \pm 0007$ & $278 \pm 016+$ & $0207 \pm 0002 \dagger$ & & $0595 \pm 006$ \\
\hline & 140 & $0076 \pm 0002$ & $222 \pm 005 \dagger$ & $0158 \pm 0002 \dagger$ & $116 \pm 003$ & \\
\hline & 185 & $0060 \pm 0005$ & $183 \pm 010^{\dagger}$ & & $115 \pm 003$ & \\
\hline & 217 & $0066 \pm 0002$ & $172 \pm 007^{*}$ & $0114 \pm 0003 \dagger$ & & $0470 \pm 0010$ \\
\hline & 337 & $0037 \pm 0001$ & $122 \pm 010^{\dagger}$ & $0076 \pm 0002 \dagger$ & $124 \pm 007$ & \\
\hline & 408 & $0037 \pm 0001$ & $106 \pm 006^{\dagger}$ & $0063 \pm 0001 \dagger$ & $122 \pm 002$ & \\
\hline & 498 & & & & & \\
\hline \multirow[t]{2}{*}{ OS 370297} & 123 & $0078 \pm 0005$ & $345 \pm 011^{*}$ & $0267 \pm 0005 \dagger$ & & $0480 \pm 005$ \\
\hline & 221 & $0054 \pm 0002$ & $196 \pm 008^{*}$ & $0156 \pm 0003 t$ & & $0408 \pm 0020$ \\
\hline \multirow{2}{*}{ OS 443300} & 135 & $0070 \pm 0005$ & $416 \pm 035^{\dagger}$ & $0251 \pm 0016 \dagger$ & $122 \pm 003$ & \\
\hline & 179 & $0060 \pm 0004$ & $380 \pm 028 \dagger$ & $0206 \pm 0004 \uparrow$ & $121 \pm 001$ & \\
\hline
\end{tabular}

* Cadmium covers 0010 in thick

tCadmium covers 0020 in thick

fCadmium covers 0012 in thick

tube containing the 4.43 percent fuel is about 35 percent thicker than that of the 3.7 percent fuel. Comment was made earlier on the disagreement shown in Fig. 21 between BNL and $B \& W$ results for the same 3.006 percent fuel.

The results of the cell-parameter measurements are given in Table 17 for the entire series of lattice measurements. In several lattices different values of individual parameters have been quoted as a result of remeasuremert. Rather than average these results, we have chosen to tabulate those values which WAPD apparently favors for comparison with theory. Several points should be mentioned concerning the data shown. The disadvantage factors are given for bare $\mathrm{U}^{235}$ folls, but additional measurements were made in some cases ${ }^{42,43}$ to remove the contribution of epicadmium fissions, the change was usually found to be less than about 3 percent. In the Multiregion Lattice measurements of $\rho_{c}^{28}$, the cadmium covers used (10 to $12 \mathrm{mils}$ ) were unusually thin, some additional measurements were made in one case with cadmium of double thickness $(24 \mathrm{mils})$, and $\rho_{c}^{28}$ was found to decrease by only $3 \pm 1$ percent. Theoretical studies by $W A P D^{40}$ have indicated unusually large disagreements between the $\rho_{c}^{28}$ measurements and corresponding theoretical results. The source of the difficulty has thus far not been identıfied.

The results from the Multiregion Lattice measurements are not summarized in any of our tables because few worthwhile data on these complex assemblies can be given in abbreviated form. However, the geometrical arrangements and core loadings for criticality are given 
Table 18 - DESCRIPTION OF MULTIREGION LATTICES (WAPD)

\begin{tabular}{|c|c|c|c|c|c|c|}
\hline \multirow[b]{2}{*}{ Geometry } & \multirow{2}{*}{$\begin{array}{c}\text { Water to } \\
\text { uranium } \\
\text { dioxide ratio }\end{array}$} & \multicolumn{4}{|c|}{ Fuel rods per region } & \multirow{2}{*}{$\begin{array}{c}\text { Critical water } \\
\text { height } \mathrm{cm}\end{array}$} \\
\hline & & $16 \%$ & $27 \%$ & $37 \%$ & $443 \%$ & \\
\hline 1-A cylindrical & 123 & & 2997 & & & 768 \\
\hline $2-\mathrm{A}$ rectangular & & & 3315 & & & 710 \\
\hline 3-A cylindrical & & & & 1936 & & 593 \\
\hline 4-A cylındrical & & & 3412 & 3648 & & 558 \\
\hline 5-A rectangular & & 3458 & 3404 & 3652 & & 574 \\
\hline 6-A cylindrical & & 1321 & 1604 & 1728 & & 977 \\
\hline 7-A cylındrical & & 1313 & 1604 & 3072 & & 559 \\
\hline 8-A cylindrical & & 1313 & 3576 & & & 1500 \\
\hline 9-A cylindrical & & 1313 & & 2332 & & 1500 \\
\hline 1-B cylındrical & 221 & & 1264 & & & 836 \\
\hline 2-B rectangular & & & 1242 & & & 1100 \\
\hline 3-B cylindrical & & & & 724 & & 953 \\
\hline 4-B cylındrical & & 3529 & 2216 & 2244 & & 450 \\
\hline 5-B rectangular & & 3529 & 2216 & 2244 & & 452 \\
\hline 6-B cylindrical & & 1051 & 1334 & 424 & & 952 \\
\hline 7-B cylındrıcal & & 1051 & 1334 & 444 & & 889 \\
\hline 8-B cylındrical & & 1051 & 1334 & 864 & & 615 \\
\hline 9-B cylındrıcal & & 1051 & 1334 & 1368 & & 537 \\
\hline 10-B cylındiscal & & 1051 & 1334 & 1120 & & 474 \\
\hline 11-B cylındrical & & 2385 & 2276 & & & 921 \\
\hline 12-B cylındrical & & 2401 & & 1592 & & 910 \\
\hline Cylindrical & 140 & & 997 & & 780 & 875 \\
\hline Cylındrical & & & 997 & & 1188 & 623 \\
\hline Cylindrical & 185 & & 795 & & 832 & 602 \\
\hline Cylındrical & & & 795 & & 1300 & 470 \\
\hline
\end{tabular}

in Table 18 to indicate the type and range of the experiments in this series. The loadings were always arranged with the fuel of lowest enrichment in the center and that with the highest on the outside. The interested reader should consult the two reports ${ }^{40,97}$ that provide the data in detail.

\section{ACKNOWLEDGMENTS}

In preparing this review article, we have been assisted by the suggestions and comments of many of the people who have been active in the area of reactor physics discussed here. The number of these contributors is sufficiently great to preclude individual acknowledgments; such acknowledgment would, in fact, nearly duplicate the list of authors cited in the references. We are, however, greatly indebted to these people for their help. 
A large part of the work of collecting the experimental data, sorting out the most recent measurements, and compiling the results has been done by Miss Helen Connell. Such completeness as has been attained in this compilation is largely due to her persistent efforts and to her meticulous attention to detall.

\section{REFERENCES}

1. Light Water Lattices, International Atomic Energy Agency Report STI/ DOC $/ 10 / 12$, November 1962 .

2. H. Kouts, G. Price, K. Downes, R. Sher, and V. Walsh, Exponential Experiments with Slightly Enriched Uranium Rods in Ordinary Water, in Proceedzngs of the Unted Nations Inter national Conference on the Peaceful Uses of Alomic Energy, Genera, 1955, Vol. 5, pp. 183-202, United Nations, New York, 1956.

3. H. Kouts, R. Sher, J. R. Brown, D. Klein, S. Stein, R. L. Hellens, H. Arnold, R. M. Ball, and P. W. Davison, Physics of Slightly Enriched, Normal Water Lattices, in Proceedings of the Second United Nations International Conference on the Peacelul Uses of Atomuc Energy, Gtnera, 1958, Vol. 12, pp. 446-482, United Nations, New York, 1958.

4. C. G. Campbell and I. S. Grant, Critical and Sub-critical Experiments with a Two-group Correlation of Results, in Proceedings of the Second United Nations Internalional Conference on the Peaceful Uses of Atomic Energy, Geneva, 1958, Vol. 12, pp. 728-746, United Nations, New York, 1958.

5. H. Bohl, Jr., E. M. Gelbard, and G. H. Ryan, MUFT-4-Fdst Neutron Spectrum Code for the IBM-704, USAEC Report WAPD-TM-72, Westinghouse Electric Corp., Bettis Plant, July 1957.

6. H. C. Honeck, Thermos. A Thermalization Transport Theory Code for Reactor Lattice Calculations, USAEC Report BNL-5826, Brookhaven National Laboratory, September 1961.

7. R. L. Hellens and H. C. Honeck, in Light Water Lattices, International Atomic Lnergy Agency Report STI/DOC/10/12, p. 27, November 1962.

8. H. C. Honeck, in Light Water Lattices, International Atomic Energy Agency Report STI/DOC/10/12, p. 233, November 1962.

9. H. J. C. Kouts, J. Chernıck, and I. Kaplan, Exponentıal Experıments on Light Water Moderated 1 Per Cent U-235 Lattices, USAEC Report BNL2094, Brookhaven National Laboratory, Nov. 28, 1952.

10. R. L. Hellens and E. Andersen, Some Problems in the Interpretation of Exponentid Experiments, paper presented at the IAEA Symposium on Exponential and Critical Experiments, with Calculations, Amsterdam, September 1963 (to be published), also USAEC Report BNL-7293.

11. A. M. Weinberg and E. P. Wigner, The Physical Theory of Neution Chain Reactors, The University of Chicago Press, Chicago, Ill., 1958.

12. J. R. Brown, D. R. Harris, F. S. Frantz, J. J. Volpe, J. C. Andrews, and B. H. Noordhoff, Kinetic and Buckling Measurements on Latticts of Slightly Enriched Uranium or $\mathrm{UO}_{2}$ Rods, USAEC Report WAPD-176, Westinghouse Electric Corp., Bettis Pldnt, Janudry 1958.

13. D. R. Harris, A Lattice of Slightly Enriched $\mathrm{UO}_{2}$ Fuel Rods Partly Immeised in Light Water, USAEC Report WAPD-TM-114, Westinghouse Electric Corp., Bettis Plant, November 1957. 
14. G. T. Petersen and F. G. Warzek, AEC Superheat Criticals-A Comparison of Experiment and Theory of Uniform Lattices, USAEC Report GEAP3882, General Electric Company, Atomic Power Equipment Department, January 1962.

15. A. F. Henry, Nucl. Scı. Eng., 3- 52 (1958).

16. R. Gwin, D. K. Trubey, and A. M. Weinberg, Experimental and Theoretical Studies of Unreflected Aqueous $U^{235}$ Critical Assemblies, in Proceedings of the Second Untted Nations International Conference on the Peaceful Uses of Atomic Energy, Geneva, 1958, Vol. 12, pp. 529-538, United Nations, New York, 1958.

17. A. Radkowsky and R. T. Bayard, The Physics Aspects of Seed and Blanket Cores with Examples from PWR, in Proceedings of the Second United $\mathrm{Na}$ tions International Conference on the Peaceful Uses of Atomic Energy, Geneva, 1958, Vol. 13, pp. 128-145, United Nations, New York, 1958.

18. S. Glasstone and M. C Edlund, The Elements of Nuclear Reactor Theory, D. Van Nostrand Company, Inc., Princeton, N. J., 1952

19. R. L. Hellens, Neutron Slowing Down in Group Diffusion, USAEC Report WAPD-114, Westinghouse Electric Corp., Bettis Plant, May 1956.

20. J. E. Wilkins, Jr., R. L. Hellens, and P. E Zweifel, Status of Experimental and Theoretical Information on Neutron Slowing-down Distributions in Hydrogenous Media, in Proceedings of the United Nations International Conference on the Peaceful Uses of Atomuc Energy, Geneva, 1955, Vol. 5, pp 62-76, United Nations, New York, 1956

21. G D. Hickman and W. B Leng, Nucl. Scı. Eng., 12. 523 (1962).

22 R W. Stoughton, J. Halperin, and M. P. Lietzke, Nucl. Sc ı. Eng., 6: 441 (1959).

23 J J. Volpe and D. Klein, Nucl. Scı. Eng, 8: 416 (1960).

24 J. J Volpe et al, Nucl. Scl Eng., 5360 (1959).

25 S. Untermyer, Fast Fissions in Natural Uranıum Rods, USAEC Report ANL5070, Argonne National Laboratory, June 12, 1953.

26 D L. Hill, USAEC Report CF-1548, Apr 1, 1944 (Classified)

27 D Klein et al, Nucl. Sc . Eng , 3: 403 (1958)

28 G A. Price, Fast Effect Measurements, USAEC Report BNL-1690, Brookhaven National Laboratory.

29. E Erdik, The Experimental Determination of Fast Fission Factor in Light Water-Moderated, Slightly Enriched Uranium Rod Lattıces, USAEC Report BNL-4715, Brookhaven National Laboratory, Mar. 11, 1960

30 A. H. Futch, Jr., Nucl. Sc . Eng., 561 (1959).

31 V. E. Grob, E. Santandrea, and Hilmar Ritz, Nucl. Sc 2 Eng , 7: 514 (1960).

32 H. J C. Kouts and R. Sher, Experımental Studıes of Slightly Enriched Uranium Moderated Lattices, Part I, USAEC Report BNL-486, Brookhaven National Laboratory, September 1957.

33. T. C. Engelder, N L. Snıdow, R. H. Clark, C. E. Barksdale, R. H. Lewis, and M. N. Baldwin, Spectral Shift Control Reactor Basic Physics Program. Critical Experiments on Lattices Moderated by $\mathrm{D}_{2} \mathrm{O}-\mathrm{H}_{2} \mathrm{O}$ Mixtures, USAEC Report BAK-1231, Babcock and Wilcox Company, December 1961

34. R. Sher, Nucl. Scl. Eng., 7: 478 (1960).

35. B. Arcipianı, D. Ricabarra, and G. Ricabarra, Nucl. Scı. Eng, 14: 316 (1962).

36. H. R. Lutz and Y. Hachiya, Trans Am. Nucl. Soc., 6: 54 (1963). 
37. C. D. Sphar, J. H. Leonard, and P. S. Lacy, Isotopic Analyses of Irradiated Natural Uranium Dioxide Fuel Rods from PWR Core 1 - Preliminary Results, USAEC Report WAPD-TM-280, Westinghouse Electric Corp., Bettis Atomic Power Laboratory, February 1961.

38. A. Radkowsky, in Light Water Lattices, International Atomic Energy Agency Report STI/DOC/10/12, p. 303, November 1962.

39. W. Baer, M. J. Galper, and N. Carbone, Nucl. Sci. Eng., 3: 113 (1958).

40. P. W. Davison, J. D. Cleary, B. Jennings, H. A. Risti, and G. H. Minton, Microscopic Lattice Parameters in Single- and Multi-Region Cores: A Comparison of Theory and Experiment, USAEC Report WCAP-1434, Westinghouse Electric Corp., Atomic Power Department, June 1961.

41. P. W. Davison, S. S. Berg, W. H. Bergmann, D. F. Hanlen, B. Jennings, R. D. Lesmer, and J. E. Howard, Yankee Critical Experiments - Measurements on Lattices of Stainless Steel Clad Slightly Enriched Uranium Dioxide Fuel Rods in Light Water, USAEC Report YAEC-94, Westinghouse Electric Corp., Atomic Power Department, Apr. 1, 1959.

42. P. W. Davison, V. Grob, D. F. Hanlen, R. D. Lesmer, H. Ritz, and E. Santandrea, Two-region Critical Experiments with Water Moderated Slightly Enriched $\mathrm{UO}_{2}$ Lattices, USAEC Report YAEC-142, Westinghouse Electric Corp., Atomic Power Department, Nov. 30, 1959.

43. V. E. Grob, P. W. Davison, D. F. Hanlen, R. D. Leamer, F. L. Kelly, and J. D. Cleary, Multi-region Reactor Lattice Studies, Results of Critical Experiments in Loose Lattices of $\mathrm{UO}_{2}$ Rods in $\mathrm{H}_{2} \mathrm{O}$, USAEC Report WCAP1412, Westinghouse Electric Corp., Atomic Power Department, Mar. 30, 1960.

44. T. Auerbach, The Effect of Foil Holders on the Flux in Uranium-Water Lattices, USAEC Report BNL-370, Brookhaven National Laboratory, November 1955.

45. Q. L. Bairdand and A. R. Boynton, Trans. Am. Nuci. Soc., 6: 248 (1963).

46. R. G. Jarvis, G. J. Phillips, and W. H. Walker, Some Close-packed Lattices in Light Water and Heavy Water. Part 1. Buckling Measurements, Canadian Report CRRP-894, April 1961.

47. W. H. Walker and R. G. Jarvis, Scme Close Packed Lattices in Light and Heavy Water - Spectrum and Fine Structure Measurements, Canadian Report CRRP-895, September 1962.

48. Canadian Report CRRP-896 (to be published).

49. D. B. Wehmeyer, J. M. Doederlein, K. E. Roach, and W. A. Wittkopf, Spectral Shift Control Reactor Basic Physics Program-Theoretical Analysis. Part I. Analysis of Experiments, USAEC Report BAW-1230(Pt. I), Babcock and Wilcox Company, March 1962.

50. L. G. Barrett and J. H. Mortenson, Exponential Experiments on Lattices Moderated by $\mathrm{D}_{2} \mathrm{O}-\mathrm{H}_{2} \mathrm{O}$ Mixtures, USAEC Report BAW-1232, Babcock and Wilcox Company, January 1962.

51. L. G. Barrett, H. J. Worsham, and T. C. Engelder, Spectral Shift Control Reactor Basic Physics Program. Exponential Experiments at Elevated Temperatures on Lattices Moderated by $\mathrm{D}_{2} \mathrm{O}-\mathrm{H}_{2} \mathrm{O}$ Mixtures, USAEC Report BAW-1233, Babcock and Wilcox Company, March 1962.

52. D. M. Roberts and W. G. Pettus, Spectral Shift Control Reactor Basic Physics Program. Age Measurements in $\mathrm{ThO}_{2}-\mathrm{D}_{2} \mathrm{O}-\mathrm{H}_{2} \mathrm{O}$ Lattices, USAEC Report BAW-1234, Babcock and Wilcox Company, December 1961. 
53. D. B. Wehmeyer, in Light Water Lattices, International Atomic Energy Agency Report STI/DOC/10/12, p. 177, November 1962.

54. R. H. Lewis, T. C. Engelder, and D. M. Roberts, Thermal Activation Method for $P_{28}$ Measurements in Slightly Enriched Uranium Dioxide Lattices, USAEC Report BAW-1268, Babcock and Wilcox Company, May 1963.

55. J. Hardy, Jr., J. J. Volpe, D. Klein, E. Schmidt, and E. Gelbard, Thermal Neutron Spectral and Spatial Distributions in Light Water Moderated Lattices, presented at the International Atomic Energy Agency Symposium on Exponential and Critical Experiments with Calculations, Amsterdam, September 1963 (to be published); USAEC Report WAPD-T-1594, April 1963.

56. D. Klein, W. Baer, and G. G. Smith, Nucl Scı. Eng., 3: 698 (1958).

57. G. Smith, J, Hardy, Jr., and D. Klein, Nucl. Scl. Eng, 8. 449 (1960).

58. J. Chernick and R. Vernon, Nucl Scr. Eng, 4- 649 (1958).

59. J. Hardy, Jr., G. G. Smith, and D. Klein, Nucl. Scl. Eng, 7: 263 (1960).

60. G. G. Smith et al., Nucl. Scl. Eng., 9: 421 (1961).

61. E. Hellstrand, J. Appl. Phys., 28. 1493 (1957).

62. J. Hardy, Jr., G. G. Smith, and D. Klein, Nucl. Scı. Eng., 14. 358 (1962)

63. J. Hardy, Jr., et al., Nucl Scı Eng, 12: 301 (1962).

64. D. Klein, $\mathrm{Nucl}$ Scr Eng., 8405 (1960)

65. J. J. Volpe and D. Klein, Nucl. Scr Eng., 10: 401 (1961).

66. H. Windsor, Trans Am. Nucl Soc , 6. 52 (1963)

67. R. S. Hardıng, USAEC Report CEND-115, Combustion Engineering, Inc., 1960

68. J. S. Crudele, C. O. Dechand, P. G. Klann, and W. B Wright, Jr., Studies on Low Enriched Cores Containing Simple Nuclear Superhedt Elements Part I. Critical Experiments, USAEC Report CEND-121, Combustion Eng1neer ing, Inc , Feb. 1, 1961

69. P. G. Klann, C. O. Dechand, and E. Fein, Critıcal Experiments With Low Enriched Double Annular Superheat Elements in Light Water and Their Analysis, USAEC Report CEND-131, Combustion Engineerirg, Inc., December 1961 .

70. W. B. Wright, Jr., USA EC Report CEND-132, Combustion Engineering, Inc., 1961

71 P. G. Klann et al., USAEC Report CEND-161, Combustion Engineering, Ine., 1962

72. P. G. Klann, C. O. Dechand, M. F. Gormley, and J. S. Crudele, Description and Analysis of NUSU Critical Experiments with Annular Multitube Superheater Fuel Elements, USAEC Report CEND-167, Combustion Engineering, Inc., August 1962.

73. W. R. Raymont and D. T. Daniels, Manufacture of the Adhesive Bonded A EC Superheat Critıcal Fuel, USAEC Report GEAP-3591, General Electric Company, Atomic Power Equipment Department, Dec. 9, 1960.

74 E. D. Clayton and E. Z Bloch, Physics Research Quarterly Report for April, May, June 1956, USAEC Report HW-44525, p. 59, Hanford Atomic Products Operation, July 25, 1956.

75. E. Z Bloch, Nuclear Physics Research Quarterly Report for October, November, December 1956, USAEC Report HW-48893, p. 43, Hanford Atomic Proaucts Cperation, Mar. 6, 1957. 
76. E. Z. Bloch, Nuclear Physics Research Quarterly Report for April, May, June 1957, USAEC Report HW-51983, p. 49, Hanford Atomic Products Operation, Aug. 14, 1957.

77. R. C. Lloyd, Nuclear Physics Research Quarterly Report for October, November, December 1957, USAEC Report HW-54591, p. 35, Hanford Atomic Products Operation, Mar. 5, 1958.

78. R. C. Lloyd, Nuclear Physics Research Quarterly Report for January, February, March 1958, USAEC Report HW-55879, p. 9, Hanford Atomic Products Operation, Apr. 29, 1958.

79. N. Ketzlach and R. C. Lloyd, Nuclear Physics Research Quarterly Report for April, May, June 1958, USAEC Report HW-56919, p. 27, Hanford Atomic Products Operation, July 21, 1958.

80. R. C. Lloyd and R. B. Smith, Nuclear Physics Research Quarterly Report for July, August, September 1958, USAEC Report HW-57861, p. 10, Hanford Atomic Products Operation, Oct. 20, 1958.

81. R. C. Lloyd, R. B. Smith, and E. D. Clayton, Nuclear Physics Research Quarterly Report for October, November, December 1958, USAEC Report HW-59126, p. 52, Hanford Atomic Products Operation, Jan. 20, 1959.

82. R. C. Lloyd, Nuclear Physics Research Quarterly Report for January, February, March 1959, USAEC Report HW-60220, p. 55, Hanford Atomic Products Operation, Apr. 20, 1959.

83. R. C. Lloyd, R. B. Smith, and E. D. Clayton, Nuclear Physics Research Quarterly Report for April, Niay, June 1959, USAEC Report HW-61181, p. 52, Hanford Atomic Products Operation, July 20, 1959.

84. R. C. Lloyd, Nuclear Physics Research Quarterly Report for July, August, September 1959, USAEC Report HW-62727, p. 61, Hanford Atomic Products Operation, Oct. 20, 1959.

85. R. C. Lloyd et al., Nuclear Physics Research Quarterly Report for October, November, December 1959, USAEC Report HW-63576, p. 65, Hanford Atomic Products Operation, Jan. 20, 1960.

86. R. C. Lloyd, E. D. Clayton, and R. B. Smith, Nuclear Physics Research Quarterly Report for January, February, March 1960, USAEC Report HW64866, p. 143, Hanford Atomic Products Operation, Apr. 20, 1960.

87. R. C. Lloyd, Nuclear Physics Research Quarterly Report for April, May, June 1960, USAEC Report HW-66215, p. 34, Hanford Atomic Products Operation, July $20,1960$.

88. R. C. Lloyd and E. D. Clayton, Nuclear Physics Research Quarterly Report for July, August, September 1960, USAEC Report HW-67219, p. 104, Hanford Atomic Products Operation, Oct. 20, 1960.

89. R. C. Lloyd, E. D. Clayton, and R. B. Smith, Nuclear Physics Research Quarterly Report for July, August, September 1959, USAEC Report HW62727 , p. 59, Hanford Atomic Products Operation, Oct. 20, 1959.

90. E. Z. Bloch and E. D. Clayton, Nuclear Physics Research Quarterly Report for July, August, September 1956, USAEC Report HW-47012, p. 12, Hanford Atomic Products Operation, Nov. 5, 1956.

91. R. C. Lloyd, E. D. Clayton, and B. L. Jones, Nuclear Physics Research Quarterly Report for April, May, June 1960, USAEC Report HW-66215, p. 30, Hanford Atomic Products Operation, July 20, 1960. 
92 T. J Powell, Nuclear Physics Research Quarterly Report for July, August, September 1960, USAEC Report HW-67219, p 100, Hanford Atomic Products Operation, Oct 20,1960

93. R. C Lloyd, Summary Listing of Subcritical Measurements of Heterogeneous Water-Uranıum Lattices Made at Hanford, USAEC Report HW-65552, Hanford Atomic Products Operation, June 8, 1960

94. V. S Crocker, W. G Davey, and K. R E Smith, Approach to Critical Experiments with Slightly Enriched Uranium in Natural Water, British Report AERE-RP/R-1810, July 1957

95. W G. Davey, The Experimental Basis of Lattice Calculations for Natural Water Moderated Assemblies, British Report AERE-RP/R-1842, December 1955

$96 \mathrm{~J}$ Mihalczo and C B Mills, Nucl Scr Eng, 1195 (1961)

97 W J Eich and W P Kovacik, Reactivity and Neutron Flux Distribution Studies in Multı-region Loaded Reactor Cores, USAEC Report WCAP-1433, Westinghouse Electric Corp , Atomic Power Department, June 1961

98 W G Davey, D A Newmarch, K R E Smith, M J Mitchell, and A C Clark, Exponential Experiments with Natural Uranium-Natural Water Systems, British Report AERE-RP/R-1787, September 1955

99 G Branch, $H$ Jones, $J$ H Rush, and A M Weinberg, Water Lattice Experiments Final Report on P A N PX10-2, USAEC Report CP-2842, Clınton Laboratories, June 30, 1945

$100 \mathrm{~T}$ Arnette et al, Exponential Experıments with Water-Metal Rod Lattices, USAEC Report CP-2048, Clinton Laboratories, Oct 3, 1944

$101 \mathrm{H}$ J C Kouts et al, $J$ Nucl Energy 2 141 (1955)

$102 \mathrm{R}$ Persson, Nucleonics, 1226 (1954)

103 W G Davey and K R E Smith, Exponential Experiments with Enriched Uranium-Natural Water Systems, British Report AERE-RP/R-1788, October 1955

$104 \mathrm{~J}$ K Fox and L W Gilley, Neutron Physies Division Annual Progress Report for Period Ending September 1, 1959, USAEC Report ORNL-2842, p 71, Oak Ridge National Laboratory, Nov 16, 1959

$105 \mathrm{H}$ Windsor, Brookhaven National Laboratory, private communication, Sept 4, 1962

106 R H Clark et a1, Spectral Shıft Control Reactor-Basic Physics Program Quarterly Technical Report No 8, July-September 1962, USAEC Report BAW-1262, p 3, Babcock and Wilcox Company

107. S Krasik and A Radkowsky, Pressurized Water Reactor (PWR) Critical Experiments, in Proceedings of the United Nations International Conference on the Peaceful Uses of Atomic Energy, Geneva, 1955 Vol 5, pp 203-214, United Nations, New York, 1956

108. D B Wehmeyer and K E Roach, $J$ Nucl Energy, 14189 (1961)

109. A L MacKınney and R M Ball, Trans Am Nucl Soc, 3 72 (1960) 


\section{APPENDIX: GEOMETRY AND BUCKLING TABLES}

Table A - GEOMETRIES AND BUCKLINGS FOR CLEAN UNFORM URANIUM METAL LATTICES

\begin{tabular}{|c|c|c|c|c|c|c|c|c|c|c|c|c|c|c|c|}
\hline \multirow{2}{*}{\multicolumn{2}{|c|}{ Lattice index }} & \multirow[b]{2}{*}{$\begin{array}{c}\text { Enrich- } \\
\text { ment } \\
\%\end{array}$} & \multirow{2}{*}{$\begin{array}{c}\text { Fuel diam } \\
\text { eter or } \\
\text { thickness } \\
\text { in }\end{array}$} & \multirow[b]{2}{*}{$\begin{array}{c}\text { Fuel } \\
\text { density } b \\
\mathrm{~g} / \mathrm{cm}^{3}\end{array}$} & \multicolumn{3}{|c|}{ Cladding } & & \multirow[b]{2}{*}{$\begin{array}{l}\text { Water to } \\
\text { uranium } \\
\text { rat } 10^{d}\end{array}$} & \multirow[b]{2}{*}{ Method $^{e}$} & \multirow[b]{2}{*}{$\begin{array}{l}\text { Reflector } \\
\text { savings } \\
\mathrm{cm}\end{array}$} & \multirow[b]{2}{*}{$\begin{array}{c}\text { Buckling } \\
\mathrm{m}^{-2}\end{array}$} & \multirow[b]{2}{*}{$\begin{array}{l}\text { Lab } \\
\text { oratory }\end{array}$} & \multirow[b]{2}{*}{ Ref } \\
\hline & & & & & Materialc & $O D$ in & $\begin{array}{l}\text { Thick } \\
\text { ness } \\
\text { in }\end{array}$ & Geometry & $\begin{array}{l}\text { Pitch } \\
\text { in }\end{array}$ & & & & & & \\
\hline MA-026 1280 & $\begin{array}{l}086 \\
233 \\
683\end{array}$ & 026 & 128 & 1895 & $\mathrm{Al}$ & 1375 & 0040 & Square & $\begin{array}{ll}1 & 60 \\
2 & 11 \\
3 & 20\end{array}$ & $\begin{array}{l}0859 \\
233 \\
683\end{array}$ & $\mathbf{E}$ & & $\begin{array}{l}-1216 \pm 34 \\
-1302 \pm 16 \\
-1862 \pm 34\end{array}$ & AECL & 46 \\
\hline MU $\begin{array}{lll}071 \quad 5201 \\
& & 1\end{array}$ & $\begin{array}{l}142 \\
199\end{array}$ & 0714 & 052 & 1840 & None & & & Square & $\begin{array}{l}072 \\
080\end{array}$ & $\begin{array}{l}1423 \\
1990\end{array}$ & $\mathbf{E}$ & & $\begin{array}{l}-96 \pm 10 \\
-32 \pm 10\end{array}$ & Harwell & $95 \quad 98$ \\
\hline MU $071-787-1$ & $\begin{array}{l}150 \\
180 \\
210\end{array}$ & 0714 & 0787 & $?$ & None & & & $\begin{array}{c}\text { Trian- } \\
\text { gular }\end{array}$ & $\begin{array}{ll}1 & 141 \\
1 & 266 \\
1 & 328\end{array}$ & $\begin{array}{ll}1 & 50 \\
1 & 80 \\
2 & 10\end{array}$ & $\mathbf{E}$ & & $\begin{array}{l}-660 \\
-278 \\
-329\end{array}$ & ORNL & 99 \\
\hline MA $-071-787-2$ & 201 & 0714 & 0787 & $?$ & $\mathrm{Al}$ & 15 & $\sim 0025$ & $\begin{array}{l}\text { Trian- } \\
\text { gular }\end{array}$ & 1781 & 201 & $\mathbf{E}$ & & 00 & ORNL & 99 \\
\hline MP-071-925-1 & $\begin{array}{l}-137 \\
189 \\
229\end{array}$ & 0714 & 0925 & 1891 & $\mathbf{P}$ & 1002 & 0031 & $\begin{array}{l}\text { Trian- } \\
\text { gular }\end{array}$ & $\begin{array}{l}1400 \\
1500 \\
1600\end{array}$ & $\begin{array}{ll}1 & 37 \\
1 & 89 \\
2 & 29\end{array}$ & $\mathbf{E}$ & $\begin{array}{ll}7 & 56^{f} \\
7 & 16^{f} \\
6 & 96^{f}\end{array}$ & $\begin{array}{r}00 \pm 055^{f} \\
-024 \pm 061^{f} \\
-367 \pm 040^{f}\end{array}$ & Hanfo.d & 87 \\
\hline MA-071 1100 & $\begin{array}{l}142 \\
149 \\
156 \\
157 \\
192 \\
206\end{array}$ & 0714 & 110 & 8 & $\begin{array}{l}\text { Al } \\
\text { Al-gap-Al } \\
\text { Al } \\
\text { Al-gap-Al } \\
\text { Al }\end{array}$ & $\begin{array}{ll}1 & 25 \\
1 & 300 \\
2 & 00 \\
1 & 25 \\
2 & 00 \\
1 & 25\end{array}$ & $\begin{array}{rrr}0 & 035 \\
0 & 050 \\
\sim & 0 & 086 \\
0 & 035 \\
\sim & 0 & 086 \\
0 & 035\end{array}$ & $\begin{array}{l}\text { Trian- } \\
\text { gular }\end{array}$ & $\begin{array}{ll}1 & 72 \\
1 & 779 \\
2 & 313 \\
1 & 72 \\
2 & 400 \\
1 & 875\end{array}$ & $\begin{array}{ll}1 & 42 \\
1 & 488 \\
1 & 56 \\
1 & 57 \\
1 & 92 \\
2 & 06\end{array}$ & $\mathbf{E}$ & $771 \pm 025$ & $\begin{array}{c}-339 \\
-166 \pm 028 \\
+027 \\
-355 \\
-020 \\
-801\end{array}$ & $\begin{array}{l}\text { ORNL } \\
\text { BNL } \\
\text { ORNL }\end{array}$ & $\begin{array}{l}100 \\
101 \\
99 \\
100 \\
99 \\
100\end{array}$ \\
\hline MU 0711180 & $\begin{array}{l}178 \\
317\end{array}$ & 0714 & 118 & $?$ & None & & & $\begin{array}{l}\text { Truan- } \\
\text { gular }\end{array}$ & $\begin{array}{c}1875 \\
?\end{array}$ & $\begin{array}{l}178 \\
317\end{array}$ & $\mathbf{E}$ & & $\begin{array}{r}-379 \\
-3495\end{array}$ & ORNL & 100 \\
\hline MA 0711184 & $\begin{array}{l}204 \\
269 \\
339 \\
416\end{array}$ & 0714 & 1184 & 7 & $\mathrm{Al}$ & $\sim 121$ & 00118 & $\begin{array}{l}\text { Trian- } \\
\text { gular }\end{array}$ & $\begin{array}{ll}1 & 9685 \\
2 & 1654 \\
2 & 3622 \\
2 & 5591\end{array}$ & $\begin{array}{ll}2 & 042 \\
2 & 686 \\
3 & 390 \\
4 & 156\end{array}$ & $E$ & & $\begin{array}{r}-6 \pm 4 \\
-18 \pm 5 \\
-35 \pm 5 \\
-54 \pm 5\end{array}$ & AA Sweden & 102 \\
\hline MU 071-1200- & $\begin{array}{r}-099 \\
201 \\
328\end{array}$ & 0714 & 1200 & 1888 & None & & & Square & $\begin{array}{ll}1 & 5 \\
1 & 846 \\
2 & 20\end{array}$ & $\begin{array}{ll}0 & 99 \\
2 & 01 \\
3 & 28\end{array}$ & $\mathrm{E}$ & & $\begin{array}{r}-36 \pm 12 \\
-21 \pm 12 \\
-394 \pm 18\end{array}$ & Harwell & 9598 \\
\hline
\end{tabular}




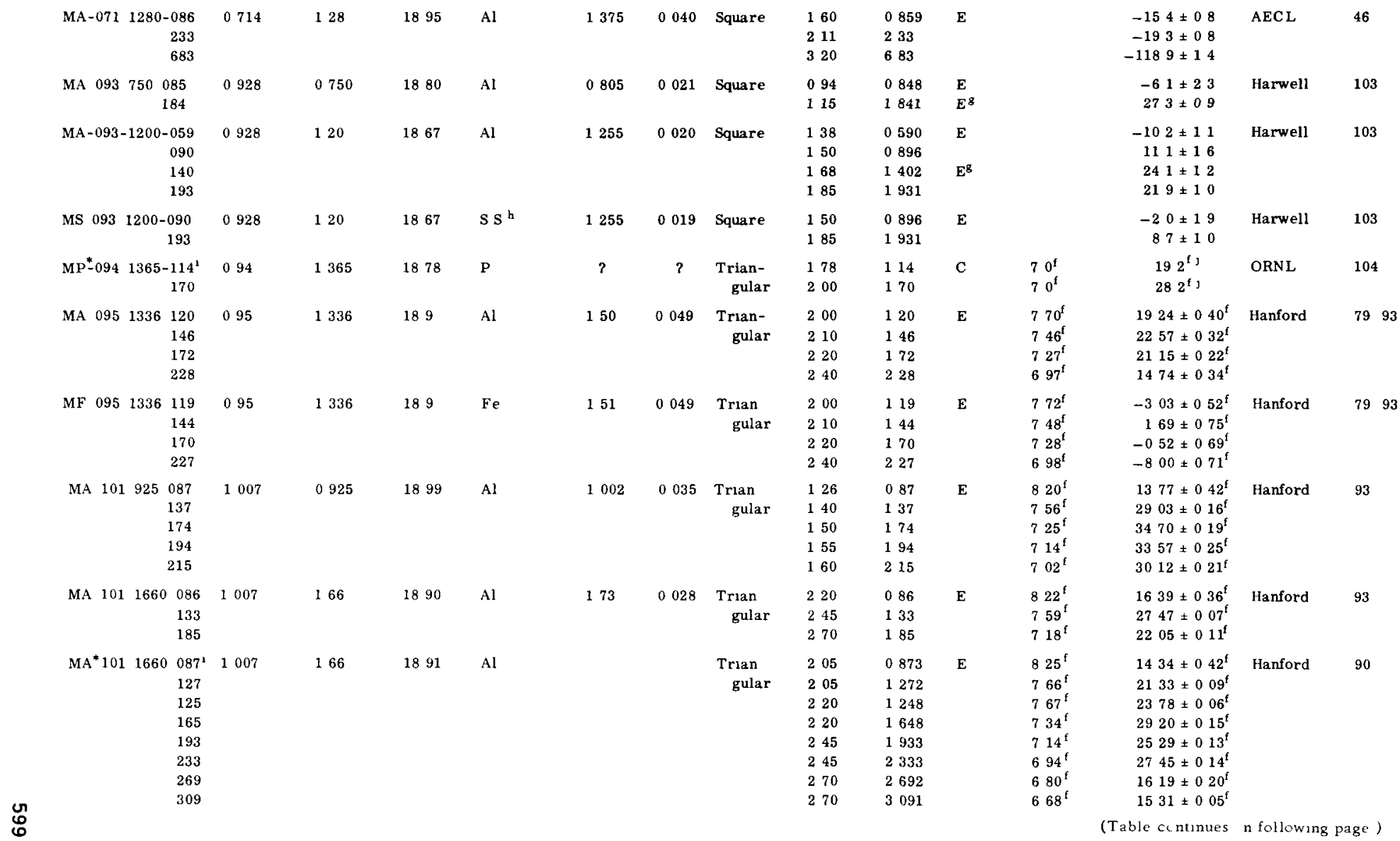




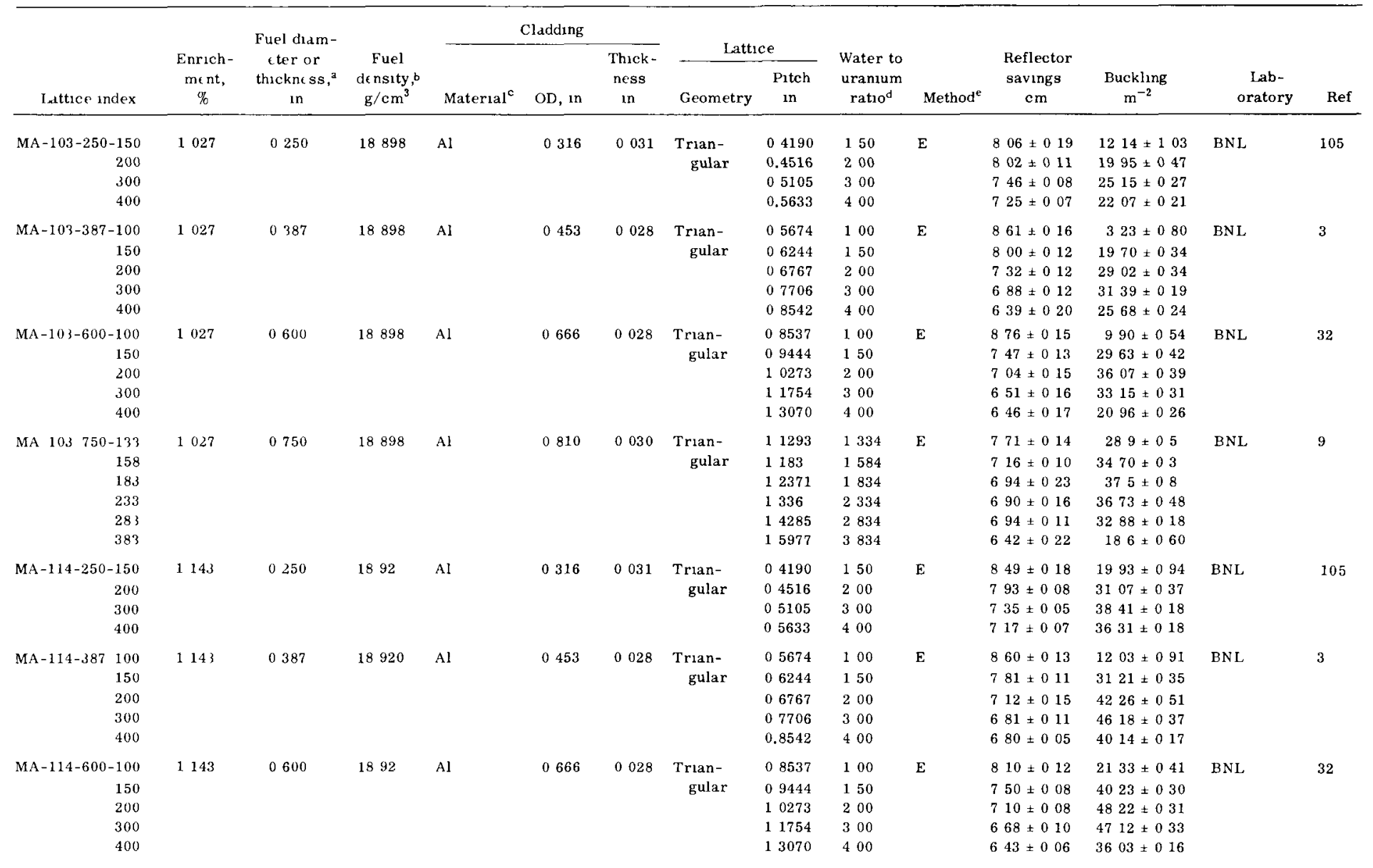




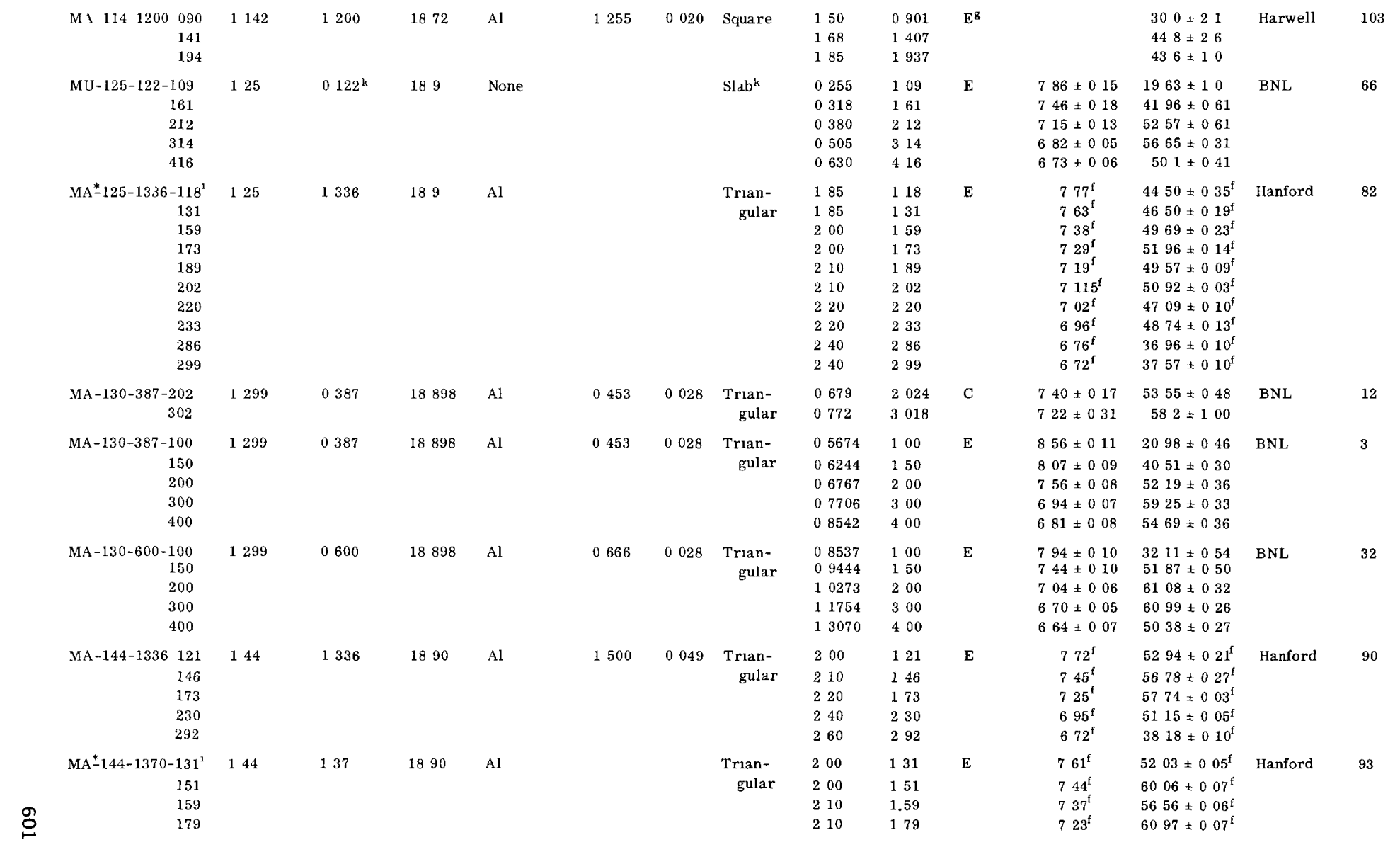


Table A-(Contınued)

\%

\begin{tabular}{|c|c|c|c|c|c|c|c|c|c|c|c|c|c|c|}
\hline \multirow[b]{3}{*}{ Lattice index } & \multirow{3}{*}{$\begin{array}{c}\text { Enrich- } \\
\text { ment, } \\
\%\end{array}$} & \multirow{3}{*}{$\begin{array}{c}\text { Fuel diam- } \\
\text { eter or } \\
\text { thickness, } \\
\text { in. }\end{array}$} & \multirow{3}{*}{$\begin{array}{c}\text { Fuel } \\
\text { density, } \\
\mathrm{g} / \mathrm{cm}^{3}\end{array}$} & \multicolumn{3}{|c|}{ Claddıng } & \multirow{2}{*}{\multicolumn{2}{|c|}{ Lattice }} & \multirow{3}{*}{$\begin{array}{c}\text { Water to } \\
\text { uranium } \\
\text { ratio }\end{array}$} & \multirow[b]{3}{*}{ Method $^{\mathbf{e}}$} & \multirow{3}{*}{$\begin{array}{l}\text { Reflector } \\
\text { savings, } \\
\text { cm }\end{array}$} & \multirow[b]{3}{*}{$\begin{array}{c}\text { Buckling, } \\
\mathrm{m}^{-2}\end{array}$} & \multirow[b]{3}{*}{$\begin{array}{c}\text { Lab- } \\
\text { oratory }\end{array}$} & \multirow[b]{3}{*}{ Ref } \\
\hline & & & & & & Thick- & & & & & & & & \\
\hline & & & & Material $^{c}$ & OD, in & $\begin{array}{c}\text { ness, } \\
\text { in. }\end{array}$ & Geometry & $\begin{array}{l}\text { Pitch, } \\
\text { in. }\end{array}$ & & & & & & \\
\hline 187 & & & & & & & & 220 & 187 & & $7.17^{1}$ & $5708 \pm 006^{\mathrm{f}}$ & & \\
\hline 207 & & & & & & & & 2.20 & 207 & & $707^{i}$ & $6048 \pm 0.07^{\S}$ & & \\
\hline 249 & & & & & & & & 2.40 & 249 & & $689^{f}$ & $51.31 \neq 014^{\mathrm{f}}$ & & \\
\hline 269 & & & & & & & & 2.40 & 269 & & $681^{1}$ & $5237 \pm 006^{\mathrm{f}}$ & & \\
\hline 316 & & & & & & & & 260 & 316 & & $666^{f}$ & $3797 \pm 015^{\mathrm{f}}$ & & \\
\hline 336 & & & & & & & & 2.60 & 3.36 & & $663^{\mathrm{f}}$ & $3696 \pm 008^{f}$ & & \\
\hline $\mathrm{MA}^{*}-147-1394-139^{1}$ & 1466 & 1.394 & 18.90 & $\mathrm{Al}$ & & & Trian- & 200 & 1.39 & $\mathbf{E}$ & $752^{f}$ & $\left.5946 \pm 040 f_{1}\right]$ & Hanford & 76 \\
\hline 165 & & & & & & & gular & 210 & 1.65 & & $732^{f}$ & $6360 \pm 005^{f}$ & & \\
\hline 192 & & & & & & & & 2.20 & 1.92 & & $714^{4}$ & $6325 \pm 070^{f, j}$ & & \\
\hline 251 & & & & & & & & 2.40 & 2.51 & & $686^{f}$ & $5695 \pm 0.90^{\mathrm{f}, \mathrm{J}}$ & & \\
\hline 315 & & & & & & & & 2.60 & 3.15 & & $667^{f}$ & $4366 \pm 090^{f_{3}}$ & & \\
\hline$M A^{*}-160-1394-125$ & 1.6 & 1,394 & 1886 & $\mathrm{Al}$ & & & Trıan- & 2.00 & 1.25 & $\mathrm{E}$ & $7.65^{f}$ & $6033 \pm 0.14^{f}$ & Hanford & 93 \\
\hline 137 & & & & & & & gular & 2.00 & 1.375 & & $753^{f}$ & $6605 \pm 007^{f}$ & & \\
\hline 151 & & & & & & & & 2.10 & 1.512 & & $7.45^{f}$ & $64.83 \pm 0.10^{f}$ & & \\
\hline 164 & & & & & & & & 2.10 & 1.637 & & $7.35^{f}$ & $6941 \pm 004^{f}$ & & \\
\hline 179 & & & & & & & & 2.20 & 1.79 & $E^{\mathrm{g}}$ & $7.25^{f}$ & $65.89 \pm 0.03^{f, j}$ & & \\
\hline 191 & & & & & & & & 2.20 & 1.91 & $\mathrm{E}^{\mathrm{g}}$ & $7.14^{f}$ & $70.00 \pm 0.07^{f}$ & & \\
\hline 237 & & & & & & & & 2.40 & 2.373 & $E^{\mathbb{g}}$ & $6.93^{f}$ & $61.36 \pm 010^{f}$ & & \\
\hline 250 & & & & & & & & 2.40 & 2.497 & $\mathrm{E}$ & $6.88^{f}$ & $64.50 \pm 0.01^{f}$ & & \\
\hline 301 & & & & & & & & 2.60 & 3.011 & & $6.70^{\mathrm{f}}$ & $4937 \pm 002^{\mathrm{f}}$ & & \\
\hline 313 & & & & & & & & 2.60 & 3.135 & & $6.68^{i}$ & $5125 \pm 010^{f}$ & & \\
\hline MP-200-600-206 & 2.00 & 0.600 & 18.82 & $P$ & $\sim 0.662$ & 0.031 & Trian- & 1.00 & 206 & $\mathrm{E}$ and & 684 & 106.60 & Hanford & 88 \\
\hline 271 & & & & & & & gular & 1.10 & 271 & AC & 6.78 & 110.47 & & \\
\hline 341 & & & & & & & & 1.20 & 3.41 & & 6.32 & 110.12 & & \\
\hline 418 & & & & & & & & 1.30 & 4.18 & & 6.18 & 102.18 & & \\
\hline 518 & & & & & & & & 1.42 & 518 & & 6.14 & 8769 & & \\
\hline 684 & & & & & & & & 1.60 & 6.84 & & 5.72 & 6185 & & \\
\hline MP $-200-925-189$ & 2.00 & 0.925 & 18.95 & $\mathbf{P}$ & $\sim 0.987$ & 0.031 & Trian- & 1.50 & 1.89 & $\mathrm{E}$ and & 6.46 & 107.35 & Hanford & 91 \\
\hline 229 & & & & & & & gular & 1.60 & 2.29 & $\mathrm{AC}$ & 594 & 111.31 & & \\
\hline 272 & & & & & & & & 1.70 & 2.72 & & 620 & 104.51 & & \\
\hline 317 & & & & & & & & 180 & 3.17 & & 6.07 & 9828 & & \\
\hline 389 & & & & & & & & 1.95 & 3.89 & & 5.44 & 87.77 & & \\
\hline
\end{tabular}




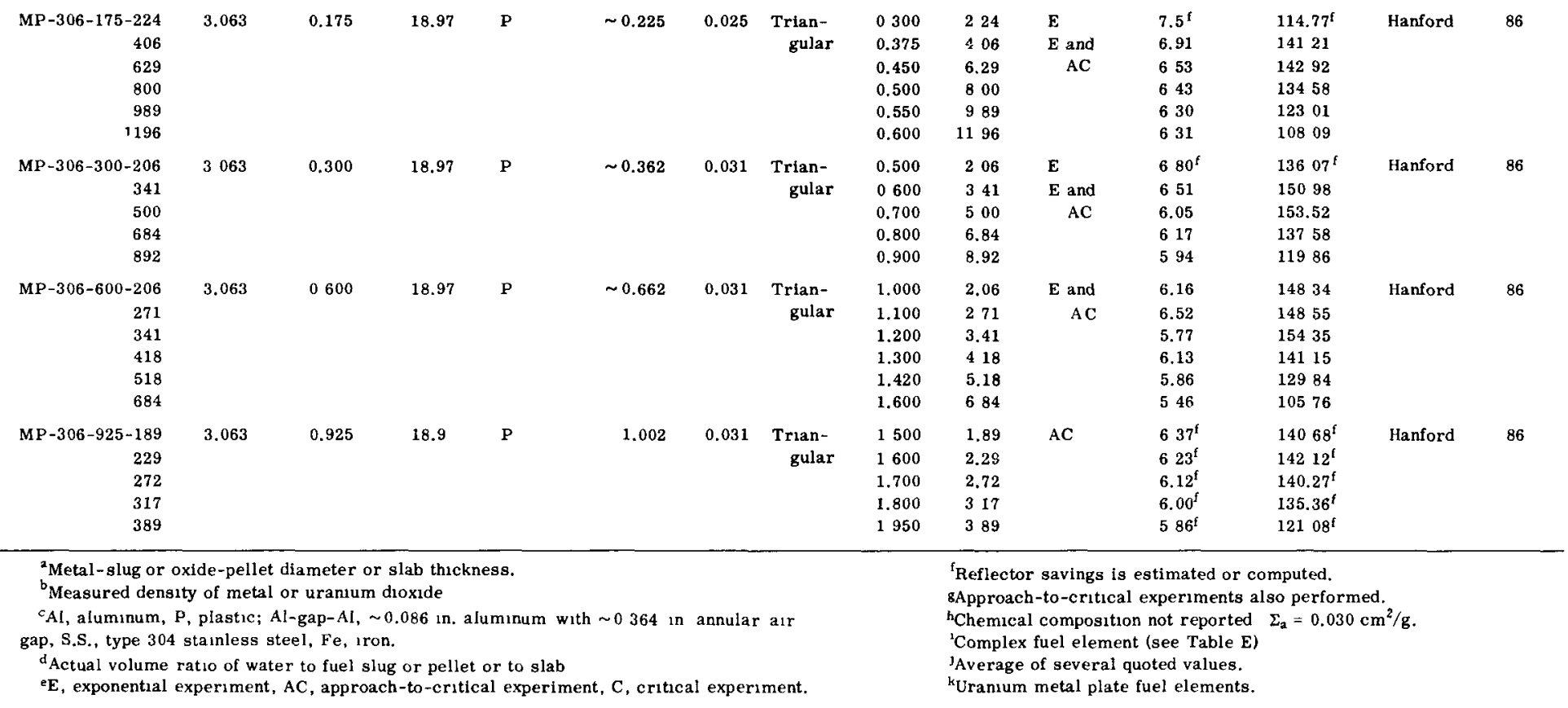


Table B-CLEAN, UNIFORM URANIUM DIOXIDE LATTICE GEOMETRIES AND BUCKLINGS

\begin{tabular}{|c|c|c|c|c|c|c|c|c|c|c|c|c|c|c|}
\hline \multirow[b]{2}{*}{ Lattice index } & \multirow[b]{2}{*}{$\begin{array}{c}\text { Enrich- } \\
\text { ment } \\
\%\end{array}$} & \multirow{2}{*}{$\begin{array}{l}\text { Fuel didm- } \\
\text { eter or } \\
\text { thickness, } \\
\text { in }\end{array}$} & \multirow[b]{2}{*}{$\begin{array}{l}\text { Fuel } \\
\text { density }{ }^{b} \\
\text { g/ } \mathrm{cm}^{3}\end{array}$} & \multicolumn{3}{|c|}{ Claddıng } & \multicolumn{2}{|c|}{ Lattice } & \multirow[b]{2}{*}{$\begin{array}{c}\text { Water to } \\
\text { uranium } \\
\text { ratio }\end{array}$} & \multirow[b]{2}{*}{ Method $^{e}$} & \multirow[b]{2}{*}{$\begin{array}{l}\text { Reflector } \\
\text { savings } \\
\text { cm }\end{array}$} & \multirow[b]{2}{*}{$\begin{array}{l}\text { Buckling } \\
\mathrm{m}^{-2}\end{array}$} & \multirow[b]{2}{*}{$\begin{array}{c}\text { Lab- } \\
\text { oratory }\end{array}$} & \multirow[b]{2}{*}{ Ref } \\
\hline & & & & Materıal $^{c}$ & OD, in & $\begin{array}{l}\text { Thick- } \\
\text { ness, } \\
\text { In }\end{array}$ & Geometry & $\begin{array}{l}\text { Pitch, } \\
\text { in }\end{array}$ & & & & & & \\
\hline $\begin{array}{r}\mathrm{OA}-131-388-139 \\
173\end{array}$ & 1311 & 0388 & 752 & Al & 0453 & 0028 & $\begin{array}{l}\text { Trian- } \\
\text { gular }\end{array}$ & $\begin{array}{l}0613 \\
0650\end{array}$ & $\begin{array}{l}1386 \\
1734\end{array}$ & $\mathrm{C}$ & $\begin{array}{l}841 \pm 012 \\
808+012\end{array}$ & $\begin{array}{l}2528 \pm 010 \\
2521 \pm 010\end{array}$ & BAPL & 12 \\
\hline $\begin{array}{r}\text { OA-121-383-143 } \\
178 \\
240\end{array}$ & 1311 & 0383 & 1053 & Al & 0453 & 0028 & $\begin{array}{c}\text { Trian- } \\
\text { gular }\end{array}$ & $\begin{array}{ll}0 & 613 \\
0 & 650 \\
0 & 711\end{array}$ & $\begin{array}{ll}1 & 426 \\
1 & 779 \\
2 & 396\end{array}$ & $\mathrm{c}$ & $\begin{array}{l}786 \pm 012 \\
741 \pm 013 \\
710 \pm 010\end{array}$ & $\begin{array}{l}3259 \pm 015 \\
3547 \pm 018 \\
3422 \pm 013\end{array}$ & BAPL & 12 \\
\hline $\begin{array}{r}\text { OA-131-601-107 } \\
140 \\
176\end{array}$ & 1311 & 0601 & 753 & Al & 0666 & 0028 & $\begin{array}{l}\text { Trian- } \\
\text { gular }\end{array}$ & $\begin{array}{l}0868 \\
0929 \\
0989\end{array}$ & $\begin{array}{l}1071 \\
1405 \\
1756\end{array}$ & $\mathrm{C}$ & $\begin{array}{l}855 \pm 0 \\
836 \pm 0 \\
752 \pm 06 \\
792 \pm 007\end{array}$ & 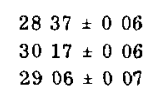 & BAPL & 12 \\
\hline$O A-246-405-137$ & 246 & 04054 & 1024 & Al & 04748 & 0032 & Square & 0595 & 1140 & $\mathrm{C}$ & 877 & $7010 \pm 078$ & $B \& W$ & 106 \\
\hline $\begin{array}{r}O P^{*} 260-705-154^{\mathrm{f}} \\
181 \\
278 \\
304 \\
424 \\
450\end{array}$ & 26 & 0705 & 1043 & $\mathrm{P}$ & $?$ & $?$ & $\begin{array}{c}\text { Trian- } \\
\text { gular }\end{array}$ & $\begin{array}{ll}2 & 540 \\
2 & 540 \\
3 & 048 \\
3 & 048 \\
3 & 556 \\
3 & 556\end{array}$ & $\begin{array}{ll}1 & 542 \\
1 & 808 \\
2 & 778 \\
3 & 043 \\
4 & 237 \\
4 & 504\end{array}$ & $\mathrm{E}$ & $\begin{array}{l}769^{\mathrm{g}} \\
743 \mathrm{~g} \\
690^{\mathrm{g}} \\
682^{\mathrm{g}} \\
662^{\mathrm{g}} \\
661^{\mathrm{g}}\end{array}$ & $\begin{array}{r}9644 \pm 037^{8} \\
10131 \pm 038^{8} \\
10084 \pm 0 \quad 15^{8} \\
10421 \pm 037^{8} \\
8467 \pm 022^{8} \\
8559 \pm 016^{8}\end{array}$ & Hanford & 92 \\
\hline $\begin{array}{r}\text { OS-270-300-105 } \\
120 \\
140 \\
185 \\
217 \\
337 \\
408 \\
498\end{array}$ & 270 & 0300 & 102 & s s & 03384 & 00161 & Square & $\begin{array}{ll}0 & 405 \\
0 & 418 \\
0 & 435 \\
0 & 470 \\
0 & 493 \\
0 & 573 \\
0 & 615 \\
0 & 665\end{array}$ & $\begin{array}{ll}1 & 048 \\
1 & 200 \\
1 & 405 \\
1 & 853 \\
2 & 166 \\
3 & 372 \\
4 & 078 \\
4 & 984\end{array}$ & $\mathrm{C}$ & 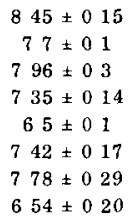 & $\begin{array}{lllll}40 & 7 & \pm 0 & 4 \\
47 & 1 & \pm 0 & 3^{\mathrm{h}} \\
53 & 2 & \pm 0 & 7 & 7 \\
63 & 3 & \pm 0 & 4 \\
68 & 8 & \pm 0 & 5 \\
59 & 5 & \pm 0 & 6 \\
54 & 4 & \pm 0 & 8 \\
51 & 0 & \pm 0 & 5\end{array}$ & WAPD & $\begin{array}{l}41 \\
97 \\
41 \\
41 \\
97 \\
43 \\
43 \\
43\end{array}$ \\
\hline
\end{tabular}




\begin{tabular}{|c|c|c|c|c|c|c|c|c|c|c|c|c|c|c|}
\hline $\begin{array}{r}\text { OS }-301-441-132 \\
163\end{array}$ & 3006 & 0.441 & 9.28 & S.S. & 0.499 & 0.029 & $\begin{array}{l}\text { Trian- } \\
\text { gular }\end{array}$ & $\begin{array}{l}0.6767 \\
0.7163\end{array}$ & $\begin{array}{l}1319 \\
1.632\end{array}$ & $\mathrm{E}$ & $\begin{array}{l}787 \pm 0.02 \\
752 \pm 0.03\end{array}$ & $\begin{array}{l}5444 \pm 0.10 \\
6245 \pm 018\end{array}$ & $\mathrm{BNL}$ & 10 \\
\hline 209 & & & & & & & & 0.7706 & $\begin{array}{l}1.032 \\
2.091\end{array}$ & & $721 \pm 0.02$ & $68.03 \pm 015$ & & \\
\hline 286 & & & & & & & & 0.8542 & 2863 & & $708 \pm 0.03$ & $6798 \pm 0.20$ & & \\
\hline 407 & & & & & & & & 0.9707 & 4.071 & & $6.71 \pm 0.01$ & $5998+007$ & & \\
\hline OS-301-443-115 & 3.006 & 0.443 & 9.28 & S.S. & 0.500 & 0.028 & Square & 0.612 & 1.15 & $\mathrm{c}$ & & 51 & $\mathrm{~B} \& \mathrm{~W}$ & 53 \\
\hline 158 & & & & & & & & 0.663 & 158 & & & 64 & & \\
\hline 358 & & & & & & & & 0.864 & 358 & & & 69 & & \\
\hline OS-370-297-122 & 37 & 0297 & 10.40 & S.S & 0.3386 & 0.016 & Square & 04180 & 1225 & $\mathrm{c}$ & $7.75 \pm 0.09$ & $683 \pm 03$ & WAPD & 97 \\
\hline 221 & & & & & & & & 0.4930 & 2.212 & & $69 \pm 0.1$ & $951 \pm 07$ & & \\
\hline OS-402-443-115 & 4.020 & 0.443 & 9.43 & S S & 0.500 & 0.028 & Square & 0.612 & 1.15 & C & & 69 & $\mathrm{~B} \& \mathrm{~W}$ & 53 \\
\hline 158 & & & & & & & & 0.663 & 1.58 & & & 86 & & \\
\hline 358 & & & & & & & & 0.865 & 3.58 & & & 93 & & \\
\hline 442 & & & & & & & & 0.937 & 4.42 & & & 92 & & \\
\hline OS-402-444-096 & 4020 & 0.444 & 9.46 & S S & 0.4755 & 0.016 & Square & 0571 & 09589 & $\mathrm{C}$ & 7.58 & $790 \pm 13$ & $\mathrm{~B} \& \mathrm{~W}$ & 33 \\
\hline 114 & & & & & & & & 0.595 & 1.140 & & 7.4 & $880 \pm 04$ & & \\
\hline OS $-443-300-135$ & 443 & 0.3001 & 10.17 & S s & 0.346 & 0.0215 & Square & 0435 & 1346 & $\mathrm{C}^{1}$ & $701 \pm 016$ & $797 \pm 08$ & WAPD & 42 \\
\hline 179 & & & & & & & & 0470 & 1.794 & & $7.67 \pm 023$ & $847 \pm 14$ & & \\
\hline
\end{tabular}

${ }^{2}$ Metal-slug or oxide-pellet diameter or slab thickness.

bMeasured density of metal or uranium dioxide.

${ }^{\mathrm{A}} \mathrm{Al}$, aluminum, P, plastic, S.S., type 304 stainless steel except where noted, Fe, iron.

${ }^{\mathrm{f}}$ Complex fuel element (see Table E).

${ }^{g}$ Reflector savings is estimated or computed.

hAverage of several quoted values.

e Exponential experiment, $\mathrm{AC}$, approach-to-critical experiment, $\mathrm{C}$, critical experiment

'Lattice contains control-rod followers. 
Table C-BUCKLINGS OF UNIFORM POISONED LATTICES

\begin{tabular}{|c|c|c|c|c|c|c|c|c|c|}
\hline Lattice index & Poison & $\begin{array}{l}\text { Polson conc } \\
\mathrm{mg} / \mathrm{ml}\end{array}$ & $\begin{array}{l}\text { Reflector } \\
\text { savings } \mathbf{c m}\end{array}$ & Bucklıng $\mathrm{m}^{-2}$ & Lattice index & Poison & $\begin{array}{c}\text { Polson conc } \\
\mathrm{mg} / \mathrm{ml}\end{array}$ & $\begin{array}{l}\text { Reflector } \\
\text { savings cm }\end{array}$ & Buckling $\mathrm{m}^{-2}$ \\
\hline \multirow[t]{9}{*}{ MA-101 925} & $\mathrm{H}_{3} \mathrm{BO}_{3}$ & 15 & $692^{\mathrm{a}}$ & $1643^{a}$ & MA-114-387-200 & $\mathrm{B}_{2} \mathrm{O}_{3}$ & 0793 & $658 \pm 022$ & $2817 \pm 100$ \\
\hline & & 30 & $692^{2}$ & $663^{2}$ & & & 1493 & $628 \pm 010$ & $1674 \pm 057$ \\
\hline & & 45 & $692^{\mathrm{a}}$ & $-269^{2}$ & & & 3660 & $577 \pm 013$ & $-1385 \pm 071$ \\
\hline & & 15 & $665^{a}$ & $1502^{a}$ & 300 & & 0793 & $602 \pm 018$ & $2643 \pm 101$ \\
\hline & & 30 & $665^{2}$ & $097^{2}$ & & & 1499 & $615 \pm 011$ & $731 \pm 054$ \\
\hline & & 60 & $665^{2}$ & $-2303^{a}$ & & & 2247 & $578 \pm 014$ & $-697 \pm 067$ \\
\hline & & 15 & $643^{2}$ & $2061^{2}$ & 400 & & 0358 & $620 \pm 017$ & $2948 \pm 052$ \\
\hline & & 30 & $643^{a}$ & $-313^{2}$ & & & 0793 & $583 \pm 021$ & $1576 \pm 085$ \\
\hline & & 45 & $643^{2}$ & $-1162^{2}$ & & & 1501 & $634 \pm 011$ & $-950 \pm 046$ \\
\hline \multirow[t]{12}{*}{ MA $103-250$} & $\mathrm{~B}_{2} \mathrm{O}_{3}$ & 0249 & $815 \pm 018$ & $754 \pm 097$ & $M A-114-600-100$ & $\mathrm{~B}_{2} \mathrm{O}_{3}$ & 298 & $616 \pm 015$ & $-254 \pm 058$ \\
\hline & & 0463 & $799 \pm 017$ & $523 \pm 095$ & & & 3327 & $623 \pm 010$ & $-644 \pm 046$ \\
\hline & & 0823 & $789 \pm 025$ & $-063 \pm 136$ & 150 & & 2022 & $647 \pm 010$ & $1312 \pm 043$ \\
\hline & & 0480 & $777 \pm 010$ & $1115 \pm 045$ & & & 3926 & $576 \pm 009$ & $-818 \pm 040$ \\
\hline & & 0733 & $731 \pm 010$ & $869 \pm 092$ & 200 & & 1911 & $652 \pm 017$ & $1236 \pm 062$ \\
\hline & & 1057 & $775 \pm 020$ & $087 \pm 099$ & & & 300 & $595 \pm 010$ & $-596 \pm 10$ \\
\hline & & 0376 & $702 \pm 008$ & $1604 \pm 032$ & 300 & & 1308 & $622 \pm 018$ & $770 \pm 058$ \\
\hline & & 0678 & $684 \pm 011$ & $931 \pm 049$ & 400 & & 0344 & $636 \pm 016$ & $2216 \pm 036$ \\
\hline & & 1028 & $661 \pm 015$ & $157 \pm 068$ & & & 0746 & $678 \pm 024$ & $558 \pm 048$ \\
\hline & & 0251 & $698 \pm 005$ & $1426 \pm 016$ & & & 1300 & $653 \pm 021$ & $-1357 \pm 046$ \\
\hline & & 0518 & $671 \pm 010$ & $644 \pm 035$ & & & & $632 \pm 027$ & $1067 \pm 148$ \\
\hline & & 0680 & $670 \pm 007$ & $135 \neq 023$ & $\begin{array}{r}M A-130-600-100 \\
150\end{array}$ & $\mathrm{~B}_{2} \mathrm{O}_{3}$ & $\begin{array}{l}2587 \\
1039\end{array}$ & $\begin{array}{l}632 \pm 027 \\
656 \pm 026\end{array}$ & $\begin{array}{l}1068 \pm 148 \\
3863 \pm 113\end{array}$ \\
\hline \multirow[t]{9}{*}{ MA $-103-750-1$} & $\mathrm{~B}_{2} \mathrm{O}_{3}$ & 0418 & $761 \pm 018$ & $2164 \pm 082$ & & & 3452 & $582 \pm 024$ & $1084 \pm 122$ \\
\hline & & 1088 & $761 \pm 046$ & $1107 \pm 217$ & 200 & & 2587 & $590 \pm 010$ & $1638 \pm 034$ \\
\hline & & 1662 & $775 \pm 012$ & $243 \pm 050$ & 300 & & 1724 & $608 \pm 012$ & $1287 \pm 083$ \\
\hline & & 0694 & $745 \pm 067$ & $2045 \pm 0255$ & 400 & & 0500 & $590 \pm 016$ & $3321 \pm 081$ \\
\hline & & 1140 & $711 \pm 078$ & $1272 \pm 314$ & & & 0855 & $665 \pm 023$ & $1693 \pm 100$ \\
\hline & & 1593 & $732 \pm 022$ & $326 \neq 094$ & & & 1059 & $631 \pm 025$ & $1097 \pm 130$ \\
\hline & & 0336 & $679 \pm 020$ & $2086 \pm 052$ & OS-270 $300-217$ & B & & & $31201^{*}$ \\
\hline & & 0667 & $637 \pm 019$ & $1137 \pm 057$ & US-270 $300-217$ & & 0732 & $548^{\circ}$ & $3017^{4}$ \\
\hline & & 0990 & $659 \pm 017$ & $019 \pm 049$ & & & 0836 & $511^{*}$ & $25603^{\circ}$ \\
\hline
\end{tabular}




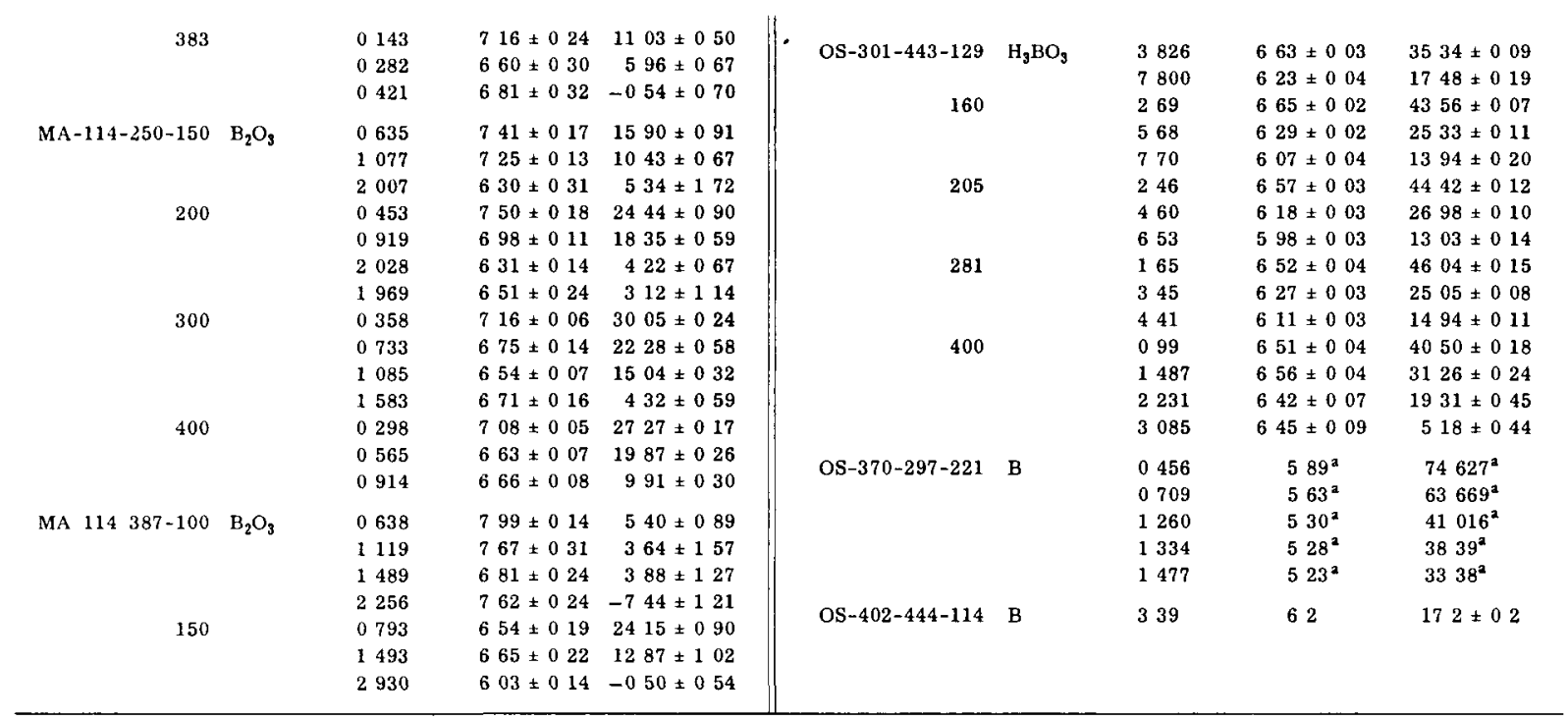

${ }^{\text {a}}$ Reflector savings is estimated or computed 
Table D - CRITICAL DIMENSIONS AND GEOMETRY OF UNIFORM URANIUM LATTICES AND URANIUM DIOXIDE LATTICES

\begin{tabular}{|c|c|c|c|c|c|c|c|c|c|c|c|c|c|c|c|}
\hline \multirow[b]{2}{*}{ Ialtice index } & \multirow[b]{2}{*}{$\begin{array}{c}\text { Enrich- } \\
\text { ment, } \\
\%\end{array}$} & \multirow[b]{2}{*}{$\begin{array}{l}\text { Fuel diam- } \\
\text { eter or } \\
\text { thickness, } \\
\text { in. }\end{array}$} & \multirow[b]{2}{*}{$\begin{array}{l}\text { Fuel } \\
\text { density, } \\
\text { g/cm }\end{array}$} & \multicolumn{3}{|c|}{ Claddıng } & & \multirow[b]{2}{*}{$\begin{array}{l}\text { Water to } \\
\text { uraniurn } \\
\text { ratiod }\end{array}$} & \multirow[b]{2}{*}{ Method $^{\mathrm{e}}$} & & & \multirow[b]{2}{*}{$\begin{array}{c}\text { Transverse } \\
\text { buckling, } \\
\mathrm{m}^{-2}\end{array}$} & \multirow[b]{2}{*}{$\begin{array}{l}\text { Lab- } \\
\text { oratory }\end{array}$} & \multirow[b]{2}{*}{ Ref } \\
\hline & & & & Material $^{c}$ & OD, in. & $\begin{array}{l}\text { Thick- } \\
\text { ness, } \\
\text { in. }\end{array}$ & _ Iattı & $\begin{array}{l}\text { Pitch, } \\
\text { in }\end{array}$ & & & $\begin{array}{r}\text { Critical di } \\
\mathrm{c}\end{array}$ & $\begin{array}{l}\text { mensions, } \\
\text { m }\end{array}$ & & & \\
\hline$M A-114-600-202$ & 1143 & 0.600 & 18.92 & $\mathrm{Al}$ & 0.666 & 0.028 & $\begin{array}{l}\text { Trian- } \\
\text { gular }\end{array}$ & 1.030 & 2.017 & $\mathrm{C}(\mathrm{curc})$ & $29.56^{f}$ & $122^{8}$ & & BAPL & 107 \\
\hline 301 & & & & & & & & 1.177 & 3.011 & & $30.60^{f}$ & & & & \\
\hline $\begin{array}{r}\text { MA }-130-600-151 \\
202 \\
301\end{array}$ & 1.299 & 0600 & 18.92 & $\mathrm{Al}$ & 0.666 & 0.028 & $\begin{array}{l}\text { Trian- } \\
\text { gular }\end{array}$ & $\begin{array}{l}0946 \\
1030 \\
1.177\end{array}$ & $\begin{array}{l}1515 \\
2.017 \\
3011\end{array}$ & $\mathrm{C}(\mathrm{c} 1 \mathrm{rc})$ & $\begin{array}{l}2761^{f} \\
2514^{f} \\
2560^{f}\end{array}$ & $122^{\mathrm{g}}$ & & BAPL & 107 \\
\hline $\begin{array}{r}\text { OA }-185-445-123 \\
374\end{array}$ & 1.85 & 0.445 & 10.35 & $\mathrm{Al}$ & 0.5035 & 0.024 & Square & $\begin{array}{l}0625 \\
0.884\end{array}$ & $\begin{array}{l}1.231 \\
3.744\end{array}$ & $\mathrm{C}$ (rect.) & $34.38^{h}$ & $13.13^{\mathrm{h}}$ & $\begin{array}{l}704 \\
5.93\end{array}$ & CEND & 68 \\
\hline OS $-255-1436-108^{1}$ & 2.55 & 1436 & 93 & s S & (See Fig. & $18)$ & $\begin{array}{l}\text { Trian- } \\
\text { gular }\end{array}$ & 1.875 & 1.085 & C (hex.) & 271 (eler & ment hex.) & 919 & CEND & 69 \\
\hline 133 & & & & & & & & 1.875 & 1326 & & & & 17.94 & & \\
\hline 172 & & & & & & & & 2.092 & 1.718 & & 169 (eler & ment hex ) & 851 & & \\
\hline 196 & & & & & & & & 2092 & 1959 & & & & 1407 & & \\
\hline $\begin{array}{r}\text { OS-302-444-115 } \\
157 \\
357\end{array}$ & 302 & 0444 & 945 & S.S & 0.500 & 0028 & Square & $\begin{array}{l}0.612 \\
0.663 \\
0.865\end{array}$ & $\begin{array}{l}11512 \\
1.5710 \\
35694\end{array}$ & $\mathrm{C}(\mathrm{curc})$ & $\begin{array}{l}267^{f} \\
238^{f} \\
242^{f}\end{array}$ & $\begin{array}{l}1689^{8} \\
1689^{8} \\
1689^{8}\end{array}$ & & $\mathrm{~B} \& \mathrm{~W}$ & 108,109 \\
\hline $\begin{array}{r}\text { OS }-340-1194-186^{1} \\
218 \\
239 \\
271 \\
265 \\
286 \\
318 \\
367\end{array}$ & 3395 & I 194 & 1016 & s S & (See Fig & 19) & Square & 1900 & $\begin{array}{ll}1 & 858 \\
2 & 178 \\
2 & 392 \\
2 & 713 \\
2 & 645 \\
2 & 859 \\
3 & 180 \\
3 & 672\end{array}$ & $\mathrm{C}($ rect $)$ & $\begin{array}{l}330^{\mathrm{f}} \\
287^{\mathrm{f}} \\
304^{\mathrm{f}} \\
270^{\mathrm{f}} \\
291^{\mathrm{f}} \\
323^{\mathrm{f}} \\
291^{\mathrm{f}} \\
326^{\mathrm{f}}\end{array}$ & $122^{8}$ & & GEAP & 14 \\
\hline $\begin{array}{r}\text { OS-402-444-115 } \\
357 \\
487\end{array}$ & 402 & 0444 & 946 & S S & 0.500 & 0.028 & Square & $\begin{array}{l}0612 \\
0.865 \\
0975\end{array}$ & $\begin{array}{l}11512 \\
3.5694 \\
4870\end{array}$ & $C($ circ $)$ & $\begin{array}{l}21.7^{\mathrm{f}} \\
186^{\mathrm{f}} \\
198^{\mathrm{f}}\end{array}$ & $\begin{array}{l}1689^{8} \\
1689^{8} \\
1689^{8}\end{array}$ & & $B \& W$ & 108,109 \\
\hline
\end{tabular}

${ }^{2}$ Metal-slug or oxıde-pellet diameter or slab thickness.

${ }^{b}$ Measured density of metal or uranium dioxide

${ }^{f}$ Actual or equivalent radius of loading

c $\mathrm{Nl}$, aluminum, $\mathrm{P}$, plastic, $\mathrm{S} S$, type 304 stainless ste $\mathrm{I}$ except where noted, Fe, ron

${ }^{8}$ Length of fuel element in fully reflected assembly.

d citual volume a atio of water to fuel slug or pellet or to slab.

${ }^{h}$ Cross-sectional dimensions, $\mathrm{cm}$, of rectangular loading.

${ }^{c} \mathrm{C}$, critical experiment

'Complex fuel element (see Table $\mathrm{E}$ ) 
Table E - GEOMETRY OF ANNULAR AND COMPLEX FUEL ELEMENTS

\begin{tabular}{|c|c|c|c|c|c|c|c|c|}
\hline \multirow[b]{3}{*}{ Ldttice index } & \multirow{2}{*}{\multicolumn{3}{|c|}{ Fuel }} & \multicolumn{5}{|c|}{ Claddıng } \\
\hline & & & & \multirow{2}{*}{$\begin{array}{l}\text { Outer } \\
\text { OD, } \\
\text { in. }\end{array}$} & \multirow{2}{*}{$\begin{array}{c}\text { Outer } \\
\text { thickness, } \\
\text { in }\end{array}$} & \multirow{2}{*}{$\begin{array}{l}\text { Inner } \\
\text { OD, } \\
\text { in. }\end{array}$} & \multirow{2}{*}{$\begin{array}{c}\text { Inner } \\
\text { thickness, } \\
\text { in }\end{array}$} & \multirow[b]{2}{*}{ Material $^{2}$} \\
\hline & $\begin{array}{l}\text { Density, } \\
\mathrm{g} / \mathrm{cm}^{3}\end{array}$ & $\begin{array}{l}\text { OD, } \\
\text { in }\end{array}$ & $\begin{array}{l}\text { ID, } \\
\text { in. }\end{array}$ & & & & & \\
\hline$M P^{*} 094-1365-$ & 18.78 & 1365 & 0485 & ? & $?$ & None & & $\mathrm{P}$ \\
\hline$M A * 101-1660-$ & 1891 & 166 & 094 & 1.73 & 0.028 & None & & $\mathrm{Al}$ \\
\hline$M A * 125-1336-$ & 18.9 & 1336 & 0500 & 1402 & 0028 & 0.492 & 0,020 & $\mathrm{Al}$ \\
\hline$M A=144-1370-$ & 18.90 & 1.37 & 0.48 & 1.50 & 0.049 & None & & $\mathrm{Al}$ \\
\hline $\mathrm{MA}^{*}-147-1394-$ & 18.90 & 1.394 & 0.464 & 1.50 & 0.049 & None & & Al \\
\hline $\mathrm{MA}^{*}-160-1394-$ & 18.86 & 1.394 & 0464 & 150 & 0.049 & None & & $\mathrm{Al}$ \\
\hline OS-255-1436-b & 93 & 1.436 & & & & & & S s \\
\hline$O P^{*}-260-705-$ & 10.43 & 0705 & 0.323 & $?$ & $?$ & None & & $\mathrm{p}$ \\
\hline OS$^{*} 340-1194-^{\circ}$ & 10.2 & 1.194 & & & & & & S S \\
\hline
\end{tabular}

${ }^{\mathrm{a}} \mathrm{Al}$, aluminum, P, plastic, S S, type 304 stainless stee

Double annuli (see Fig. 17).

${ }^{\mathrm{C}}$ Annulus with process tube (see Fig, 18). 
0

0 


\section{Index}

\section{A}

Advanced commercial power reactors, 71-129

fast reactors, $85-98$

BR-5 reactor, 93

Dounreay Fast Reactor (DFR), 91

Enrico Fermi plant, $34,85,90$

Experımental Breeder Reactor No I, 87

Experımental Breeder Reactor No. II, 88

fast ceramic-fueled reactors, 95

Los Alamos Molten Plutonıum Reactor Experiment (LAMPRE), 97

prelıminary reactor programs, 98

RAPSODIE, 95

technical aspects, 86

heavy-water-moderated reactors, 99-114

CANDU, 108

Carolınas-Vırgınıa Tube Reactor (CVTR), 103

coolants other than heavy water, 111

economics, 112

EL-4 reactor, 108

Halden reactor, 108

Heavy Water Components Test

Reactor (HWCTR), 102

Lucens reactor, 109

Nuclear Power Demonstration

(NPD) Peactor, 106
Plutonıum Recycle Test Reactor (PRTR), 103

R-3/Adam reactor, 110

Spectral-shift-control reactor, 111

technical aspects, 100

organic-moderated reactors,

114-125

Experimental Organic Cooled Reactor (EOCR), 120

fuel-element development, 123

organic-cooled with other moderators, 124

Organic Moderated Reactor Experiment (OMRE), 116

Piqua Nuclear Power Facility (PNPF), 118

problems with organic coolants, 121

technical aspects, 116

sodium-graphite reactors, 72-84

advanced sodlum-cooled reactor, 83

Hallam Nuclear Power Facility (HNPF), 81

costs, 82-83

Sodium Reactor Experıment (SRE), 73

component development, 80

fuels and materials development, 78

operating experience, 75

technical aspects, 74

Advanced Gas Reactor (AGR), 13 cost, 29 
Advanced power reactors, 26

boiling superheater reactors, 26

BONUS, 26

BORAX-5, 26

design data, 26

Pathf inder, 26

supercritical reactors, 27

Aluminum alloys for fuel cladding,

50, 215-223

applicability, 221

corrosion, 215-221

reactor experience, 218-219

Aluminum process for uranium processing, 460

Alumınum - uranium alloy fuels, 391

Americium-241, production, 513, 516-519

uses, $486,488,500,514$

Approach-to-critical-loading experiments, 544-546, 583, 584

Argonne National Laboratory (ANL) water-moderated lattice data, 564 , 589

Army Stationary Medium Power Plant (SM-1), staınless-steel cladding in, 231, 234, 238

Atomic Energy of Canada Limited (AECL) water-moderated lattice data, 565

Atomic Energy Research Establishment (AERE) water-moderated lattice data, 544-546, 584

\section{B}

\section{Babcock \& Wilcox Co. (B \& W)} water-moderated lattice data, 558 , $560,566,589$

Behavior of cladding materials in water and steam (see Claddıng materials, behavior in water and steam)

Beryllum in commercial power reactors, 49

Bettis Atomic Power Laboratory (BAPL) water-moderated lattice data, 547, 556, 558, 562, 568
Bolling "burnout" for reactor design, 132-176

boiling burnout data, 155-168

bolling curve, 133

bolling in ducts, 141 complications of data interpretation, 148

empirical studies, 145

mechanısm and analysis, 142

burnout (description), 135

pool bolling, 138

Bolling-water reactors, 22-24

cost, 30-32

Dresden reastor, 24

cost, 31

Experimental Boiling Water Reactor (EBWR), 22

stainless-steel claddıng in, 236

BONUS, 26

BORAX -3 and -4 , aluminum alloy cladding in, 220

BORAX-5, 26

BR-3 lattice data, 588

BR-5 reactor, 26,93

Brookhaven National Laboratory (BNL) water-moderated lattice data, $535-538,540,543,558$, $568-570,574,589$

Buckling coefficient of reactivity, 549-553

Buckling and geometry tables, 598-609

Bucklıng measurement, 534-544, 546-548, 564-567 574, 584, 588

Burnout (see Bolling “burnout" for reactor design)

By-products from reactors (see Reactor by-products and Pyroprocessing of reactor fuels)

\section{C}

Cadmium ratio of $\mathrm{U}^{\mathbf{2 3 8}}$ captures and $\mathrm{U}^{235}$ fissions, $554,555,558$

Calder Hall reactors, 8-11

Canada, Atomic Energy of Canada Limited water-moderated lattice data, 565

CANDU reactor, 108 
Nuclear Power Demonstration

(NPD) Reactor, 106

CANDU Reactor, 108

Carbide-fuel processing, 448, 456

Carbon-14, shipments from ORNL, 486

Carolinas-Virginıa Tube Reactor (CVTR), 103

Cell-parameter measurements, $553-564,566,575,588$

Cerium-144, 479, 480 production, $482-486$ recovery, 509 uses, $486,493,496$

Cesium-137, 479-481

half-life, 486

production, 481-486

recovery, 506-508

uses, 487, 491-494, 500

Cladding materials, behavior in

water and steam, 214-330

aluminum alloys, 50, 215-223

applicability, 221

corrosion, 215-221

high temperature, 215

low temperature, 215

powder metallurgy products, 219

reactor experience, 218,219 steam, 218

other metals, 310

stainless steels and related a1loys, 50, 223-288

in superheated steam, 260-288

corrosion, 262-271

mechanical and metallurgical properties, 275-286

radiation effect, 284

temperature and fatigue ef-

fects, 275-284

reactor applications, 286

reactor exposure effects, 271-275

in water, 223-260

application to reactors, $231-258$

fuel lifetime, 233

reactor-coolant conditions, 233

reactor experience, 238-257 requirements, 233

corrosion, 224-231

development programs, 258

zirconium alloys, 50, 289-309

corrosion, 290-305

high-temperature water, 290-299

new theories, 303

steam, 299-302

evaluation, 308

superheated steam reactors, 309

water-cooled reactors, 308

mechancal and physical properties, 305

reactor experience, 307

Cobalt-60, 481

production, 485, 486, 519

uses, 487, 491-494

Combustion Engineering, Inc., Nuclear Division (CEND), watermoderated lattıce data, 578

Commercial power reactors, advanced type (see Advanced commercial power reactors)

Commercial power reactors cooled with gas or light water (see Gascooled commercial power reactors and Light-water-cooled commercial reactors)

Consolıdated Edison Thorıum Reactor (CETR), 22

Corrosıon of claddıng materials, aluminum alloys, 215-221

stainless steels, 224-231, 262-275 zırconıum alloys, 290-305

Corrosion of uranium fuel elements, 335

Critical assemblies, 546-553, 568, 581,586

Critical heat-transfer condition (see Bolling "burnout" for reactor design)

Critical loading and buckling, 546-548

Curium-242 and $-244,481$ production, 483, 484, 513, 517-519 uses, $487,498,500$ 


\section{D}

Design and construction problems of commercial power reactors, 47-60

design staff, 48

materials of construction, 49

aluminum, 50

beryllum, 49

magnesium, 50

moderator materials, 51

stainless steels, 50

zirconium, 50

operating data use, 48

thermodynamic cycles, 51

Doerner-Hoskins coefficients, 421

Dounreay Fast Reactor (DFR), 85, 91,378

DRAGON reactor, 6,14

Dresden Nuclear Power Station, 24

Dresden reactor, 24

cost, 31

fuel rupture detection, 204

power monitoring, 184

sta inless-steel cladding in, 236

zirconıum cladding in, 307

\section{E}

EBR-II fuel processing, 436-448

blanket process, 445

engineering procedures, 446

fuel cycle, 437

melt refining, 437-441

nonmetal fuels, 448

plutonium fuels, 447

skull reclamation, 441-445

zinc metal solvent, 442-445

EDF reactors (French), 5, 12

Eigenvalue equation, 549-551

EL-3 reactor fuel, 379

EL-4 reactor, 108, 111

Enrico Fermi plant, 34, 85, 90

Experimental Boiling Water Reactor (EBWR), 22

aluminum cladding in, 220

irradiation tests in, 244

Experimental Breeder Reactors, EBR-I, 85, 87
EBR-II, 85, 88

(See also EBR-II fuel processing)

Experimental Gas Cooled Reactor (EGCR), 13

Experımental Organic Cooled Reactor (EOCR), 120

Exponential experiments for lattice data, 534-544, 567, 575, 583

\section{$\mathbf{F}$}

Fast reactors, 85-98

BR-5 reactor, 26, 93

Dounreay Fast Reactor, 91

Enrico Fermı plant, 34, 85, 90

Experimental Breeder Reactor

No. I, 87

Experimental Breeder Reactor

No. II, 88

Fast ceramic-fueled reactors, 95

Los Alamos Molten Plutonium

Reactor Experıment (LAMPRE), 97

prelımınary reactor programs, 98

RAPSODIE, 95

technical aspects, 86

Fermı, Enrico, reactor, 34, 85, 90

Fission-product detection, in-core, 203

coolant-activity monitoring, 203

fission-product precipitation, 204

Fission-product elements, production in 1990, 512

Fission products, production and recovery (see Reactor byproducts)

Fission products, separation from reactor fuels (see Pyroprocessing of reactor fuels)

Fission ratio of $\mathrm{U}^{238}$ and $\mathrm{U}^{235}, 554$, 556

Fissıum, definition, 437

Flux-shape method for exponential experiments, 534-541

France, commercial reactors, 4

EDF reactors, 5,12

EL-3 reactor fuel, 379

EL-4 reactor, 108, 111

G-1, G-2, and G-3 reactors, 5, 12 
gas-cooled reactor programs, 5

RAPSODIE, 95

reactor design and operation experience, 12,55

Free energies of formation, carbides, 423

chlorides, 422,423

intermetallic compounds, 424

oxides, 422

Fuel assemblies, instrumented, 209

Fuel cycle, EBR-II, 437

Fuel-element cladding (see Cladding materials, behavior in water and steam)

Fuels, costs, 32-37, 62

fast reactors, $85-99$

gas-cooled commercial reactors, $8-12,32-37,62$

heavy-water-moderated reactors, 99-114

light-water-cooled commercial reactors, 32-37, 62

metallic (see Fuels, metallic)

organic-moderated reactors, 114-125

paste (APDA), 98

plutonium, 35, 97, 103

sodium-graphite reactors, 78

(See also individual reactors by name)

Fuels, metallic, 332-410

aluminum-base uranium alloys, 391

fuels for beta-phase operation, 392

other alloys, 394

thorium, 398

uranium and its dilute alloys, $332-378$

grain-boundary cracking, 372-377

cracking during irradiation, 374

tensile properties, 372

grain size and wrinkling, 344-351

measurement, 344

recrystallization of betaquenched material, 348

small grain size attainment, 346 in-pile creep of alpha uranium, 358

irradiation growth mechanism, 337-344

preferred orientation, $351-358$

growth of fuel elements, 356

texture measurement by dif-

fraction, 352

texture measurement by other methods, 353

texture origin, 355

properties, 332-337, 372

compatibility (corrosion), 335

density, 425

diffusion, 333,425

tensile, 372

thermal conductivity, 332

status, 377

swelling in alpha uranium, 362-372

intermetallic precipitates, 367

mechanism, 362

wrinkling, 350

uranium-molybdenum alloys, 379-387

corrosion, 387

dilute alloys, 379-381

gamma alloys, 382

status, 387

u ranium - niobium alloys, 390

uranium-zirconium alloys, 388

Fuels, processing of reactor (see

Pyroprocessing of reactor fuels)

G

G-1, G-2, and G-3 reactors, 5, 12

Gas-cooled commercial power reac-

tors, costs, 27-46, 61, 62

actual, 44

construction, $27,28,32$

effect of subsidies, 45

fuel, $32-37,62$

fabrication, 34

fuel cycle, 37

plutonium recycle, 35

reprocessing, 36

table, 35

use charge, 37 
future costs, 46,47

design and construction problems, $47-60$

construction, 56

design staff, 48

heat-production rates, 53

materials of construction, 49

operating-data use, 48

pressure vessels, 54

thermodynamic cycles, 51

names, owners, locations, power

levels, and status (table), 4

prototype reactors, 13-15

Advanced Gas Reactor (AGR), 13

DRAGON reactor, 14

Experimental Gas Cooled Reactor (EGCR), 13

Julich reactor, 15

Philadelphia Electric Company reactor, 13

steam-cooled reactors, 15

reactor design and operation, 5-12

design data, 6-7

French experience, 12

United Kingdom experience, 8-11

reactor programs, 3-5

France, 5, 12

United Kingdom, 3

United States, 5

safety, 57-60

codes and standards, 57

containment, 59

disposal of radioactive wastes, 60

shipment of irradiated fuels, 60 site selection, 58,63

General Electric Co., Atomic Power Equipment Department (GEAP), fast ceramic-fueled reactors, 95

water-moderated lattice data, 548 , 562,580

General Electric Co., Hanford Laboratories, water-moderated lattice data, 544, 582

Geometry and buckling tables, 598-609

Germany, Julich reactor, 15

\section{H}

Halden reactor, 108 aluminum cladding in, 220

Hallam Nuclear Power Facility (HNPF), 81

(See also Sodium-graphite reactors)

Hanford Laboratories, watermoderated lattice data, 544,582

Hanford salt-cycle process for fuel recovery, 451-455

chemistry, 452

engineering scale studies, 454

Hastelloy as cladding for fuel elements, corrosion, 265-271, 274, 280-284

Heat power from radioisotopes, 483 , $484,494-500$

Heat transfer, critical condition (see Boiling "burnout" for reactor design)

Heavy Water Components Test Reactor (HWCTR), 102

Heavy-water-moderated reactors, 99-114

CANDU, 108

Carolinas-Virginia Tube Reactor (CVTR), 103

coolants other than heavy water, 111

economics, 112

EL-4 reactor, 108

Halden reactor, 108

Heavy Water Components Test

Reactor (HWCTR), 102

Lucens reactor, 108

Nuclear Power Demonstration

(NPD) Reactor, 106

Plutonium Recycle Test Reactor (PRTR), 103

R-3/Adam reactor, 110

Spectral-shift-control reactor, 111

technical aspects, 100

Hermex process for fuel processing, 458

High Temperature Gas Cooled Reactor (HTGR), 13 


\section{I}

Incoloy and Inconel as cladding for fuel elements, corrosion, 265-271, $274,280-284$

In-core instrumentation, $178-211$

fission-product detection, 203 coolant-activity monitoring, 203 fission-product precipitation, 204

instrumented fuel assemblies, 209

pressure measurements, 192 absolute pressure, 194 pressure differential, 193 radiation measurement, 179 Ion chambers, 183 material activation, 181 solid-state devices, 191 the rmopiles, 188

telemetering, 206 electronıc multiplexing, 207 mechanical scanning, 206 temperature measurement, 198 capacitance temperature sensors, 202

sonic flow orifices, 201

thermocouples, 199

velocity measurement, 195 rotating vane meters, 196 standing wave measurement, 197

Instrumentation, in-core (see Incore instrumentation)

Ion chambers for flux measurement, 183

Irradiated materials, processing of (see Pyroprocessing of reactor fuels)

Ir radiation cracking of uranıum, 374 Irradiation growth mechanısm, uranium fuel, $337,356,358,362$

Irradiation swelling of uranium, 362

Irradiation tests, fuel-element cladding , 218, 238-257, 271-275, 284,307

EBWR, 244

VBWR, 239-243

Isotopes, distribution from ORNL, 486
(See also Reactor by-products and

Pyroprocessing of reactor fuels)

Isotopic power costs, 484

Isotopic power program, 495-500

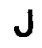

Julich reactor, 15

\section{K}

Kinetic response measurements in critical assemblies, 548-553

Krypton- 85 , production, 482 recovery, 510

uses, 487

Lattice data for water-moderated, slightly enriched uranium, 530-609

experimental measurements, 533-563 approach-to-critical-loading experiments, 544-546, 583, 584

buckling coefficient of reactivity, 549-553

buckling measurement, 534-544, 546-548, 564-567, 574, 584, 588

cadmium ratio of $\mathrm{U}^{238}$ captures and $\mathrm{U}^{235}$ fissions, 554, 555, 558

cell-parameter medsurements, $553-564,566,575,588$

critical assemblies, 546-553, $568,581,586$

critical loading and buckling, 546-548

eıgenvalue equation, 519-551

exponential experiments, $534-544,567,575,583$

fission ratio of $U^{238}$ and $U^{235}$, 554,556

flux-shape method, 534-541 
kinetic response measurements, 548-553

lattice-cell parameter, 554 , $558,568-571,580,590$

materials buckling, inference from exponential experiments, 534-544

modified conversion ratio (MCR), 554, 561, 582

reflector savings, $536-537,539$, $540,548,576,587,589$

thermal-neutron disadvantage factor, $554,562,566,582,585$

variable-loading method, 535 , 541-544, 578

geometry and buckling tables, appendix, 598-609

clean, uniform uranlum dioxide lattices, 604

clean, uniform uranium metal lattices, 598

critical dimensions and geometry of uniform $\mathrm{U}$ and $\mathrm{UO}_{2}$ lattices, 608

geometry of annular and complex fuel elements, 609

uniform poisoned lattices, 606

range of data, 531, 532

summary of experimental results, 563-591

AECL, 565

AERE, 584

ANL, 564, 589

BAPL, 586

BNL, 570, 574, 589

B \& W $, 566,589$

CEND, 578

GEAP, 580

Hanford, 582

ORNL, 586

WAPD, 587

Light-water-cooled commercial reactors, $18-46$

costs, $27,46,61,63$

actual, 44

construction, $29,30,32$

effects of subsidies, 45

fuel, $32-37,62$

tabrication, 34,35

fuel cycle, 37 plutonium recycle, 35

reprocessing, 36

use charge, 37

future costs, 46,47

operating, 39

predicted, 40

design and construction problems, $47-60$

construction, 56

design staff, 48

heat-production rates, 53

materials of construction, 49

operating-data use, 48

pressure vessels, 54

thermodynamic cycles, 51

name, owner, location, power

levels, 16-17

pressurized-water reactors, 19

Consolidated Edison Thorium

Reactor (CETR), 22

Shippingport reactor, 19

Yankee reactor, 21

safety, 57-60

codes and standards, 57

containment, 59

disposal of radioactive wastes, 60

shipment of irradiated fuels, 60

site selection, 58,63

status, 18

Liquid Metal Fuel Reactor (LMFR)

fuel processing, 461

Los Alamos Molten Plutonium Reactor Experiment (LAMPRE), 97

Lucens reactor, 109

\section{M}

Magnesium, in commercial power reactors, 50

in fuel processing (see Pyroprocessing of reactor fuels)

processes for Th-U fuels, 449

solubility of $\mathrm{Ca}, \mathrm{Y}, \mathrm{La}, \mathrm{Ce}$, and $\mathrm{Th}$

in, 450

Materials buckling, 534-544, 549-553, 598-609

(See also Lattice data etc.)

Materials of construction, commercial power reactors, 49-51 
fuel-element cladding (see Cladding materials)

(See also individually named reactors)

Mercury process for fuel processing, 458

Metallic fuels (see Fuels, metallic)

Modified conversion ratio (MCR), $554,561,582$

Molybdenum-uranium alloy fuels, 379-387, 395

corrosion, 387

dilute alloys, 379

gamma alloys, 382

status, 387

Multiregion Lattice program, 533, $578,588,591$

\section{N}

National Reactor Testing Station (Idaho) fuel-cycle facility, 436

Neptunium processing, 513-515

Neutron-flux measurement, 179 ion chambers, 183

material activation, 181

solid-state devices, 191 thermopiles, 188

Niobium-95, 482, 488, 490

Niobium-uranium alloy fuels, 390 , 396

Norway, Halden reactor, 108

Nuclear power capacity, growth, 482

Nuclear power costs, actual, 44 construction, 27

effect of subsidies, 45

fuel, 33

fabrication, 34

fuel cycle, 37

plutonium recycle, 35

reprocessing, 36

use charge, 37

future costs, 46,47

Hallam Nuclear Power Facility

(HNPF), 82, 83

heavy-water vs. light-water reactors, 112

isotopic, 484

operating, 38 predicted, $40,42,44,61,63$

Nuclear Power Demonstration

(NPD) Reactor, 106

\section{0}

Oak Ridge National Laboratory (ORNL), isotope shipments from, 486

water-moderated lattice data, 586

Organic-moderated reactors, 114-125

Experimental Organic Cooled Reactor (EOCR), 120

fuel-element development, 123

organic-cooled with other moderators, 124

Organic Moderated Reactor Experiment (OMRE), 116, 121

Piqua Nuclear Power Facility (PNPF), 118

problems with organic coolants, 121

technical aspects, 116

Oxide-fuel processing, 448, 455

\section{$\mathbf{P}$}

Pathfinder superheat reactor, 26

Philadelphia Electric Company reactor, 13

Piqua Nuclear Power Facility

(PNPF), 118

Plutonium, distribution between molten $\mathrm{U}$ and $\mathrm{Ag}$, $\mathrm{La}$, and $\mathrm{Ce}$, 426

distribution between $\mathrm{Zn}-\mathrm{Mg}$ and $\mathrm{MgCl}_{2}, 432,433$

distribution between $\mathrm{Zn}-\mathrm{Mg}$ and $\mathrm{LiCl}-\mathrm{MgCl}_{2}, 432,433$

extraction by $\mathrm{Mg}-\mathrm{Ag}$ alloys, 427

fuel reactor, 97

liquid density, 425

partition coefficients in $\mathrm{Pb}-\mathrm{Zn}$

and $\mathrm{Al}-\mathrm{Cd}, 428$

recovery, from blanket elements, 445

in EBR-II fuel processing, 436

by electrolytic processes, 463 
by Hanford salt-cycle process, $451,452,454$

by melt refining, 437

from plutonium fuels, 447

rècycle cost, 35

solubility in metal solvents, 420

Plutonium-238, as heat-power source, 498,499

production, $512-513$

Plutonium-242, uses , 513-514

Plutonium Recycle Test Reactor (PRTR), 103

Plutonium-zinc phase diagram, 420

Polonium-210, heat-power source, 484,499

production, 519

Power, isotopic, 483, 484, 494-500

Power costs (see Nuclear power costs)

Pressure measurements, in-core, 192

absolute pressure, 194

pressure differential, 193

Pressure vessels for commercial operating plants, 54

Pressurized-water reactors, 19-22 cost, 29-33

stainless-steel cladding in, 234

Processing of reactor fuels (see Pyroprocessing of reactor fuels)

Promethium-147, 479, 480

production, 482-485

recovery, 509

uses, 489,499

Prototype reactors, gas-cooled, 13-15

Purex waste, storage cost, 503

Pyroprocessing of reactor fuels, $412-476$

cost, 36

fundamental data, recent, 418-436

distribution between metal phases, 425

distribution between liquid metal and fused salt, 426-433

extraction by $\mathrm{Mg}-\mathrm{Ag}$ alloys, 427

partition coefficients in $\mathrm{Pb}-\mathrm{Zn}$ and $\mathrm{Al}-\mathrm{Cd}, 428$ reactions of metals in $\mathrm{Zn}$ and

$\mathrm{KCl}-\mathrm{LiCl}, 431$

engineering studies, 435

metal preparation, 433

phase relations, 418

liquid-metal solvents, 419

physical properties, 425

thermodynamic properties,

419-424

activity coefficients, metals, 424

free energies of formation, carbides, 423

chlorides, 422,423

intermetallics, 424

oxides, 422

materials of construction, 464

process applications, $436-463$

aluminum process for uranium, 460

EBR-II fuel processing, 436-448

blanket process, 445

engineering procedures, 446

melt refining, 437-441

nonmetal fuels, 448

plutonium fuels, 447

skull reclamation, 441-445

zinc metal solvent, $442-445$

electrolytic processes for thorium, 462

Hanford salt-cycle process, 451

chemistry, 452

engineering-scale studies, 454

LMFR processing, 461

low-decontamination processes, 455

carbide fuels, 456

oxide fuels, 455

magnesium processes for $\mathrm{Th}-\mathrm{U}$

fuels, 449-451

mercury process for uranium

(Hermex process), 458

unit operations, review, 413

chemical extractions between

two phases, 416

crystallization, 414

electrochemical reactions, 417 , 452-455

evaporation, 415 
liquid-liquid extraction, 414

selective oxidation, 416

(See also Reactor by-products)

$\mathbf{R}$

R-3/Adam reactor, 110

Radiation measurement, in-core, 179

ion chambers, 183

material activation, 181

solid-state devices, 191

thermopiles, 188

Radiation tests, fuel elements, 239-244, 284-286

Radioisotopes, production and recovery, 478-519

distribution from ORNL, 486

as heat-power sources, 483,484 , 494-500

output, $478-481$

properties, 488

as radiation sources, 482, 491-494

recovery, 500-519

transportation, $60,519-522$

uses, 491-500

(See also Reactor by-products)

RAPSODIE reactor, 95

Reactor by-products, 478-528

general characteristics of fission products, $486-491$

properties, 488

history, 478-481

major applications, 491-500

heat-power sources, 494

radiation sources, 491

SNAP programs, 495-500

output, $481-486$

electric power available, 484

fission products, $482,511,512$

future production, 511,512

isotopic power costs, 484

production capability, 483

radioisotopes, distribution from

ORNL, 486

sources, 481,486

thermal power available, 483

recovery, fission products, $500-512$ processing, 504-511

relation to disposal methods, 501

storage costs, Purex waste, 503

transu ranium isotopes, 512-519

chemical processing, 515

from reactor targets, 513

from reactors, 512

transportation, radioactive materials, $60,519-522$

(See also Pyroprocessing of reactor fuels)

Reactor design and operation of commercial plants, fast reactors, 85-99

gas-cooled, 5-12

heavy-water-moderated, 99-114

light-water-cooled, 47-60

organic-moderated, 114-125

sodium-graphite, 72-84

Reactor fuels (see Fuels, metallic)

Reactor fuels processing (see Pyroprocessing of reactor fuels)

Reactor programs, commercial, fast reactors, 85-99

gas-cooled, 3-5

heavy-water-moderated, 99-114

light-water-cooled, 15-19, 47-60

organic-moderated, 114-125

sodium-graphite, 72-84

Reactor-physics data for watermoderated lattices of slightly enriched uranium (see Lattice data for water-moderated, etc.)

Reflector savings, 536, 537, 539, $540,548,576,587,589$

Russia, BR reactors, 93

Ruthenium-106, 491, 510

\section{S}

SADE loop, 271, 276

Safety, commercial power plants, 57-60

Savannah, N.S., reactor-physics data, 566

Shippingport reactor, 19-21

cost, 30

zirconium cladding in, 307 
SM-1 reactor, stainless-steel cladding in, 231

Sodium-graphite reactors, $72-84$ advanced sodium-cooled reactor, 83

Hallam Nuclear Power Facility

(HNPF), 81

costs, $82-83$

Sodium Reactor Experiment

(SRE), 73-81

component development, 80

fuels and materials development, 78

operating experience, 75

iechnical aspects, 74

Spectral-shift-control reactor, 111

Stainless-steel cladding, in superheated steam, 260-288

in water, 223-260

(See also Cladding materials, behavior in water and steam)

Steam-cooled reactors, 15

Strontium-90, 479-481

production, $482-485$

recovery, 502, 508, 509

uses, $489,490,492,493,498,499$

Supercritical reactors, 27

Fuel Bearing Graphite Reactor (FBGR), 27

Supercritical Once-Through Tube Reactor (SCOTT-R), 27

Superheaters, 26, 52

Sweden, R-3/Adam reactor, 110

Switzerland, Lucens reactor, 109

Systems for Nuclear Auxiliary

Power (SNAP), 495-500

\section{T}

Technetium-99, recovery, 511 uses, 490

Telemetering, in-core data, 206 electronic multiplexing, 207 mechanical scanning, 206

Temperature measurements, incore, 198-203

capacitance temperature sensors, 202

sonic flow orifices, 201 thermocouples, 199

Thermal-neutron disadvantage factor, $554,562,566,582,585$

Thermocouples for in-core measurements, 199

Thermodynamic cycles, commercial power reactors, 51

Thermopiles for flux measurement, 188

Thorium, electrolytic processes for fuel treatment, 462

solubility in metal solvents, 420

Thorium fuel, 398

Thorium-uranium fuel processing, 449-451

Thorium-zinc phase diagram, 418

Transportation of radioactive materials, $60,519-522$

Transuranium elements, production, 512-519

chemical processing, 515

from reactor targets, 513

from reactors, 512

Tungsten for fuel processing, 464

U

United Kingdom, commercial power reactors, Advanced Gas Reactor (AGR), 13, 29

Atomic Energy Research Establishment (AERE) watermoderated lattice data, 544-546, 584

Calder Hall reactors, $6,8-12$

DRAGON reactor, 6,14

Dounreay Fast Reactor (DFR), 85, 91

gas-cooled reactor program, 3-5

Advanced Gas Reactor (AGR), 13,29

commercial reactors, 4

construction costs, 28

effect of subsidies, 45

reactor design and operating experience, 8-11

Hinkley Point reactor, 5 
United States, commercial power reactors, fast reactors, 85-98

Enrico Fermi plant, 90

Experimental Breeder Reactors (EBR), 87, 88

fast ceramic-fueled reactors, 95

Los Alamos Molten Plutonium Reactor Experiment (LAMPRE), 97

preliminary programs, 98 gas-cooled reactor programs, 5 commercial reactors, 4 design data, 6-7

Experimental Gas Cooled Reactor (EGCR), 13

High Temperature Gas Cooled Reactor (HTGR), 13

prototype reactors, 5

heavy-water-moderated reactors, 99-114

Carolinas-Virginia Tube Reactor (CV'TR), 103

Heavy Water Components Test Reactor (HWCTR), 102

Spectral-shift-control reactor, 111

technical aspects, 100

light-water-cooled reactors, 15-27

advanced power reactors, 26

BONUS, 26

BORAX-5, 26

design data, 26

Pathfinder, 26

boiling-water reactors, 22

Dresden reactor, 24, 29, 31

Experimental Boiling Water

Reactor (EBWR), 22

pressurized-water reactors, 19-22

Consolidated Edison Thorium

Reactor (CETR), 22

Shippingport reactor, 19-21, 30

Yankee reactor, 21, 30, 44

organic-moderated reactors,

114-125

Experimental Organic Cooled
Reactor (EOCR), 120

fuel-element development, 123

Organic Moderated Reactor Experiment (OMRE), 115, 116

other concepts, 124

Piqua Nuclear Power Facility (PNPF), 118

problems with organic coolants, 121

sodium-graphite reactors, $72-84$ advanced sodium-cooled reactor, 83

Experimental Breeder Reactor (EBR) $, 73,87,88$

Hallam Nuclear Power Facility (HNPF), 81, 82

Sodium Reactor Experiment (SRE), 73

Uranium, activity coefficients in $\mathrm{Bi}$, $\mathrm{Cd}$, and $\mathrm{Zn}, 424$

diffusion coefficients in $\mathrm{Cd}, \mathrm{Bi}$, and $\mathrm{Zn}, 425$

distribution between $\mathrm{Al}$ and $\mathrm{AlCl}_{3}-$ $\mathrm{KCl}, 430$

electrolytic methods for recovery, 463

lattice data in water-moderated, slightly enriched (see Lattice data for water-moderated, etc.) liquid density, 425 partition coefficients in $\mathrm{Pb}-\mathrm{Zn}$ and $\mathrm{Al}-\mathrm{Cd}, 428$

solubility in metal solvents, 420 solubility in $\mathrm{Zn}-\mathrm{Mg}, 421$

Uranium fuels (see Fuels, metallic)

Uranium processing with aluminum, 460

Uranium processing with mercury, 458

Uranium in reactors (see individually named reactors and types of reactors)

Uranium -thorium fuel processing, 449-451

Use charge, 37

\section{V}

Vallecitos Boiling Water Reactor (VBWR) 
fuel-element testing, $247-257$

irradiation tests, $239-243,247$

SADE loop, 271, 276

stainless-steel cladding in, 225 ,

$231,236,238-243,247-257$

Variable-loading method for buckling measurement, 535, 541-544, 578

Velocity measurement, in-core, 195 rotating vane meters, 196 standing-wave measurement, 197

\section{W}

Waste disposal, radioactive, 42,60 , $479,500-512$

Water-cooled reactors (see Lightwater-cooled reactors)

Water-moderated lattices of slightly enriched uranium (see Lattice data for water-moderated, etc.)

Westinghouse Electric Corp., Atomic Power Division (WAPD), water-moderated lattice data, 558, 562,587

\section{$X$}

Xenon from reactors, 510,512

\author{
$\mathbf{Y}$ \\ Yankee reactor, 21 \\ cost, 30,44 \\ stainless-steel cladding in, 231 , \\ $234,238,259$ \\ water-moderated lattice data, 587
}

\section{Z}

Zinc in fuel processing (see Pyroprocessing of reactor fuels)

Zinc-plutonium phase diagram, 420

Zinc-thorium phase diagram, 418

Zirconium-95, 482, 488, 490

Zirconium alloys for fuel cladding, 50, 289-309

corrosion, 290-305

properties, 305

reactor experience, 50,307

Zirconium-uranium alloy fuels, 388,396

\section{LEGAL NOTICE}

Th1s book was prepared under the sponsorship of the U $S$ Atomic Energy Commission. Neither the Unuted States, nor the Commission, nor any person acting on behalf of the Commission

A Makes any warranty or representation, expressed or impled, with respect to the accuracy, completeness, or usefulness of the information contained in this publucation or that the use of any information apparatus, method, or process owned rights, or

B Assumes any liabiluties with respect to the use of, or for damagea resulting from the use of any information, apparatus, method, or procese disclosed in this publication.

As used in the above "tperson acting on behalf of the Commission" includes any employee or contractor of the Commission, or employee of such contractor, to the extent that such employee or contractor of the Commission, or employee of such contractor prepares, disseminates, or provides access to, any information pursuant to his employment or con tract with the Commission, or his employment with such contractor 